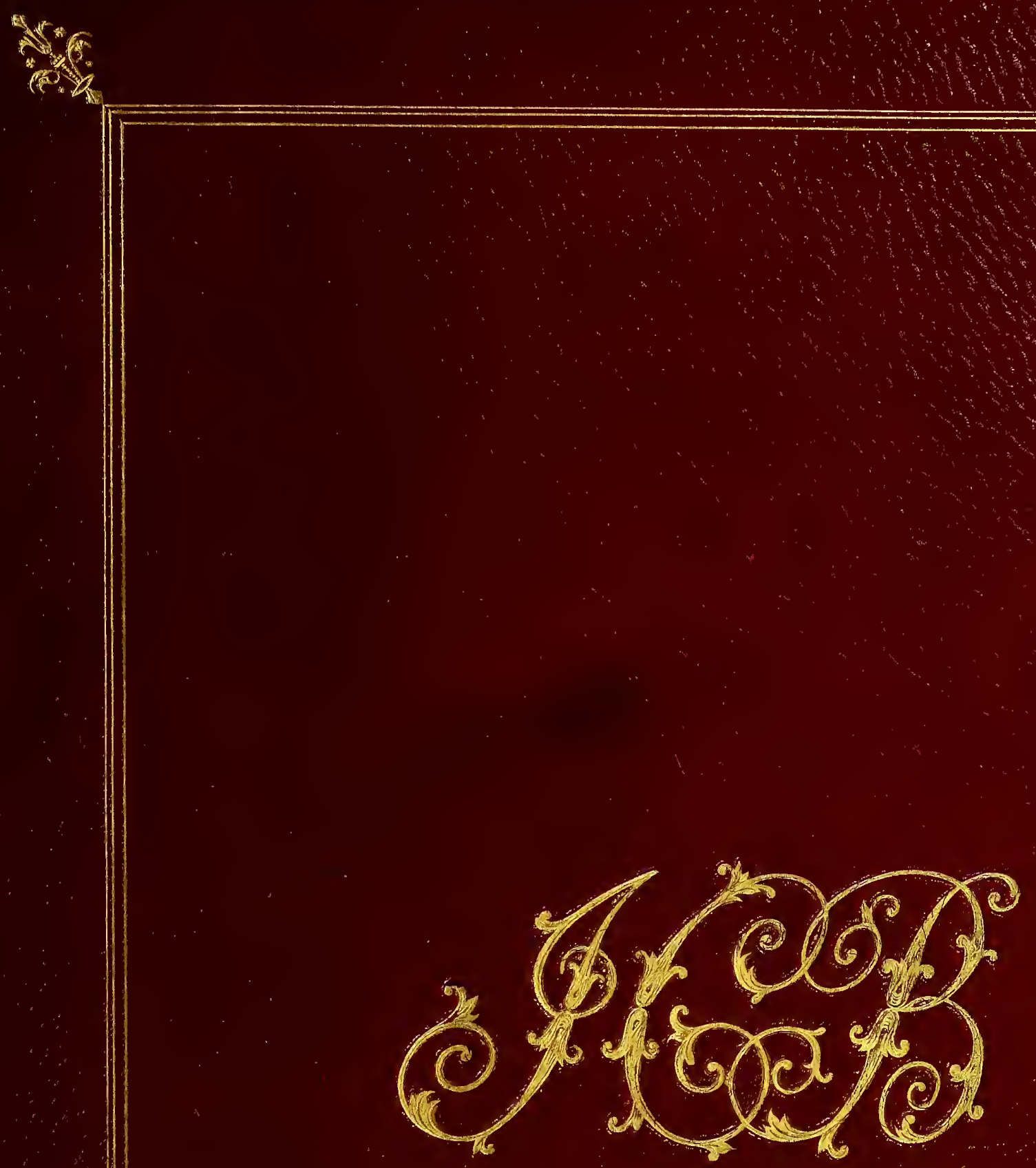

, 


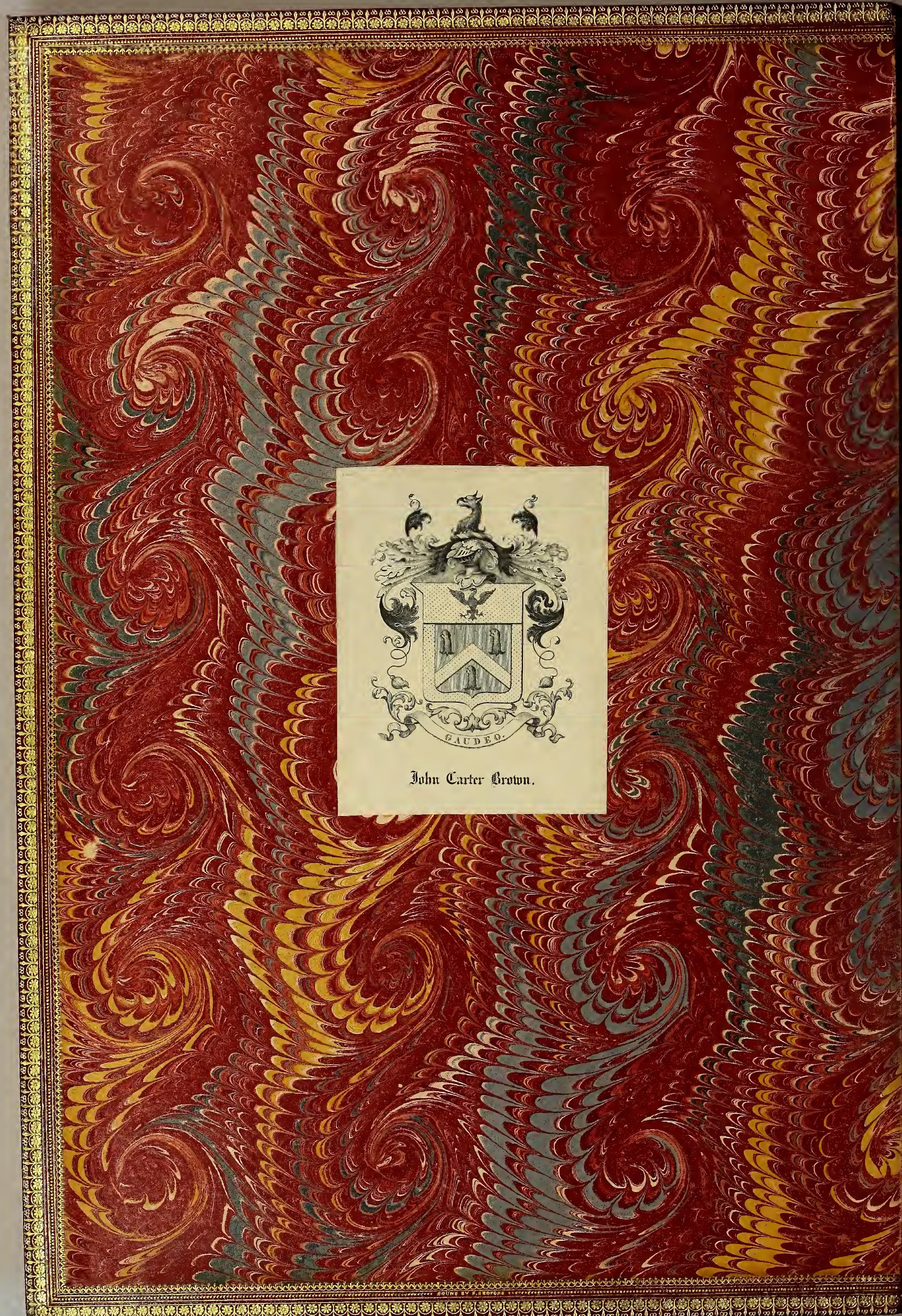




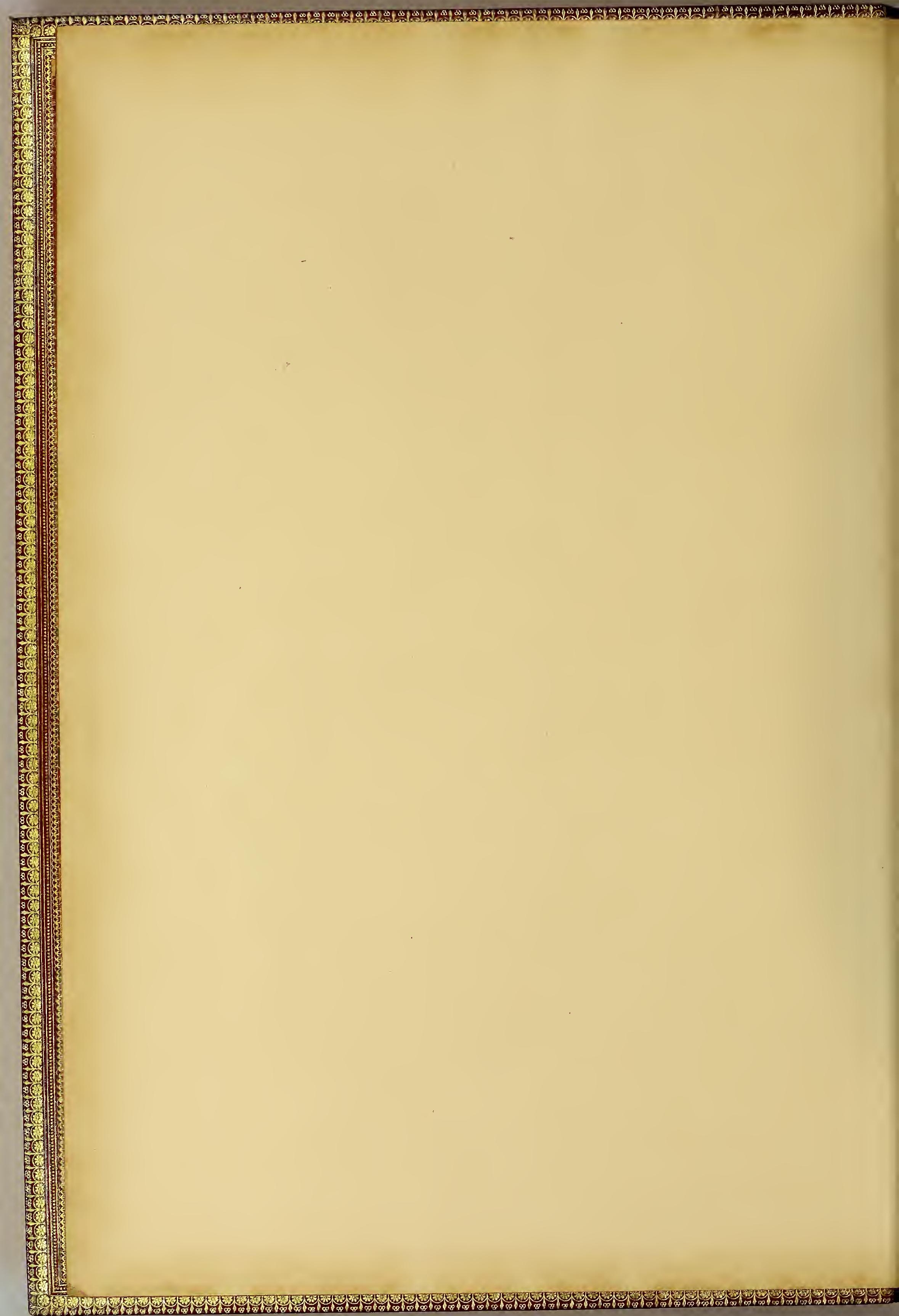




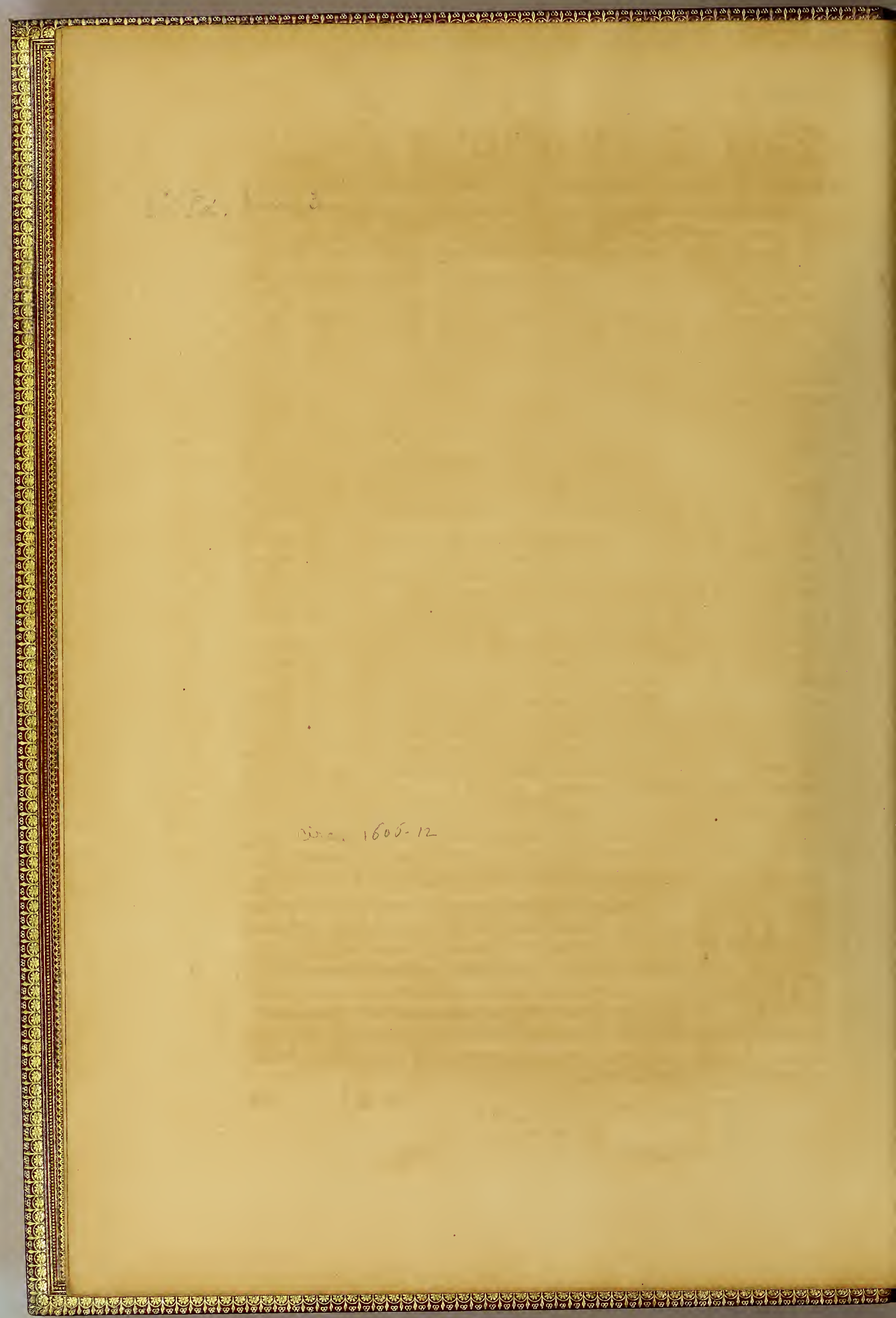




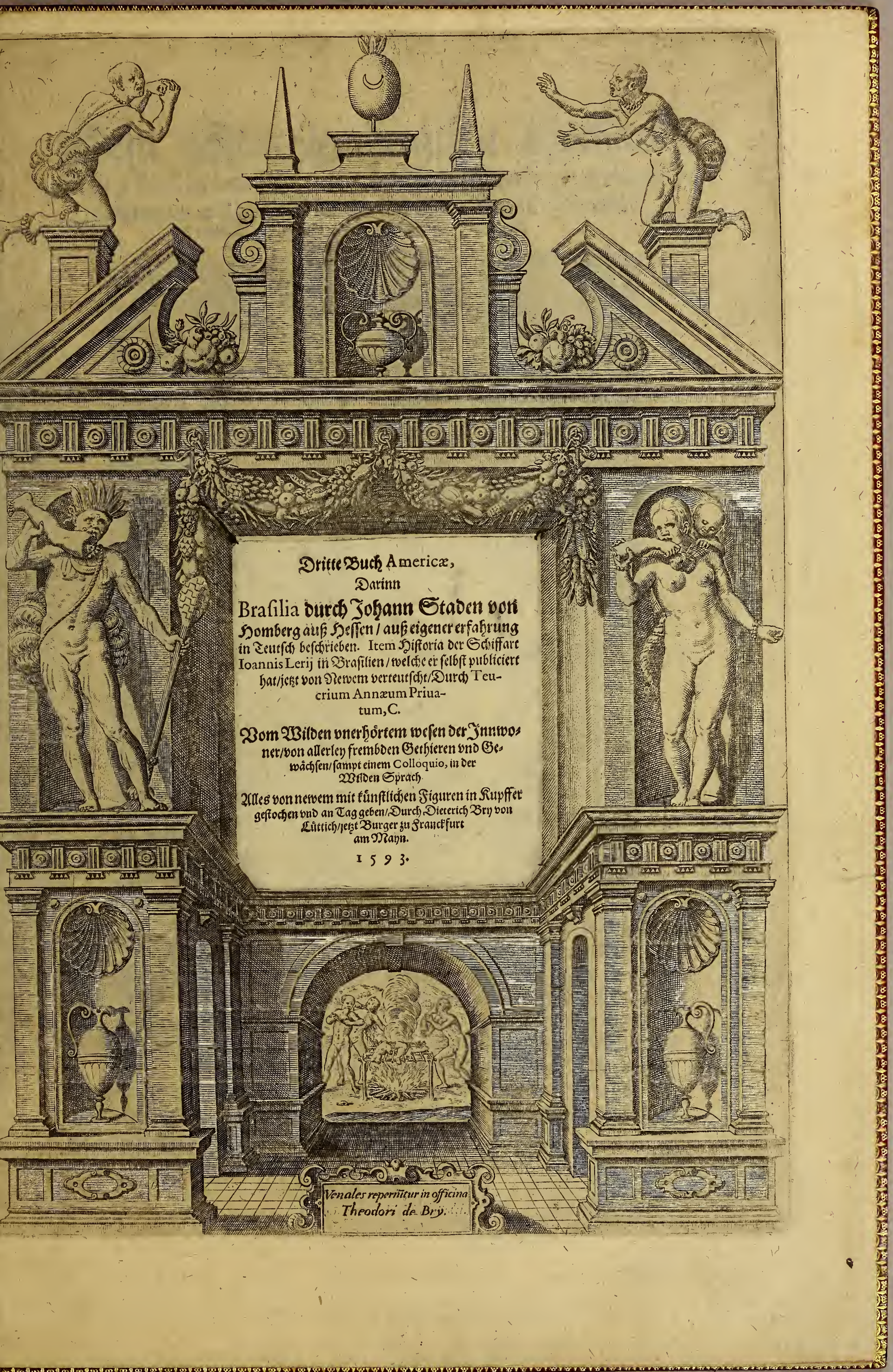




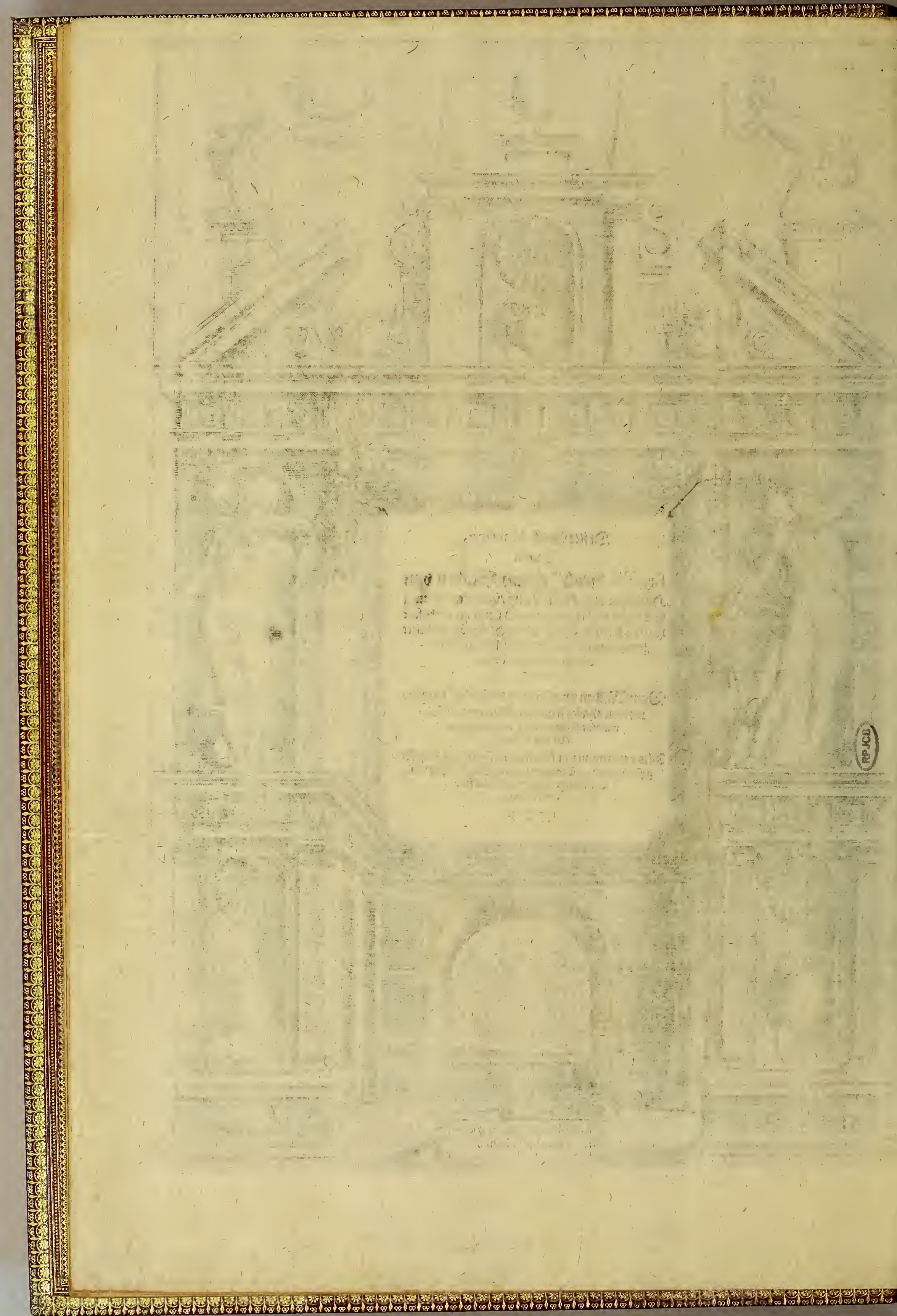




\section{Qem \&utchleutchtigften}

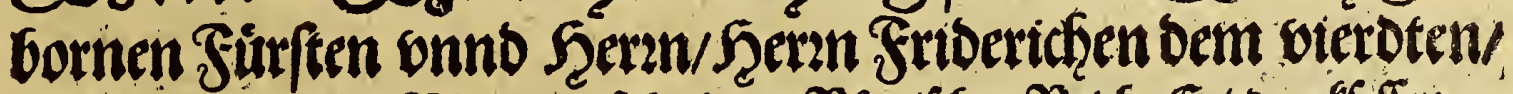

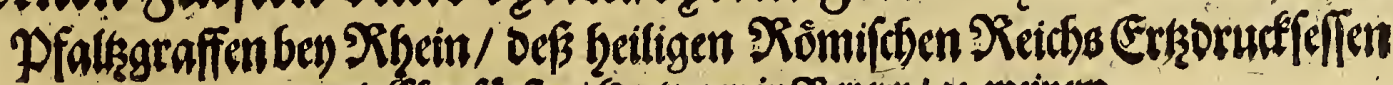

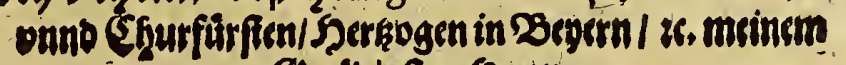

Estrábigfeen Sertem.

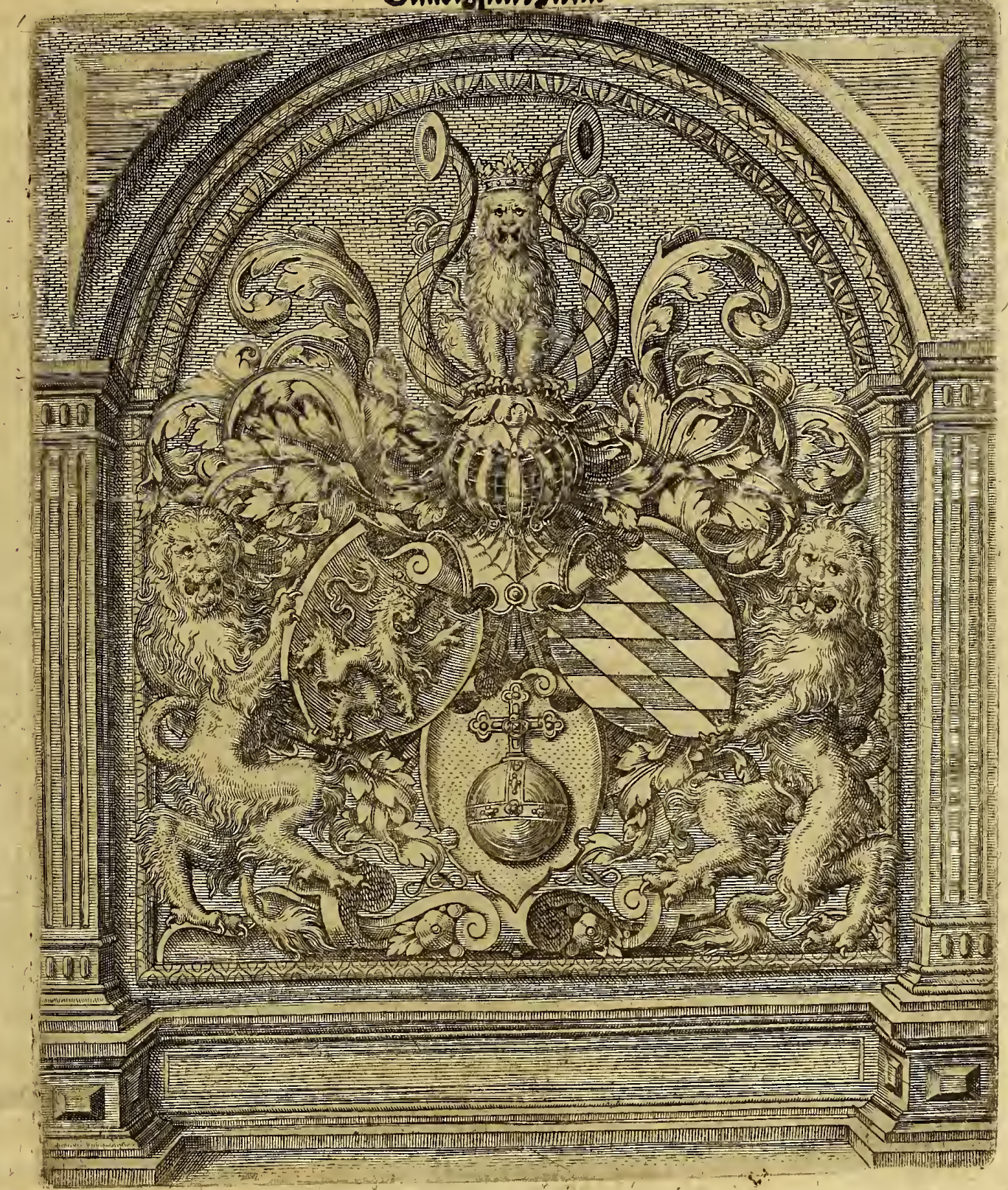

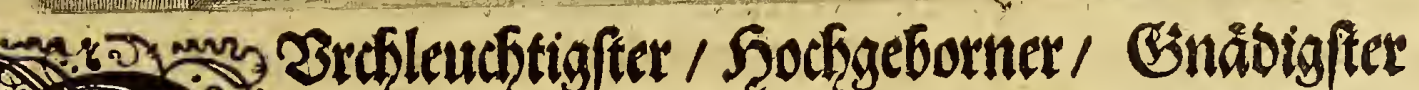

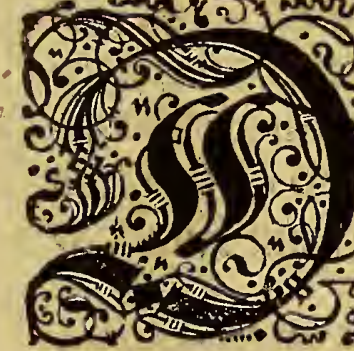

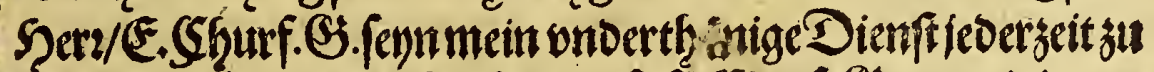

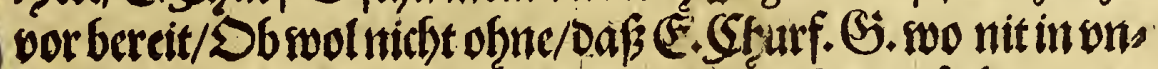

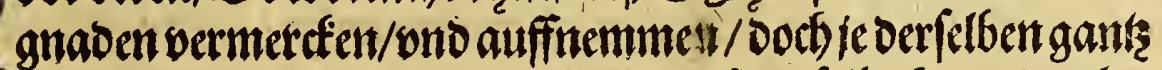

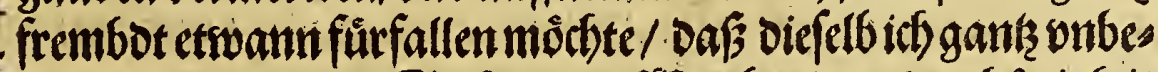

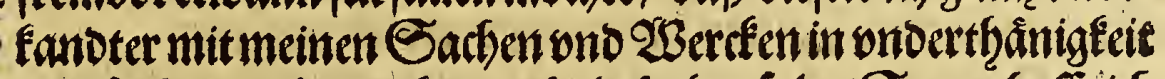

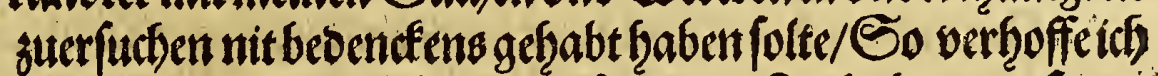

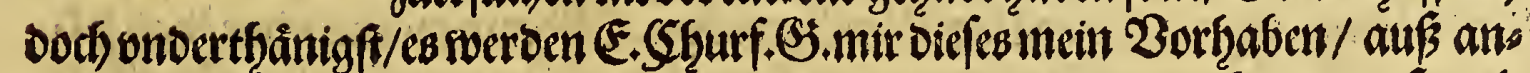

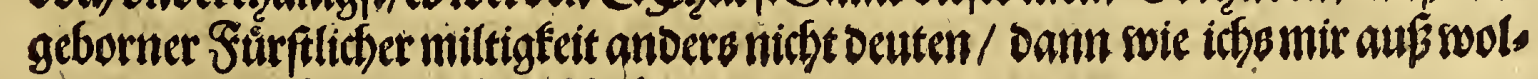
meinender cinfalt eingebildot ţăbe.

(i) ii

(E)

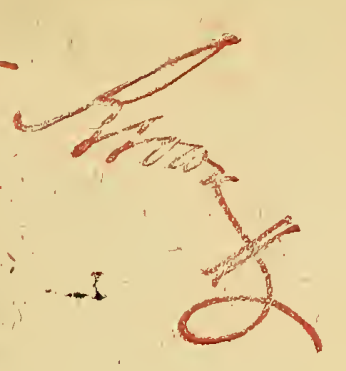




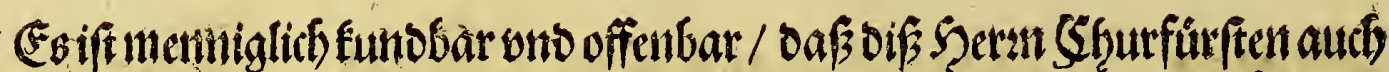
Güurfitlich de

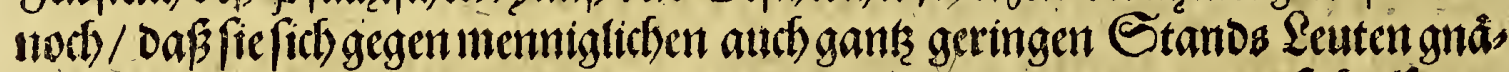

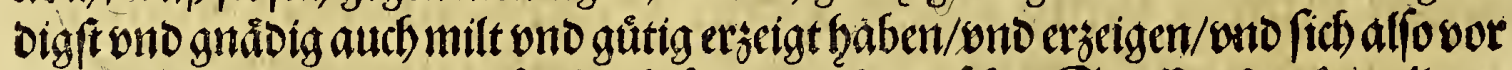
andern bober Potentaten folcher befonberenserofifhen Eanfftmútigfeit allent"

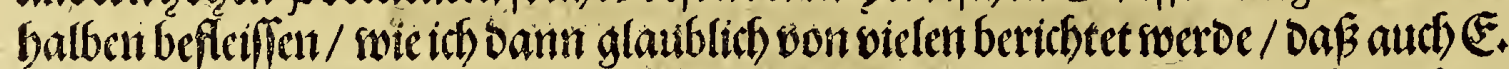

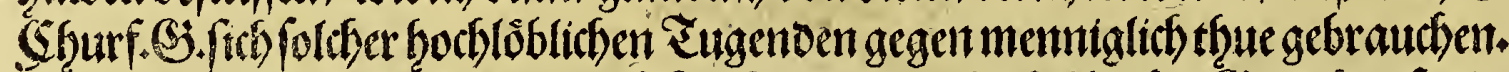

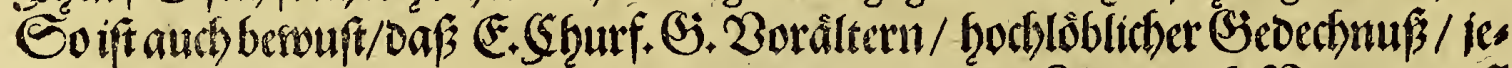

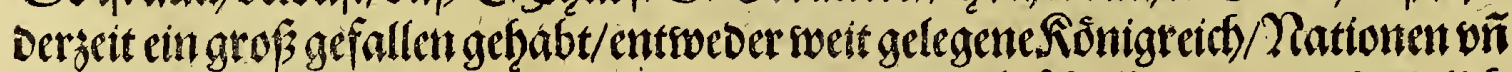

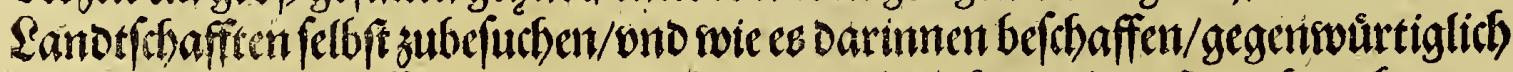

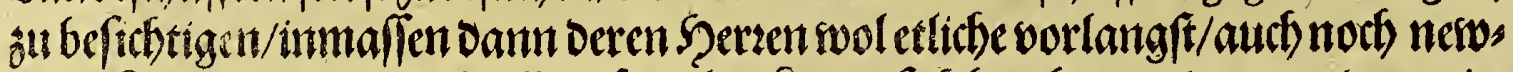

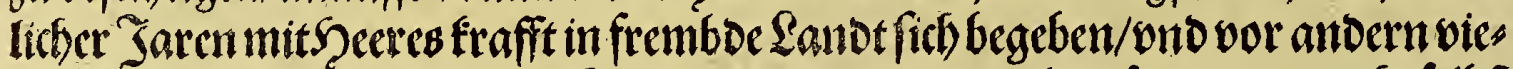

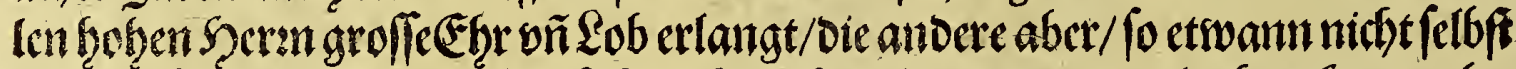

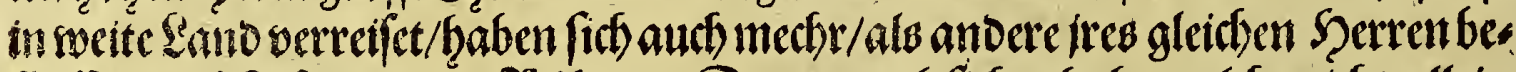

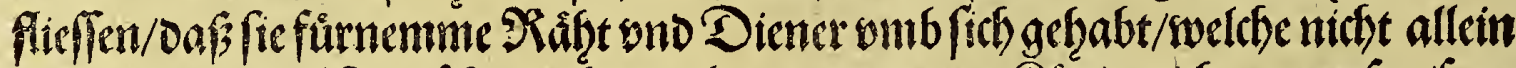

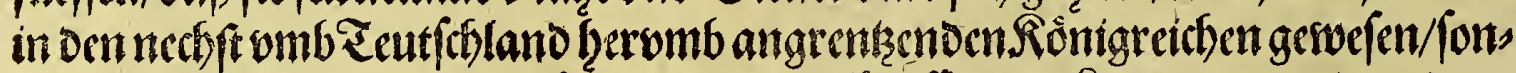

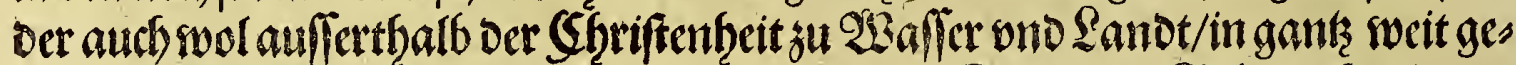

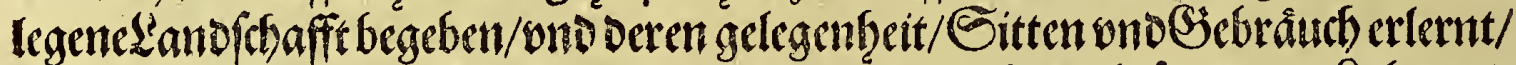

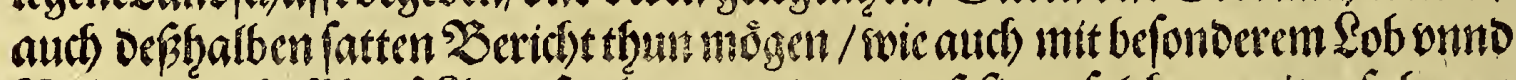

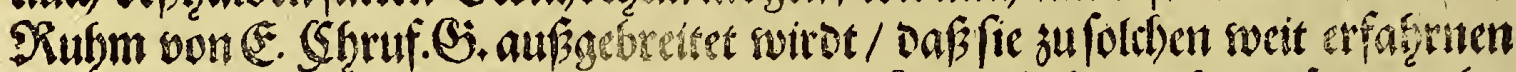

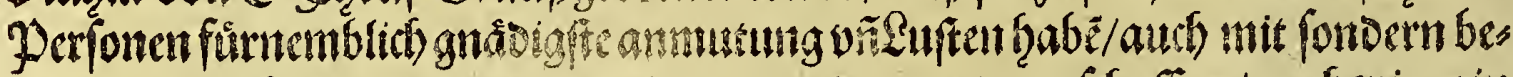

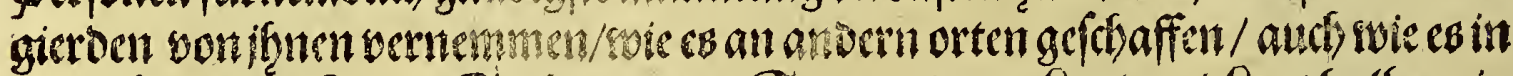

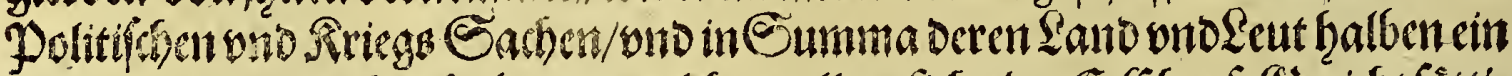

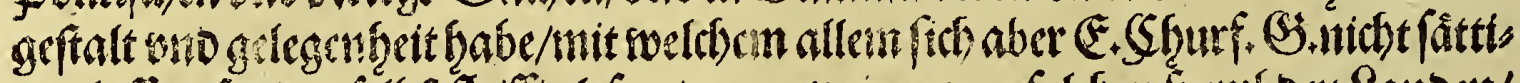

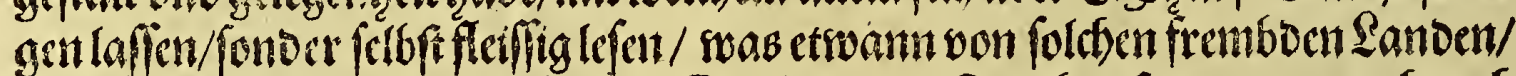

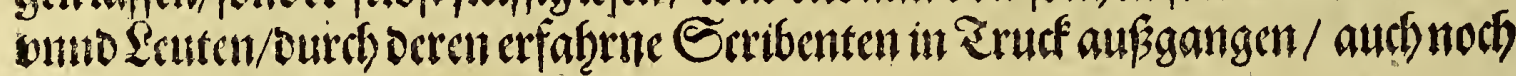

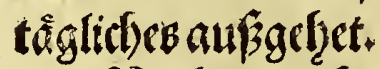

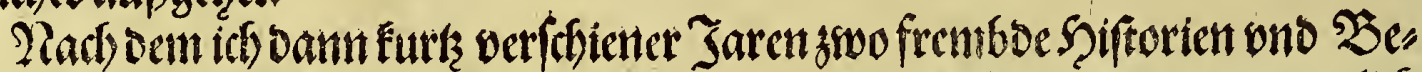

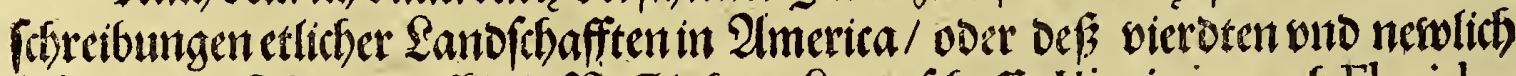

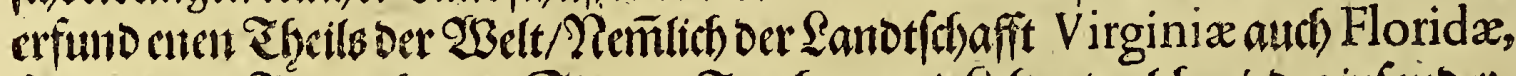

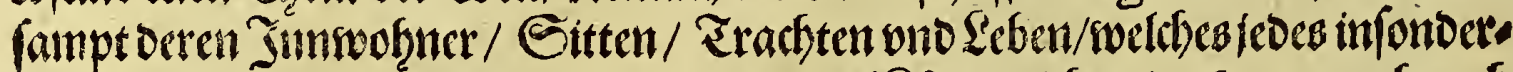

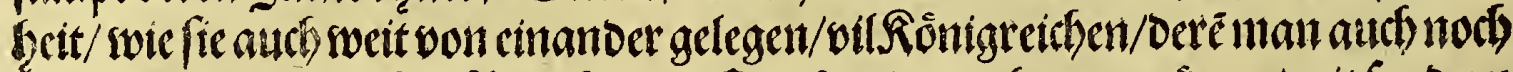

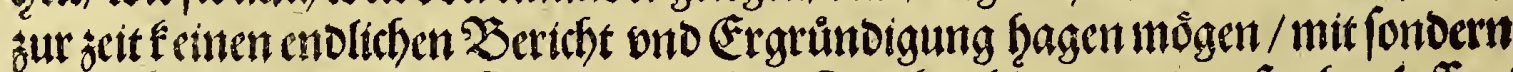

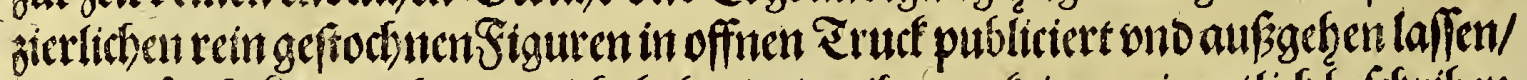

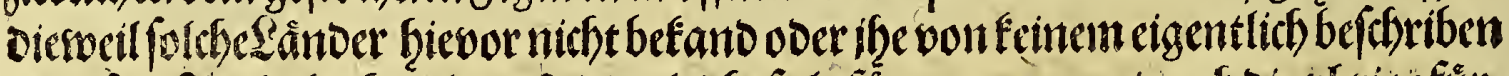

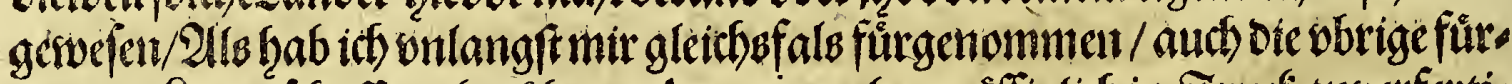

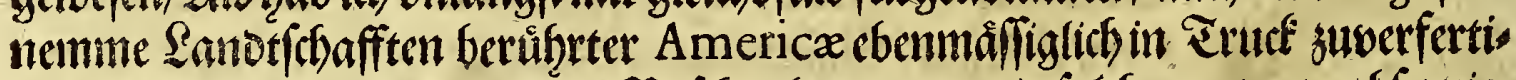

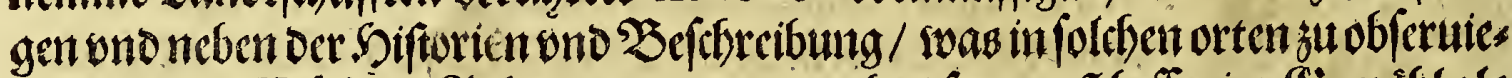

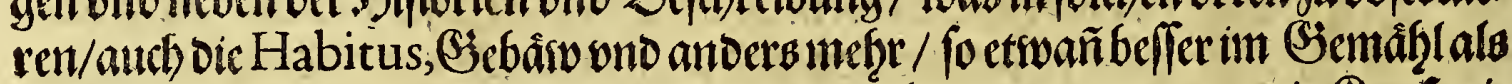

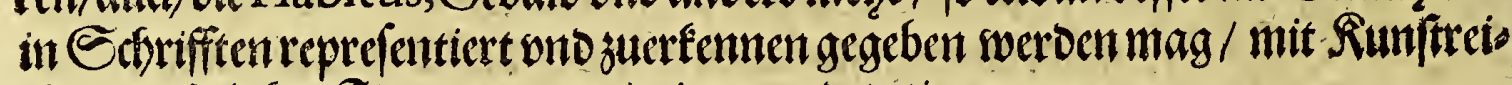
chan naturlichen Figuren suerprimteren ono suzisteren.

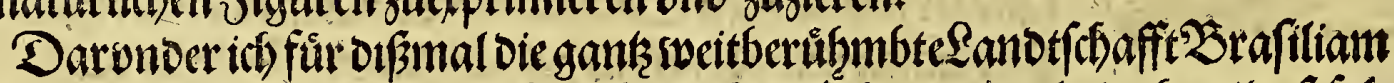

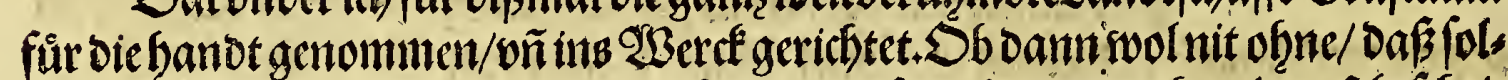

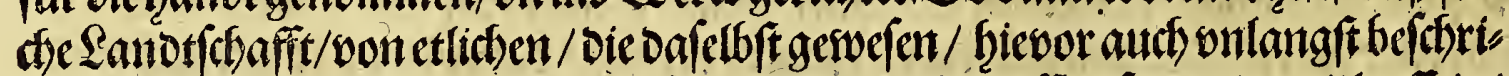

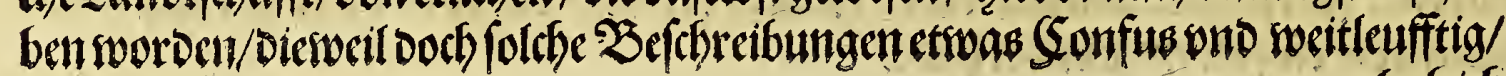
babiach 


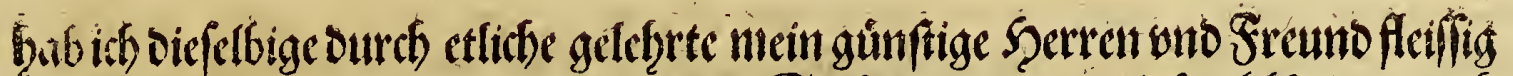

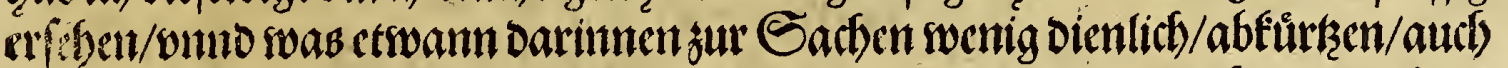

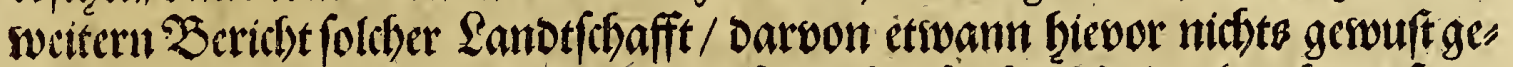

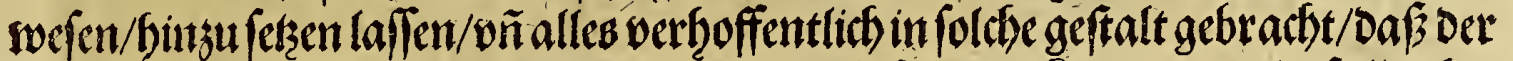

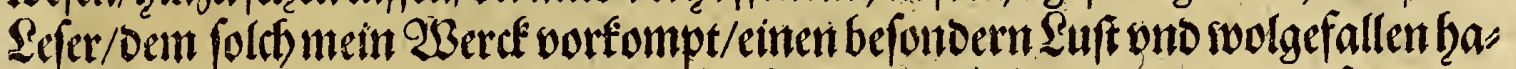
ben wordt. Esift aber furnemblich in biefen orenen allbereit von mir gefertigten

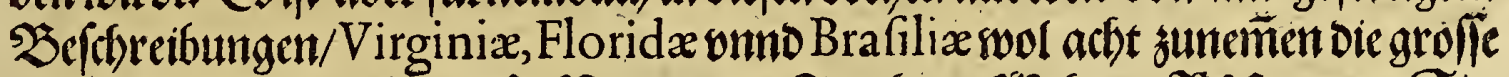

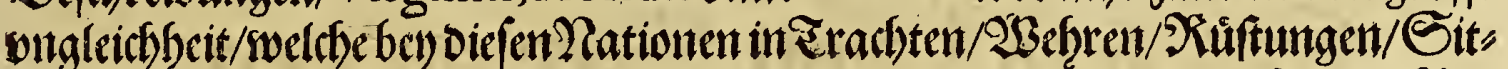

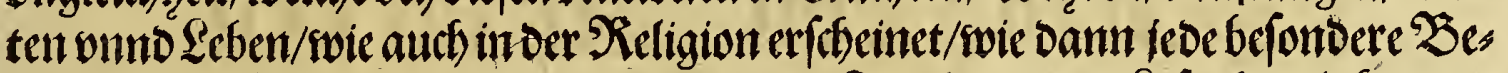

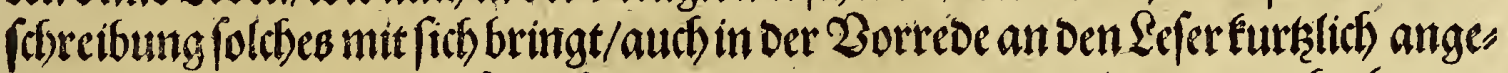

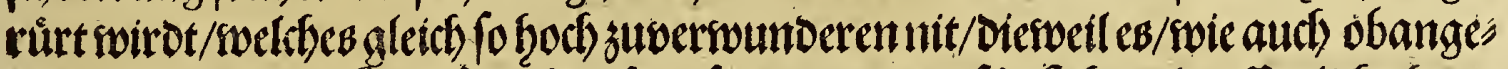

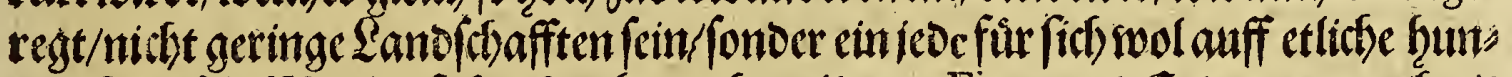

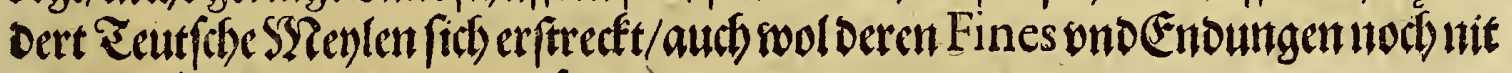

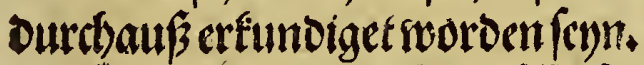

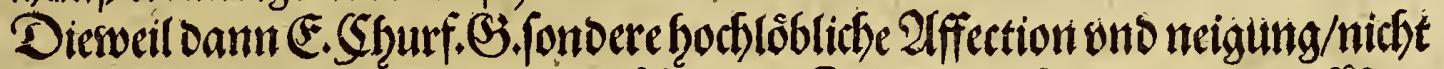

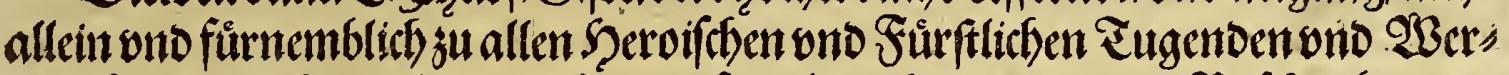

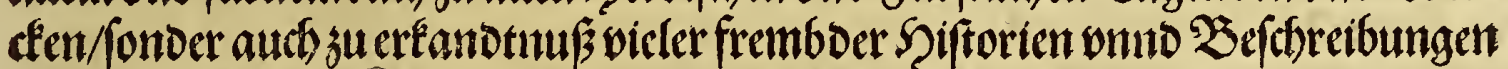

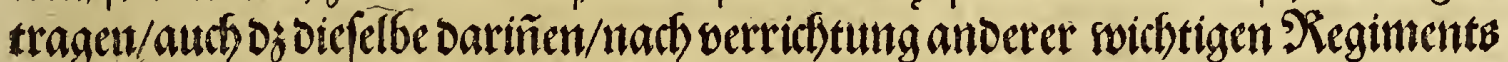

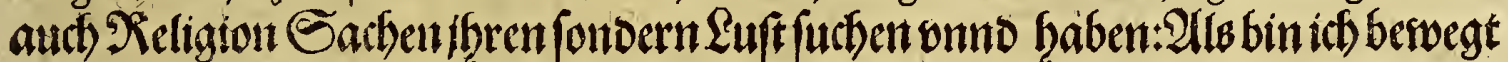

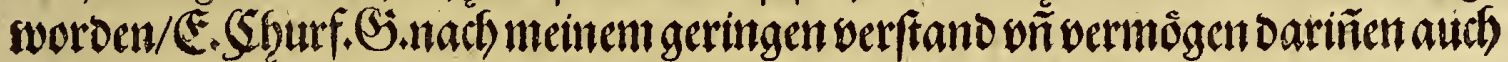

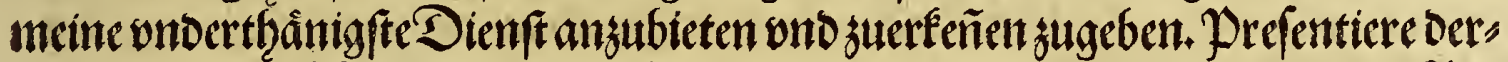

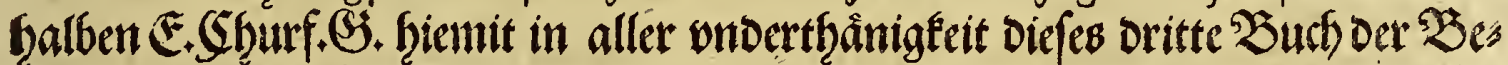
(f) reibung Americx, Darinnen nach Der lầnge ontho eigentlief bon oer sweitbes

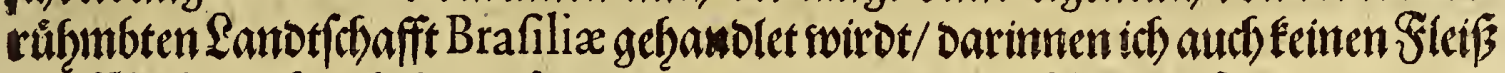

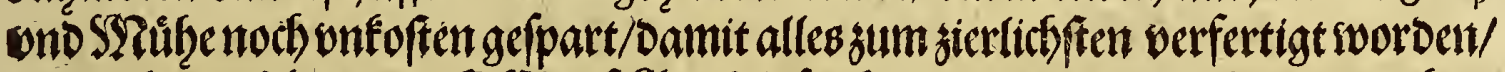

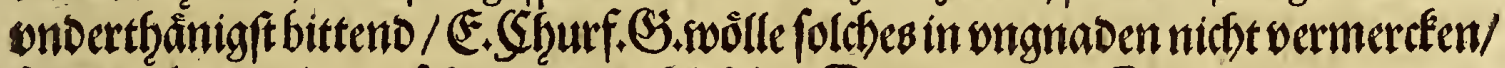
fonder ob es wol in anjef̧ung Deren feôth/ten Dignitet ono Standets etros gerins

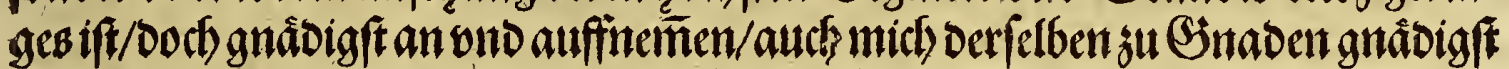

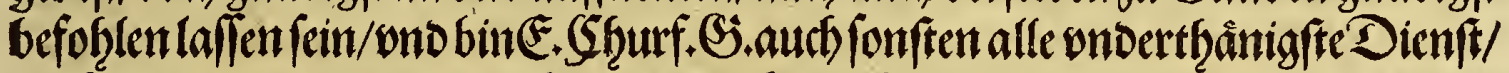

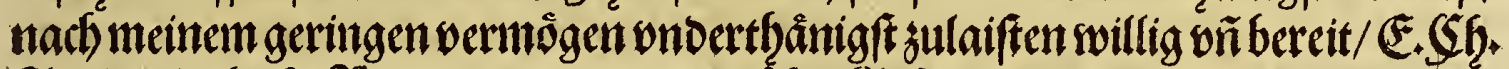

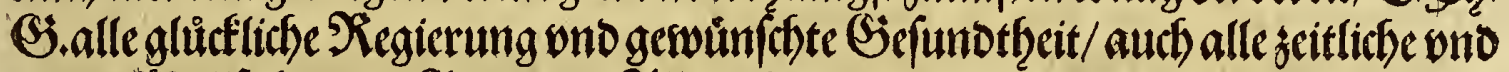

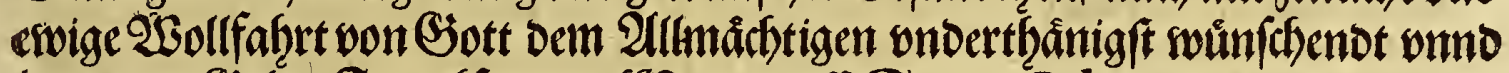
bittend. Geben Frandfurt am SIann/auff Sontag Palmarum, Anno Is93,

经.Churf.G.

Ondertboitingfter Dien/twolltiger/

Dieterich von 25ry/von Littid/jent

25urger 3u Srancliurt/Golots

fomiot vits Züpfferfecber.

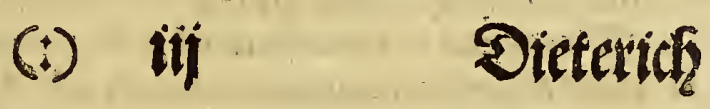




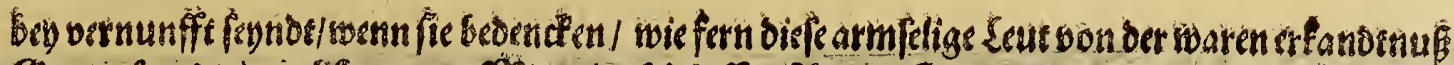
Goffes fevsto/sin volfommene

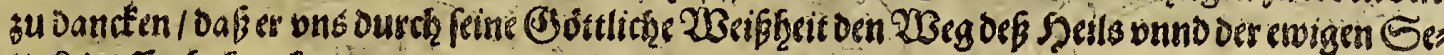
ligfeit offenbafiret hat.

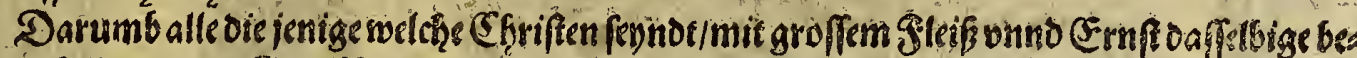

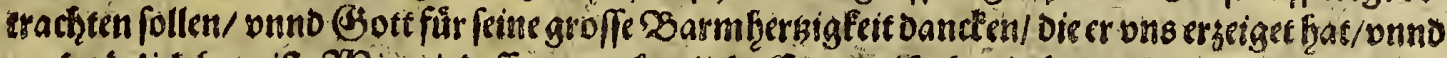

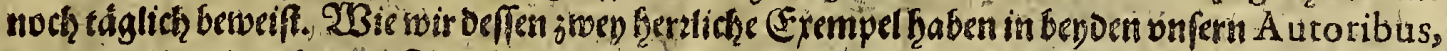

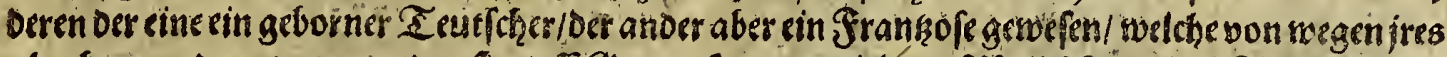

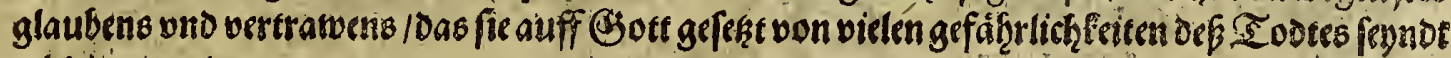
erleoiget worben.

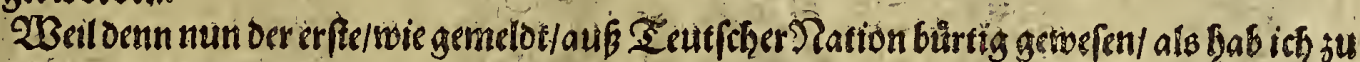

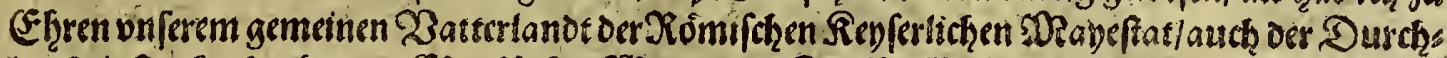

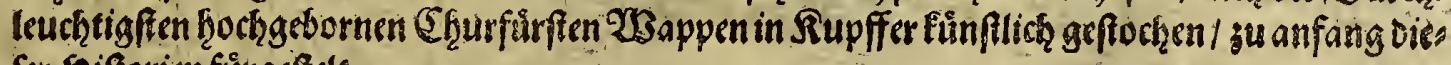
fer Siftorien furgefele.

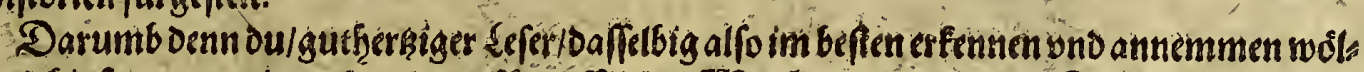

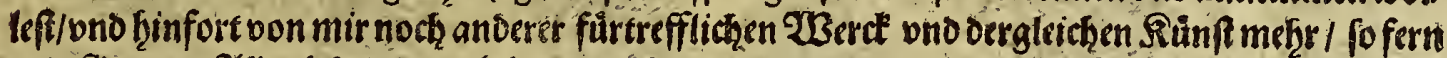

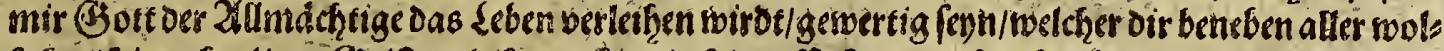

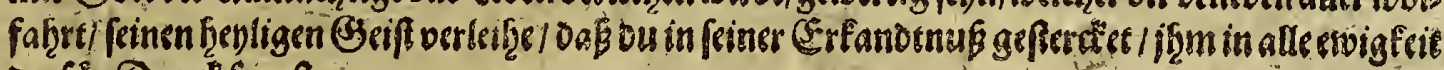
Darfirir Dand fagef:

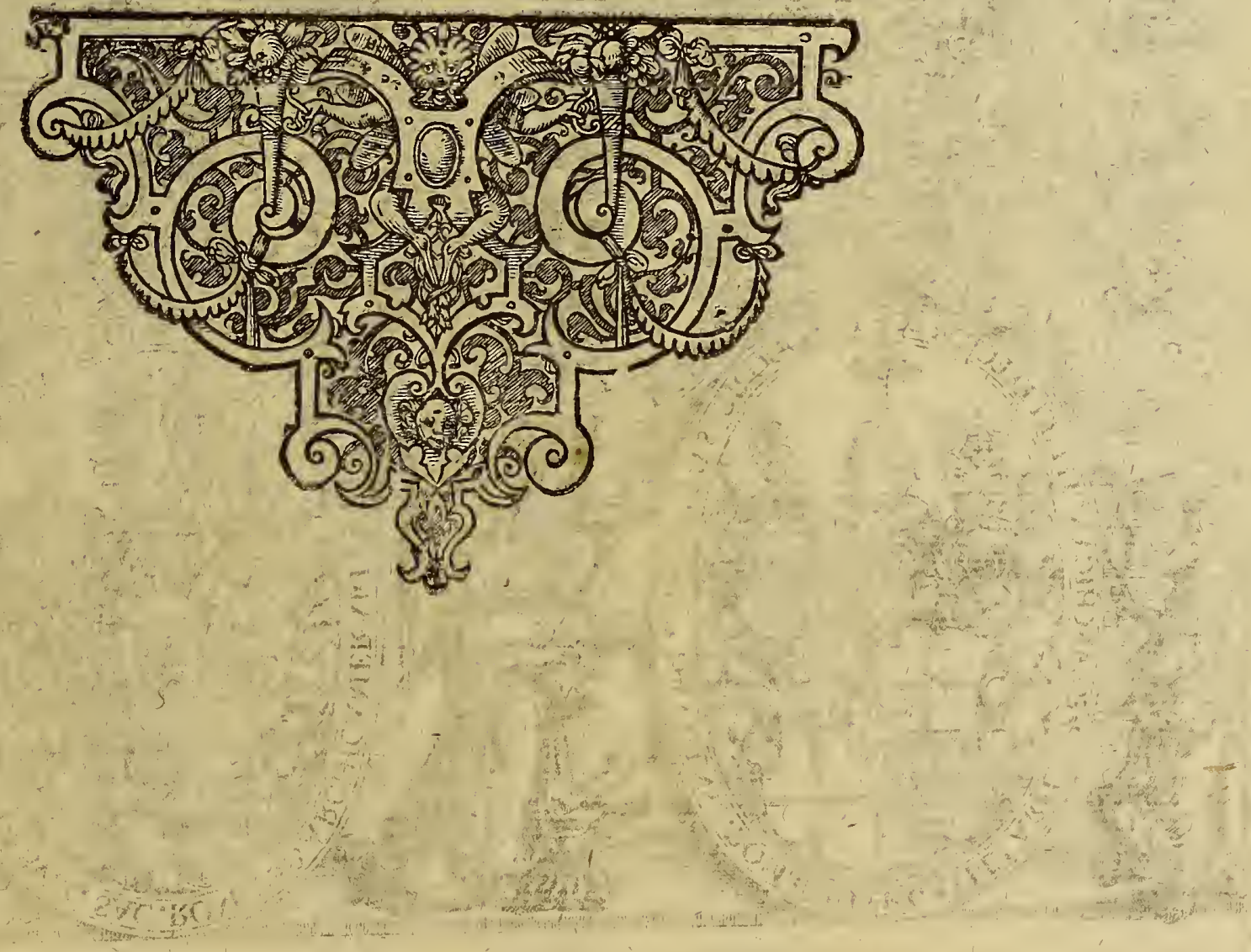




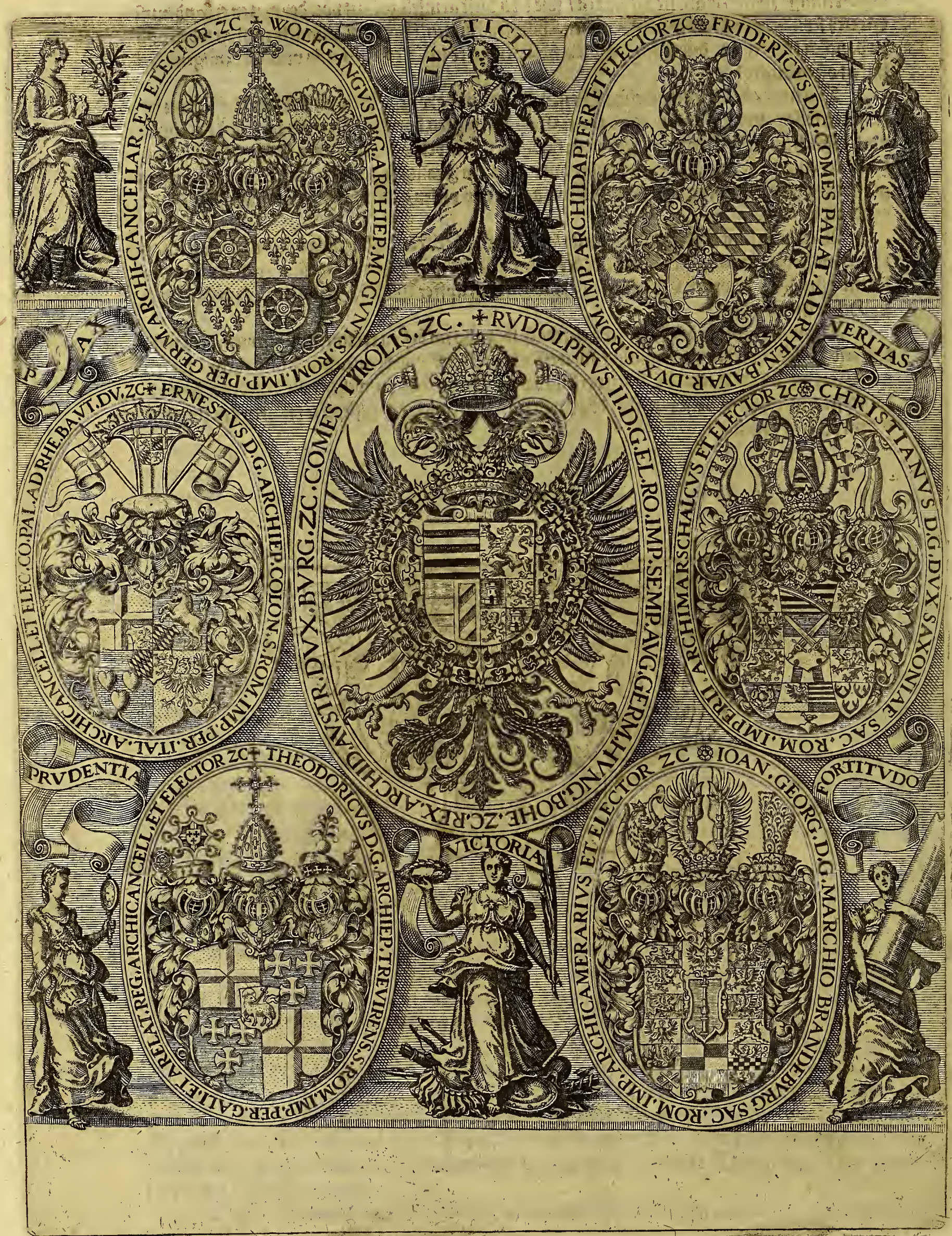

(1) 


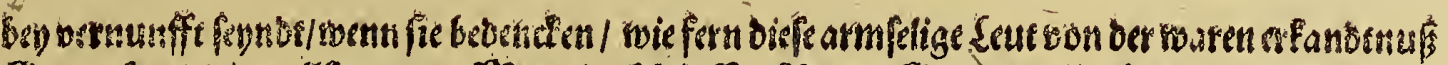

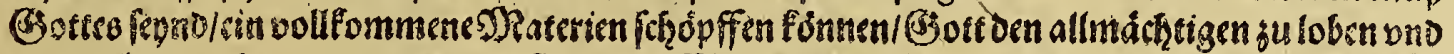

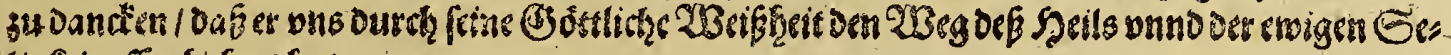
ligfeit offertbahref hat.

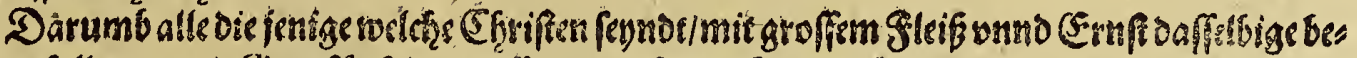

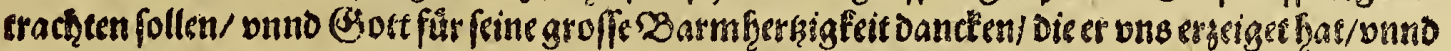

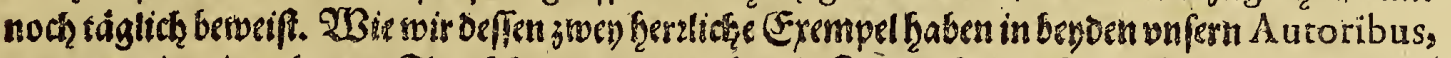

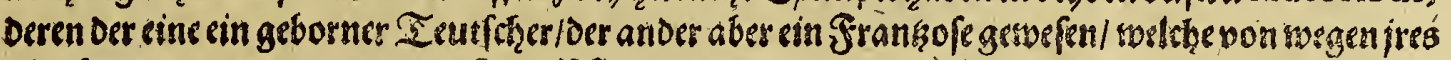

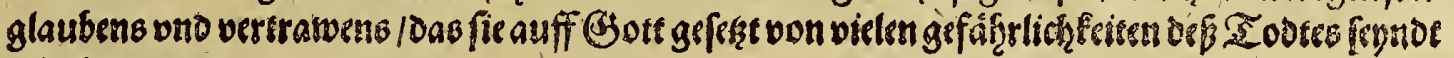
erleoiget moldoen.

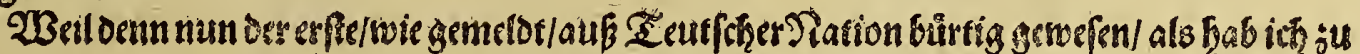

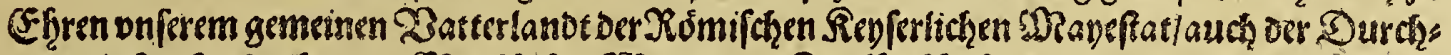

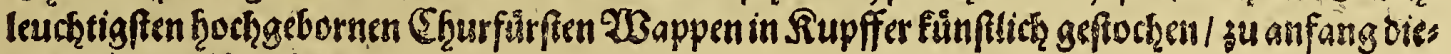
fer Sifforien fürgefelt.

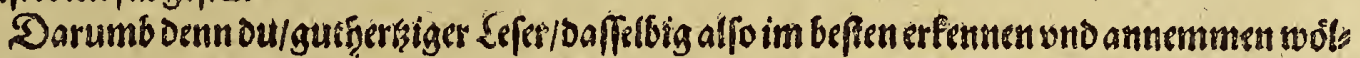

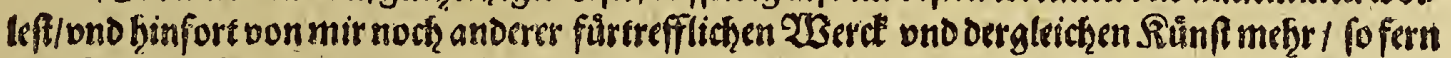

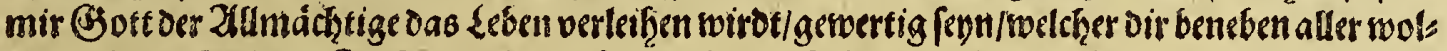

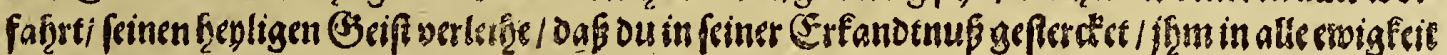
Darfür Dand' fagef?

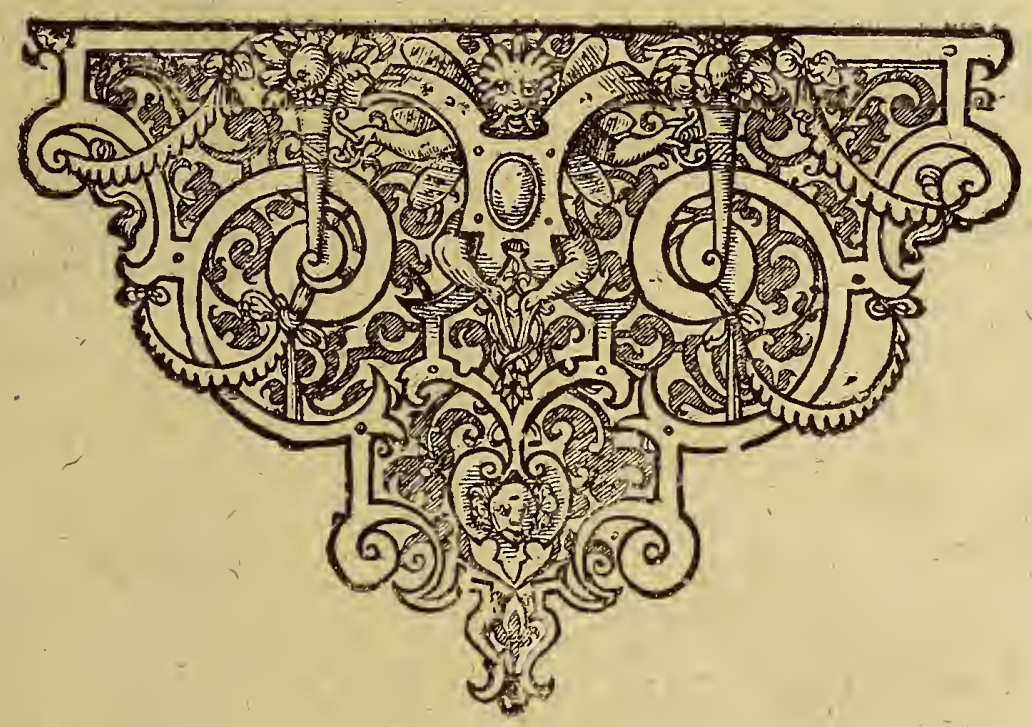


784 (2)

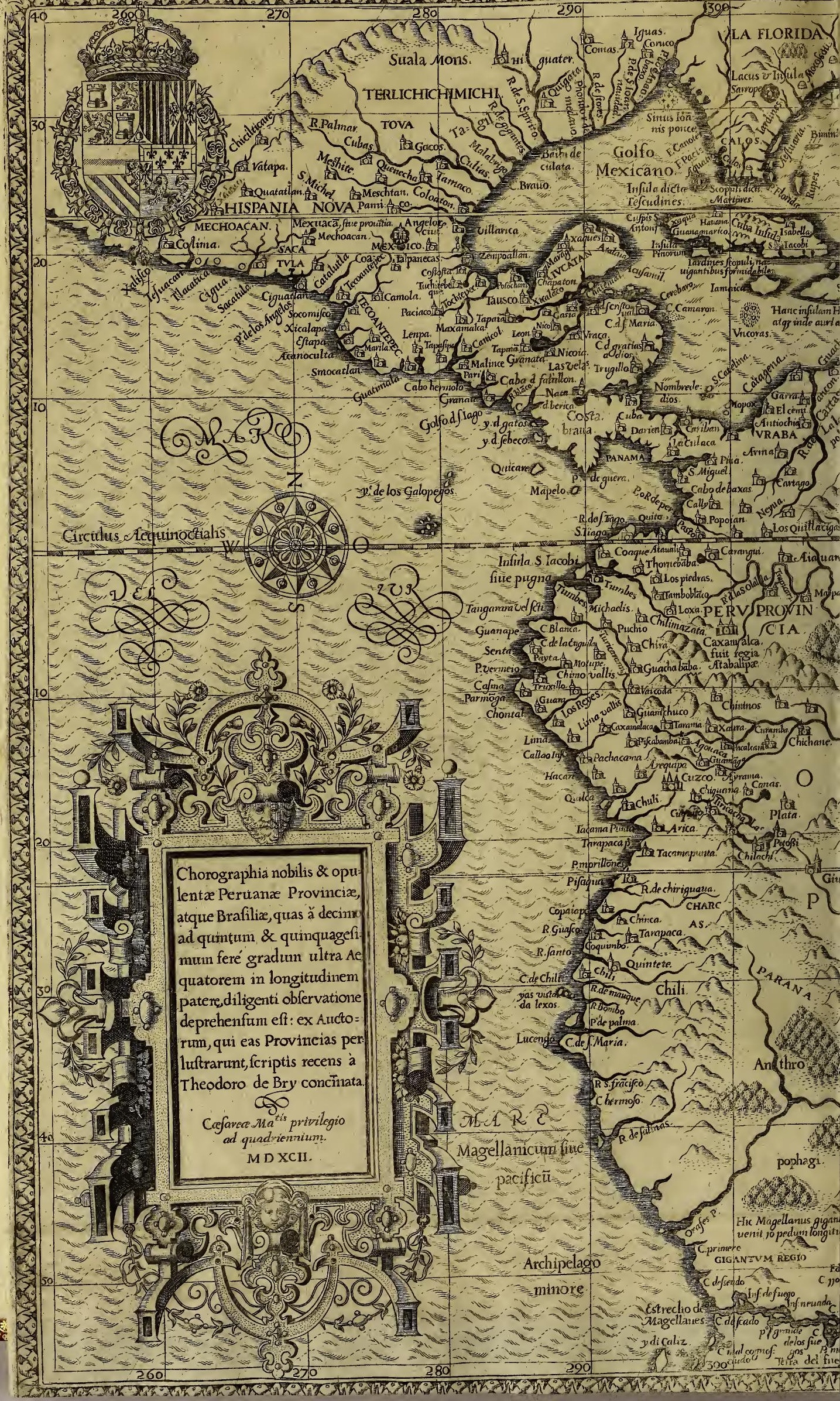




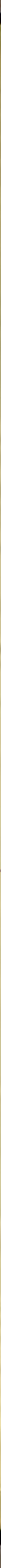




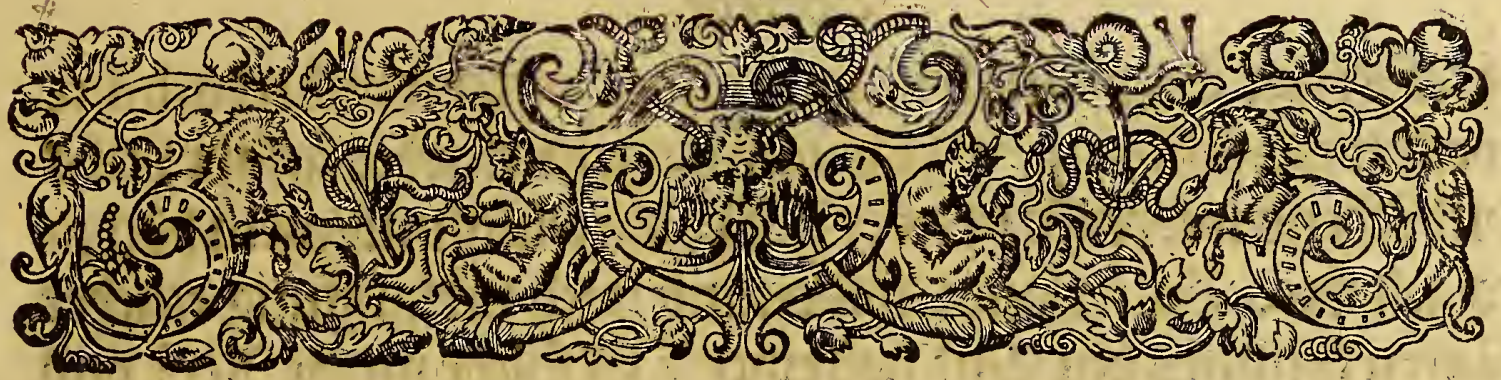

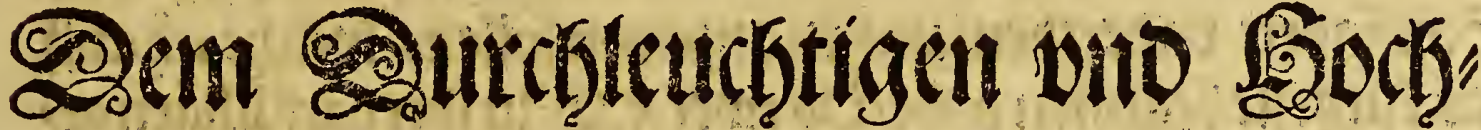

gebornen furrten onno Serrn/ Gerrn Pfilip fen Sand:

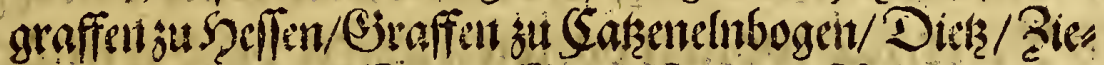
genfain uno Nioda/2c. Wlemem Enadigen Fitrfen vno jerzn.

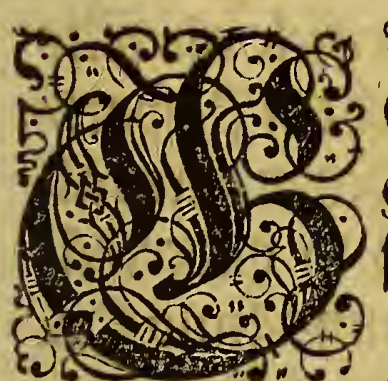

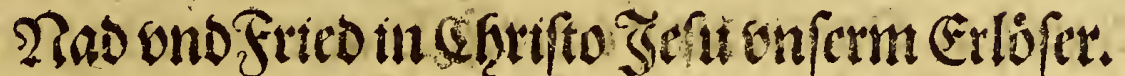

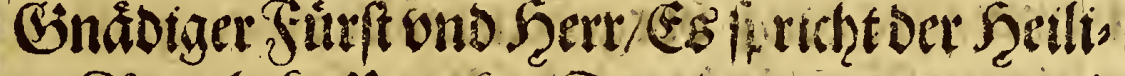
ge rionigltthe Proptet Salto/mintuntert ono fiebenden pralm:

Die mit Schiffen auff ocms?ere forfert/

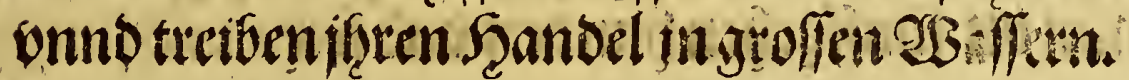

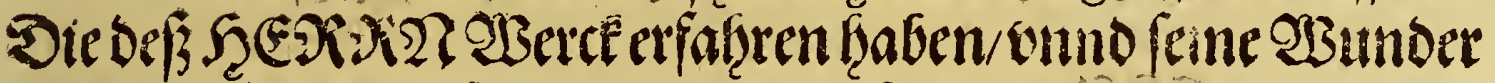
im SRedr. Wenn er fpract//ond cinen Sturmivinot erregete/ort

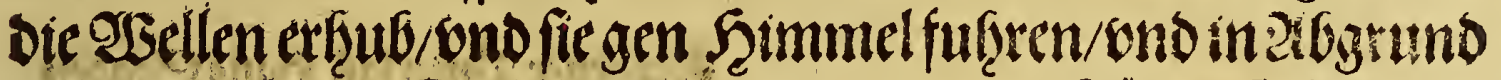

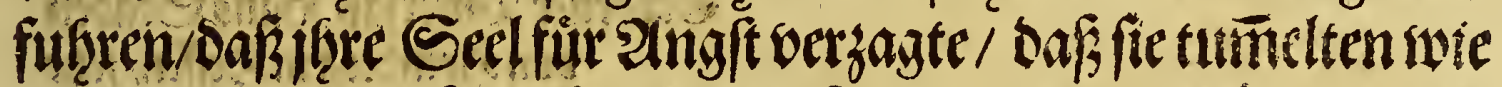

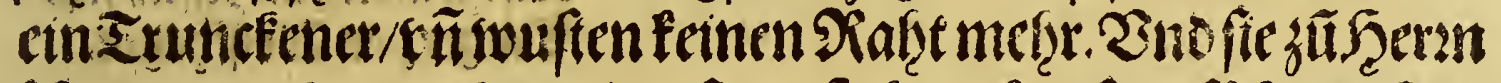

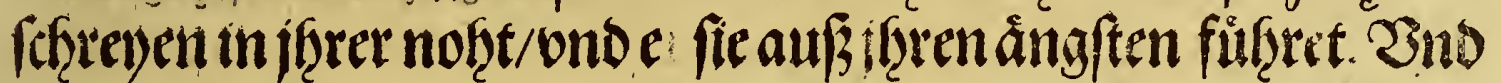

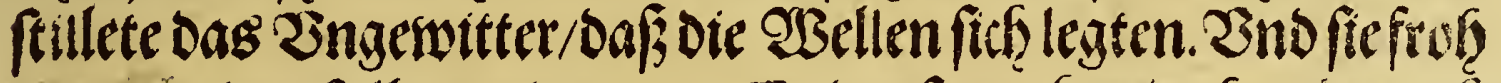

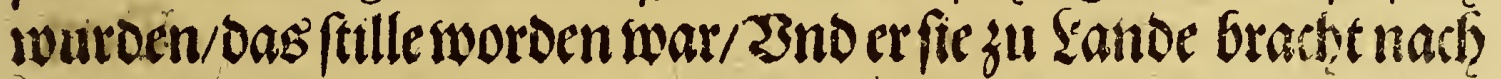

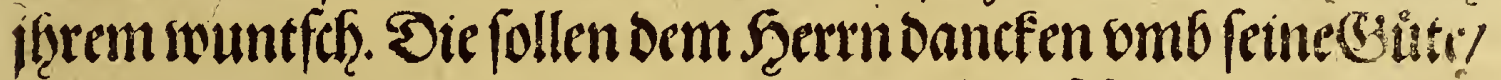

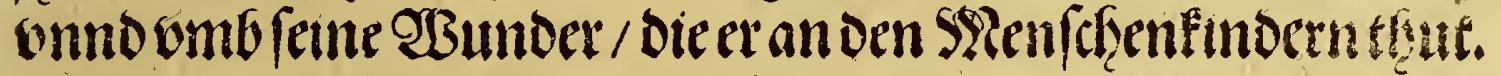

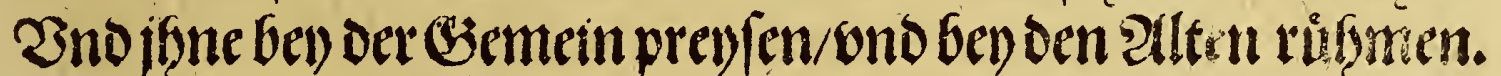

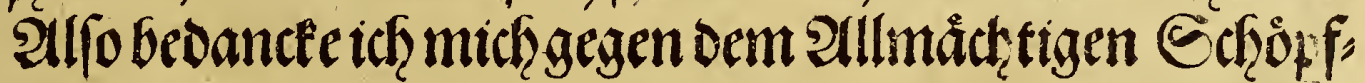

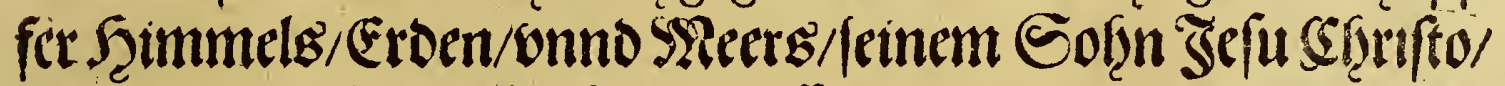

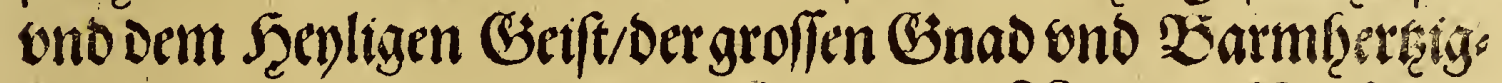

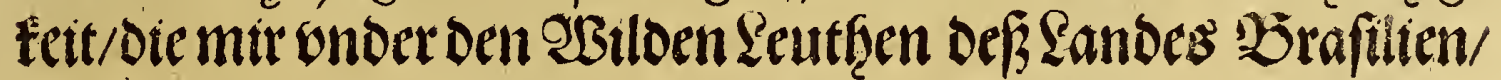

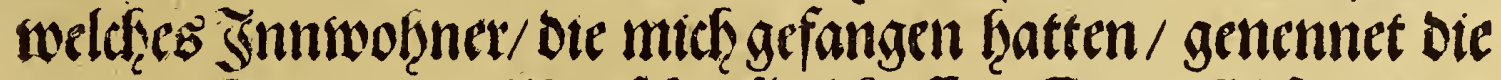

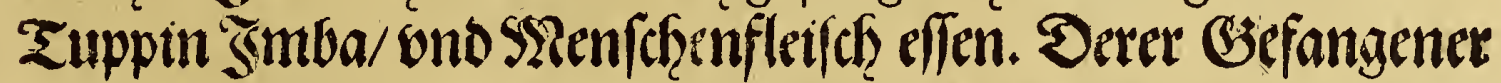

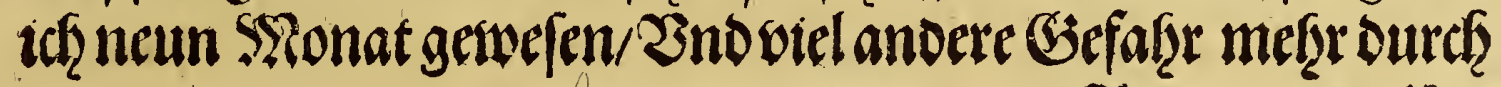
$\mathfrak{A}$

iffere 


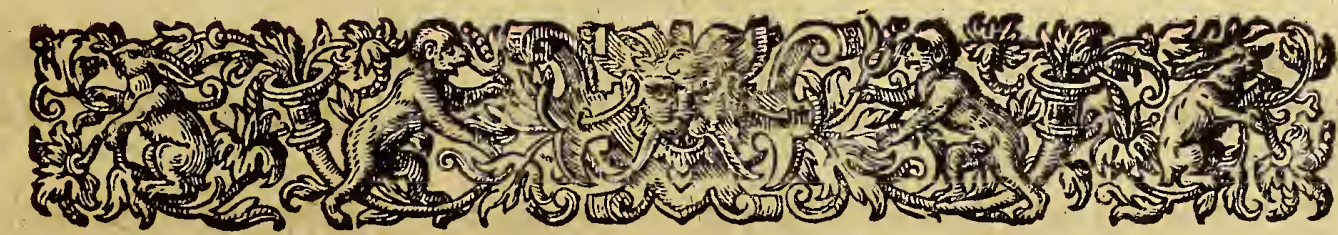

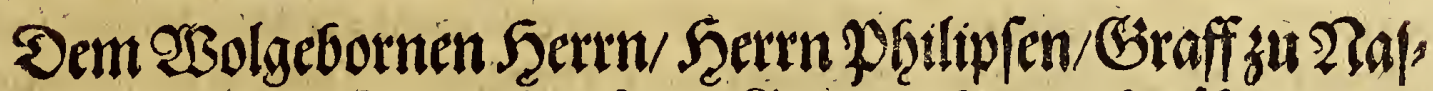

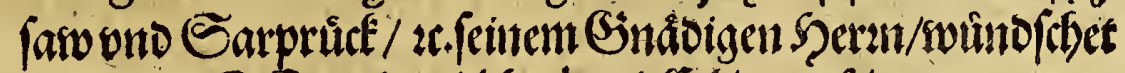
D. Drmander viel Seyle vno Erbietung foiner Dienft?.

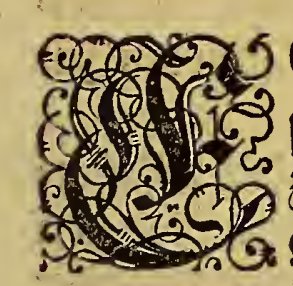

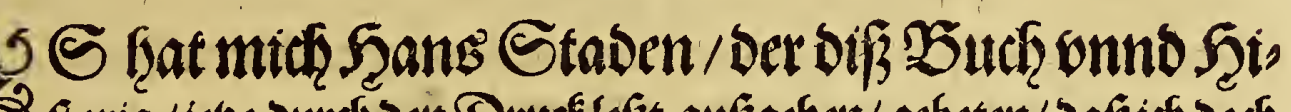

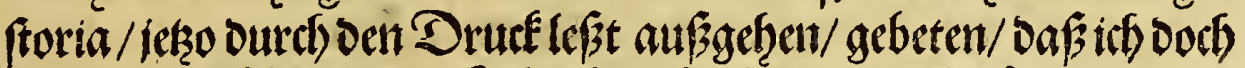

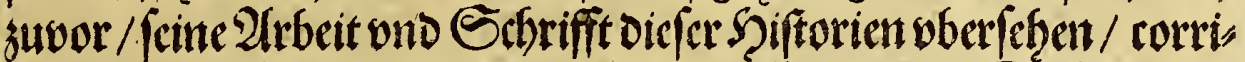

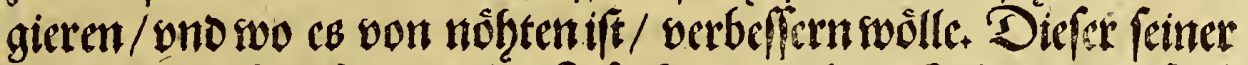

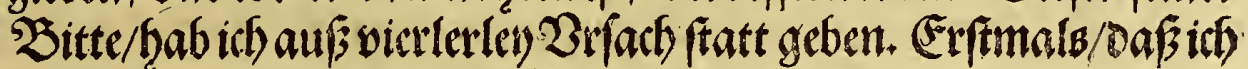

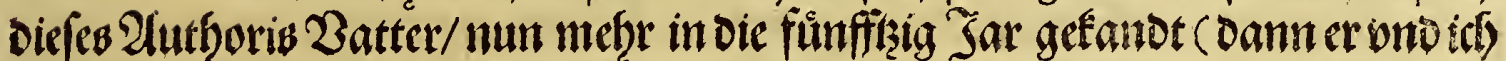

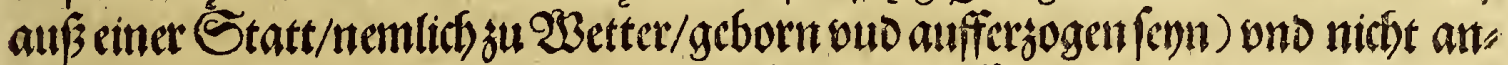

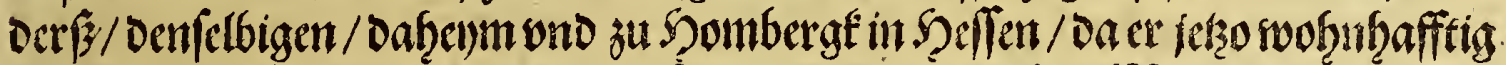
ift / Dant als für ein aufferthtigen / frommen onto Dapffern SYam / Der etroam

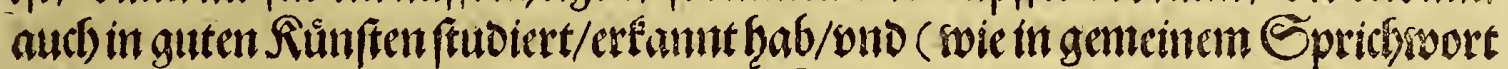

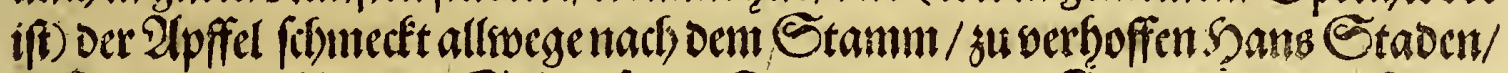

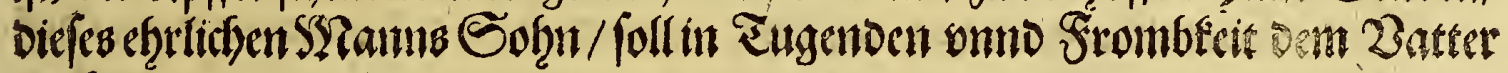
nacbarten.

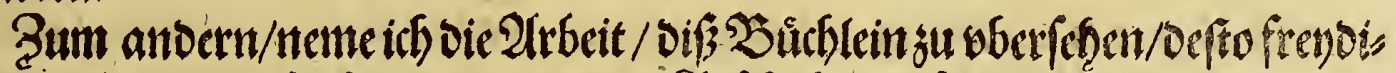

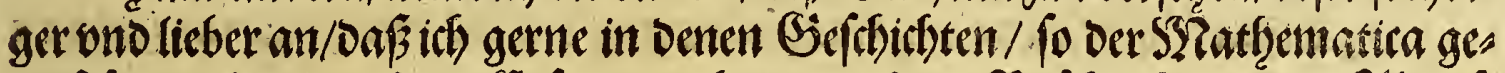

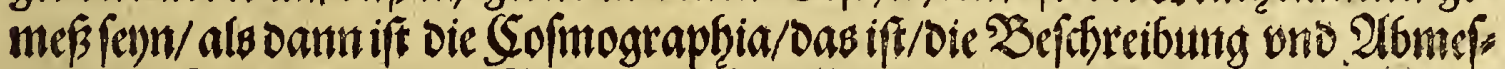

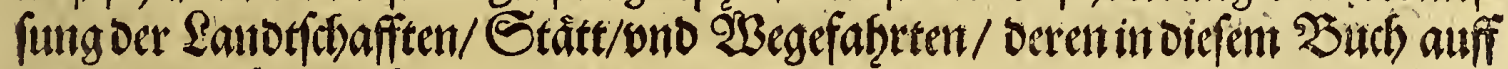

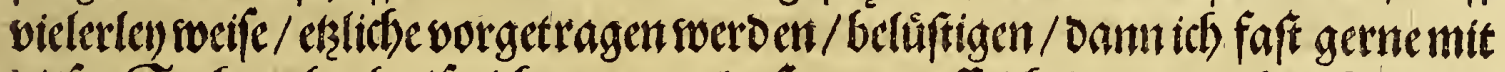

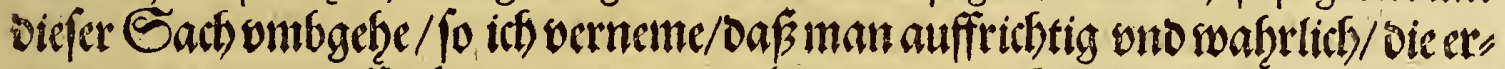

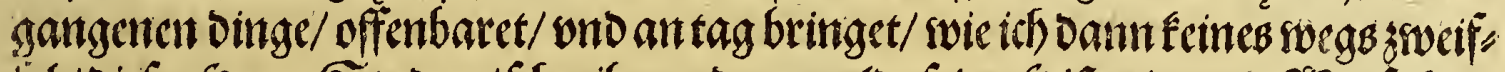

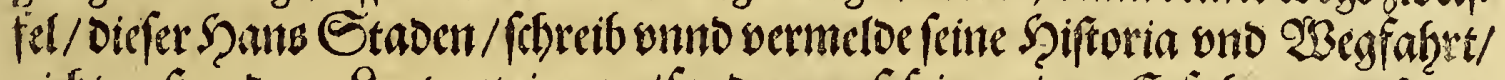

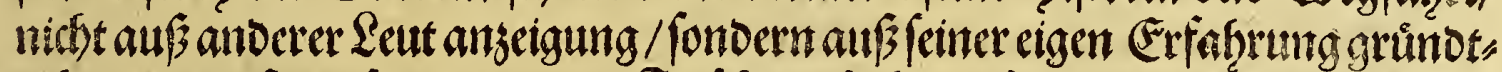

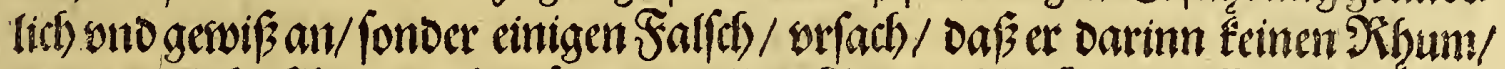

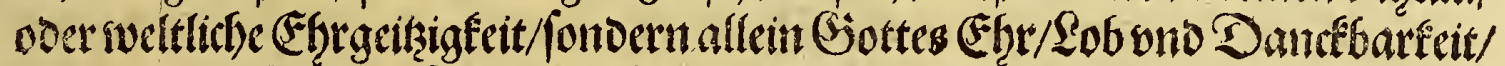

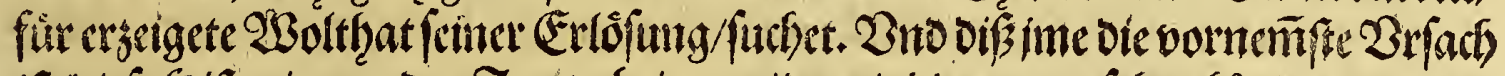

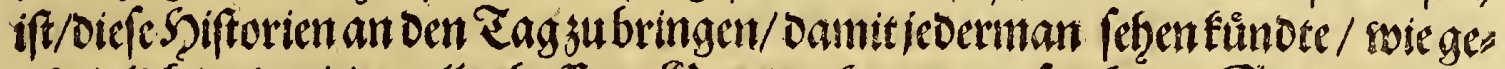

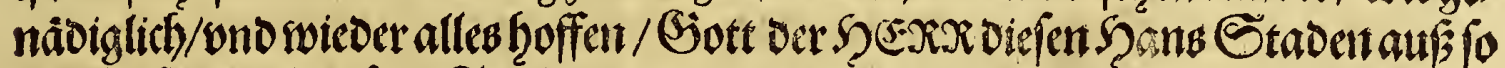

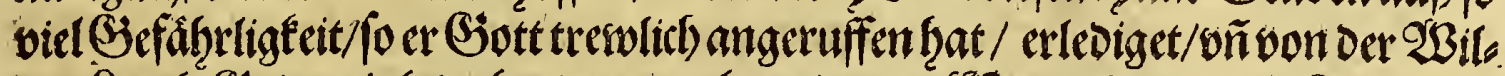

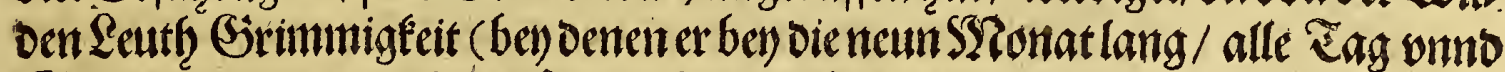

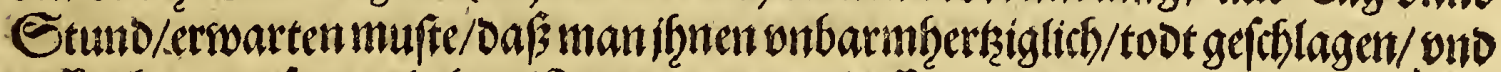

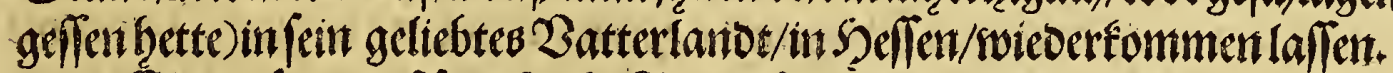

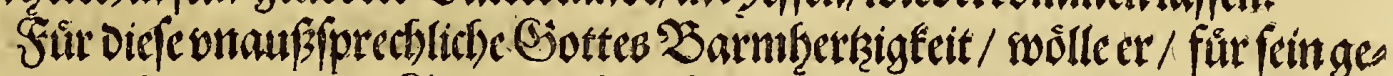

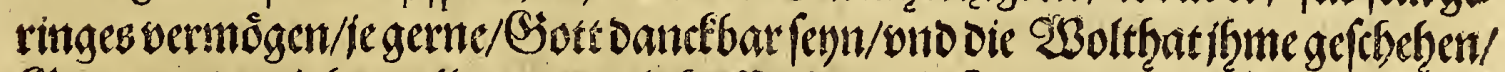

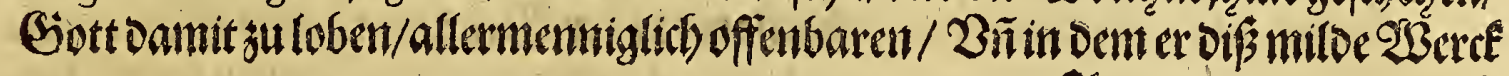
$\mathcal{A}$ if alfo 


\section{Zorrede.}

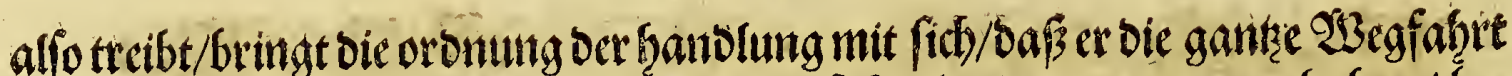

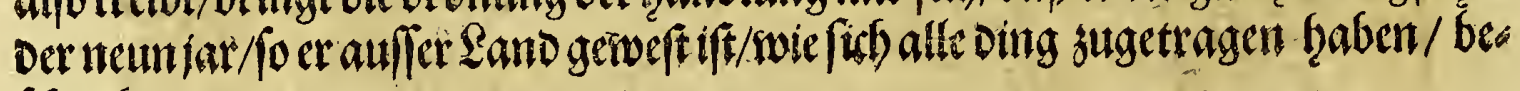
fatreibe.

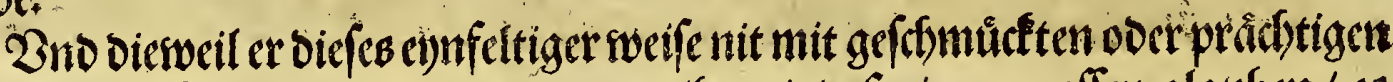

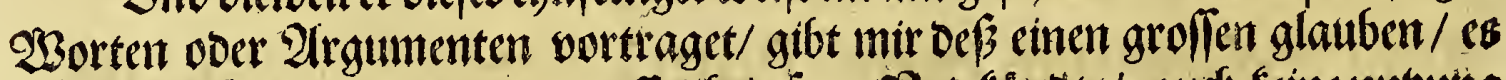
mulfe fein Sach beftendig ond auffrieftig /evn/2 Bno funt te fe auth feine nulzung

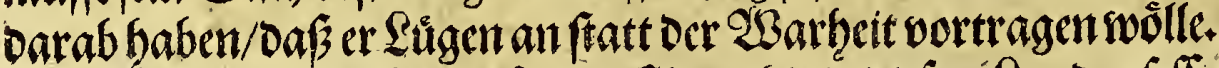

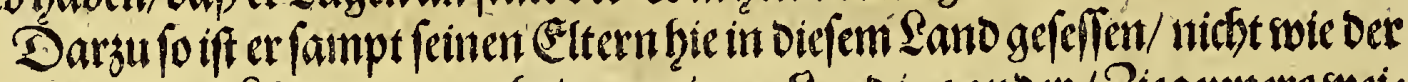

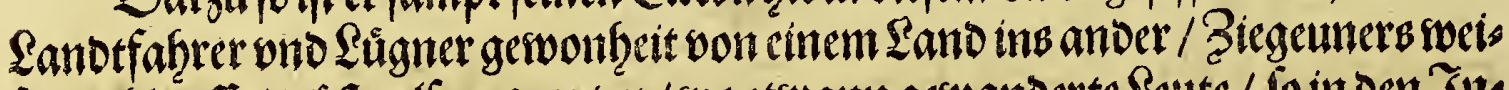

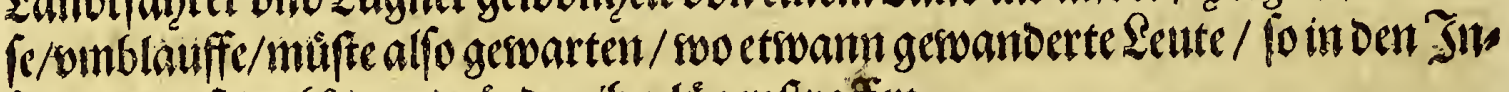

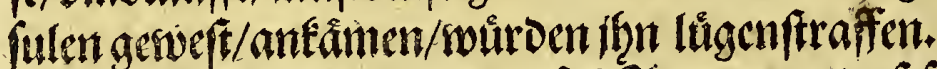

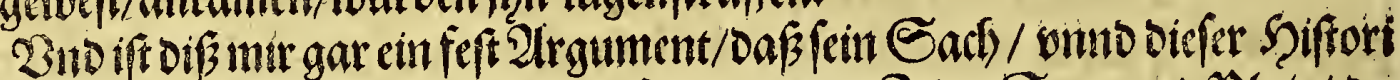

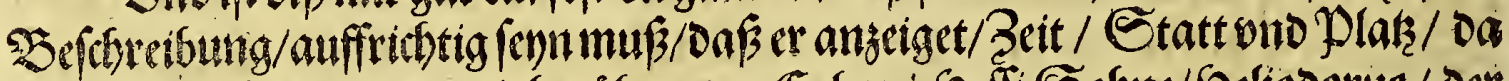

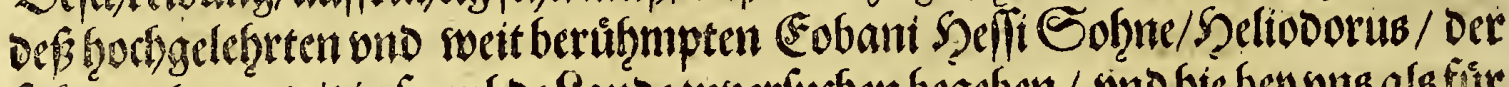

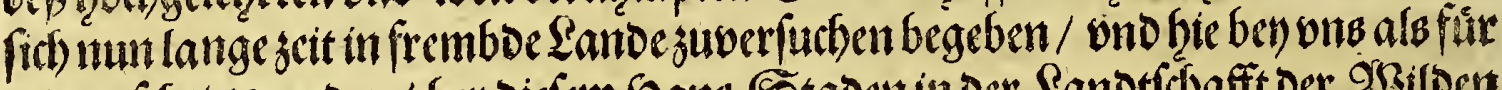

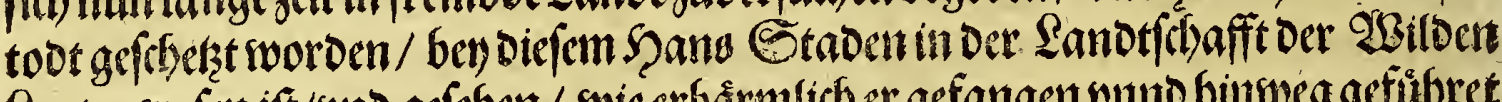

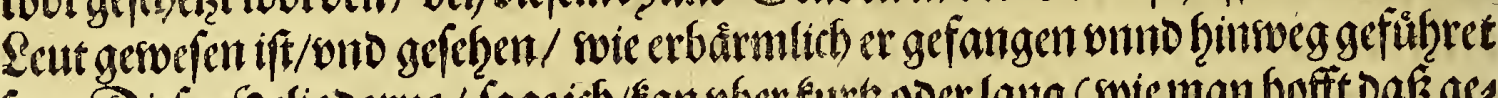

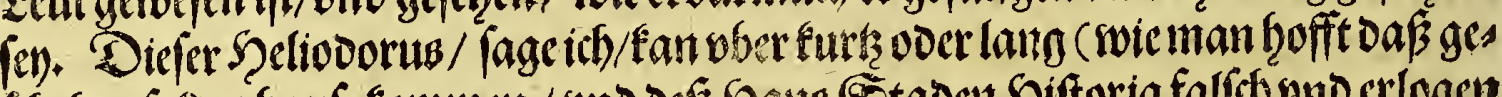

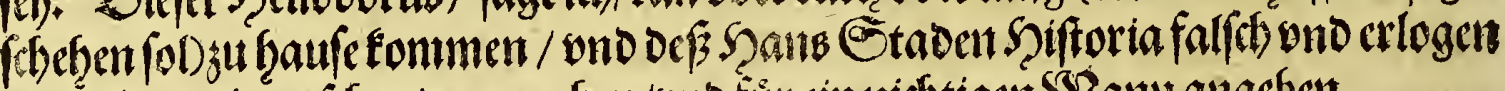
were/fan erin ju/chanoen mactsen/ono fur cin nichtigen SSTam angeben.

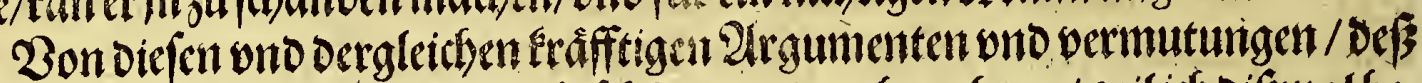

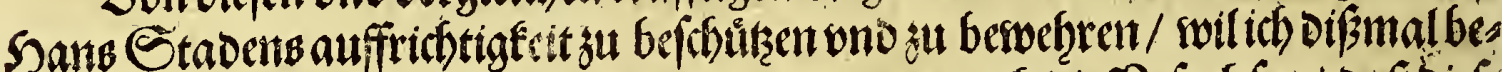

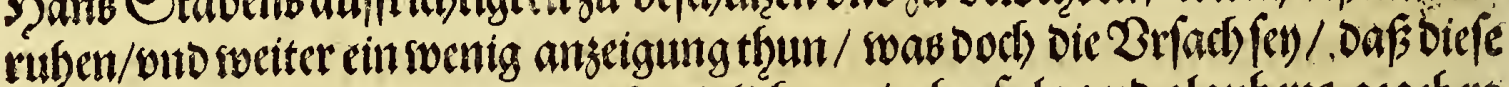

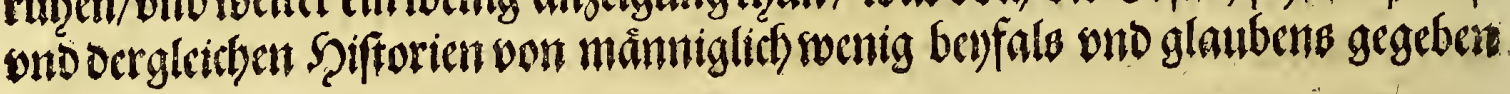
soerbe.

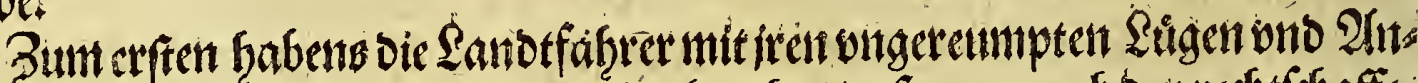

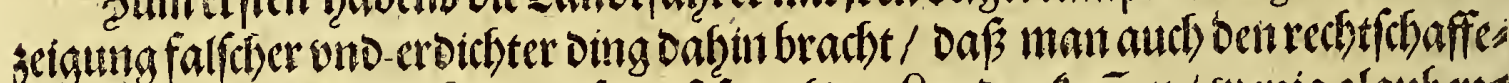
nett ono swarbafftigen Ietten/fo aus fremboen Sanoentomen/ wenig glaubens

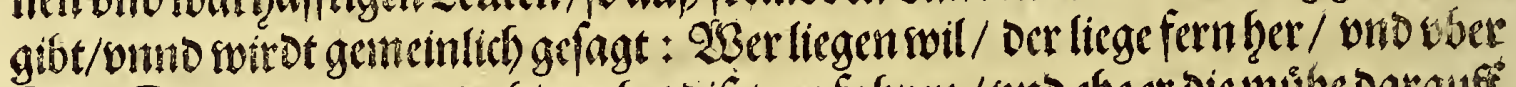

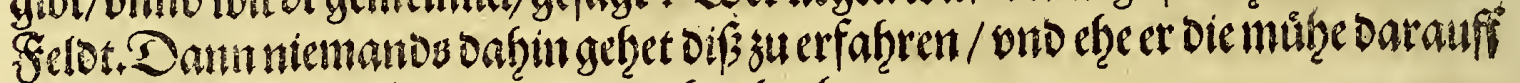

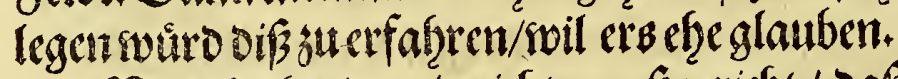

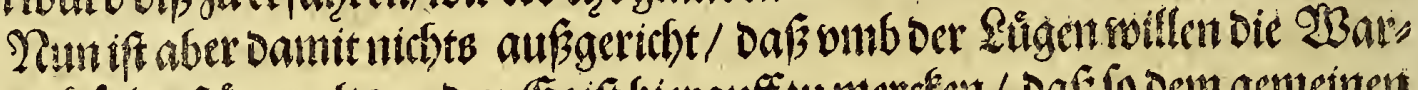

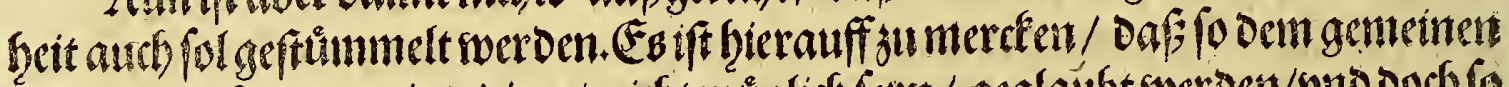

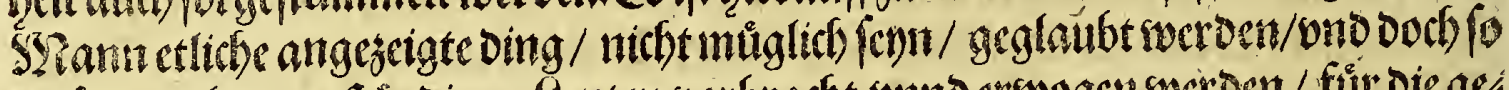

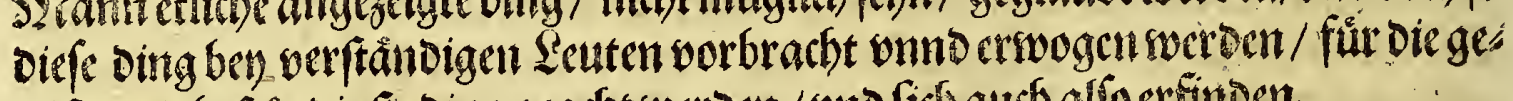

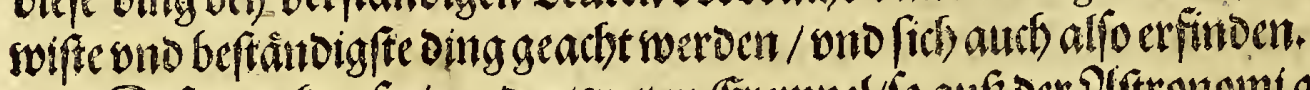

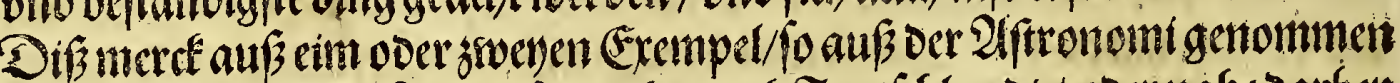

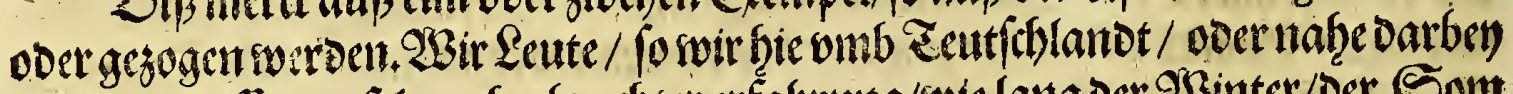

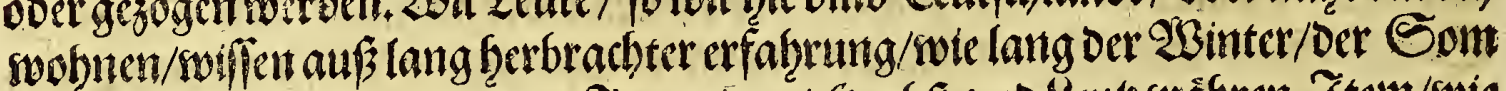

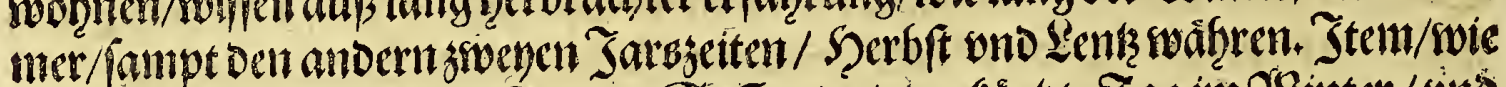

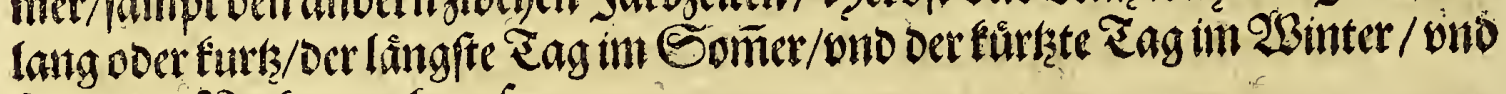

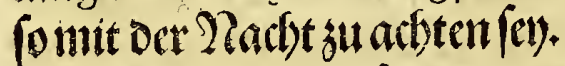

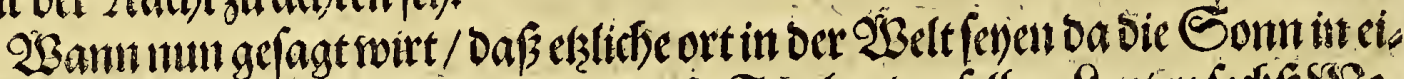

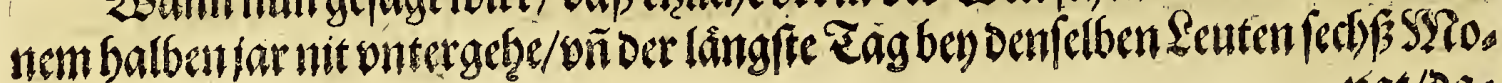
$\mathrm{mat} / \mathrm{Das}$ 


\section{3orrebe.}

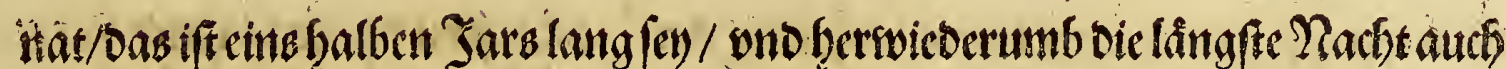

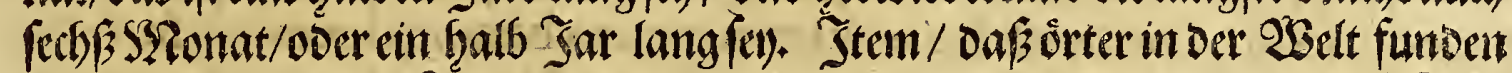
fwerden / Dain einem Jar / Die quatuor tempora, Das if bie viet zet Def Jarb

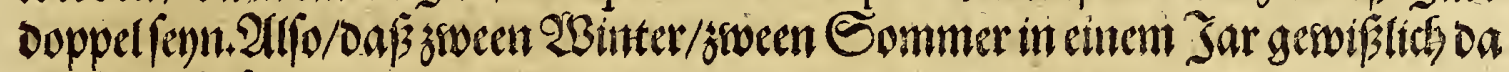
vorbeanoenfeynt.

Item/Daßjoie Soñampt andern Sternen / soie fleinfie ons bie fennoun

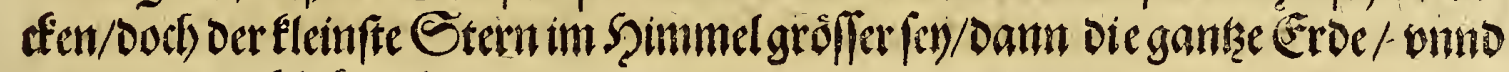
Der bing onzethlich wiel.

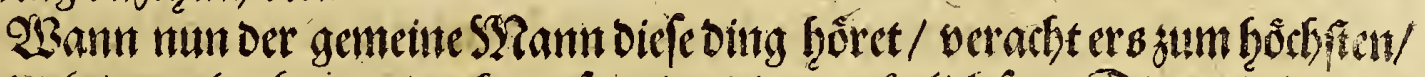

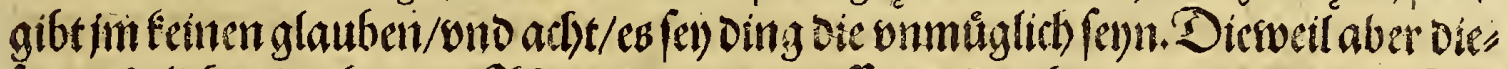

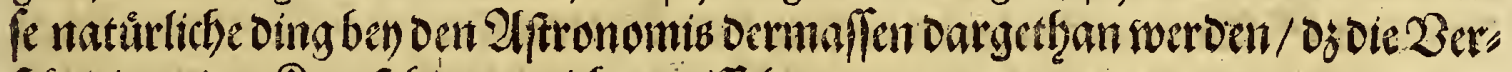

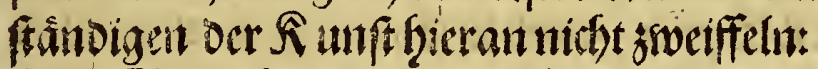

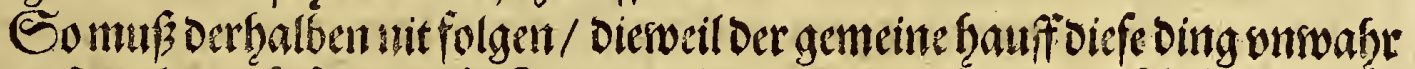

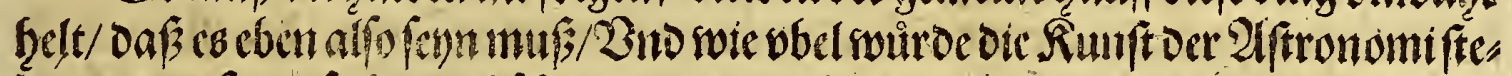

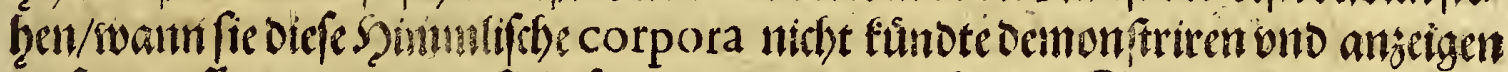

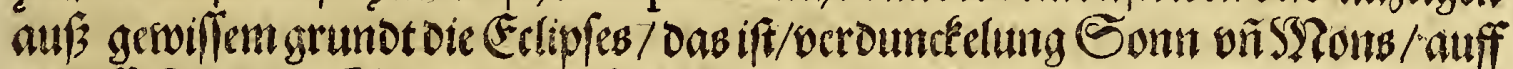

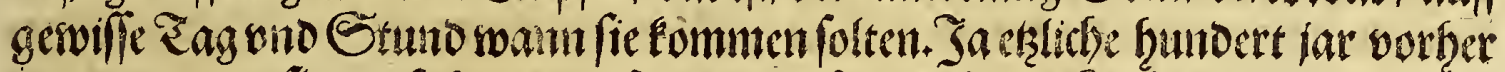

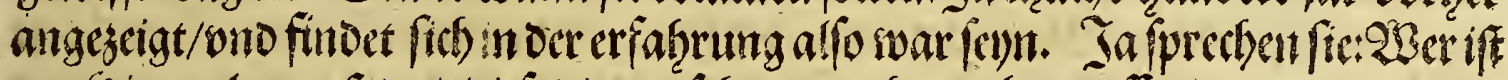

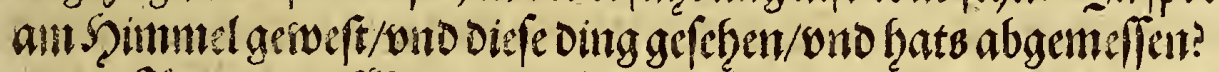

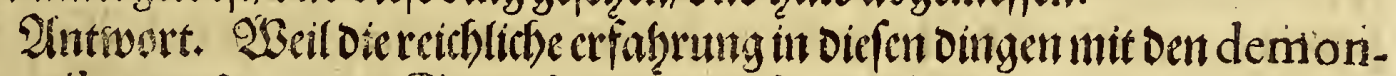

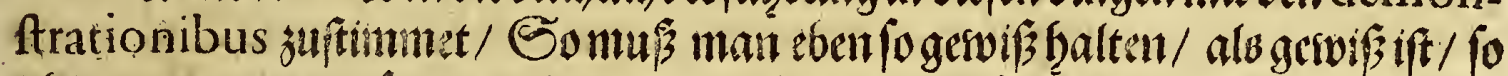

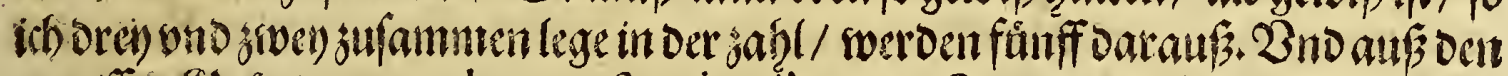

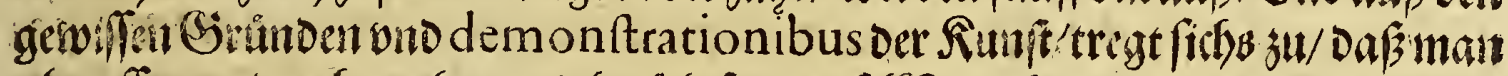

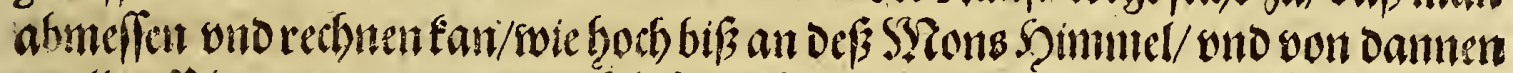

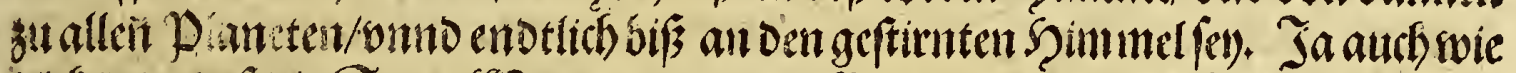

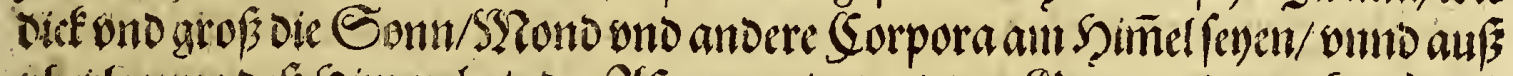

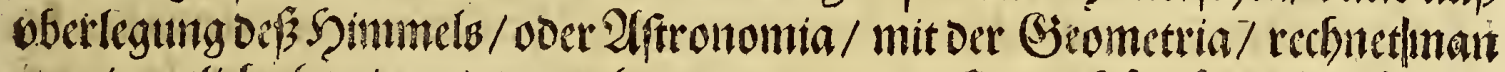

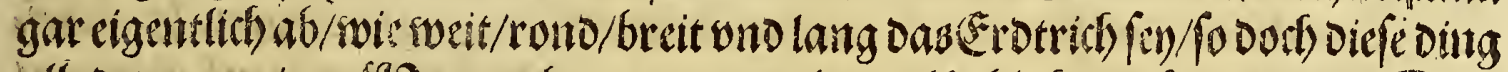

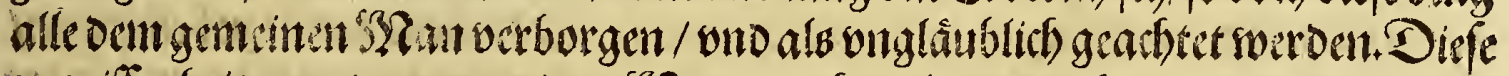

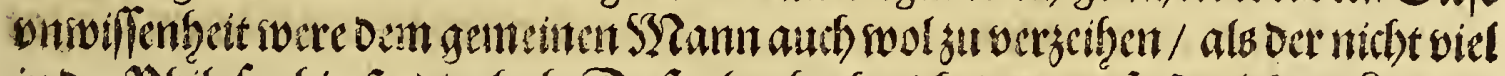

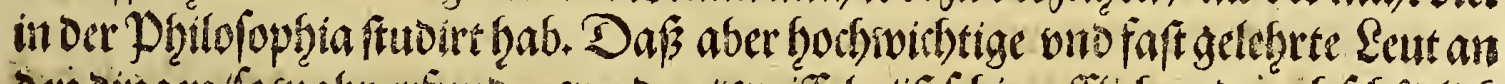

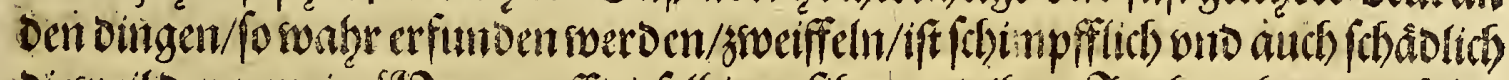

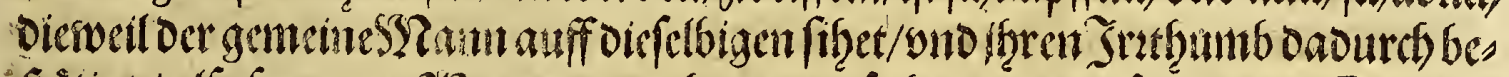

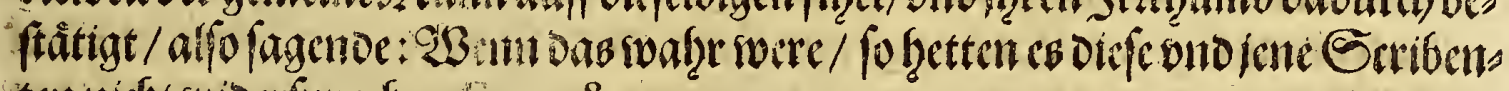
ten nicht rwideriprodben. Ergo, \&c.

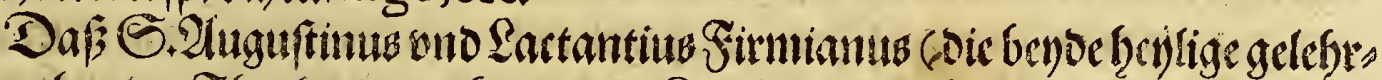

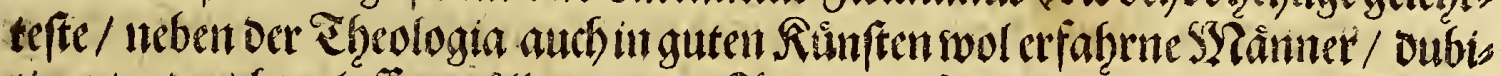

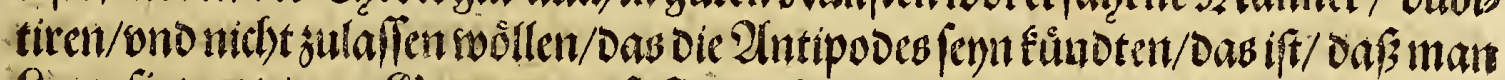

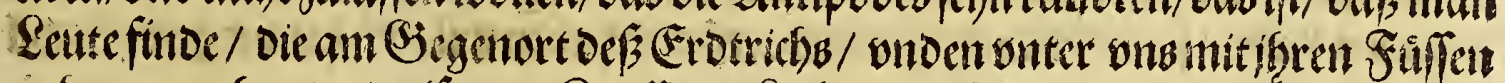

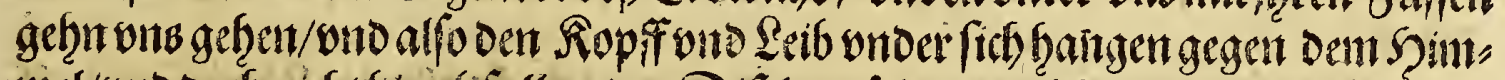

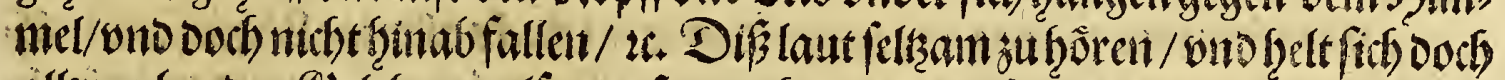

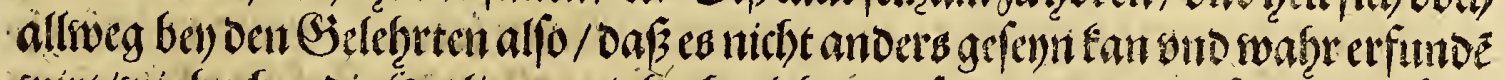

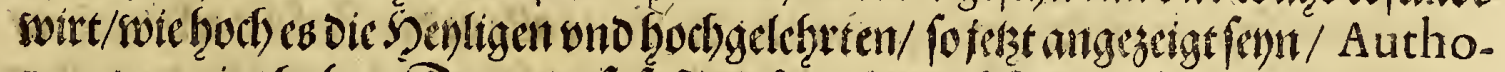

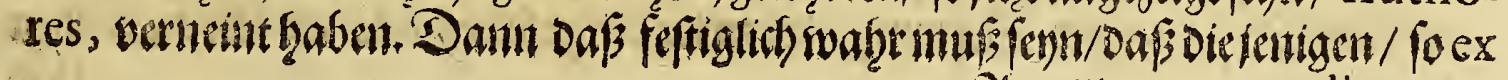

2 iij diametro 


\section{Borred.}

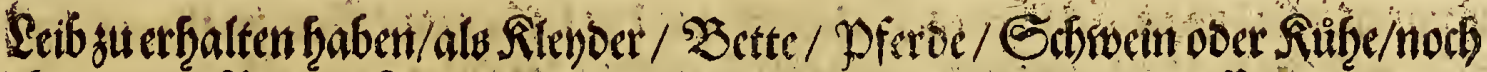

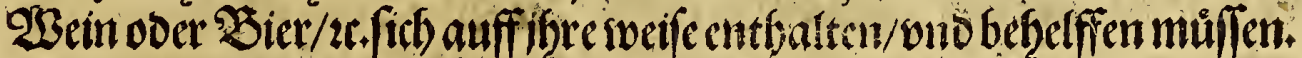

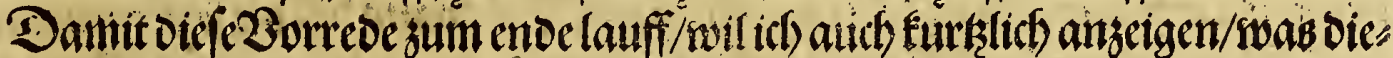

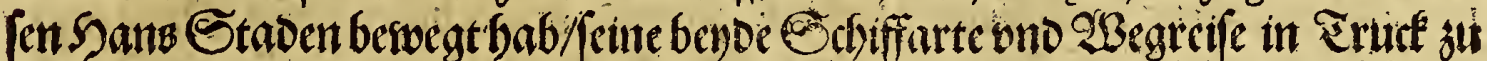

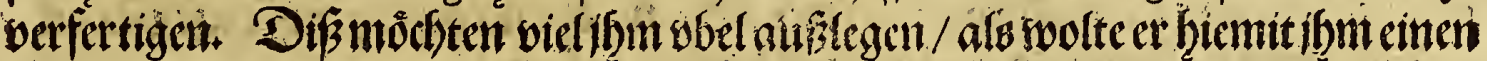

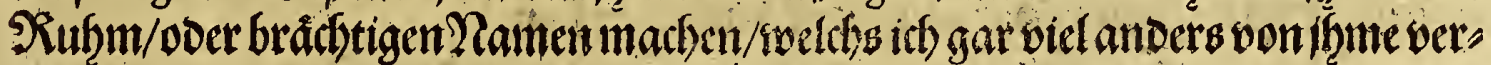

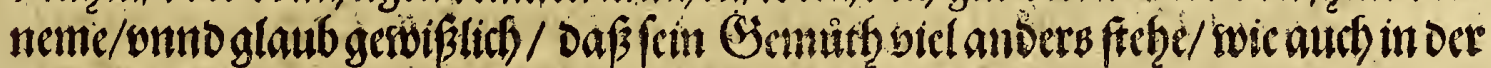

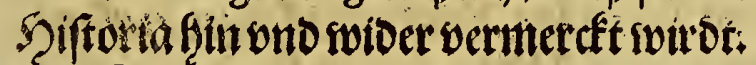

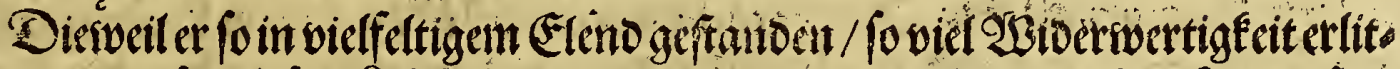

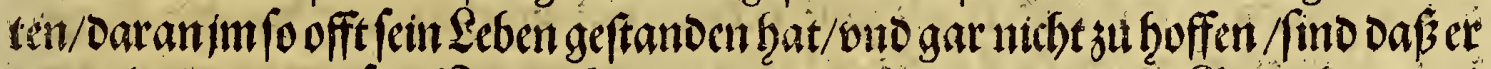

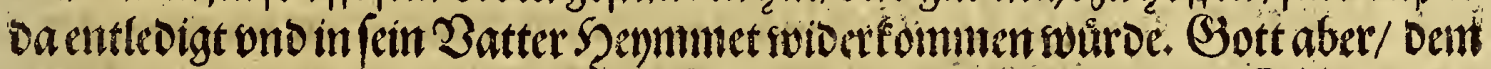

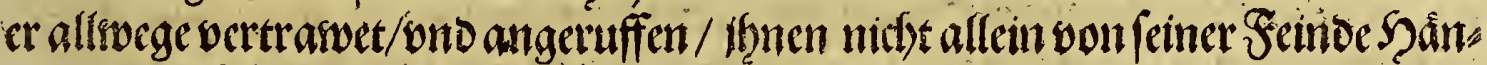

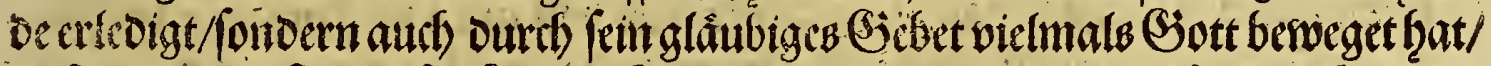

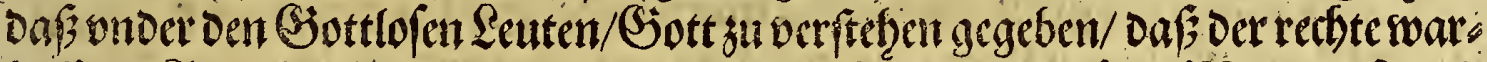

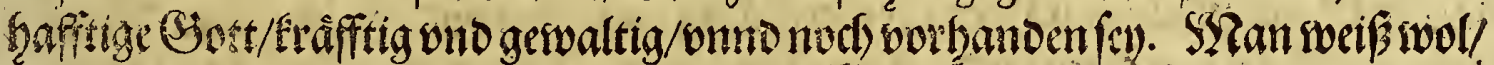

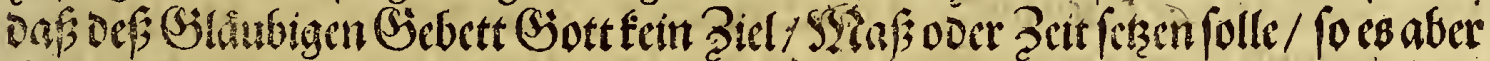

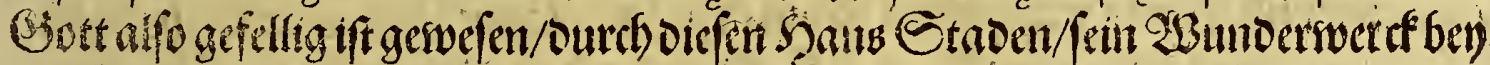

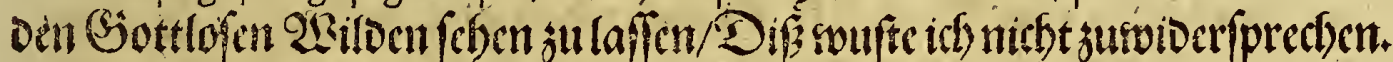

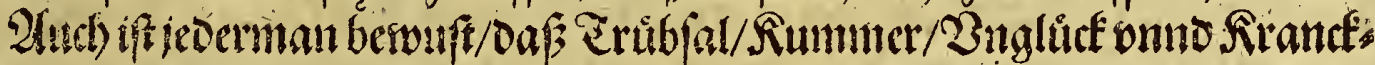

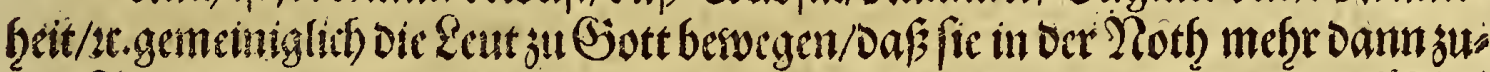

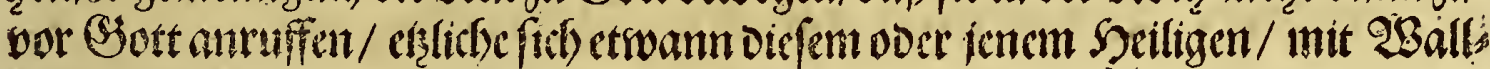

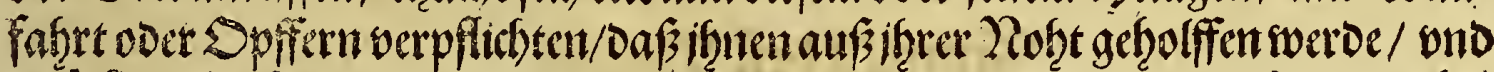

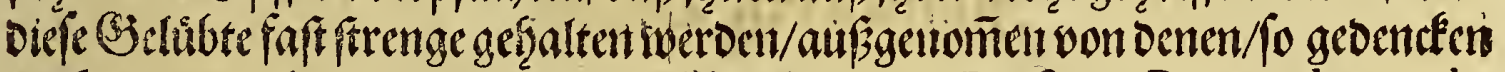
Die Sheiligent Colloquiis in oem Naufragio fobrtibet/os einer in Schiff S. Shriftophorum/

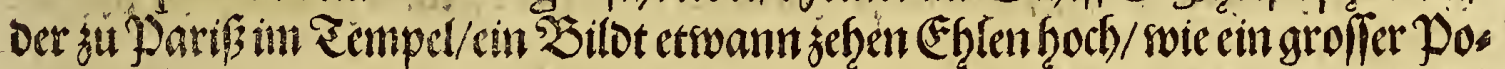

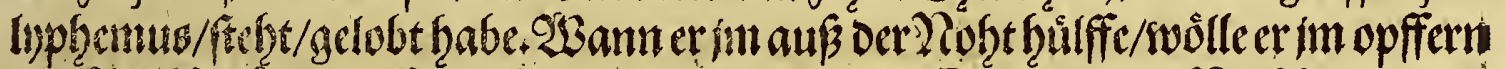

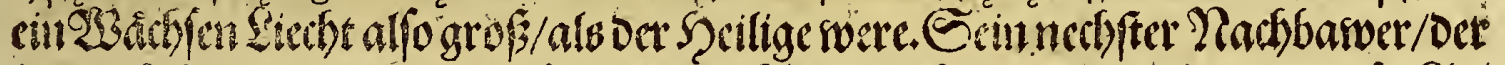

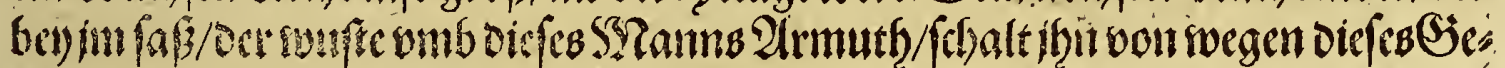

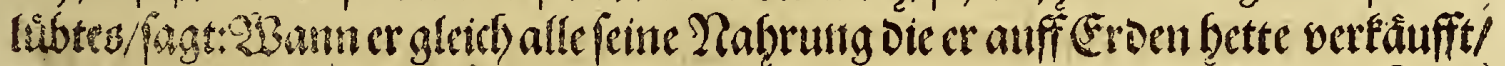

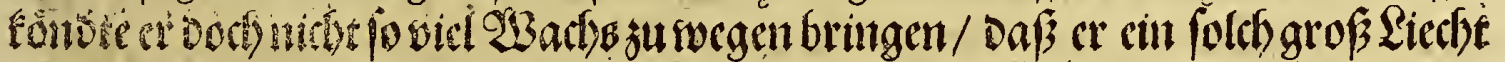

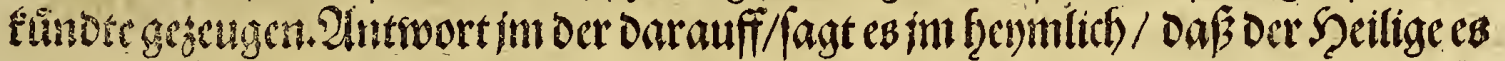

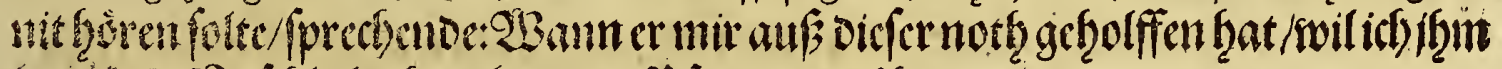

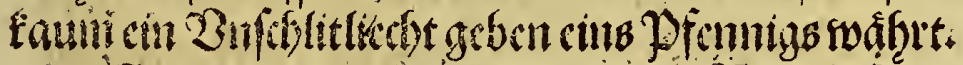

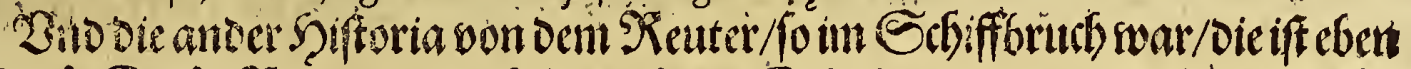

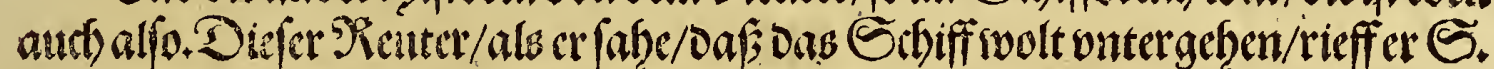

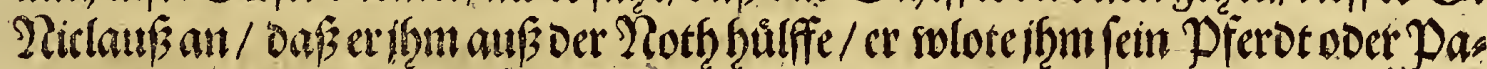

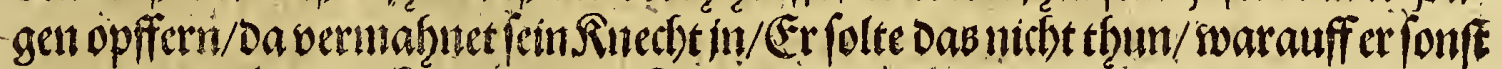

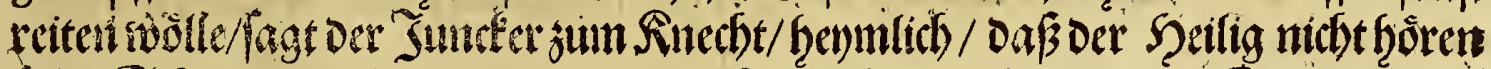

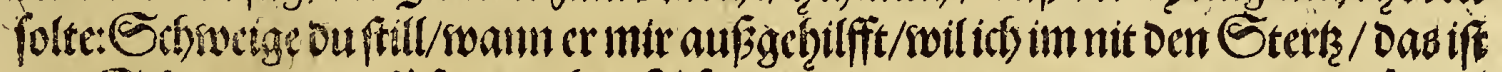

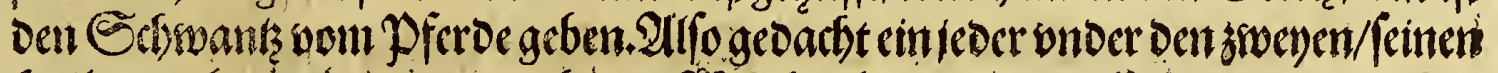

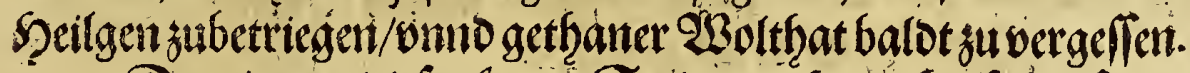

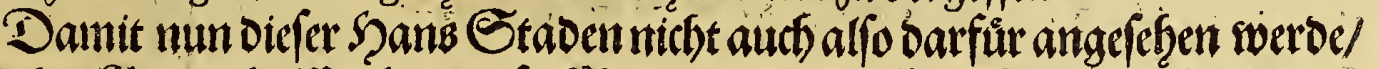

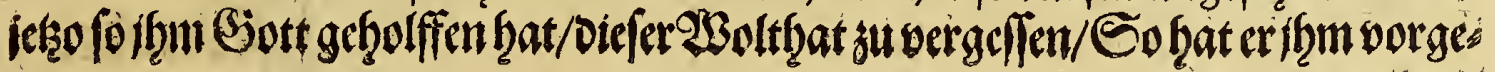
nommen 


\section{Zortede.}

nommen/mit Diefem Eruck/vitb Seffretbung Det Siftorien/Sott in allwege wu

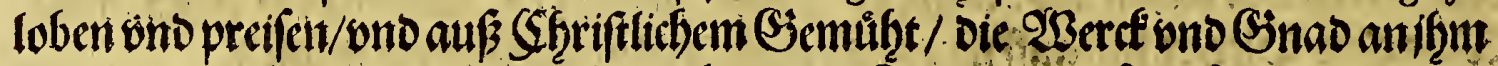
crzelgt/wo er fan vono mag/ant tag zubringen.23no wann oif nit fein wornemens

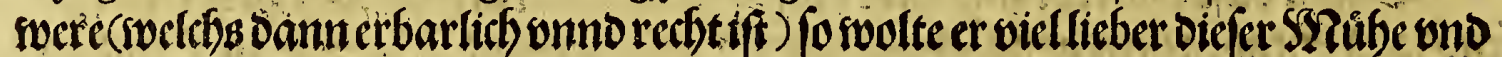

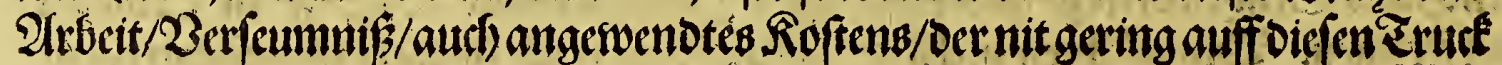
onv Formen jum iffineibenergangen ifi/enthaben fenn.

Db swol diefe Siftoria aber Durd Den Aluthorem oem Durchleuthtigen/

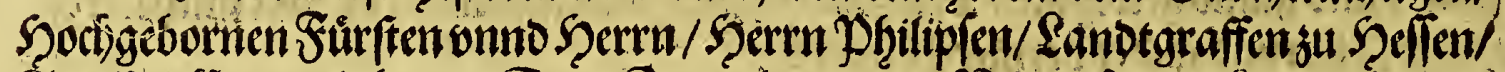

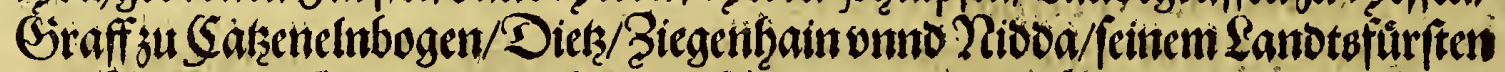

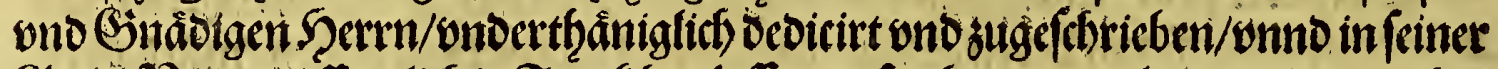

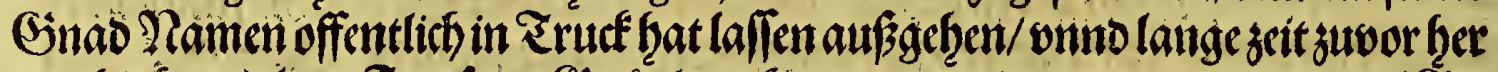

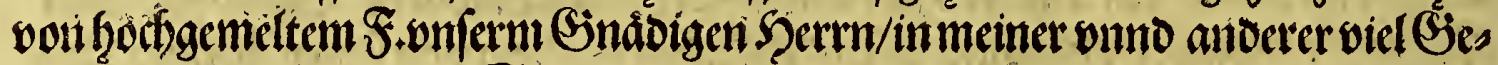
genswertigfeit/Den Şans Staden examinirt/ono von allen fruefen /einer Sebifs

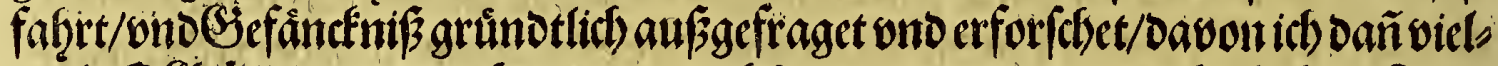

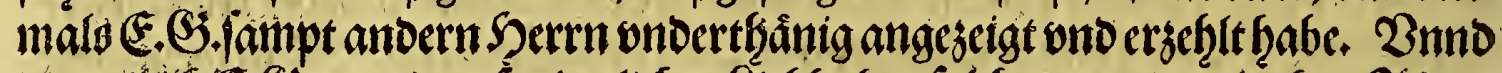

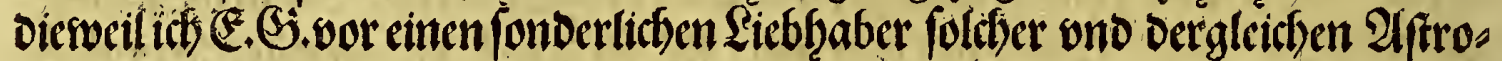

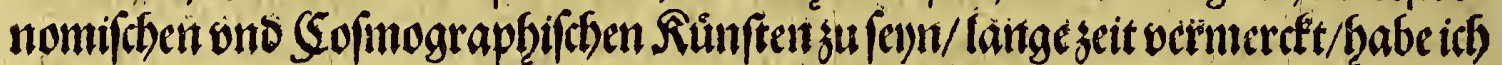

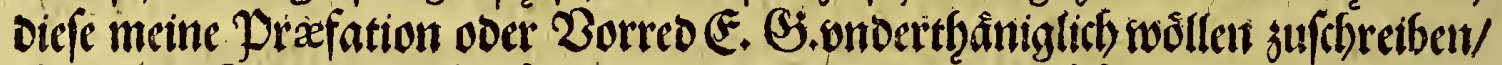

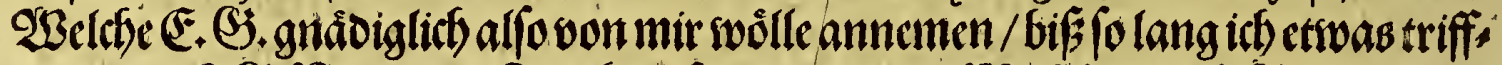

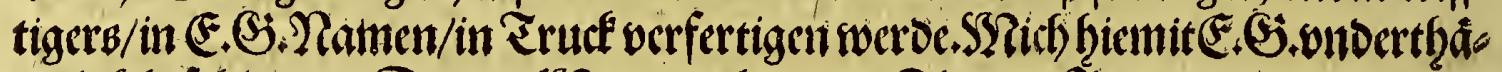

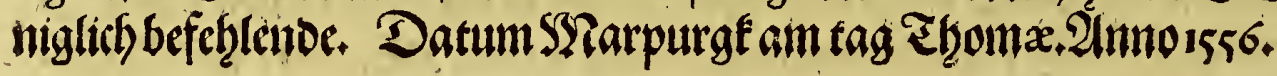

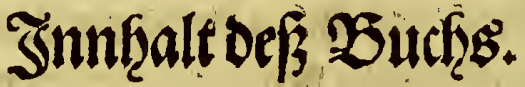

I.

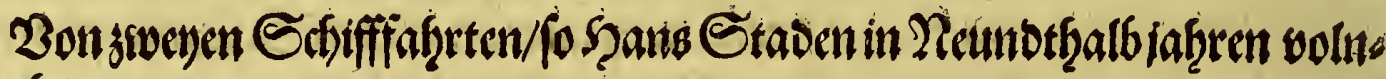
bractithat.

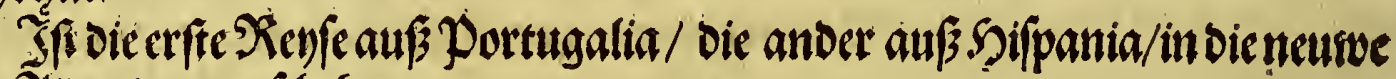

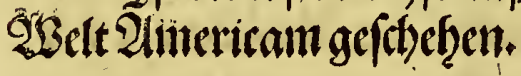

II.

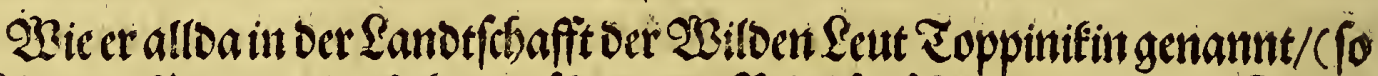

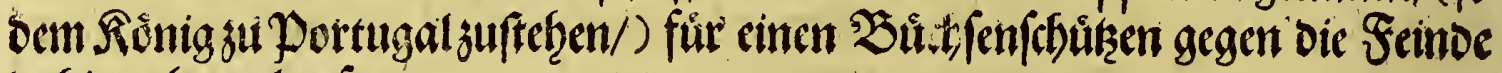
Dafing getrantbet ( ery.

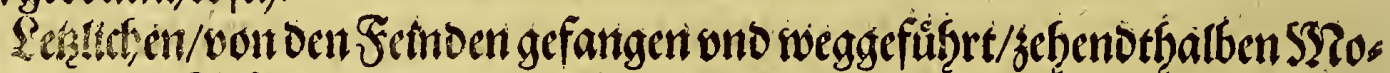

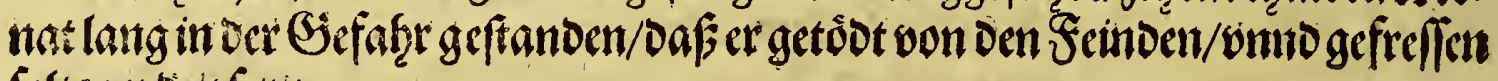
folt foorbenferit.

\section{III.}

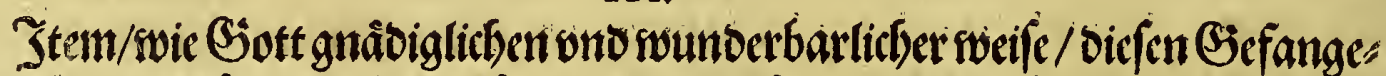

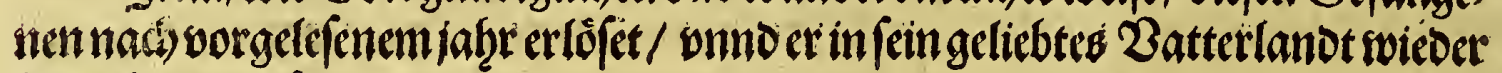
bevm fonmen (on)

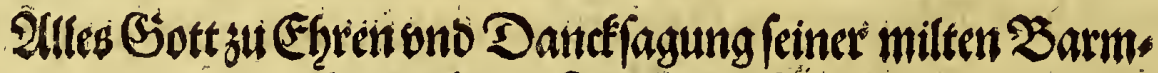 berkzigfeit in Erud gegeben.}




\section{Capittêl.}

\section{SSimoerbartiche vund warfaffitige}

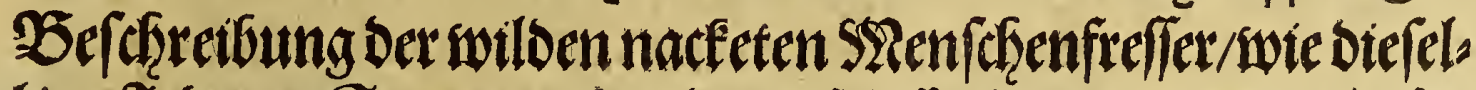

bigen Johantes Staben/wonSomberg auf Soffenburtig/in engener Perfon

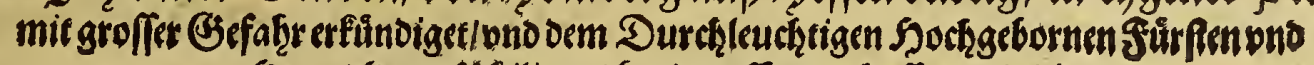

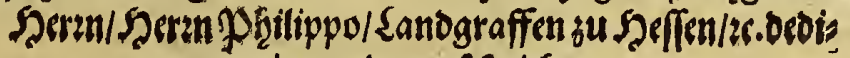
ciret ond sugejoftrisben.

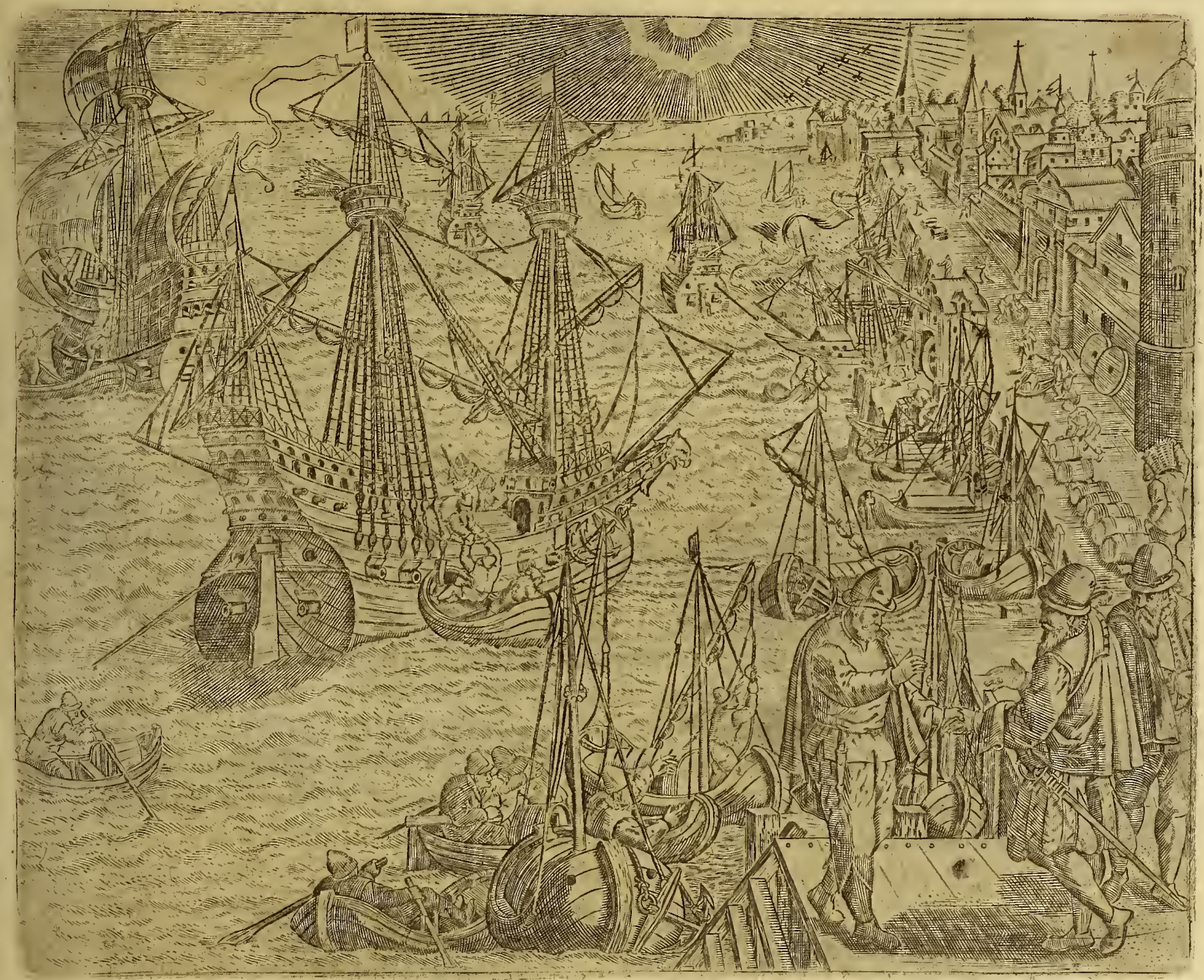

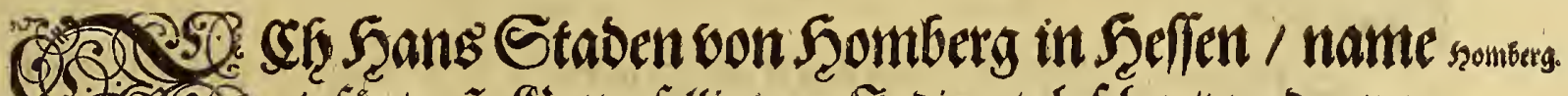

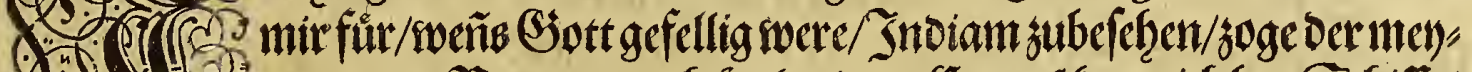

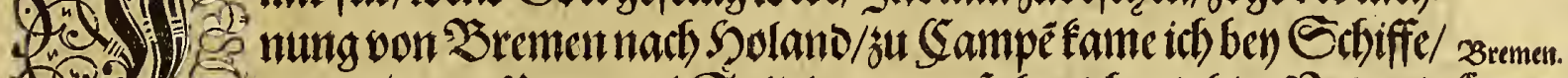

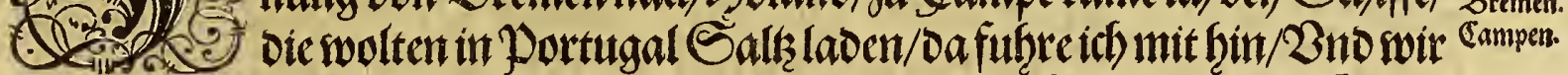

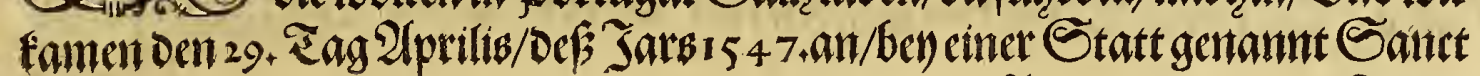
$\mathfrak{B}$ Iunal 


\section{Orantfanftitige Beffrretibung}

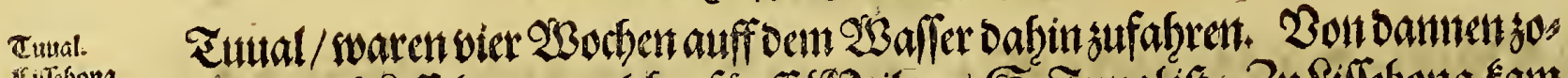

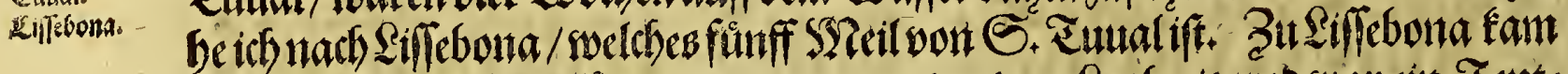

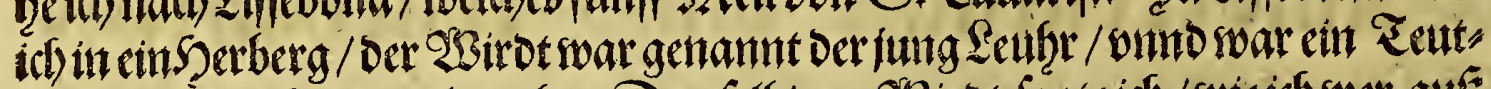

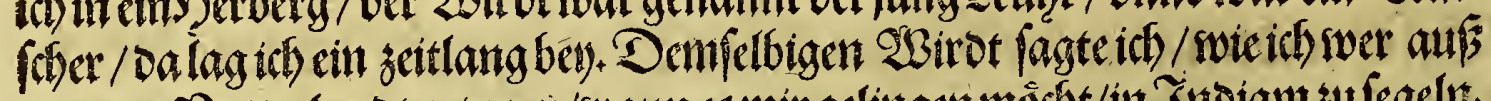
meinem Baftetland gesogen/swann eBmir gelingen mocht/int Snoiam zulegelr.

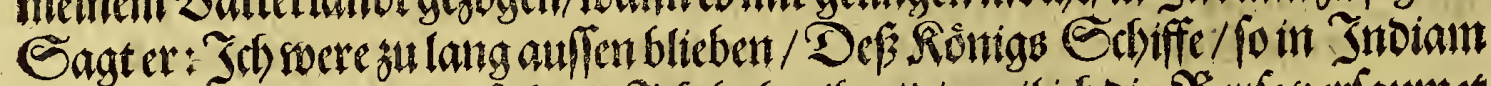

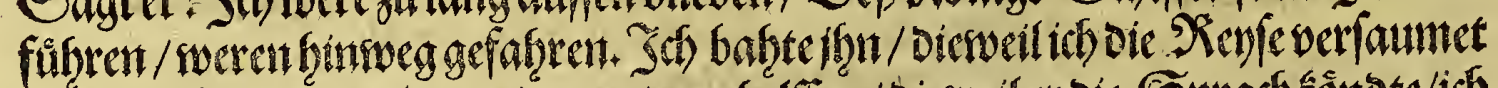

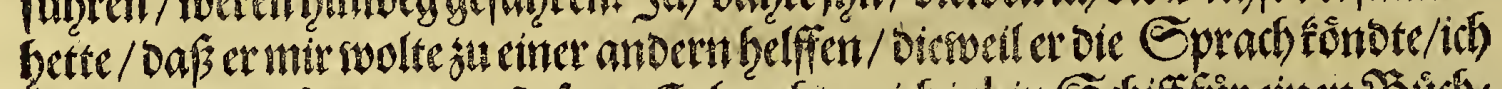

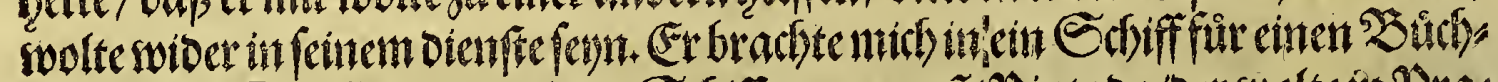

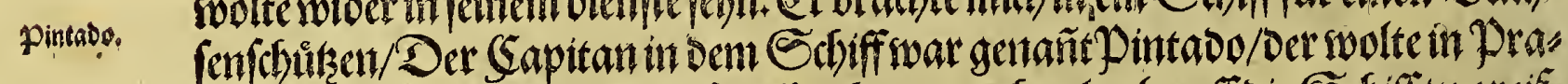

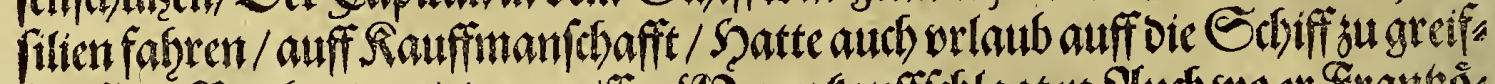

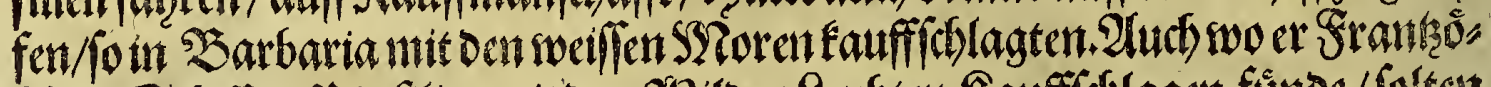

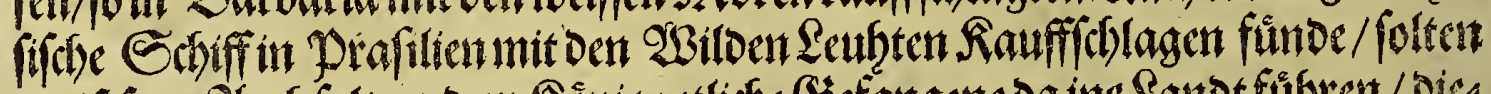
Contmiffion manns.

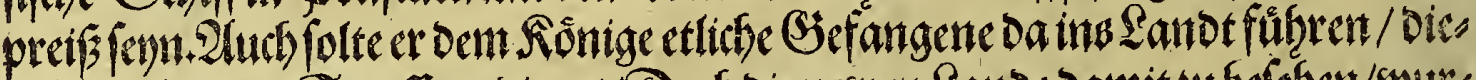

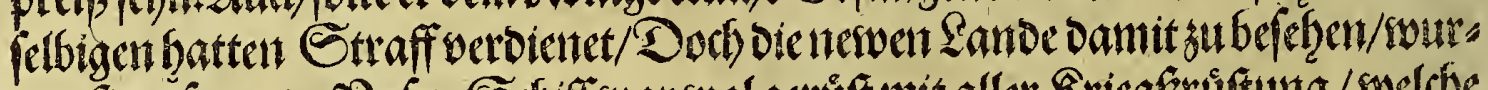

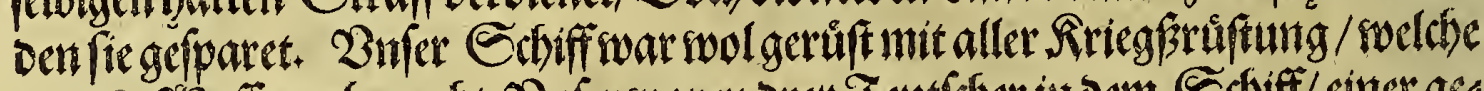

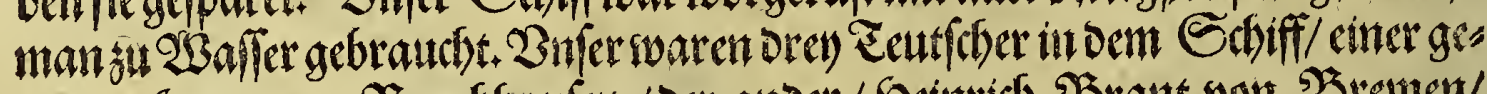
Shanswon

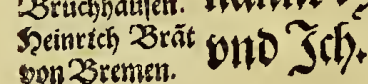

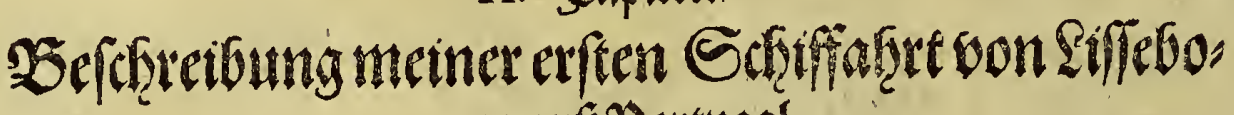 naausportugal.}

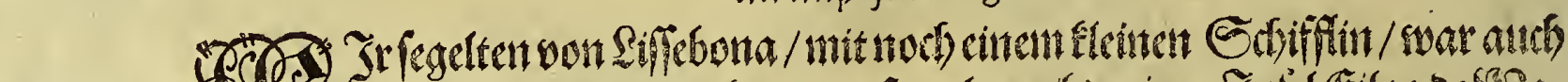

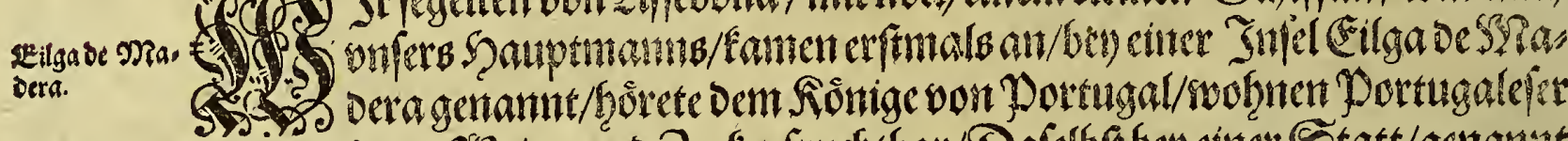

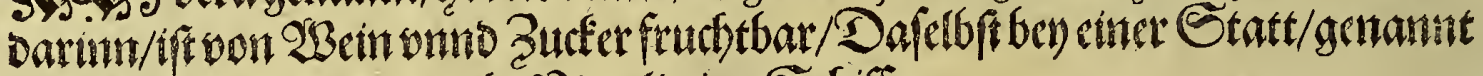

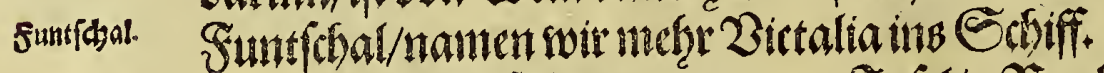

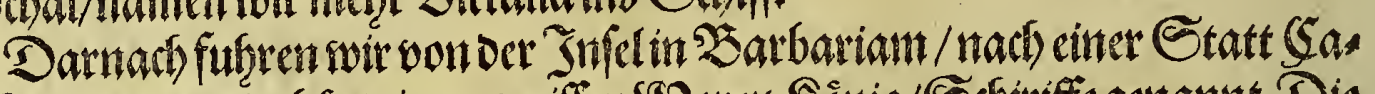

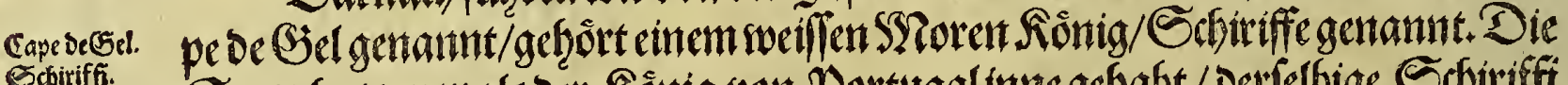
Statt hat wormals oer Routig von Portugal imme gehabt/ Derfelbige Echiriffi

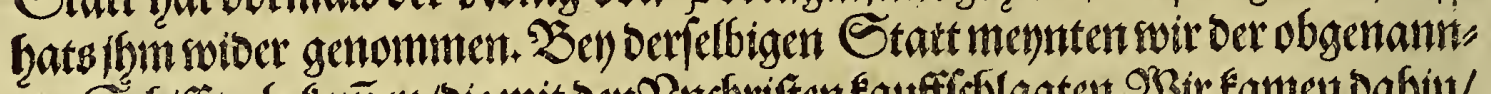

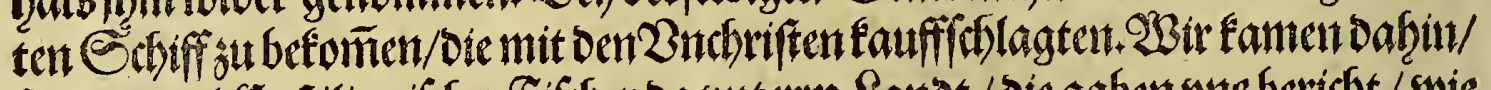

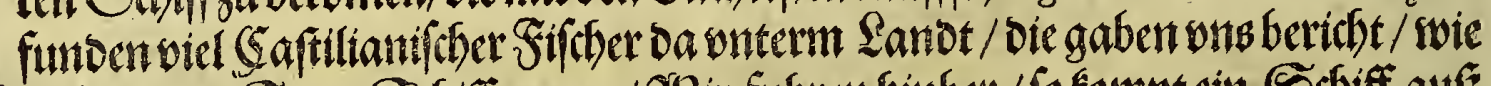

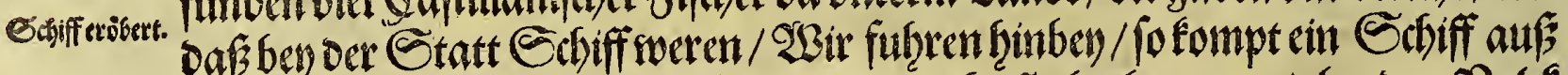

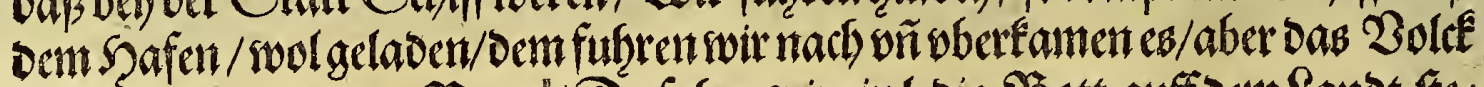

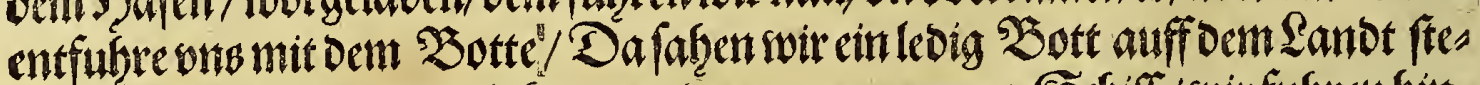

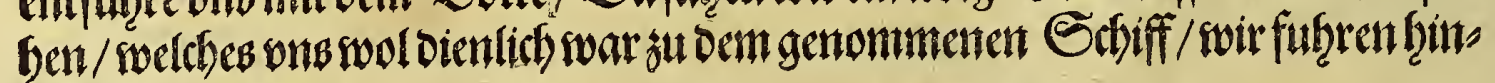
ben ond foltent.

Die weiffenss 2oren famen ftaref angeritten/wolten eb vertheibingen/aber Bieuts-

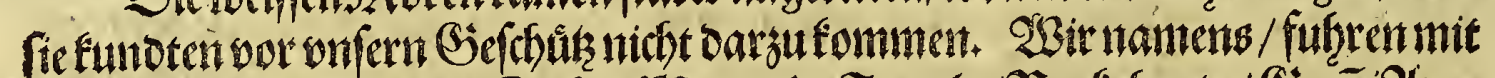

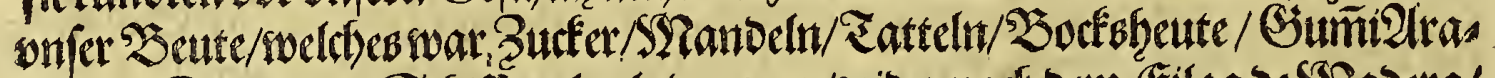

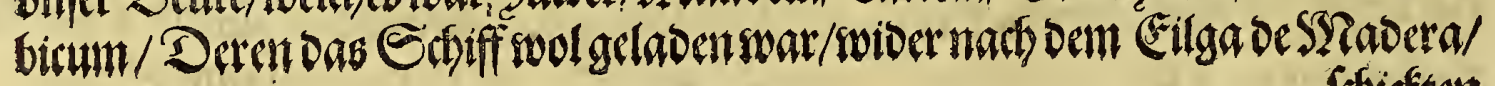
foricften 


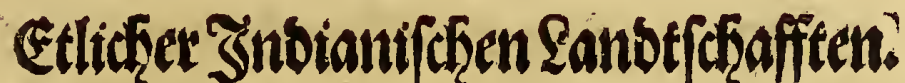

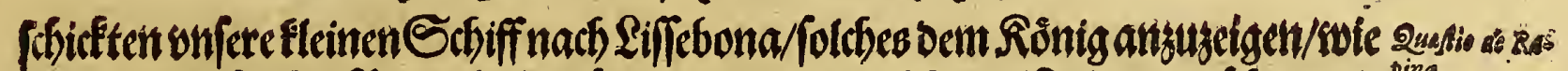

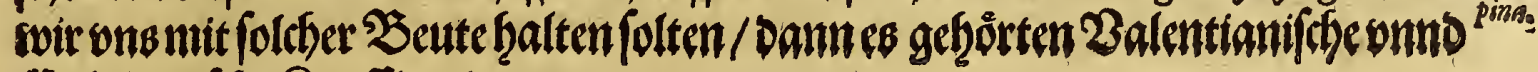

Saftilianif(d) Siauffieut darsu.

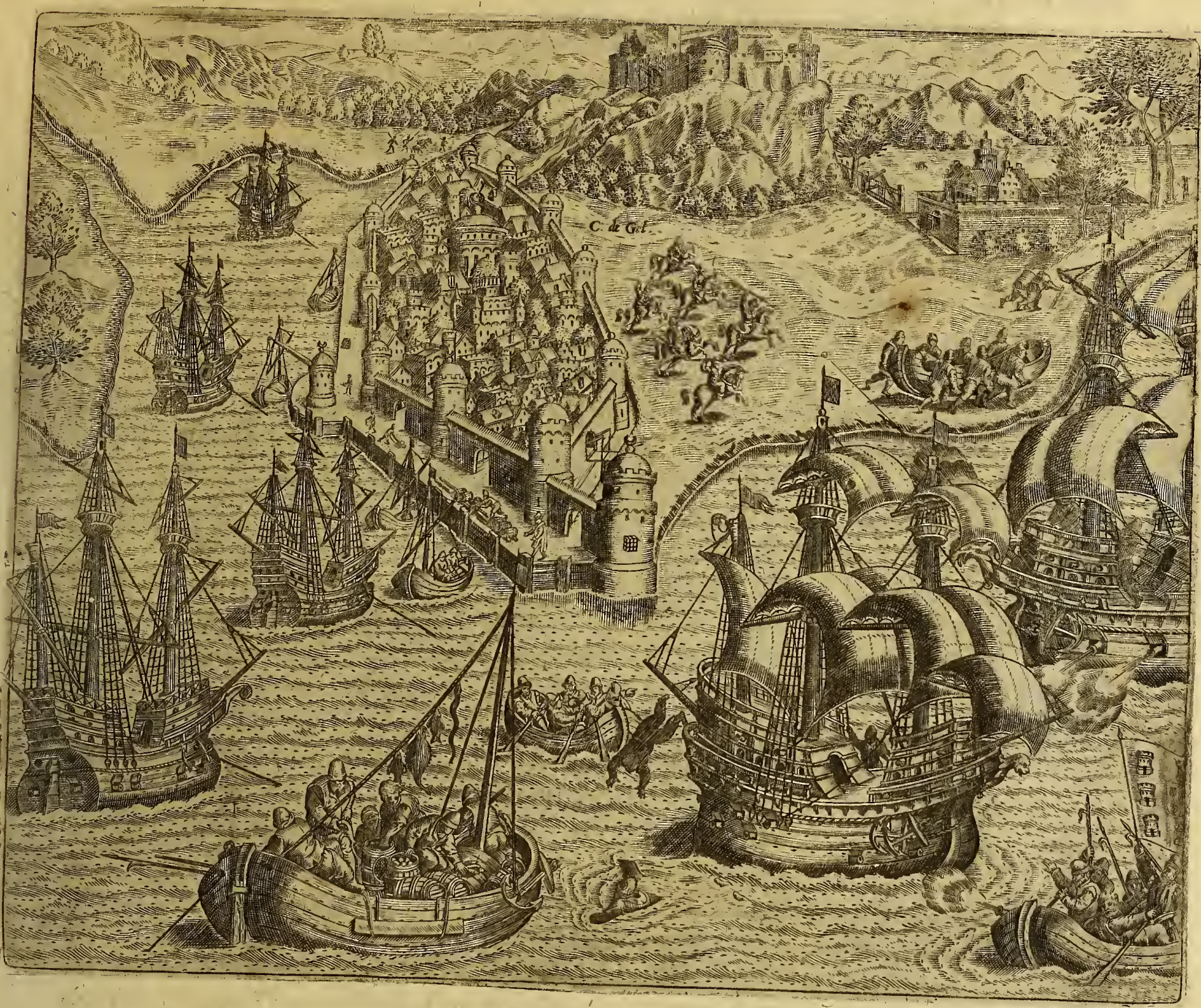

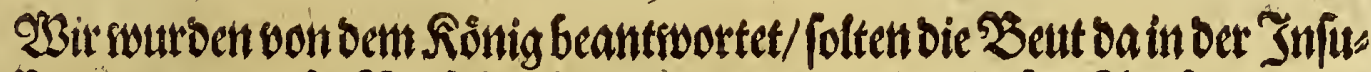

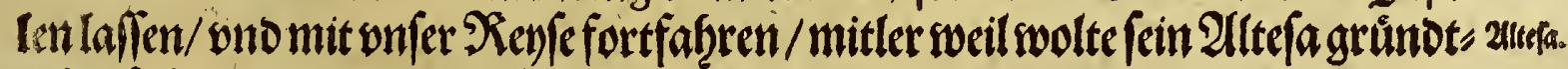
lich erfafren/svic eb Darumbsere.

Dem nach thaten woir/vñ fubren woiber nad) Sape be (Siel/zubefeben ob woir

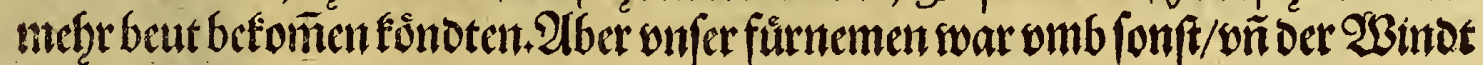

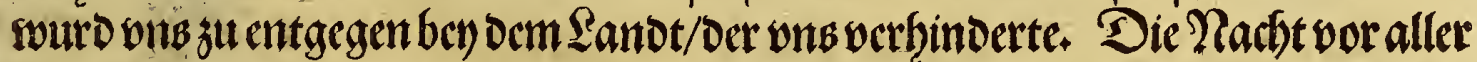
Seiligen tag / fubren wir von Barbaria mit eitem groflen Sturmwino nach

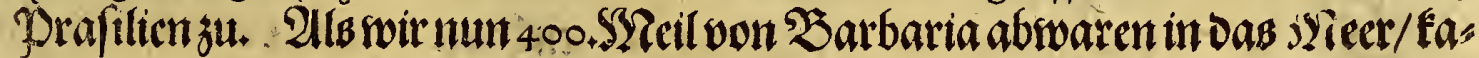

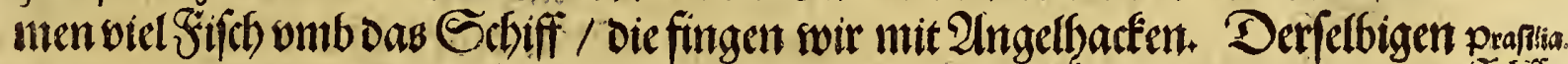

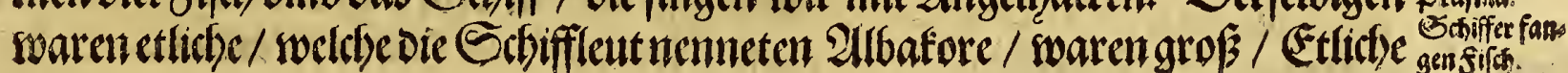




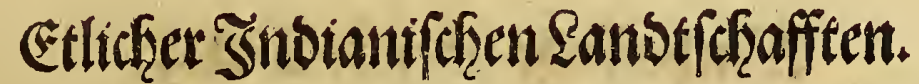

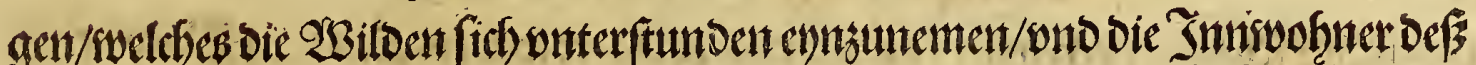

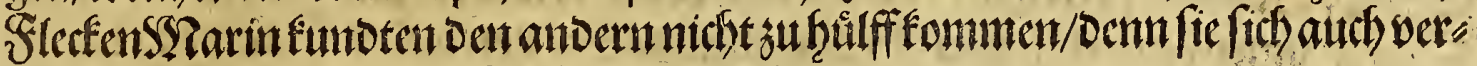

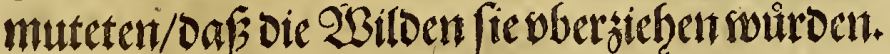

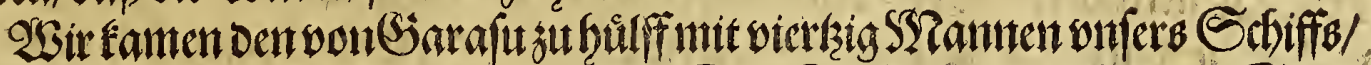
fubren incinem fleinen Ectsifflein babin / Dab Flectlin lag auff cinem Stras

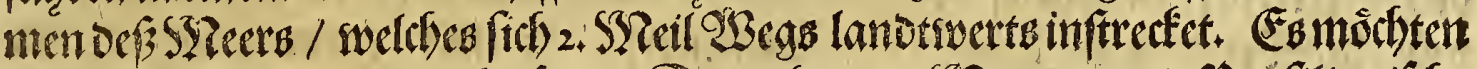

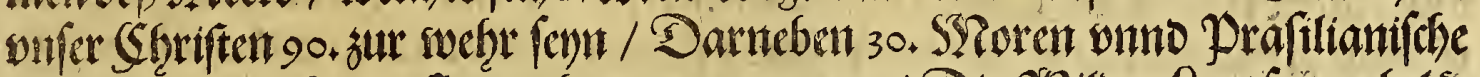

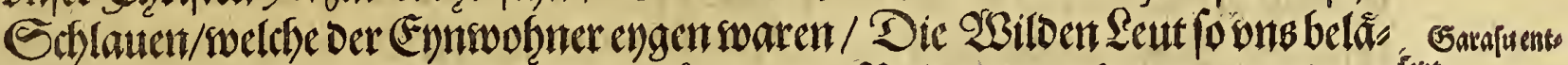

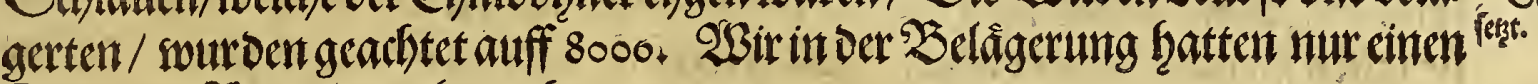

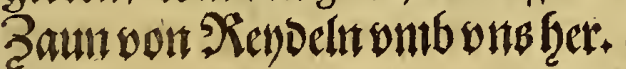

IIII. Sapittel.

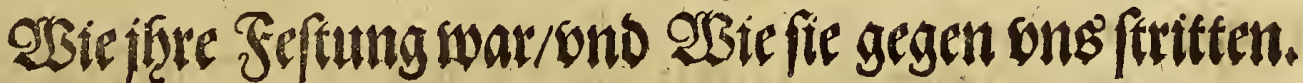

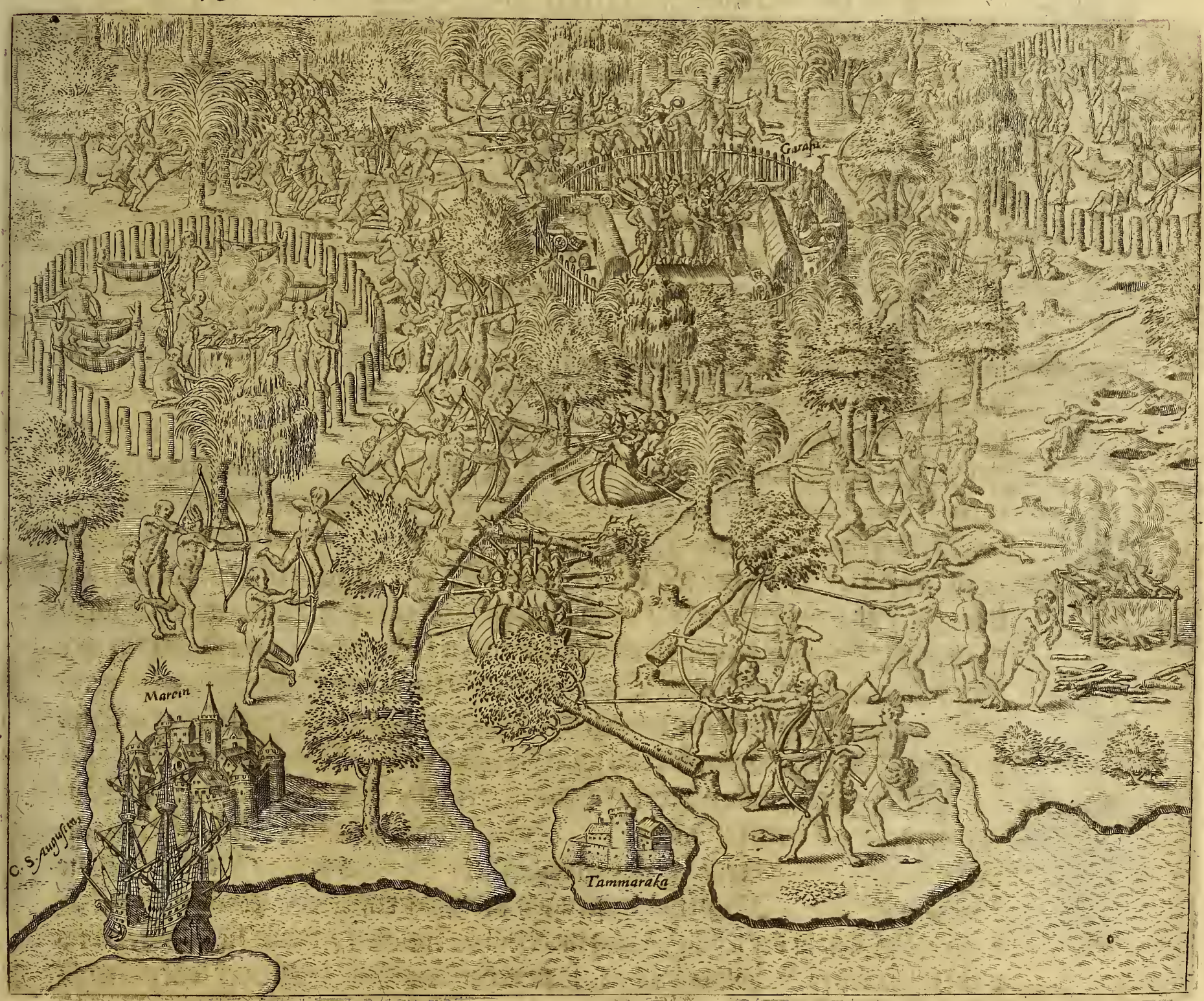

ti. if

I iii

Bmb 


\section{OGarf̧afftige $\mathfrak{B}$ efchrectoung}

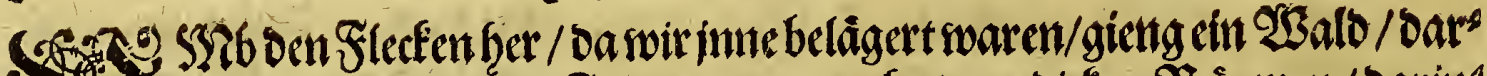

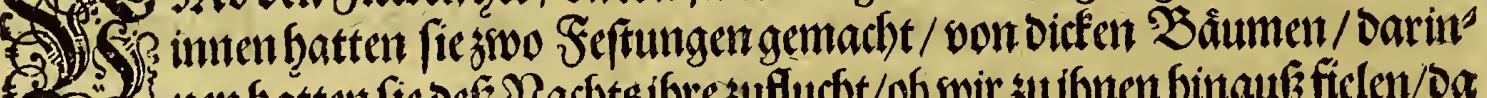

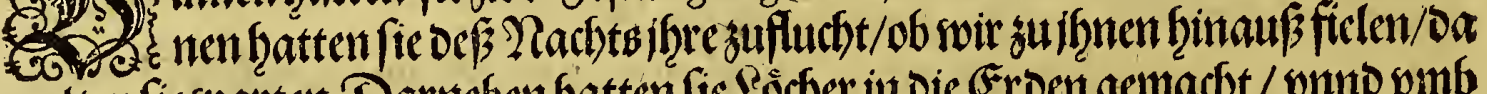

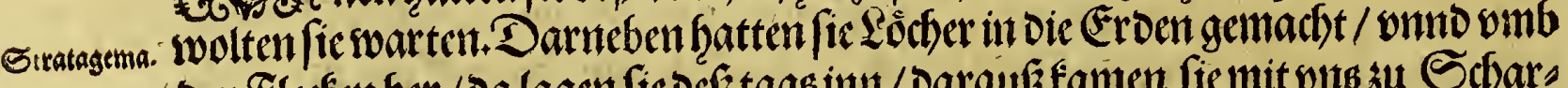

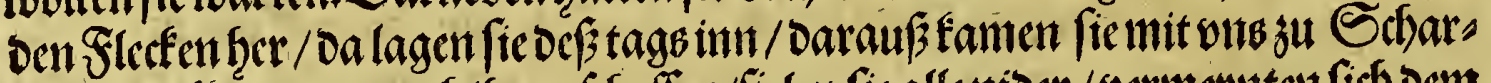

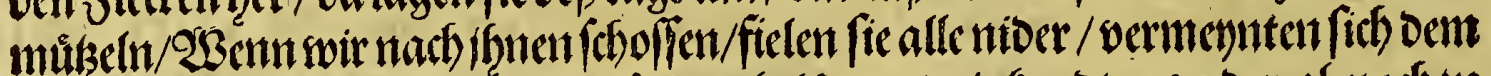

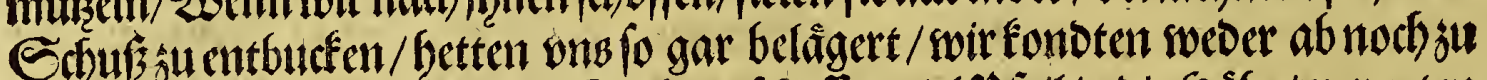

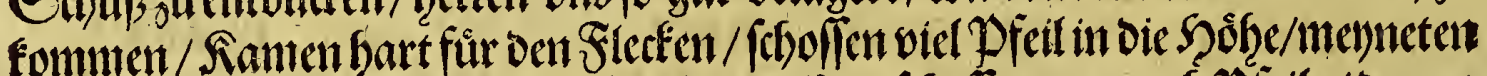
fie folten im niberfallen wns int Flecfen treffen/ f 6 offen ons aud P P feile / Daran

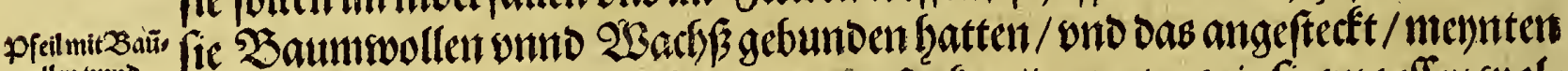
Waaçs. tetr/wenn fie vons fricgten.

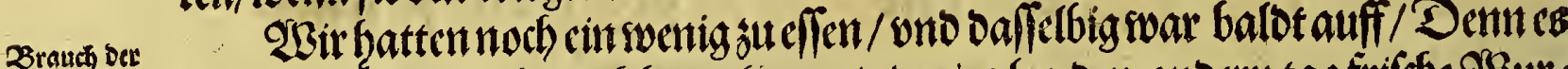
Eperfe.

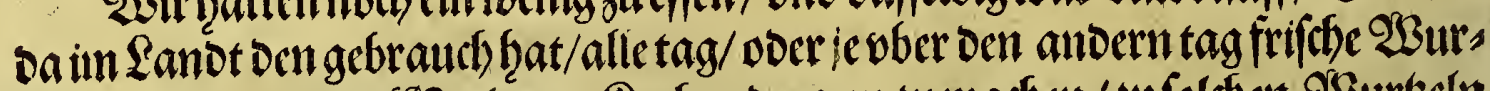

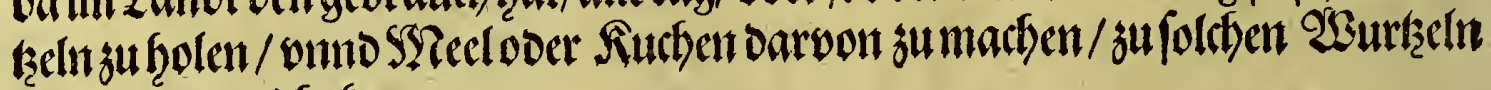
fondern woir nieft fomment.

Cammarata.

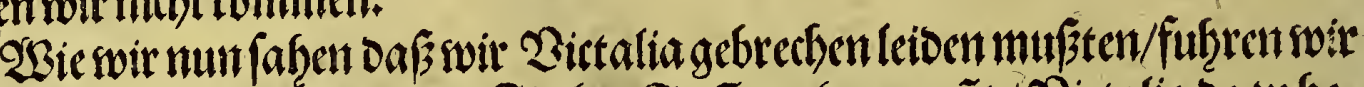

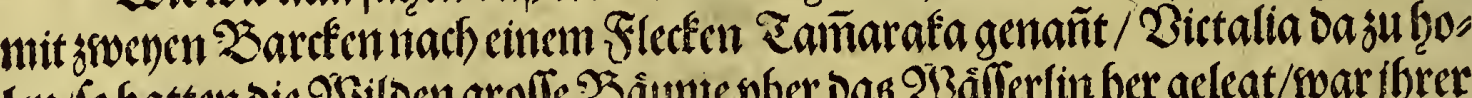

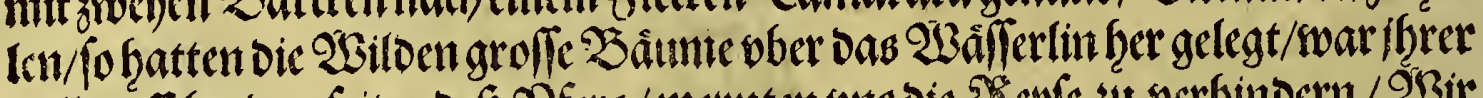

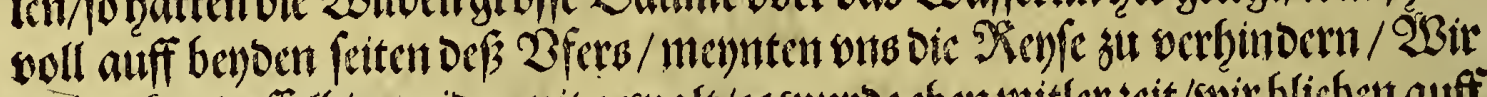

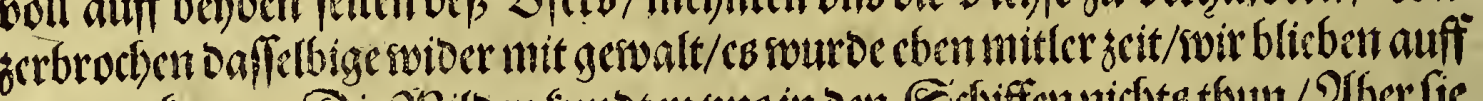

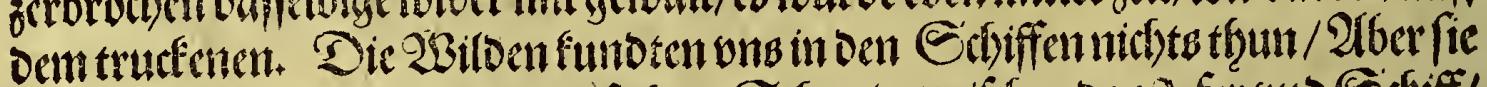

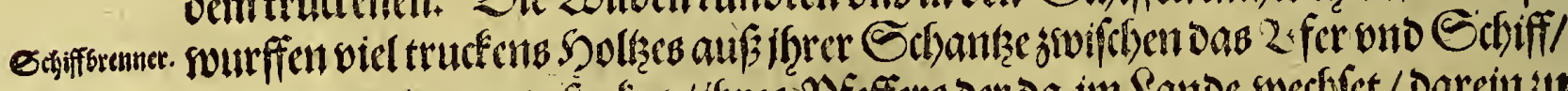

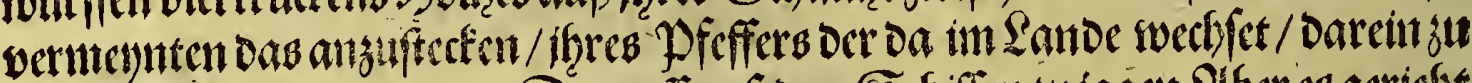

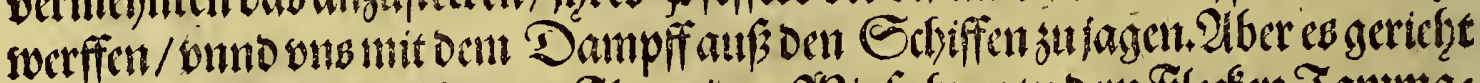

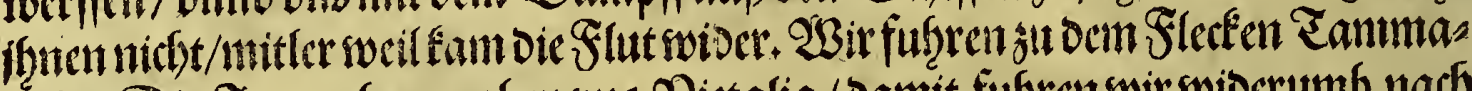

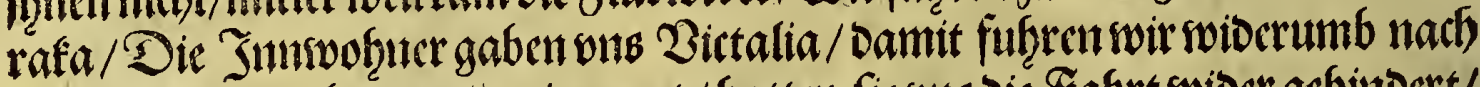

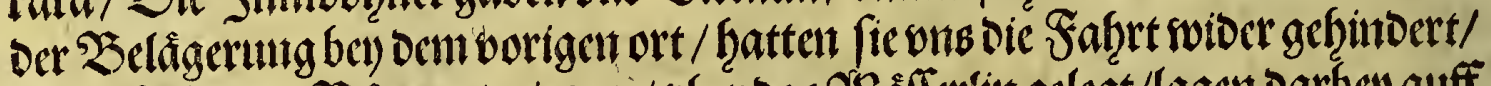

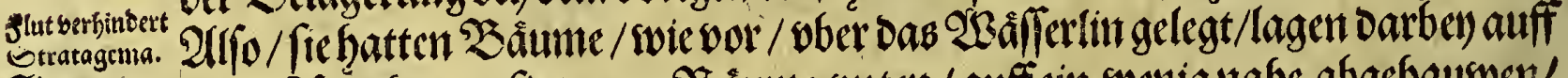

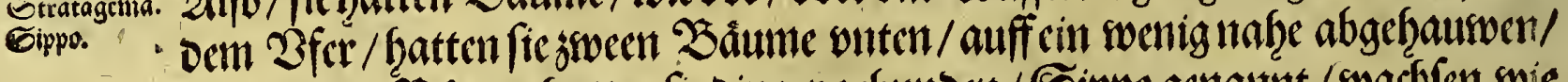
oben an oie Baume hatten fic oinger gebunden / Sippo genaunt / waedjen wie

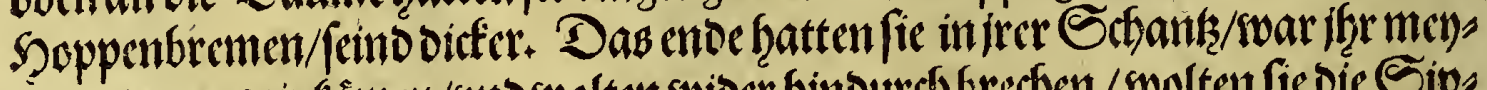

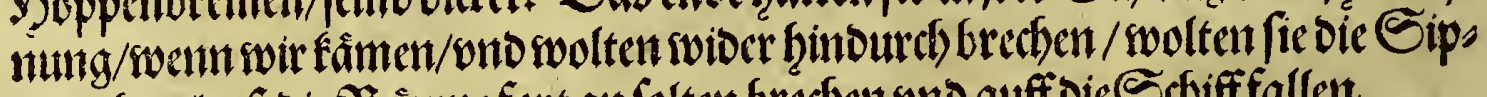

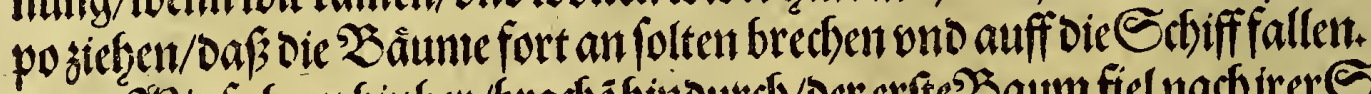

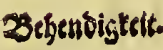

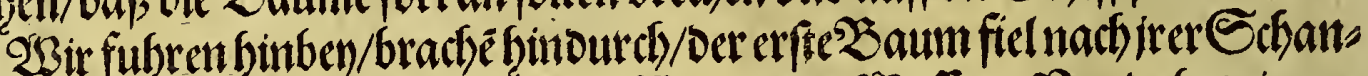

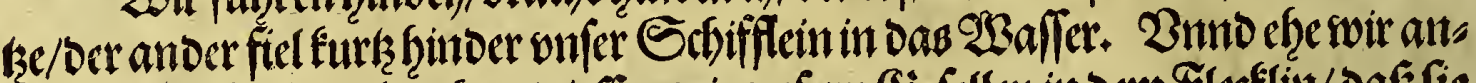

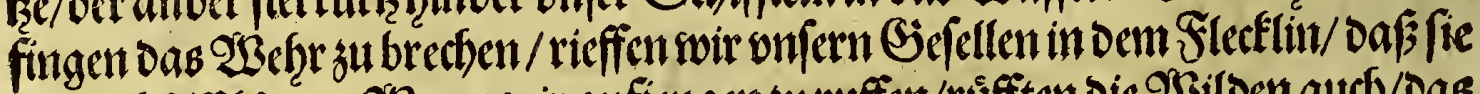

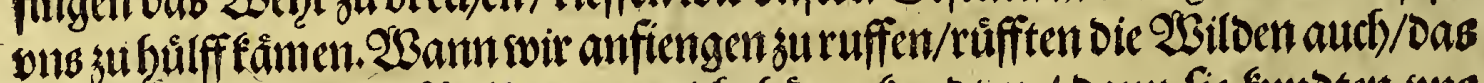

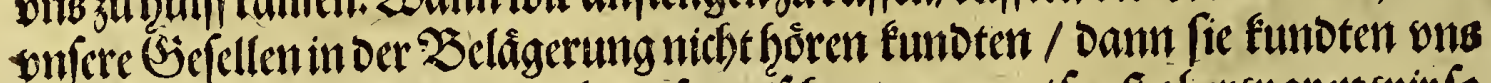

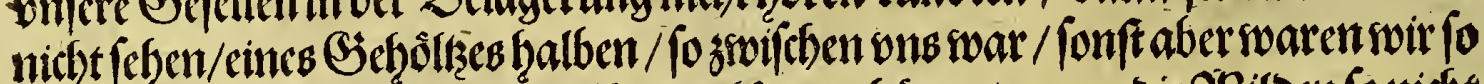

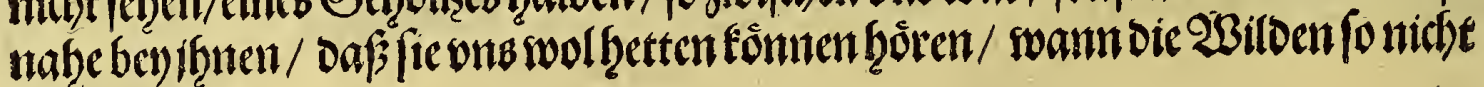
geruffen betten.

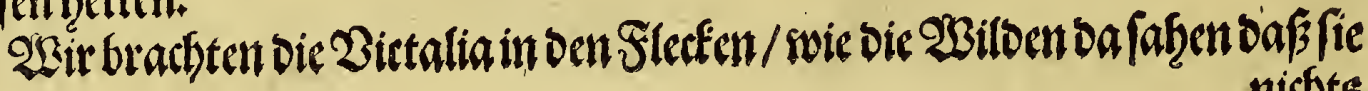
nichts 


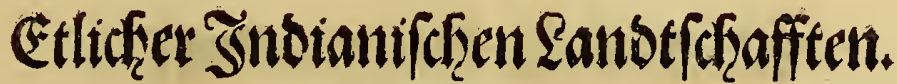

nichts fonbten anfsrichtě//begerten/ie frico/oñzogen swioer ab. Die Selägerung weret ber nabe cinen SYonat / Der WBillon blieben etliche toot / aber Der wn/ernt

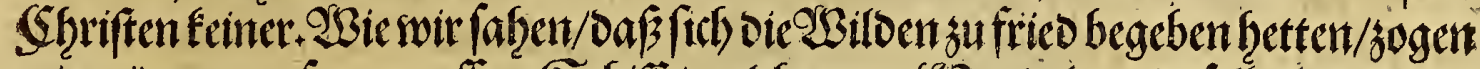

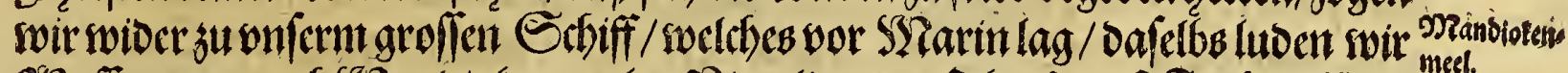

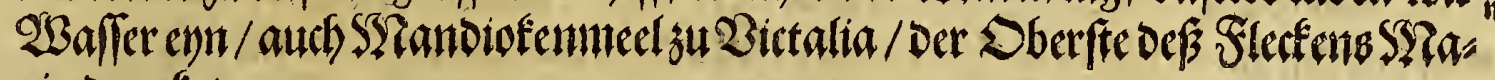
rintoancétons.

\section{Sapittcl.}

\section{Wie wir auß 3 Prannenbucke fufren nach ciner Sanbtf çaffe

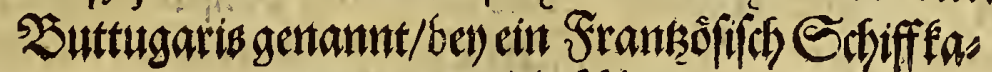 men/pno ons mit in fchlugen.}

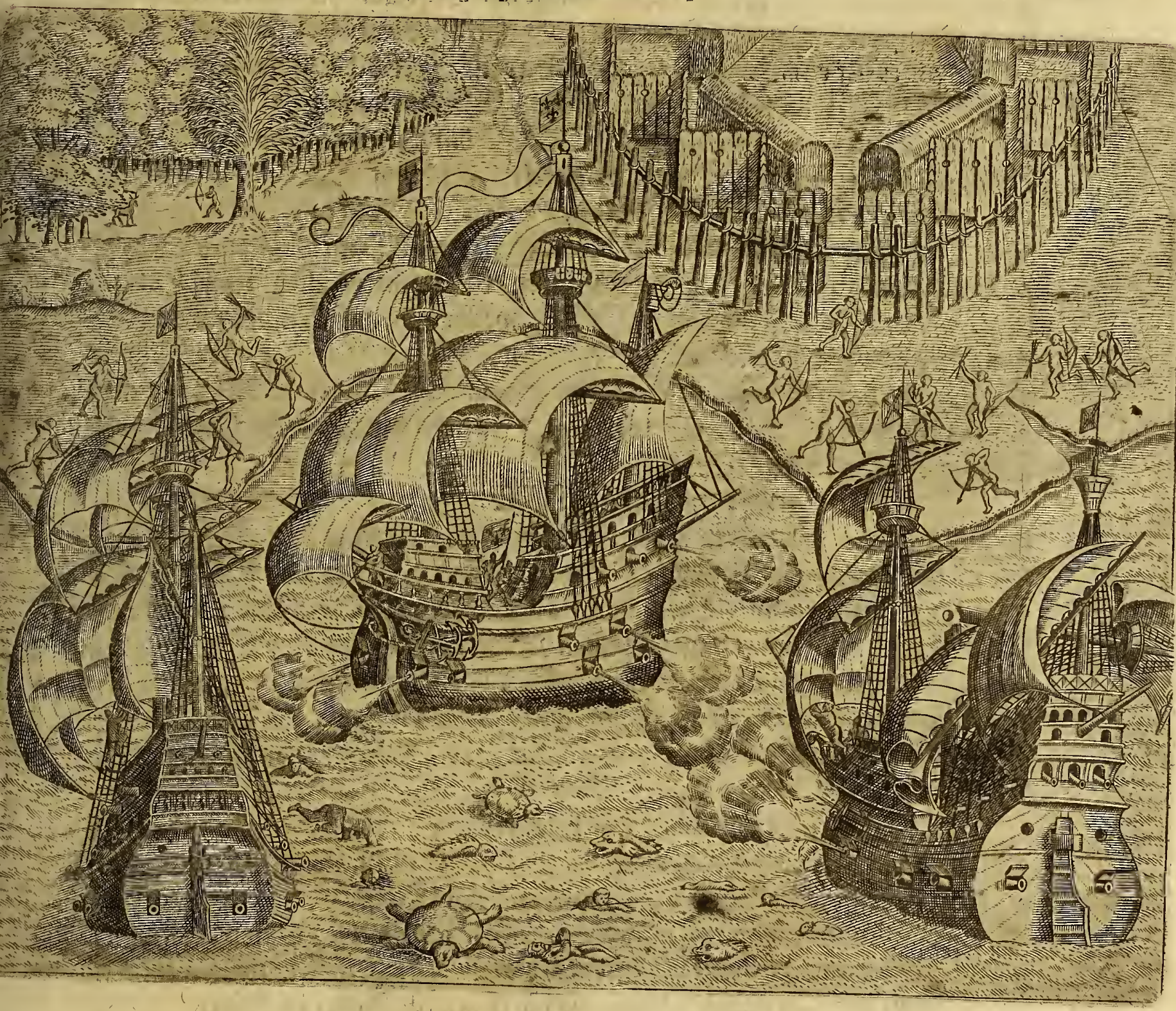

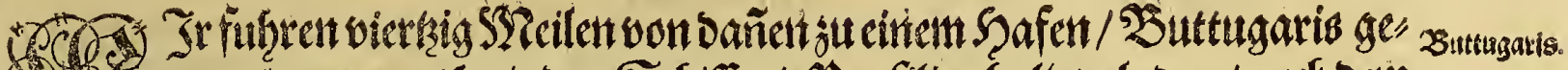

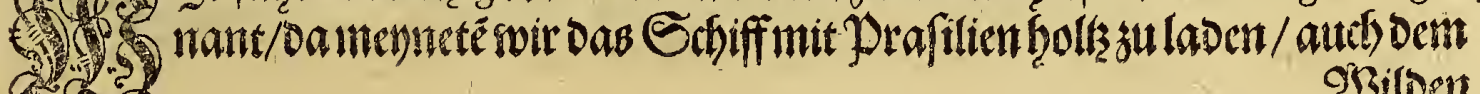




\section{TGarthaffitige Befforteribung}

Gibiffaufs

franctireich 6

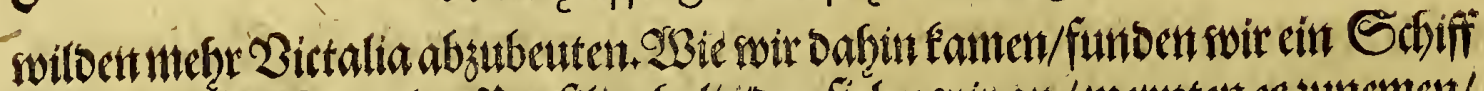

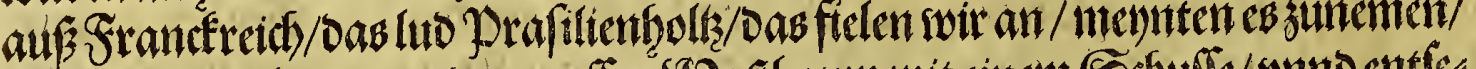

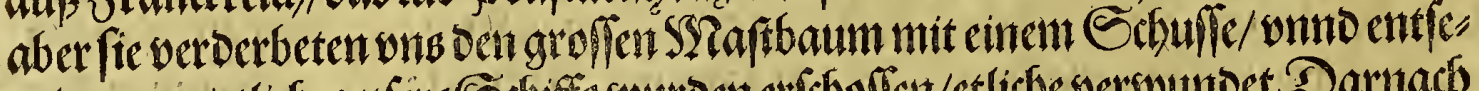

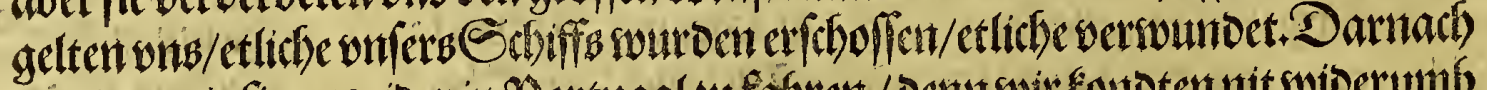

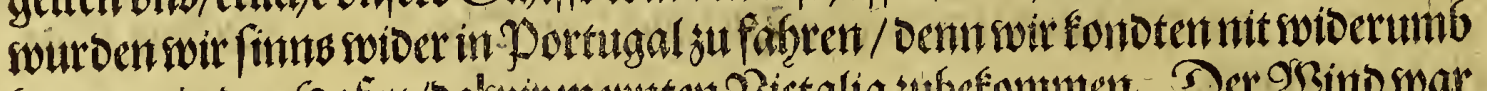

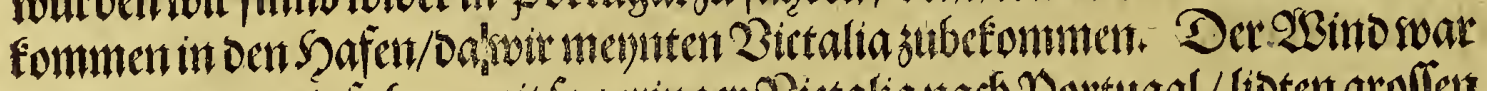

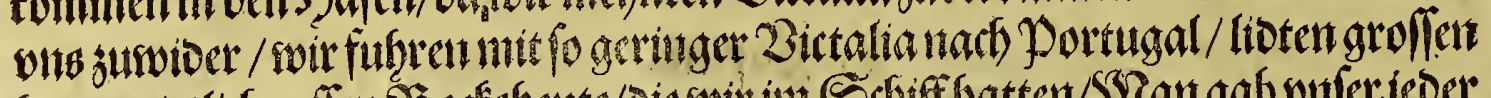

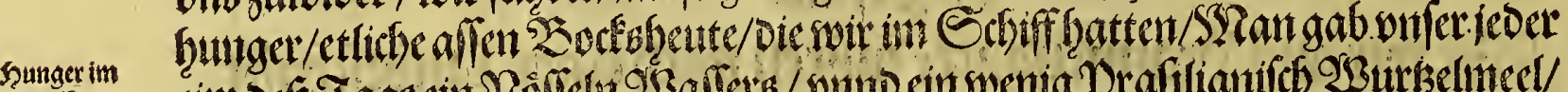
Gibiff.

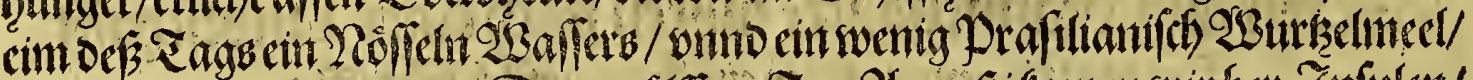

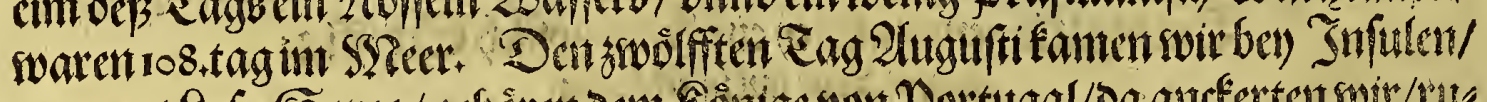

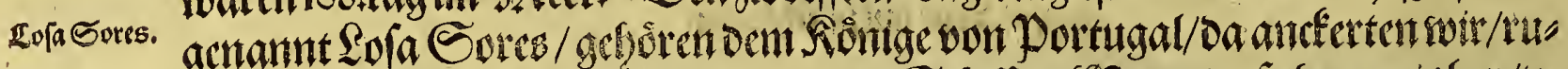

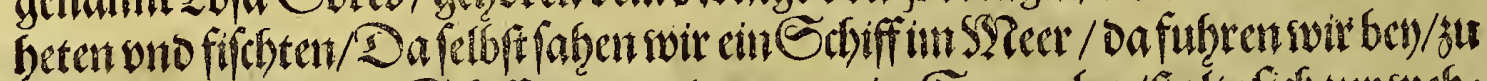

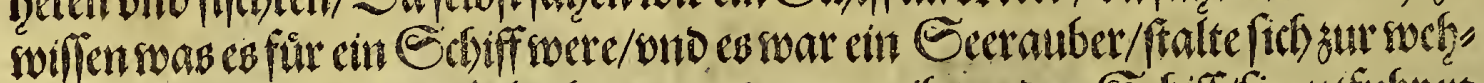

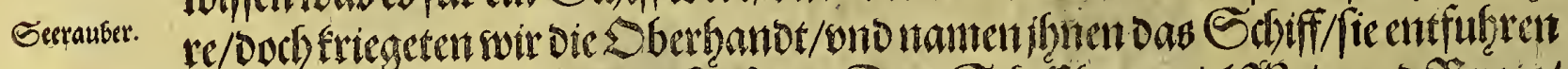

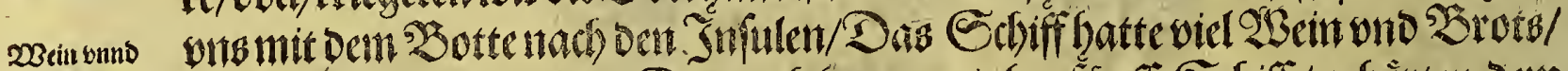

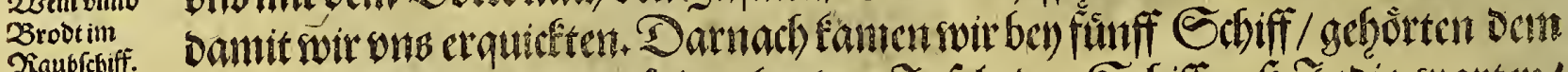

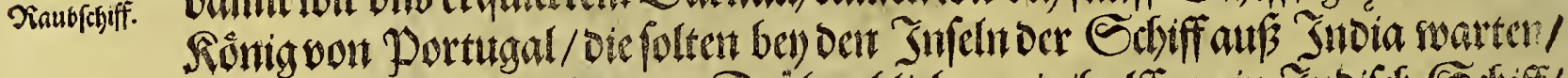

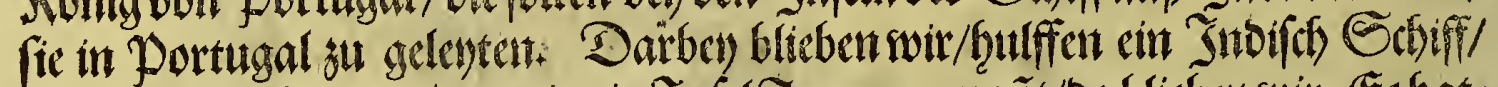

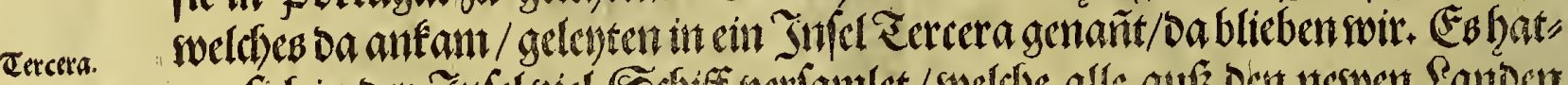

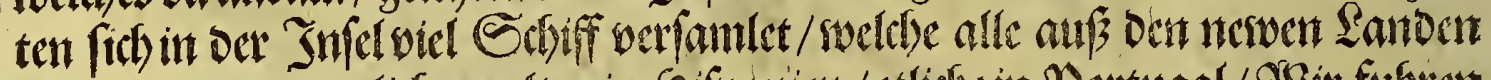

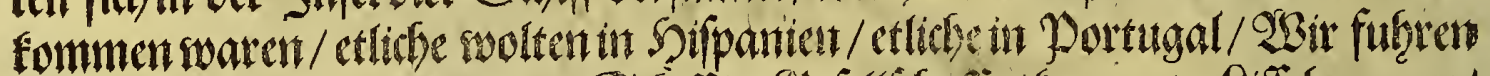

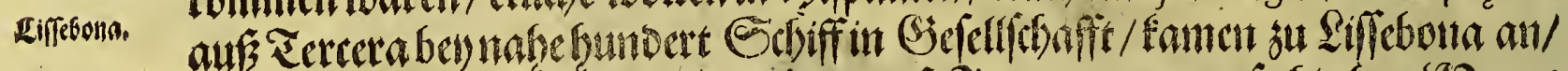

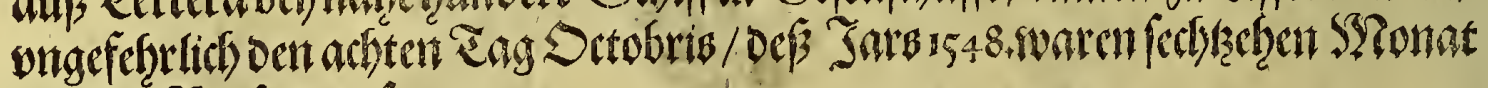
auffoer Sienjegerwejett.

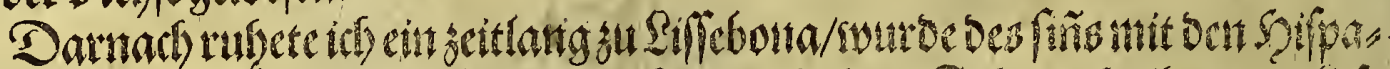

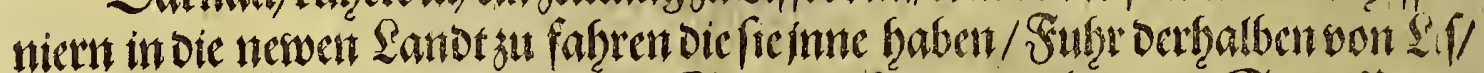

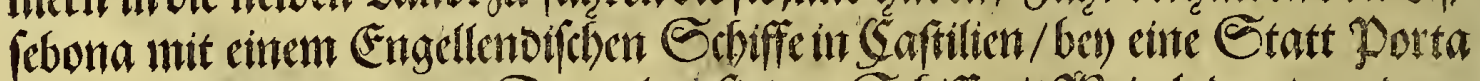

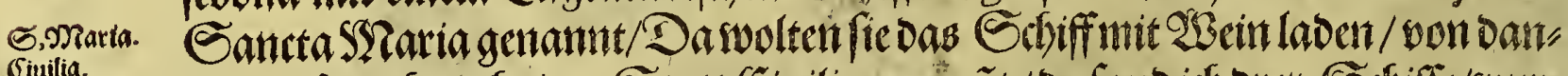

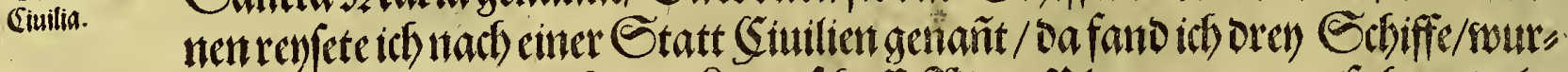

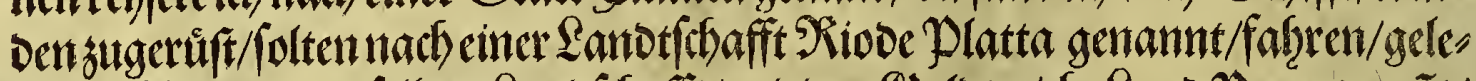

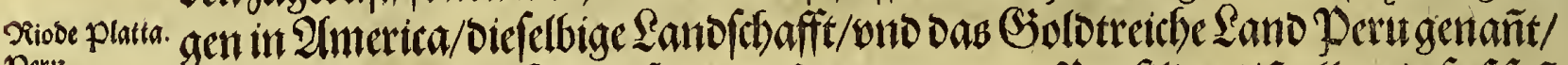

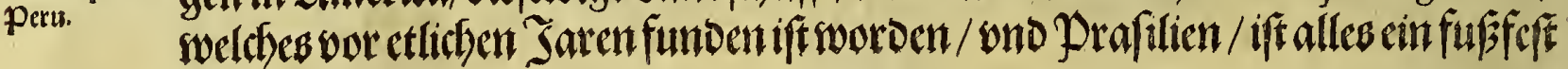
Sanot.

Dafferbig Sand fortennsutemen waren wor etlicbenjaren Eefiff bafin

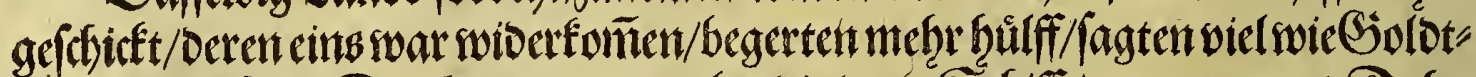

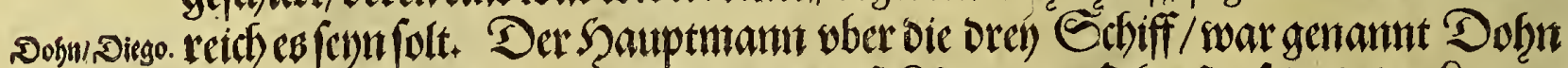

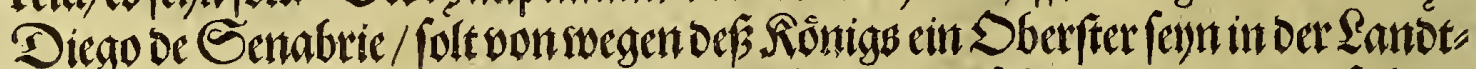

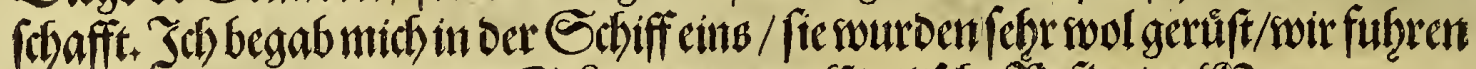

S. Lueas.

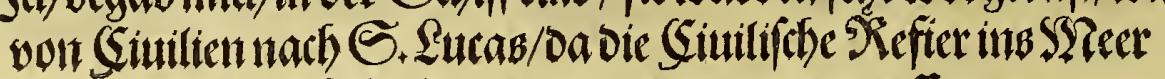
gefet/oafelbft lagen wir who wartetenauffgus ten 2 Binot. 


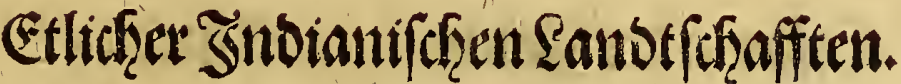

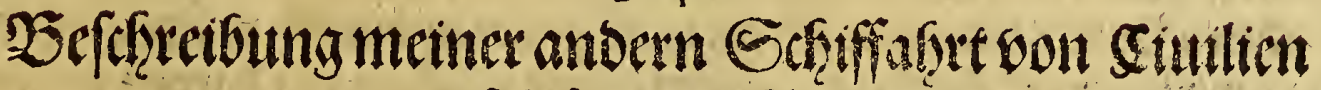

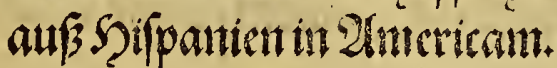

आ

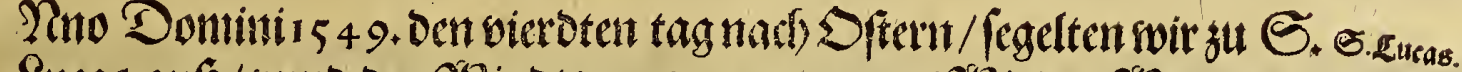

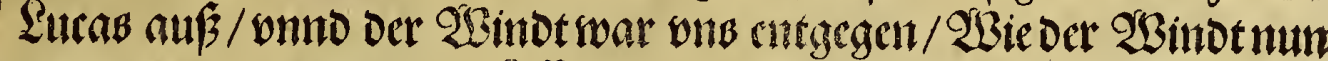

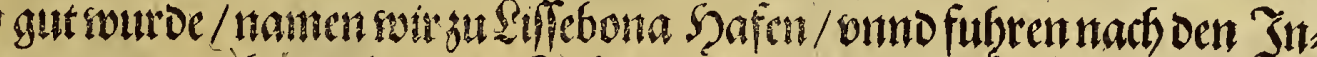

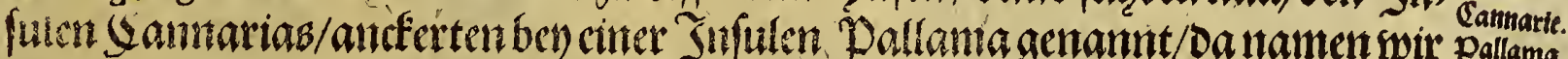

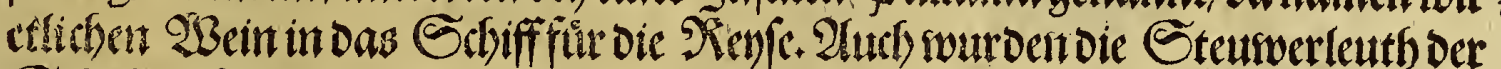

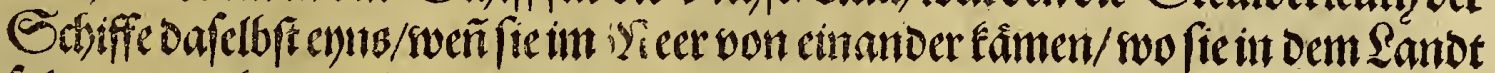

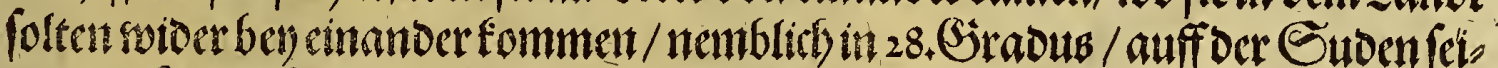
tew/Der Sinien Lequinotial.

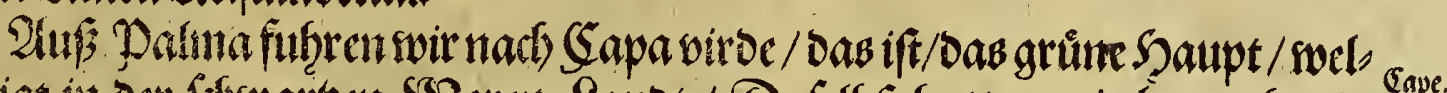

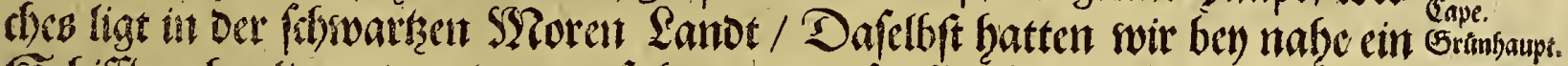

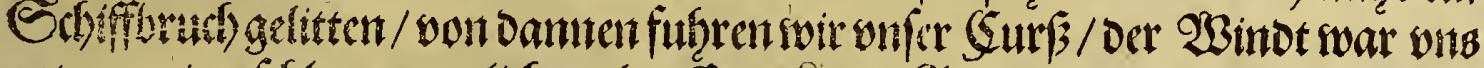

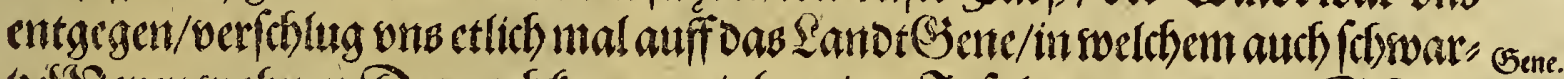

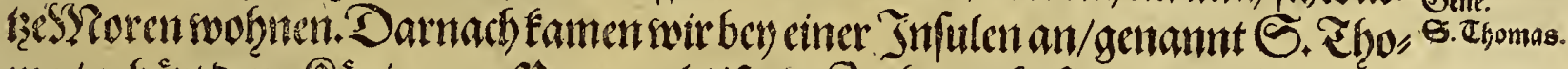

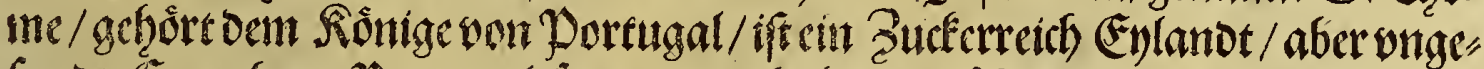

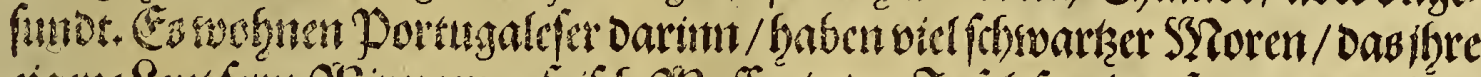

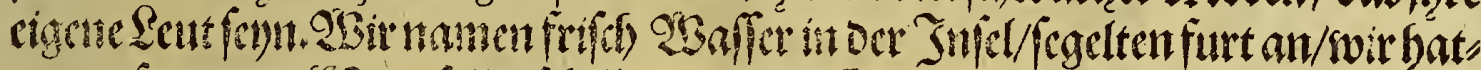

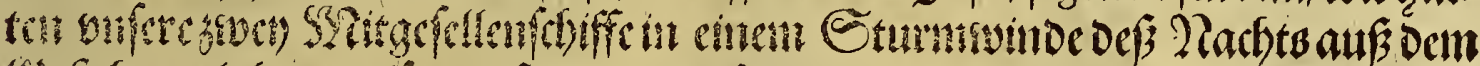

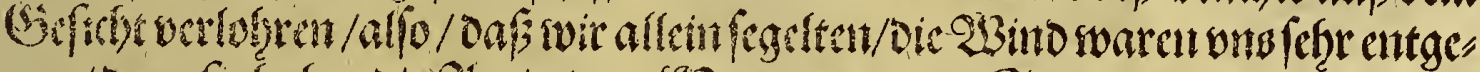

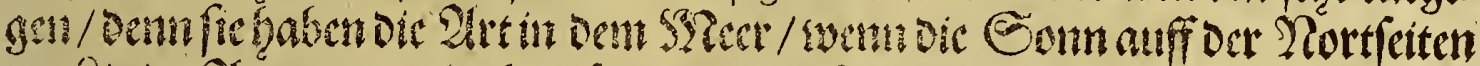

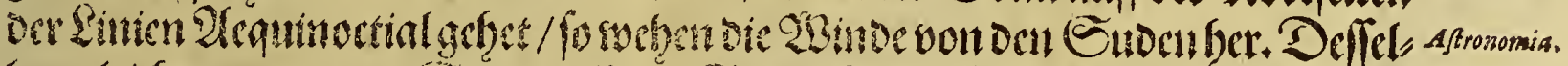

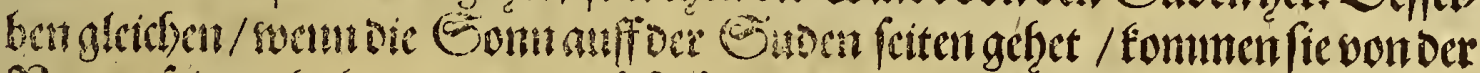

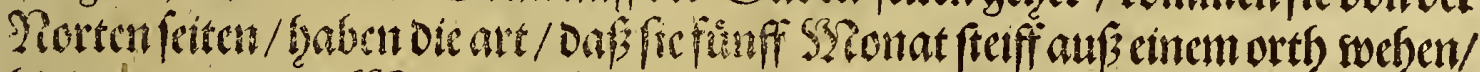

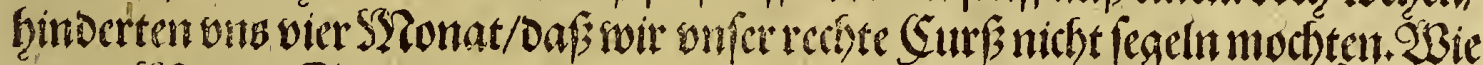

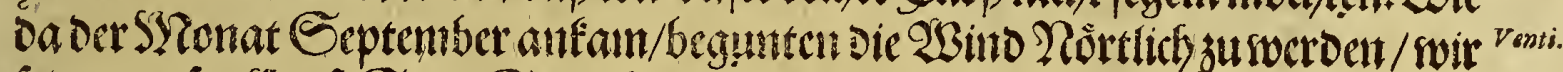

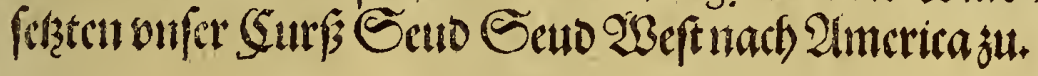

\section{Capittel.}

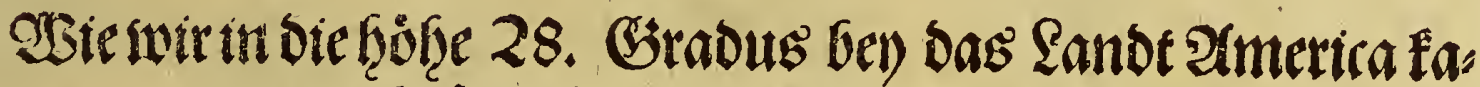

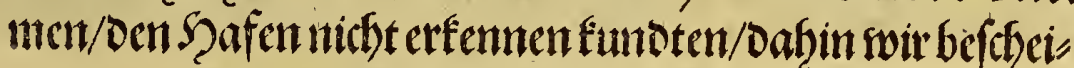
den waren/ono cin groffer $\sigma_{\text {furm } / i c h}$ ben Dem Eand errfiub.

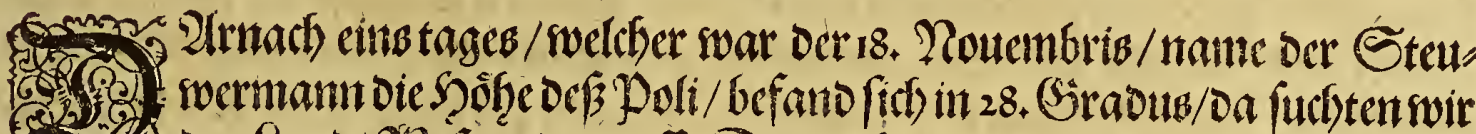

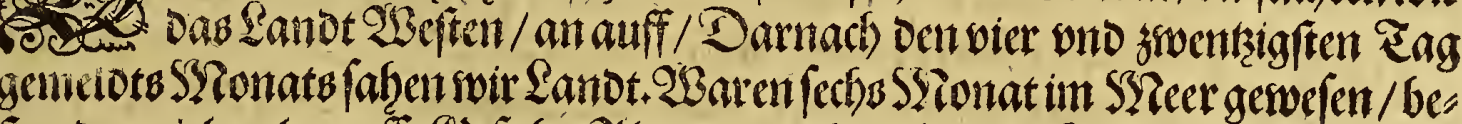

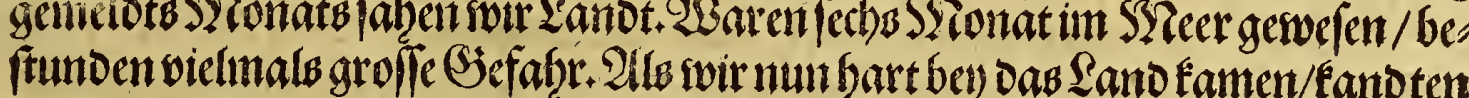

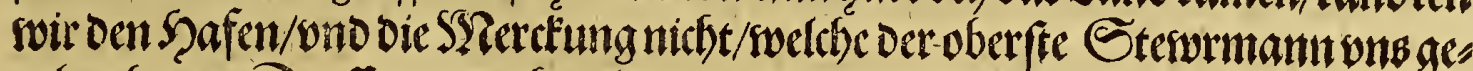

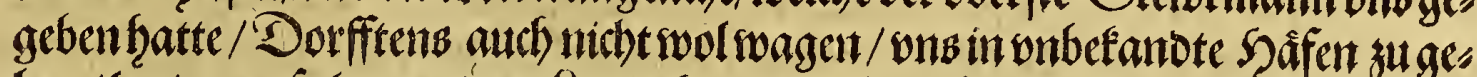

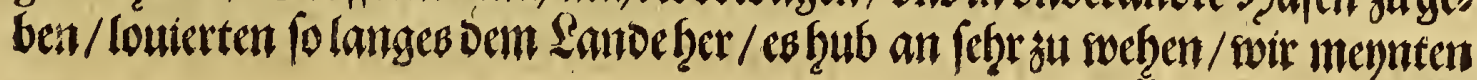

S nidt 


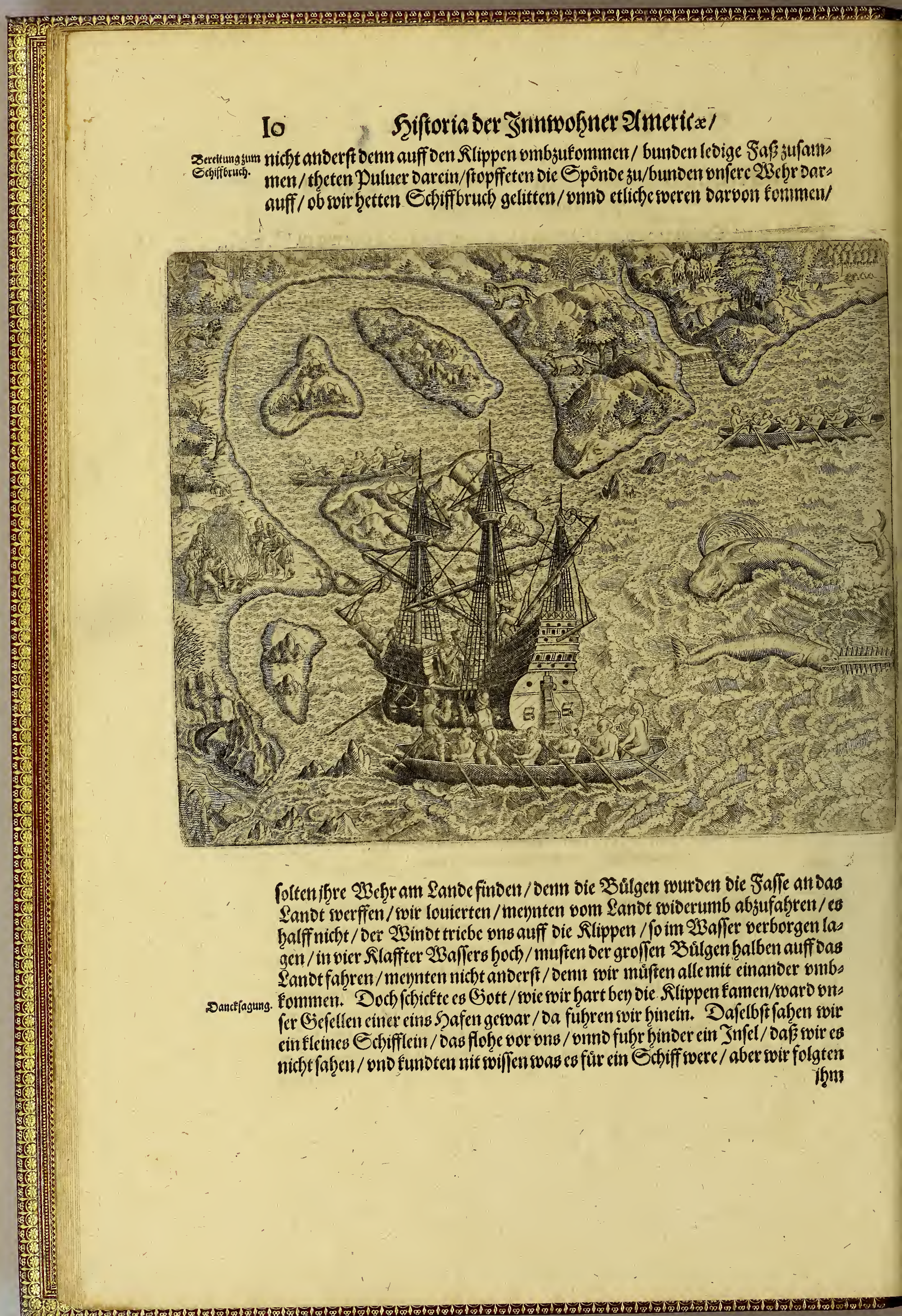




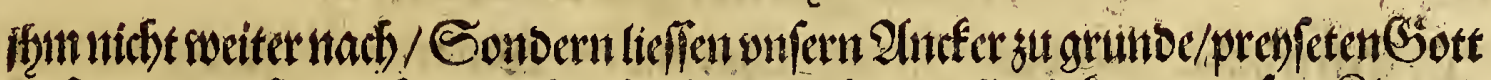

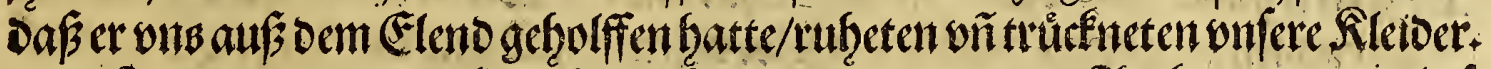

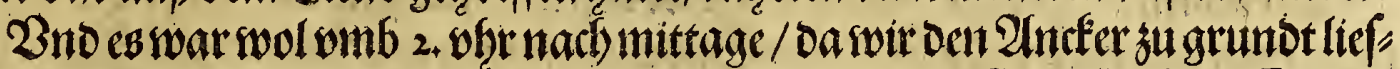

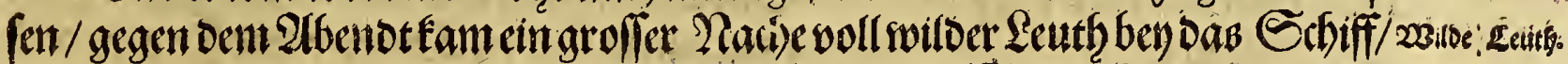

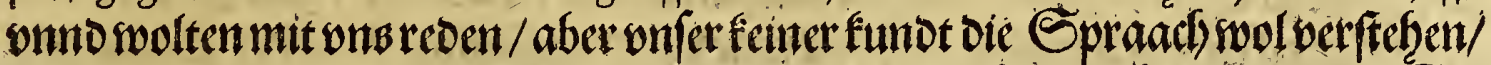

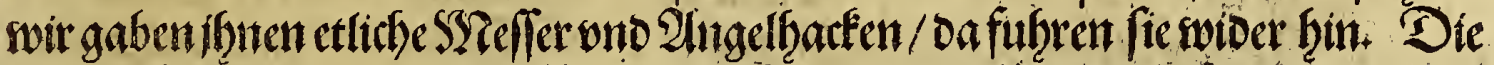

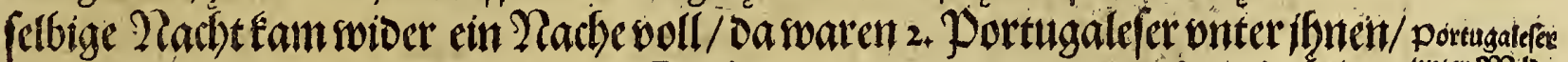

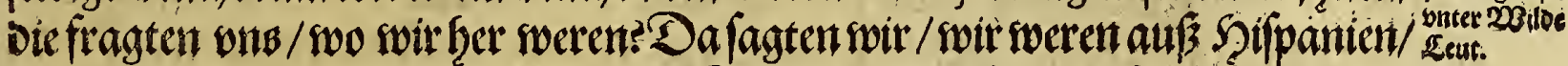

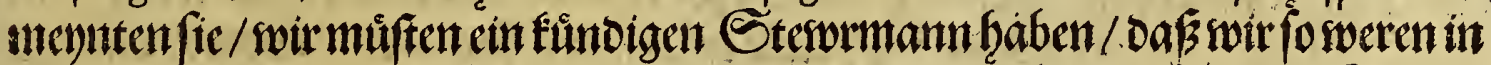

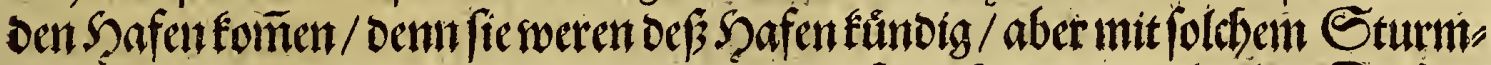

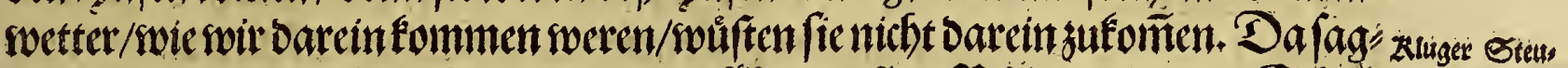

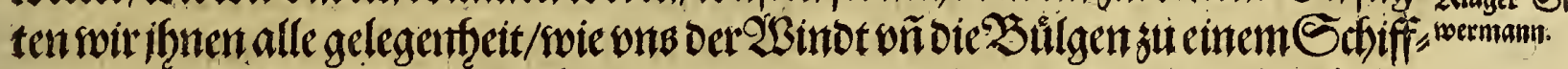
bruch hetten bringen wôllen / OSBe wir nun nit ander/t mennten/ oenn wir folten

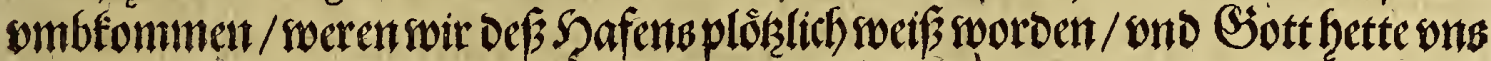

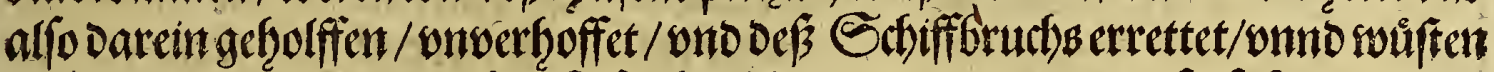

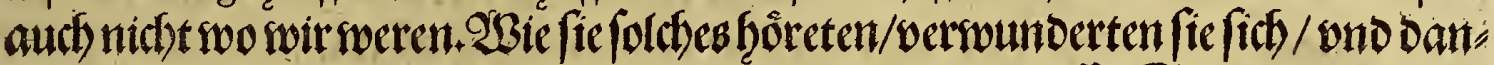

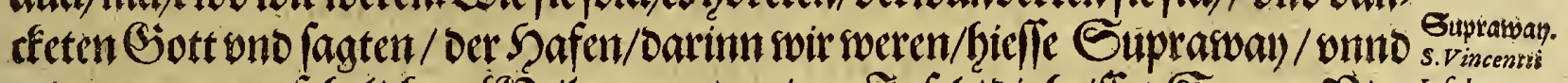

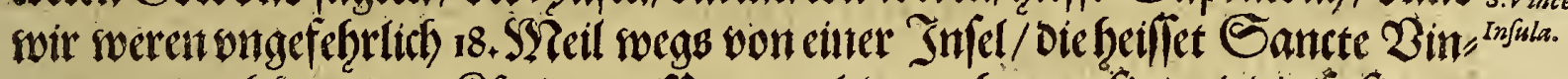

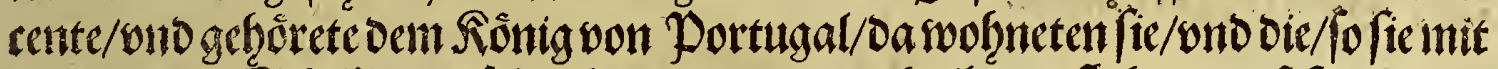

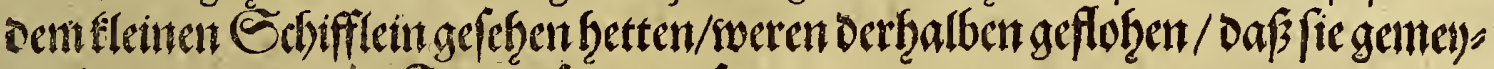

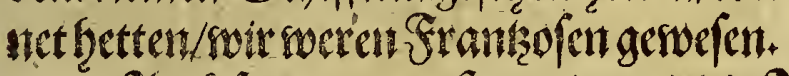

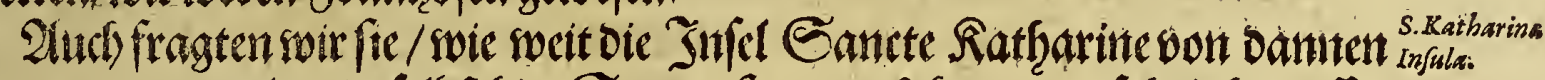

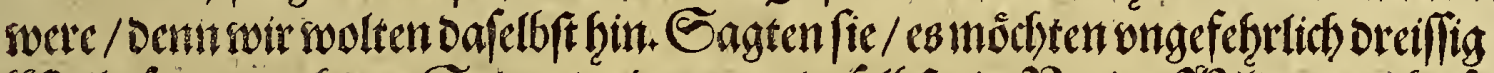

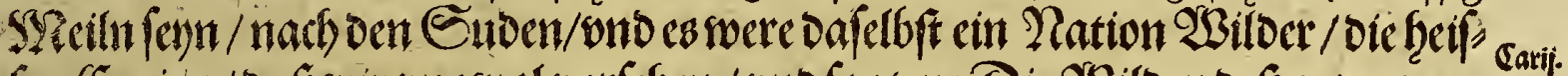

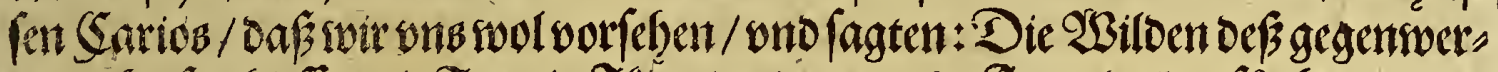

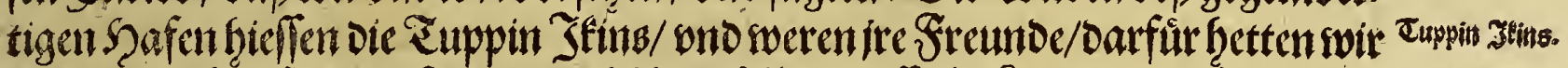

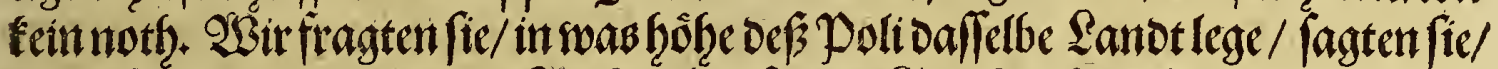

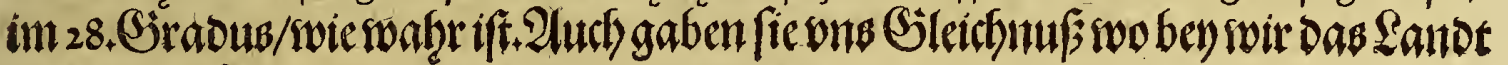
erfennen folten.

\title{
VIII. Sapittel.
}

\section{Wie wir bawiberumb auf oem Safen futren/Das Sanot}

\author{
soiderumbzu fucken/babintwir wolten.
}

a

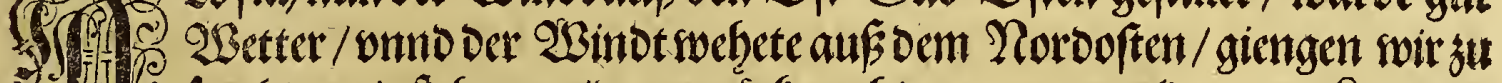

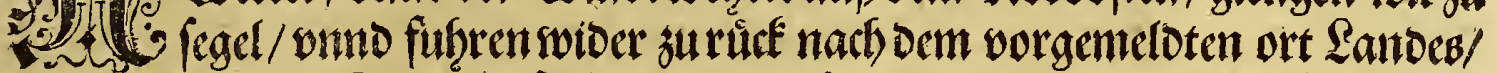

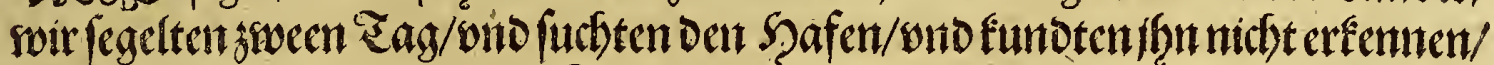

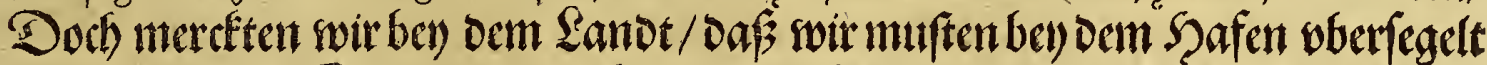
baben/Denn die Gonne verduncfelt swar/Dafs soir nichts inerden funden/fund

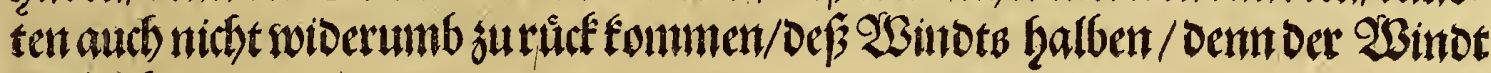
oerftadi vitb.

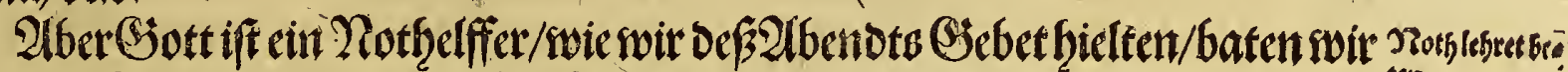

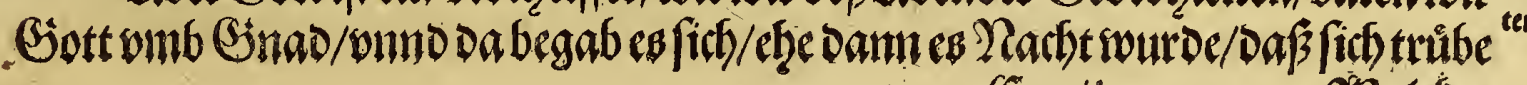

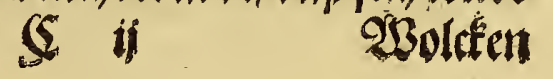




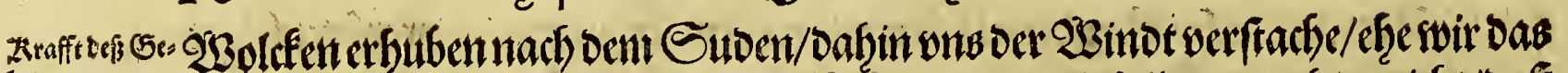

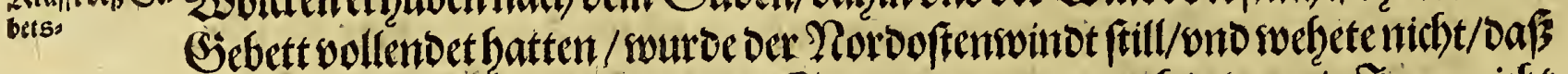

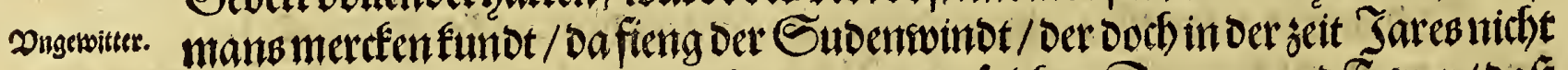

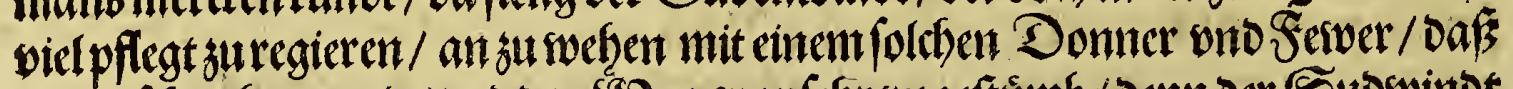

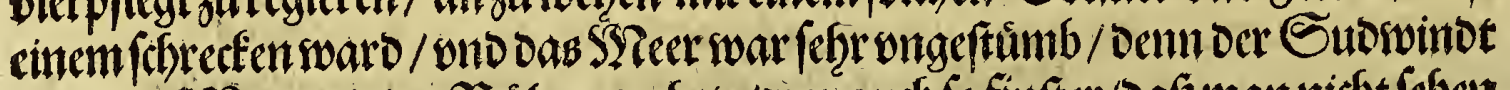

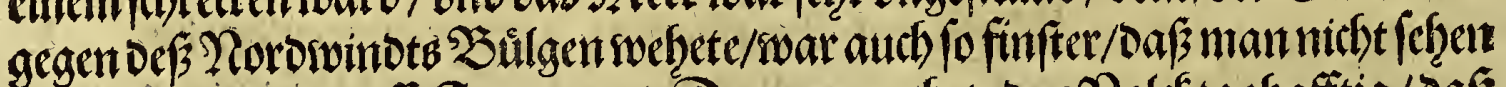

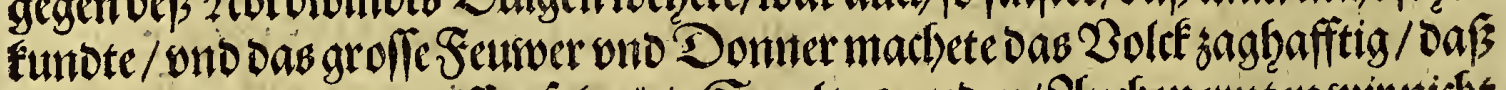

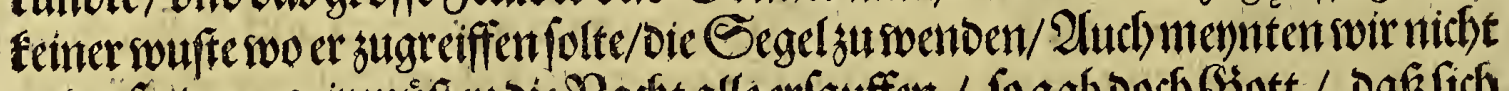

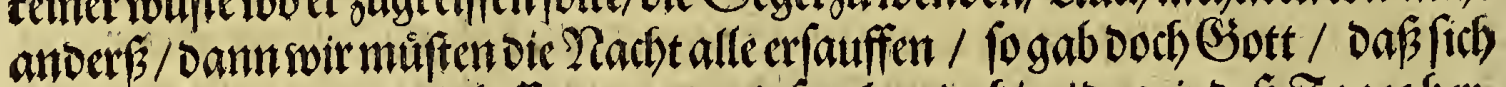

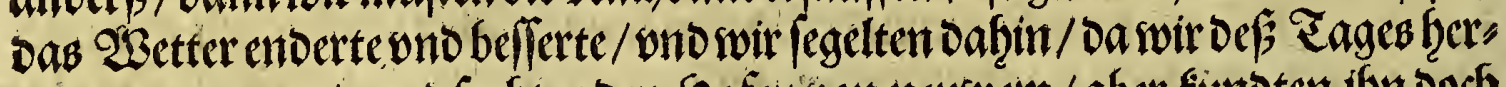

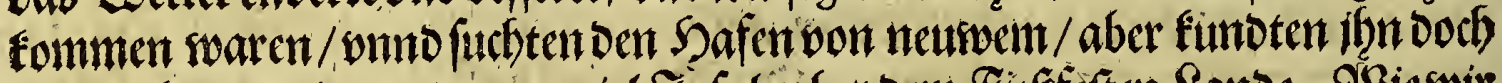

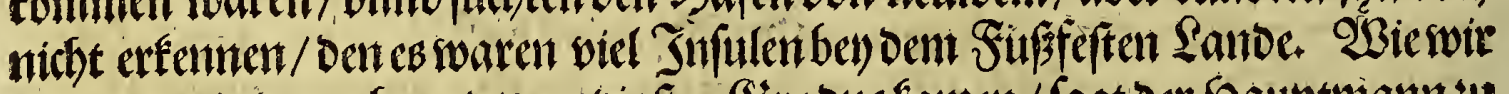

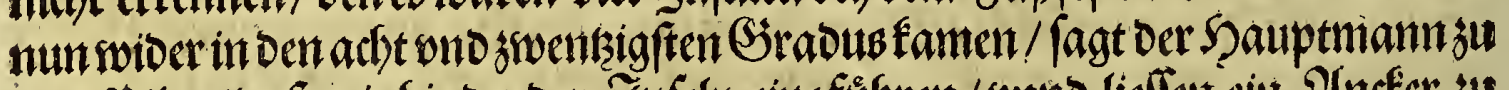

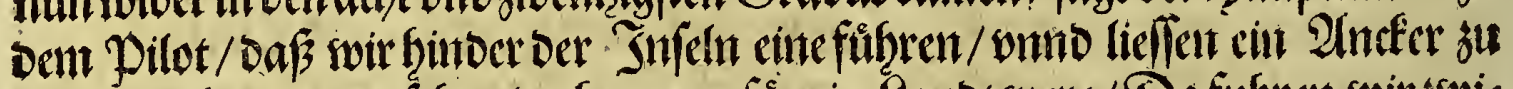

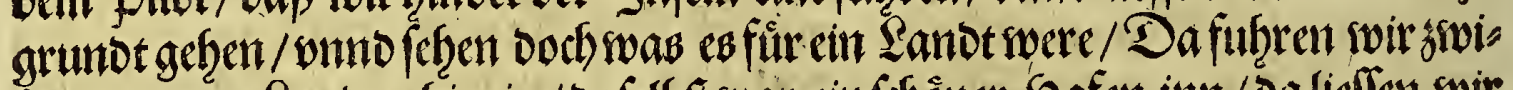

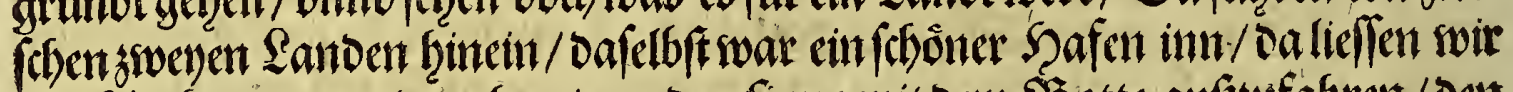

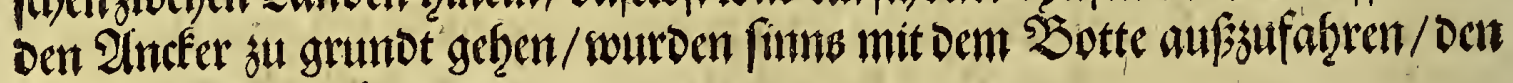
Şafensweiter öuerfundent.

\section{Sapittel.}

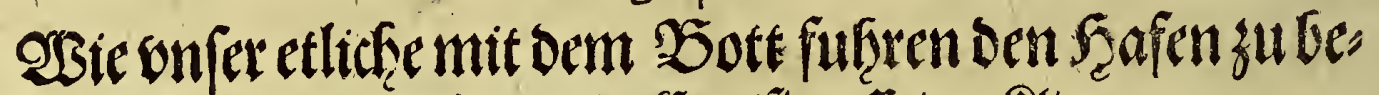 firftigen/funder ein Srucifitauff einer Flippar peften.}

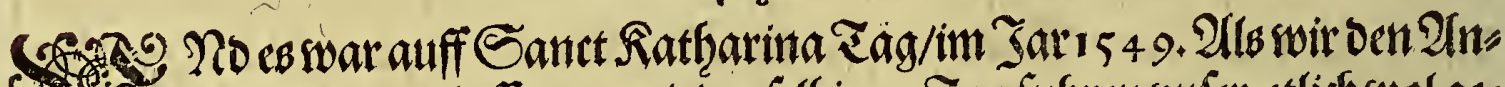

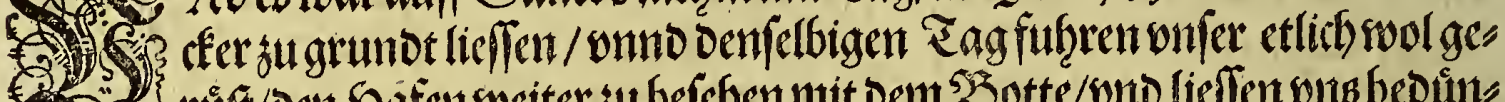

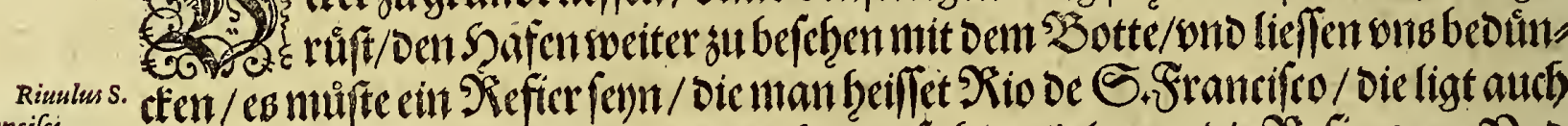

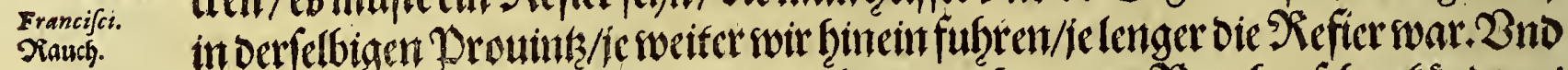

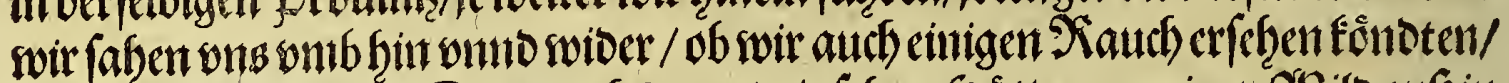

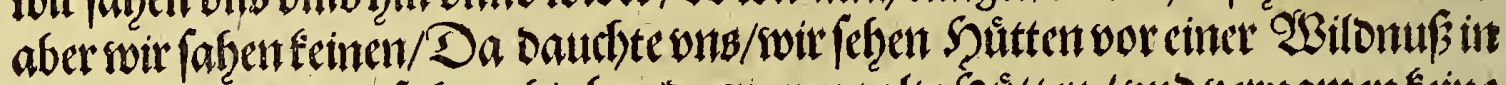

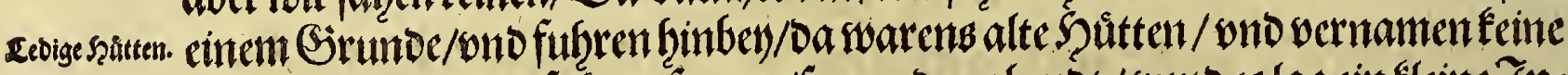

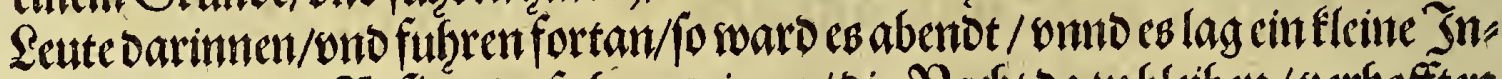

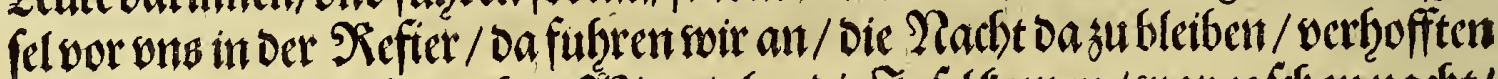

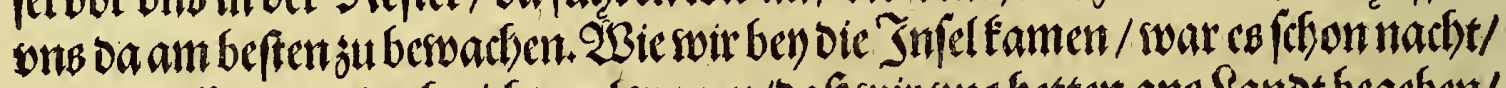

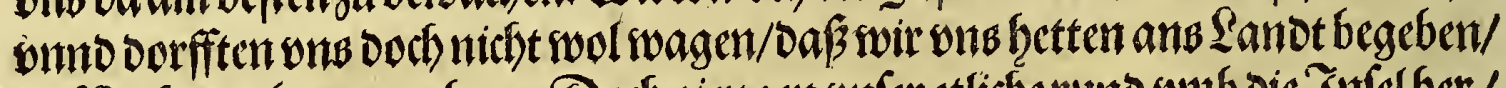

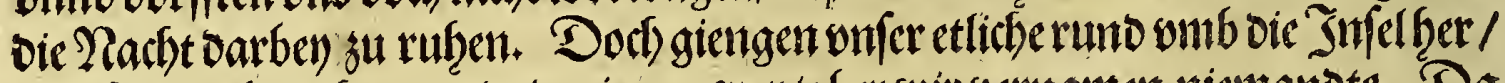

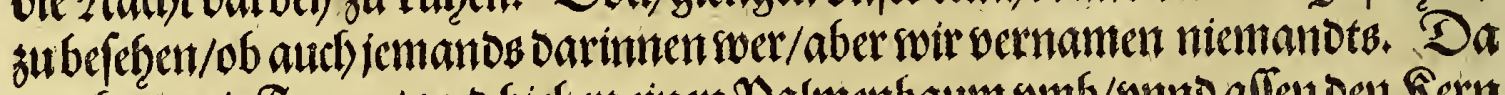

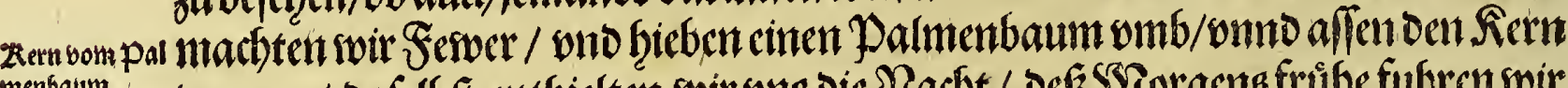

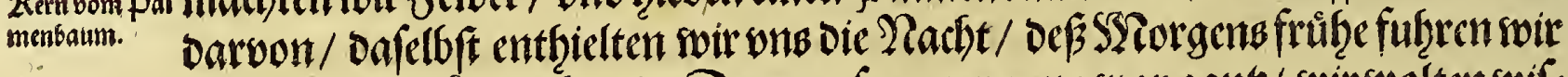

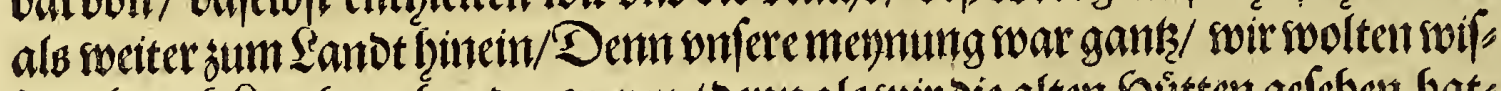

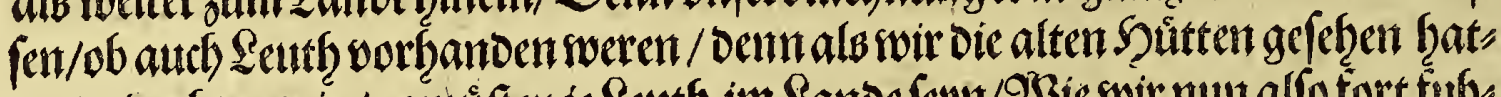

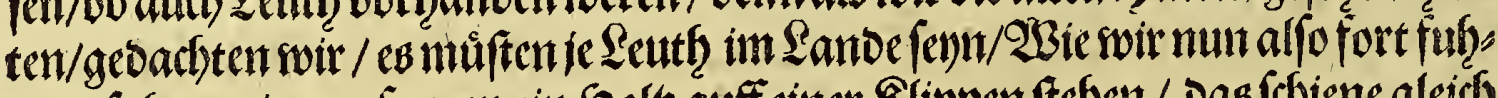

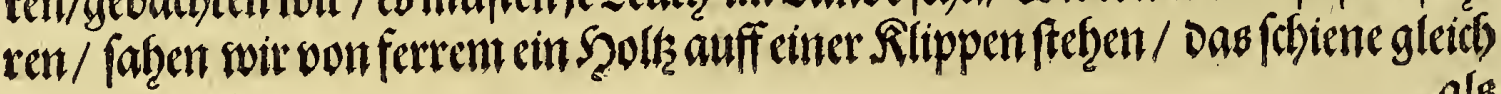


Sasbritte Theil.

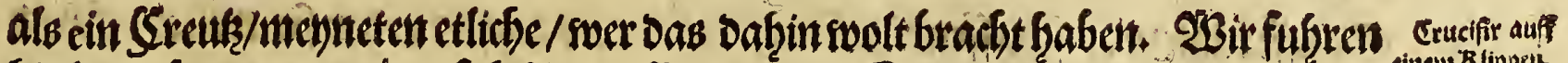

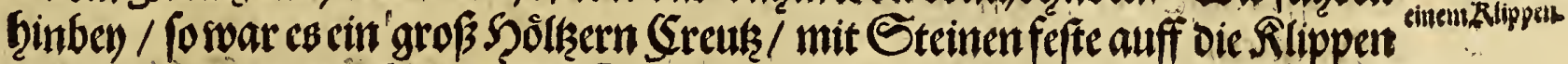
gemacht/ ond cin/tucf bon cinem Sa sboden war Darangebunden/onno in oem

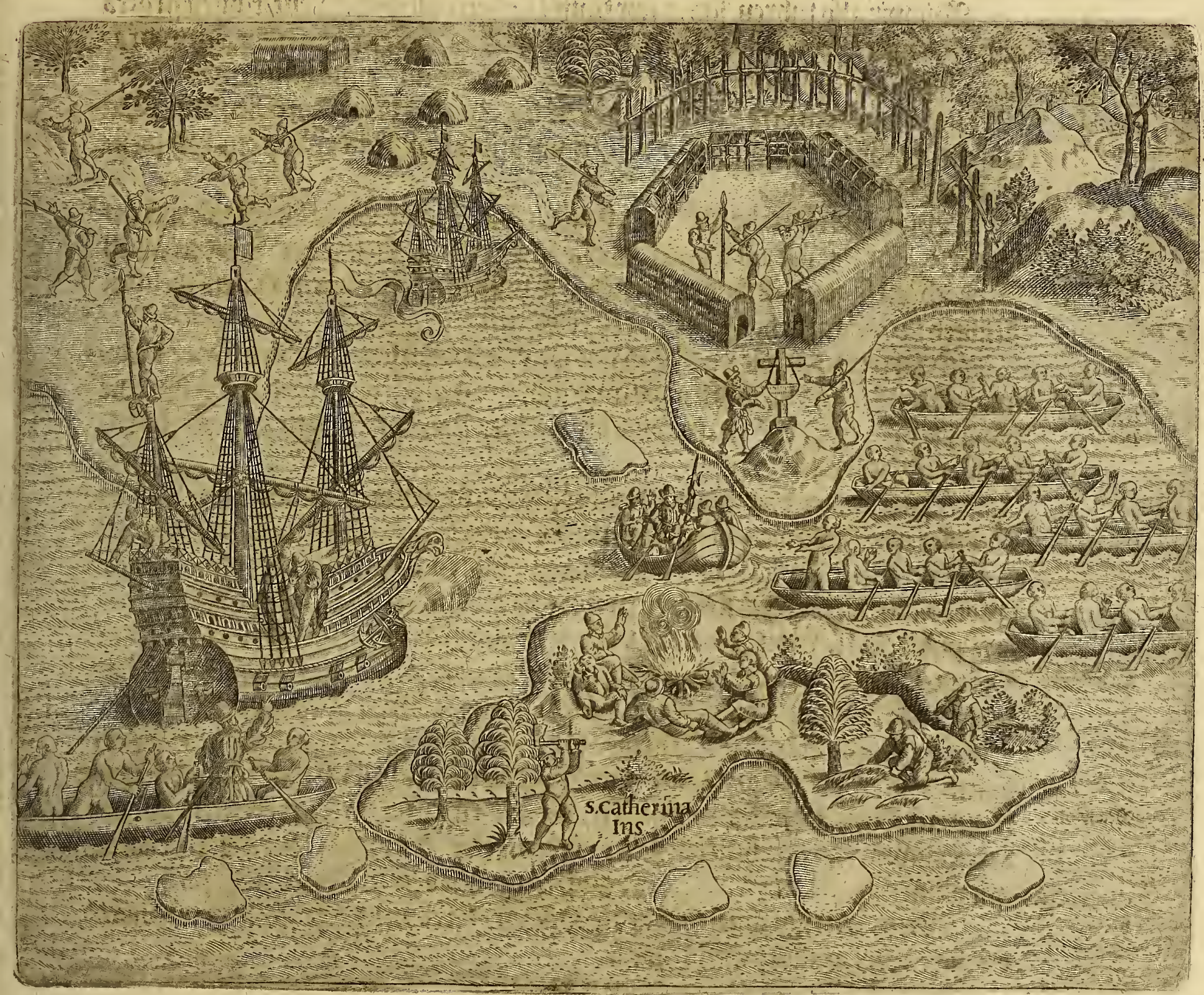

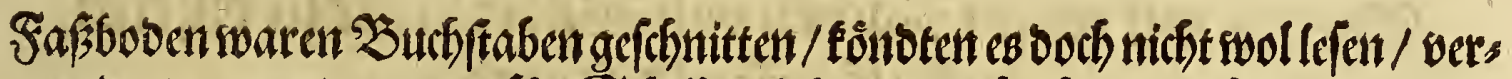

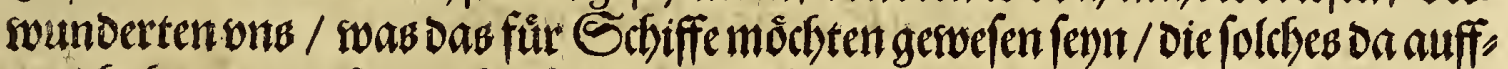

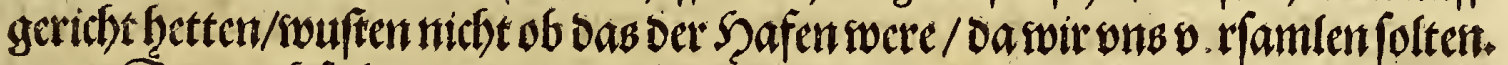

Darnach futheret soir swioer fort an / binein wont bem Streuk/weiter $\mathfrak{a n t}$ ot

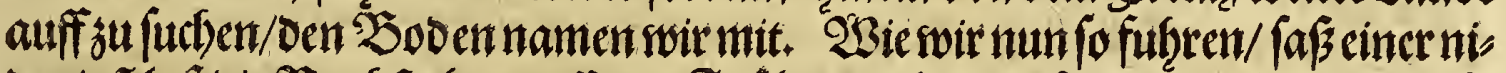

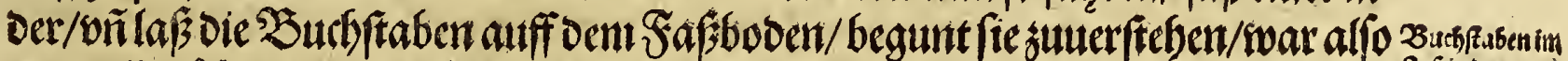

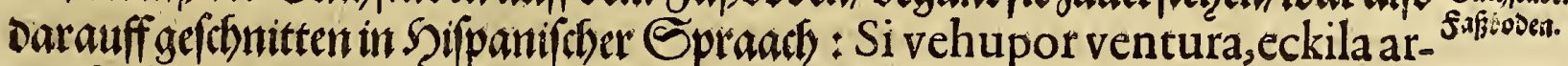
mada defu Maieftet, Tiren vhn Tireay Aueran Recardo.

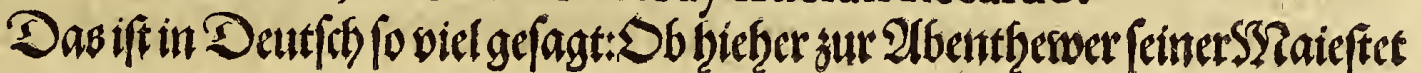
S iij Echiffe 


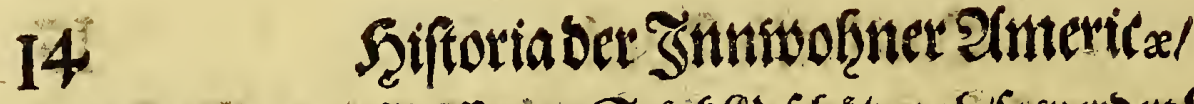

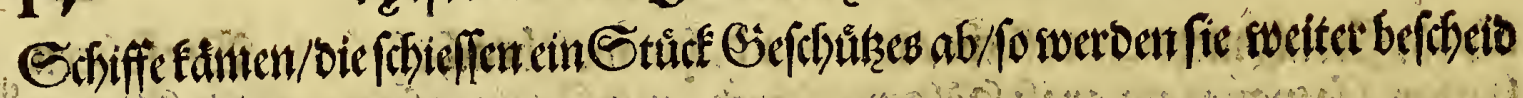
beformmen

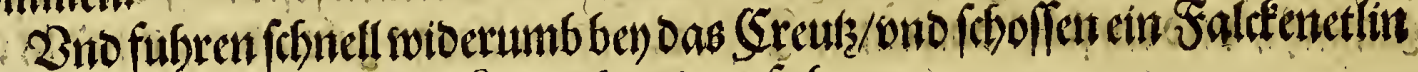
chüses. $\quad a b /$ wno begunten weiter zum Sande binein zu fafcrett.

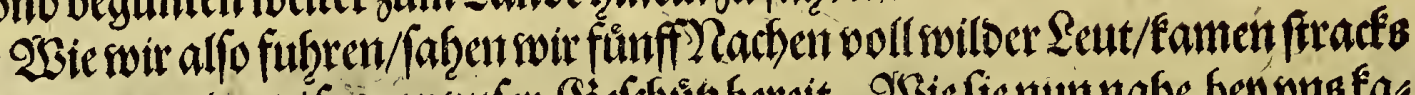

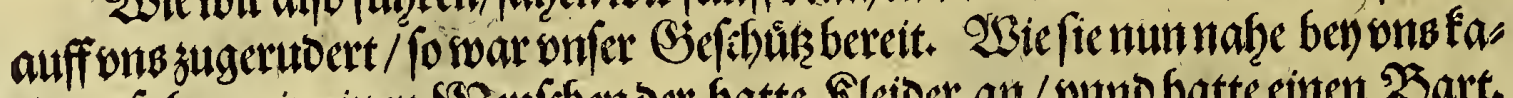

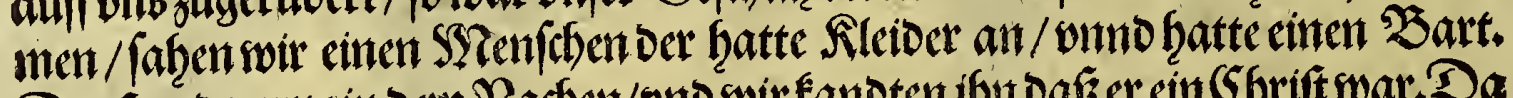

Chriftianess nterferos.

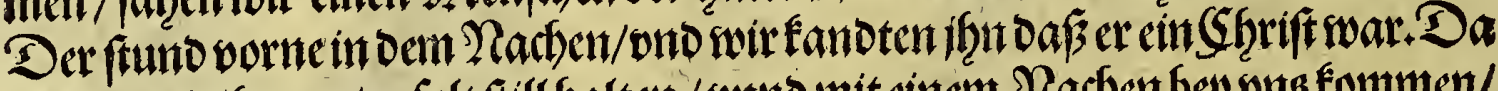

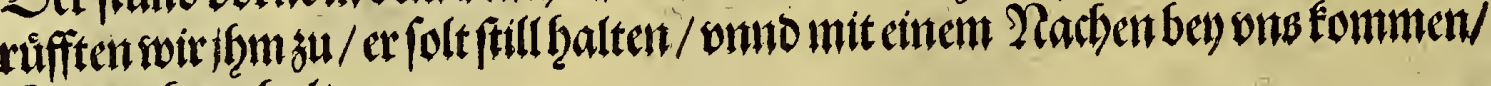
Epraachesubzalten.

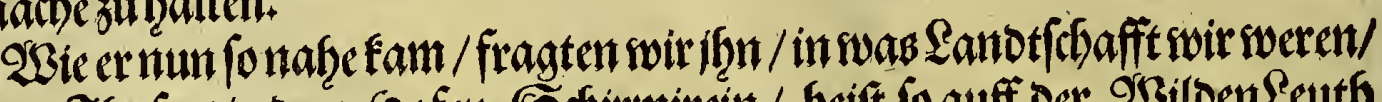
Gohitmireit.

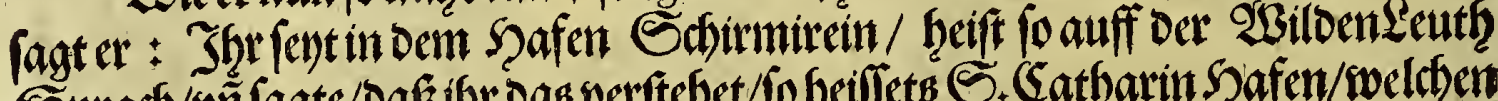

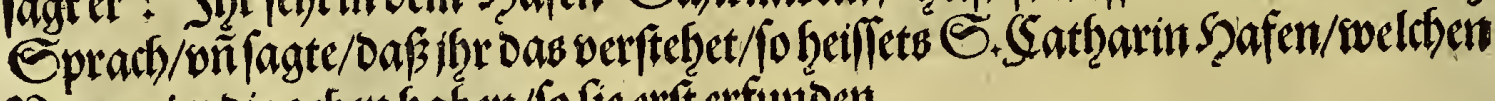
Namenim die geben haben//o/fe er/f erfunden.

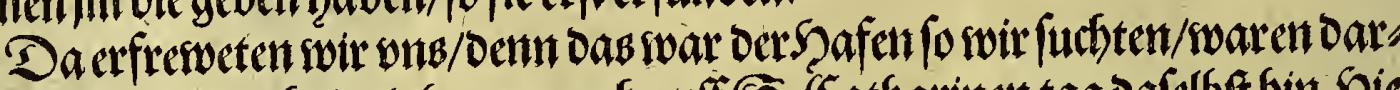

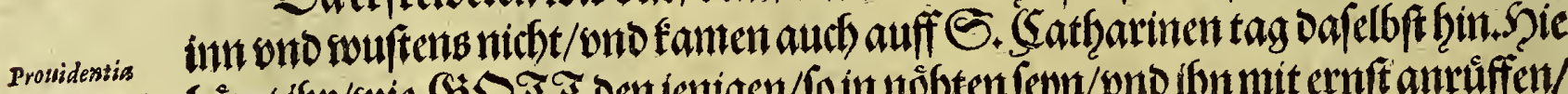
Dei. bôret/frer/woic 5 S bilffet vino fie errettet.

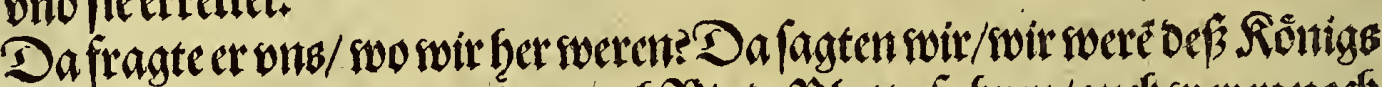

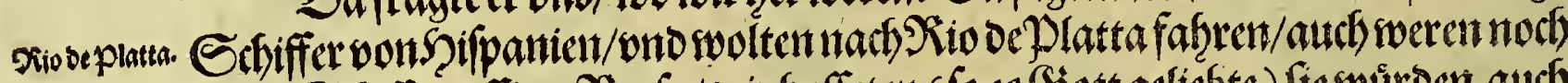

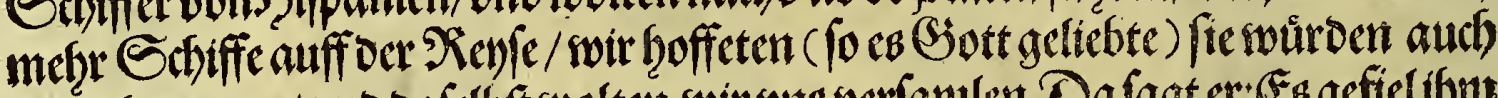

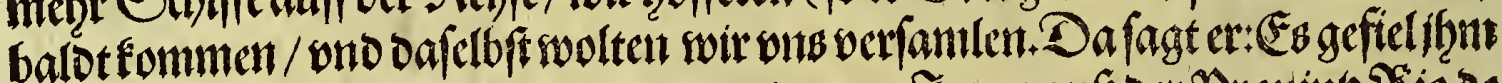

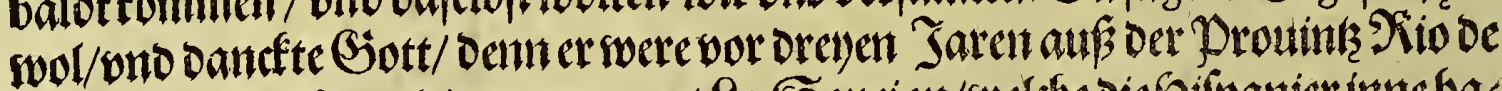

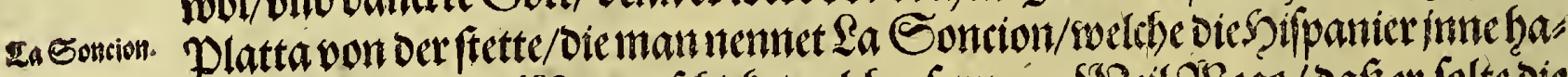

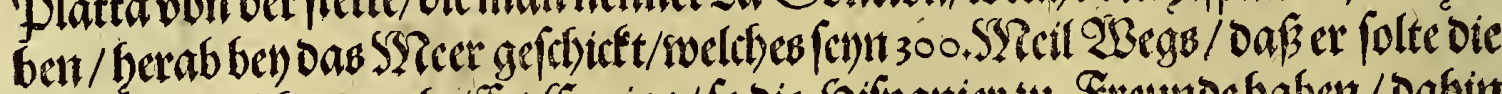

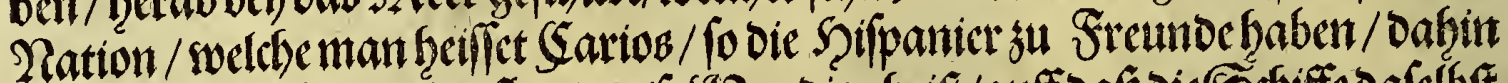

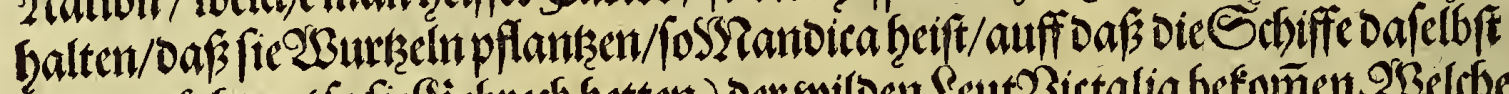

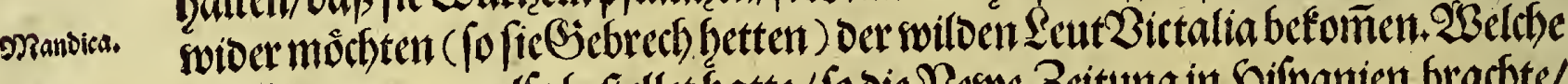

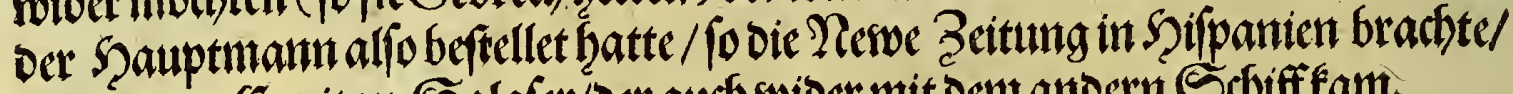
capitan Eala mit namen Sapitan Salafer/Der auth woider mit Dent andern Sebiff fam. fer.

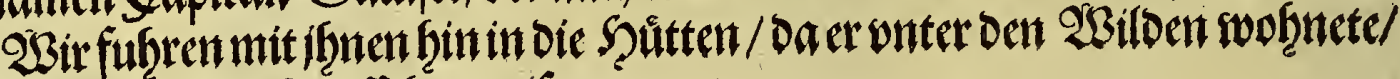
oie thetenong guttich auffibere weile.

\section{OSie ith mit einem 2 achen voll}

groflen Sebiffe gefthidft rourde.

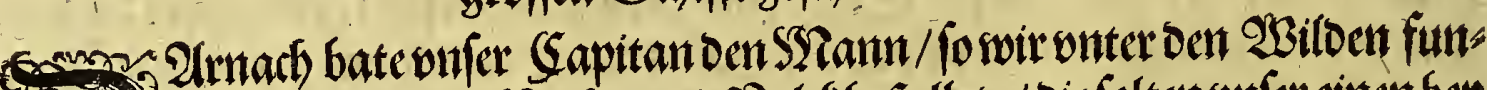
Den / o a ser einen Rachen mit Zolé beftellete / oie folten whfer cinen bey)

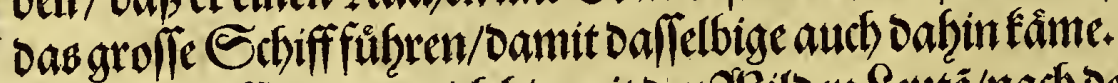

Spans ธrtaben

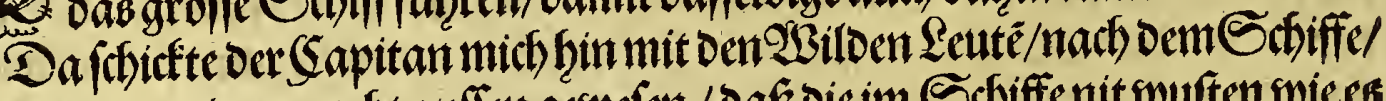

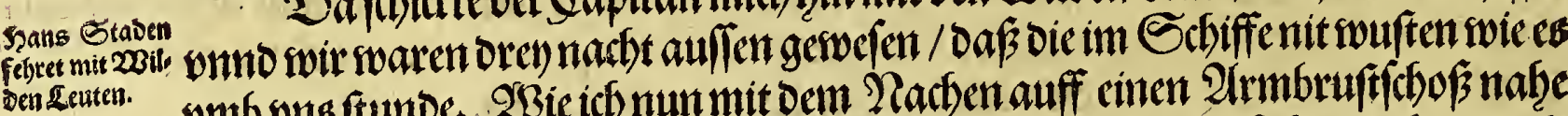

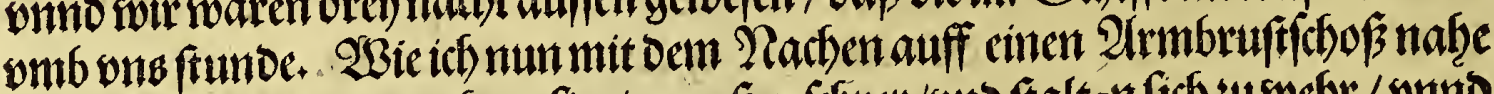

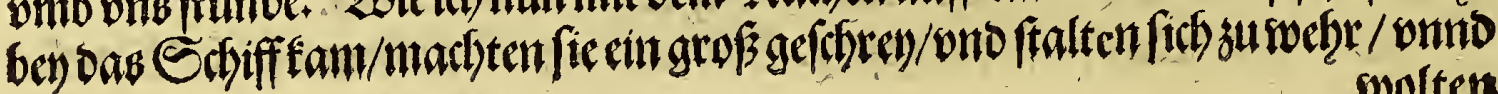
wolten 
Das britte Theil.

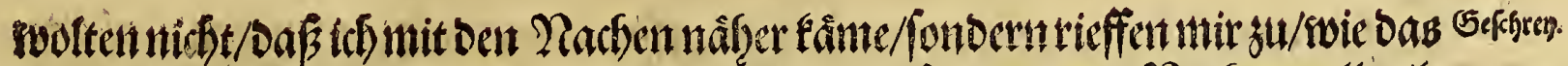

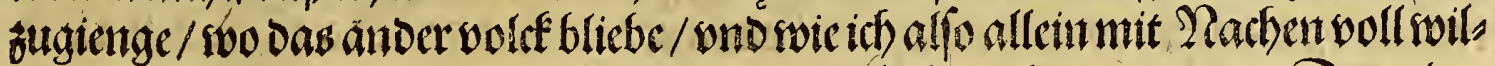

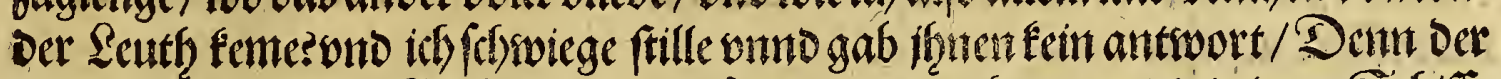

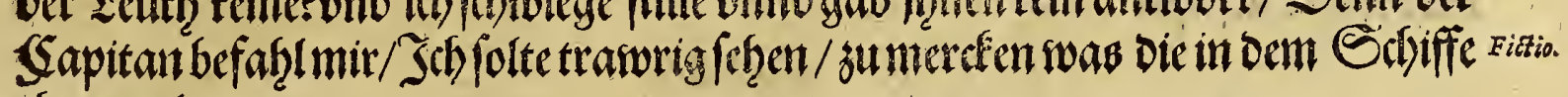
thun soolten.

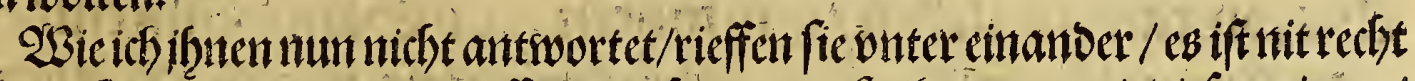

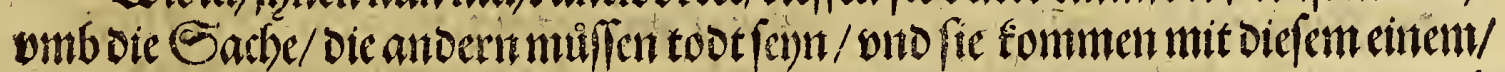

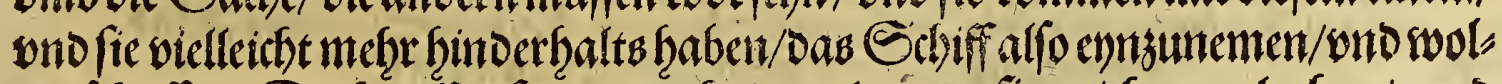

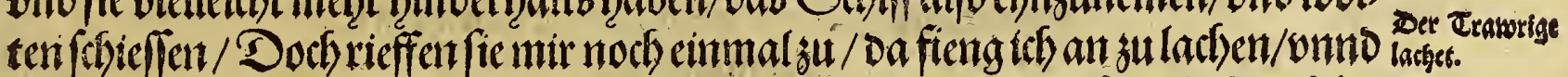

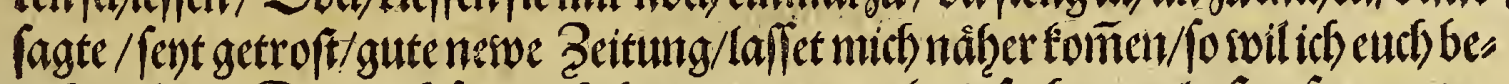

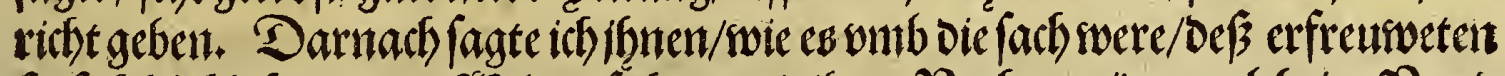

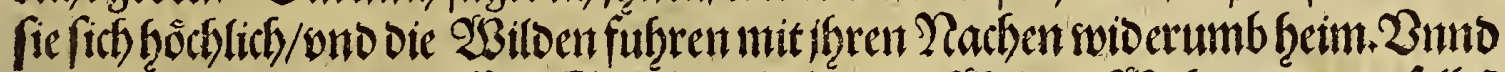

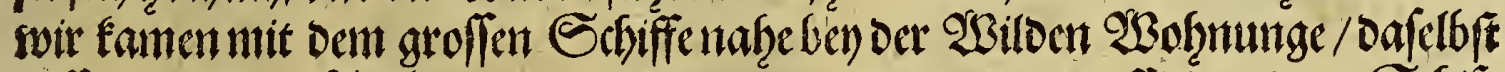

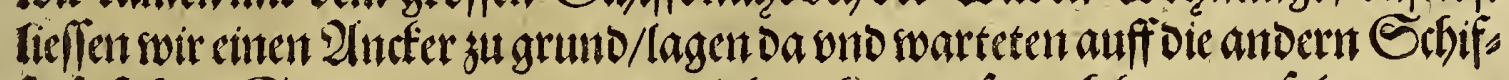
fe/fo fieb in Sturntwind won whb verlohren featten/fo nod fommen jolten.

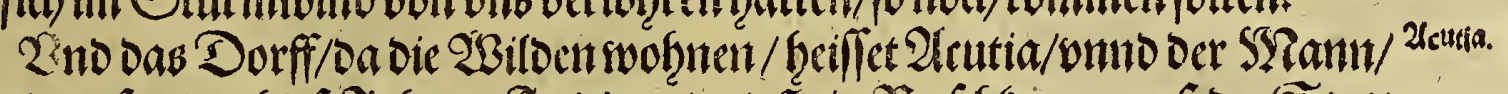

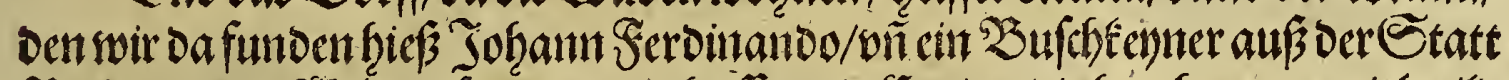

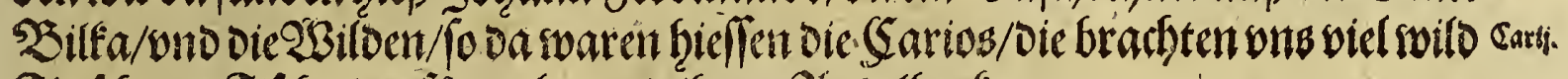

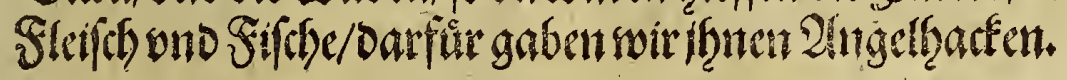

\section{Sapittel.}

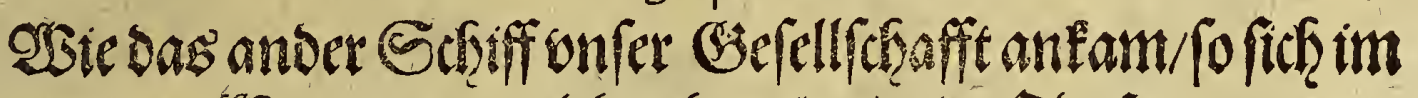

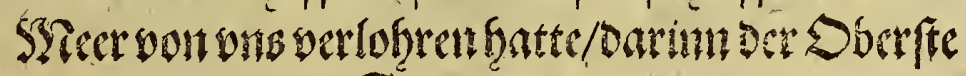

Stramannator.

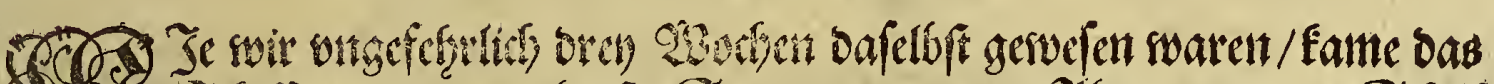

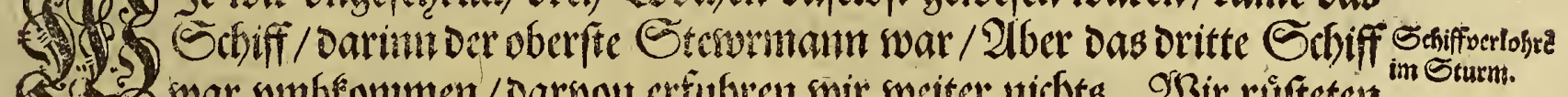

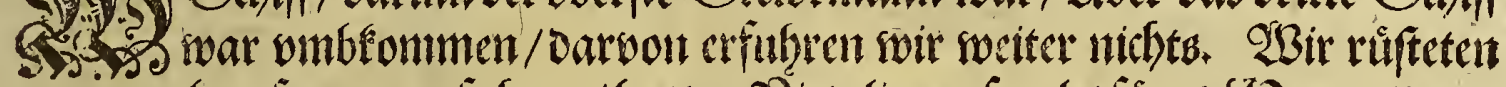

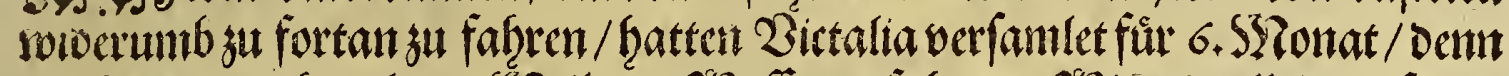

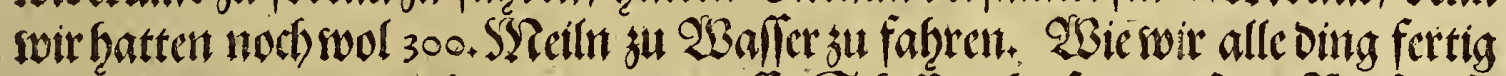

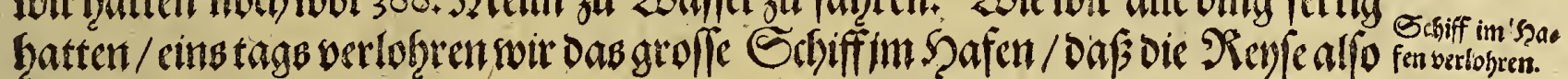
verţinost swaro.

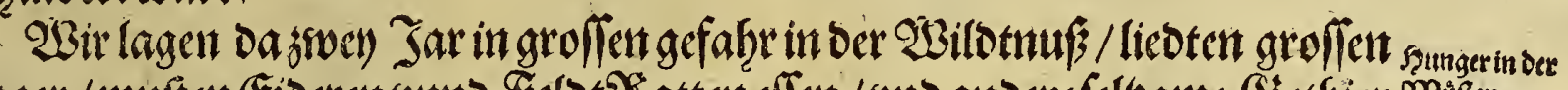

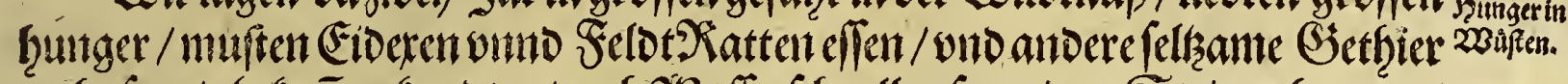

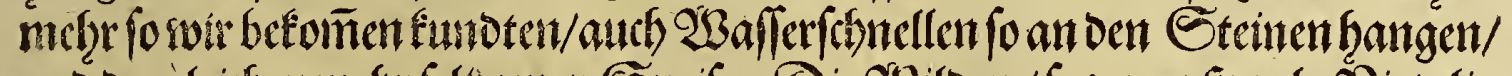

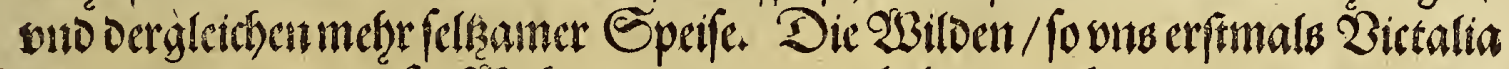

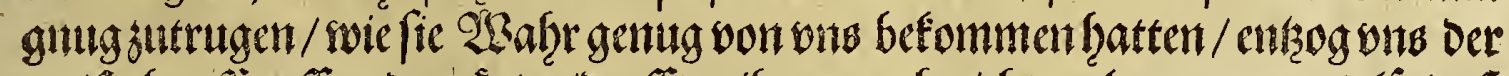

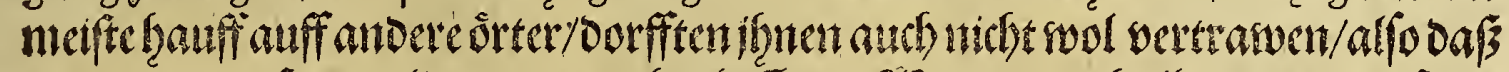

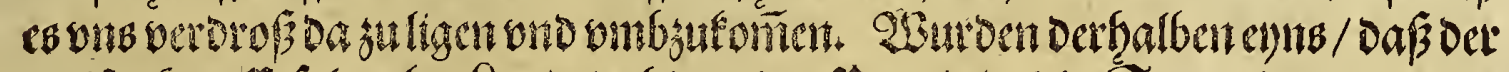
incifte Şauffe folte vber Santot dabint ju Der Prontins/ Die Sumption genannt/ Sumption.

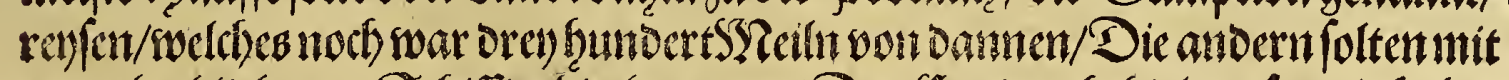

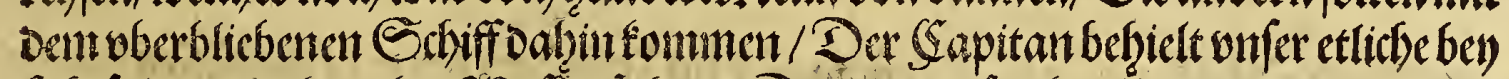

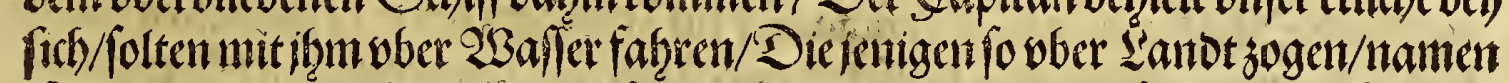
Bictalia mit / ourth oic Q Genfiul 


\section{6}

\section{OSarfbaftige $\mathfrak{B}$ efforeibung}

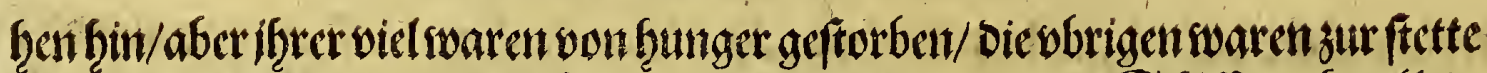

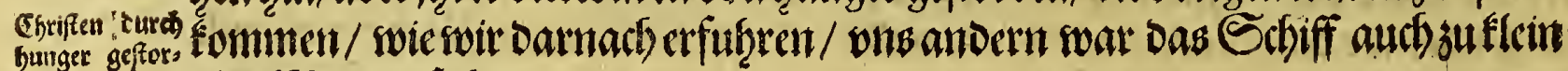

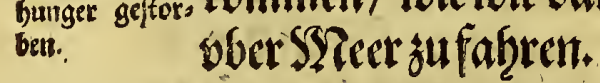

\section{Sapittel.}

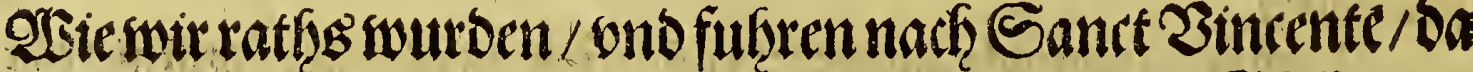

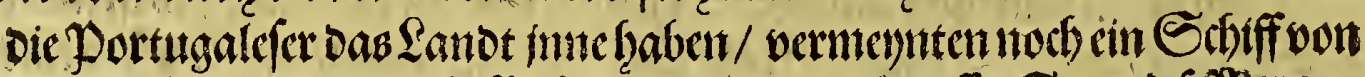

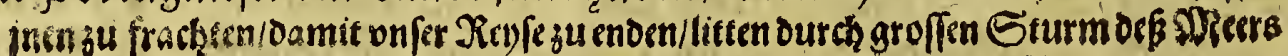
Echiffbruch/mufen doch nicht/we ferme wir oon 5 .

Dincentewaren.

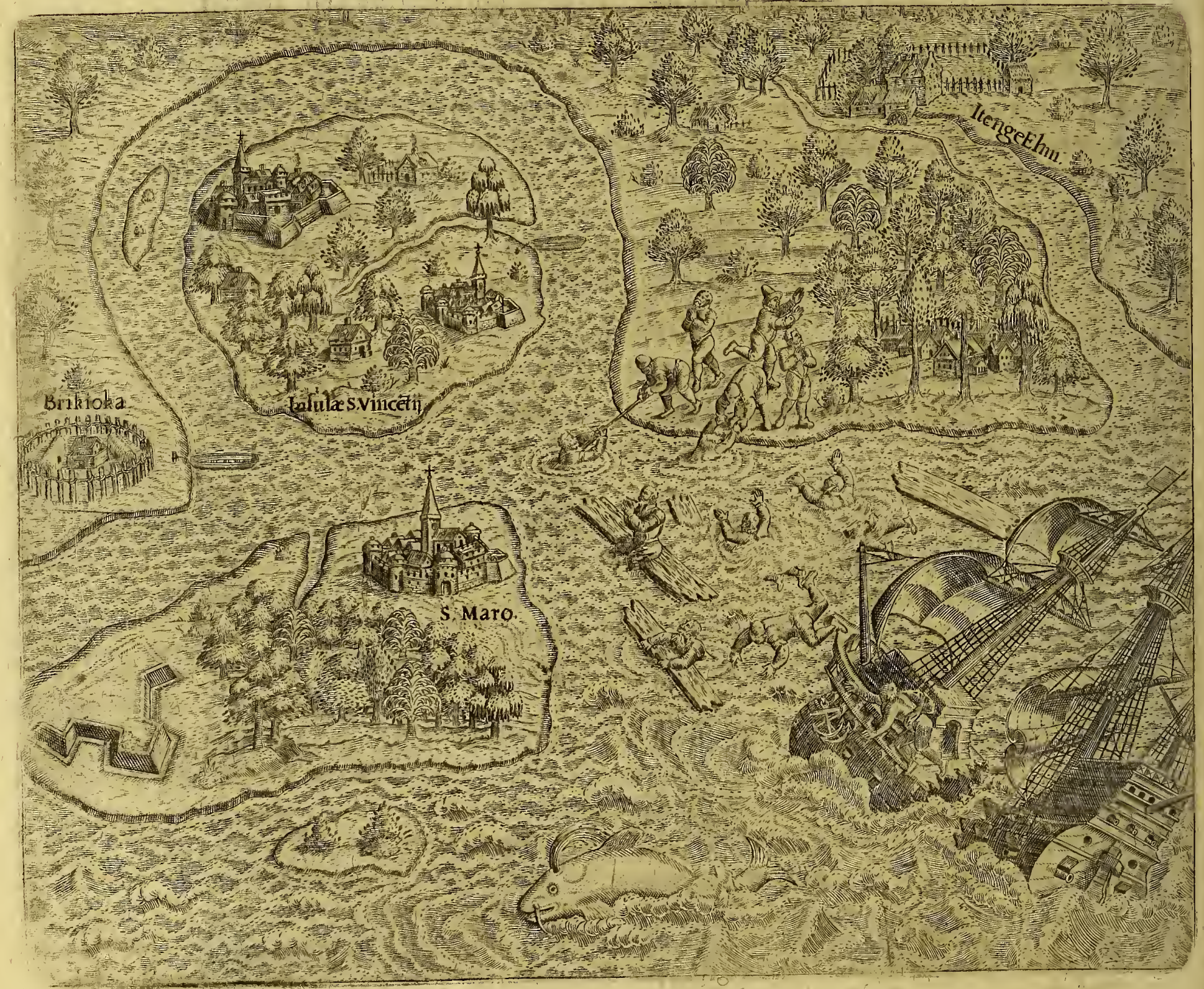

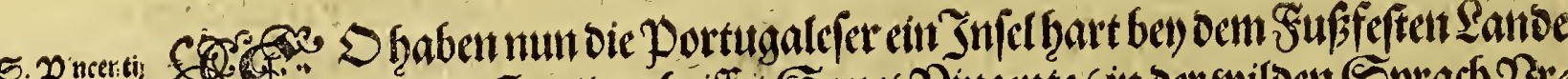

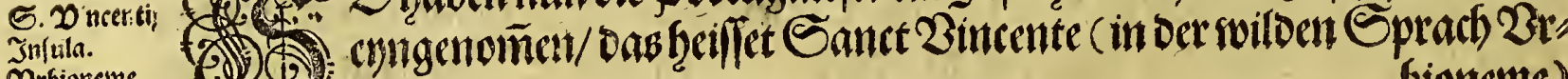
cortios (bioneme) 


\section{Sasbritte Sfieil.}

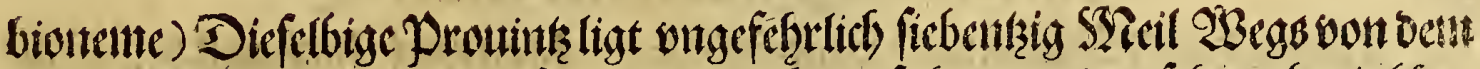

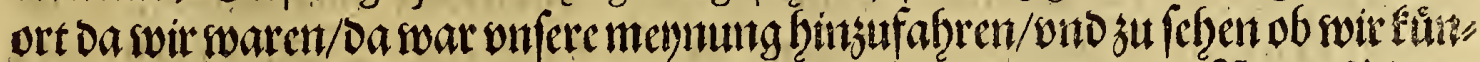

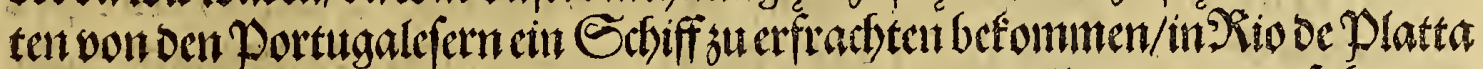

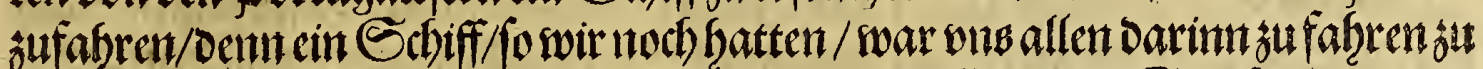
flein. Das zu erfor/chen fuberen vuler etlich mit DentSapitan/Salafer genant/

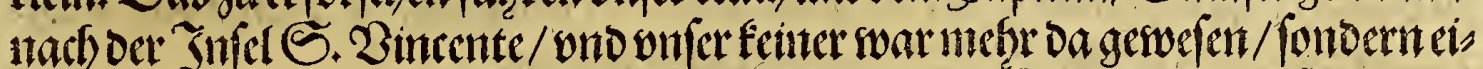

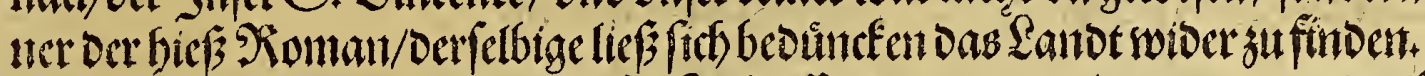

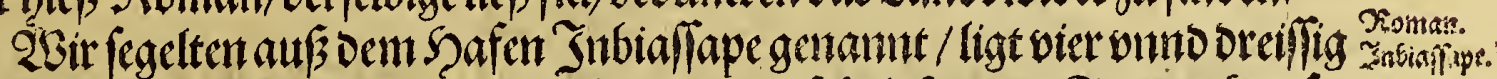

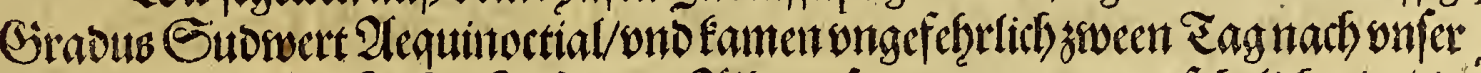

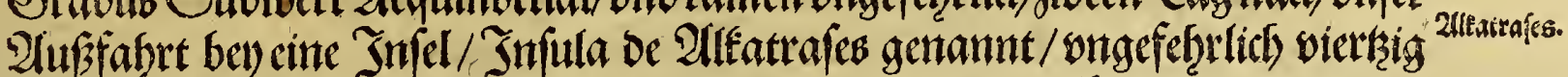

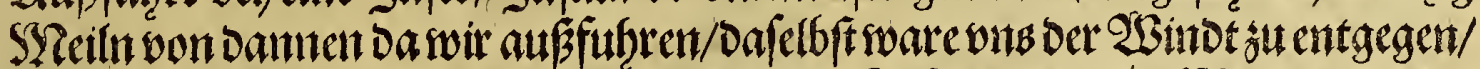
Daßs wir muften Dabey antern. In berfelbigen Infel waren vier SYeervögel/ oie mann nentet 2llfatra/eb / Diefelfigenfino rool zubefommen/fo swar es'ant der zat

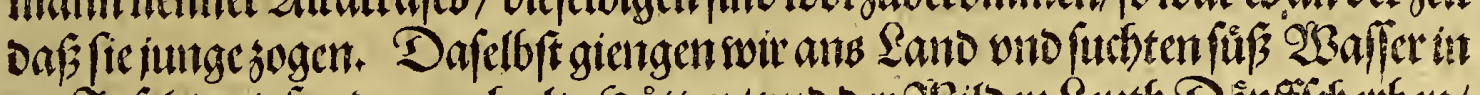

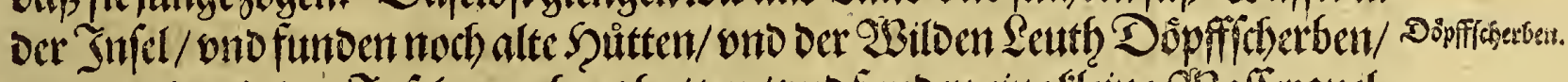

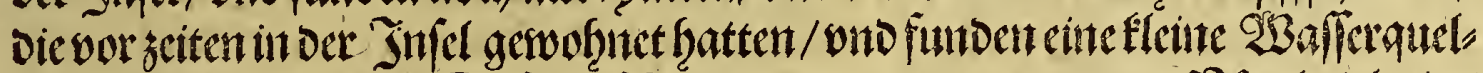

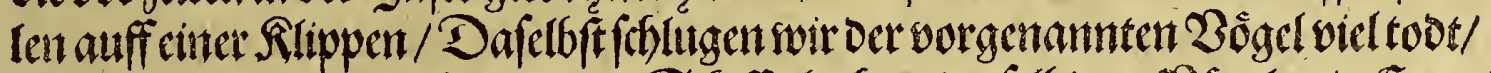

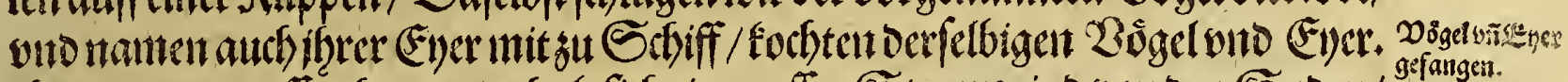

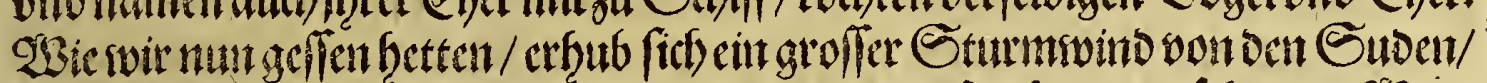

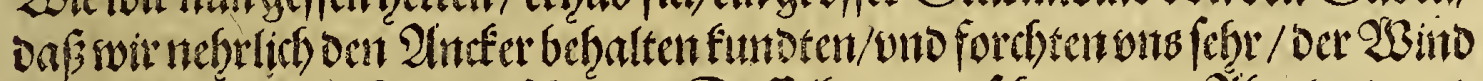

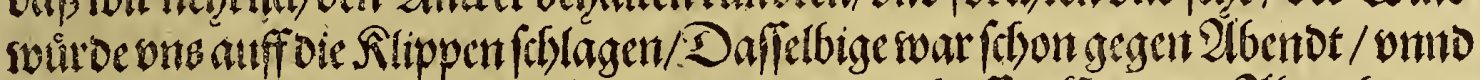

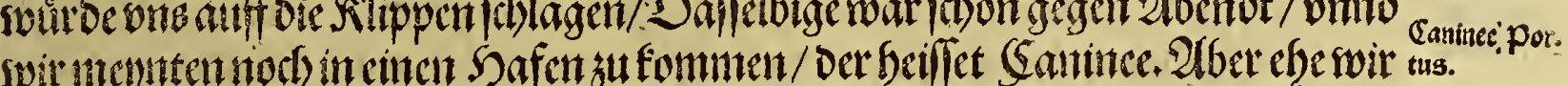

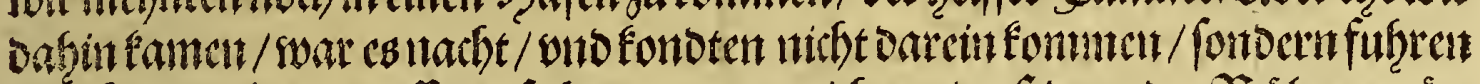

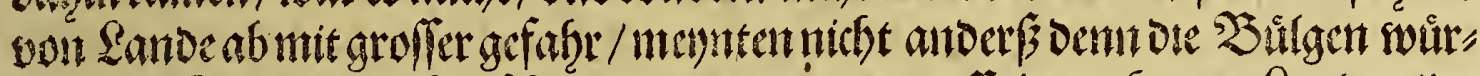

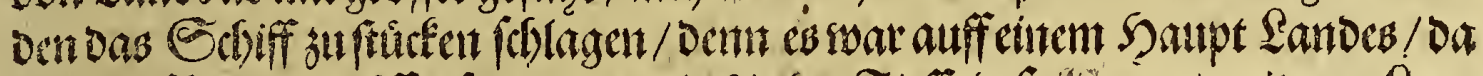

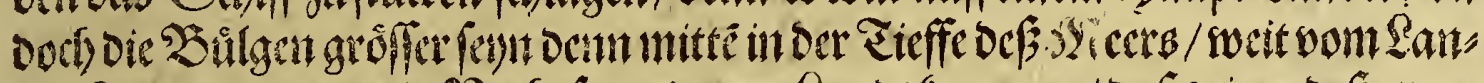

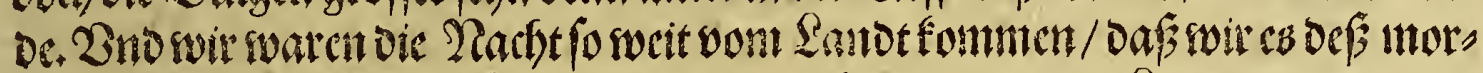

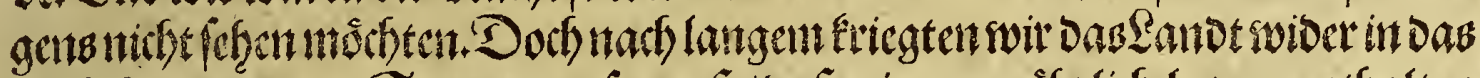

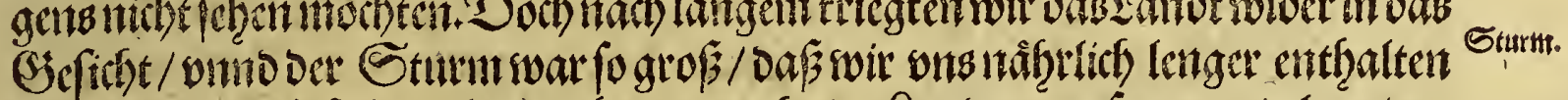

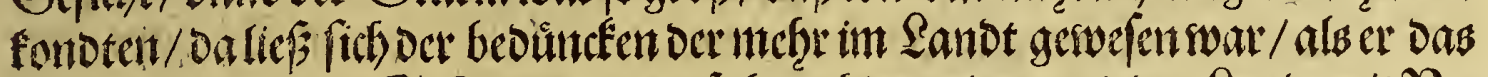

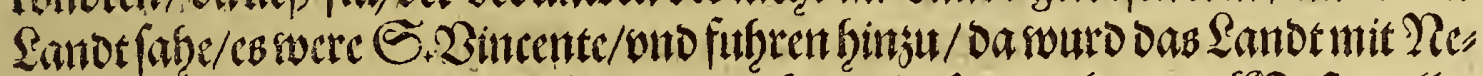

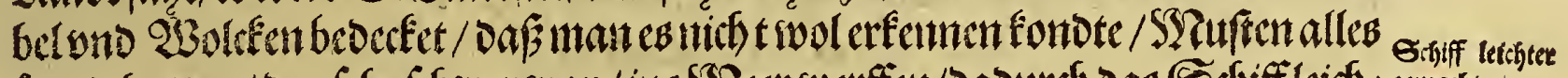

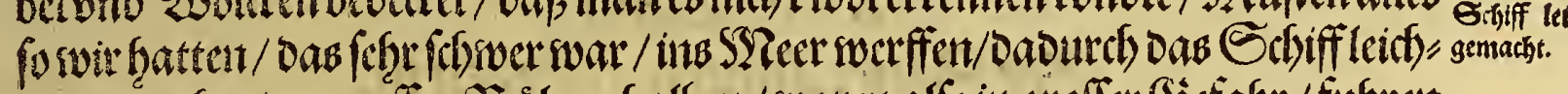

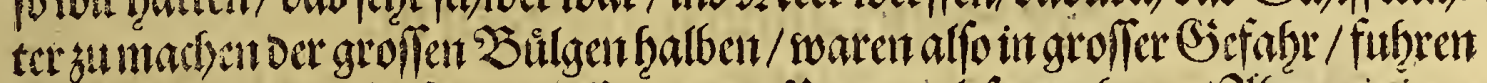

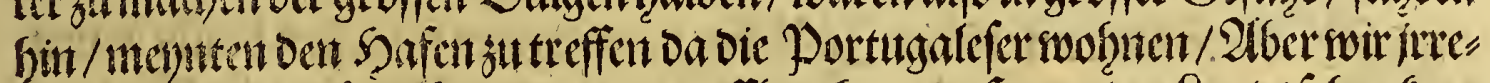

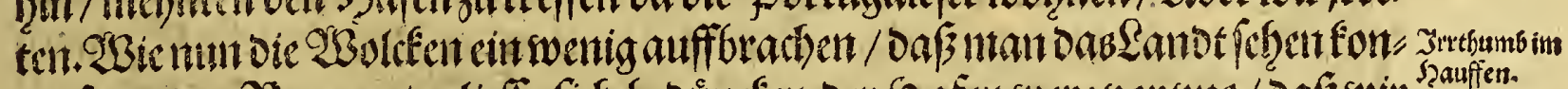

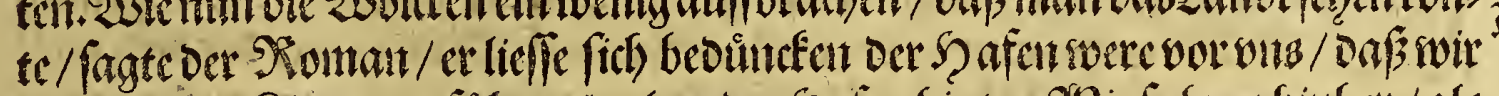

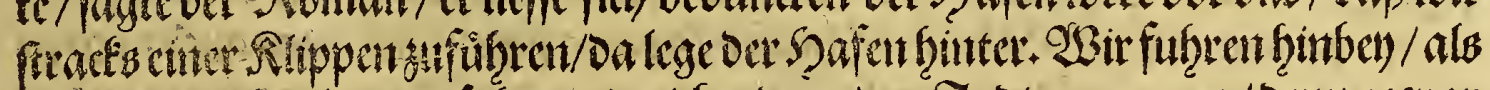

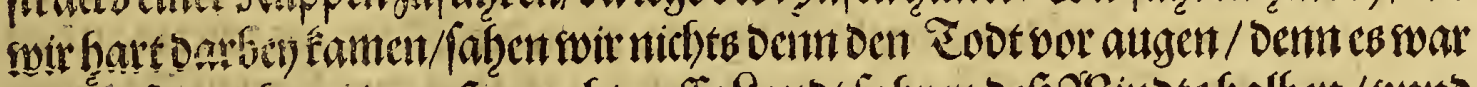

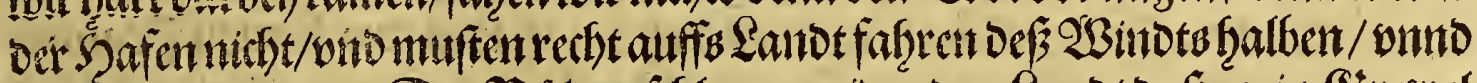

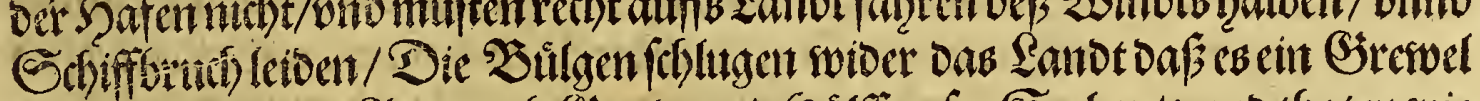
swar/Dabatenswir Gott bunb Sinade vono Sulff unfer Seclen/vinto thaten wie

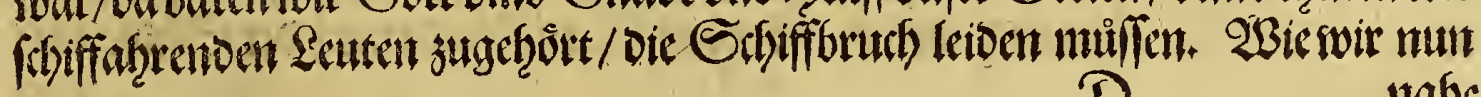
D $\quad$ nahc Sajifíturuth. 


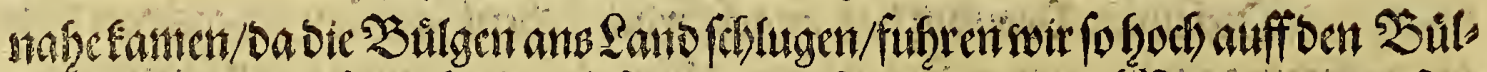

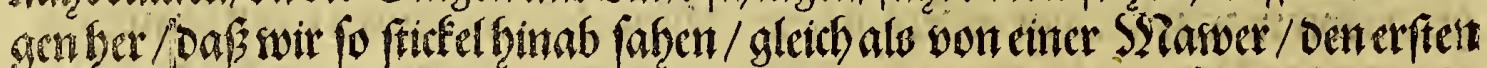

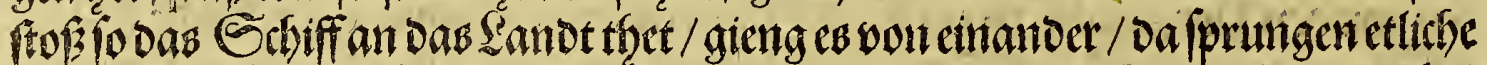

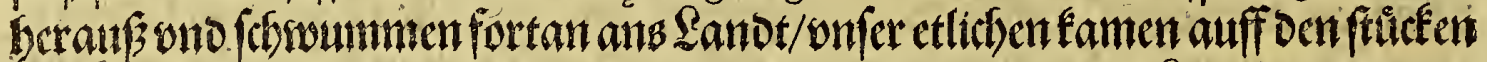

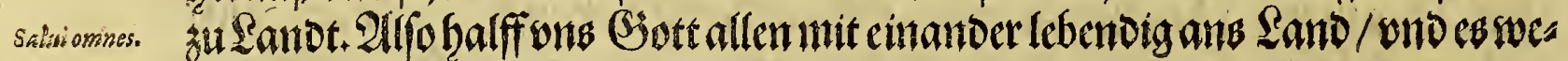

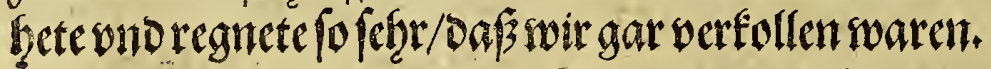

XIII. Sapittel.

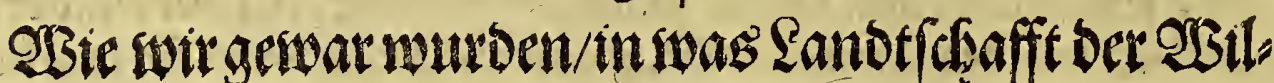 Den Sentroir ben Eetbifforuch gelitten Gratten.}

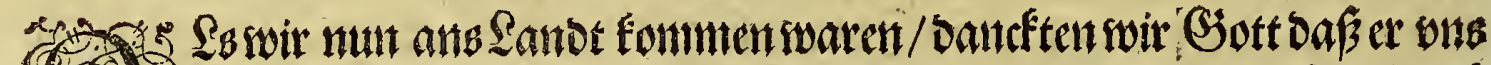

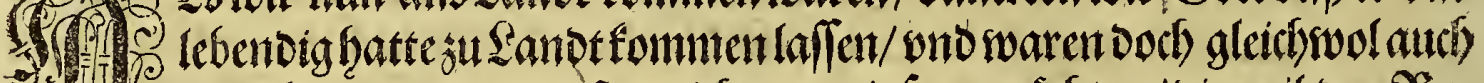

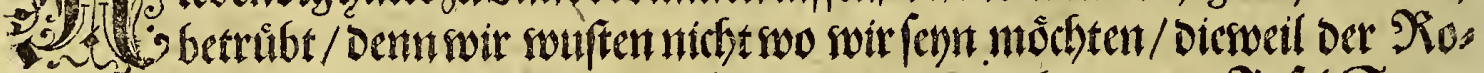

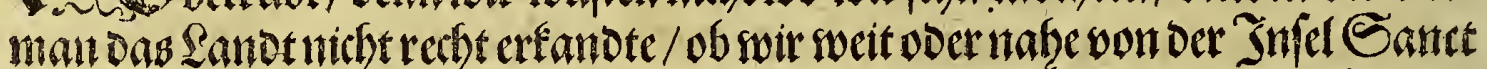

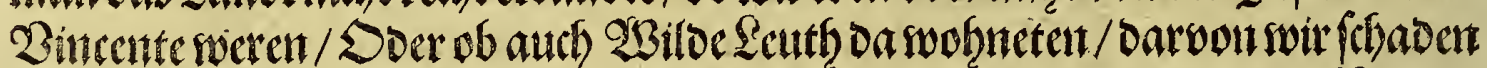

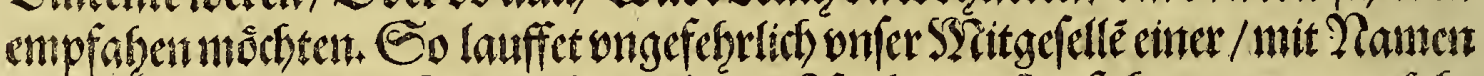

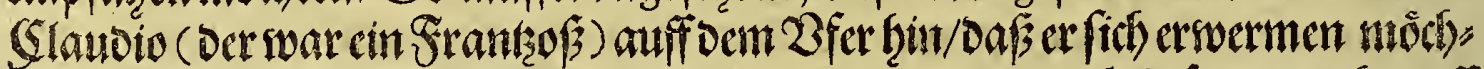

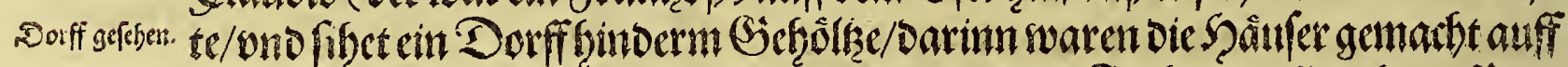

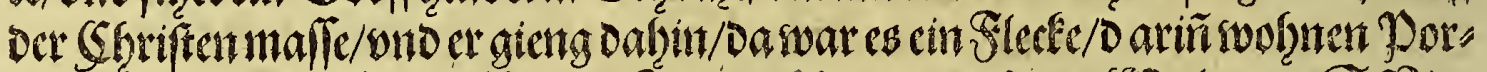

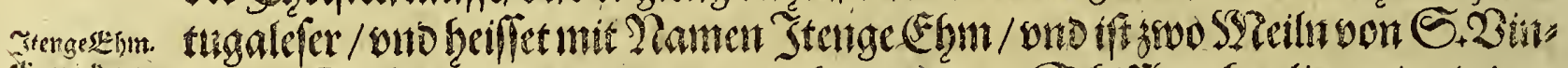

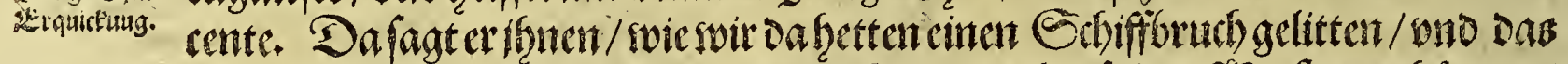

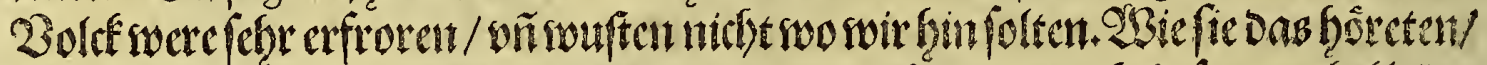

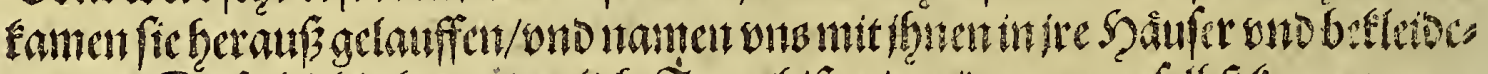

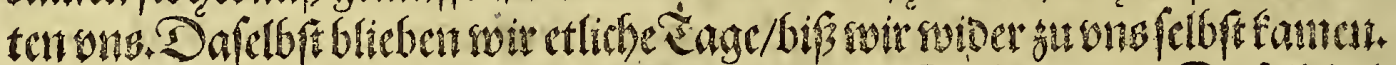

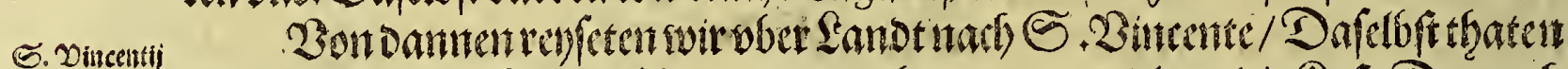

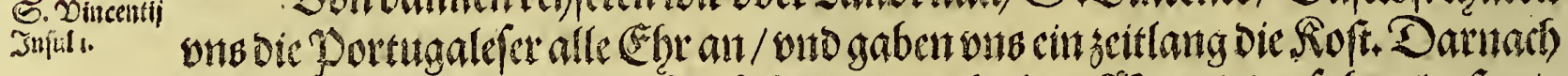

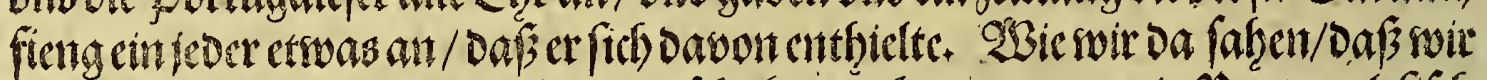

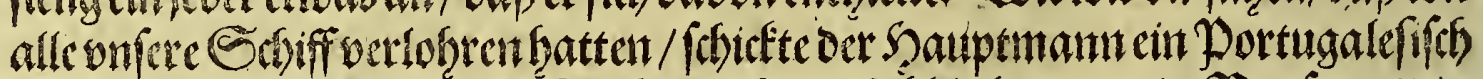

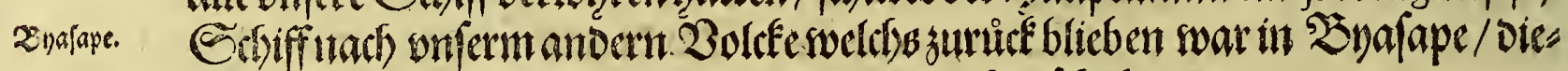

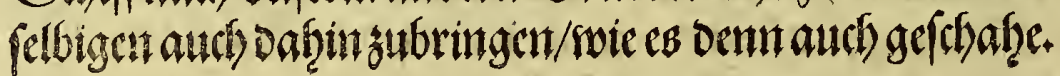

\section{XIIII. Sapittd.}

\section{OBic Sant Zincentegelegen ift.}

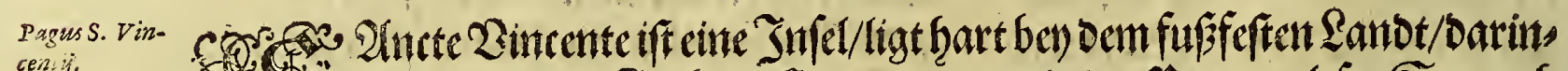

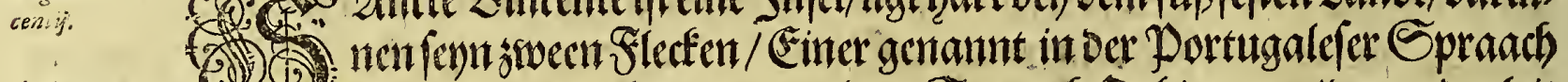
20rtioneme.

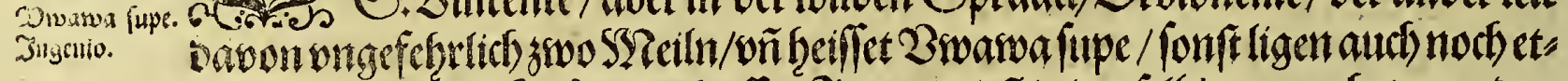

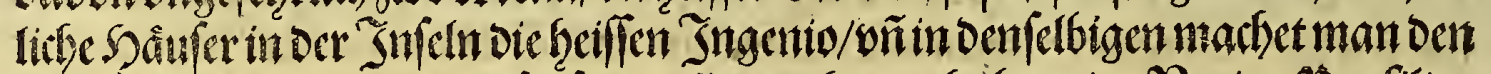

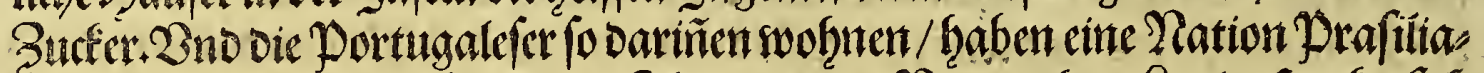

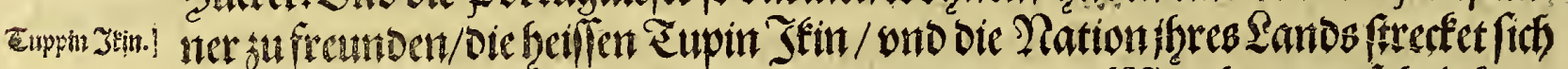

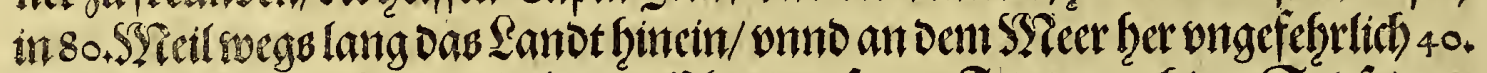

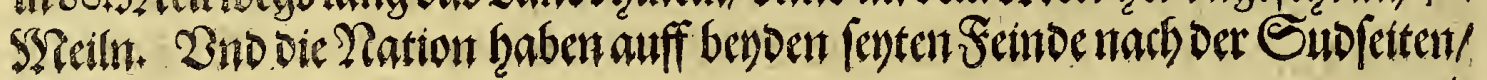

onto 


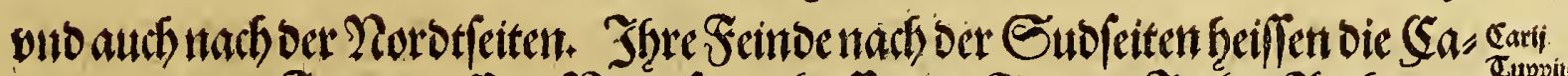

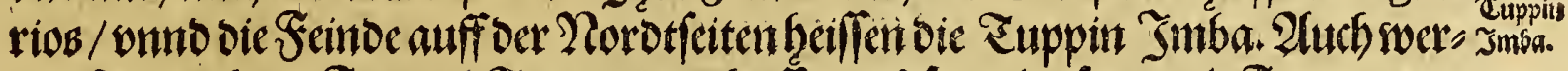

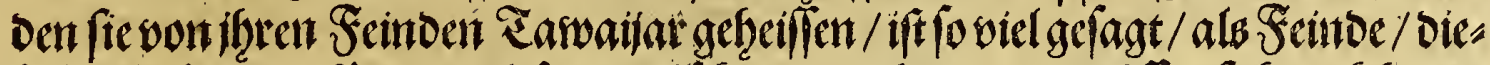

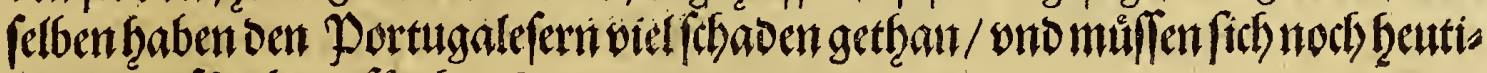

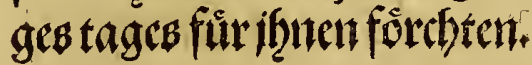

XV. Capittel.

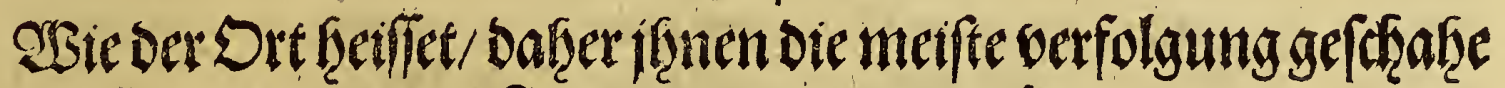

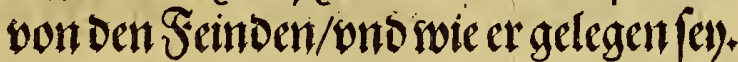

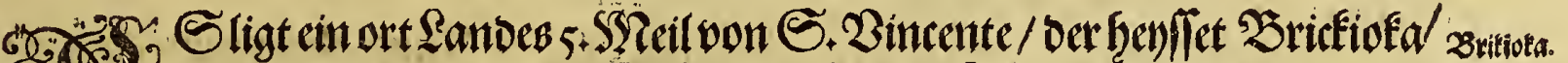

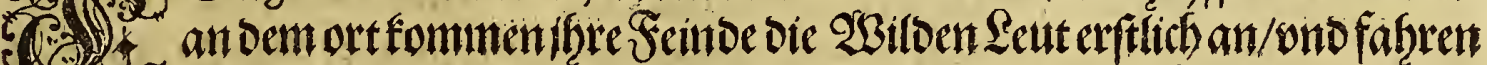

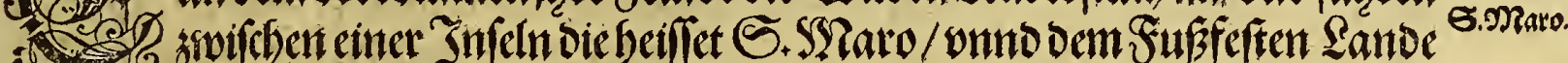

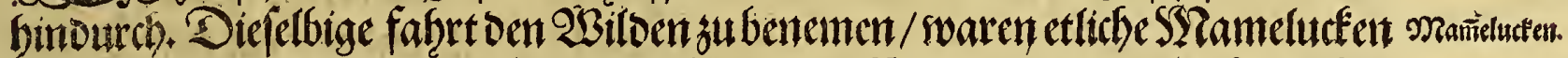

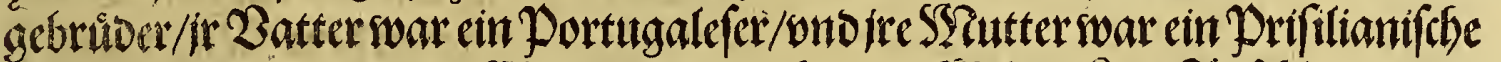

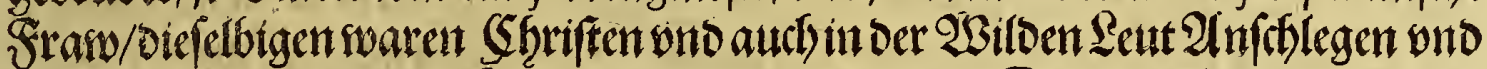

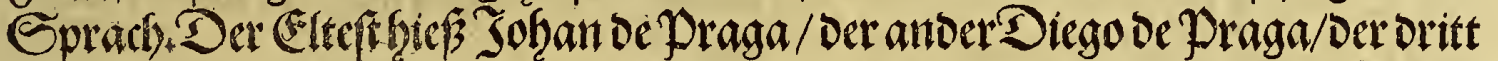

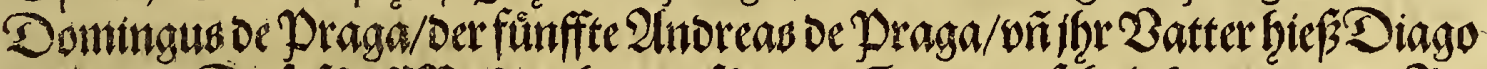

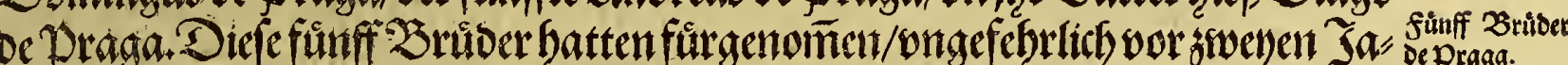

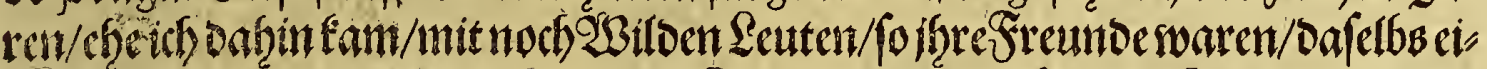

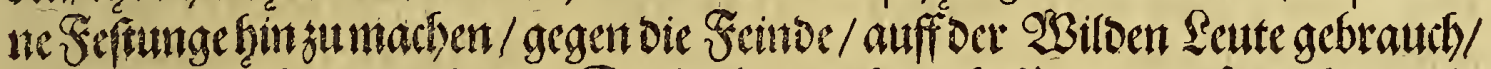

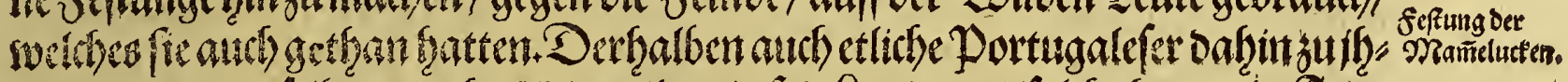

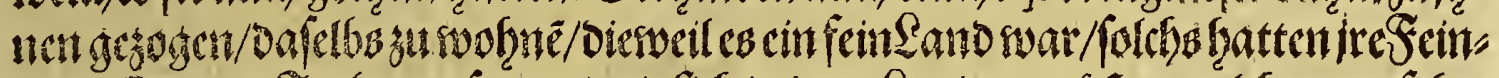

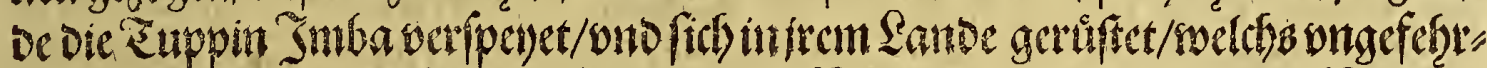

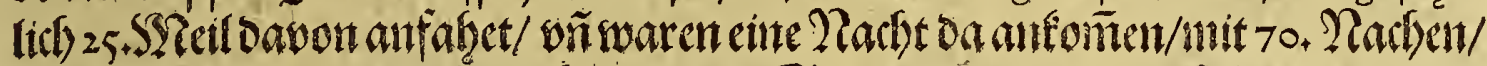

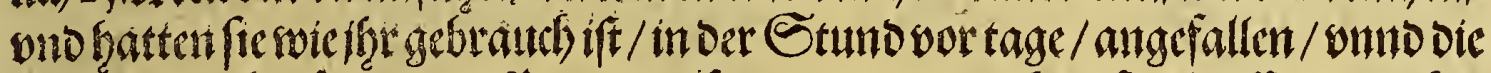

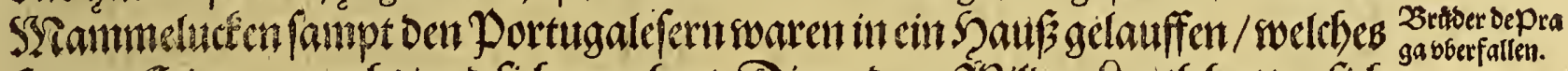

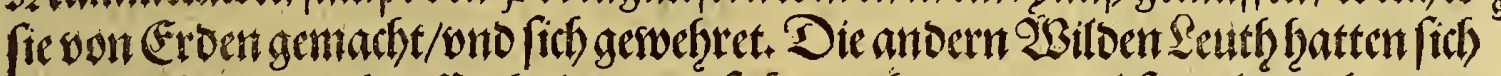

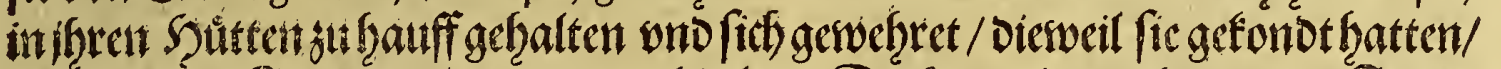

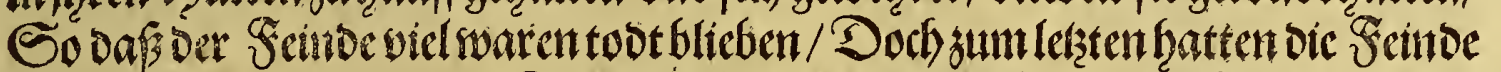

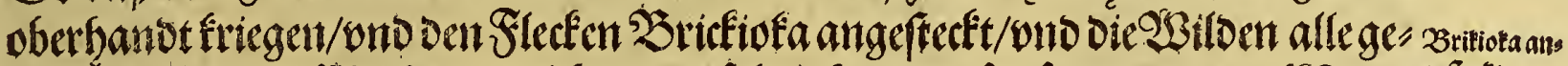

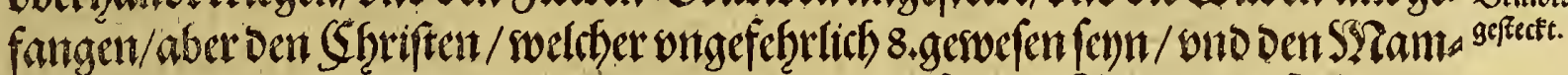

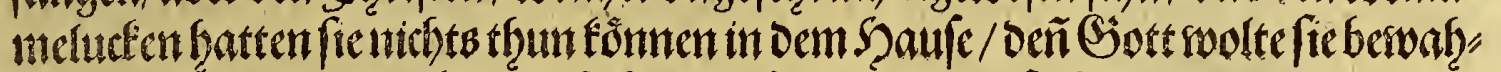
ren/2lber bie andent 2 Biloen fo fie oa gefangen/hattē fie balot vonteinanoer ge"

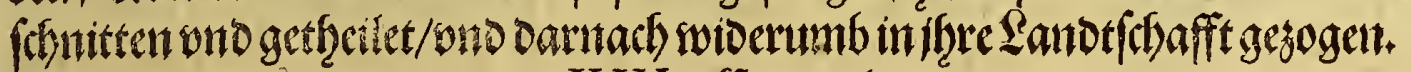

\section{Srapittel.}

\section{OBte bie Portugale/er/Drifiofa wotoer auffigeritgetgatten/}

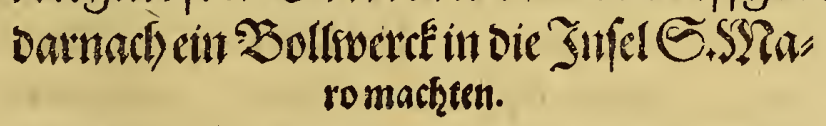

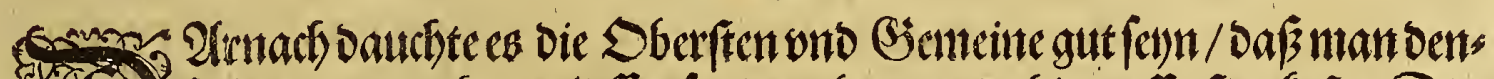

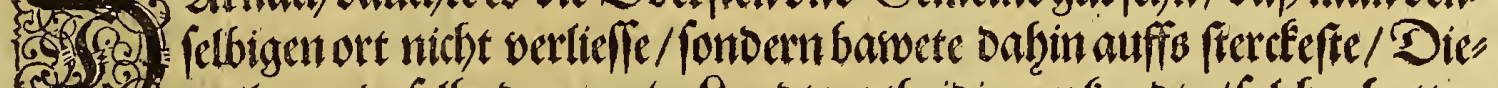

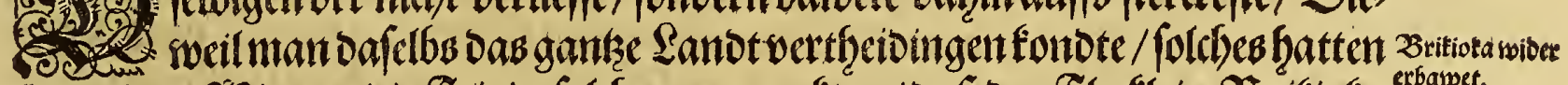

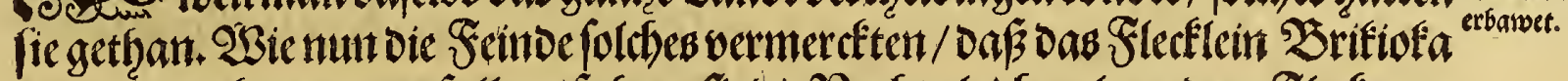

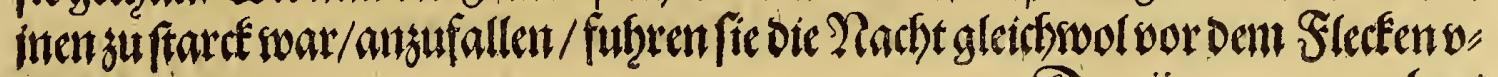

$D$ if ber/




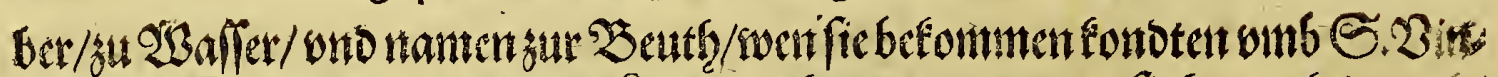

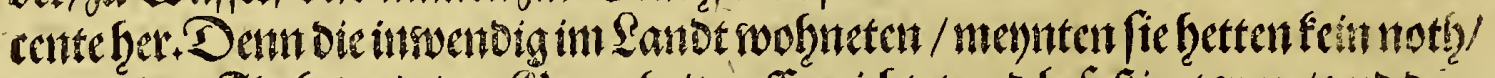

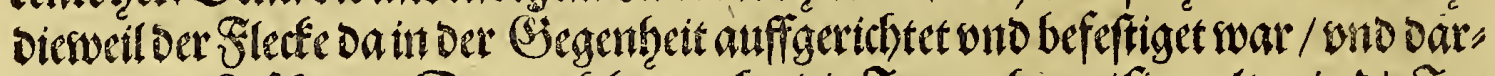

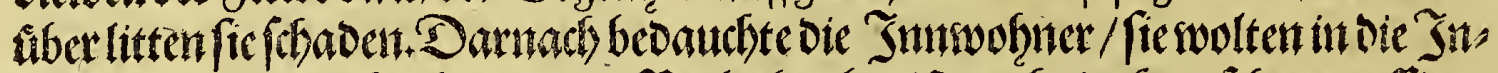

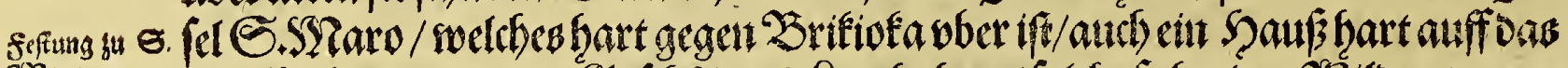

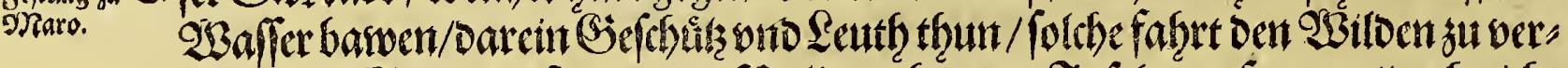

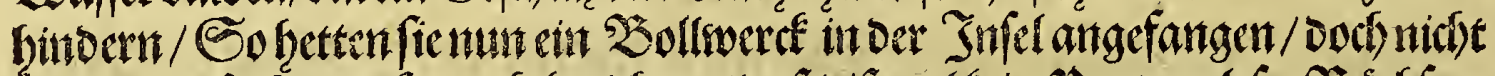

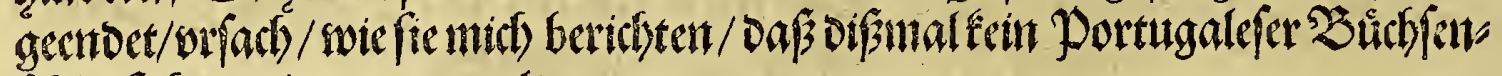

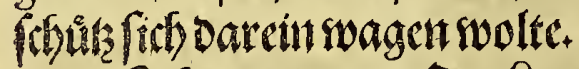

5?. Stabeu soirot gum Butchlenmet fter.

Grabigro

2 intunftetoes Dberifen. Dut wath

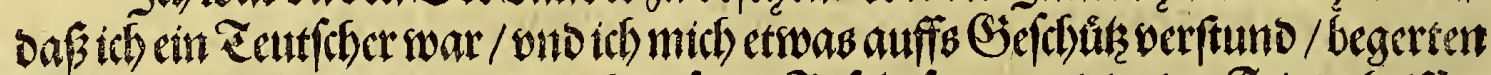

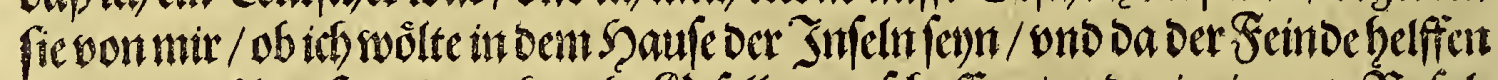

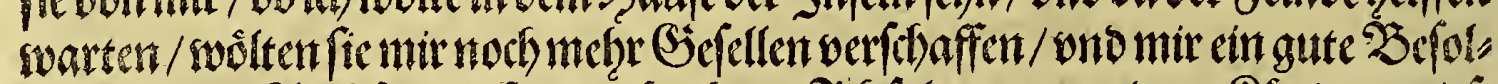

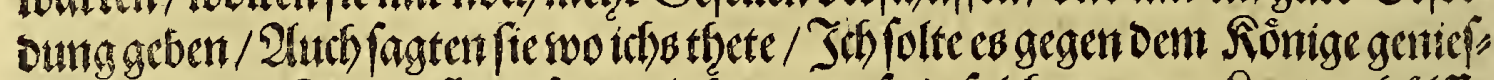

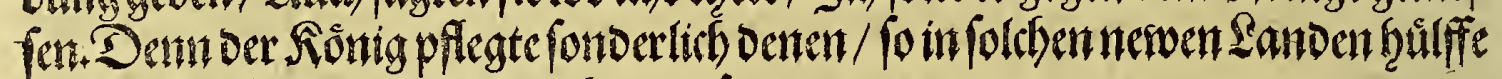

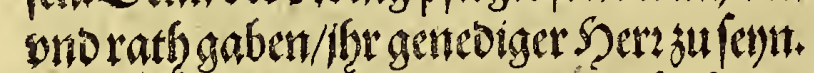

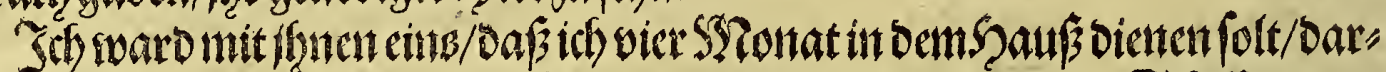

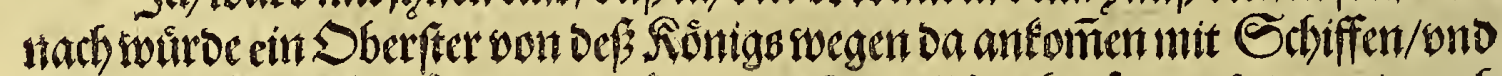

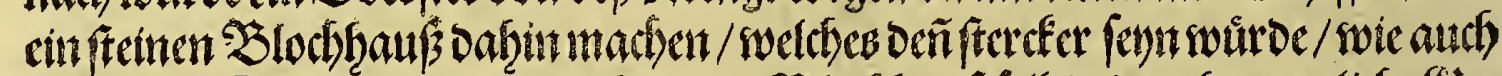

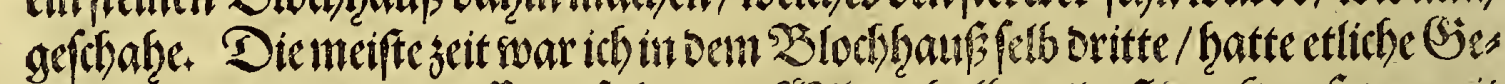

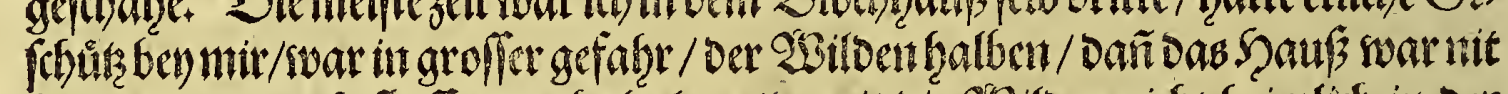

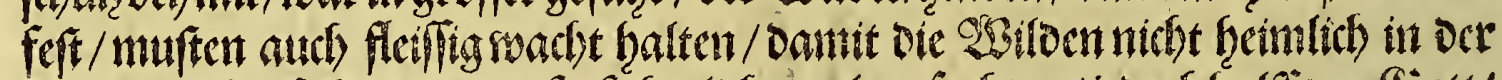

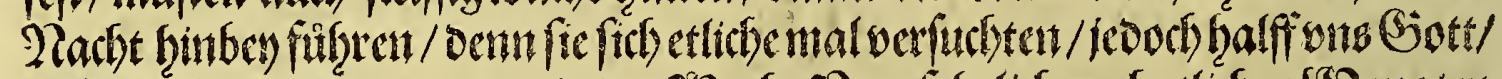

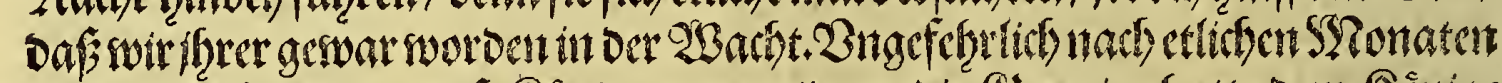

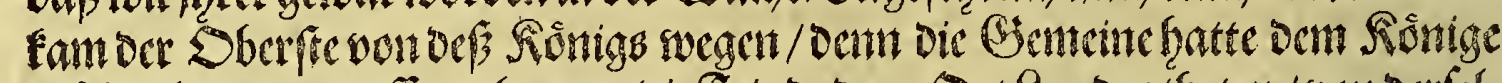

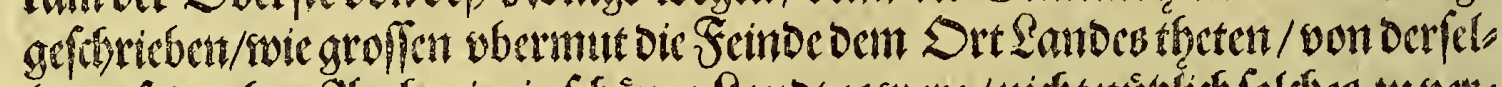

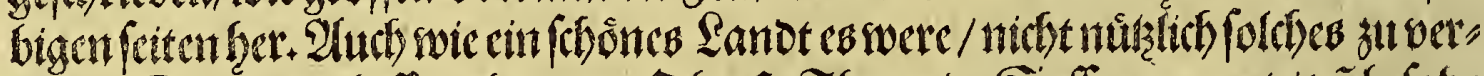

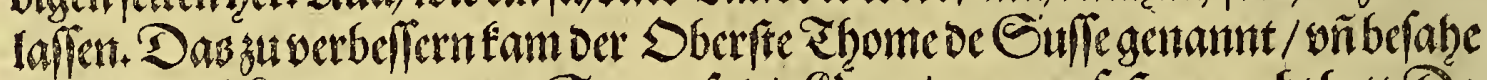

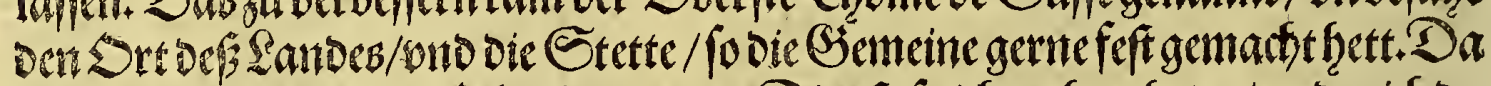

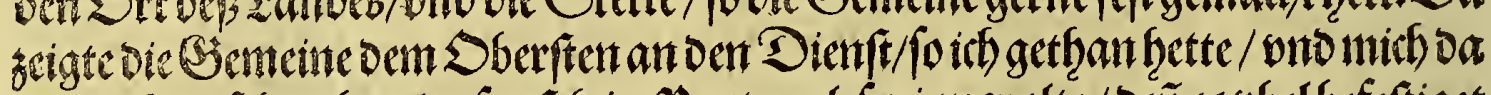
in Das S auts begeben/oa fonft fein Portugalefer intm wolte/ Deñ eb obel befeftiget

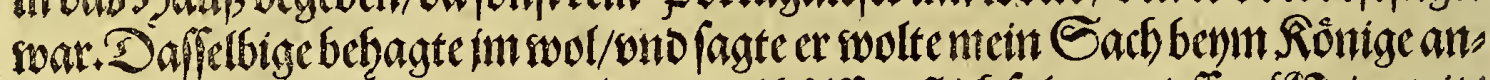

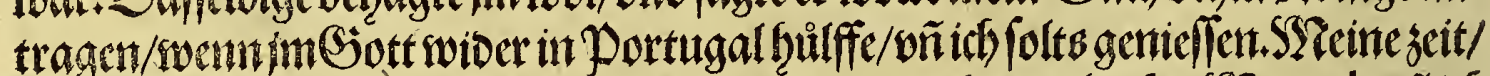

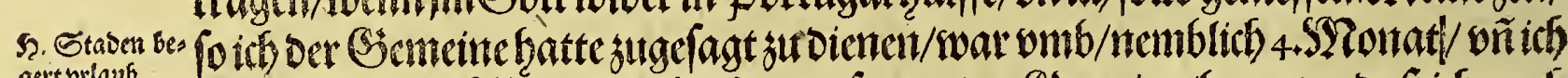

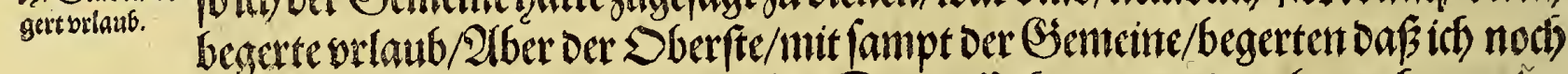

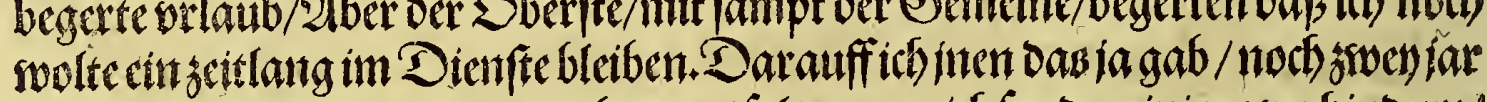

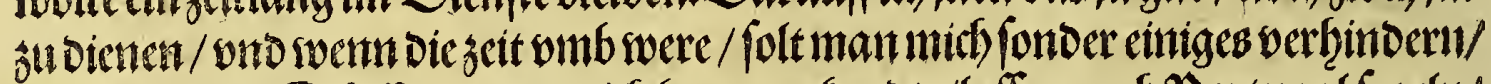

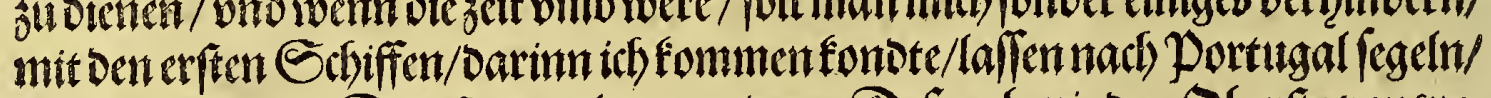
Dafoltemir meit Dienft vergolten werden. Def gab mir Der Sberfte von roe

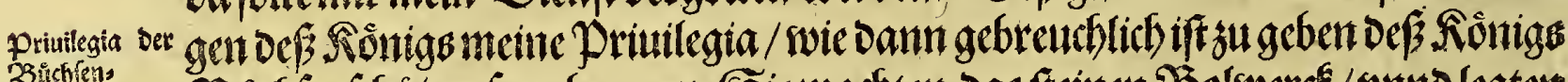

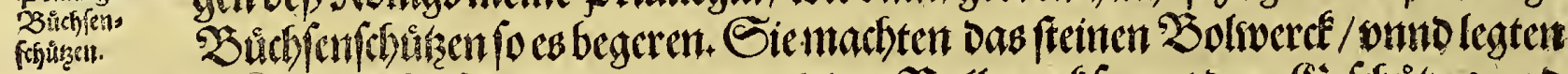

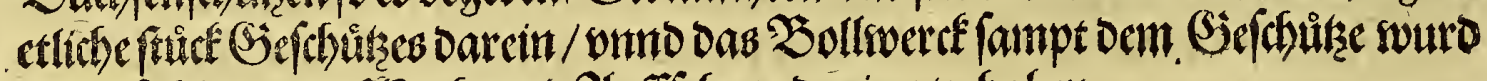

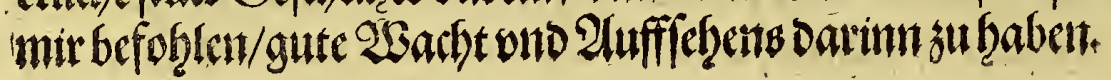

XVII.Sapits 


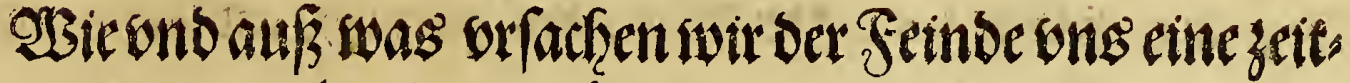

XVII. Capittch

lang im iar meb̨r denn bie andern vermu

ton måpen.

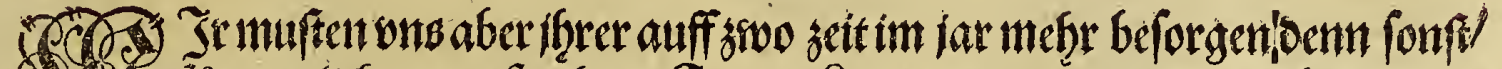

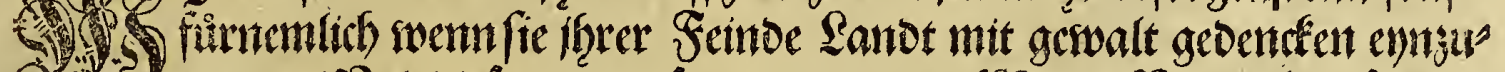

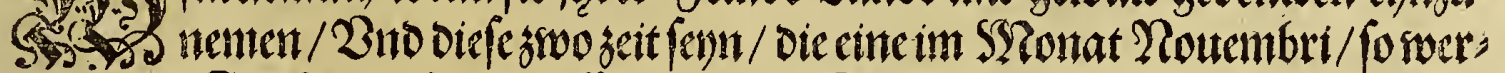

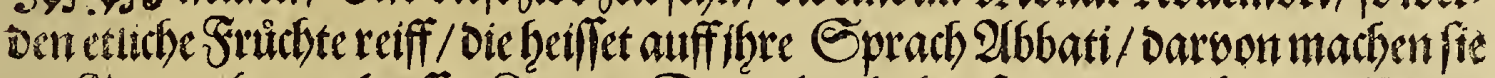

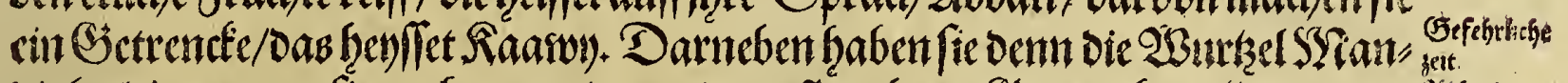

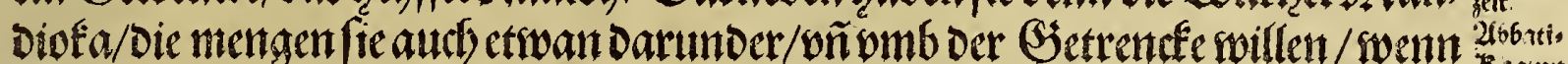

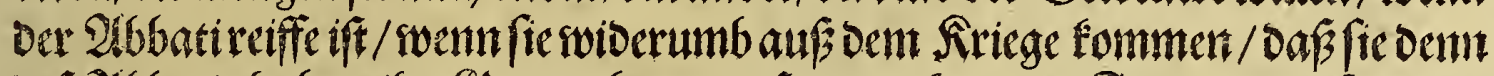

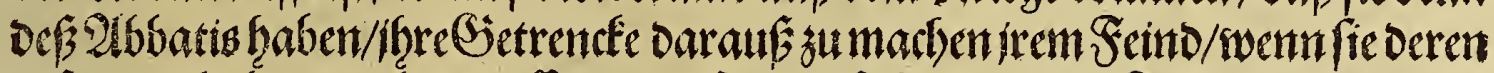

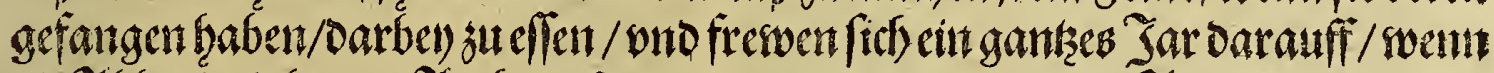

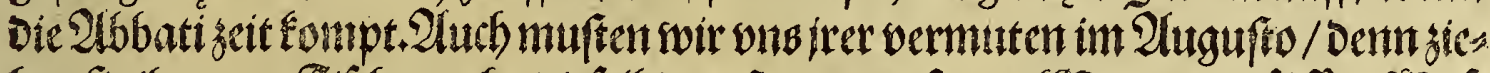

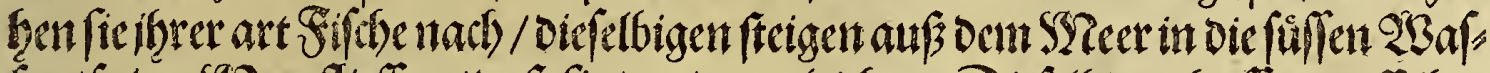

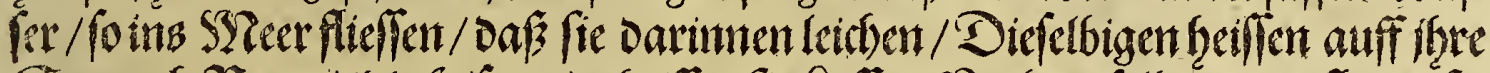

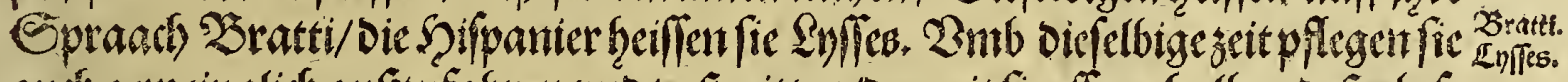

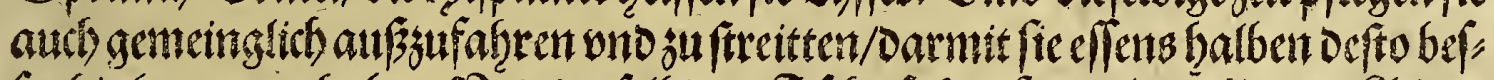

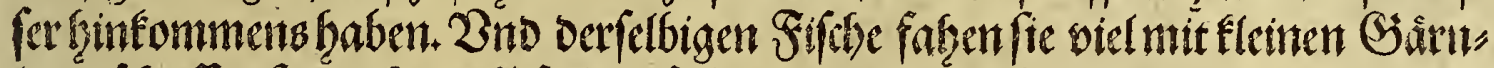

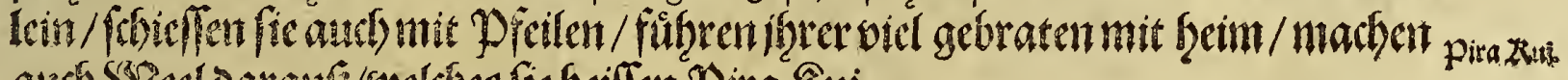

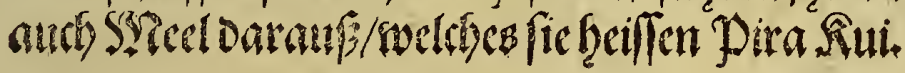

\section{Sapittel.}

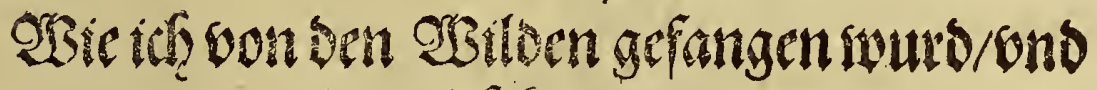

foiefirlyg outtrug.

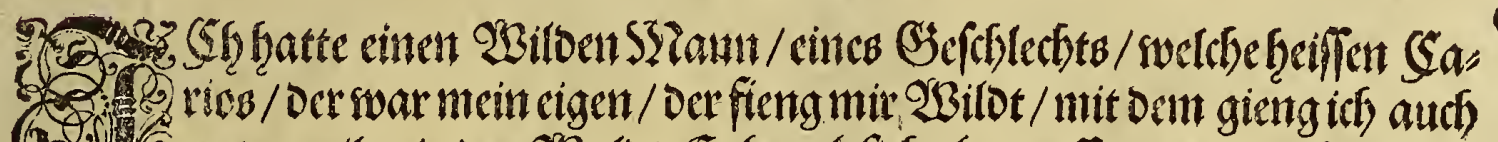

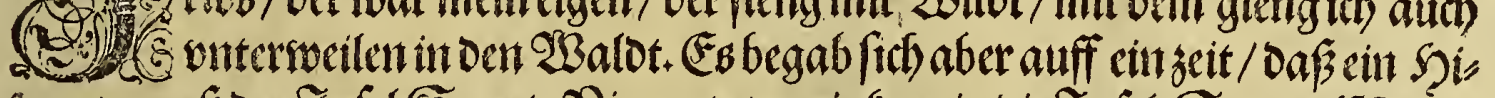

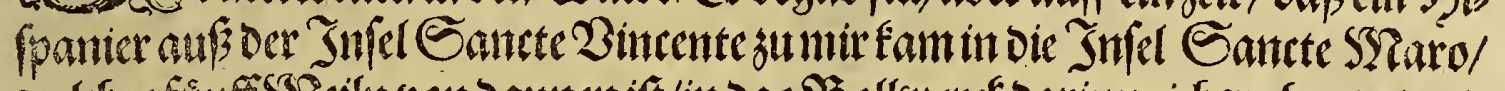

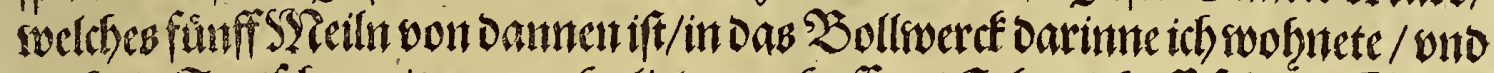

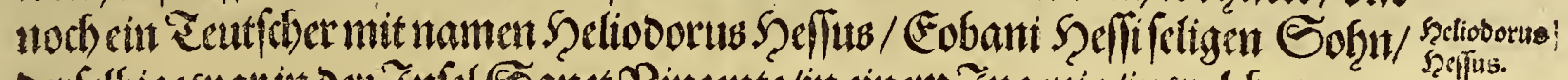

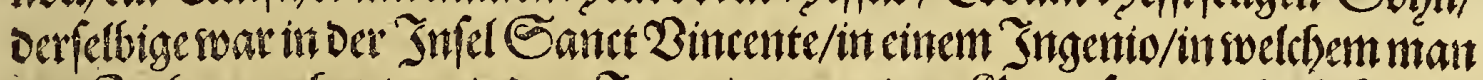

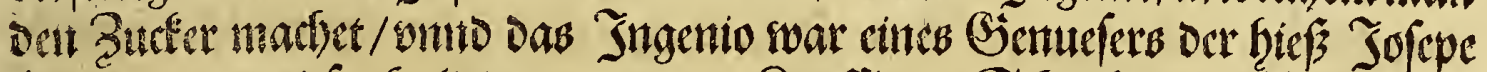

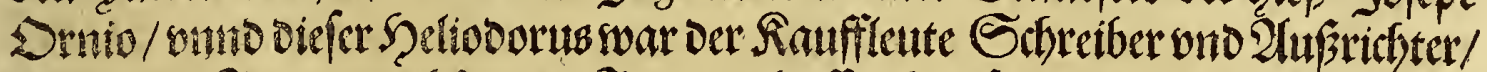

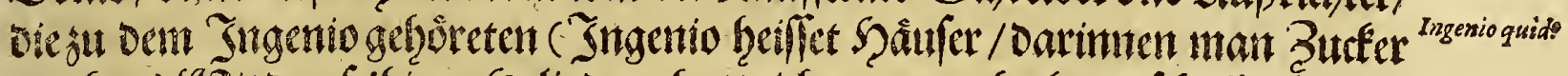

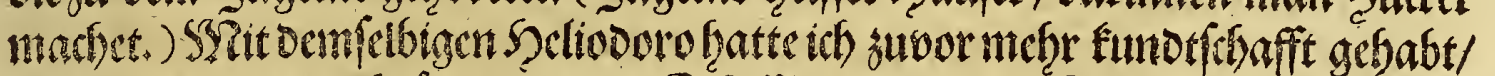

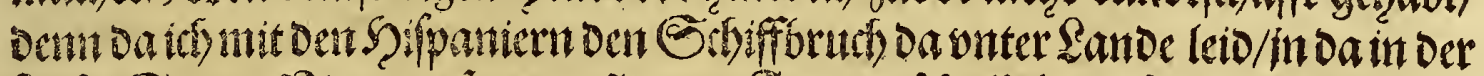

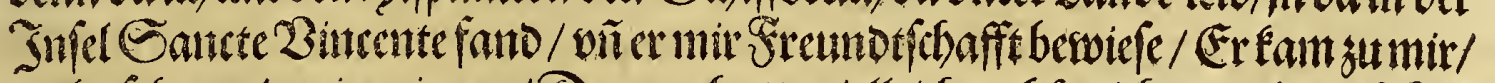

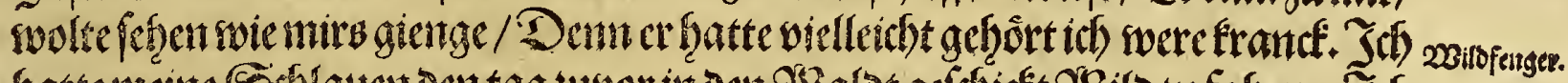

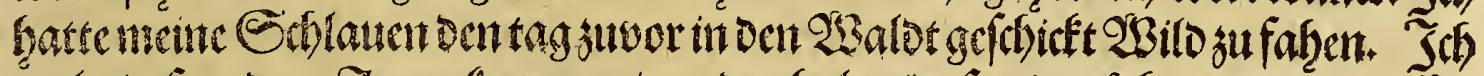

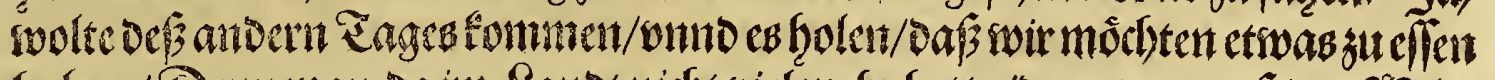

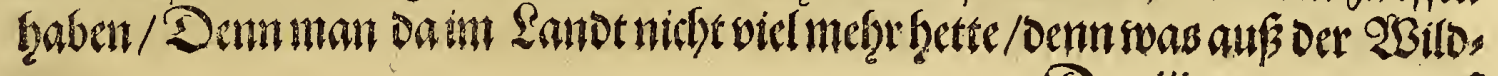

$D$ iif 


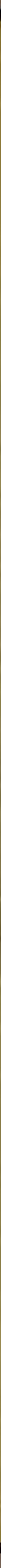




\section{Dasbritte Ifed}

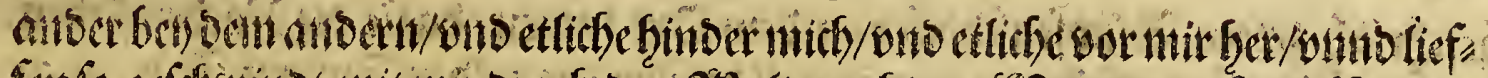

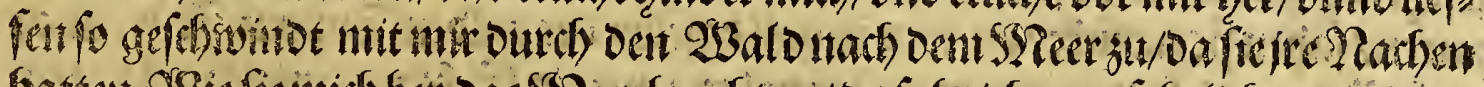

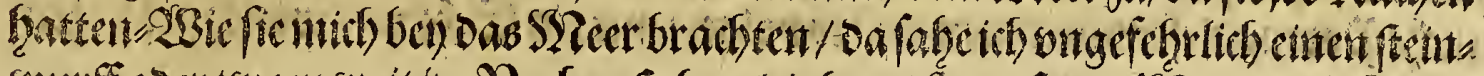

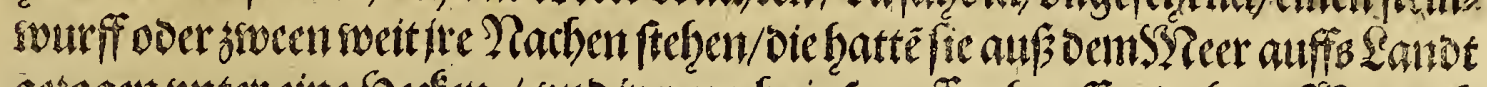

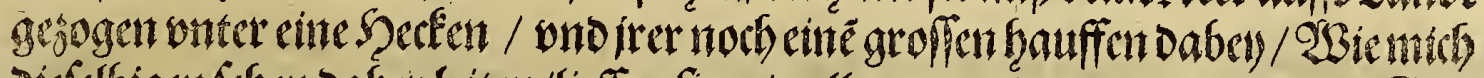

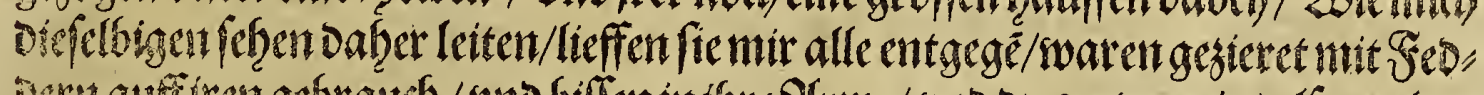

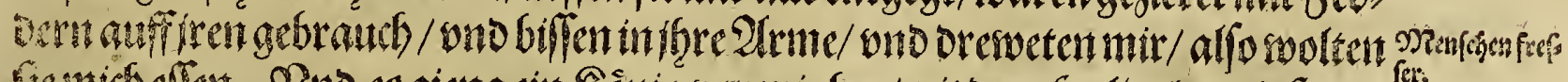

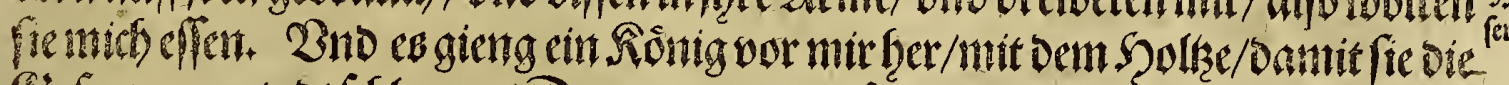

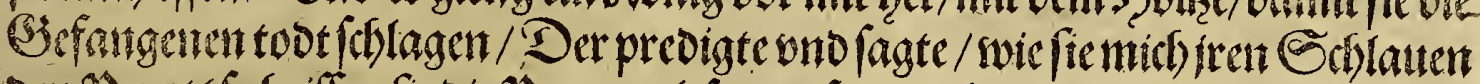

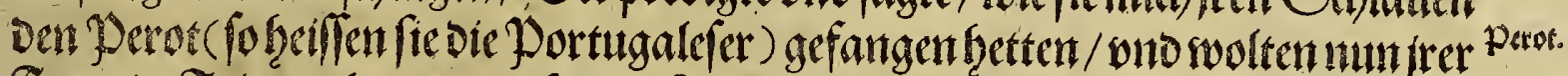

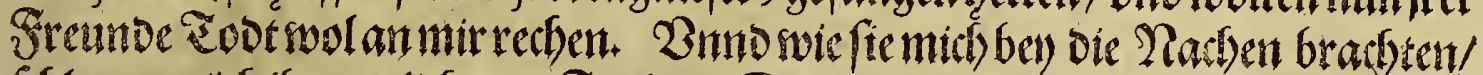

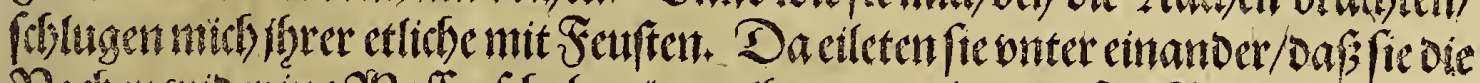

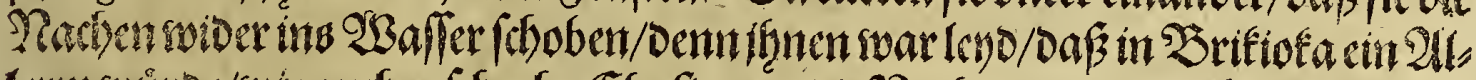

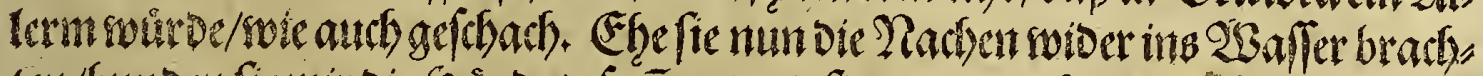

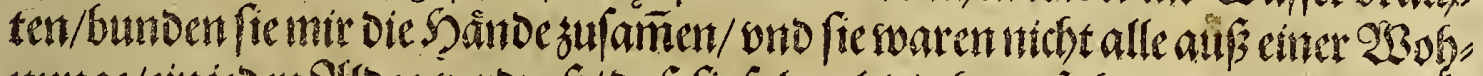

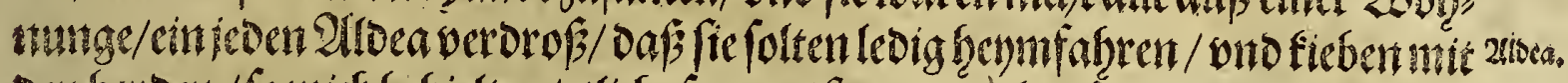
Den benoen / fo mich befielten/ctliche fagten/fie roerent eben fo nabe bey mir geswe

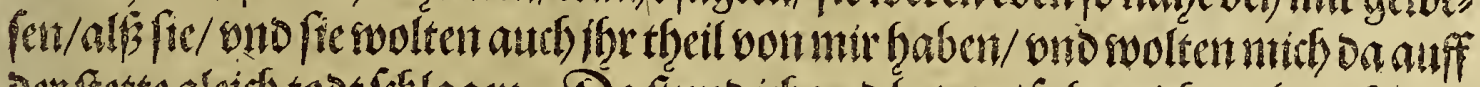
oer ferteglectl to ot folagen. Daftund ich ono betete / fabemich omb nath Den

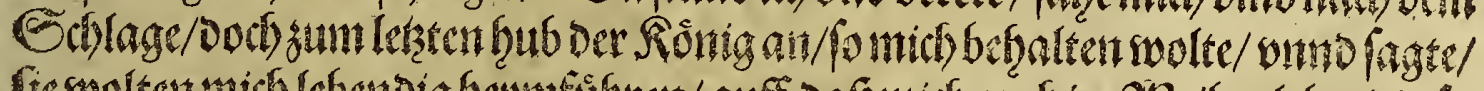

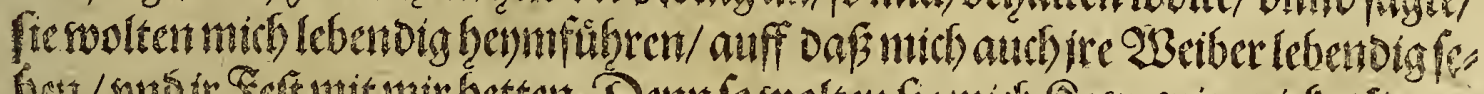

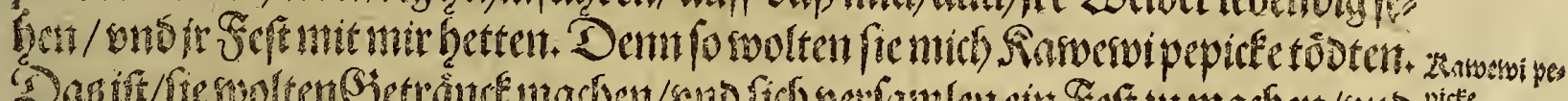

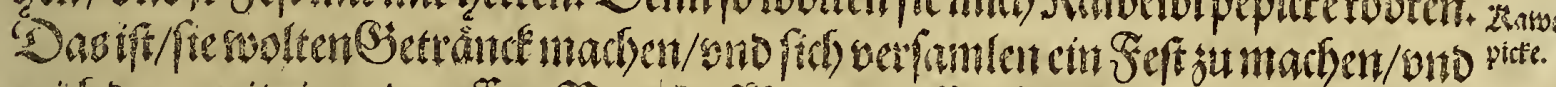

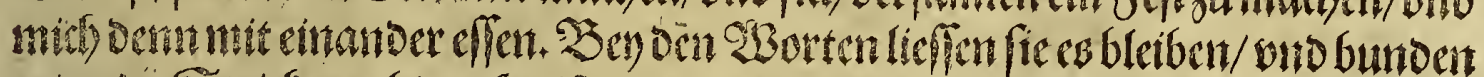

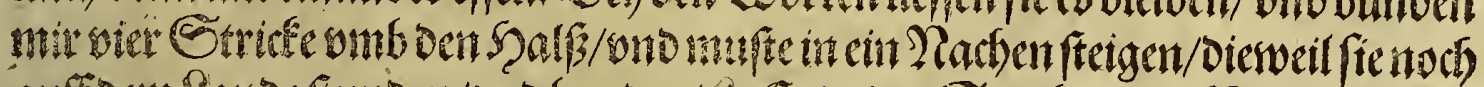

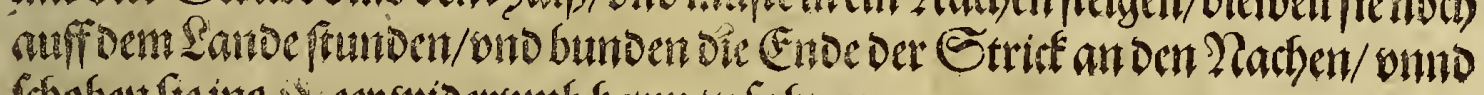

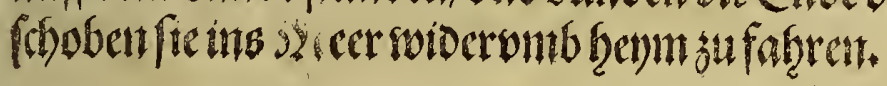

\section{Capittel.}

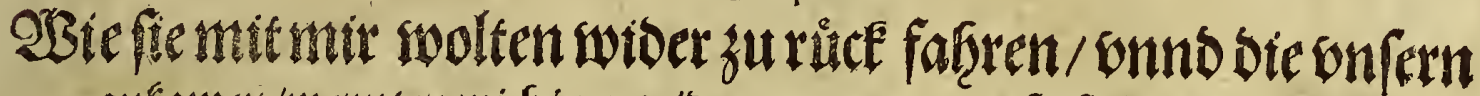

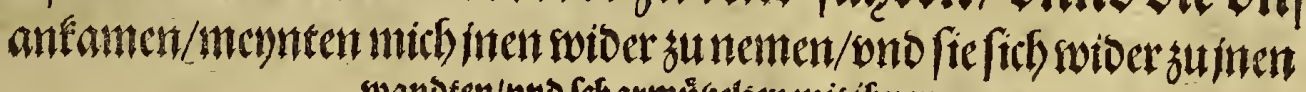 wandern/vno fcharmư}

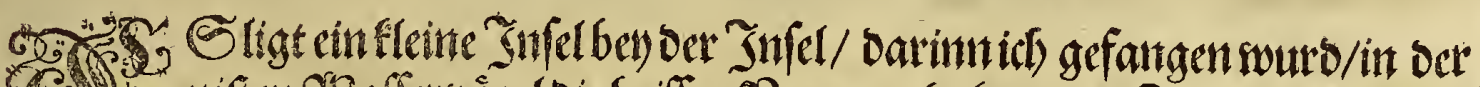

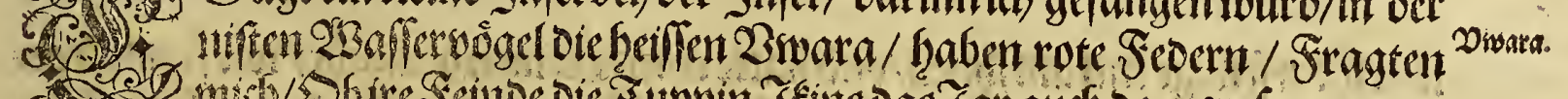

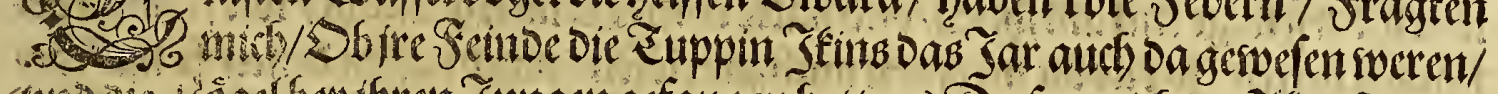

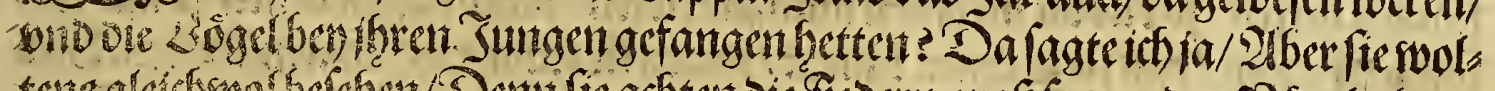

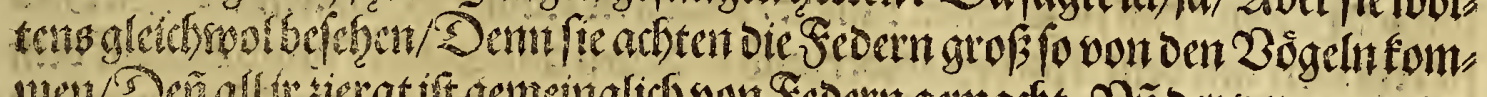

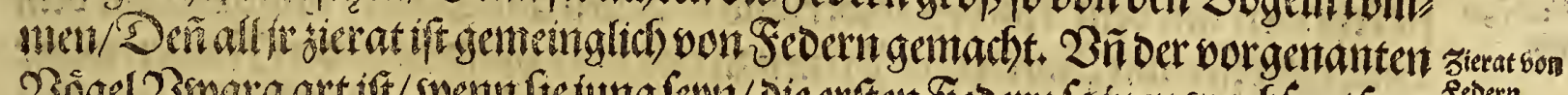

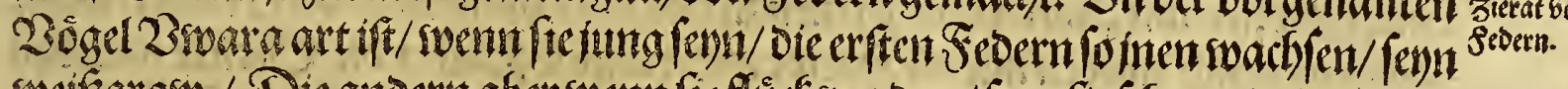

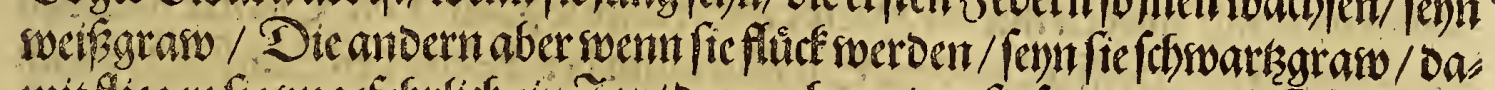
mit fliegen fie ongefegrtich ein Jar/ oarnad) swerdenfieforot als rote Farbe. $3 \tilde{n}$

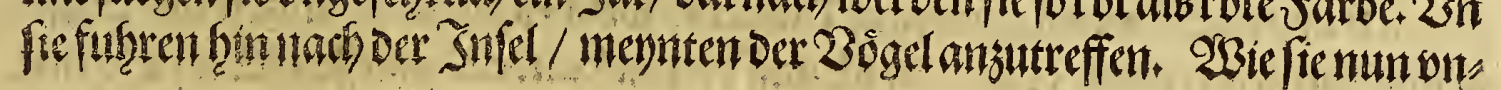
gefebzrlict) 
24. Siftoriaber Snnwofrner Simetixal

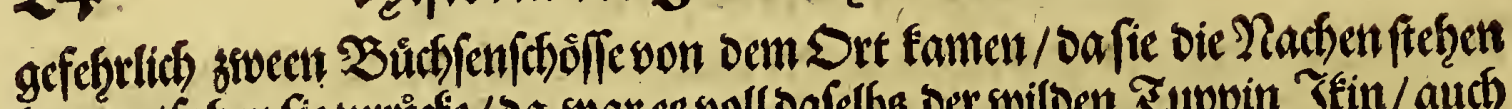

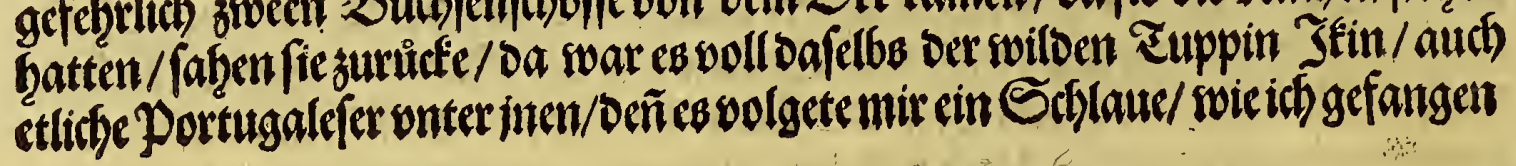

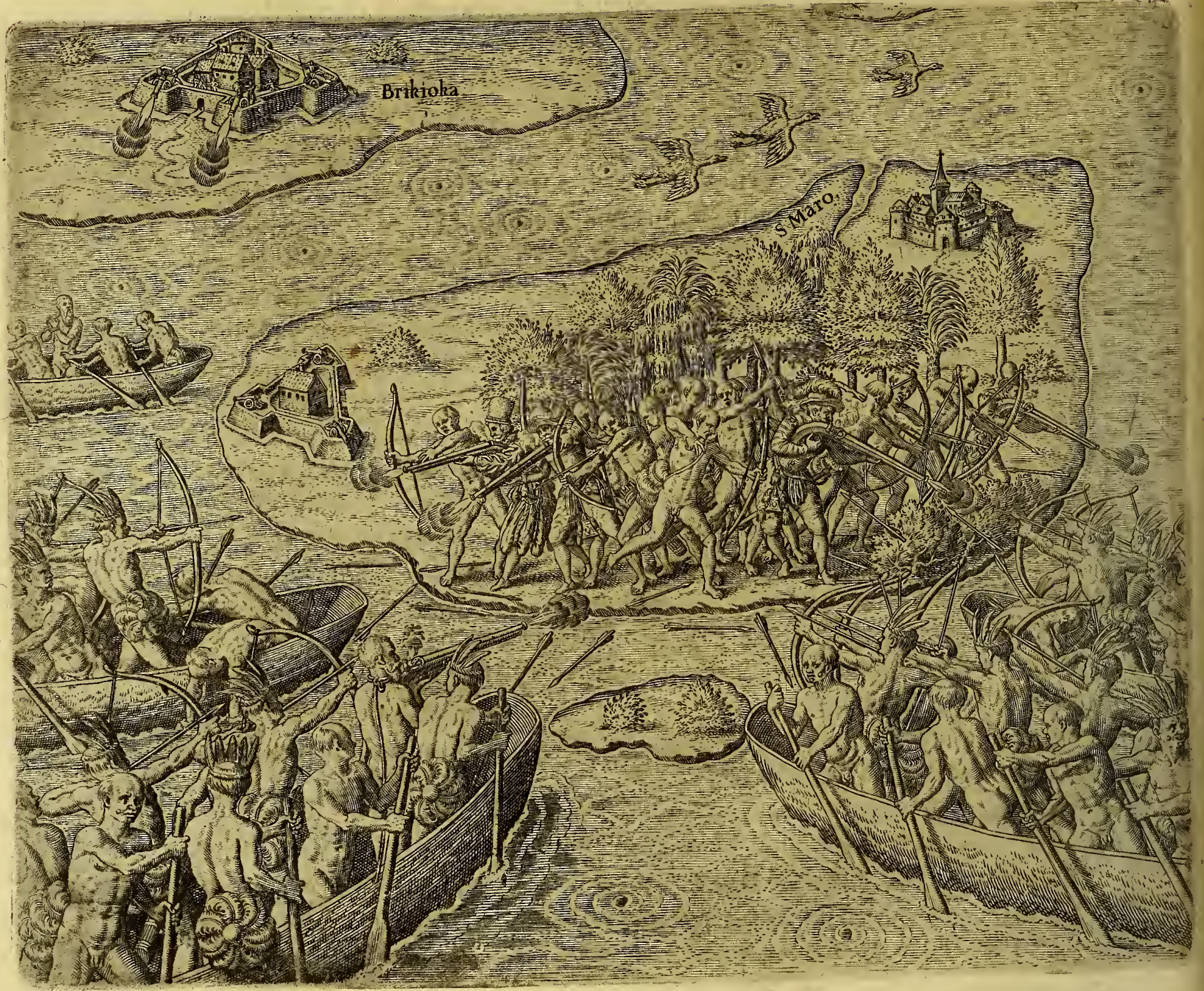

5s. Stabege

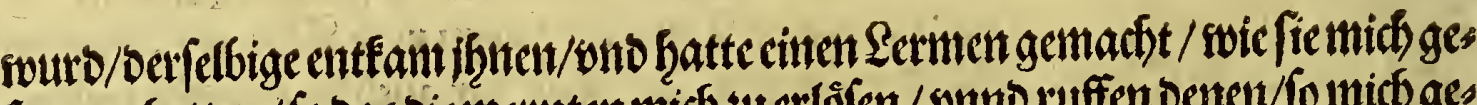

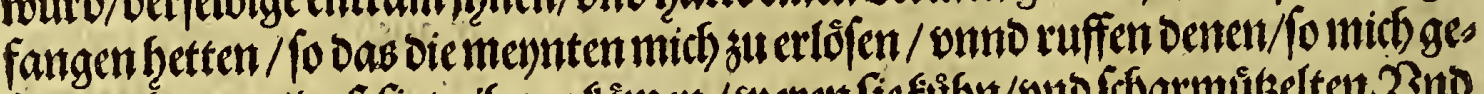

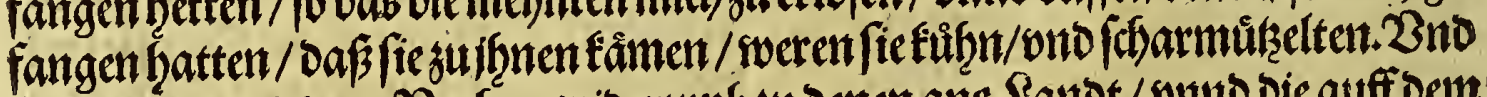

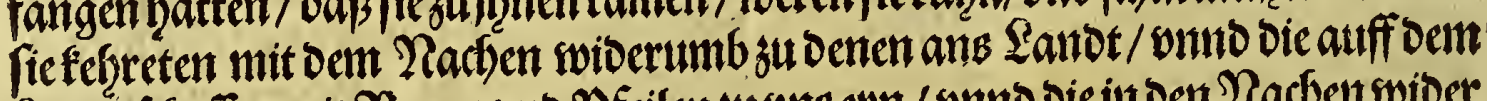

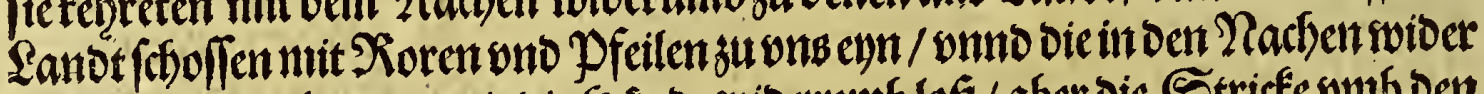

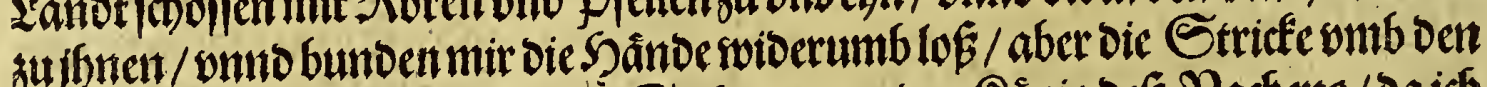

Bahachs fint Drafticiento

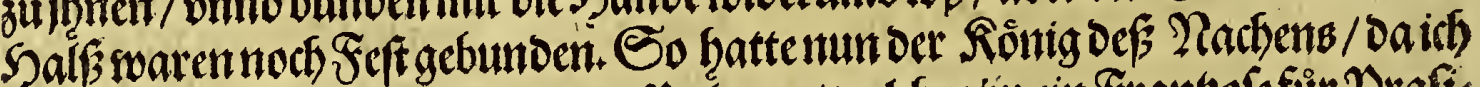

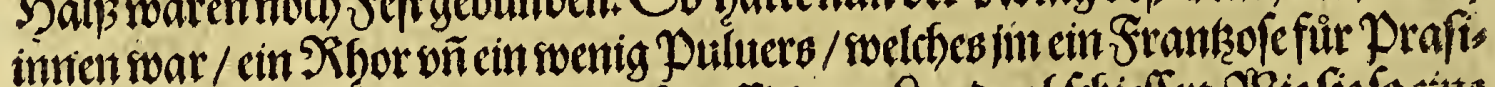

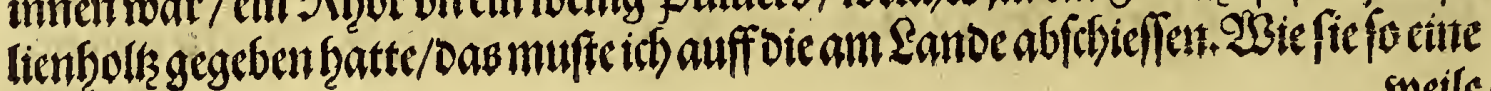
rocile 


\section{Das brifte Trteil.}

weile geftharmutzelt hatten/beforgten/ie fich/ Daf fich bie andern autb etswann

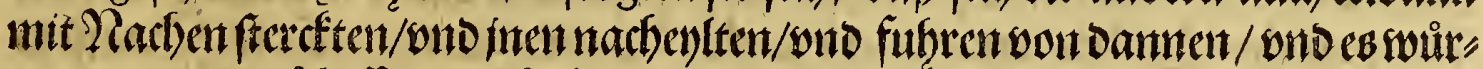

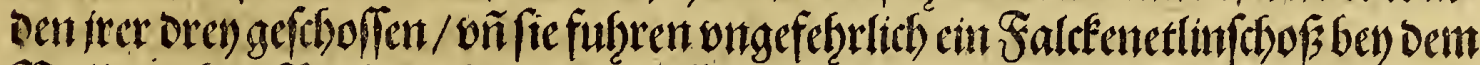

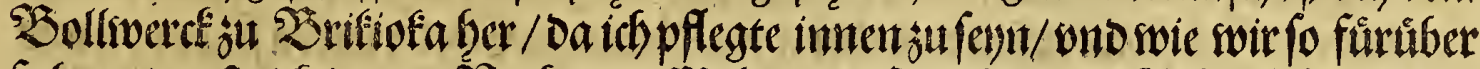

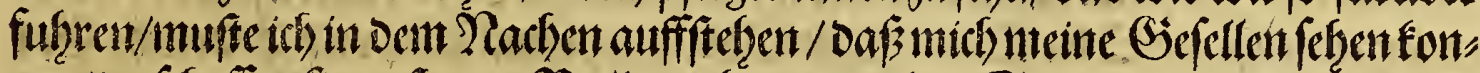

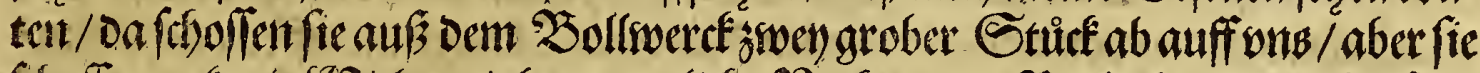

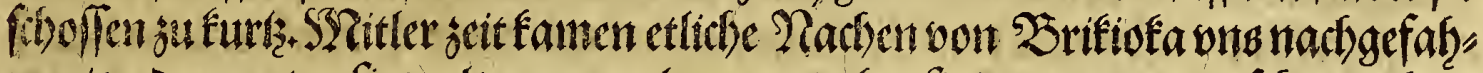

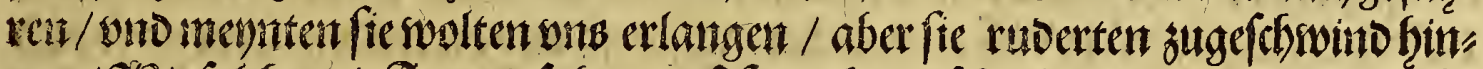

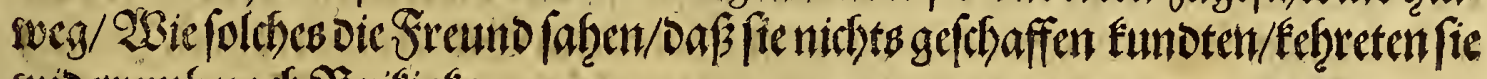
wioerumb nach Brifiofa.

\section{Capittel. \\ Wbas fich auff berwieberumbsed) fébegab nach \\ ifrem Sande.}

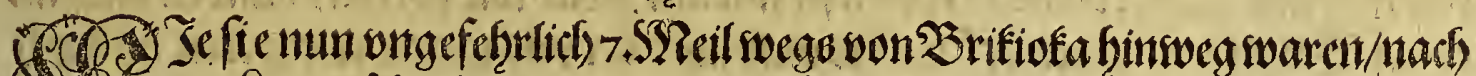

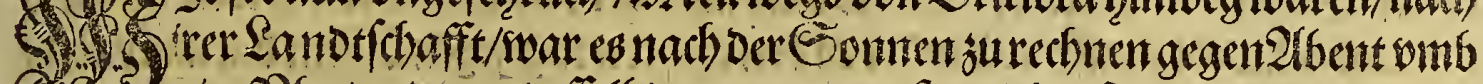

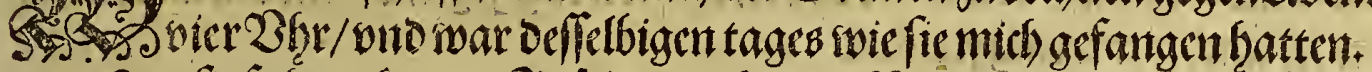

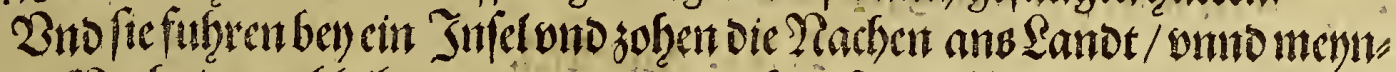

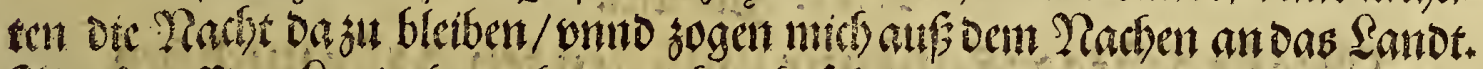

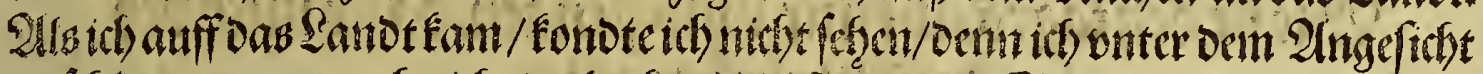

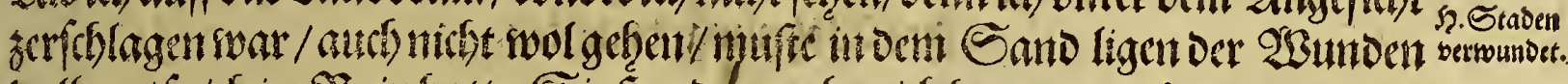

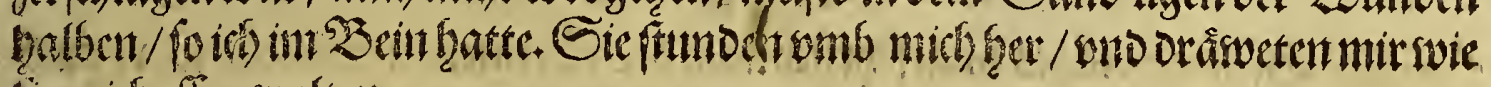
lie mirbs efferisolten.

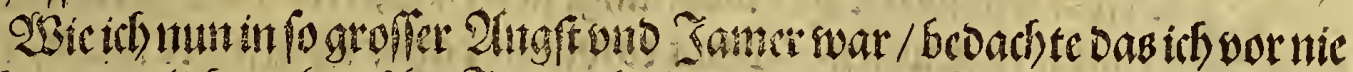

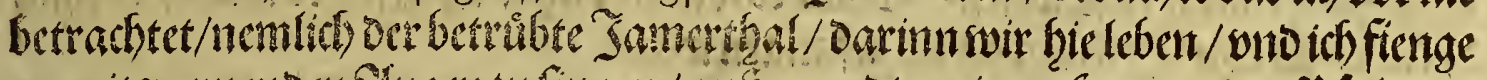

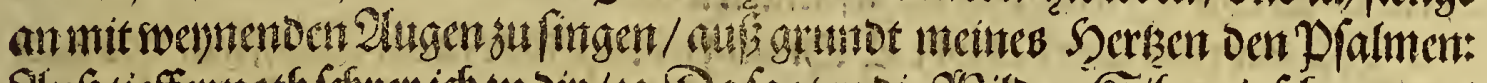

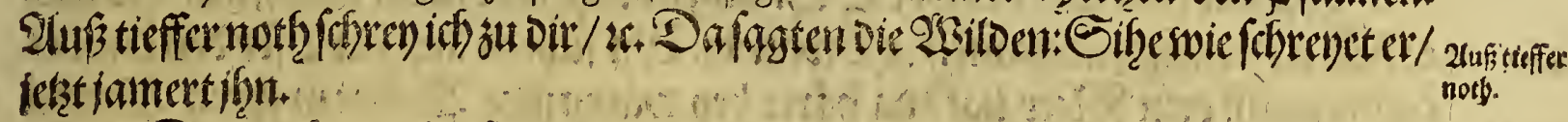

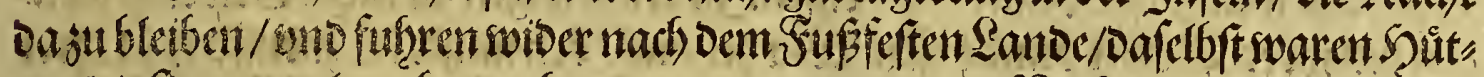

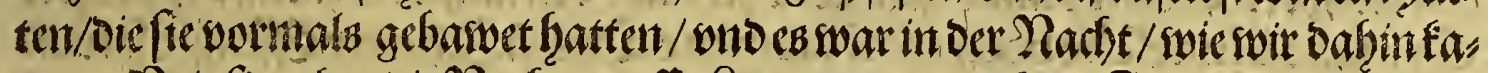

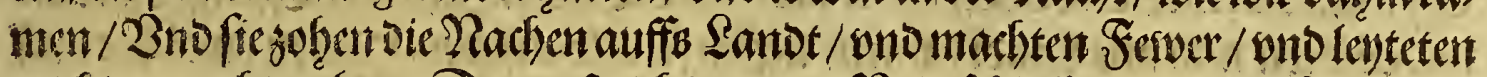

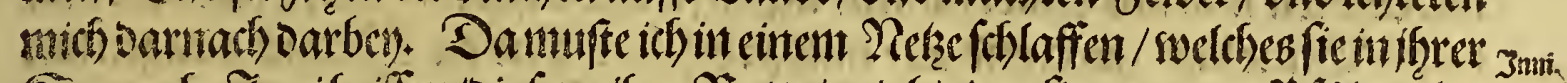

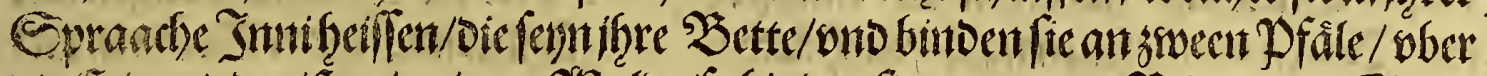

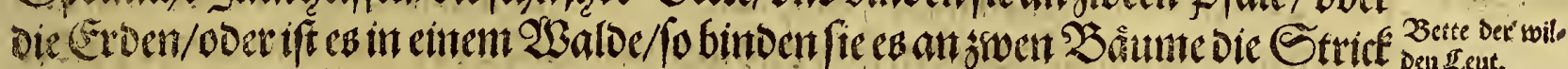

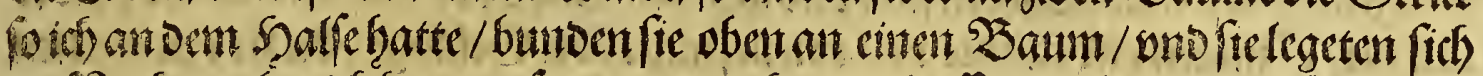

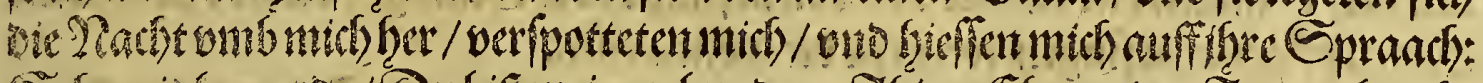

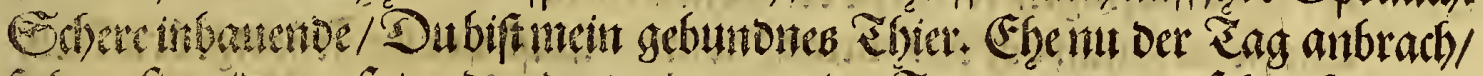

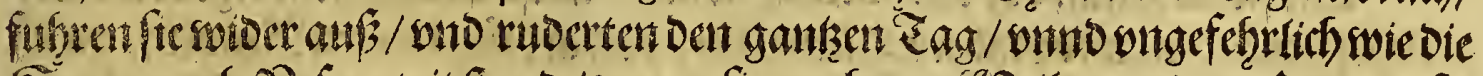

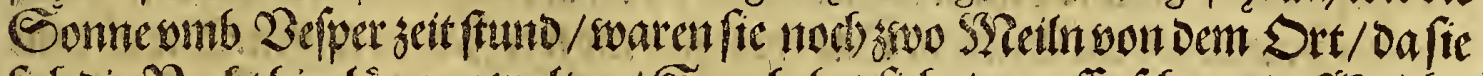

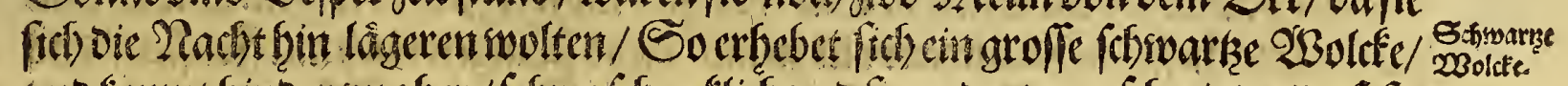

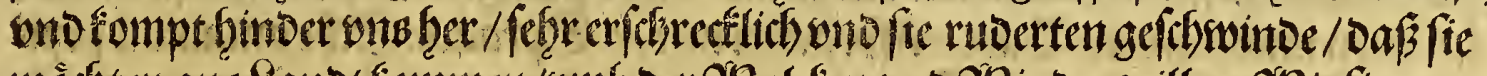

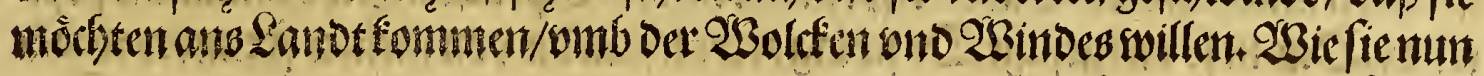
E faben/ 
Jabew/oaphie Tuppan do Quabe, amanafu yan dee Imme Ranni mefisfe. Pasitto

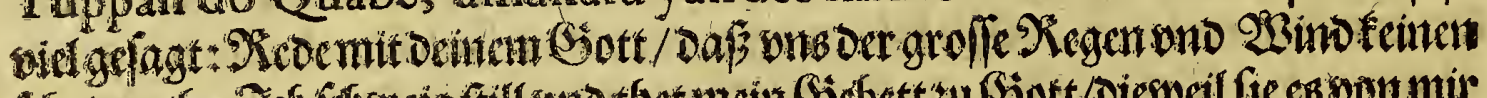

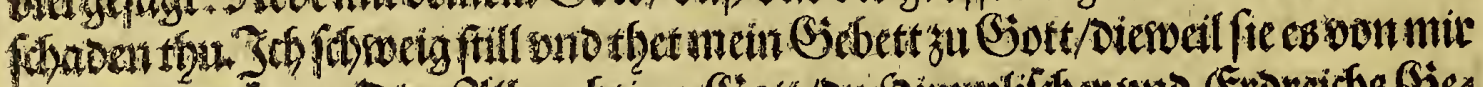

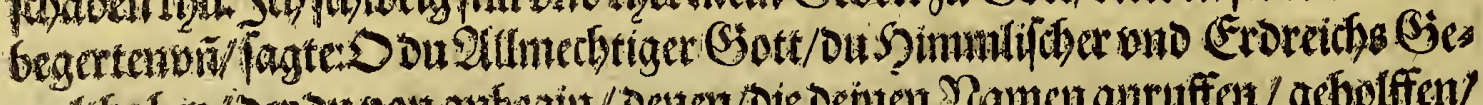

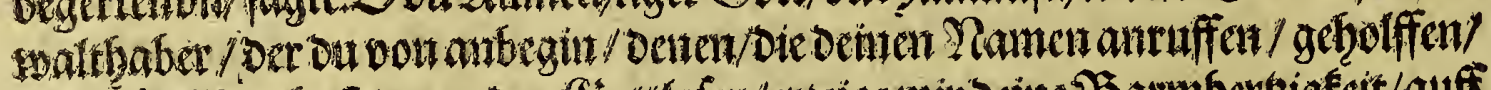

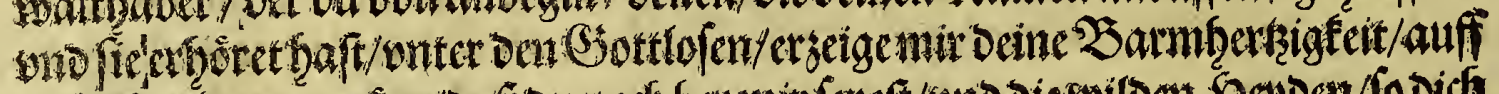

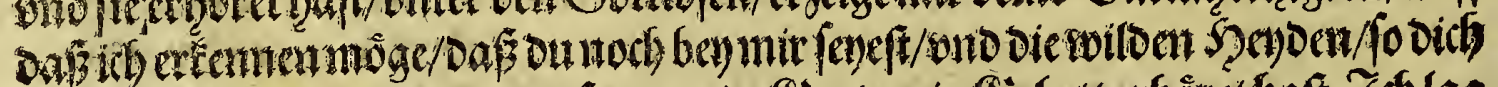

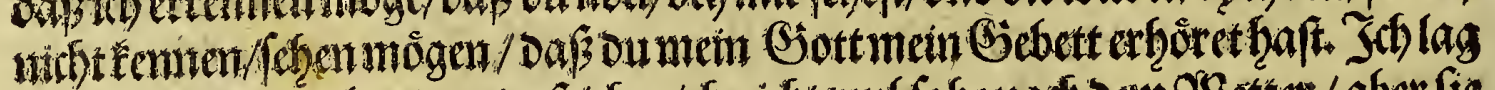

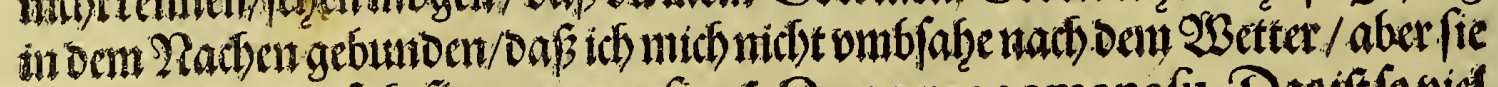

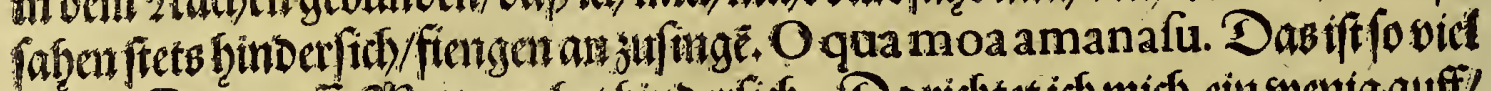

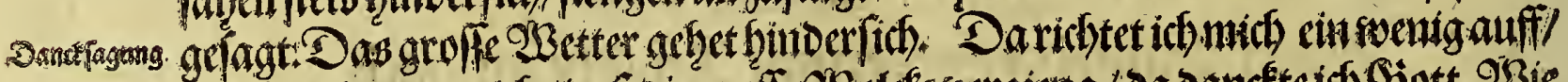

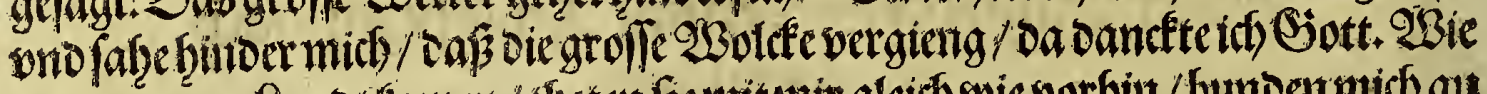

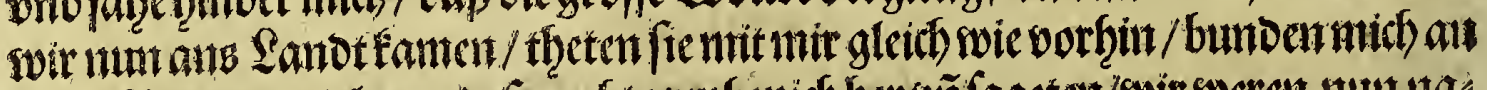

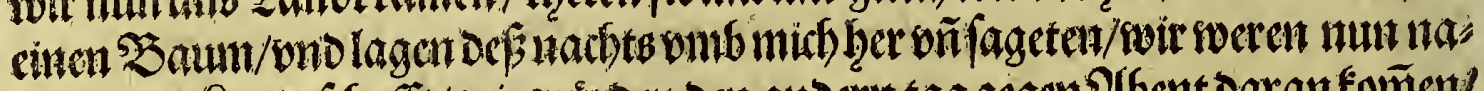

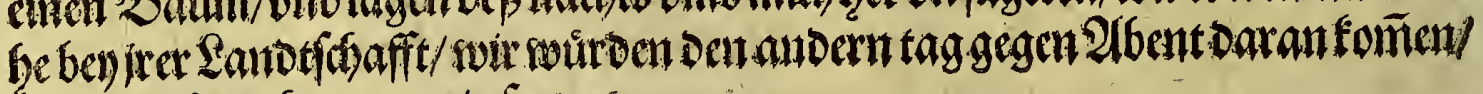

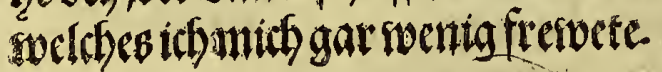

\section{Sapittel.

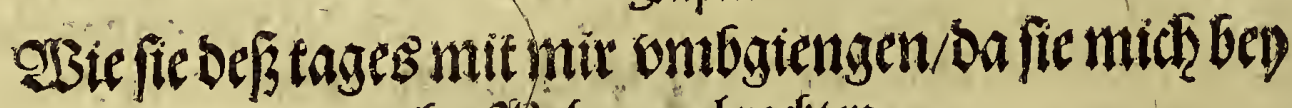
iffere 23 ofonumge bradten.

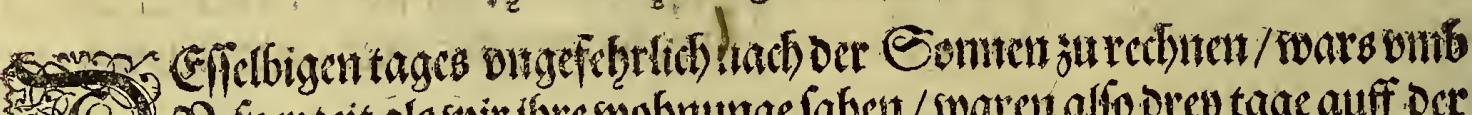

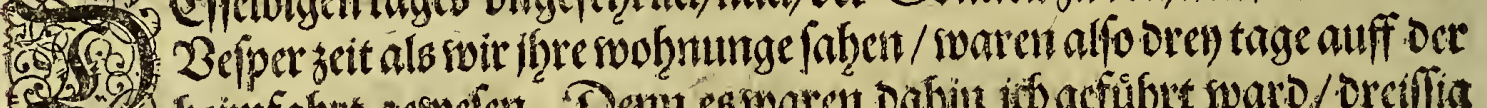

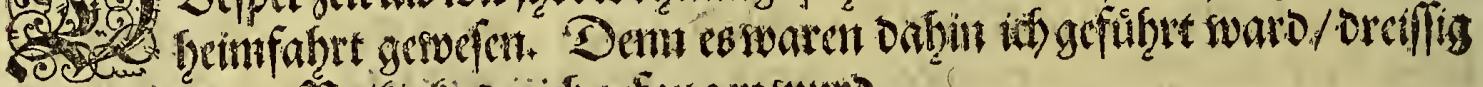

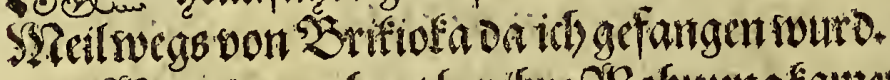

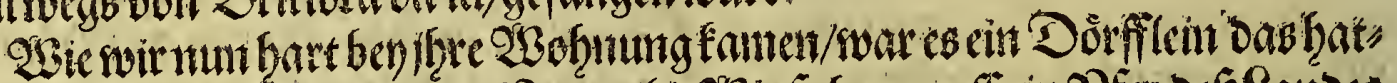

Dossattibi.

Franbiota.

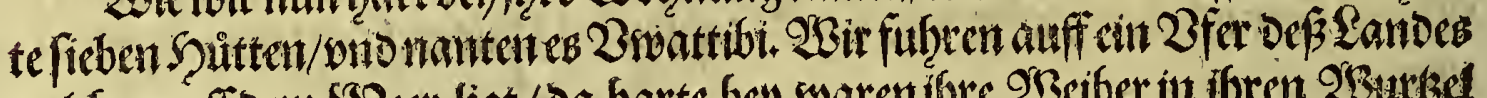

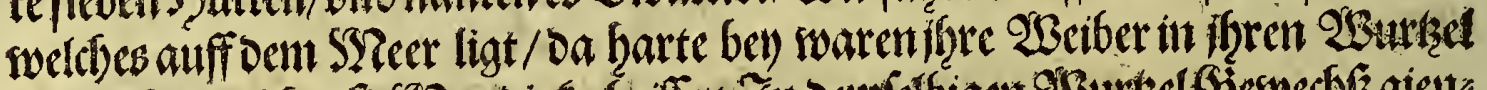

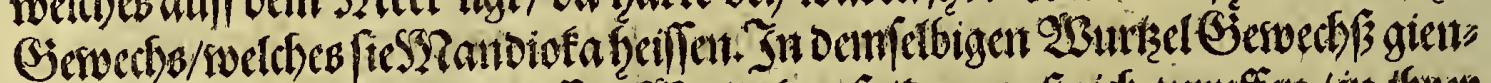

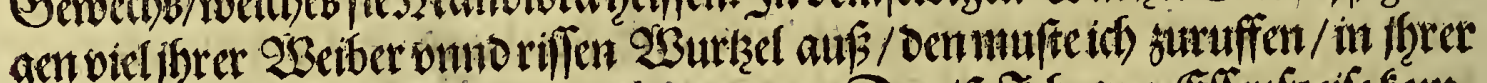

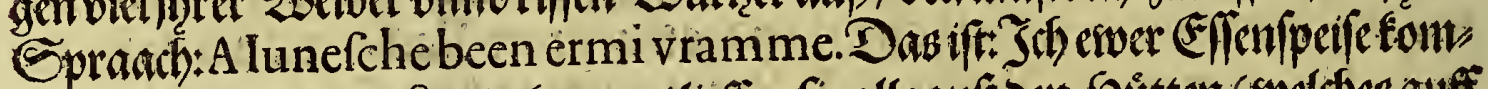

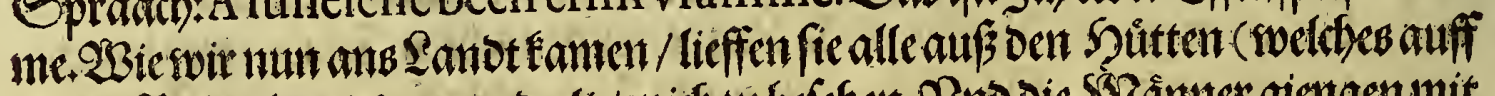

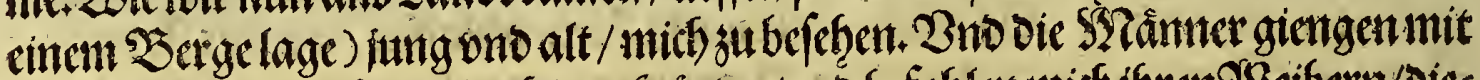

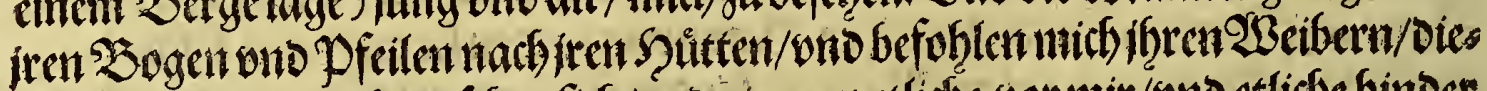

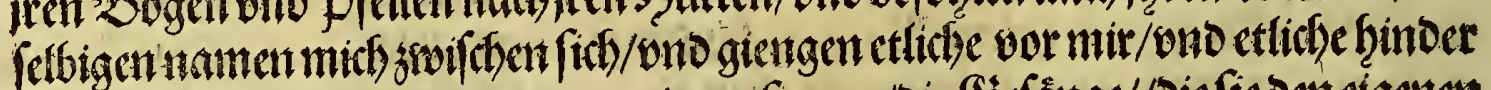

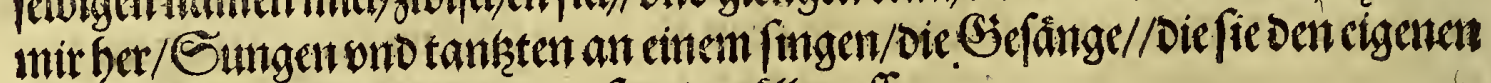

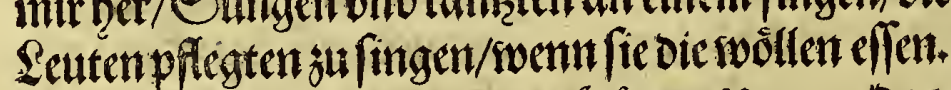

gyratas.

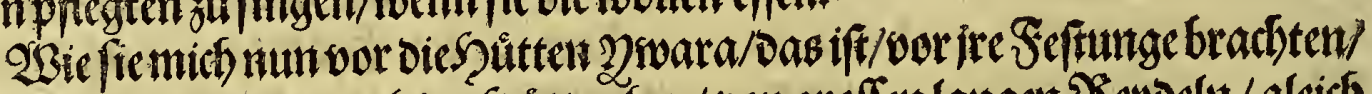

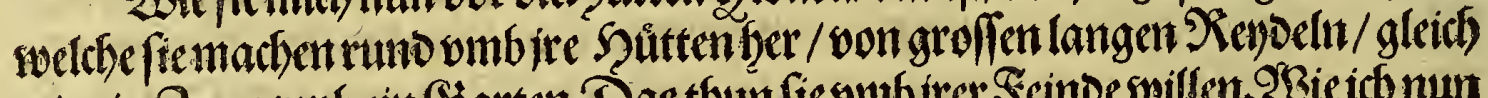

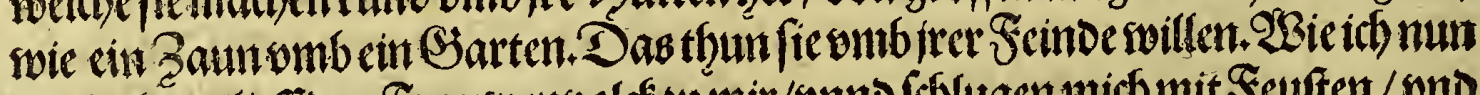

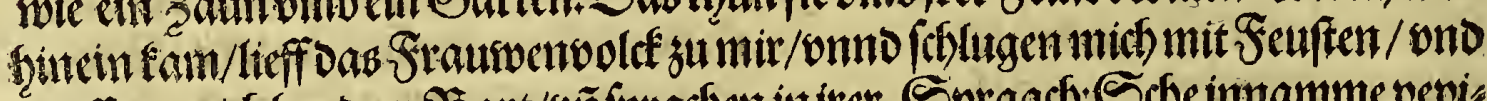

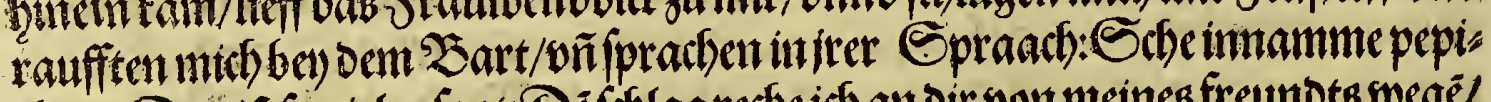

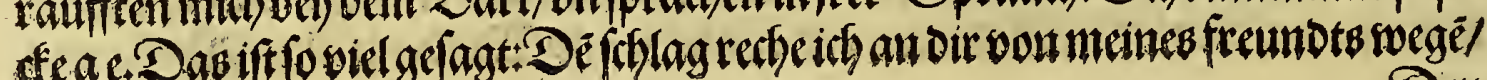
Den 


\section{Dasbritte Thetl.}

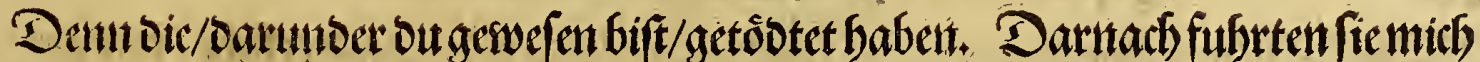

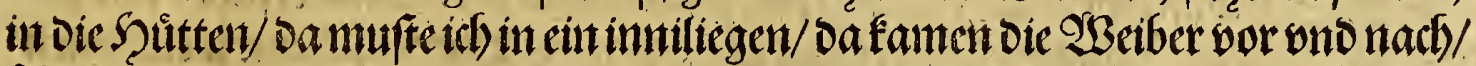

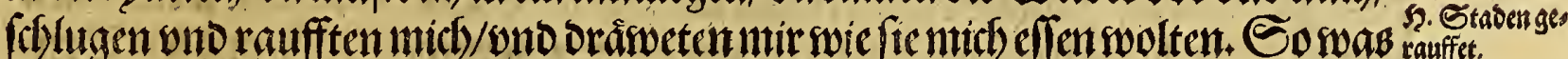

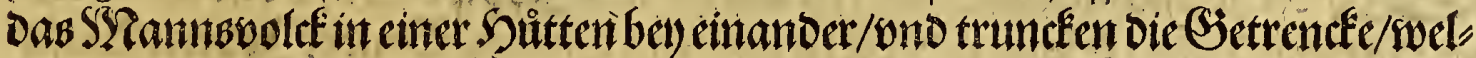

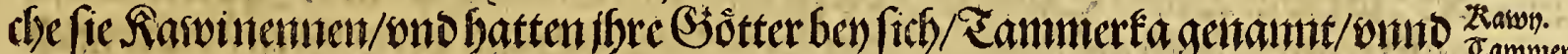

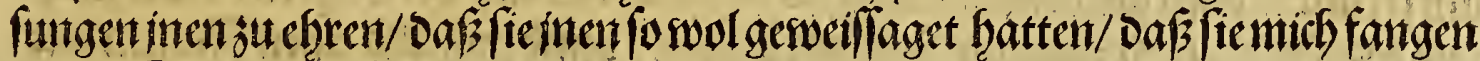

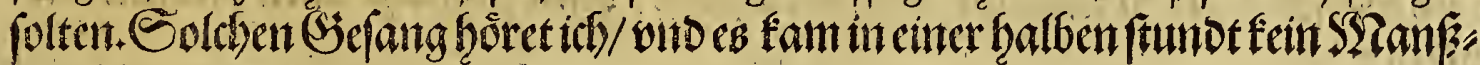

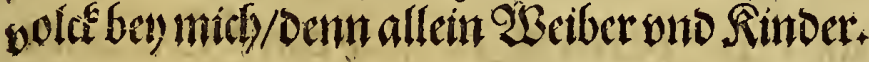

$$
\text { XXII. Sapittel. }
$$

\section{Wie meine benbe Seten zumir famen / ono fagten mir wie fie}

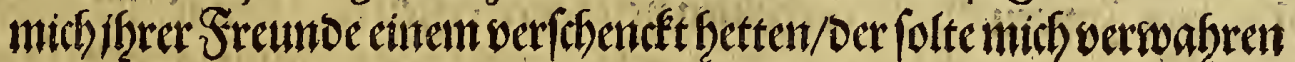
ond tod ffrchlagen/wenn man mich effen wolfe.

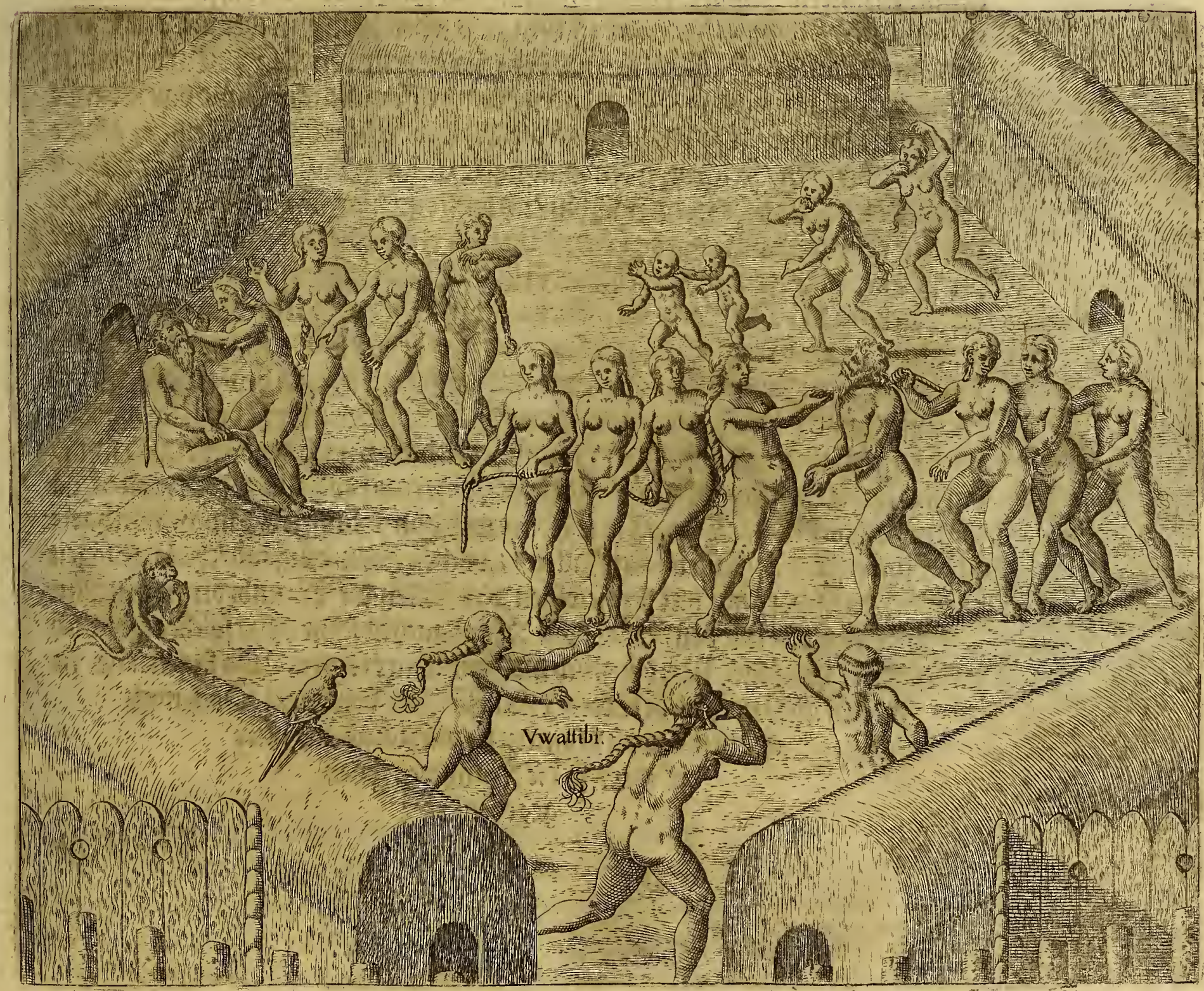

(E) ii 


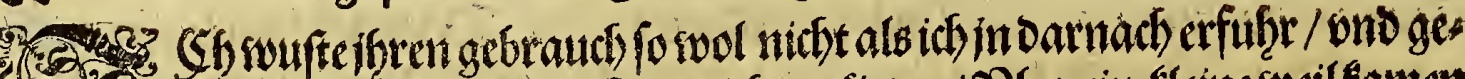

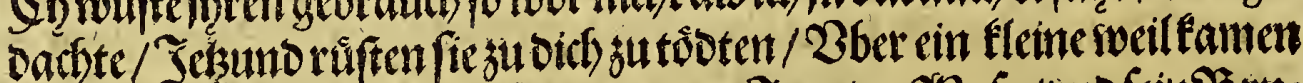
Die/fo mich gefangen batten/mit namen Jeppipo 2 Bafu/bno/ein'Brus

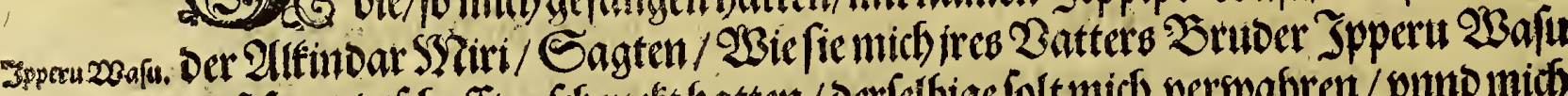

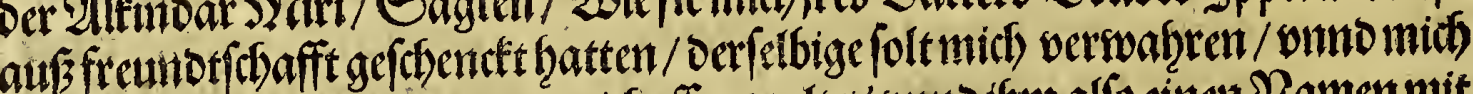

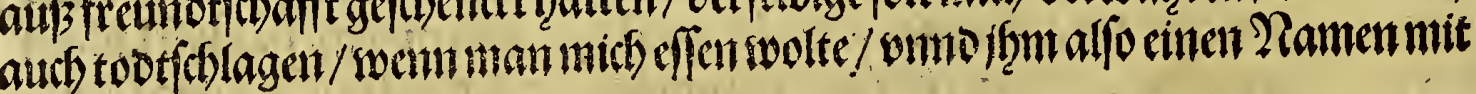
mirmacball.

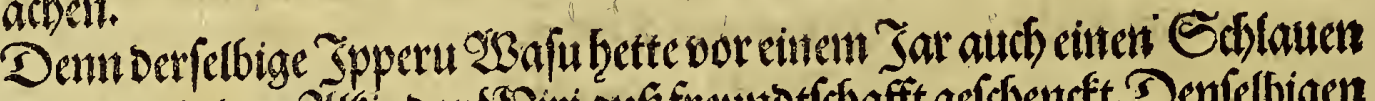

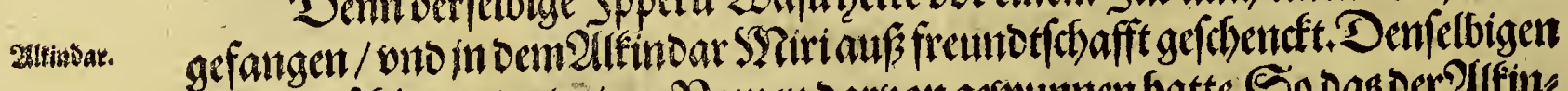

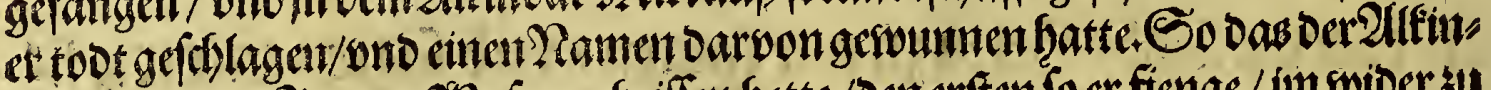

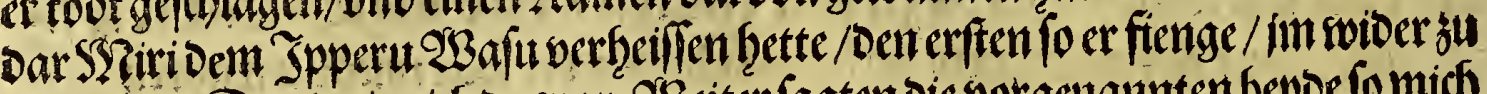

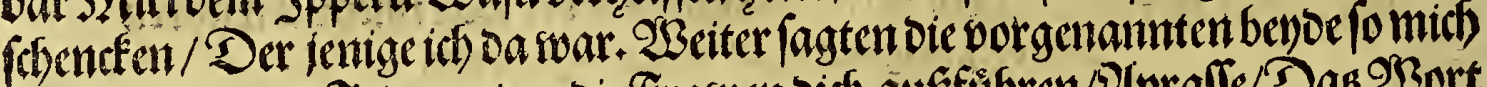

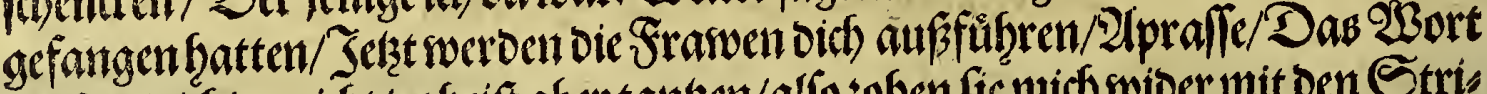

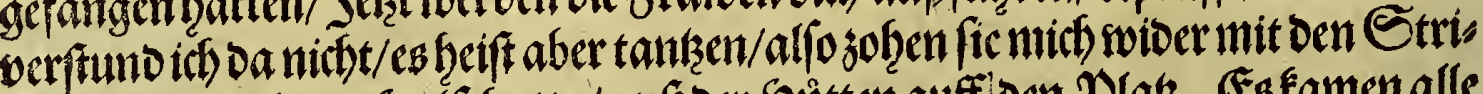

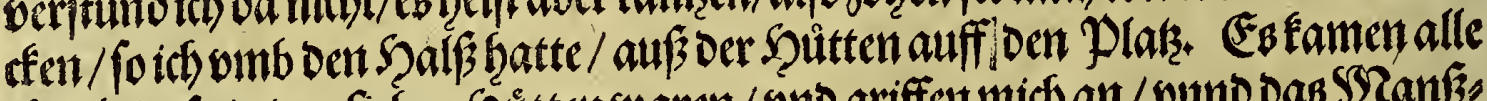

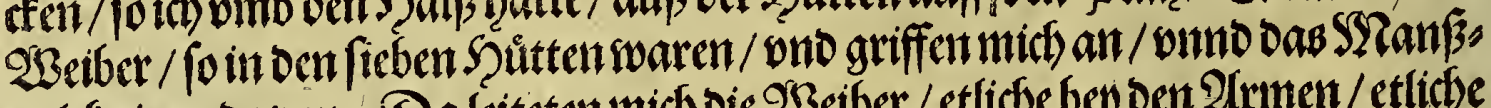

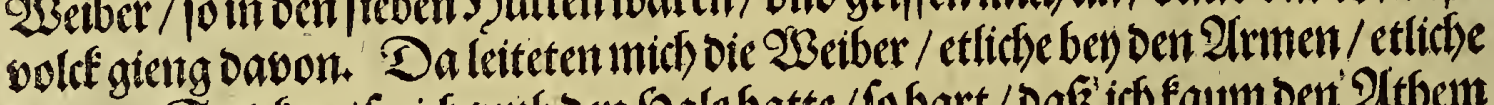

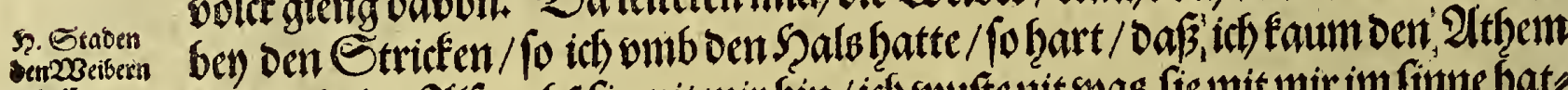

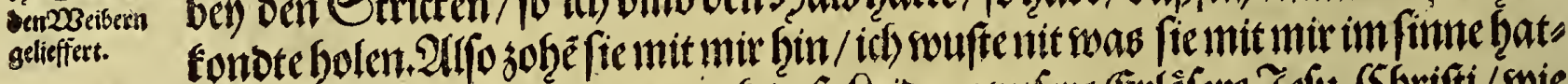

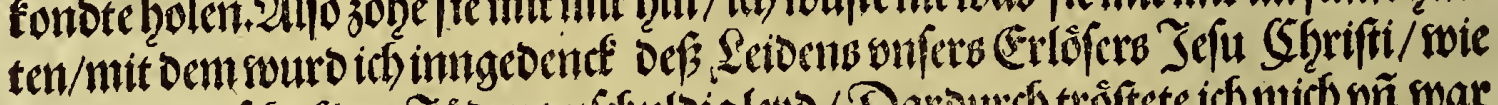

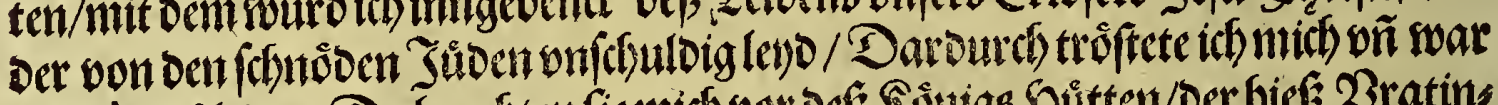

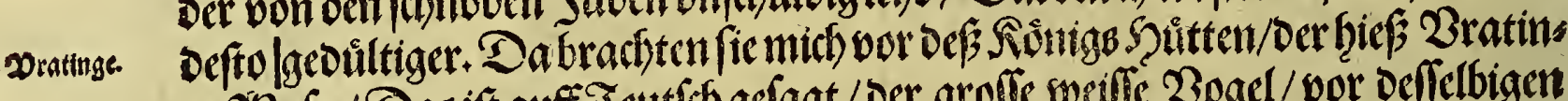

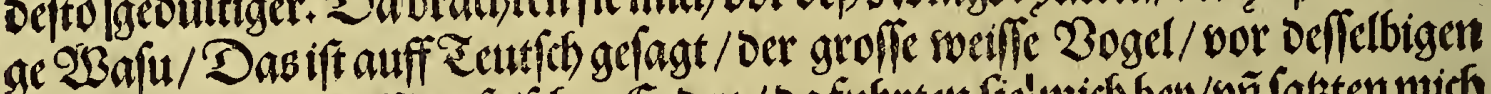

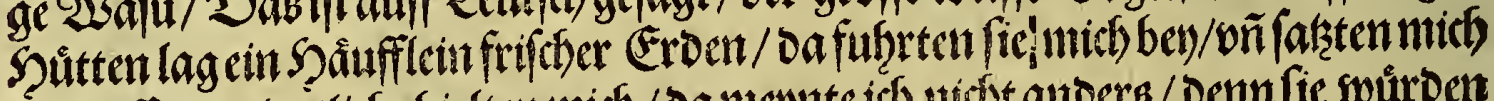

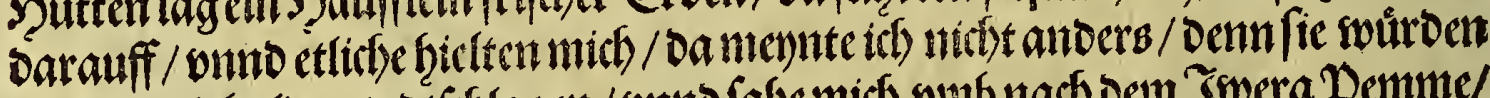

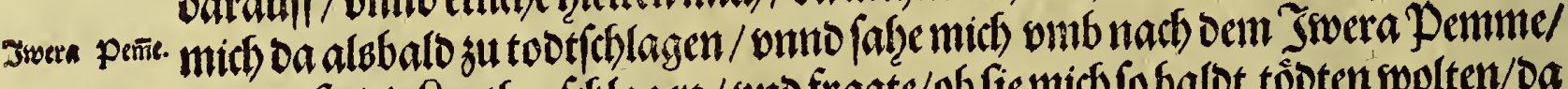

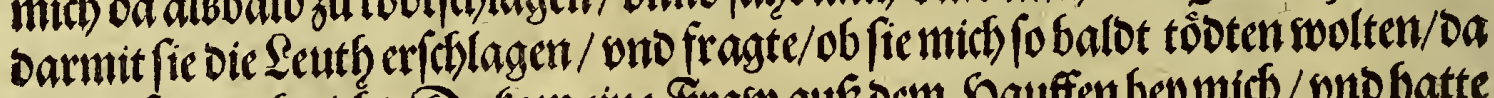

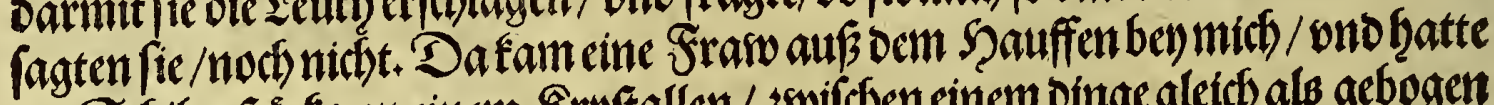

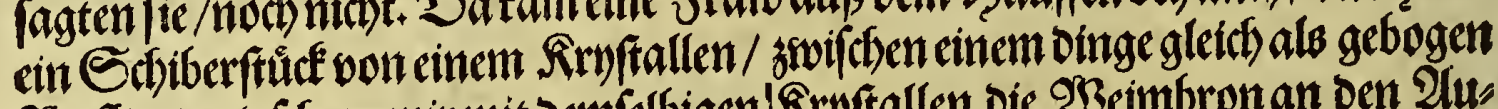

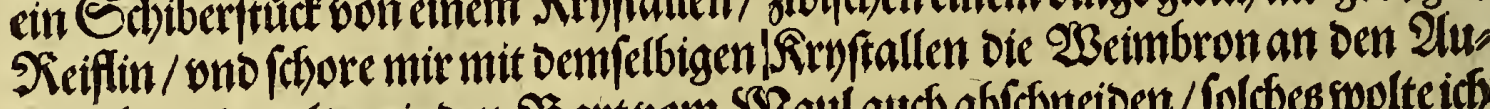

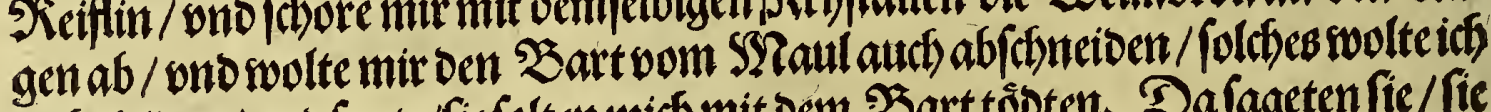
nicht leioen/wno/agte/fie folten mich mit oem Bart tobten. Da fageten fie/fie solten mich noch nicht tóbten/onto lieflen mir oen Bart. Doch nach etlichen Sagen fonitten/iemir frnab mit einer Sater/fo die Franterolenifnen

whoretr. gegeben. 
Dasbritte Thetil.

XXIII. Sapittel.

\section{Wie fiemitmir tankęen borben Shutten/barinnen fie bie} 2lbgôtter Tammerffa hatten.

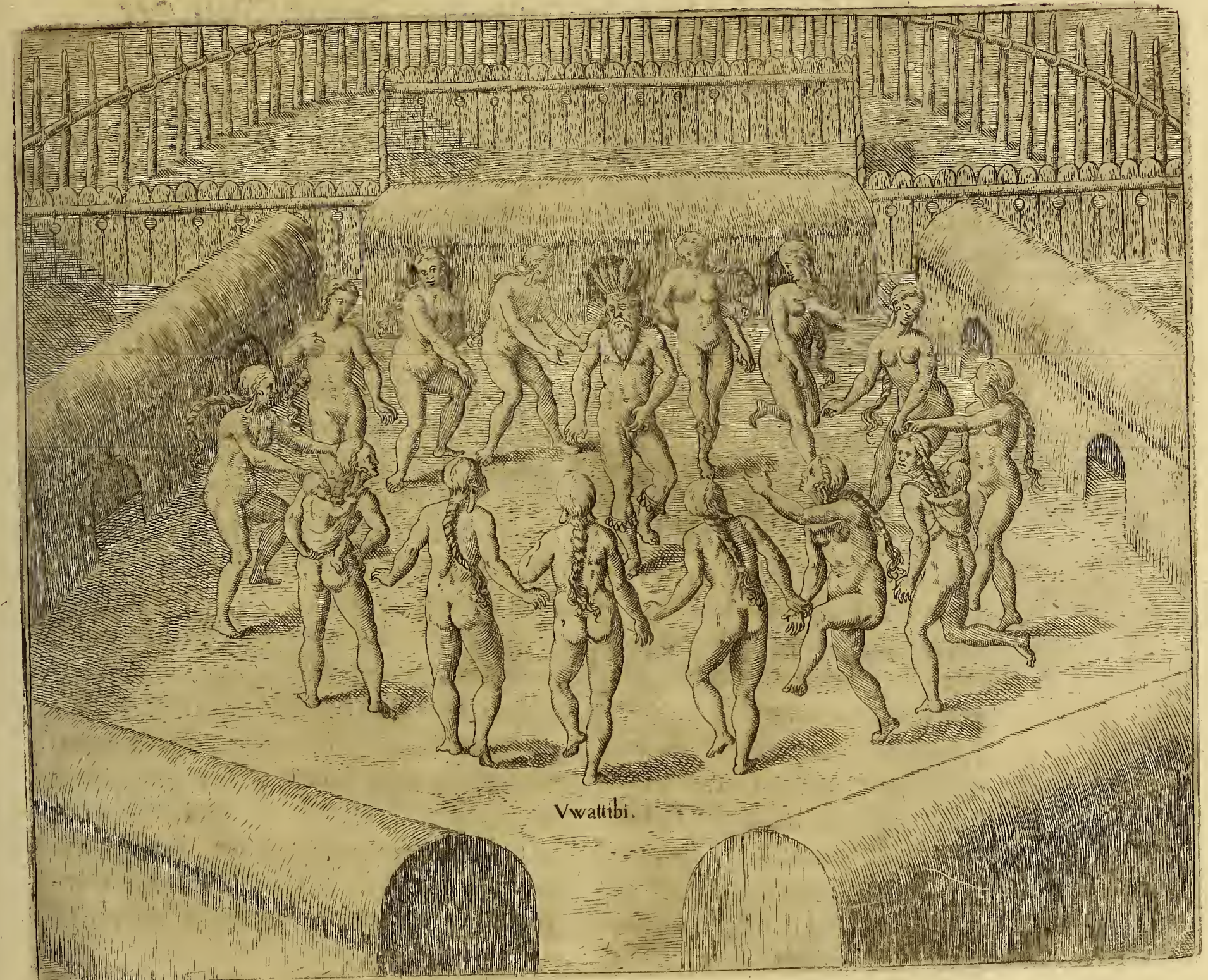

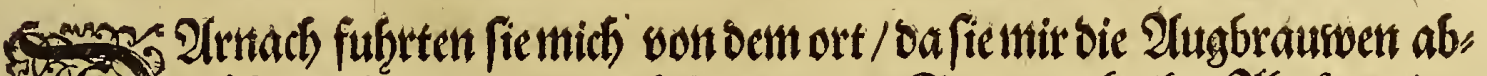

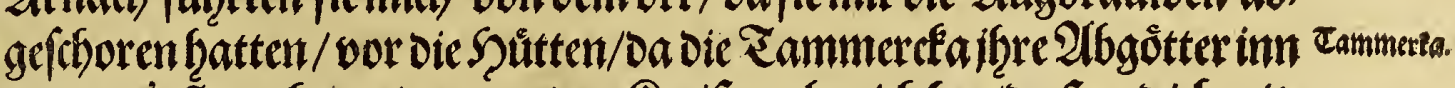

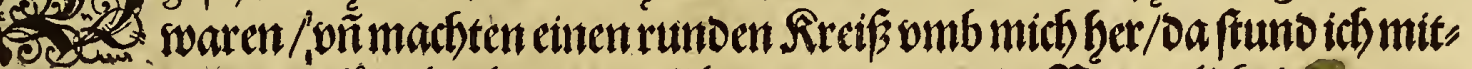

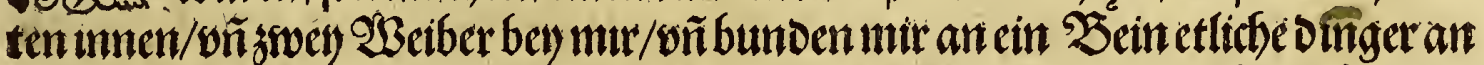

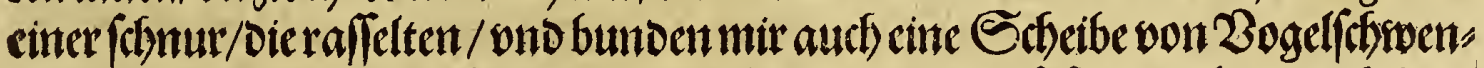

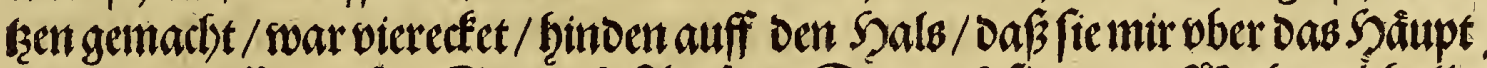

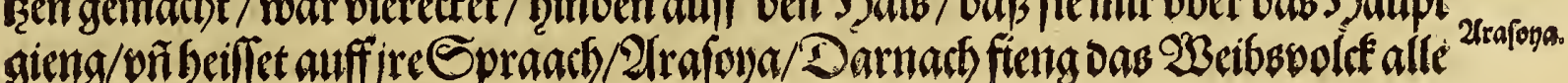
(E) iif mit 


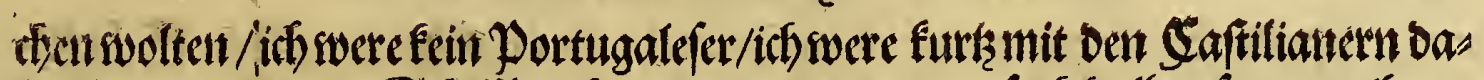

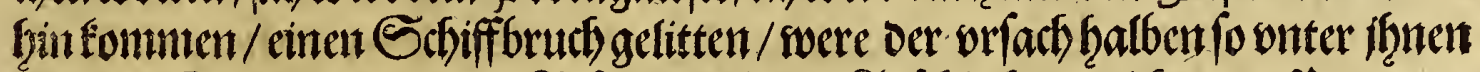
bliebent. So war cinjunger Gefell vonthrem Gefchlecht / weleber Der Dortugas tefer Saltaue gerwefentwar/onno oie 2 Bilden/Darunder die. Portugalefer woh"

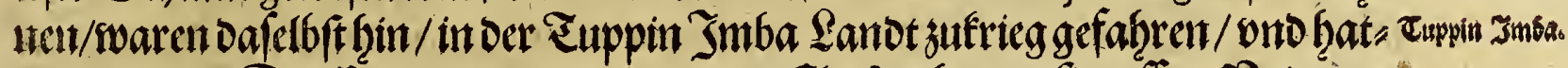

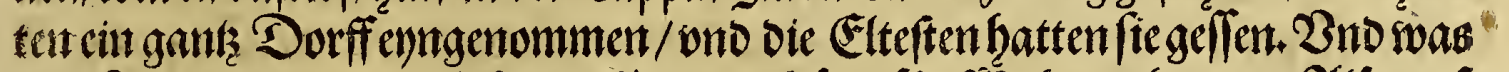

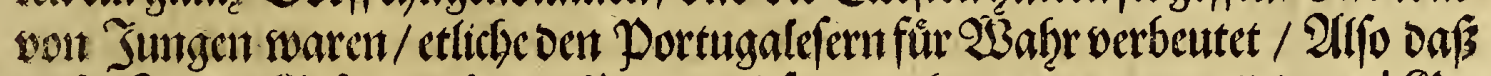

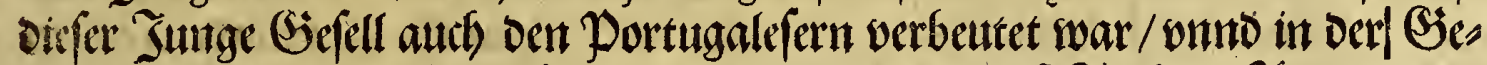

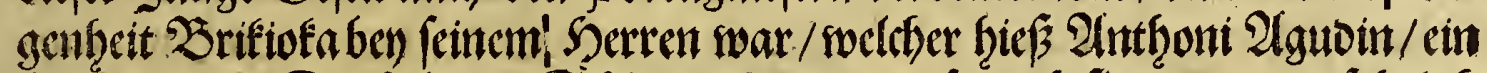
Sallicianer. Denfelbigen Sildauen batten oie fo mich fiengen/ongefebrlich

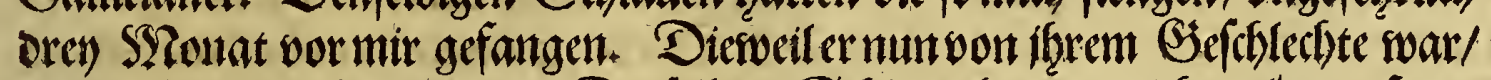
hatten-fie fictn nicht getootet / Derfelbige Sthlaue fande mich wol'/ oen frag:

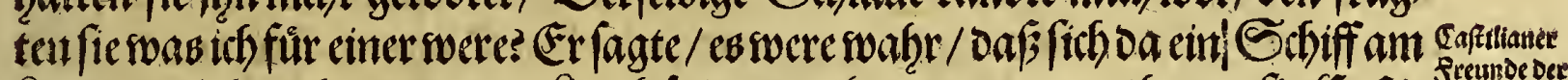

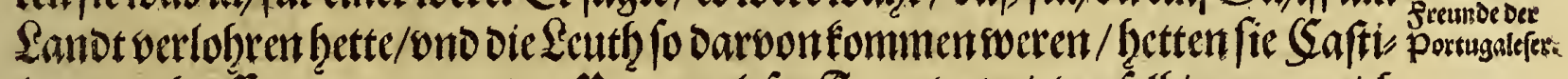

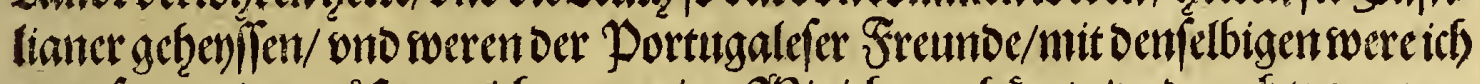

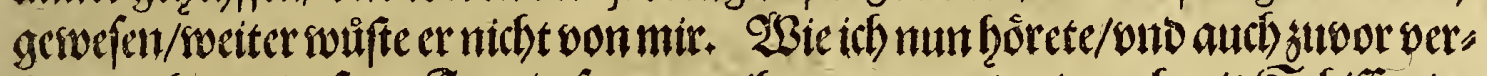

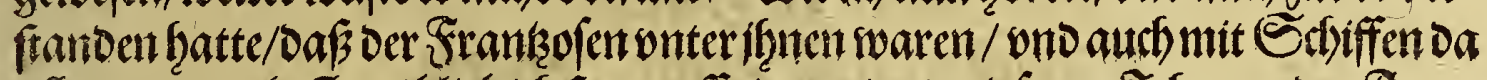

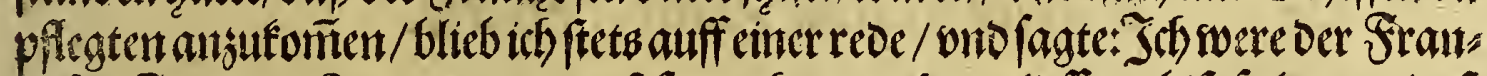

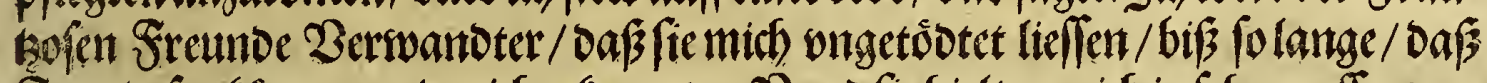

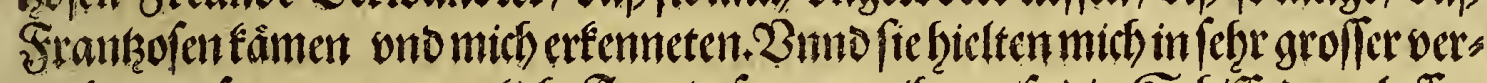

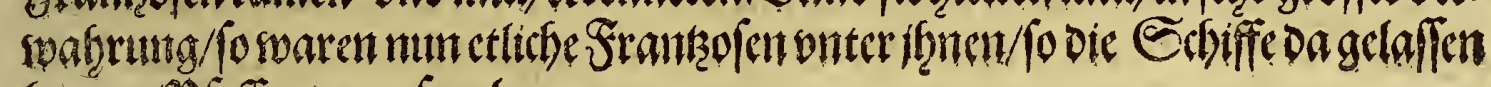
batten/Pfeffer zuorramlen.

\section{Sapittel.}

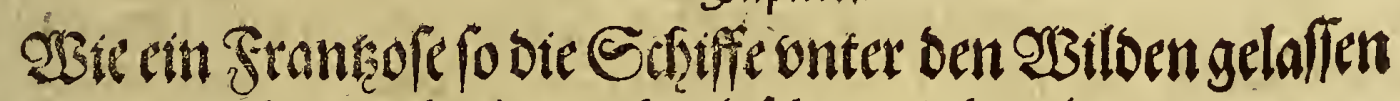

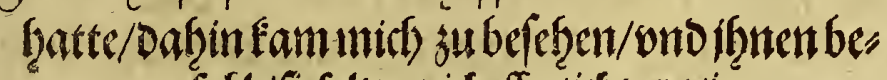 faftel/fie folten mich eflen/ith werecin Portugalefer.}

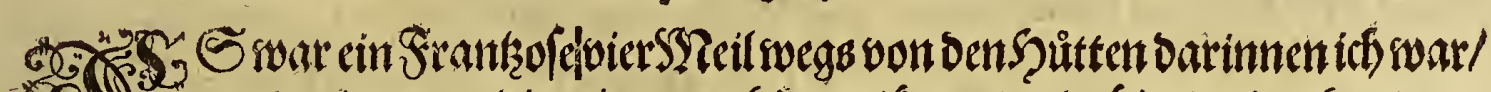

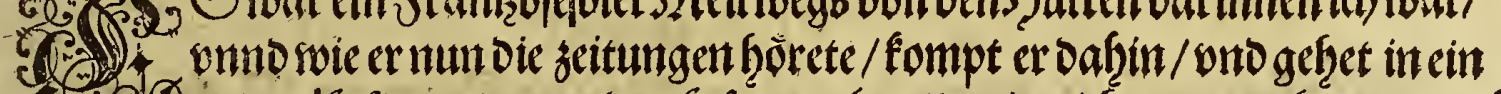

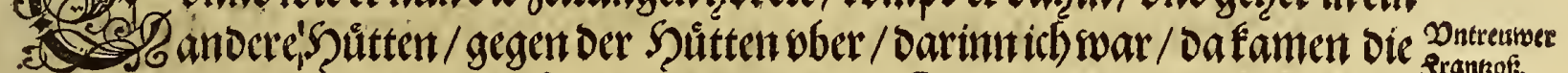

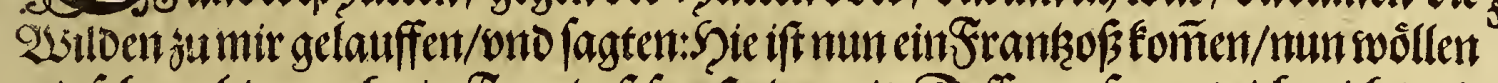

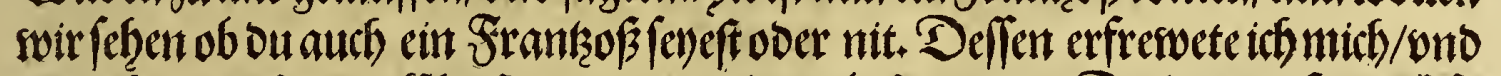

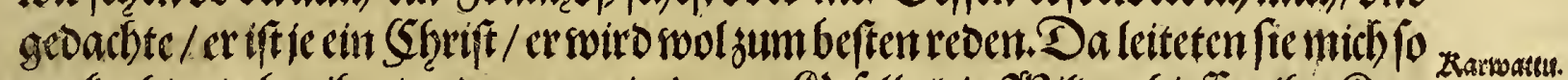

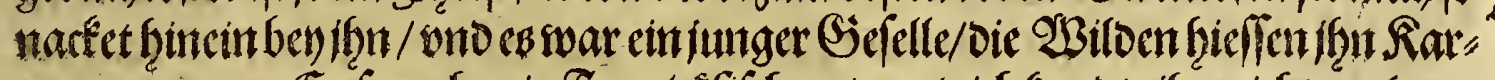

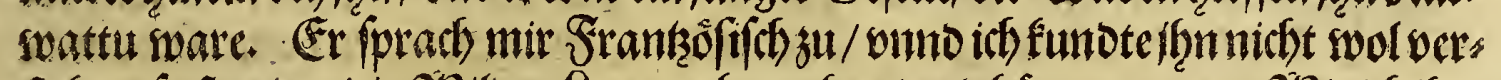

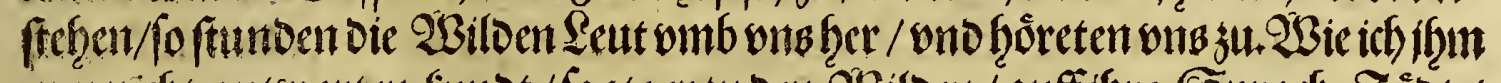

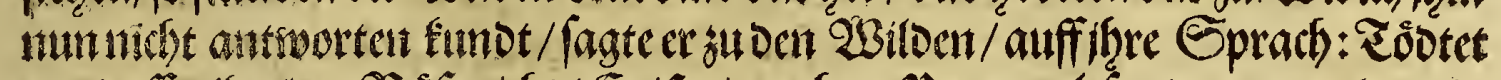

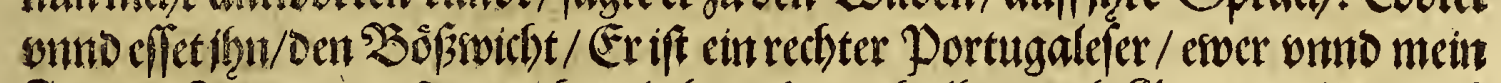

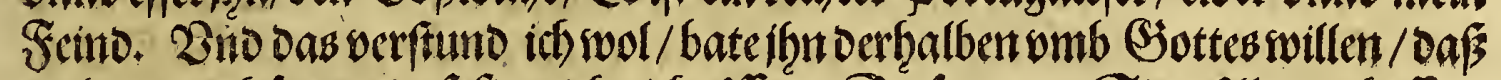

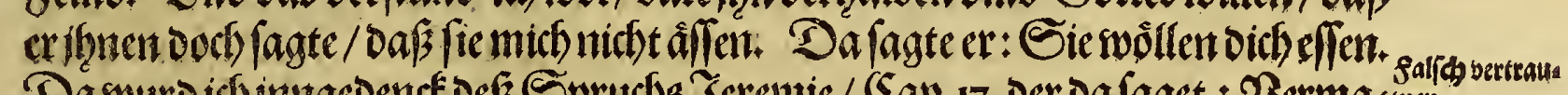

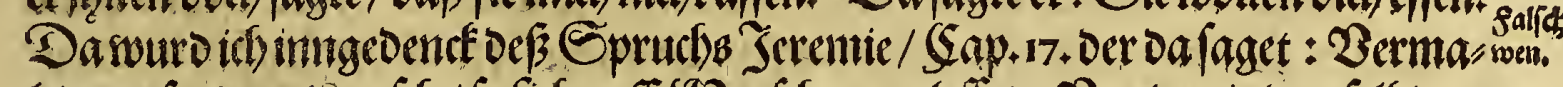

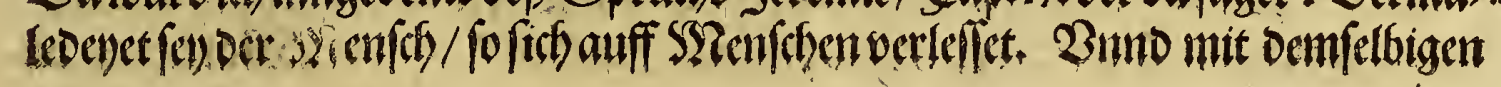
gieng 


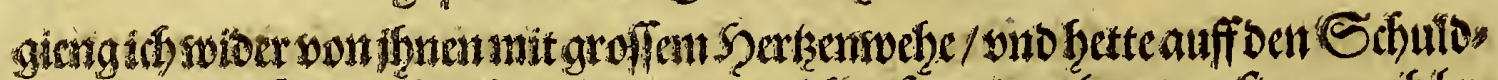

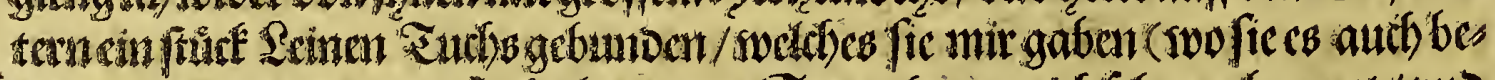

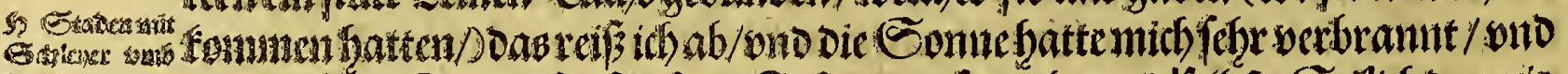

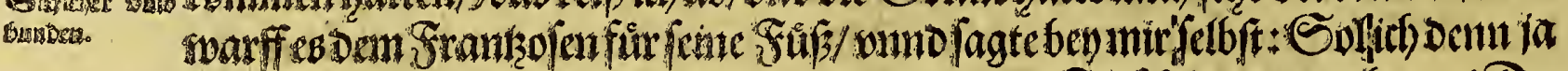

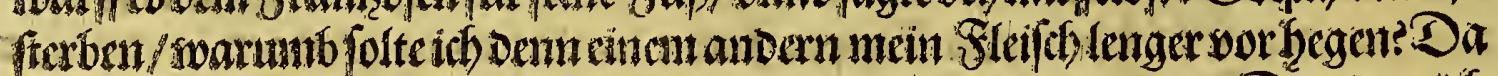

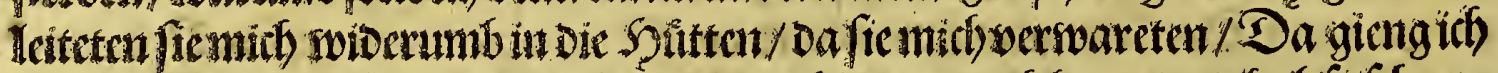

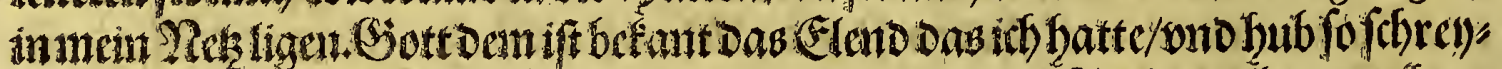

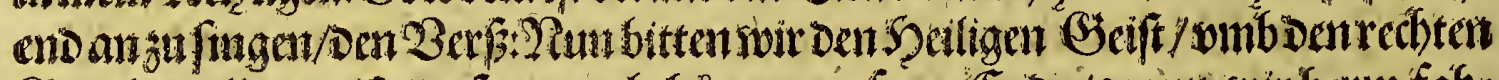

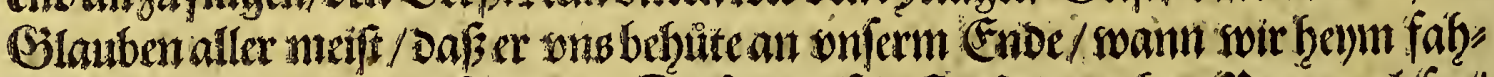

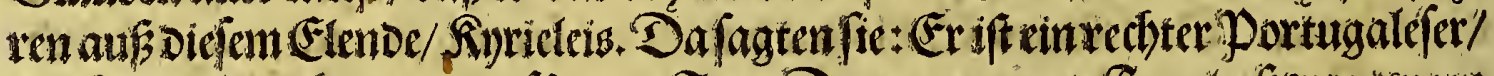
Tramsoำ $56 \mathrm{~s}$.

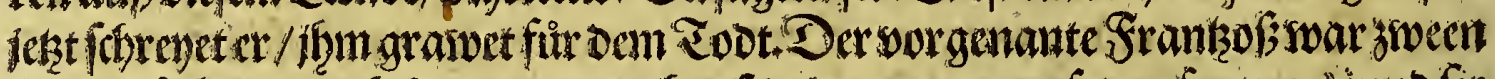

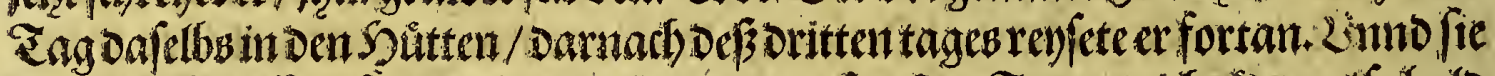

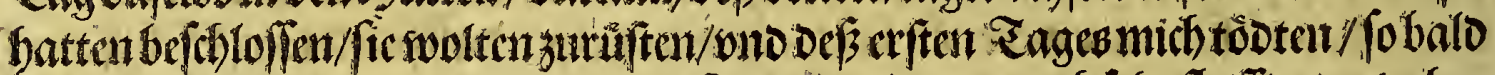

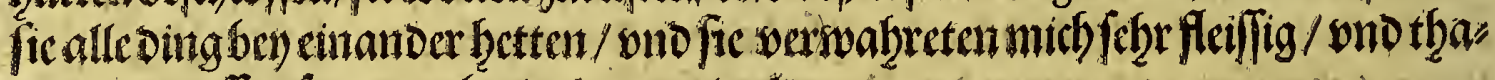
ten mir grolfen/pott an/betjocjung wito alt.

\section{V II. Sapittel. \\ OBieich fo grof 3aniverfe fratte.}

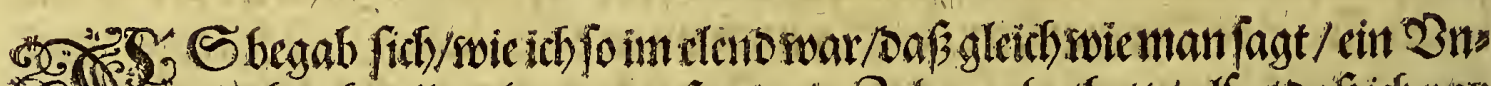
(9.)

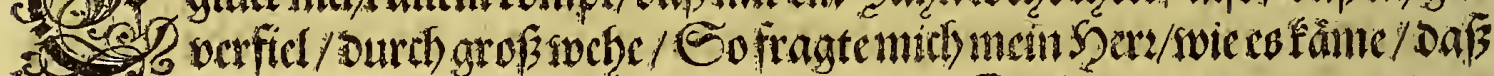

zastratate

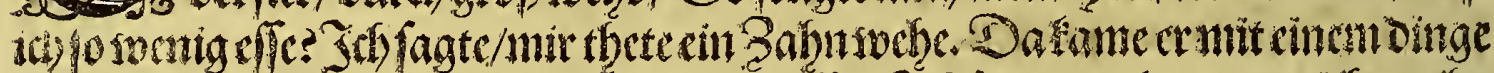

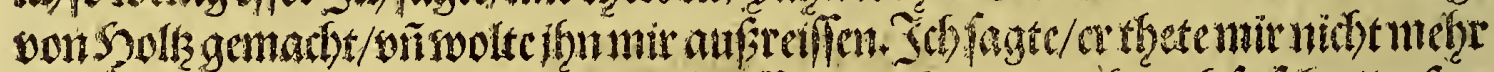

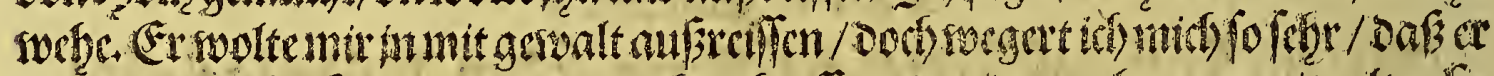

5.. Erabm reicenct Das 3.rano:g?

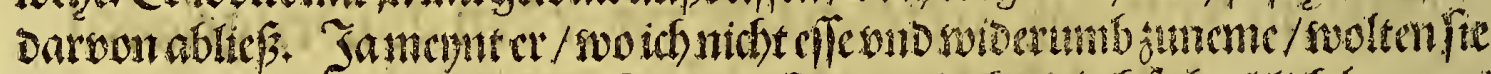

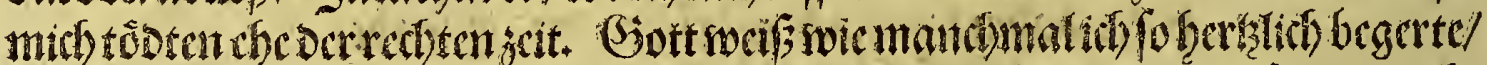

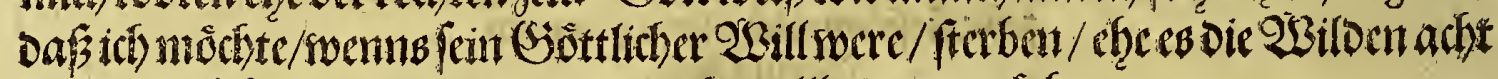

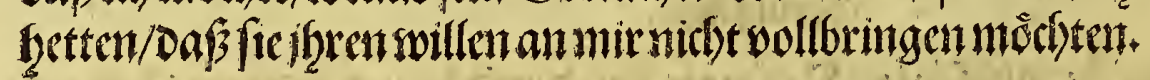

\section{Sapittch.

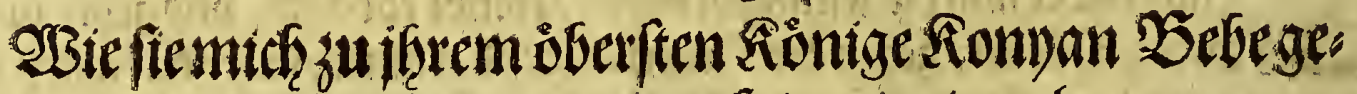 nant/fúfecten/wno swic/ic ba mitmir wmbs giengen.}

2trirab. Zicos.

Dhartayas

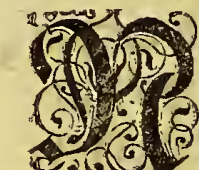

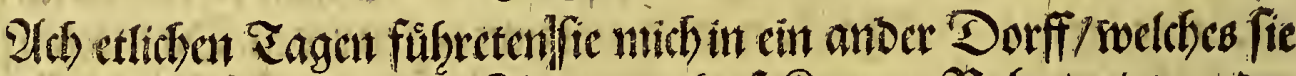

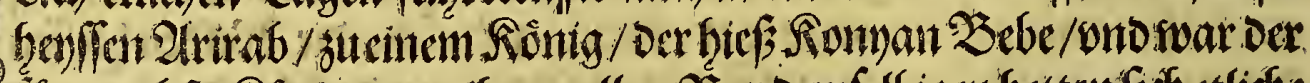

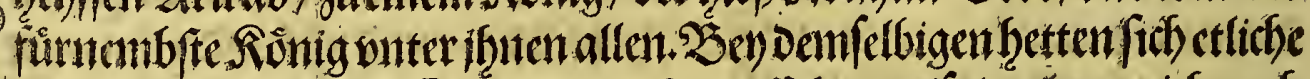

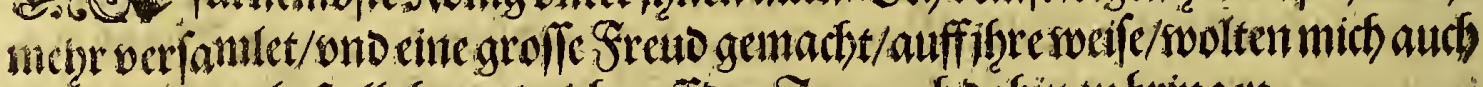

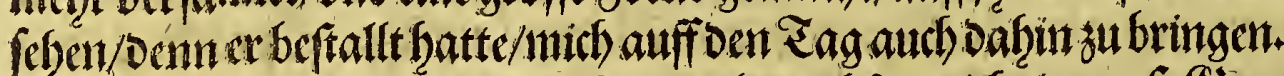

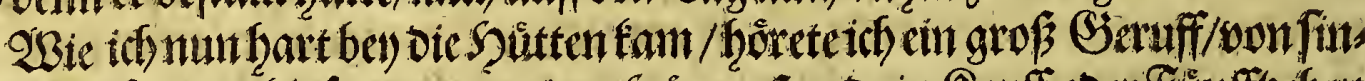

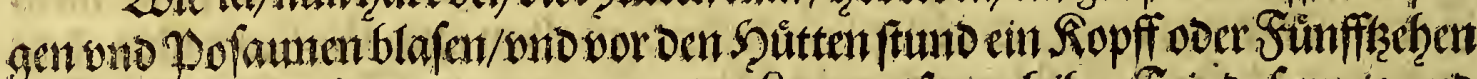

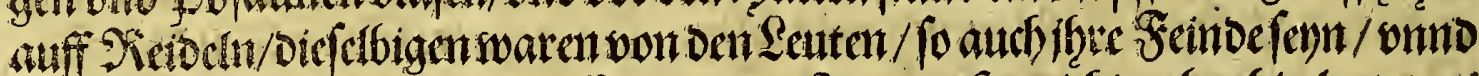

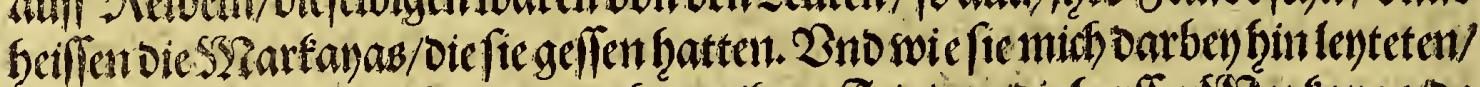

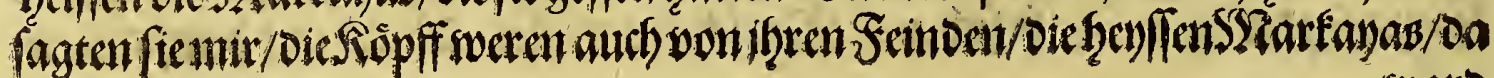
waro 


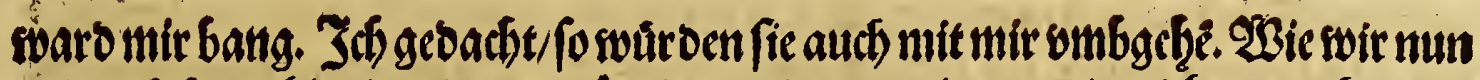
gu ben Sưtten hinein giengen / fo gienge einer von benen die mich) verwab̨reten/

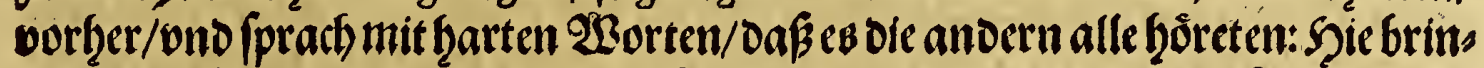
ge ieb oen Siblauen ben Portugalefer her/wno meynete es fwere ein fein oing ans oulehen/wenn einer feinen feindt in feiner gerwalt ḩette. 2 no er rebete viel andes re oing meftr / wie ir gebrauch if / lentete mich) Da der Rönig / mit ben andern a 3 ono trandf / onno hatten fict mit cinander truncfen gemadt) / in Dem Setrencfe

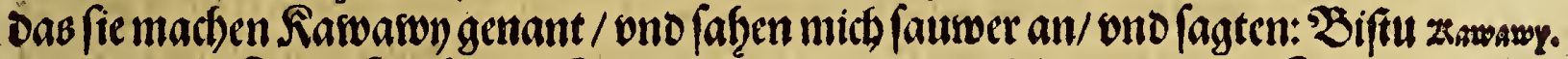
fomen on/er feino? Jeb) fagete: Jab bin fommen / aber ich bin nict)t esver feinot. Da gaben fie mir audbu trinden. So batte ich nun viel von oem Rionige Ros

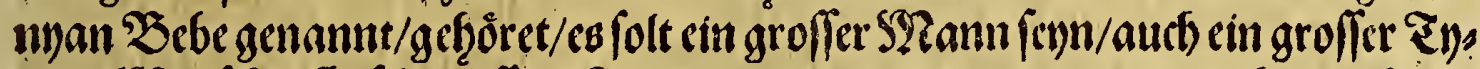
rann S2 enf f(chenfleif(h) ju effen. Bno es war einer onter inen oer baucbte mich wes

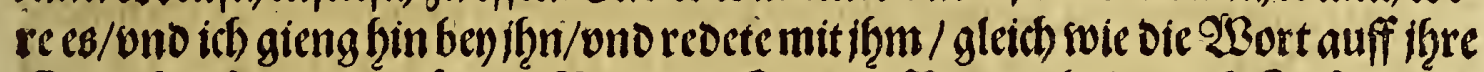

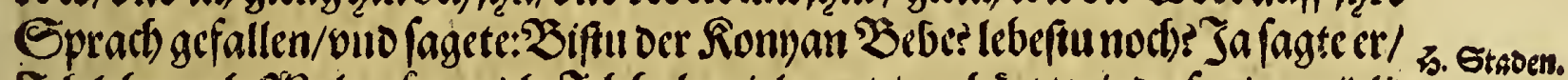

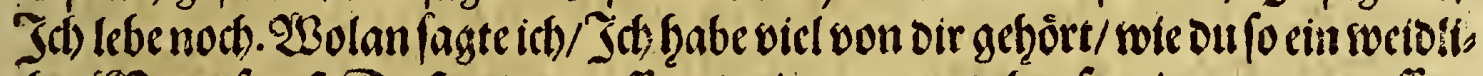

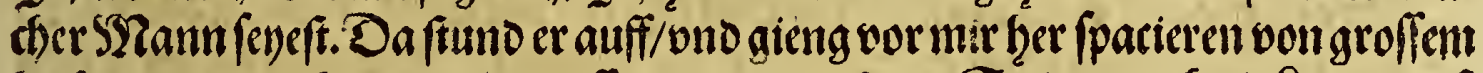
Gocbmut/ono er hatte einen groflen rumben grinen Stein/ ourch oie Sippen oef Grimer

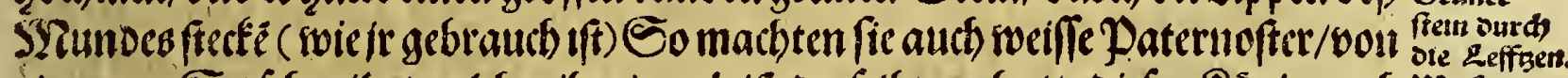

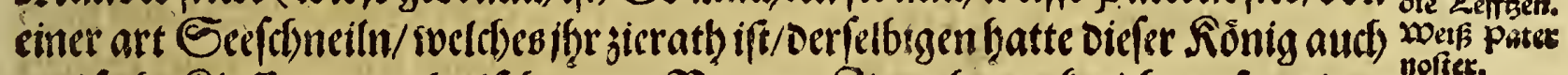

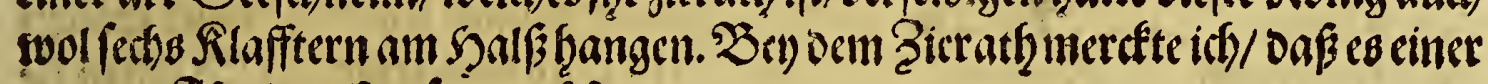
oon oen Sưrnemeftenfein múfte.

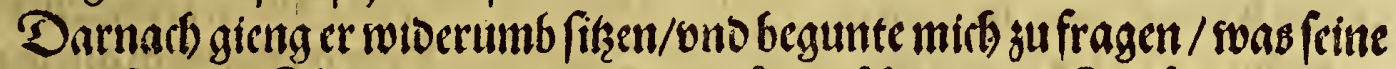

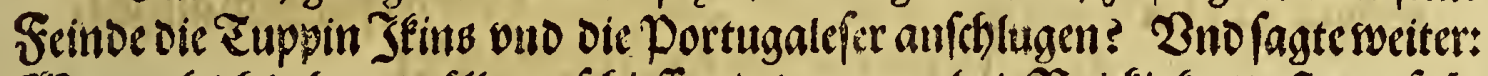

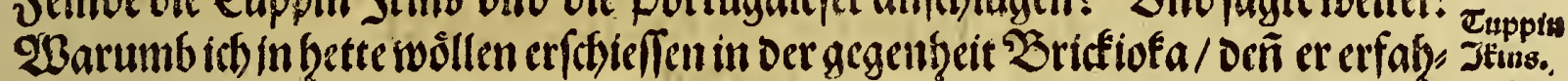

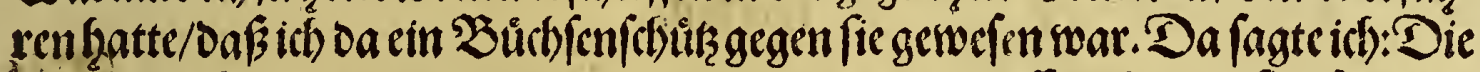
Dortugalefer hetten micb oafin gefitallt/ vollo hett es mulfen thun. 'Da fagter: Jeb) were Ja aucb ein Portutgalefer/oñ bief oen Frankzofen/ fo mich gefehen hats

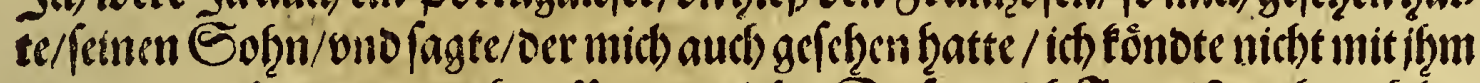

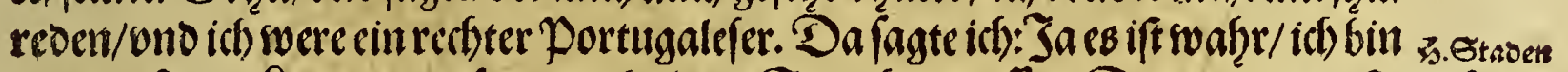

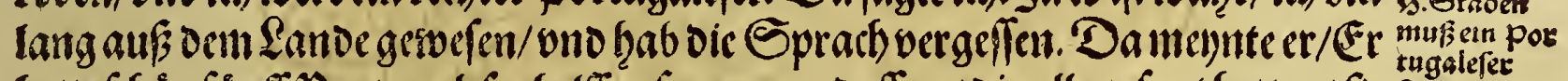
bettefchö fünff Portugalefer helfien fangen vono effen / oie alle gefagt hetten/ fie fegn.

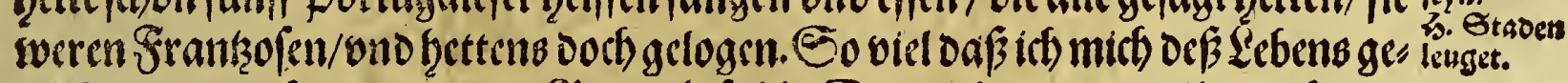
troffet/ono mich in Den willen Sottes befable. Denn ich voninen allen nict) ans oers vername / oenn ich foltefterben. Da bub er wideromb anju fragen/ $28 a b$

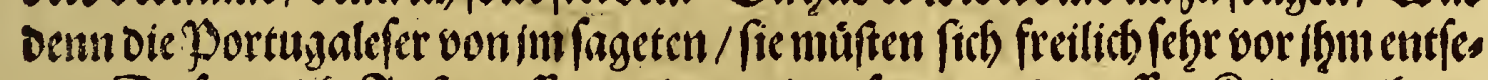

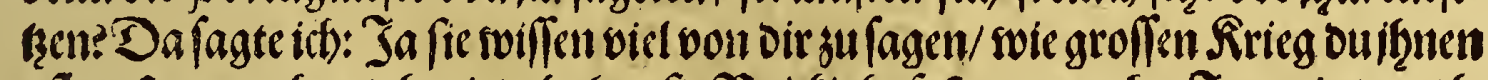
pllegeft zu macken/aber iefit haben /ie Wrictiofa fefter gemadht. Ja meinte er/ fo swolte er fie in oem 23 al be hin ono swiber fo fangen/swie fie mict) gefangen hetten.

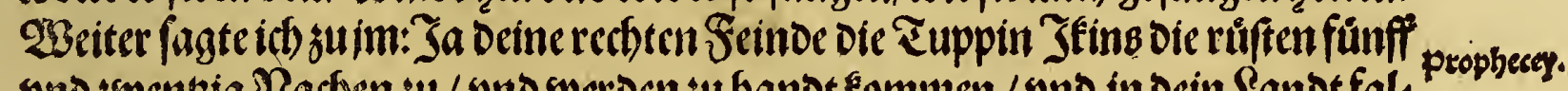

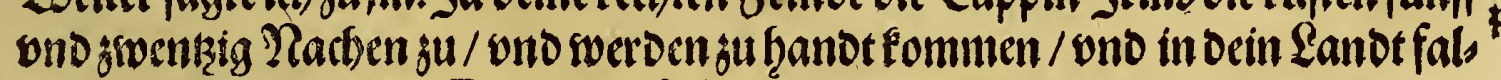

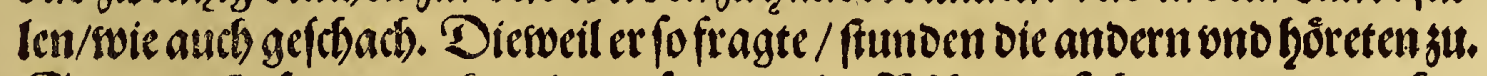
Summa/Er fragtemich viel/vito fagte viel. Rithmpte fich mir/ wie manthen

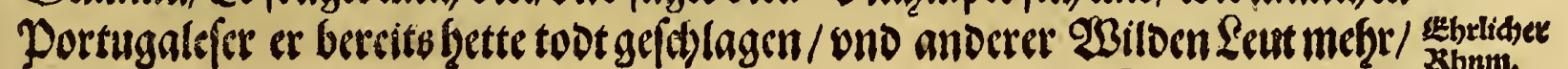
f Das 


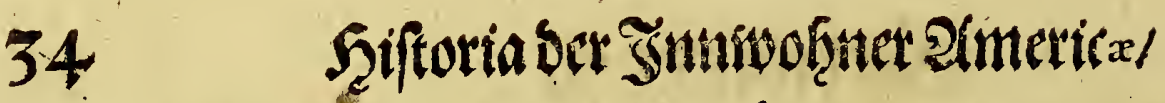

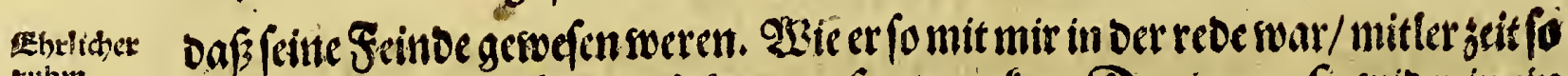

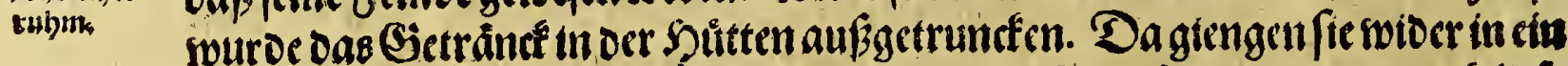

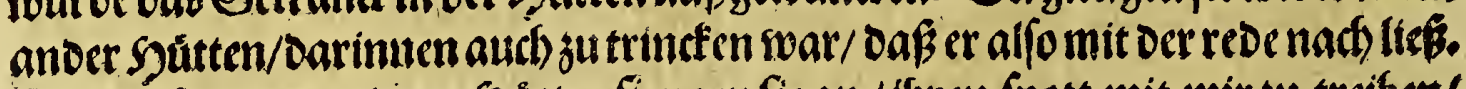
Darnadb in Der andern Sutten fiengen fie au / ffren fpott mit mir zu treiben/

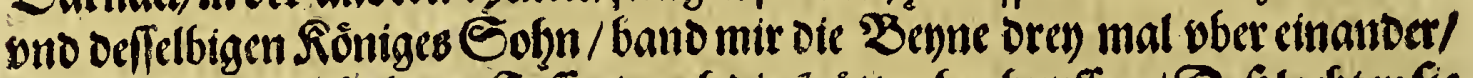

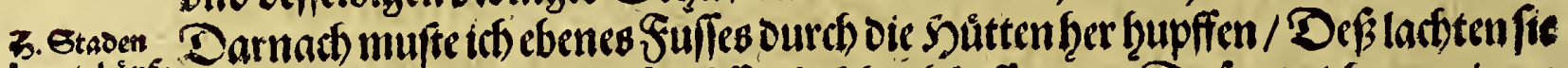

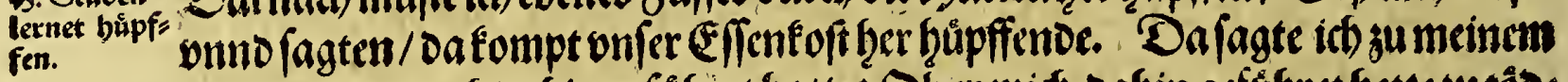

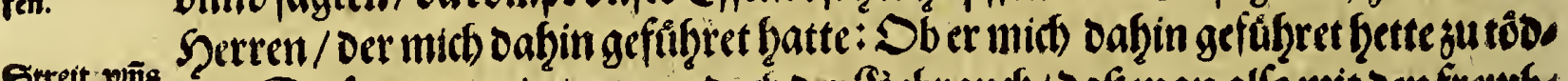

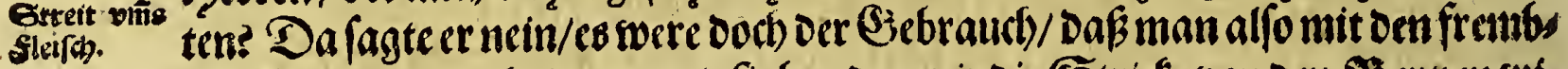
Den Sthlauen vmbgienge/vno fir bunden mir die Stricfe von oen $\mathfrak{B}$ ennen Der $a b /$ Darnadb fame fie omb mich fer geften/ono griffen mir an mein Fteifa/

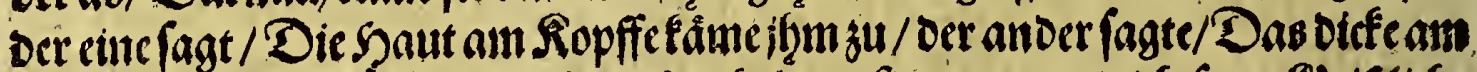
Benne farme ifbm

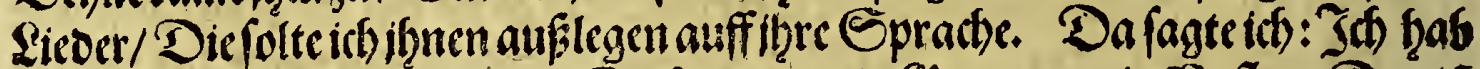
von meinem Bott gefungen. Eiefagten mein Gott soere cin 2 nflat / Dabif

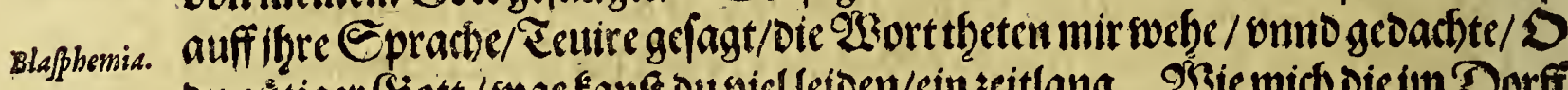

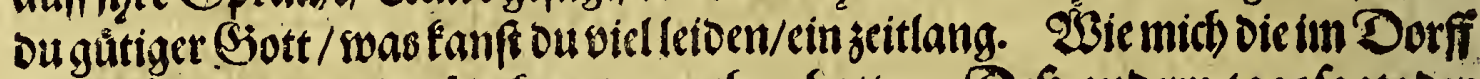
nun geferen/ono allen Sochmut angethan hatten. Def anbern tags fagte bet

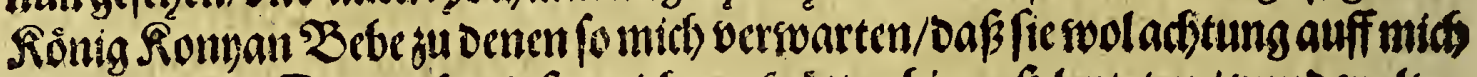

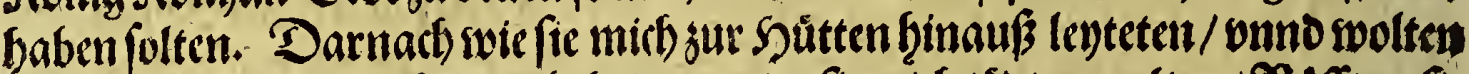

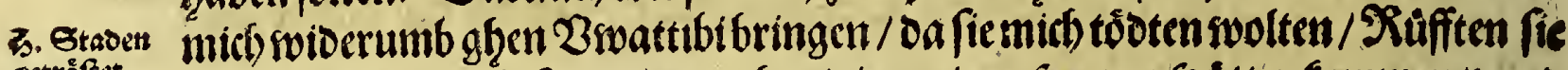

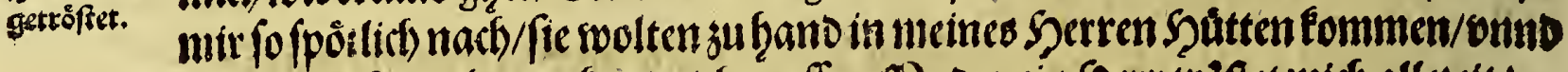
meinen Soot beosnctein/mich ju effet/23no mein Şerr troffet mich allezett/ fagte/lit) folte now fo balot nicht getoot werden.

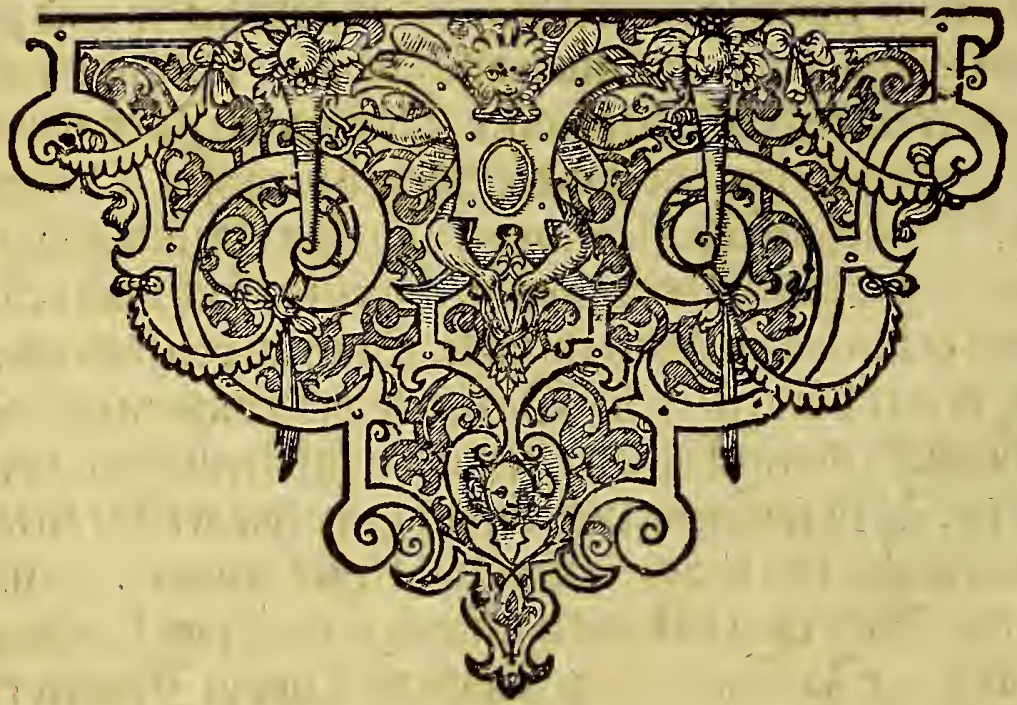


Dasbritte Theil.

XXIX. Sapittel.

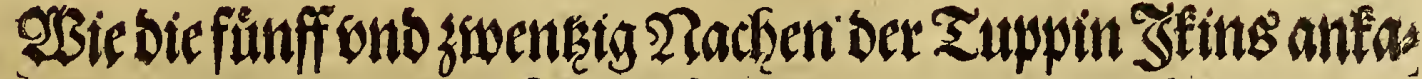
men/Davontich Dem Rônig gefagt hatte/wno wollten Die Shutten anfallen darimnichswar.

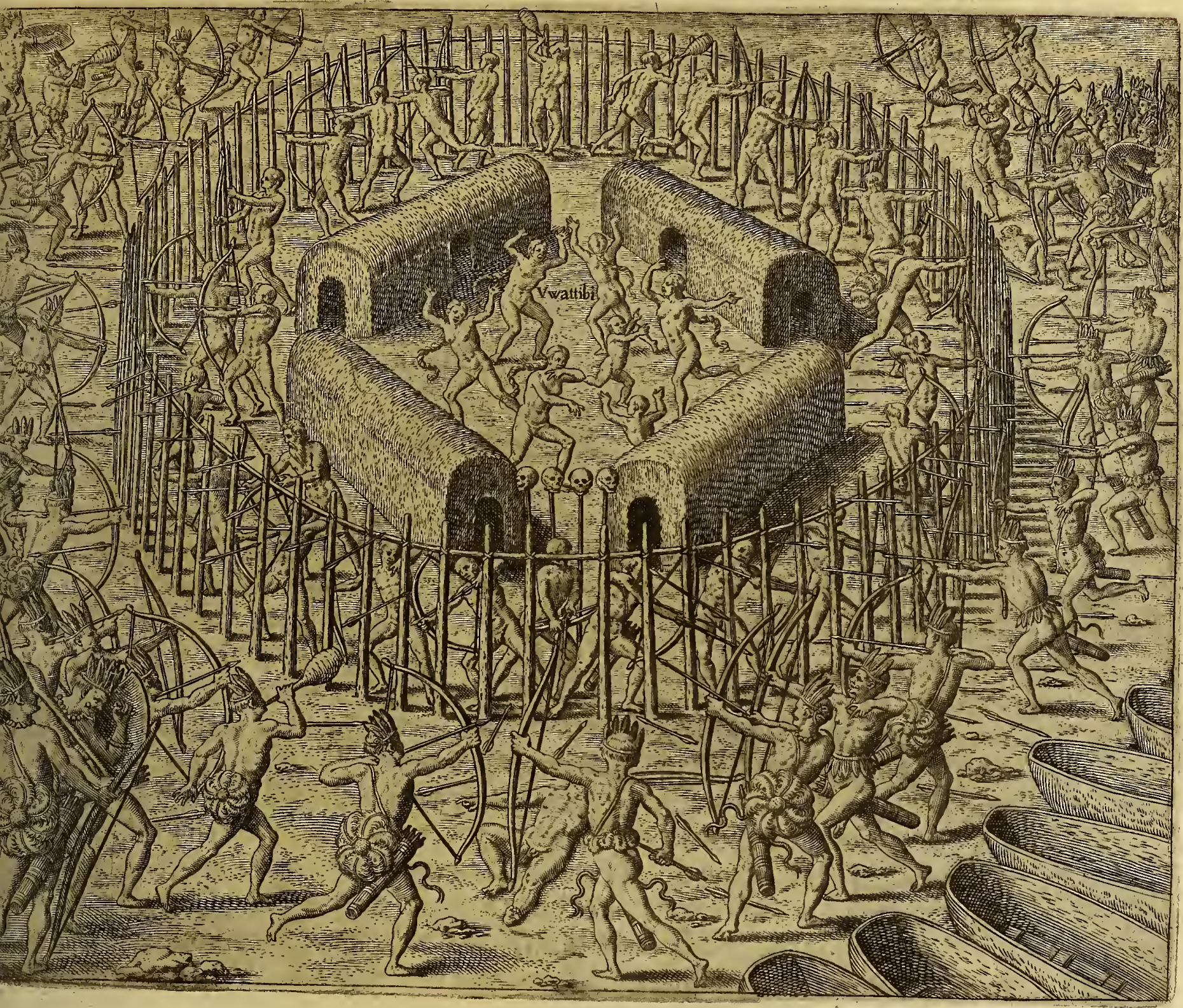

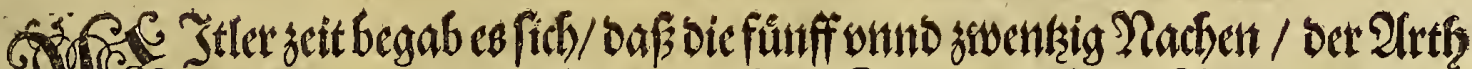

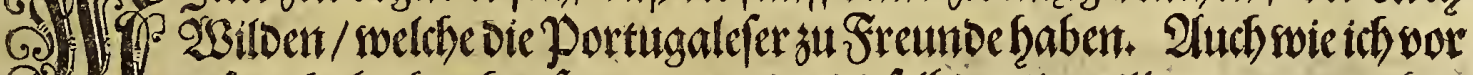

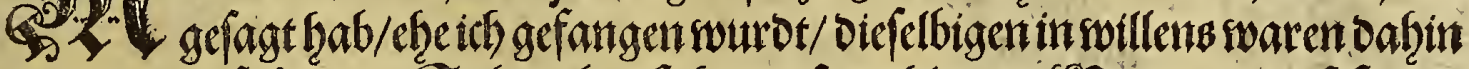

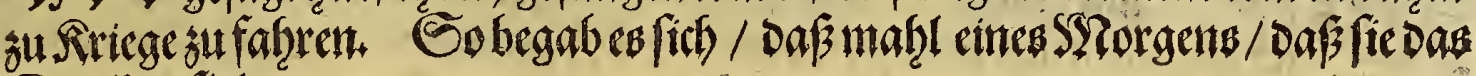
Dorffanficent.

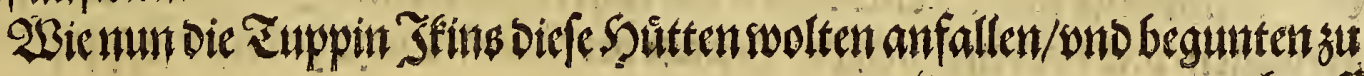
if if baufi 


\section{Siffortaber Simnofiner Smeriex/}

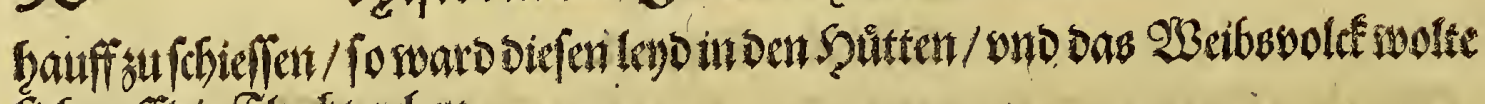

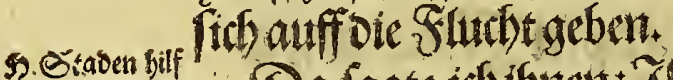

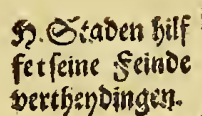

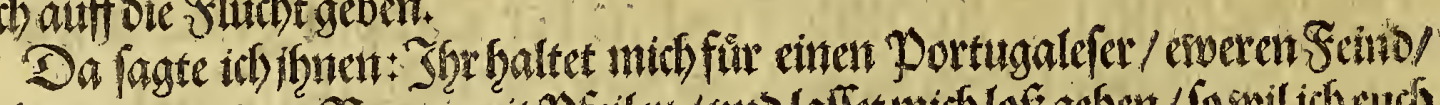

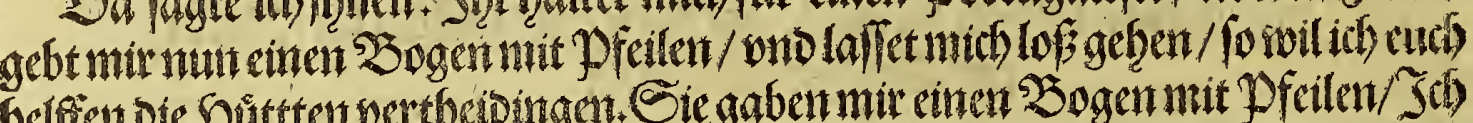

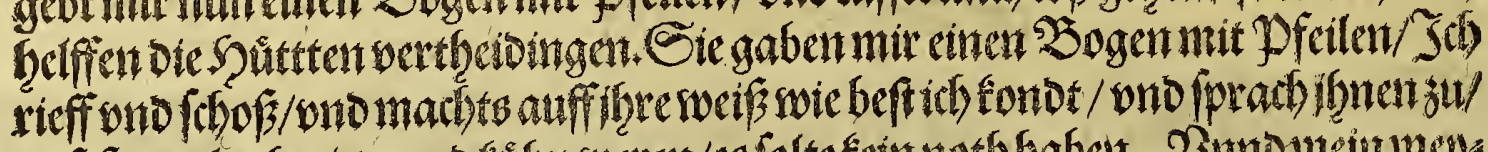

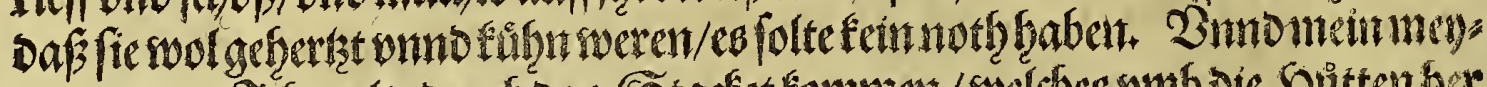

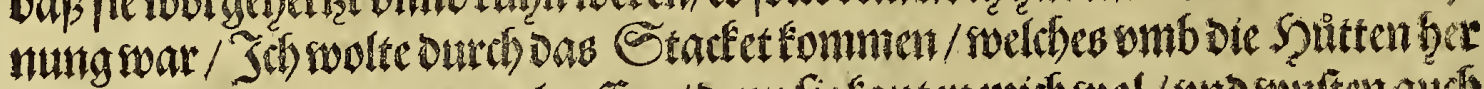

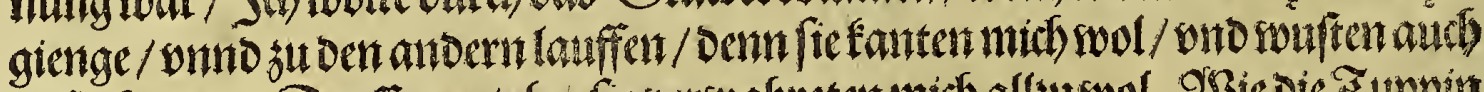

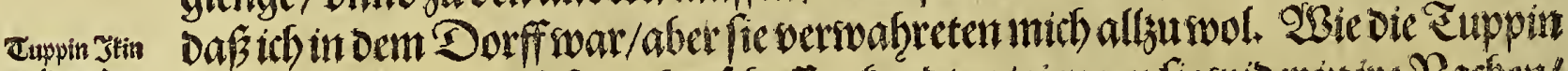

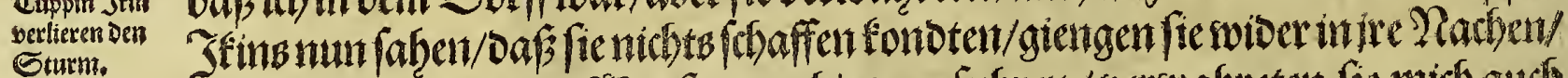

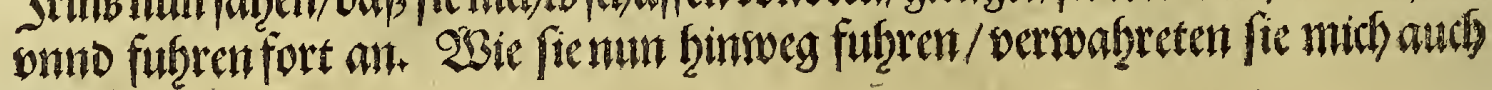
wotoer.

\section{XXX.Sapitted.

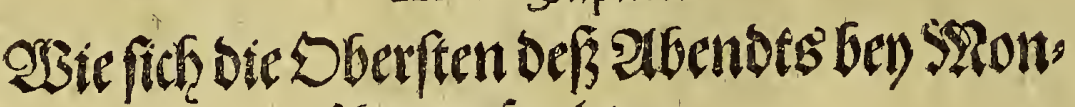 forein werfanleten.}

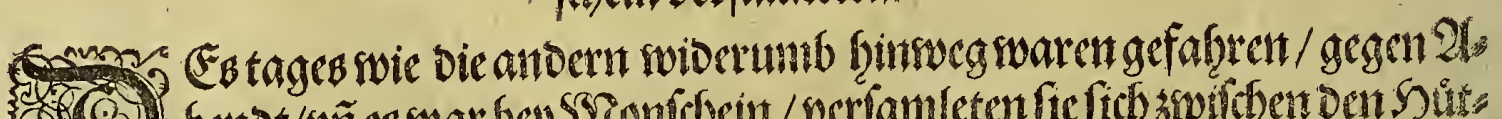

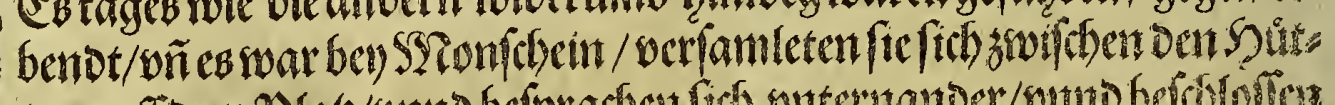

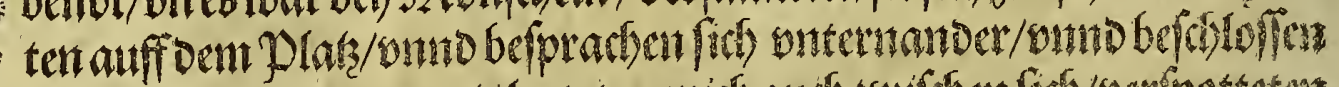

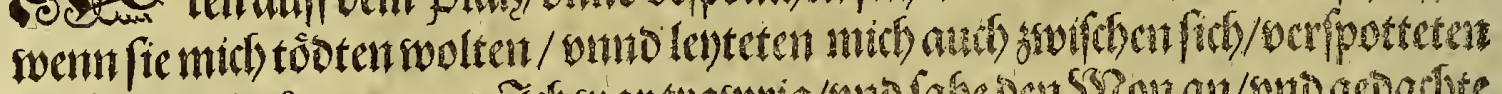

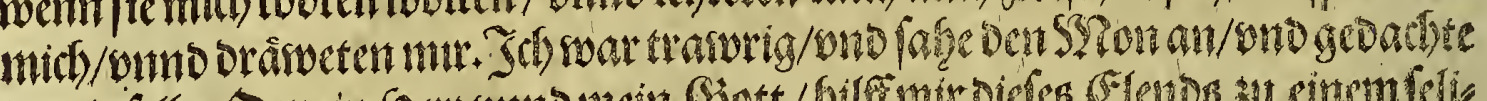

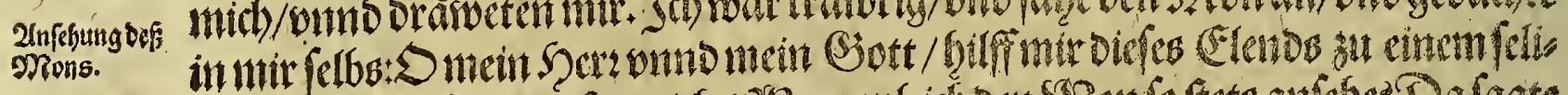

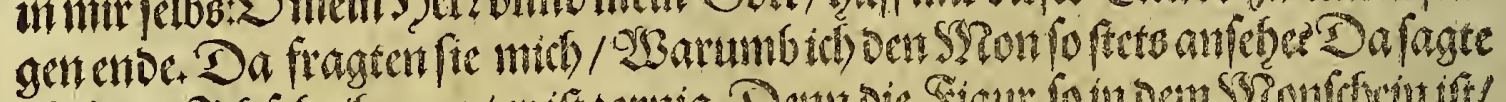

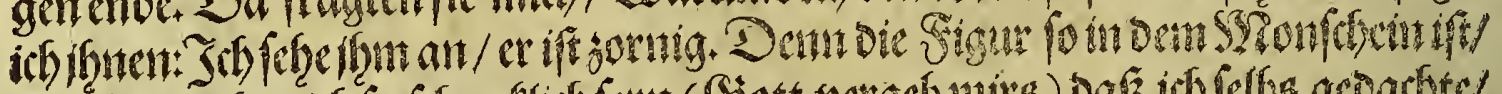

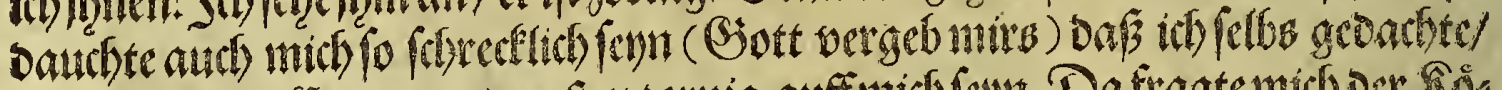

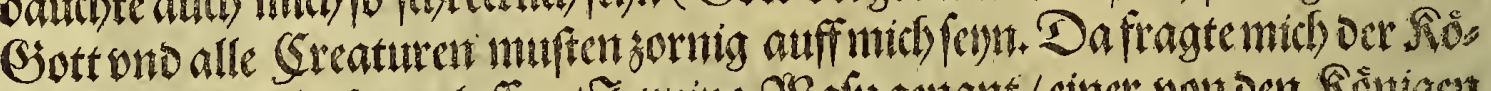

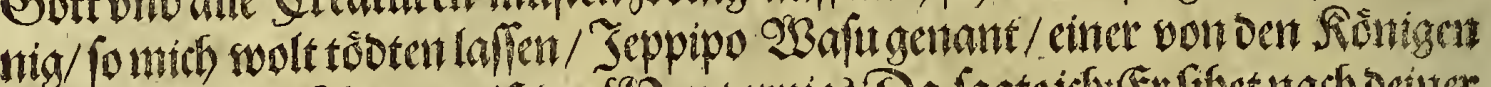

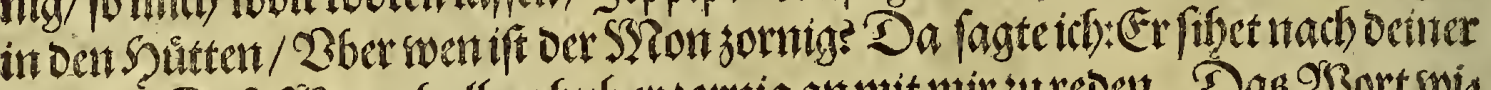

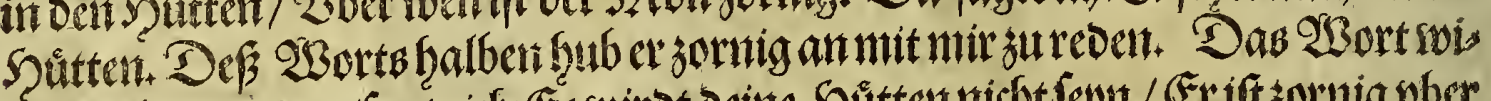

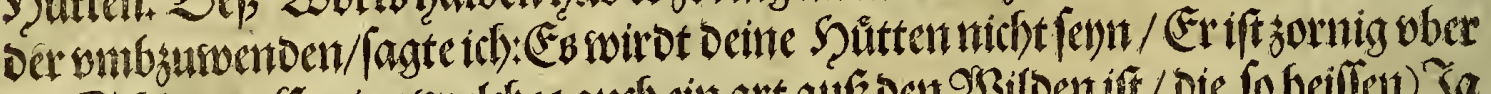

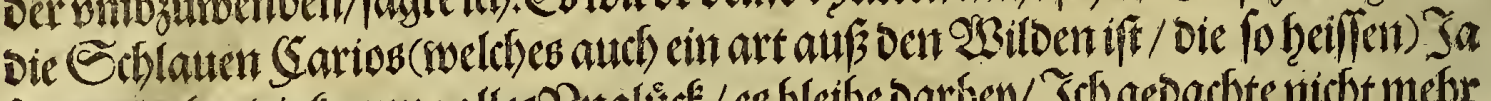

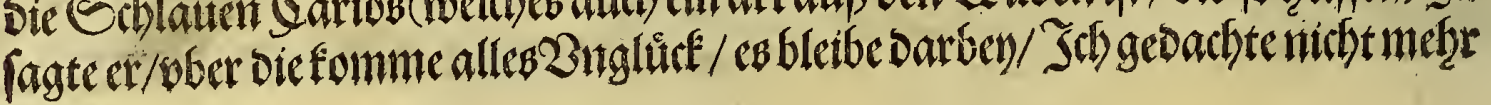
Daran.

\section{Sapitted.}

\section{Wie bie Suppin Sfins cin andar Dorfi/\$2 am}

bufabe gentant / ocrbrennet f̧attent.

97ambutabe

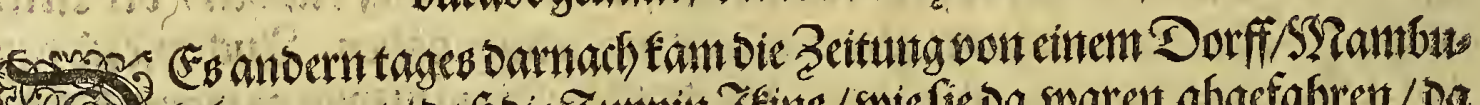

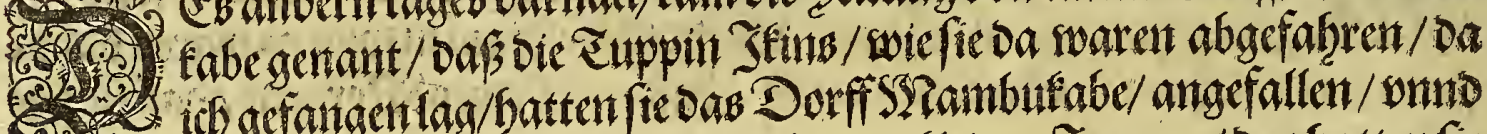

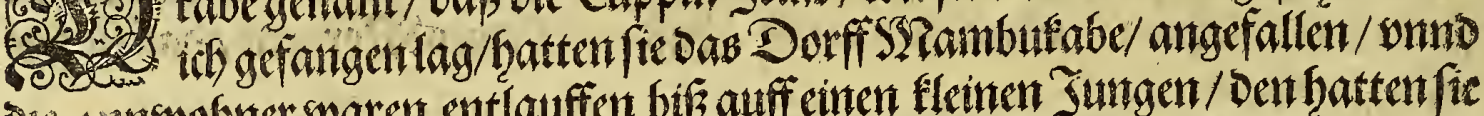
ou sunwoofner waren entlauffen bis auffecten fleinen Jungen/Den hatten/ie

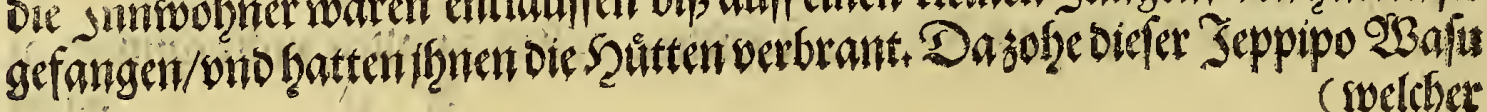




\section{Das britte $\mathfrak{I}$ freti.}

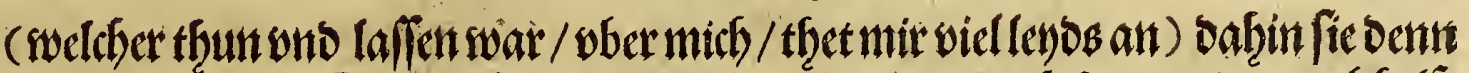

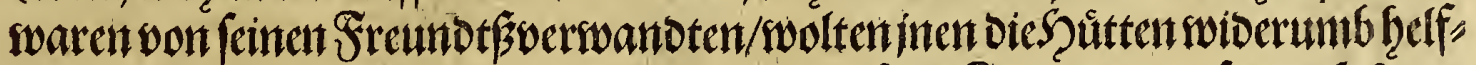
fen auftrichten / Sonane er gemeinglief) alle feine Freunto von feiner Şütten

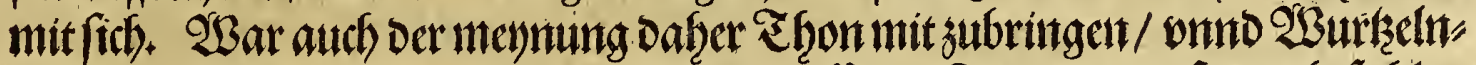

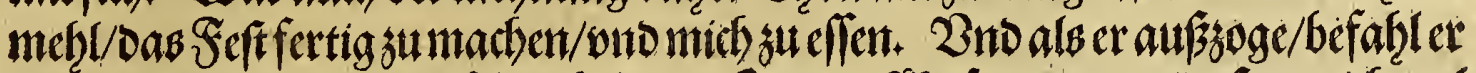

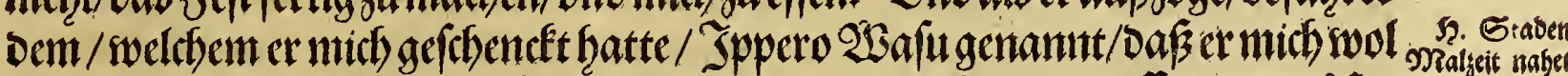

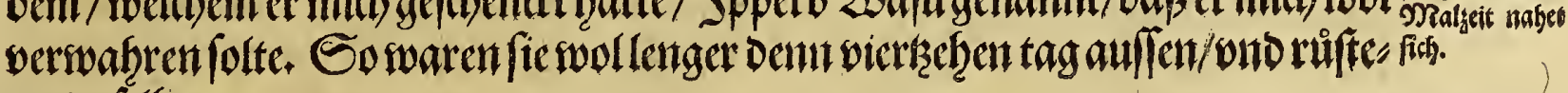
tendoafelbs $\mathfrak{j u}$.

\section{Sapittel. \\ Wie cinSchiffion Brictiofa fam/nach mir fragte/ond \\ fieifim furtsentertichtgabent.}

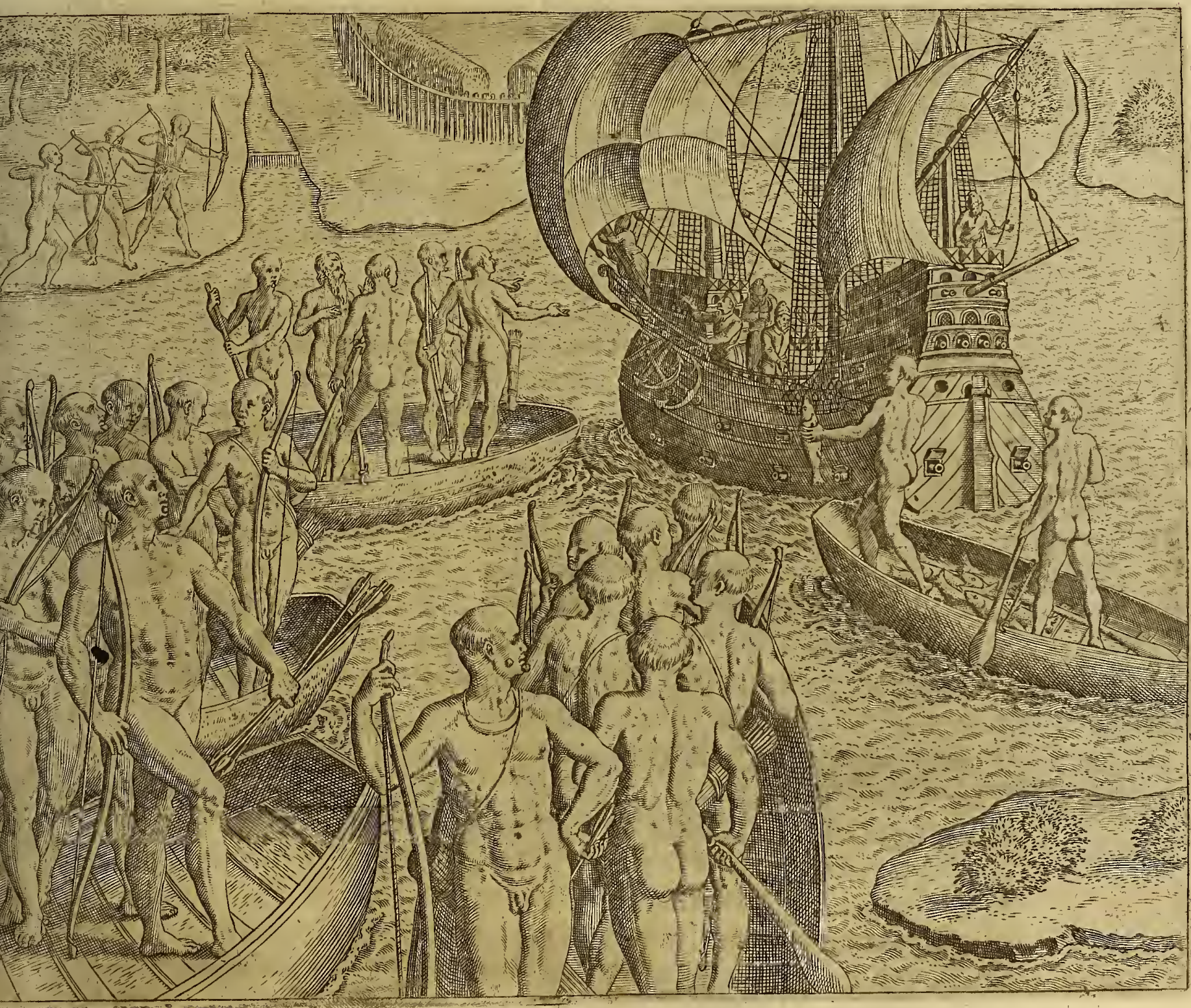

F iif

STiter 


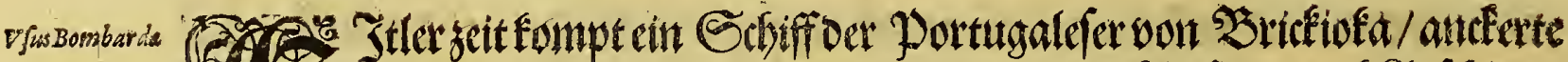

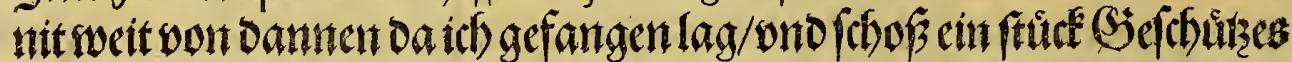

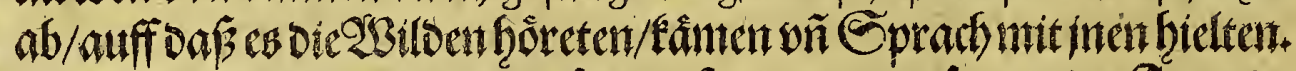

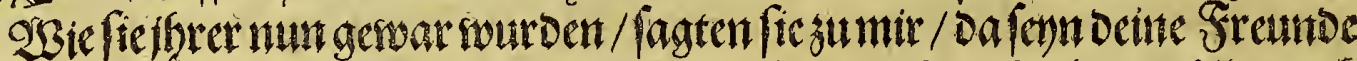

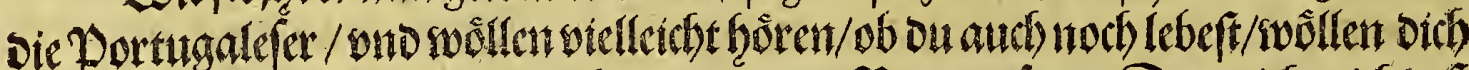

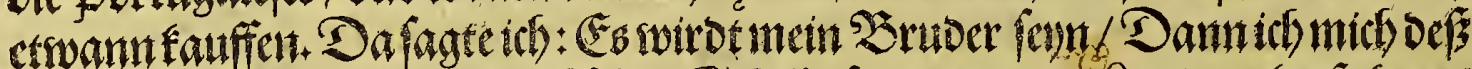

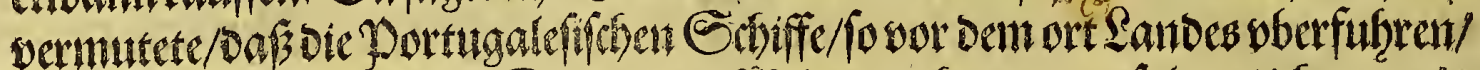

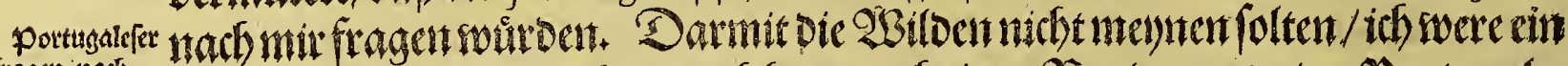

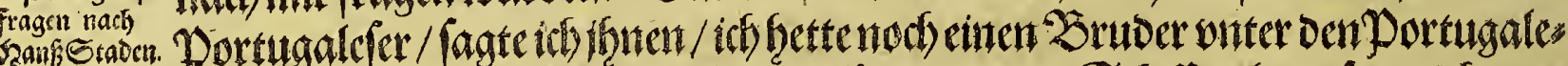

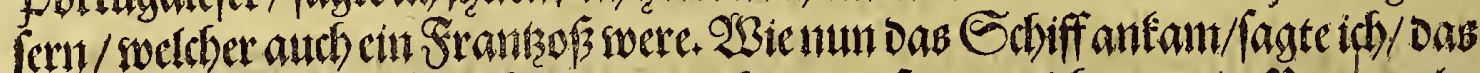

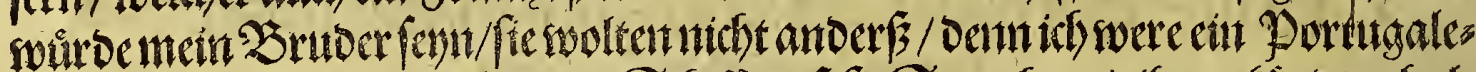

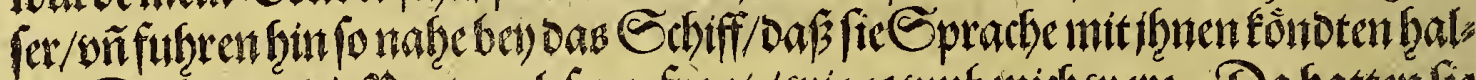
ten. Da hatten die Dortugalefer gefragt/ wie eb vinb nieb were. Da hatten fie

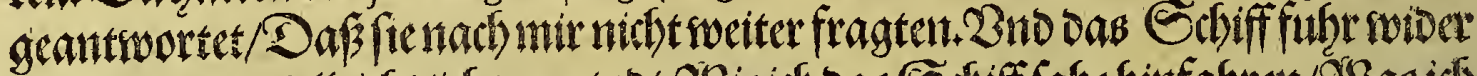

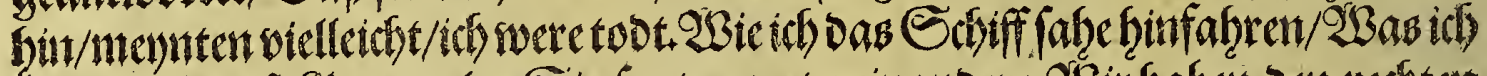

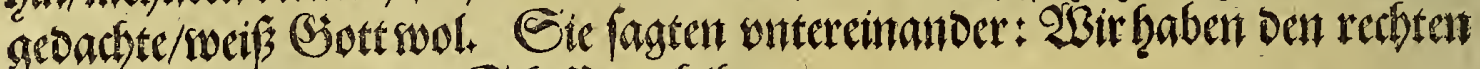

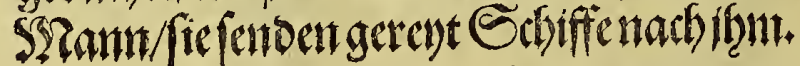

\section{Sapittel.}

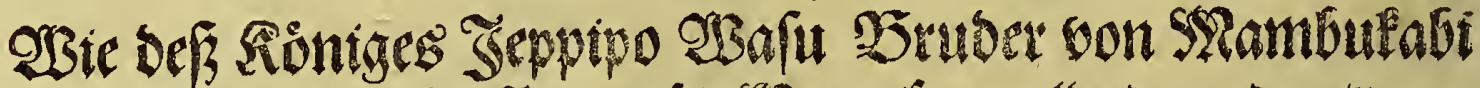

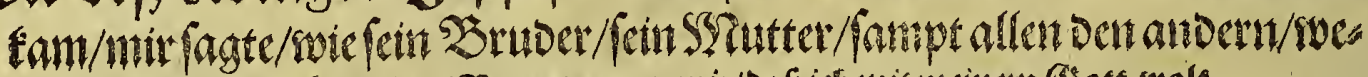

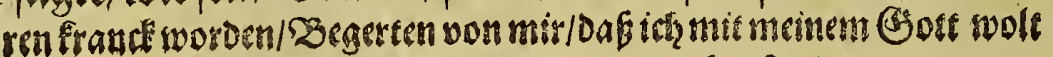

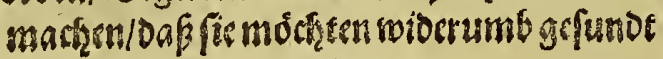
sosroen.

fretubeber Dicuifhenfref fer rwiberturffr.

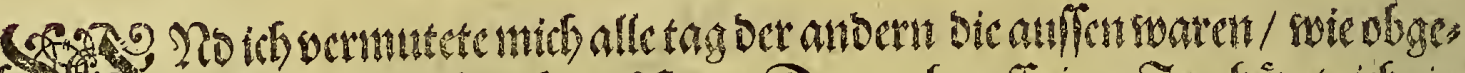

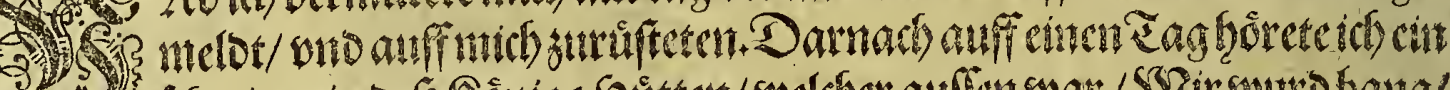

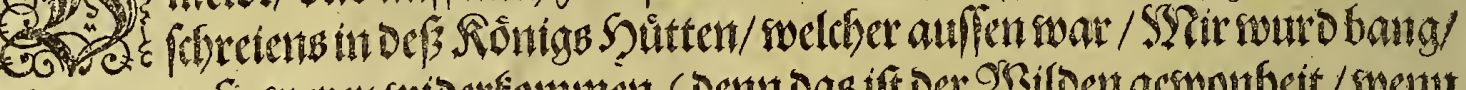

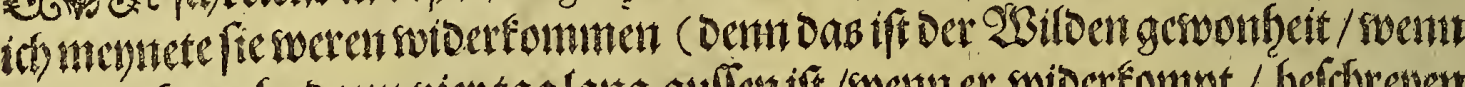

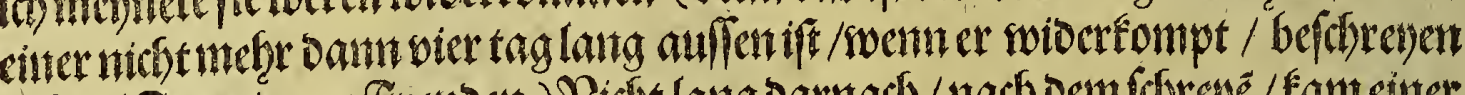

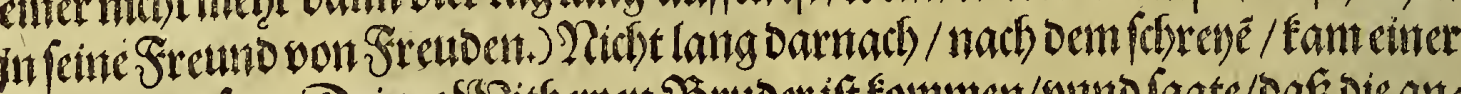

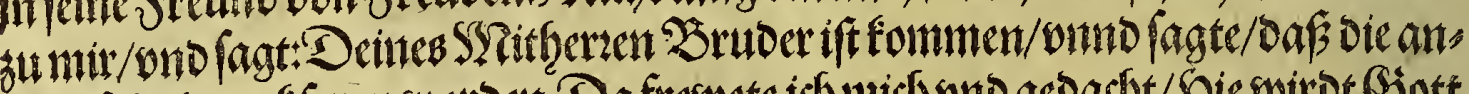

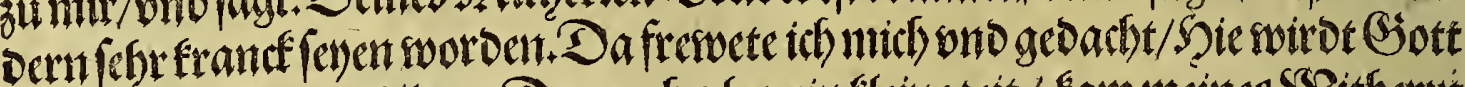

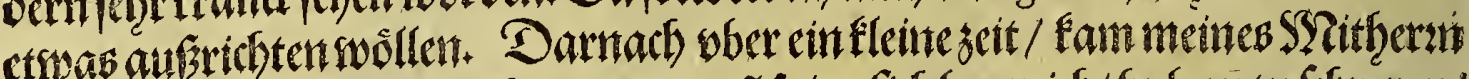

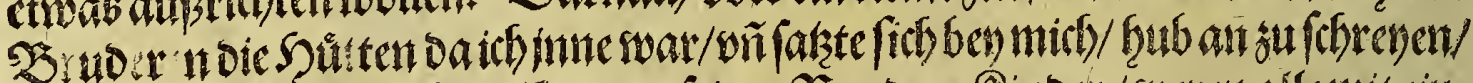

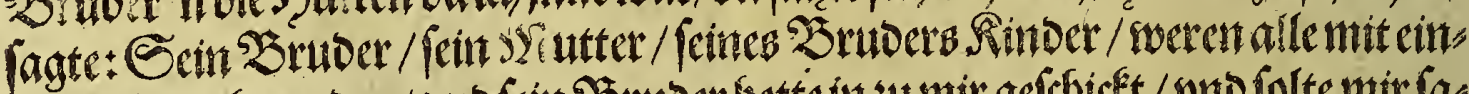

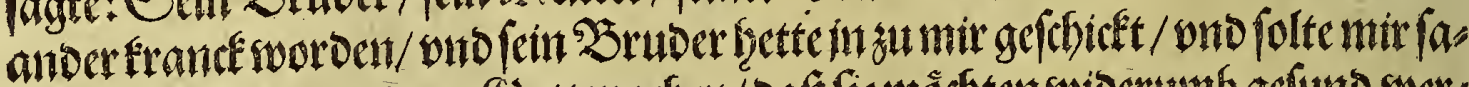

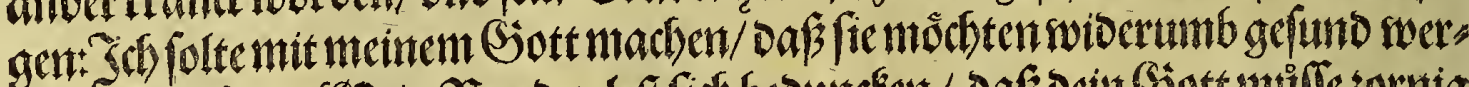

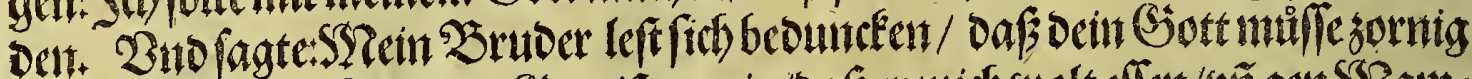

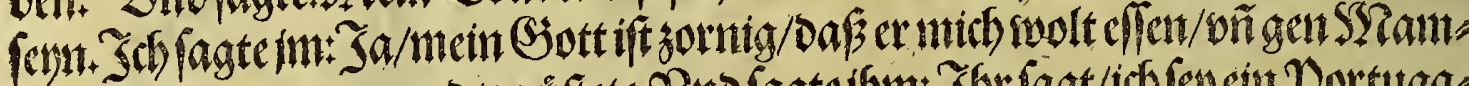

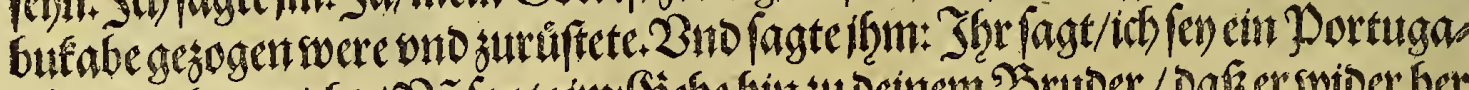

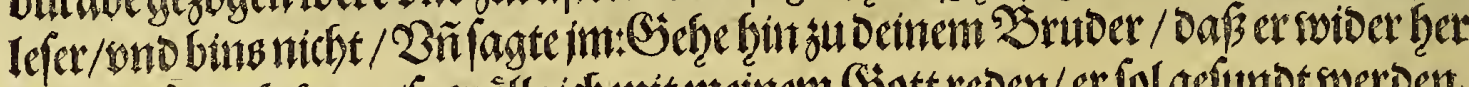

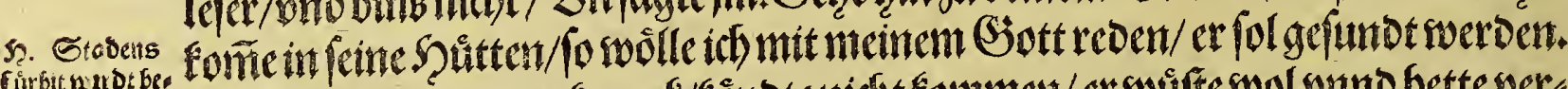

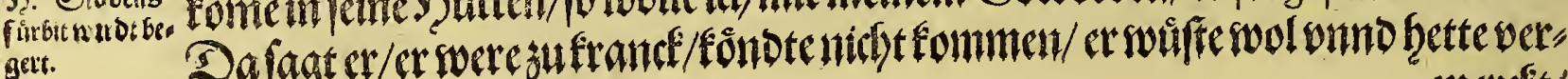




\section{Dasbritte 3 fich. 39}

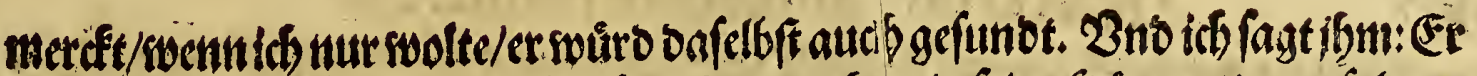

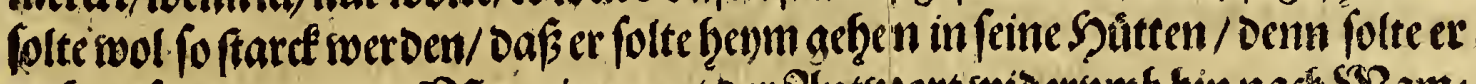

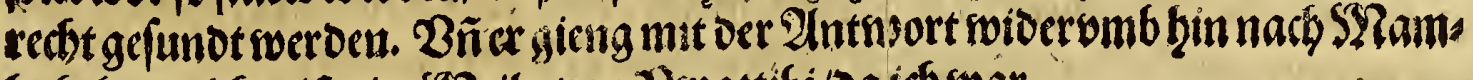

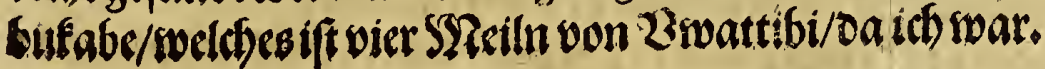

X XXIIII. Sapittel.

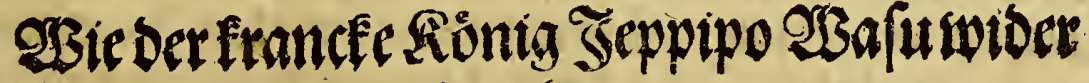
bevmenm.

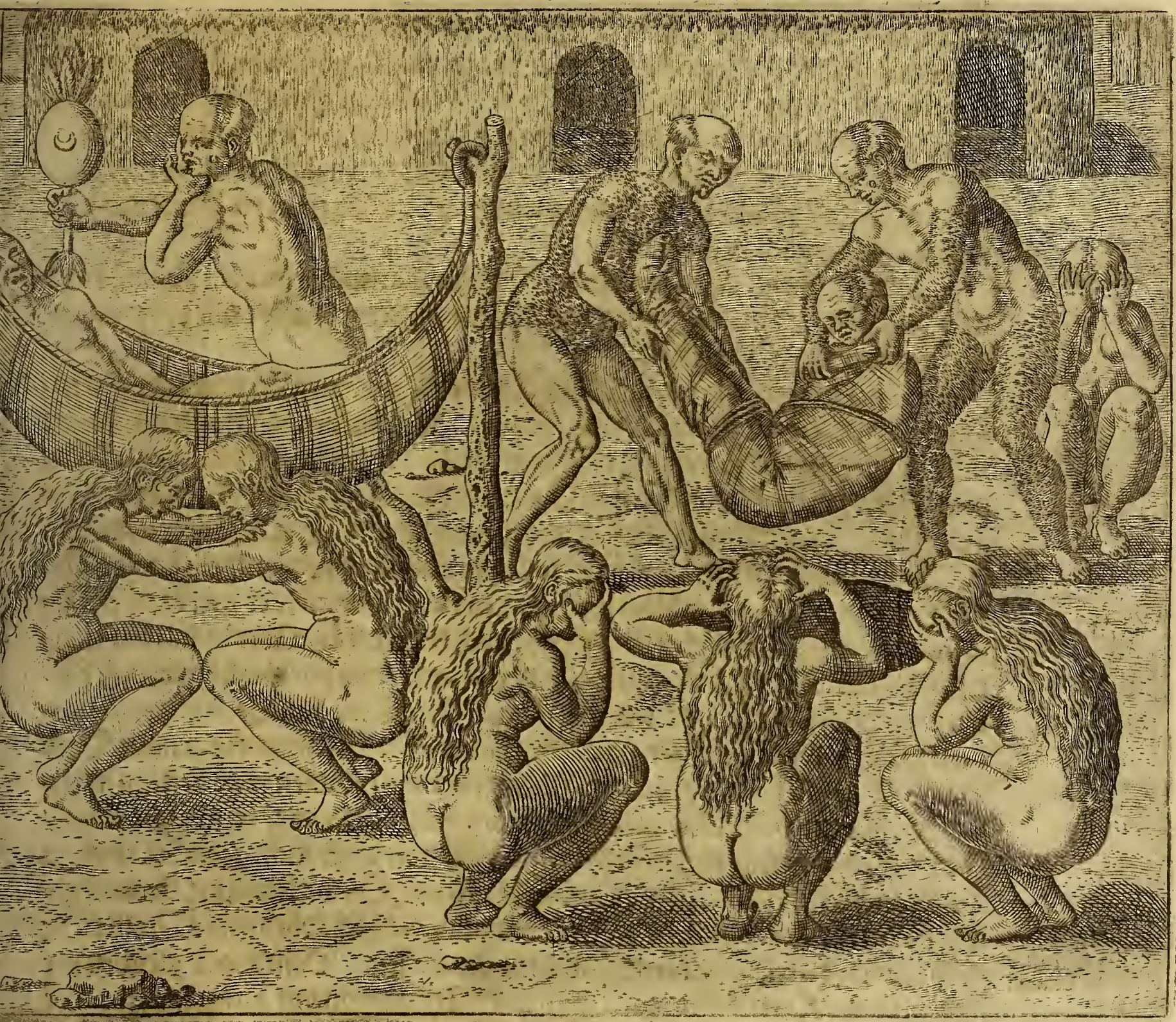

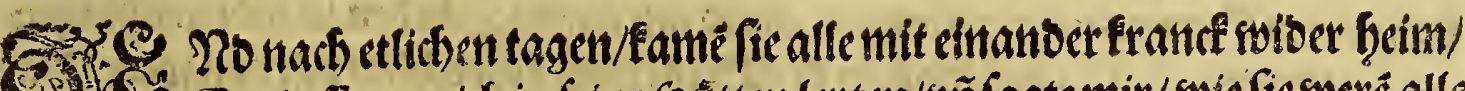

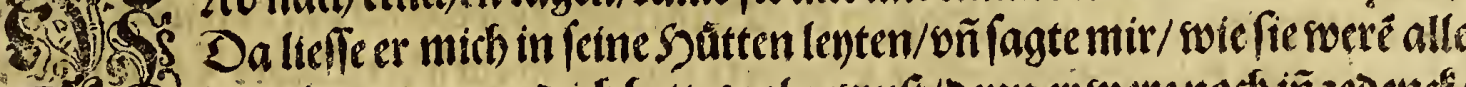
2.

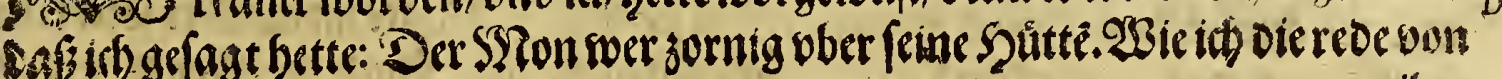




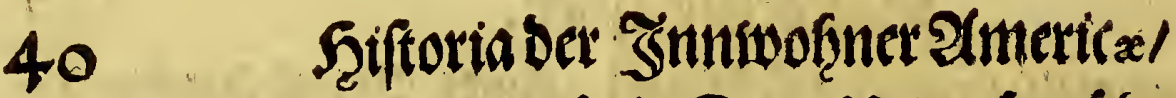

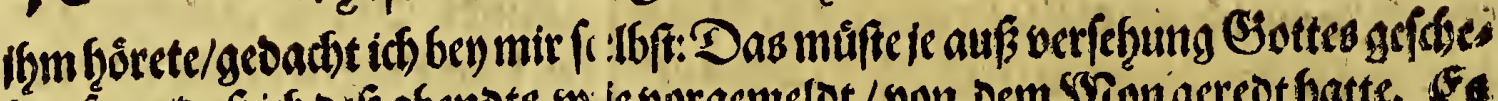

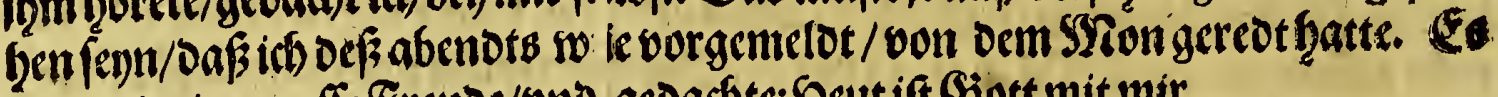
war mir eine groffe Freude/ono ged acfest Sheut if Siott mit mir.

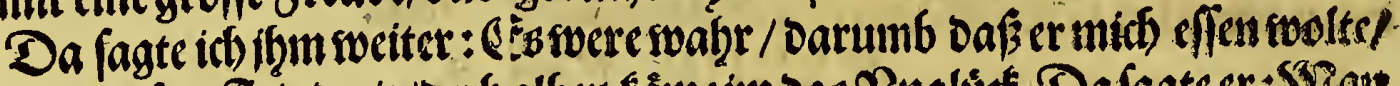

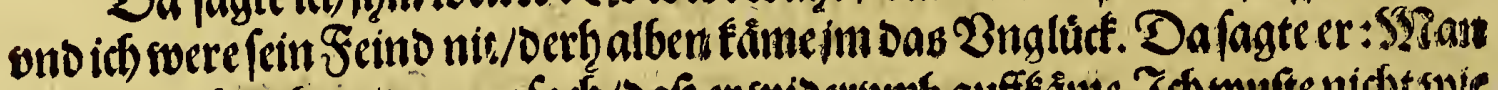

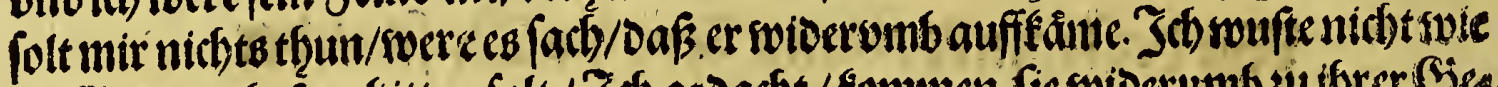

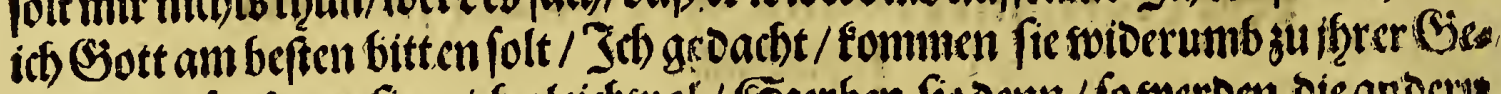

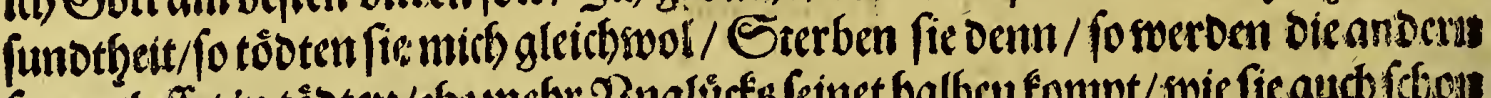

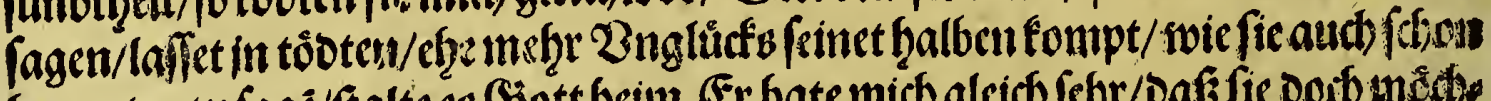

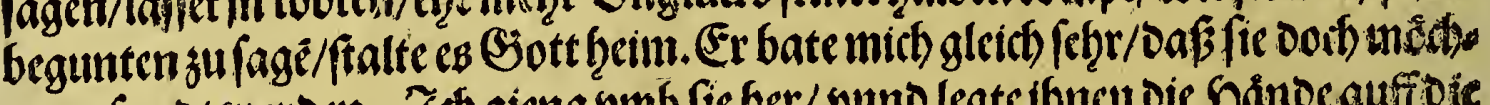

Zirandie

2rienfonen:

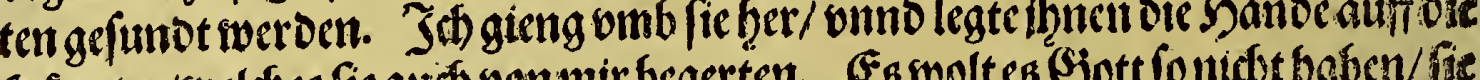

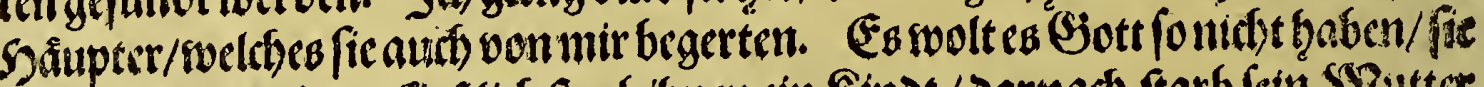

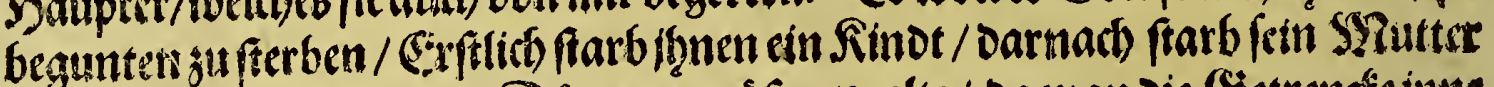

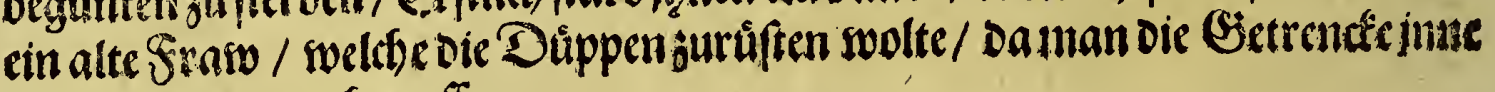
machen ivolte/mitch s'teffen.

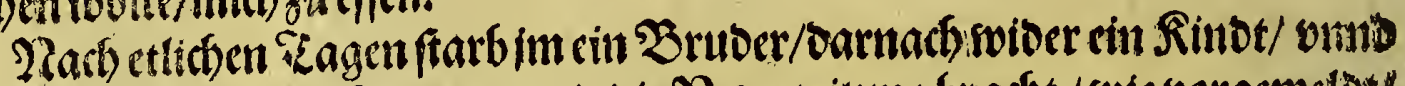

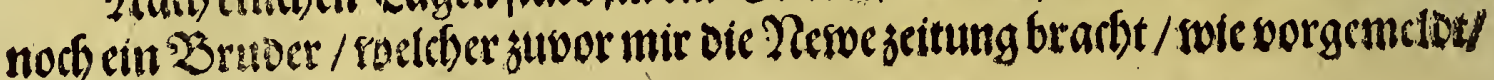
Daff fie frantf werensworden.

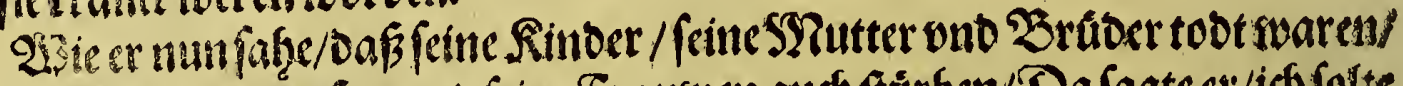

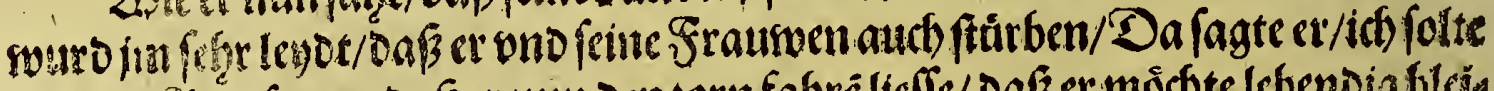

3. Etasen bett.

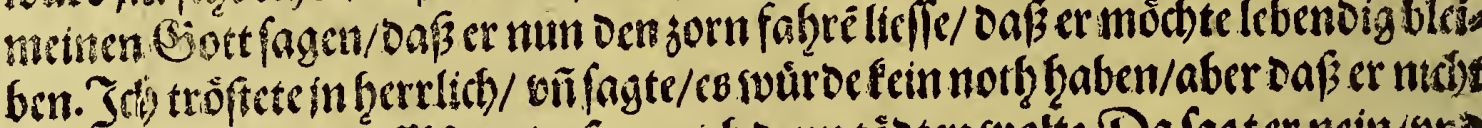

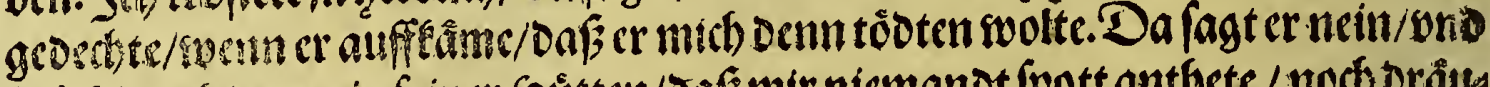

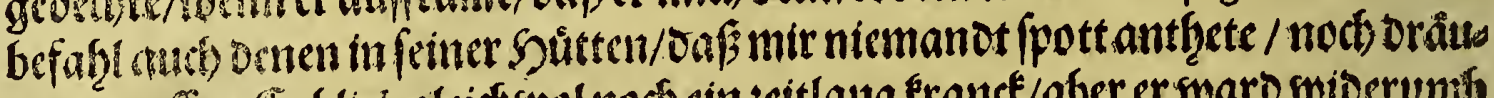

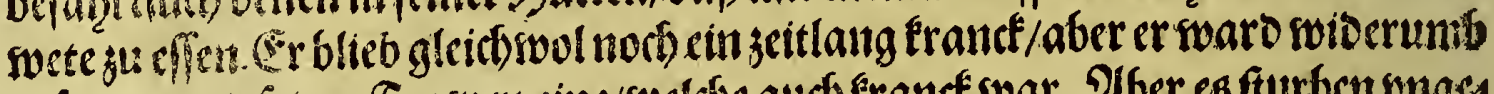

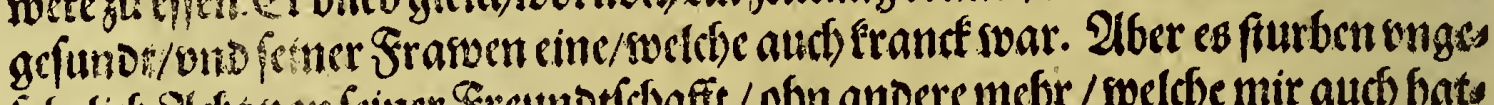

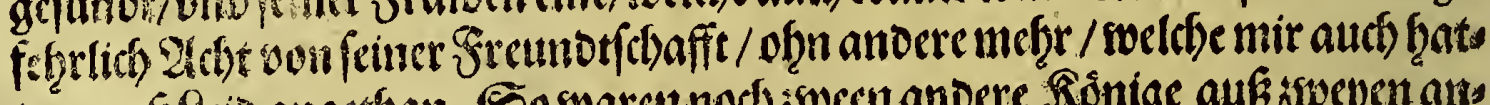

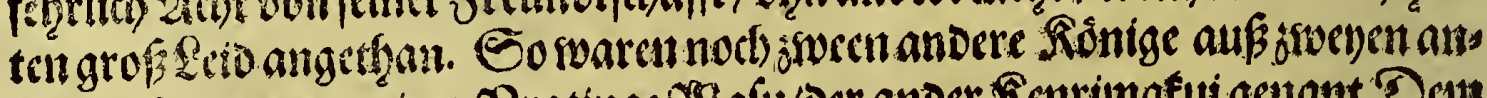

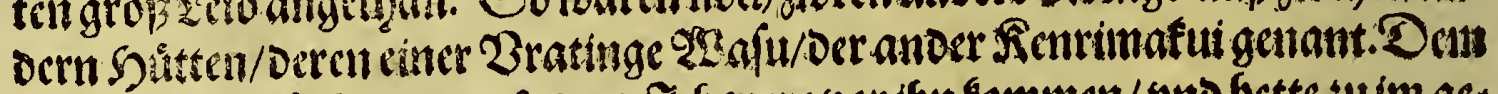

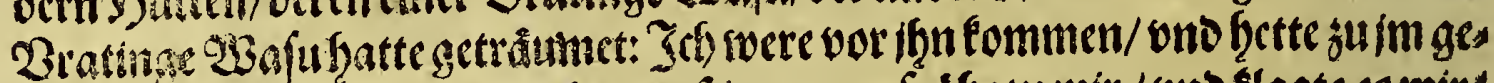

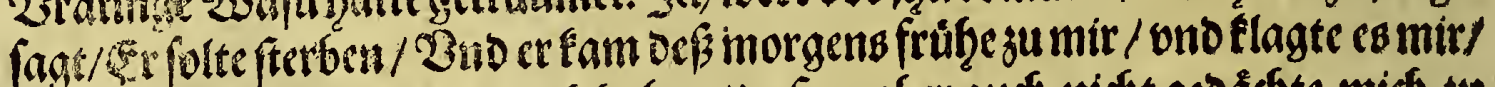

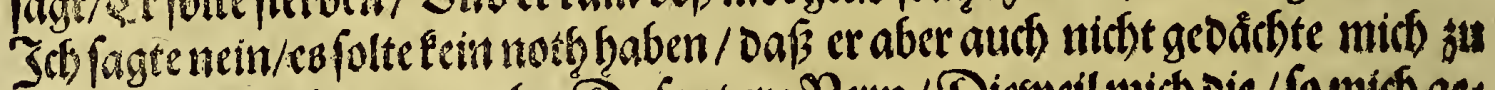

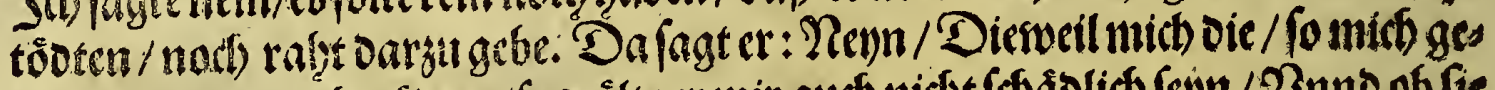

3. Gtiosen

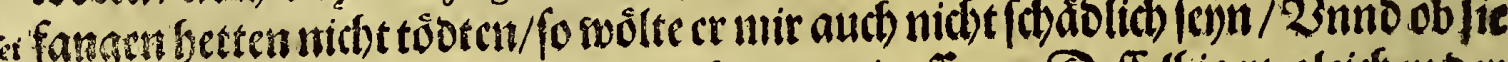

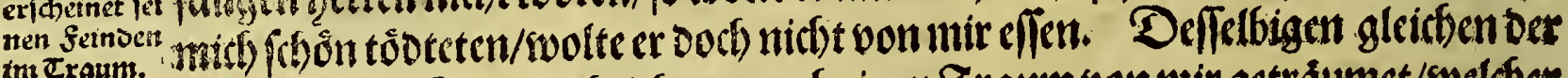

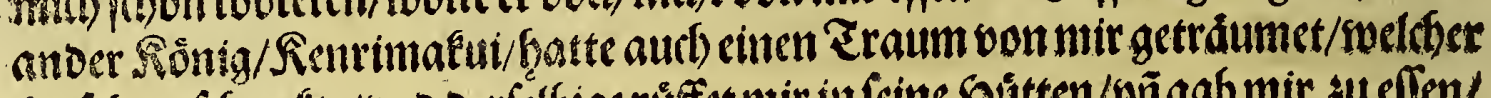

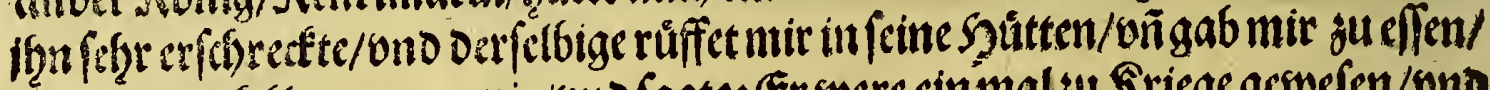

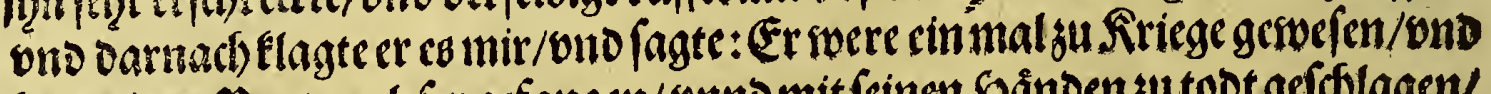

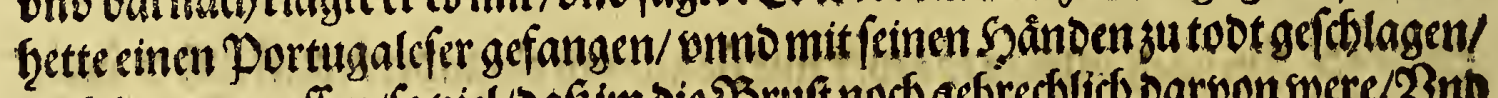

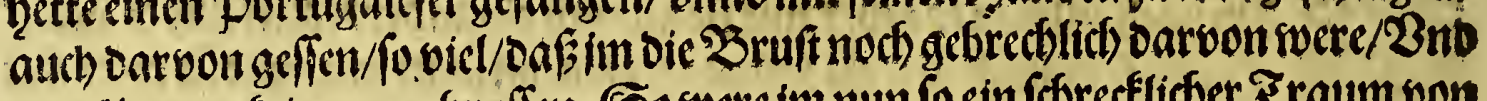

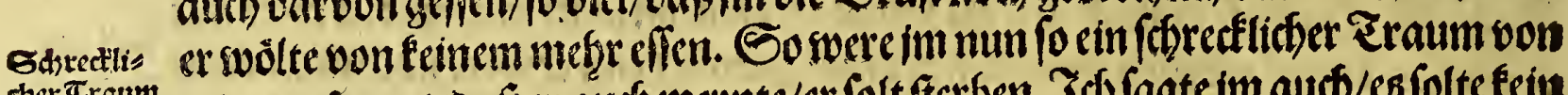

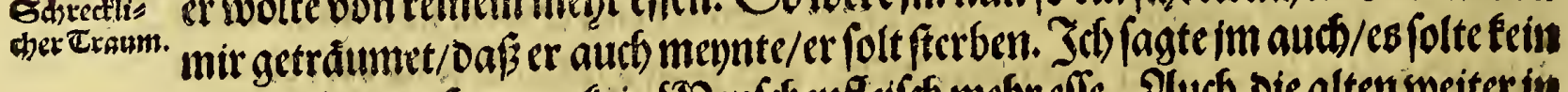

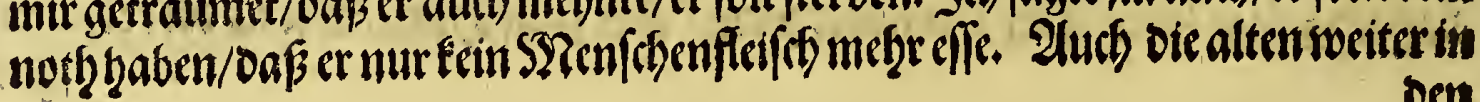




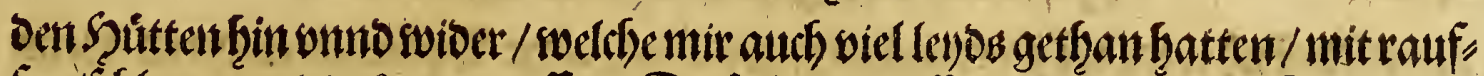

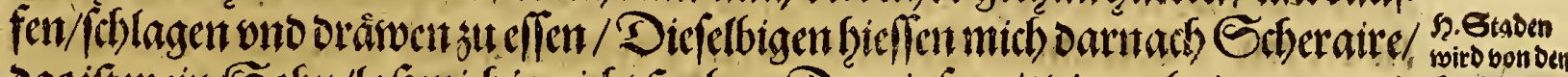

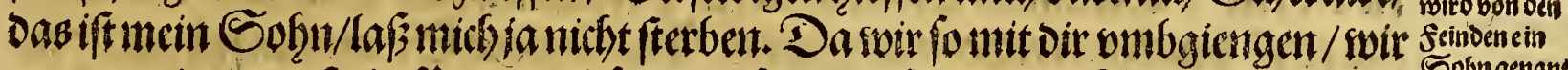

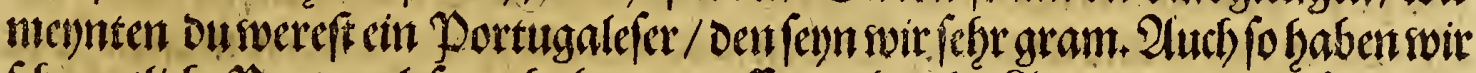

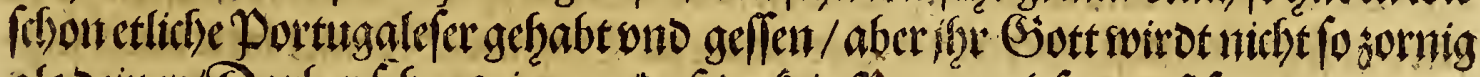

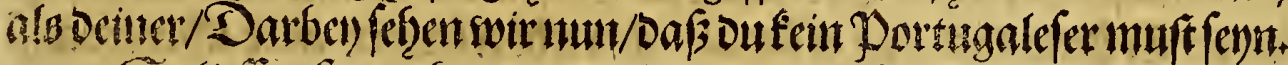

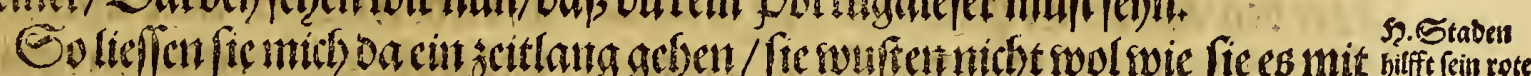

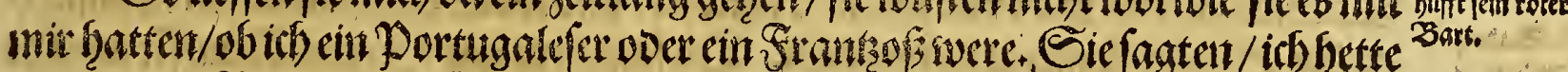

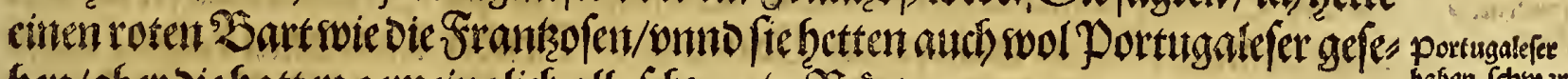
ben/aber bie hatten gemeinglich alle fhhwarke 2 âtte.

Zno nach oenterfftecten/swie oer eine mein Serzanffam/fagten fiemir

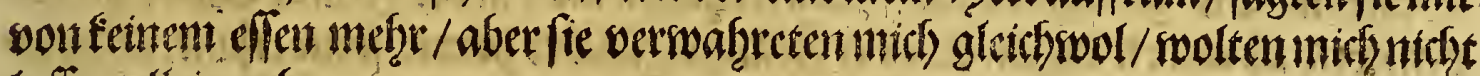
laffen allein gethen.

\section{Sapittel.}

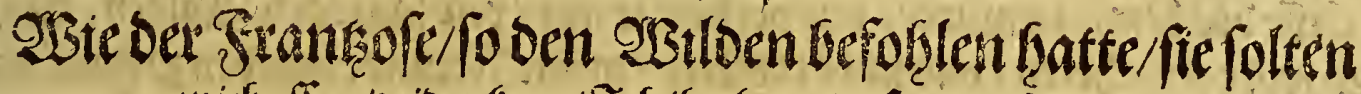

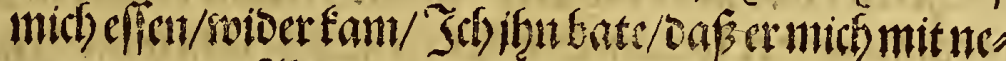

$$
\begin{aligned}
& \text { me/Zber meine Serren mich nicht weriaffen } \\
& \text { bolten. }
\end{aligned}
$$

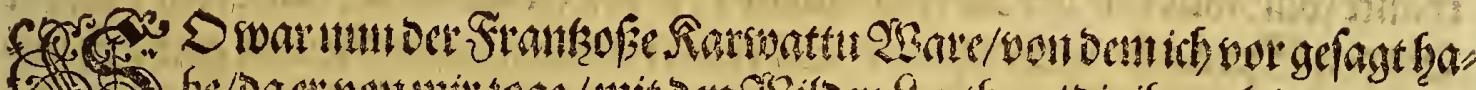

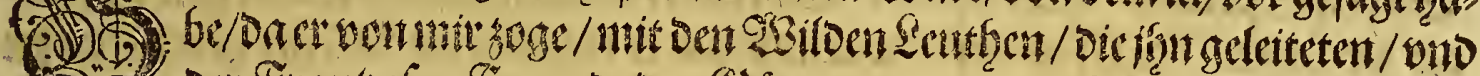

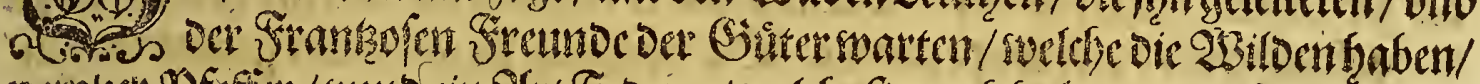

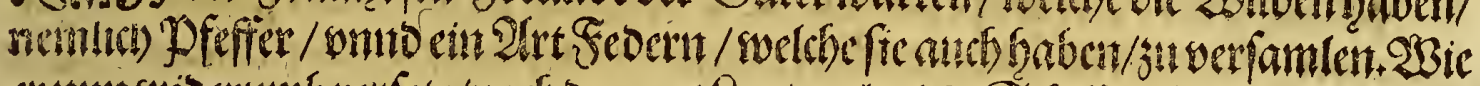

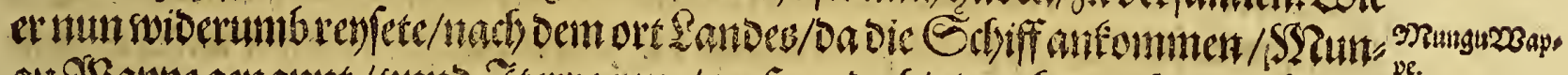

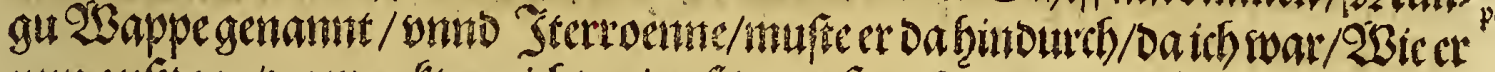

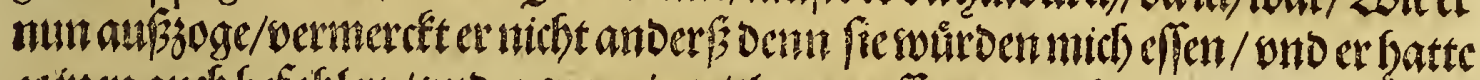

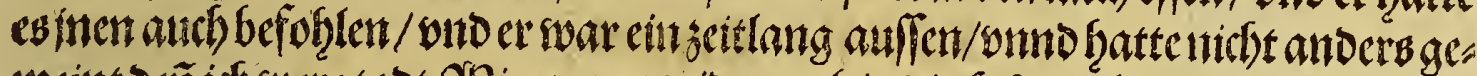

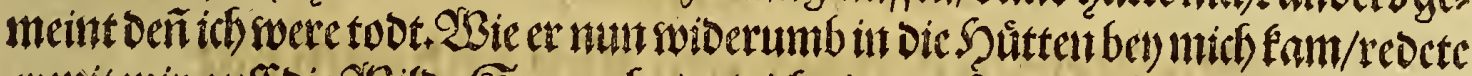

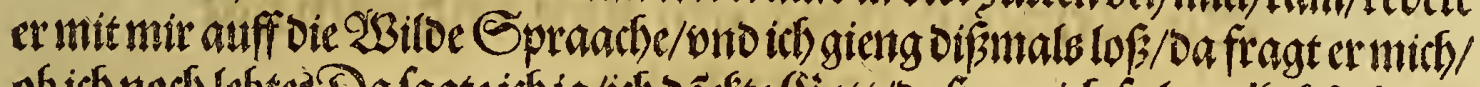

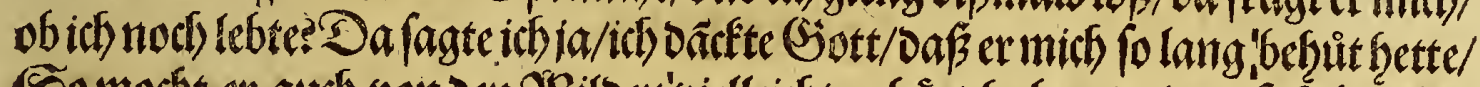

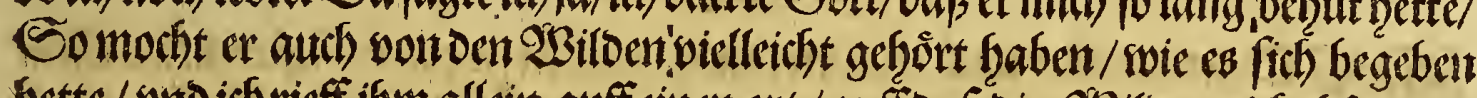

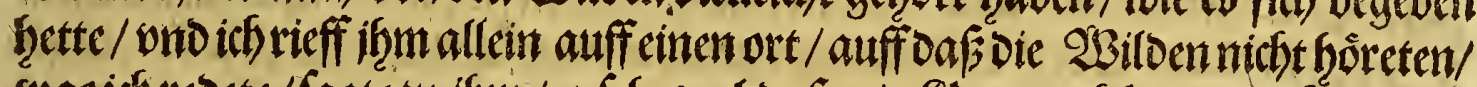

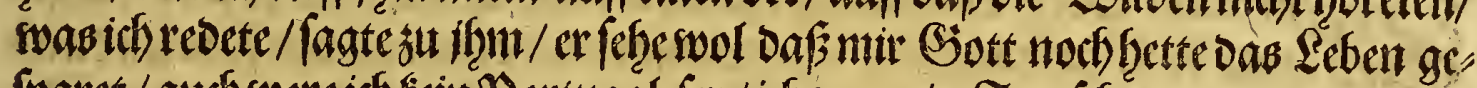

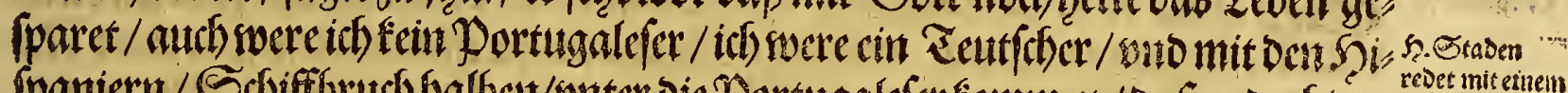

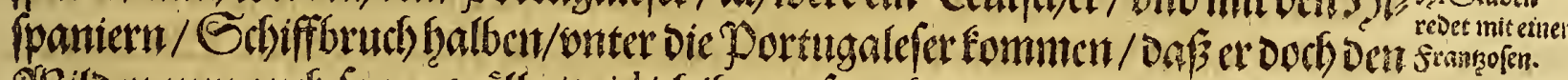

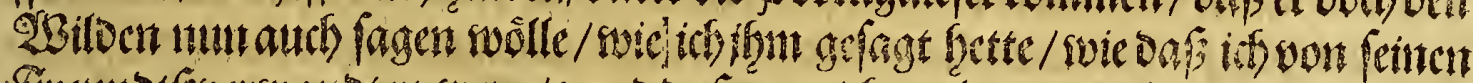

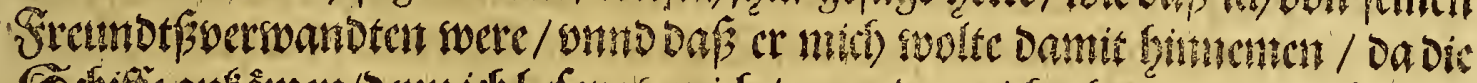

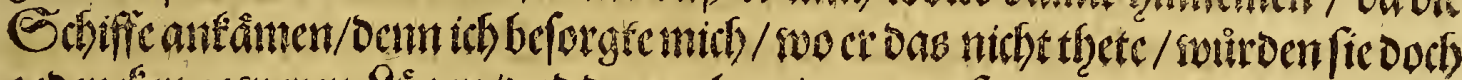

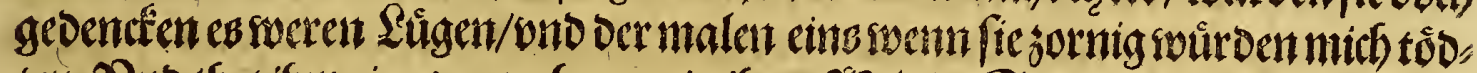

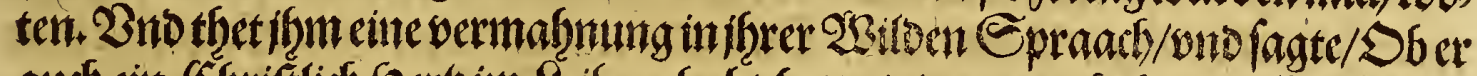

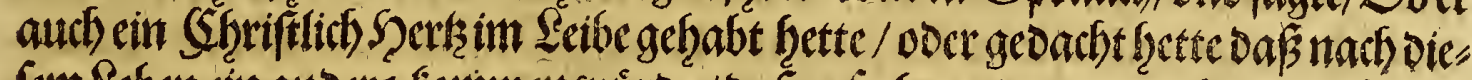

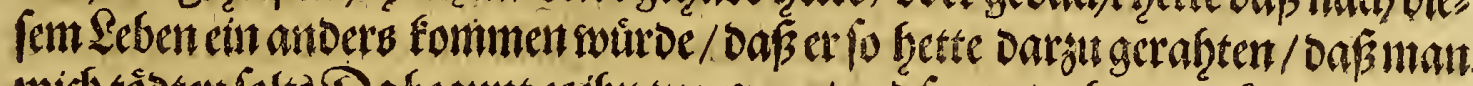

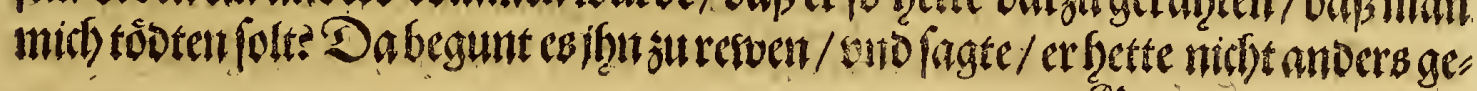




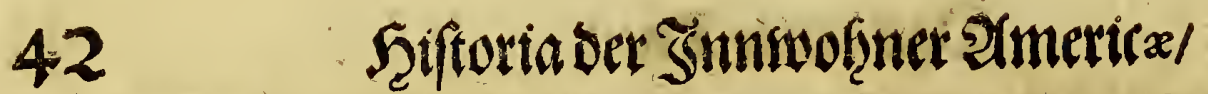

Stantzoletu retroce je⿻上丨 ontrew:

5.Etaben ivirot artes Fictit,

5. Etabenet ofeget troft:

suppicto.

eiaquarippe

Dattaya niti grfeffen. DPenichen bes trindett. zawi.

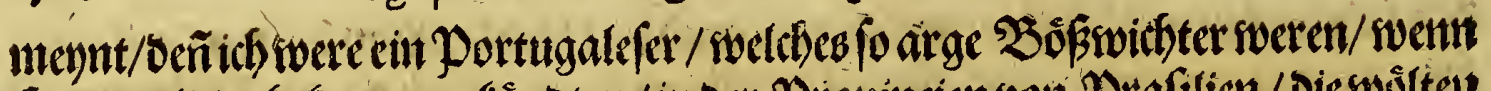
fie Da etli : e befommen fónoten/in or Prouncien oon Prafilien/ Die wosltent

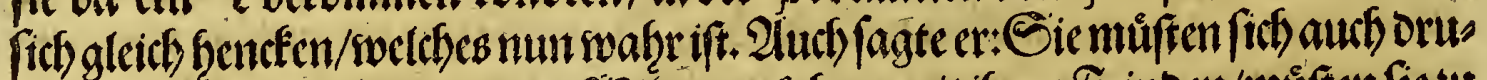

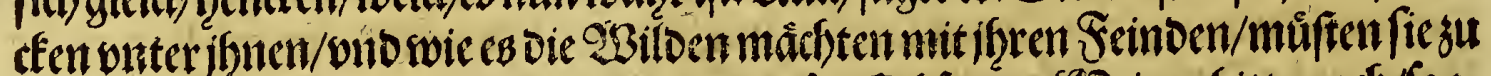

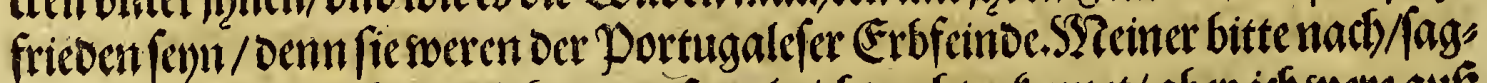

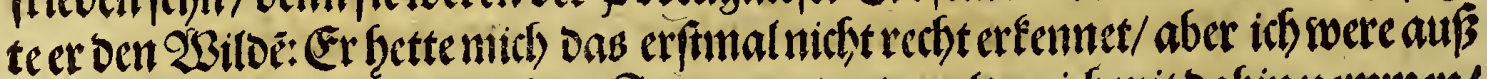
Qllemanien/ond were von/bren Freunoen/ond wolte nich mit bafin nemmen/ Da die Echiffpflegenanjufommen. Pafagtenmeine Serren:Rein/fie woltent mitis niemano laflen/mein engen Batter oder $\mathfrak{B}$ ruber fame oenn Dabin/ onno

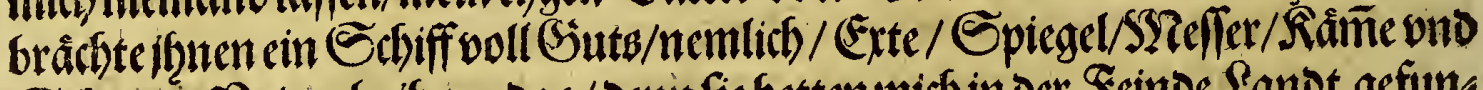

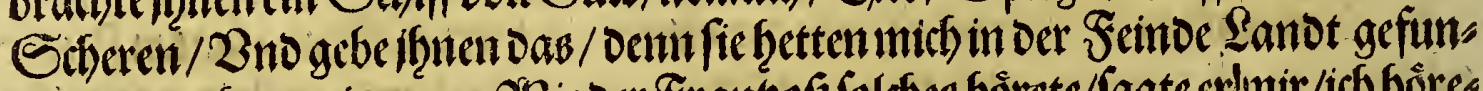

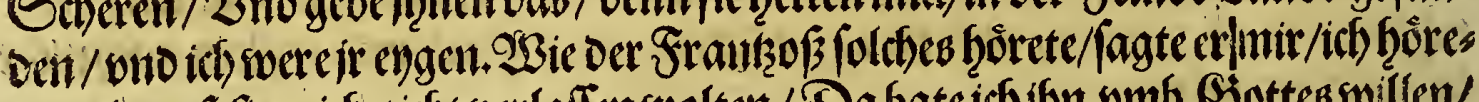

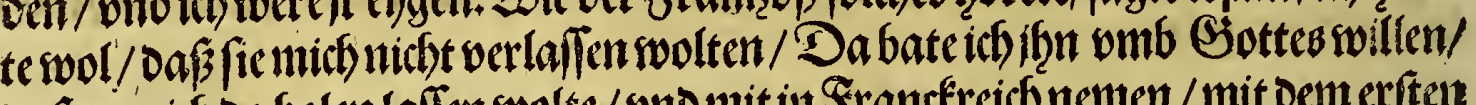

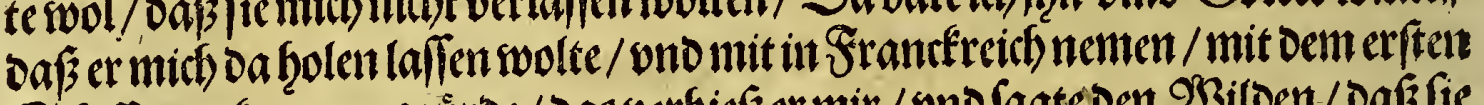

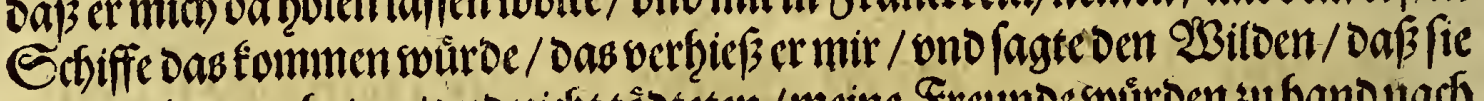

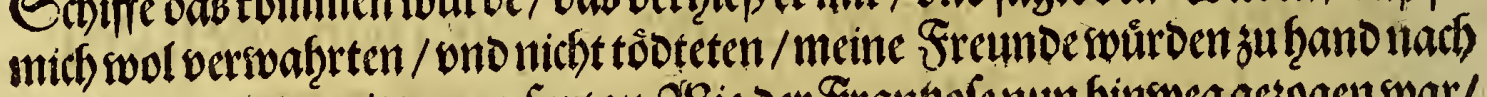

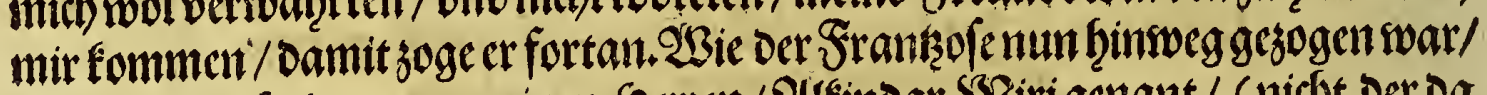
Da fragte mich ciner vonmeinen Serzen / Qlféndar \$Siri genant / (nicb) Der Da

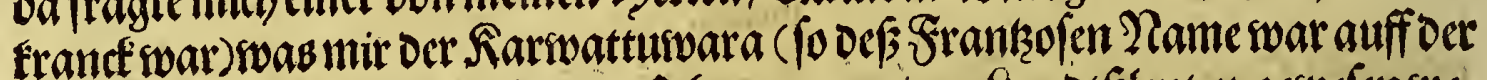

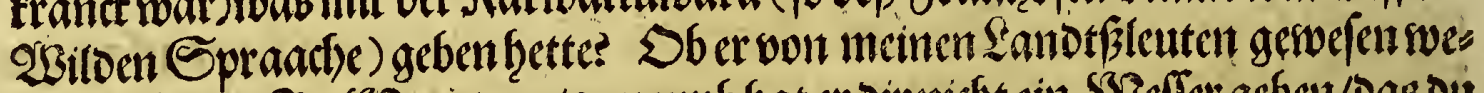

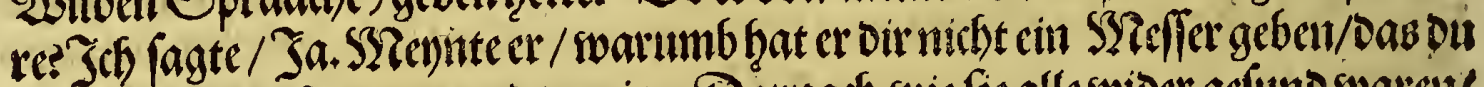
mir gebent betteft/ono swurd sornig. Darnadb wie fic alle swider gefuno waten/ begundern fie widerumb ober mich jumurneln/ono jagten onter einander. Die

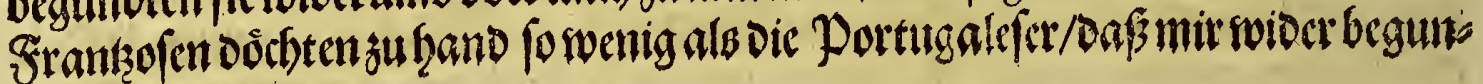
telendo zlt fueroch.

\section{Sapittel.

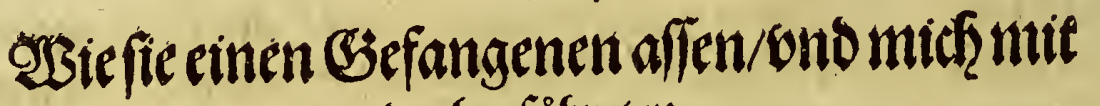 Darbey fiufreten.}

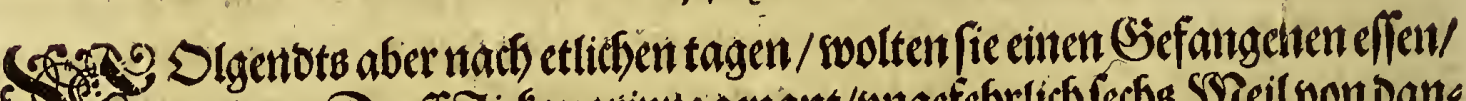
a)

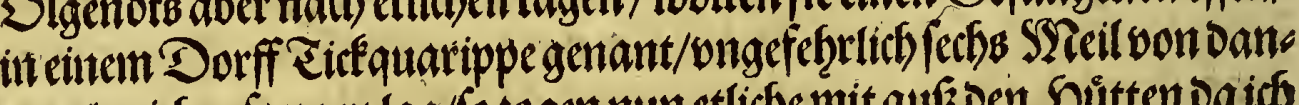

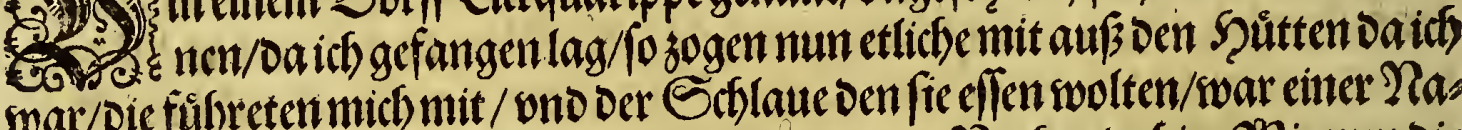

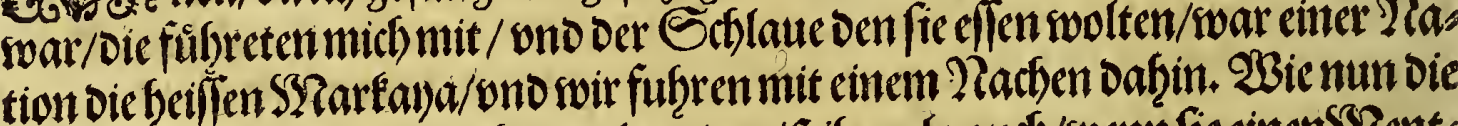

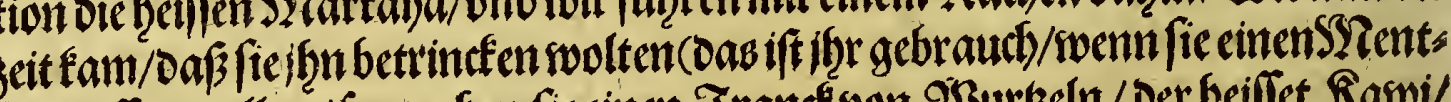

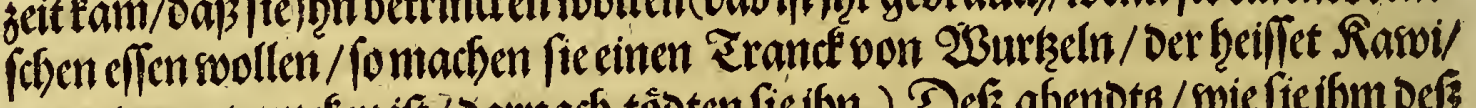

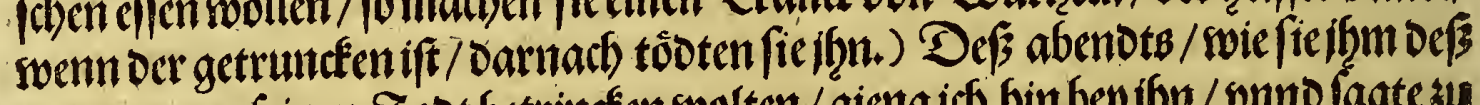

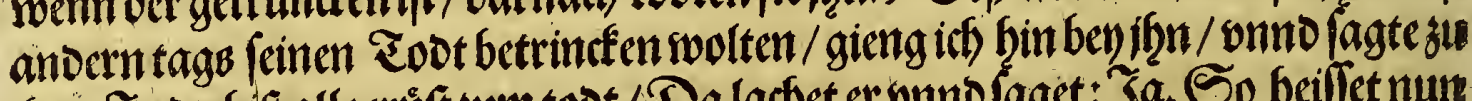

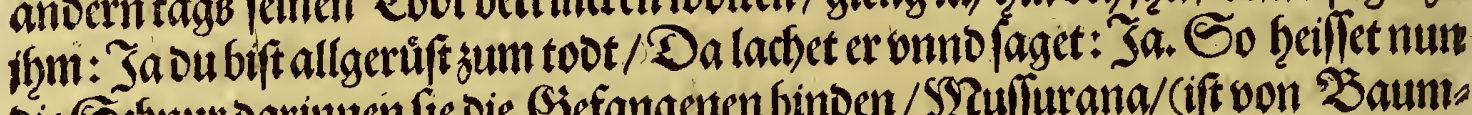

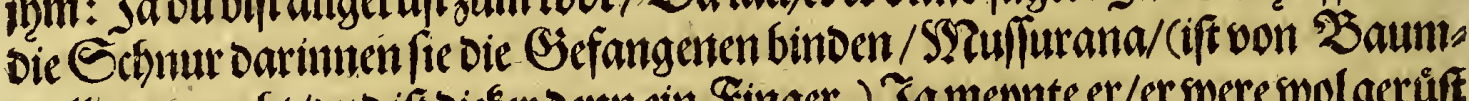

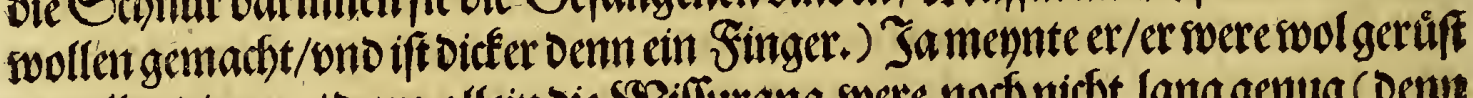
unit allen bingen/ Denn alleit bie S?iffurana soere noch nicht lang genug (Denn $\mathfrak{e d ~ f c h t s ~}$ 


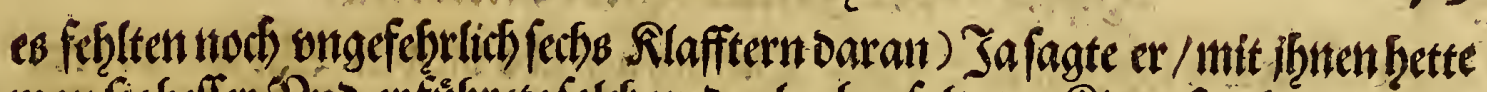
manfie beller. Bno er fübrete folche rede als ob er folte zur Rirme

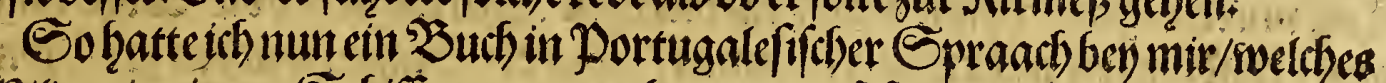

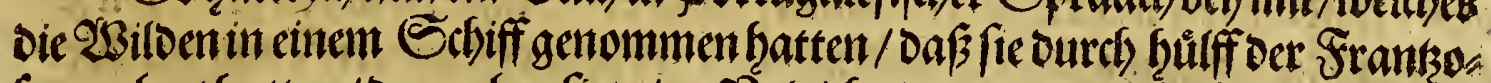
fen erobert batten/Das gaben/iemir. Zno ich gieng won oem Siefangenen/lafe

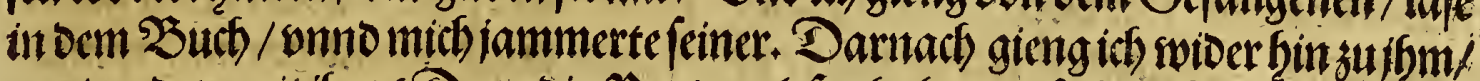
vnto redete mit ffin ( Dent bie Portugalefer haben oiefelbige Art syiarfayal

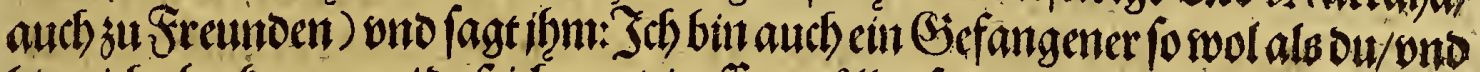

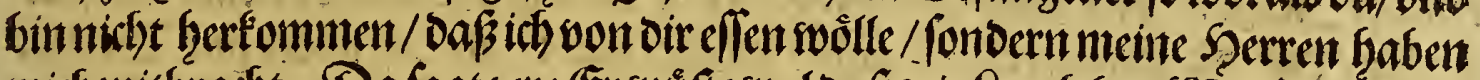

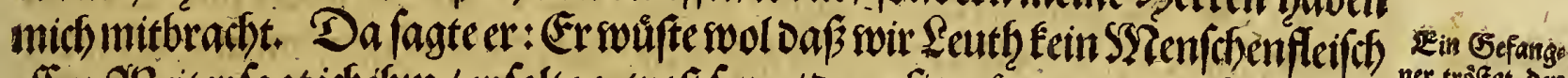

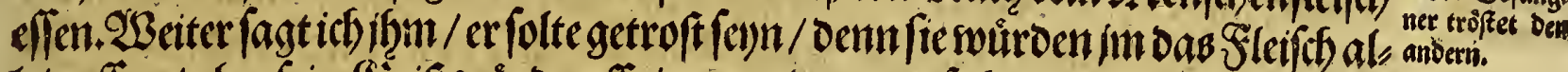

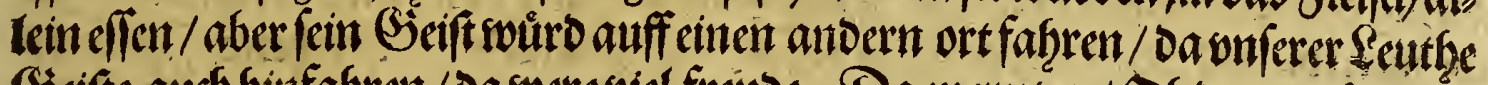

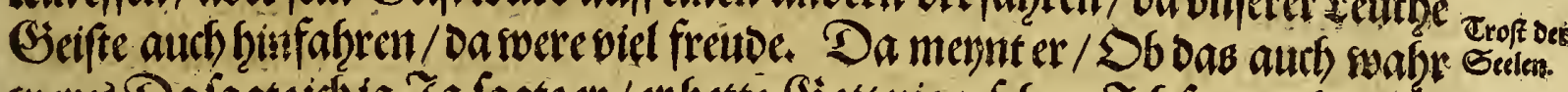

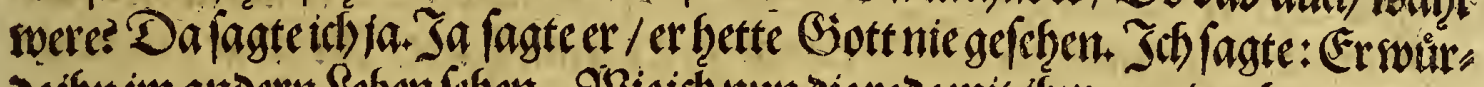

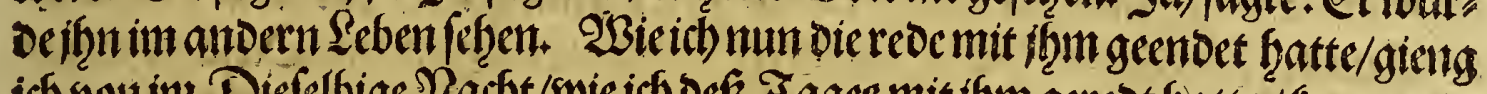

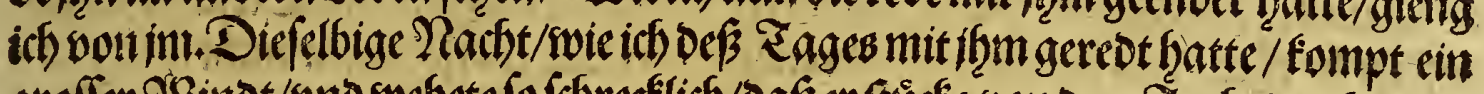

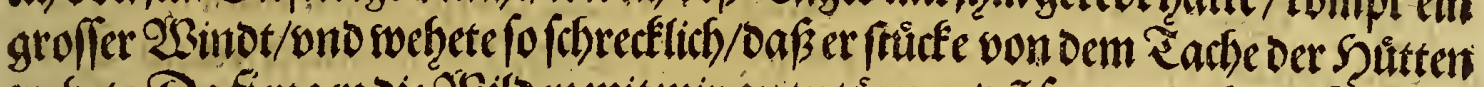

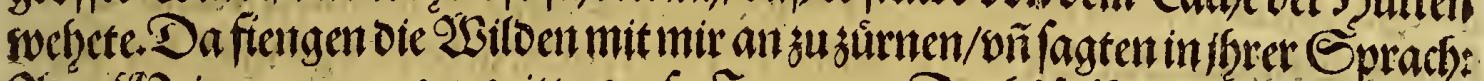

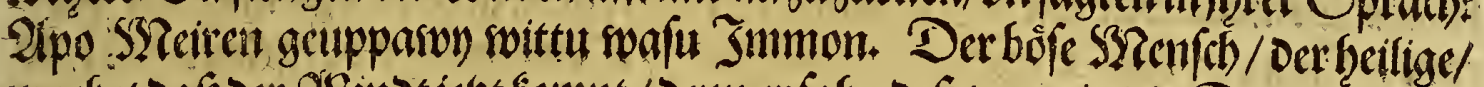

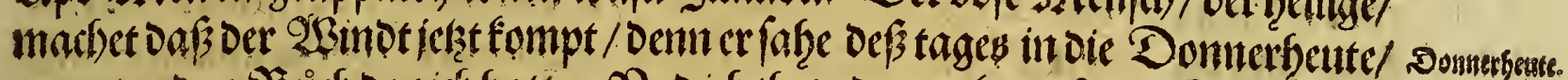

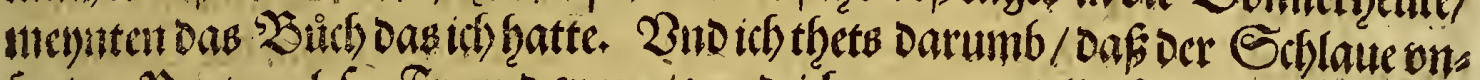

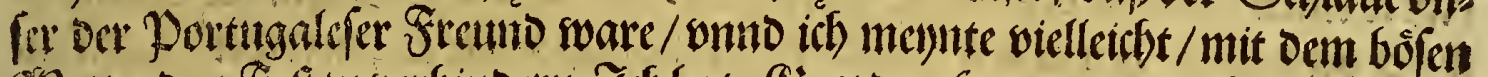

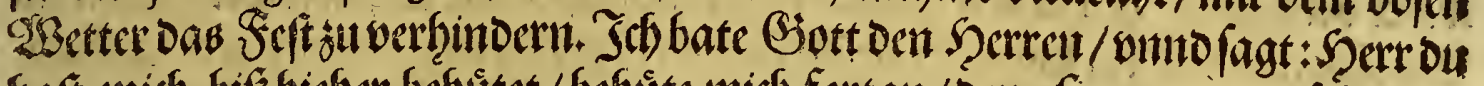

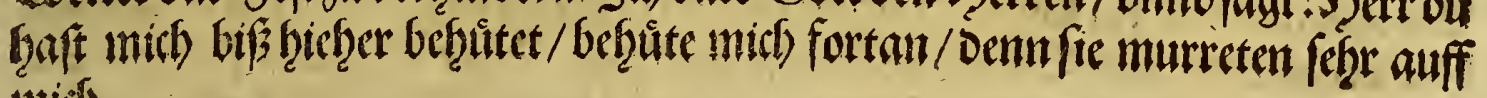
(nition.

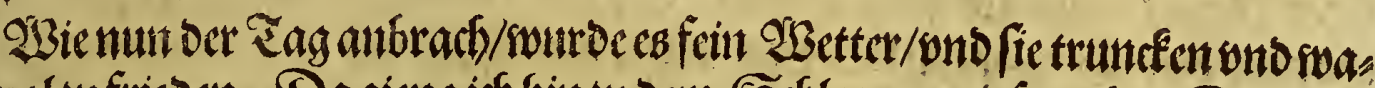

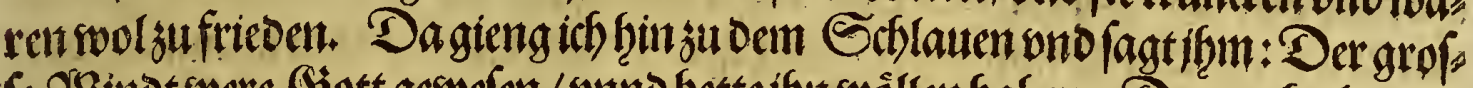

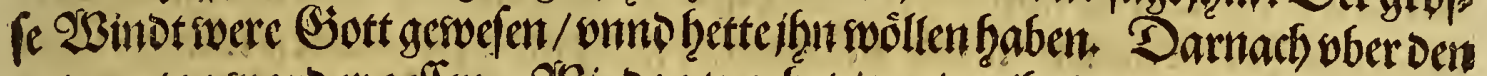
andern tag warder geflen. QSie das sugebet/swerdet ifgr in ben bimberfen Sa pitelnfinden.

\section{Sapittel. Wag fith begabe auff bem henmzuge/wic fie ben geffen batten.}

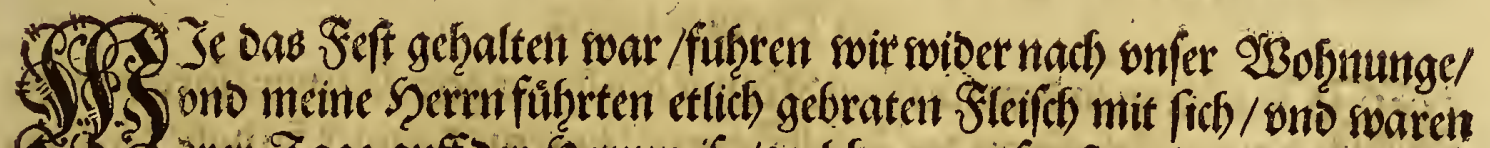

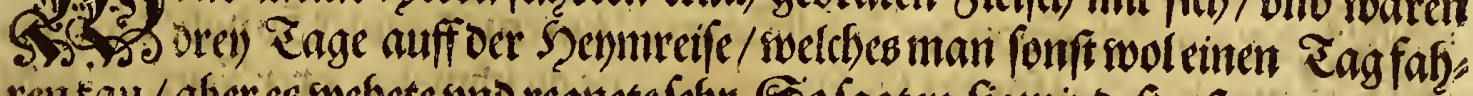

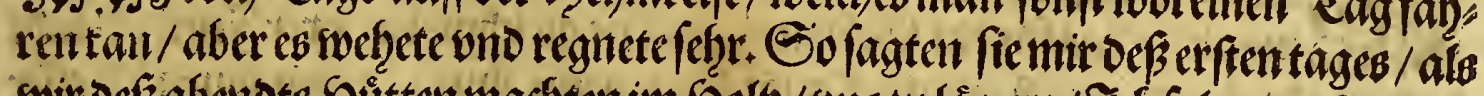

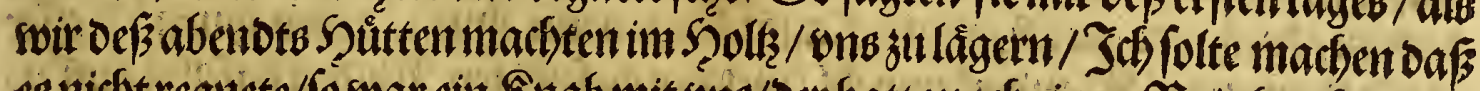

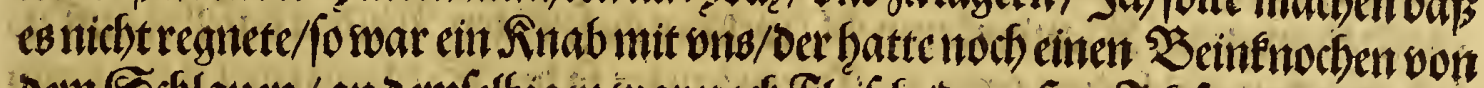

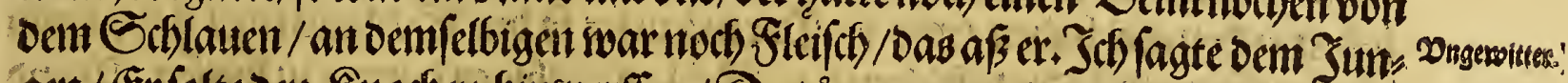

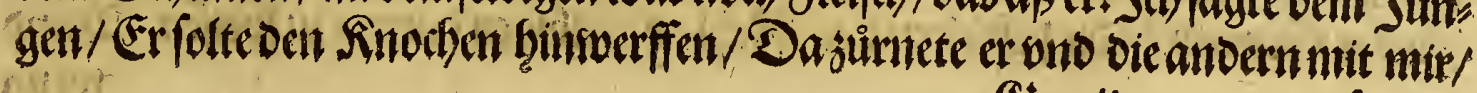

(S) if fagten: 


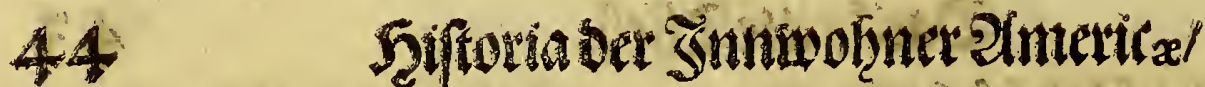

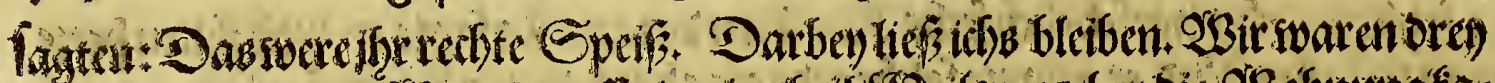

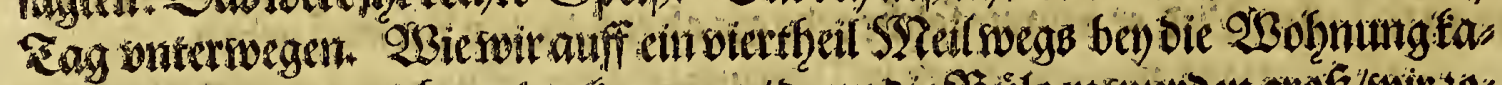

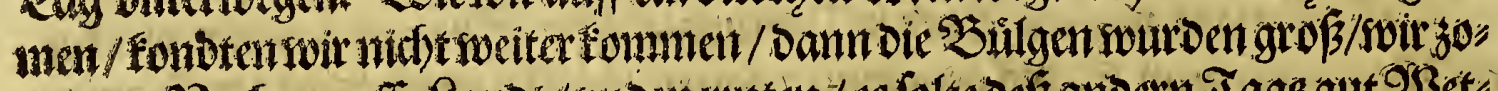

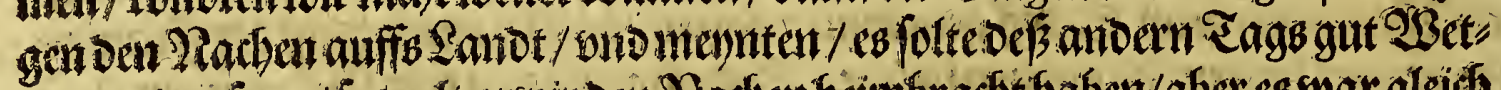

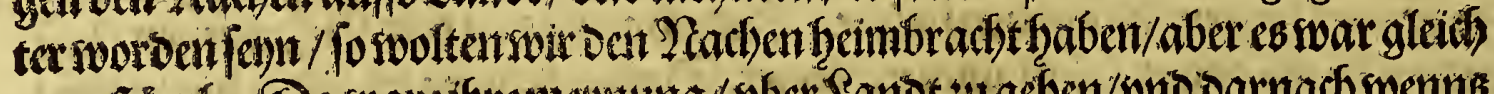

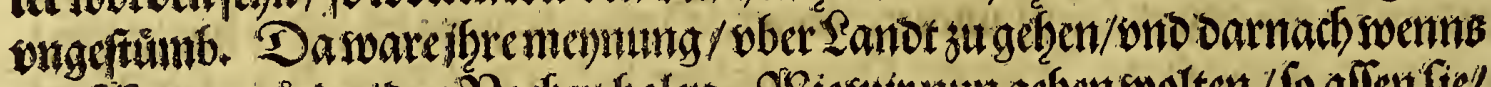

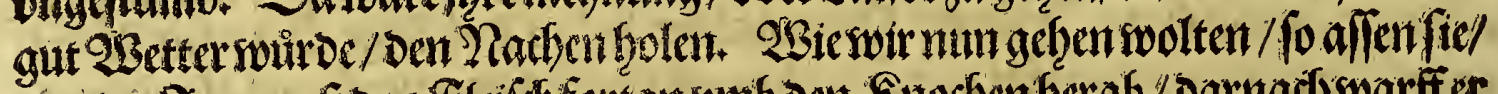

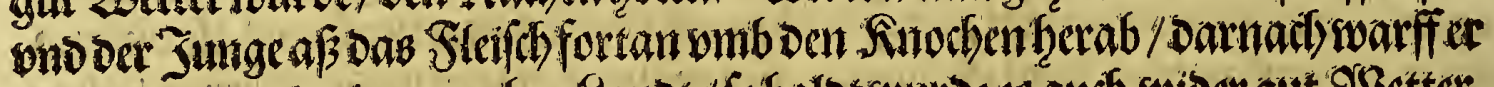

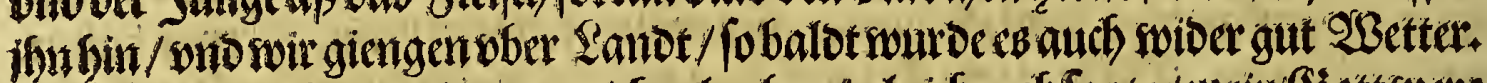

Drfactices;

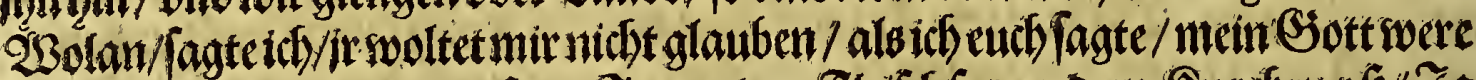

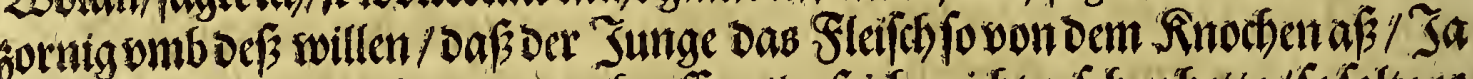

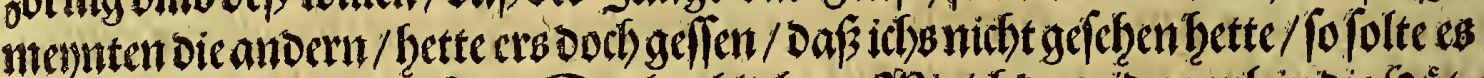

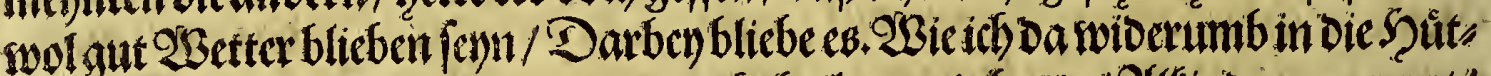
ten fan/oa fragte micb oer eine/oer aud) theil annit batte / A(finbar genannt/

amenediens frefferer.

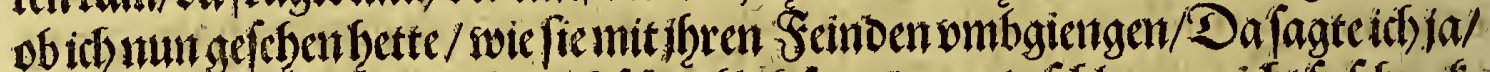

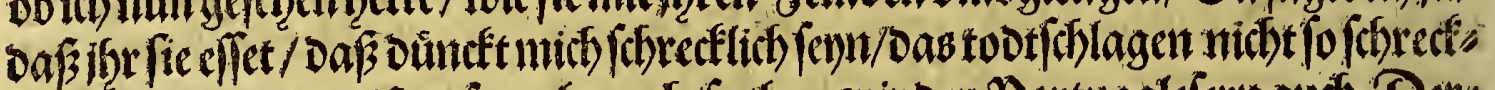

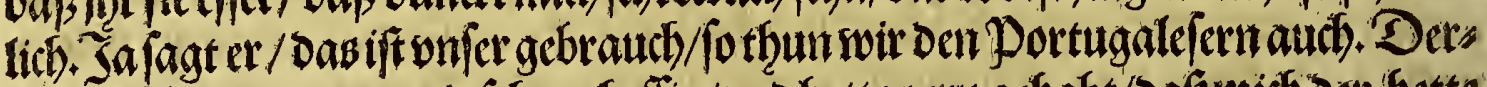

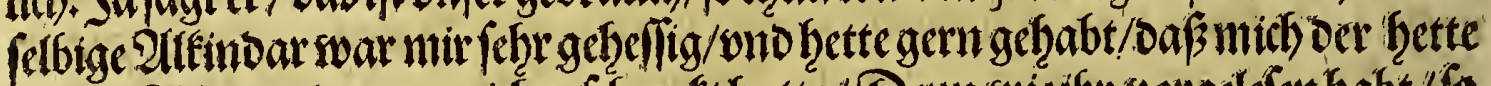

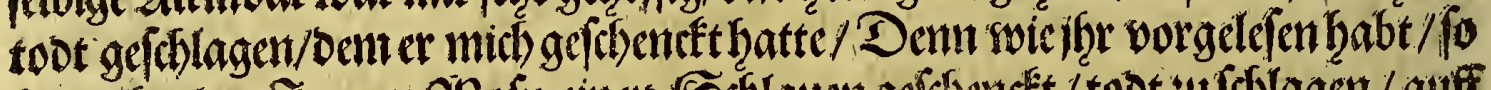

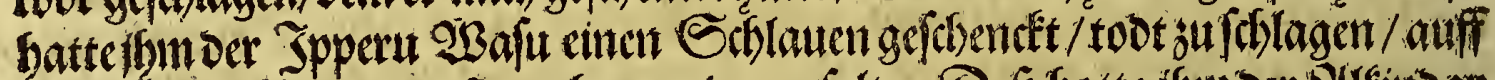

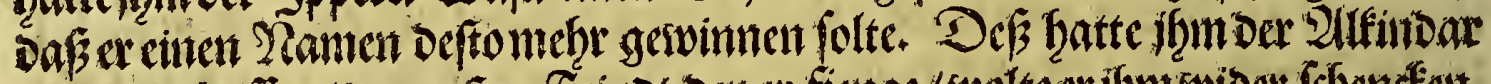

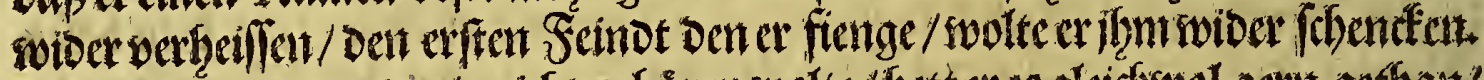

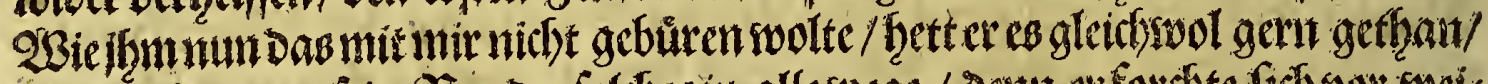

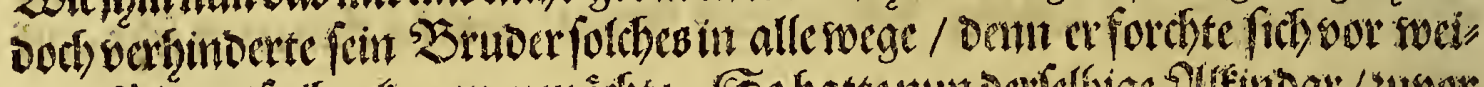

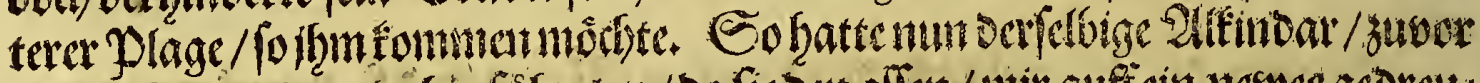

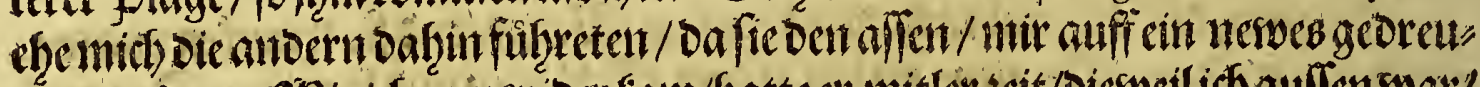

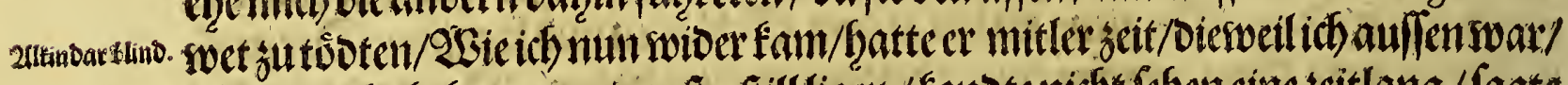

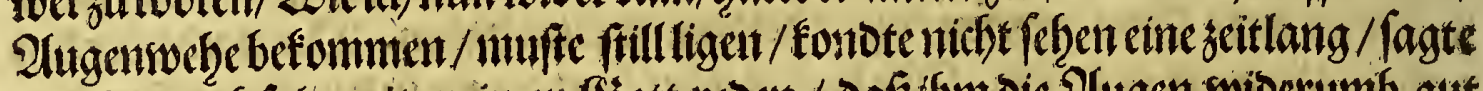
mirftetb/ith foltemit meinem (Sott reden / o a f flom oie 2lugen swiberumb gut

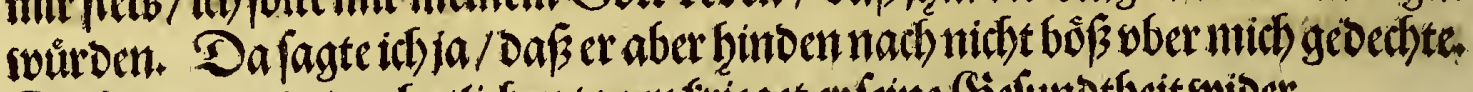
Da fagte ermein/nachetlidbent tagen frieget er feine Gejund theit woider.

\section{VIII. Sapittel.}

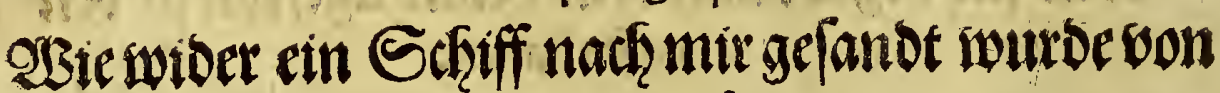
oen Portugalefern.

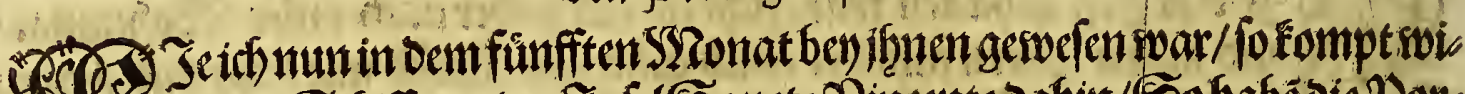

poturgalefer holen Diand. (5)

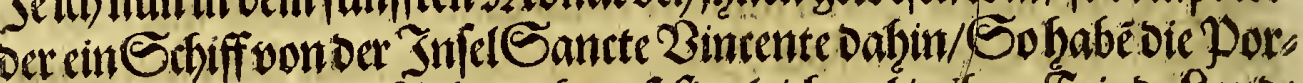

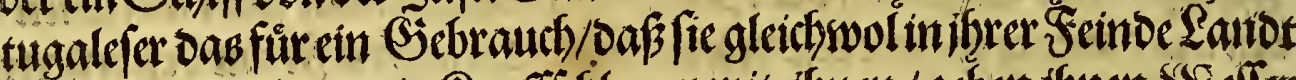

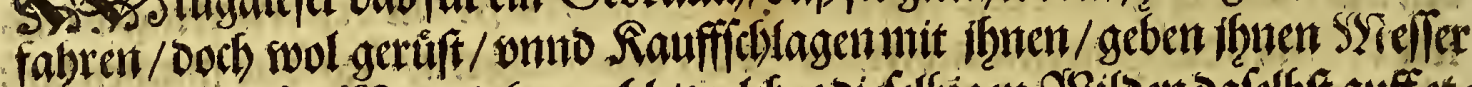

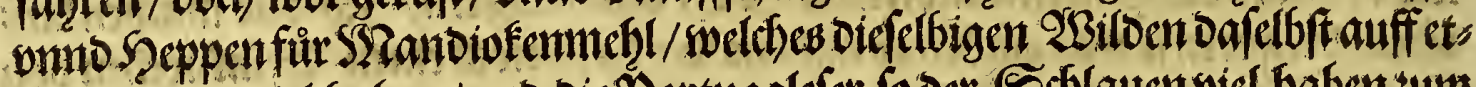
lieben enoen vid haben/who bie Portugalefer fo oer Galauenviel baben \%um

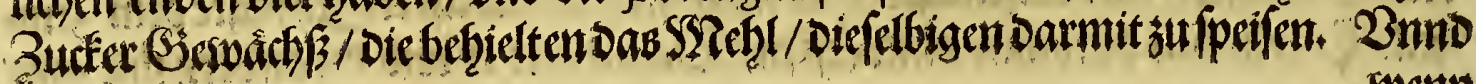




\section{Dasbritte Theil.}

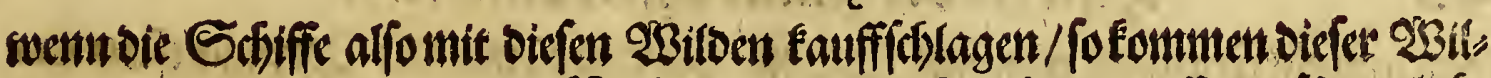

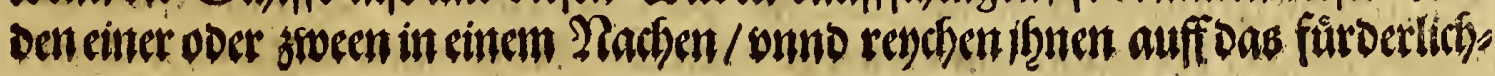

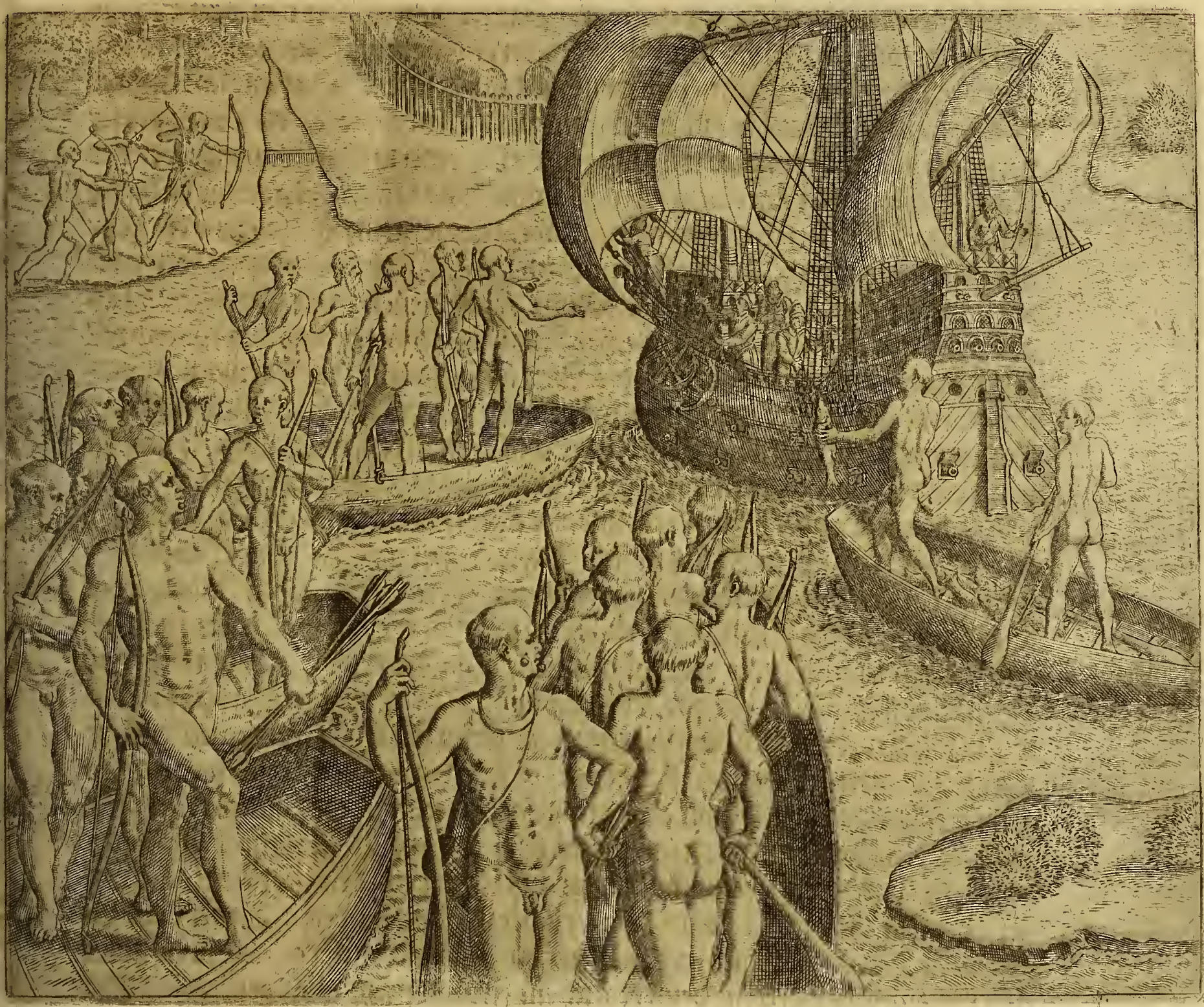

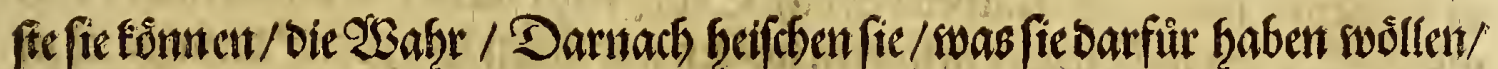
Das gebentfinen bent die Portugalefer. Diesweil aber bie siveen ben Dem Selsiff

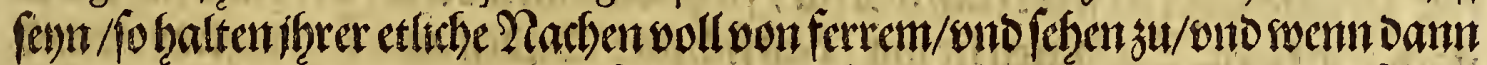

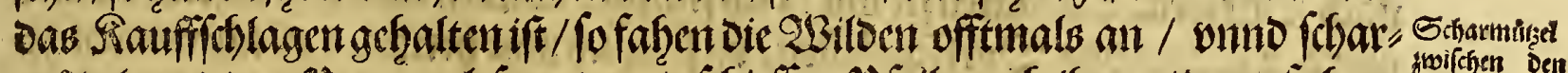

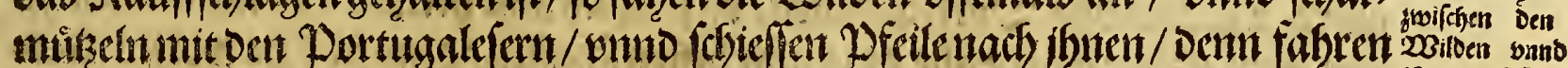

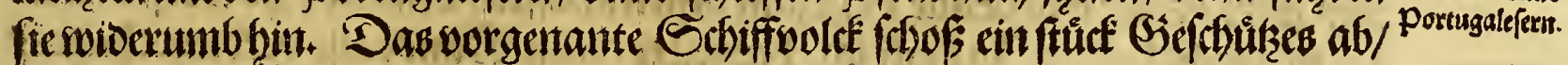

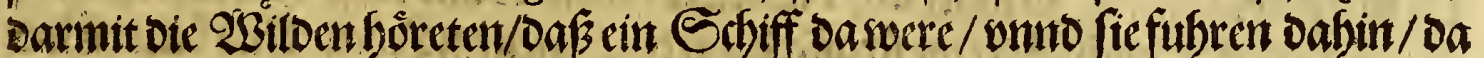

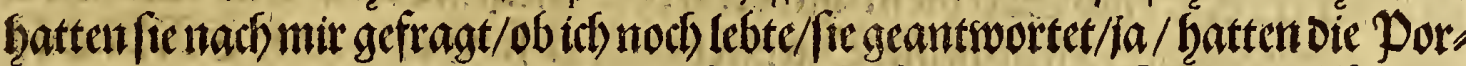

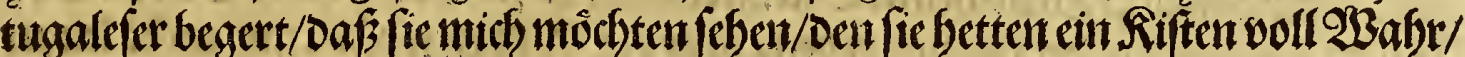

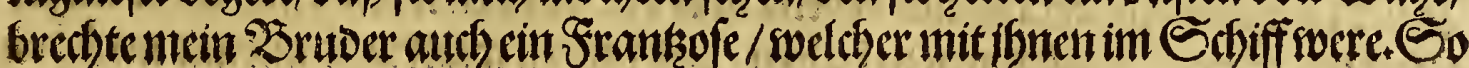




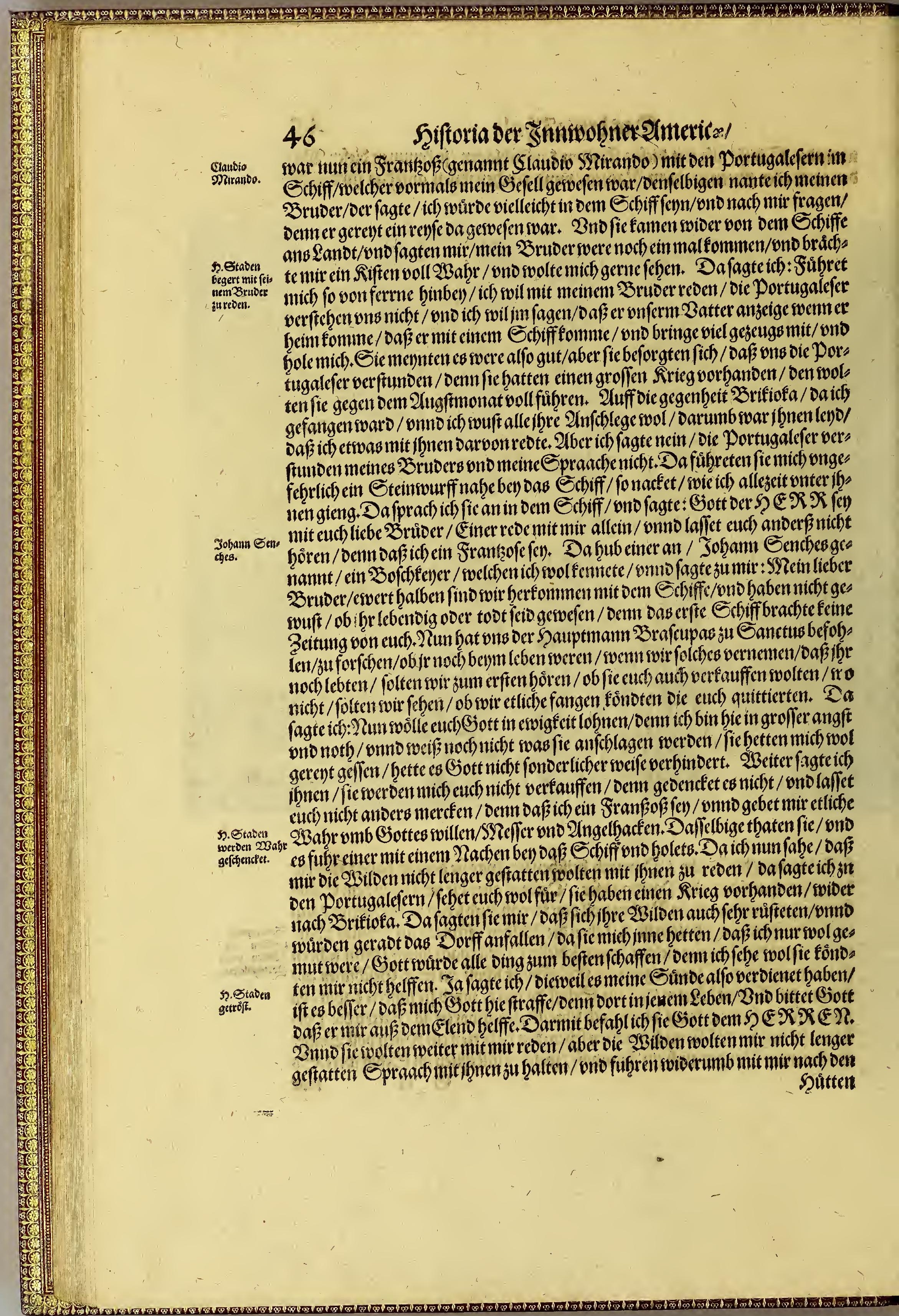




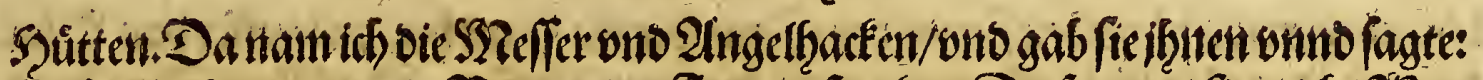
Dis alles fat mir mein Bruder Der frantico eb alles so

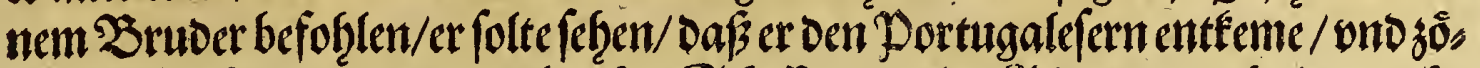
ge in onfer Batterlandt/ond brechte Schiffmit bielen (Siutern/ond holete mich/

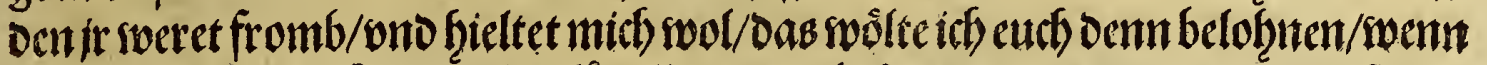

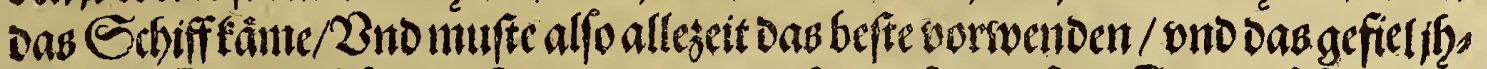

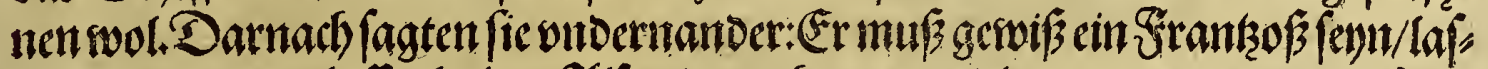

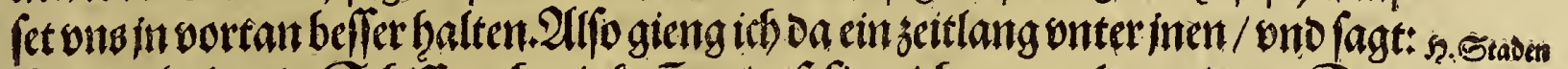

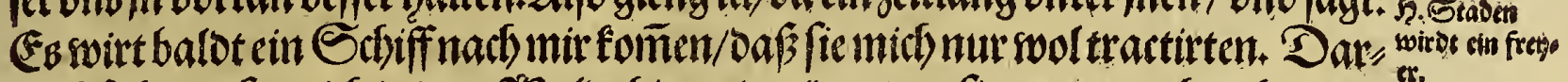

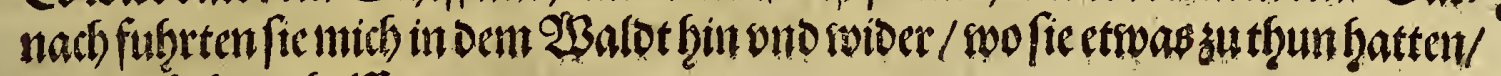
mufere ichifgnenbelffen.

\section{Sapittet.

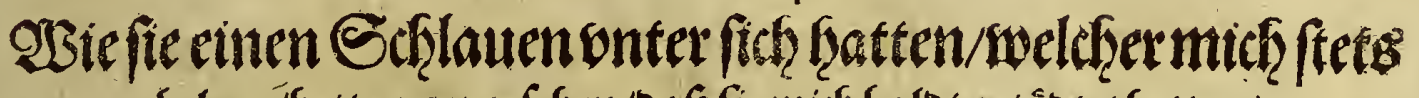 beloge/hette gern gefeben/Daf fie midb balot getootethetten/ oerfelbigefruro getoofet bnd geffen in meiner ges genwertigfeit.}

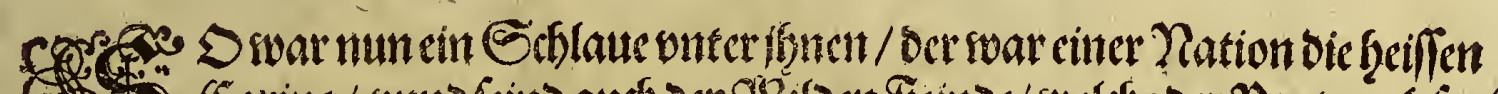

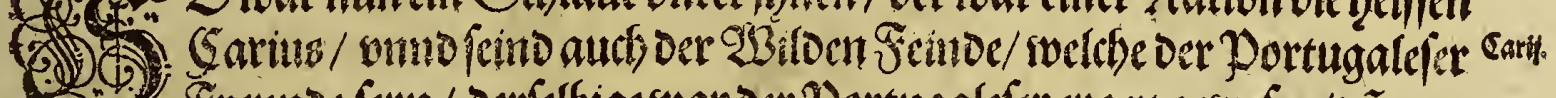

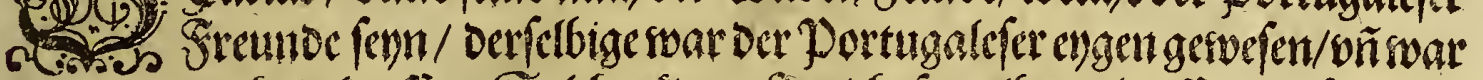

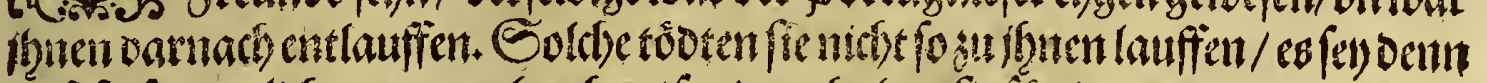

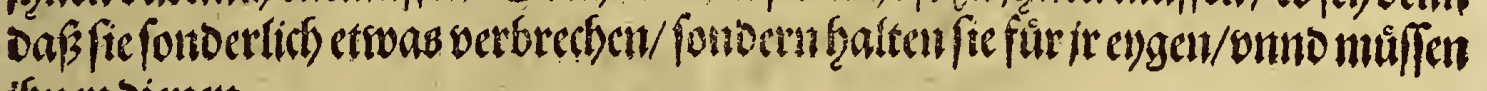
ifnen bienent.

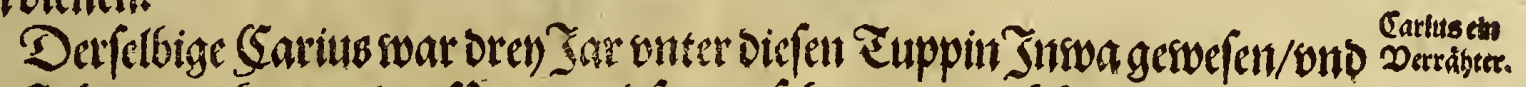

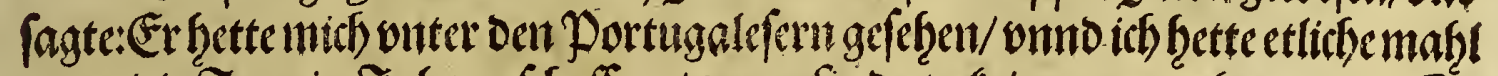
onter die Euppin Inba gef fisoffen / worn fie da zu fricge weren fommen. So

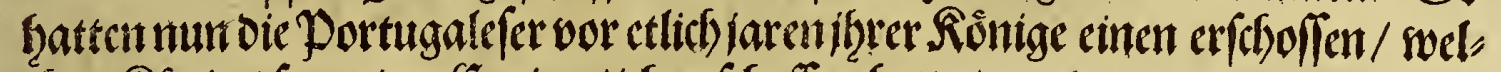
d)en Ronig/ fagte Der Sariub/ich geffyoffen hette / onno regeteimmerdar an/ man folte nich tobten/Denn ich were Der rechte feind/er fette es gefehen/ ont ber

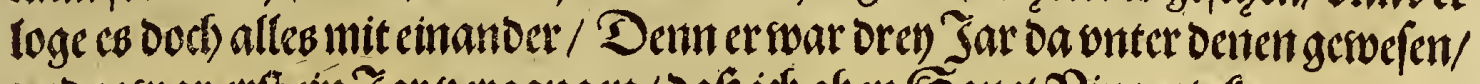

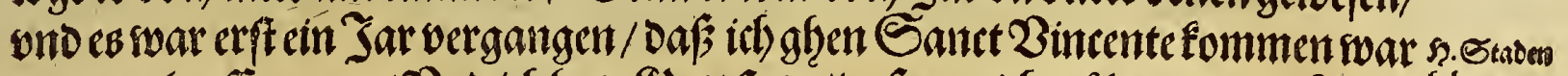

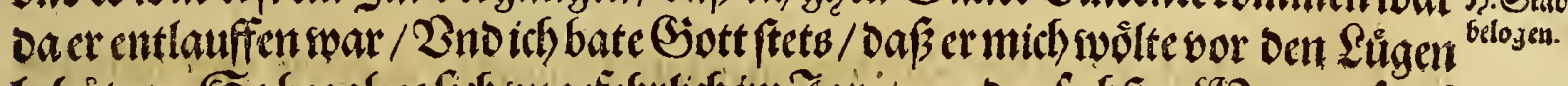

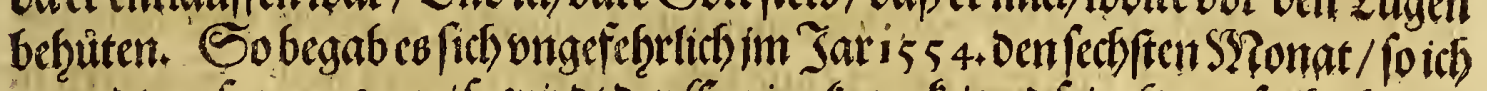
gerevots gefangenwat/ fo wirot Der Sariub frandf / onto fein Serz/ fo ffin batte/

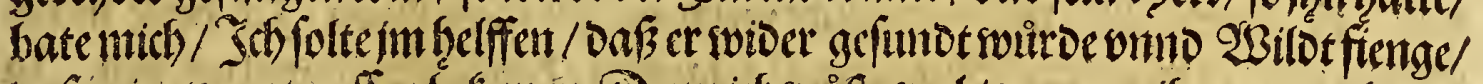

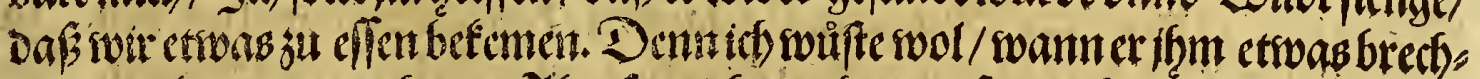

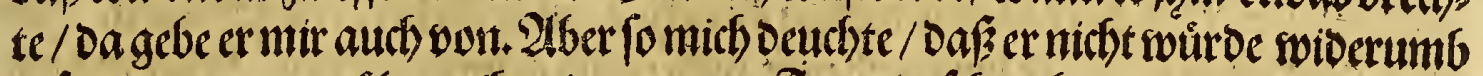

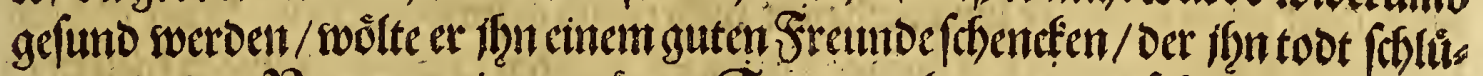

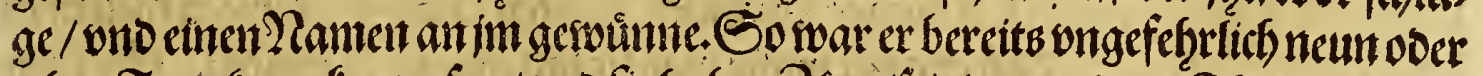

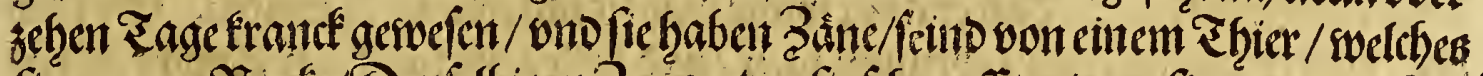

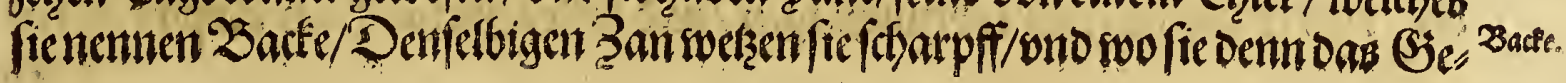

blưt 


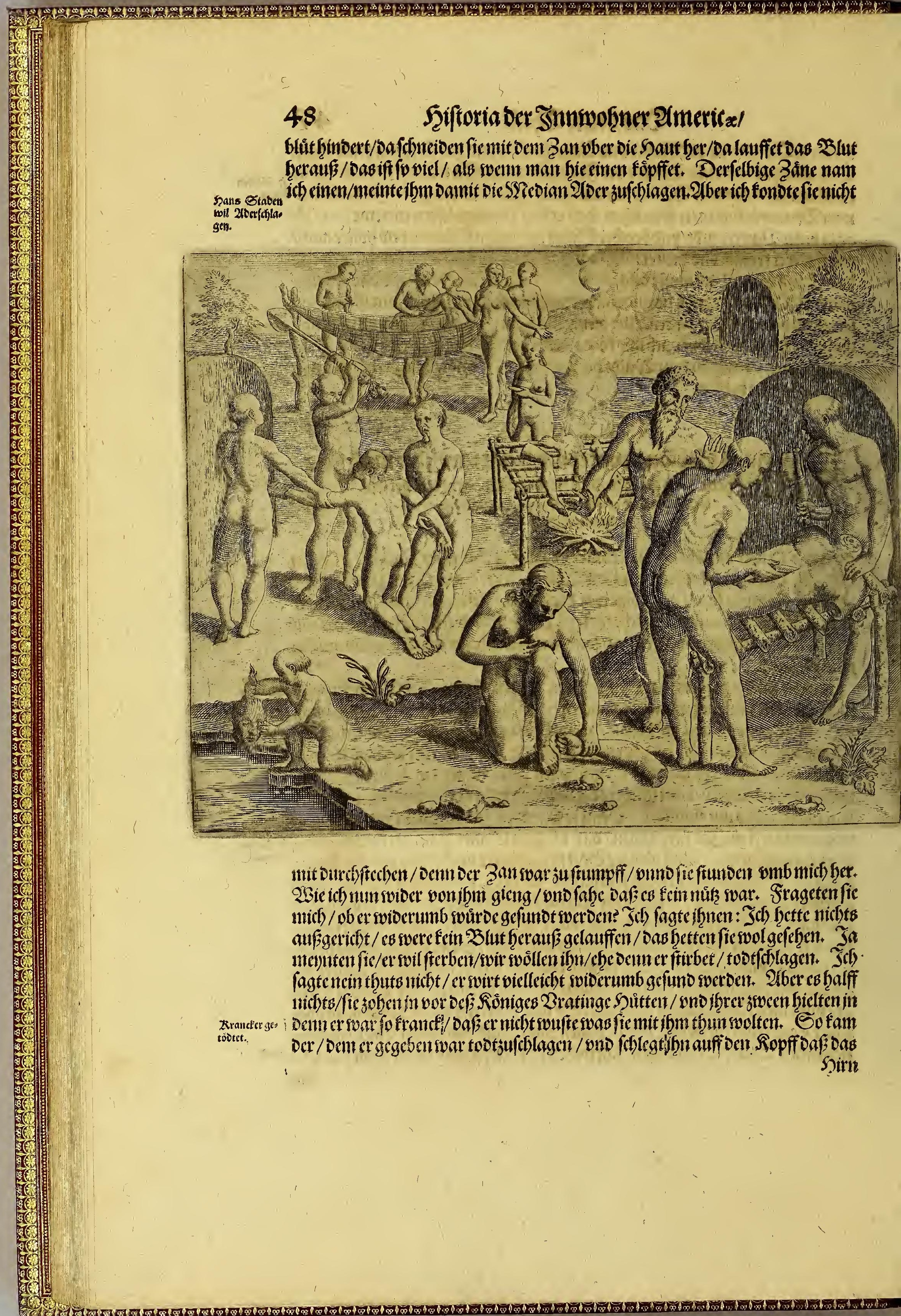




\section{mitur Das britte Ifrall.}

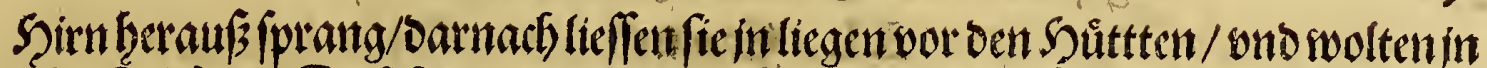

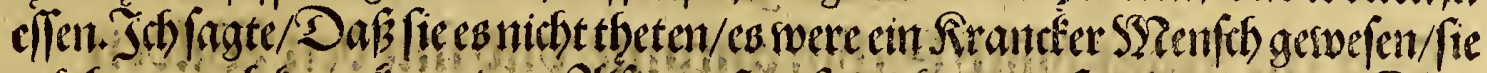

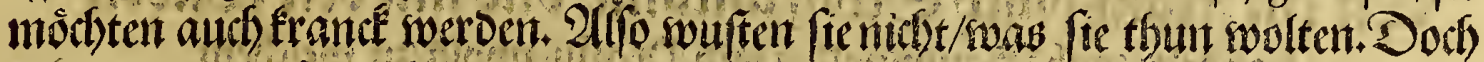

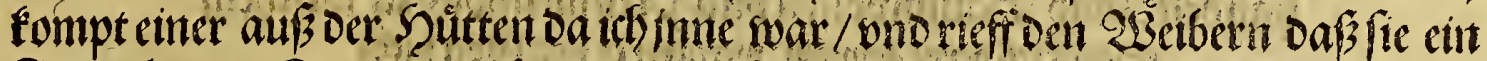

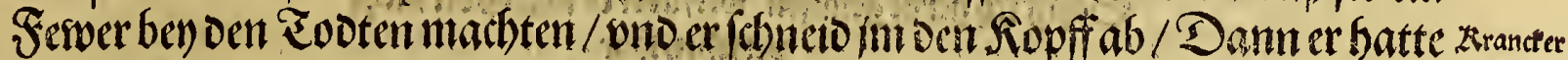

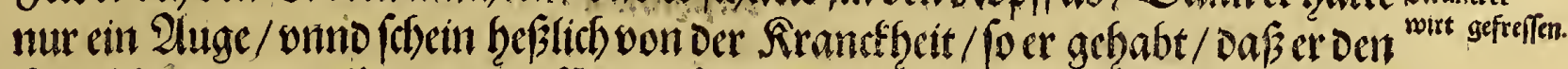

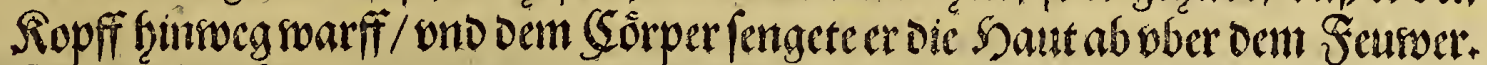

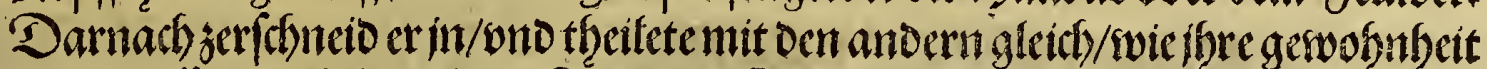

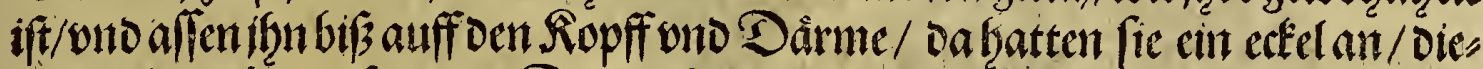

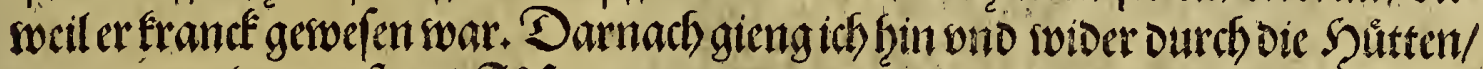

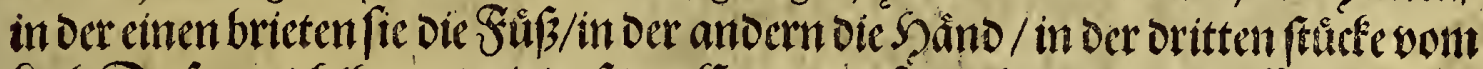

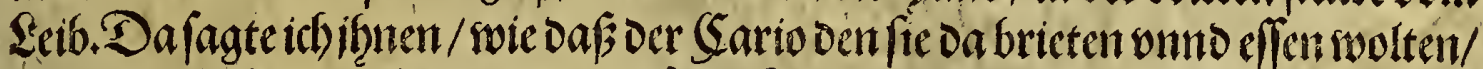
mich allezcitbelogen hette / onno gefagt: Sch hette curverer Sreuntotetlitbe / oie, sweil ich bey oen Portugalefern gewefentwere / erfeboflen/ontio es wete crlogen/

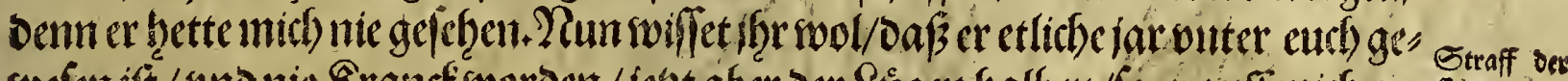

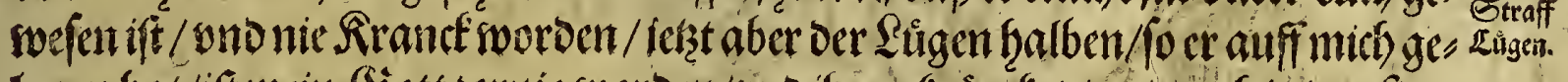
logen hat/ift mein Gott zornig worben/ond jon gefrancter / ono cuth in oen/inn

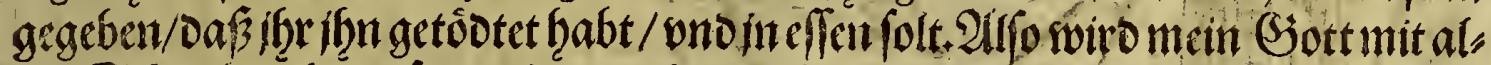

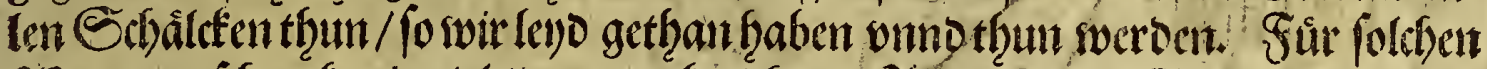

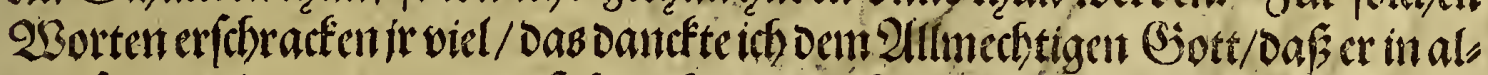

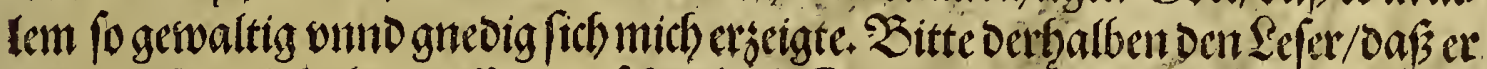

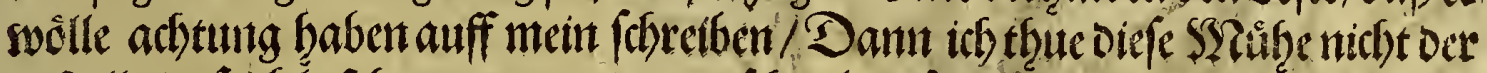

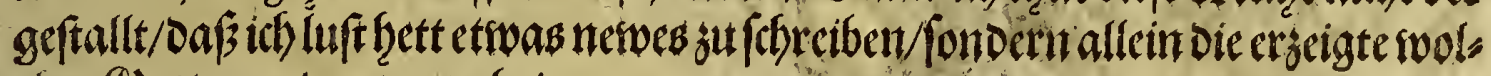
that Siottes an Dent tag zu bringen.

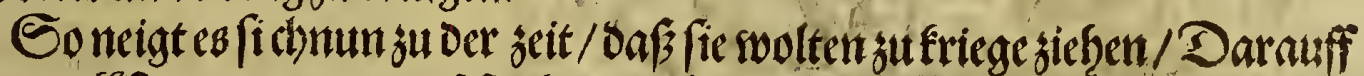

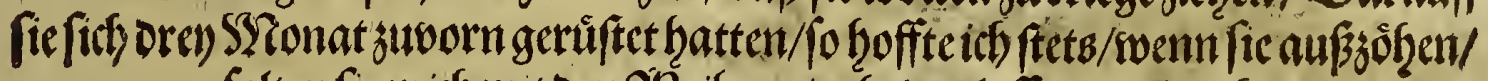
foltenfiemich mit Den 2 Beibern dafeime lafen/swolteich/ Diesweilfic auffensweren/entlauffen fenti.
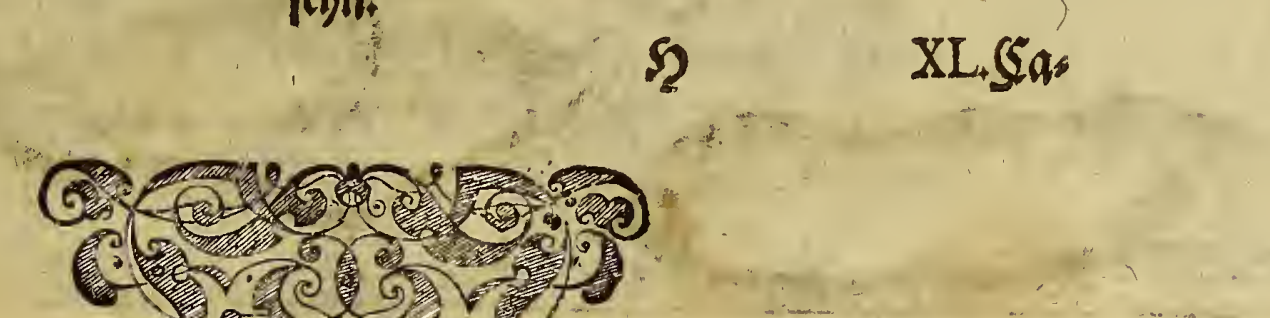

ce
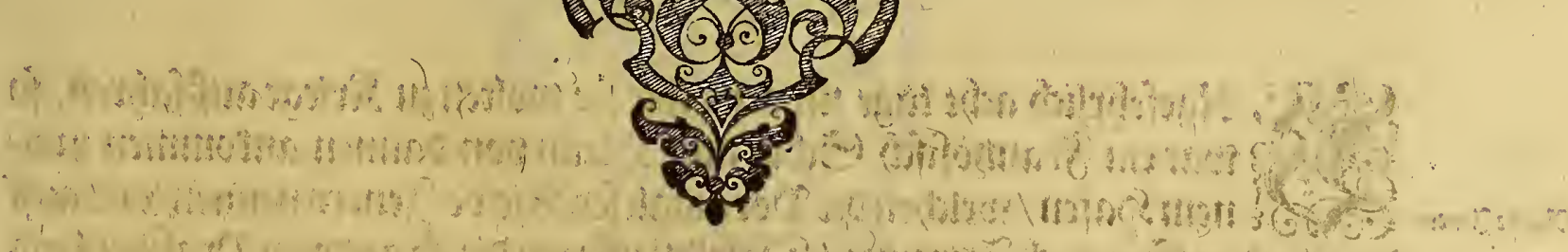


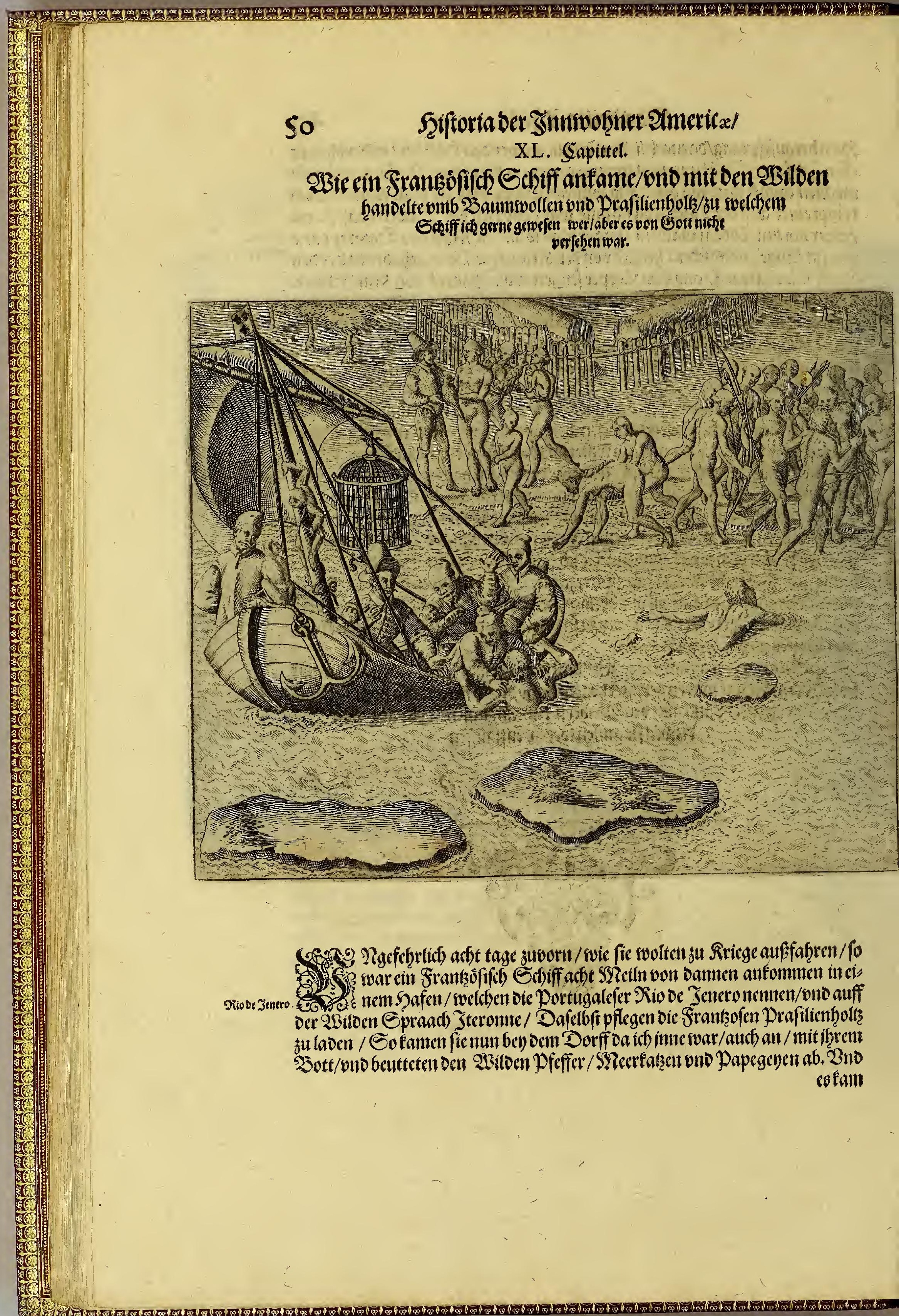




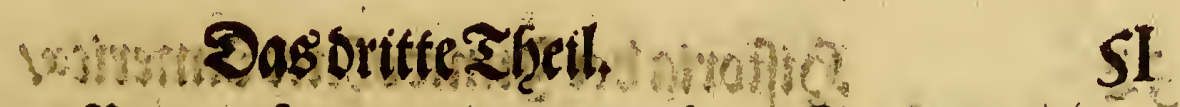

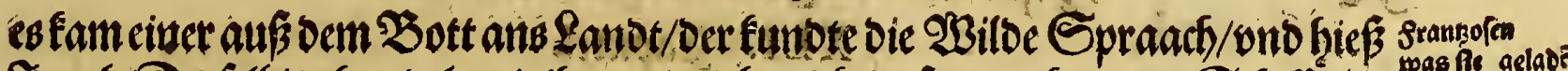

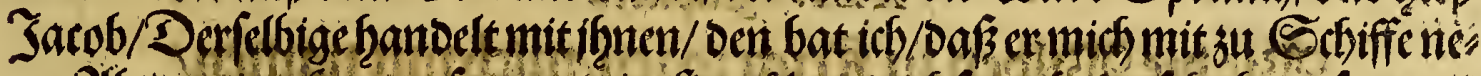

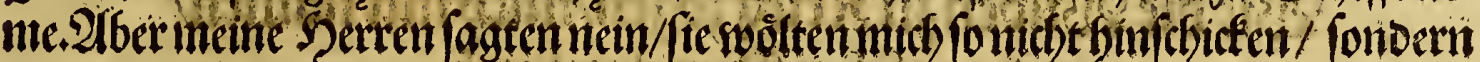

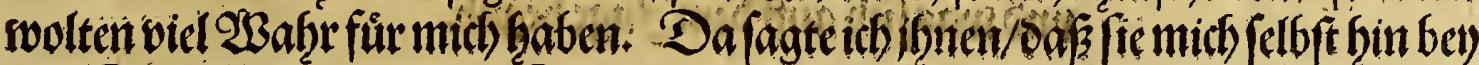

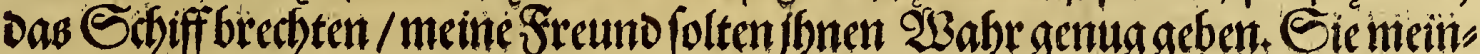

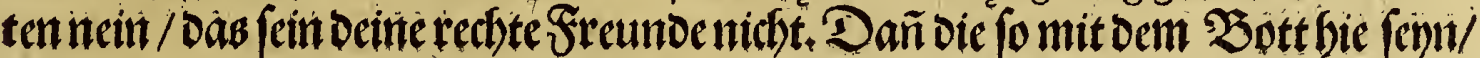

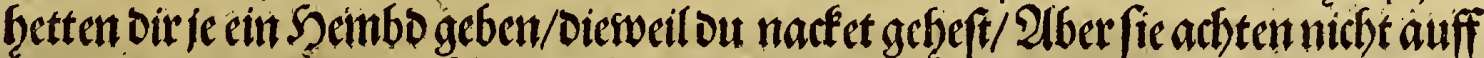

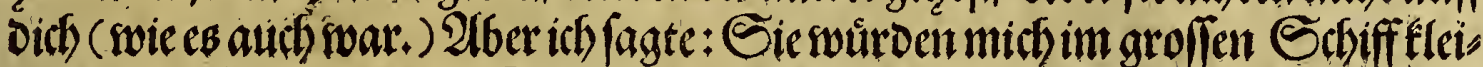

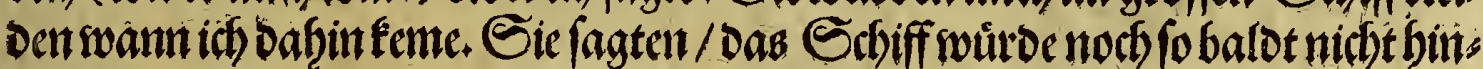

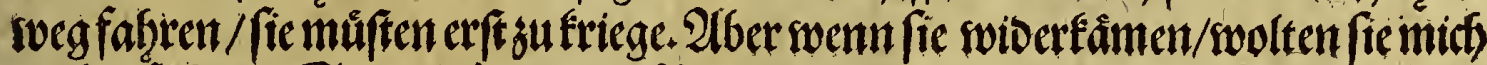

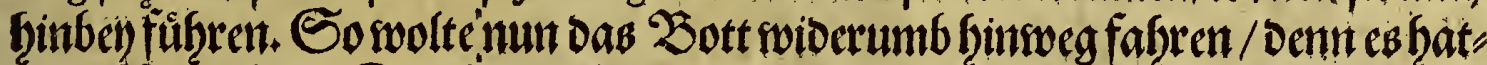

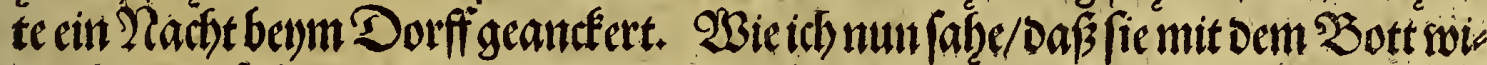

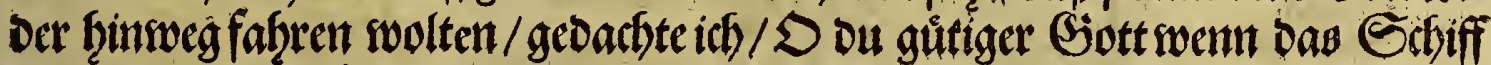

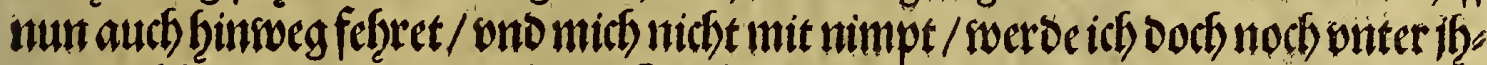

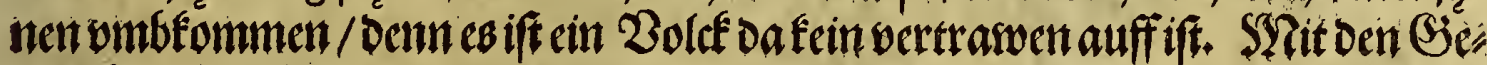

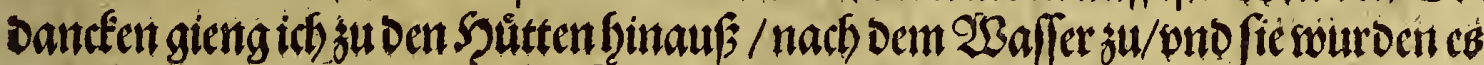

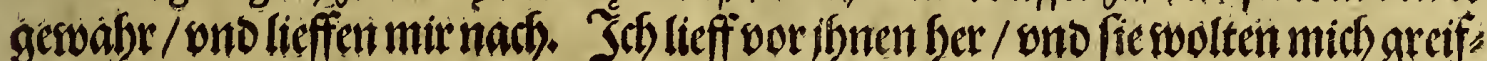

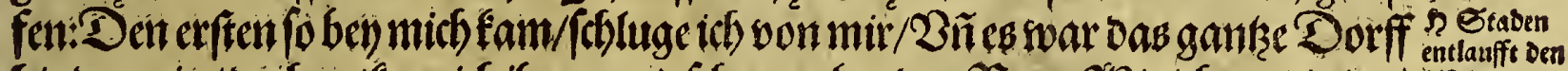

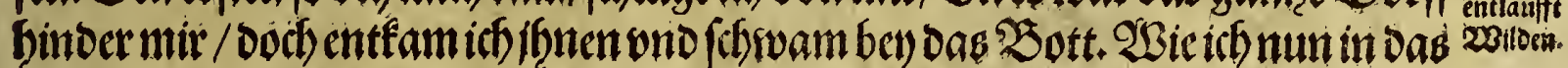
Wott fteigen wolt / fiteffen mich oie Frantzo/en woider bintwerg/menneten / wo /ie

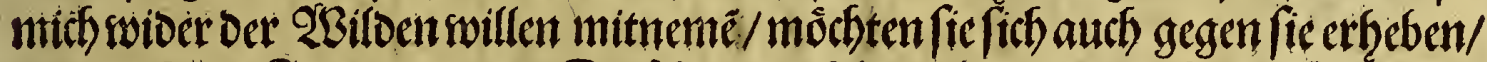

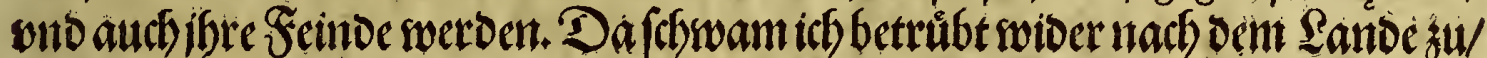

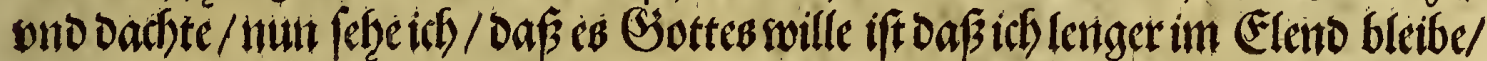

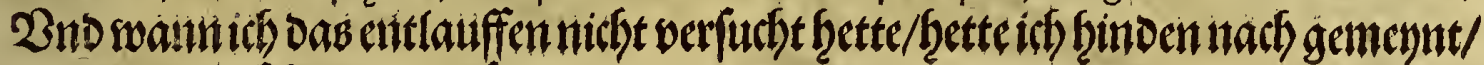
es swere mein folduld getwefen.

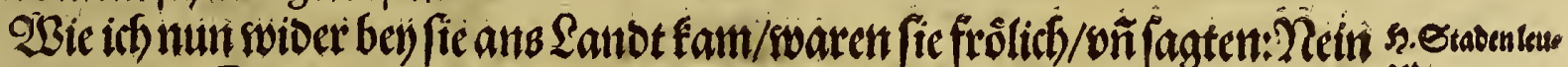

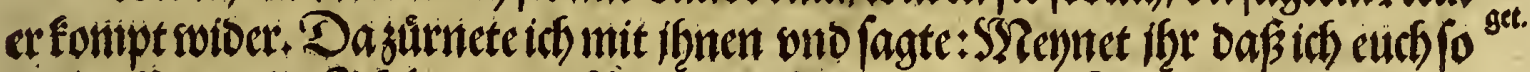

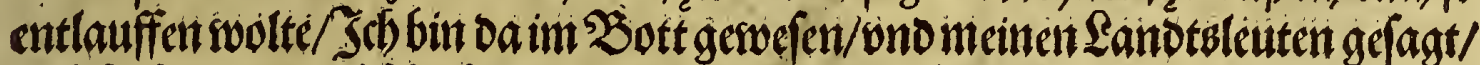

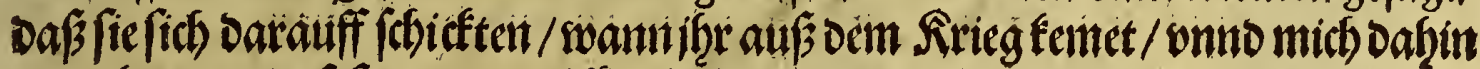

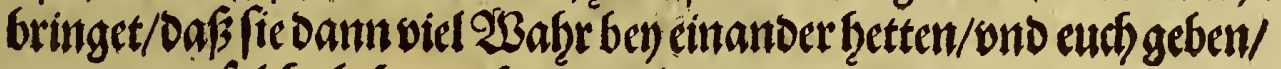

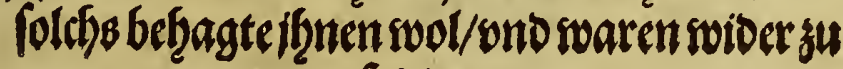
frieden.

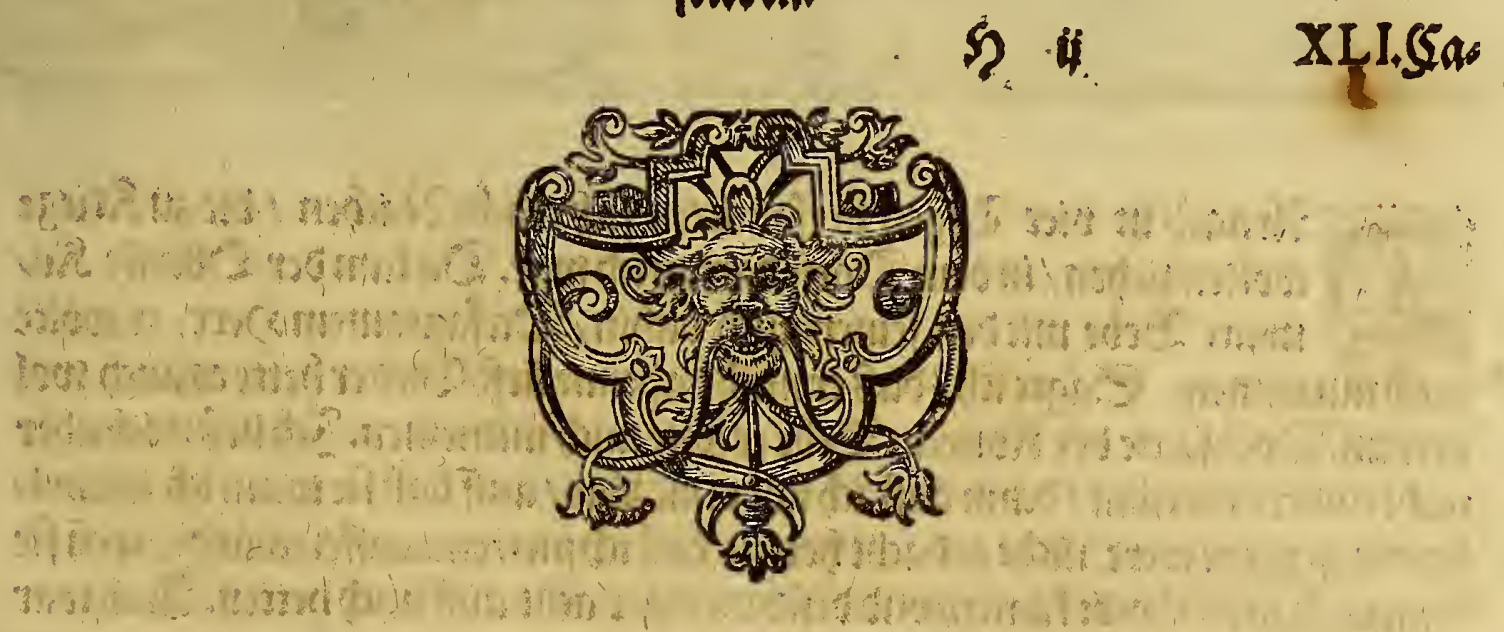




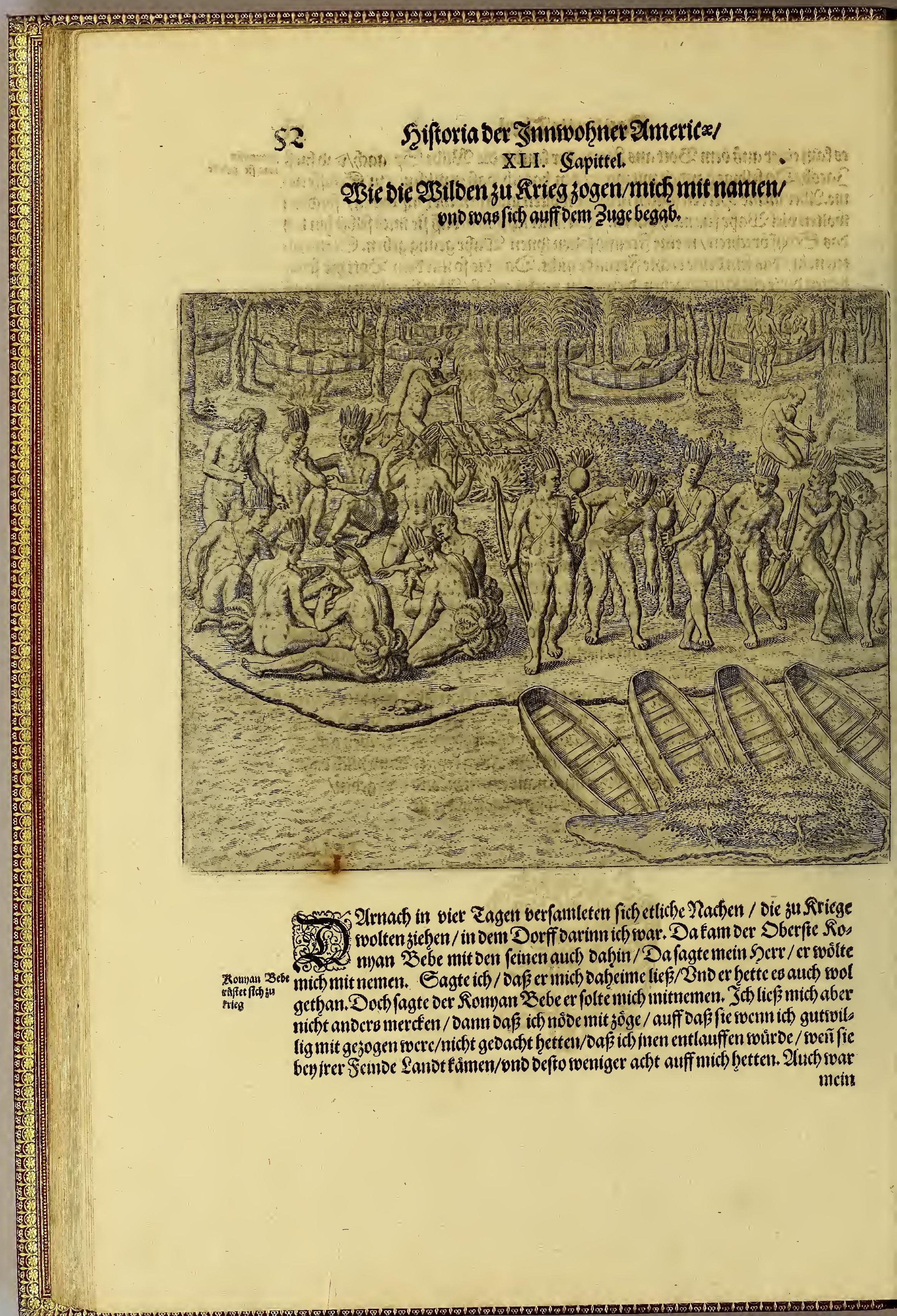




\section{Whin Sos britterget. and}

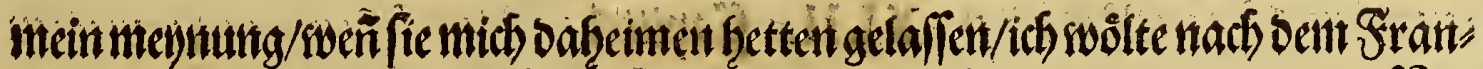

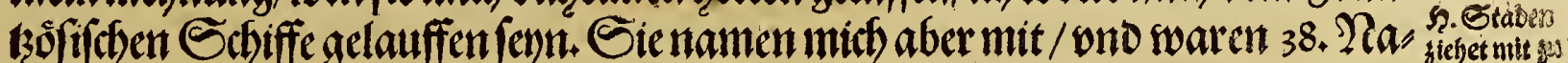

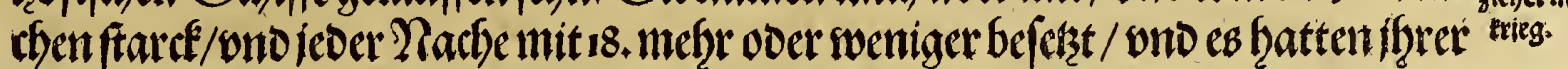

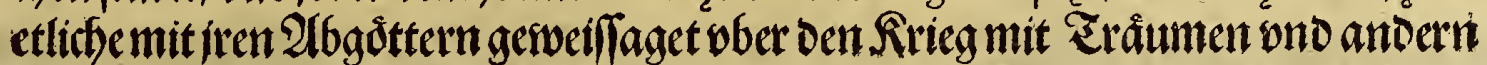

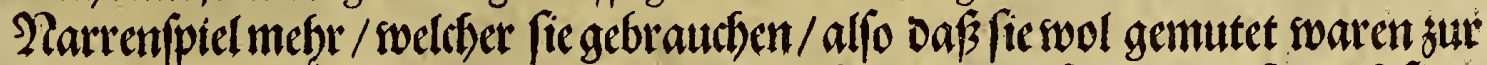

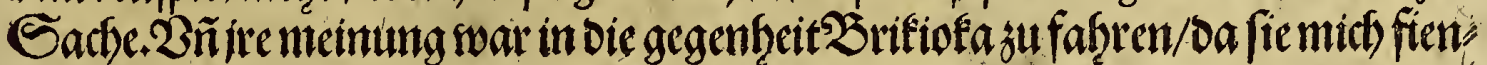

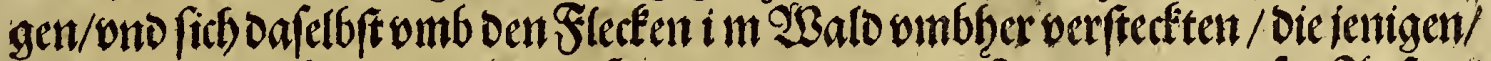

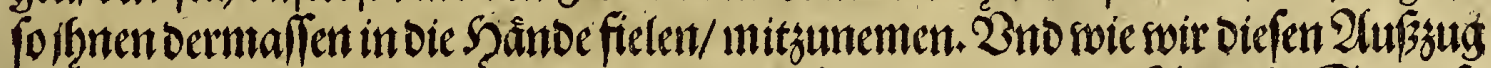

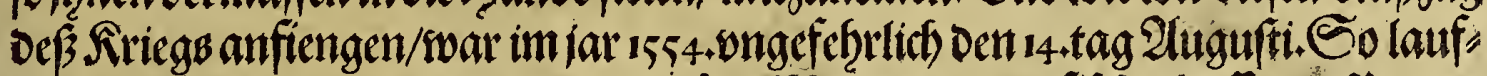

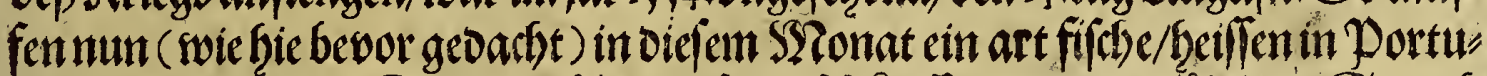

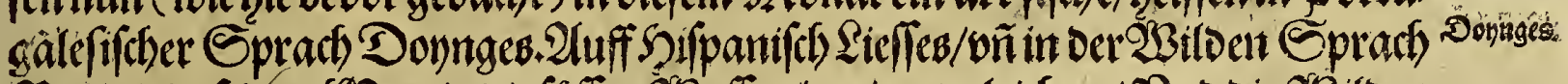

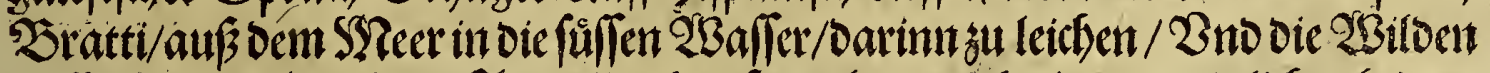

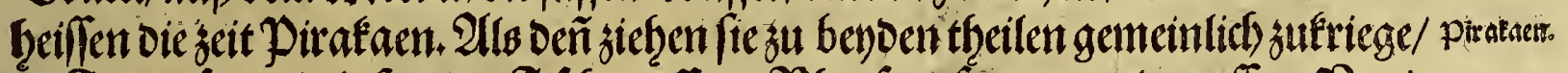

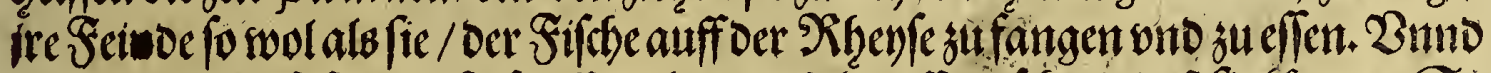

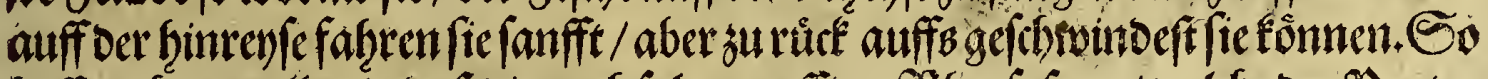

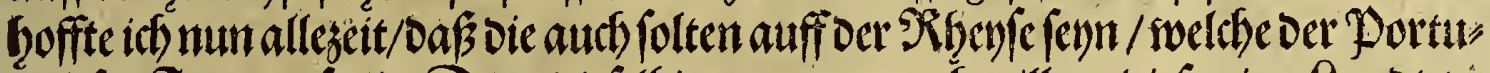

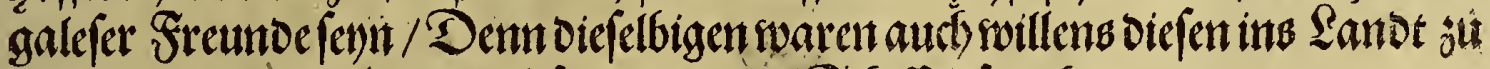
fallen/swie mir Die Dortugale/er zuoorn im Eifhifigejagt battent.

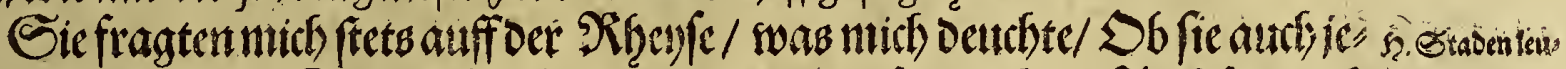

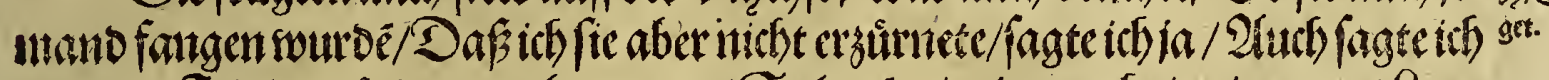

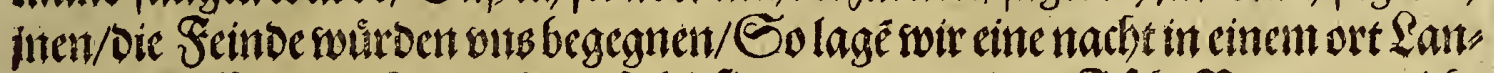

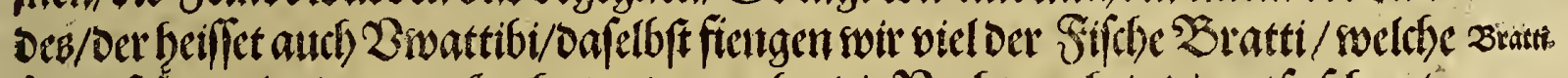

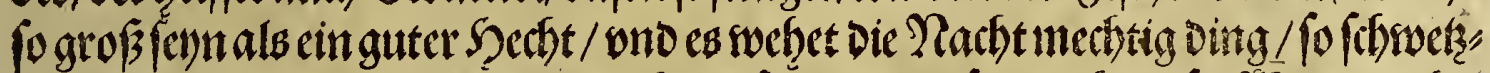

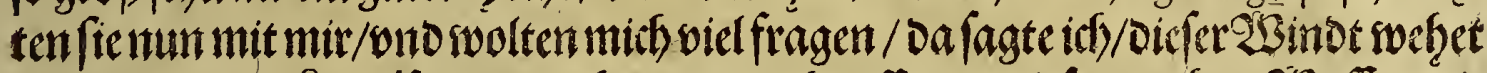

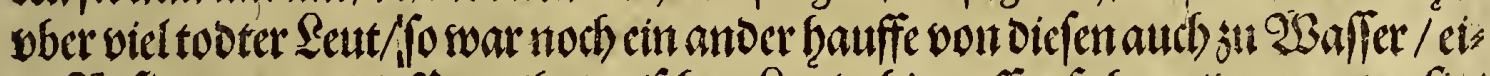

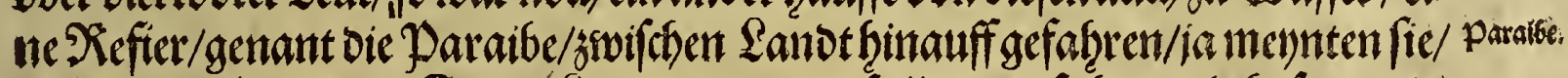

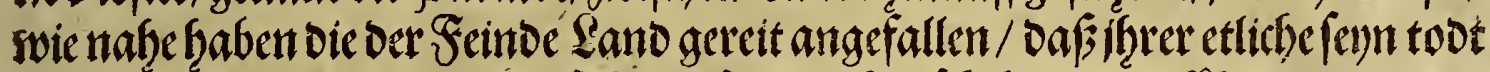

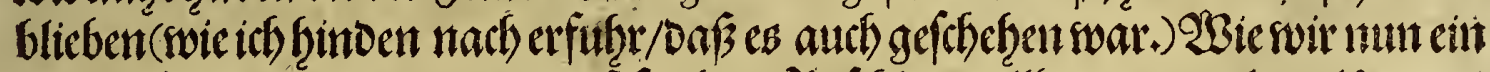

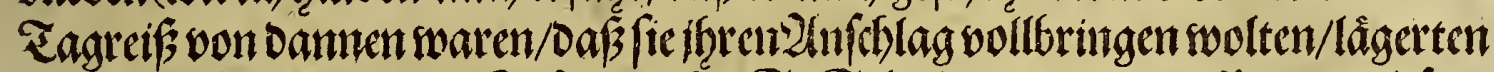

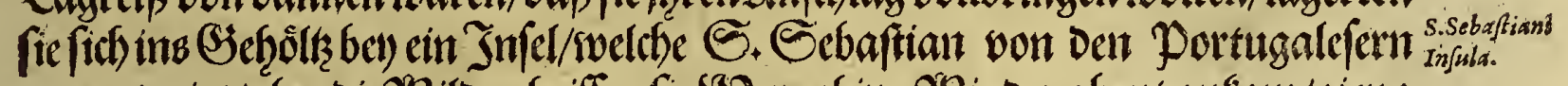

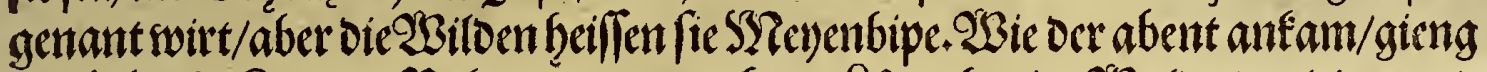

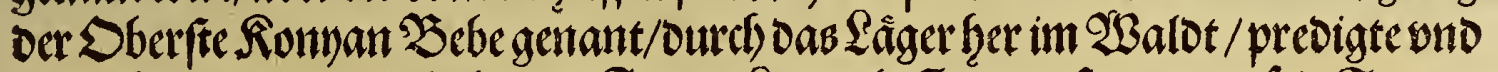

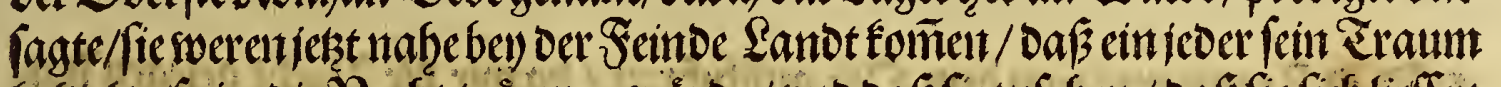

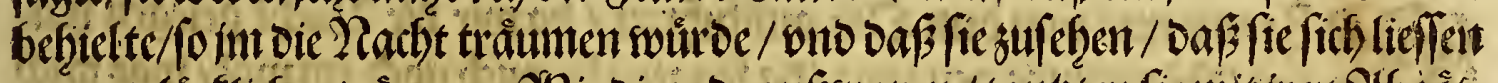

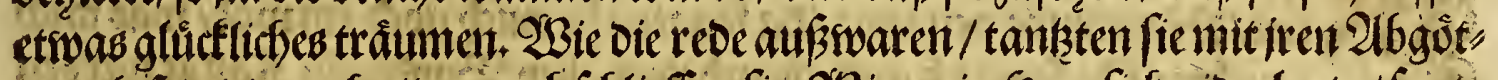

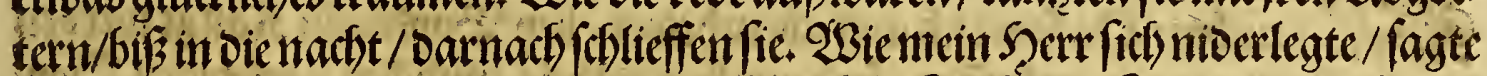

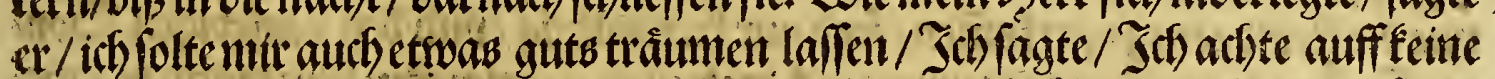

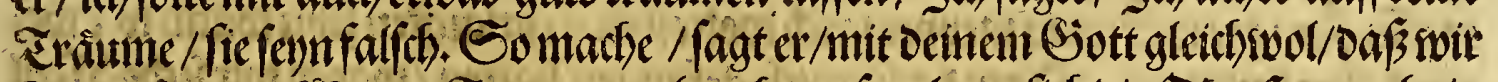

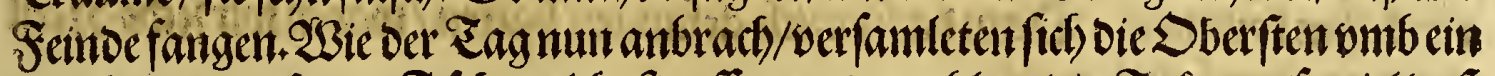
Berfen voll gefotner Fif

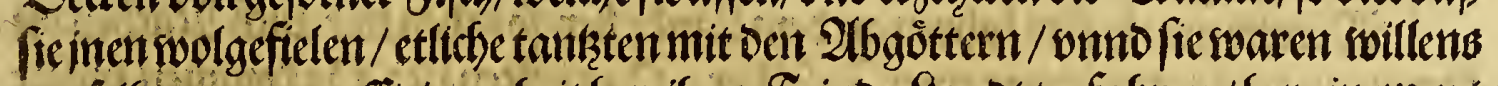

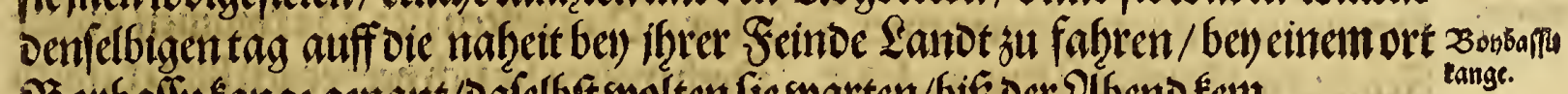

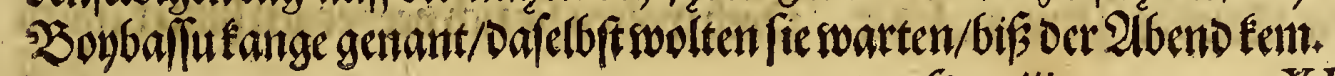

$$
\text { S. ii XLII. Sa: }
$$




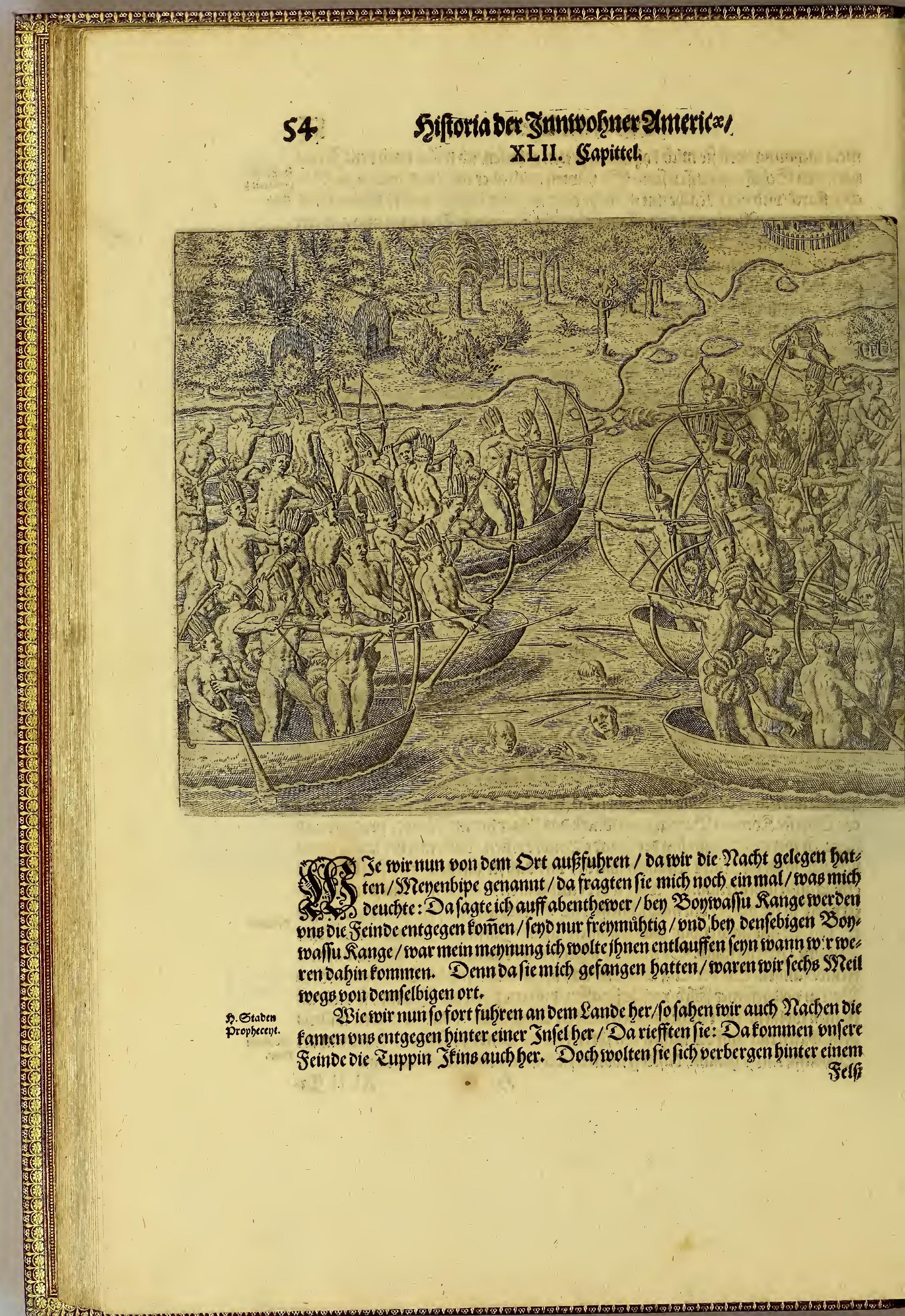




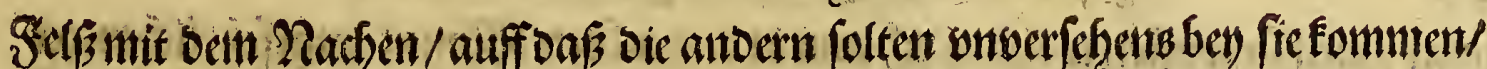

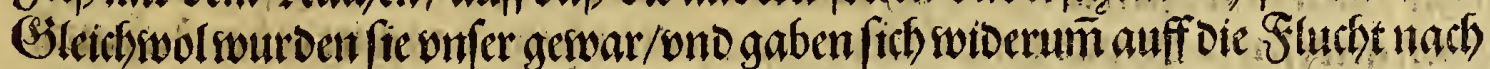

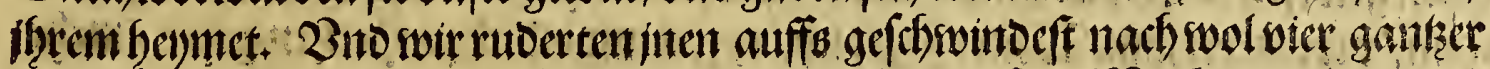

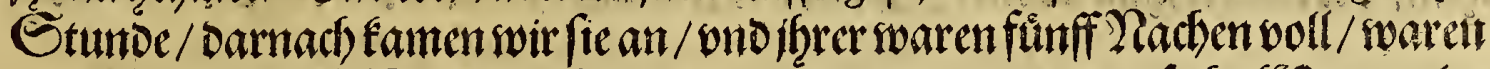

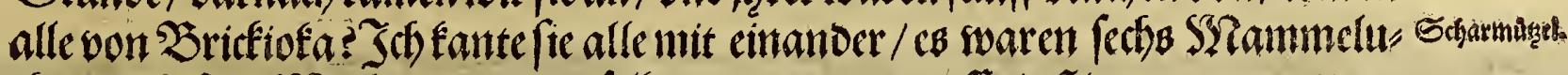

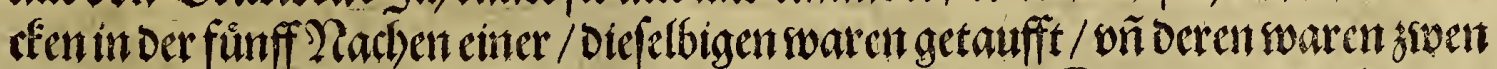
Gebriber/eitter genaut Diego oer Praga/Der ander Domingos De Praga/

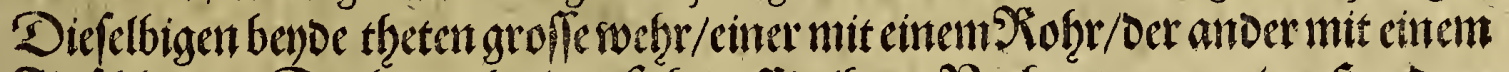

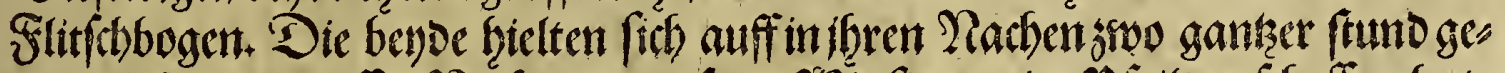

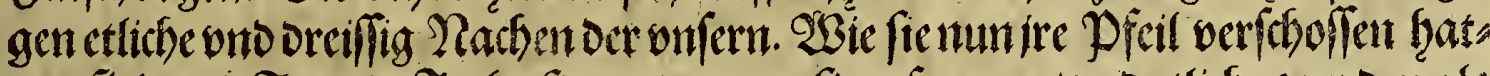

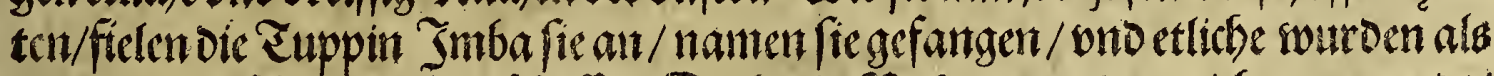

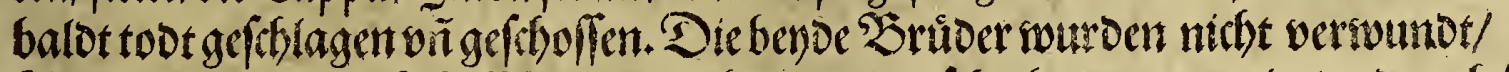

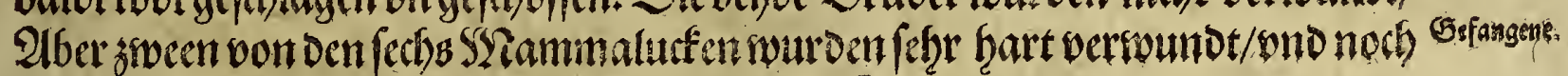

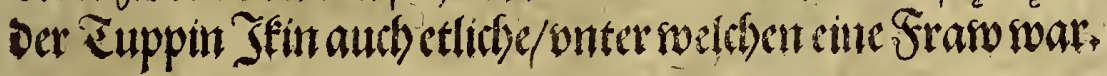

XL111. Sapittel.

\section{OBaffemit ben Gefangenen onbogiengēn/auff Dem ferintuger}

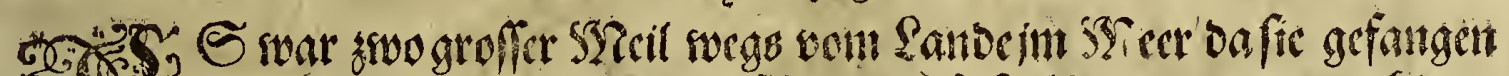
C.

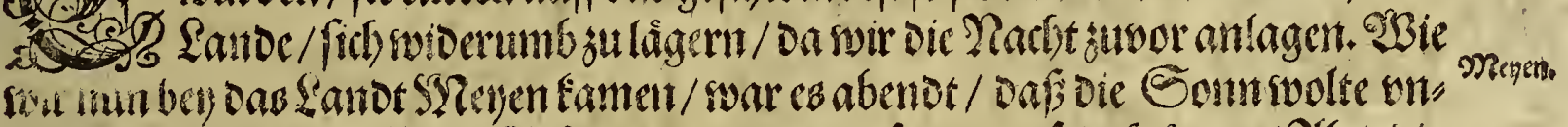

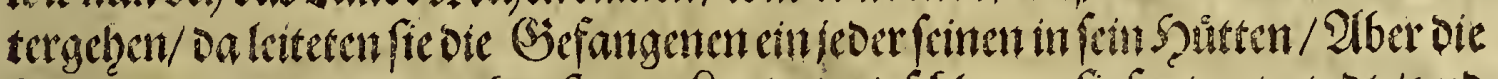

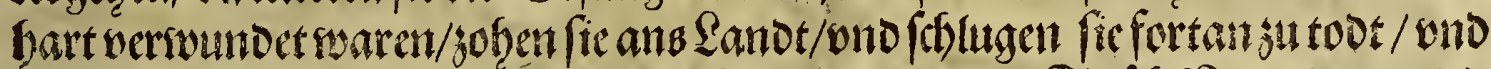

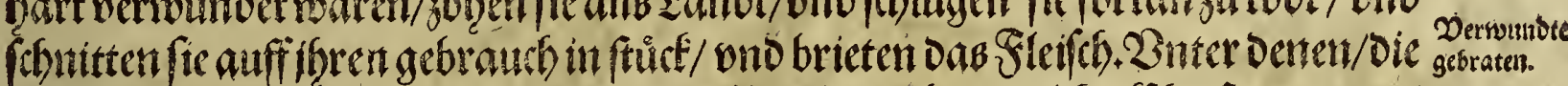

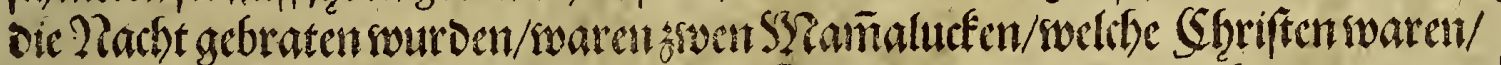

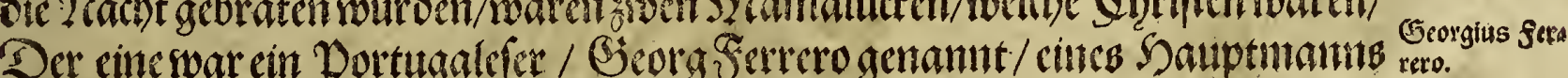

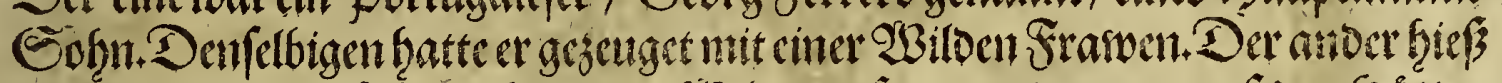

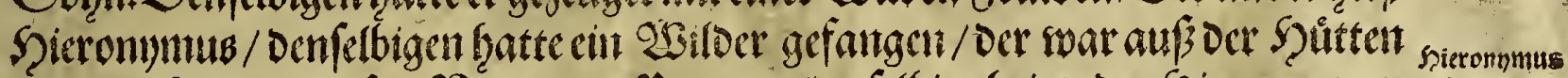

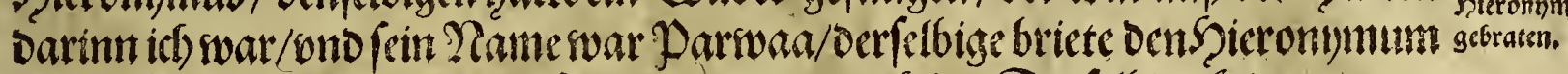

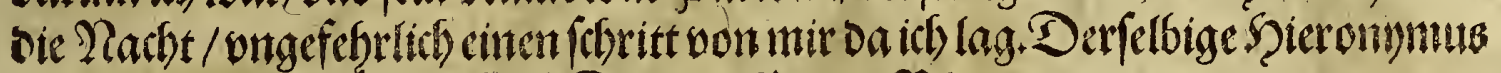

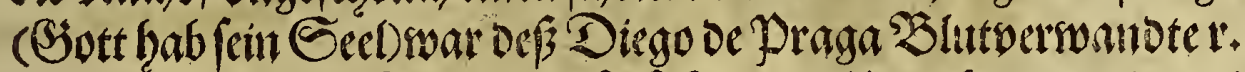

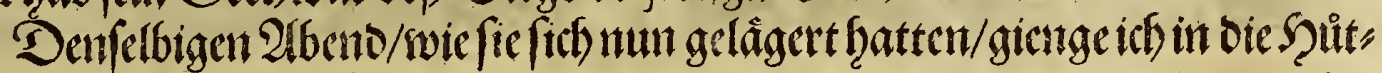

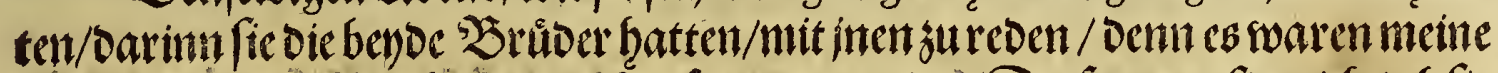

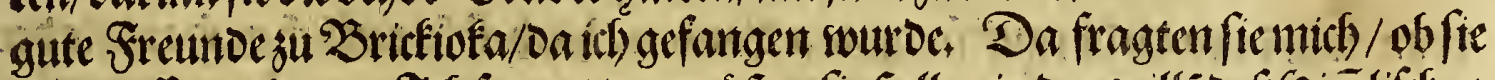

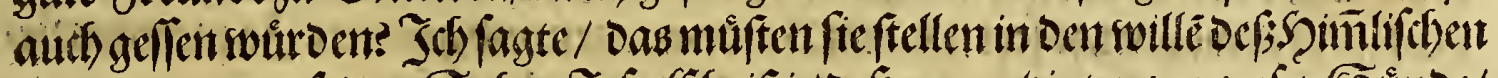

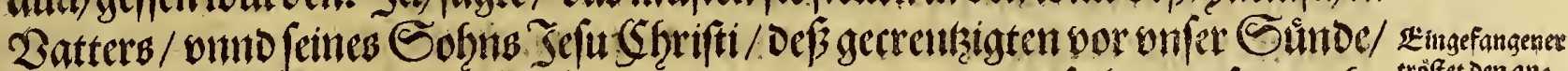

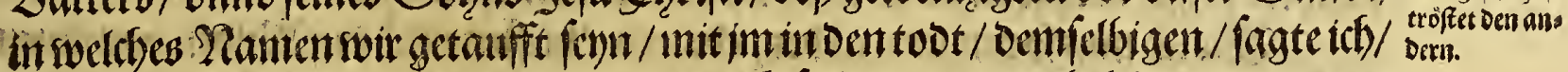

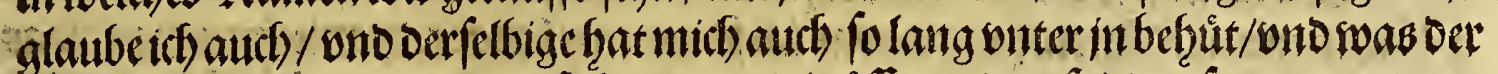

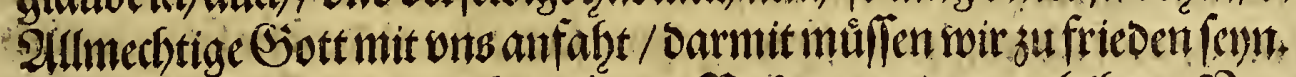

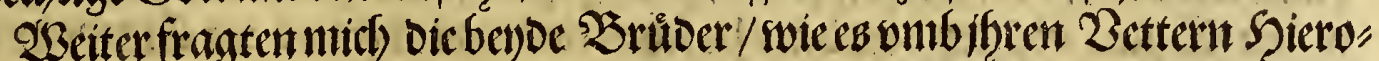

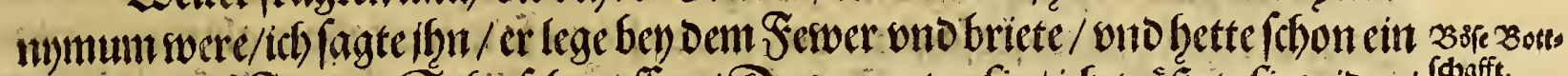

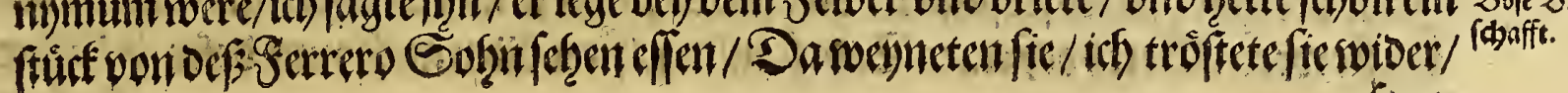

lagte 


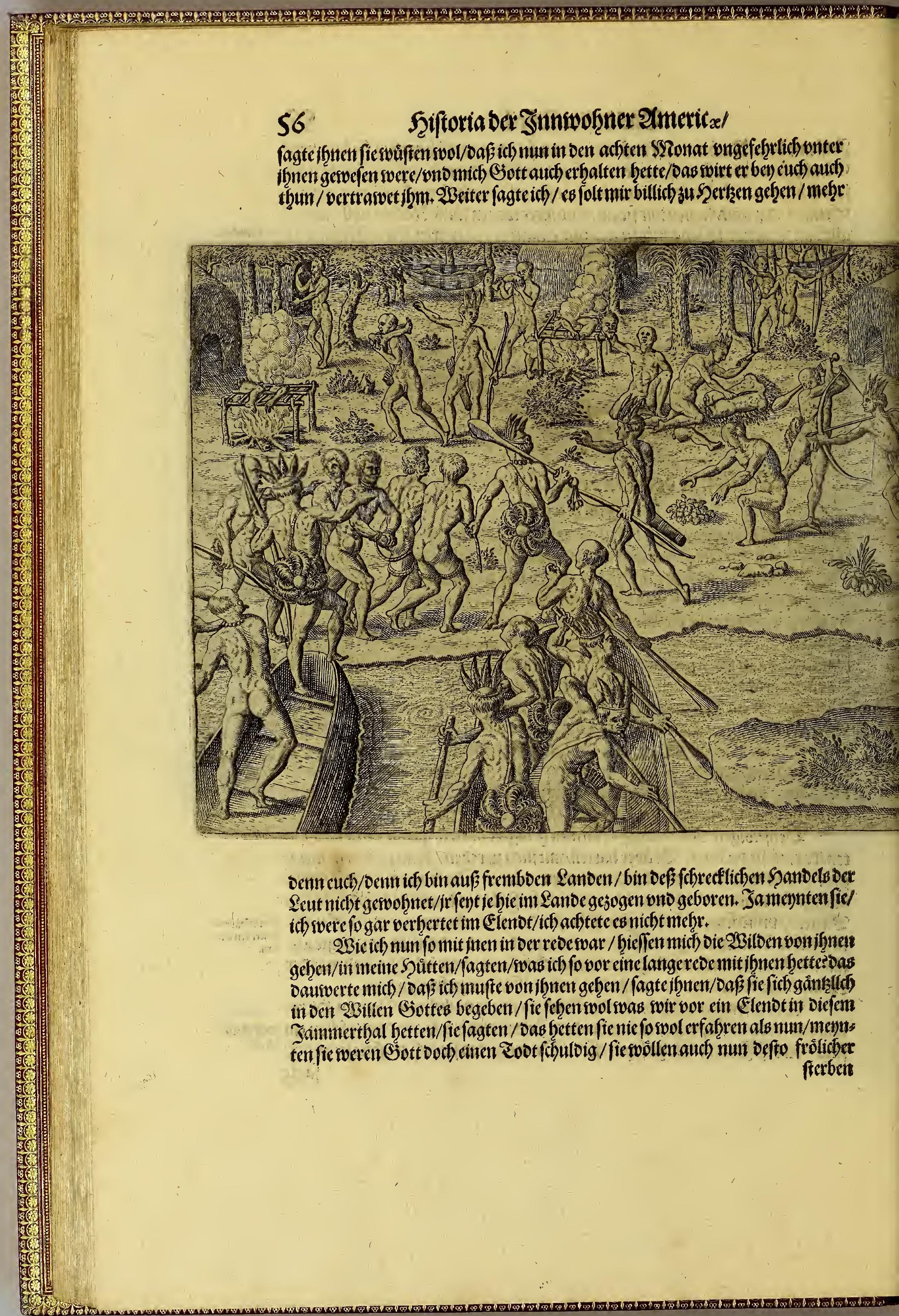




\section{Das britte Ţheil.}

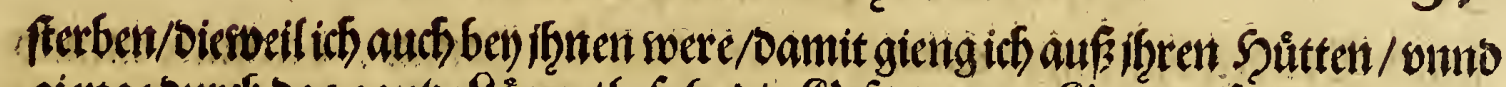

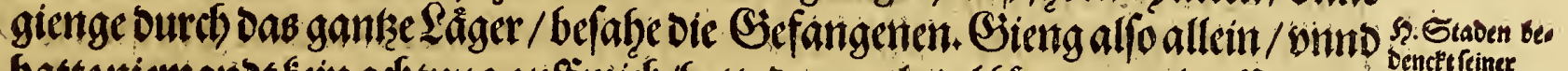

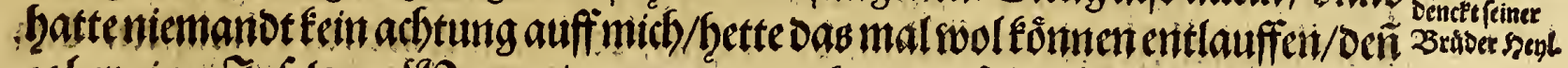

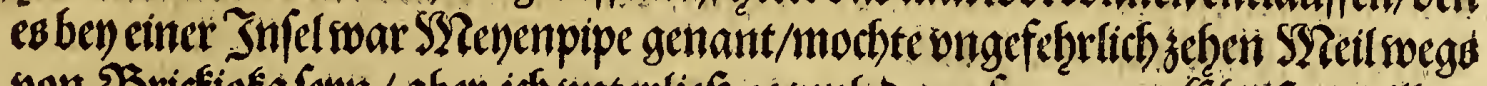

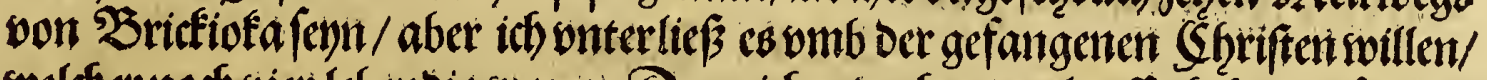

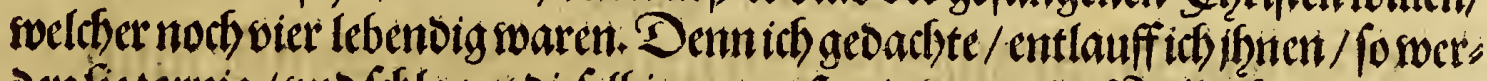

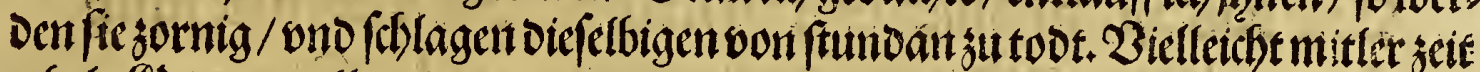

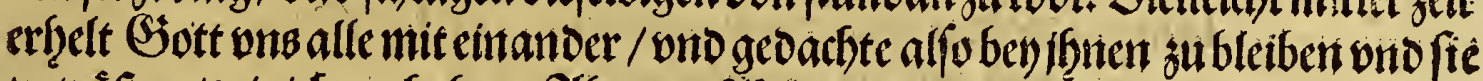

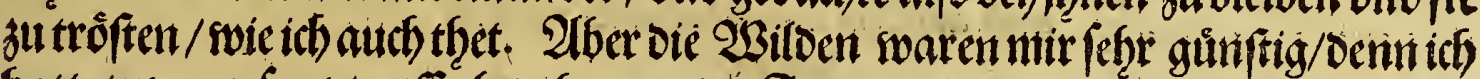

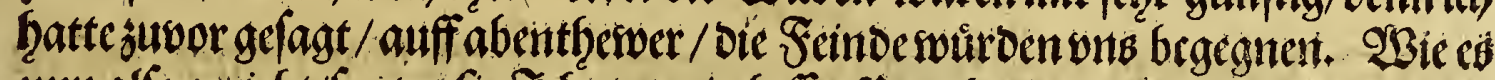

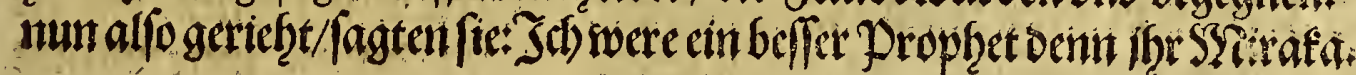

\section{XLIIII. Sapittel.

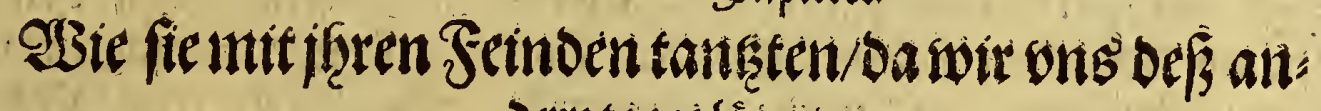 \\ Derntägé lâgerteti.}

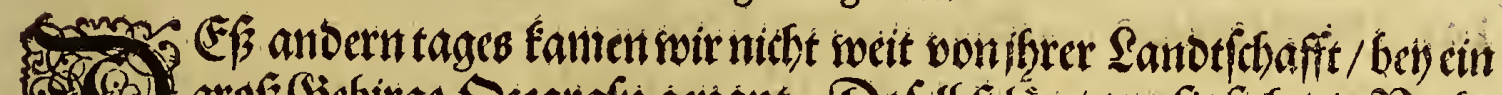

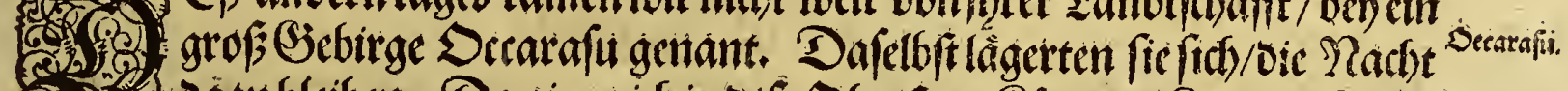

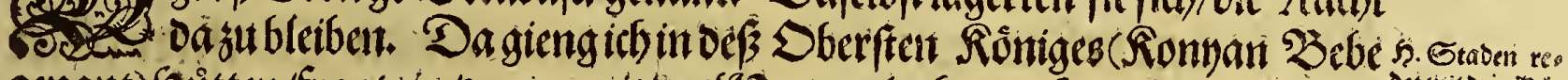

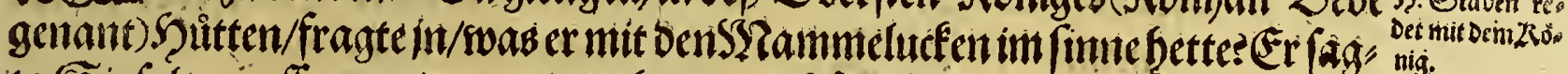

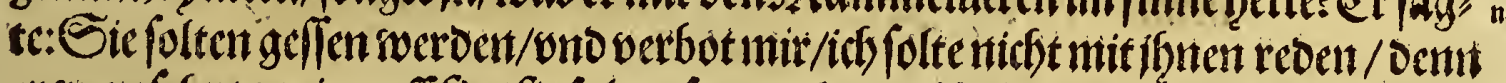

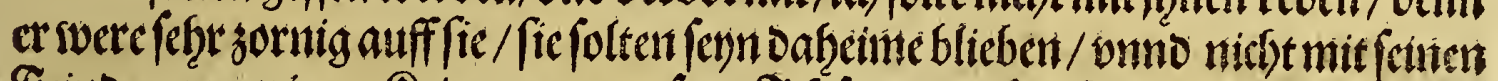

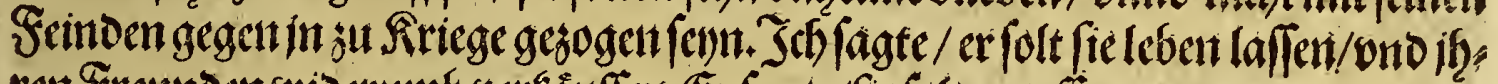

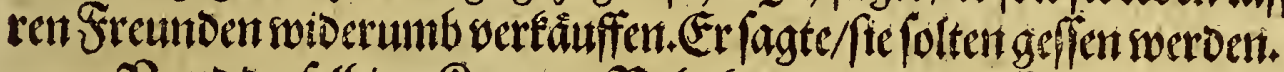

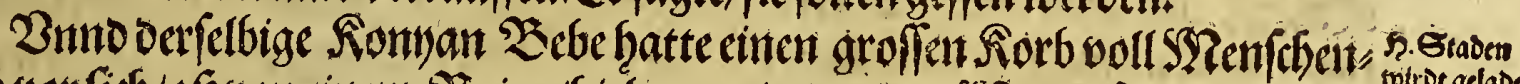

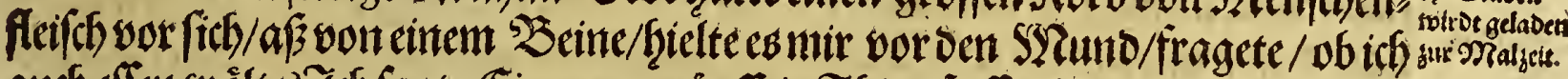

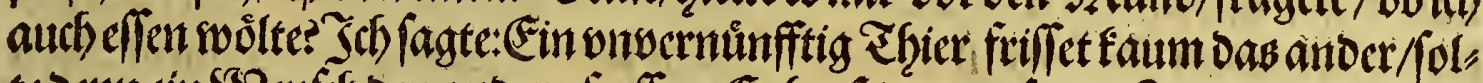

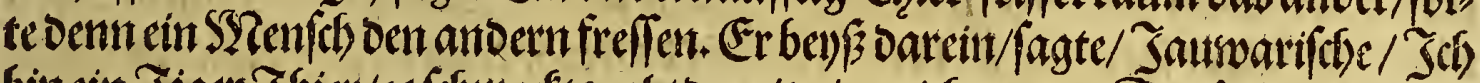

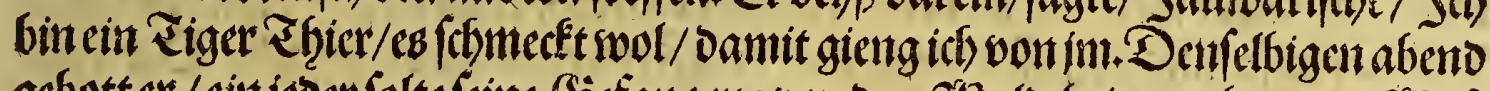

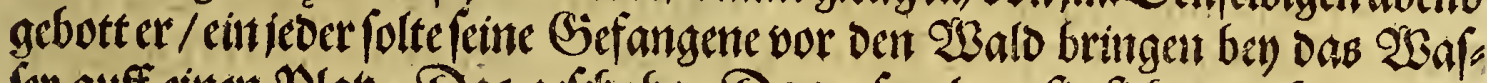

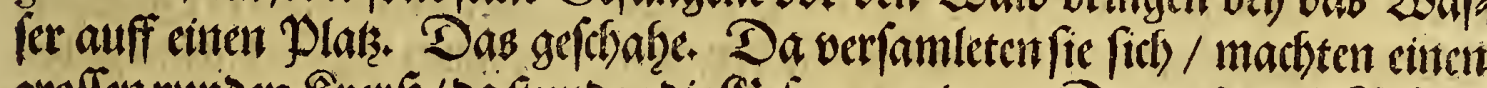

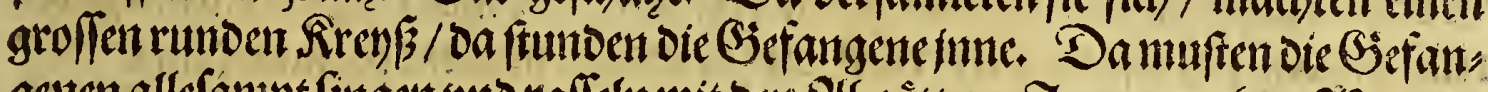

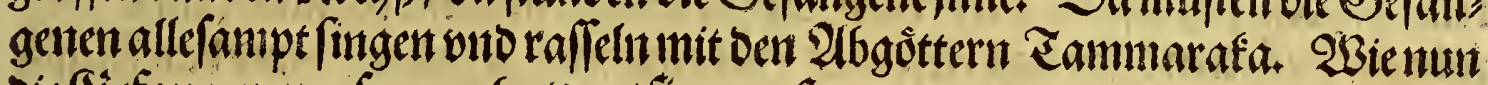

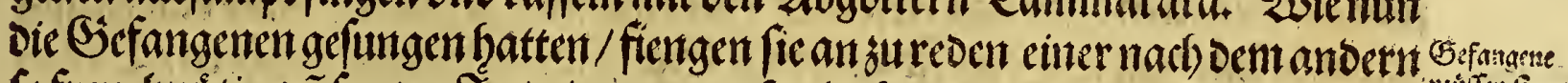

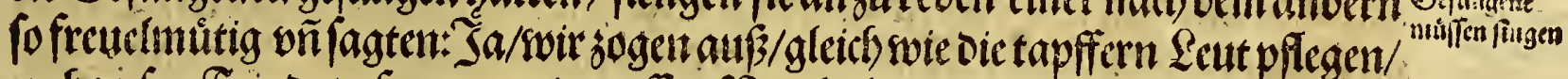

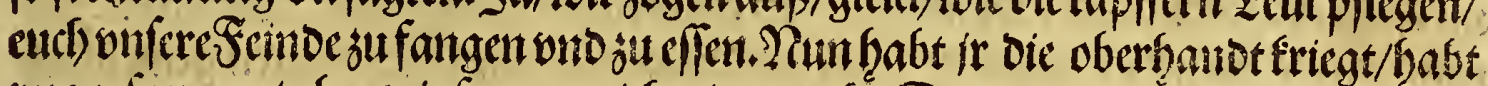

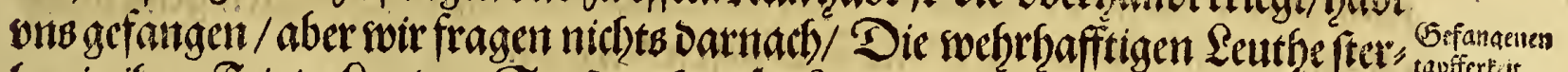

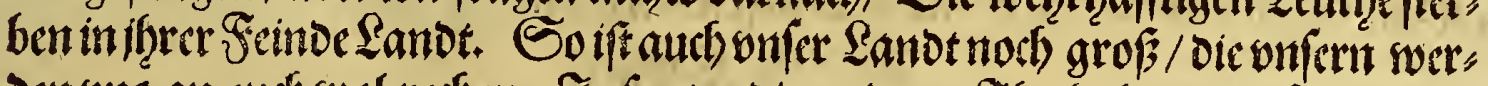

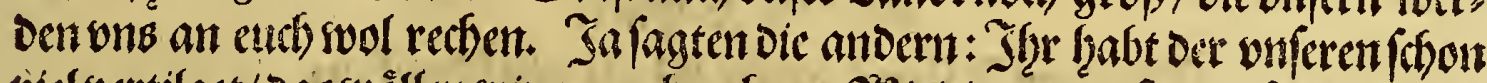

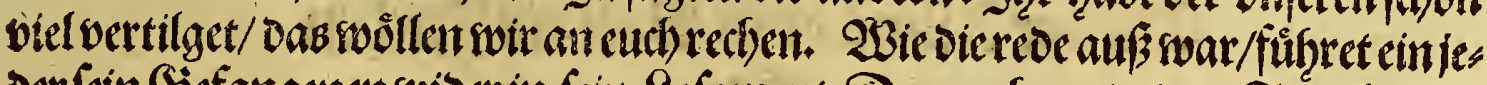
Der fein Sisfangenen roiber in feit Qofanent. Darnach aum oritten ₹age famen

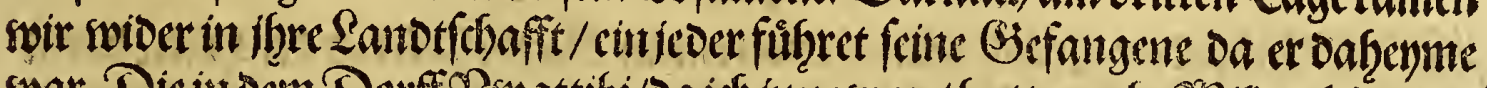

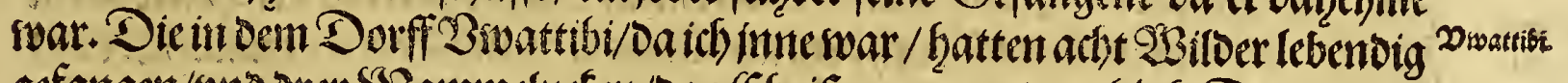

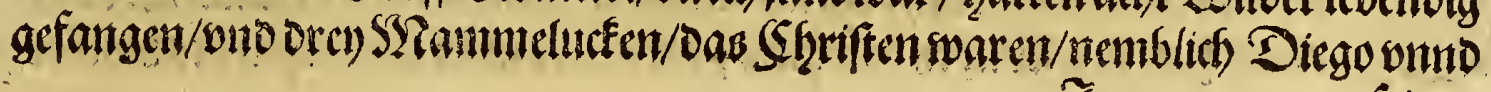
I finen 


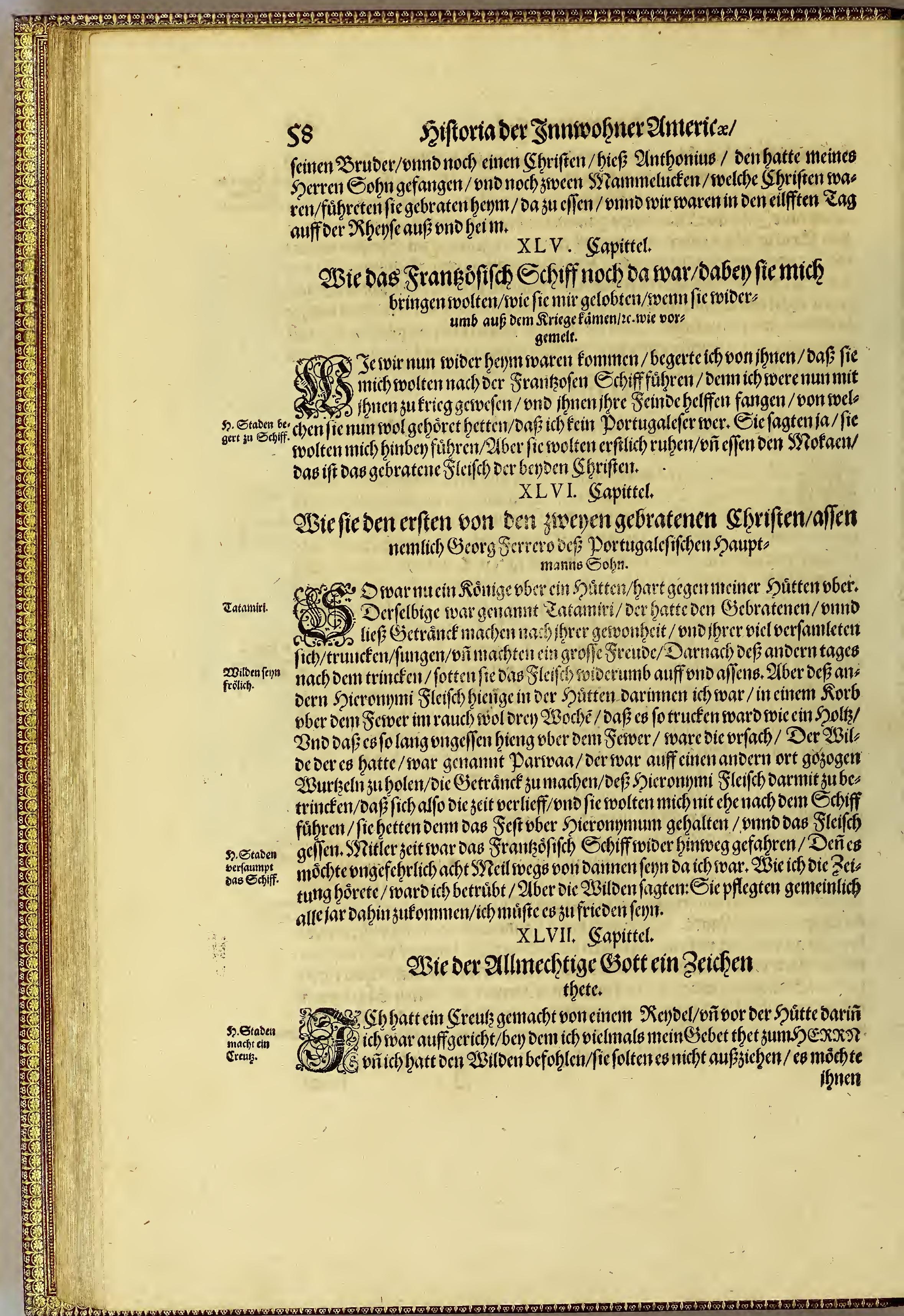




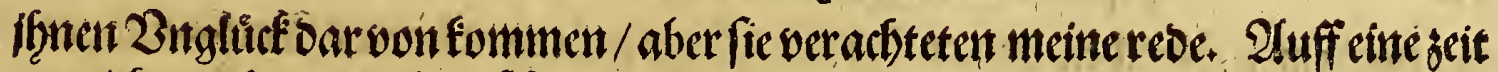

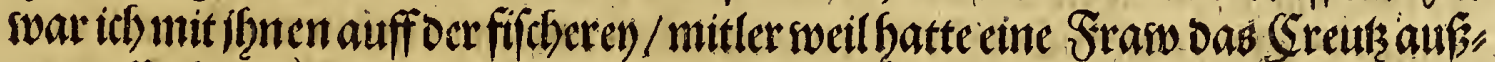

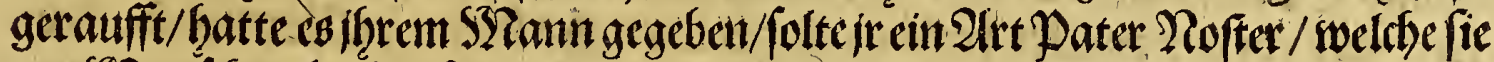

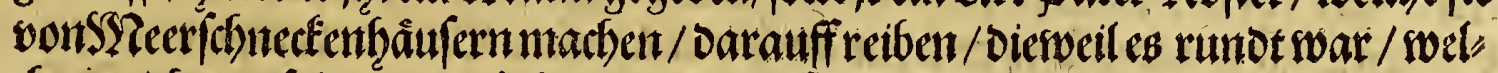

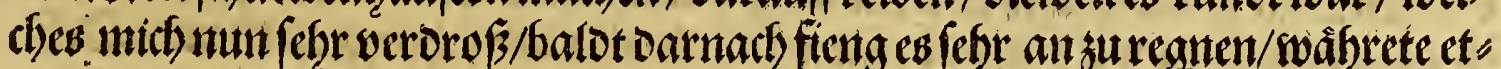
licbe Eage. Sickamen in meine Şutten / begerten / Sch folte mit meinem Gott

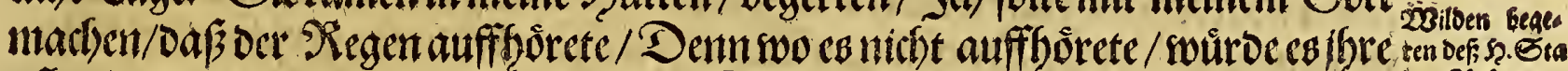

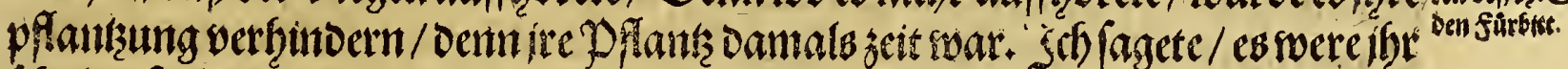

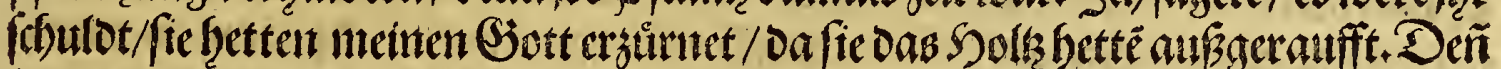

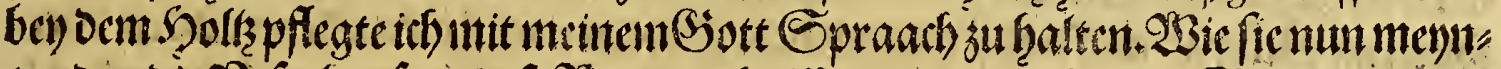

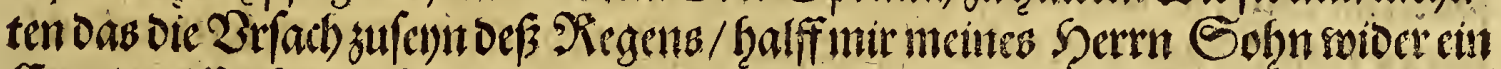

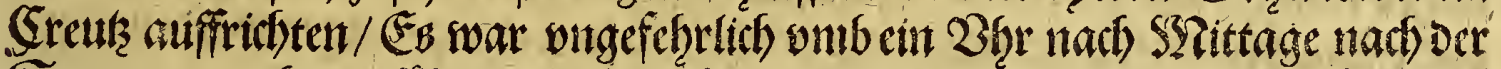

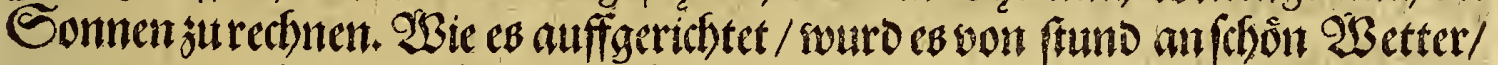

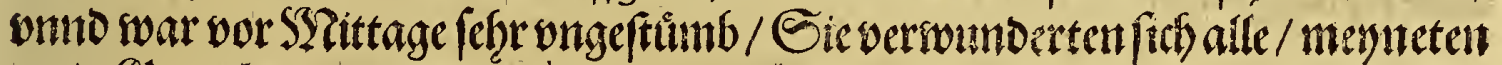
mein $\mathfrak{o t t}$ thet wab ich fooltte.

\section{Capittch.}

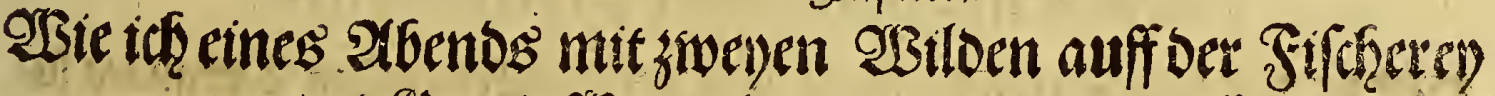

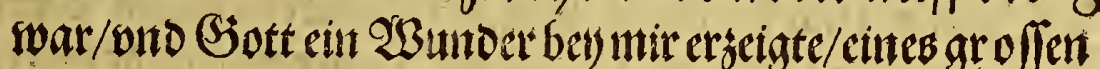
Xegens vno 2 ngewifters halben.

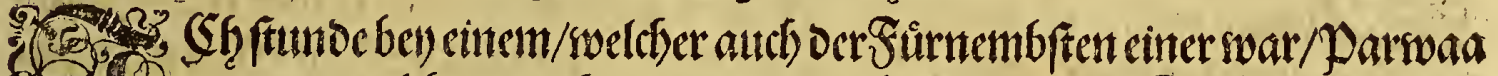
(2)

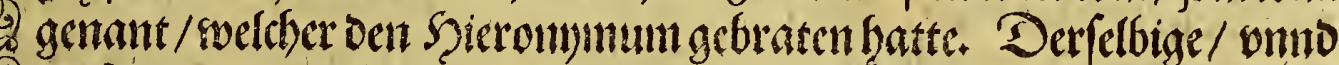

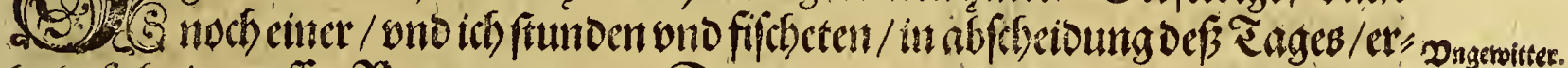

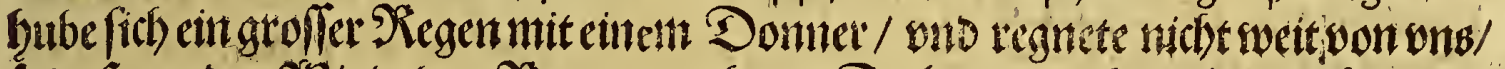

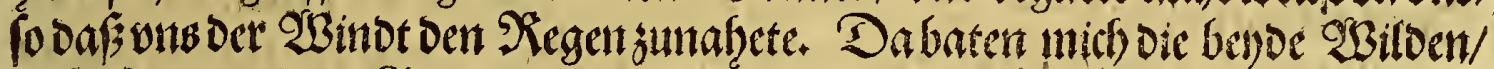

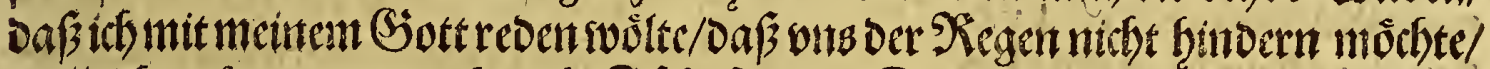

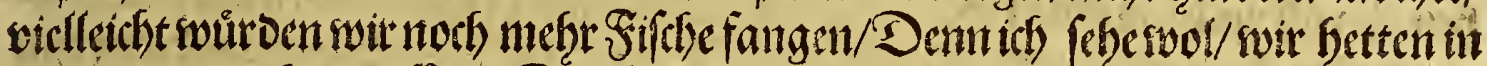

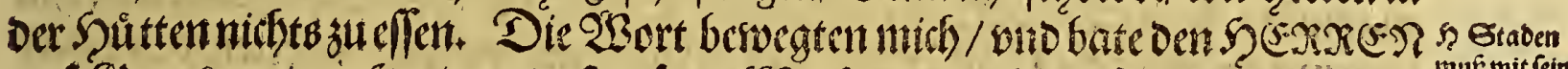

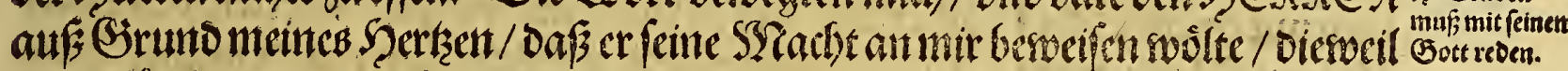

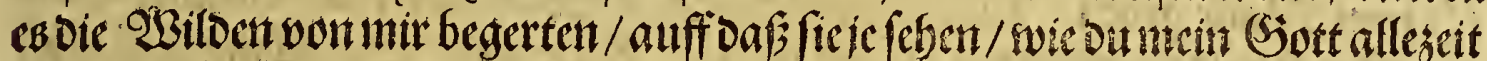

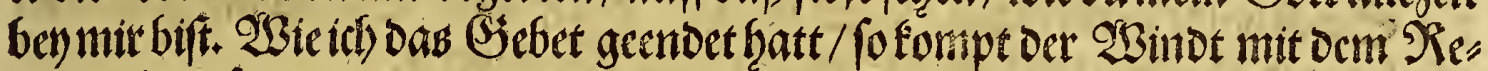

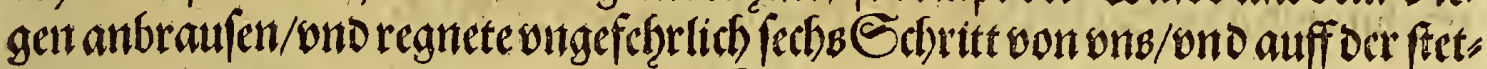

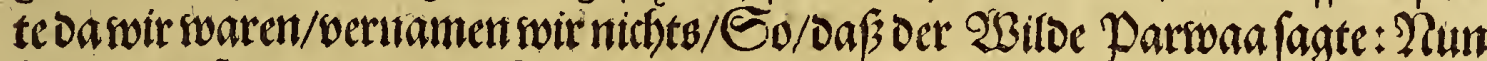

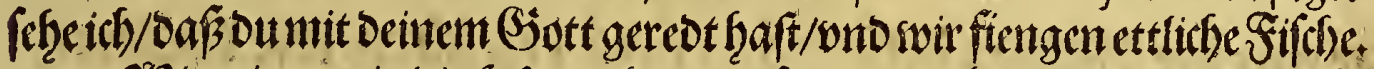

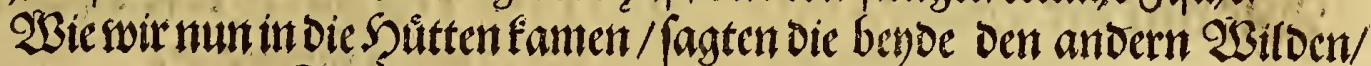

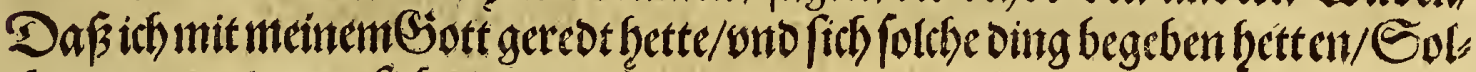
ches bersunderten fich oie antocn.

XLIX. Sapittel.

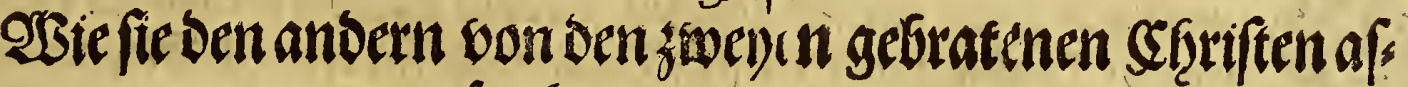
fen/s)ieronmmus genannt.

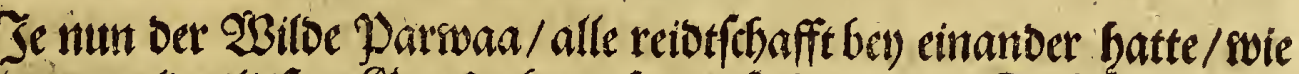

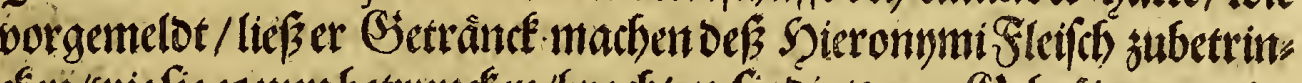

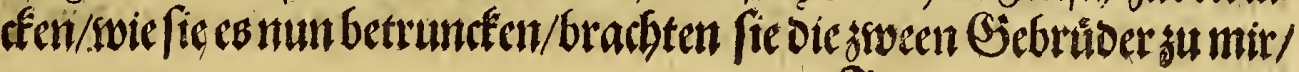

$$
\text { I if ons }
$$

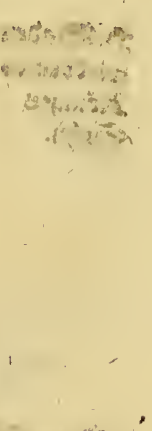




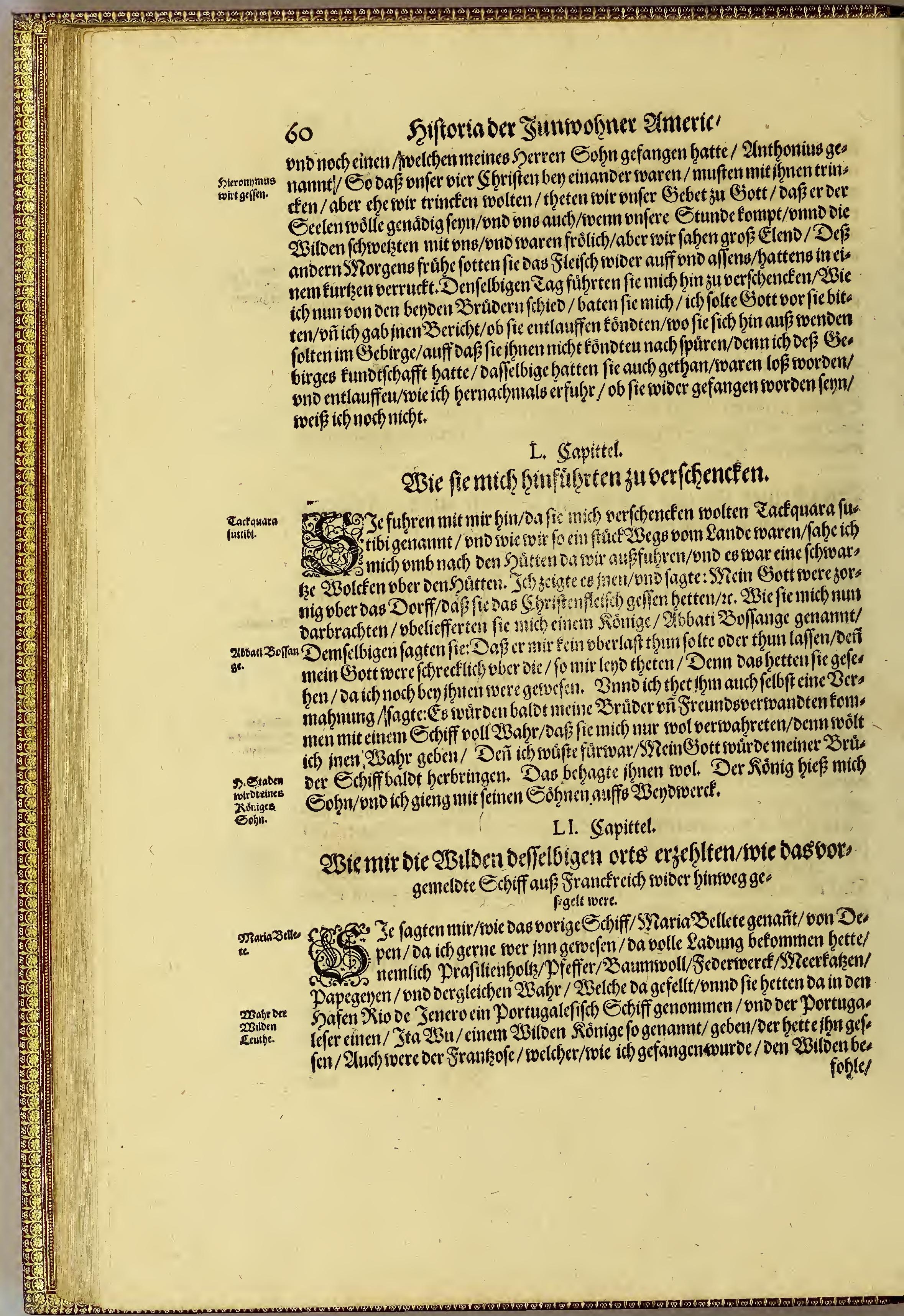


Das britte Thęl.

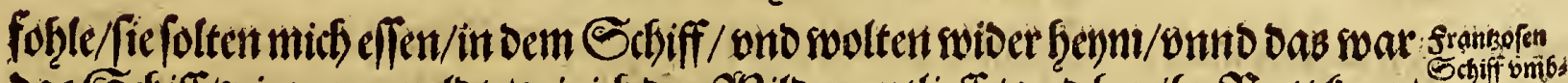

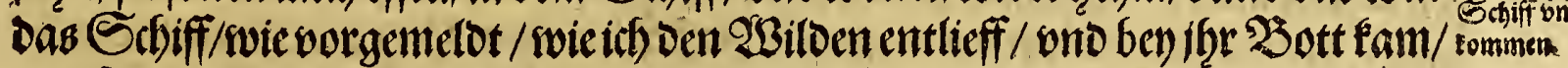
bno /ie mich nicht innemen swolten/Daflelbige Sethiff war vombfommen/auffoer

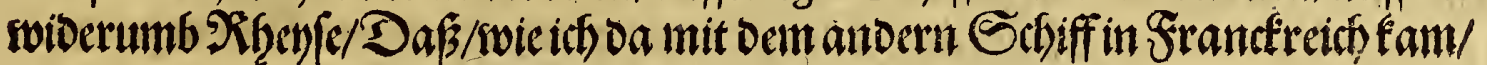

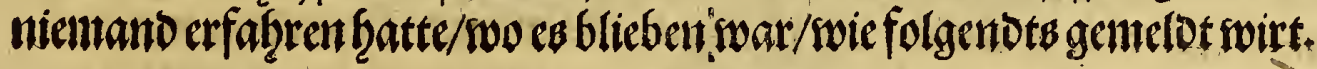

\section{Sapittel.}

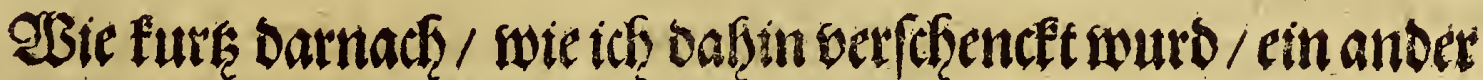
Erhiff auß Frantéreich Eam/oic Ratharina be Battauilla genomnt/

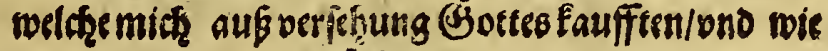
es fith jutrug.

\section{5}

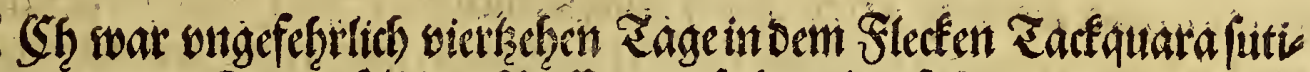

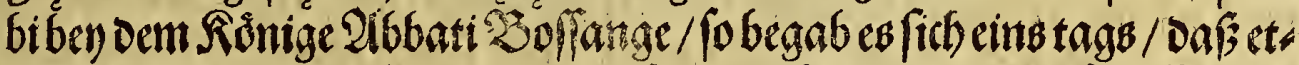

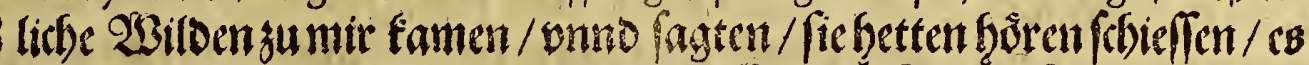

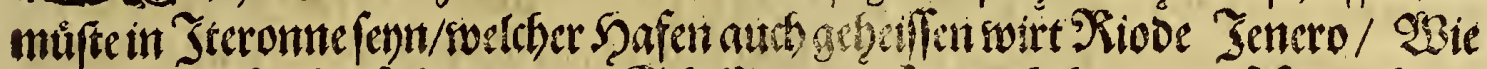

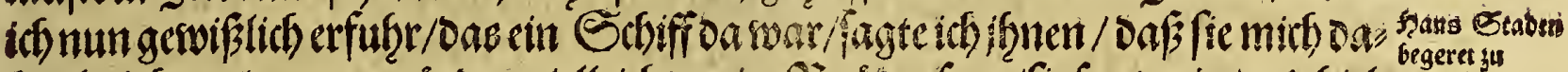

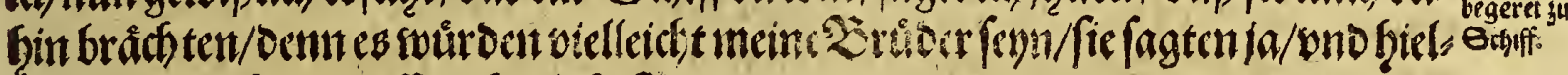
tert mich gleiclywol auff noch etlicise Tage.

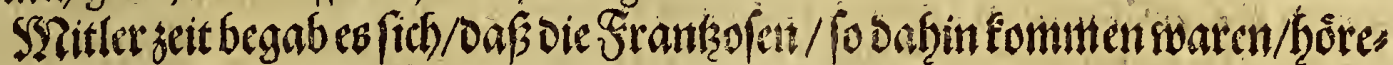

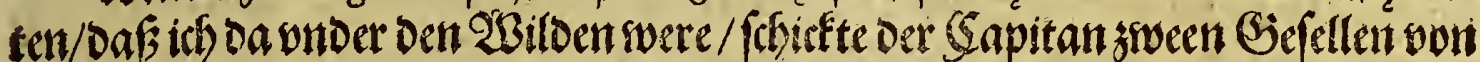

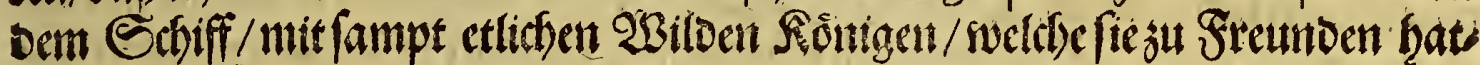

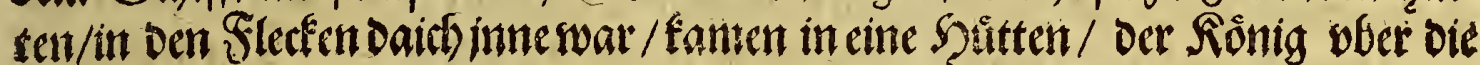

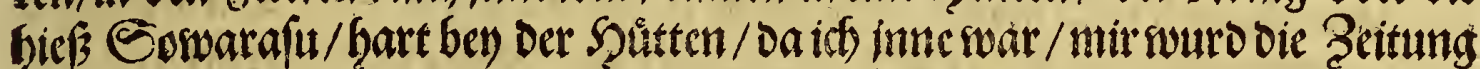

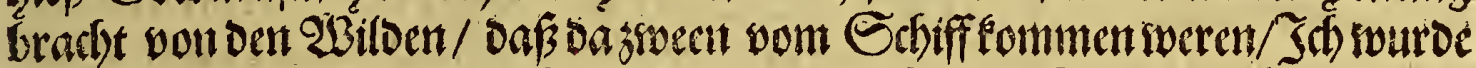

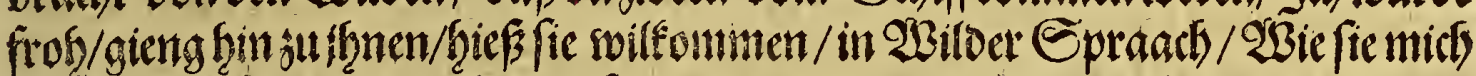

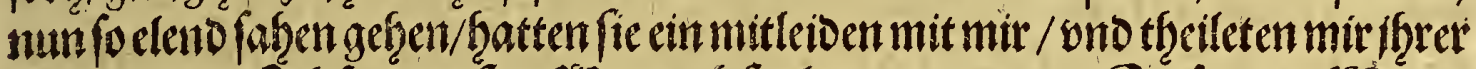

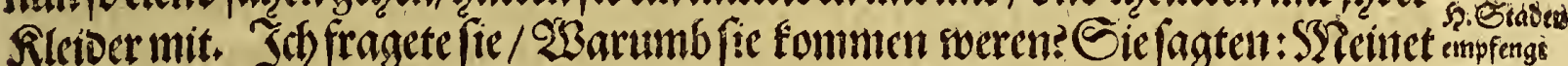

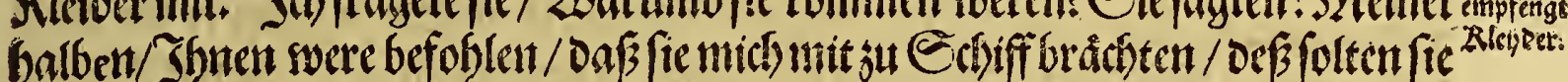

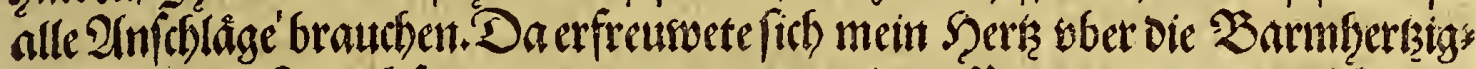

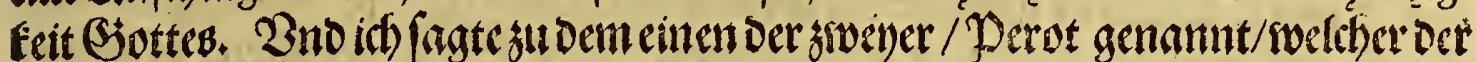

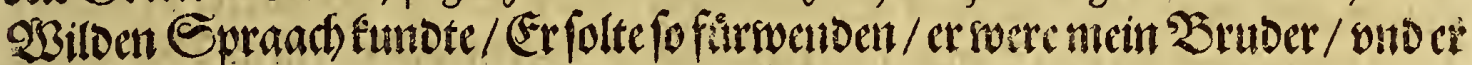

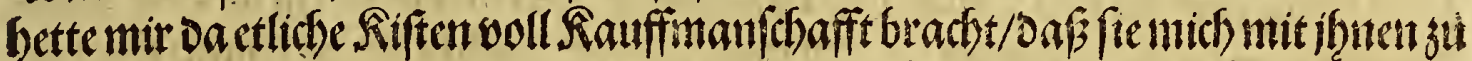

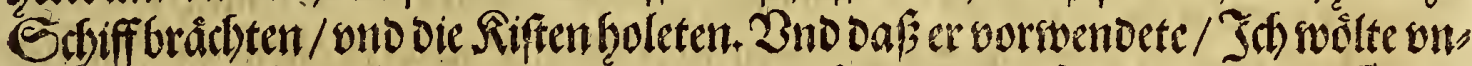

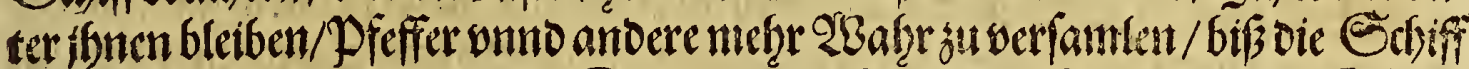

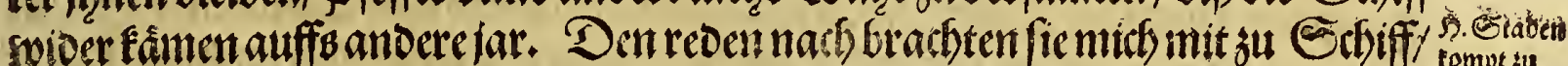

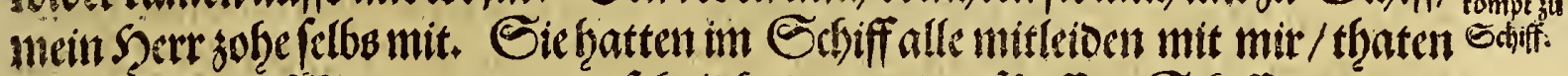

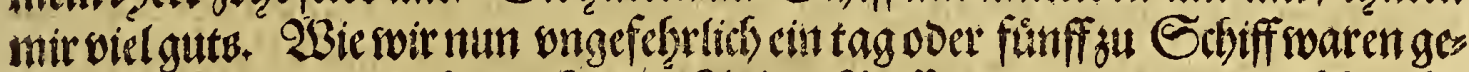

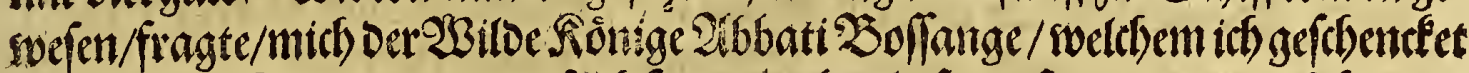

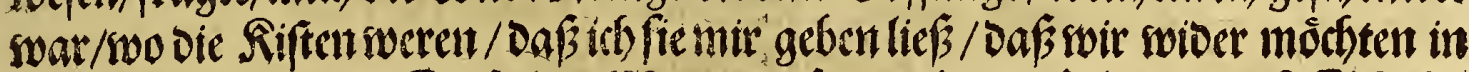

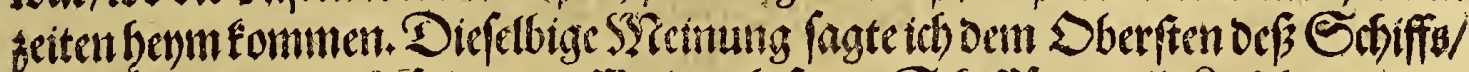

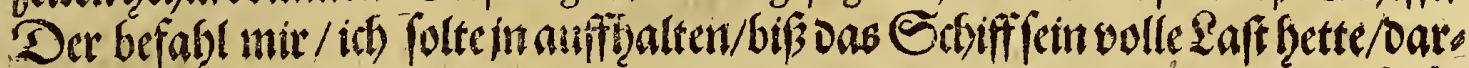

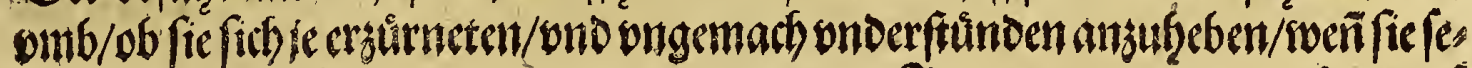
J in. hen 


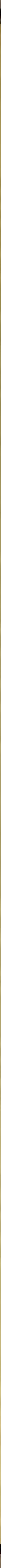


LIII. Sapittcl.

OBie bie Sberften bef Sefriffs genennt waren/ wint wo bas

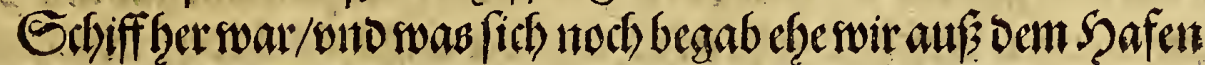

fufren/ondowie lang wir auffoer Regle nach Jrand",

reich waren.

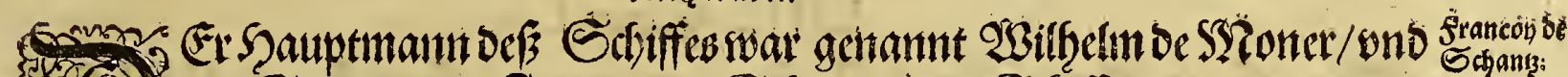

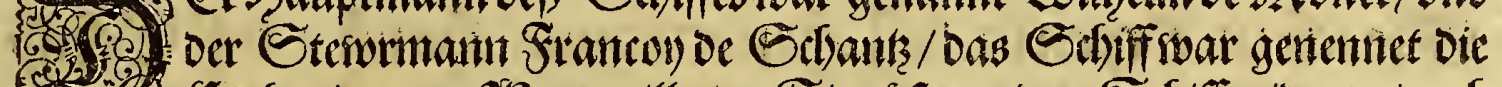

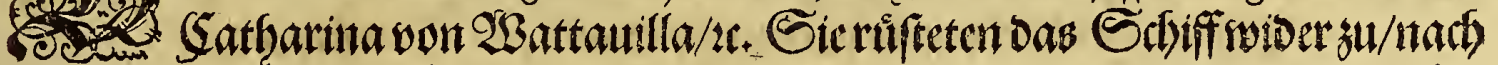

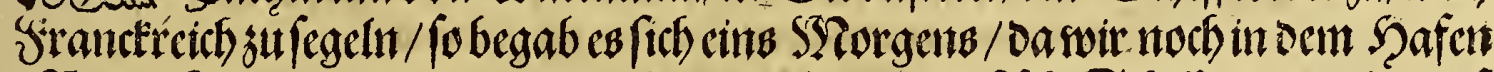
(Pio be Jenero genannt)lagen/fame ein Portugalefilfh) Sebifflein/ wodte aus

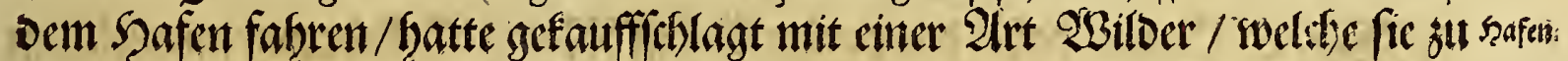

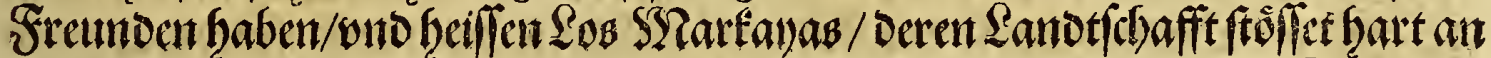

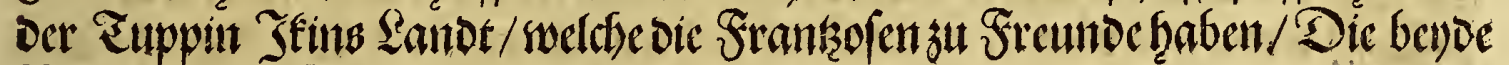

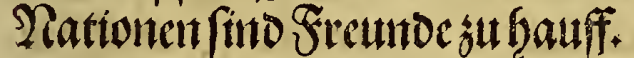

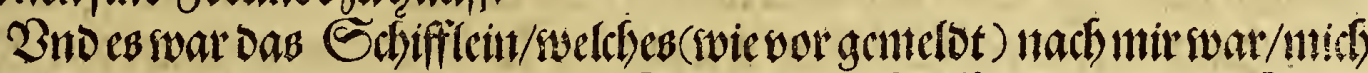

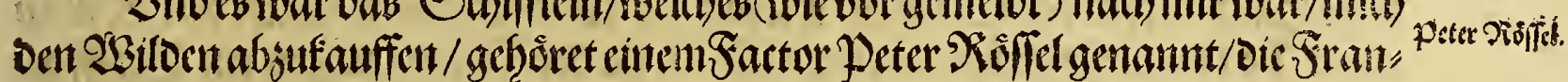

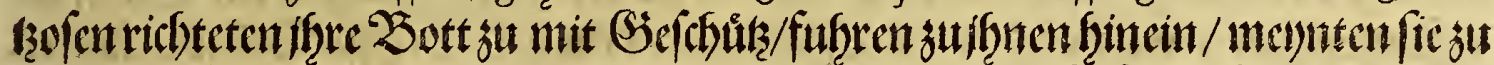
nement. Ramer mich mit / Da

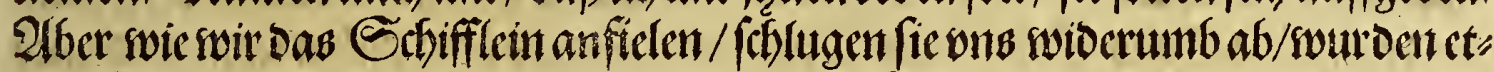

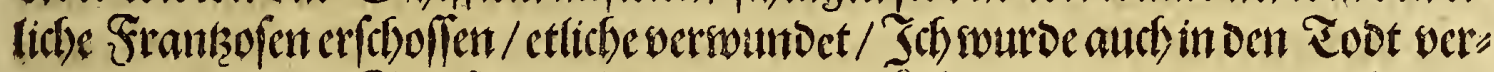

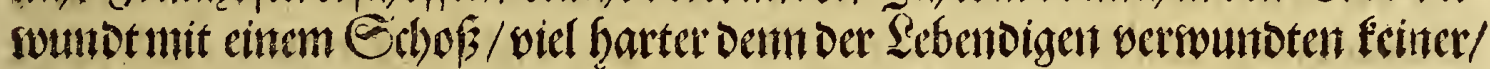

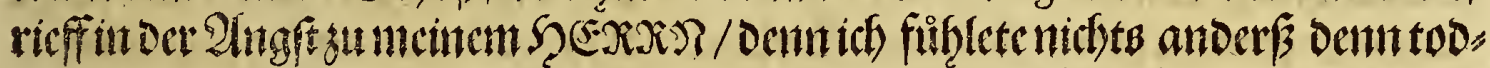

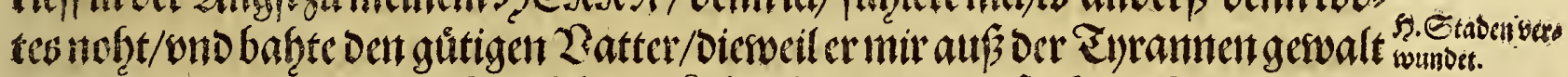

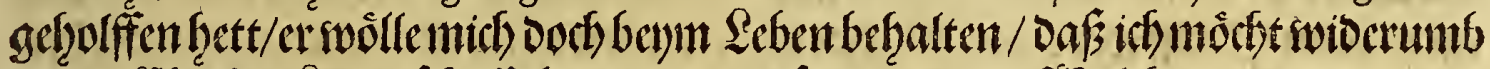

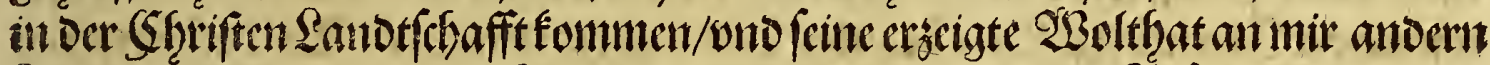

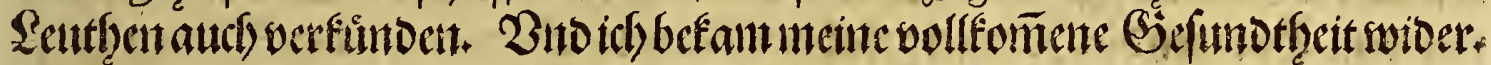

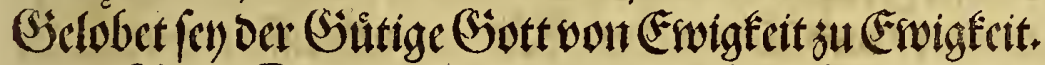

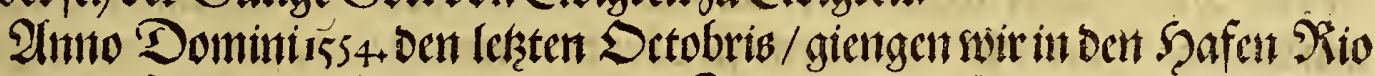

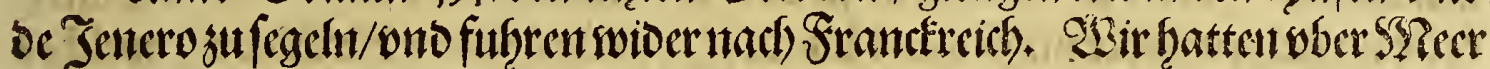

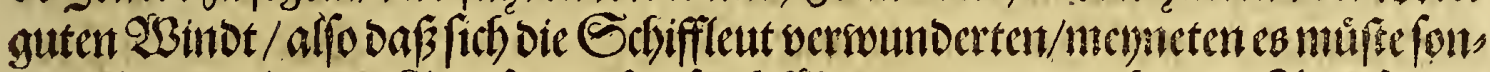

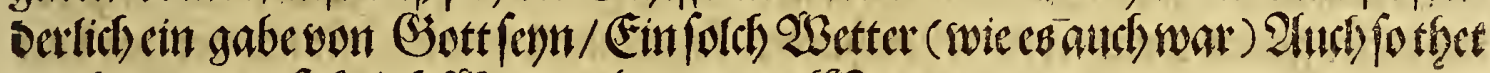

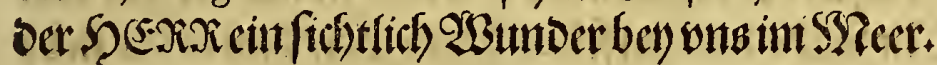

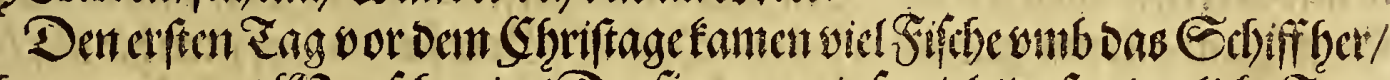

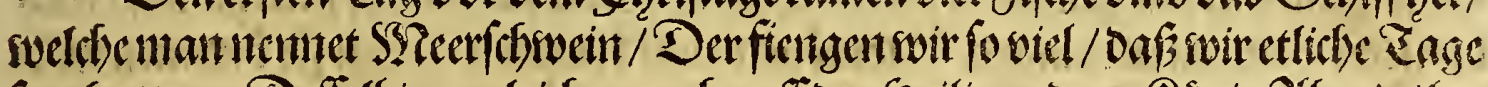

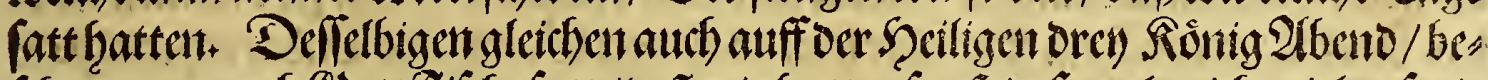

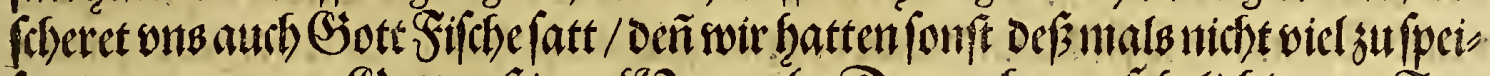

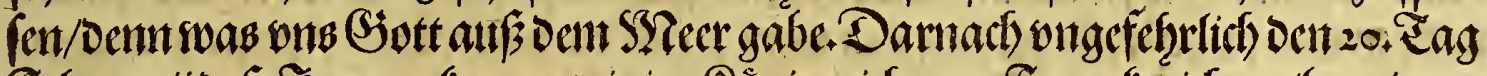

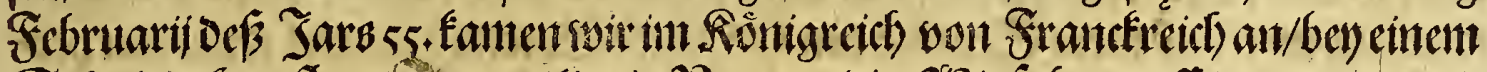

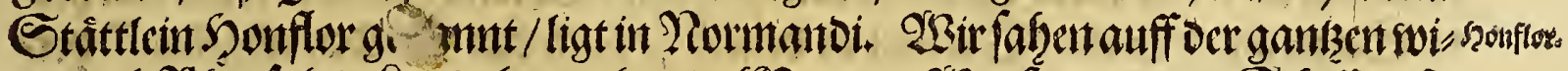

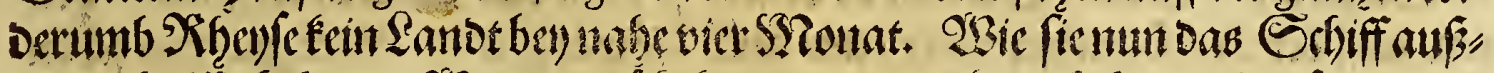

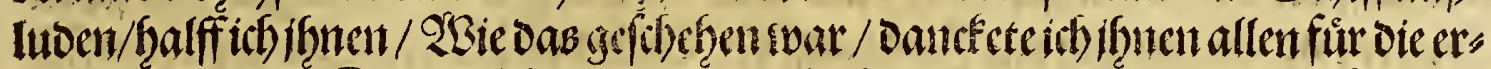

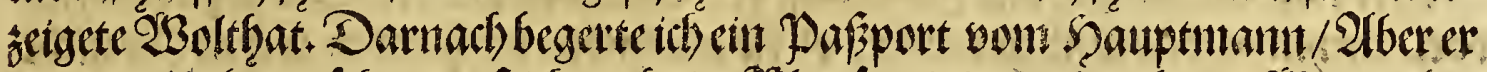

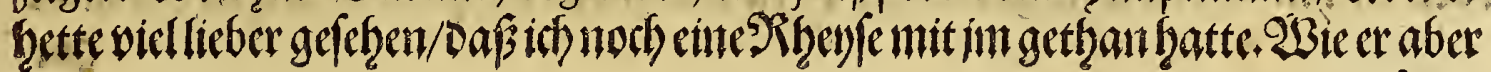

faf̧el 


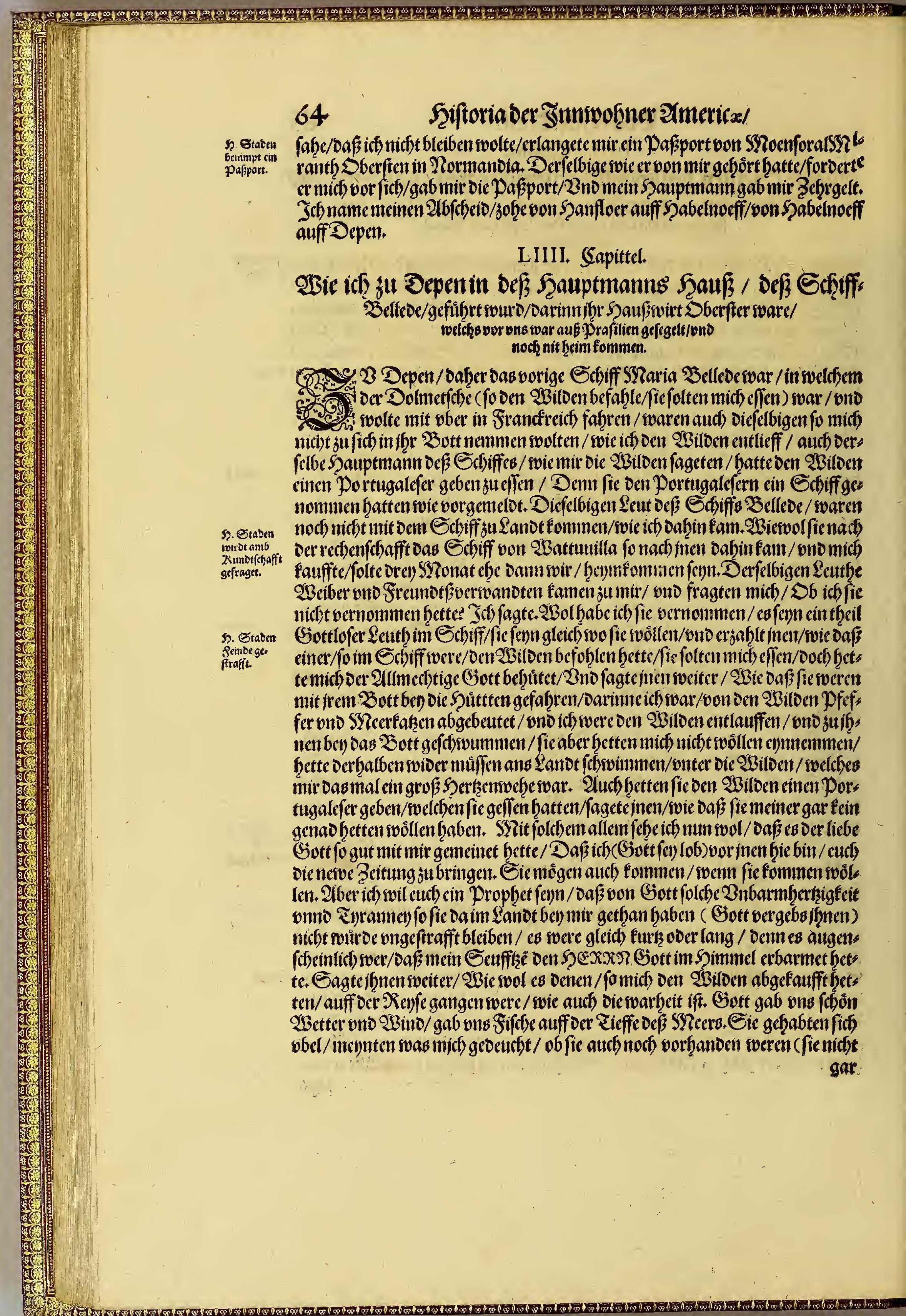




\section{Jas britte Thentl ondthe}

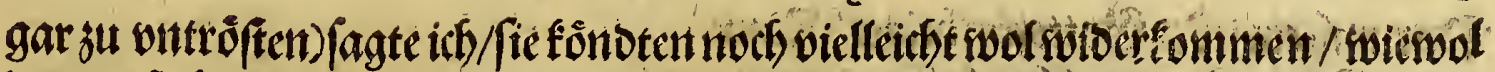

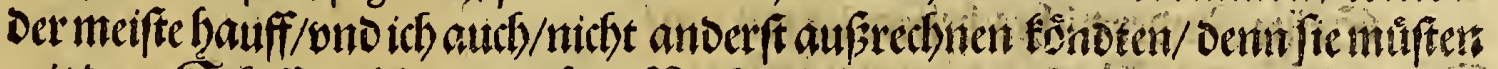

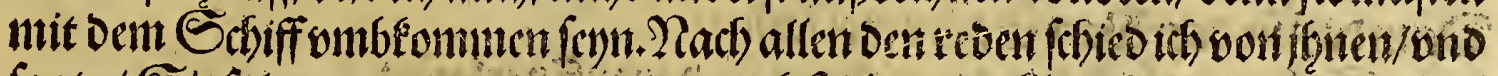

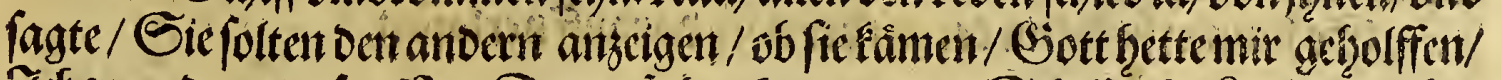

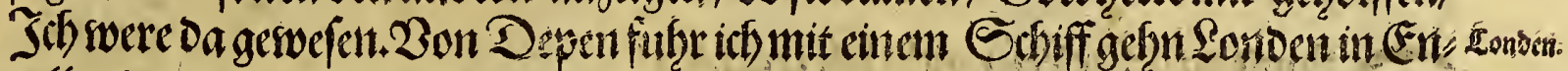

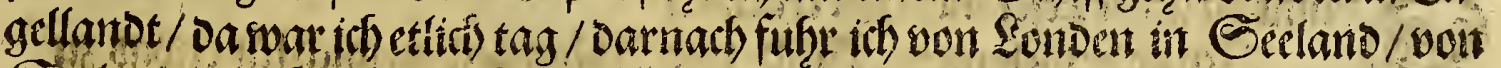

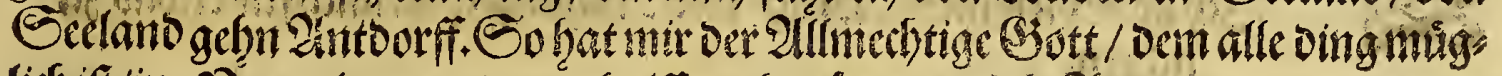

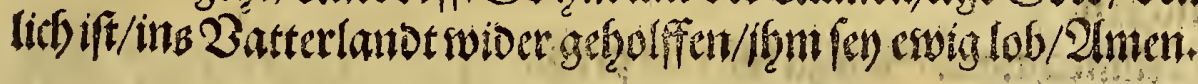

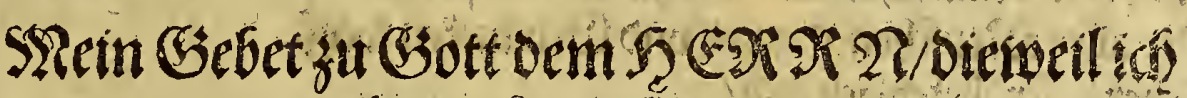

$$
\begin{gathered}
\text { in oer SBiloen Leuthe (Serwaltwarmich } \\
\text { sueffon }
\end{gathered}
$$

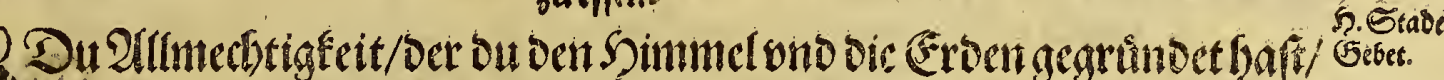

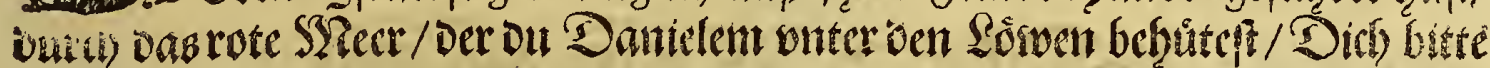

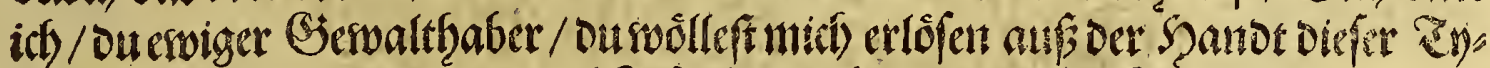

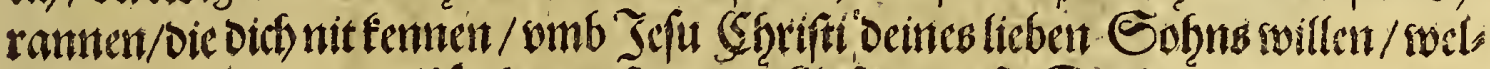

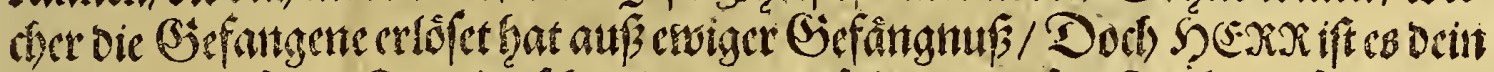

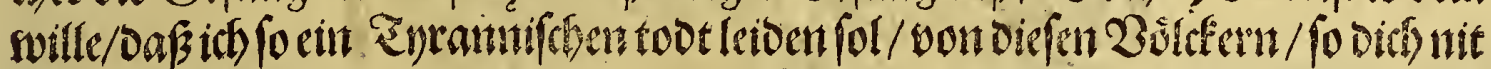

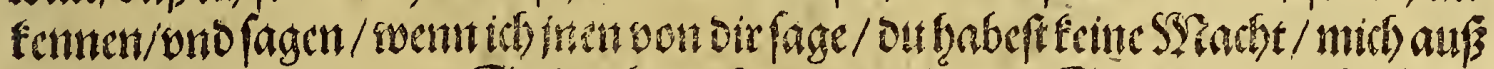

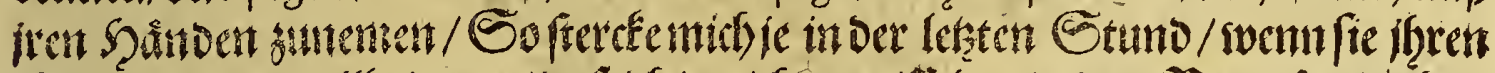

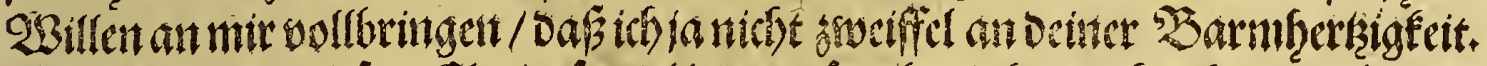

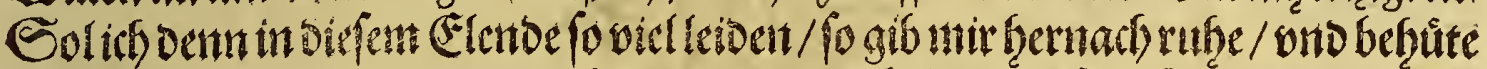

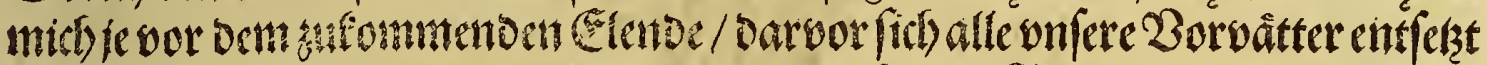

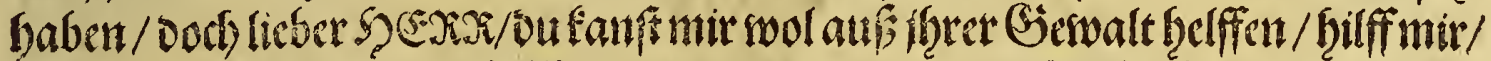

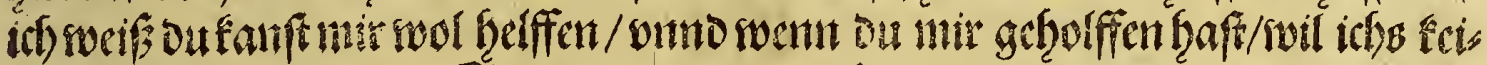

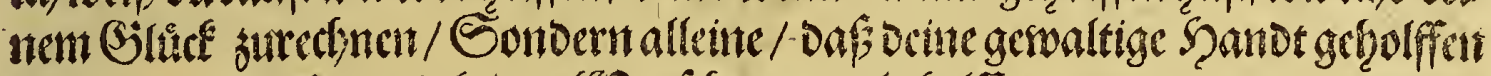

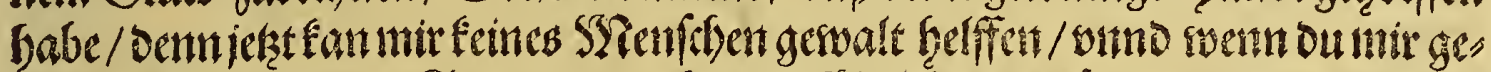

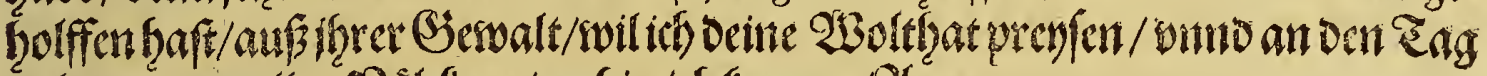

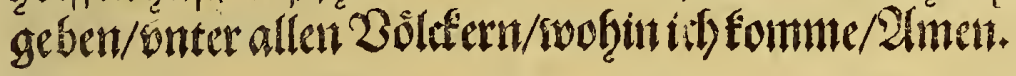

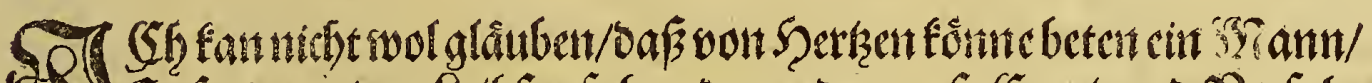

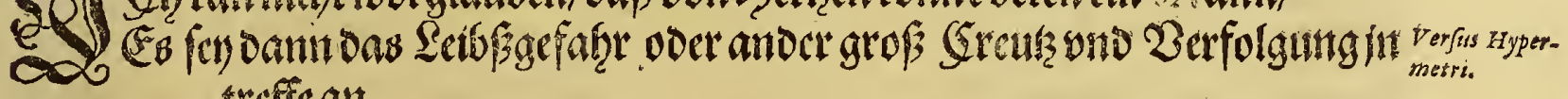
treffeant.

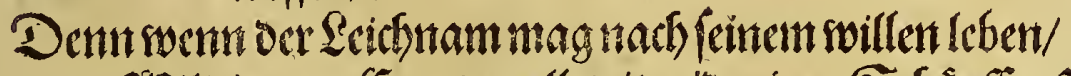

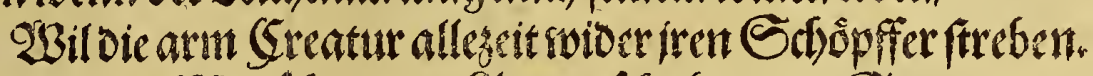

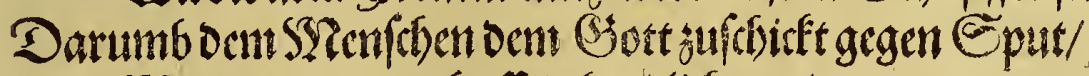

SYiennet er eb fwarbafitig bertslich gut/

Daranniemanot sweiffel habc.

Soldhes iftein Sottesgabc.

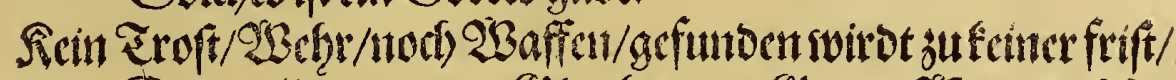

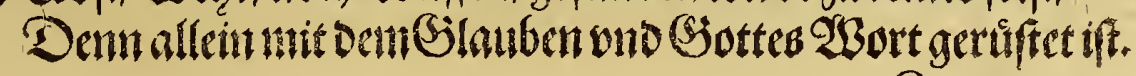
$\stackrel{\mathfrak{K}}{\text { Darumb }}$ 


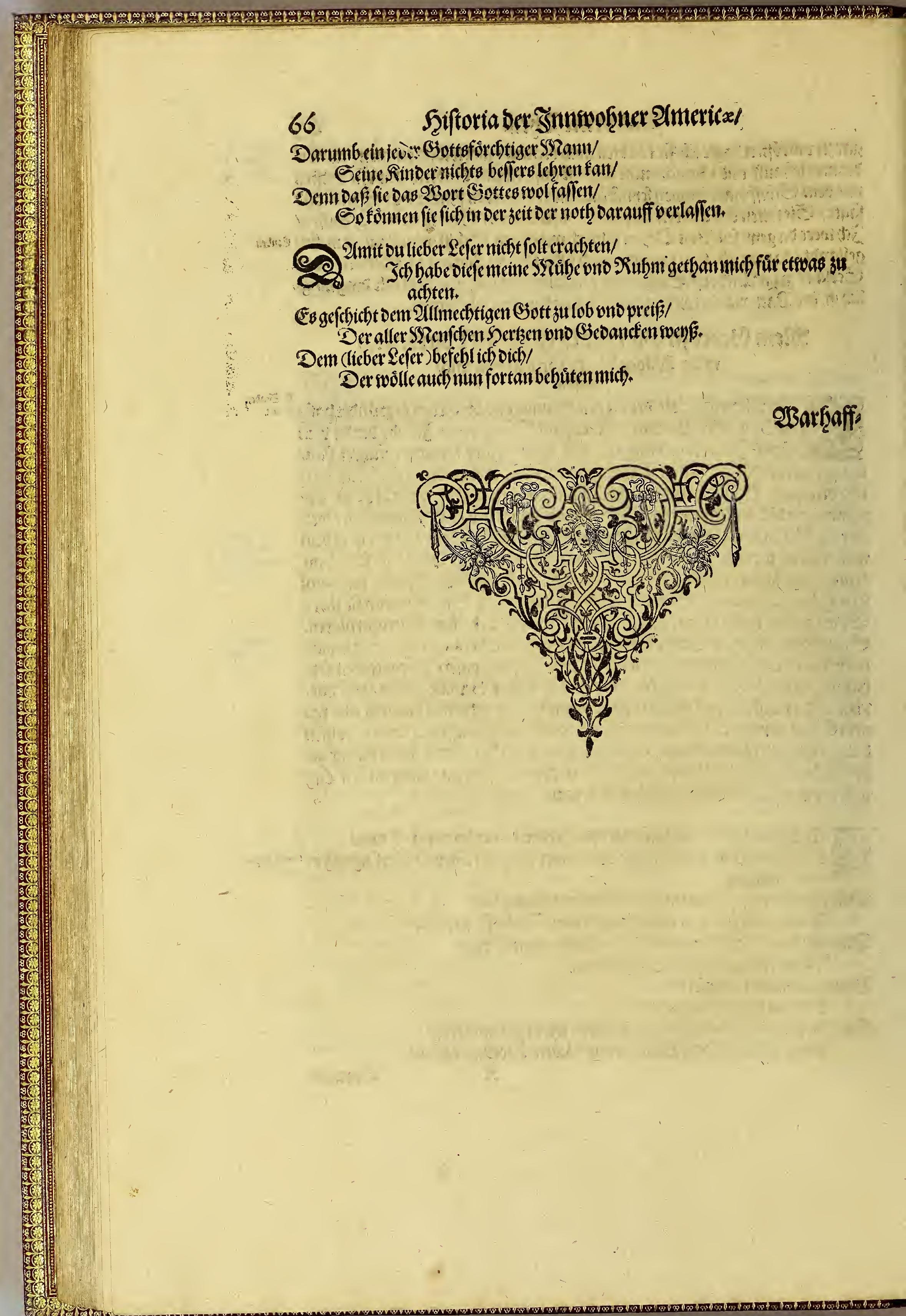




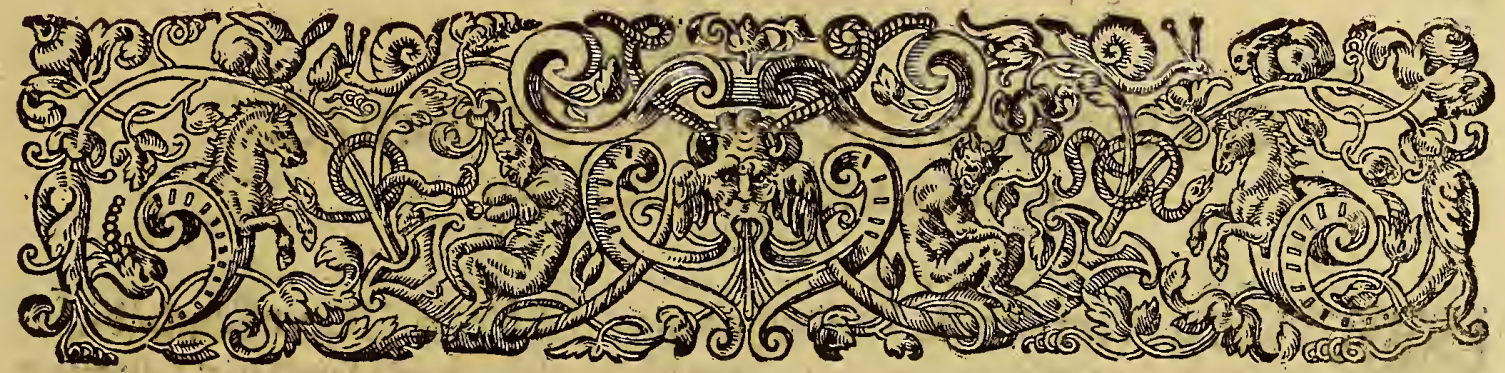

\section{Sriarbaffitiger futrber \$2ericht allet}

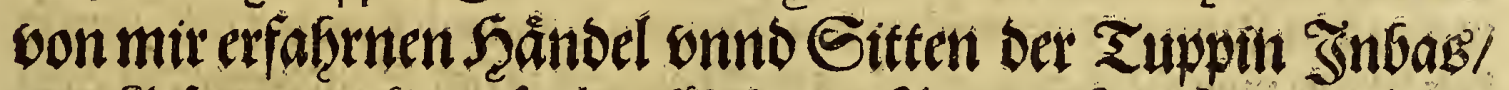

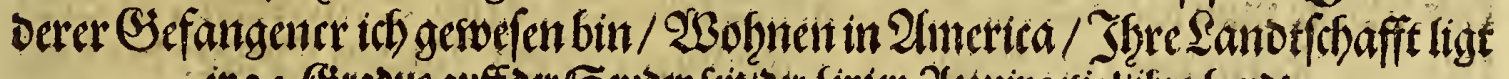
in 24. Sirabue auffoer Seuben feit/oer sinien 2lequinoctial/ifier sandes reshafft fioffer an ein Xefiet/2Rio be Jencro genannt.

I. Sapittel.

Wiefich bie Sctiffafint anfathet/au/zPortugal nach Pio be

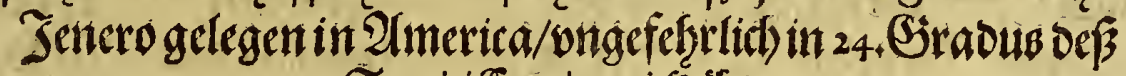
Fropict Capricorni Şofice.

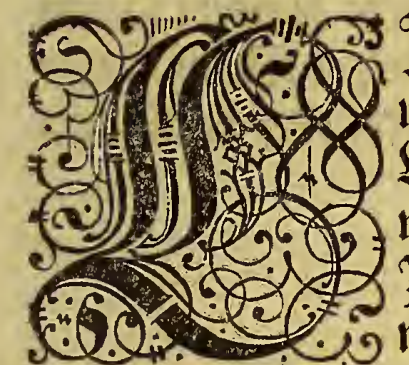
Silebona / cinc Statt in Portugal gelegen / int

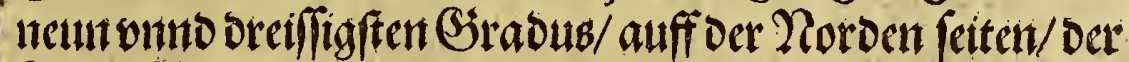

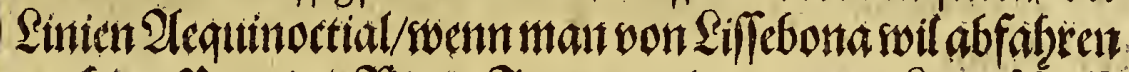

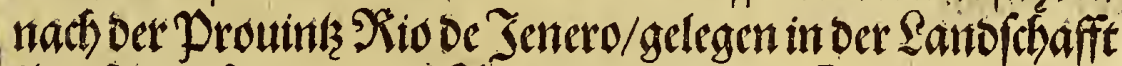

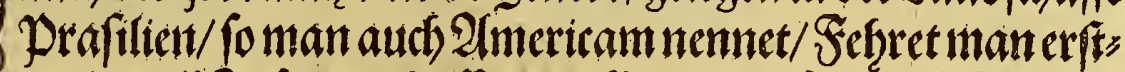

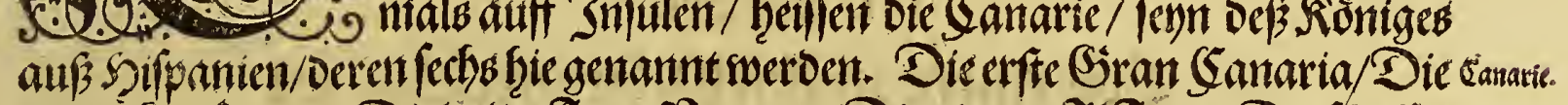
ander Eanferutta/Diec oritte Forte 2 entura/Die bierote \I Ferro/ Die fünffite

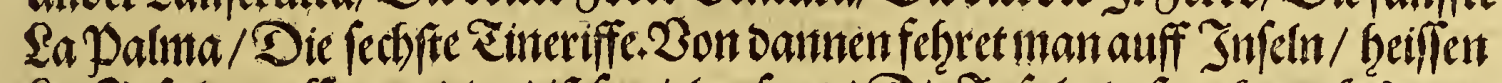

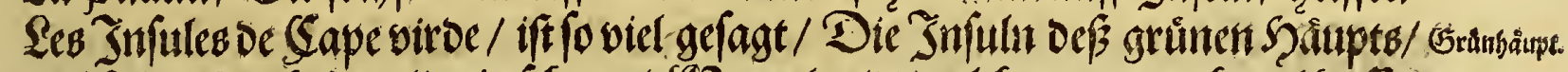

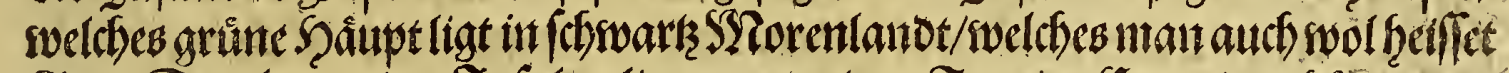

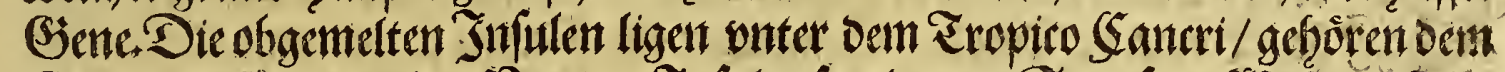

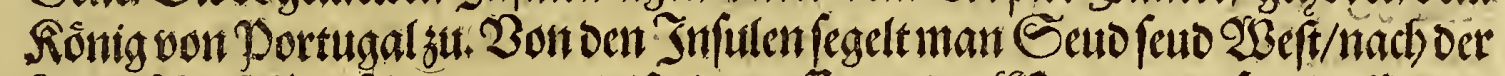

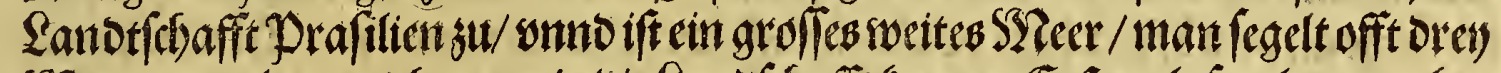

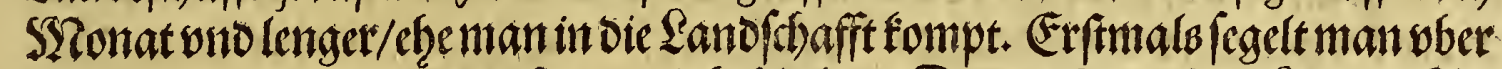

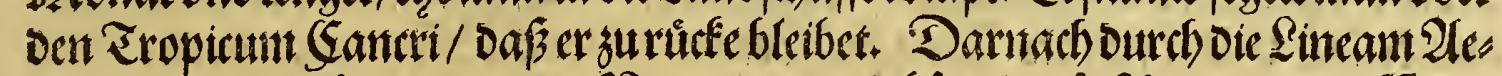

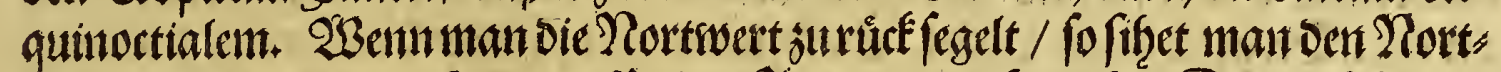

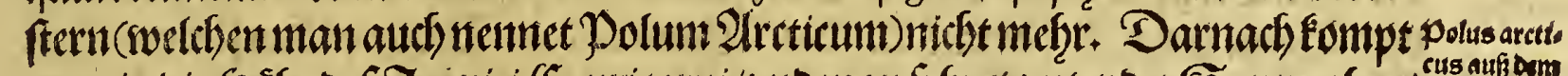

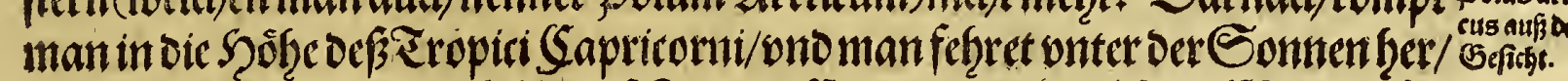

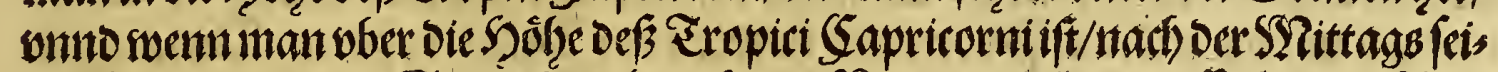

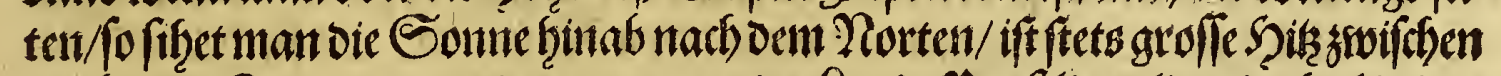

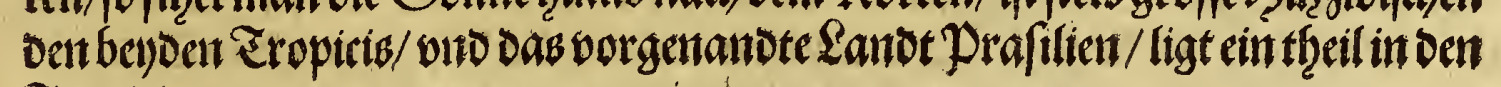
Eropicis.

$$
\text { R if II. Ca: }
$$




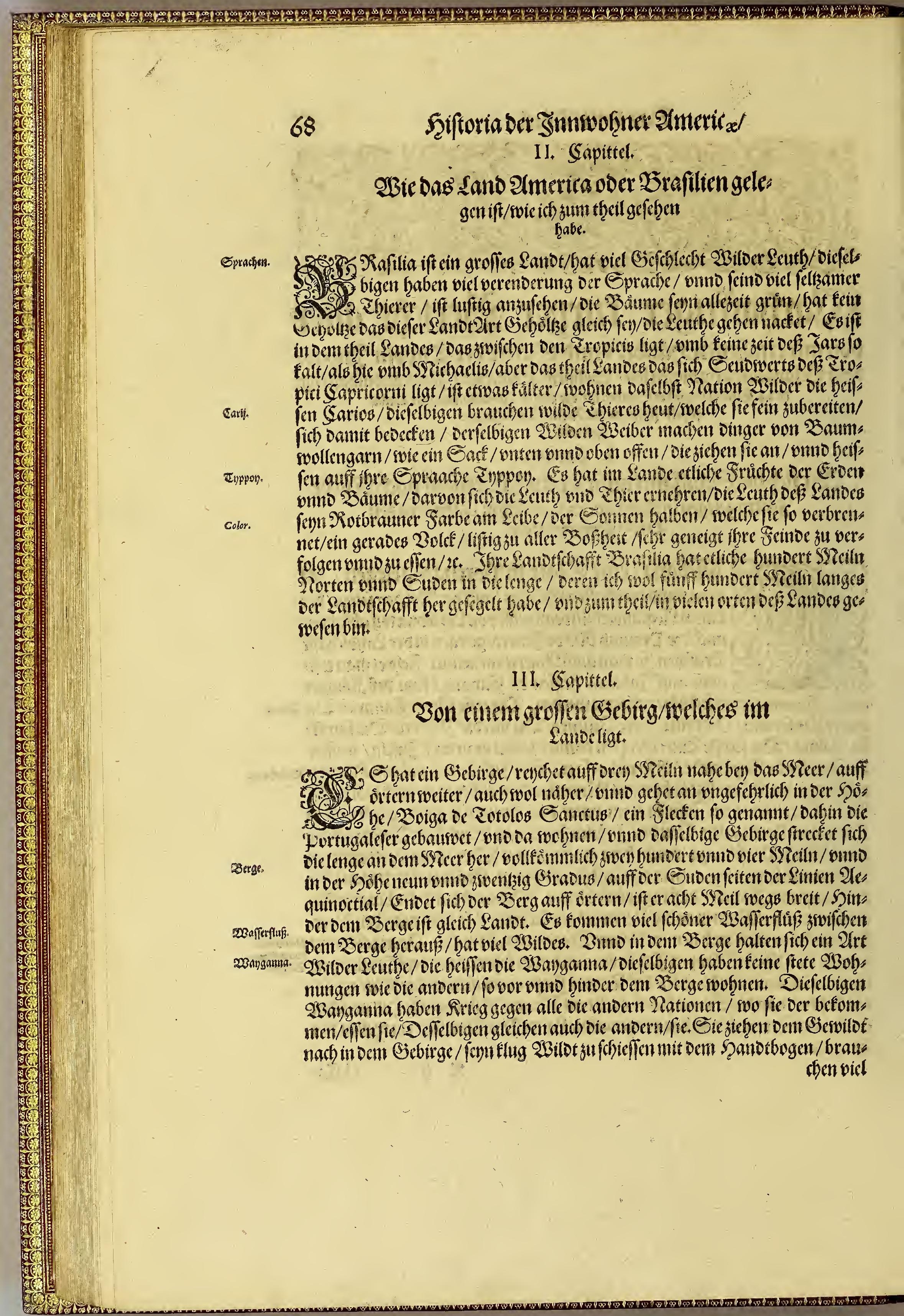




\section{Das britte SGeil.}

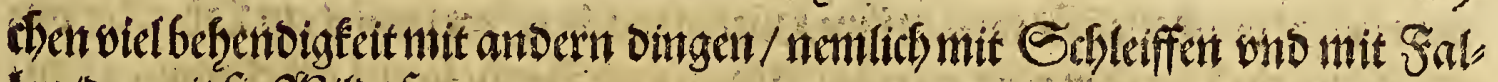
Itn/Darmit fie 93 ild t fangent.

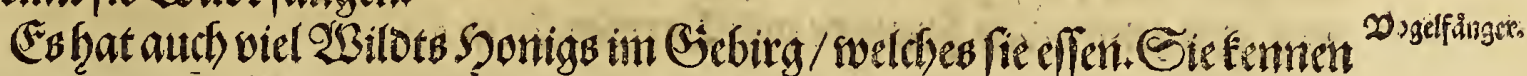

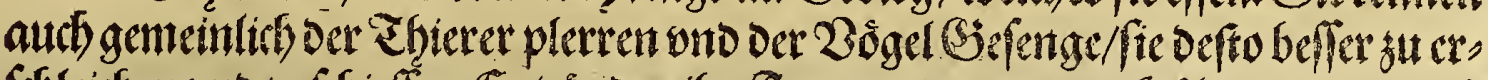

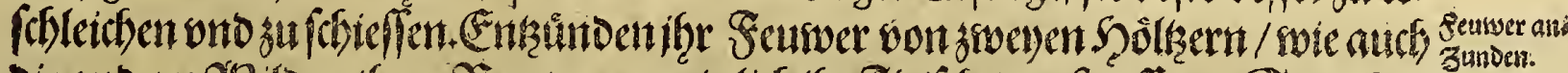

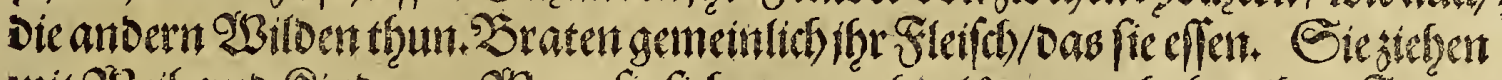

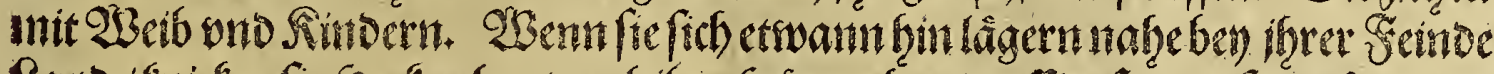

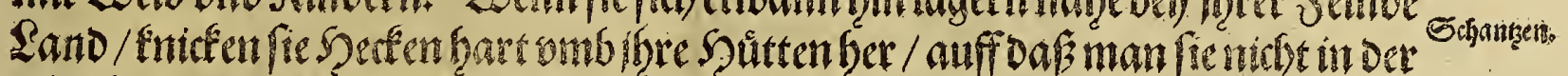

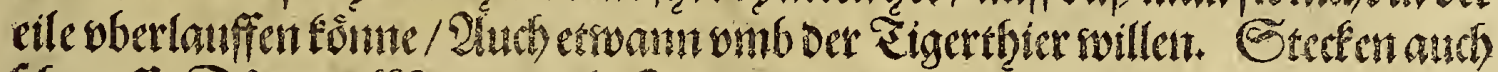

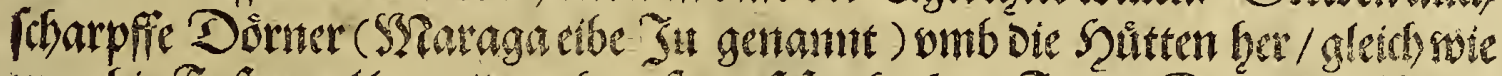
man bie Fuf

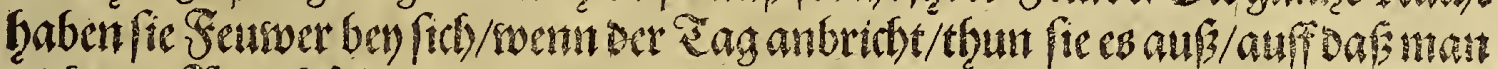

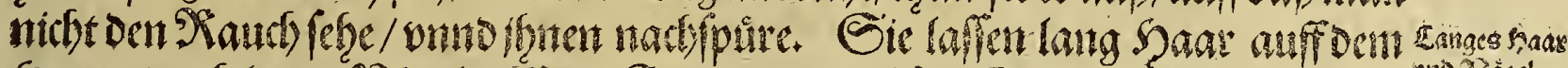

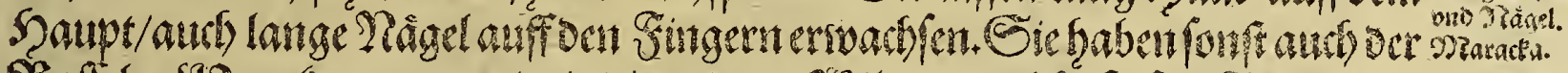

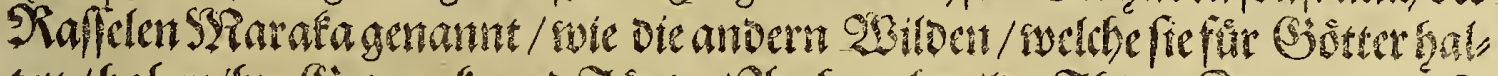

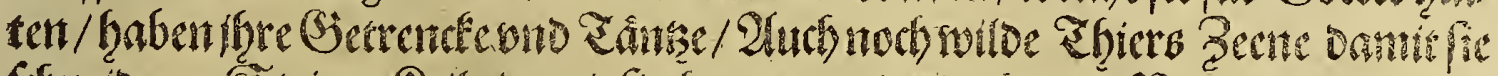

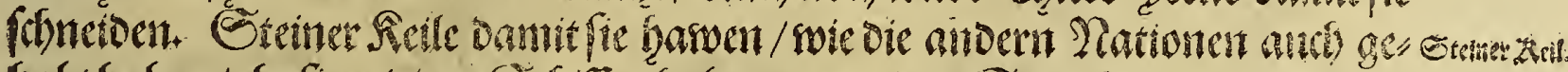

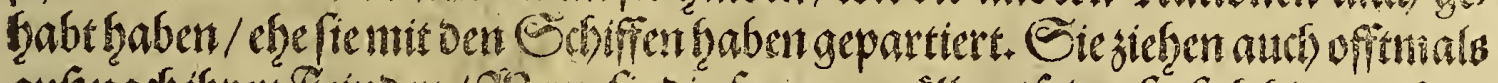

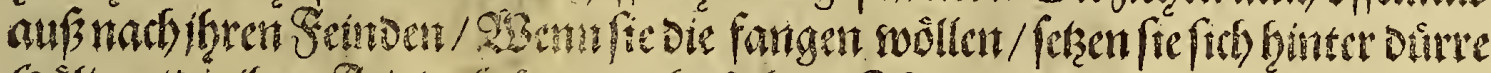

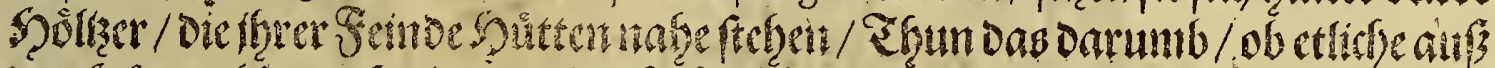

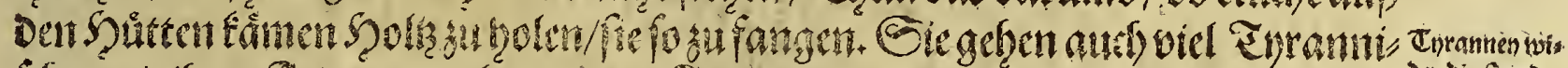

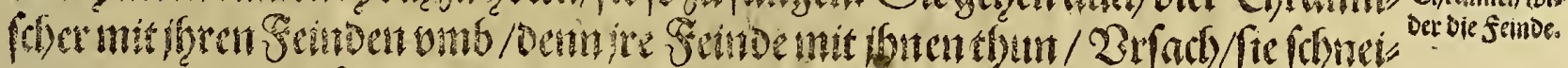

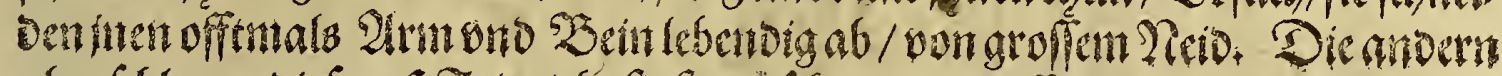

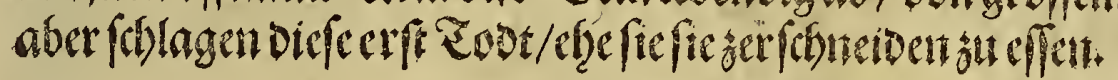

\section{IIII. Sapitteh.}

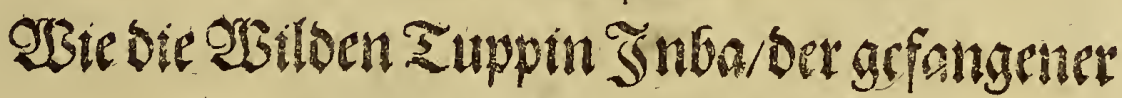

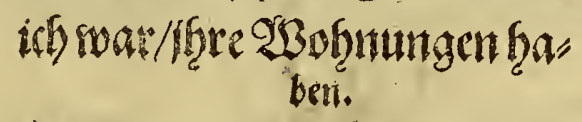

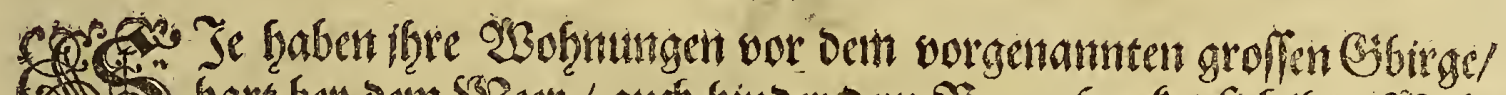

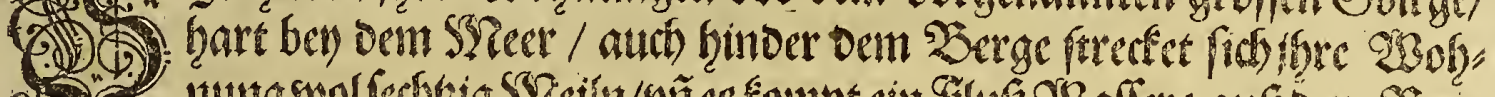

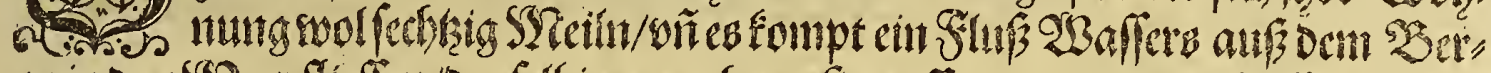

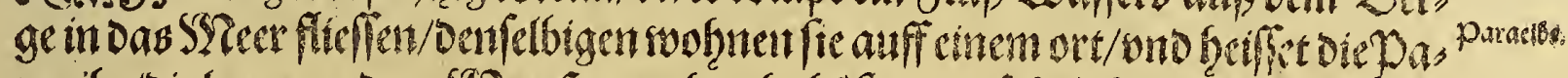

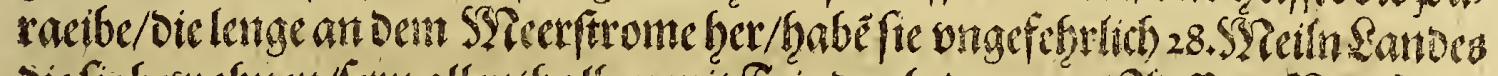

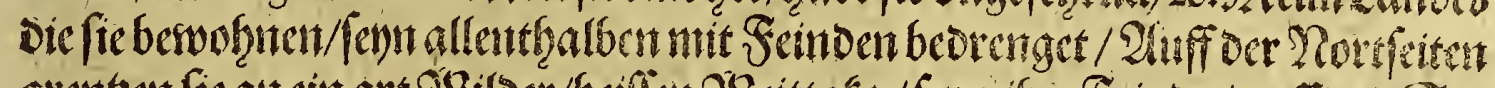

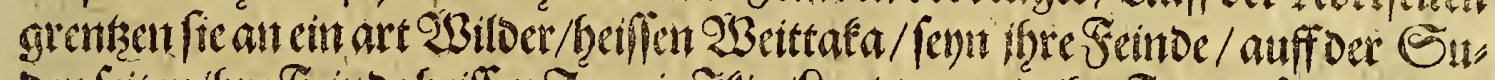

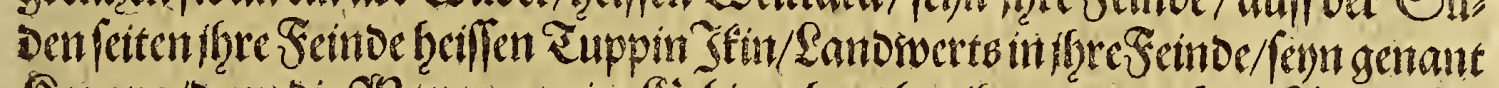

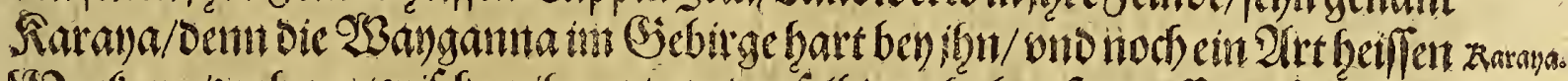

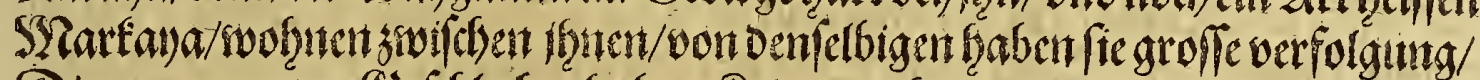

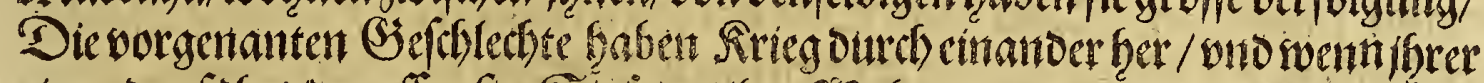

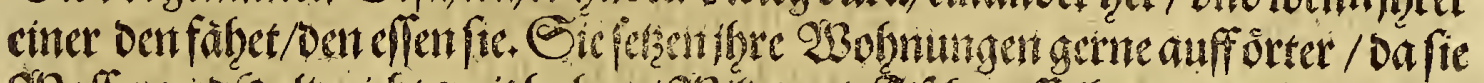

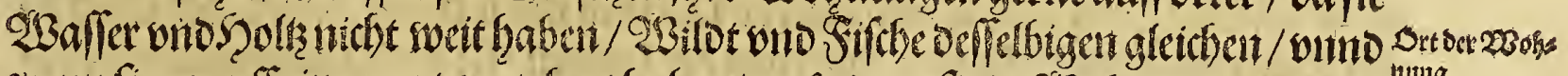

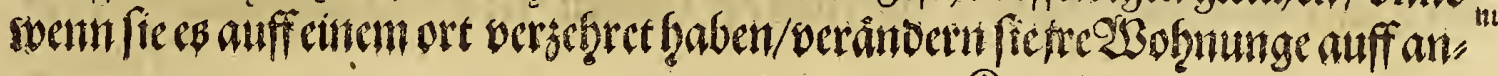

$$
\text { oij Dere }
$$




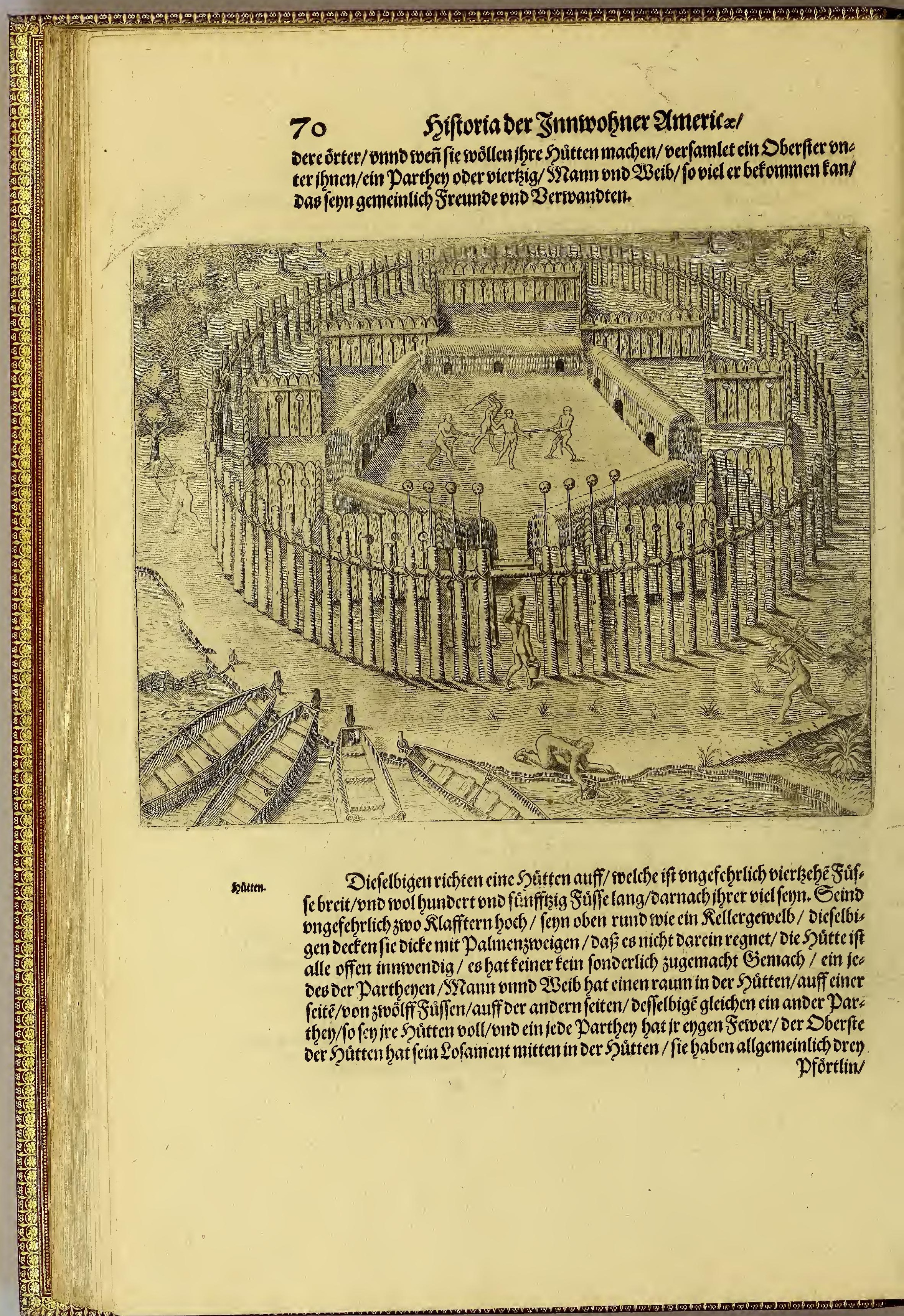




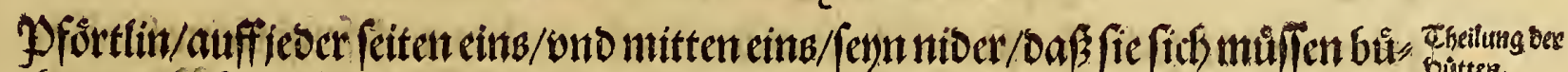

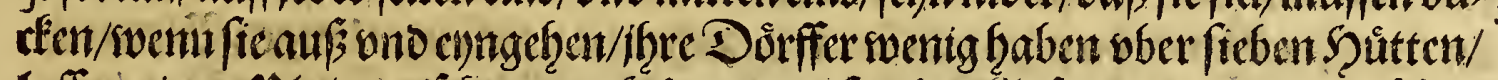

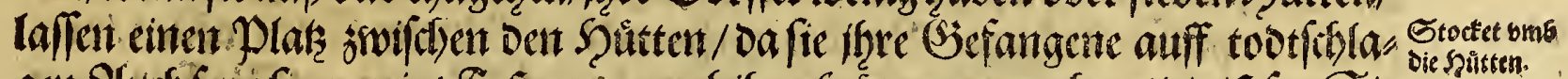

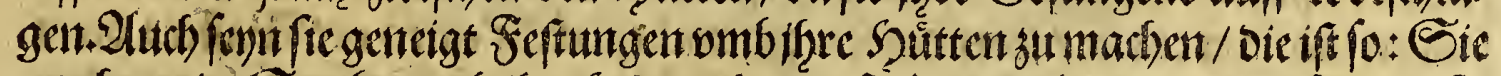
machen ein Stocket omb ifcreşutenter auß Palmenboumen/oic paltentie

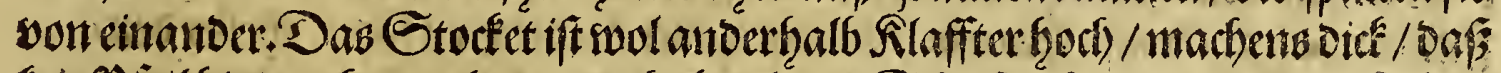

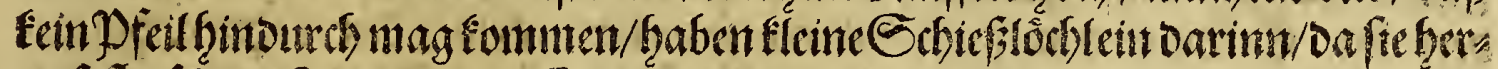

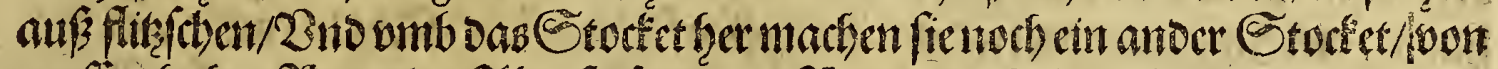

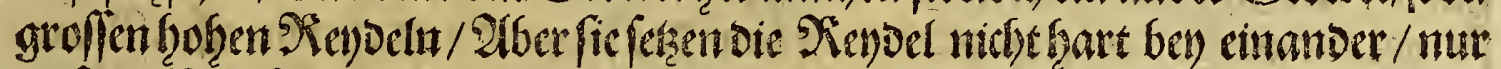

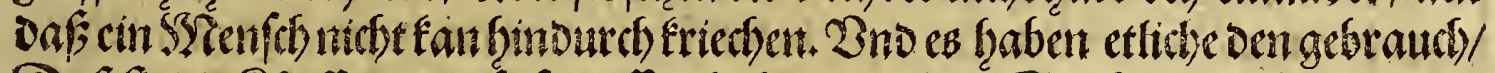

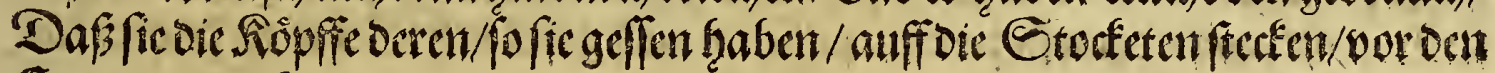
Enngang oer şưttent.

V. Sapittel.

\section{SBiefie Feutwer mactien.}

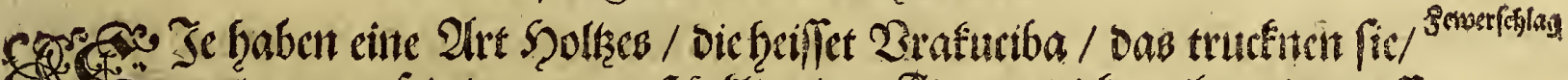

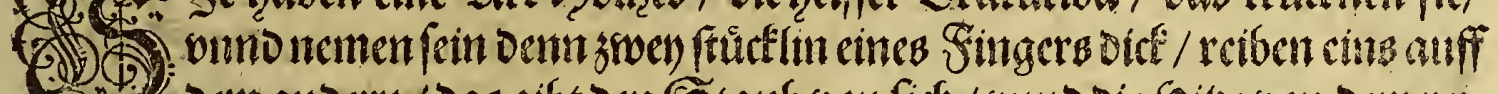

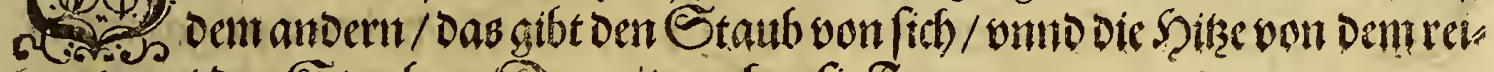
ben fredtet oen Staub an/Sarnitmadien/is Feumer.

\section{Sapittd. Sabrim fie foclaffen.}

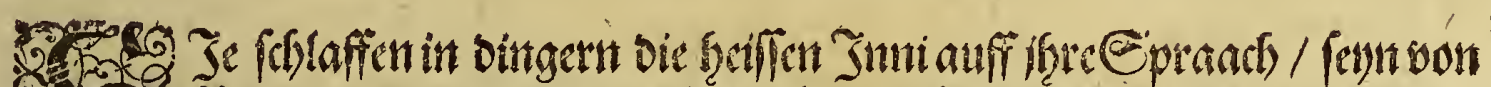

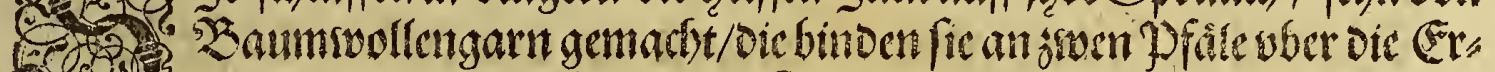

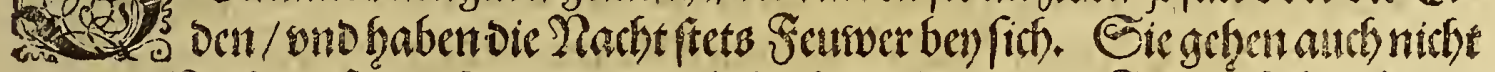

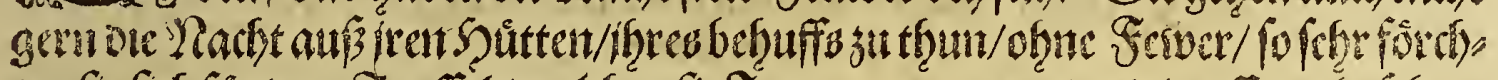

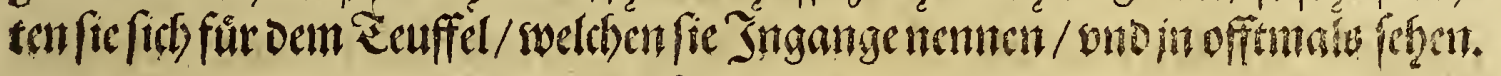

VII. Sapittel.

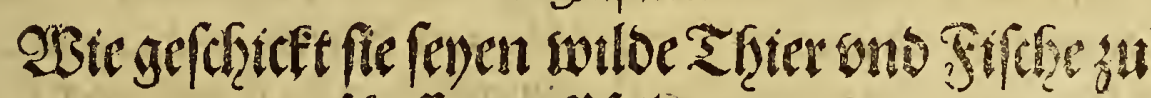 \\ forteffen nit P Peilent.}

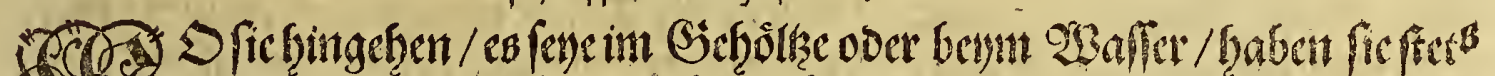

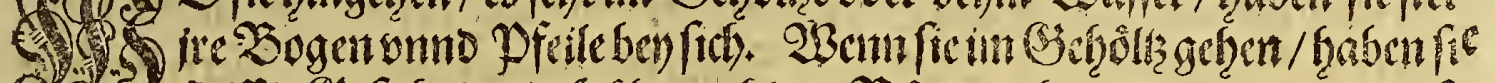

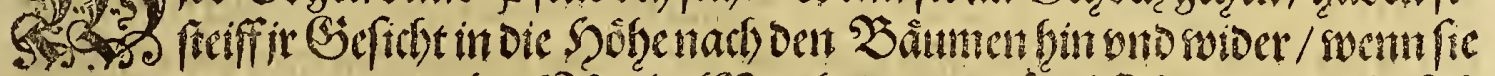

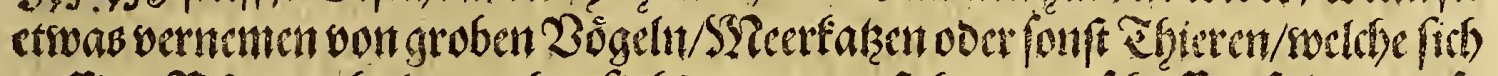

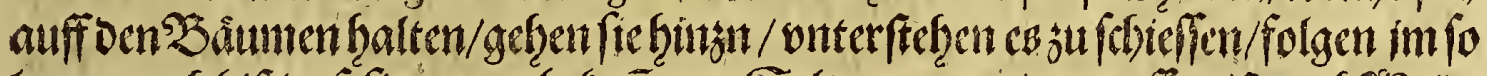

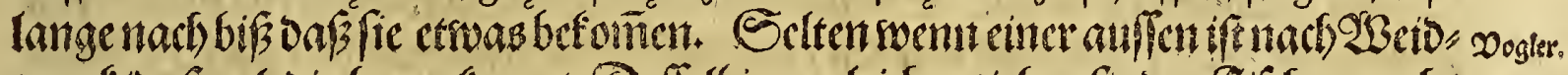

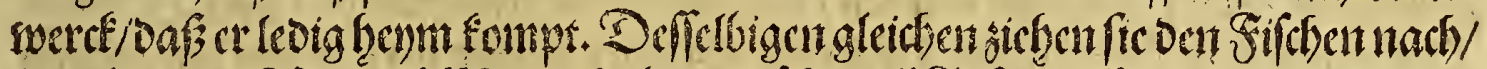

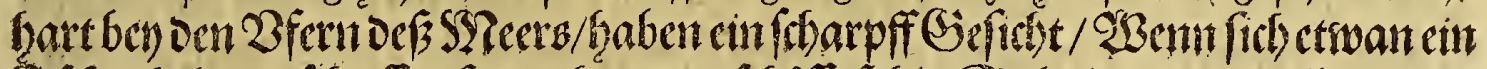

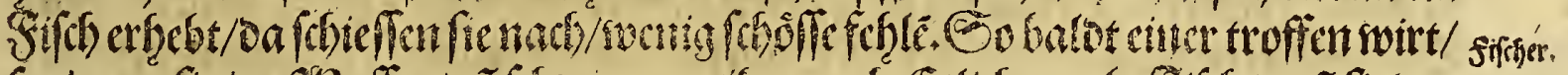

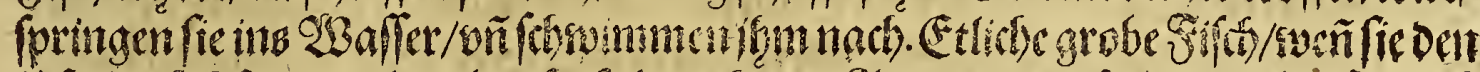

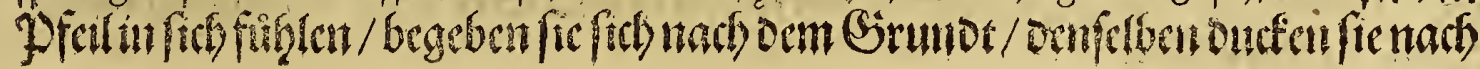

etwann 


\section{Dag britte Thteil.}

\section{Sapittel.}

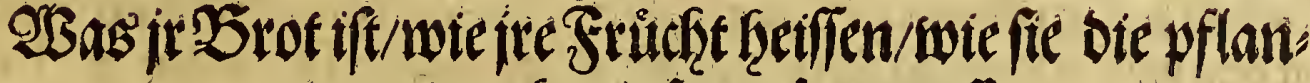

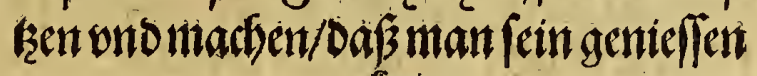

fan.

然,

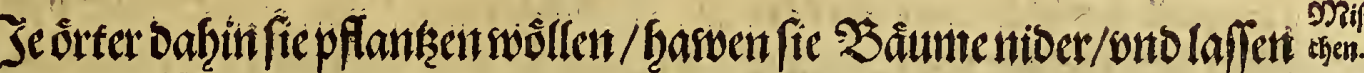

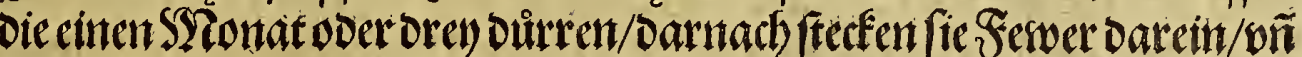

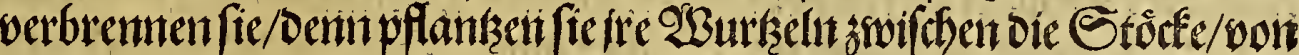

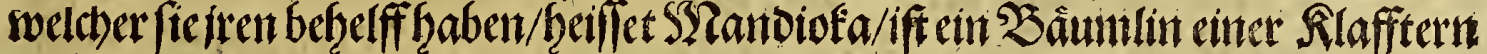

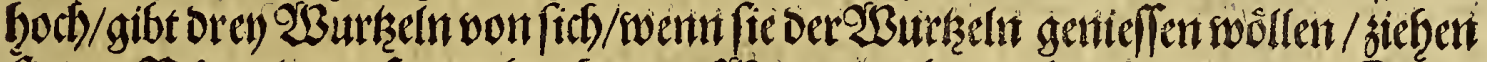

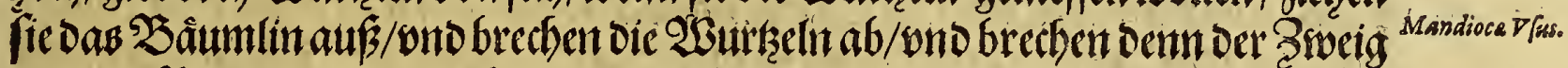

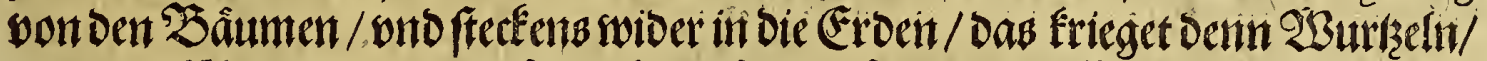

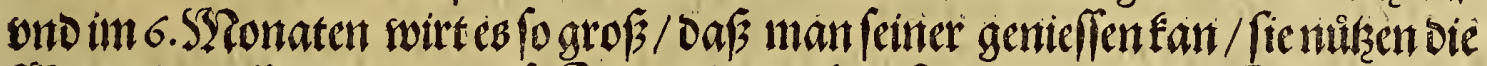
SBurtzeln aufforenerlen weile. Bum erften reiben fie bie alffecitent Stein/gar in

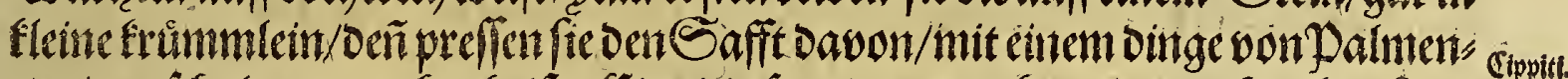

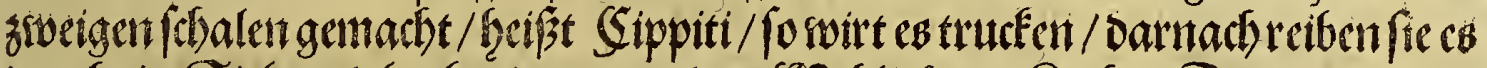

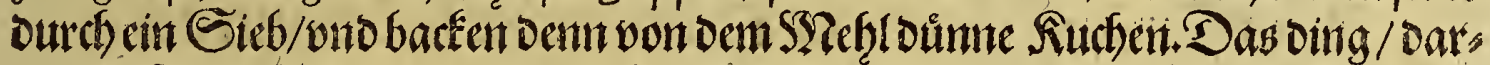

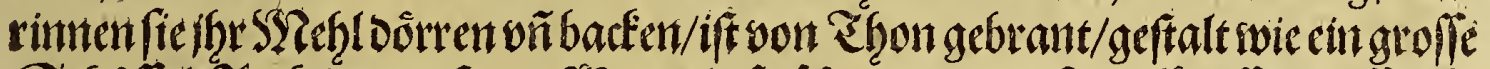

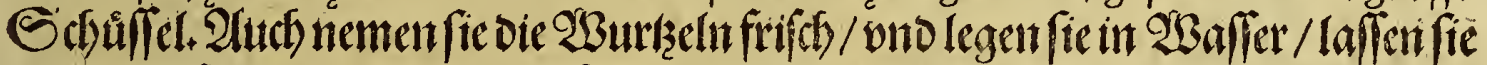

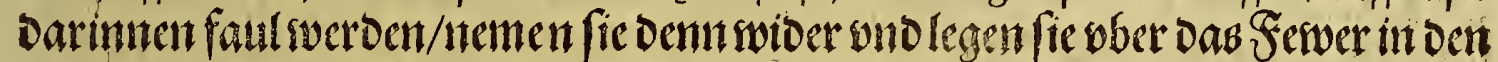

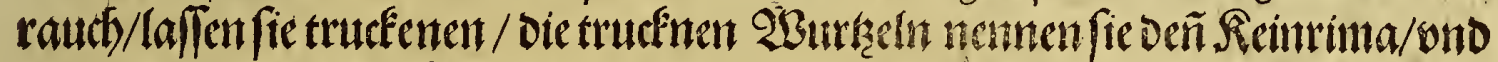

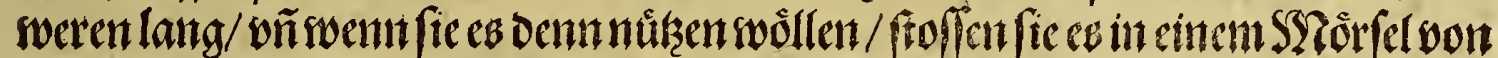

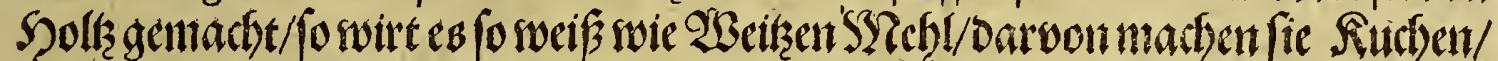

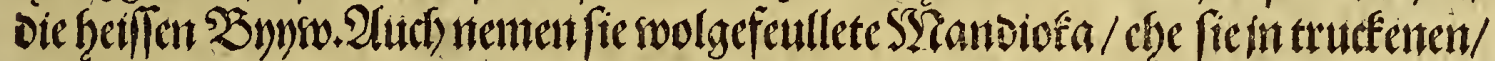

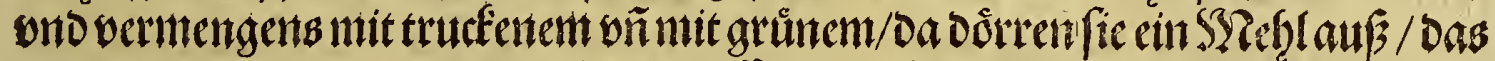

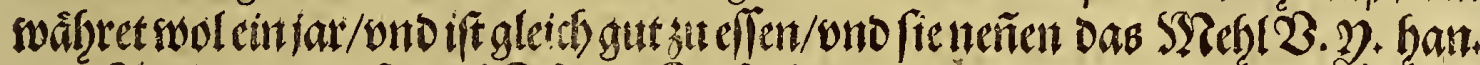

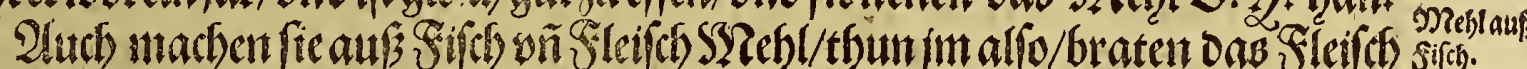

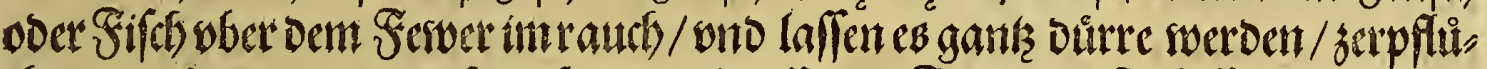

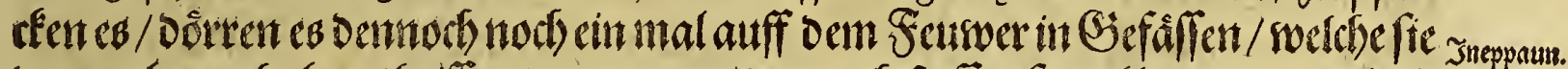

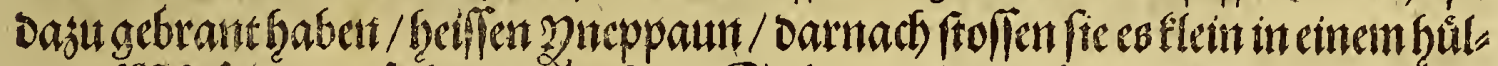

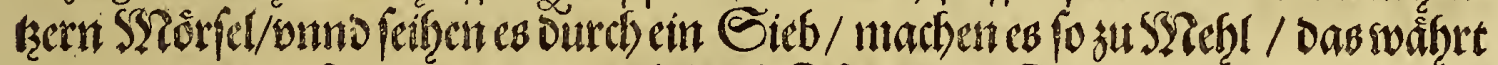

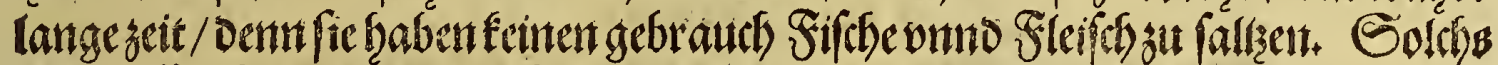

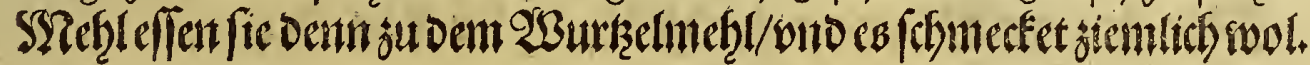

\section{Sapittel.}

\section{OSie fie frete Sperfizarmachen.}

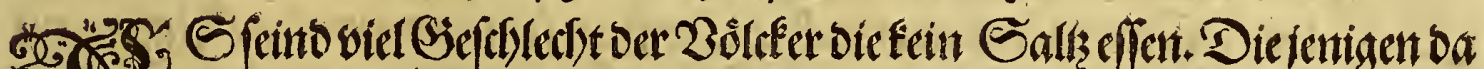

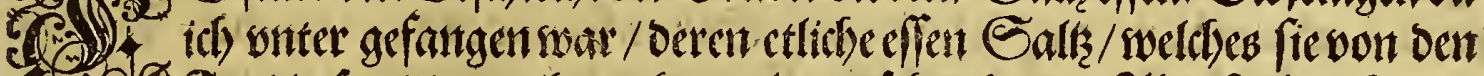

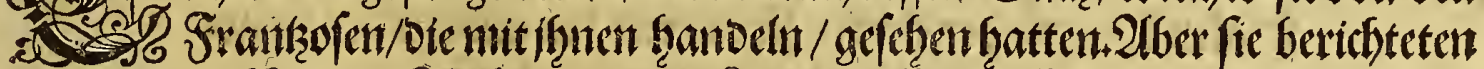

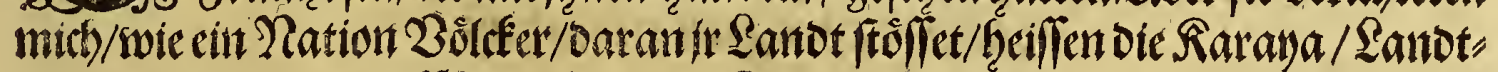

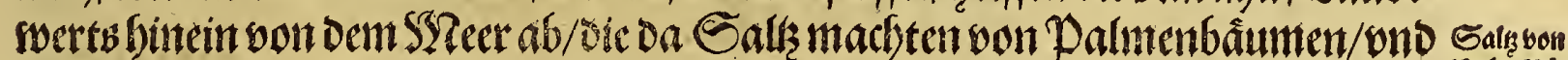

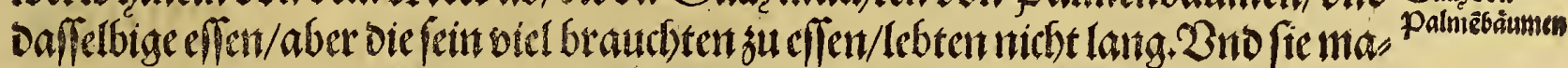

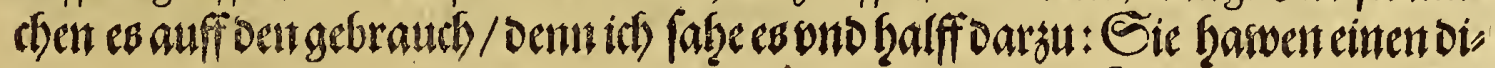
$\{$ dfen 


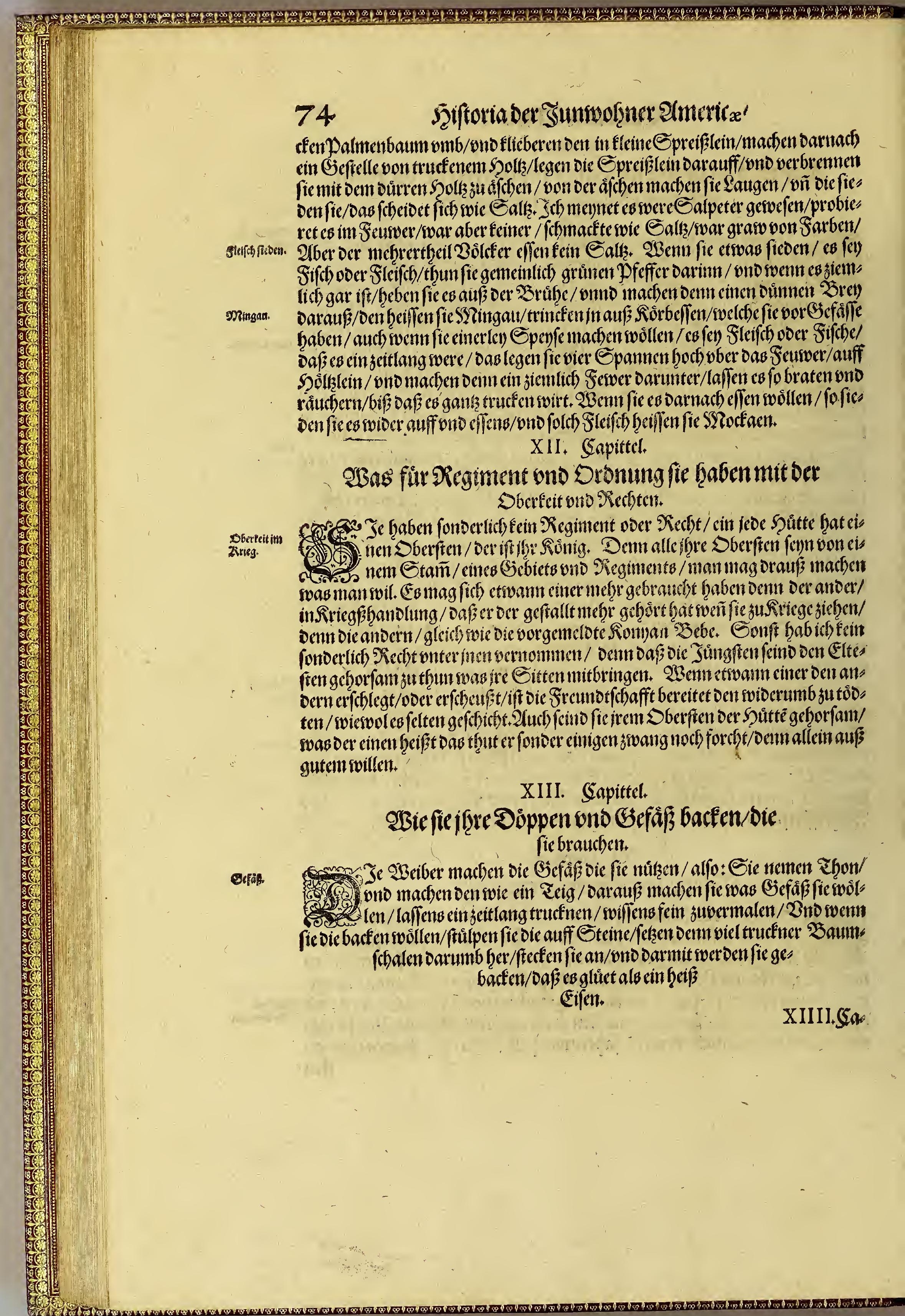




\title{
Dagbritte Tfeil. 75
}

\author{
XII. Sapittel.
}

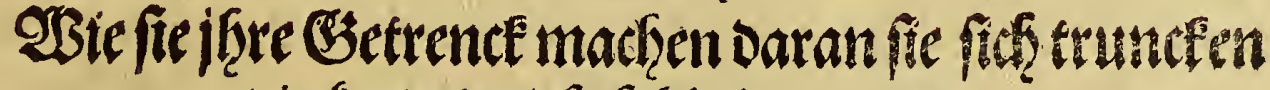
trincfen/wno wie fie fith bealtem mit bent trincter.

$$
\text { 端 }
$$

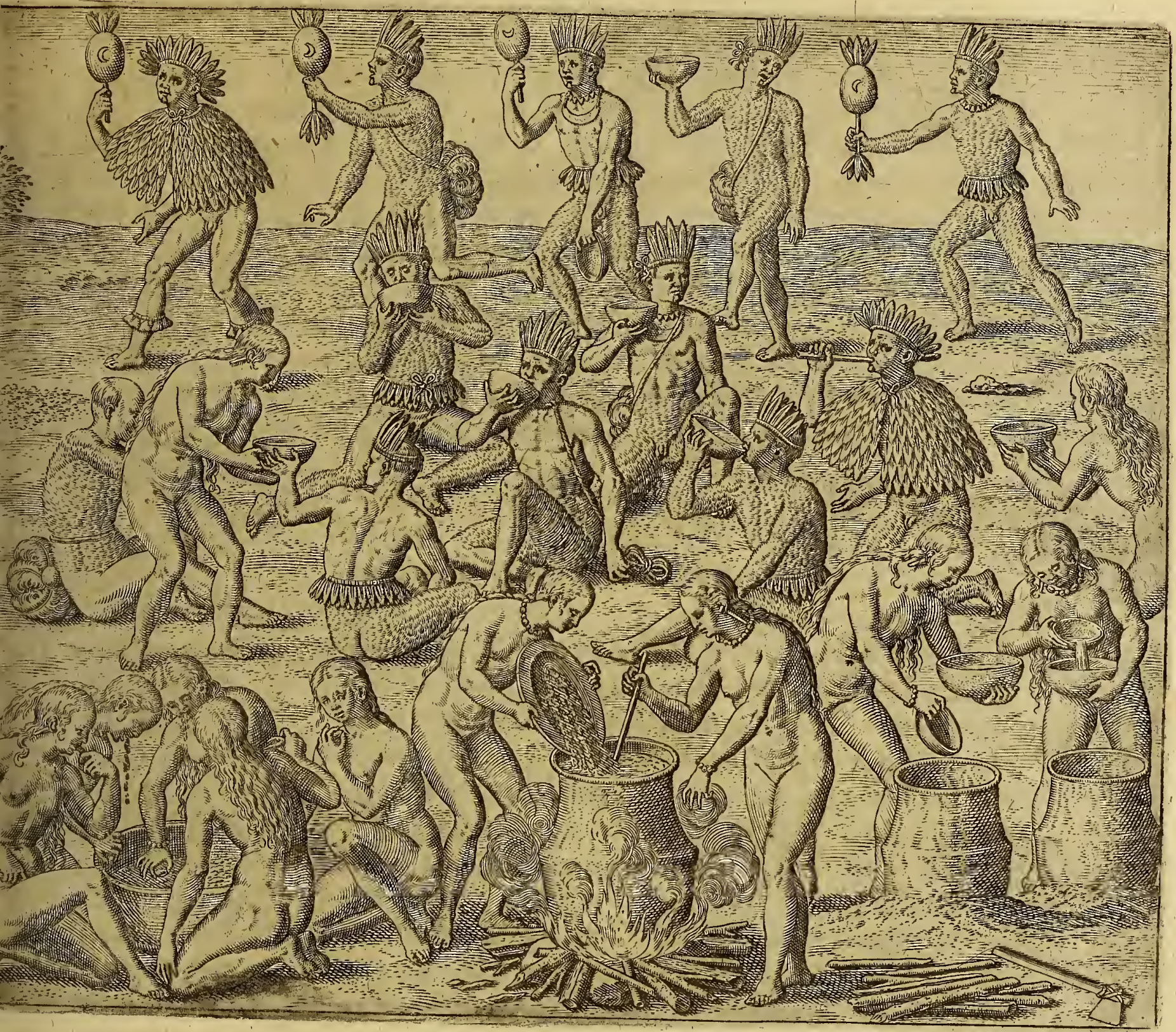

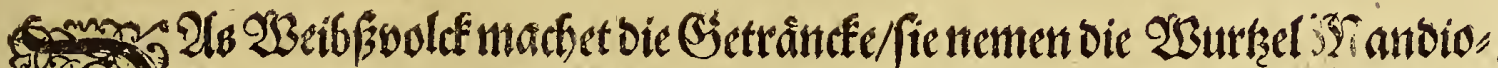

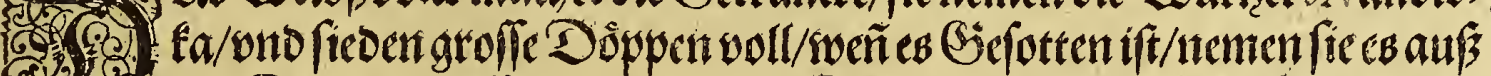
Erand:

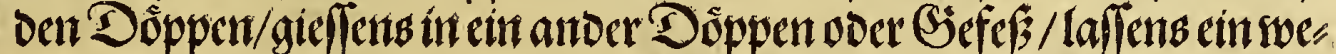

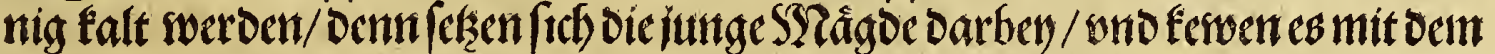

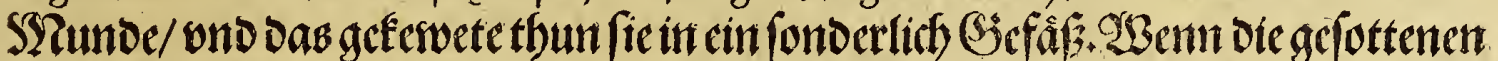

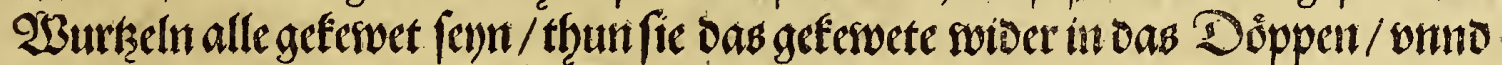

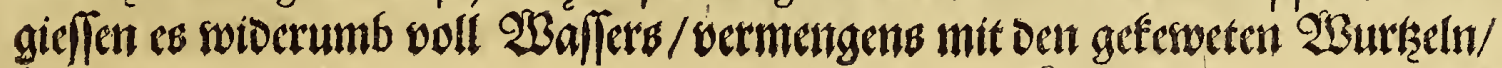

$$
\{\text { if wito }
$$




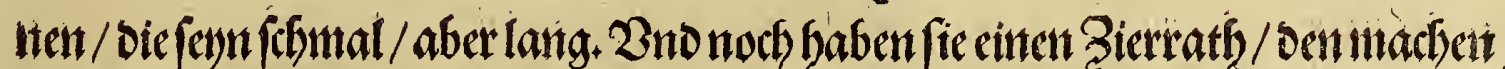

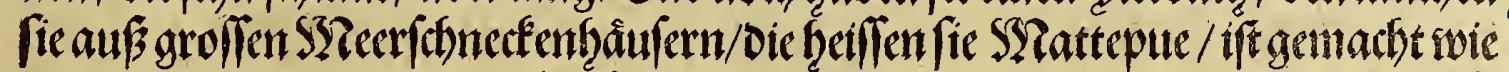

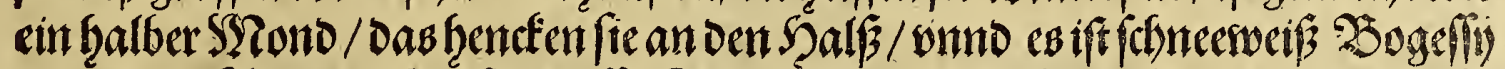

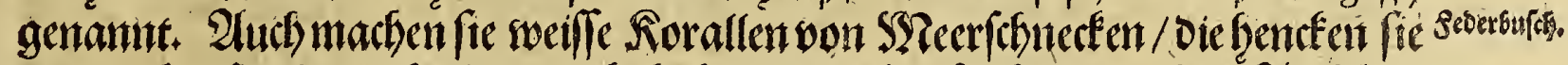

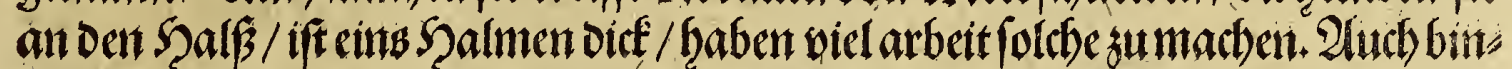

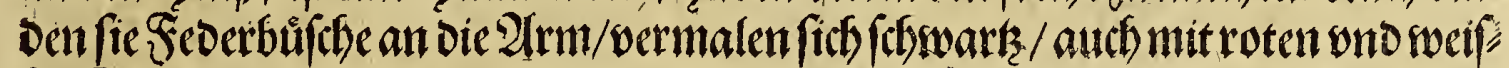

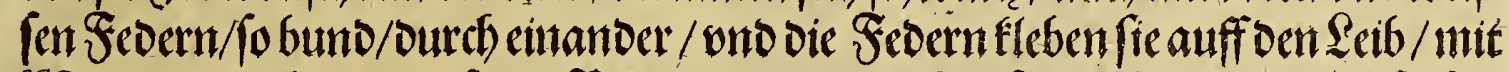

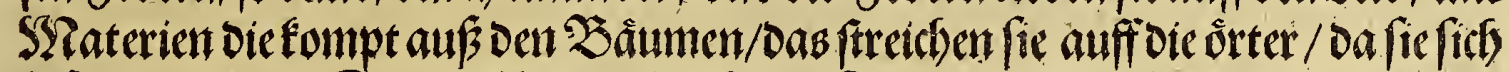
befedernwoollen. Daraufi beftreichet fie die Federn/Das bleibet fleben. Zno fie

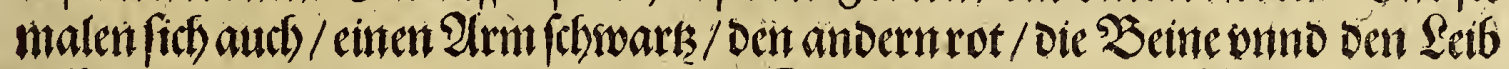

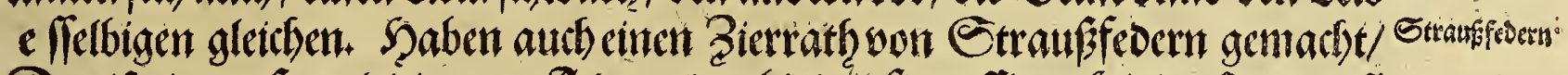

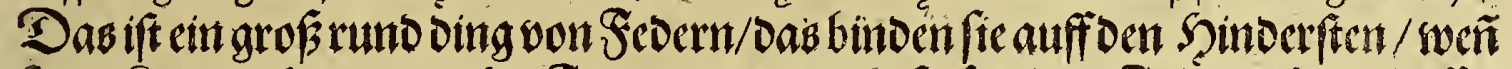

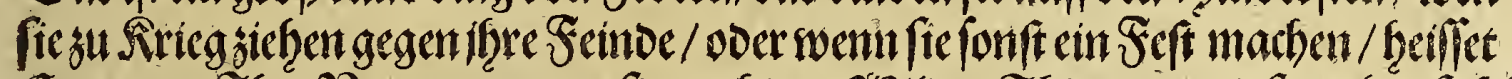

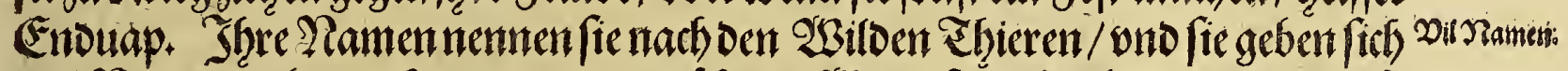

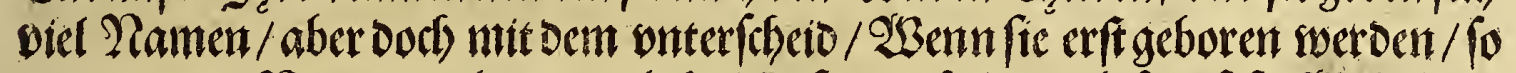

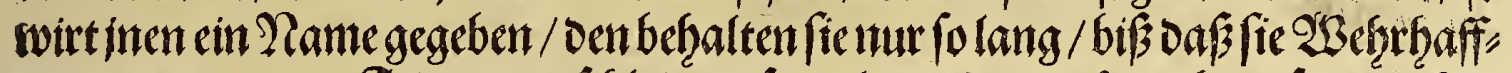
tig raerden/oumo Feinde todtichlagen/ po vieler oenn getootet hat / fo manchen Mamen batat.

XVI. Sapittel.

\section{Wasoer Wetber Bierrathi,}

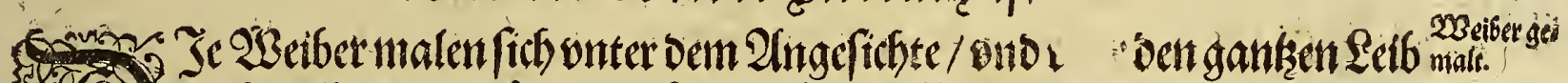

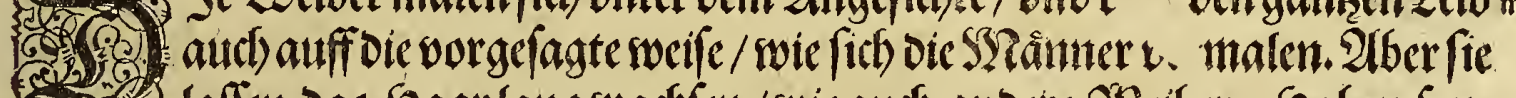

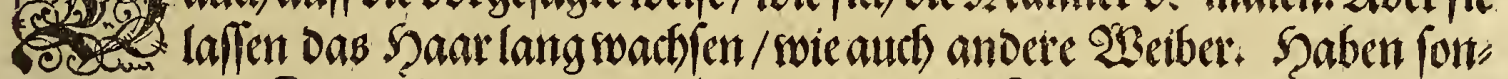

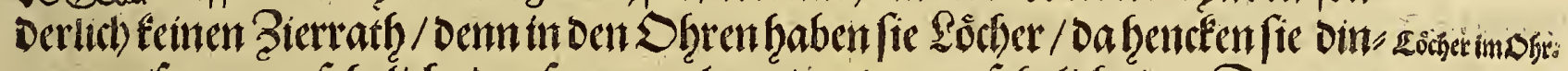
ger enn/fenn vitgefeferlich einer paumen lang/runt/ongefebrlich cinte Daument

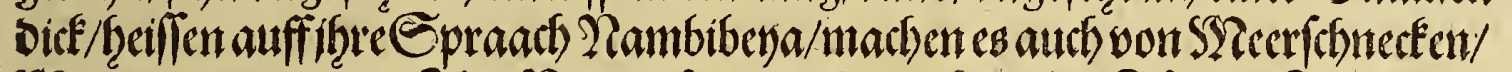

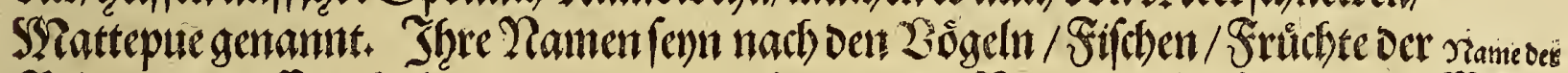

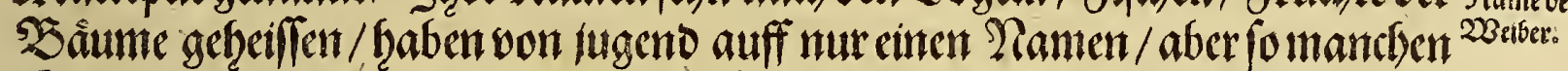

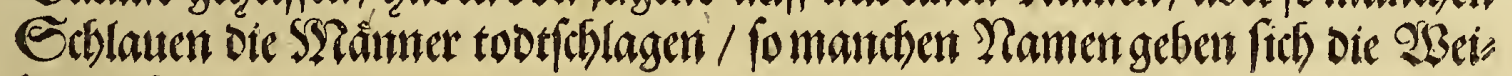
betauth.

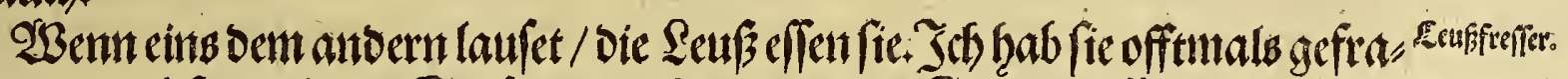
get / swarumb fie es thunt? Sie fagten : Es weren ffere Feinde / eflen ifgnen vont

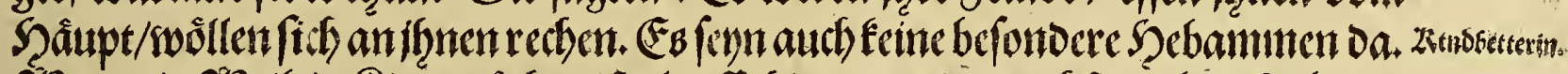

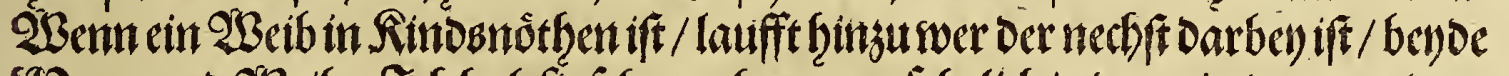

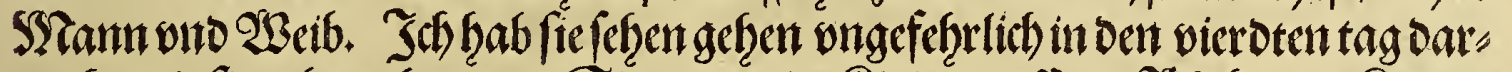

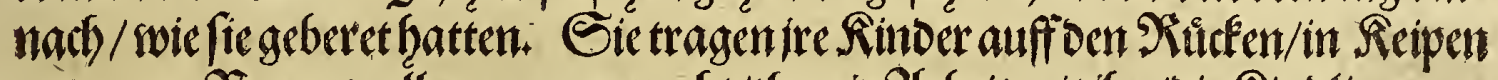

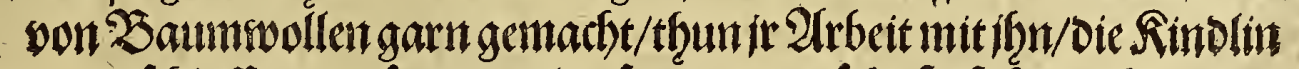

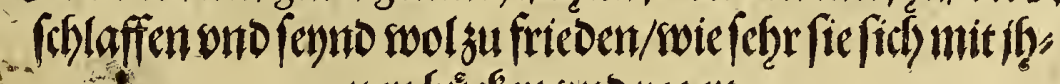
nenbưcéchworegen. 


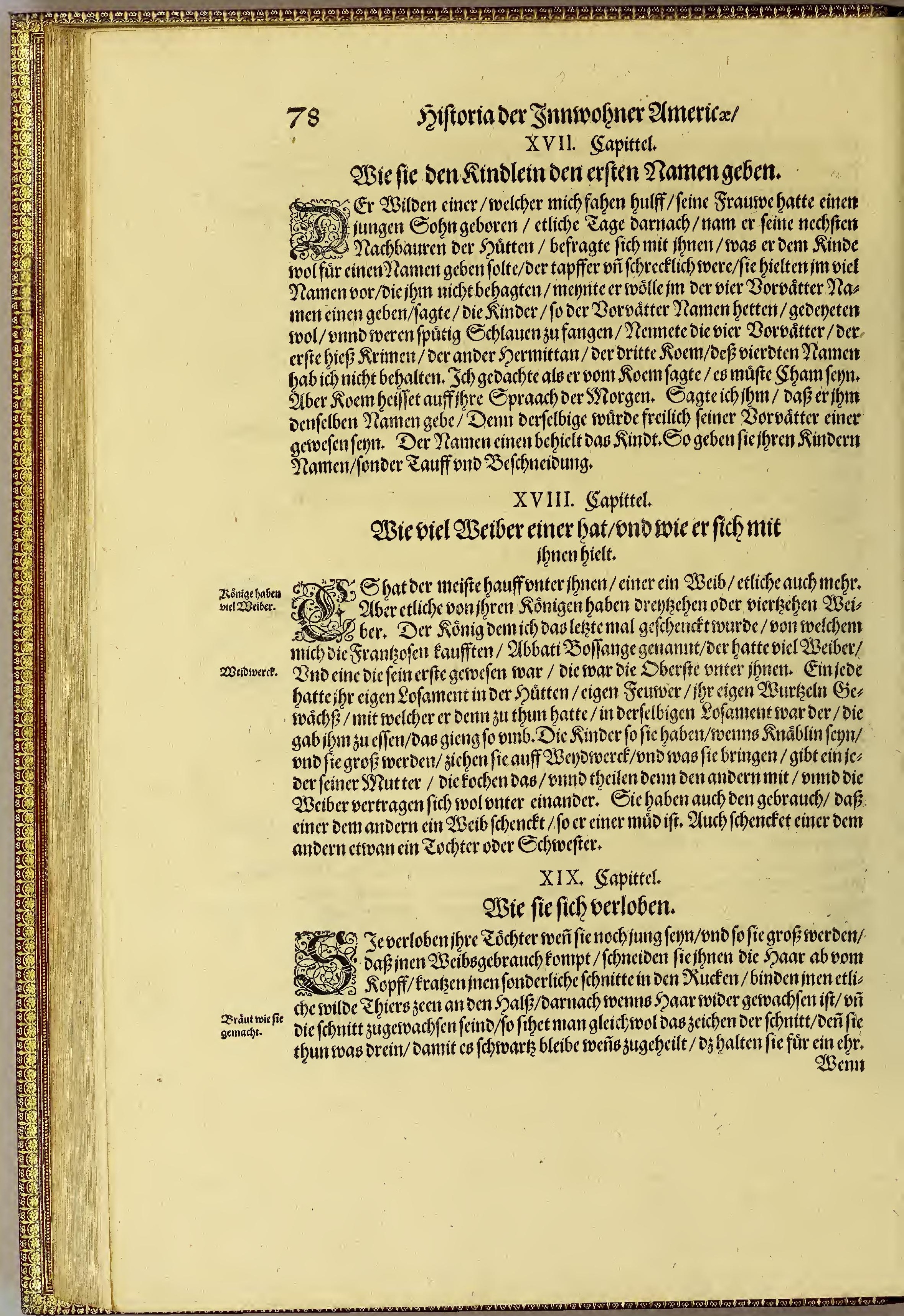




\section{Das britte Theil.}

3 enn foldhe Seremonien geenbet fenn / Darnach wberlieffern fie bem ber fie bas

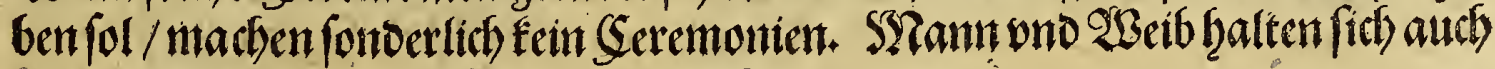
gebur lich/mactsentfre Sachen beimlich.

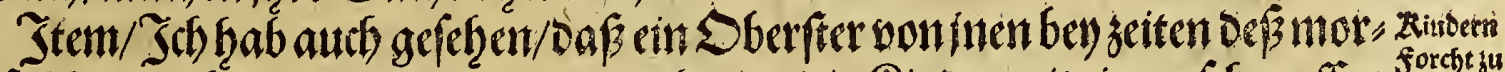

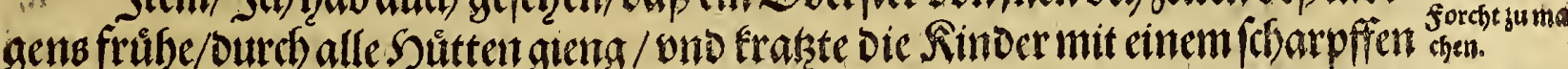

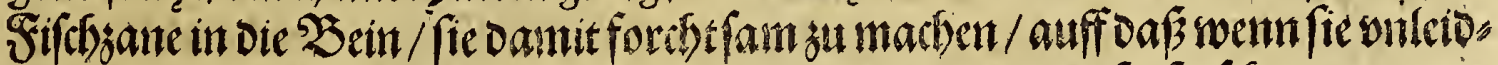

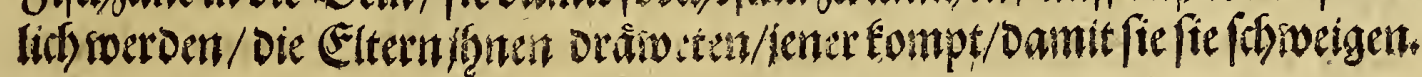

\section{X. Sapittel.}

OBas ifure binter fenn.

to Sifrew Parthicrung onter

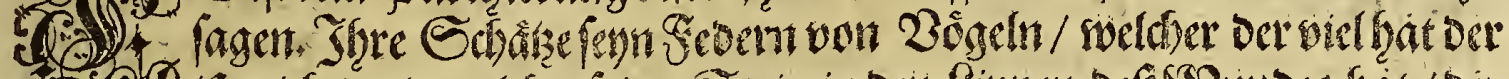

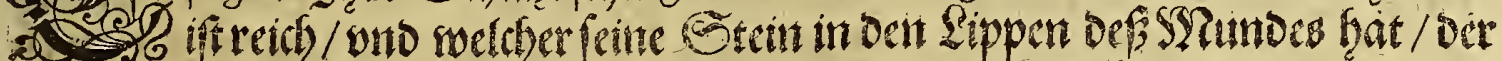

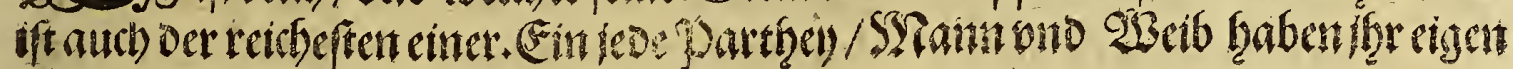

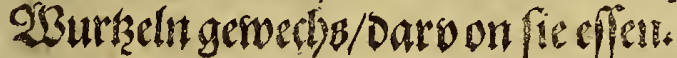

\section{Sapittcl. \\ Whas ibre aroficlte Ebr ift.}

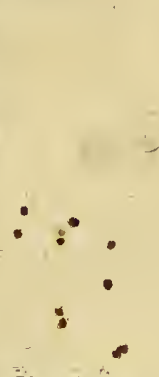

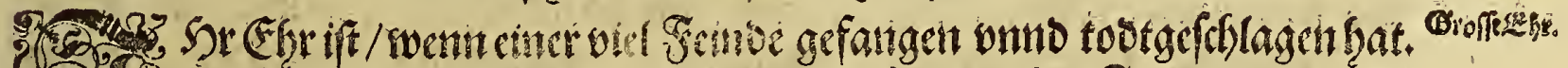

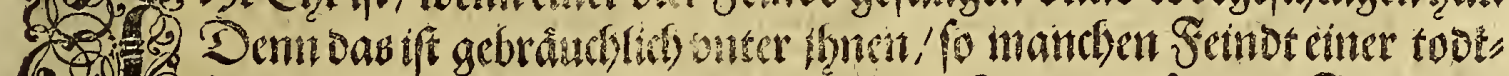

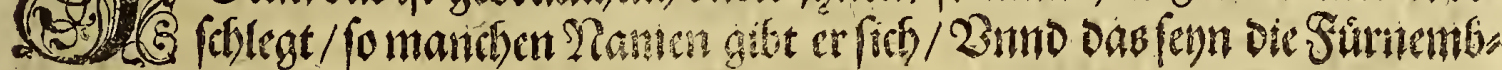

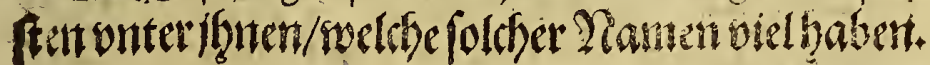

\section{XX11. Sapittel.}

\section{SBaranfiegtơtben.}

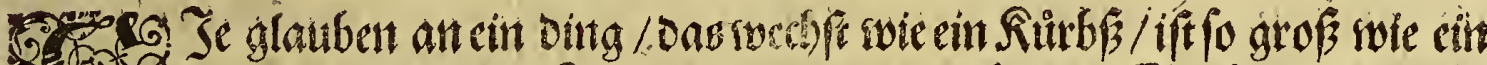

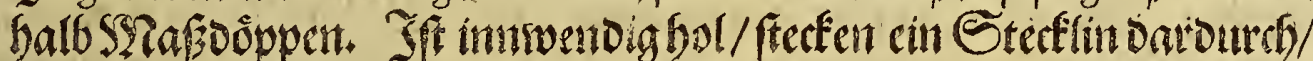

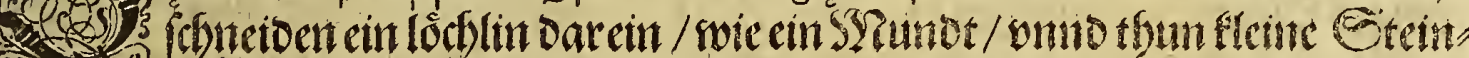

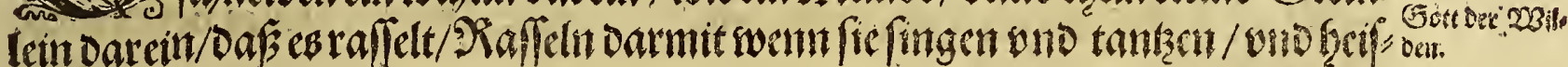
fenes Tammarafo.

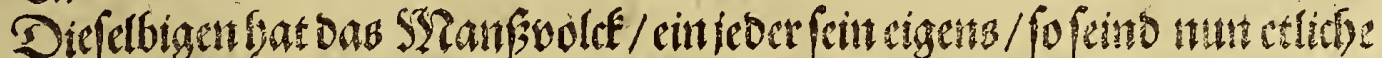

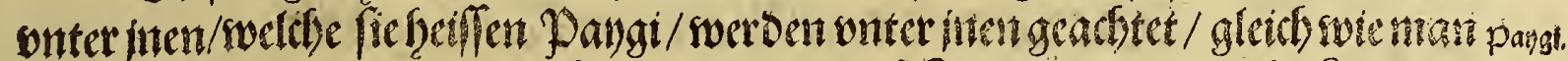

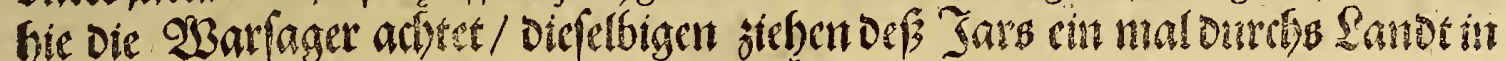

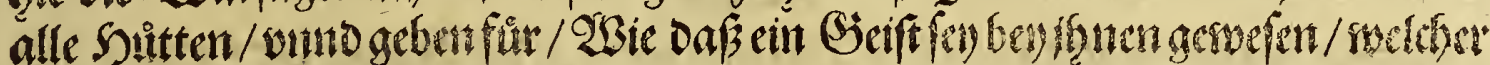

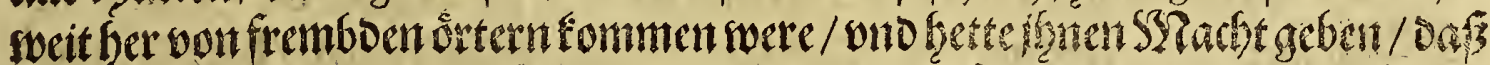

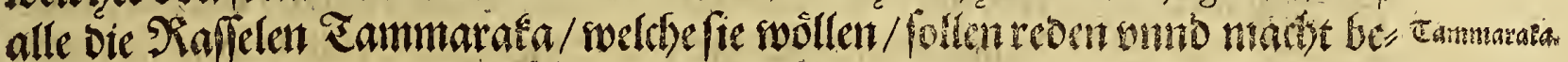

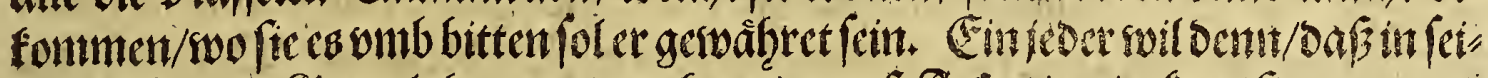

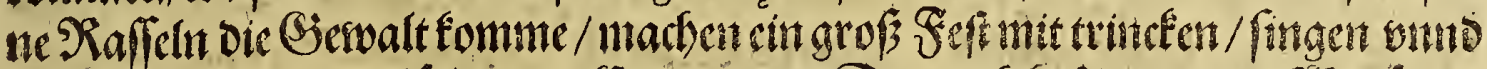
weiffagen/Galten viel felfamer Seremonien. Darnads befimmen oiezsarjager

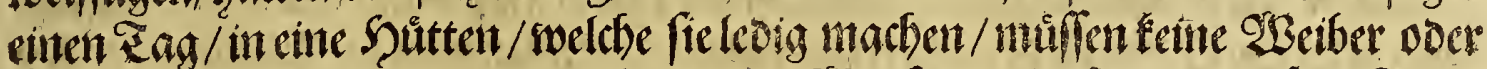

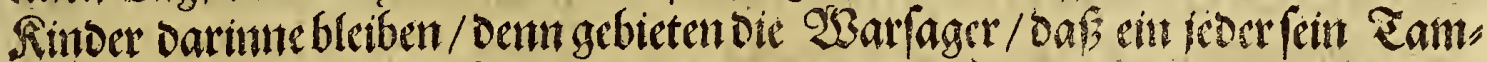

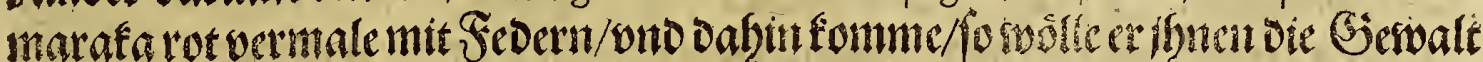

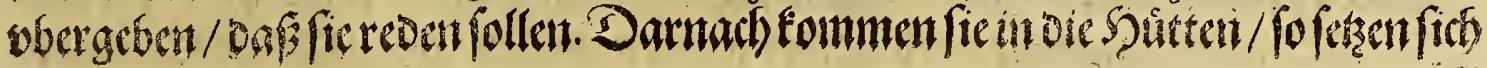




\section{Das oritte Tfiell.}

tet swerben / ond fragtenach) oem Şolls/ Damit man mich folte toot/fhlagen/sod Das were? (Er antwortet fbr: (Es were nicf)t weit/alle oing weren fertig/nur allein/

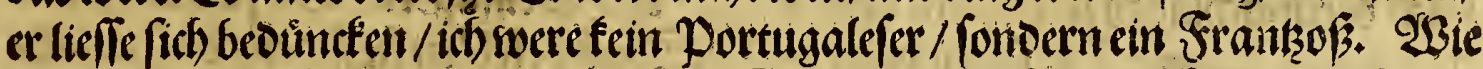

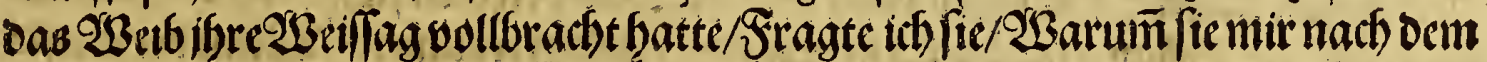

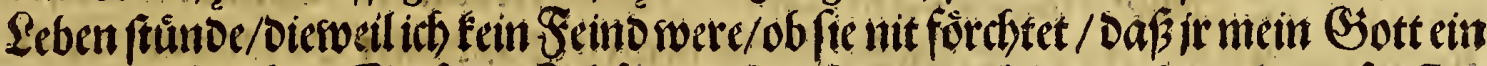
Plage zulchicfet? Sie fagte: Seb folt nichnict)t Daran feren/Deñ es sweren fiemoe

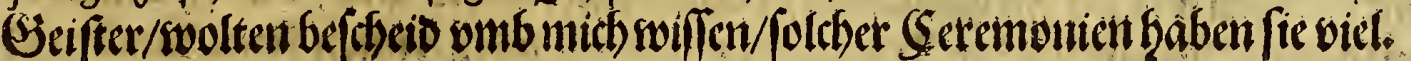

XXIIII. Sapittel.

Worinnfie auff Dem $\mathscr{W}$ alfer fafren.

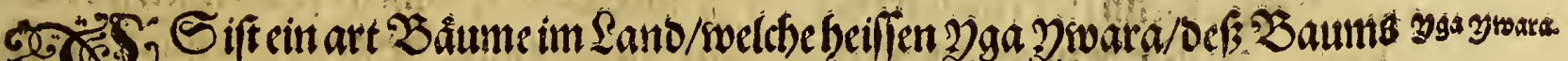

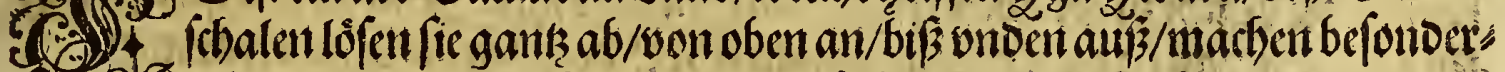

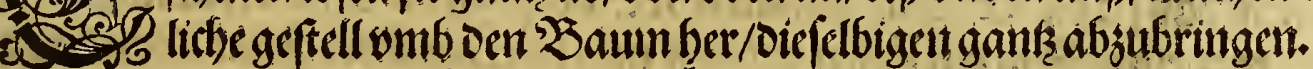

Warnach itemen fie oie Sibale / ono tragen fie aus Dem $\mathfrak{Z}$ erge / bey Das

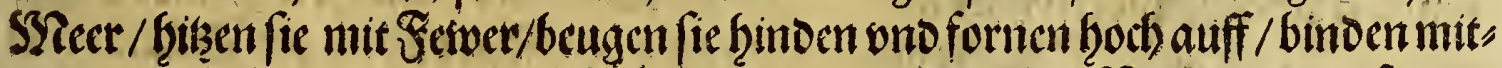

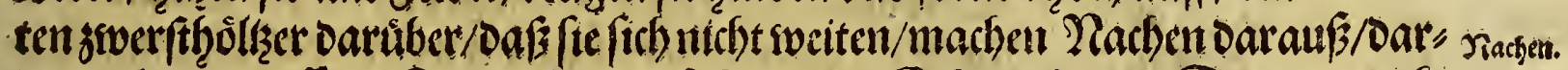

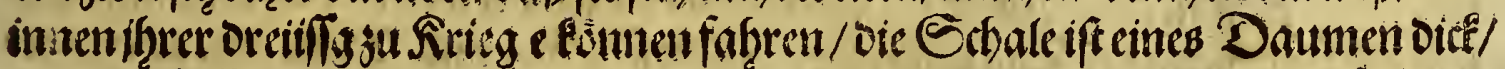

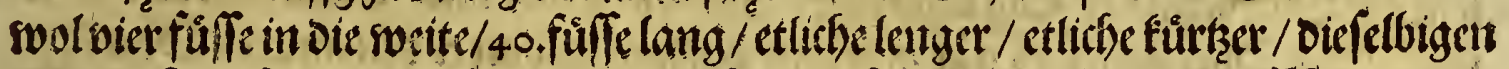

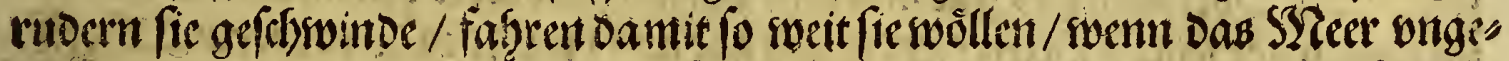

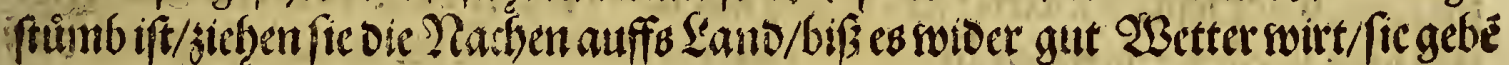

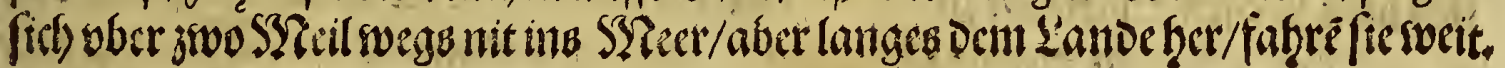

XXV. Sapittel.

\section{OBarumb cin Feind Den andern effe.}

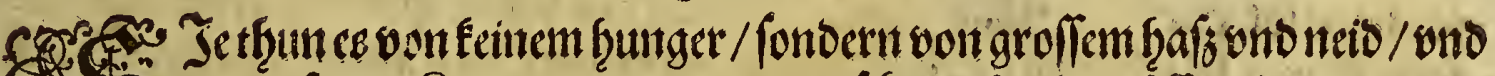

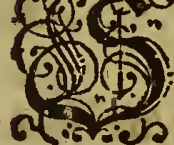

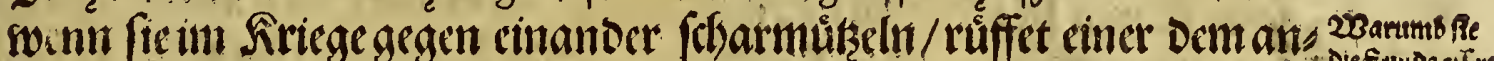

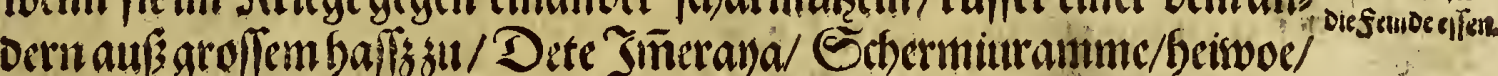

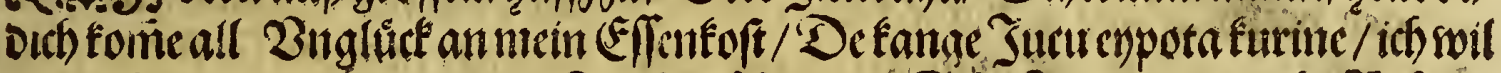

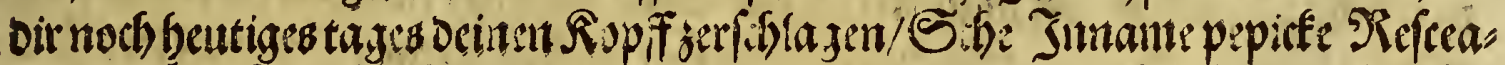

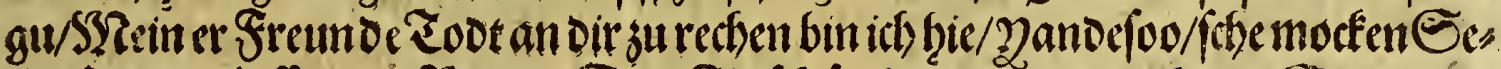

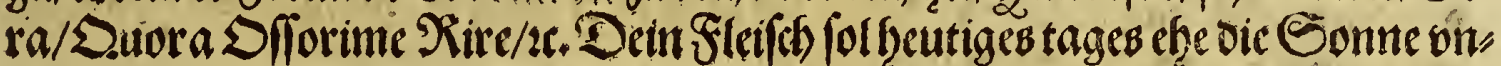

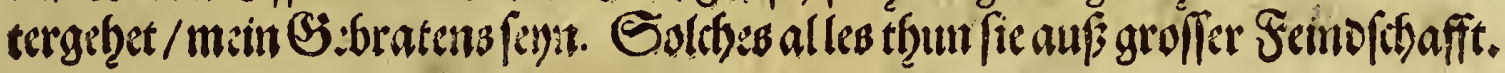
X XVI. Sapittel.

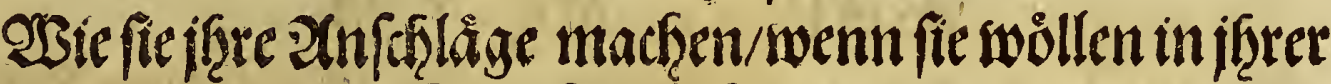

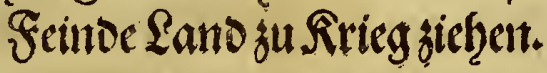

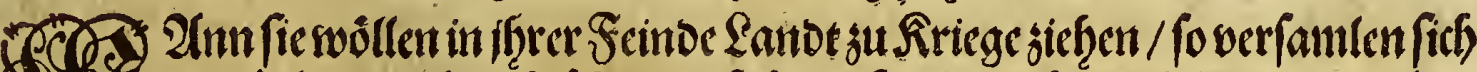

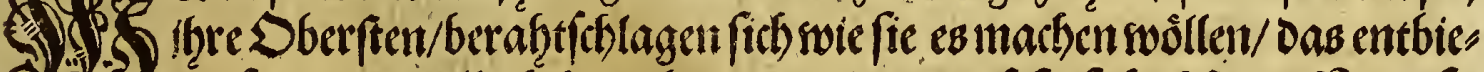
- 2 ) 7.7. So ten fied

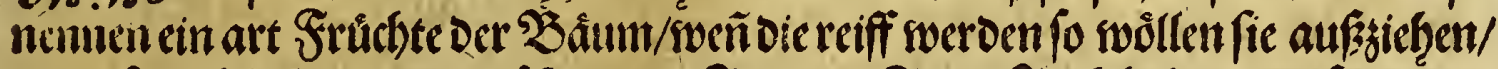

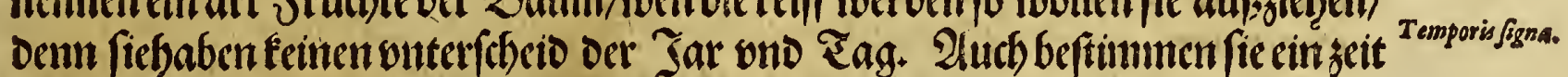

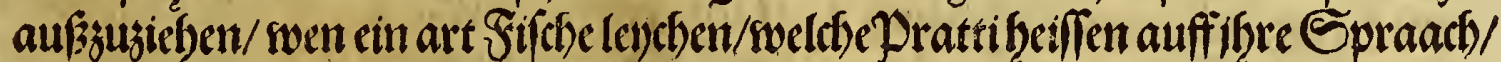

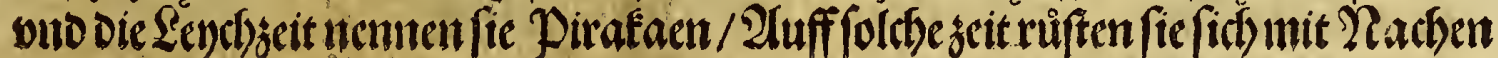
SIZ: : vito 


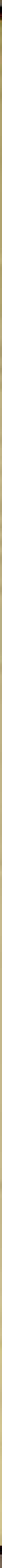


Das britte Theil.

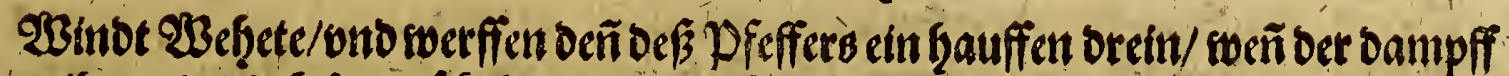

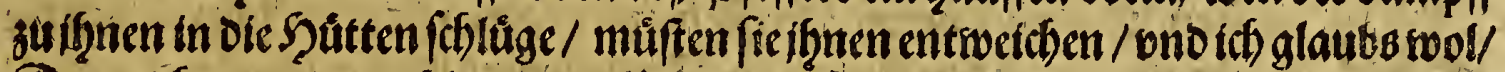

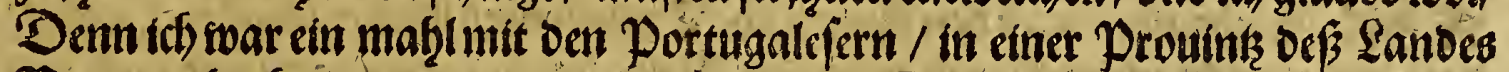

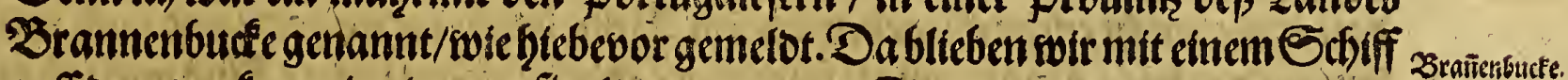
auff bem tructenen in etnem refier liegen/Dent bie S'lut war ons entgangen/ ond es famen viel 28 llder/meynten ons gu nemen/aber fonbtens nicht. Dasourfien

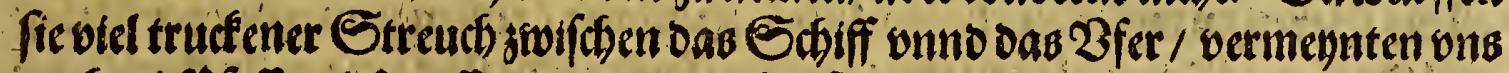

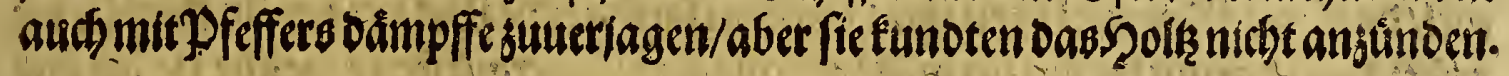

\section{XXVIIII. Sapittel. \\ \$2it was Seremonten fie jore Fetnoe tóbten onb effen

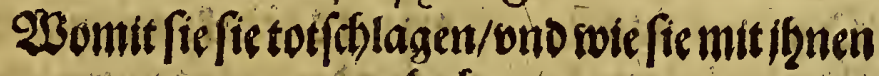 vmbgetien.}

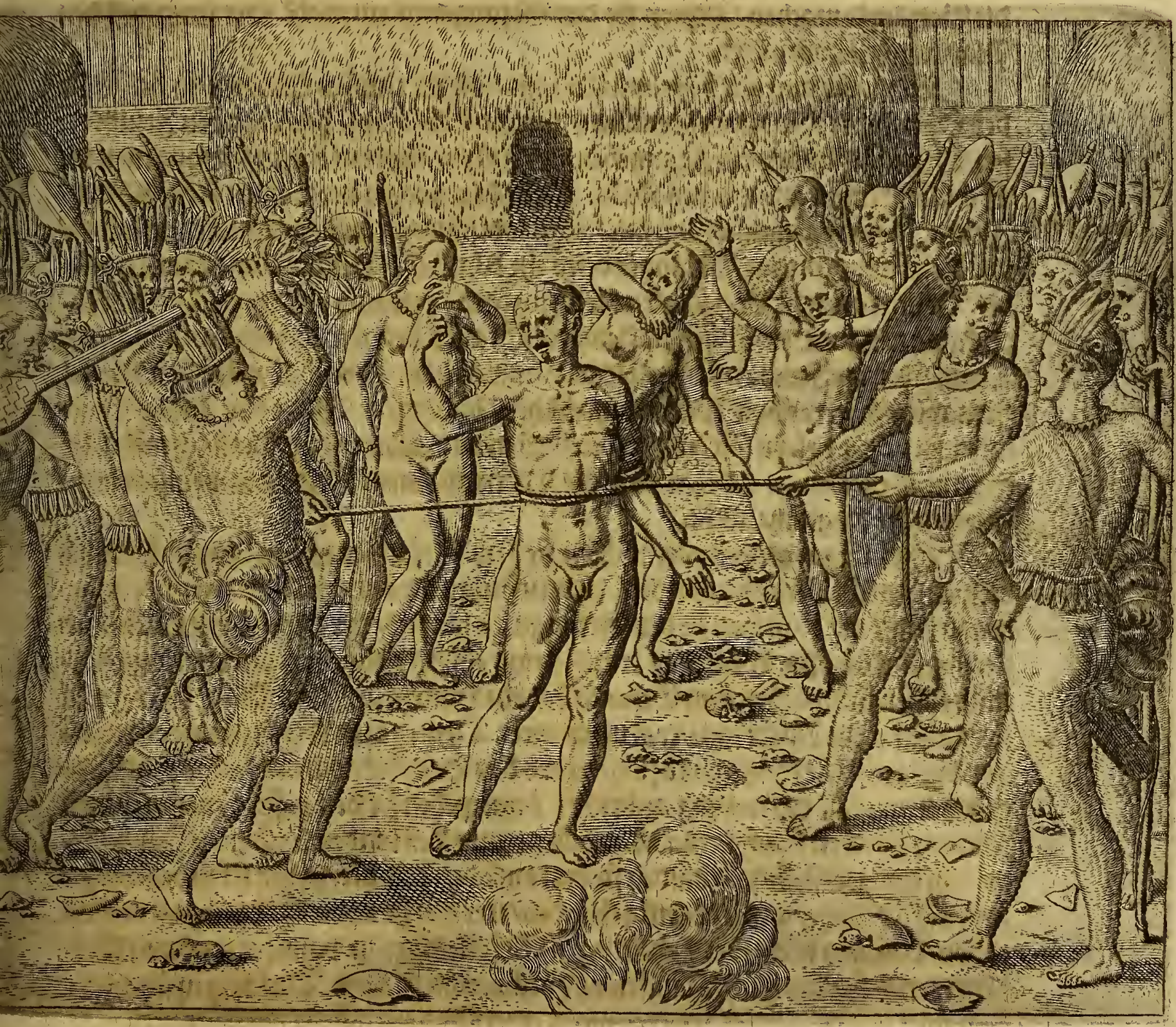

IS if 23ann 


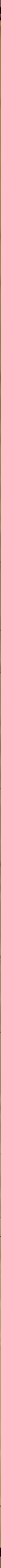




\section{Dag britte Ificil.}

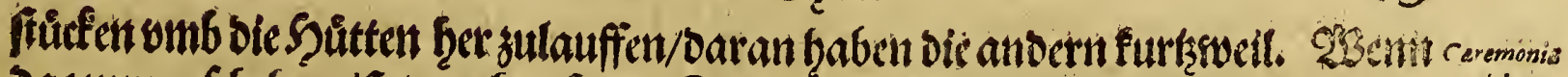

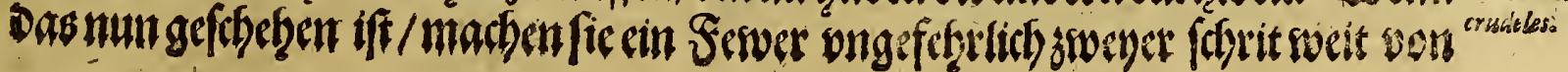

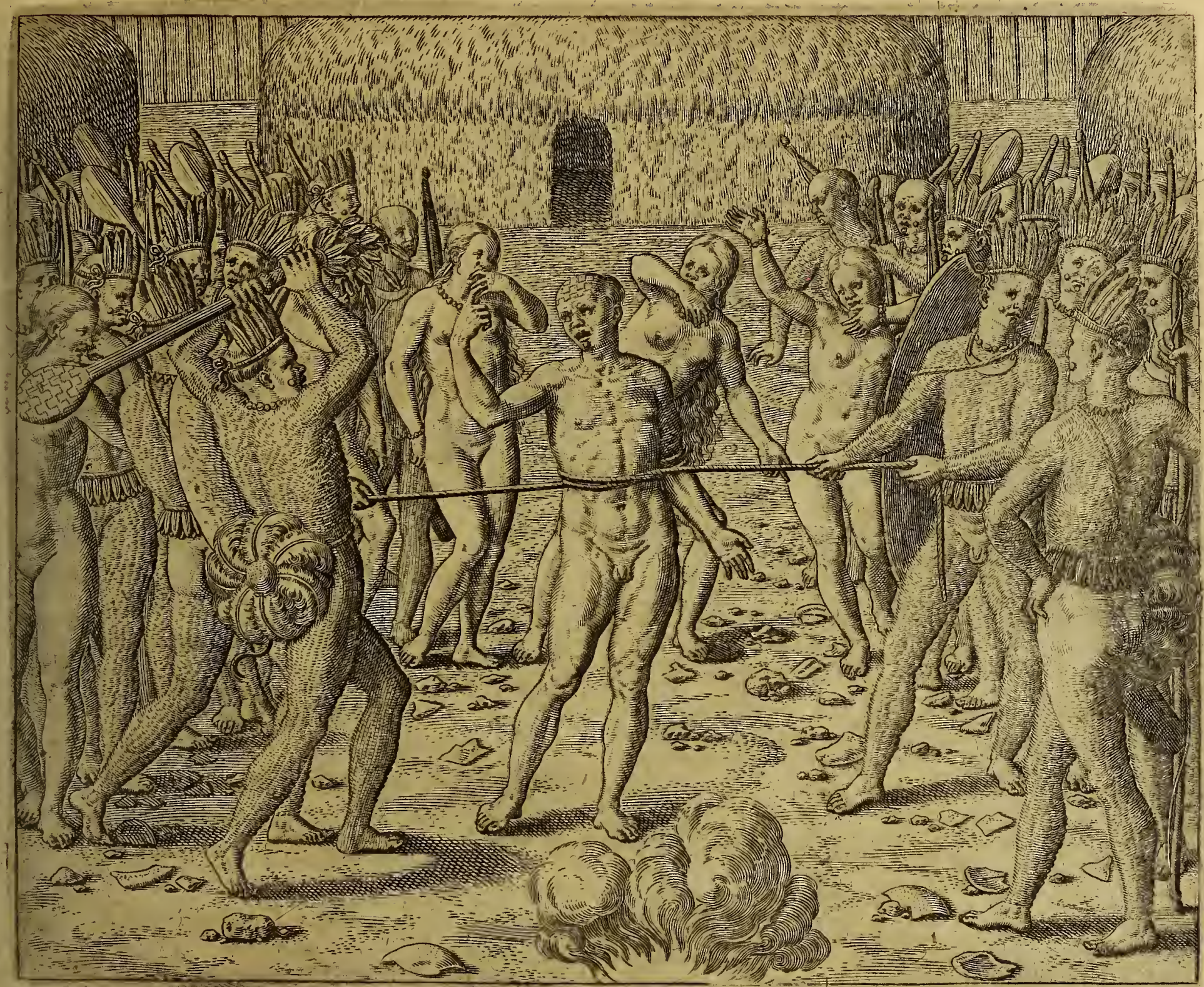

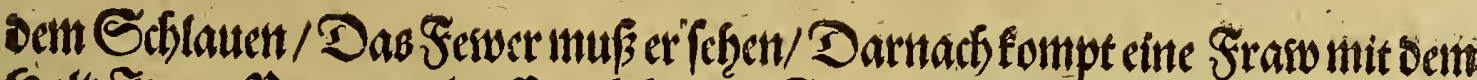

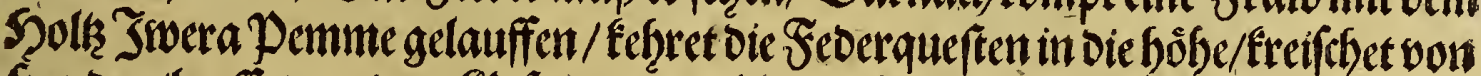

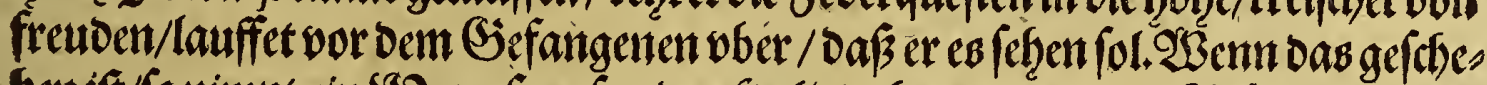

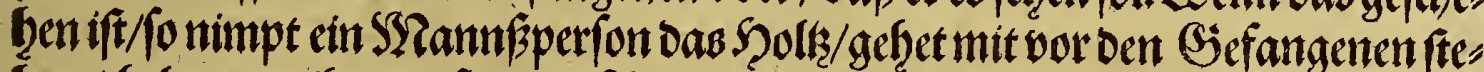

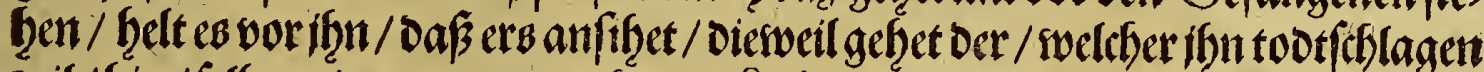

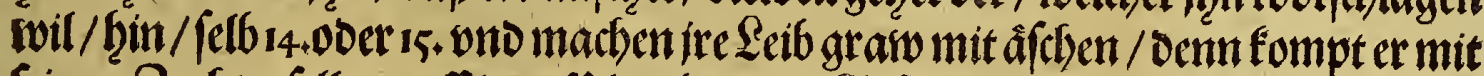

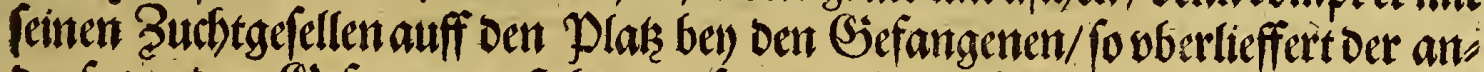

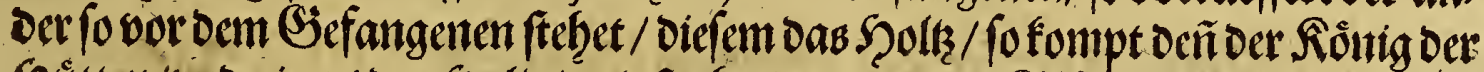

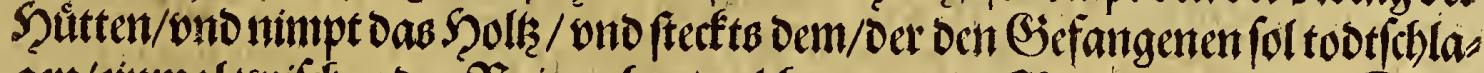

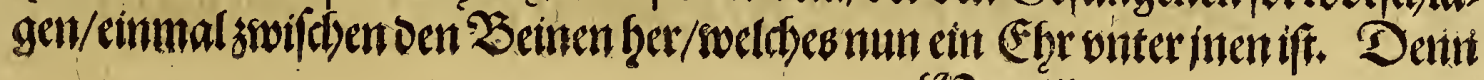
\$II iij ; nimpt 


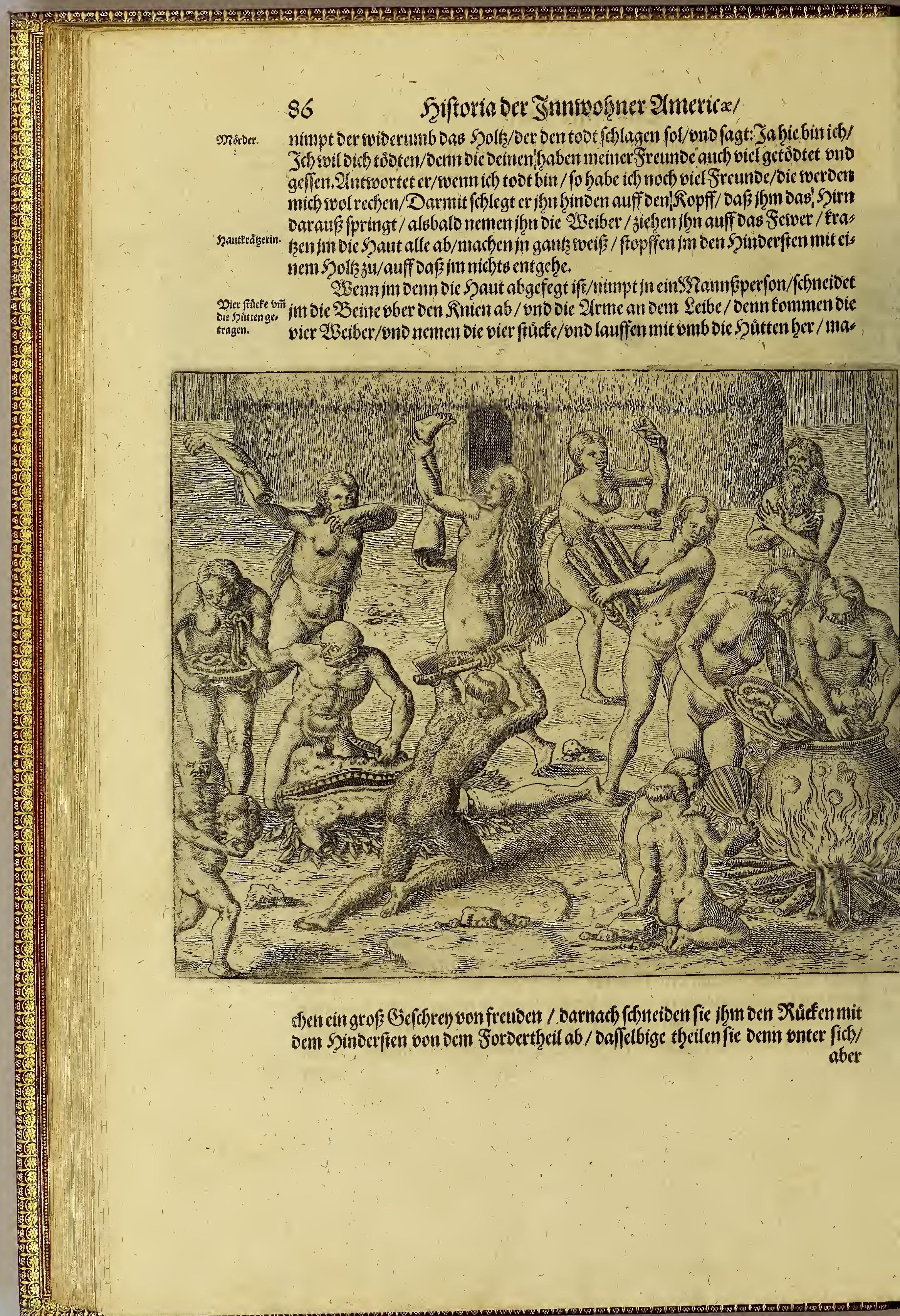




\section{Dag britfe Tfeth.}

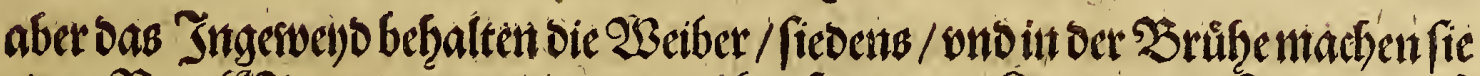

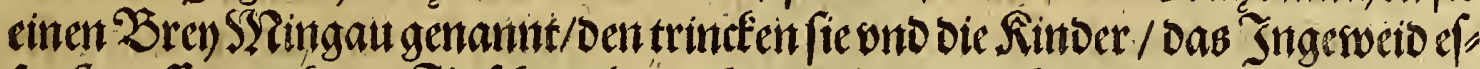

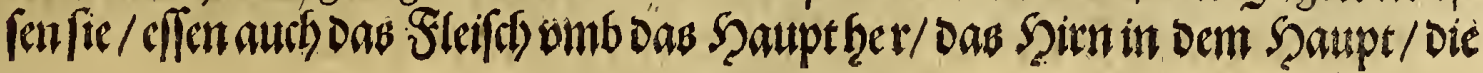

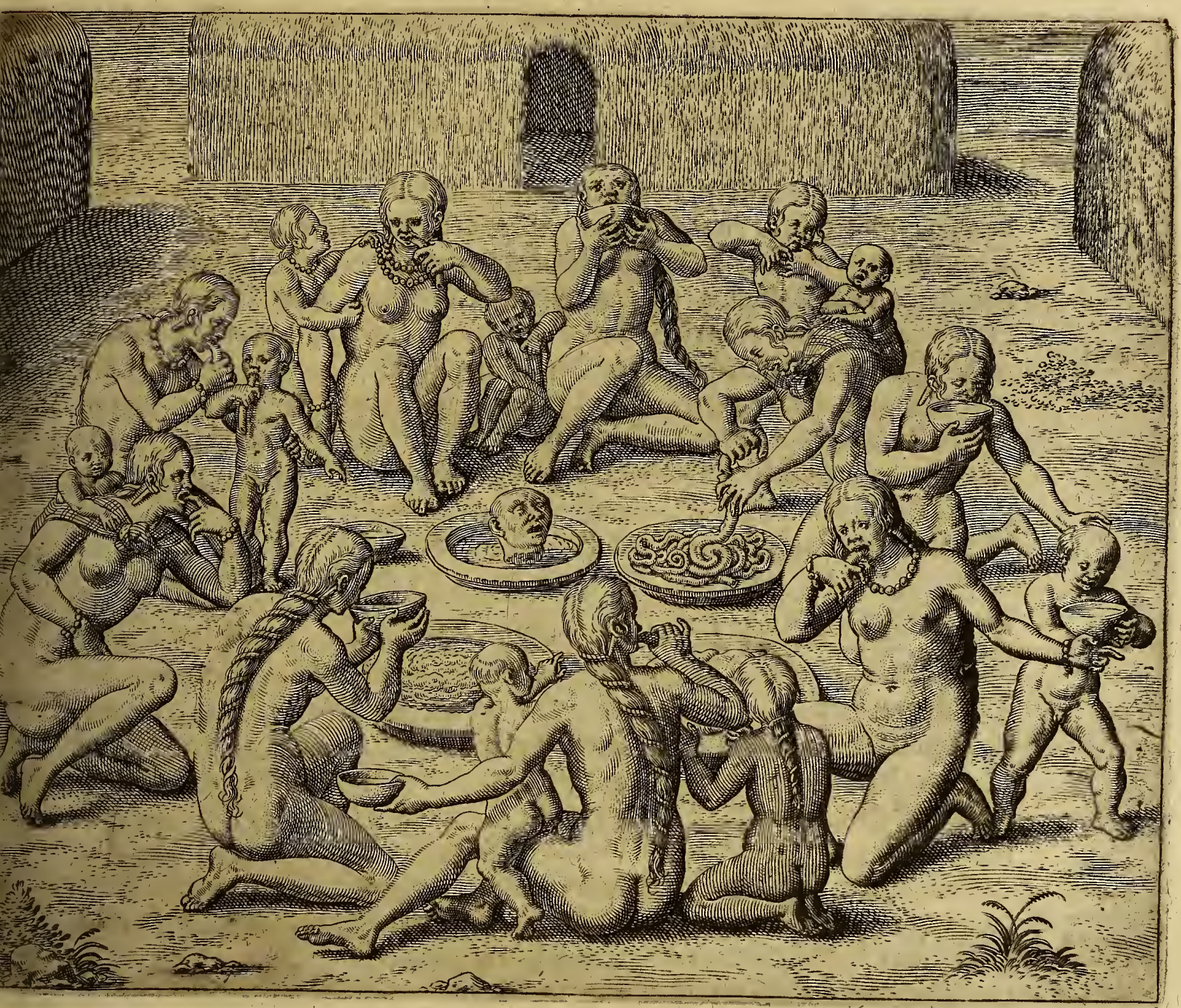

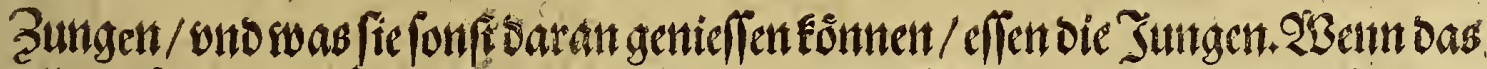

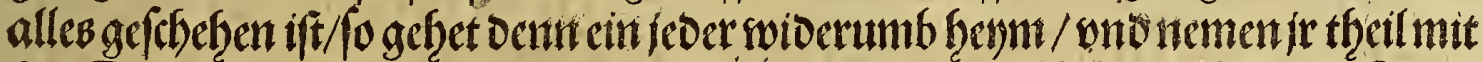

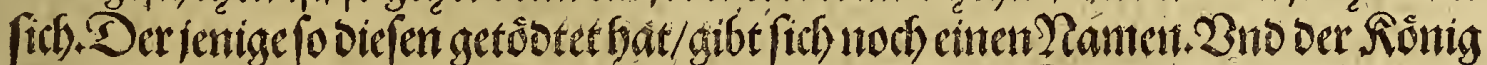

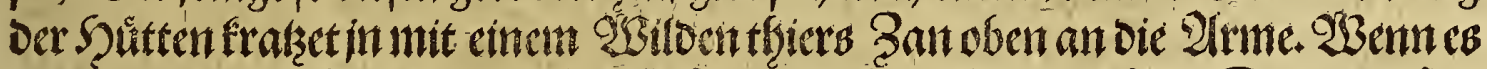

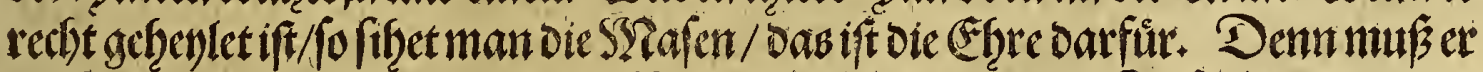

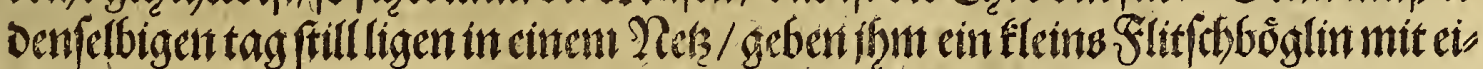

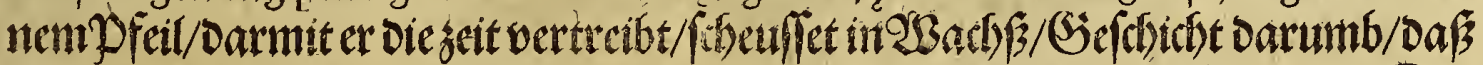

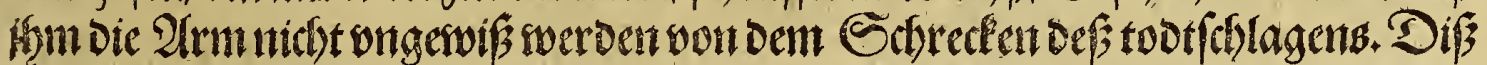

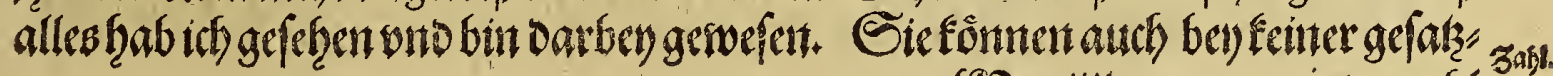

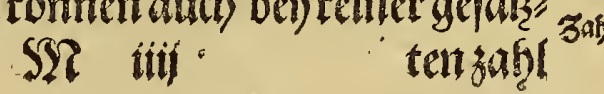




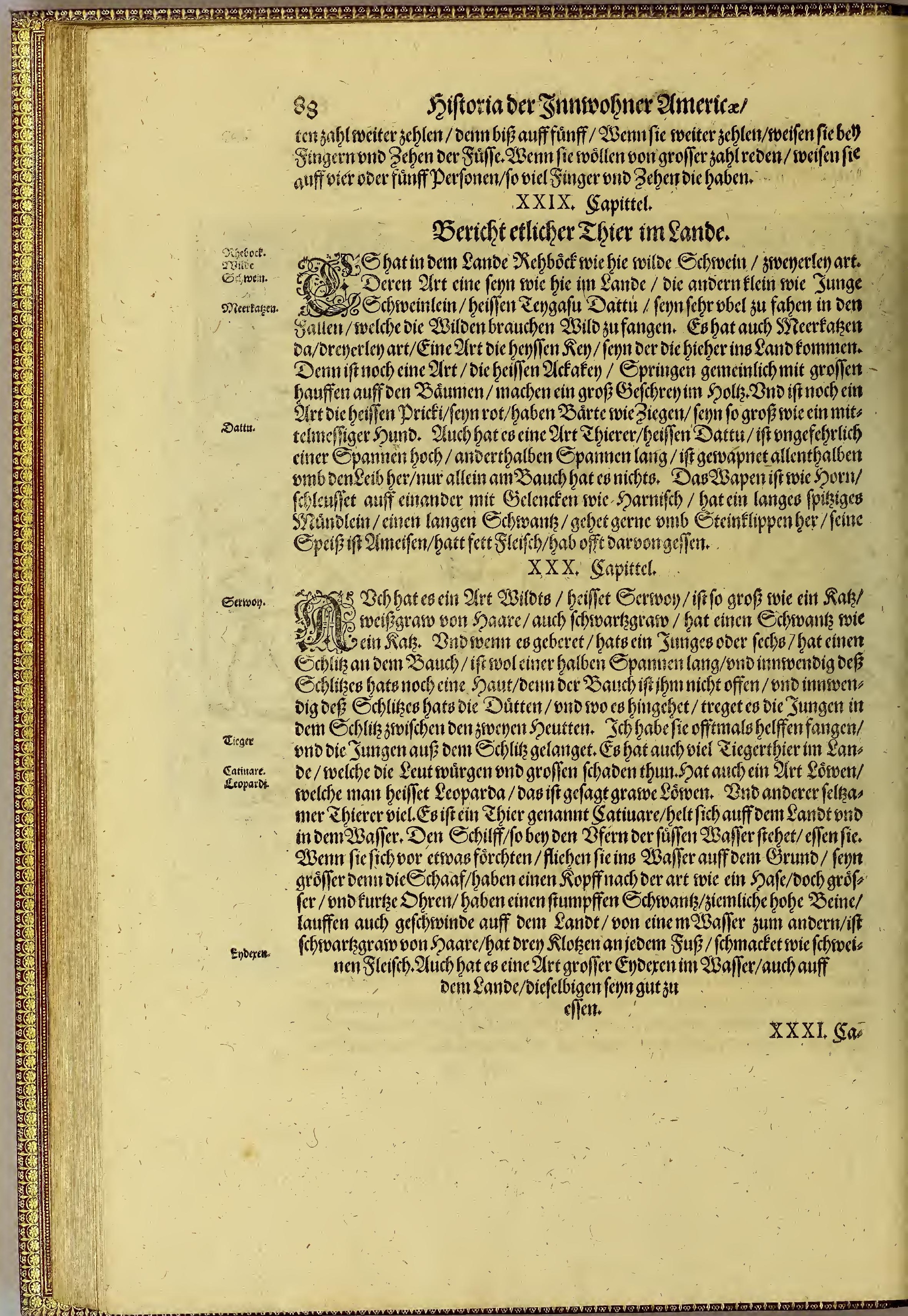


Dagbritte Tgetl.

XXXI. Sapitet.

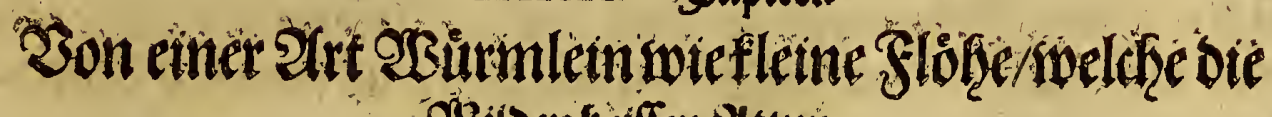

Qibiben bieifen Uttun.

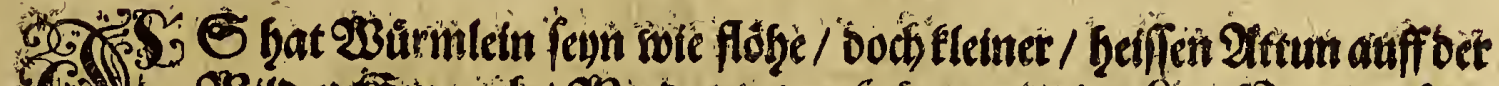

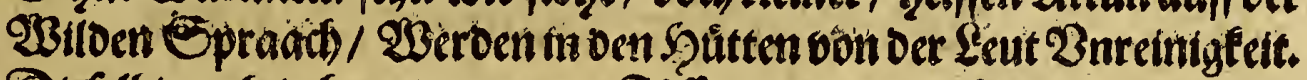

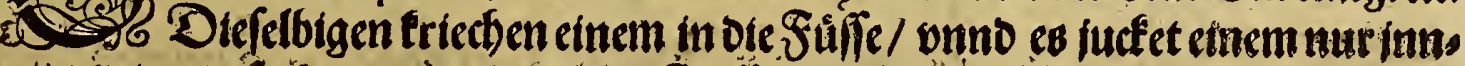

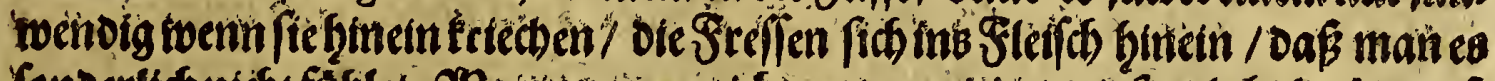

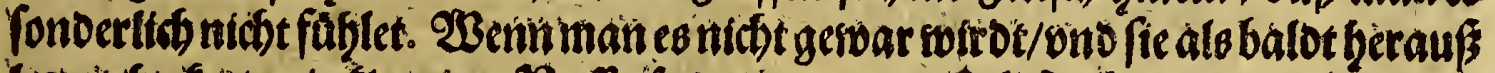

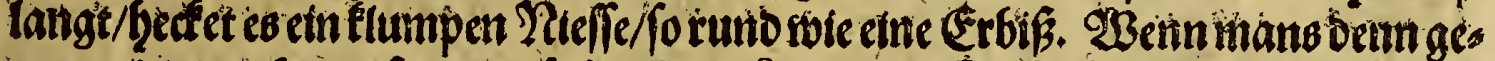

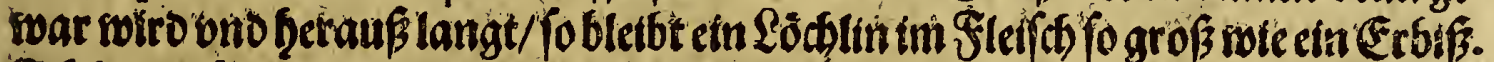

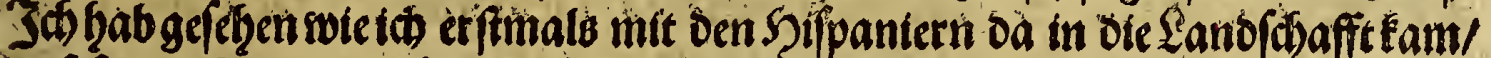

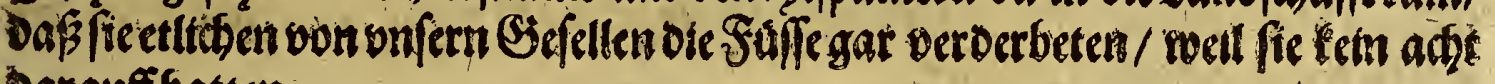
Qaraufibatten.

XXXXI. Sapitet.

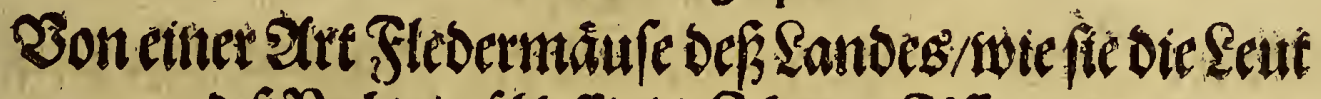

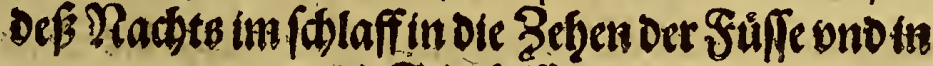
bic Stirnbiffen.

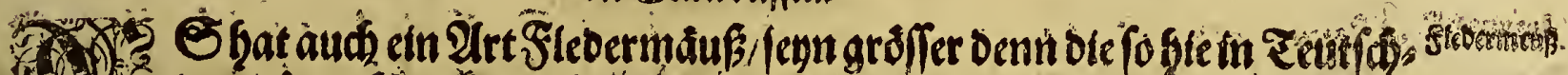

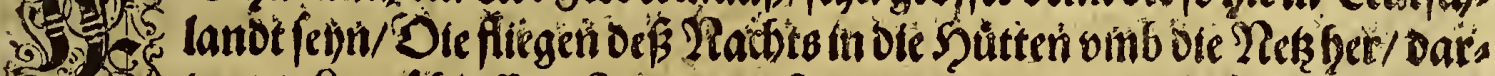

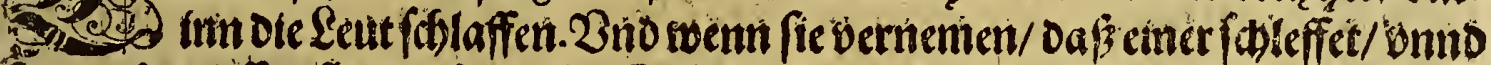

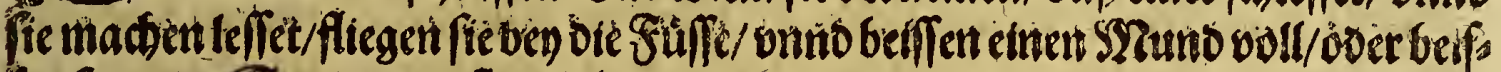

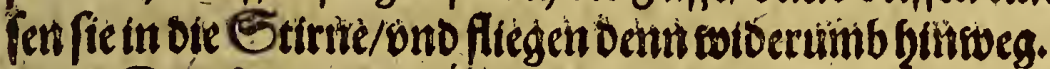

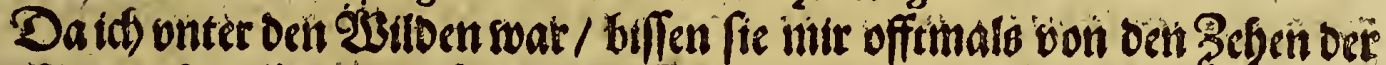

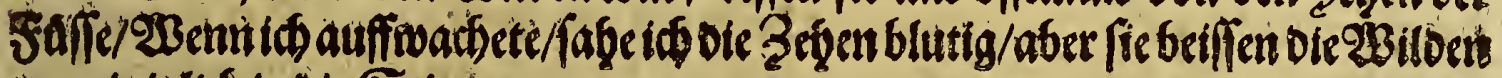
Eemeintglich in bie Stith.

\section{XXXXîî̀. Sapipitél. \\ Son Bienen ober S̈mmen be}

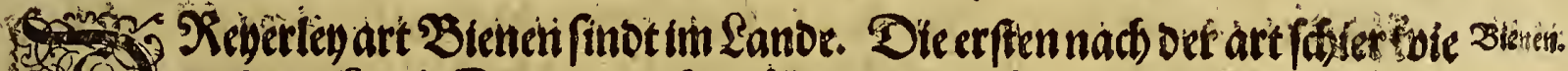

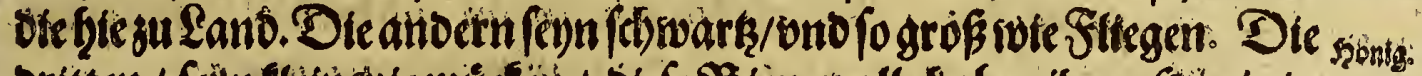

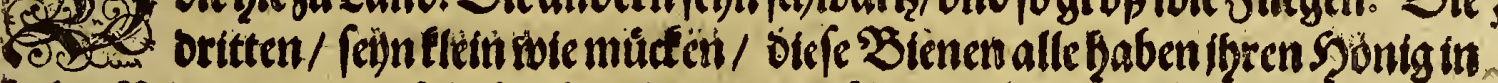

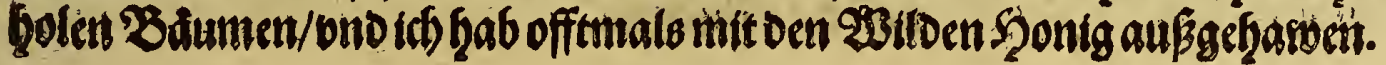

\section{XXXIV: Sapitel:}

\section{Bon}

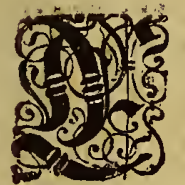

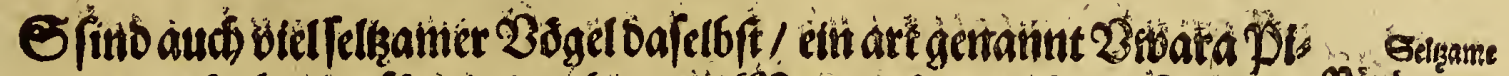

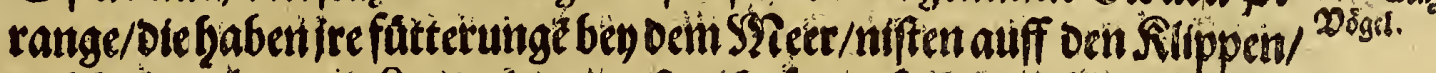

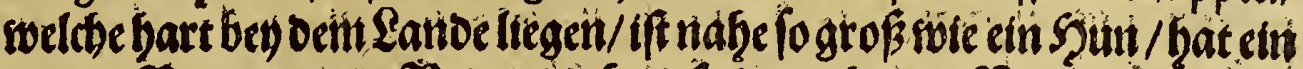

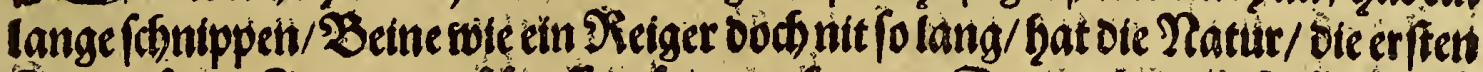

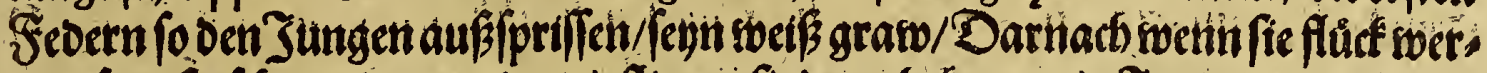

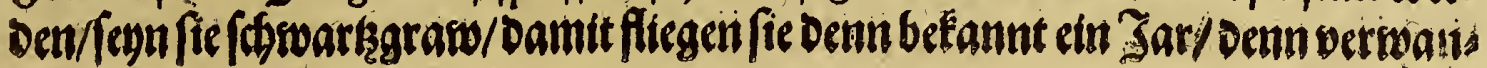




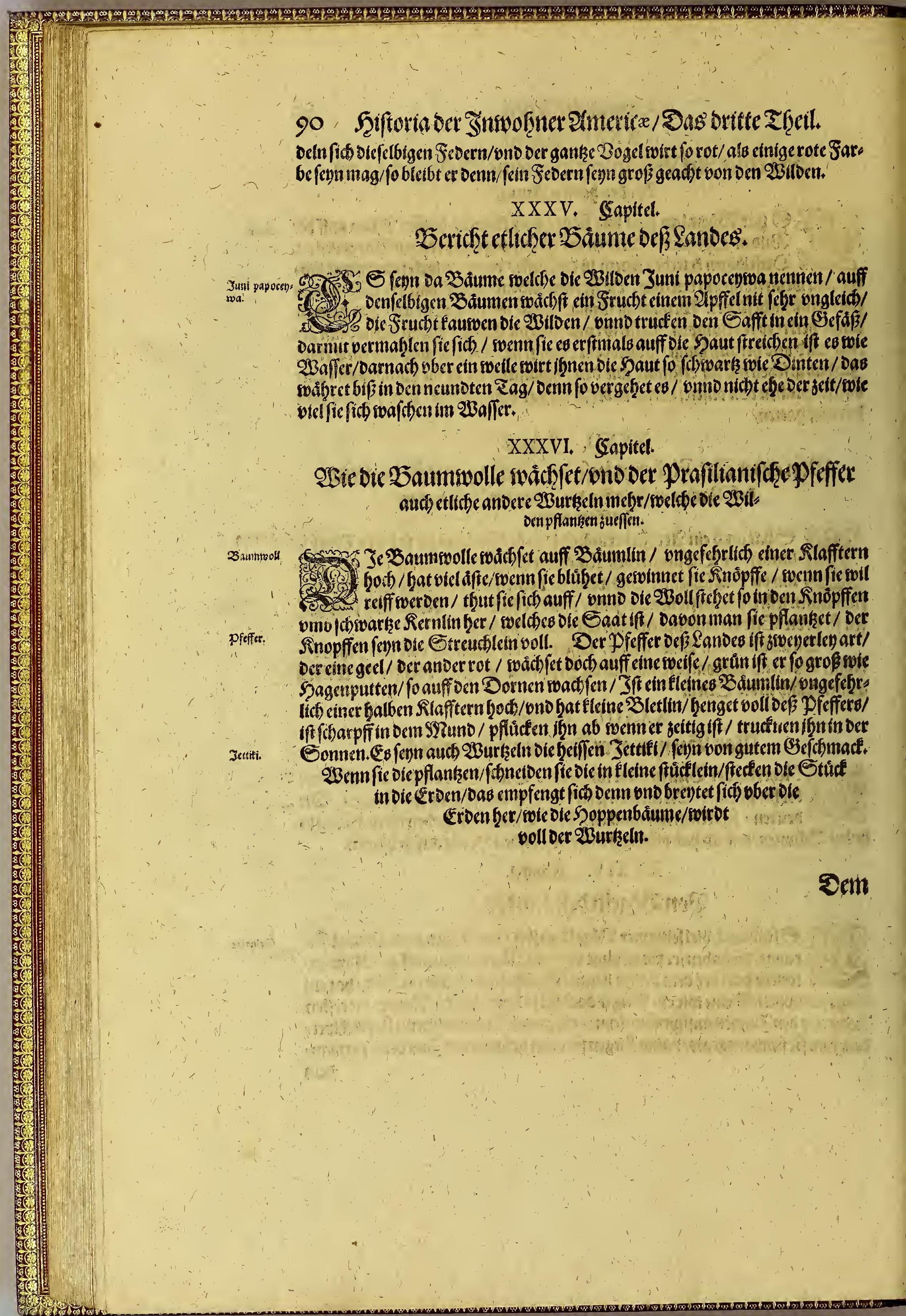




\section{Befcḩlufirtébé.}

\section{Dem Sefer wünfhet J Jang Gtaben Gottes}

Ginaoono frito.

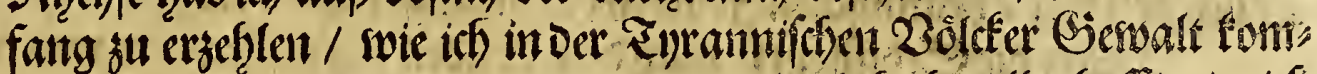
men bin. Darmit anzuzeigen/ woie gerwaltiglich) of hin alles boffen / mich

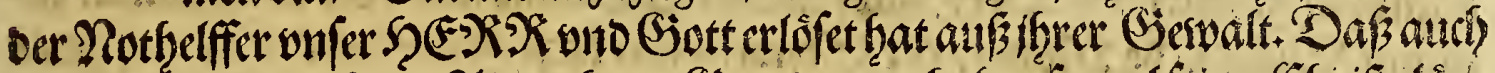

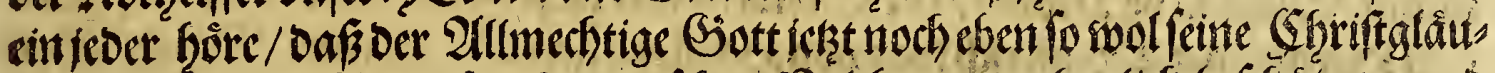

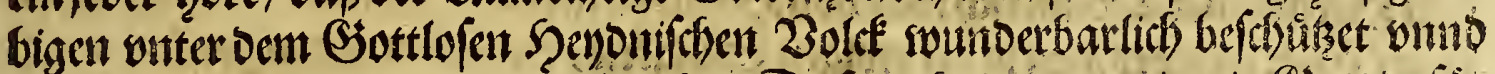
gelentet als er wö anbegin ie getf̧an bat/Daß

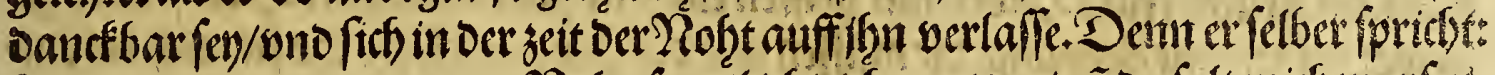

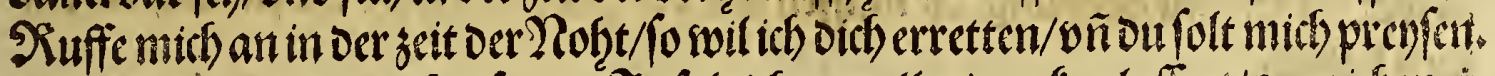

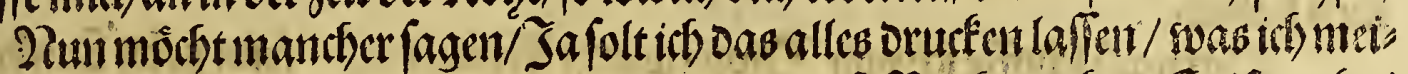

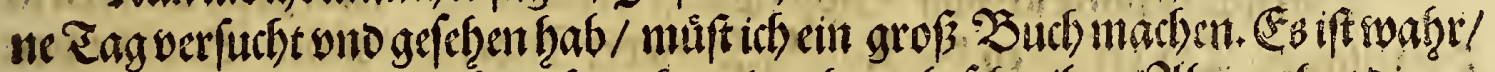

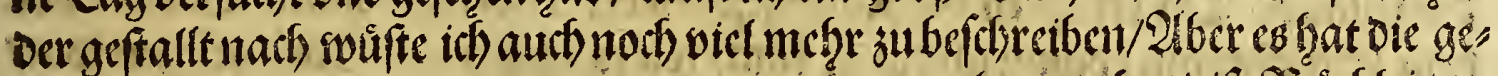

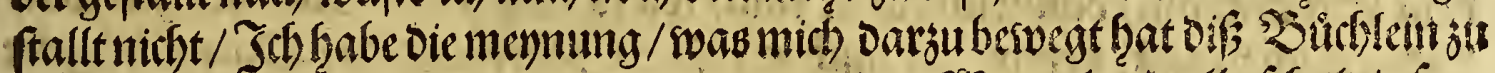

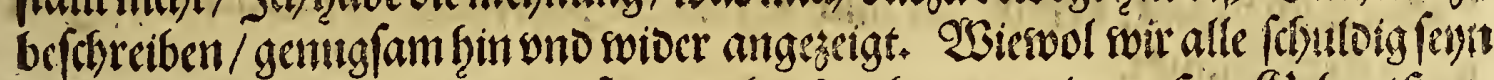

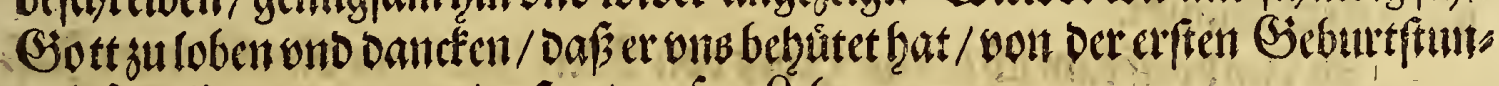
be biß auff Die gegenwertige fund onlare Sebens.

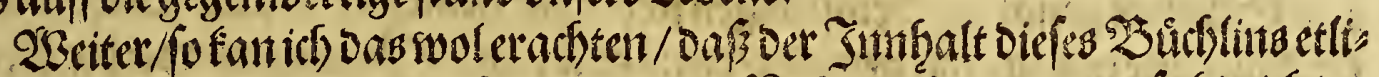

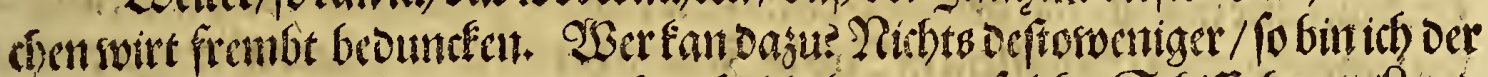

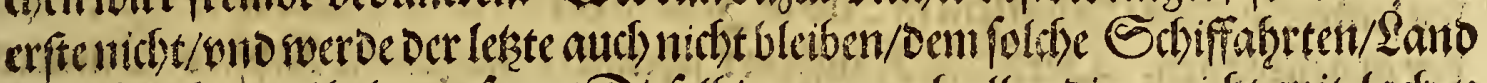

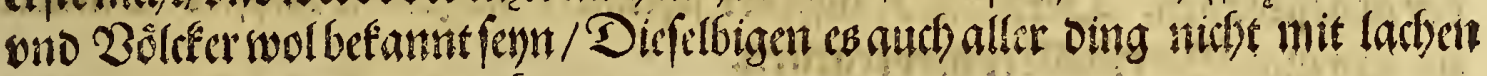
fenninnen woorocn/ono noch/much focroen.

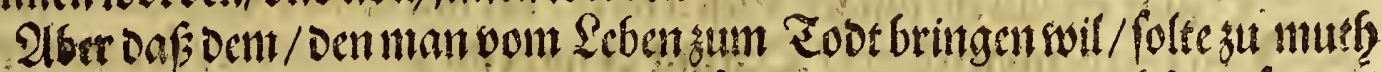

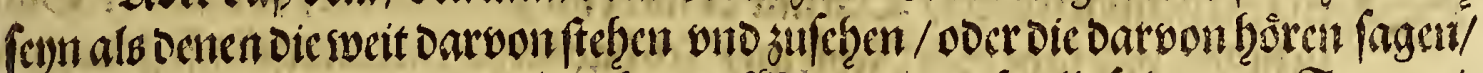

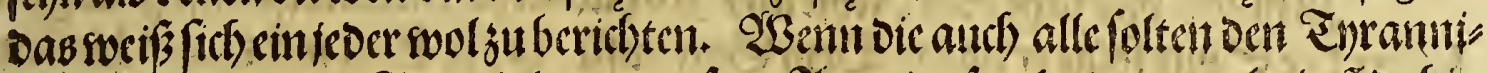

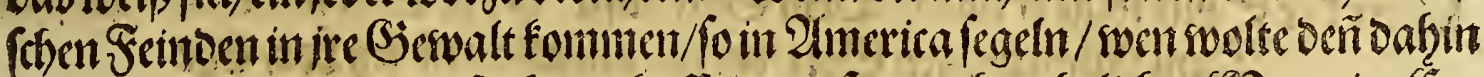

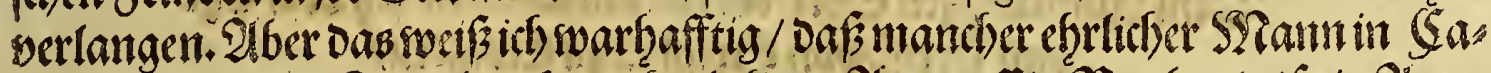

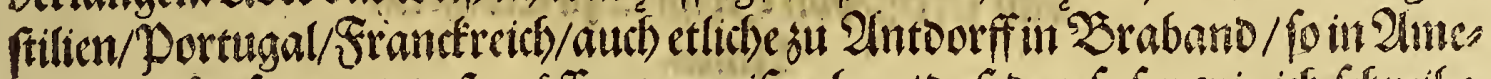

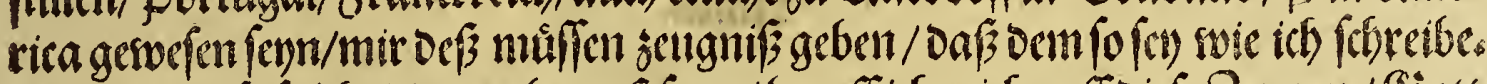

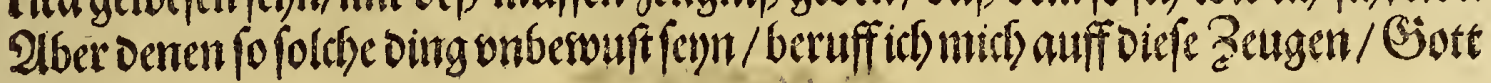
ouvorait.

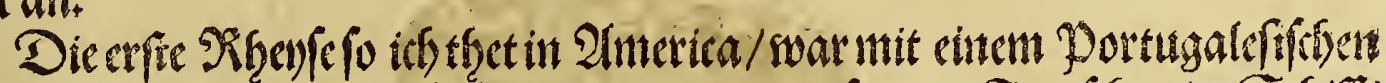

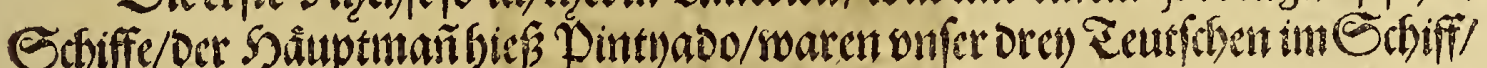

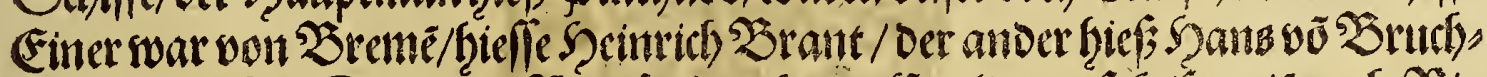

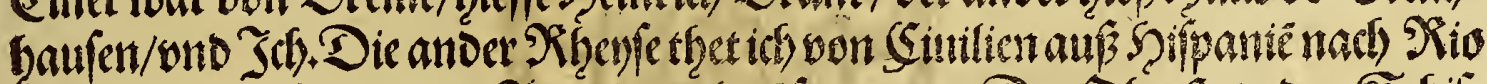

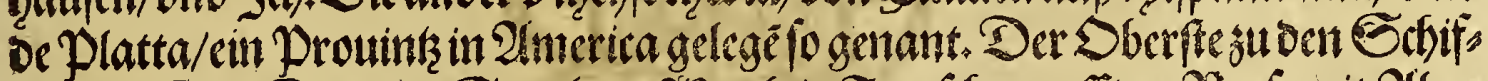

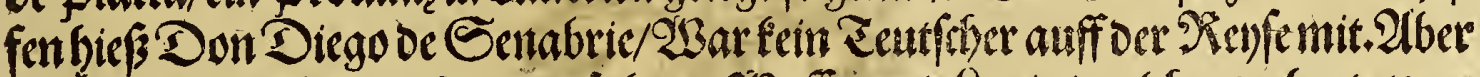

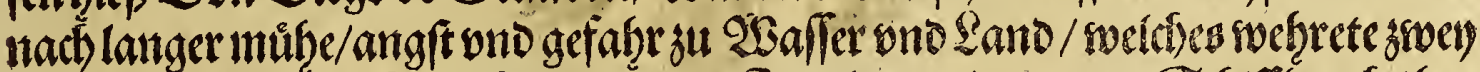

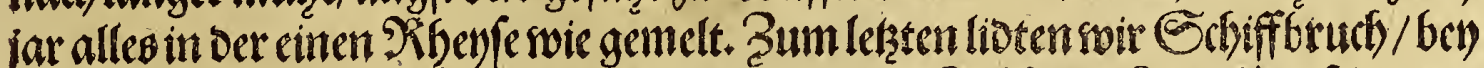

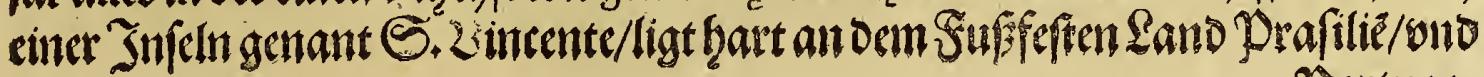




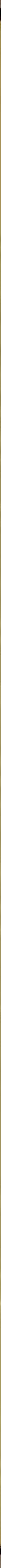




\section{Ectriffart in \\ BRASILIEN in AME-}

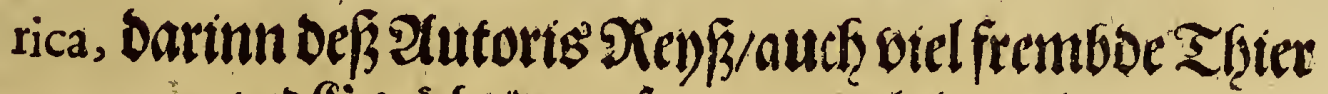

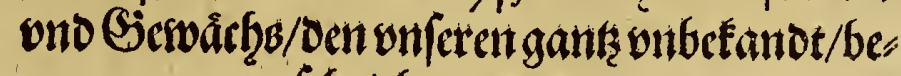

fithrieben werden:

Dureb lohannem Lerium Burgundum; $;$ elb/ten verathtet ono

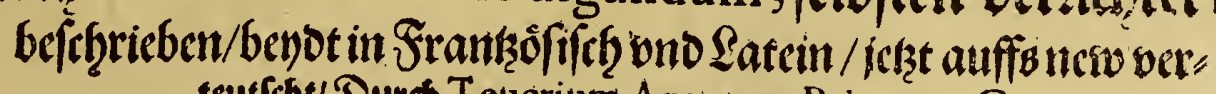

teutfcht/Durd T eucrium Annæum Priuacum, C.

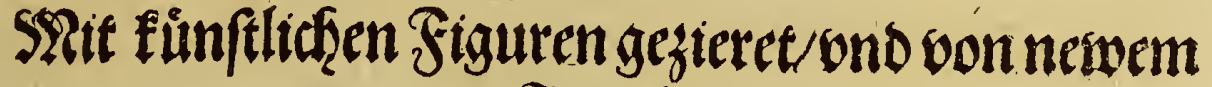

an Eaggeber/

Durch

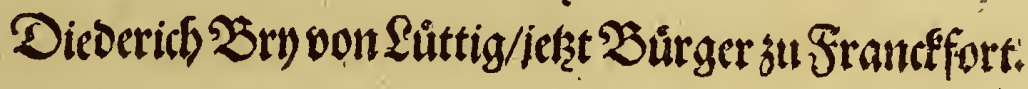

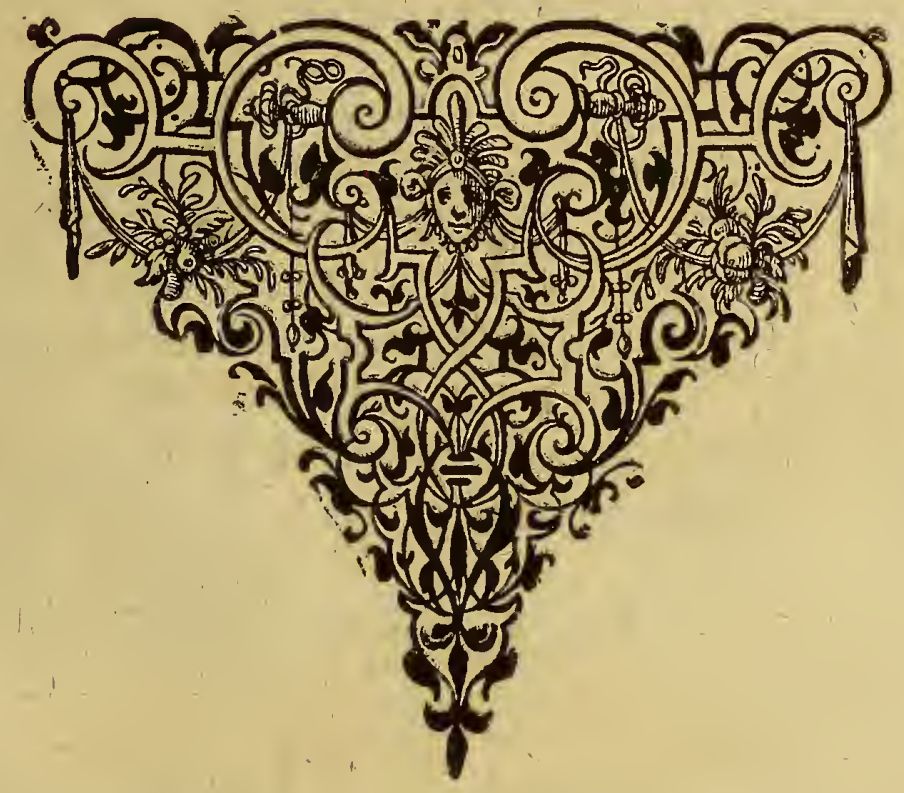

Betructit tu Srancffort.

2inno 159 3. 


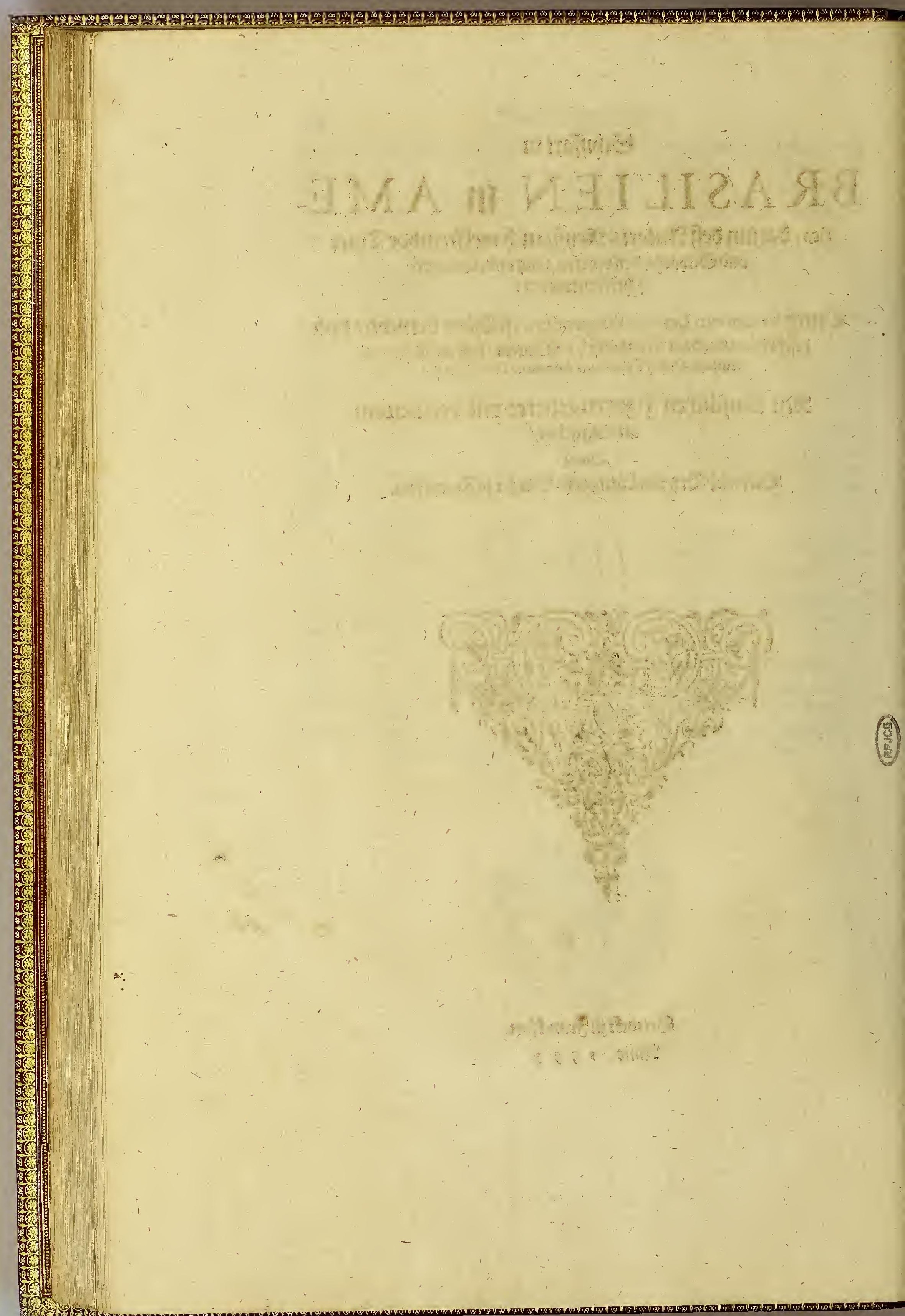




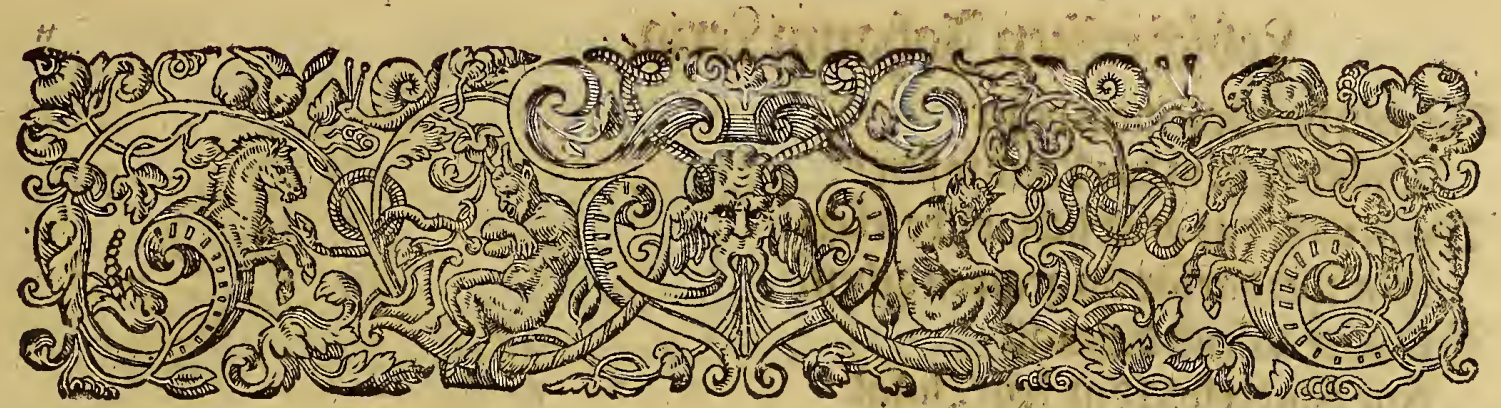

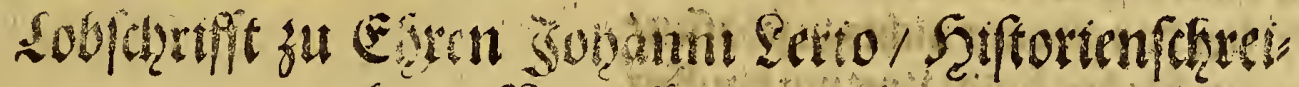

bar ber Nerven 23 eft gemadit.

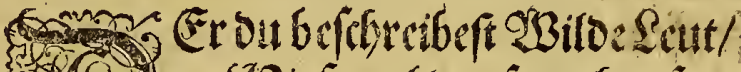

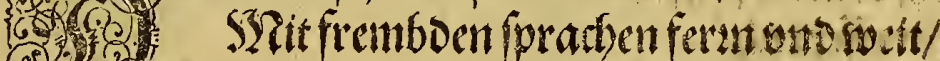

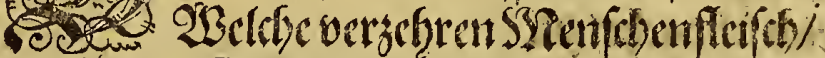

Gagmir/S Seriswoher fompe/

Dab ont verwoundert allermetif/

Daficin fo gut Eand fod gerifont

Solfaben Eent fogrobsind QBitot/

Sodoct das (Evoriff geil wntomilt/

Dhn Ifferbarwend andere Sunft!

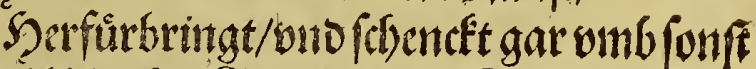

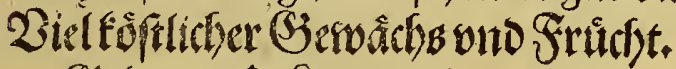

Gib wns/DSeri/gic bertitht.

\section{Intwort.}

Defintoogen Dic Philofopgi

Dich leftern/welebefthreibatsvie

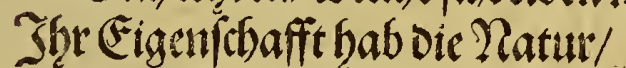

Doch wil ich our bie fagent nury

Dafimant bey ons in onferm!anot)

Da Kumft bno \&edgr iff allerbandot/

Bielfchrectlicher wino vingefberwer

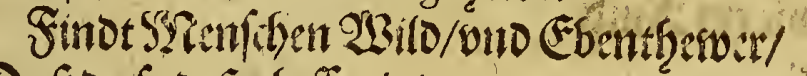

Dafoufodefto befleriel

Samfíglaubenneinen Gothreiben fice.

I. I. B.

Ein andere Sobfofriffe zuterern bem

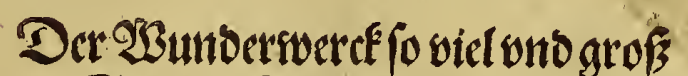

Echreibt \&crius ofynzicl vno maß;

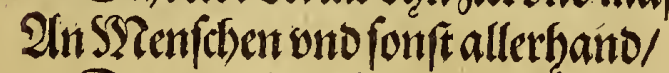

Diecrims?iecr ond auffoem \&antet

$\mathfrak{A}$ ij $\quad$ Gefeffen 


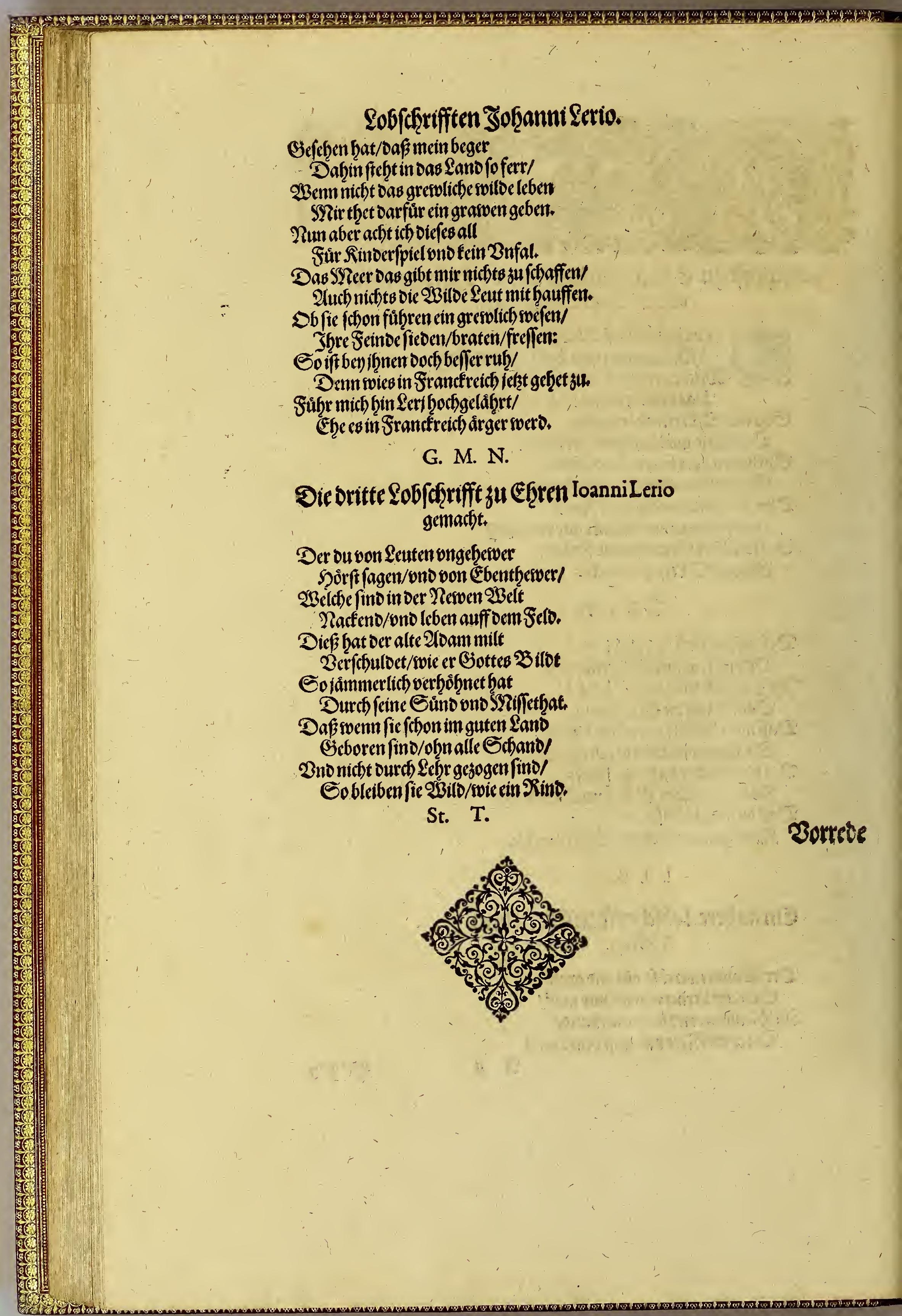




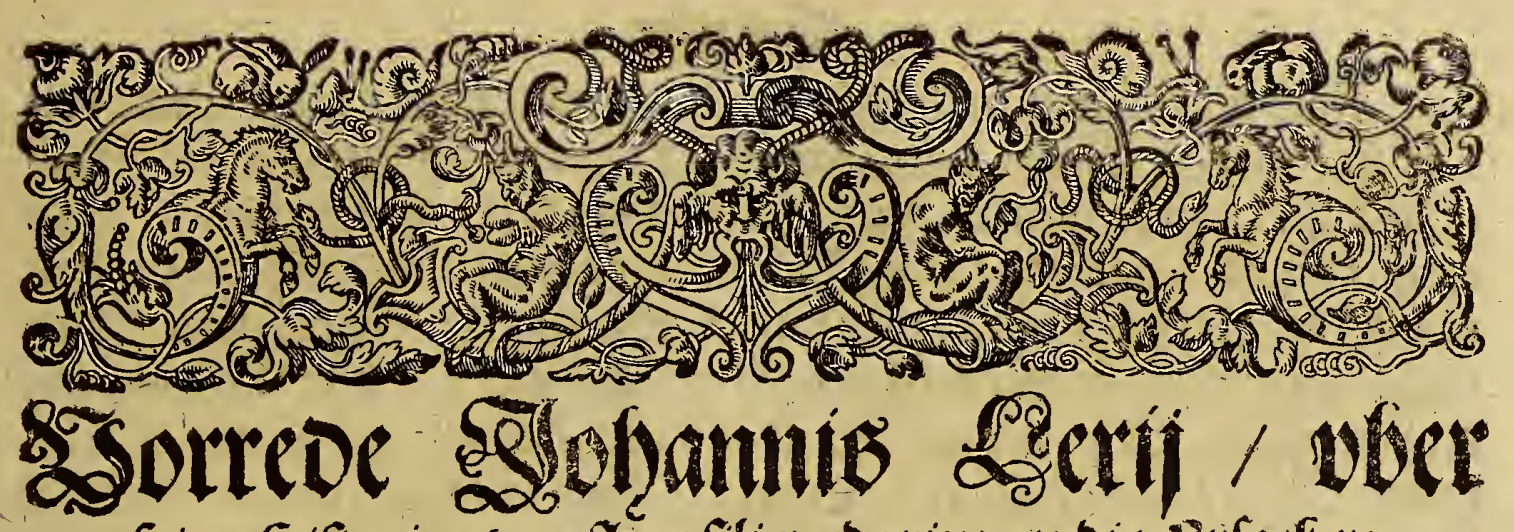

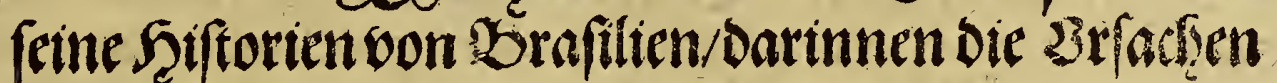
vermeloet/warumb oer 2 lutor biefe Siftorien publis cisthata.

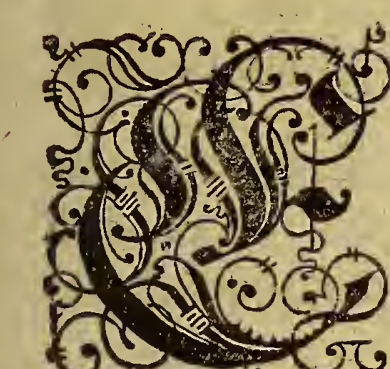

Swerben fith ofin allen zweiffel viel wertwan,

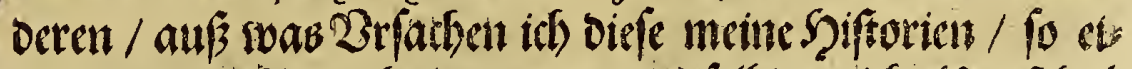

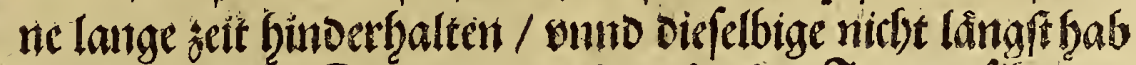

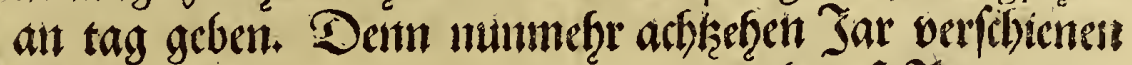
fino / von der seit an / als ich wiederumb aup 2(merita su

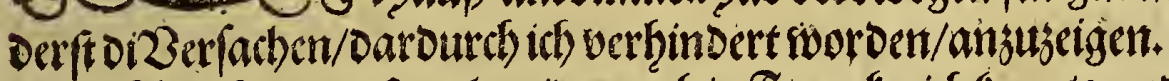

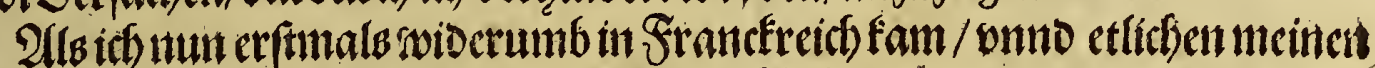

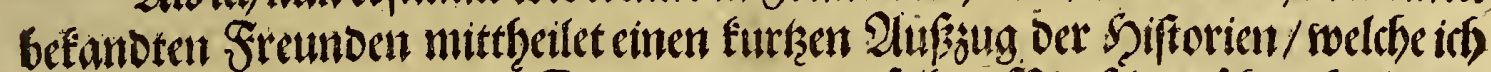

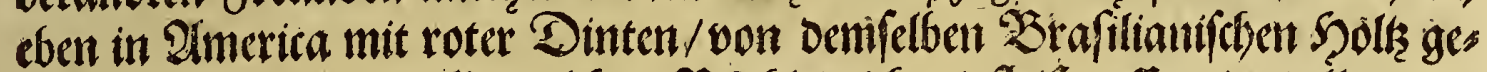

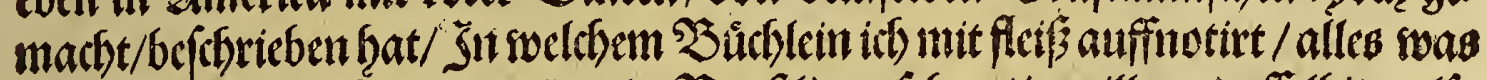

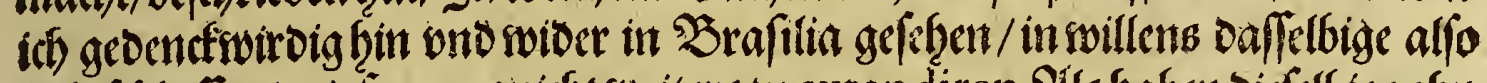

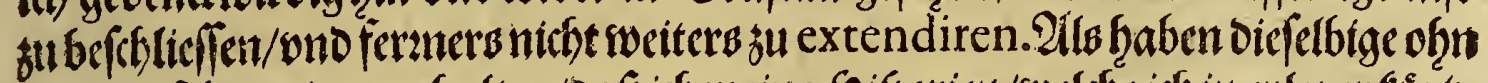

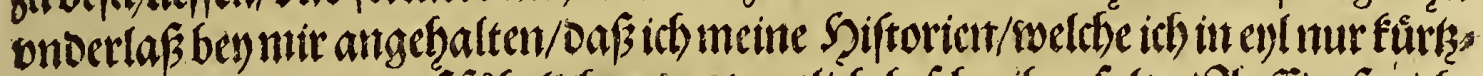

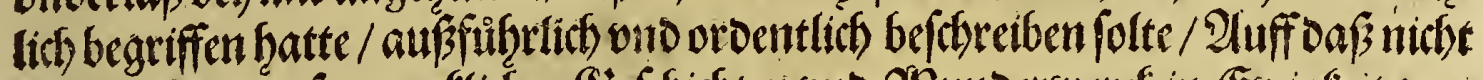

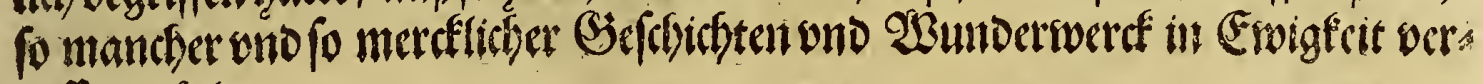
gefien wurbe.

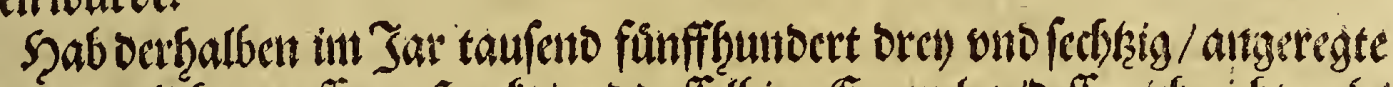

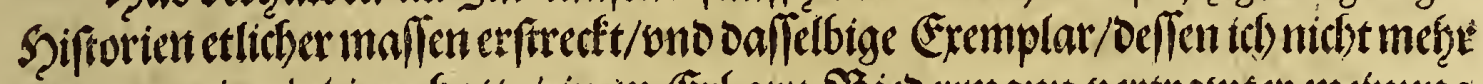
bannnur ein cinkiges hatte/einem Erbarn Biedermann vertratoter meinung

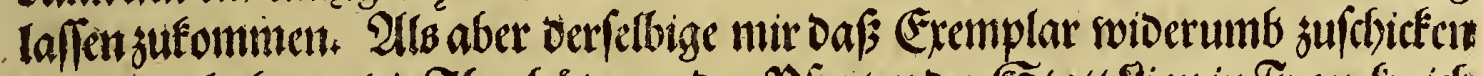

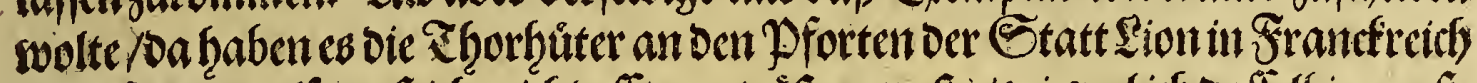

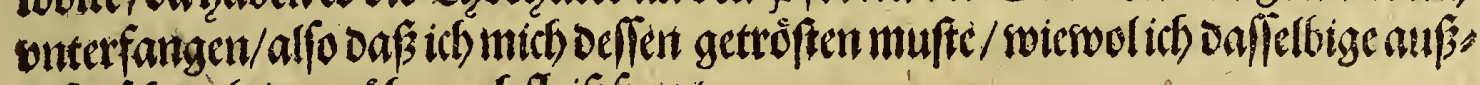

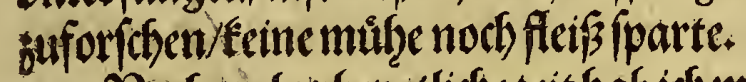

?achnials vber etliche zeit hab icf) meinConcept won oem A manuenfe sois

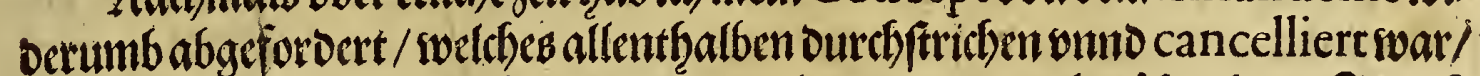
bab oalfelbige miteigenter Sand wiberumb wonnewem abgefebrieben / Jeboch

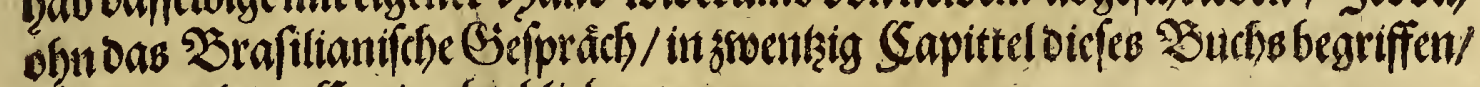
Deflenmir feine Sopia berblicben war.

I iii Rad 


\section{Borrebe.}

Rach bent ith aber autb biefe 2lrbeit vollenoet hatte / in ber Statt won

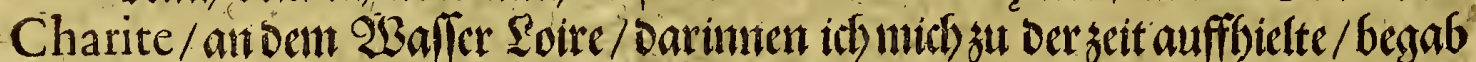

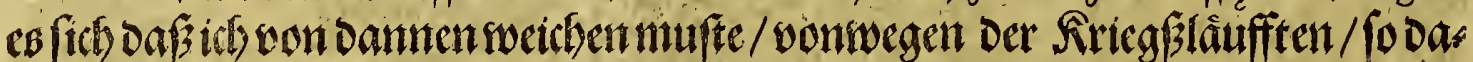

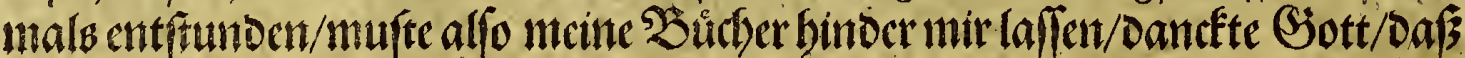

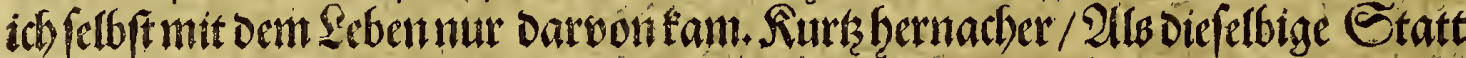

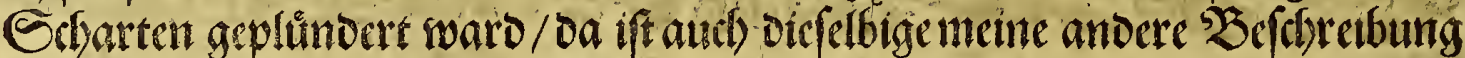

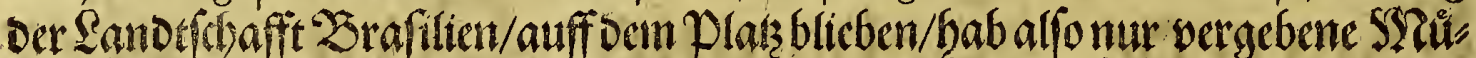

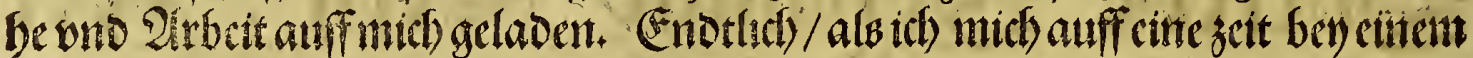

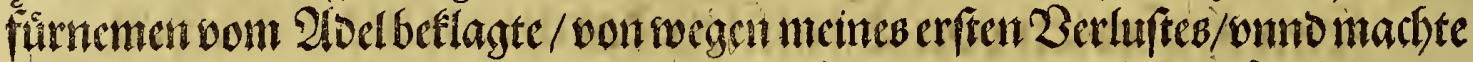

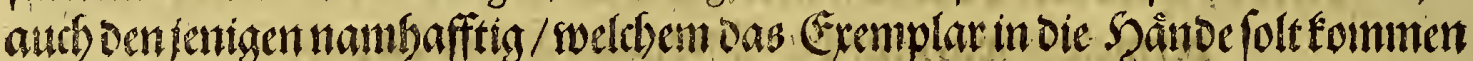

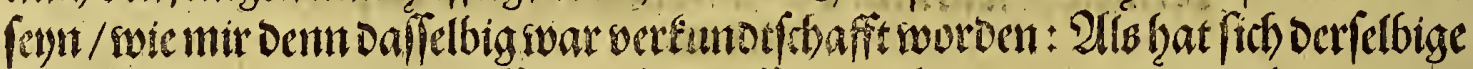

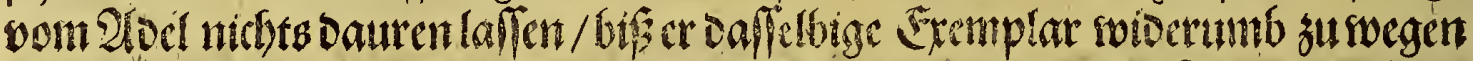

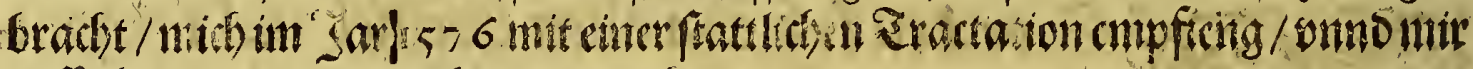
Daffer bige rvicoerumb infándigmadite.

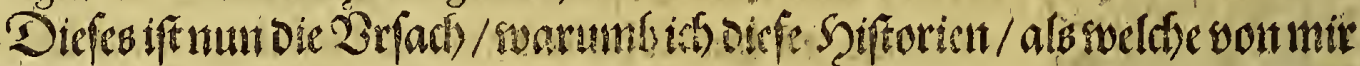

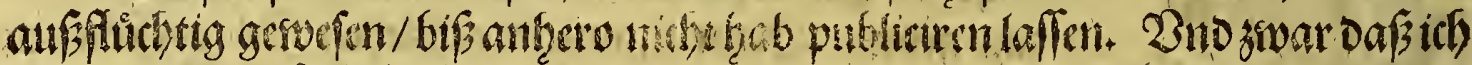

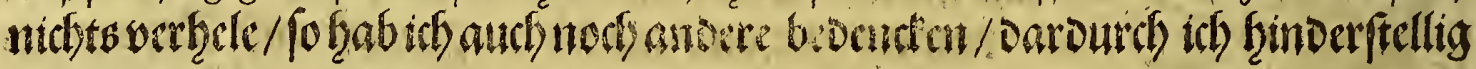
sworbent.

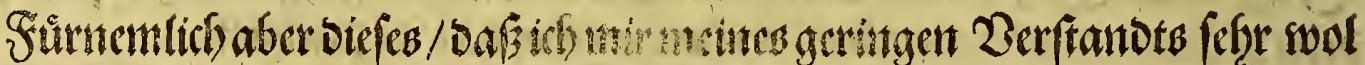

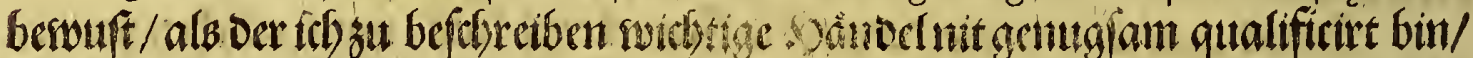

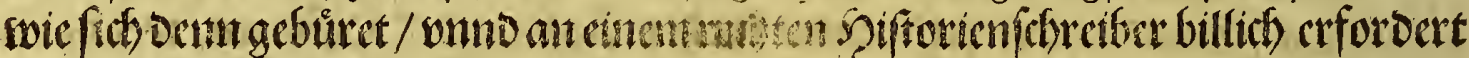

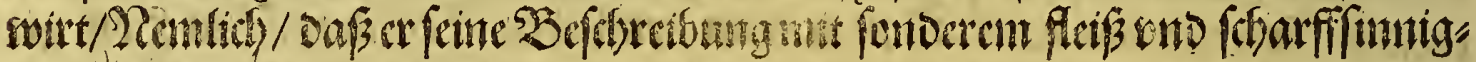
feit ersiegenteunte.

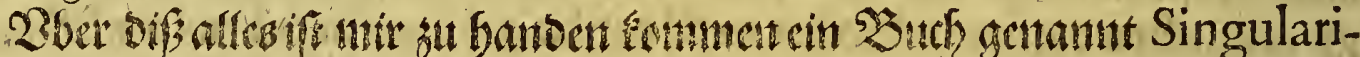

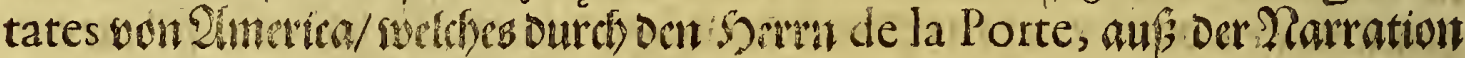

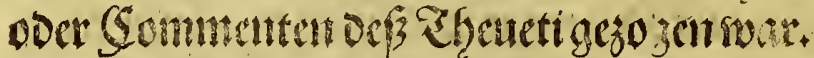

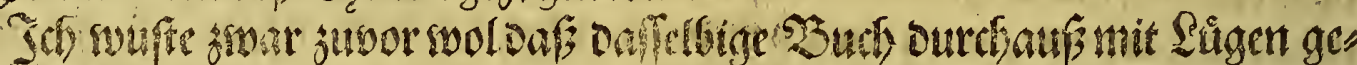

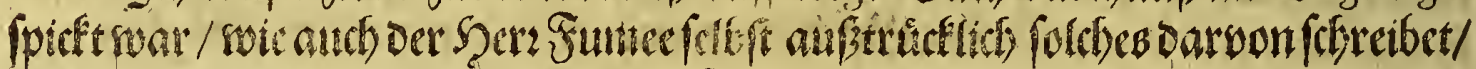

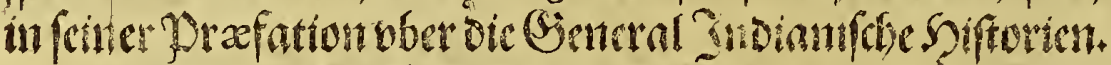

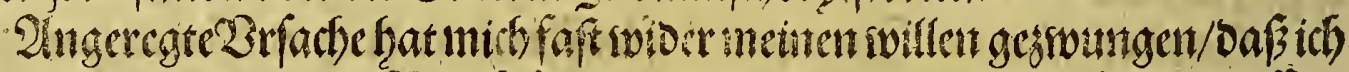

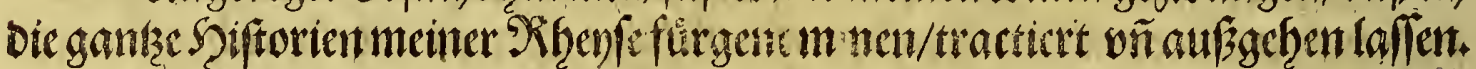

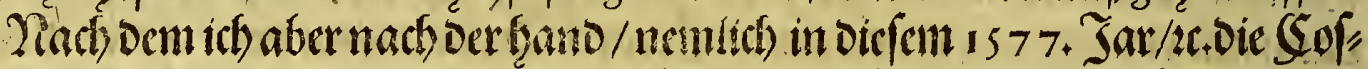

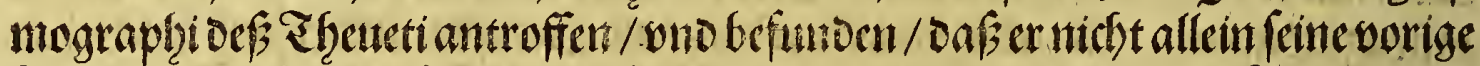

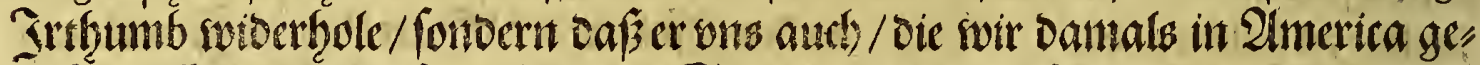

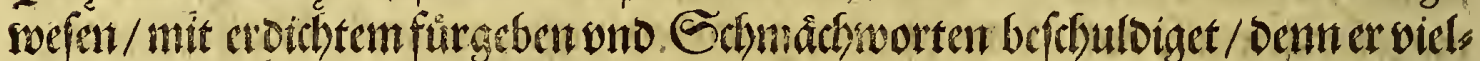

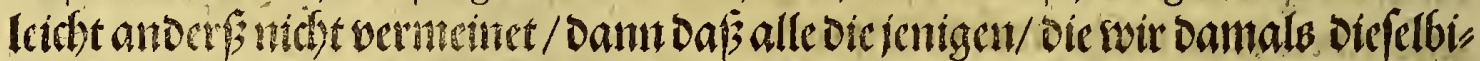

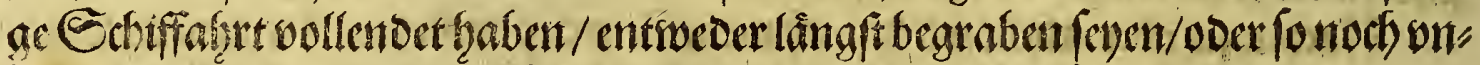

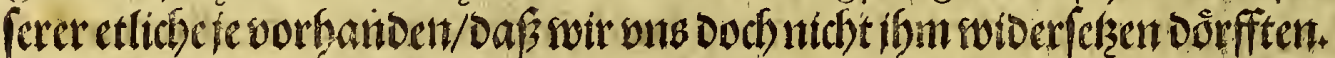

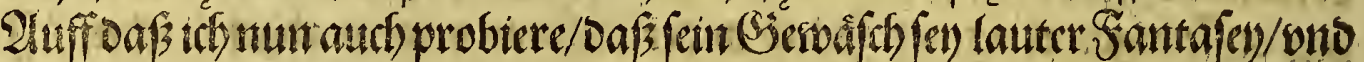

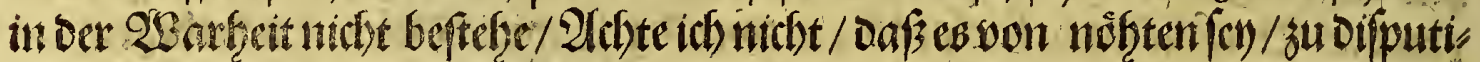

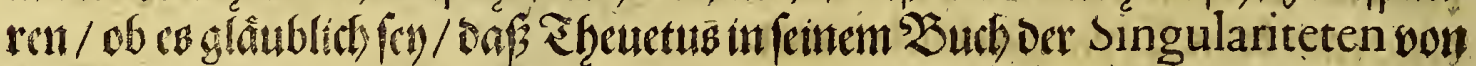

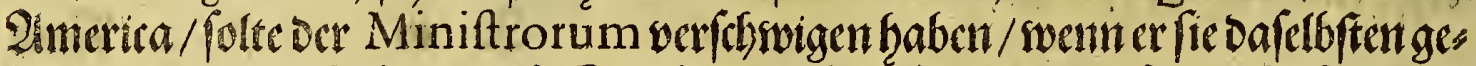

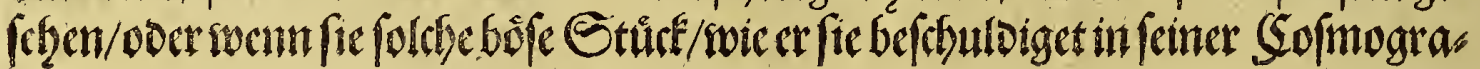
$\mathrm{phri} /$ wells 


\section{rorrebe.}

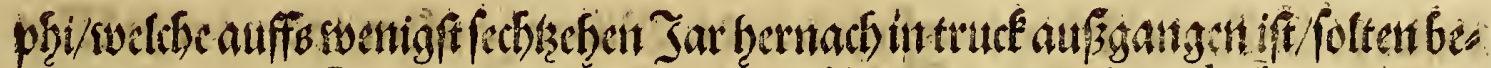
gangen baben / Eo cr boch in obgemeltem $\mathfrak{B u c h}$ cein oer Singularitaten alles

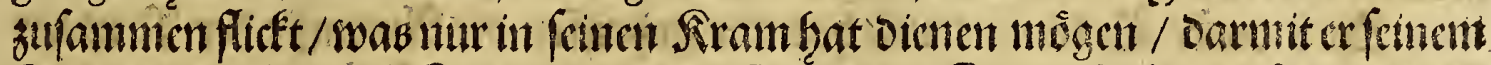

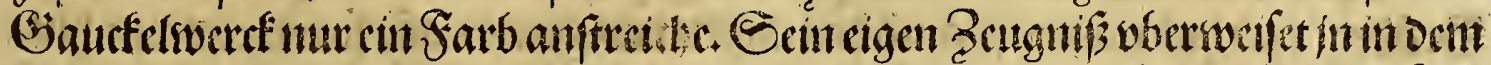

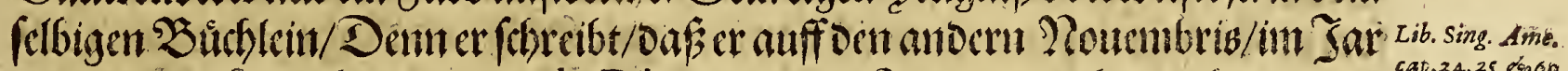

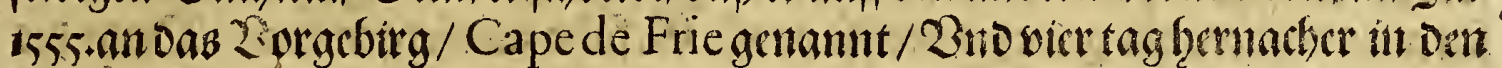

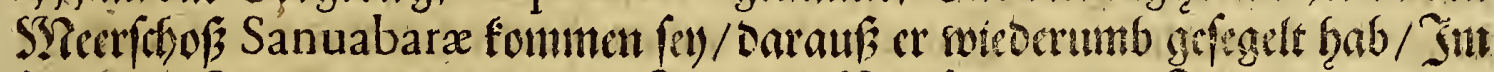

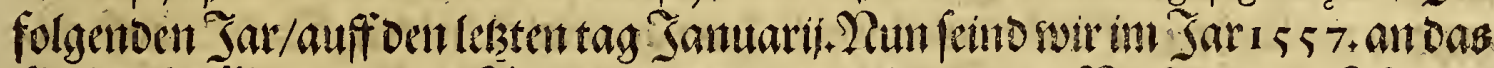

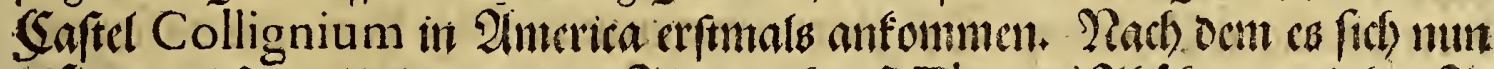

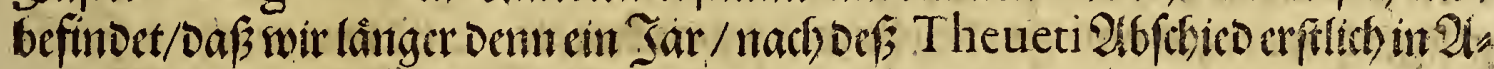

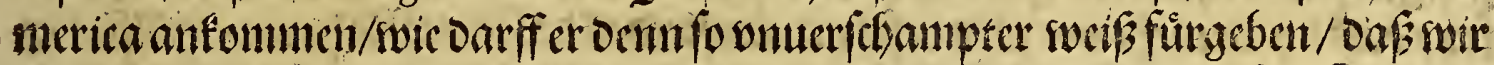

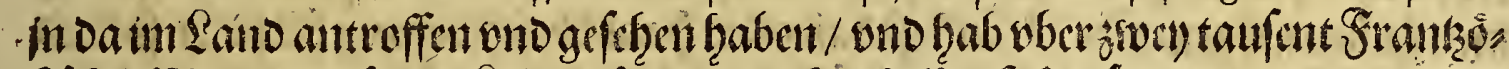

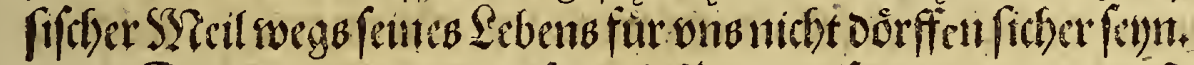

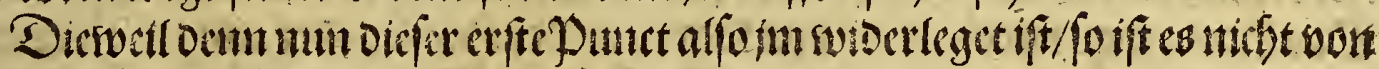

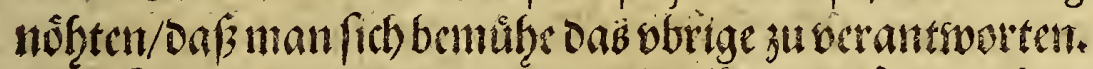

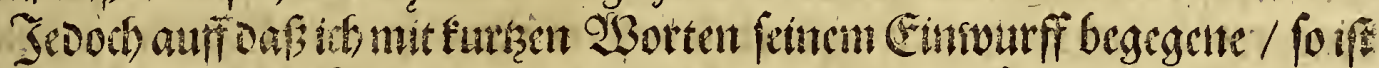

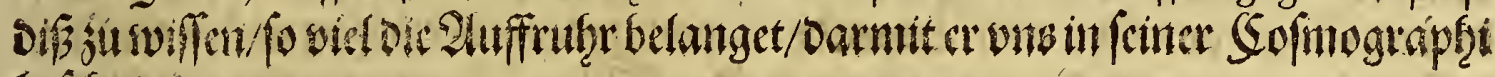
befichtibiget.

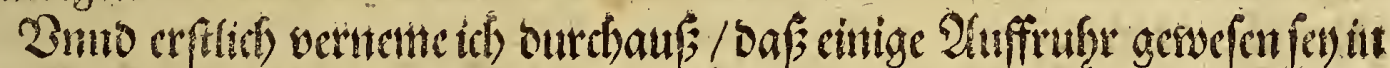

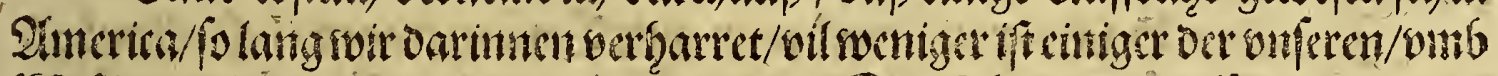

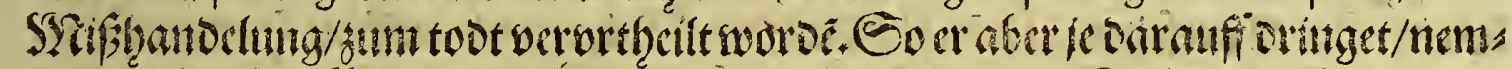

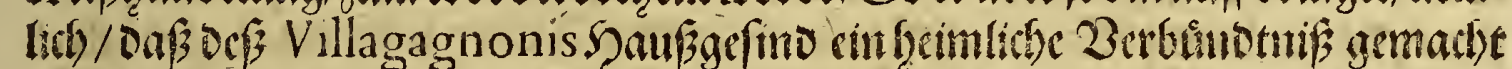

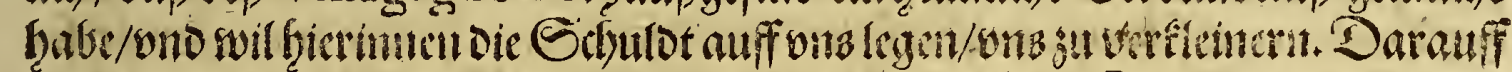

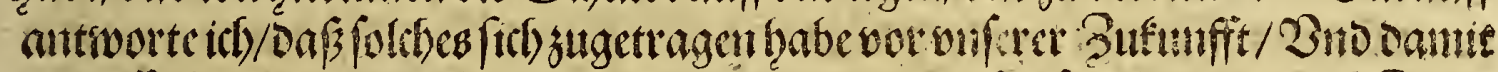

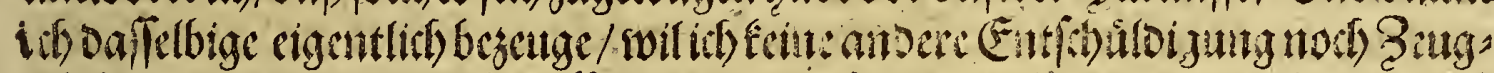

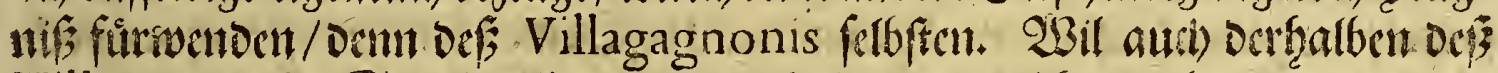

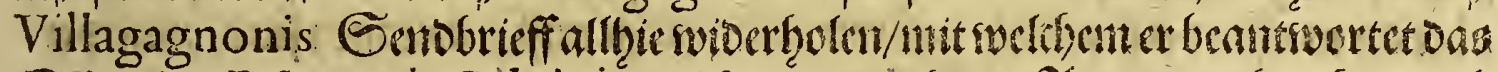

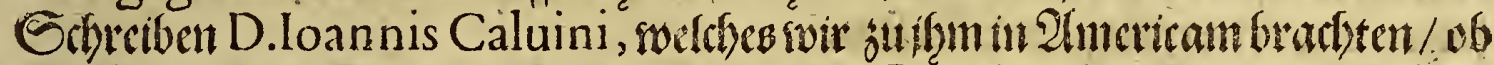

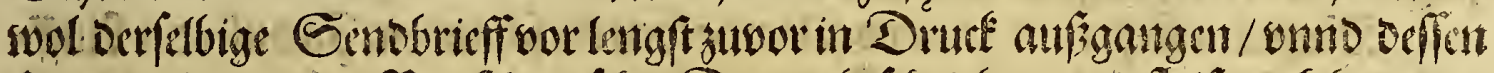

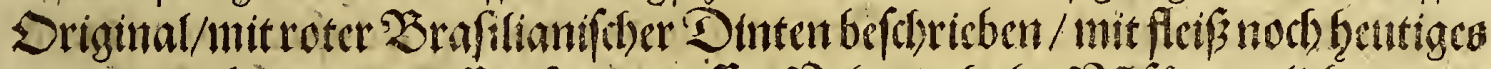

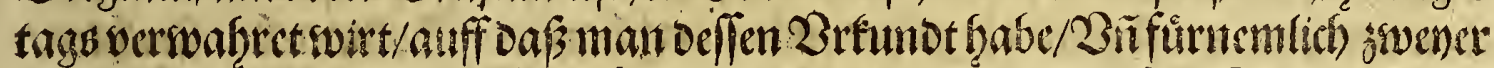

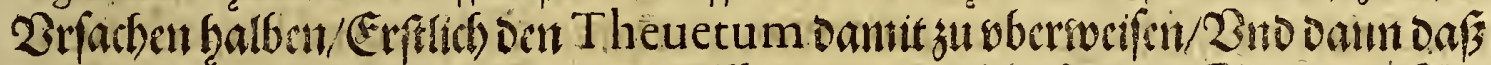

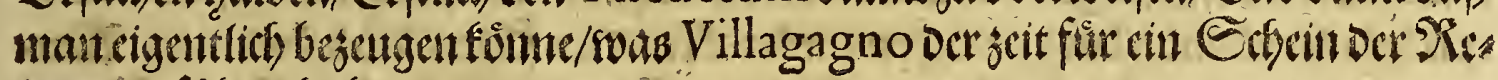
ligiongefinfrett ţab.

\section{Btllagagnonis Eendtbrieffan Calumum.}

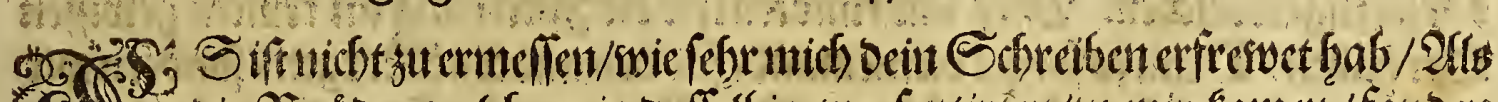

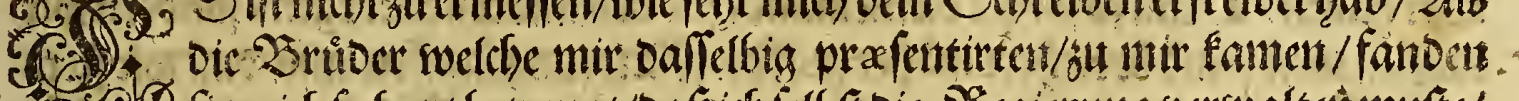

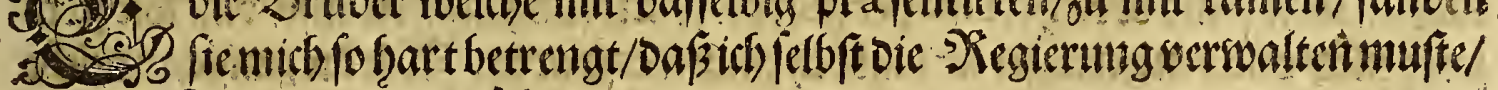
bndoub Rirchenampt verfechen.

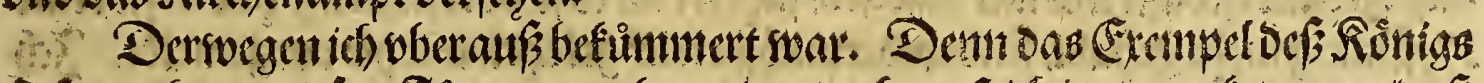

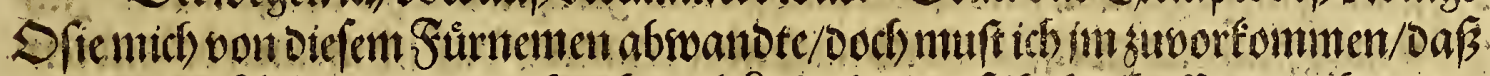

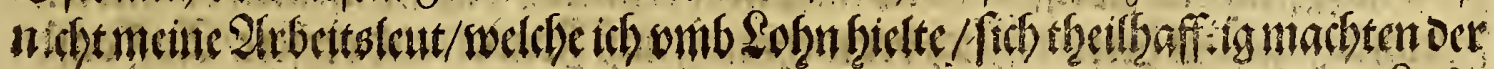

Eaftic 


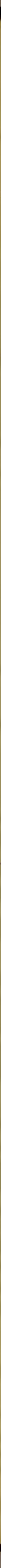




\section{Tortebe.}

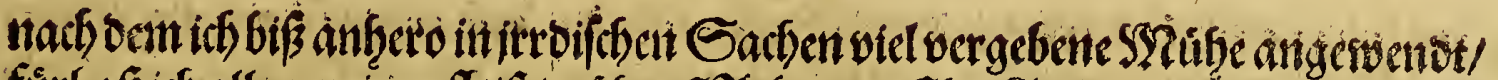

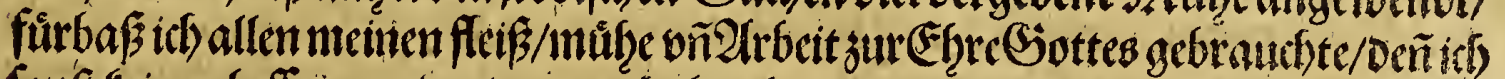

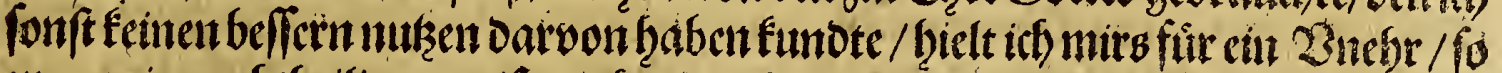

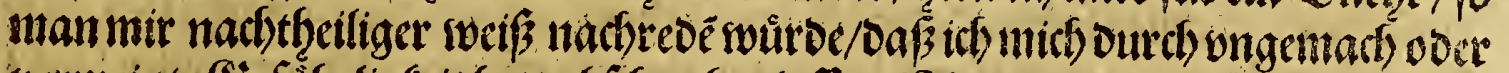

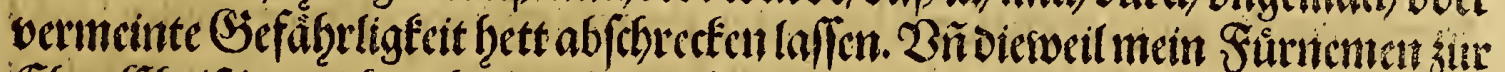

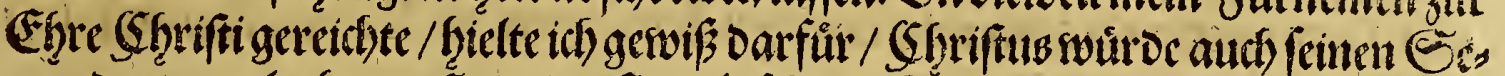

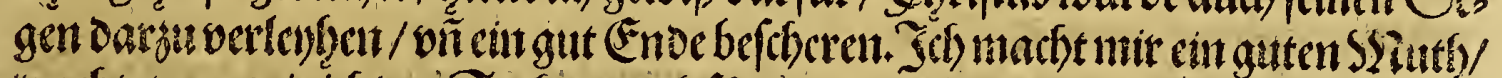

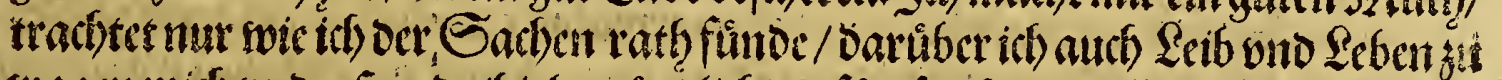

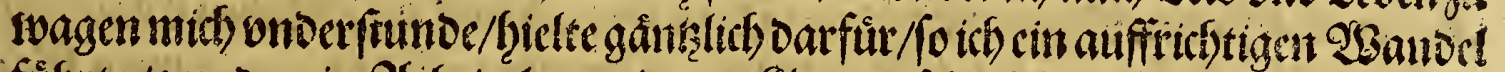

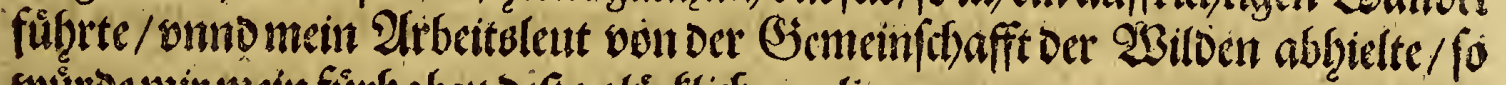

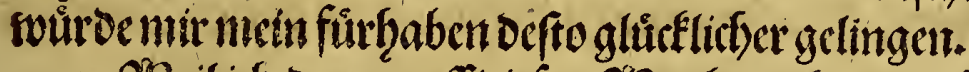

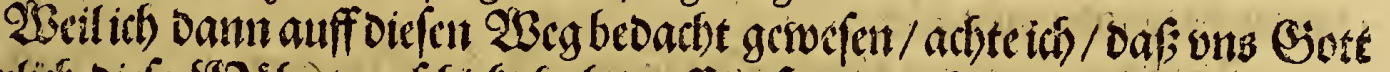

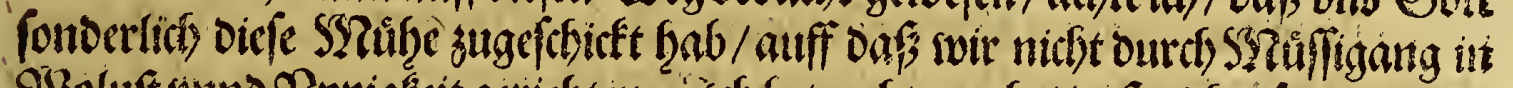

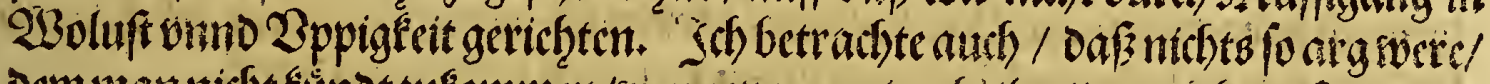

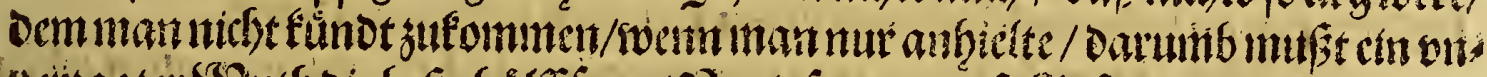

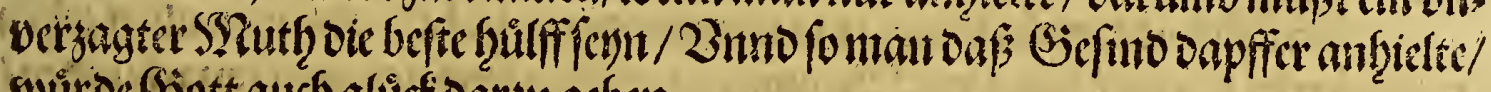
wurree Sott autch gluif Darä geben.

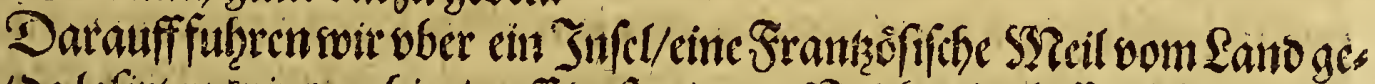

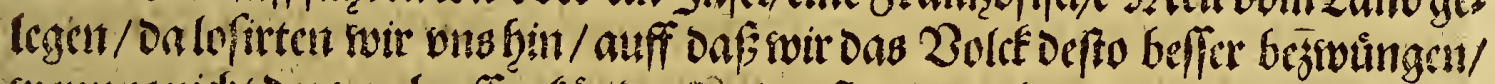

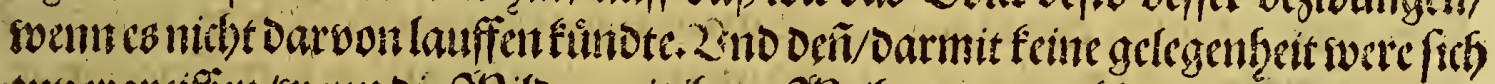

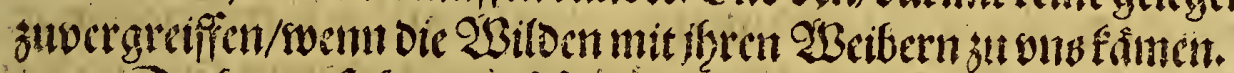

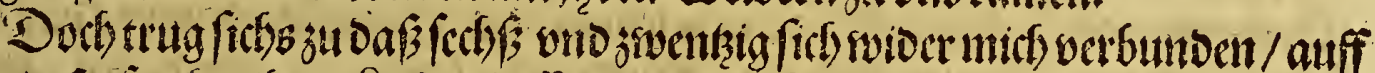

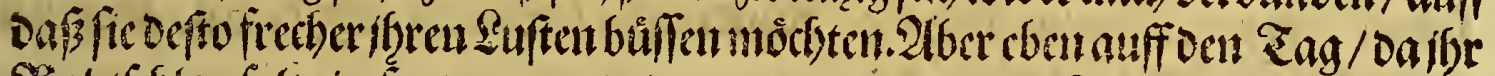

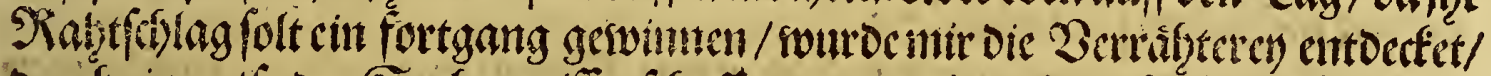

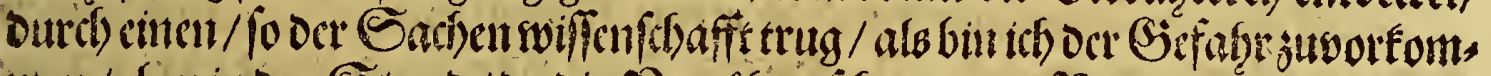

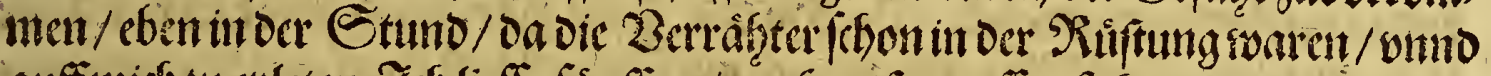

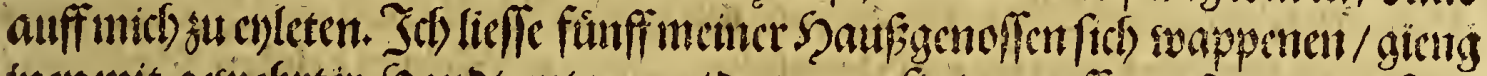

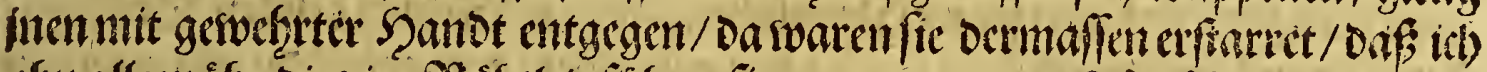

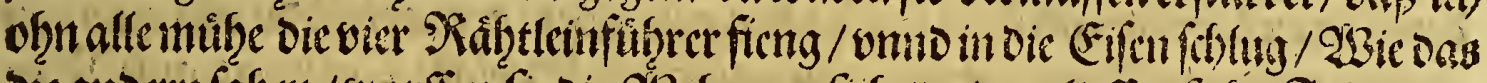

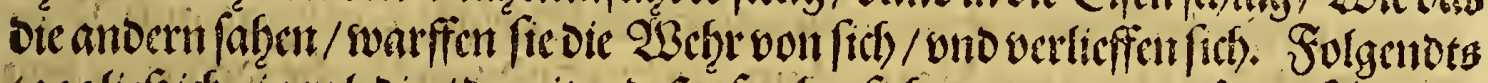

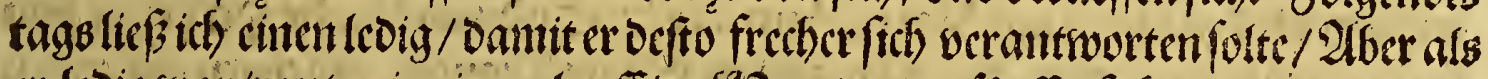

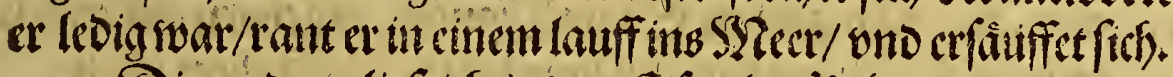

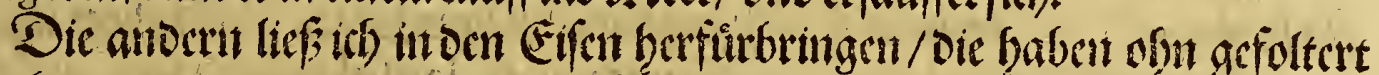

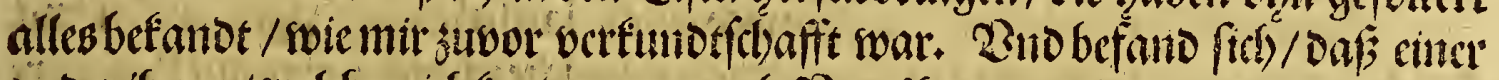

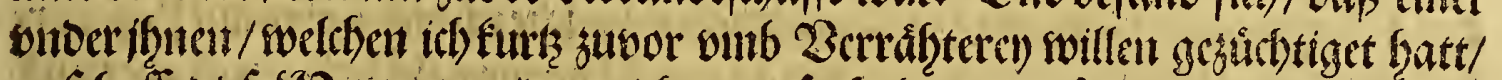

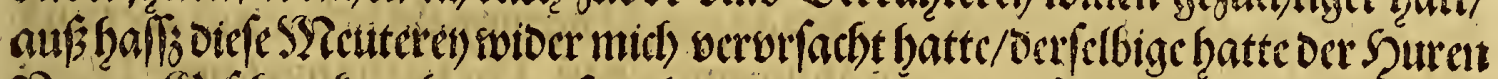

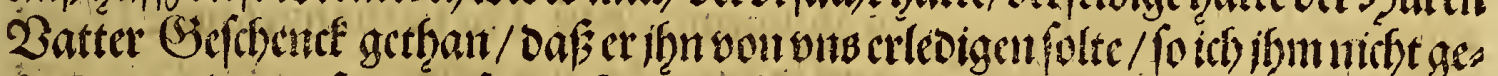

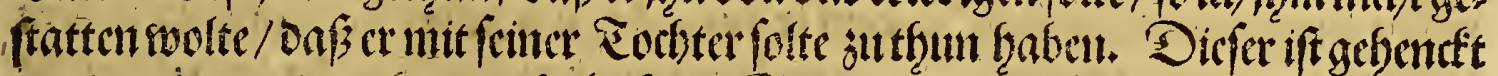

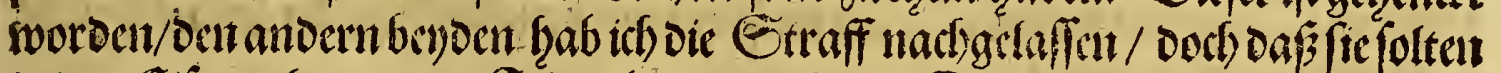

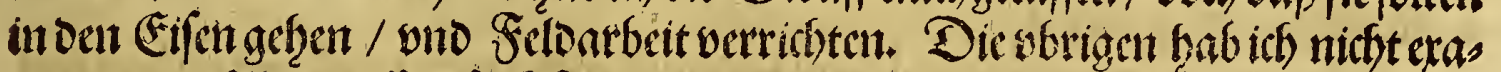

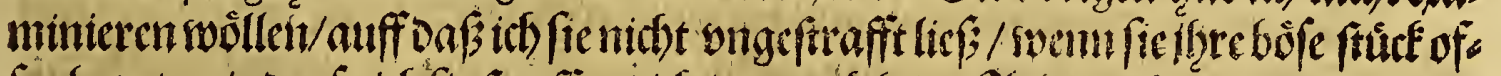

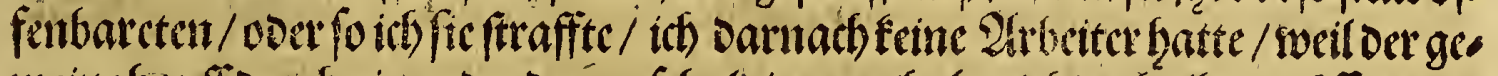

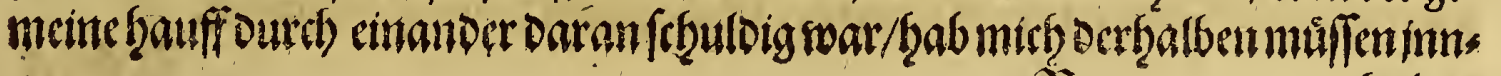

33 : ţalten 


\section{Bortet}

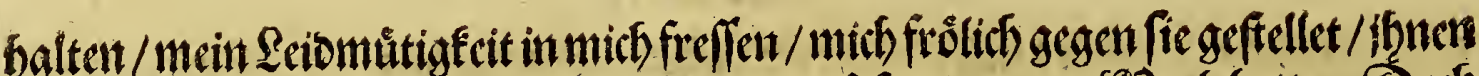

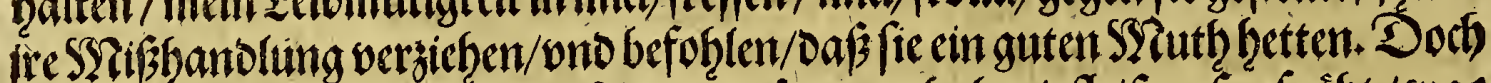

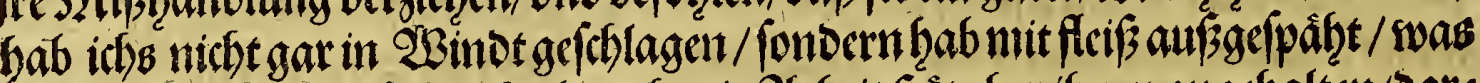

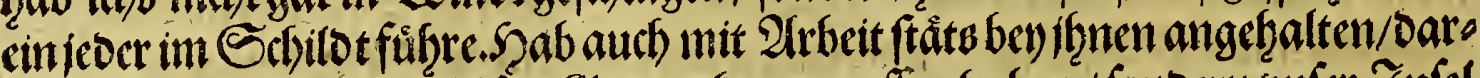

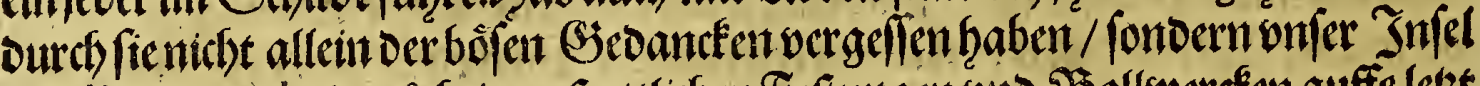

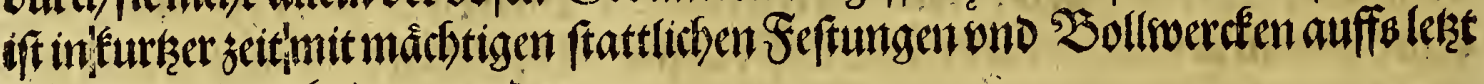
erbarwet who ombringt fworden.

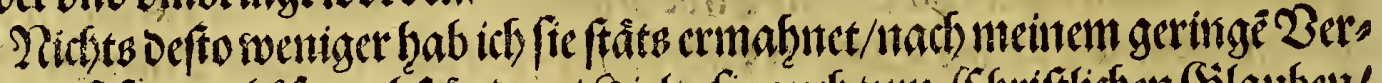

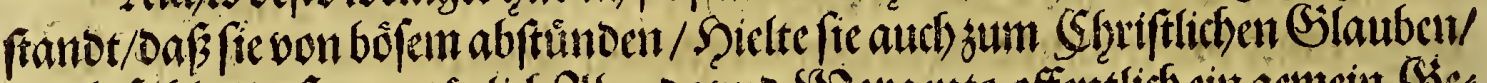

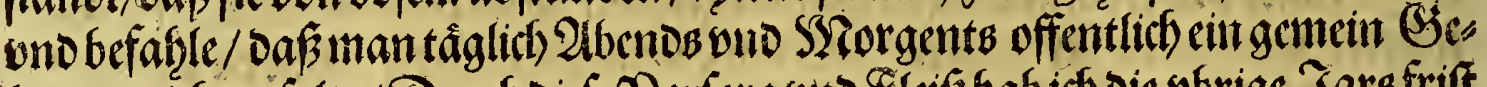

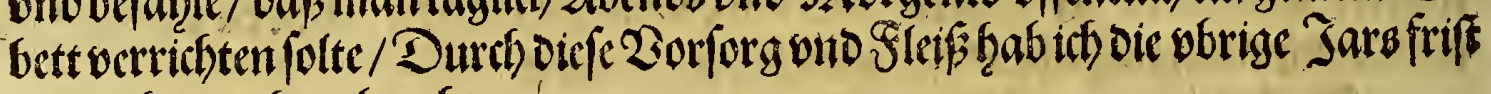
mit meforer rube zubradtyt.

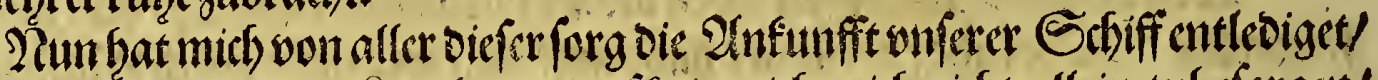

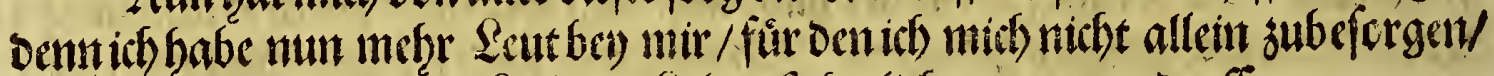
fondern ben ich habe auts \&eib ond \&eben ficter lich wertraswen oarff.

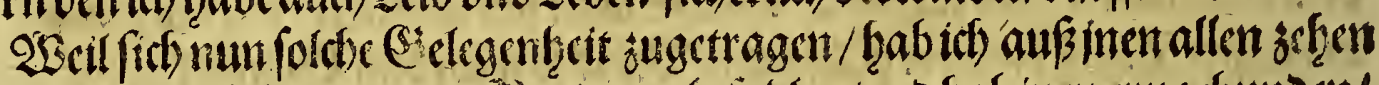

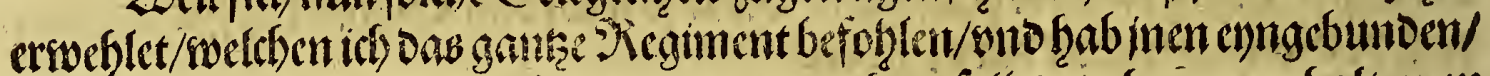

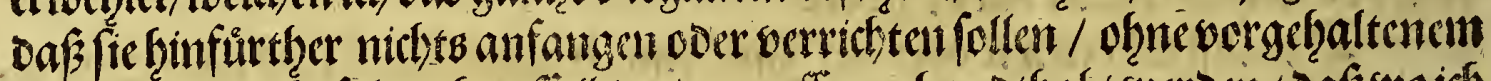

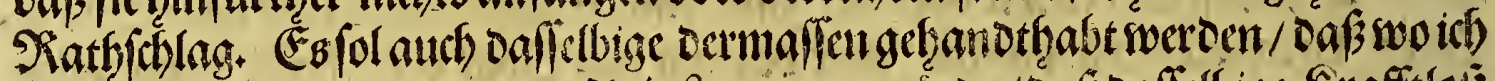

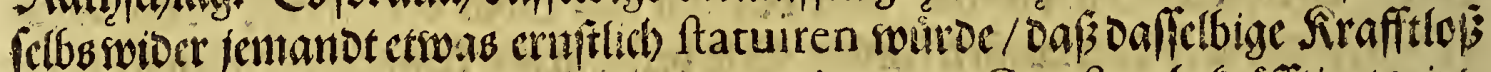

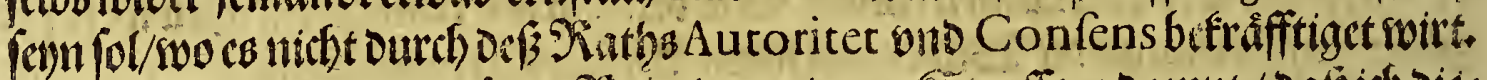

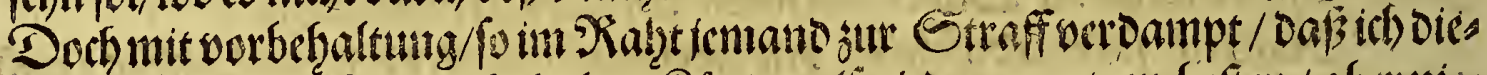

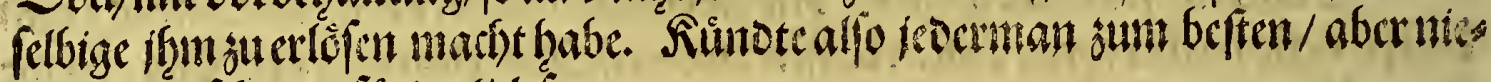
mano tall fhaden fürecrlich foynt.

Dif if incine Simf

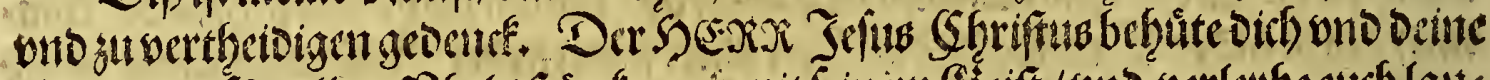

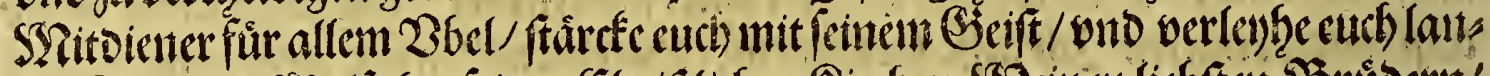

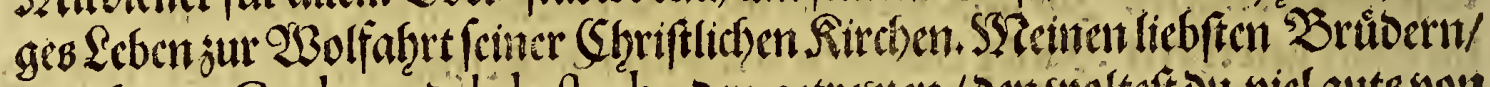

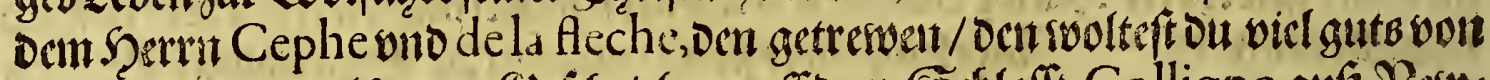

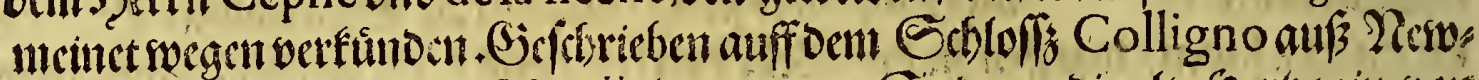

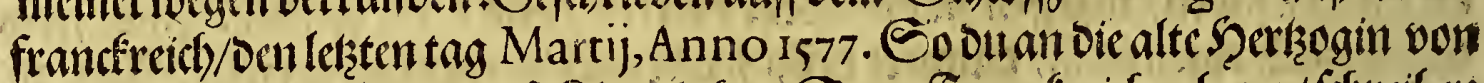

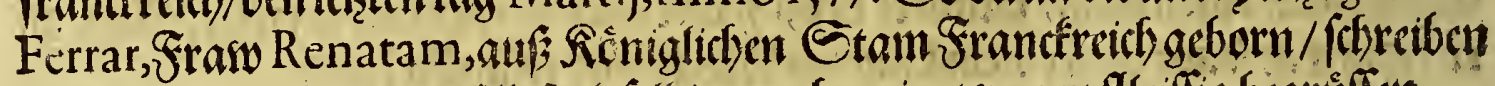

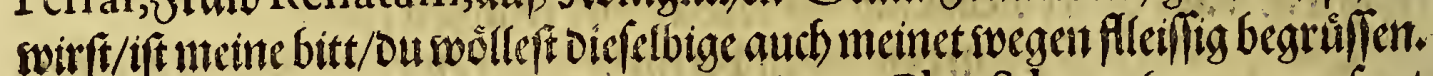

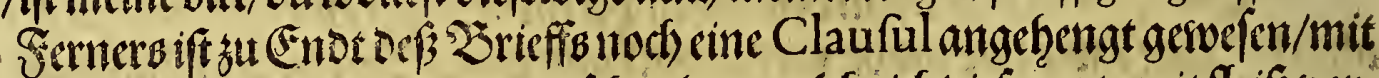

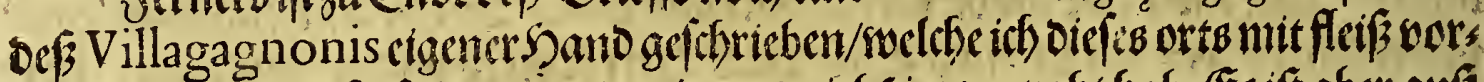

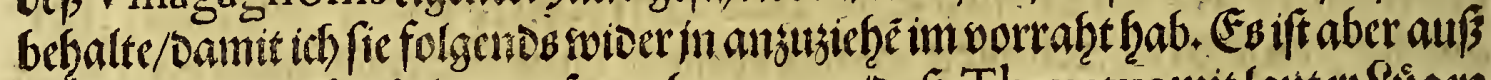

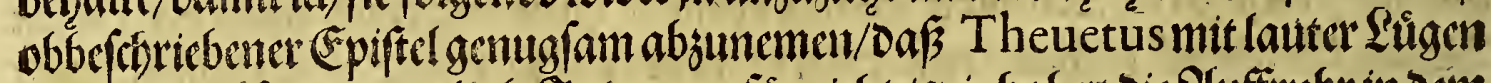

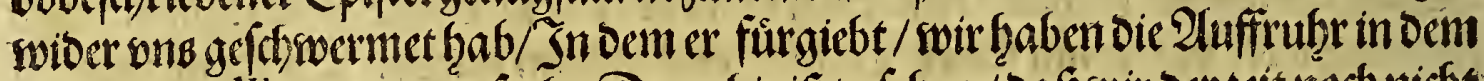

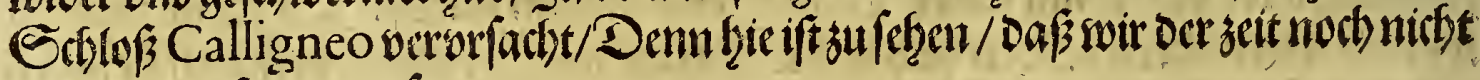
anfonmen fino gerwefent.

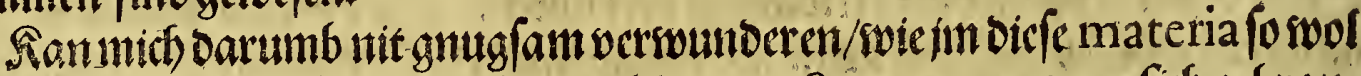

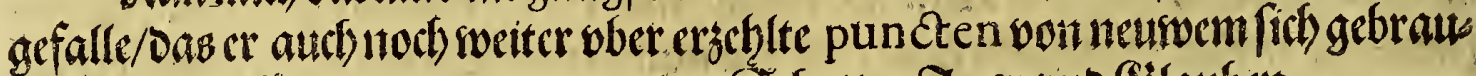

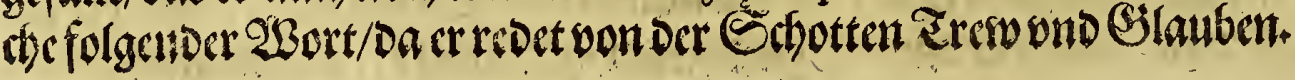

2Belcher 


\section{2artebe.}

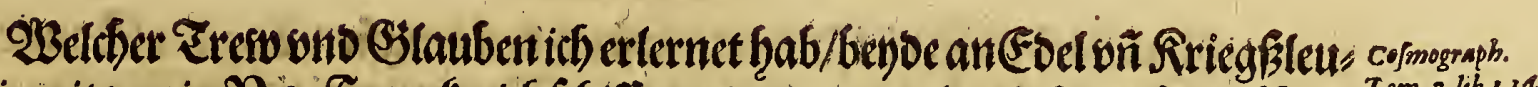

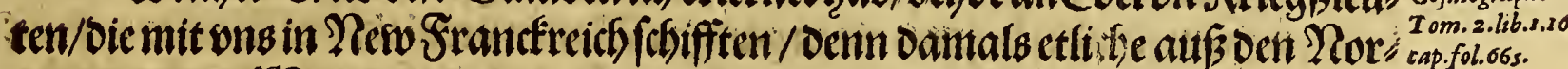

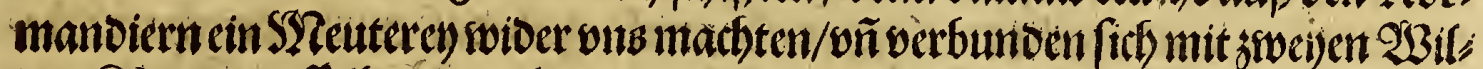

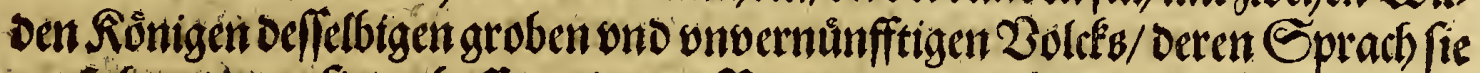

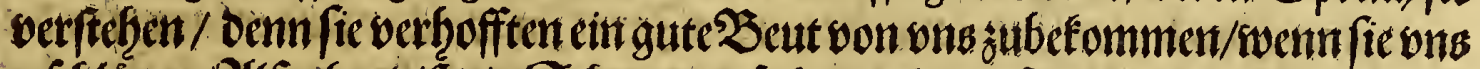

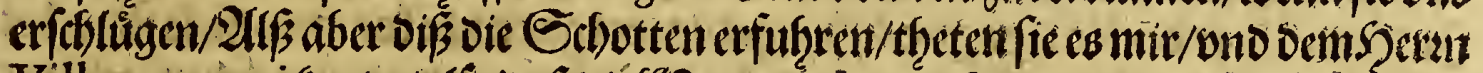

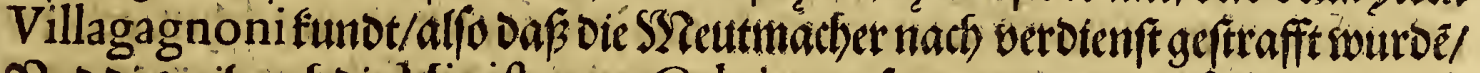

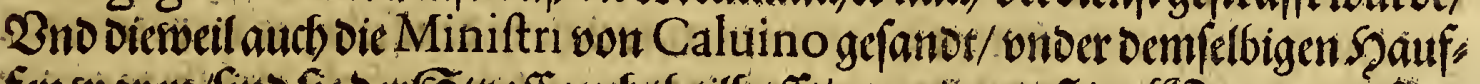

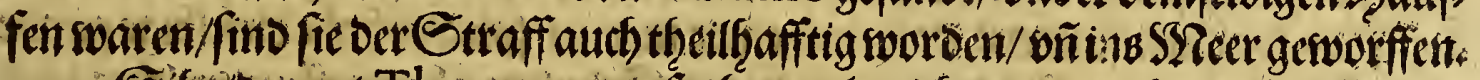

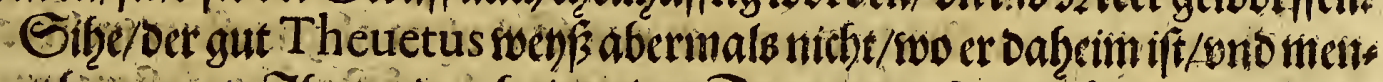

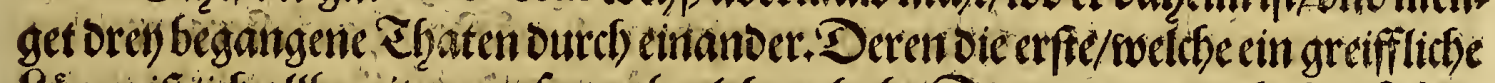

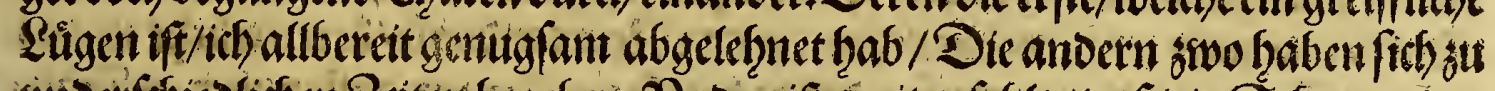

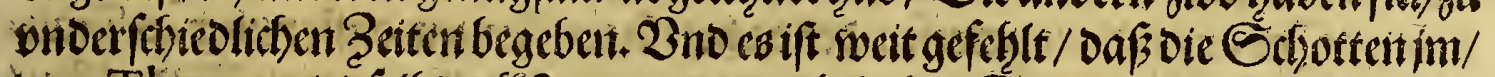

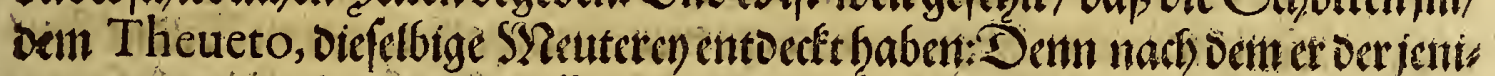

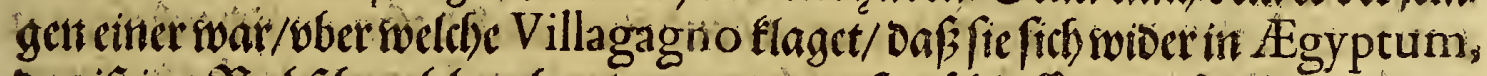

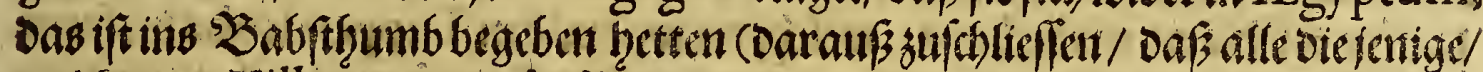

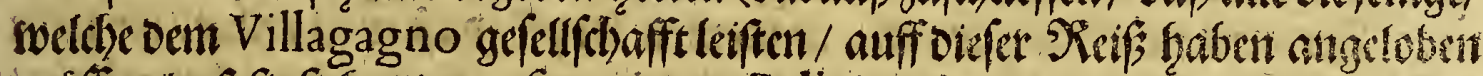

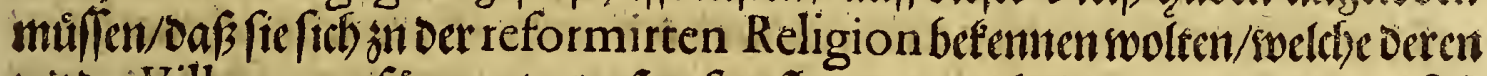

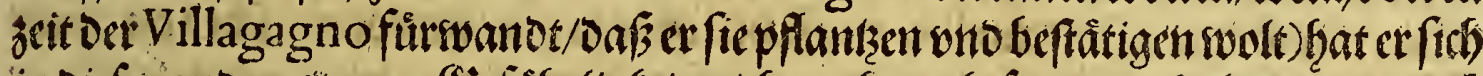

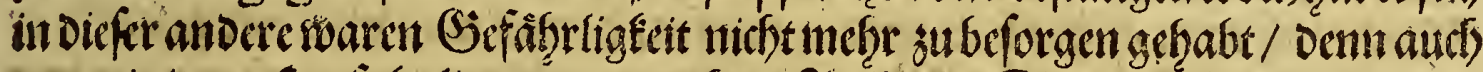

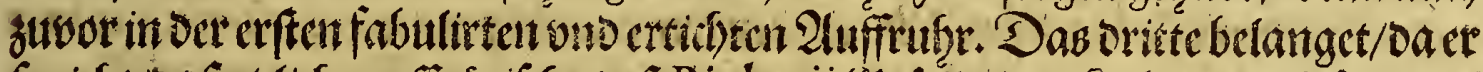

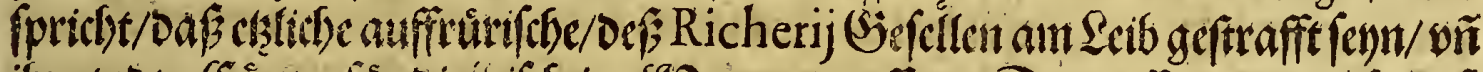

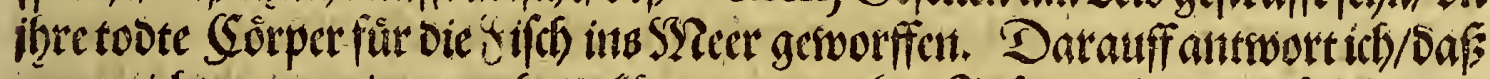

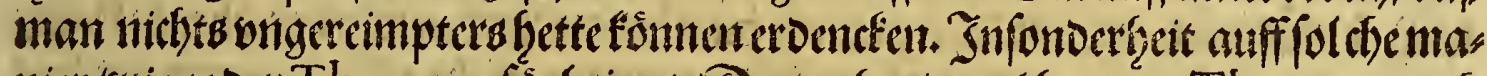

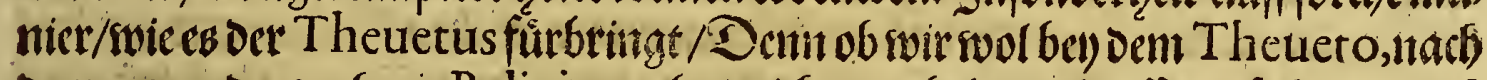
demer bont derswafbren Religion abgerwichen / wbel angelauffen / fo hat er Doch

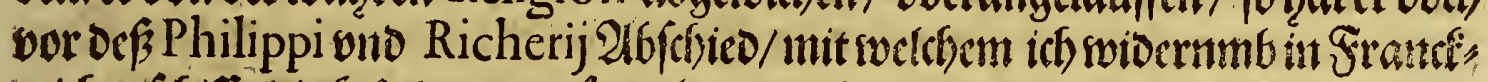

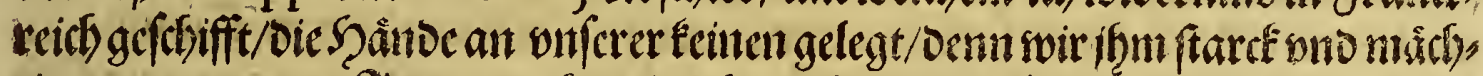

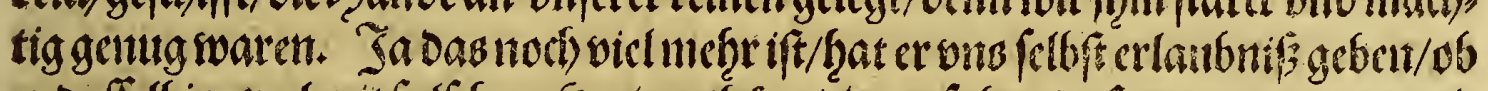

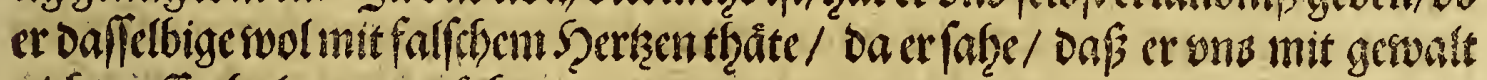
nictit auffizthalten wermèchte.

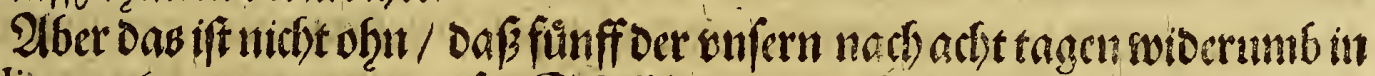

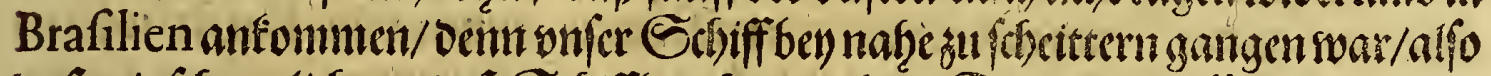

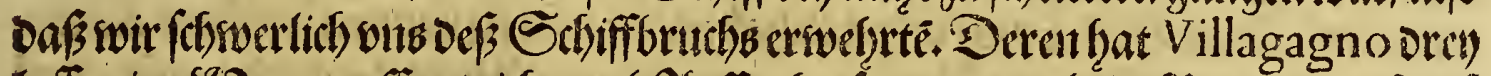

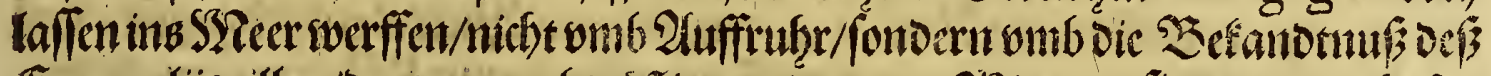

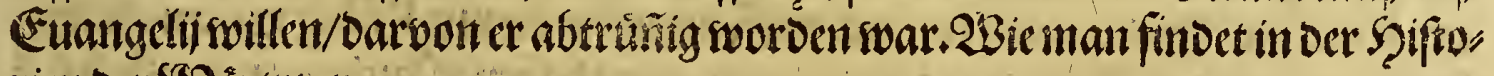
rien Der SIZârturer.

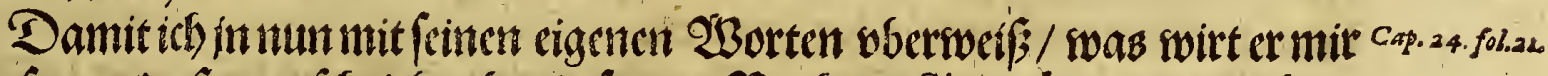

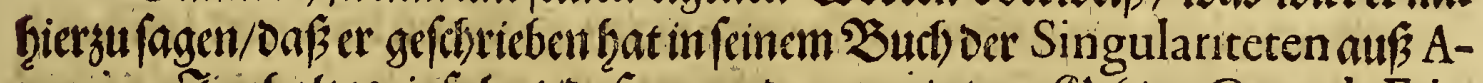

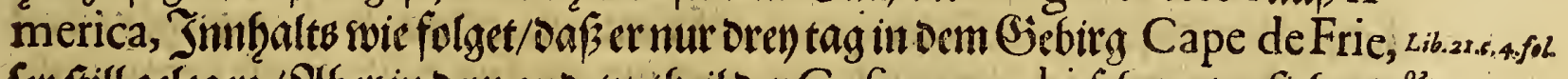

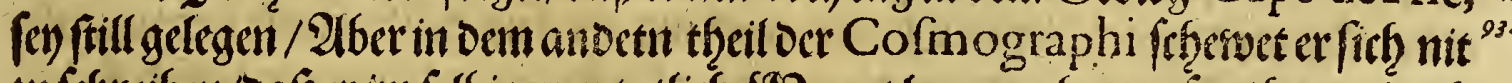

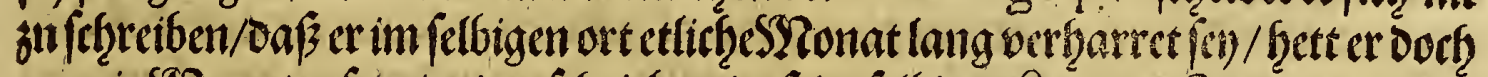

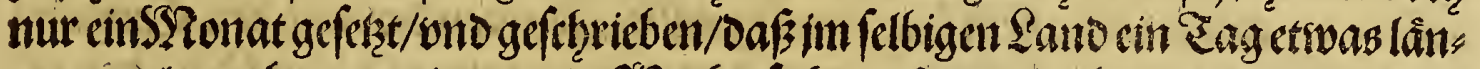

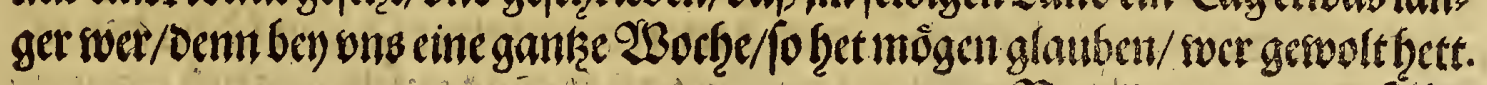

$$
\mathfrak{B} \text { if } 26 \mathrm{er}
$$




\section{Zortede.}

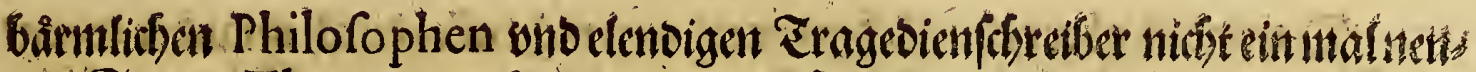

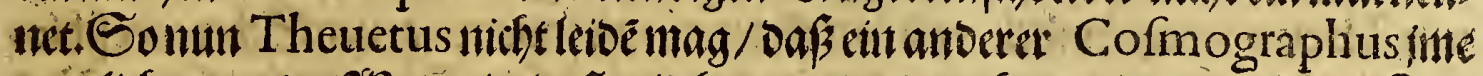

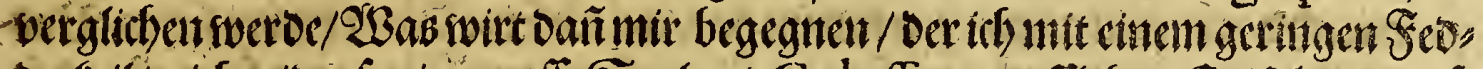

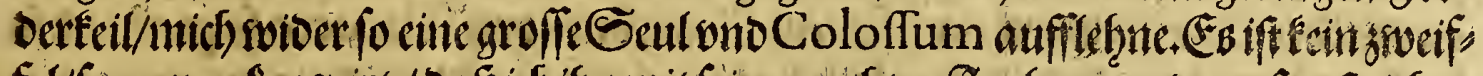

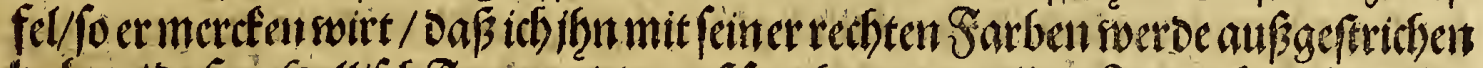

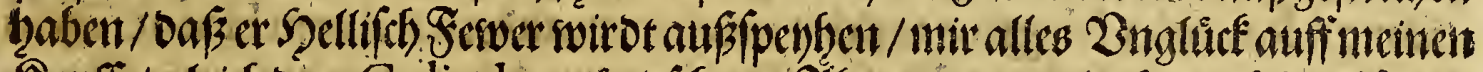

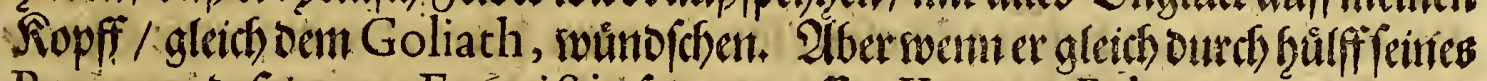
Patrons, De

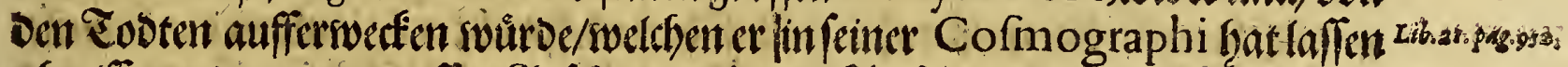

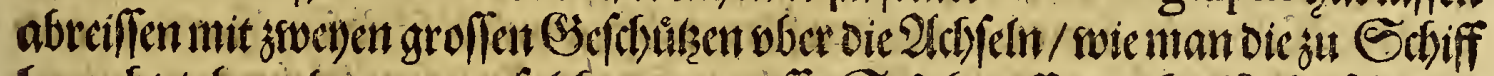

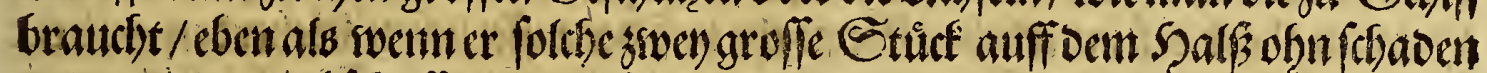

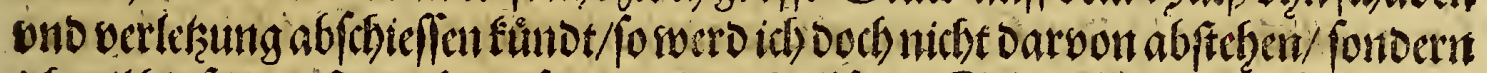

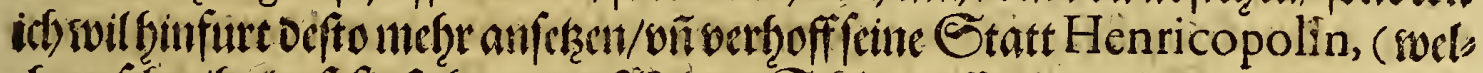

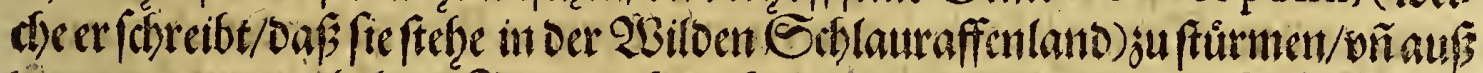

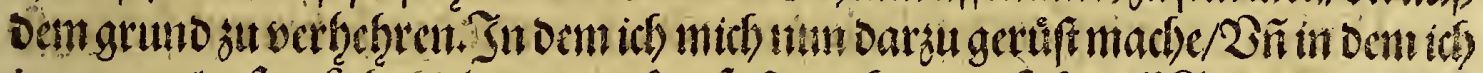

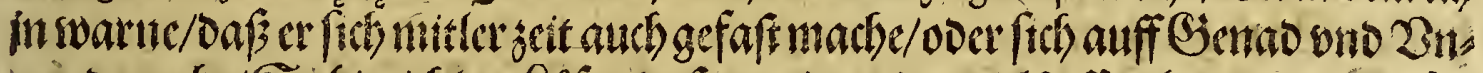

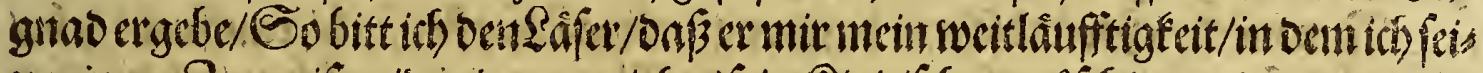

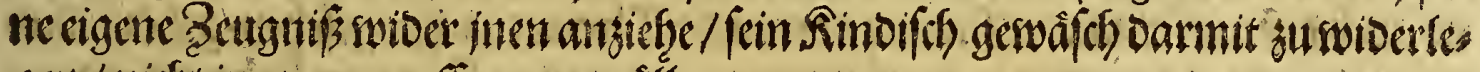
$\mathrm{get} /$ nicht in atgom aufinomen swèls.

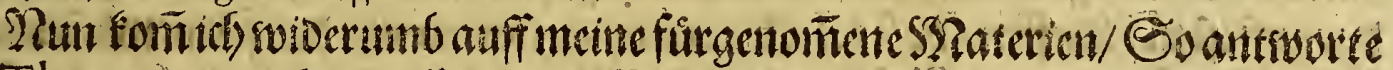

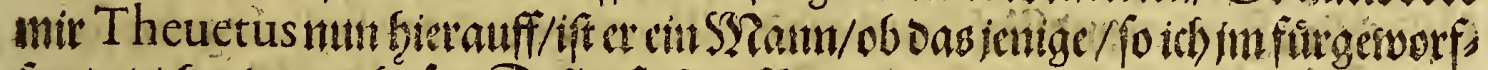

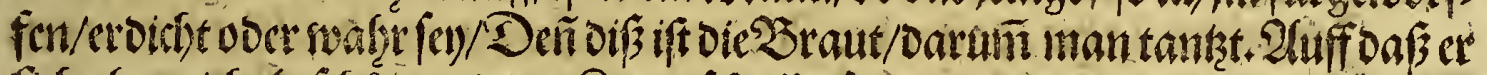

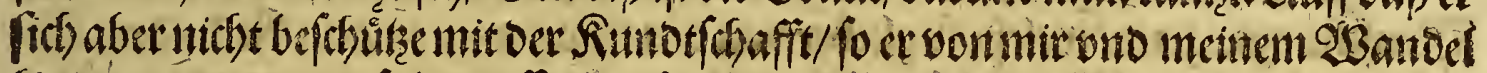

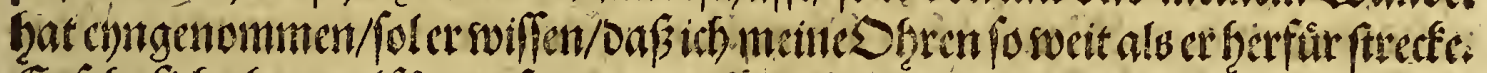

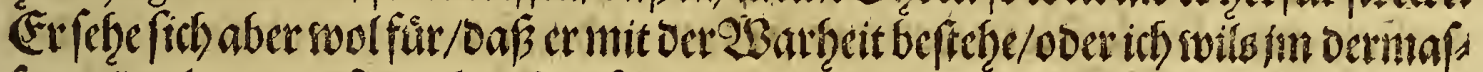

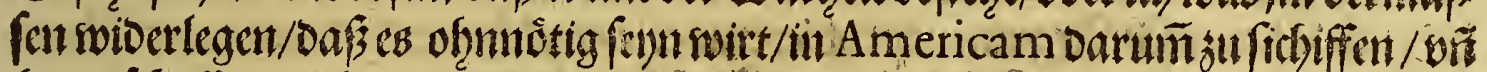

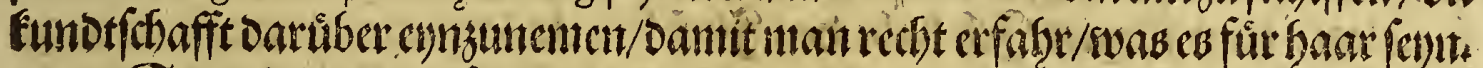

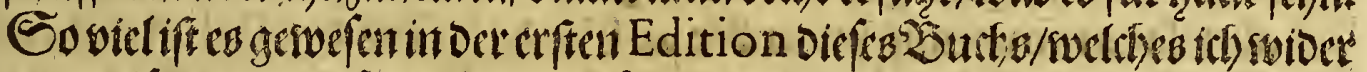

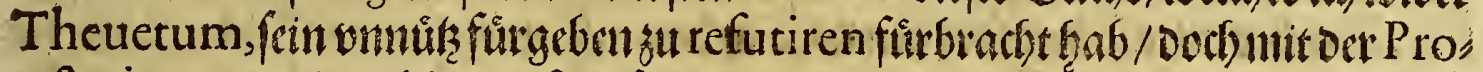

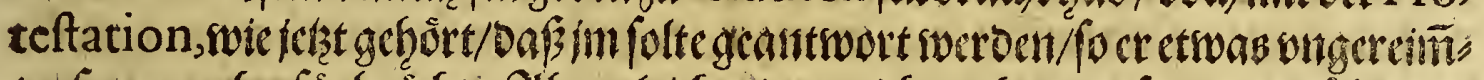

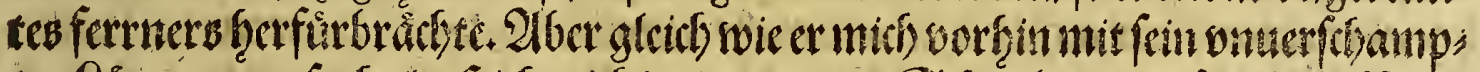

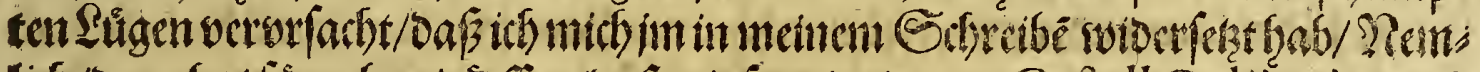

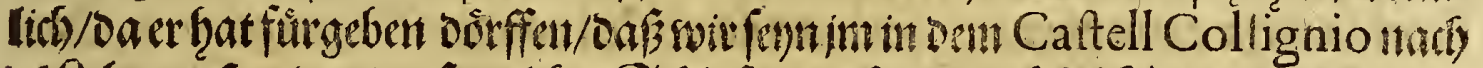

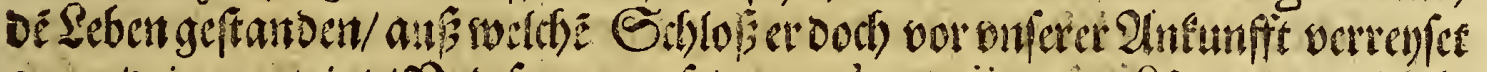

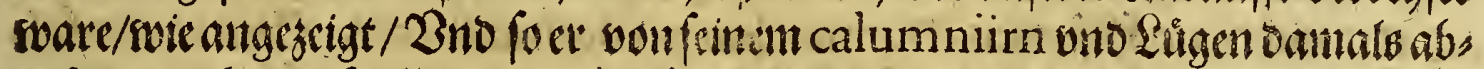

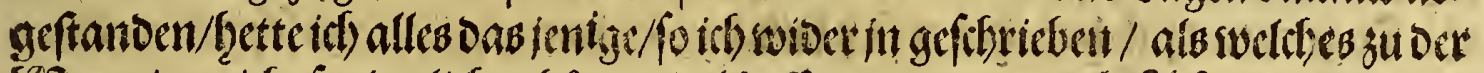

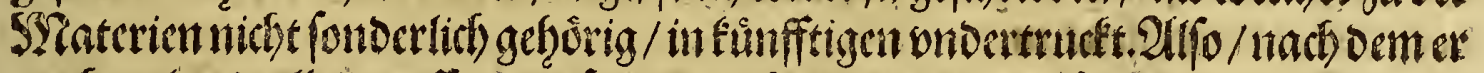

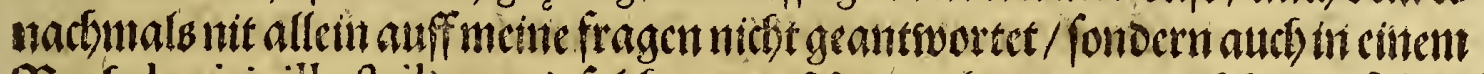

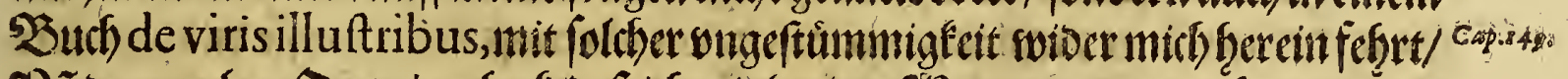

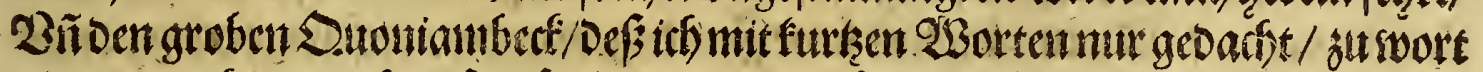

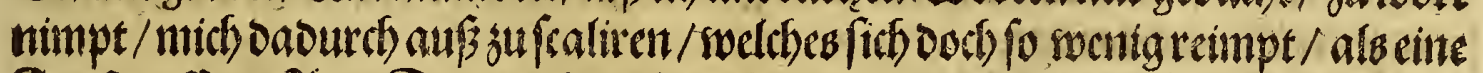

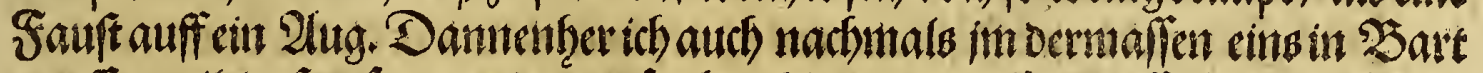

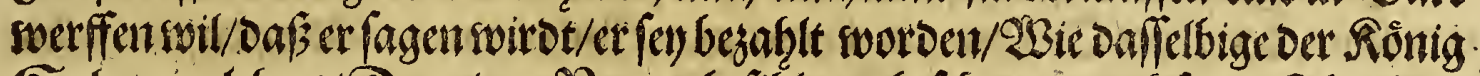

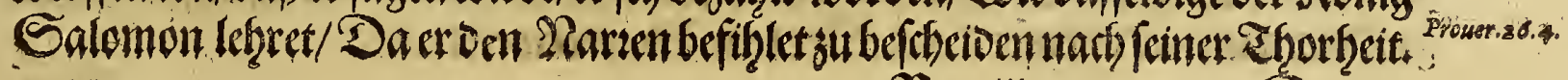

$$
\mathfrak{B} \text { iii : Darnit }
$$




\section{Borteber.}

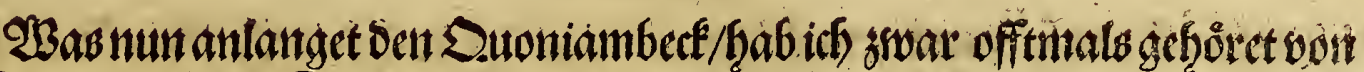

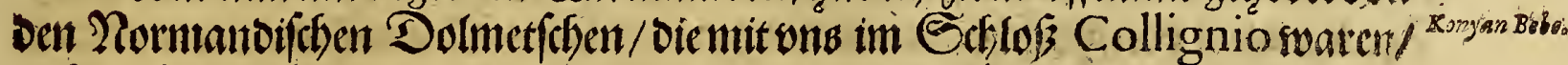

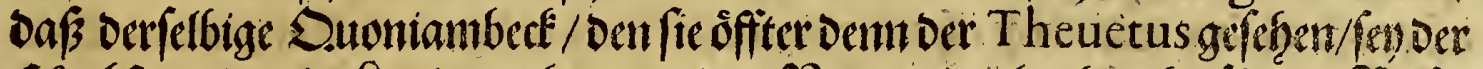

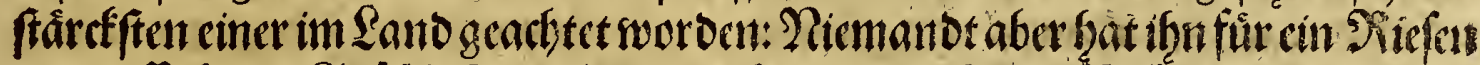

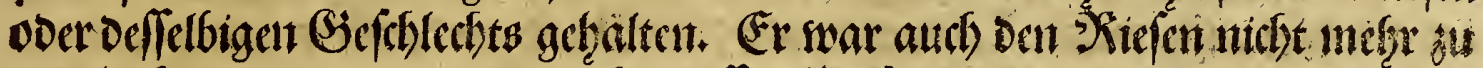

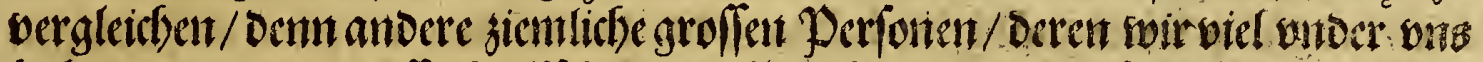

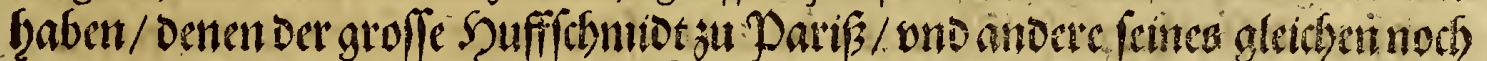

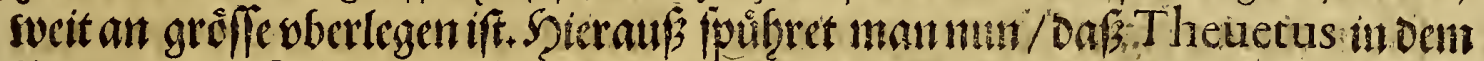

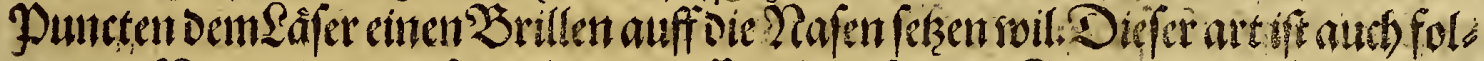

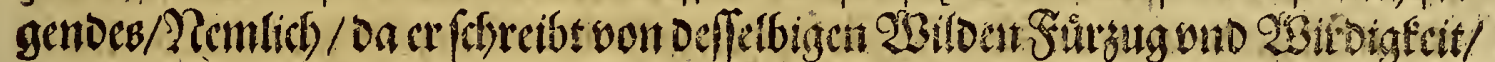

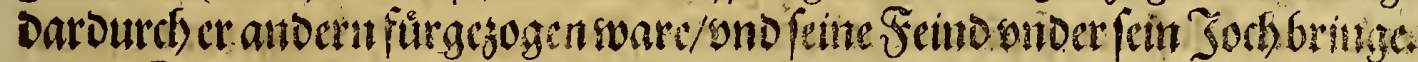

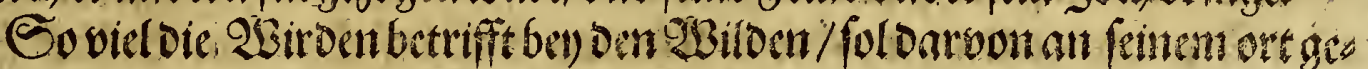

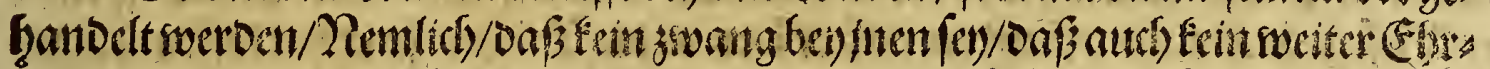

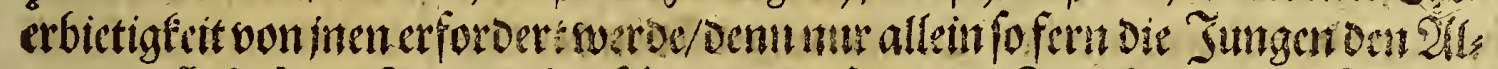

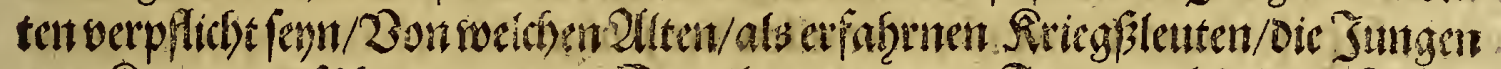

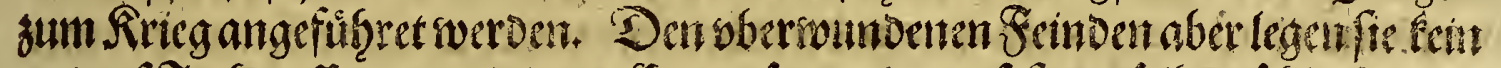

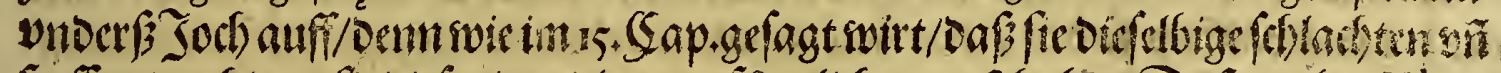

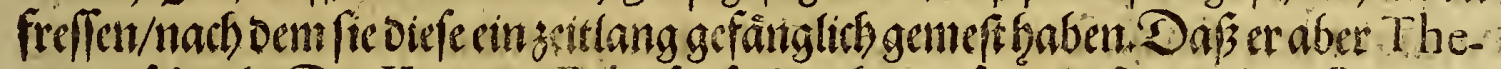

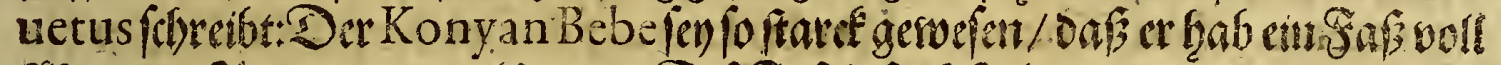

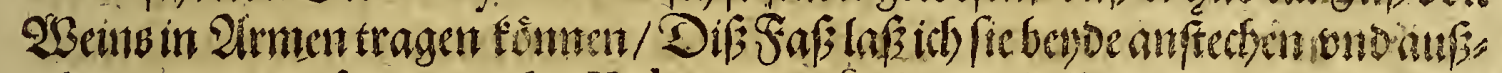

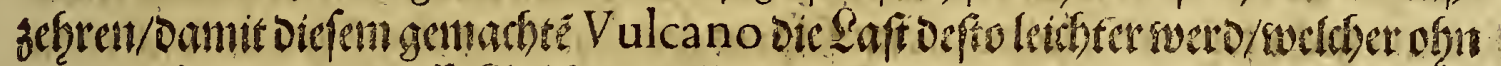

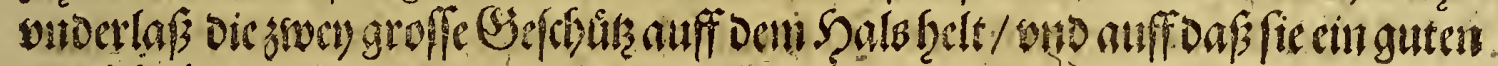
muth fabcot.

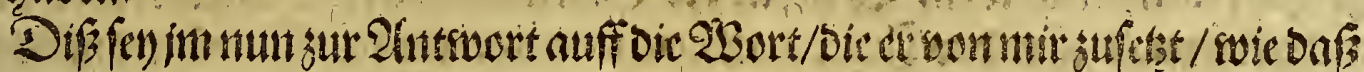

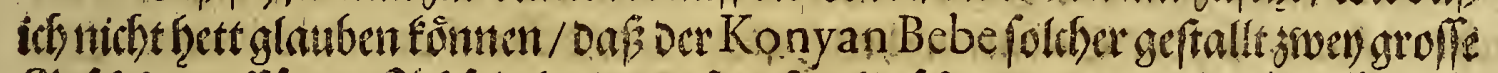

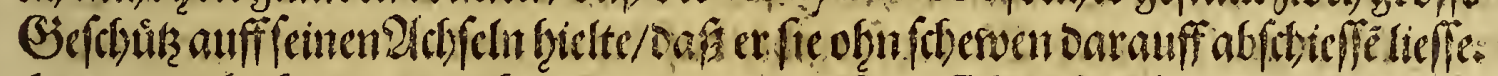

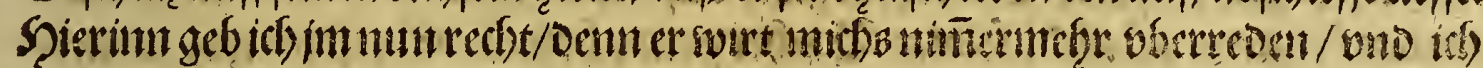

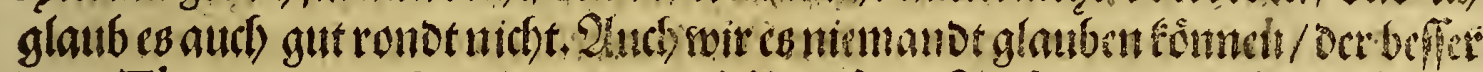

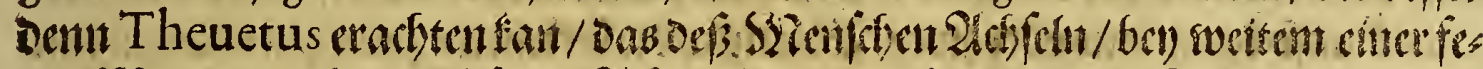

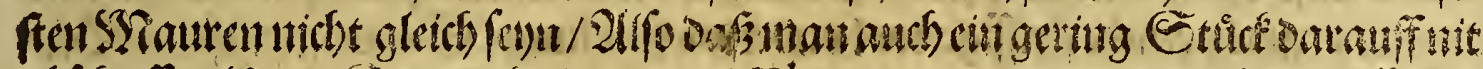

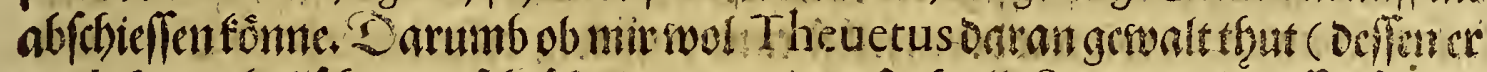

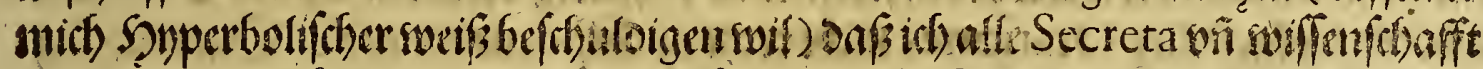

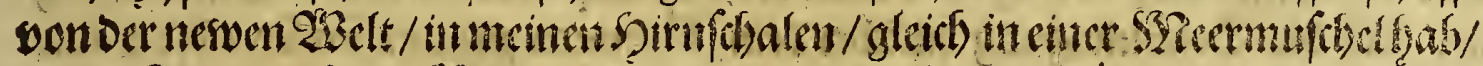

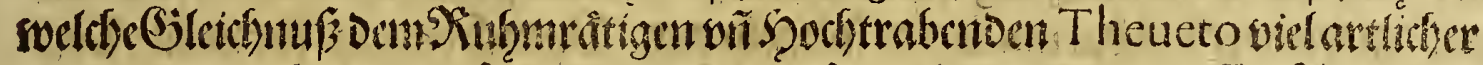

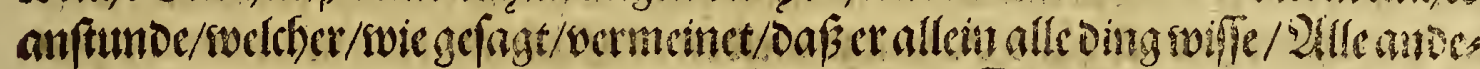

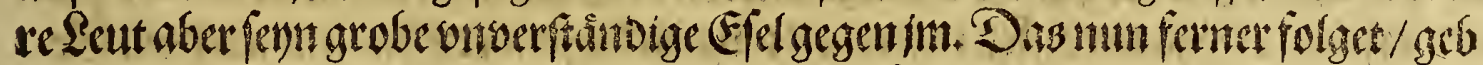

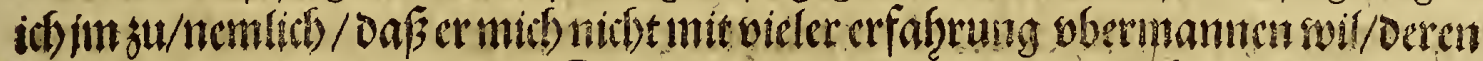

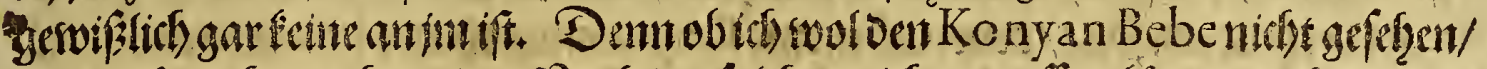

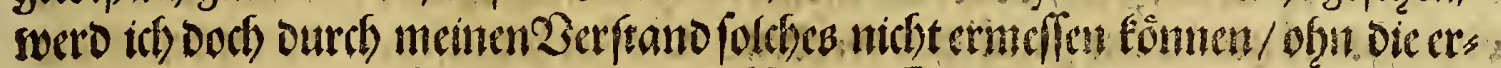

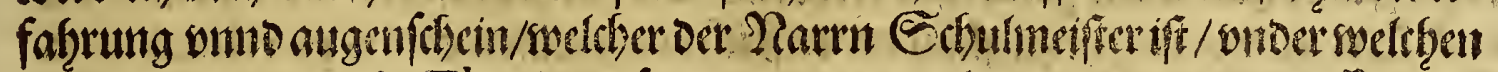

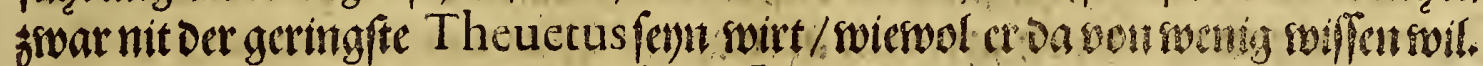

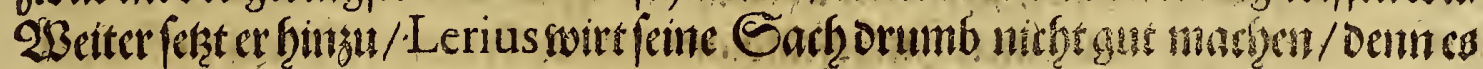

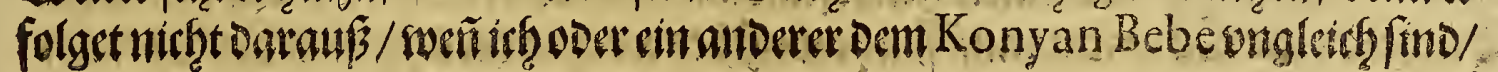




\section{Borrete.}

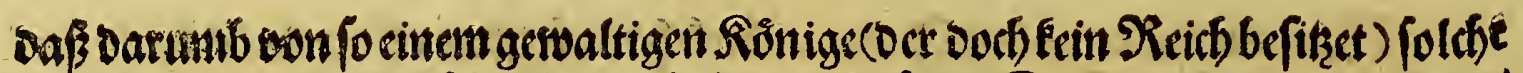

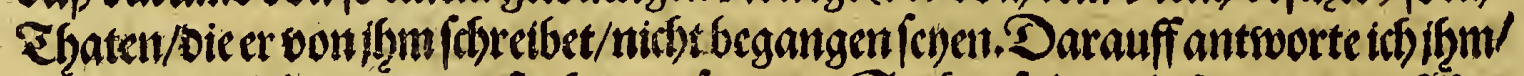

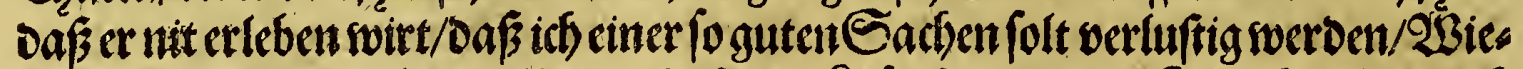

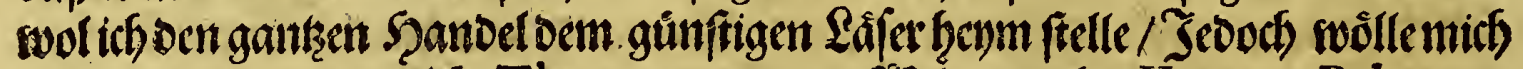

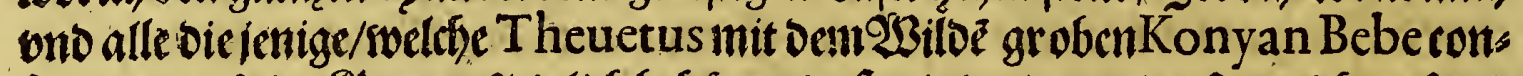

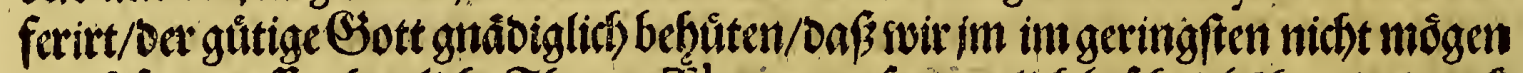

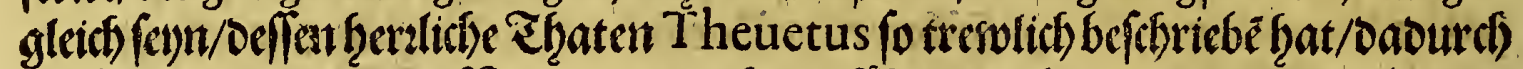

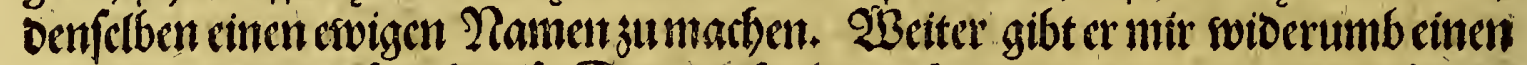

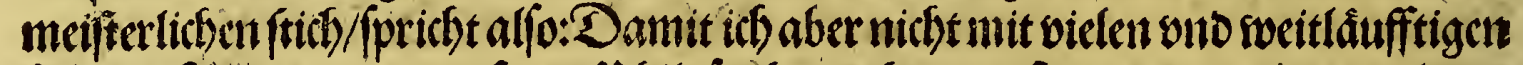

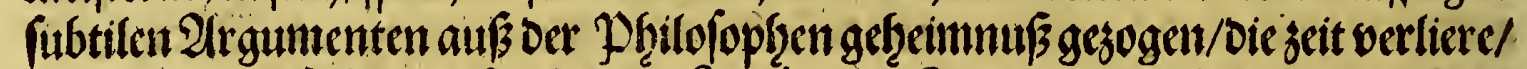

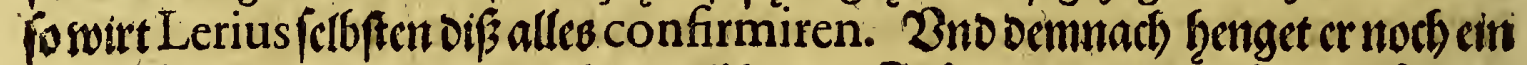

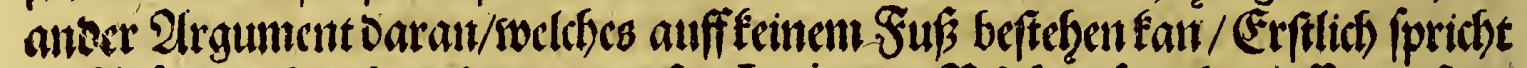

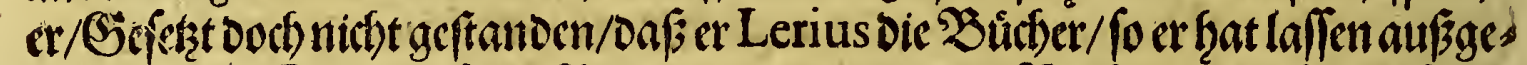

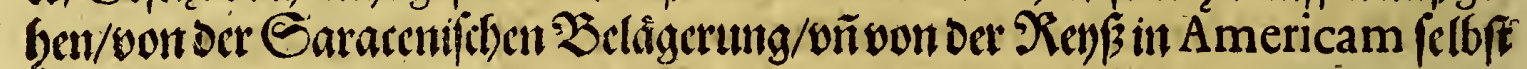

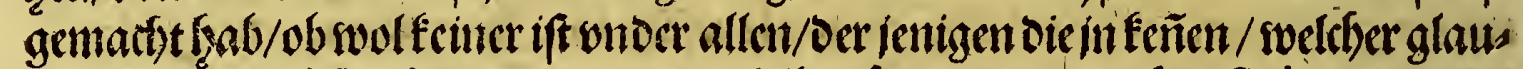

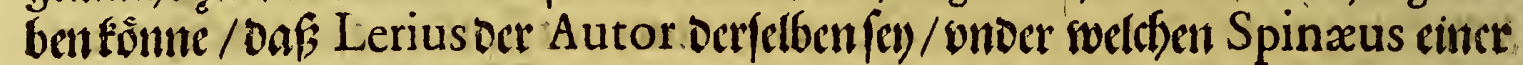

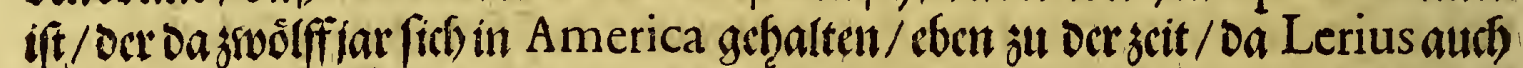

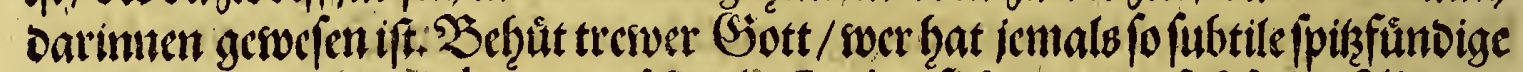

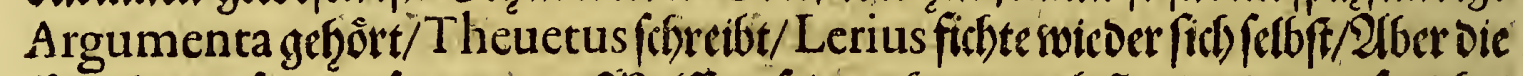

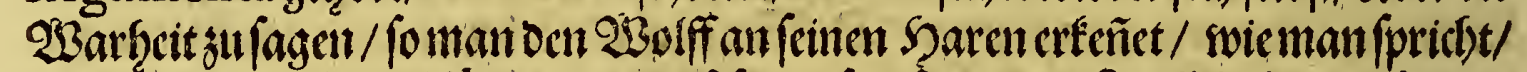

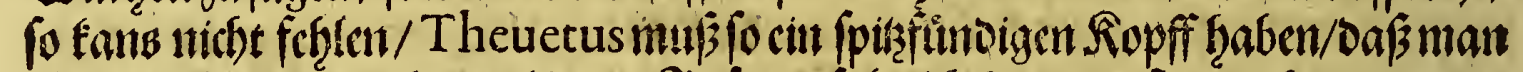

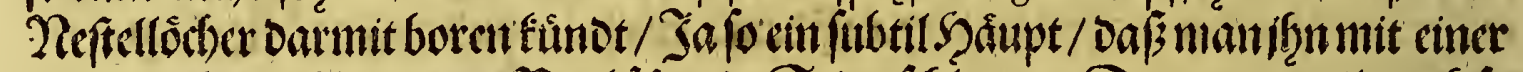

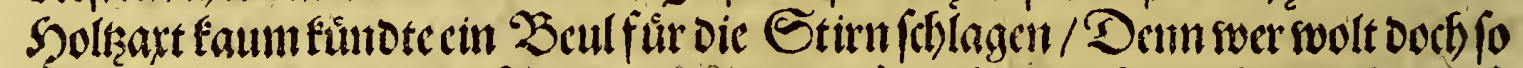

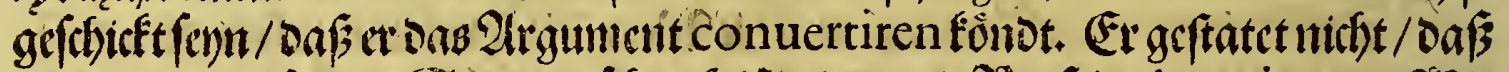

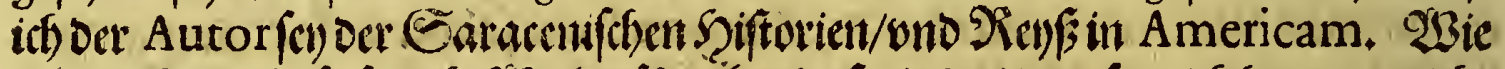

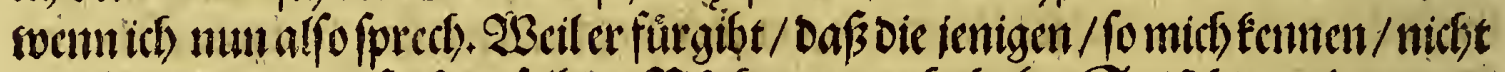

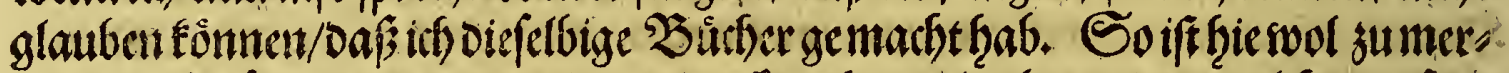

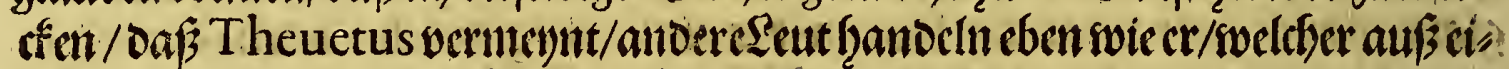

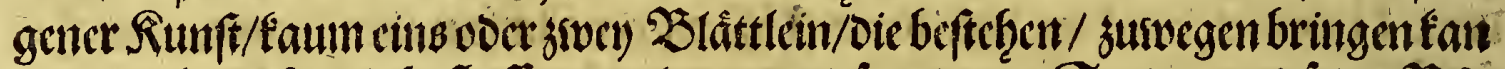

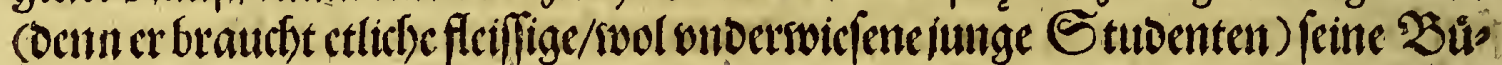

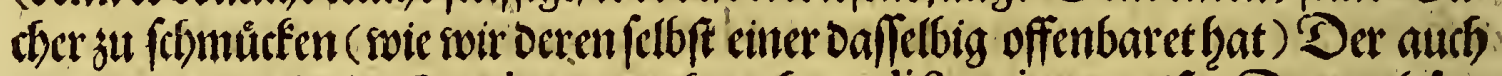

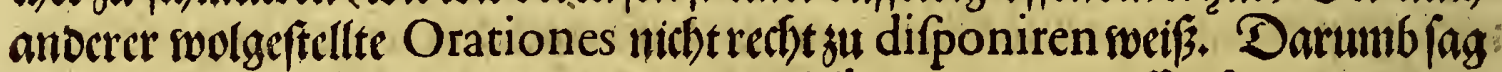

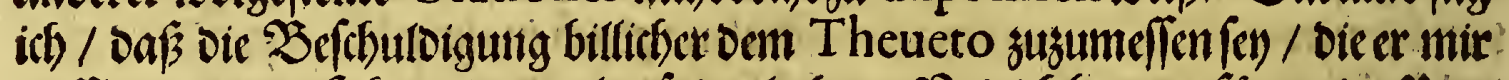

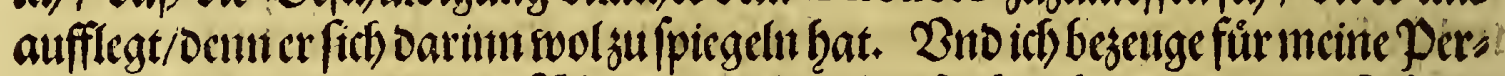

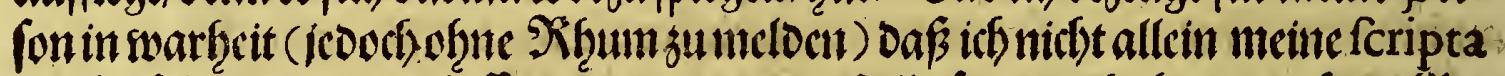

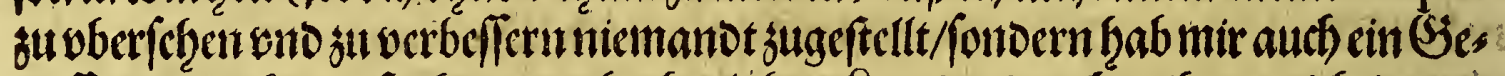

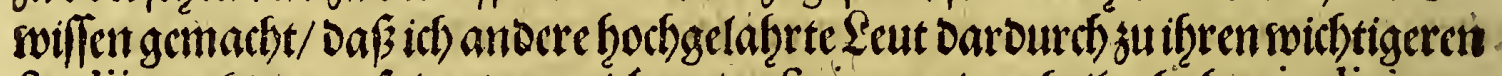
ftudijs verfindoern folte / Denen ich meine fcripta mitgetheilet hâb att iudiciren,

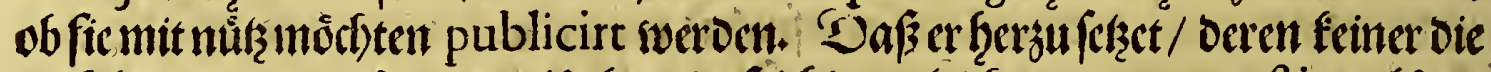

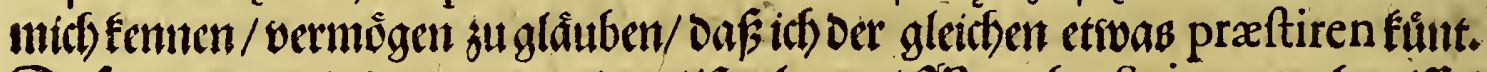

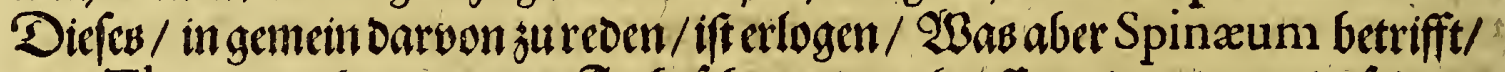

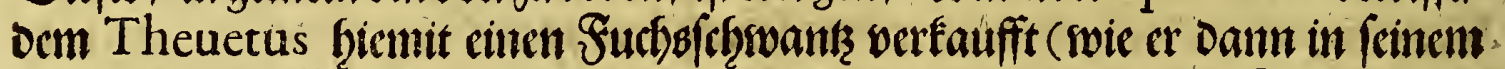

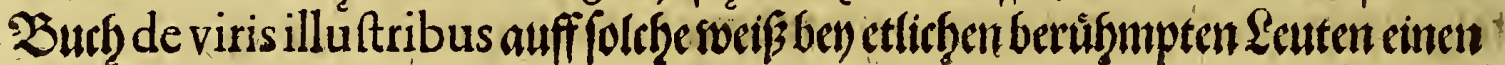
fondern 


\section{Borrede.}

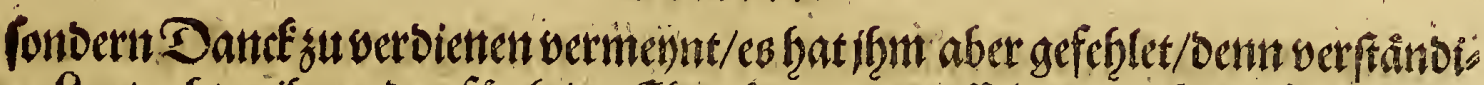

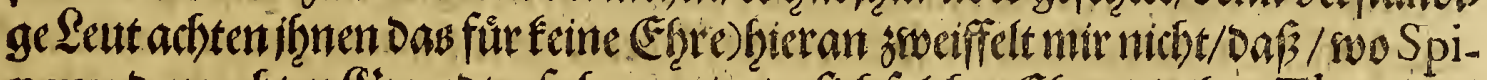

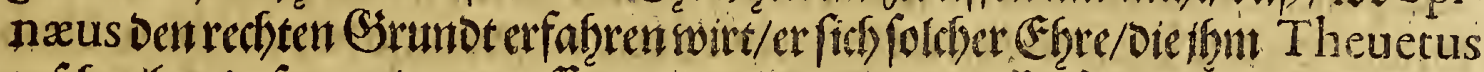

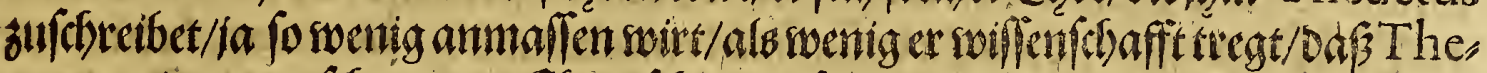

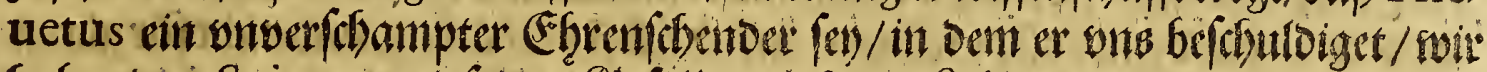

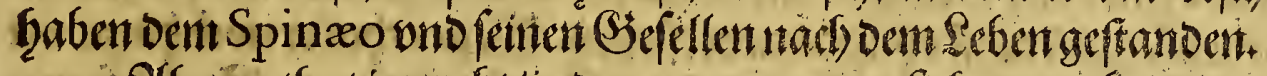

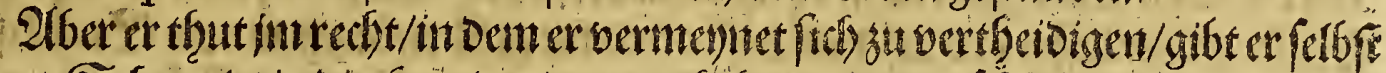

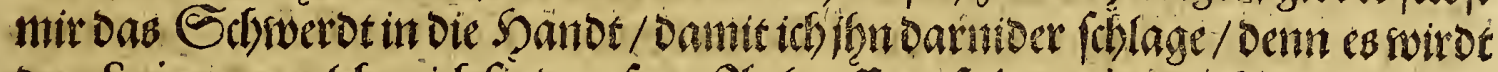

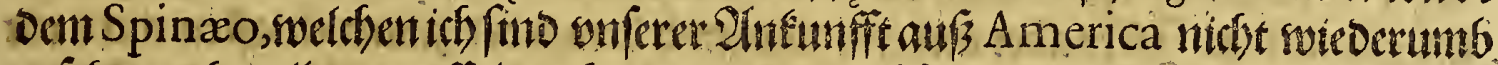

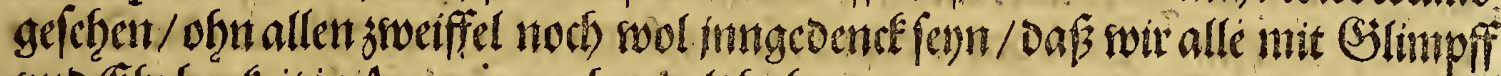

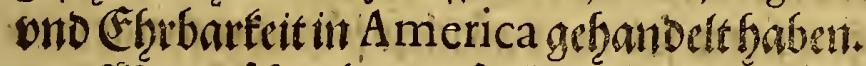

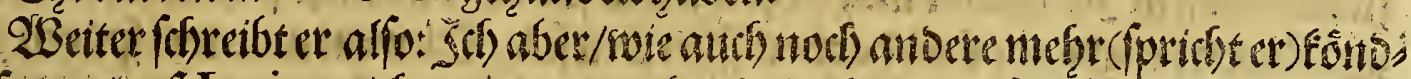

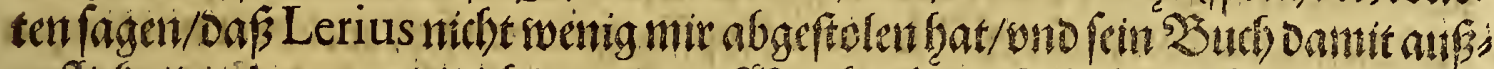

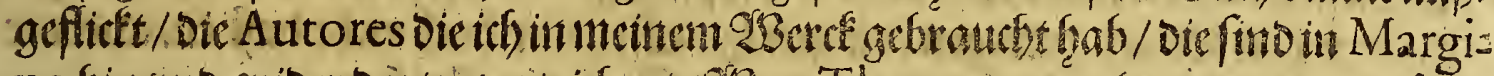

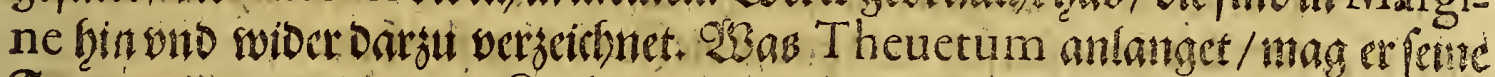

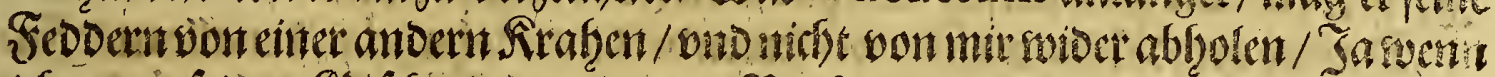

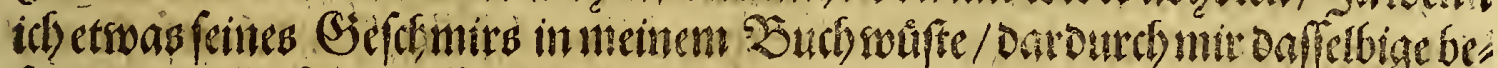

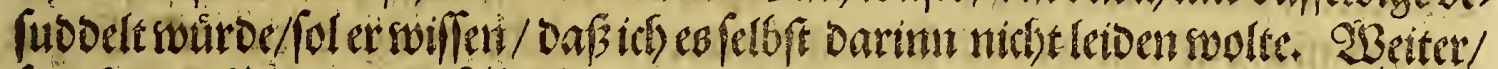

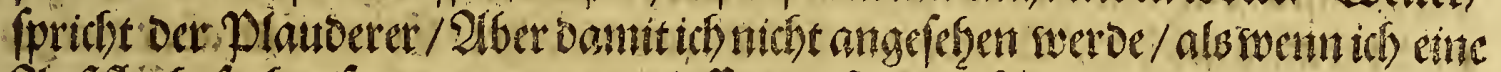

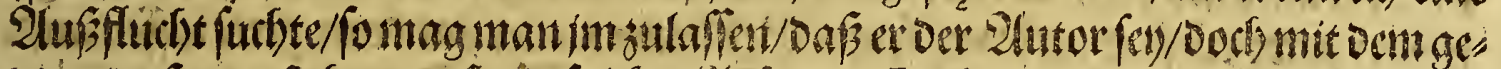

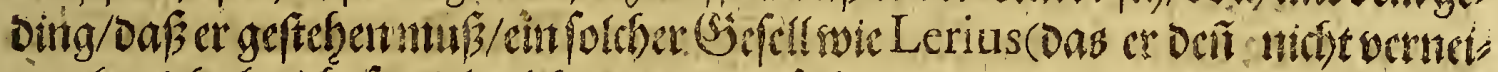

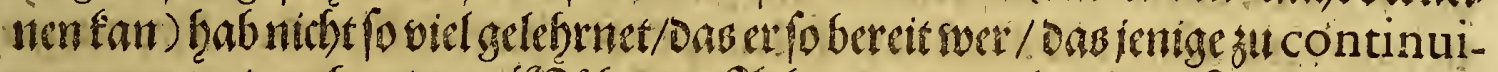

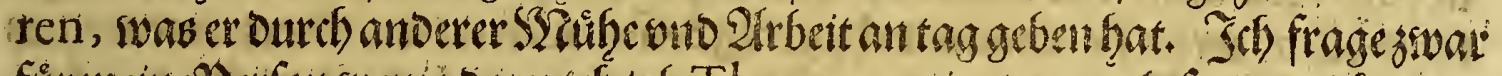

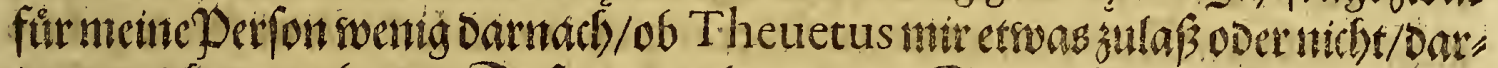

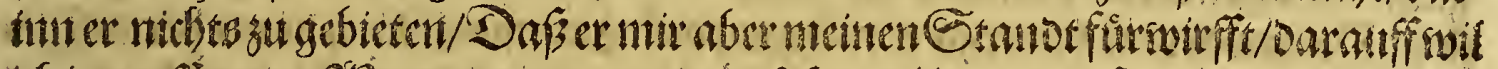

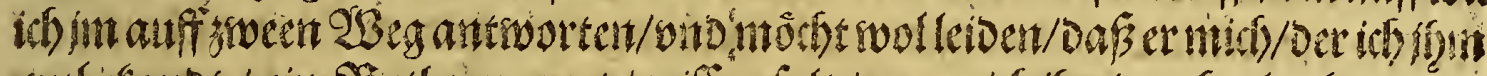

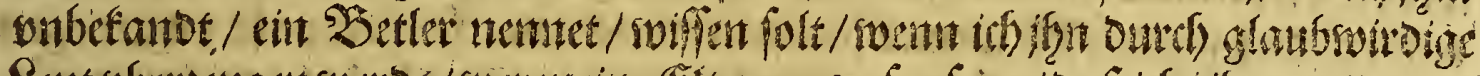

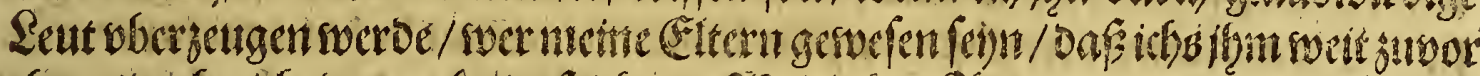

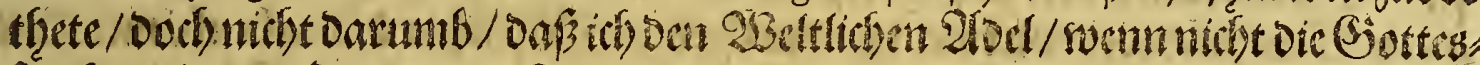

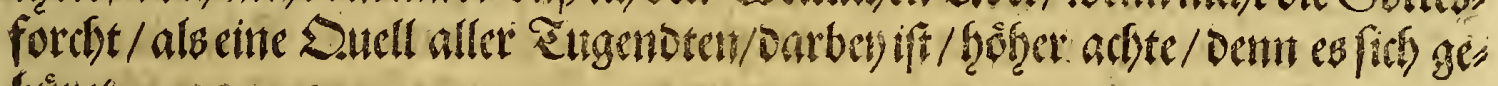
buret.

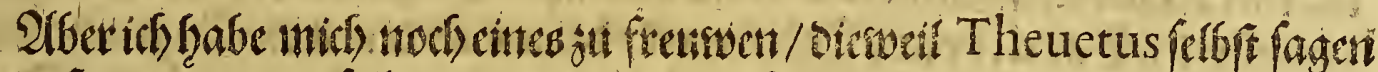

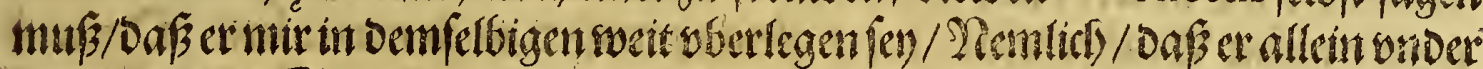

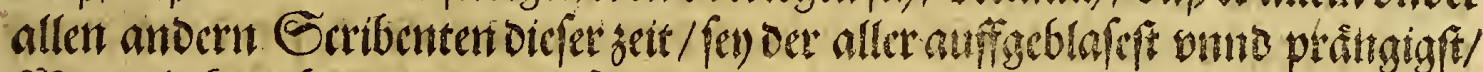

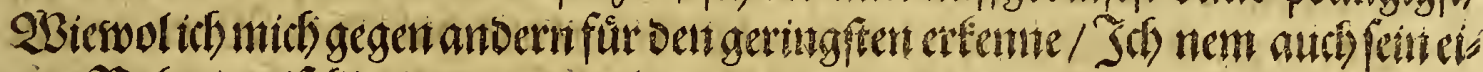

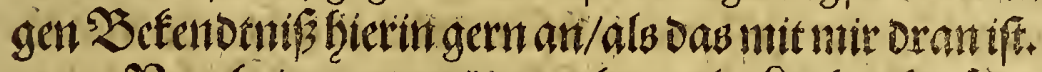

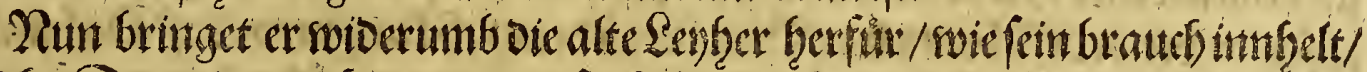

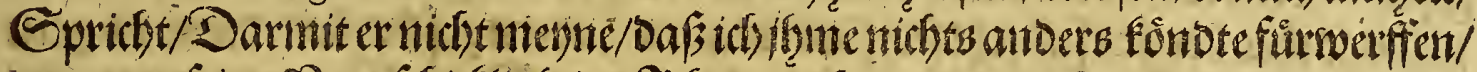

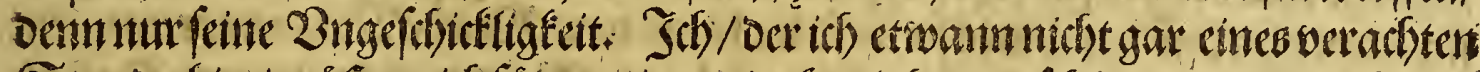

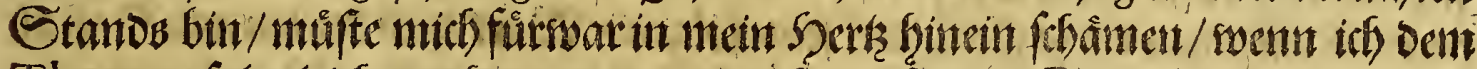

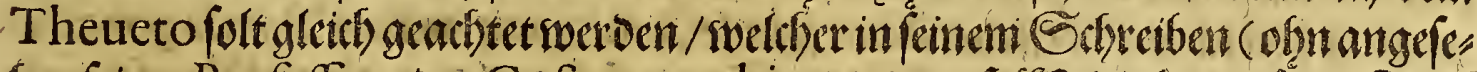

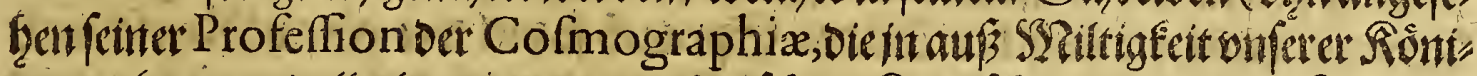

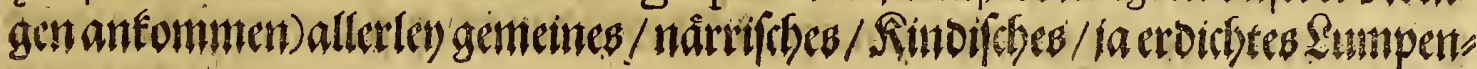

$$
\text { s }
$$




\section{Borrede.}

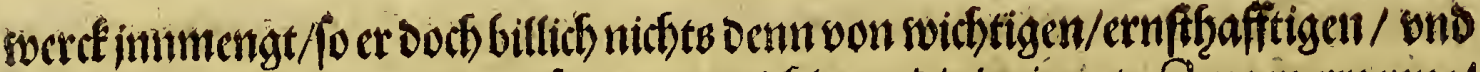

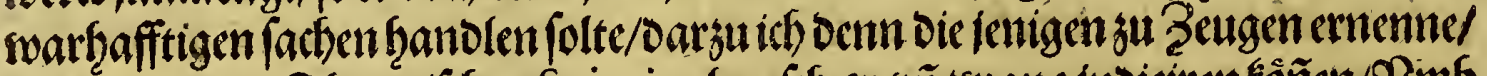

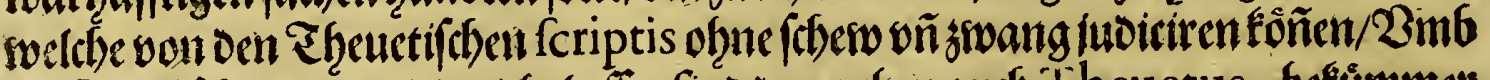

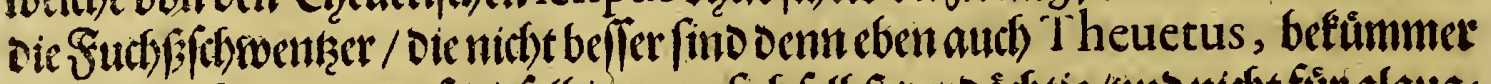

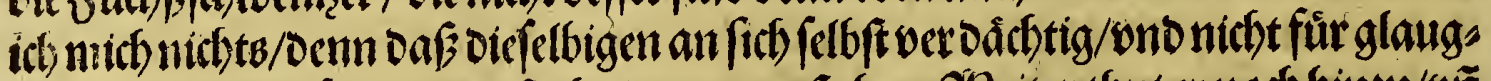
swirdig

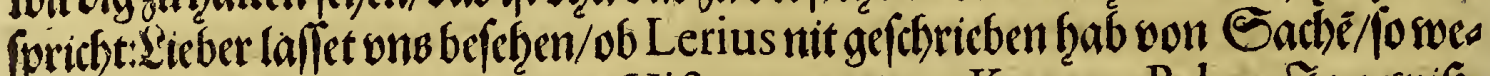

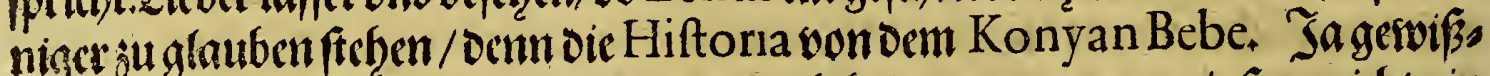
(idf) gar nict)tb. Jft eg aber anoerb / warumb bringet er sum wenigften nicht ein

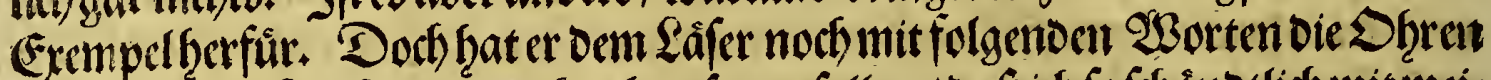

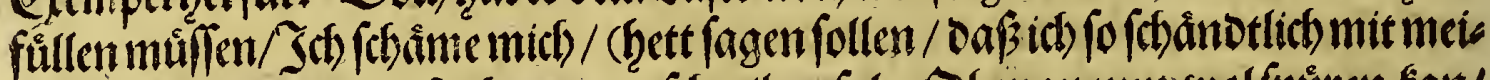

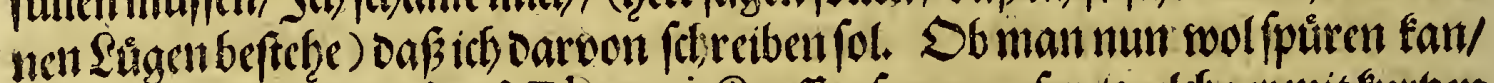

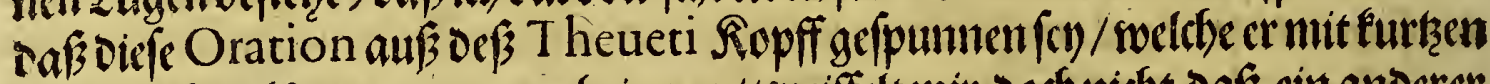

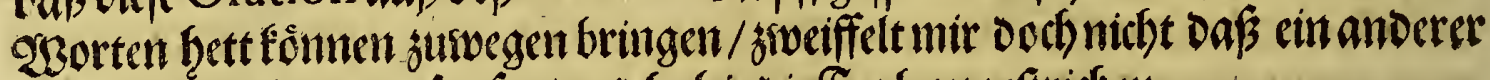

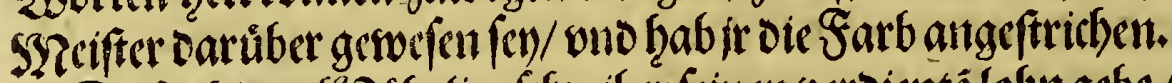

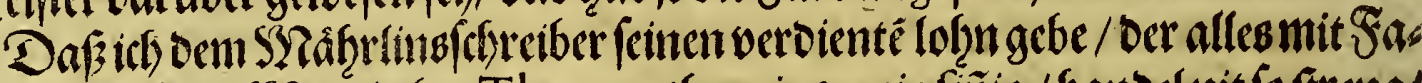

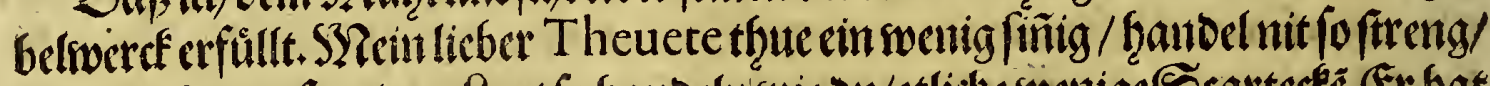

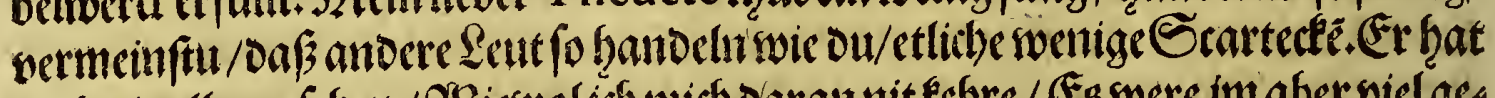

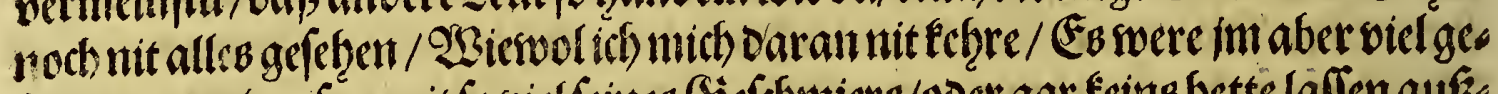

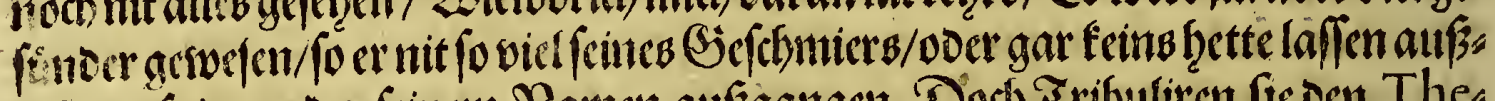

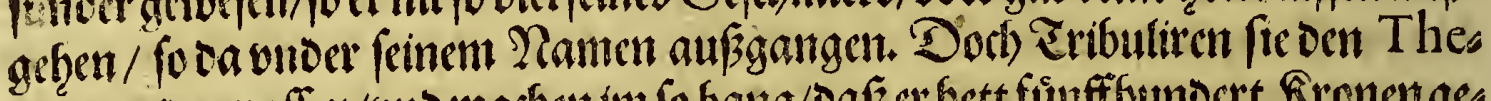

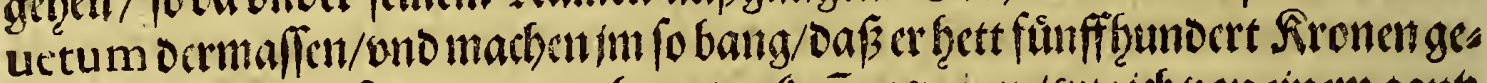

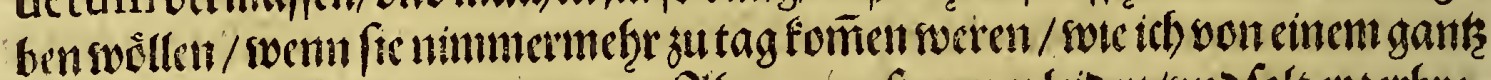

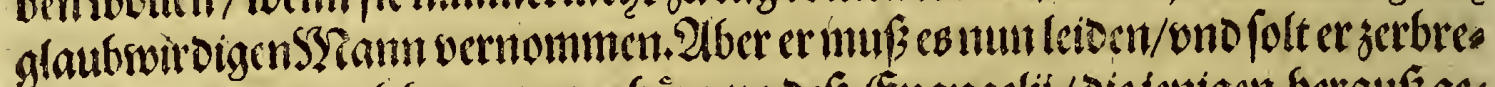

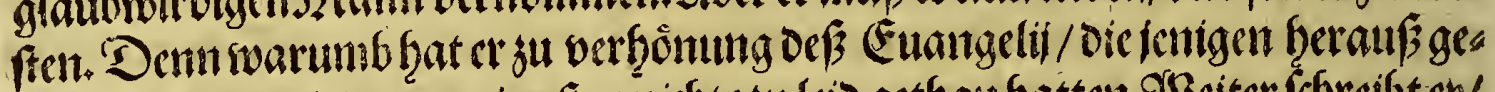

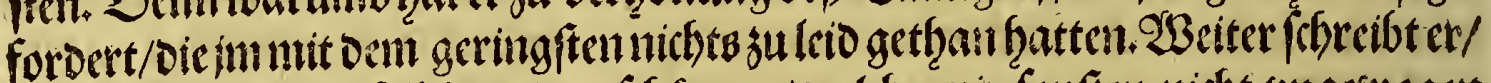

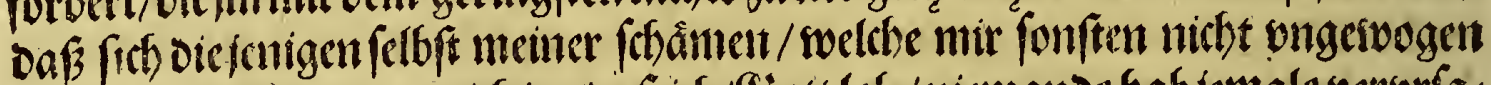

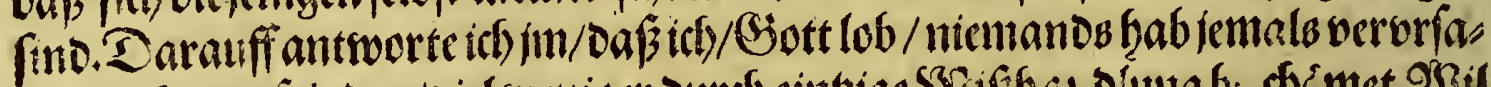

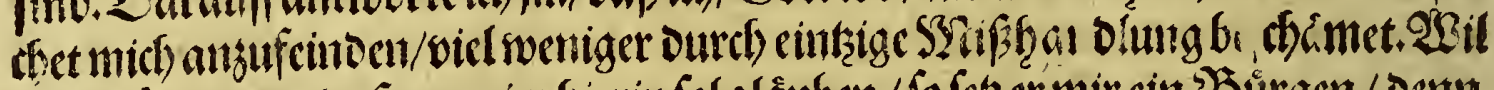

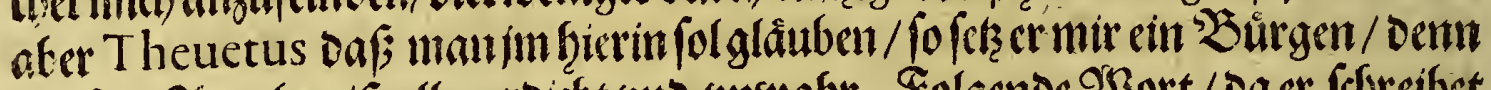

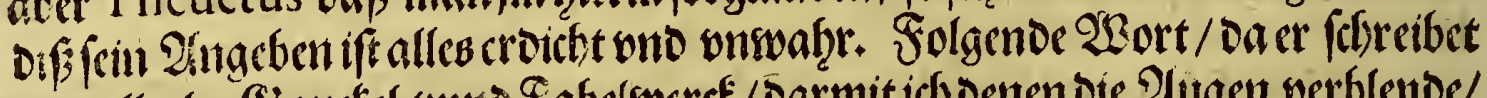

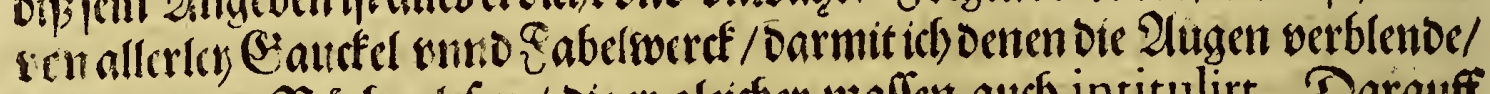
fwelche meine $\mathfrak{B}$ ücher lefon / oie er gleict)er maffen auch intitulirt. Darauff

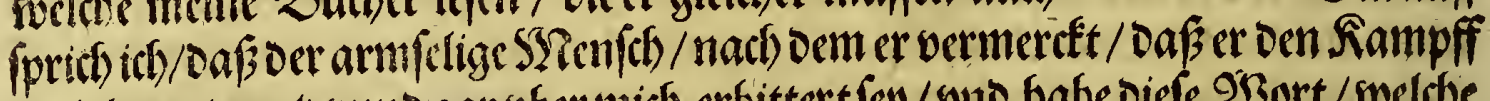

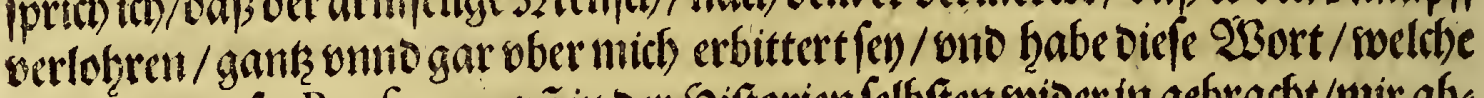
(cb) bevo in oisfer Prxfacion vin in oer Siftorien felb/tentwiderin gebractst/mir ab"

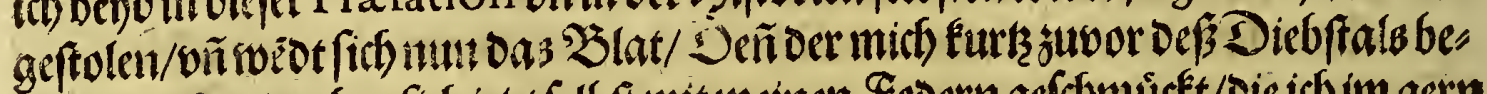

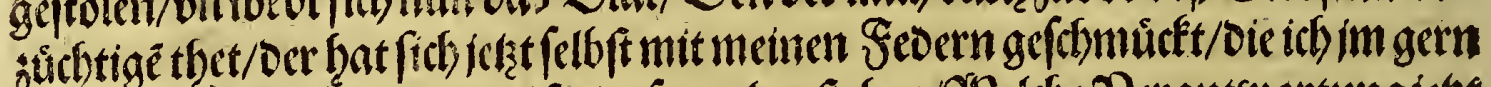

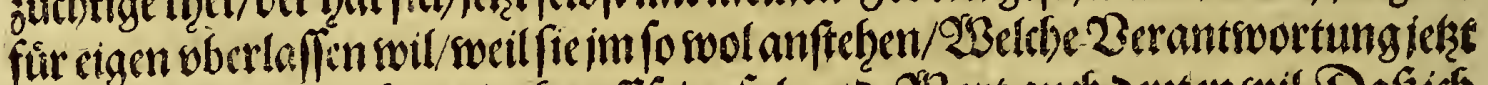

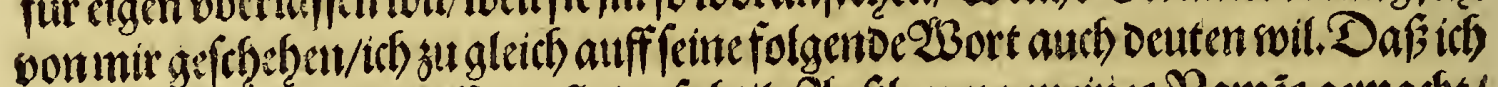

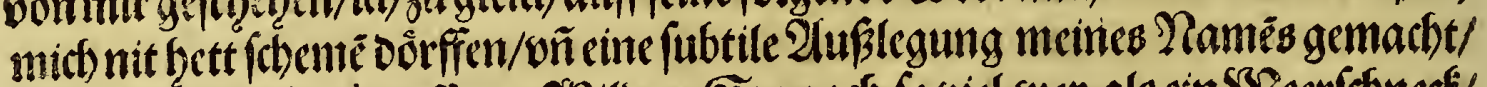

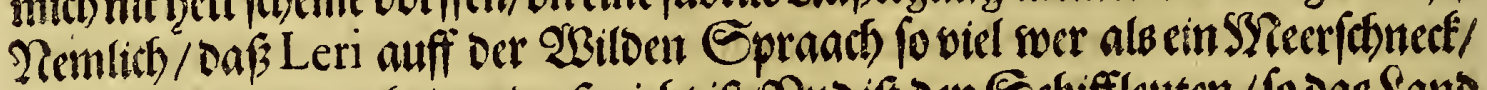

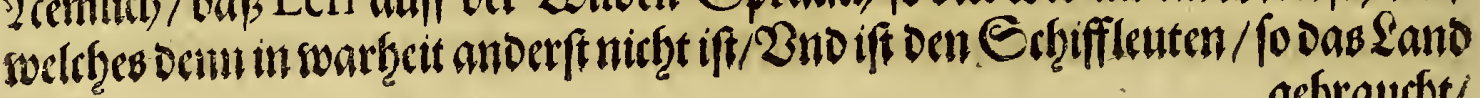
gebraucft/ 


\section{Zorrete.}

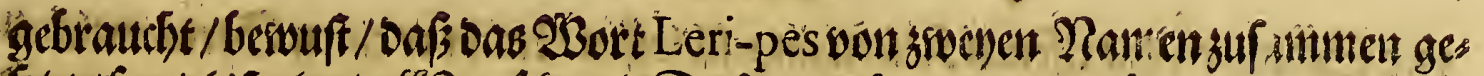

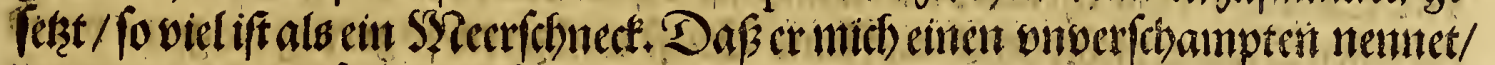

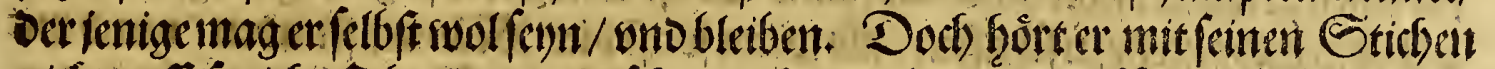

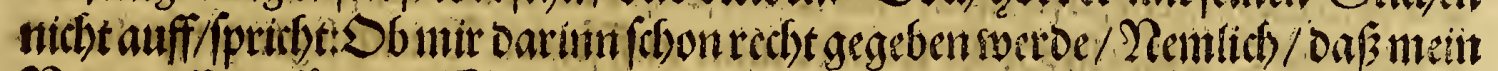

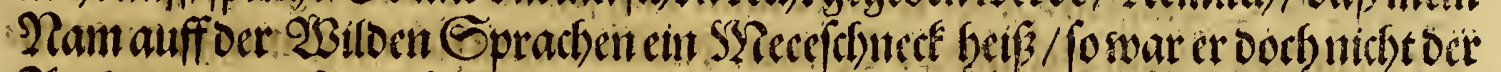

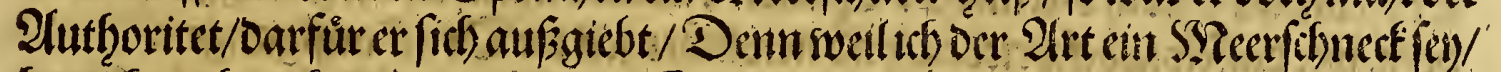

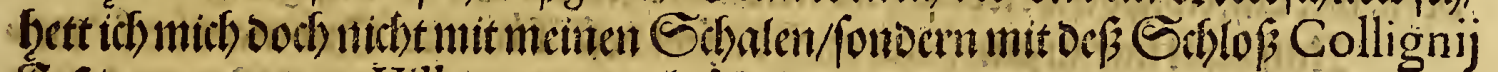
Fefrigung vor ben Villagagnone befosuiset.

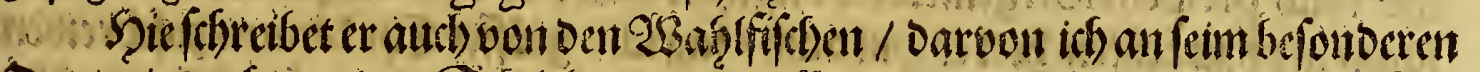

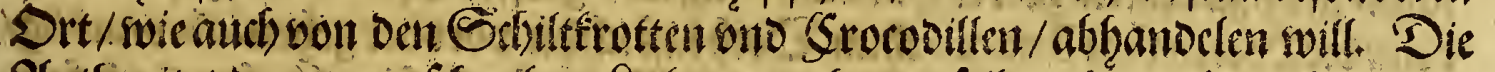

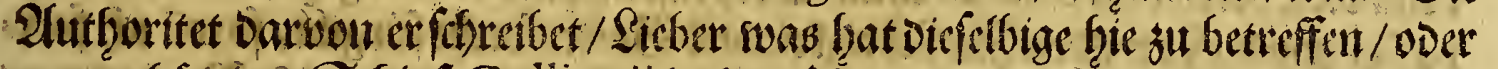

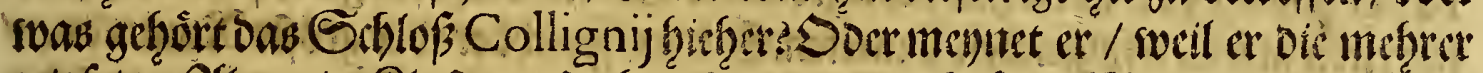

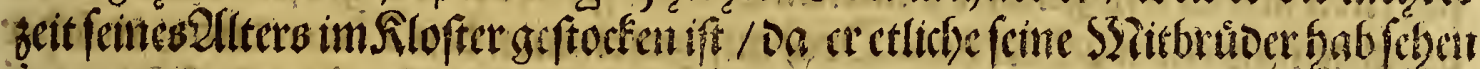

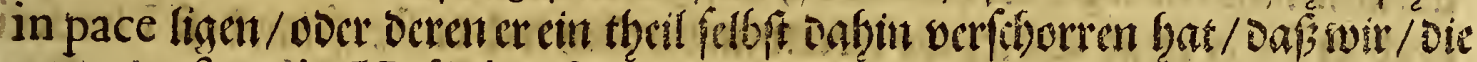

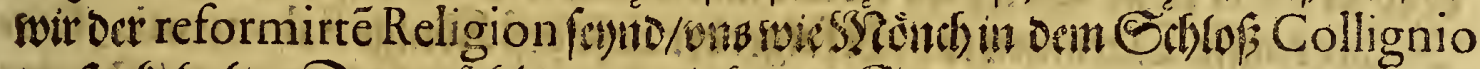

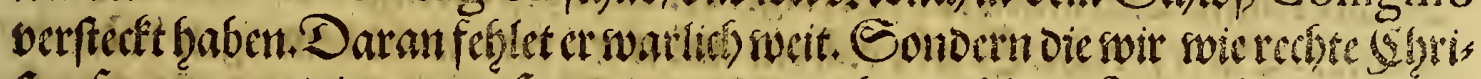

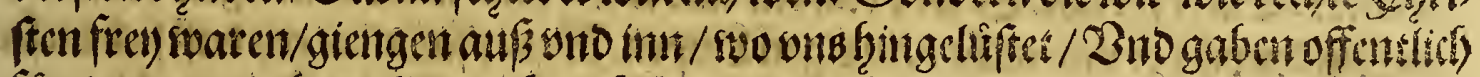

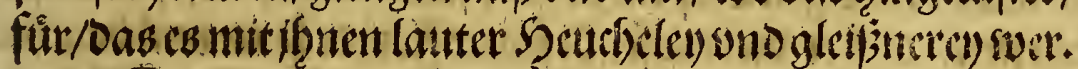

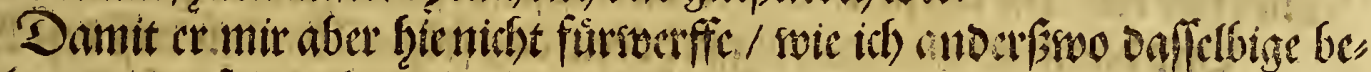

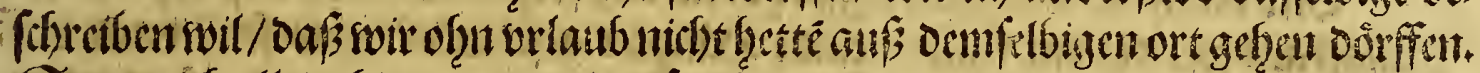

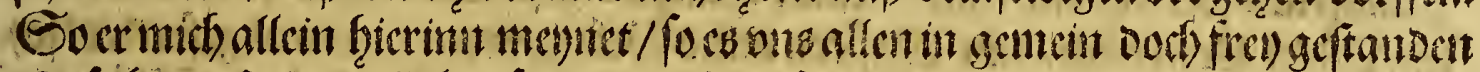

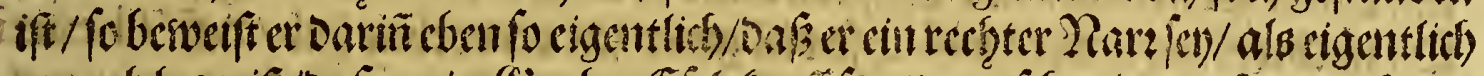

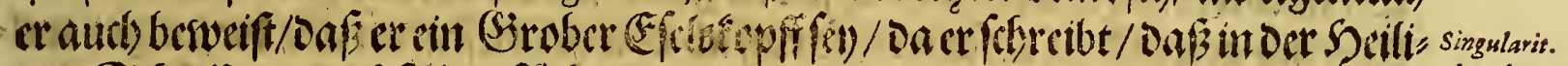

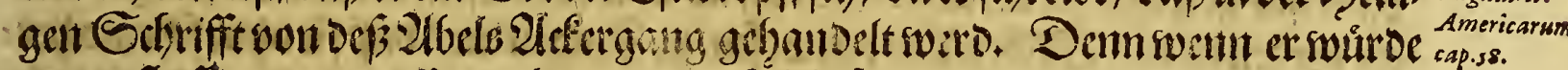

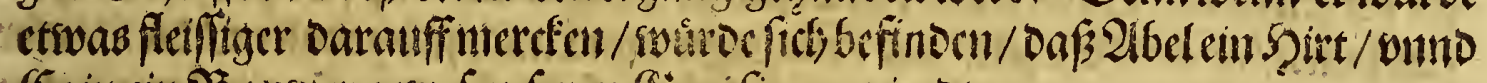

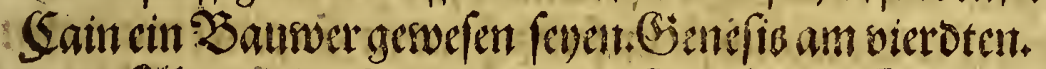

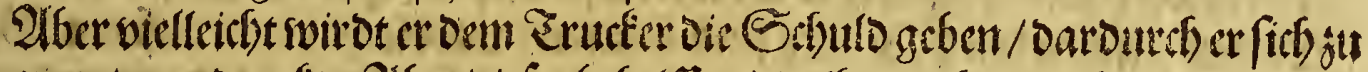

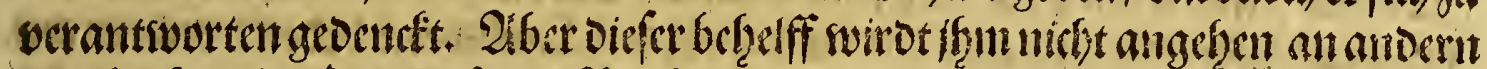

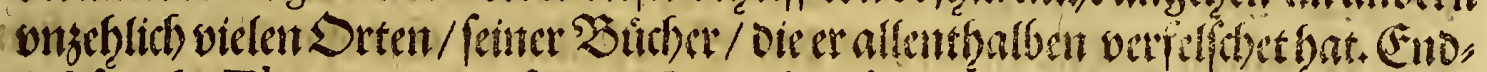

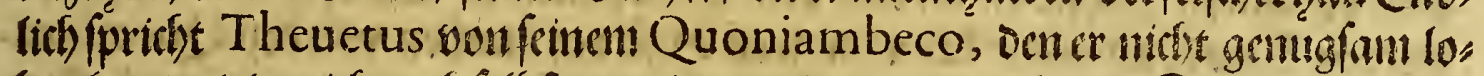

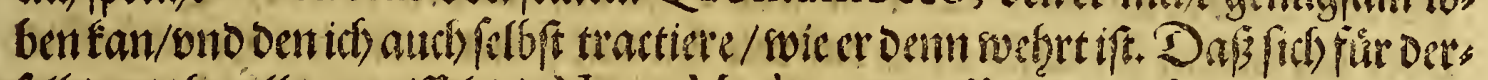

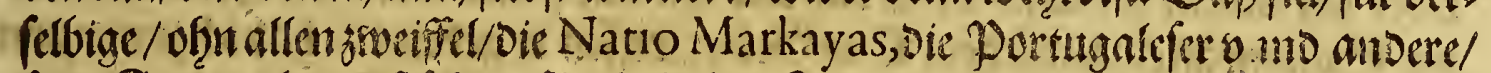

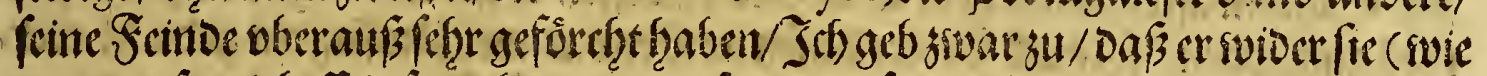

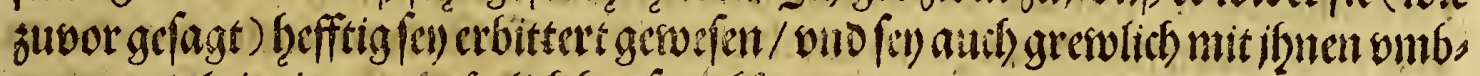

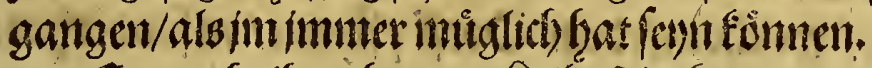

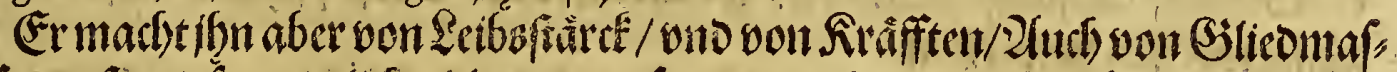

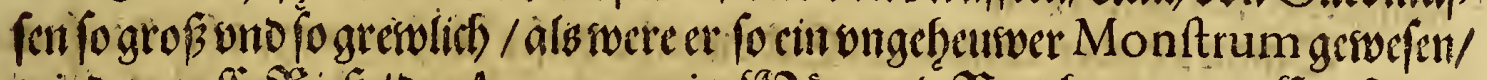

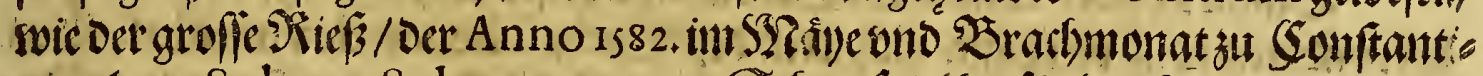

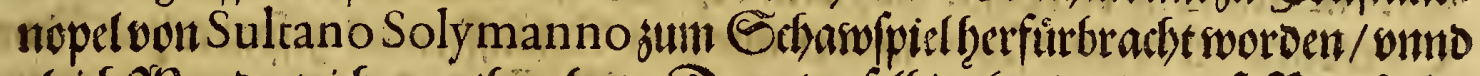

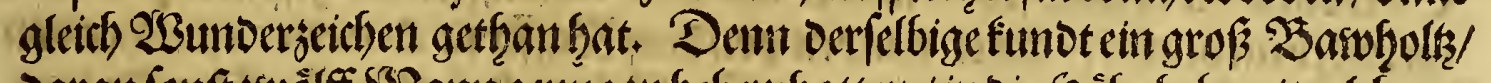

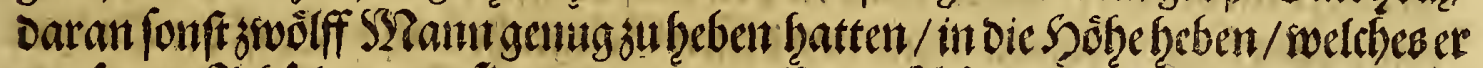

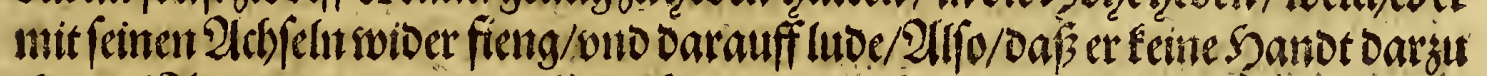

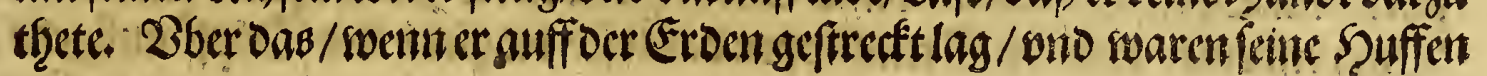
$S$ if wo 


\section{Borreber.}

let fino / marben baß 2 alfer Ronne genennt / fo vitben an bem Sorg/ Cre

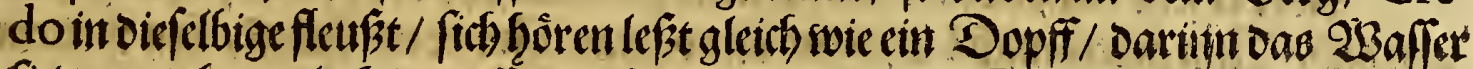
fiedet ono bruttelt. Sierauff woil ich furk antworten / Daß oicier Echmorrulzer

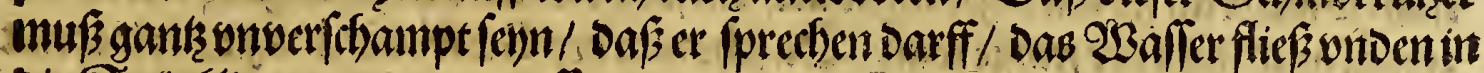

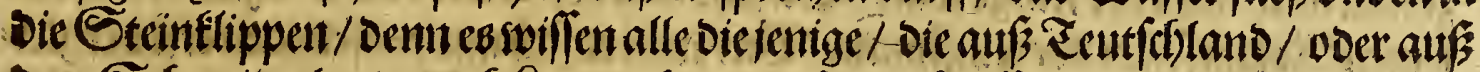

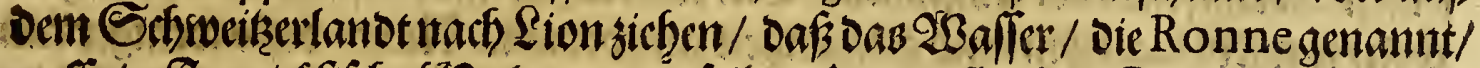

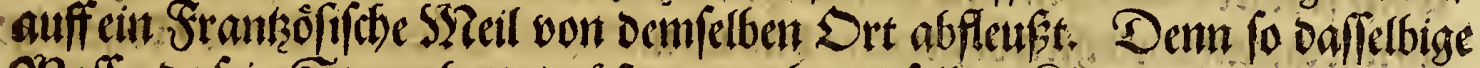
23 afler oa fein Stram hette/mufte man ober diefelbige Flippenfteigen/Darau/s

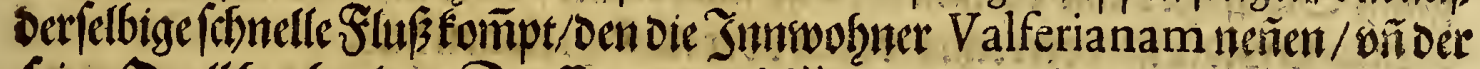

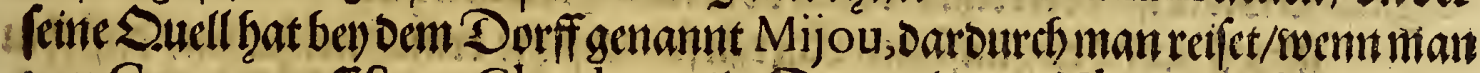
on Geneua auff Sant Claud ourwil. Darumb mag Theuetus fich wol cin sweil an oiefen ongebobelten Rilippen vnofefhen/ Damit er oie gelegenbsit cigent"

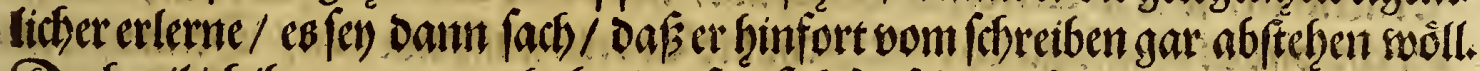

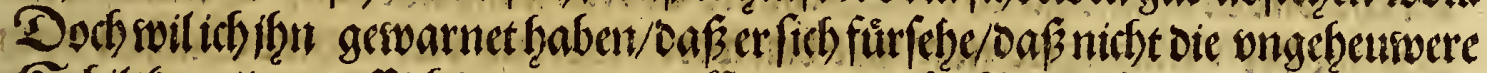

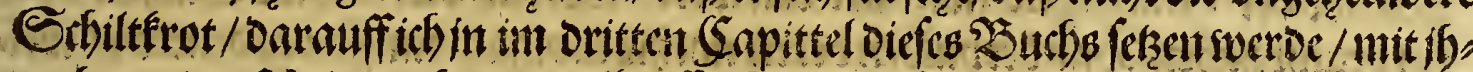

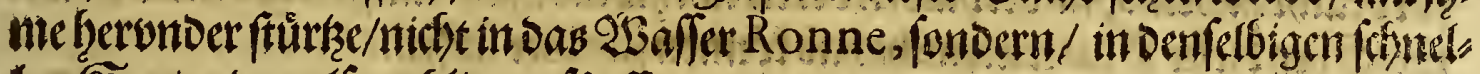
len Eec/ono er alfogefling erfâuffet weroe.

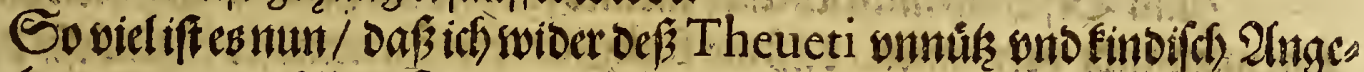

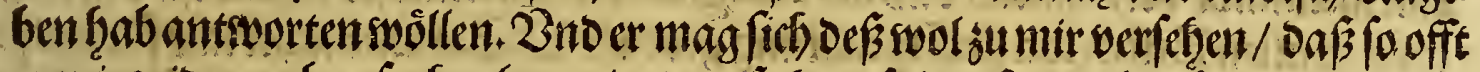
er mir soiberumb orfact geben wirt/er erfaforen fol/oaf wir cben fo viel gebé omb

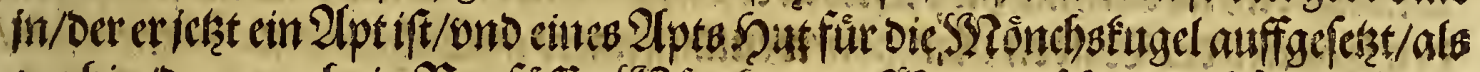

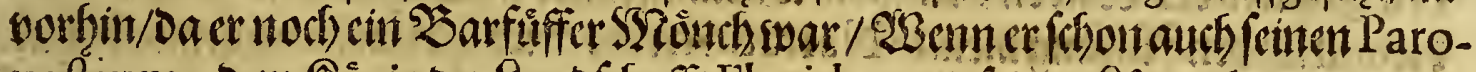

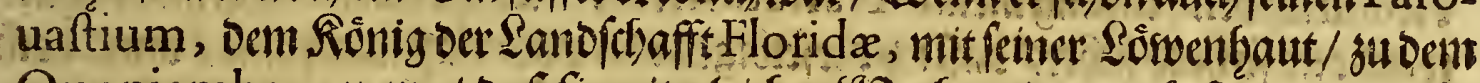
Quoniambeco neme/ Daffiemit gleidhersiacht wioer mich fturmeten/ Er

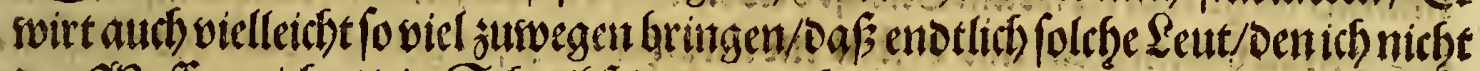

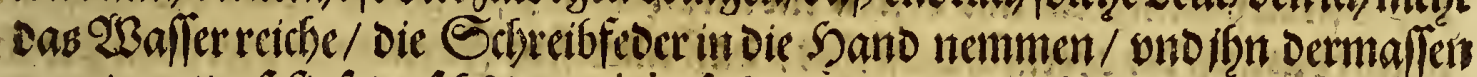

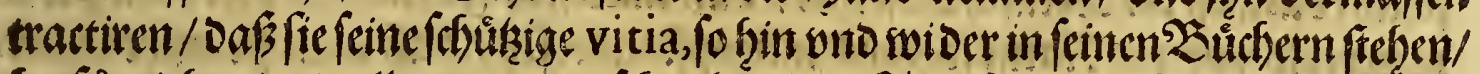

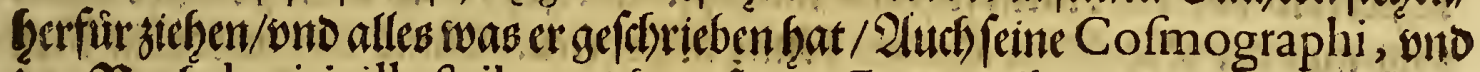

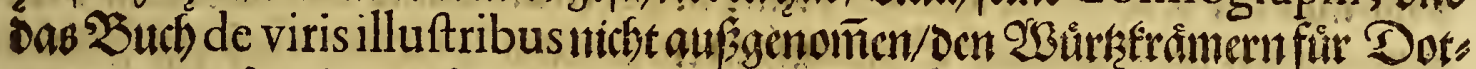

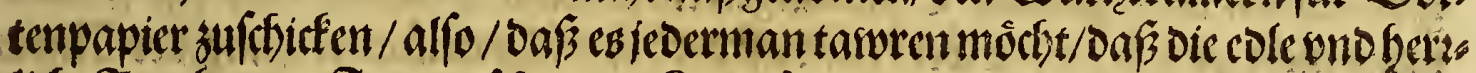

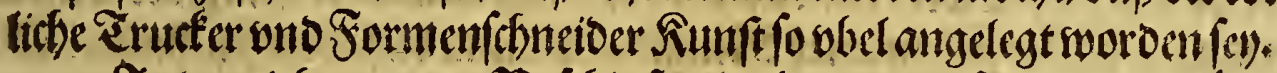

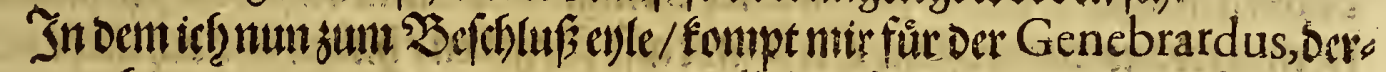

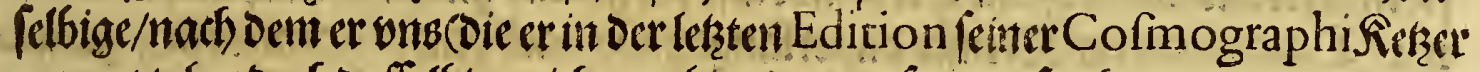
nennet/abar bod) Daffel(bige nicl)t probiert) genugfant auffgehipet/ono cin ort Det

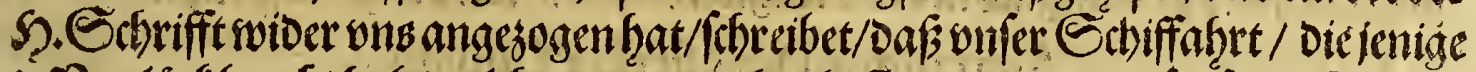

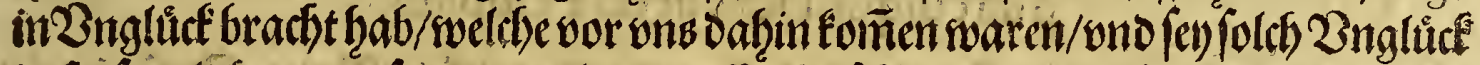

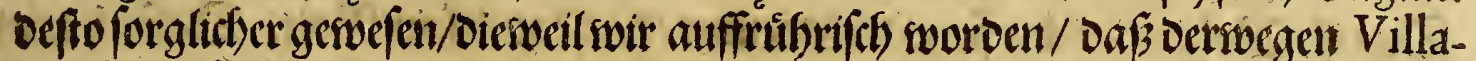
gagno vnfer ein theil hab hencken laffen / cin theil aber baber swider naeb Sou;

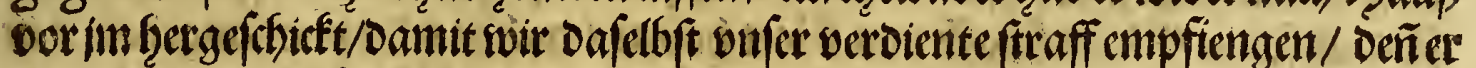
Anno is 58. vitsfo balot nackjufolgen in willens. Sierauff geb ich oenbejebeio/

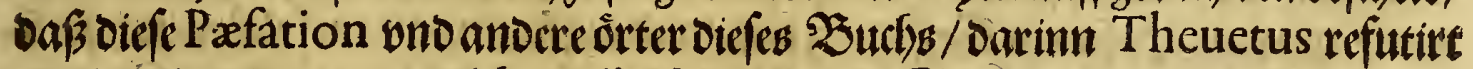
swarben/benjentigen/sweldbe aufirichtigvontor Sachen fubicieren fwollen/ges

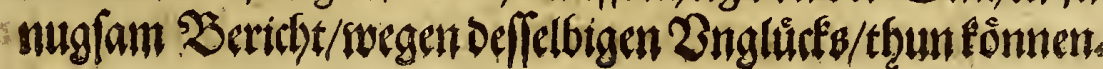

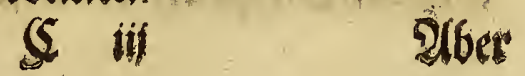




\section{Borrebe.}

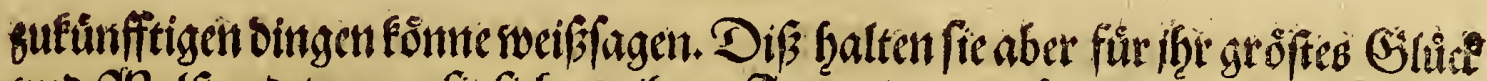

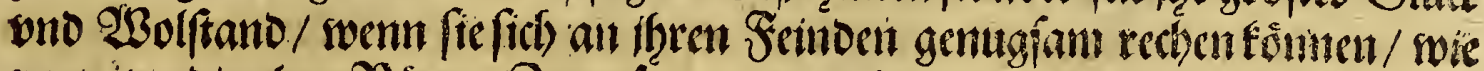

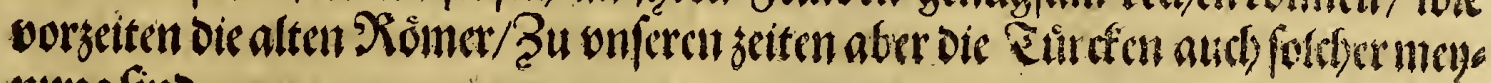
nungfino.

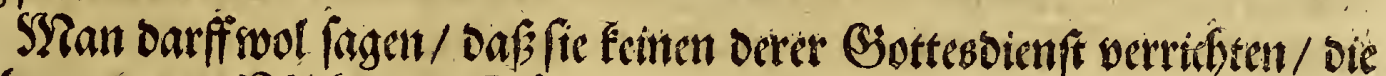
man bety anderen Bódefern die Religion nentet / Bnno oas noch wol mebrift

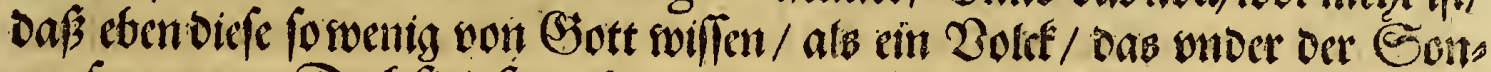

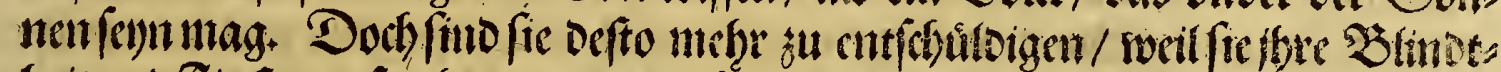
becit vno Finfternuf

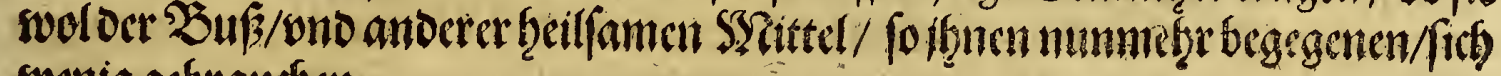
swenig gebrauclisen.

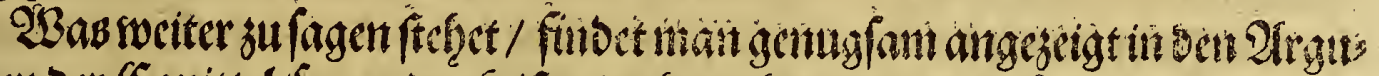

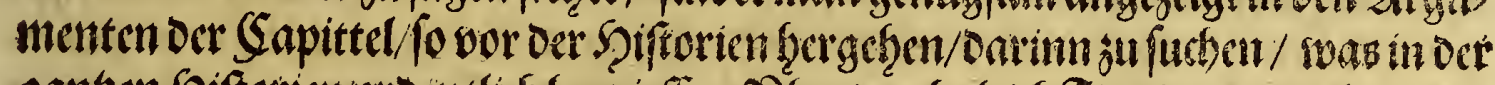

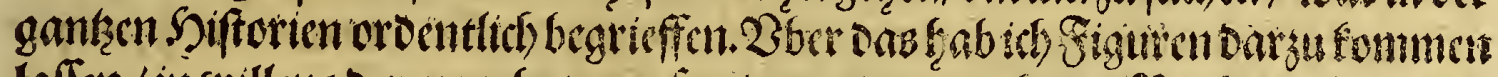

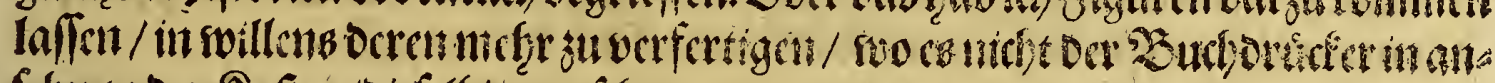

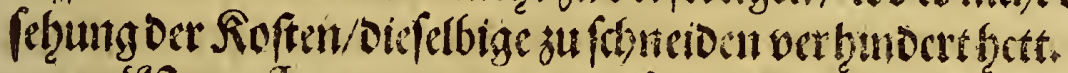

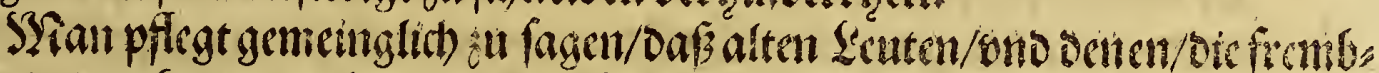

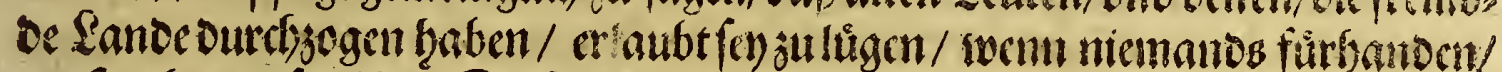

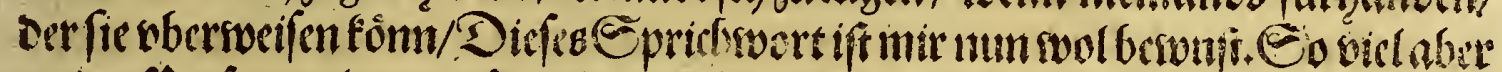

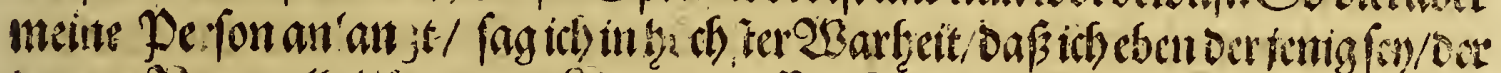

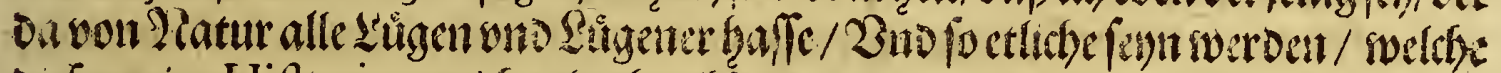

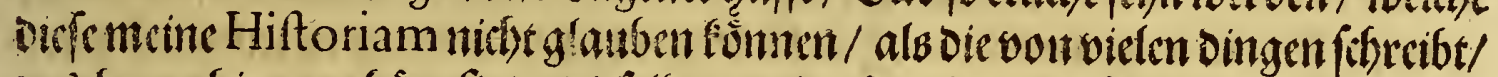

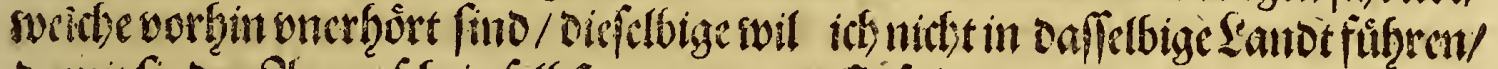

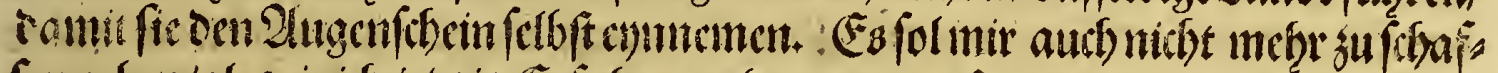

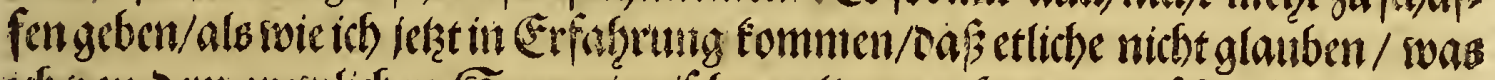

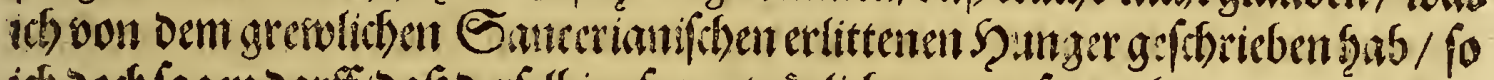

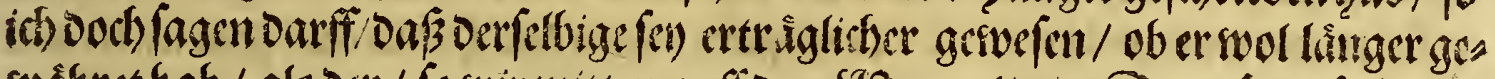

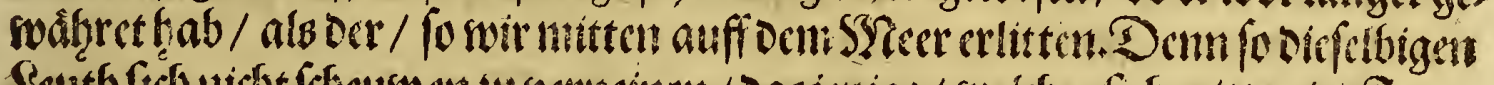

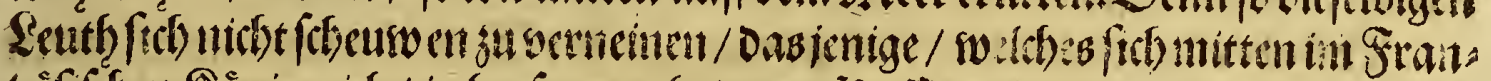

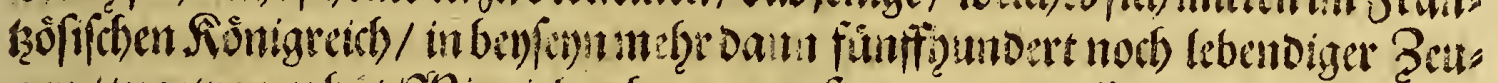

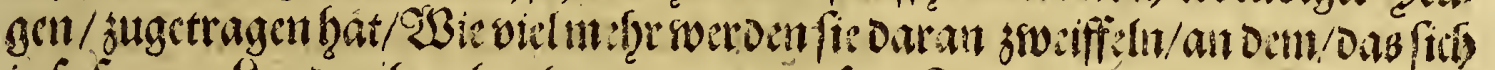

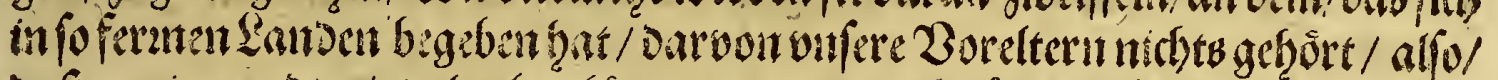

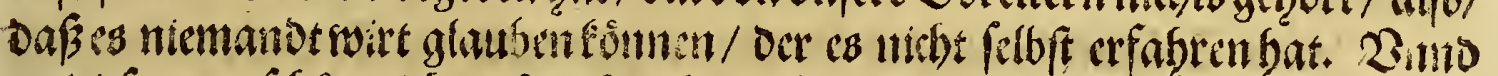

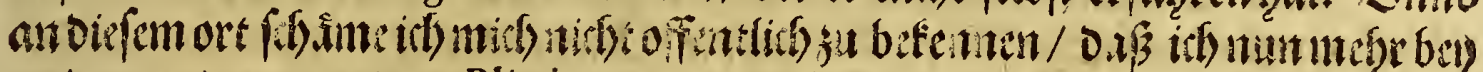

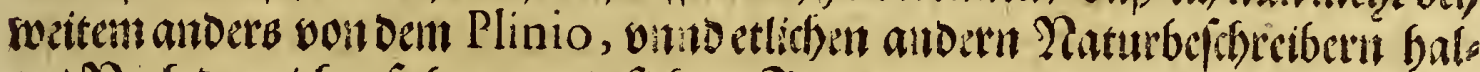

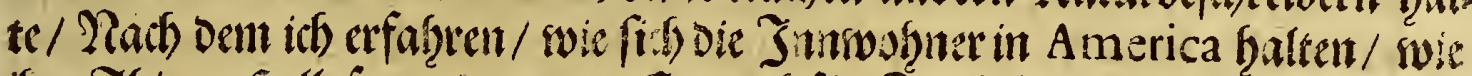

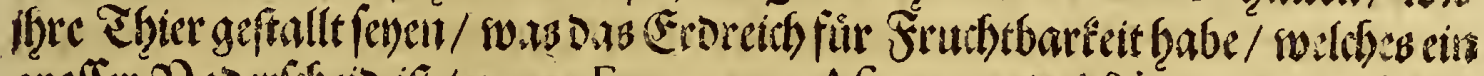
groffer 23 nerrfficid if / gagent Europen, Afien womb Africam, vinno biflith

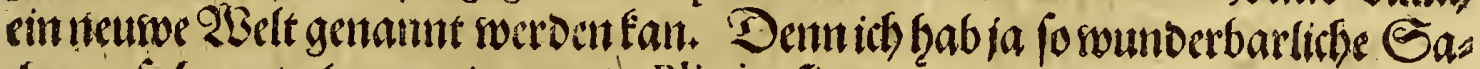

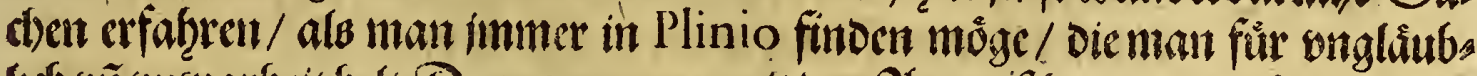

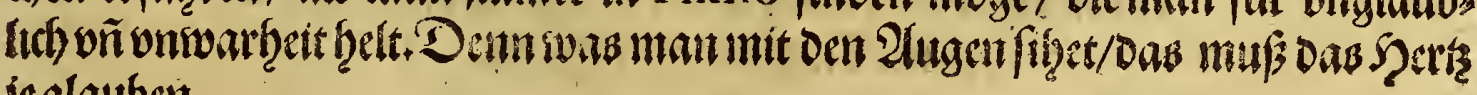
jeglaubent.

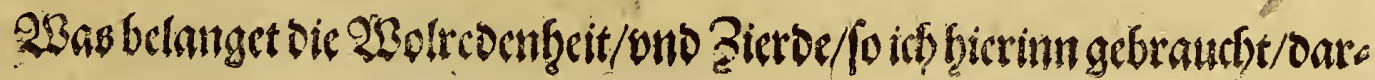
fürbang 


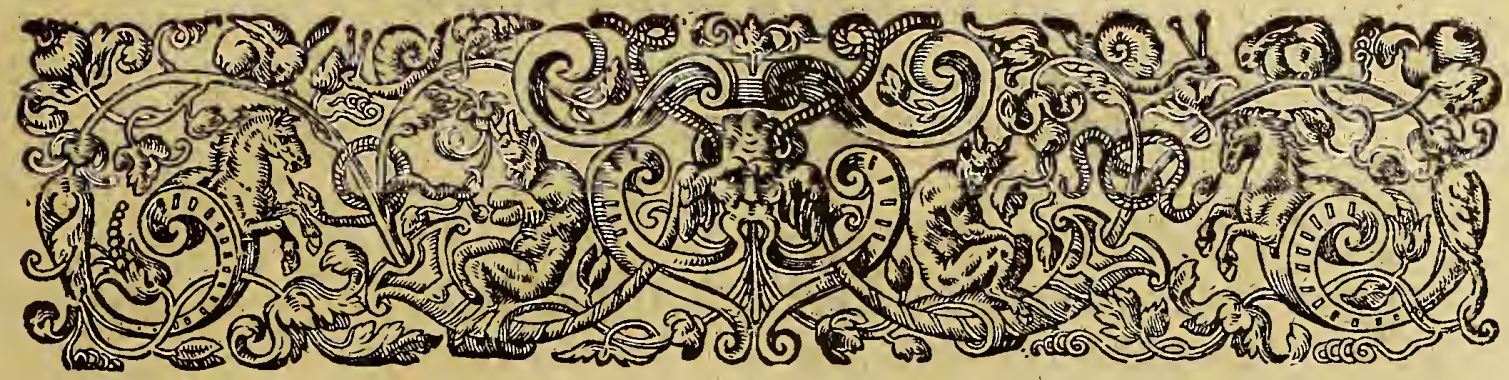

\section{PLVS VIDERE, QVAM HABERE.

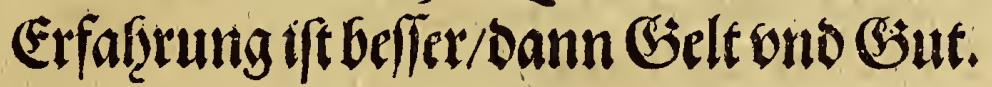

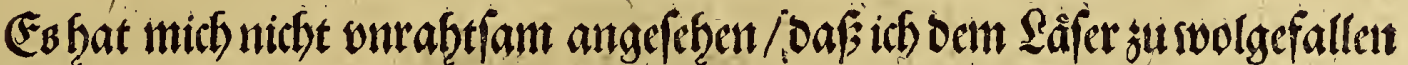

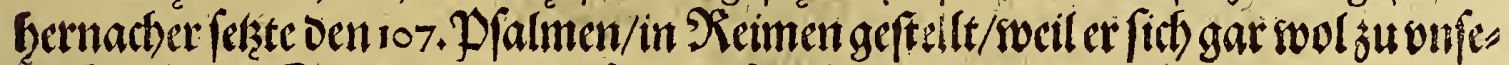

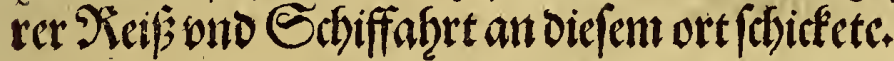

\section{Der Io7.PPalm Eatibs.}

I.

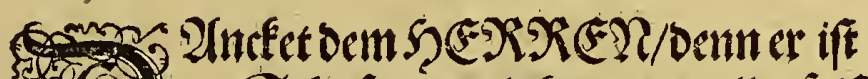
(6) Sefrefreundtich/vnd zualler frift/

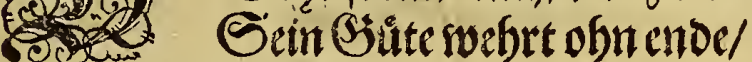

Allo fagt birifri fenterlofit/

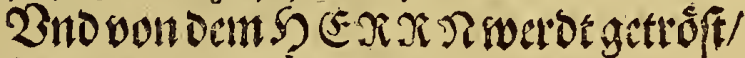

InTotben vino Elende/

Diecr bulammenthat gebradist

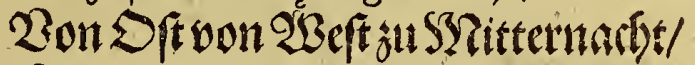

Bno von Def STicere Sidênde.

2.

Die in ber $\mathscr{G}$ ůften giengen vmb/

Bno inden Straffenirrond frumb

Da Riemande fich binsucnoet/

Bno funden feine fratt noch Plan/

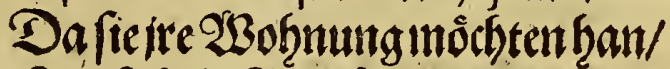

Bnofichifir Trubfalcndet/

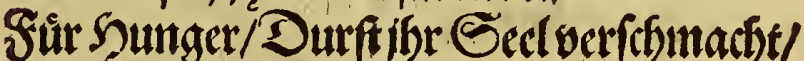

In 2(ngft fie ruffen Eag vind Ractst/

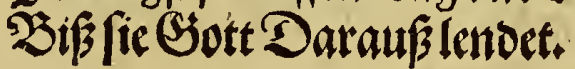

Bnd führect fie sur recthenf ftatt/

Darauffibr 28 ofnumg Frieden hat/

Bnd funde in rube beftehen/

Diefelben follen Dandfen Ėott/

Sur feine groffe SBumbertfat/

3no feine Sưutt erbófien/

Diectansy entfonenfindermubs/ 


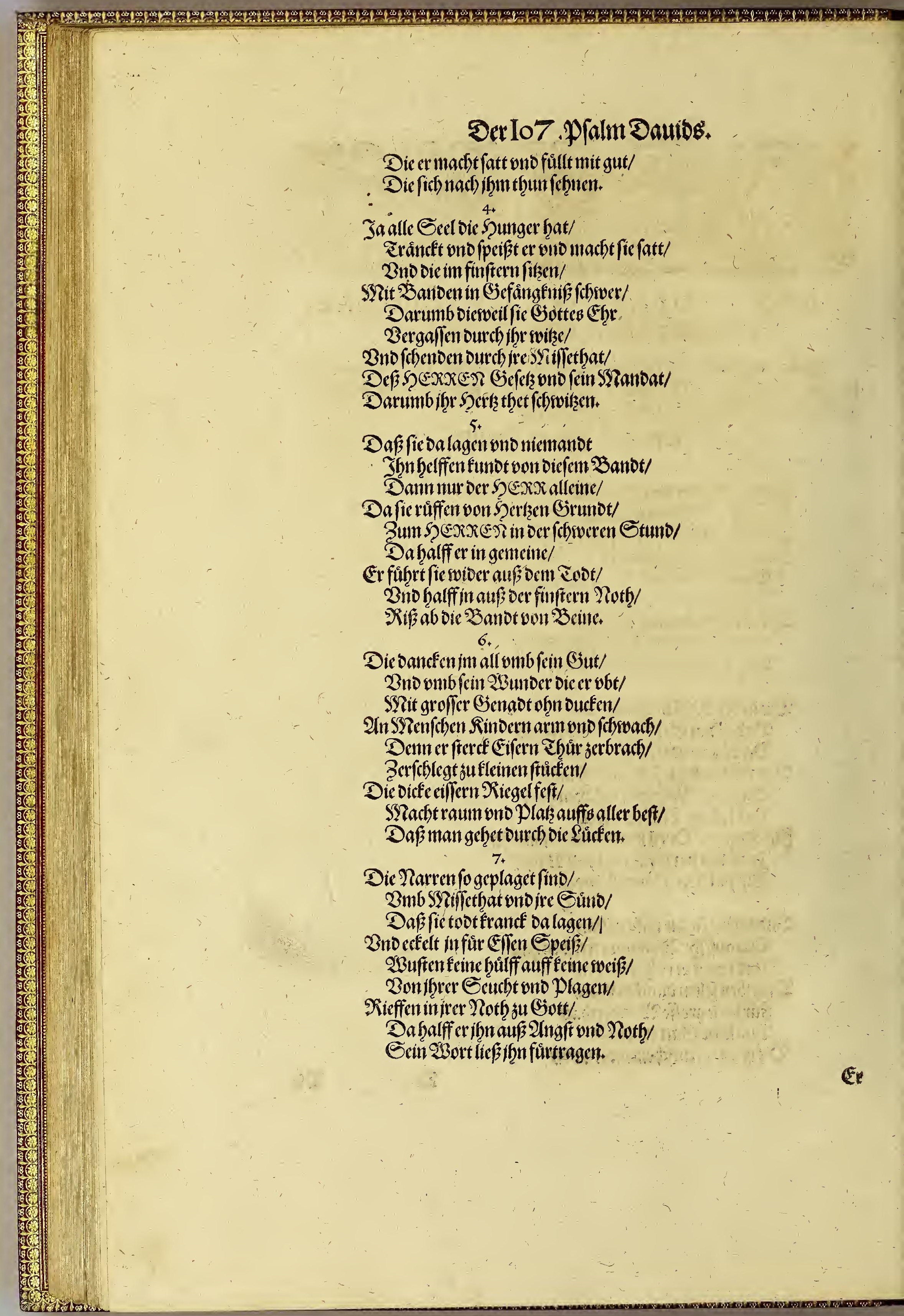




\section{Dirlo7.Pfalm Dautb:}

8.

Erbalfinauk/wnogabifin Rraffit/

Daffie der Eoot gar wegrafft/

Diefelbenfollent erzeblen

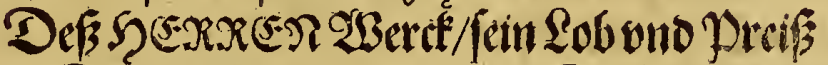

Frốliç rüfmen mit allem Flciß।

Eein $\mathscr{W}$ olthat nicht verbâhlen/

Ihm oancfen für fein gitofie biut/

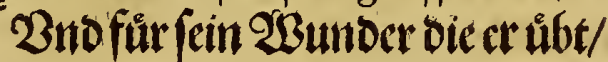

2lnonjer armen $S_{\text {edent }}$.

9.

Dicauffoen 2 Bilben woiten SZeer/

SYit Sebiffen fabententund ber/

Bnointen tieffen $\mathfrak{z}$ åchen/

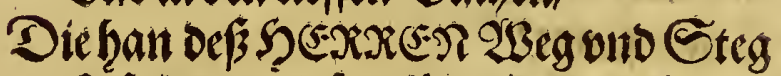

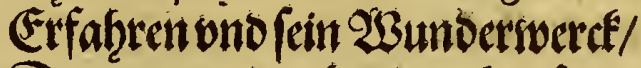

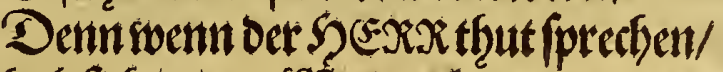

Erfubfichin bem Siect subanto/

Ein Stummint/oer gen Simmel anant

Die $2 B$ afferswellen frect)

10.

Gie fubren auff geinn Sinmel bods/

Bno ftirrizten balot in 2logrinto ooch/

Jhe Eecl wor 2hyft verzagte/

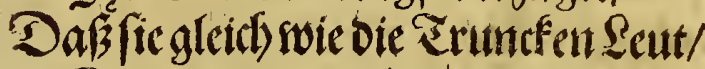

Daumelten/wouftentétitbeftheio/

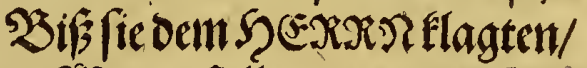

Dab $Q \mathcal{B}$ etter fitllet er mit macht/

Bno/ie auß 2 iotben wiberbracbt/

Daruber fie froblocften.

II.

Die 2 Ballen legten ficts sumal/

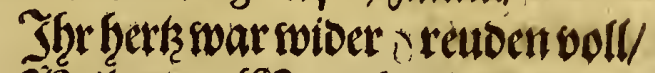

QBeil er bas SZect thet fillent/

Bno rourdenzat Dem \&ano gebractit/

Durt) S

Rachifrem swuntiff ono willen/

Zno danten Siott won Sertectigrund

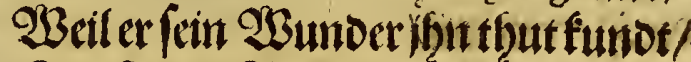

Bnofiemit Ginad thut fúllen.

12.

Diepreylenin bey Der Siemeit/

Daalle $\mathbb{E e u t}$ bey $\{$ ammen $\{\mathrm{enn} /$

Bonsegen feiner Giute/

$\mathfrak{D}$ if $\mathfrak{D}$ 


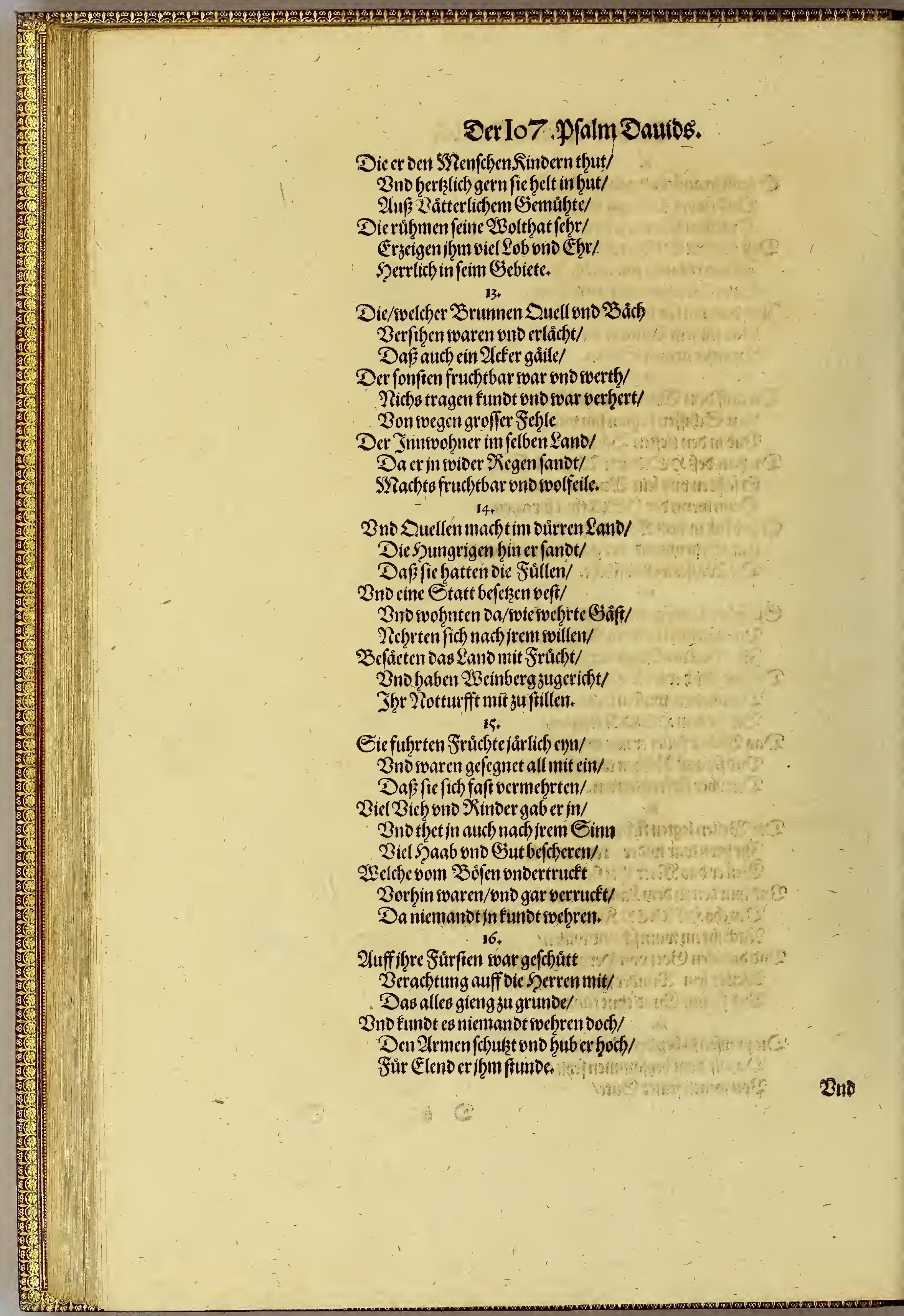




\section{Der Io7.Pfalm Dautos.}

Znt fein Gefoledtermefret fefr/

Dafifhersurocniemebriemebr/

SHeich woic cin Sperd gut Stunde.

17.

Die Frommentwerdenfolebegfeben/

Bno werden alle in frende gehn"

SYit froflichen Geberdeten/

Der fog

QBird to vbel geteen wberall/

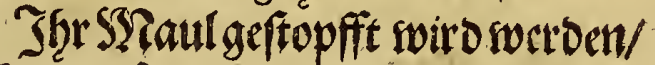

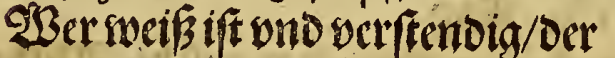

(Sibtfleifig actit auffoiefe $\mathbf{E} e$ r)

Behelt Die 2 Berdé Dé S Serren.

\section{E $\mathfrak{N} \mathfrak{E}$}

Teucrius Annæus Priuatus faciebat.

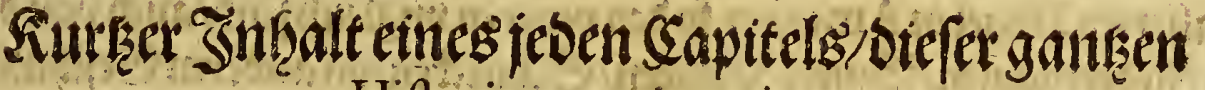
Hiftorien von America.

I. Sap.

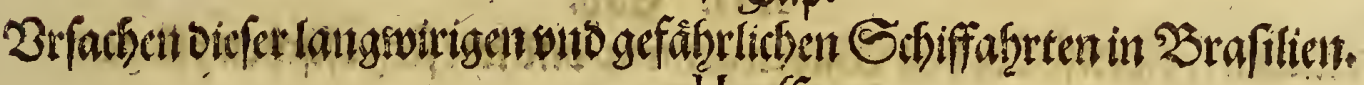

$$
\text { II. Sap. }
$$

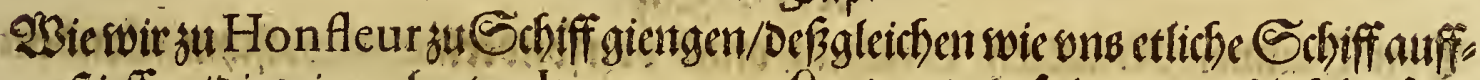
ftieffen/ oic fwir croberten. Item an wab Sano ond snfulentwir crftlich hinfuh, ren.

\section{Sap.}

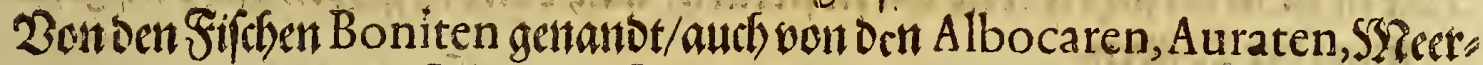

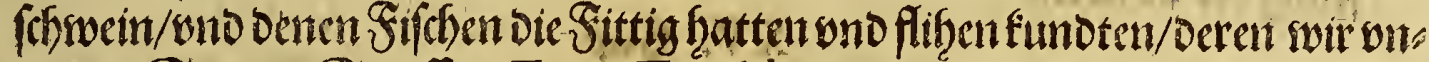
Der der Eomten Straffen/Zona Torridagenanot/nichtalleingefchen/fons Dernaud gefangen haben.

$$
\text { IV. Sap. }
$$

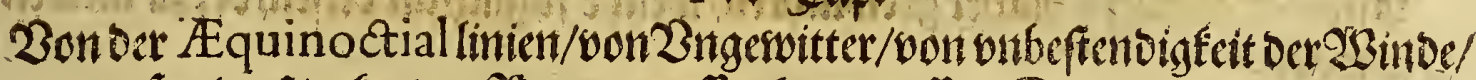

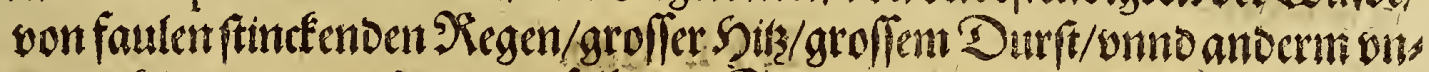

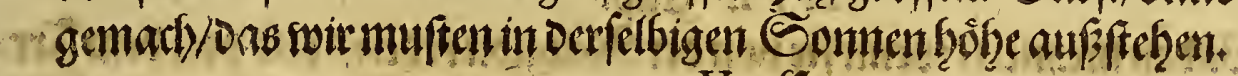

$$
V+\text { Sap }
$$

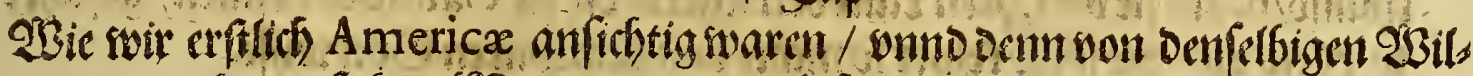

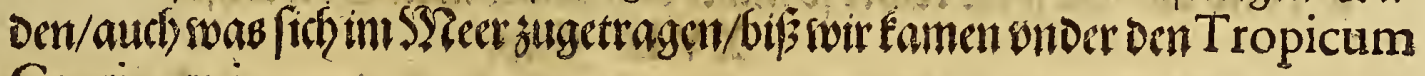
Capricorni.

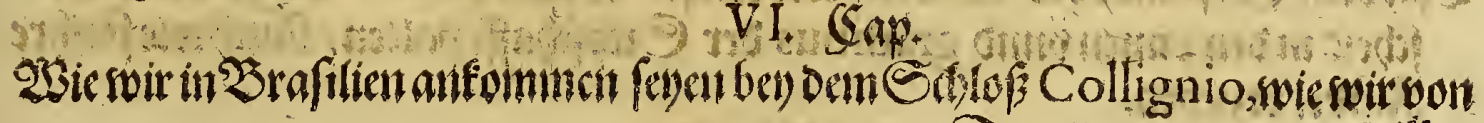

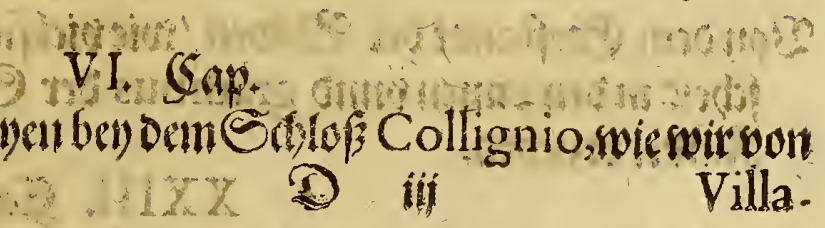

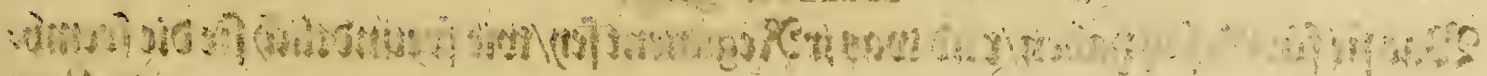
$2+y^{4}+3$ 


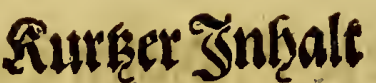

Villagagnone emp fangen worben/weie fich oer Villagagno angelaffen/beno in Religions factben/ond Dann fonften in feinem Regiment.

VII. Sap.

Bejctreibung oef Şaffen Ganabre, Den man auch nenet Rio de Iennero. Jtem befthreibung ber Infulenono Schlof Collignij ond antern benactbarten In $\mathfrak{i} \mathfrak{u l e n}$.

V III. Sap.

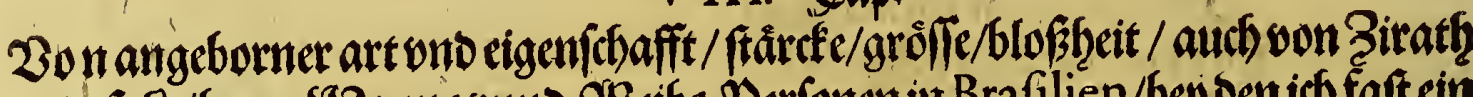

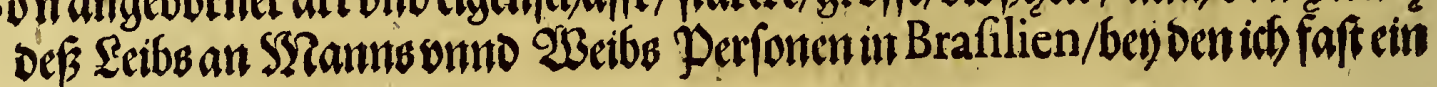
gantz Jarverbarret.

IX. Sap.

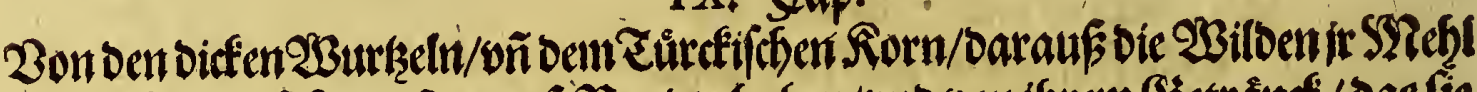

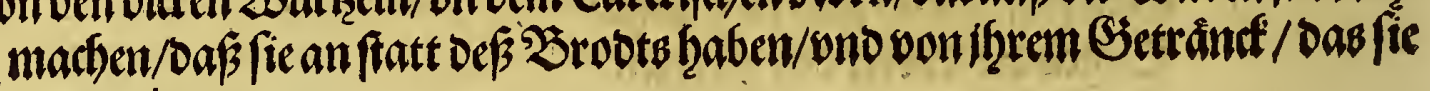
Caou-inneunen.

\section{Sap.}

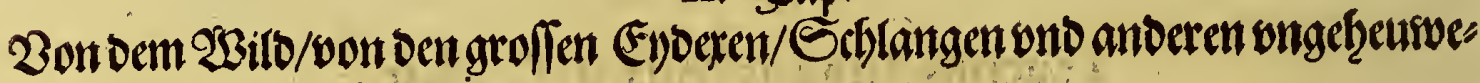
ren Ihteren in America.

\section{Sap.}

Bonallerlen Bögel in America, fo ben onferenonglecth/ind/auth vonten grofs

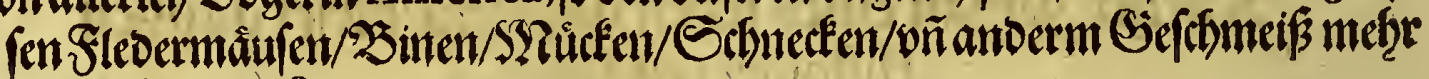
in Denrfelbigen Sando.

XII. Sap.

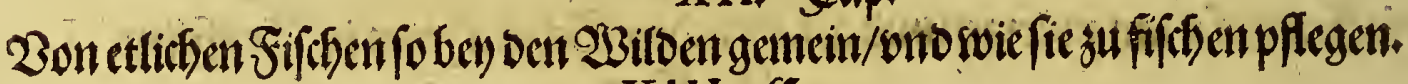

$$
\text { XIII. Sap. }
$$

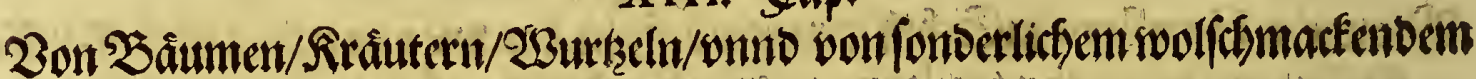
Sbb/fo ntan in America f̧at.

\section{XIIII. Sap.}

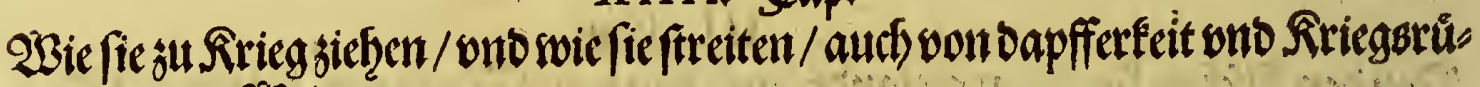
ftung oer $2 \mathfrak{B i l b e r t}$.

XV. Sap.

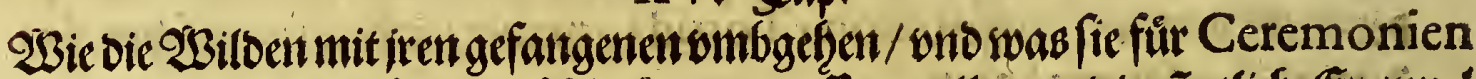
baben/weñ fie olefelfigenteblachten ond eflen wollen/wno bañ etlief)e (Exermpel

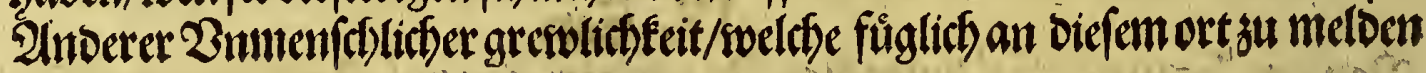
gewefert.

XVI. Sap.

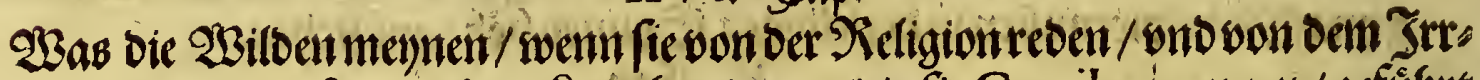

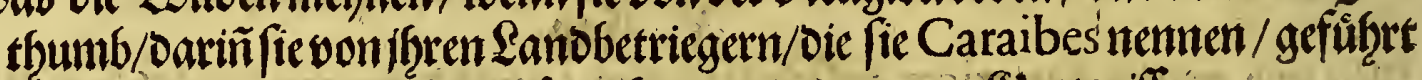

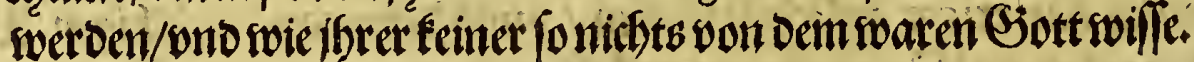

$$
\text { XVII. Sap. }
$$

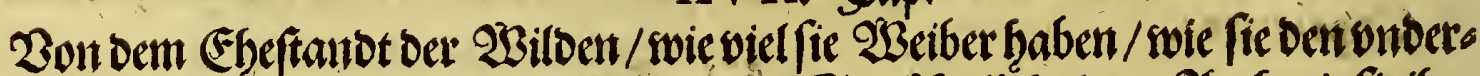

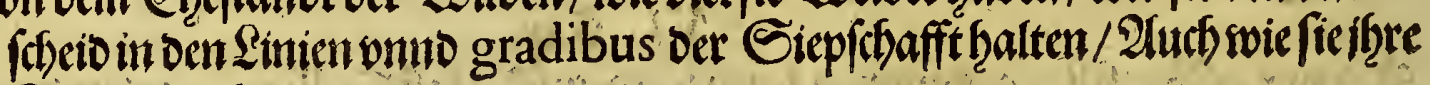

"Tinber ersiehen.

XXIII. Sap.

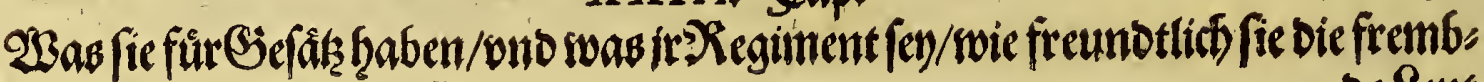
De $\mathfrak{S e u t}$ 


\section{Der Capitel.}

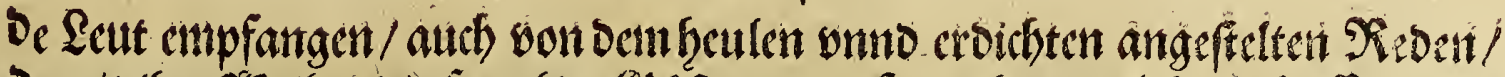

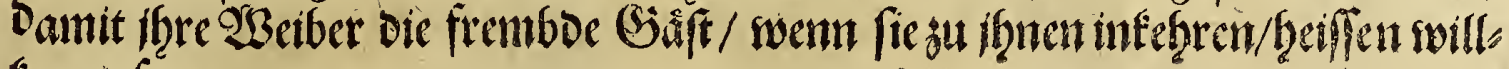
fomm (e)tit.

XIX. Sap.

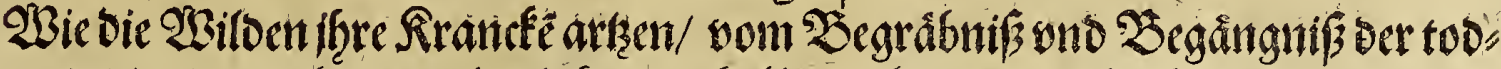

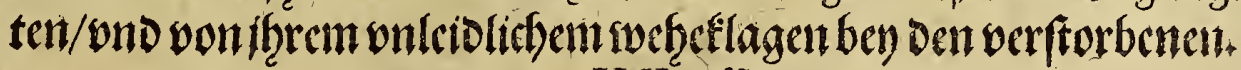
$X X+$ Sap.

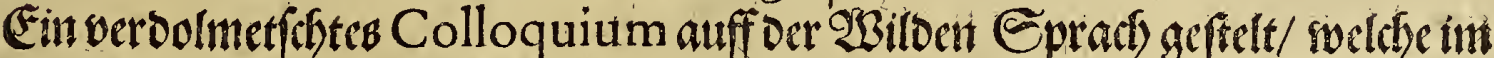

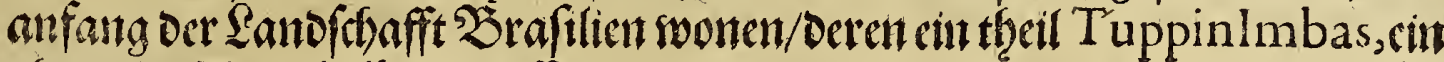
theil aber Tuppinikins feiffert.

XXI. Cap.

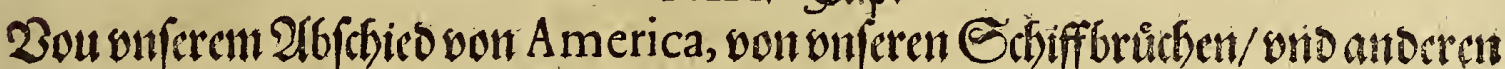

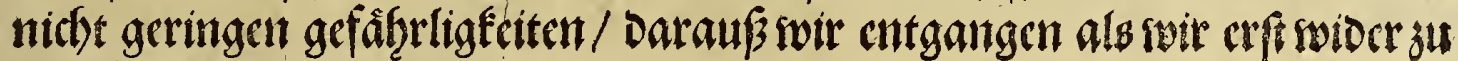
Şauß antommen soaren.

XXII. Sap.

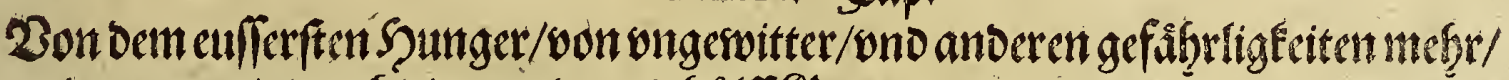

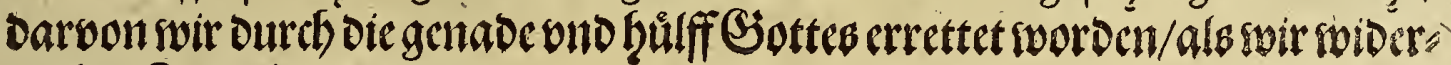
umb in Srancfreidf fạmen.

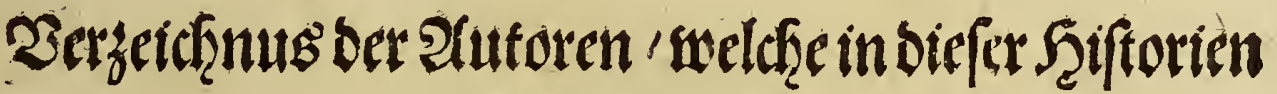 angezogensweroen.}

Biblia facra.

Iofephus.

Eufebius.

Nicephorus.

Plutarchus.

Cicero.

Ouidius.

Appianus.

Ororius.
Gomara.

Benxo.

Calchondilus.

Viretus.

Hiftoria Ecclefiaft. Gallica.

Matthiolus.

Bodinus.

Popeliuerius.

Theuetus refutatus.

Hiftoria 


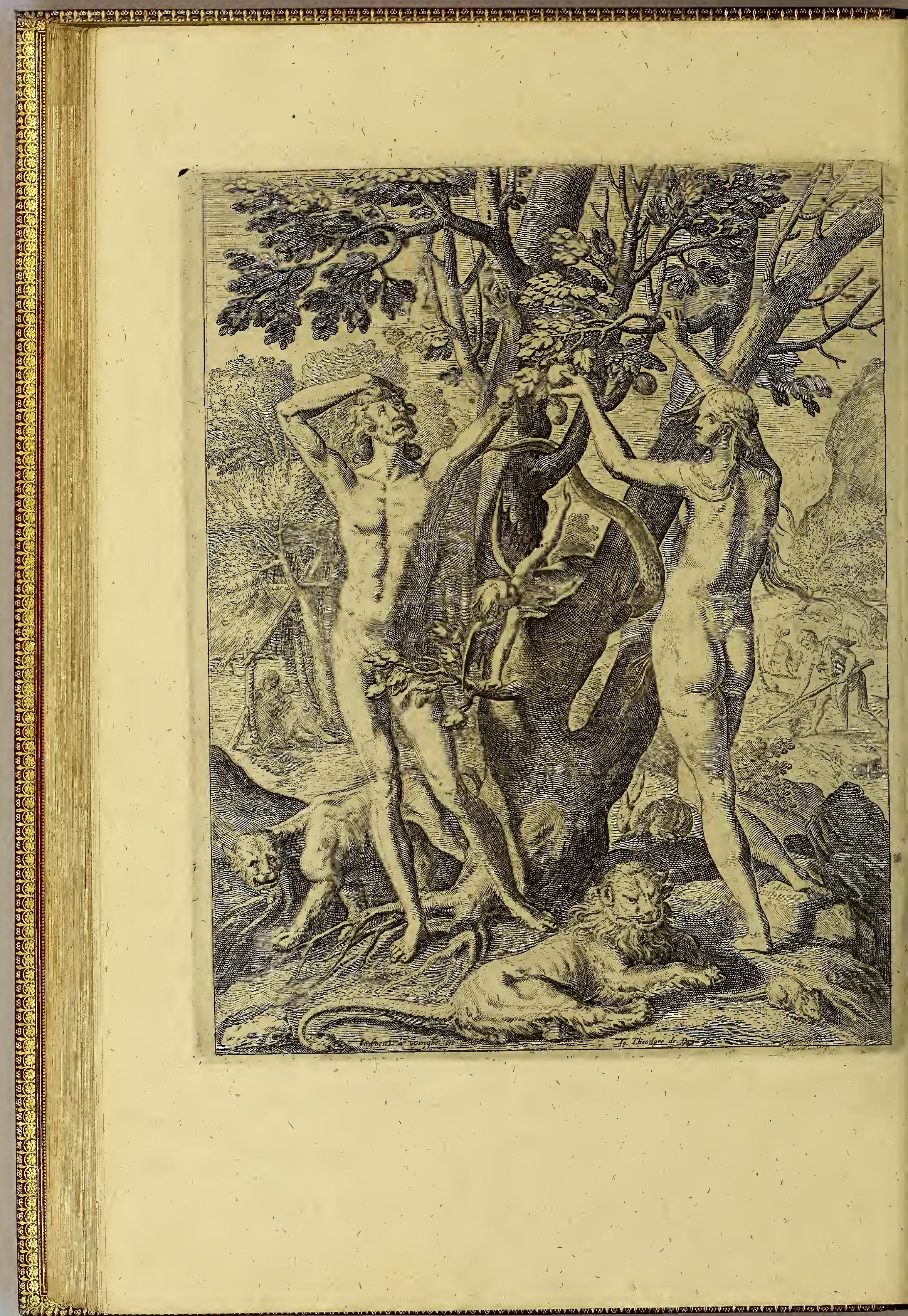




\section{Dercapitel.}

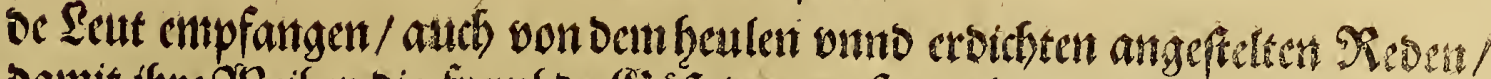

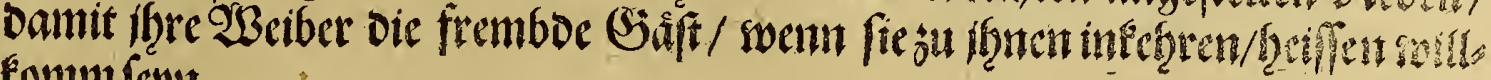
fomm lertit.

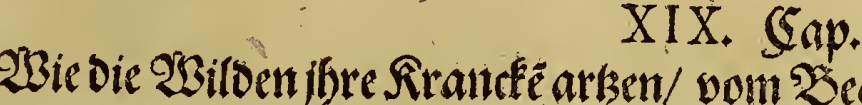

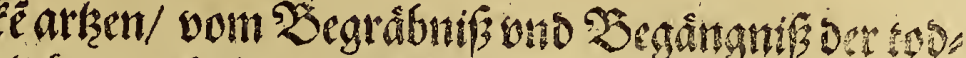

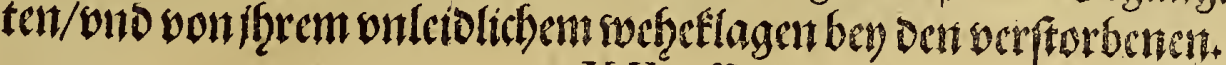

$\mathrm{XX}$. Sap.

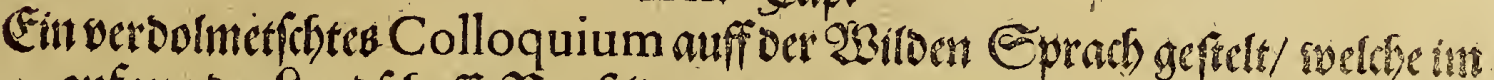

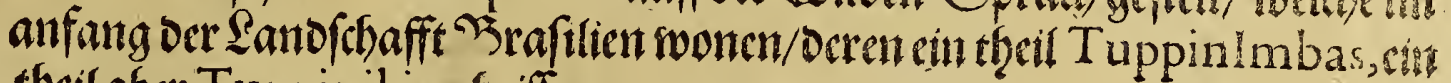
theilaber Tuppinikins feiffert.

XXI. Sap.

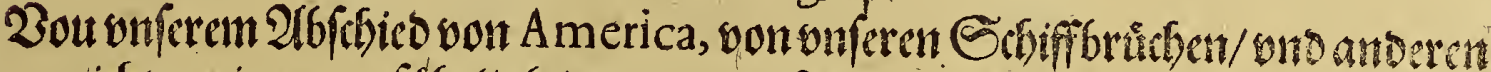

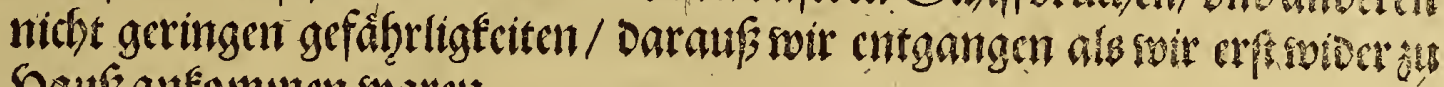
Şauß antomunen watren.

XXII. Sap.

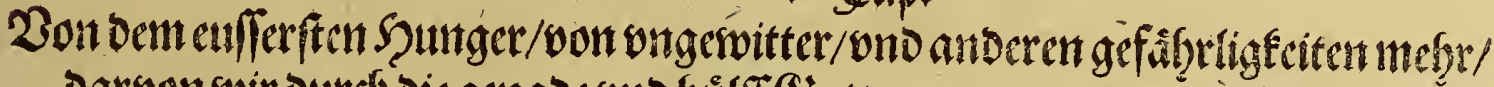

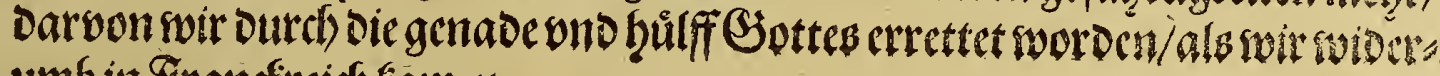
umb in Frandrecich faumen.

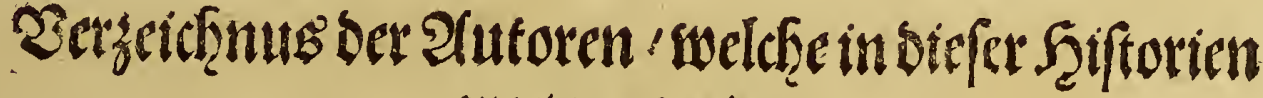

angerogentwerien.

Biblia facra.

Jofephus.

Eufebius.

Nicephorus.'

Plutarchus.

Cicero.

- Ouidius.

Appianus.

Oforius.

Gomara.

Benxo.

Calchondilus.

Viretus.

Hiftoria Ecclefiaft. Gallica.

Matthiolus.

Bodinus.

Popeliuerius.

Theuetus refutatus.

Hiftoria 


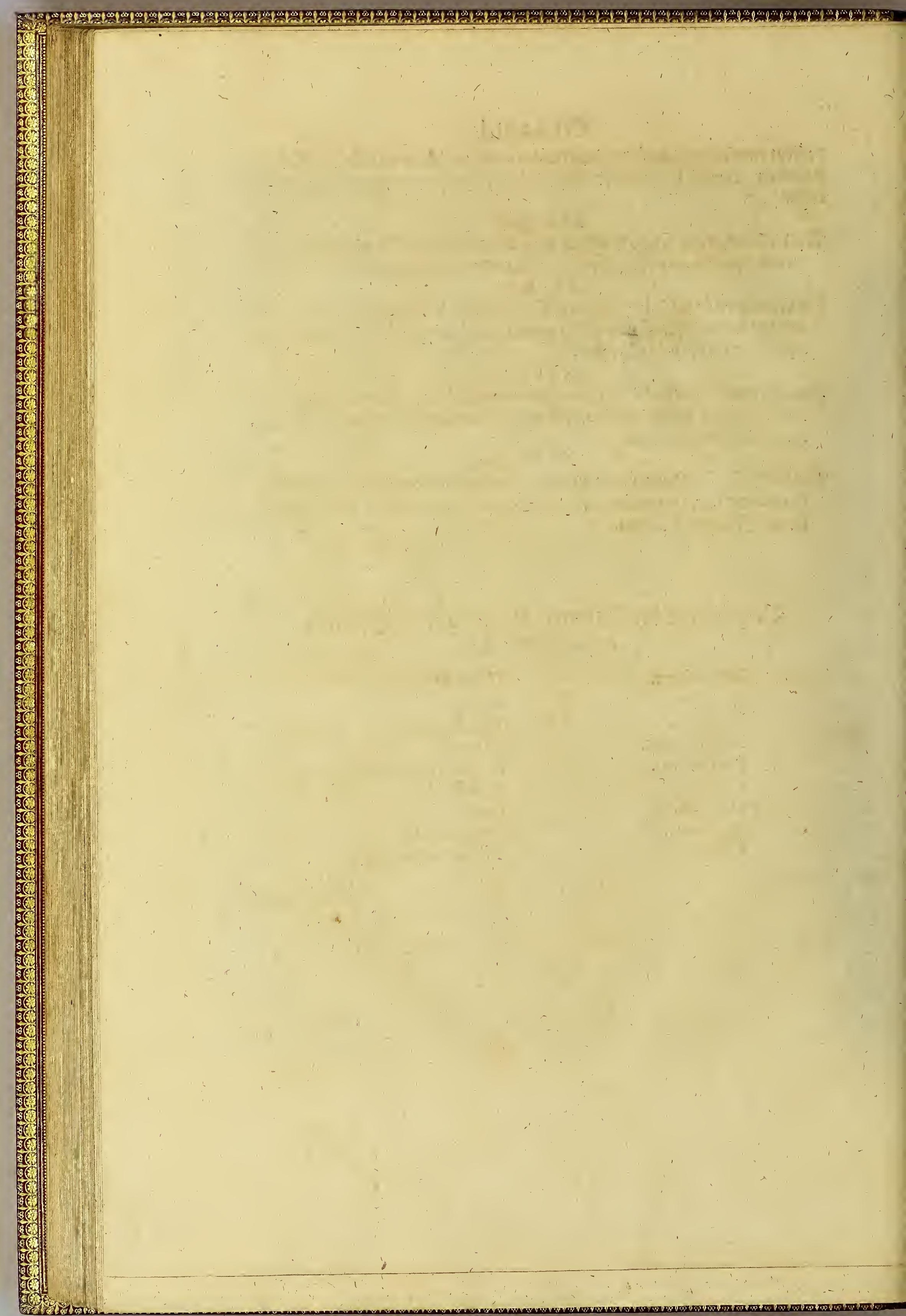




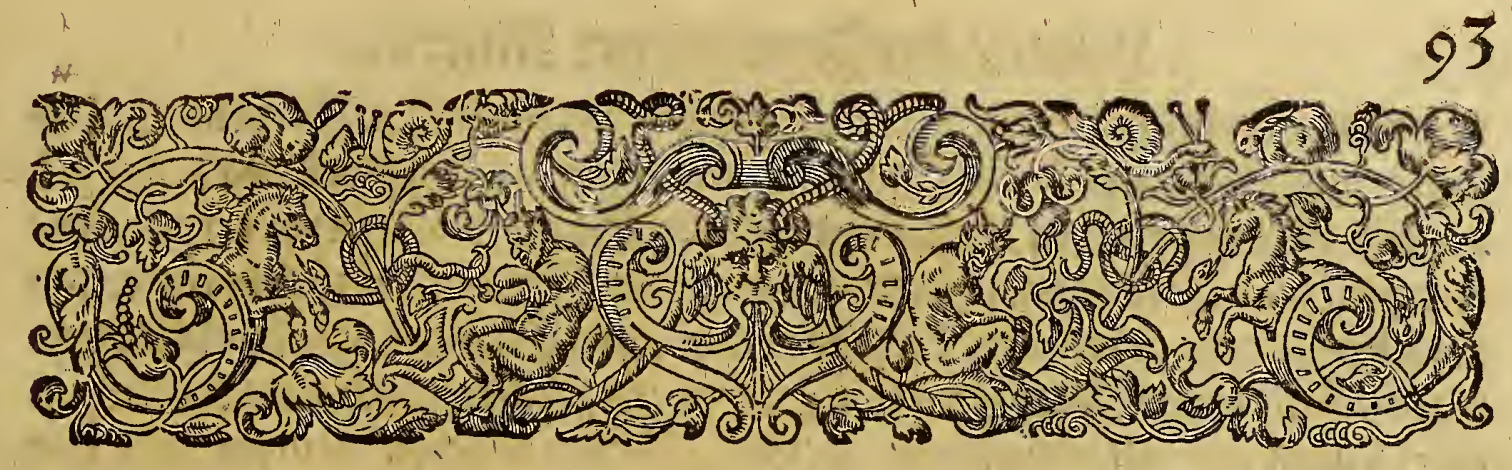

HIST OR IA

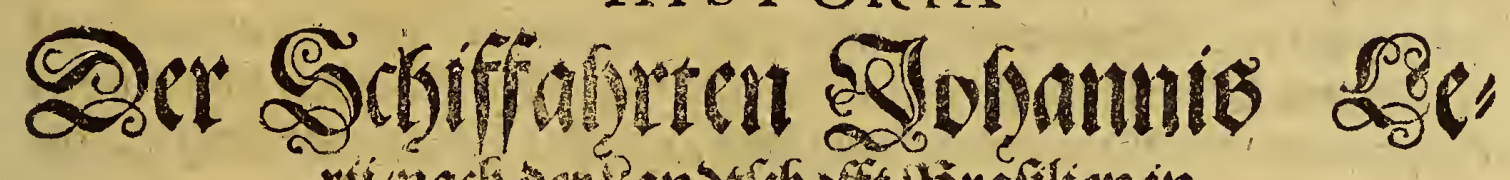

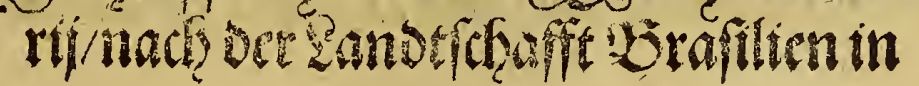

America.

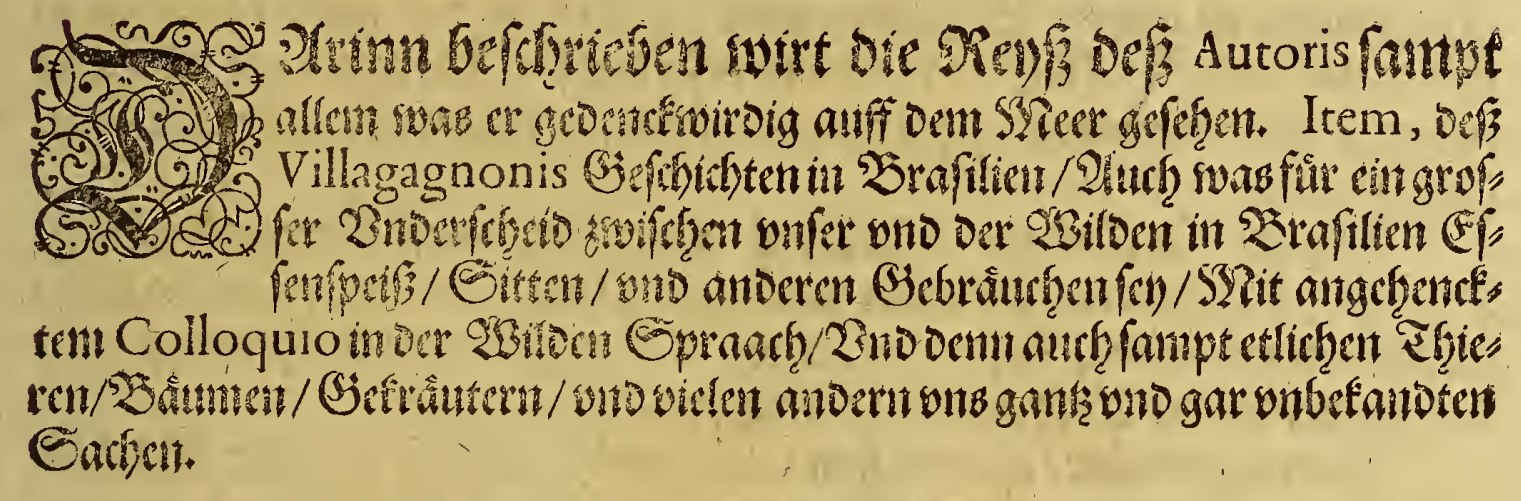

1. Sapittel.

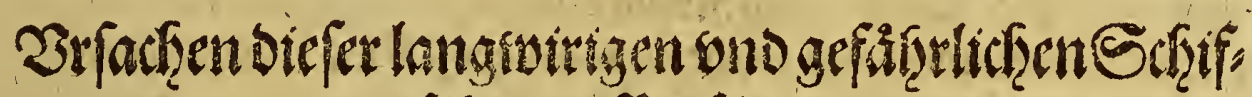

faffertan in $\mathfrak{B}$ :afilien.

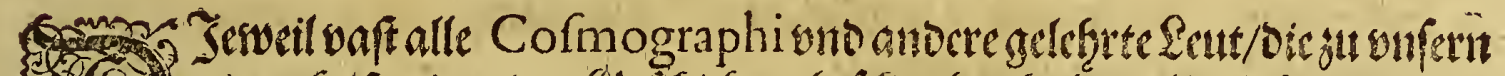

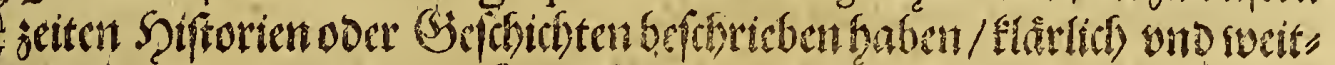

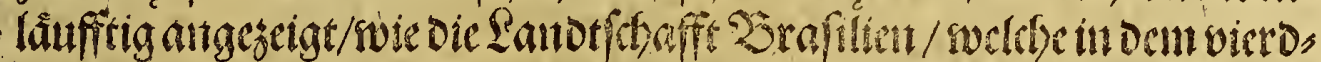

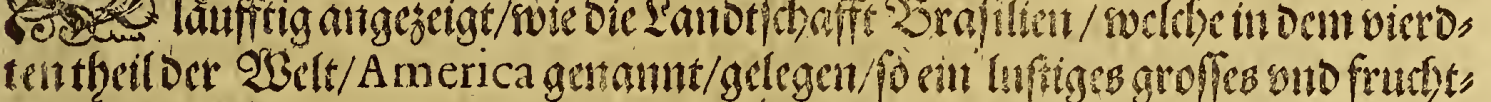

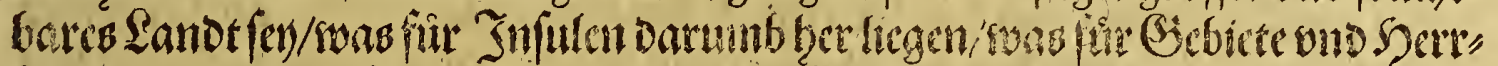

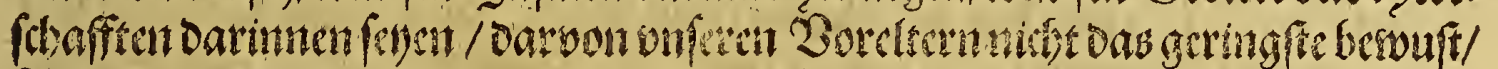

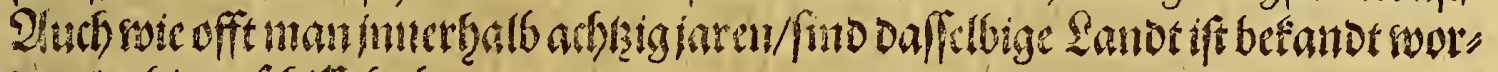
Den/oasingeforifot gat.

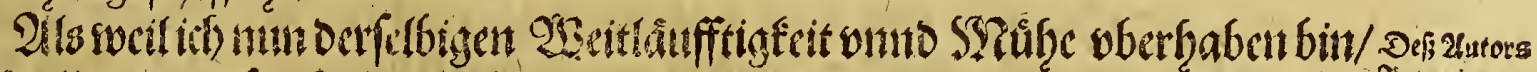

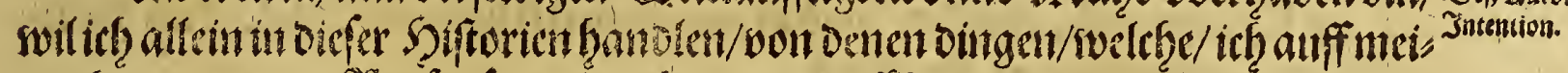

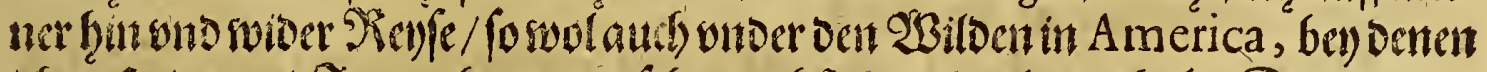

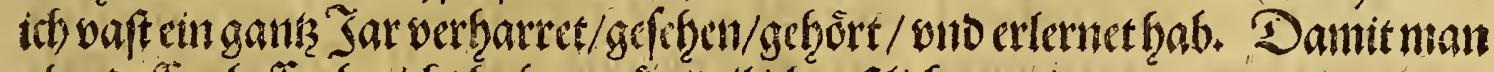

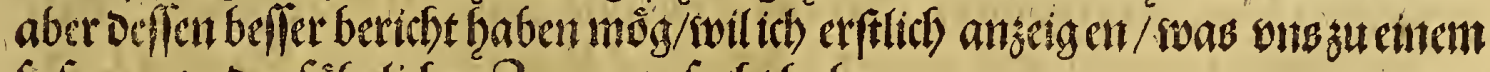

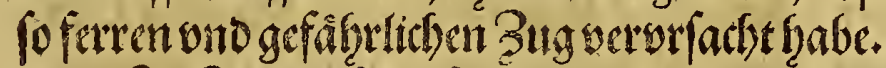

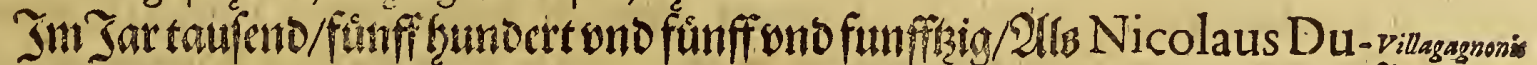

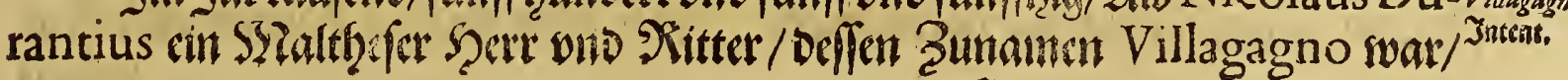
E num mefte 


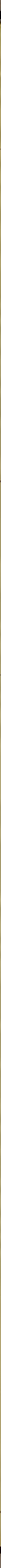




\section{Das britte Tfect.}

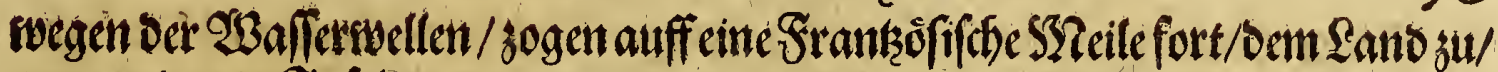

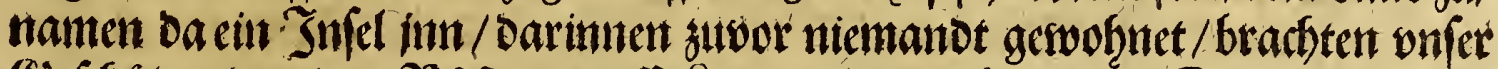

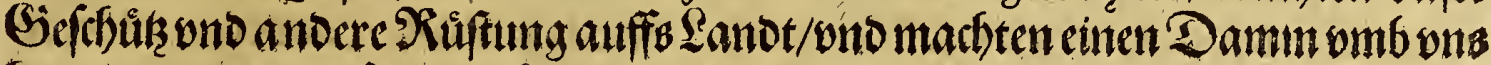

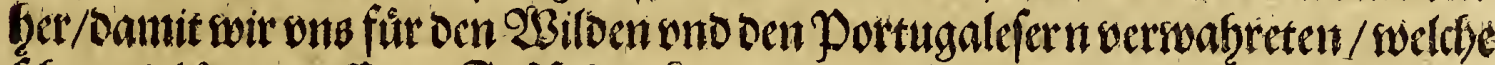
fibon viel orter auff dem Fus feften Sallotingenommen ond befribiget batten.

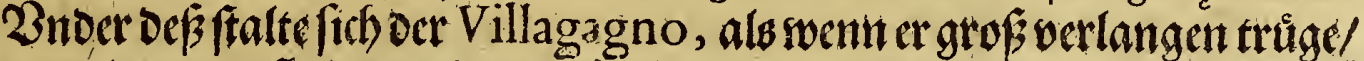

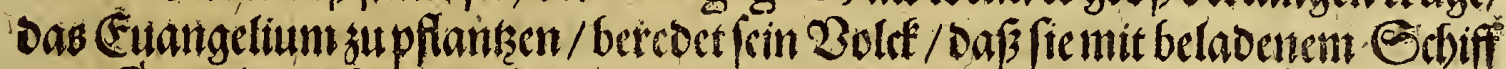

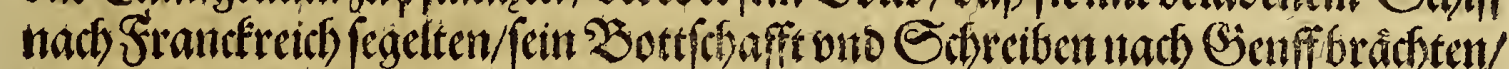

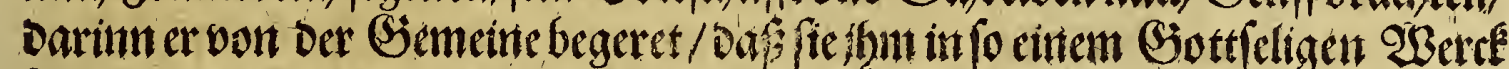

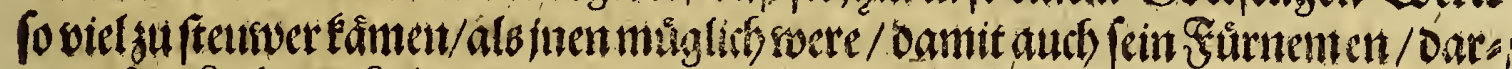

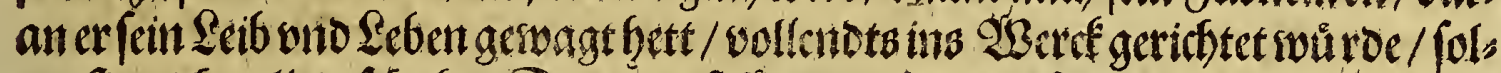
tenfie nicht allecin fothitfen Dicner of

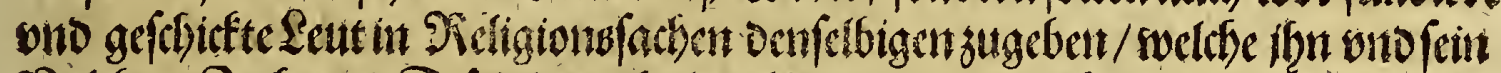

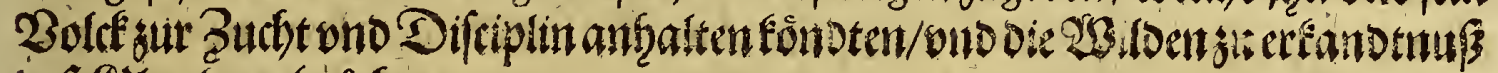
DeFBlaubchs brâchten.

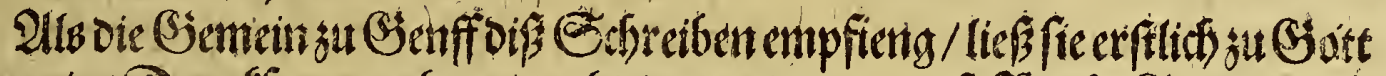

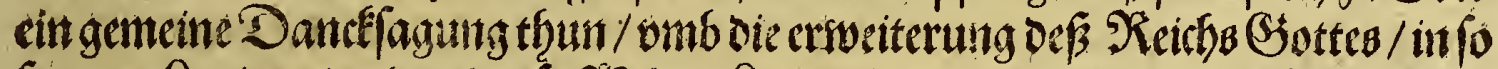

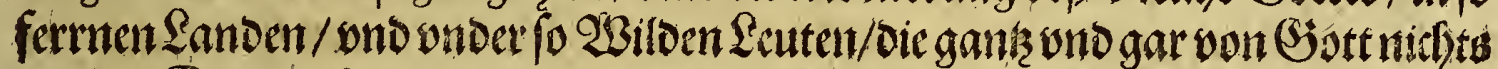

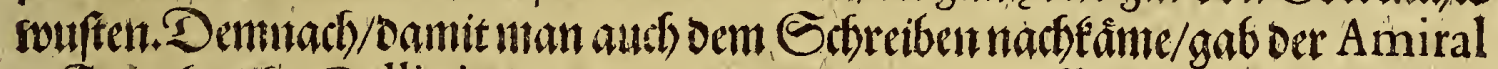

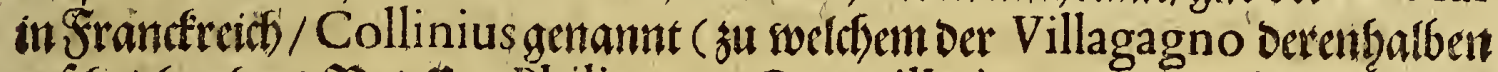

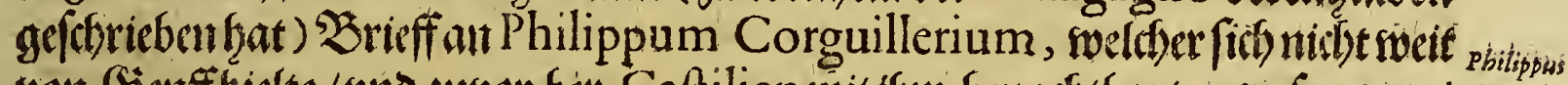

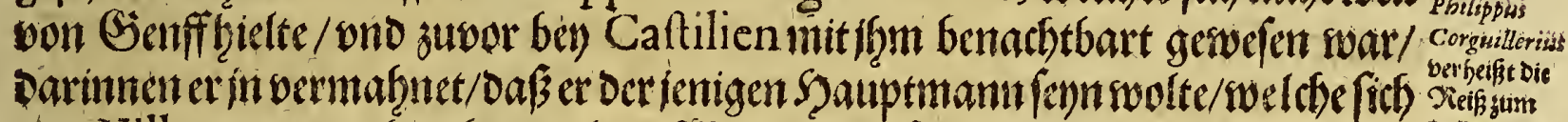

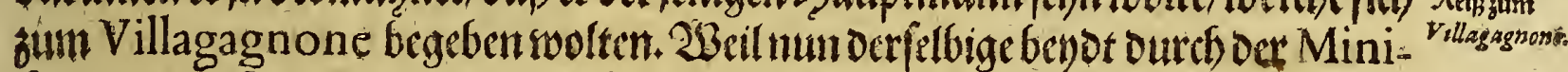

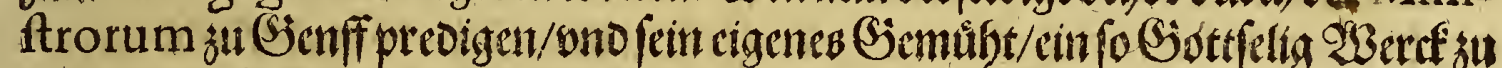

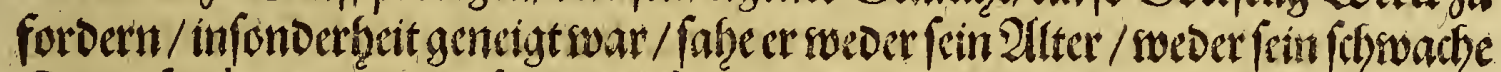

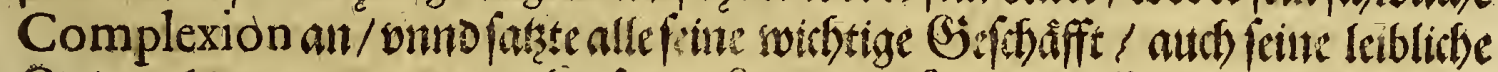

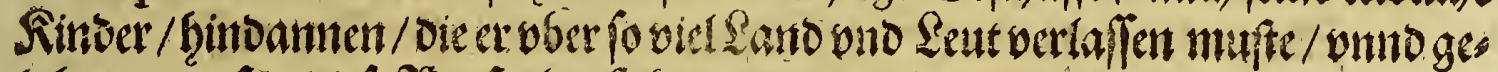

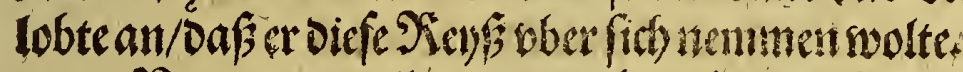

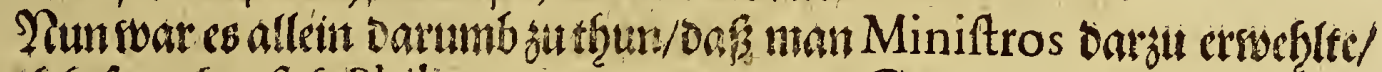

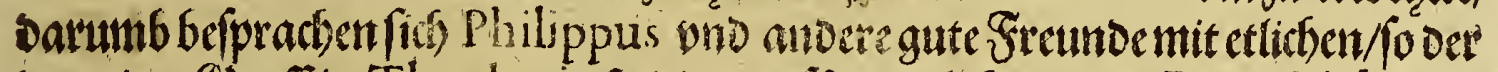

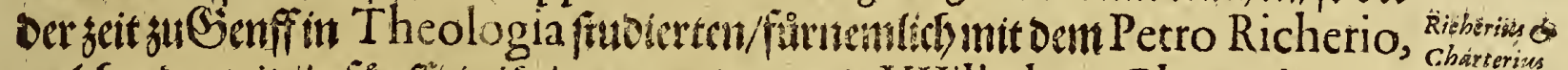

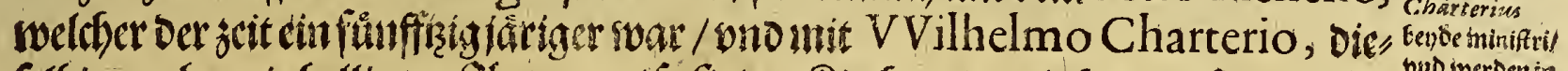

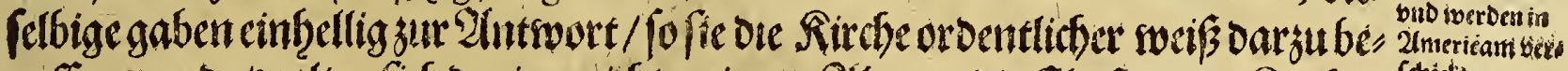

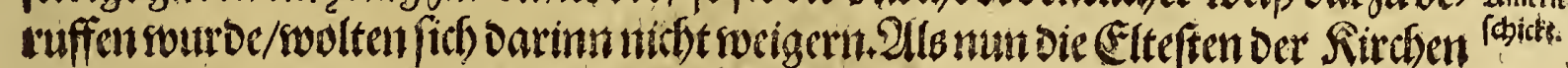
Ifrem brauth nady etliche orter ber Eefrifift gebetet batten/ wourden fie beftattis

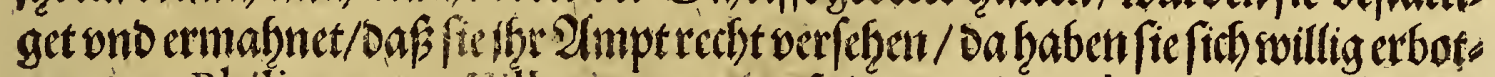
ten/Dem Philippo zum Villagagnone zu folgen in Americam/wnto da/elbfien Das Euangelium zupredigen.

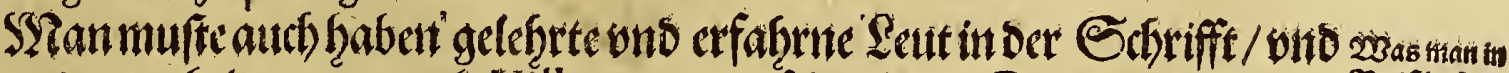

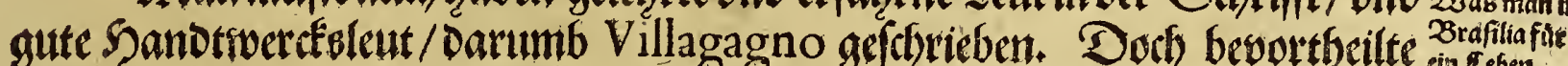

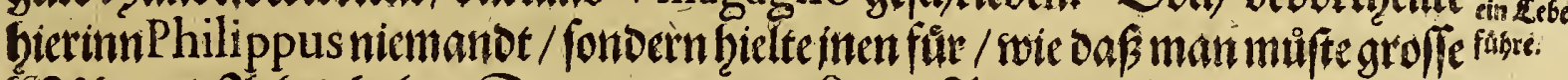

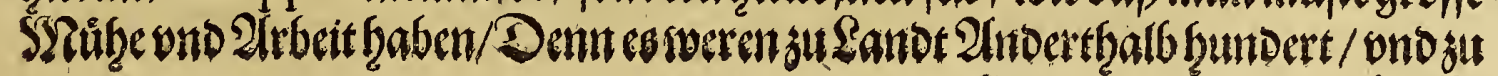

$$
\text { E. ii , } 23 \text { alfer }
$$




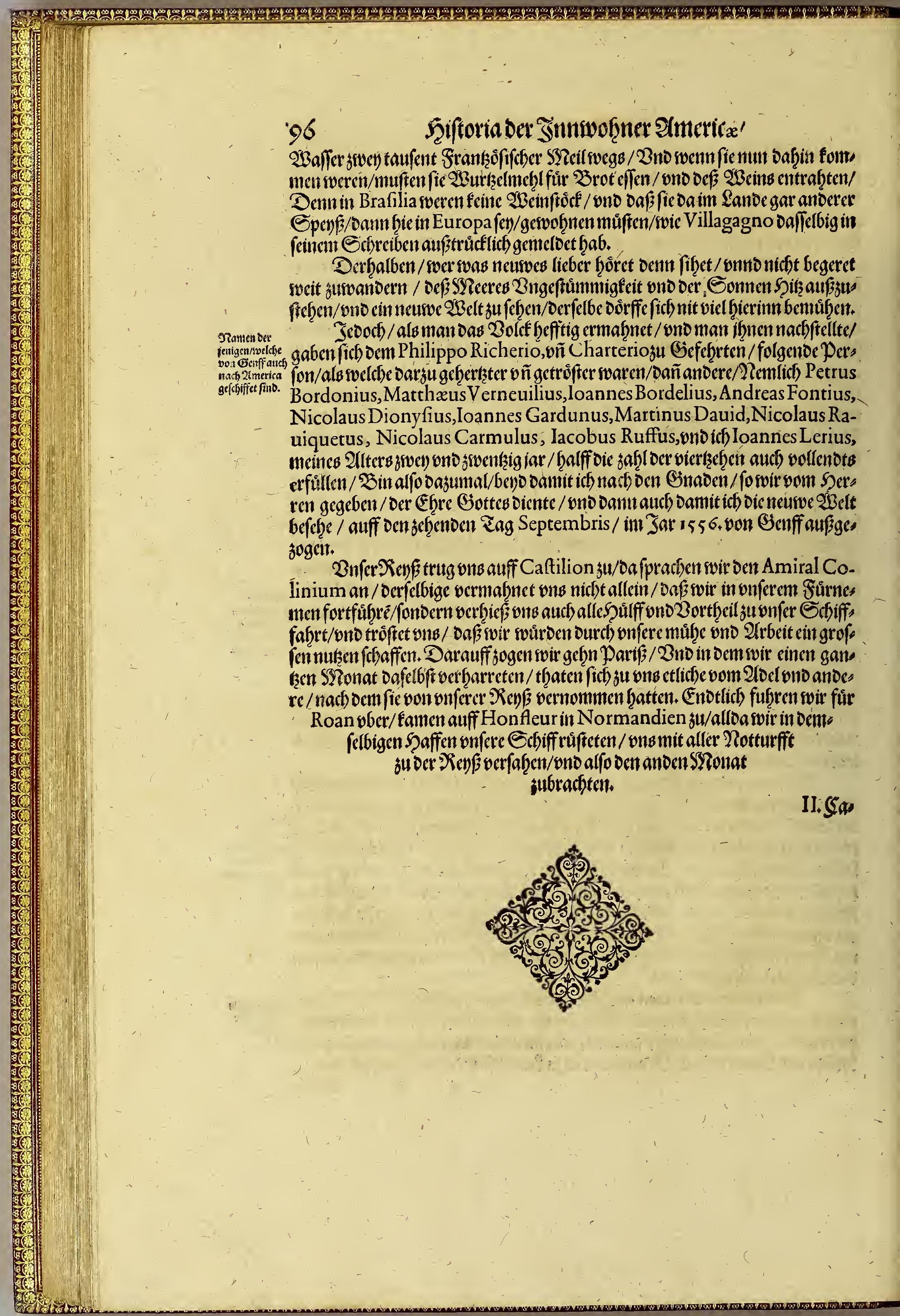




\section{Das britte ŢGed.}

II. Sapittel.

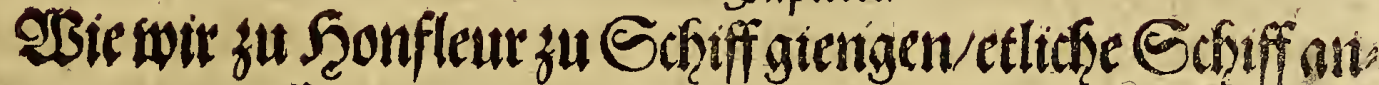

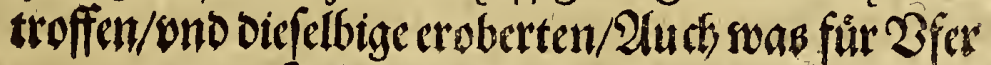

ono Jnfulen one exptuals begegnes

teri.

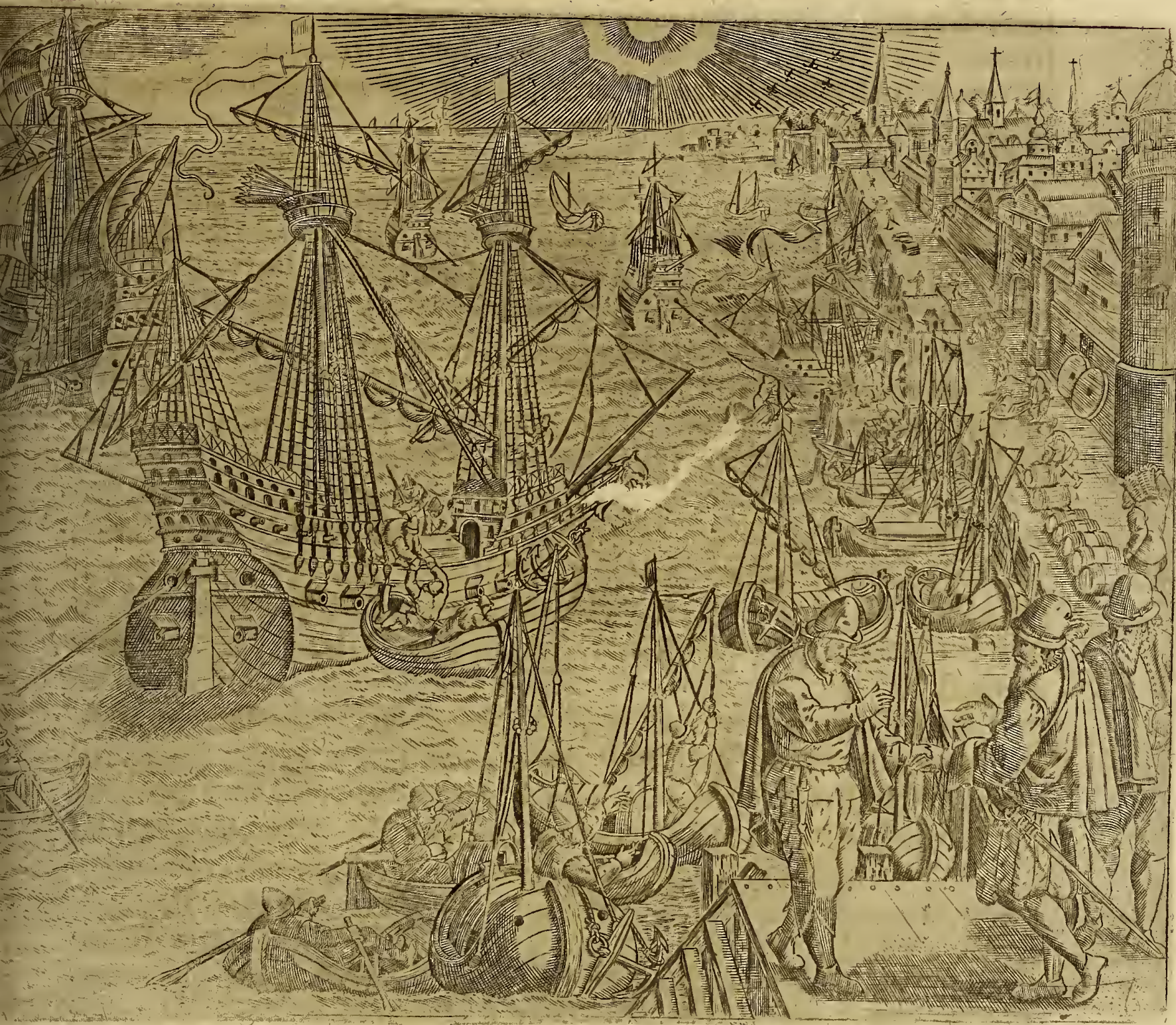

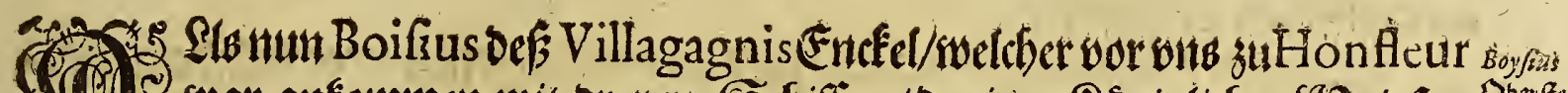

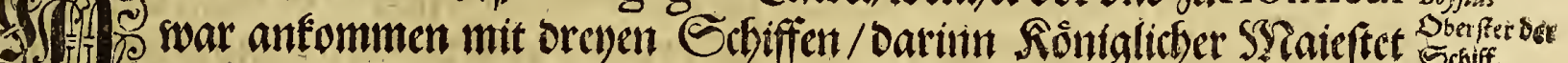

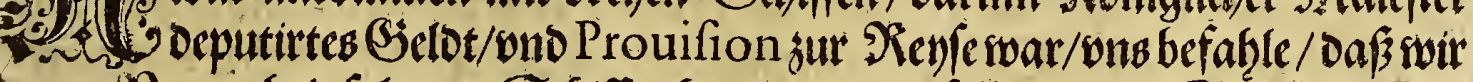

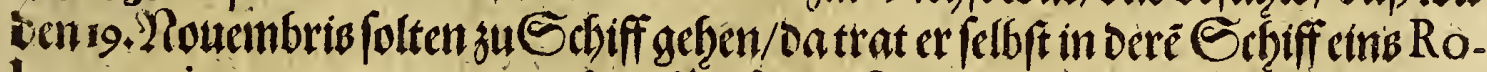

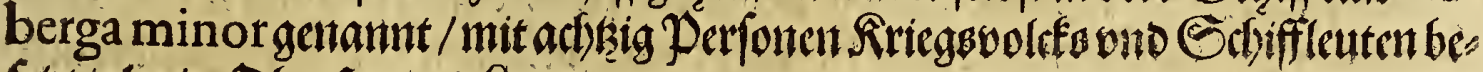
ferkt/ali ein Ober/ter who \&egat.

Imandern Selbiffgenant Roberga maior war der Shaptman Marous

$$
\text { (ii) Der }
$$




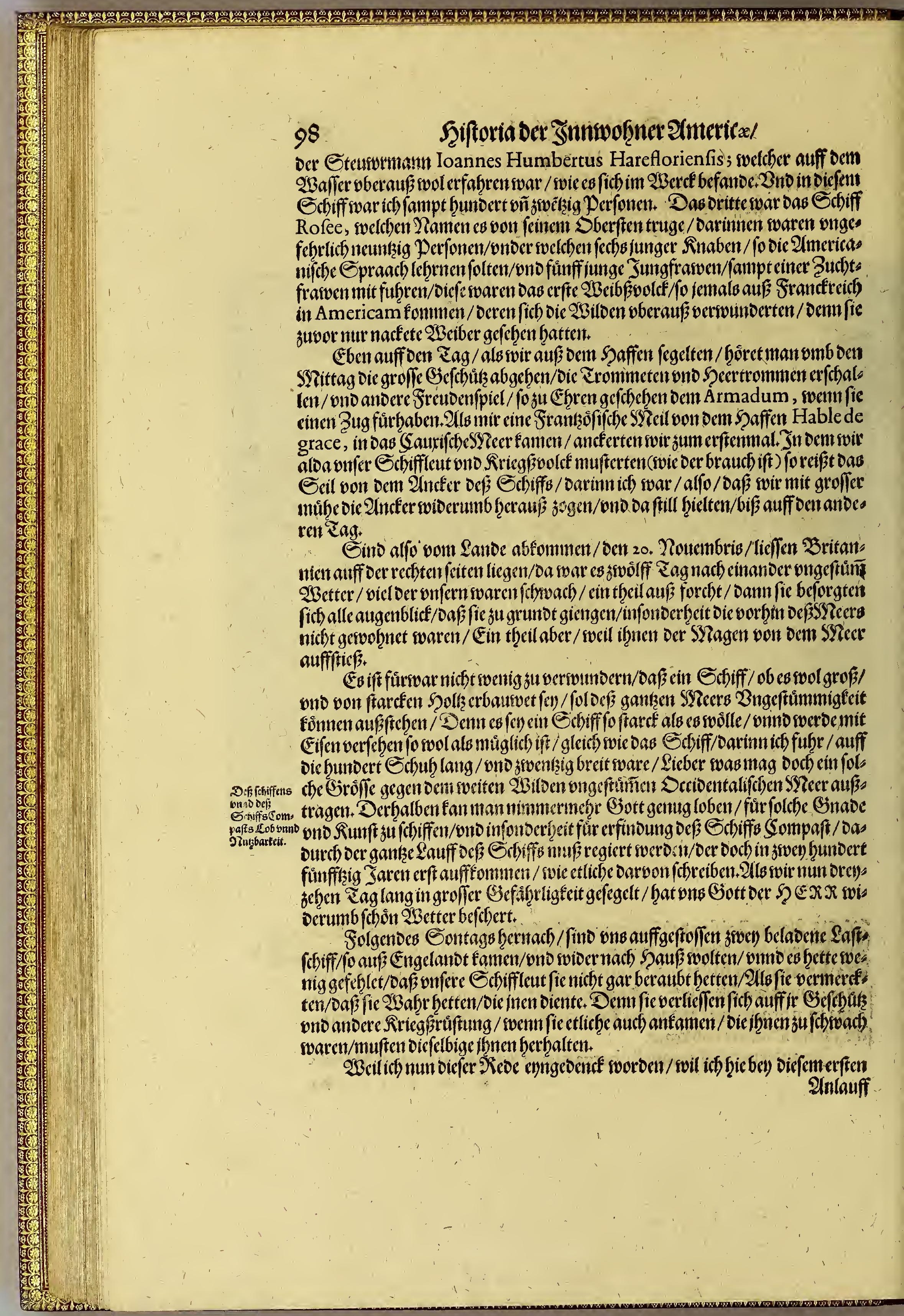




\section{Das britte Tfeil.}

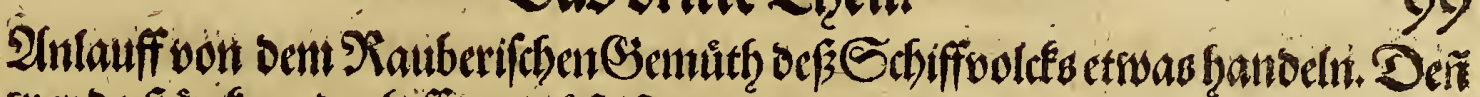

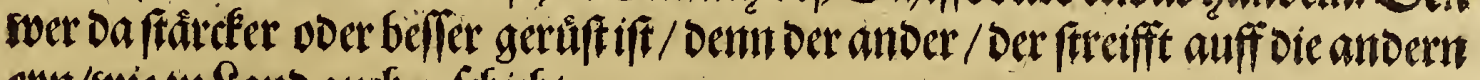
cyn/woie zu Lant auth gefohicht.

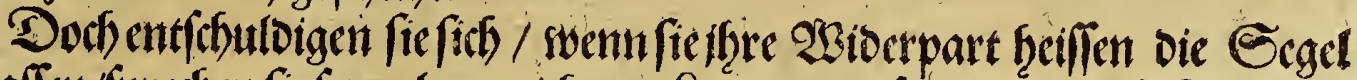

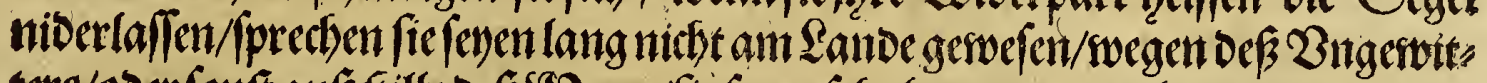

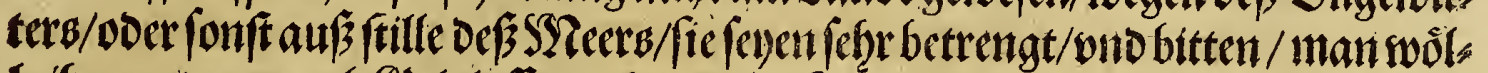

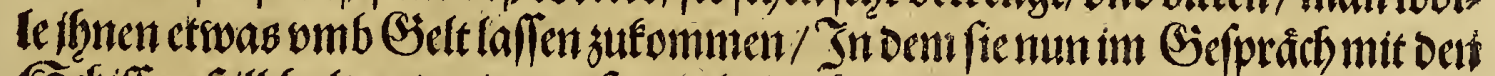
Eebiffen ftill balten/zwingen fie die befte QBabr ienenab/nentich/bamit die

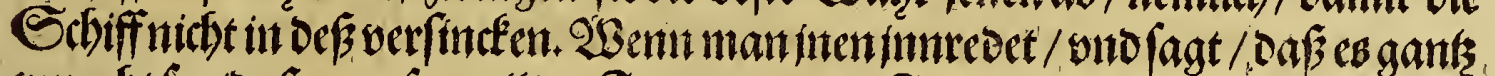

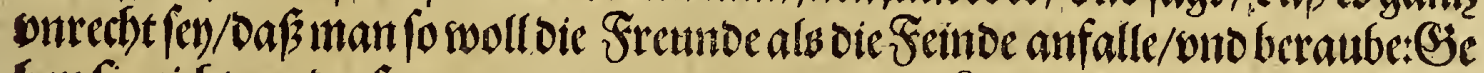

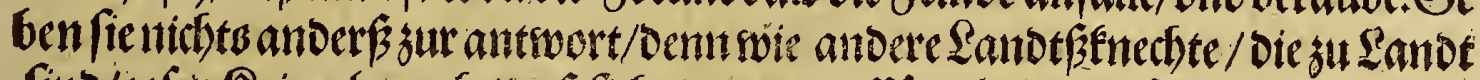

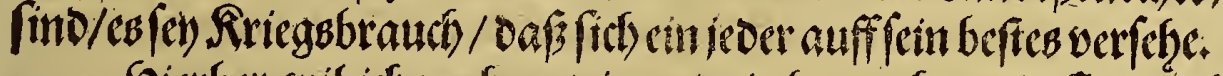

Sierbey wil ief nodl anseigen / wie hernacher mit Exempeln fol berwiefen

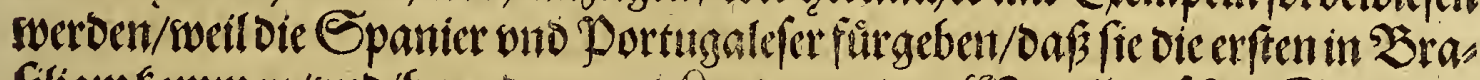

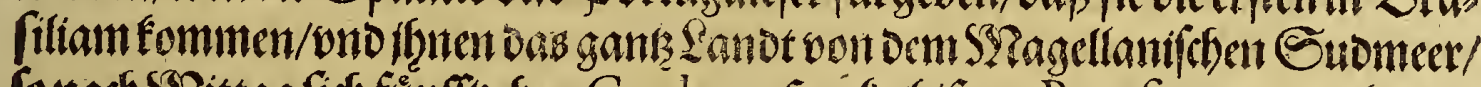

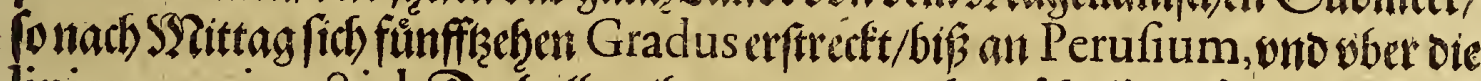

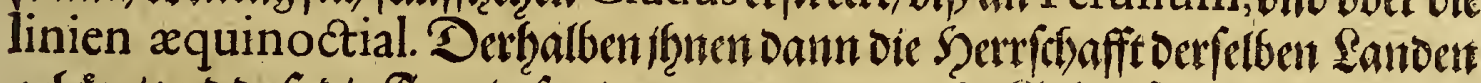

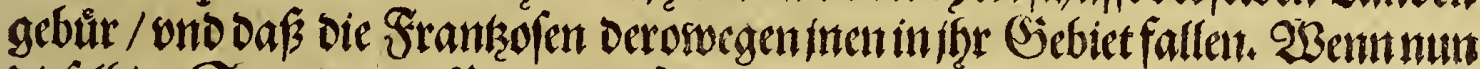

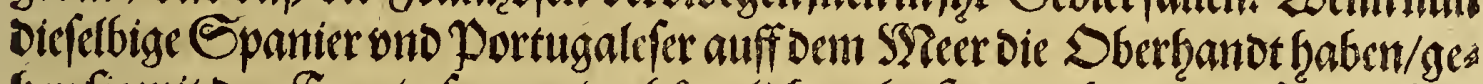

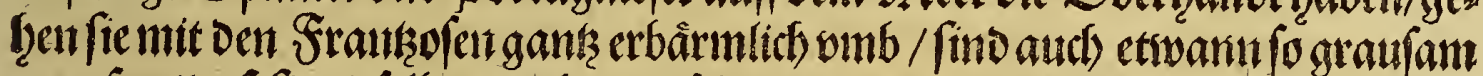

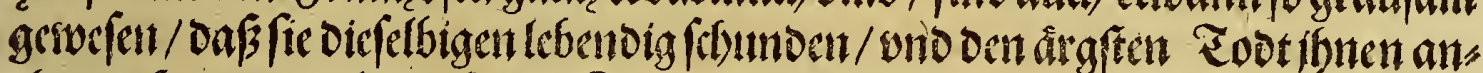

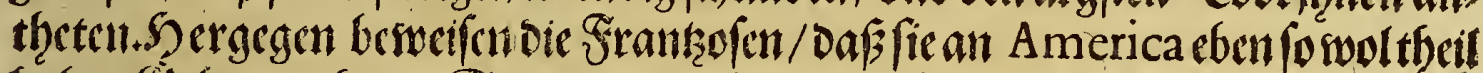
Gaben:(Sicben audb den Epantern oñ Portugalefern leichtlich nichts nach/o oer

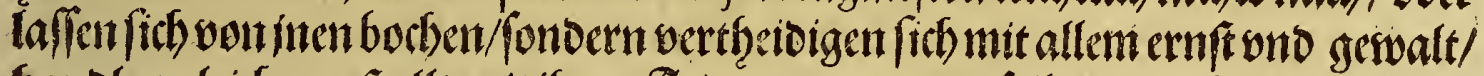

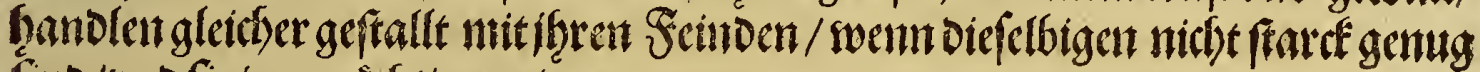
fino/vno fiefier matettignerben.

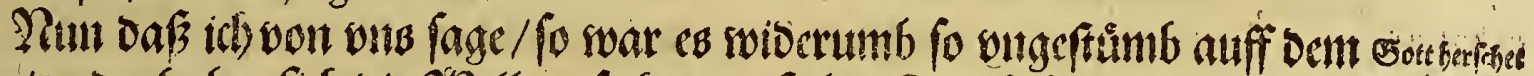

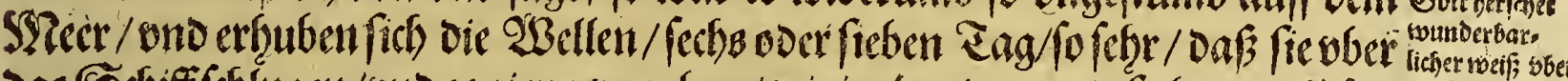

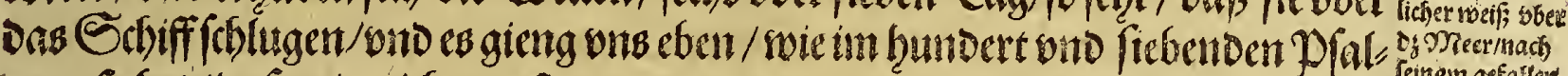

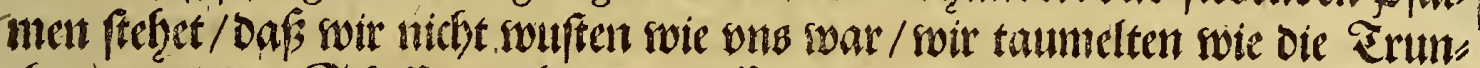

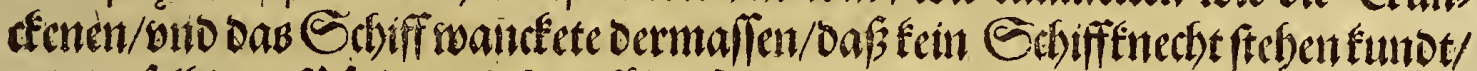

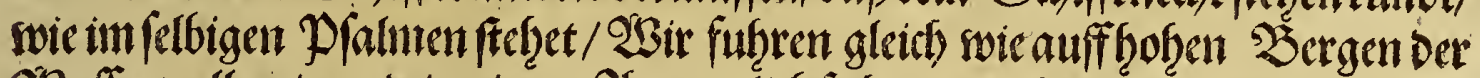

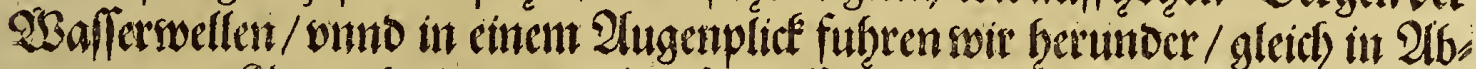

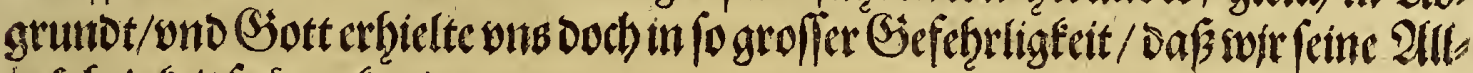
inâdbtigket ppuren fundten.

Gonun deienige/fo auffocm Shecr fabren/infogroller Gefabr/teher/lät

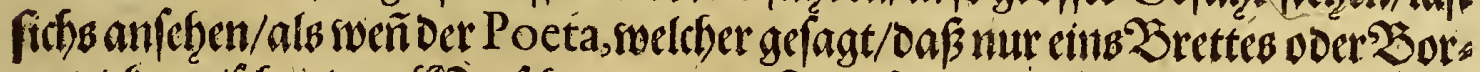

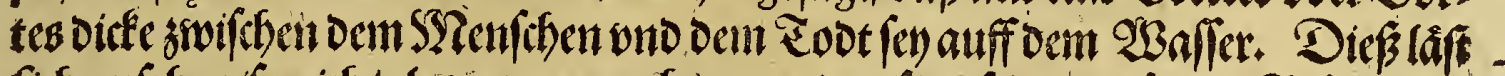

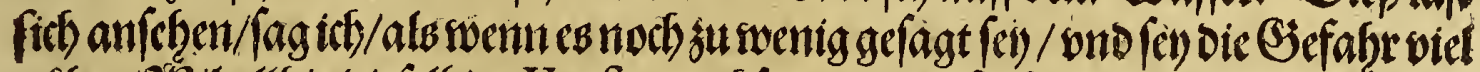

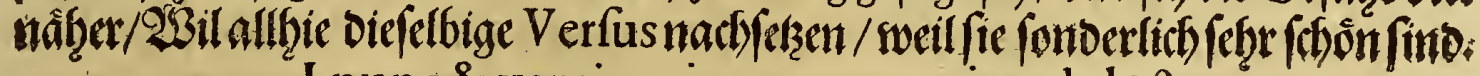

I nunc \& ventis animam committe, dolofo

Confifus ligno, digitis à morte remotus

Quatuoriaut feptem, fi fit latifima teda: 


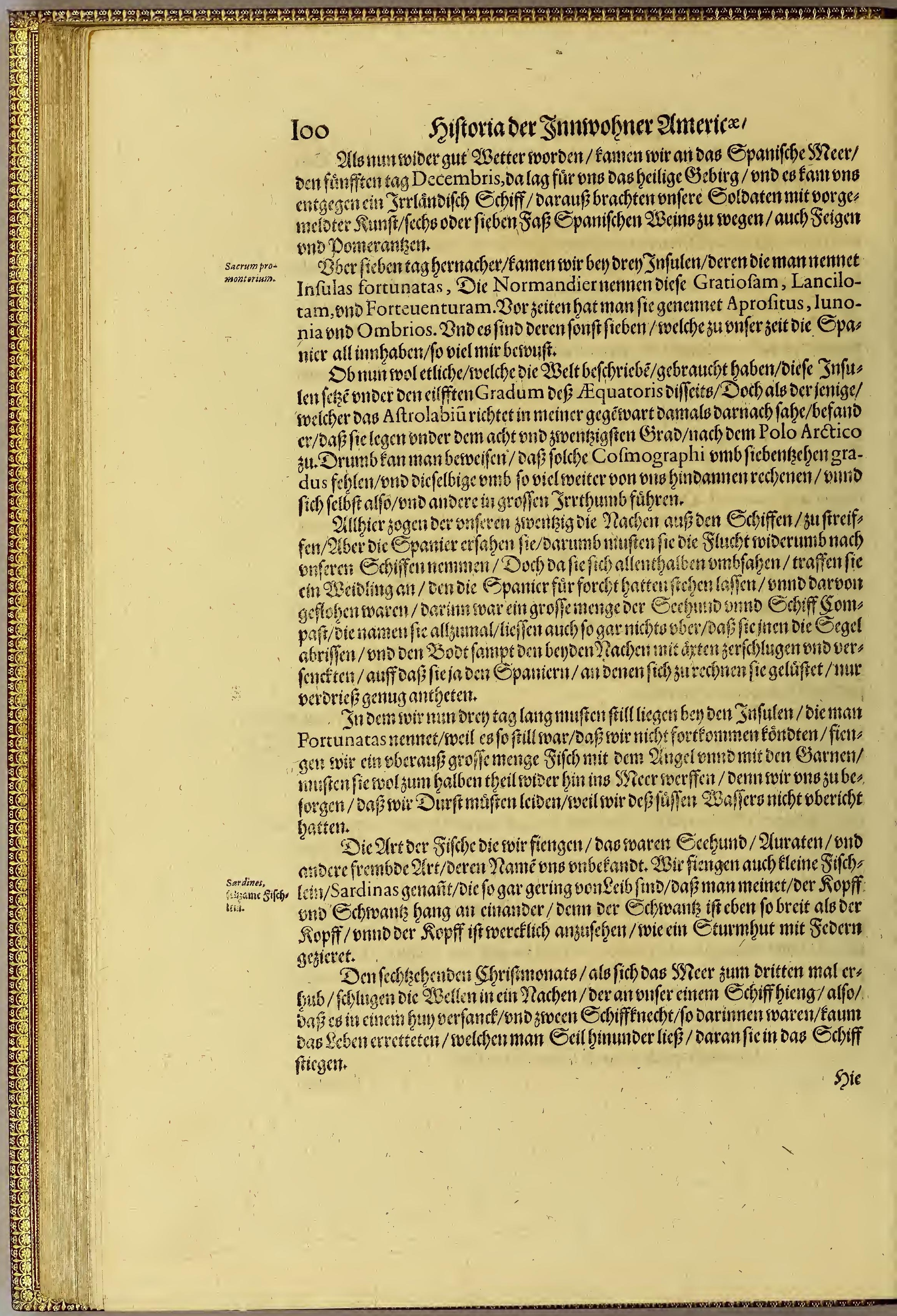




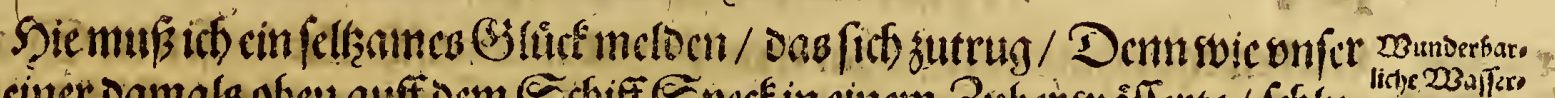

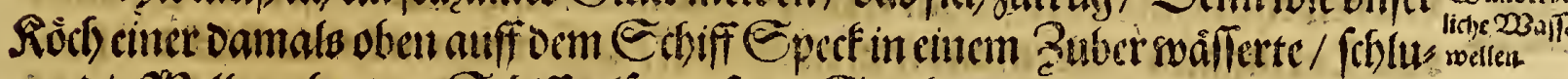

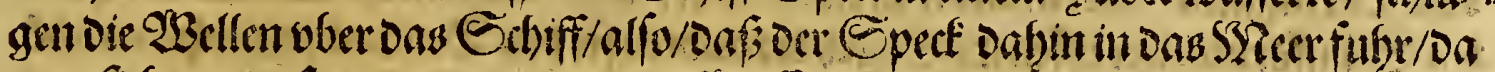

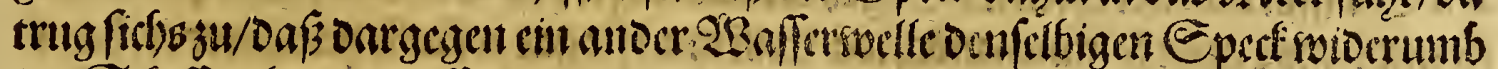

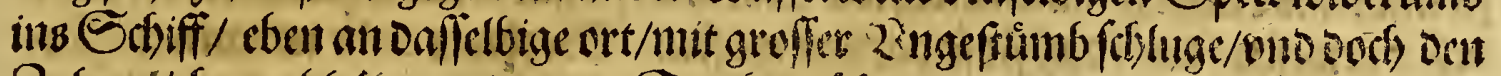

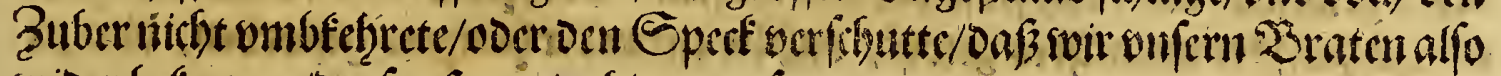
wider befamen/ocr fonft wer oabin geibefen.

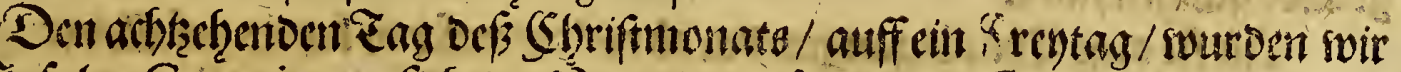

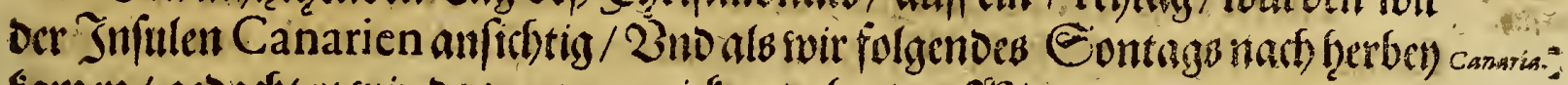

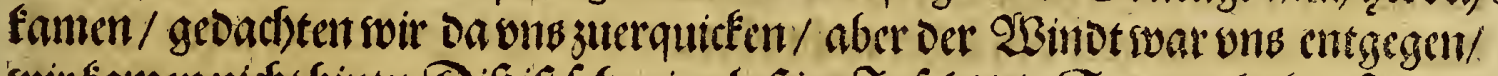

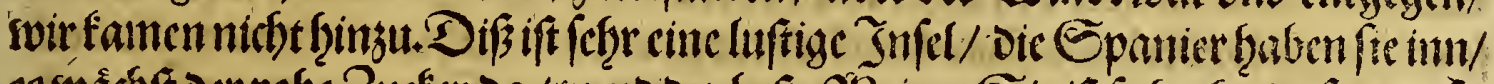

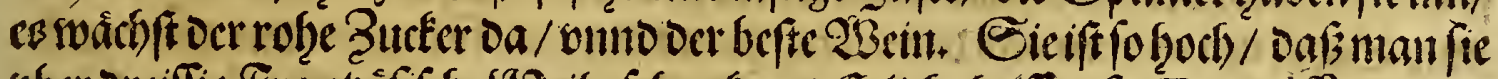

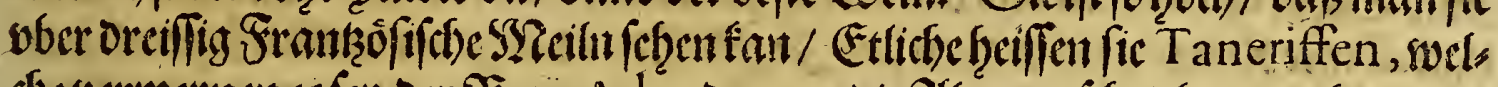

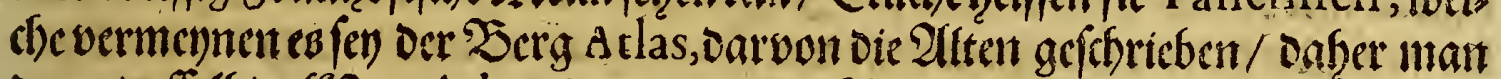

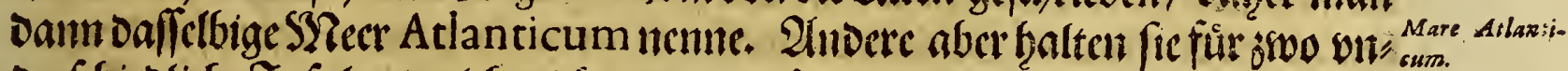

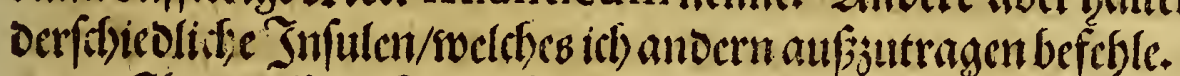

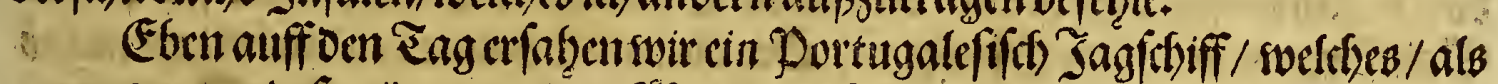

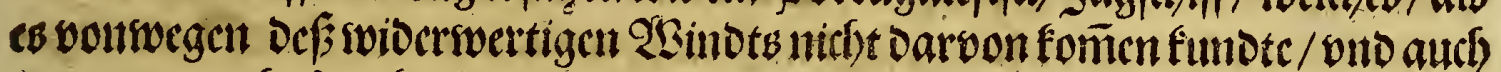

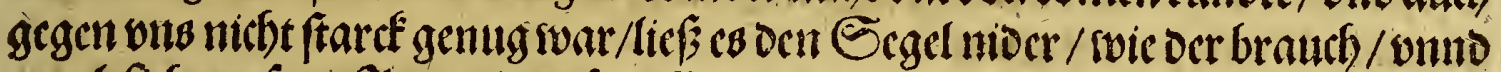
ergabfich onferm Amiral / vulere Sapitenen betten lengft gern nocl) cin Schiff - juirer Armada gehabt / Denn fie hofften immer Den Epanicn ober Dan Portus

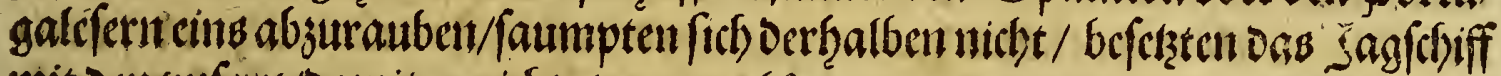

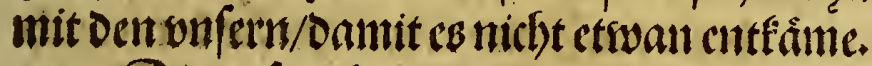

Dic bulern landelten mit oem Dortugalefer / aus wab Brfact)en aber/ift

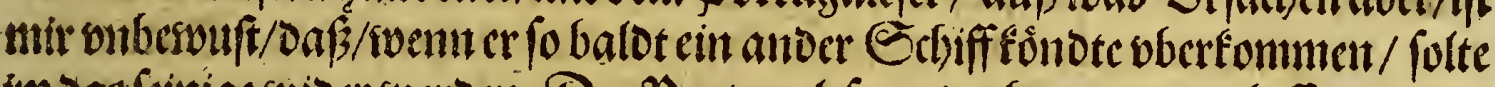

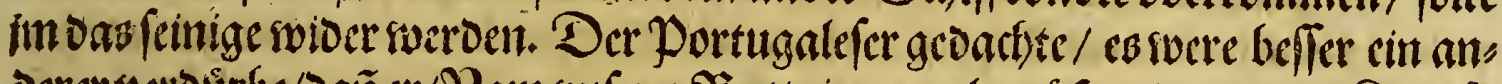

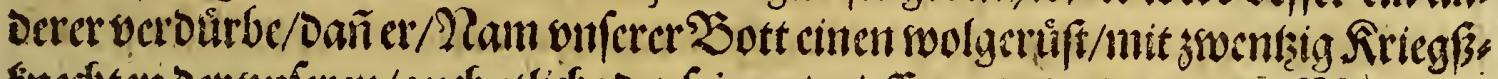

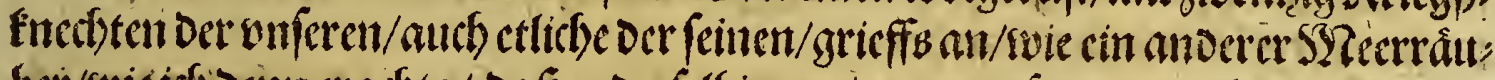

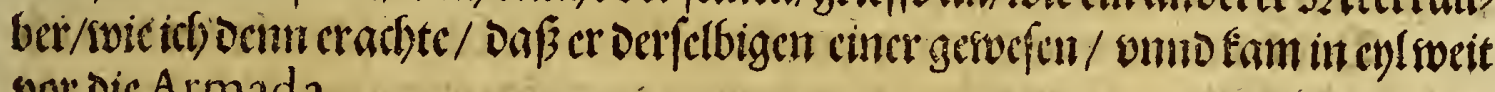
vor dic Armada.

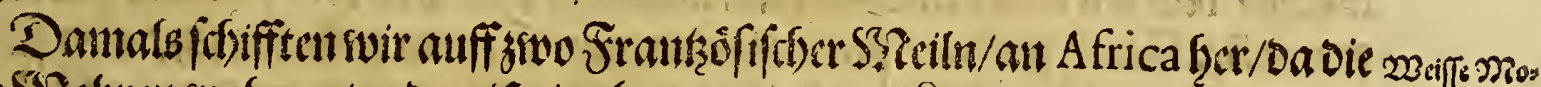

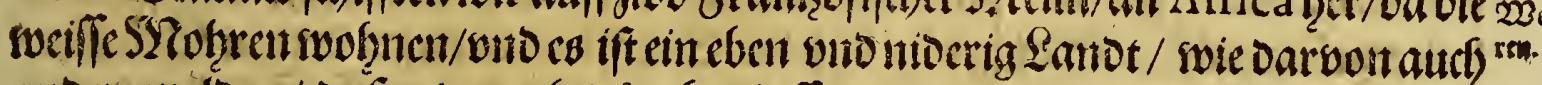

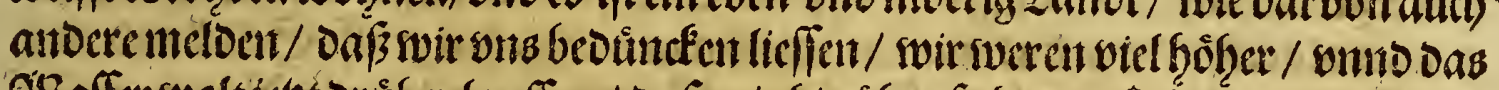

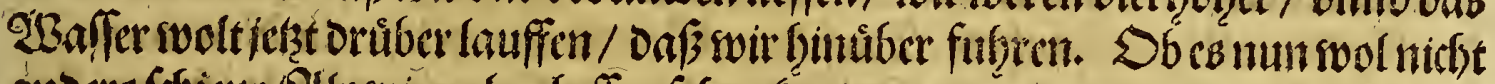

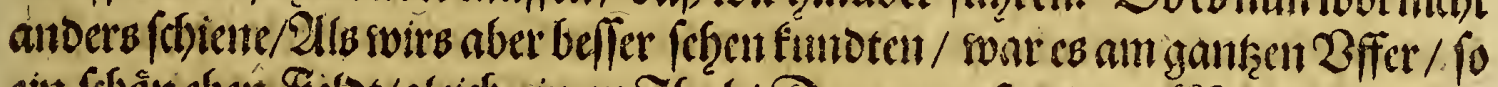

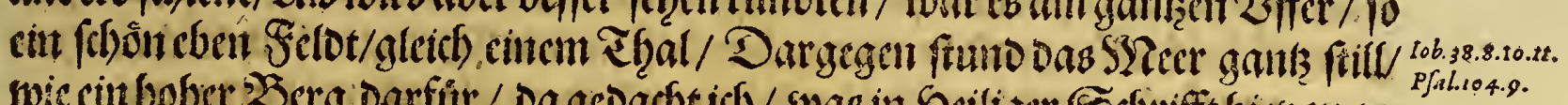

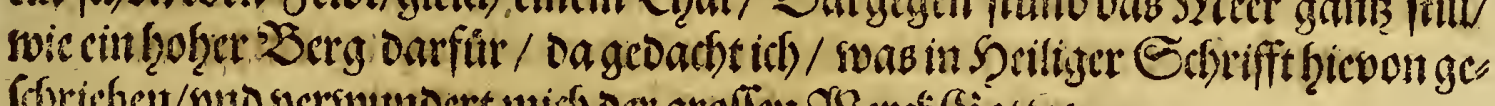

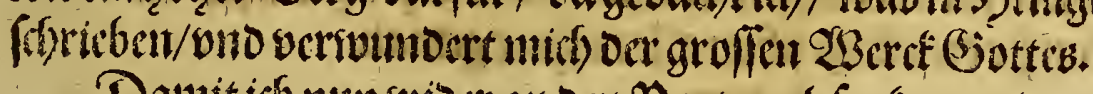

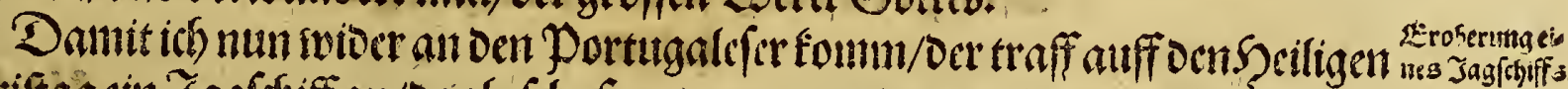

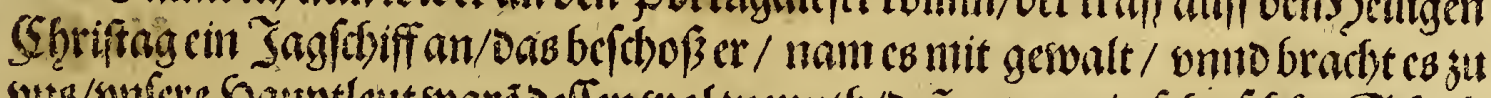

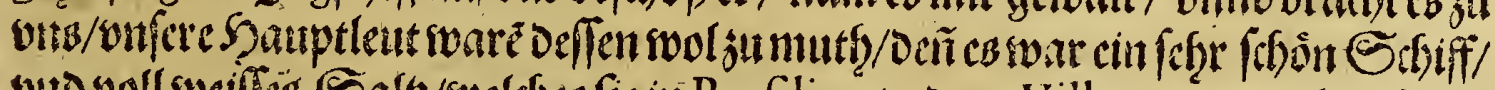

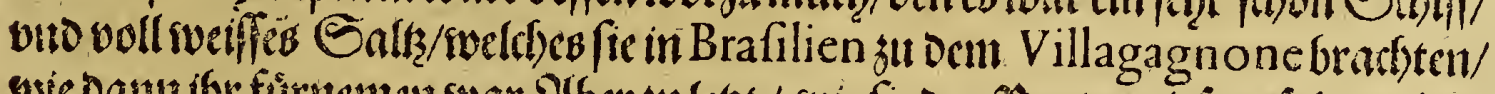

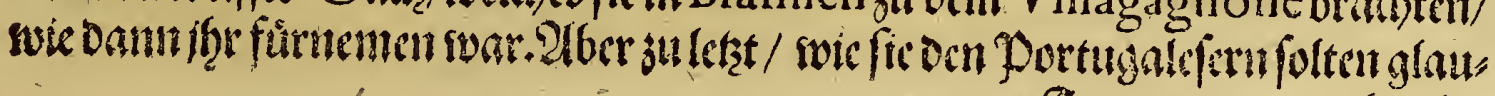

$$
\text { b. benbes }
$$




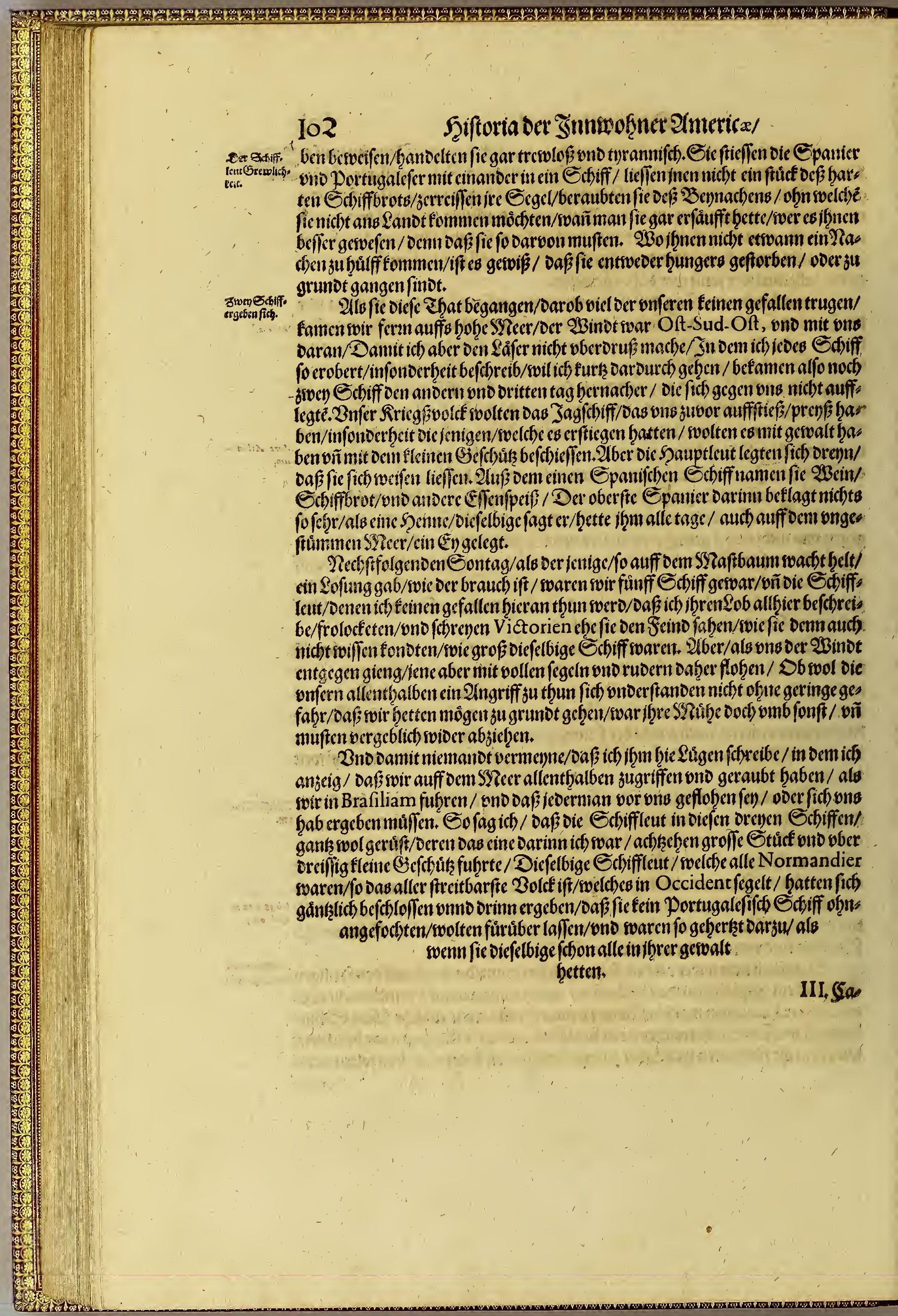




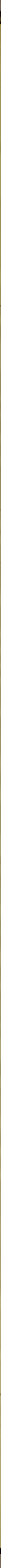


Dag brifte Thetl $\quad$ Io

III. Sapittel.

Bonden fifchen Bonitten genannt/2uch won ben 2 (lb aco:

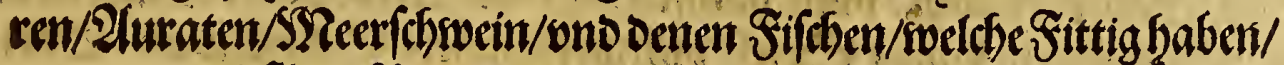

end fliegen fónnen/benen mir vnoer der Sonnen Straffenl

Zona T orrida genaunt/niche allein ge[eften/

fondern auc gefangen thas

bsm:

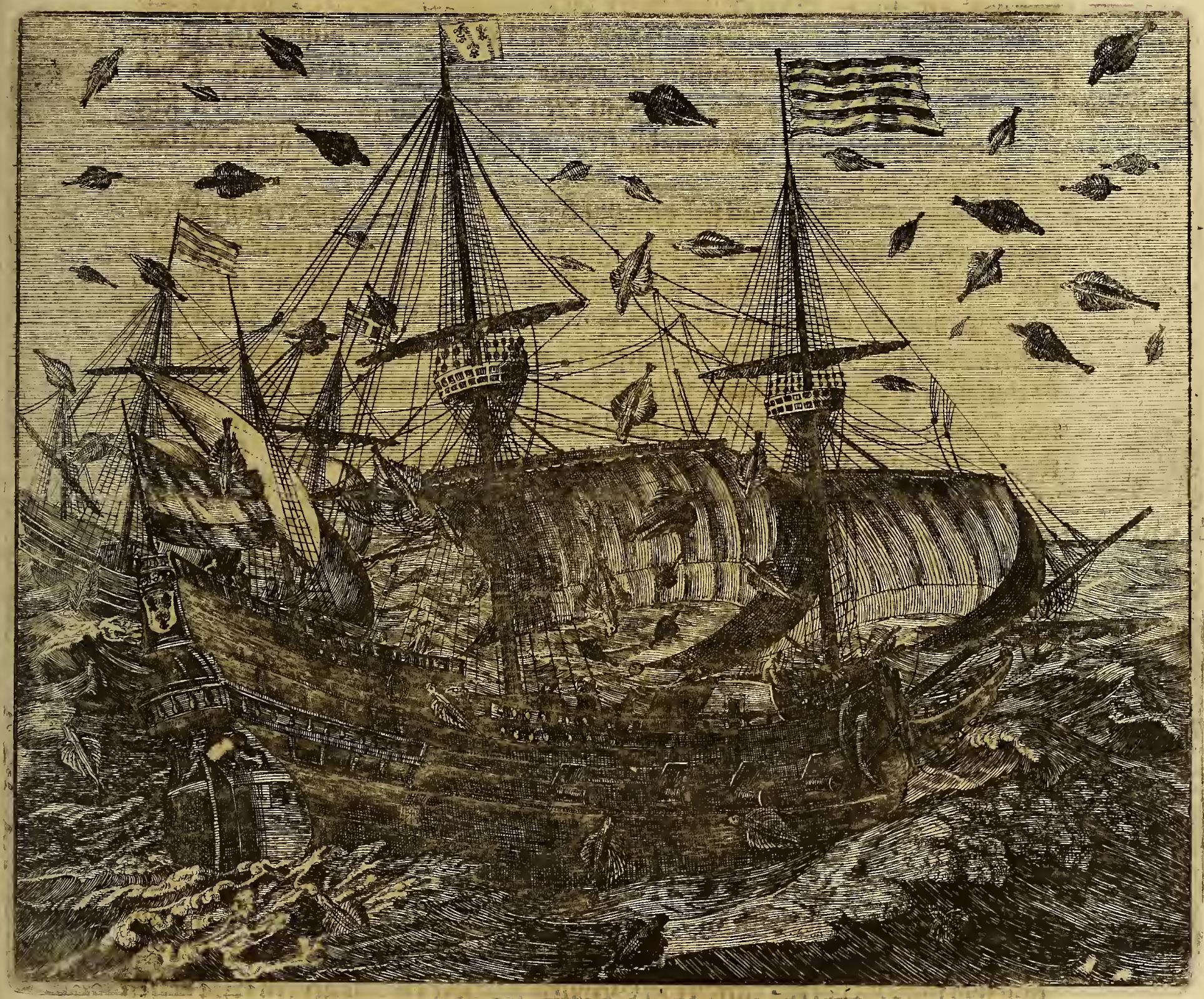

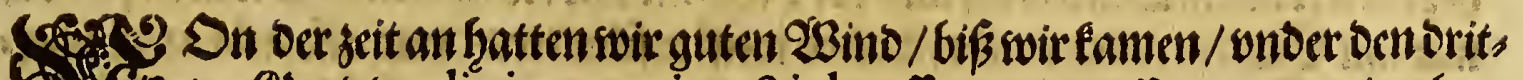

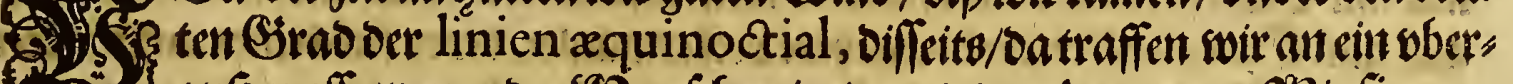

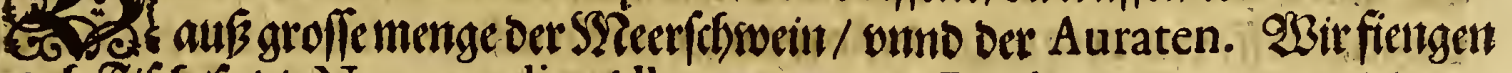
autef Sif(c)/fo die Normandier Albacoren vnno Bonitten nenttett/ ond Danut firge mit stit

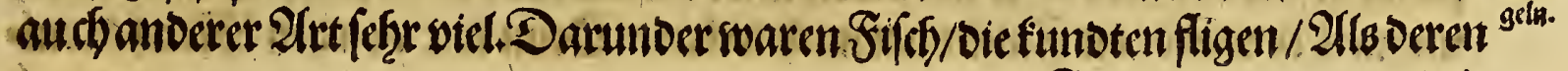
thus the 


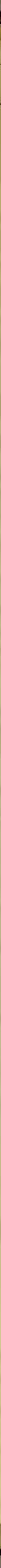




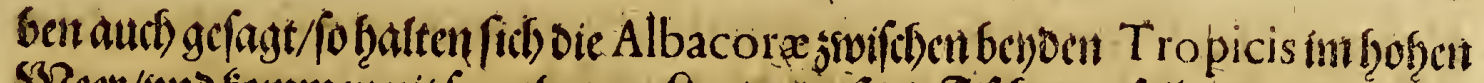

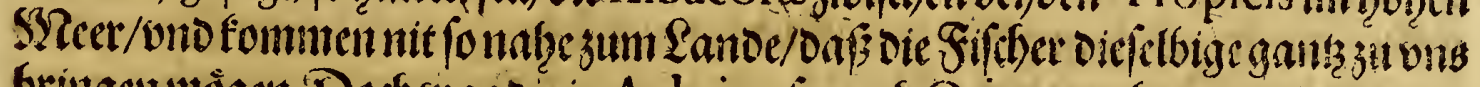

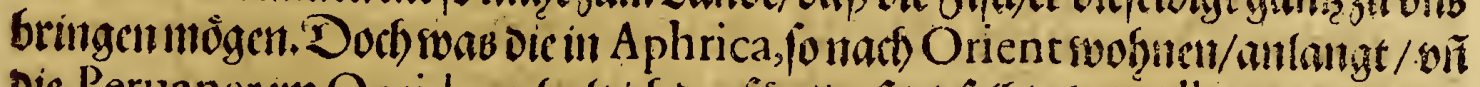

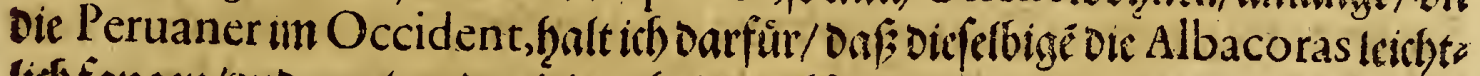
lidh fangen/onto gank zat Den irigen bringen fơment.

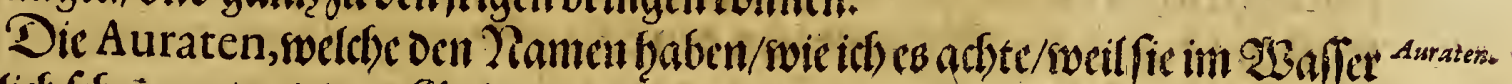

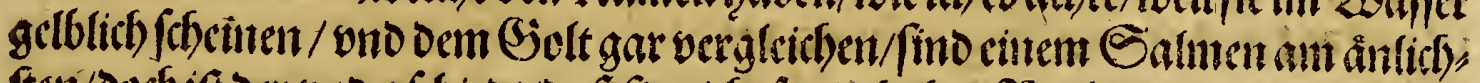

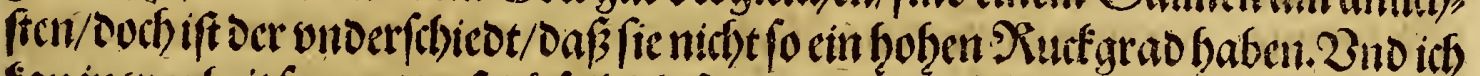

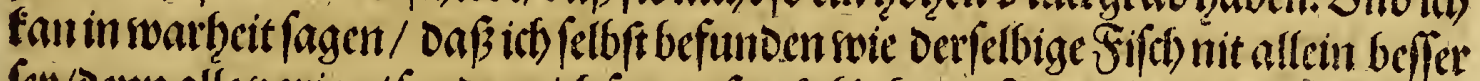

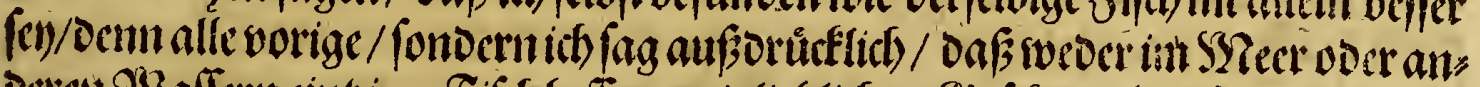

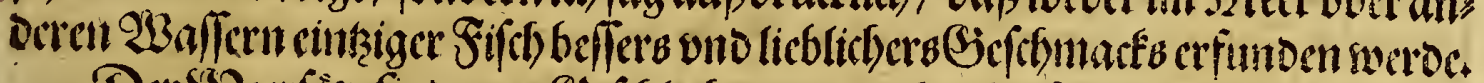

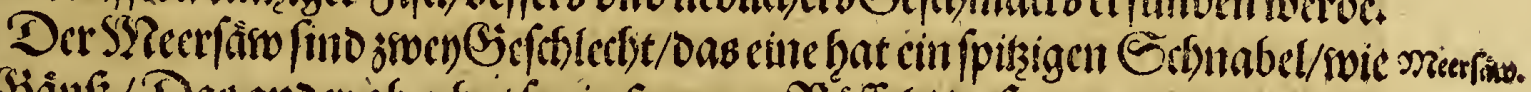

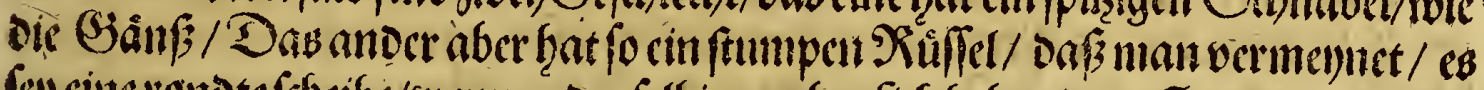

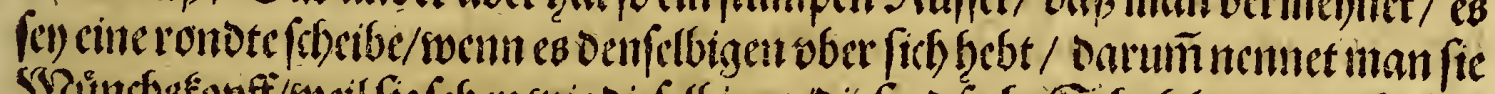

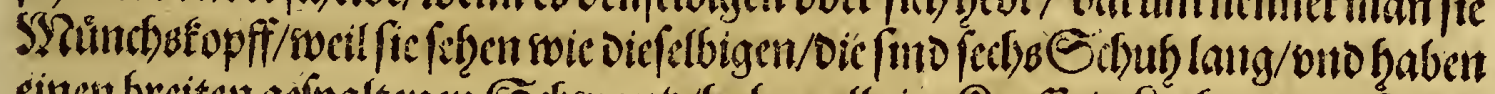

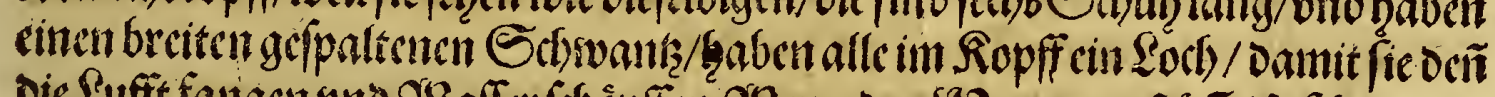

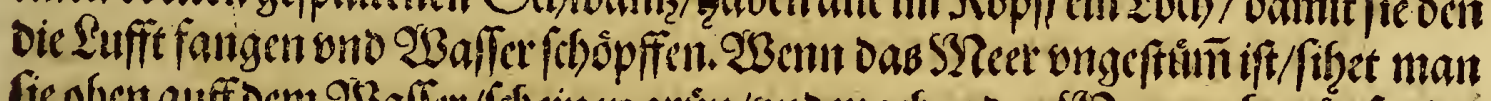

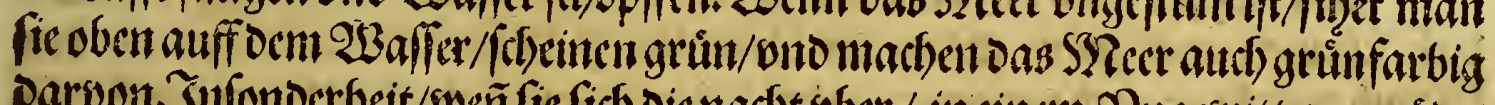

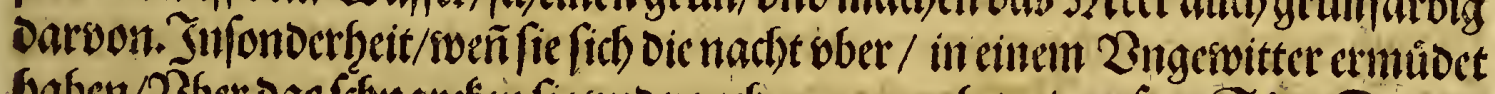

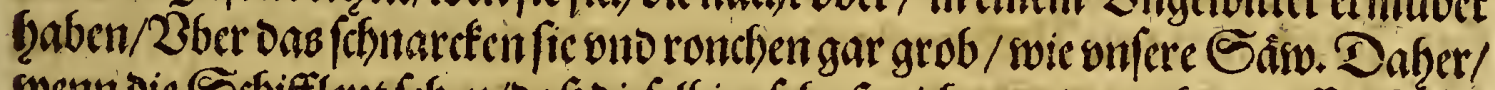

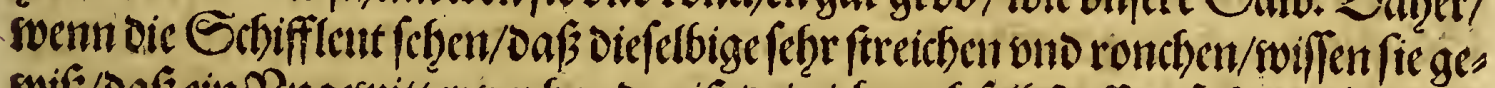

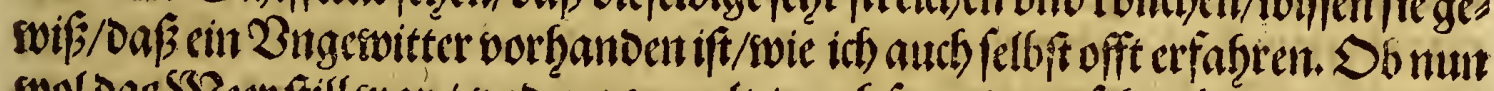

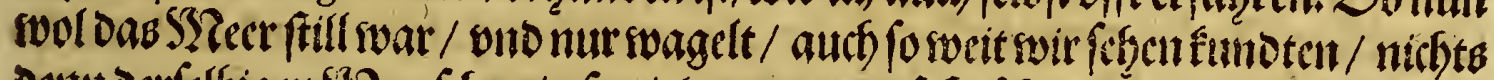

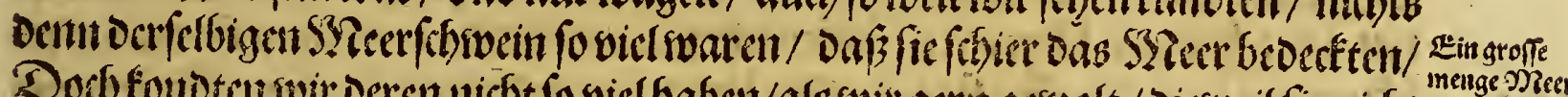

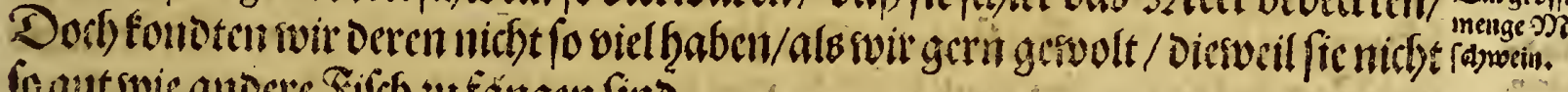
fo gatt wic andere Fif ch ju fángen fint.

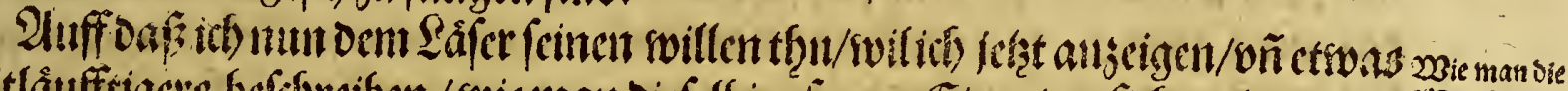

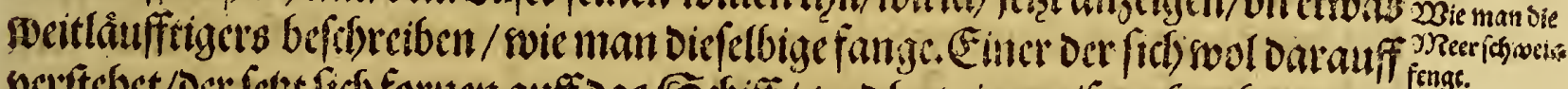

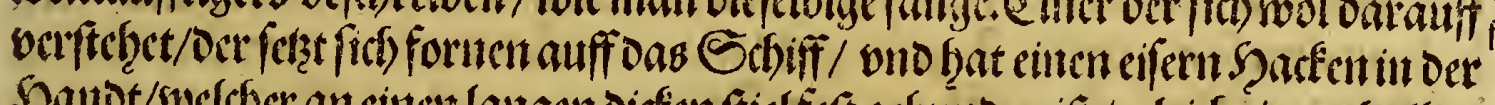

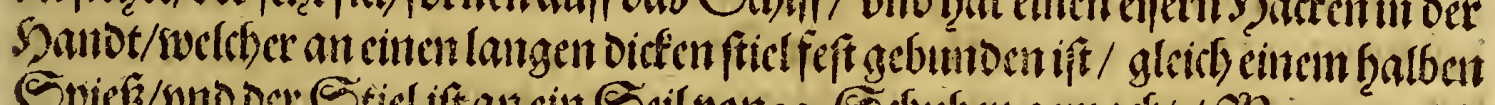

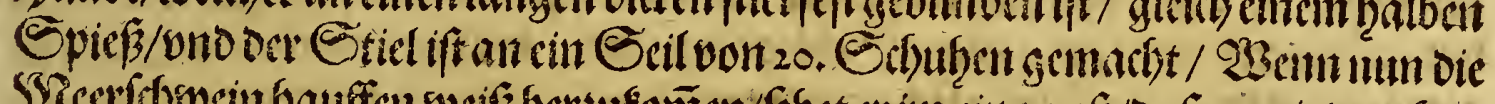

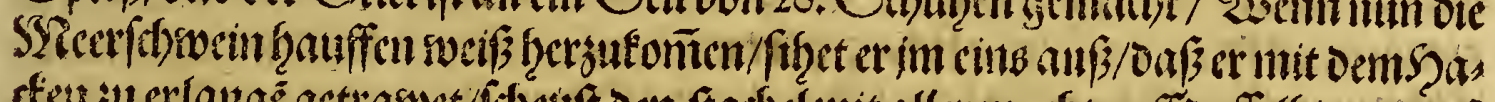

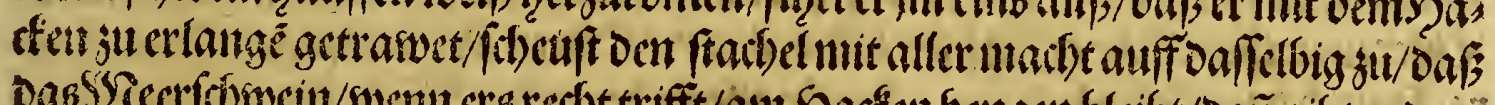

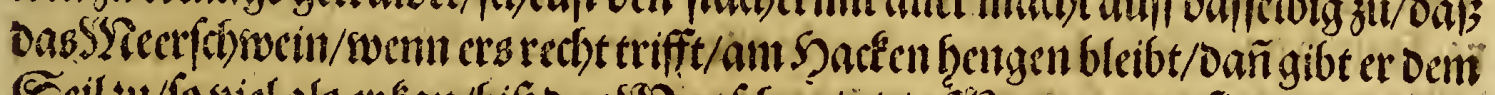

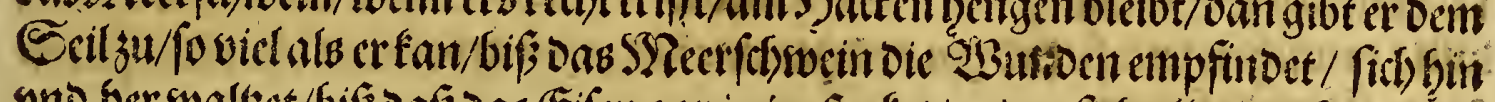

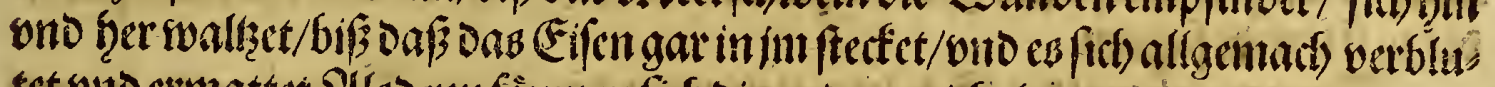

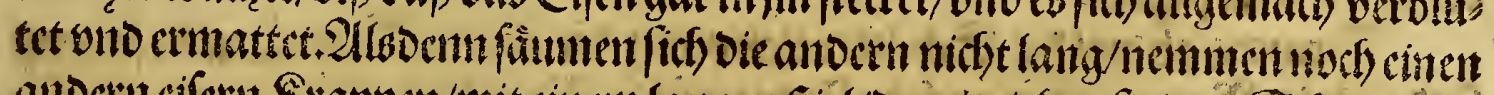

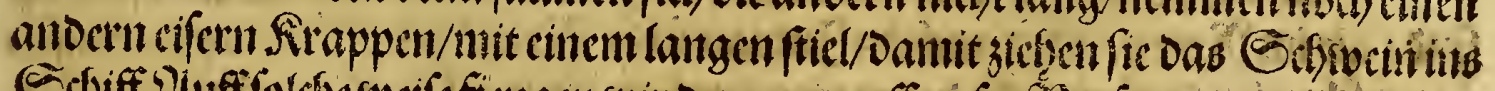

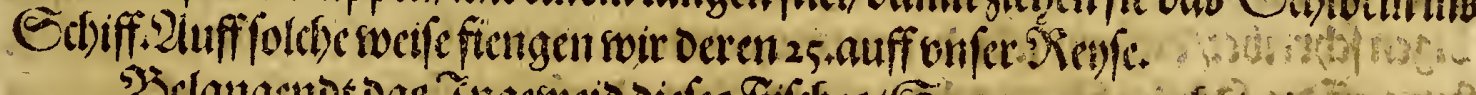

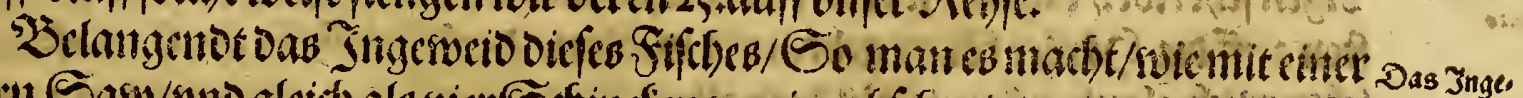

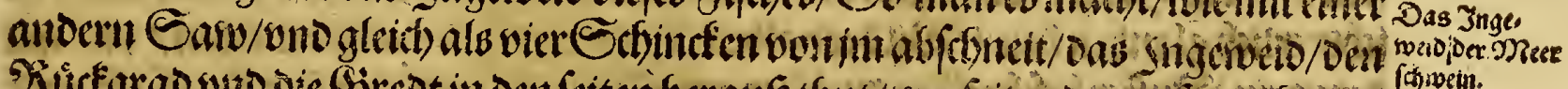

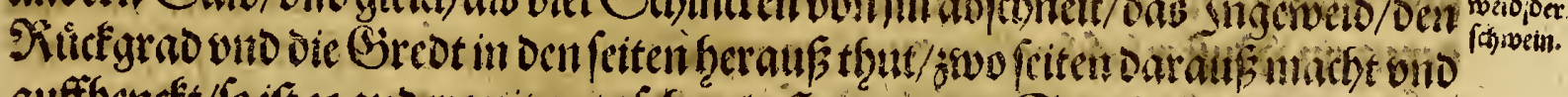

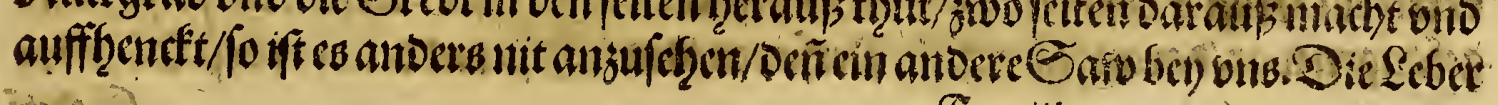

$$
\text { fiij iftebci }
$$




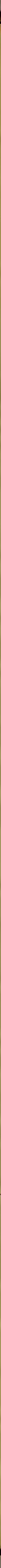




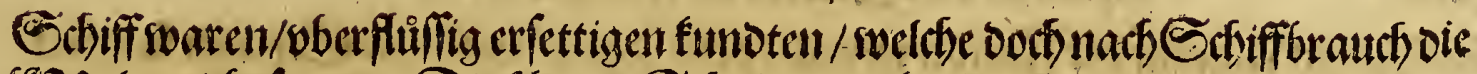

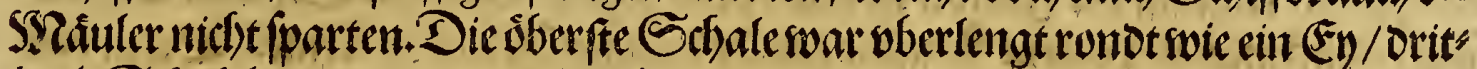

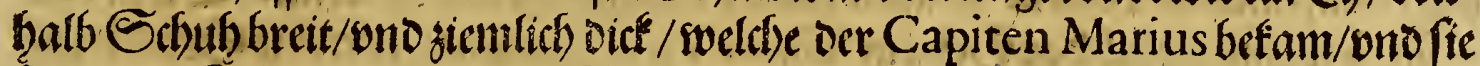

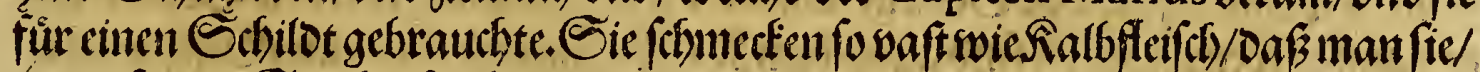

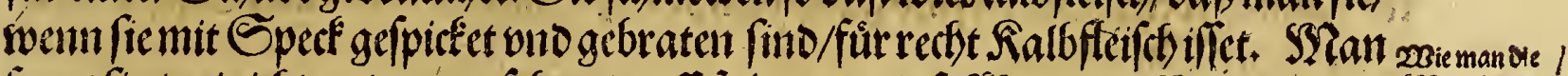

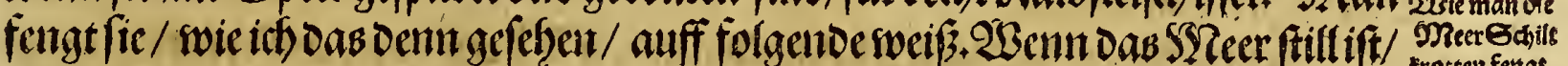

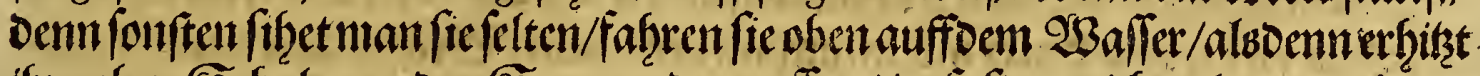
ibre ober Schale von oer Somen ocrmaflet/ oaf fie es nichterleioen mögen/

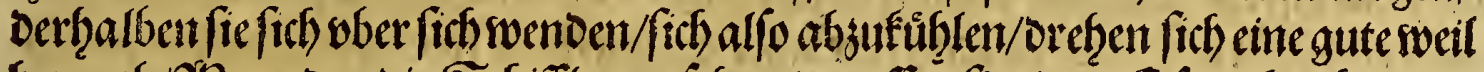

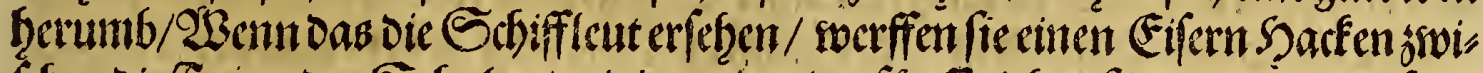

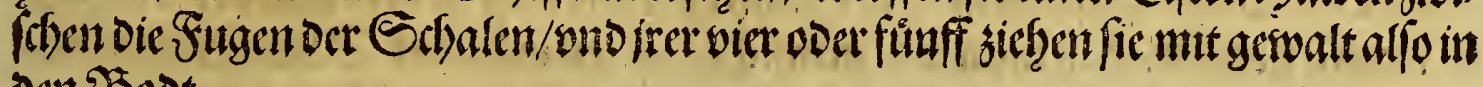
ocn Bodt.

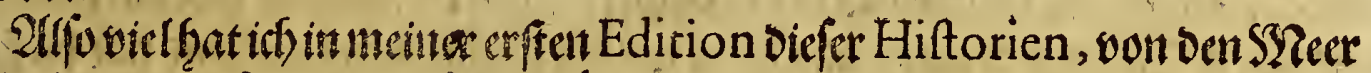
Edrilotfrotten geforieben / Sber Theuetus beweif biemeifterlich fein bohen

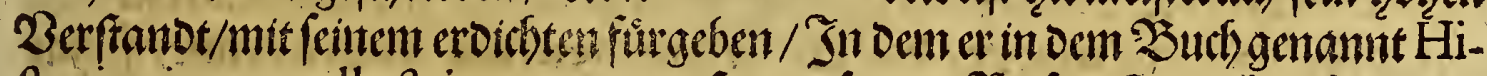
ftoria virorum illuftrium, oa er oef graufamen Riefen Quoniambeci ges Dencfet / im 2lifang oiefes Commentarij mit folgenden gants ongereimpten

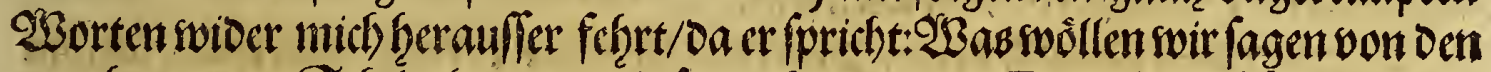

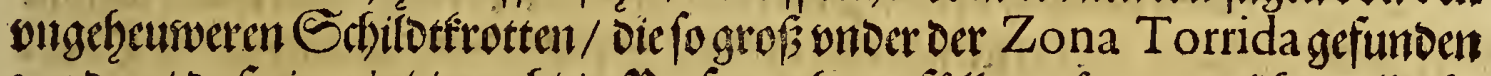

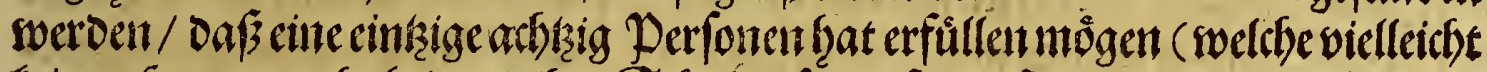

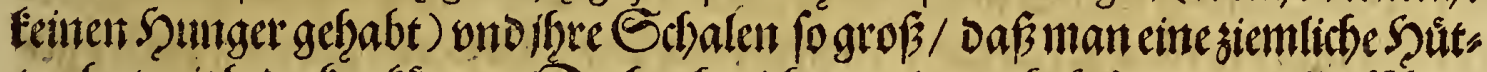

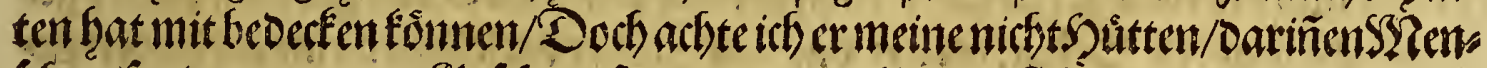

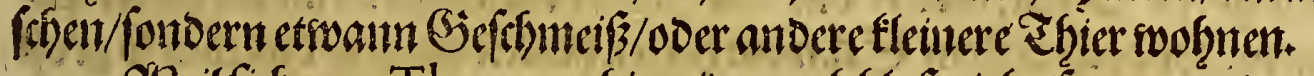

QBeilfiefonum Theuetus fie fwioerumb blof gieb//fomager immer fo fort

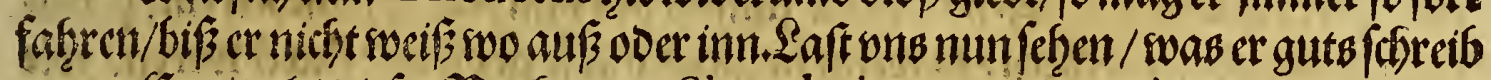

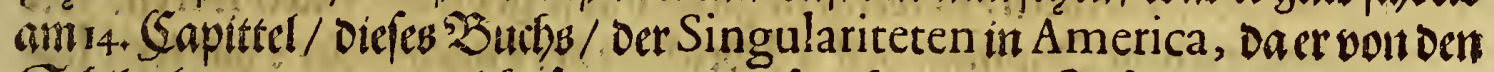

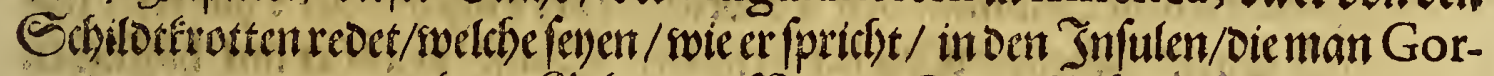

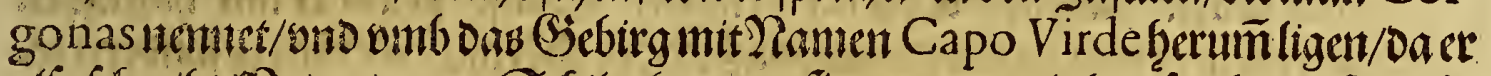

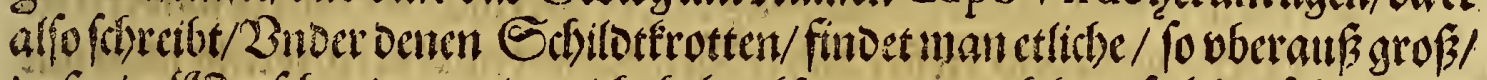

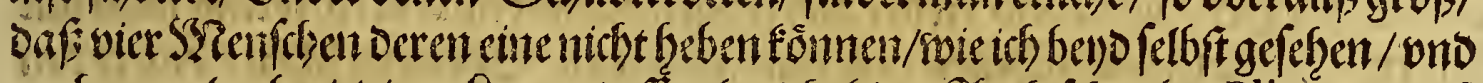

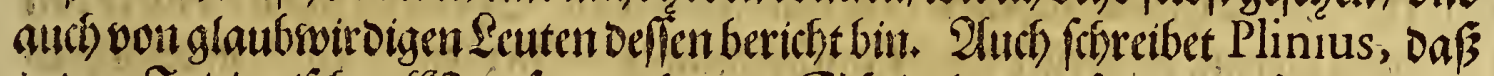

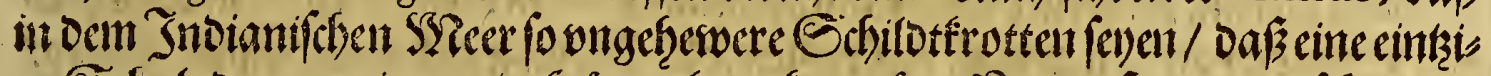

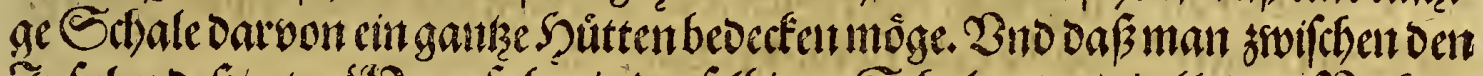

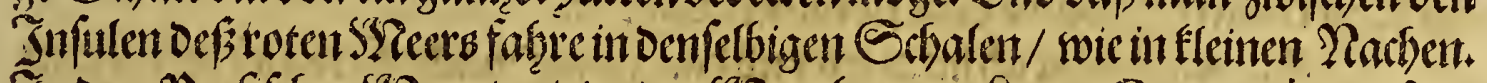

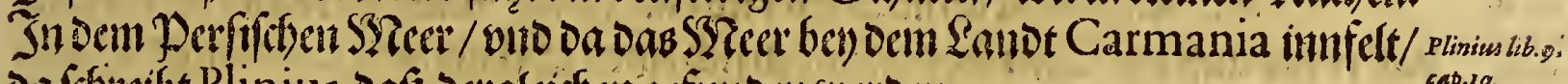
Dafefretbet Plinius, Daf bergleichengefundenswerden.

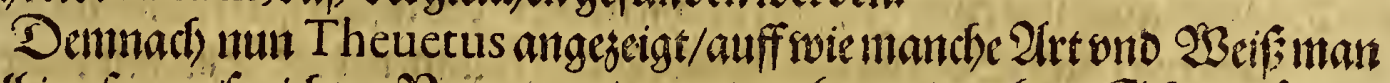

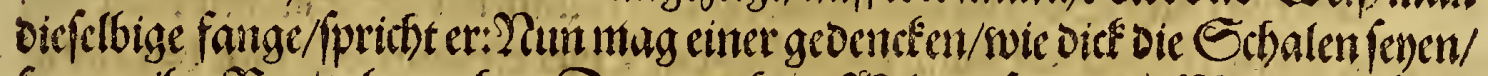

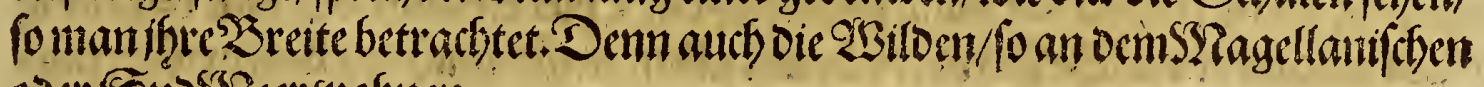
ooar Eubsyecrivofnen.

Gitciclar geftalle braucben biefe Schalen die Amazones, fo an bent

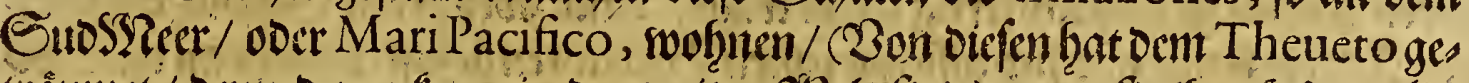
trân 


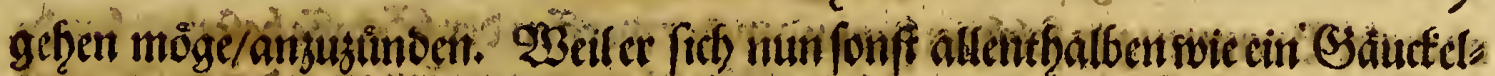

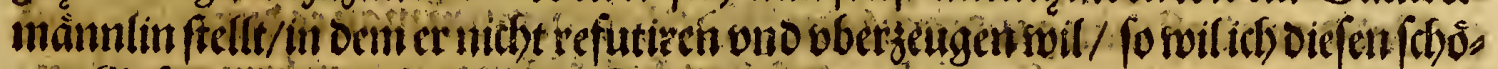

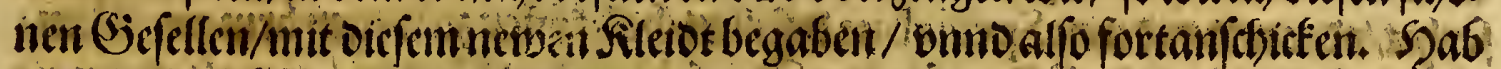

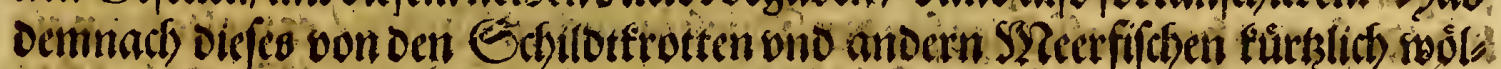

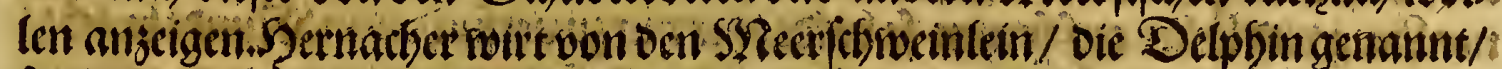

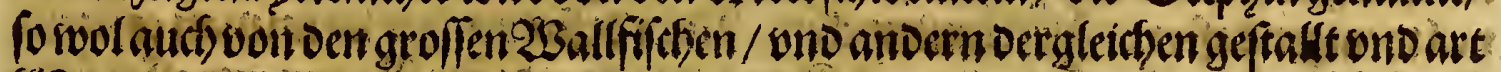

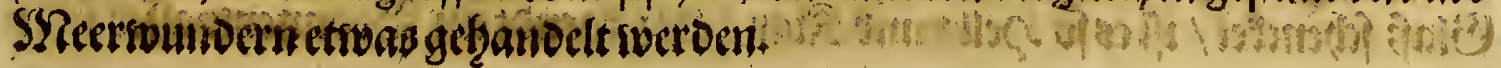

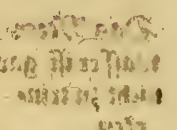

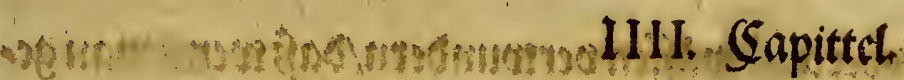

ง)

a)

Bon ber Aquinoctial linien, bon 2 ngewitter/bon onbeftăt

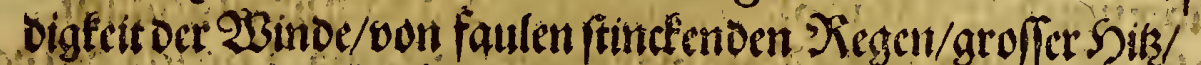

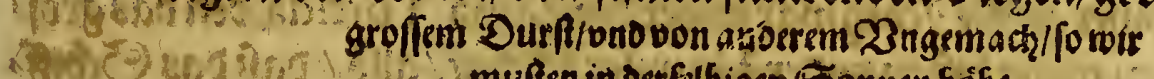

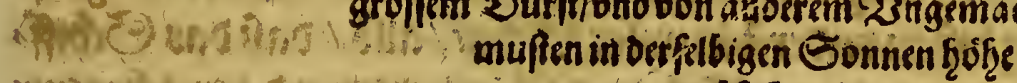

yesios.

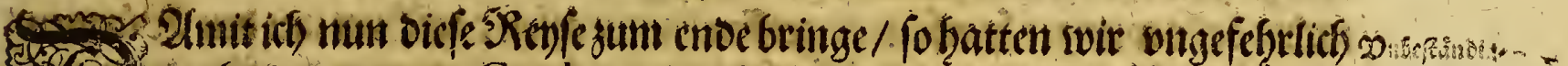
6.

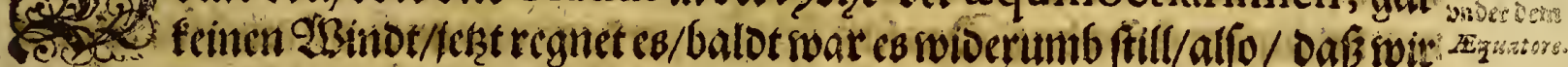

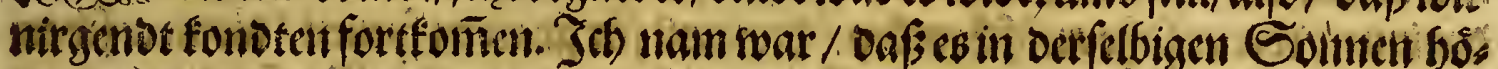

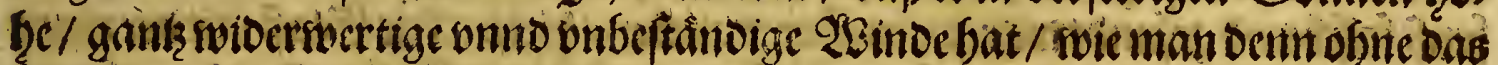

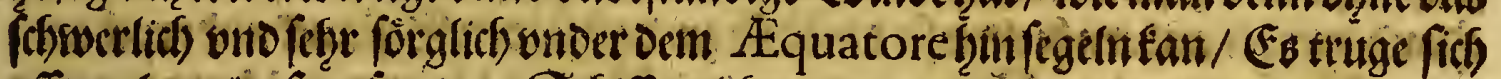

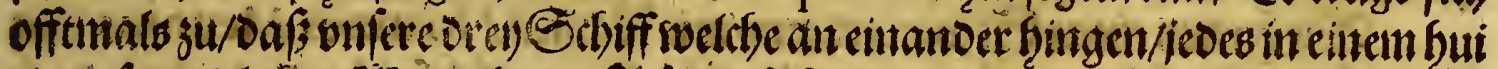

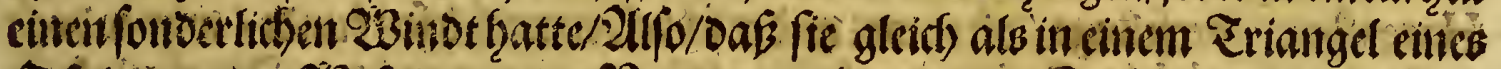

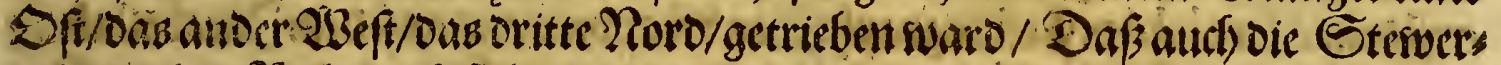

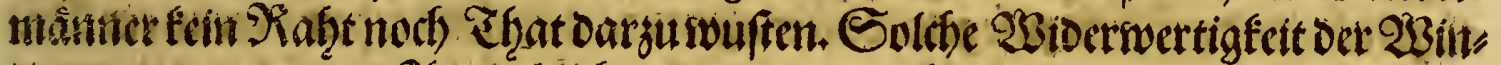

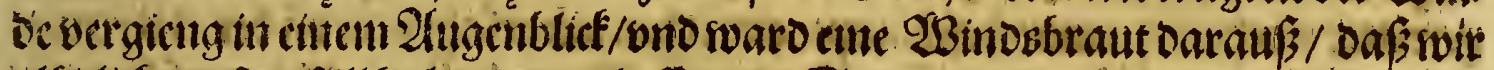

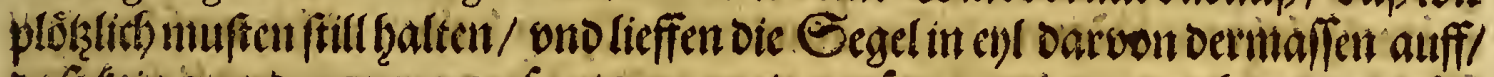

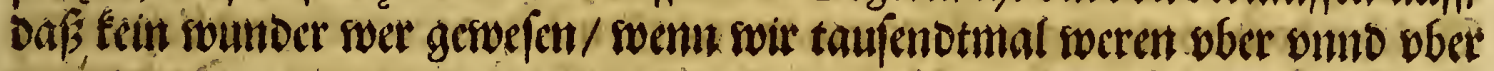
gangen.

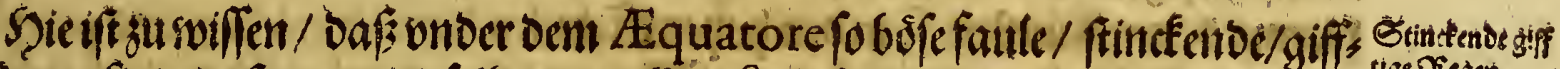

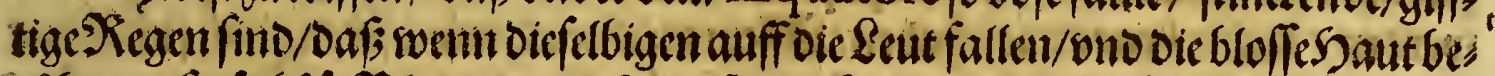

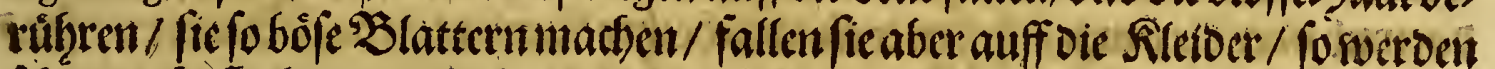

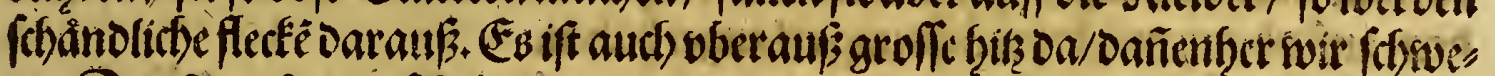

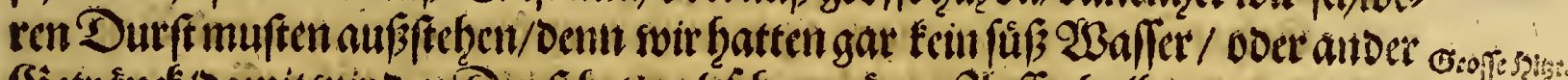

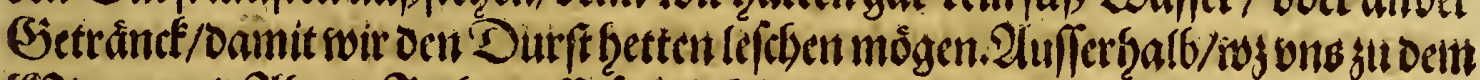

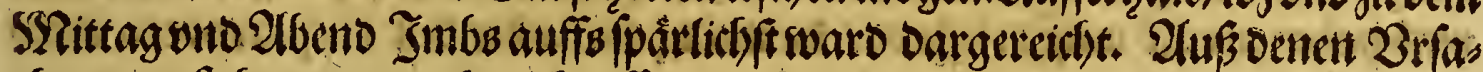

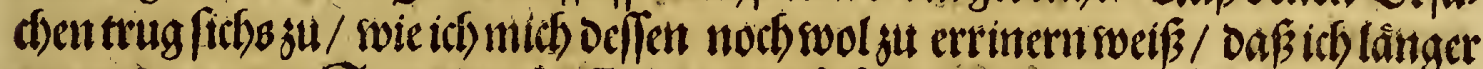

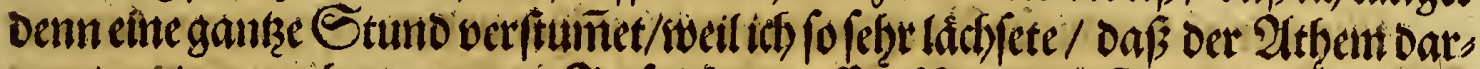

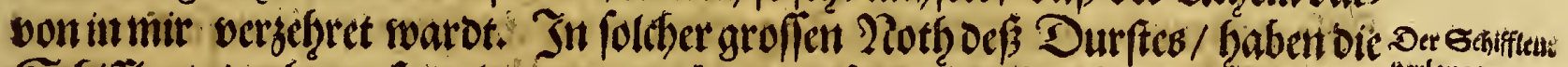

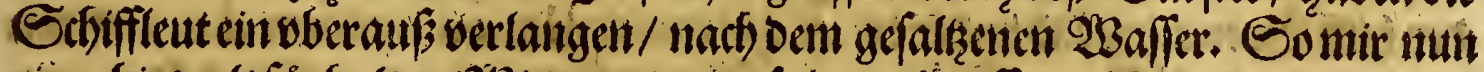

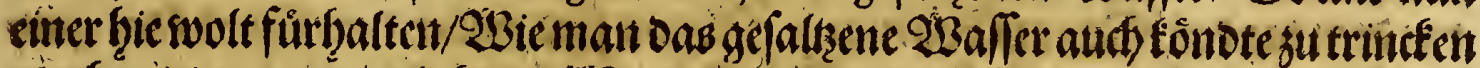

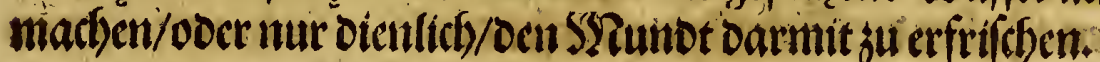

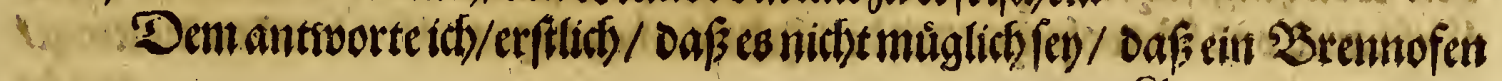
(5) oder 


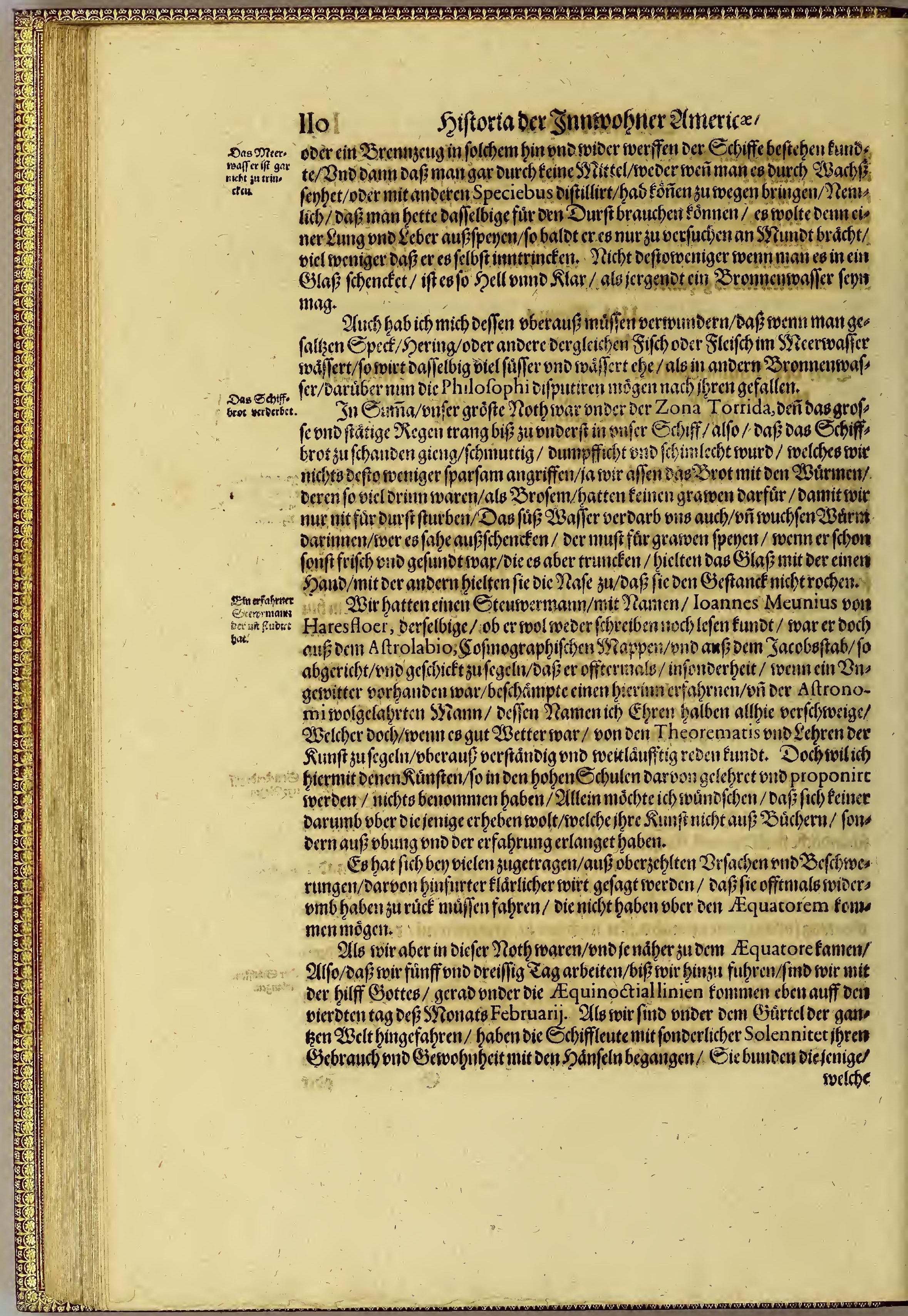




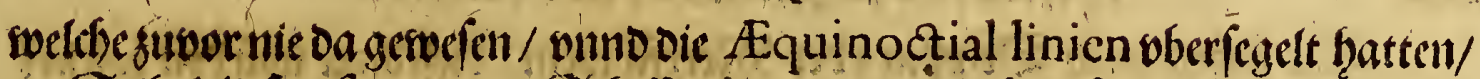

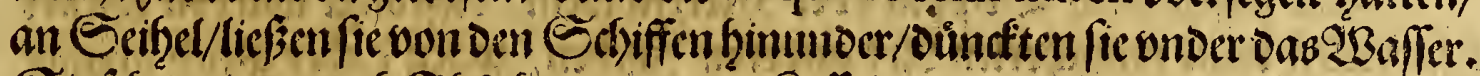

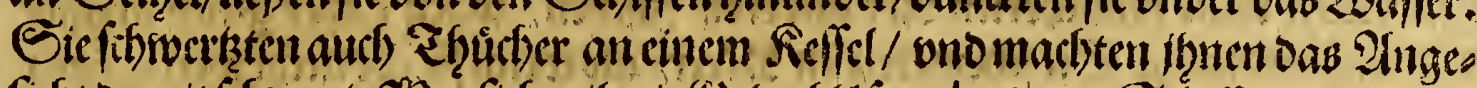

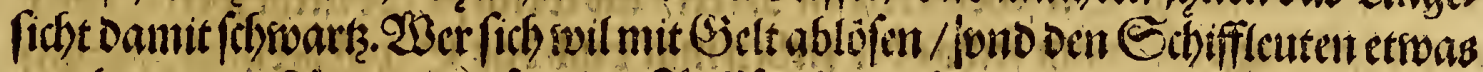

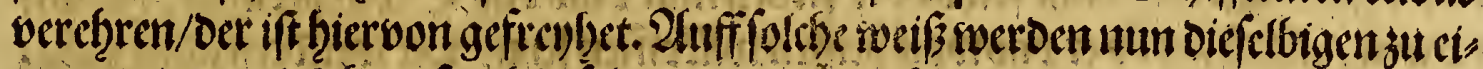

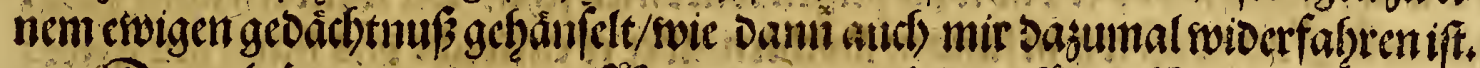

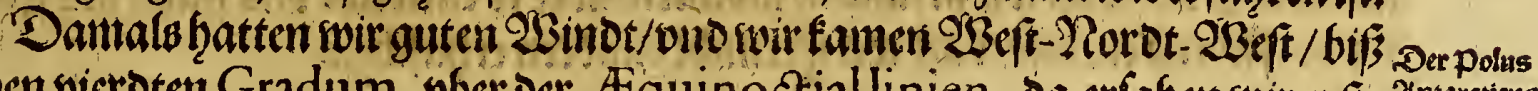

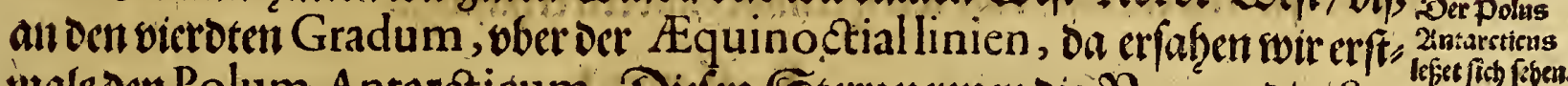
inals den Polum Antarcticum. Diefen Stern nennan bie Pormandier Su,

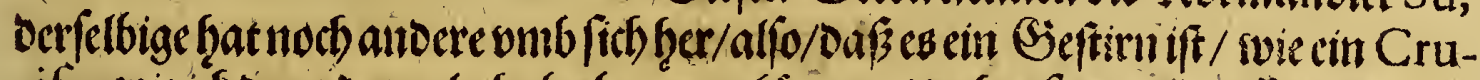

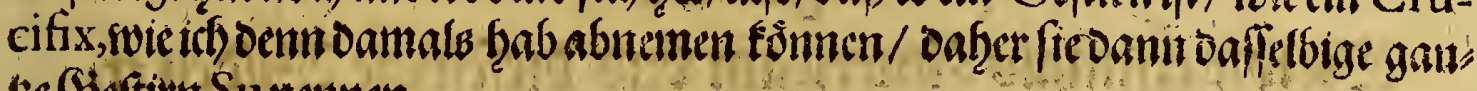
be BeftitnSunennen.

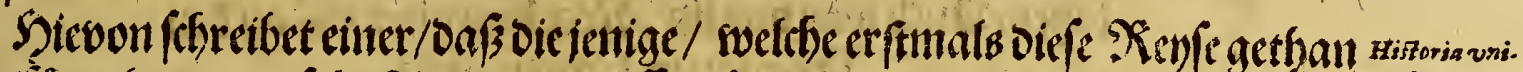

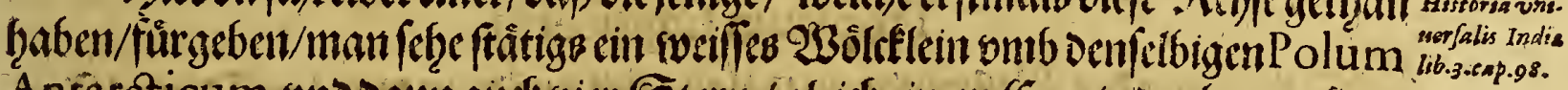

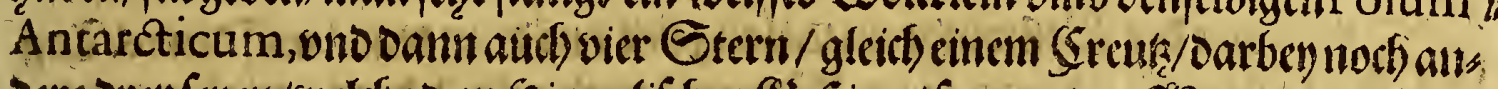

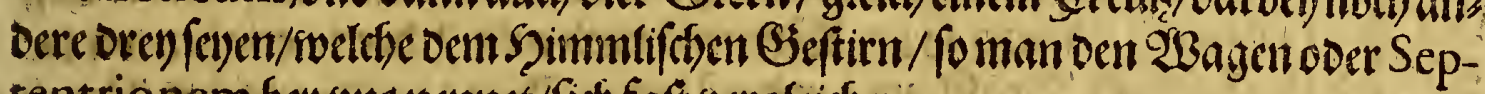
tentrionem bey vins itemet//ich faft vergleichen.

Bnferen Polum Arcticum, oen man oen 2 agaen nentet / hatten swit

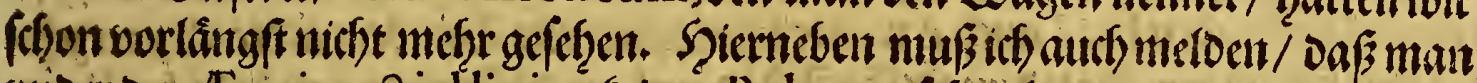

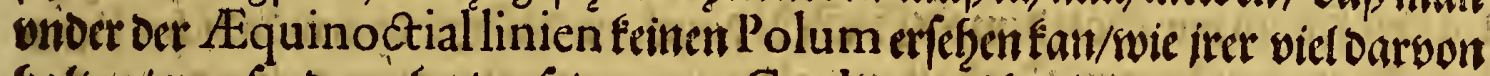

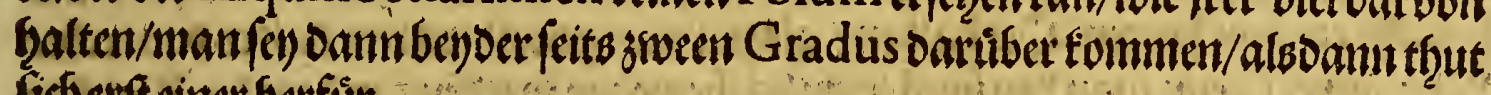
fidberfteiner fietfir.

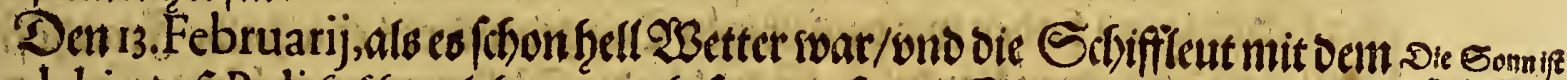

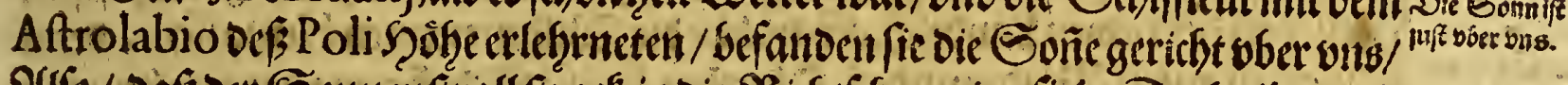

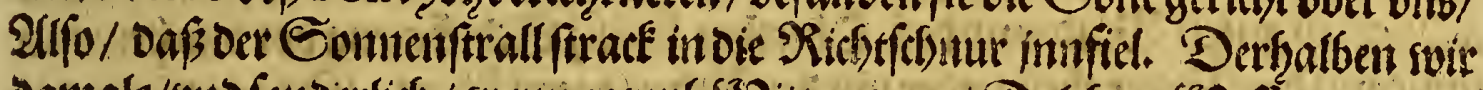

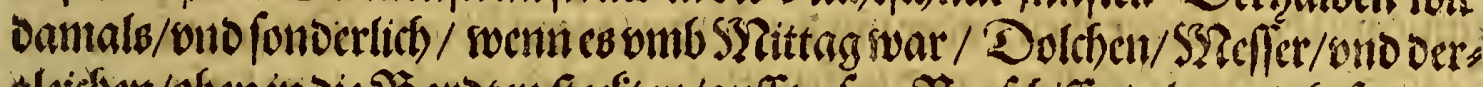

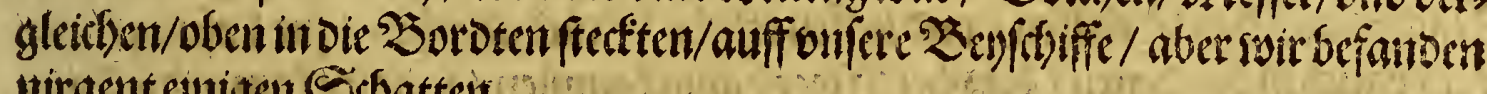
thirgent ewigen Eehattein.

2on Dannen fint woir anffoween Gradus fortge/egelt/f̧aben orel) ober vich

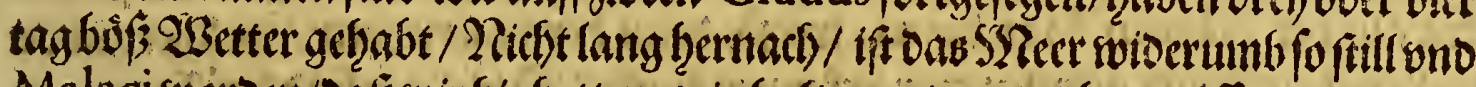

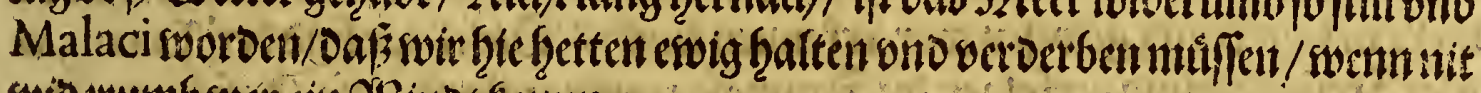
soiberumbser cin oinot fommen.

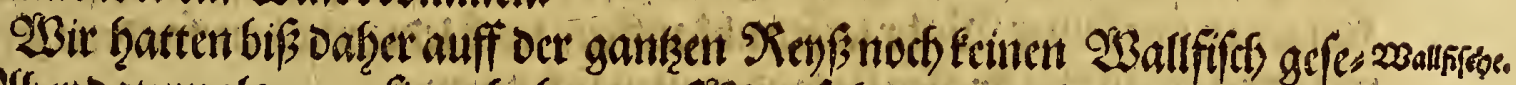

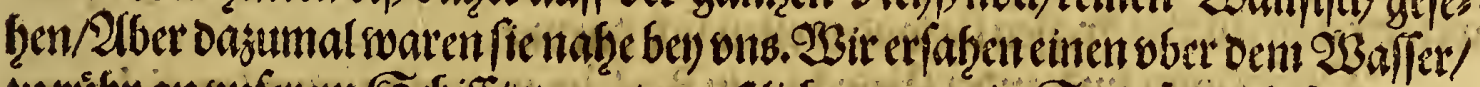

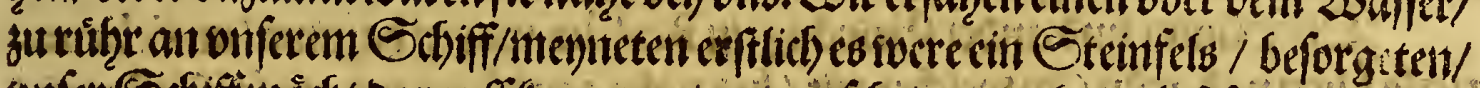

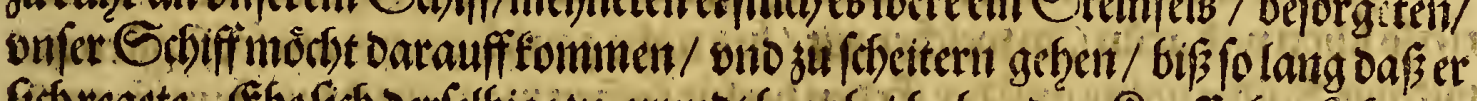
fich regete (Ebefich oerfalbige fu grund begab / fub er oen Ropfi ober fich/ono

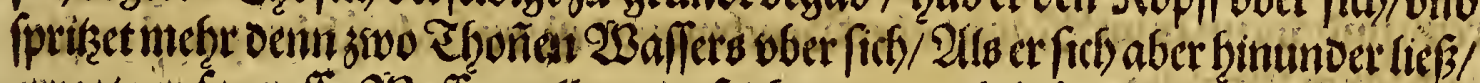

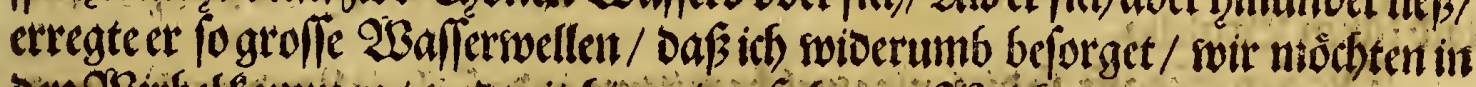

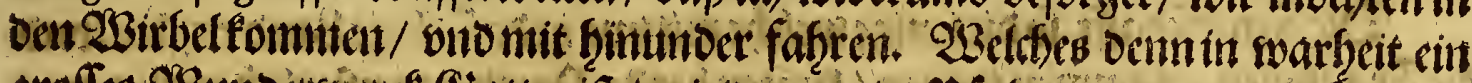

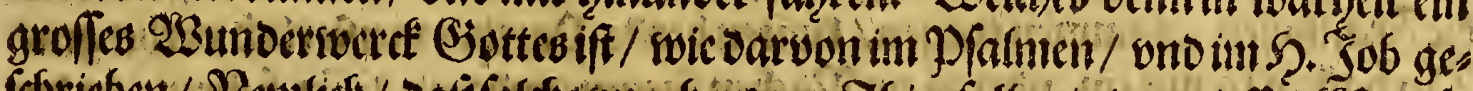

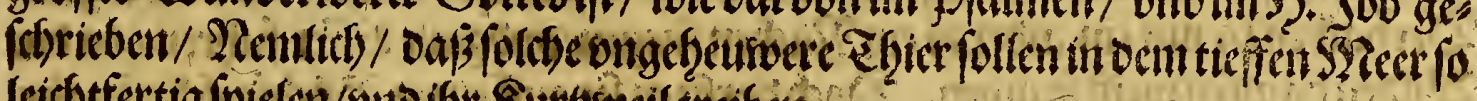
leichtfertiglpielen/onoibr Ruttşbeil treibent.

(b) if 


\section{II2}

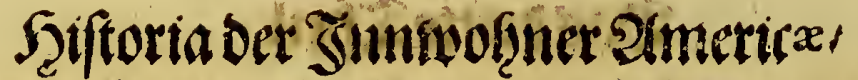

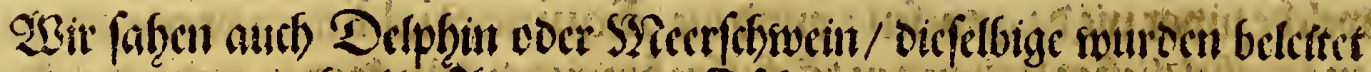

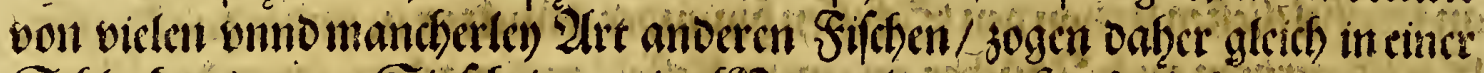

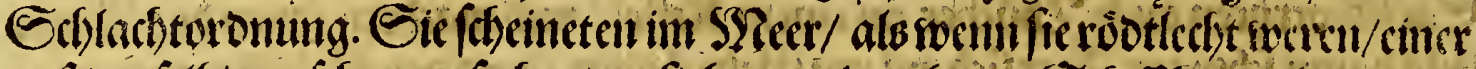

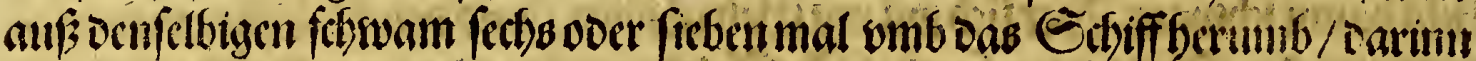

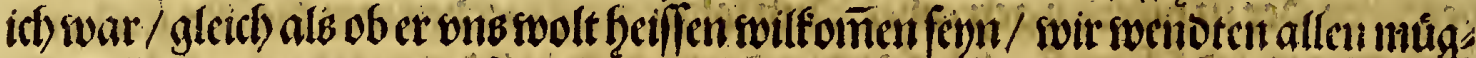

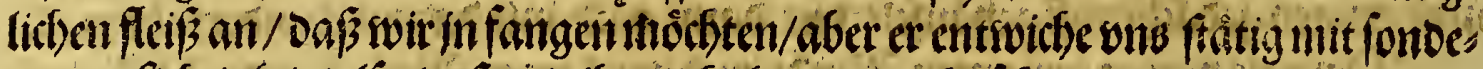

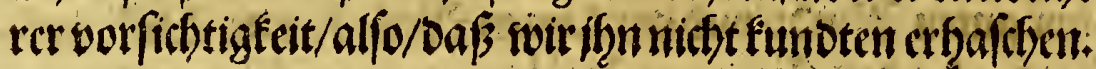

\section{Sapittcl. \\ Argument.}

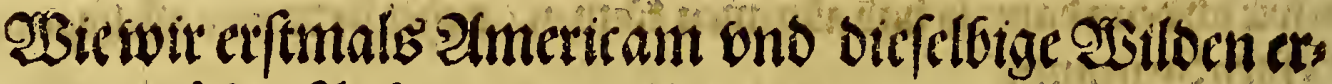

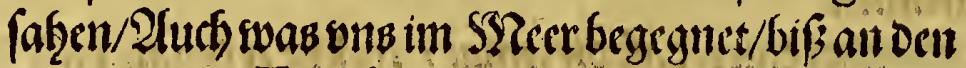
Tropicum Capricorni.

Der Tagba 2 lmerica orfer. gen woard-

Amsricus $V_{e f p u c i k s}$ nfintert Americam.

\section{(1)}

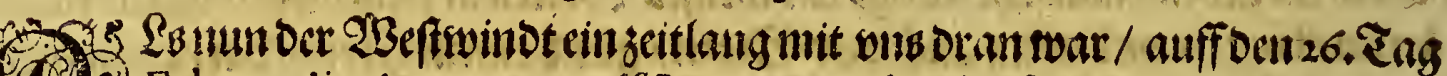
2.

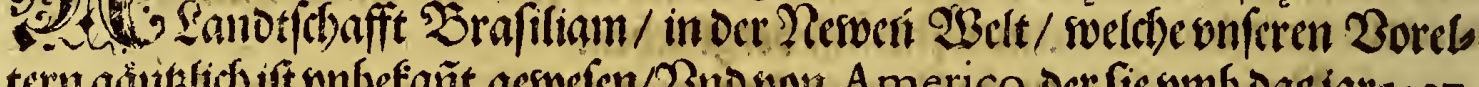

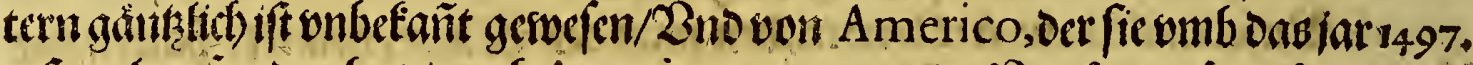

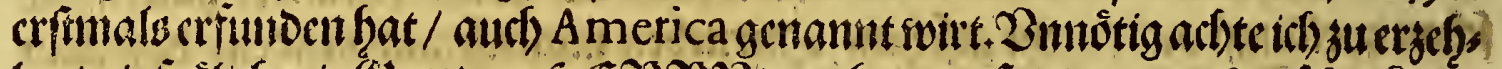

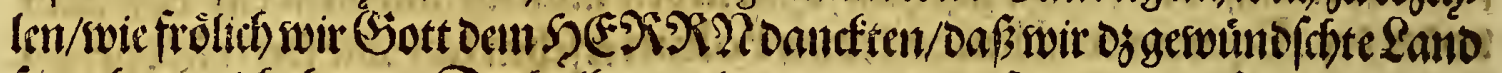

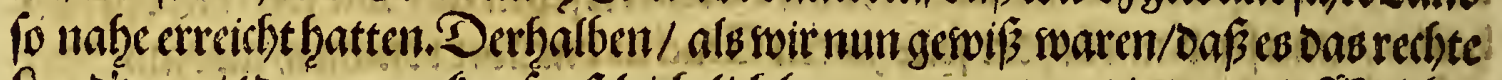

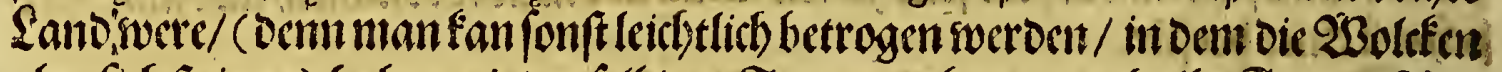

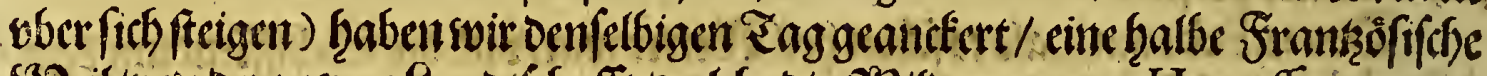
Erusafou, cistralscyer ort.

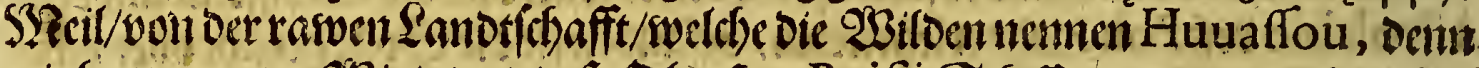

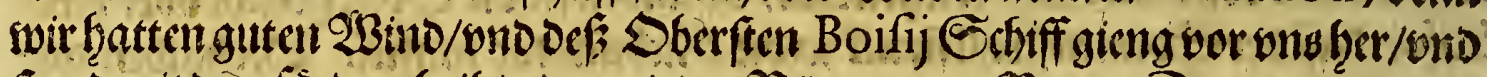

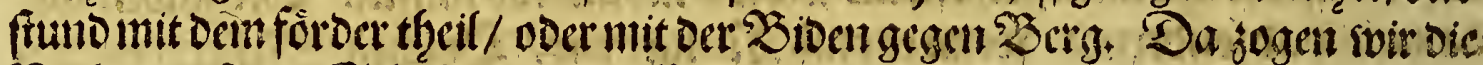

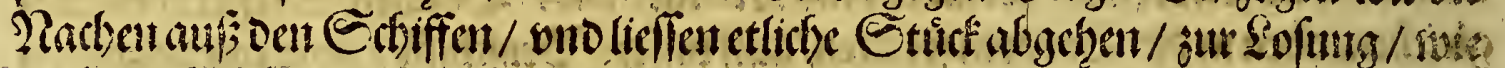

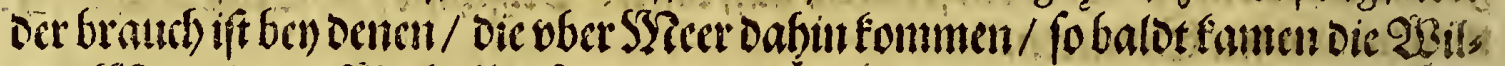

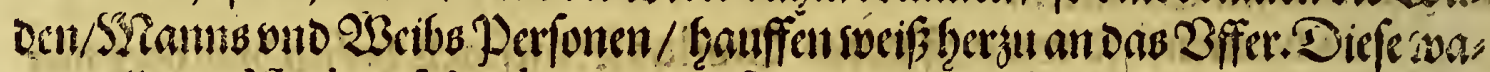

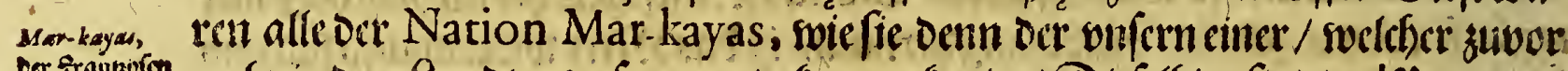

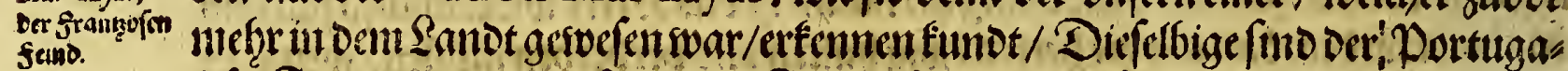

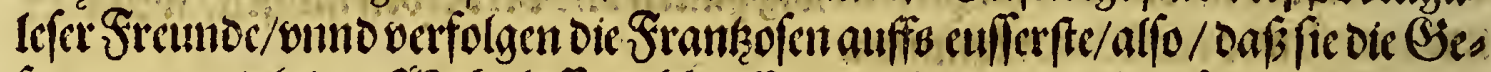

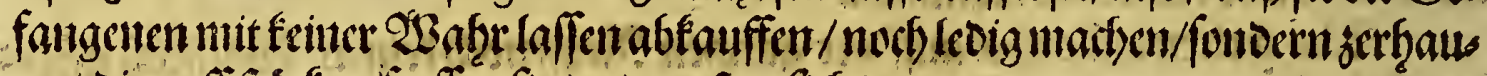

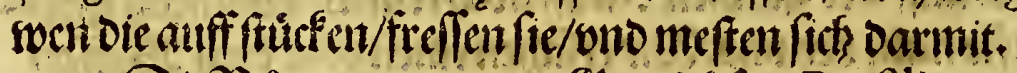

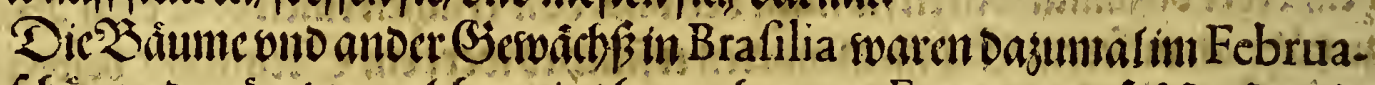

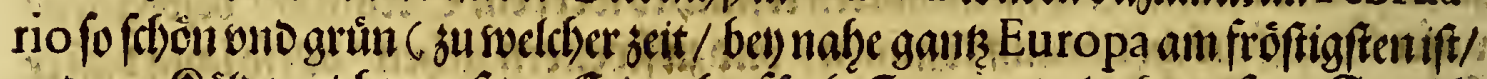

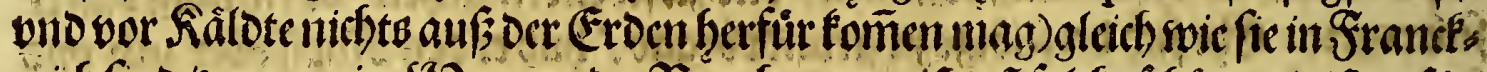

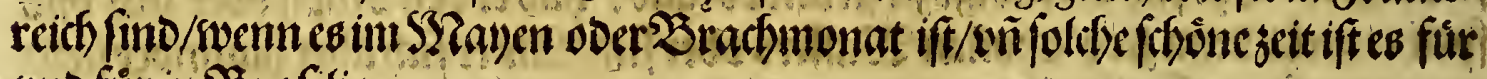
ond für in Brafitia.

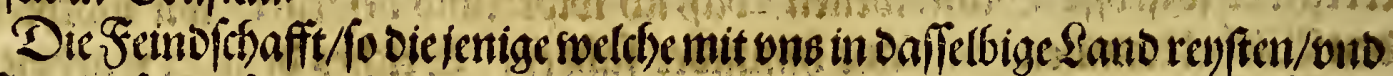

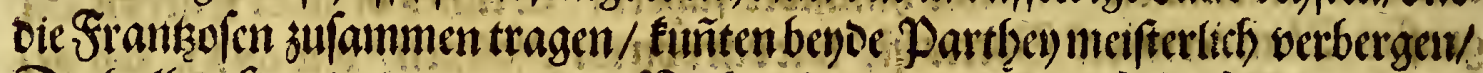

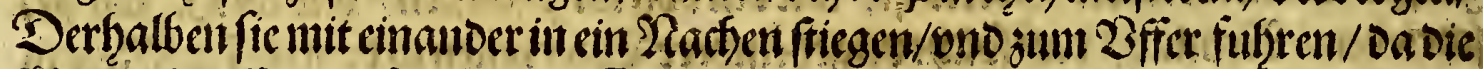

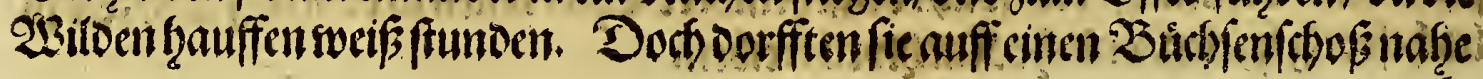
niclit 


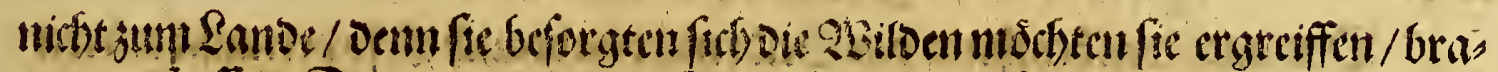

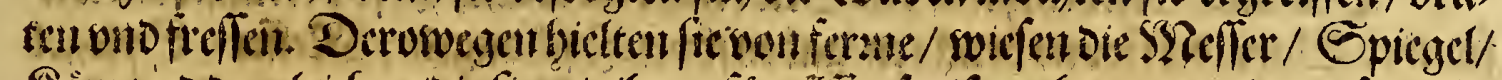

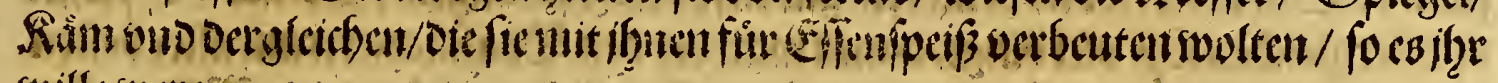
swille sucte.

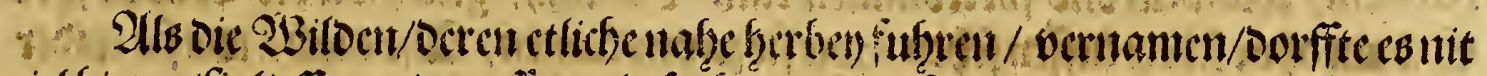

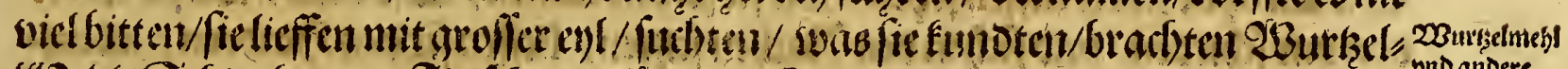

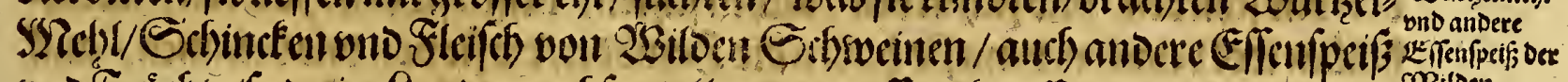

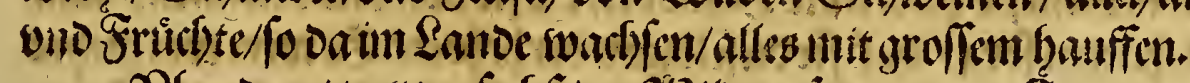

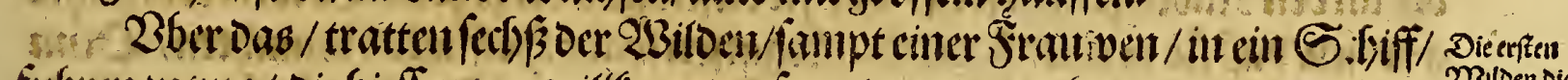

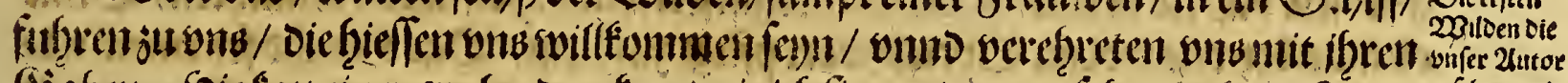

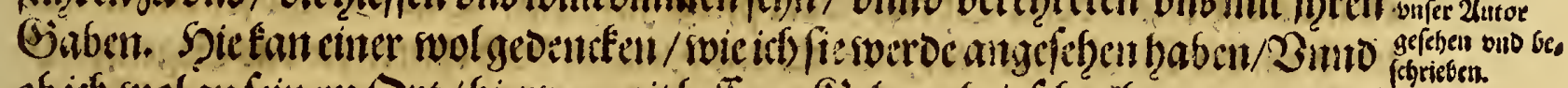

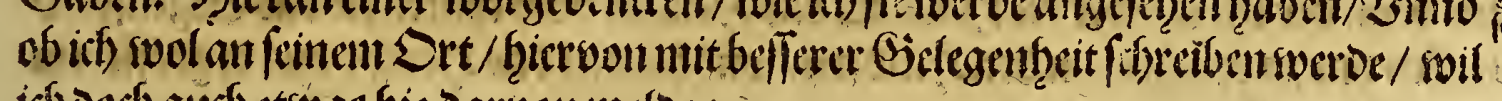

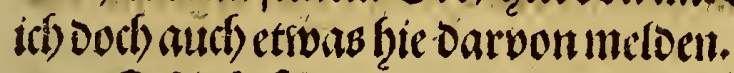

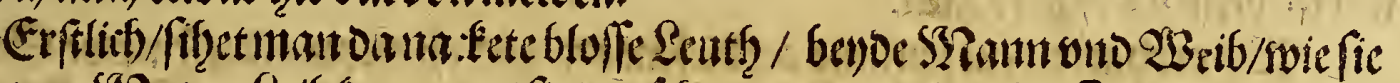

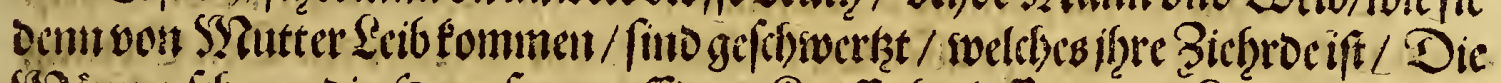

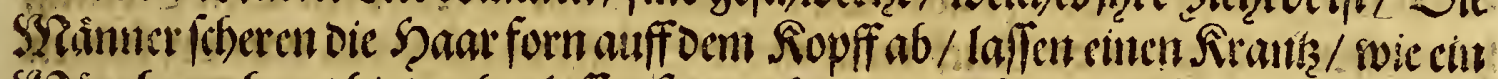

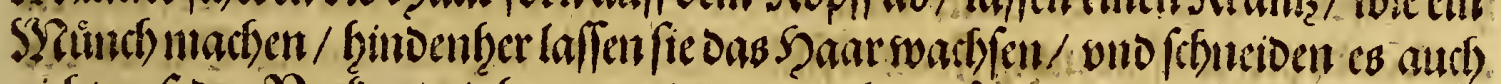

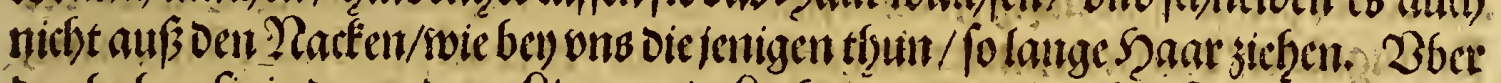

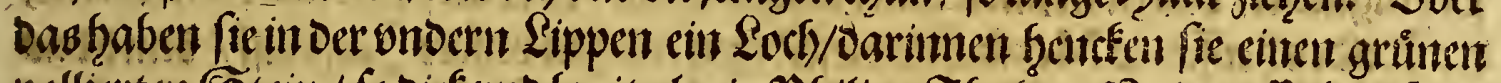

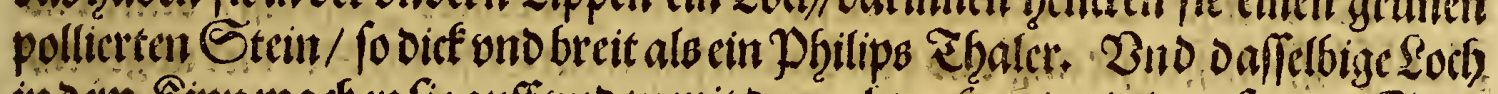

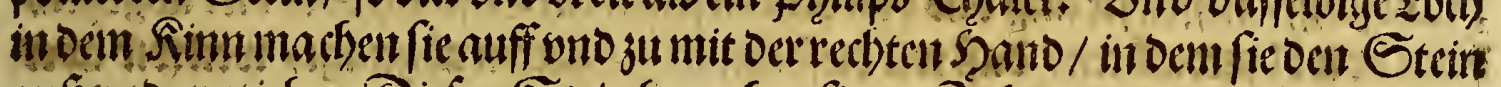

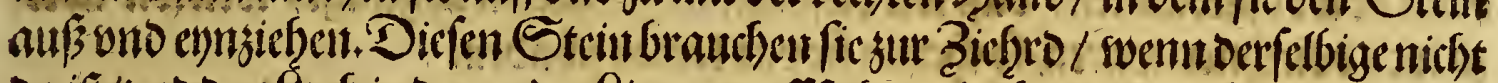

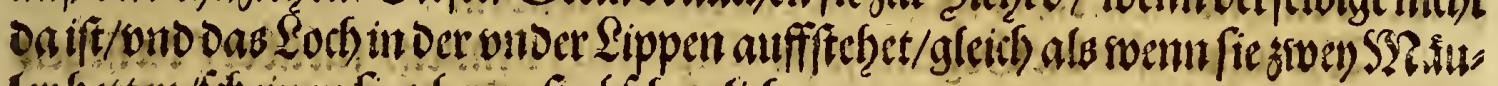
ler hetten/fifinen fie vberau/zabjeberolich).

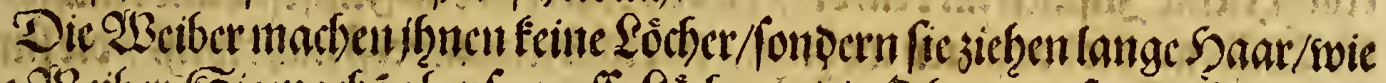

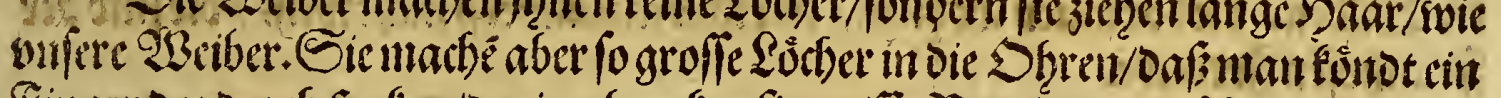

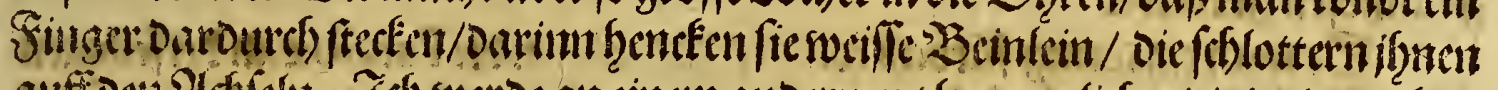

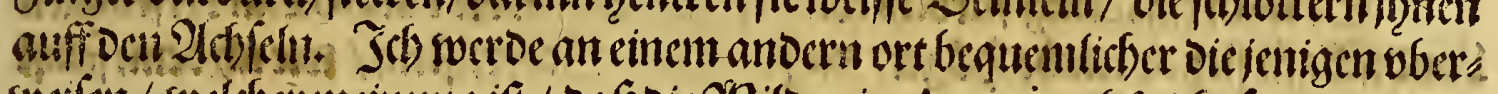

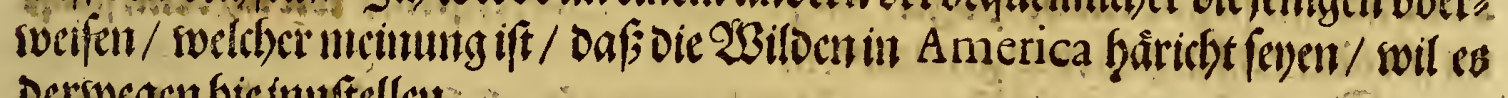
Dersoegen ficiniftellai.

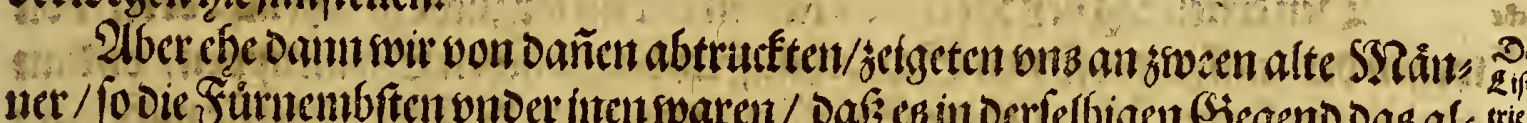

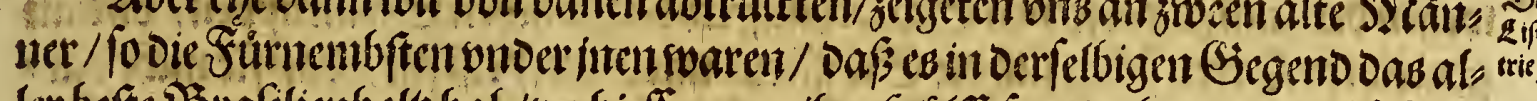

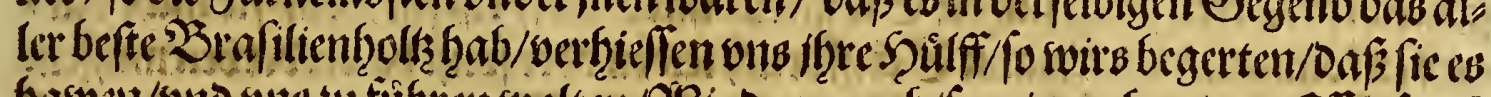

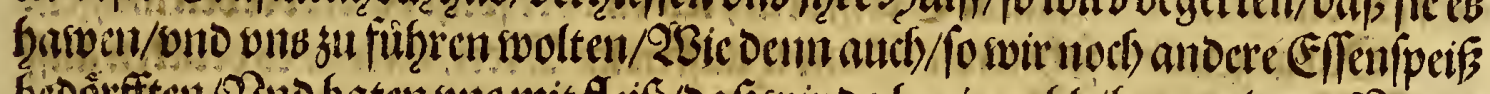

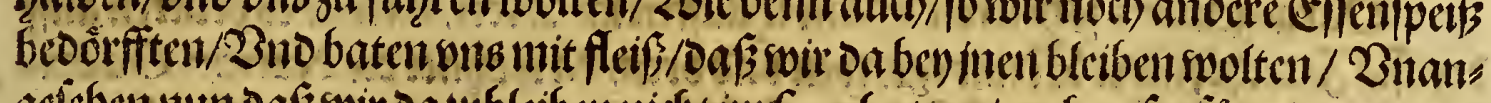

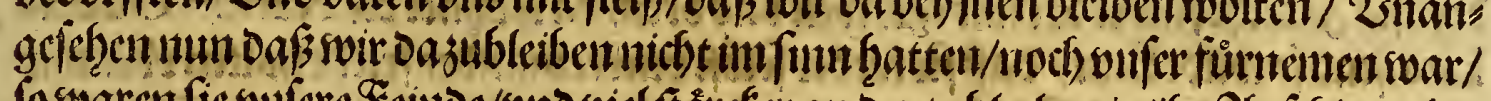

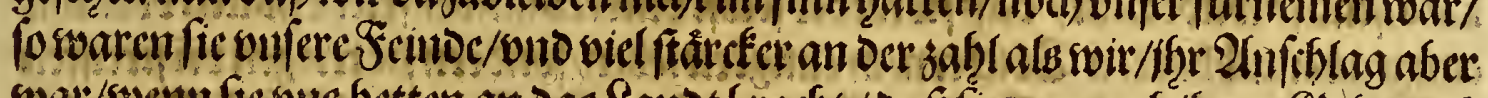

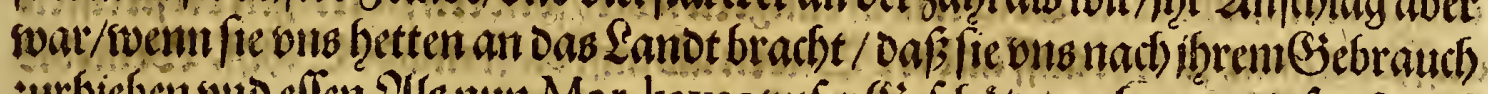

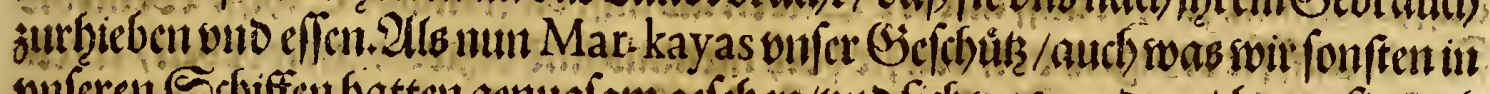
vilferen Erbiffen fatten gentglam gefehen/sno fiels werwoundert/ boten fic omb

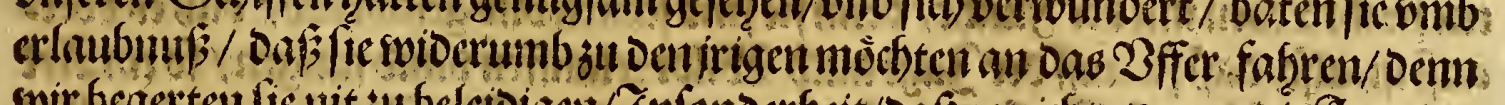

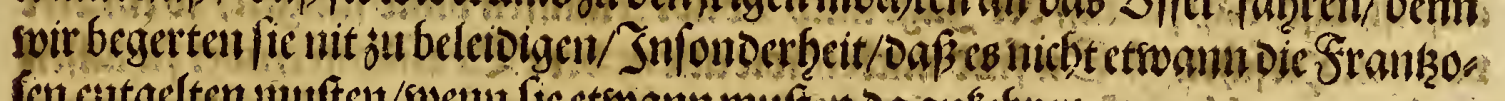

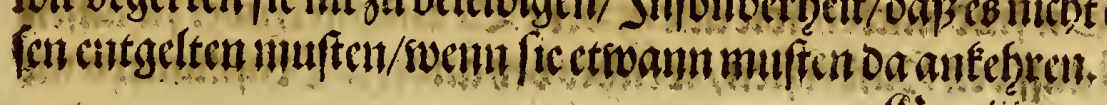

.

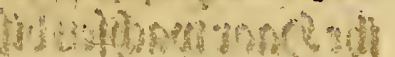




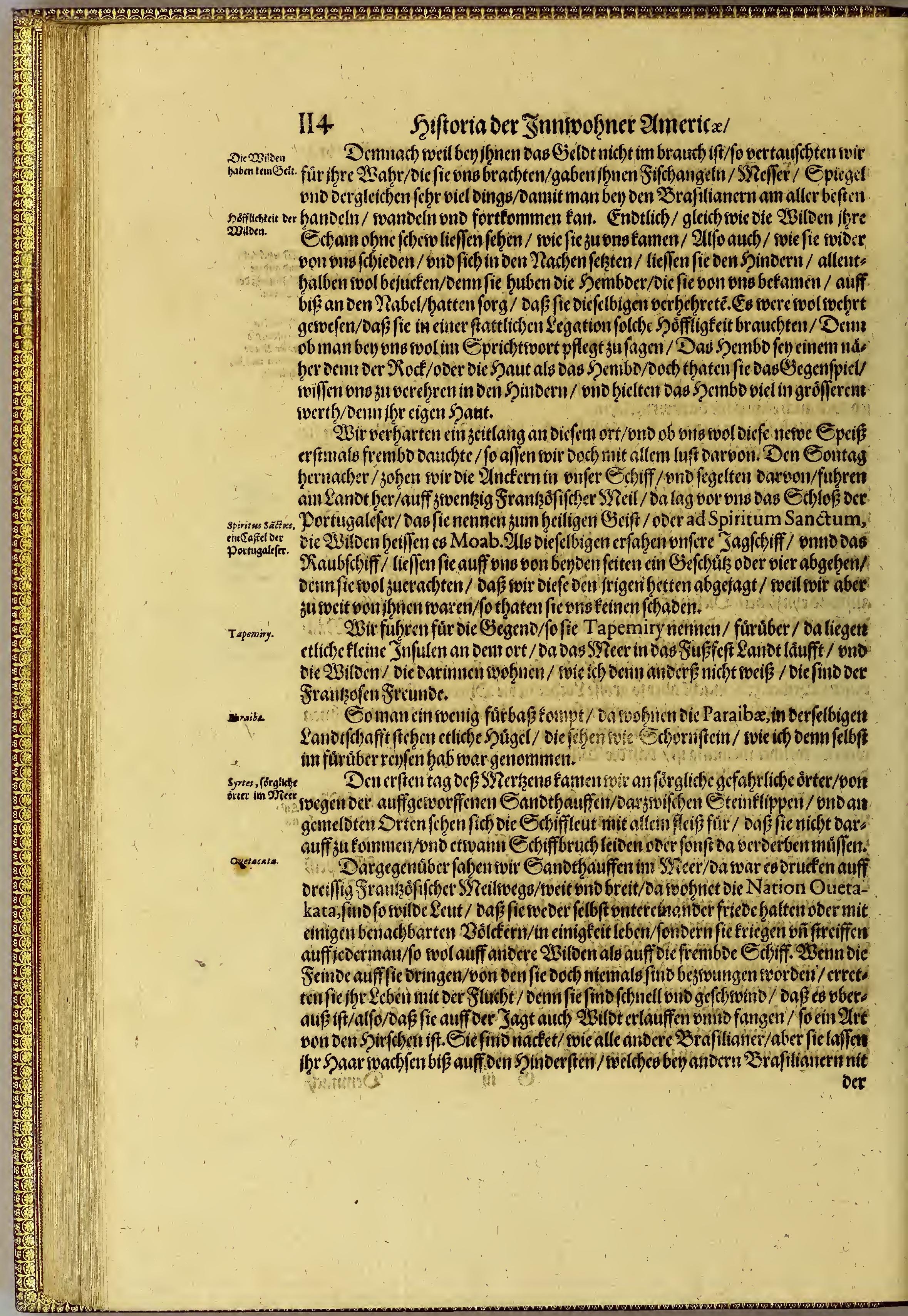




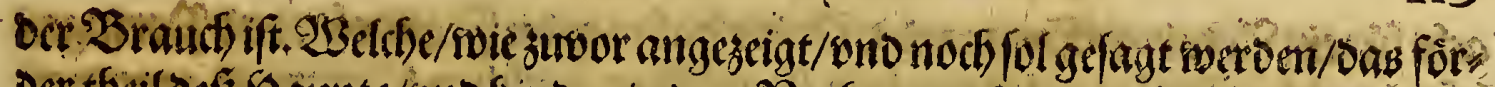

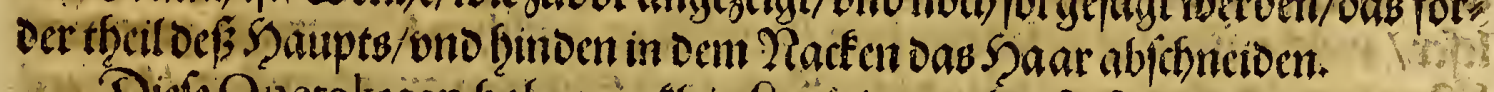
Diefe Ouetakaten gaben ch fleit Quno int/ aber fie finto nit Daritu jubes

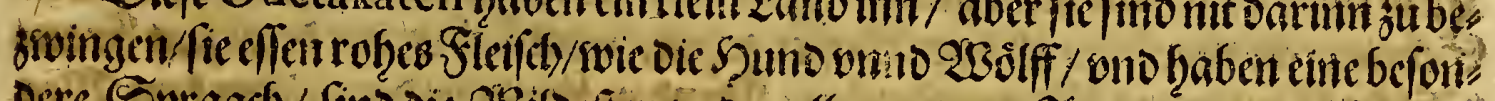

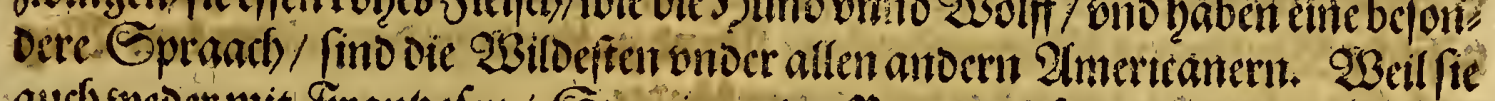
audb focoer mit Srantzofen / Epanten voer Portugalder entige gemen/chafft

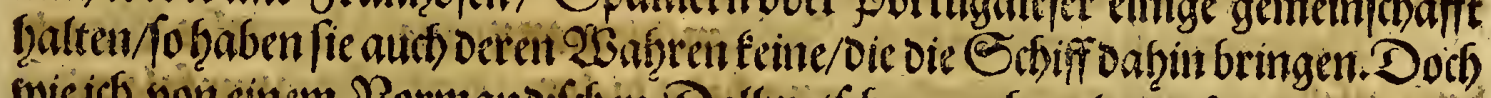

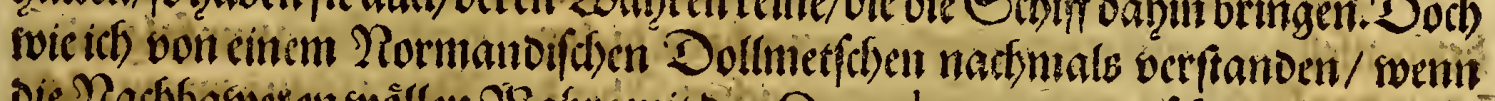

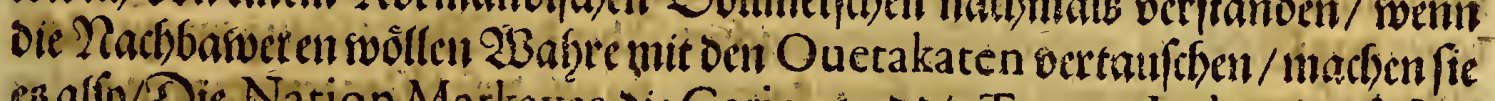
ez alfo/Die Nation Markayas, oie Carios, bnd ote Tuppin Imbx, (Diffifino

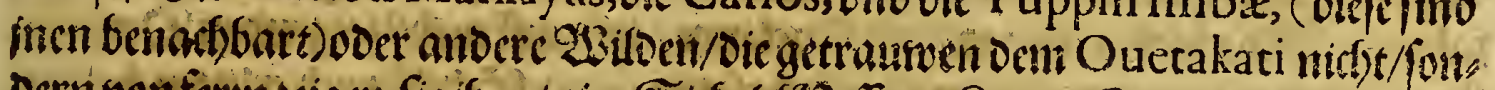

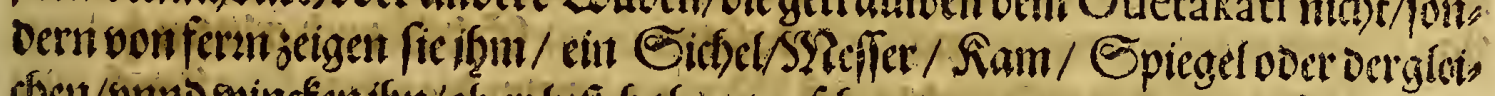

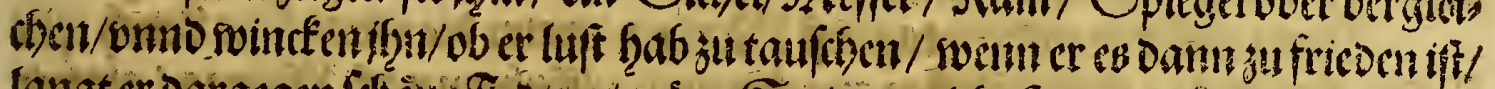

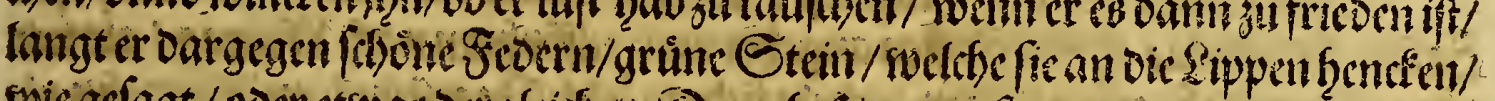

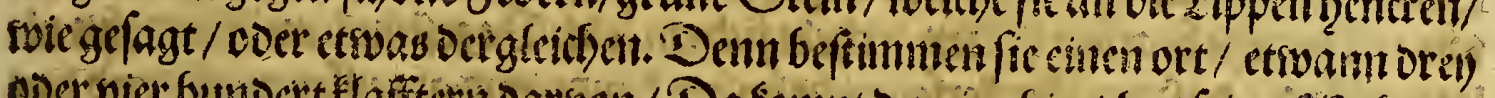

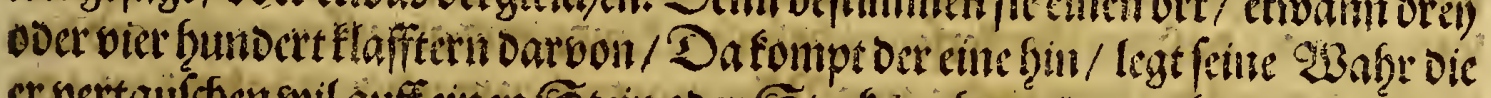

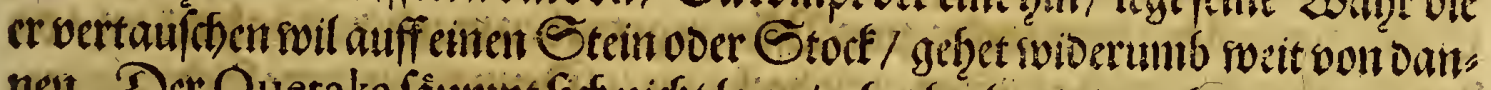

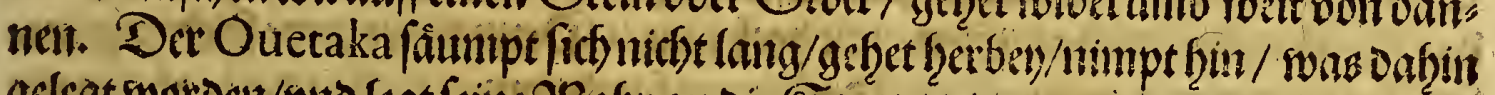

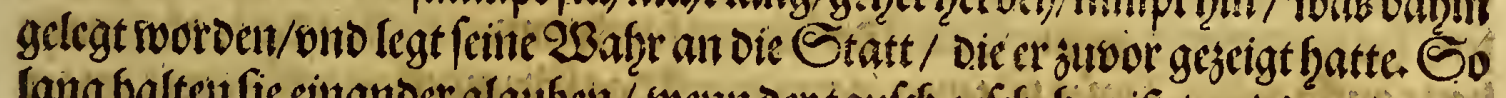

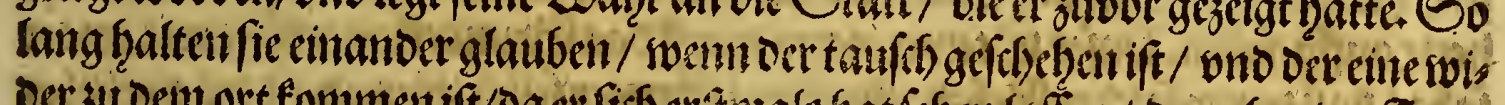

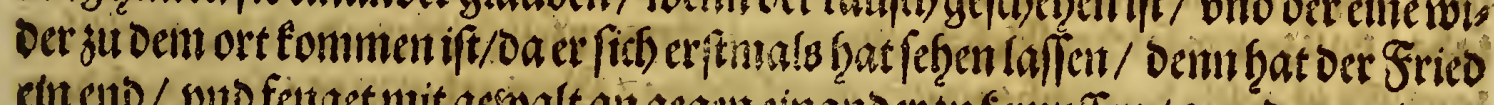

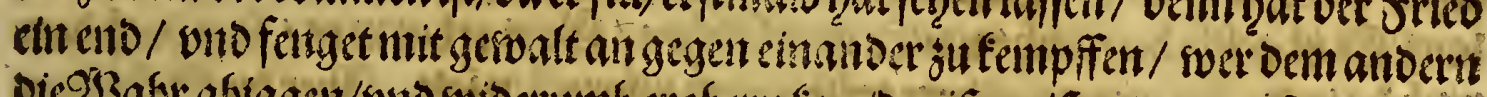

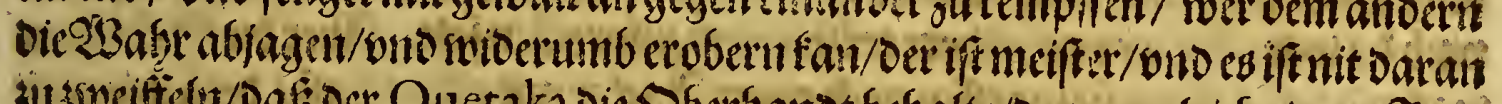

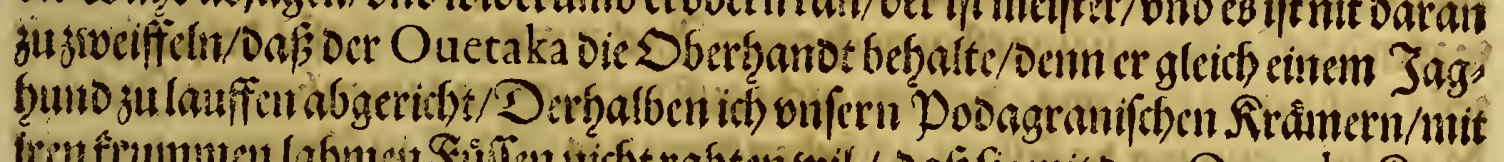

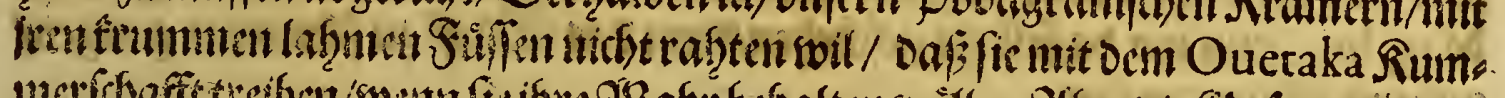

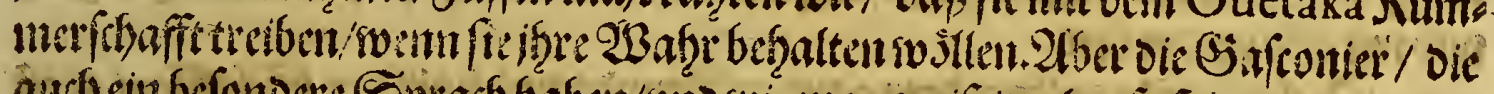

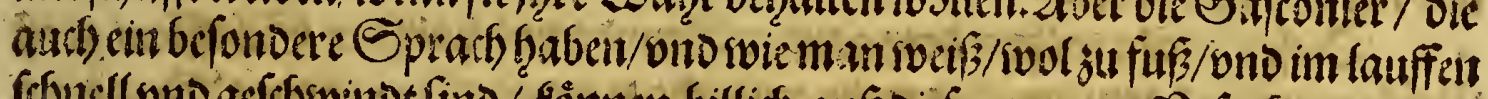

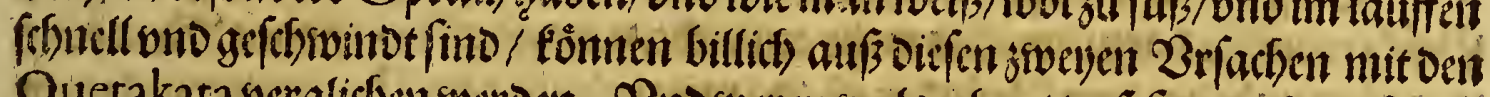

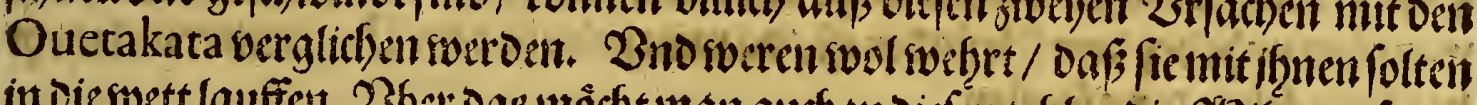

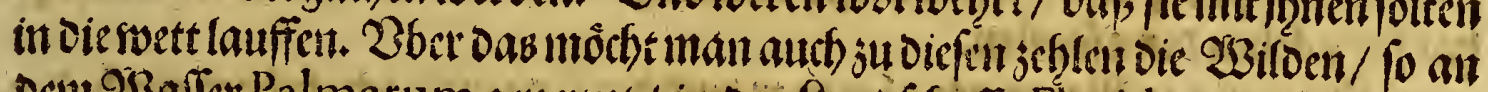

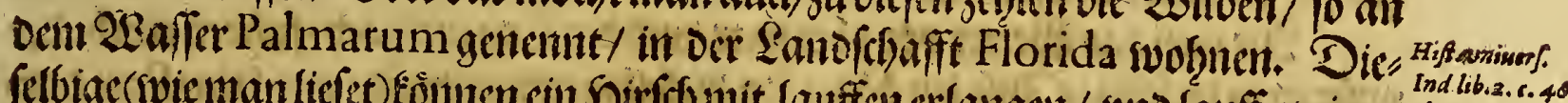

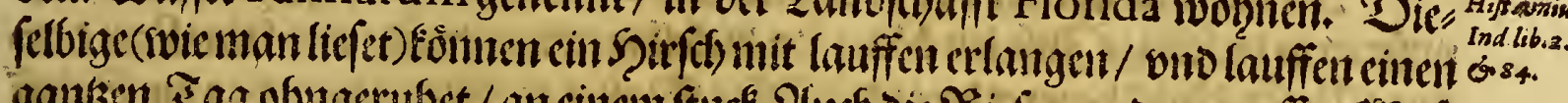

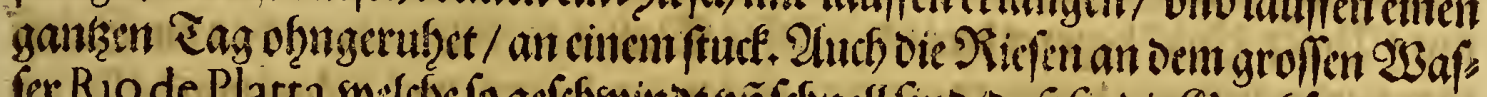

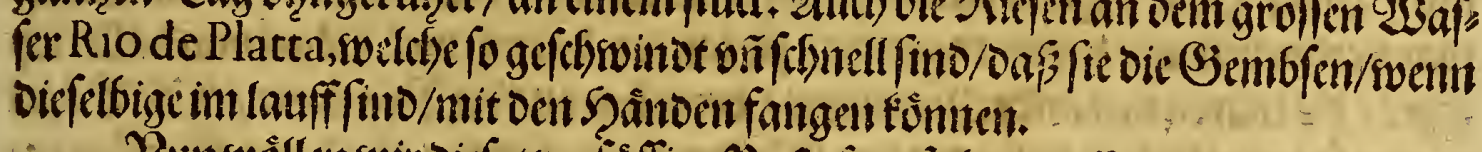

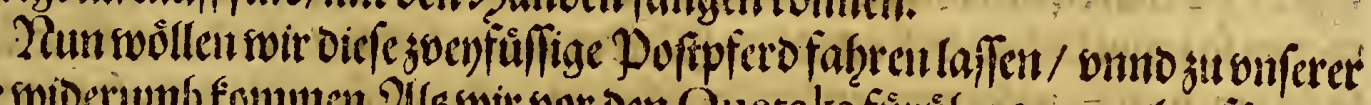

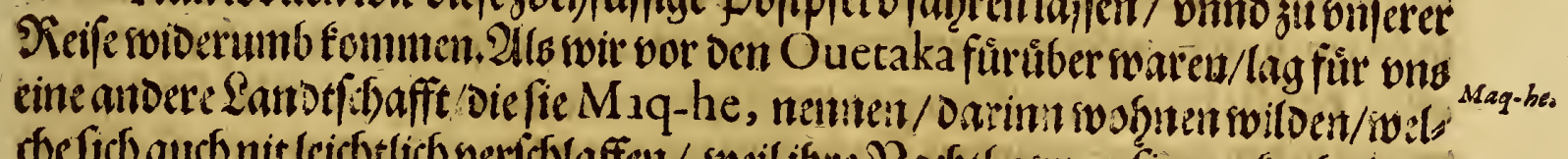

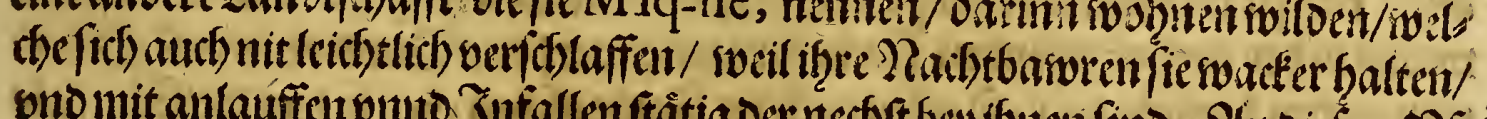

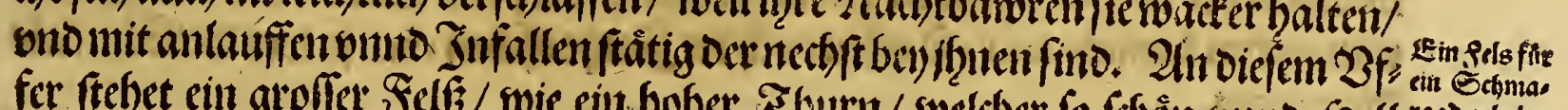

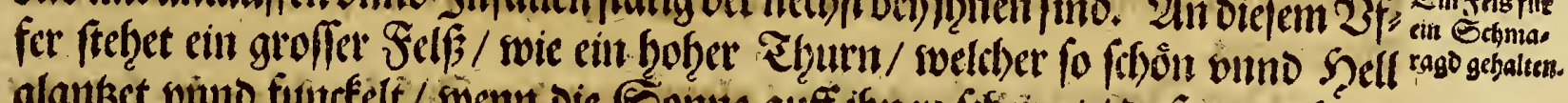

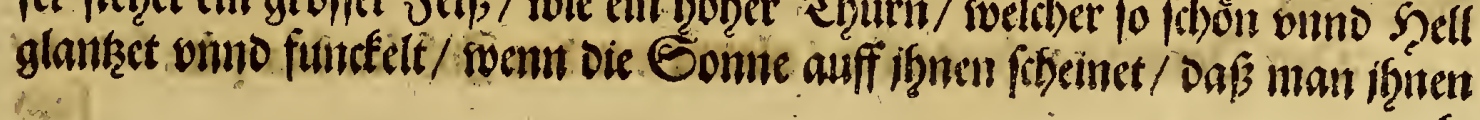

add 6 


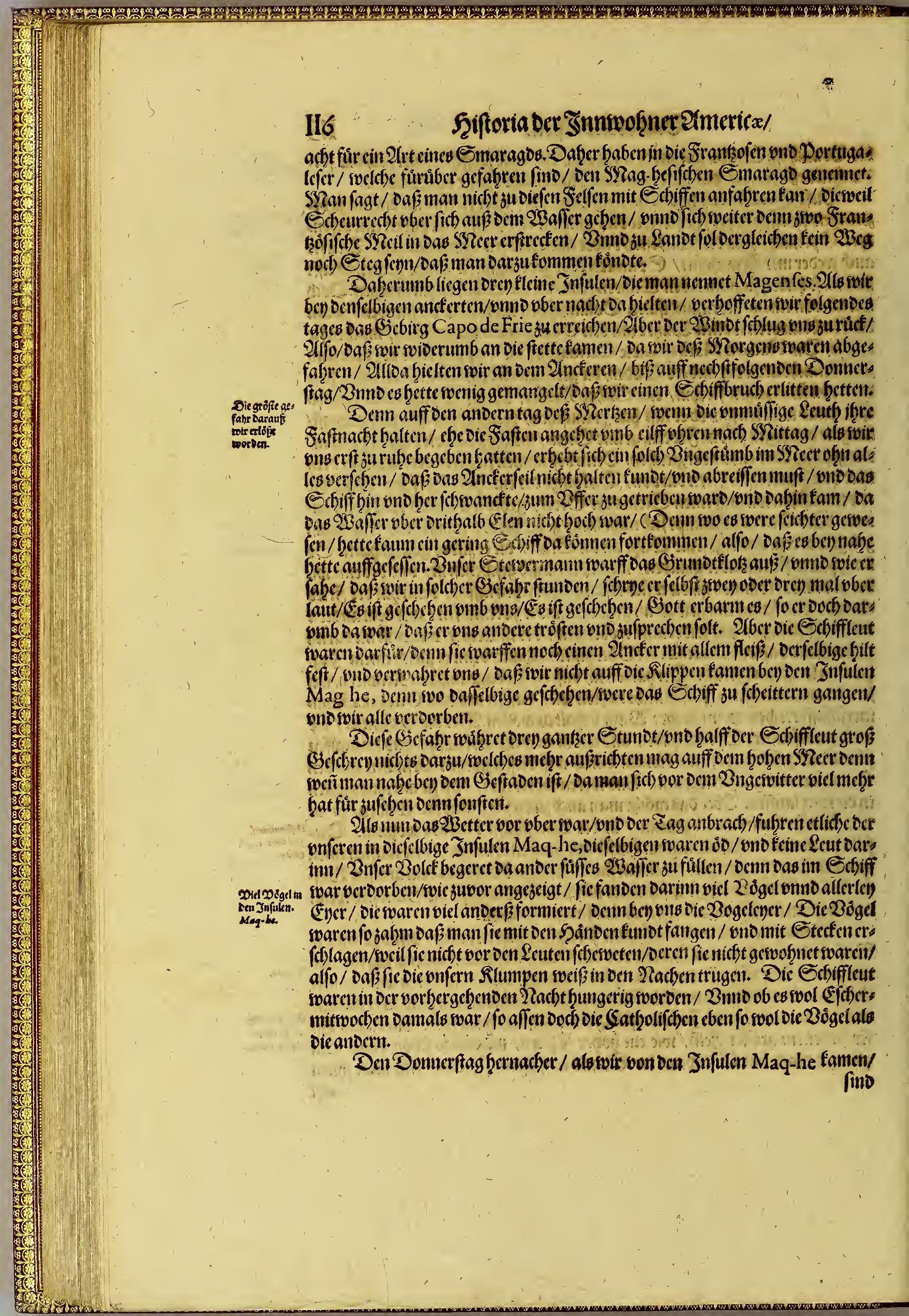




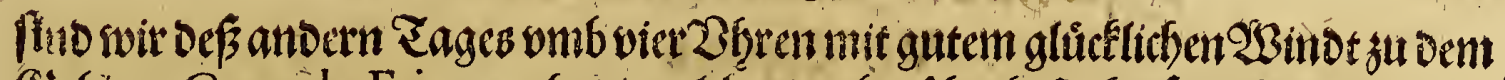

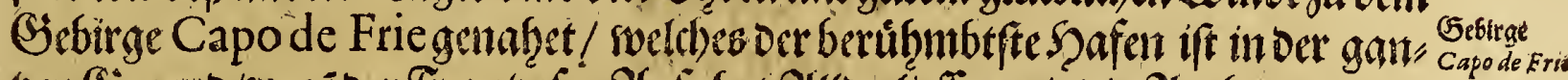

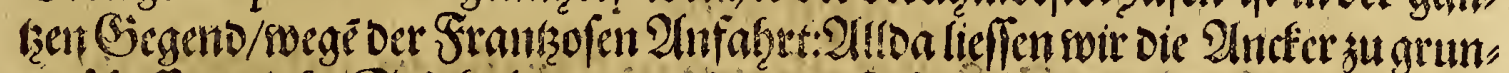

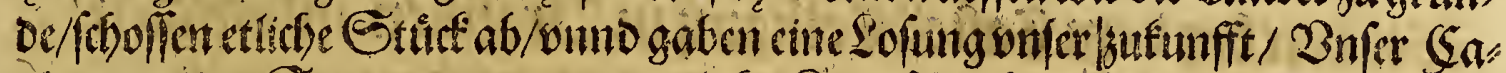

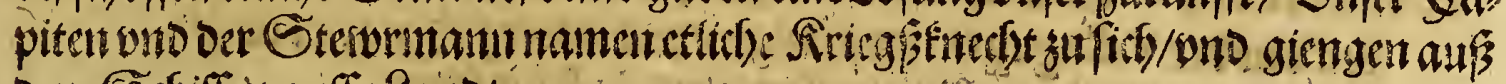
ocn Echiffen auffisant.

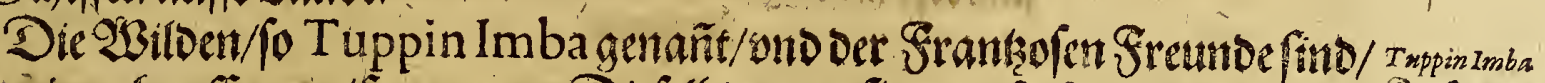

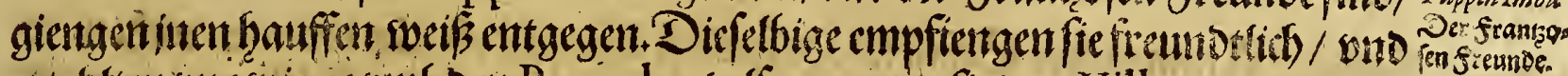
etsehften bns suie es bimb ben Pay colas (alfo nenteit fie oen Villagagnonem)

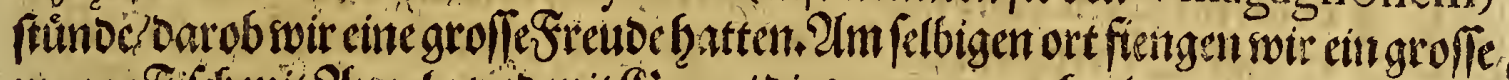

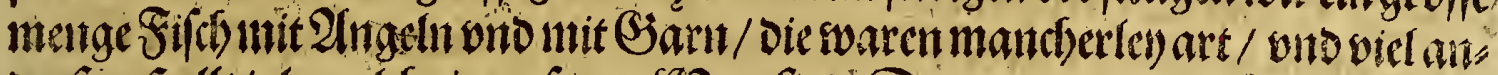

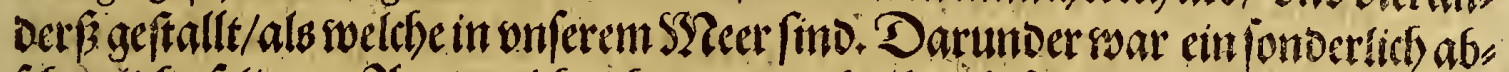

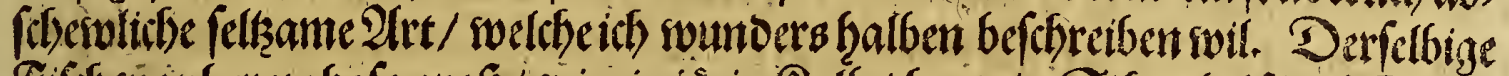

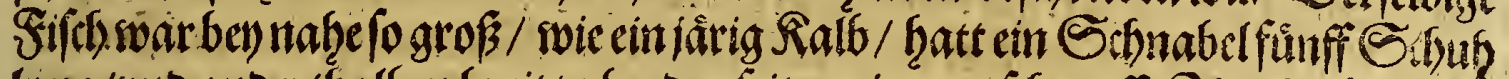

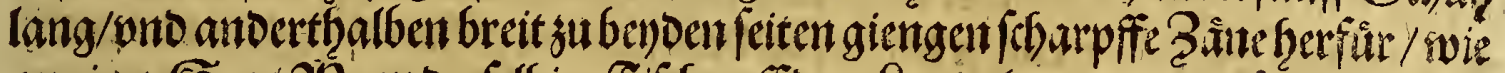

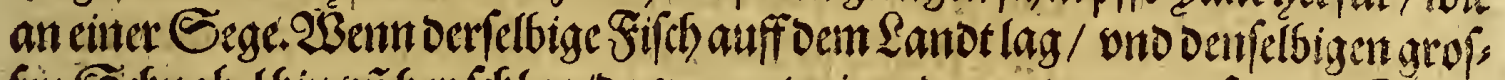

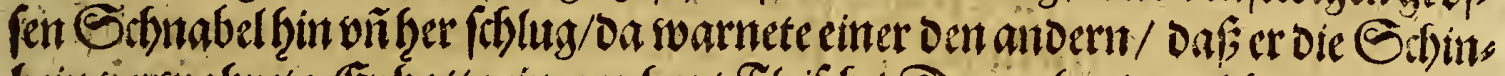

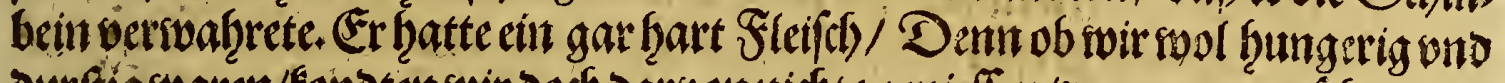

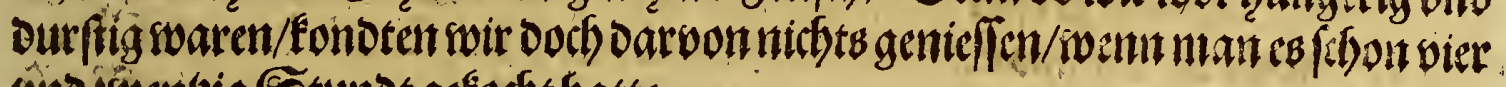
onto siventicig Grund gefocht beatte.

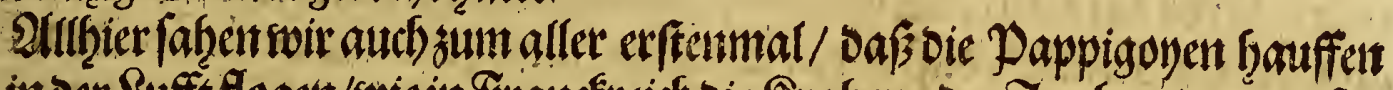

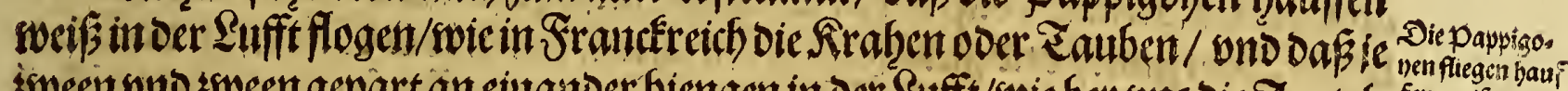

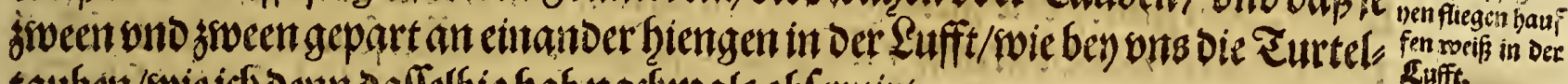

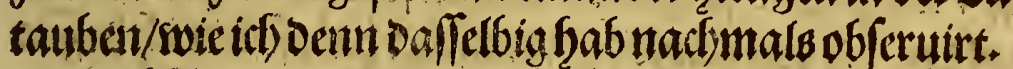

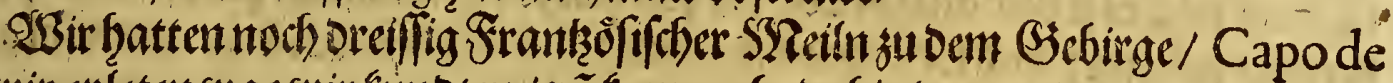

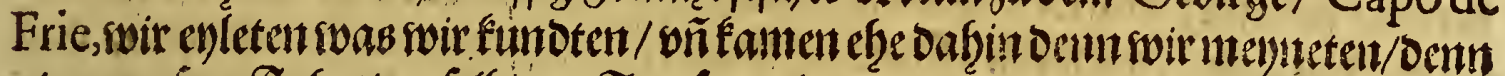

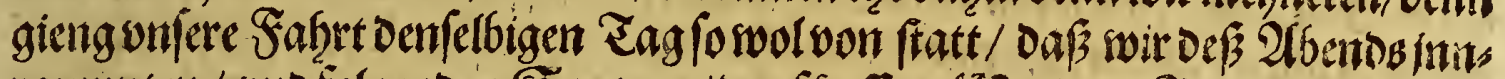

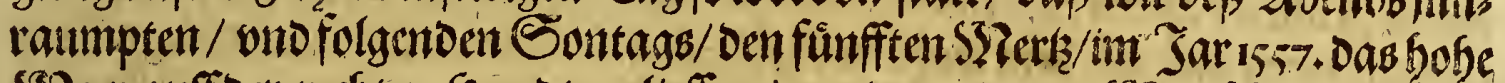

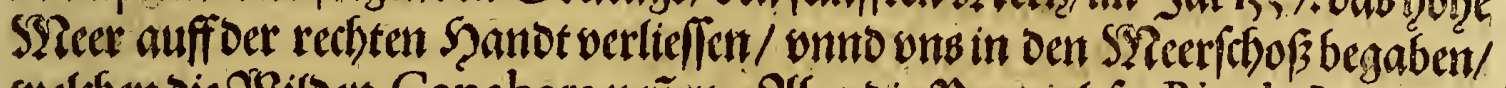

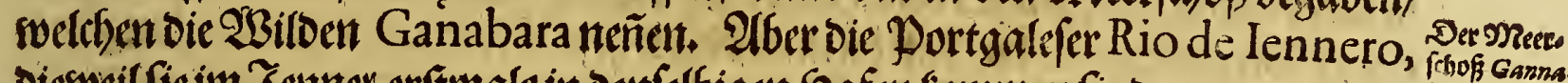
Diewsilfie im Jenner erftmals in benfelbigen Safen fommen finto.

Demnadb babentwir dem Villagagnoni suebren falt einte balbe Statieni:

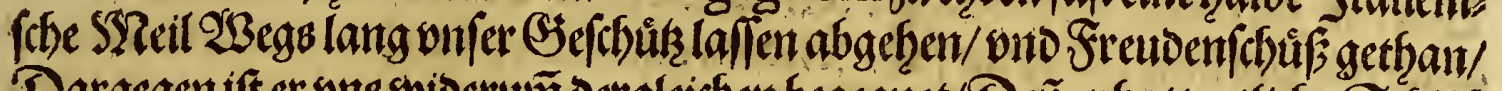

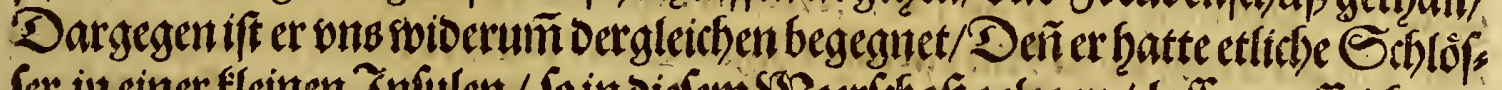

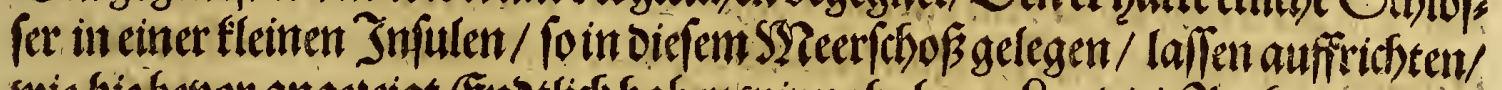

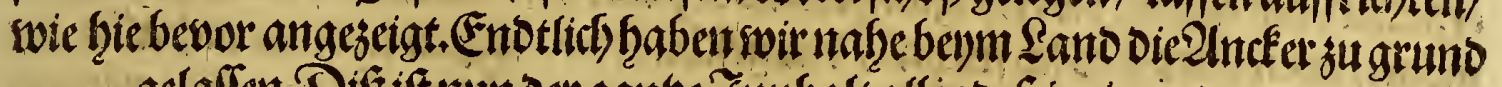
gelaffen. Dis ift num oer gantze Snnhalt alles oefienigen/swas wir

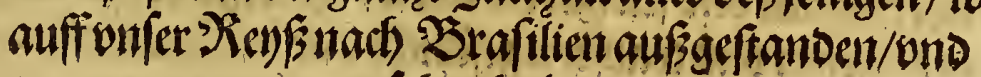
gefeternfzaben. 


\section{Das Dritte Therl.}

Ils.

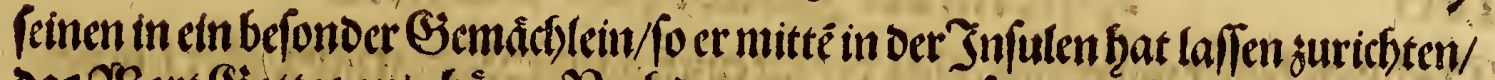

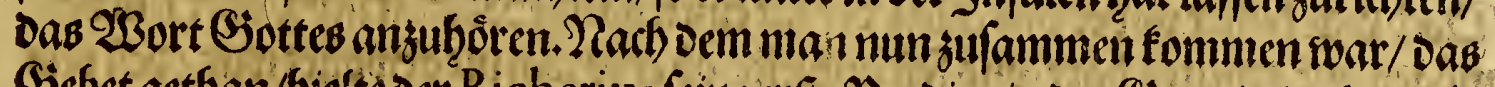

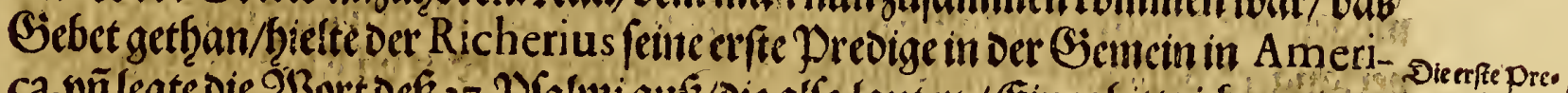

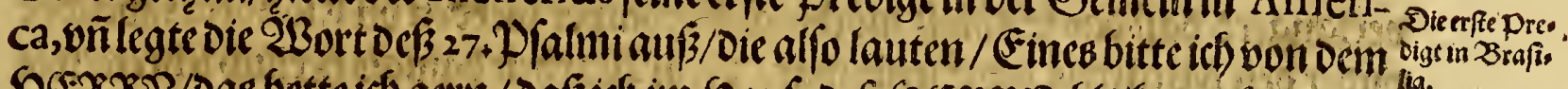

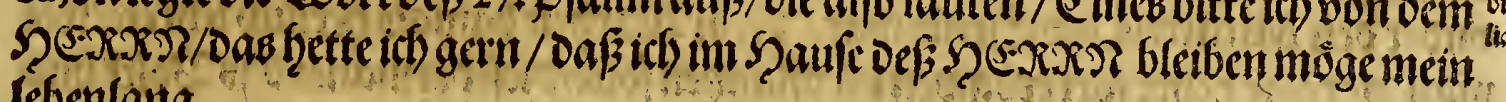
lebenlaitg.

Jit bem nun Richerius feine Predige thete/ono diefen Text erflaret/Gube

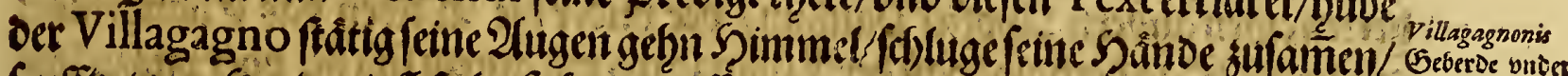

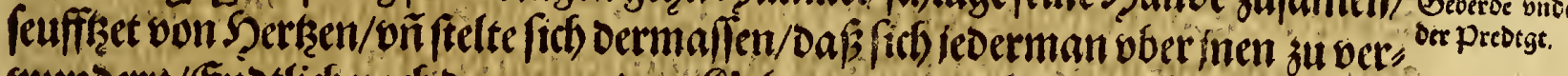

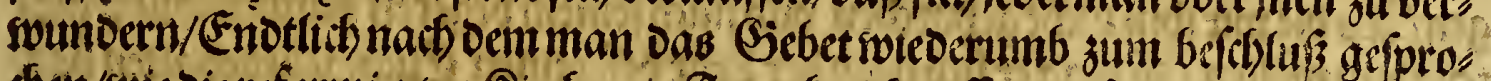

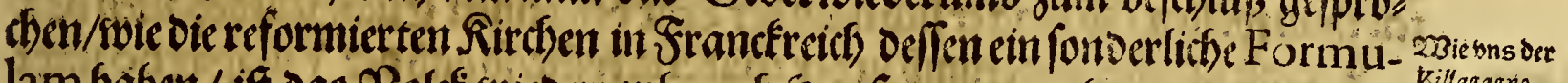

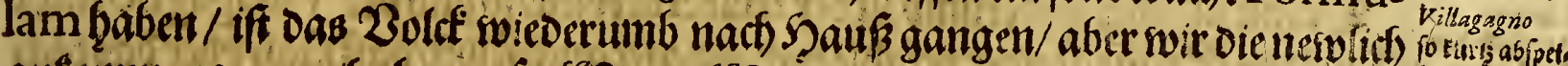

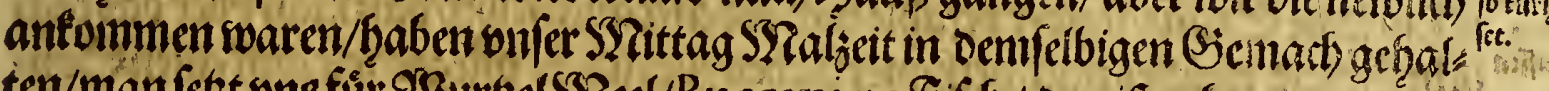

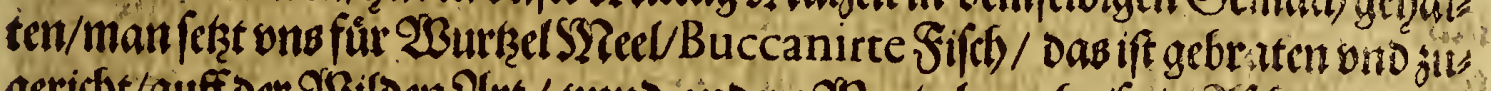

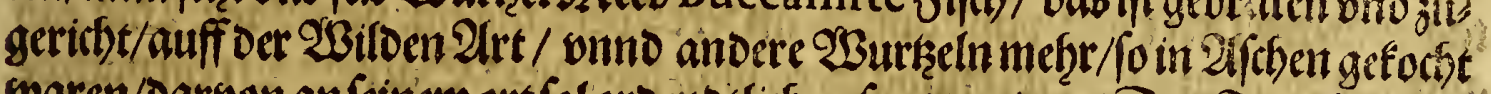
swaren/Daroon an feiriem ort fol ordenttlich gefagt werben/Dab erinden wat

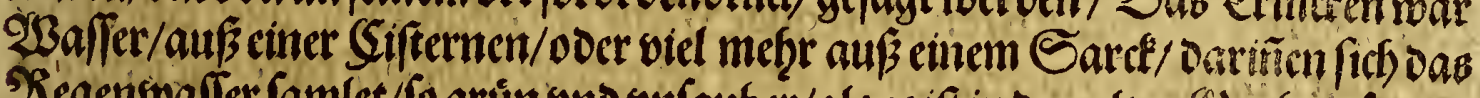
Pegentwaffer famlet/fo gruin ono vifauber/als es ift in ben alten Sraben/fo vols

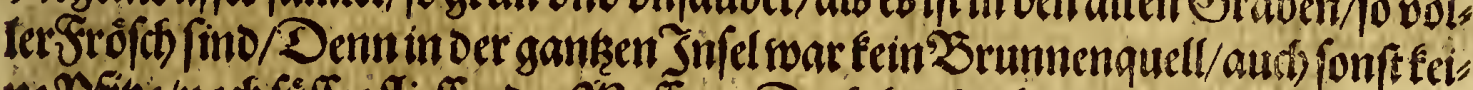

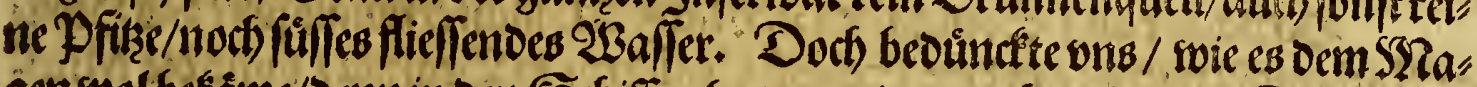
genswol befáme/Dennin den Sefiffen beatten woir es nodb pielärger. Die Collation wat endtlich.

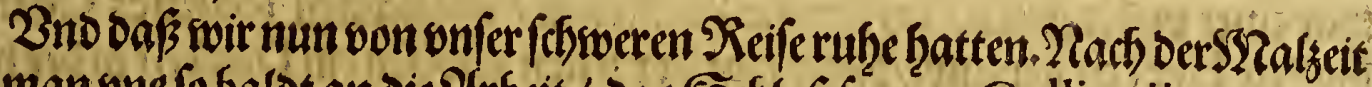
fuftet man ons fo balot an Die 2(rbeit / Das Seflofs fo man Collignijnennet/zu befeftigen. Sogar freunotlickempfieng ons oer Villagagno fo balot Dent erfen

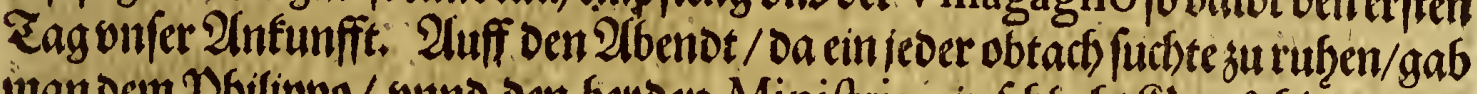

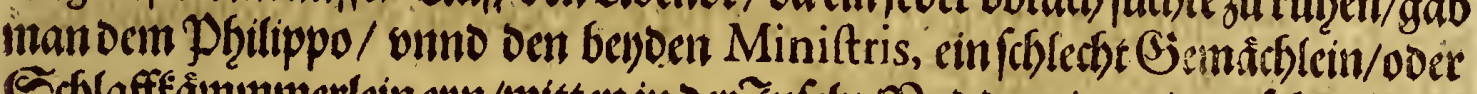

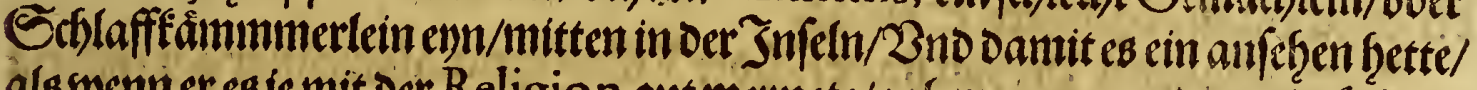
als wenn er ebie mit oer Religion gut mennete/gab man ons antern ein Stutten

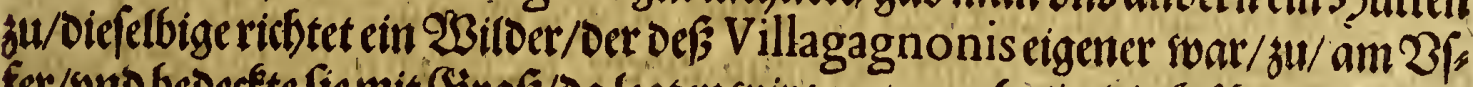

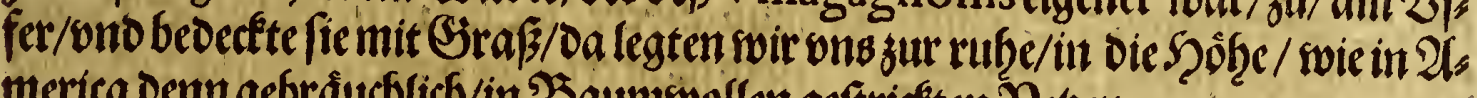

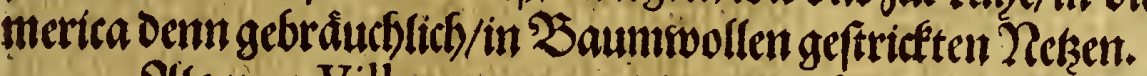

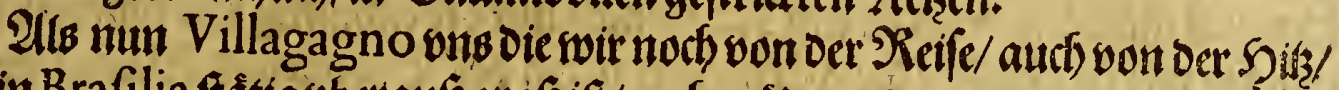

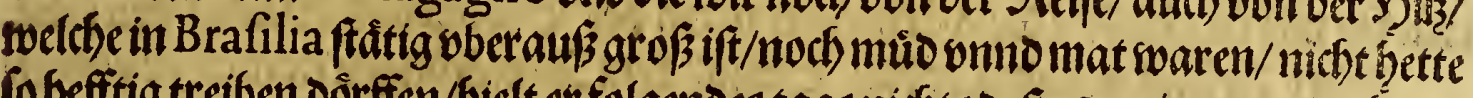

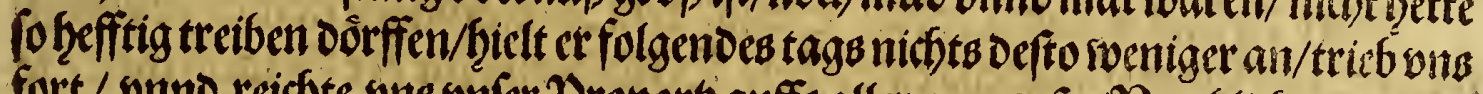

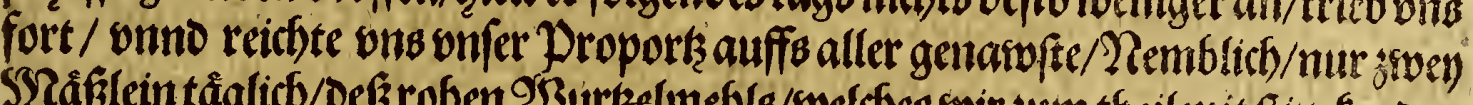

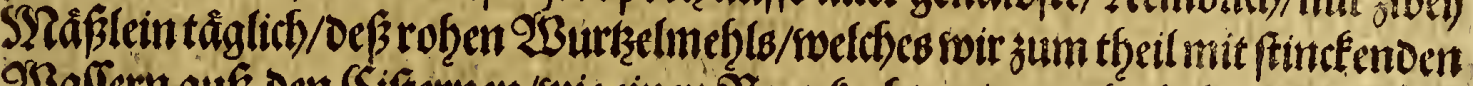
$\mathfrak{W}$ affern aus Den Sifternen/woie einen $\mathfrak{B}$ ren forften/zum theil aber robe affen/ swie andere $23 i l d e n / 3$ no muften einen Tagrwie den andern arbeiten. Solfber

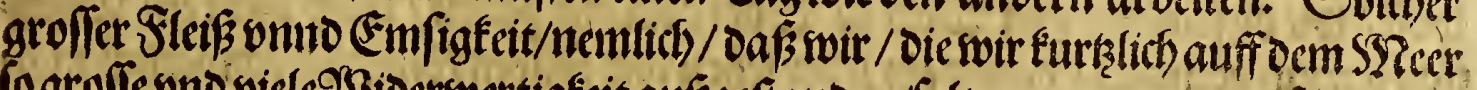
fo groffe ono viele

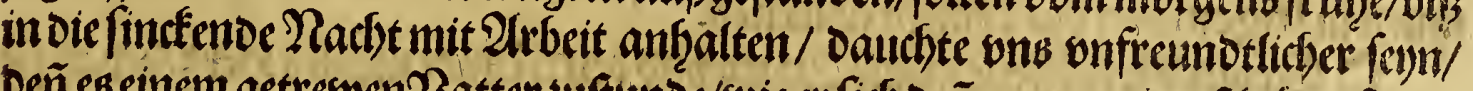

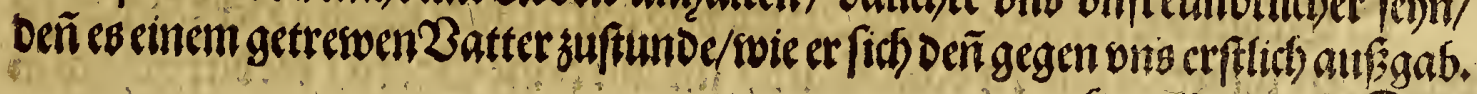

S) if Doch 


\section{Dasoritte Theil.}

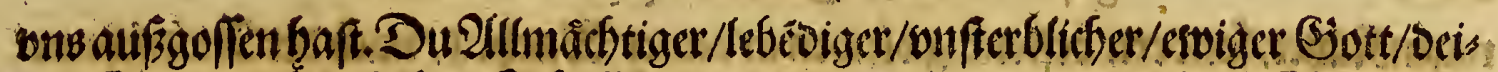

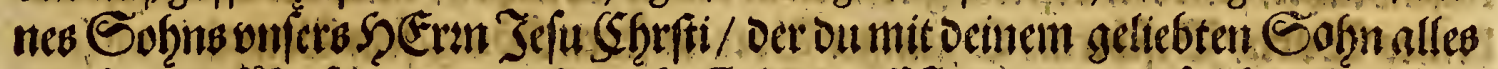

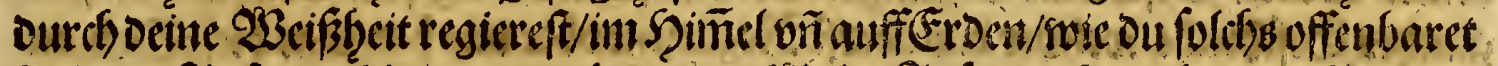

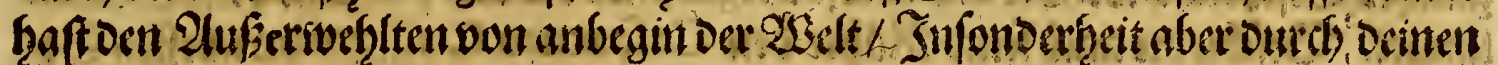
Sofn/Den ou in oie 2 Belt gefanot/ourch oe ou dich ons theilsafftigmacheft. Det

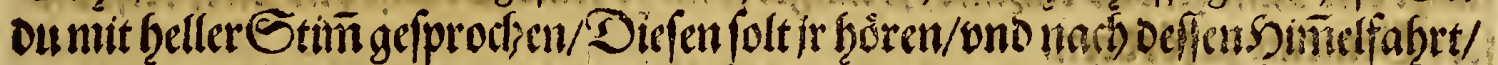

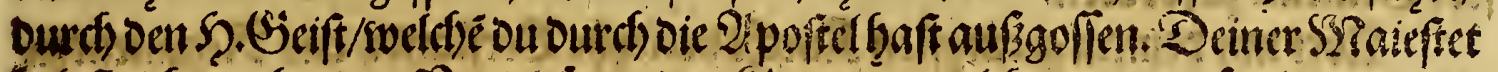

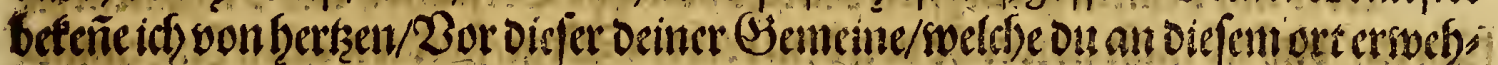

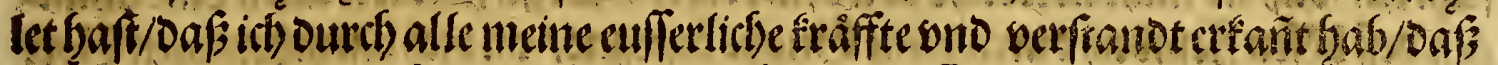

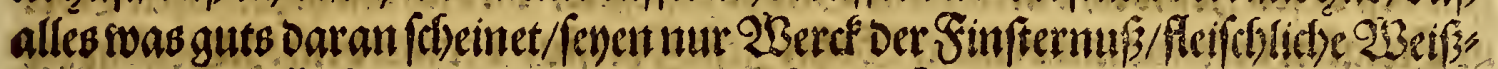

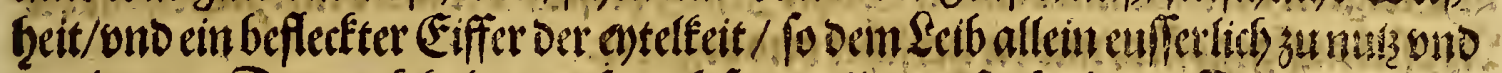

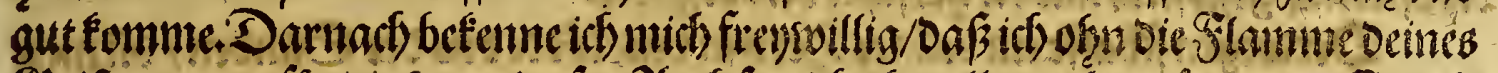

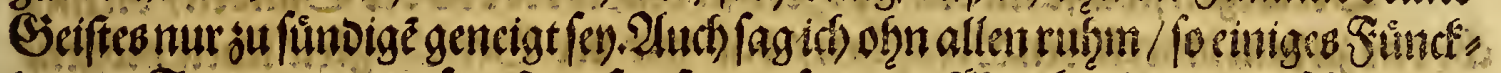

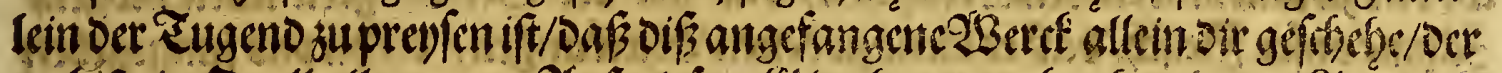

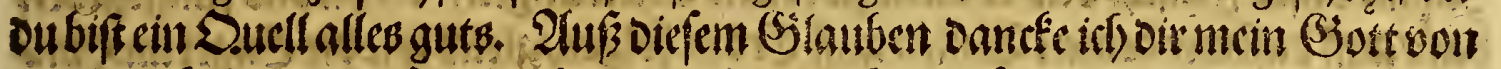

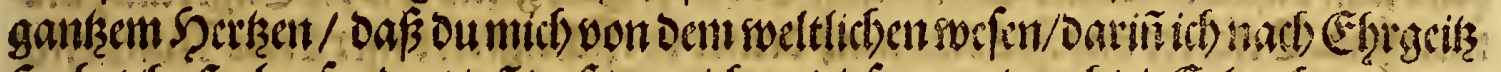

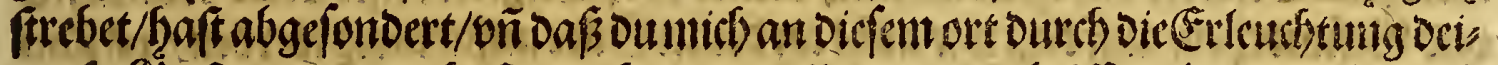

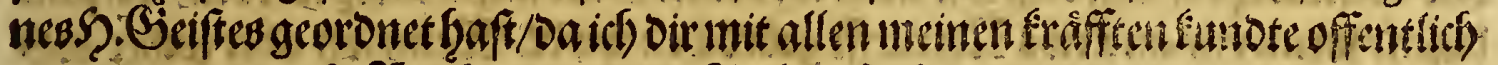

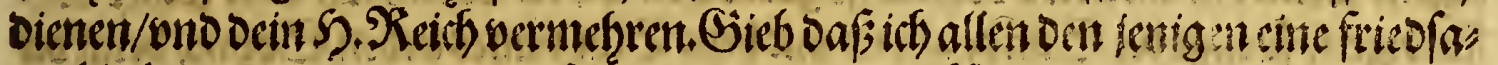

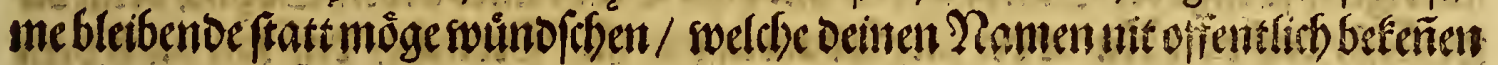

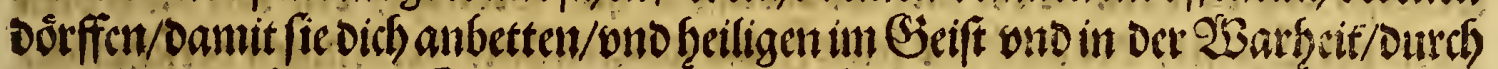

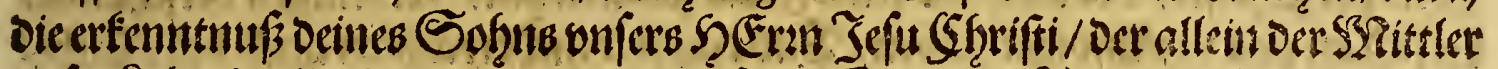

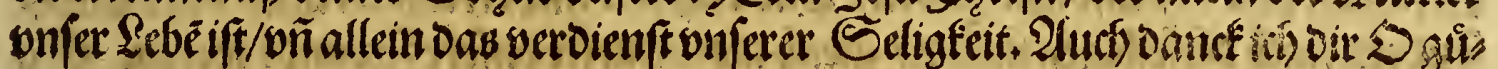

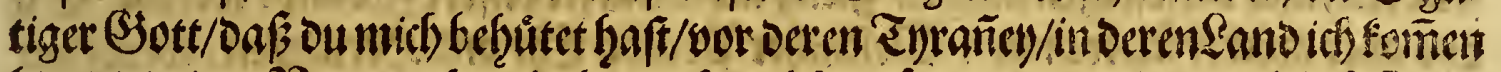

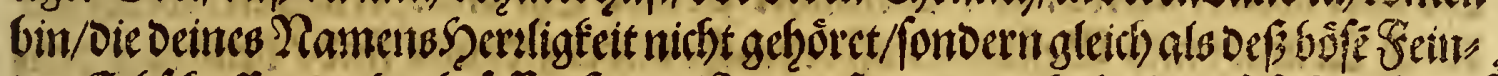

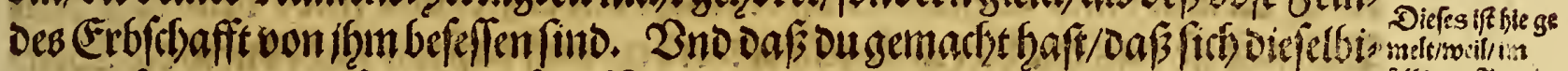

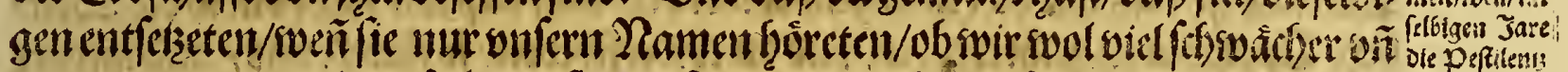

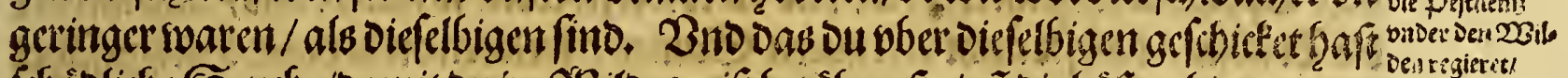

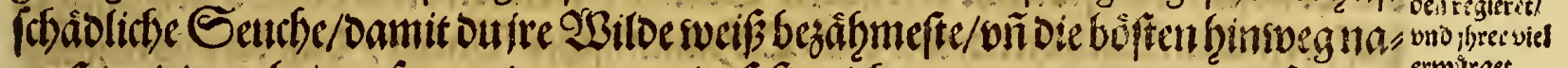

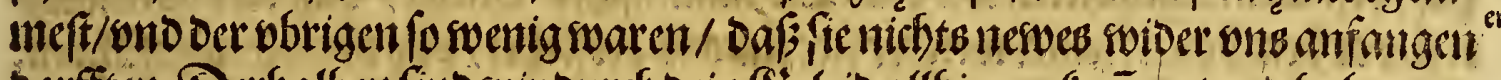

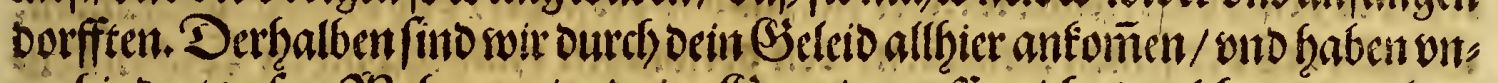

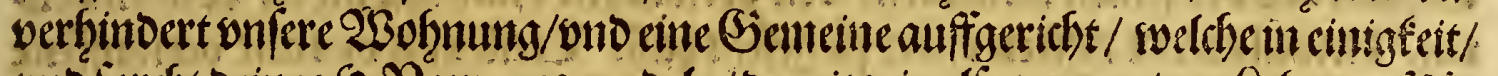

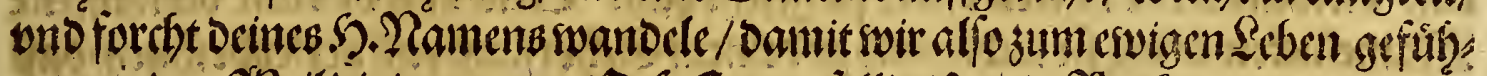

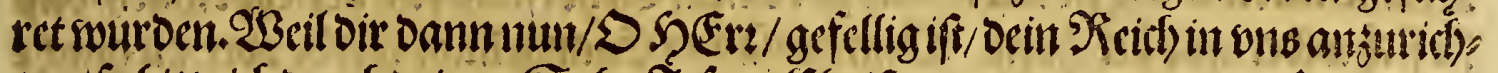
tew/ fo bitte id) ourel) ocinen Sofn Jefuni Shriftum/ Den ou ju cinem Dpfer ge

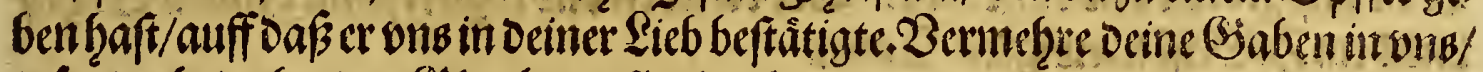

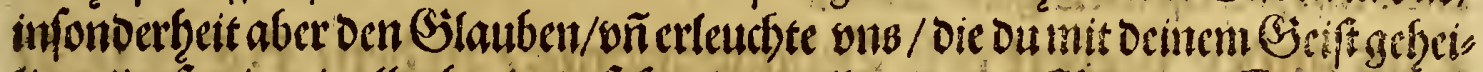

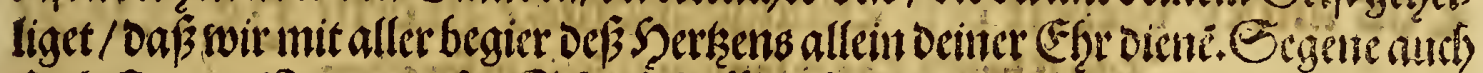

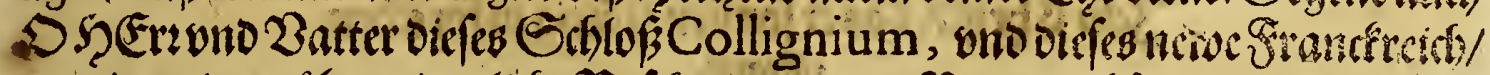

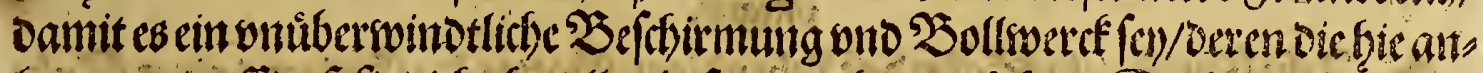

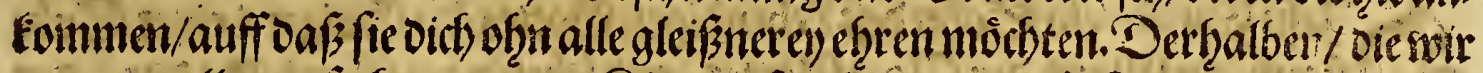

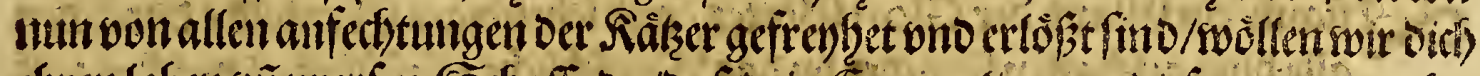

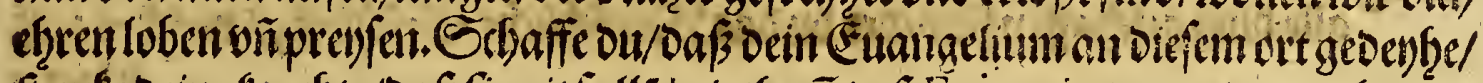

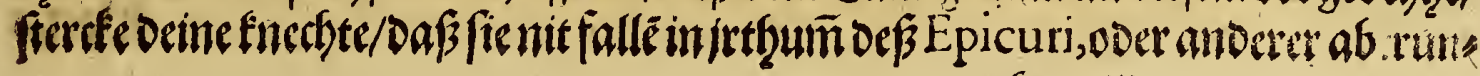

$$
\text { S马 iil nigen }
$$




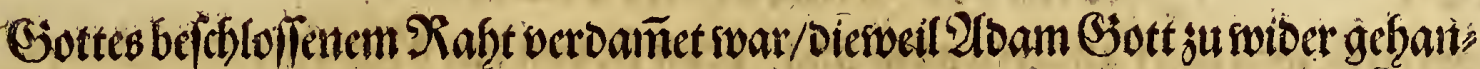

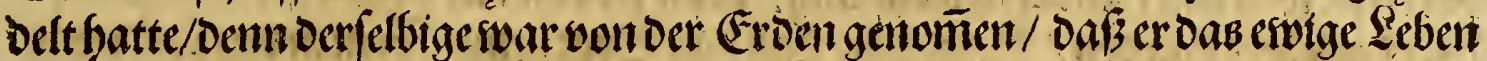

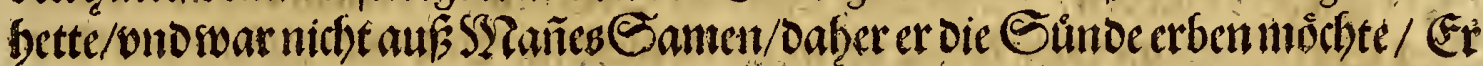
rwar mit allen Iugenben/auth mit bem Sreven willen begabet/fedocbonoergab

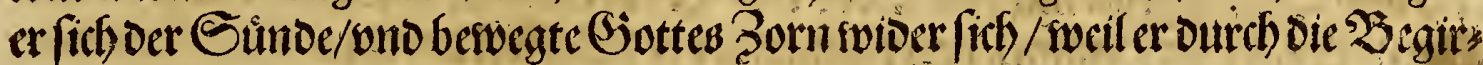

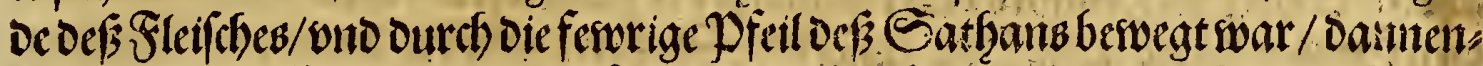

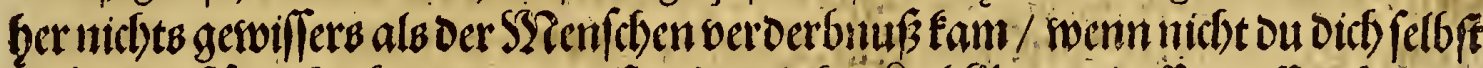

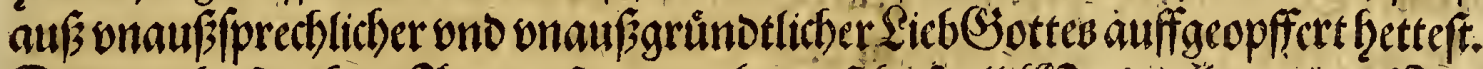

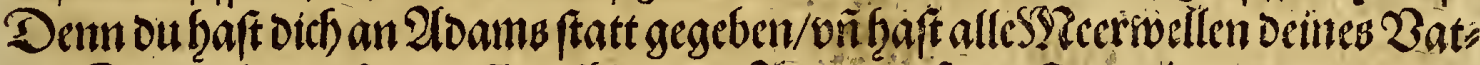

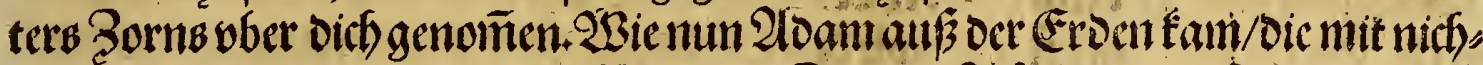

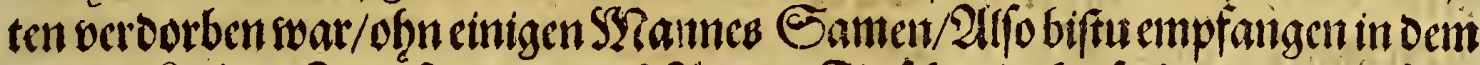

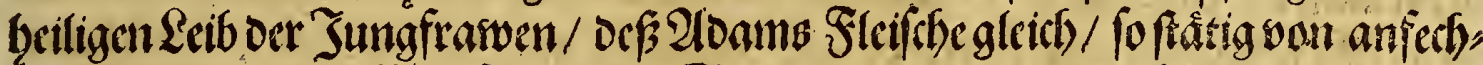

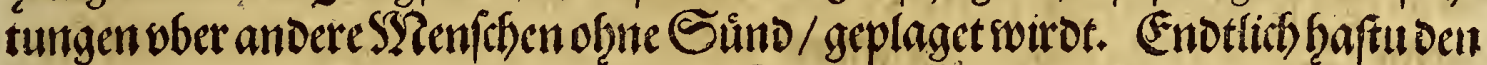

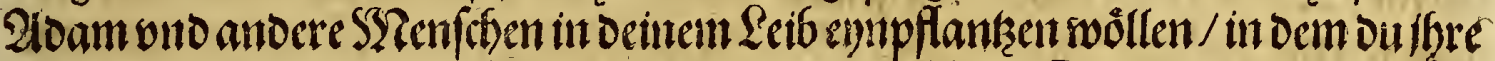

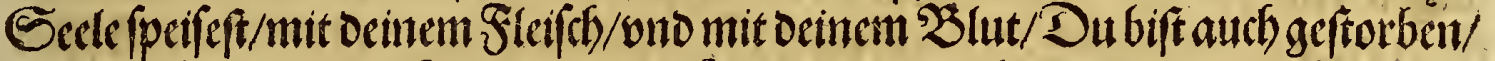

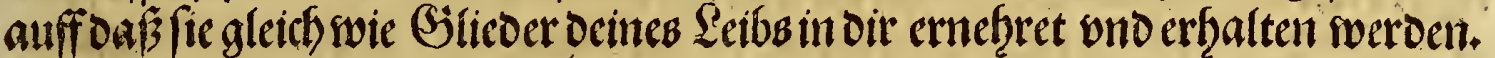

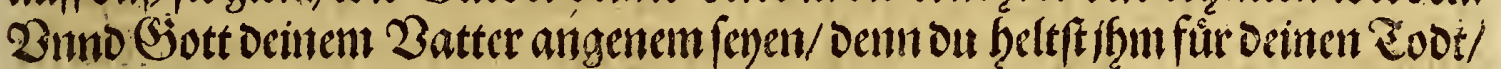

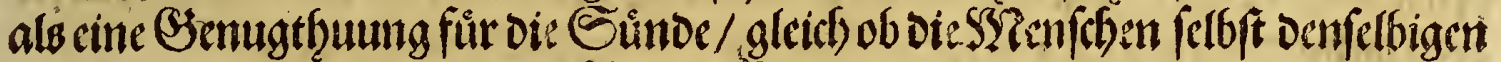

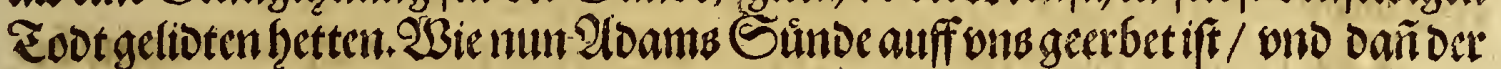

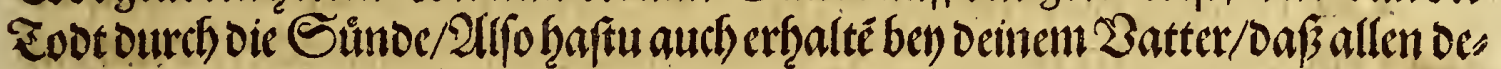

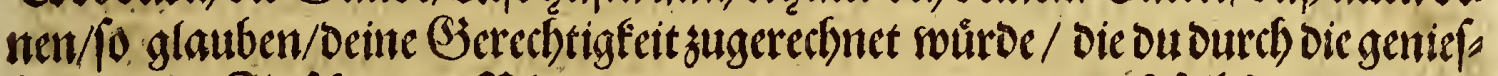

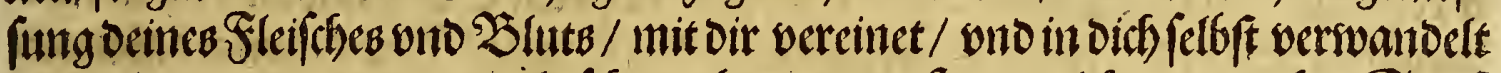

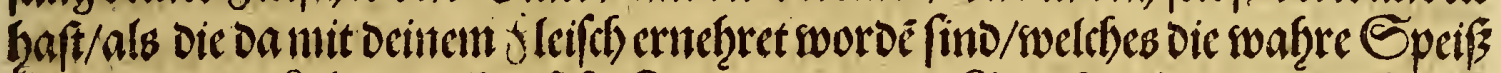

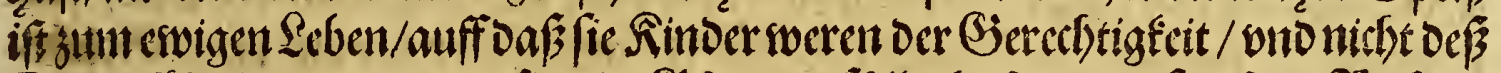

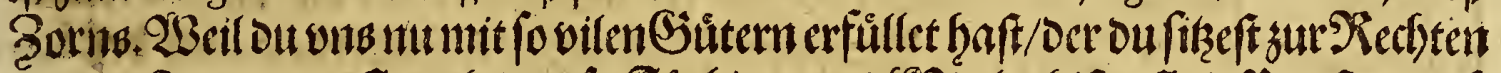

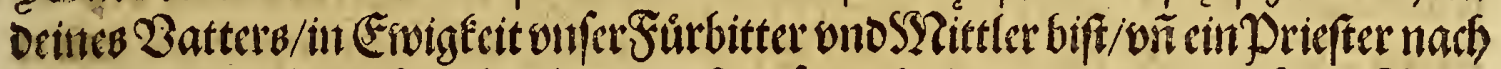

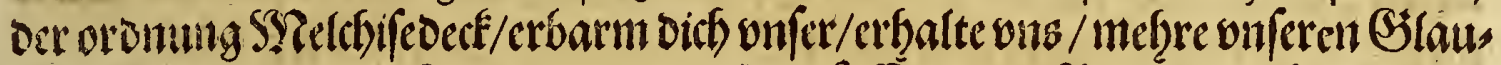

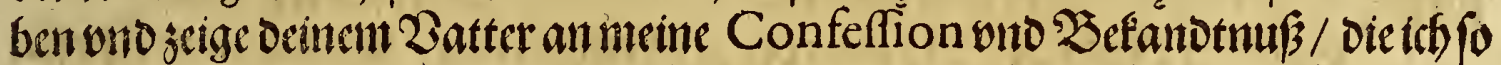

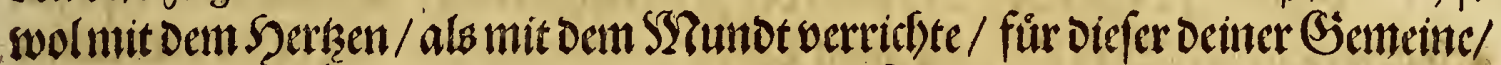

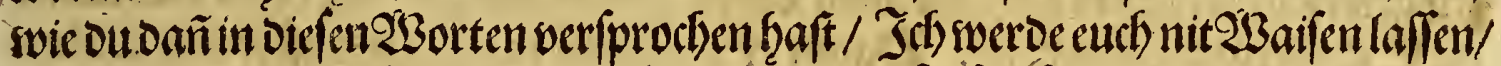

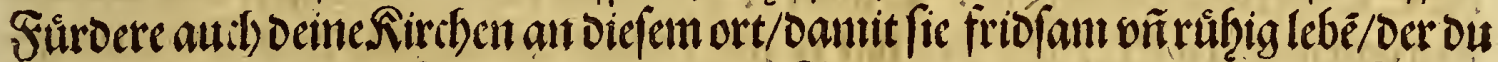

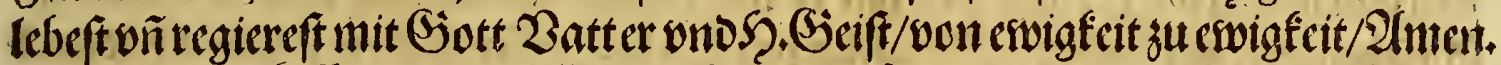

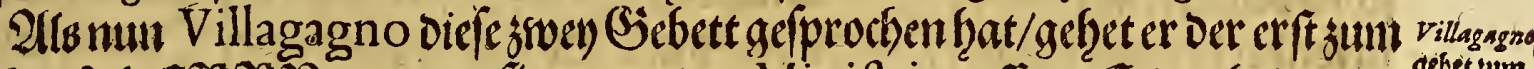

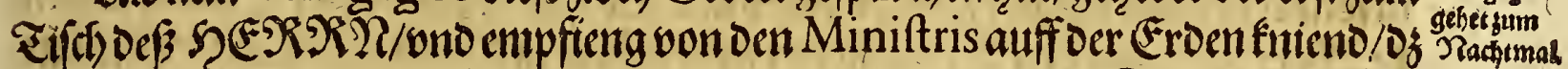

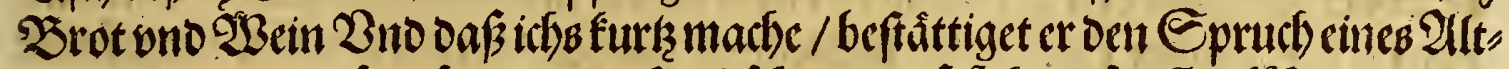

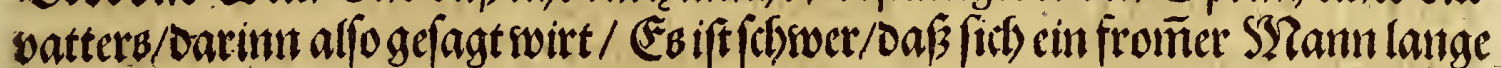
feit verlångnen foll. Dennody/ob wolerono ber Cointas alle bewoedas $\mathfrak{B}$ apft:

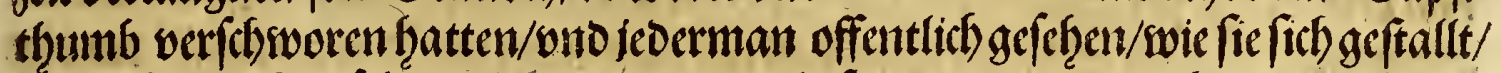

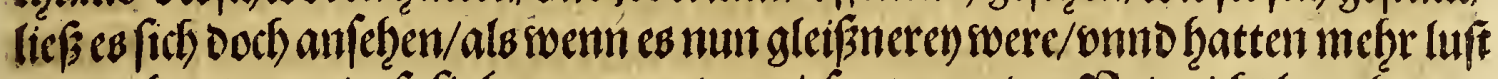

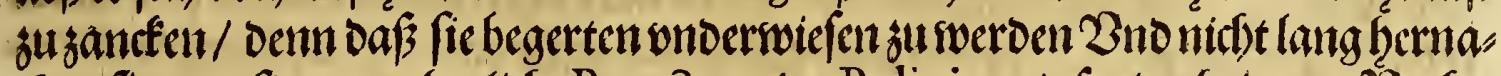

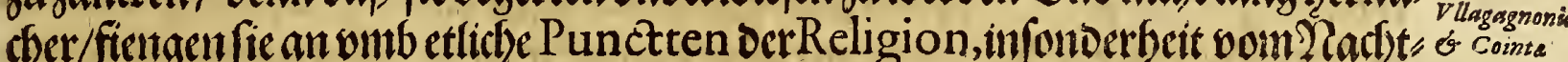

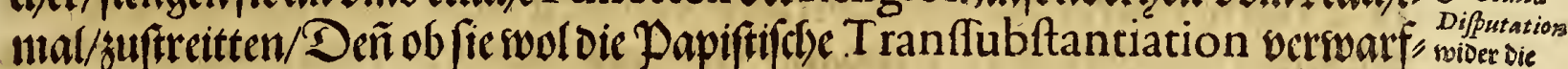

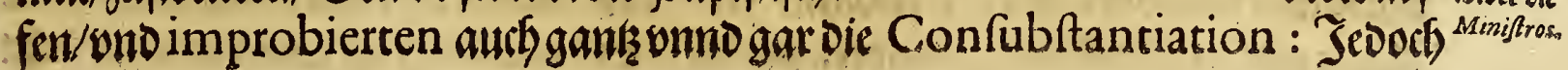




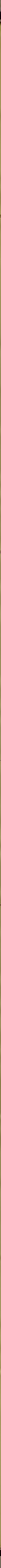


Oas britte Thent 125

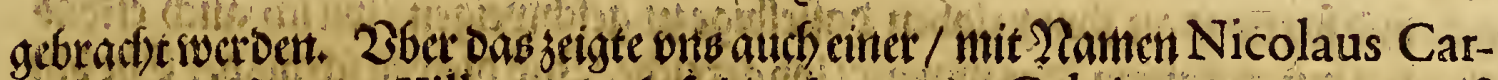
neus, an/o af im oer Villagagno befollen bette/oem Caluino anjusetgen/oaf

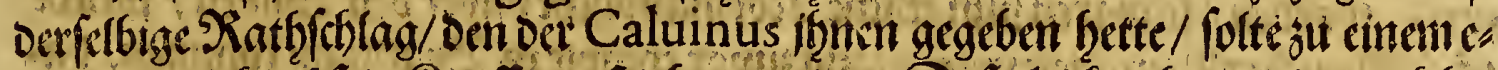

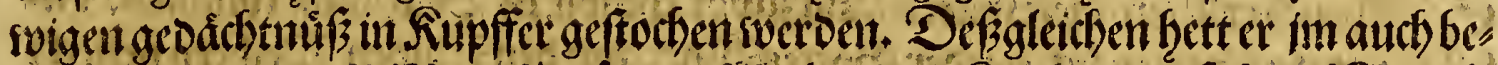

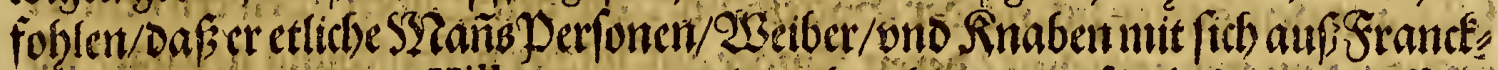
reich braichte/onno det Villagagno wolte cs besalelen/roas für foftet Darauff ges benswitrde.

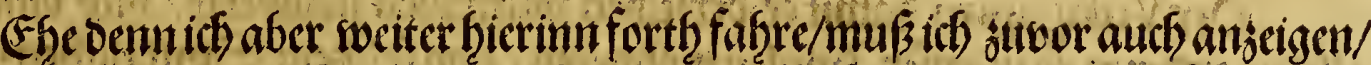

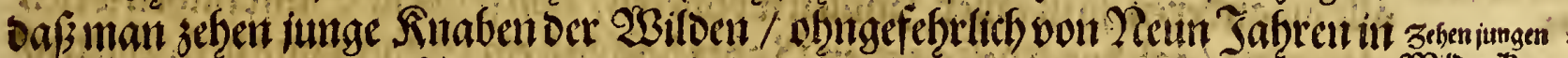

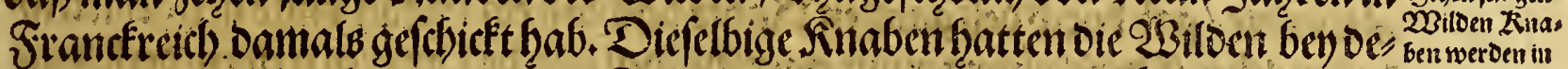

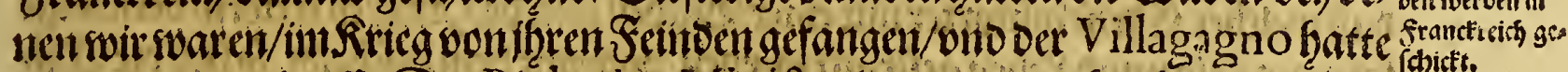

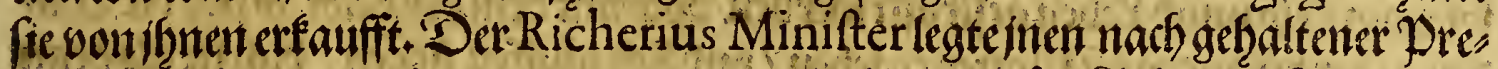

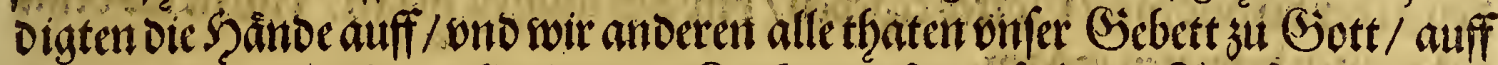

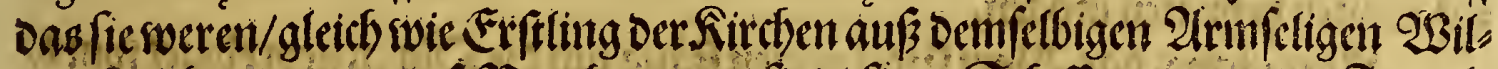

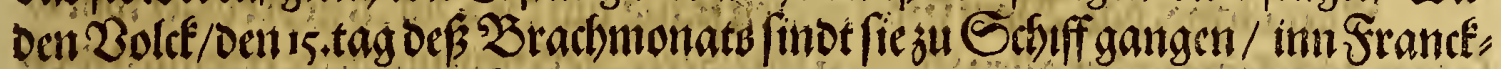
reich gefegelt / ounto dem. Rönig Stenrico der Damals regieret/ prafentirt soor"

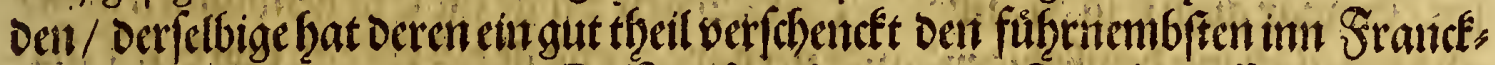

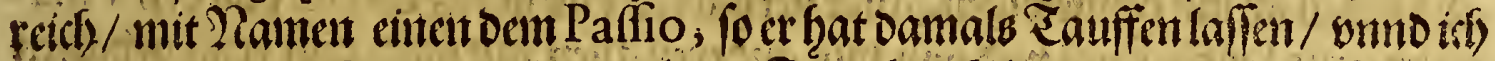

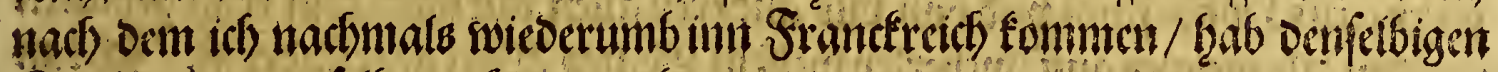
Sitaben ben Demlelbigeu Serzen erfenitet.

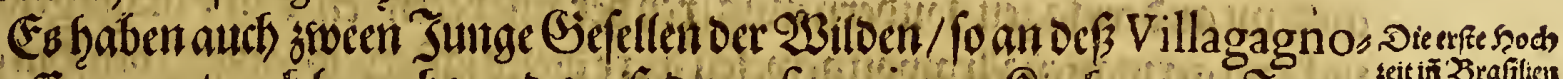

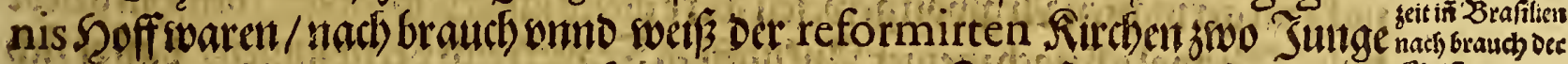

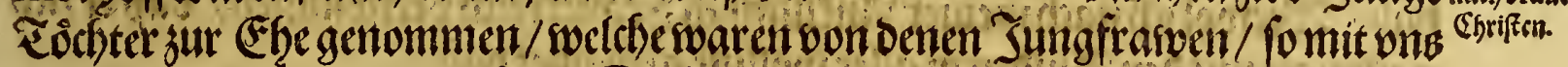

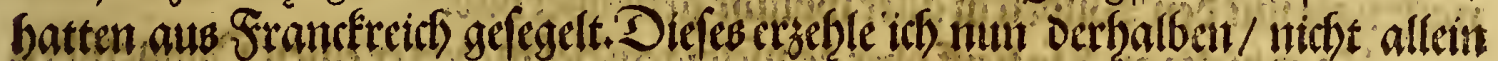

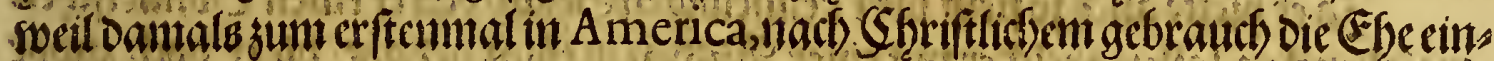

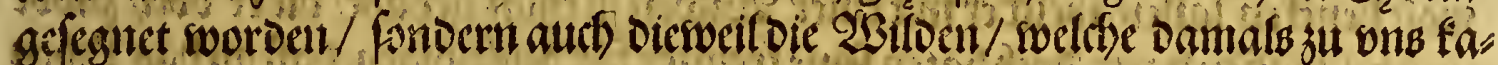

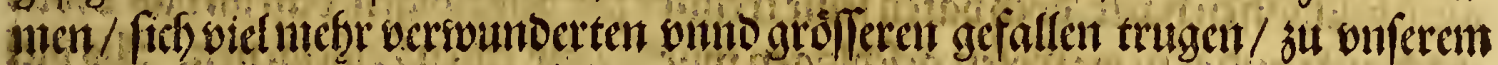

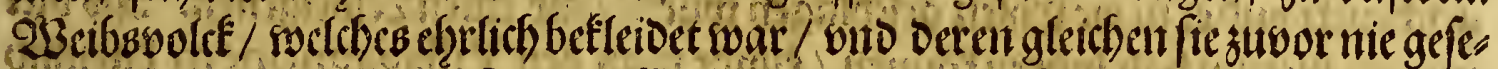

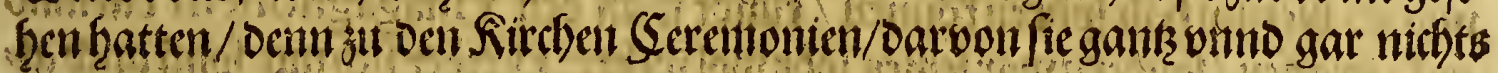
ocrítundell.

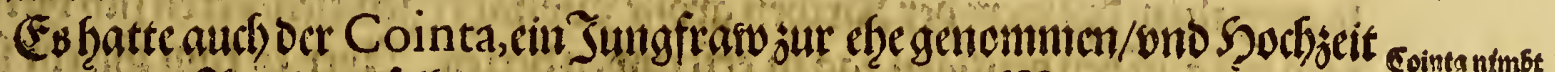

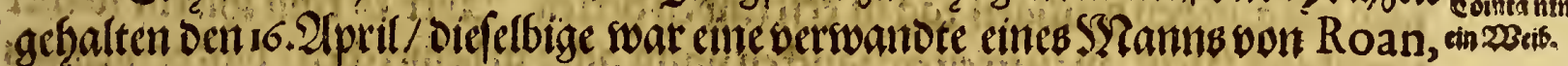

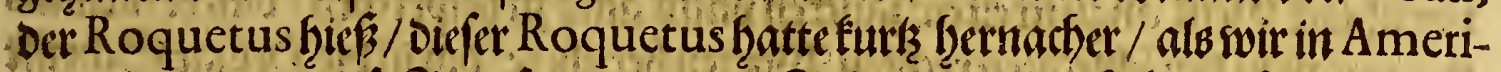

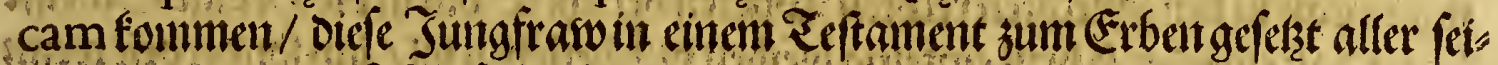
ner war/ oie er mit fict geführt hatte/ono war balot oarnadb ocr ftorben/EB war

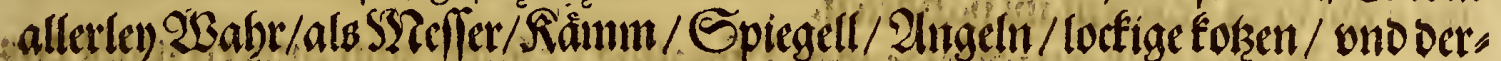

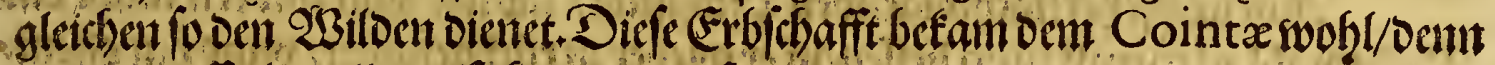

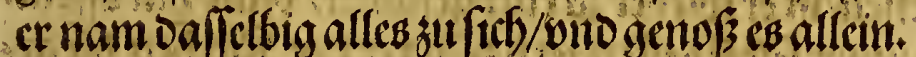

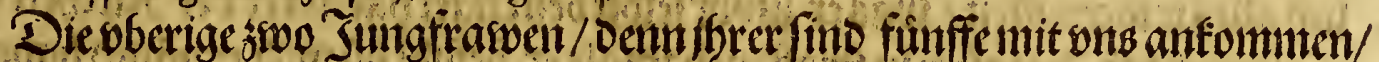
swie oroben gehort/ Die faben sween Der Pormandifchen Doimetfeben genom,

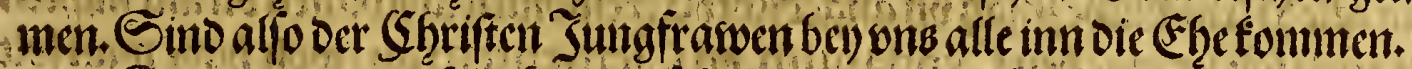

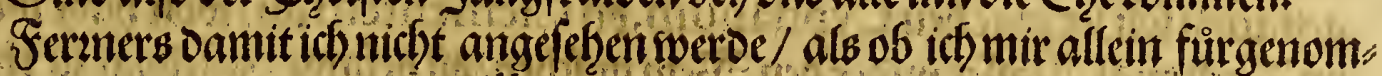

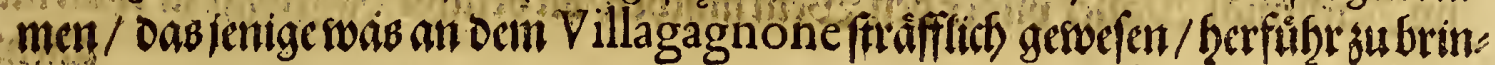

Э $\mathrm{gen}$




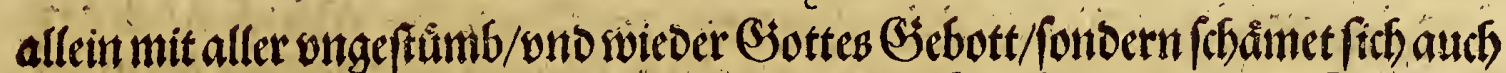

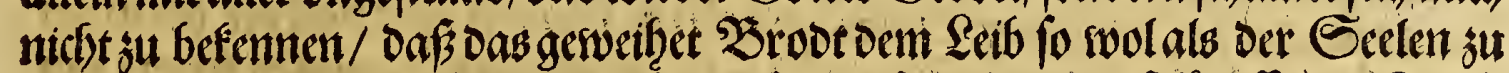

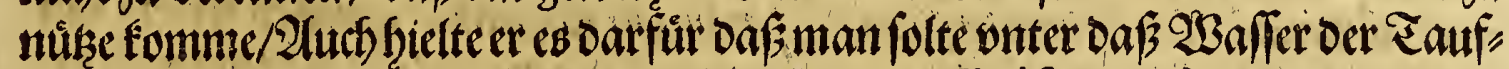

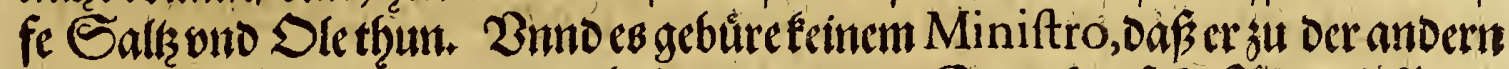

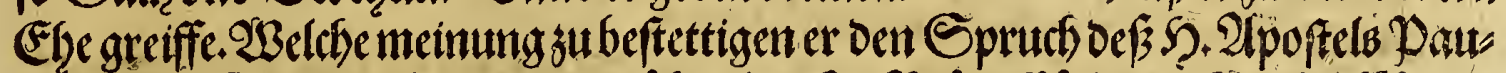

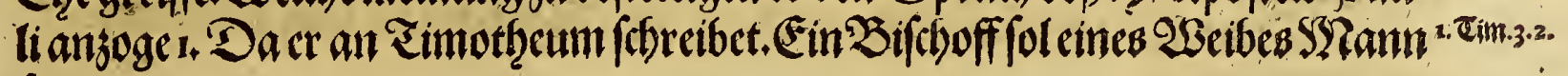
fein.

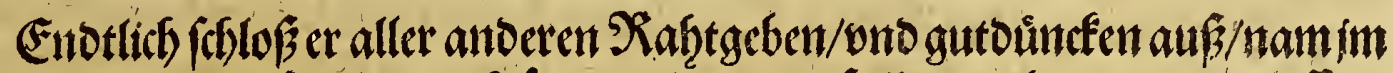
allein gerwalt / alles forthin nach feinem eigenen gefallen zu thun onno zulanjen/

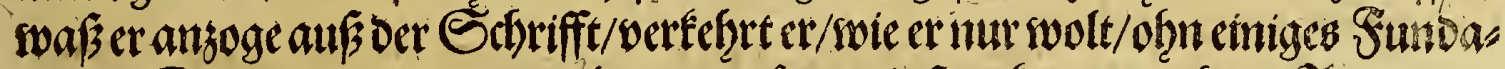

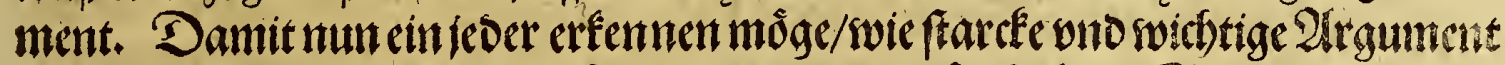

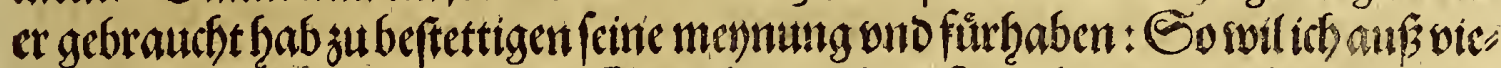

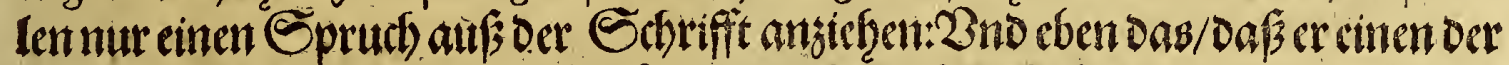

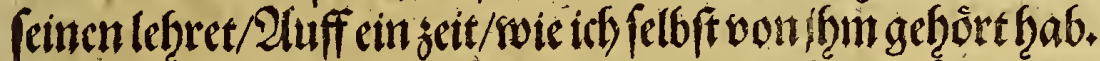

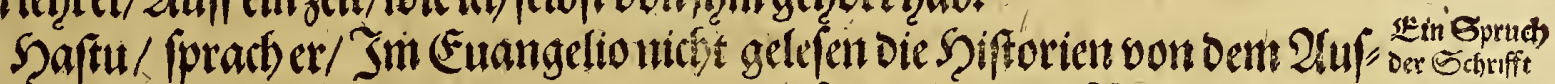

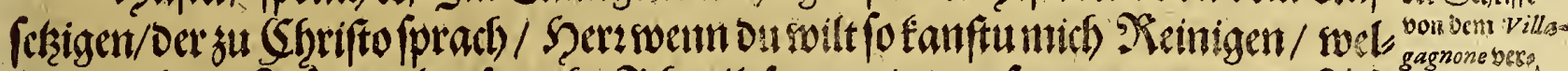

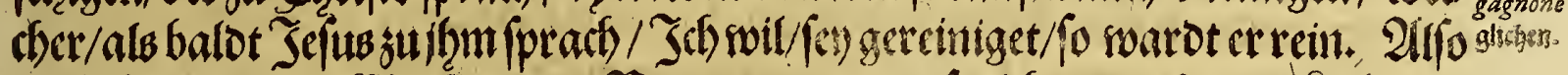

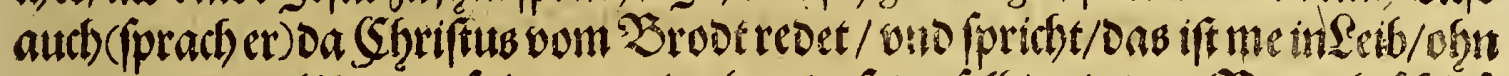

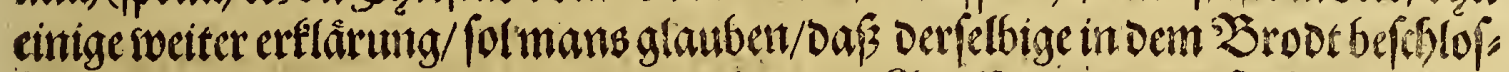

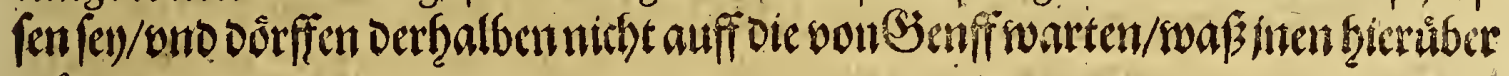
trâuromet.

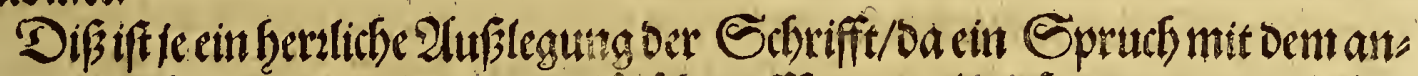

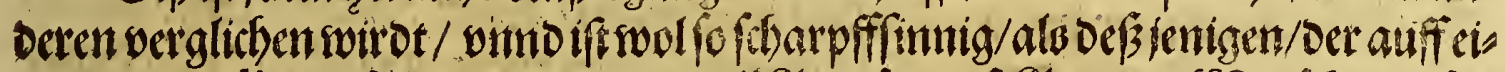

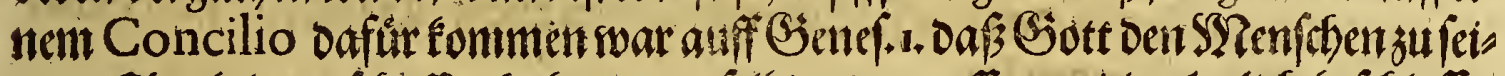

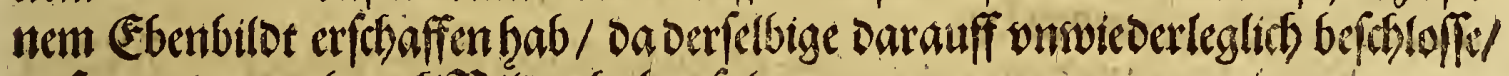
Dấ man barumbauch' Silder faaben folte.

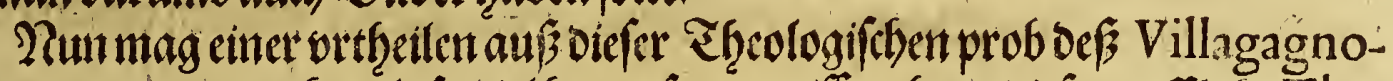

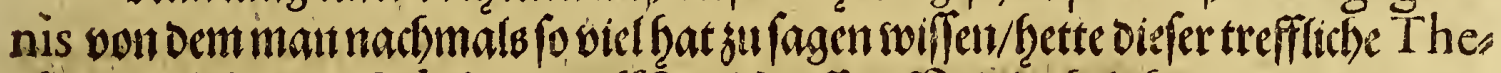

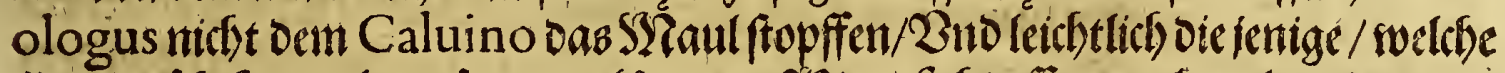

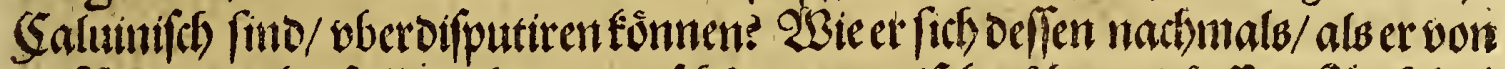

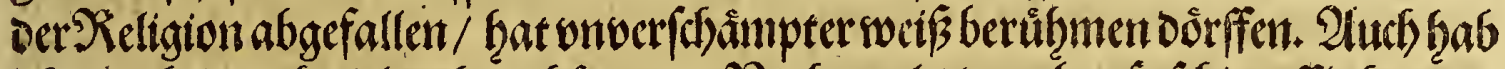

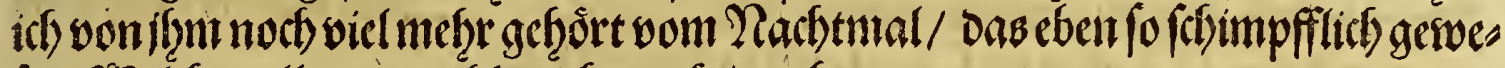

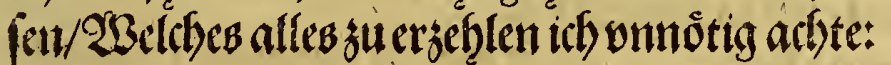

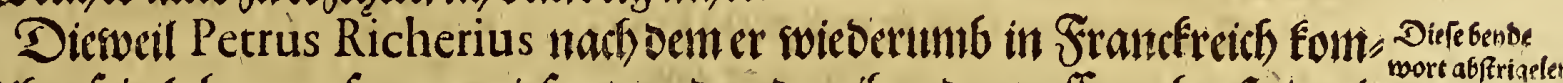

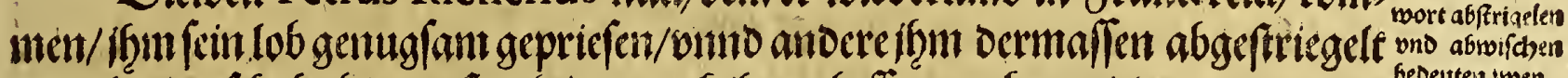

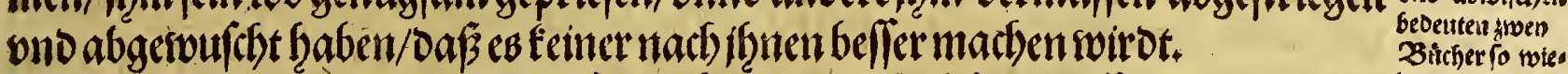

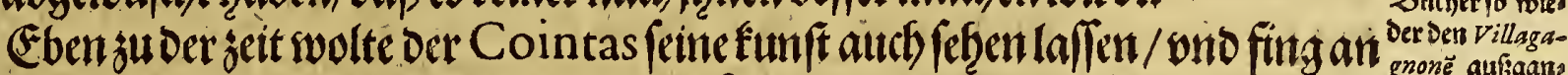

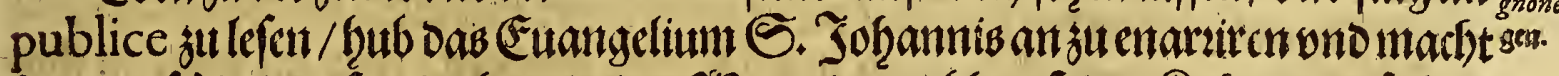

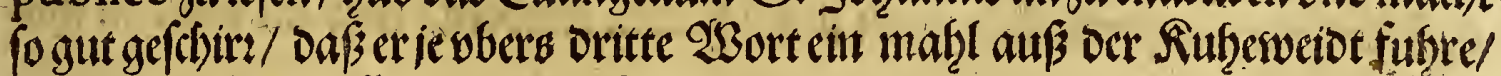

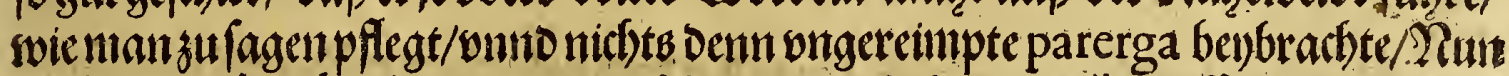

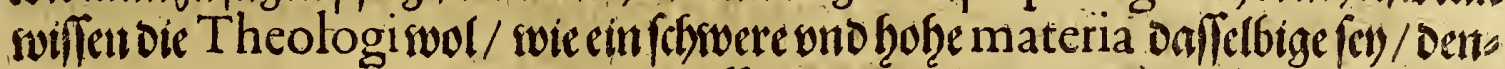

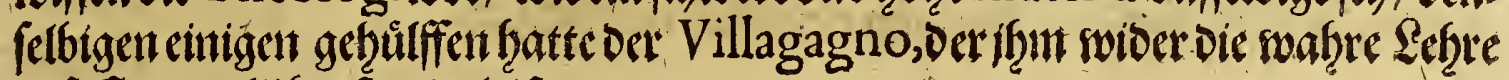
oes (Euangelif ben)|tand leifte.

ร il : Nut 


\section{Sas britte Therl.}

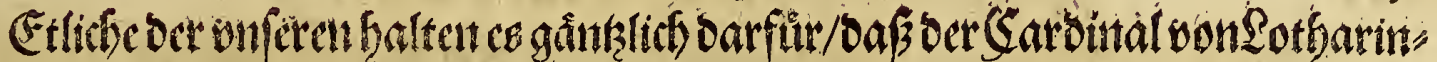

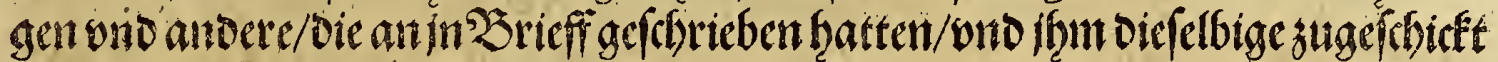

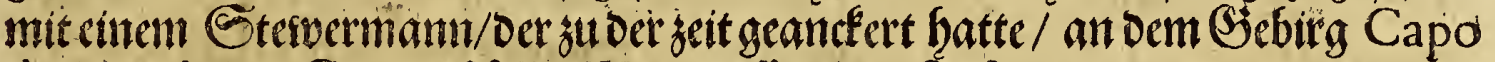

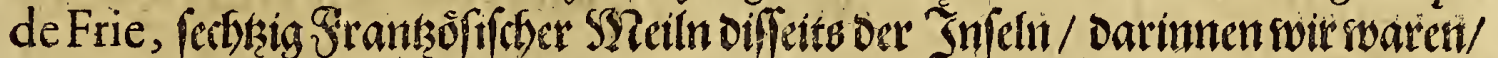

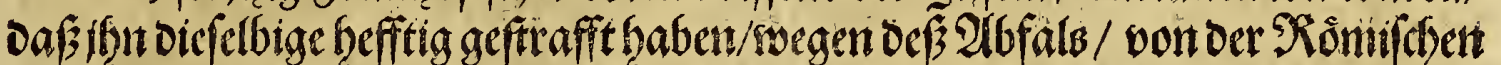

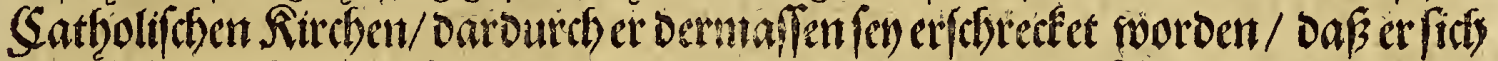

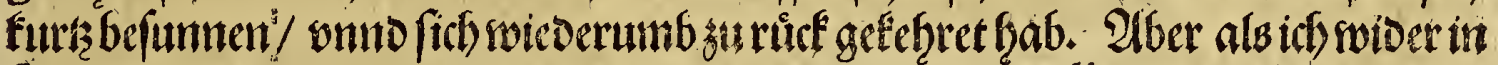

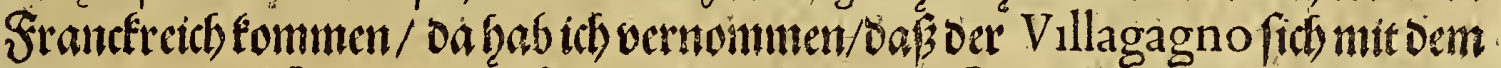

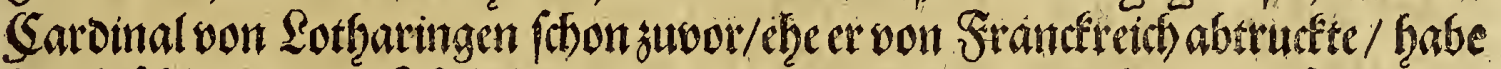

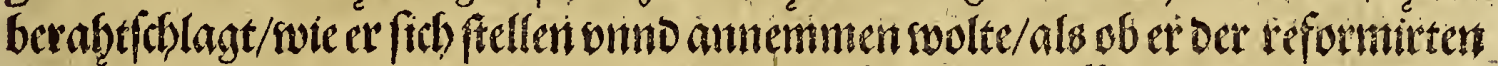
Religion jugethan were/ oamit er bei) Dem 2lmiral Collignio offo grôfere

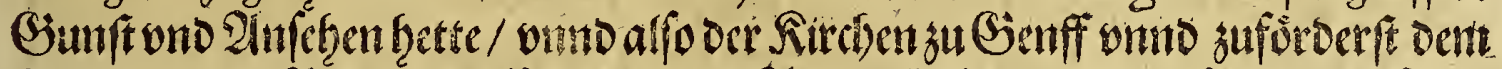

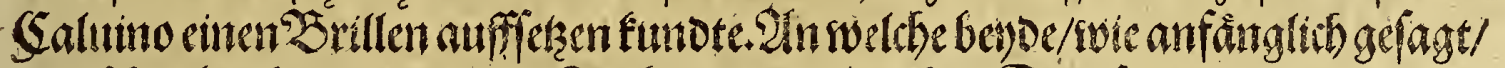

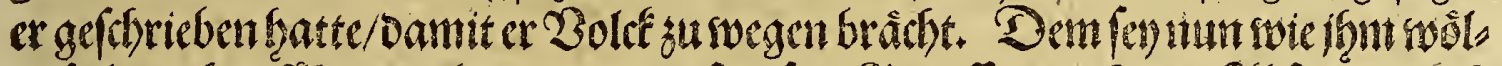

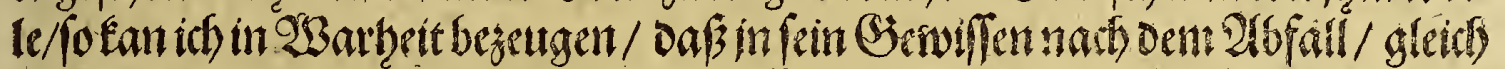

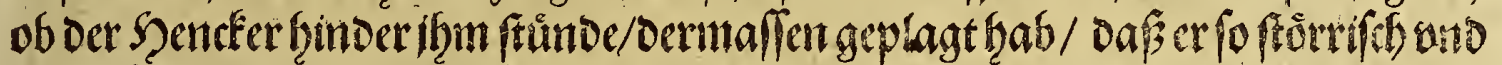

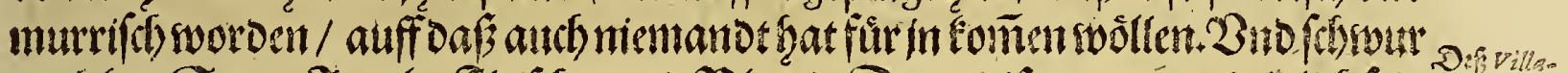

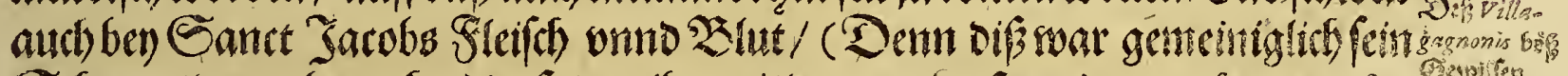

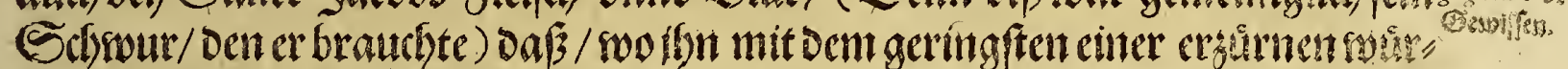

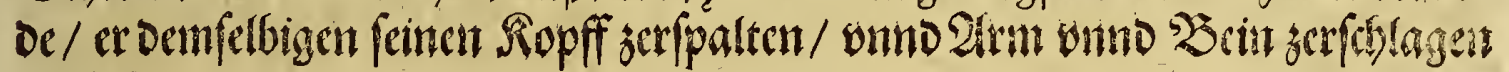
noolle.:

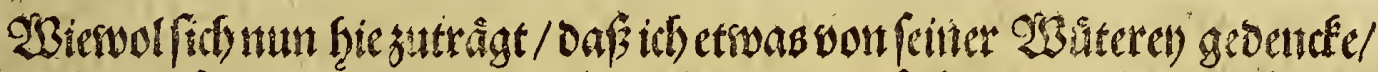

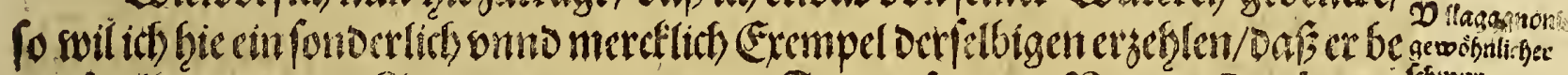

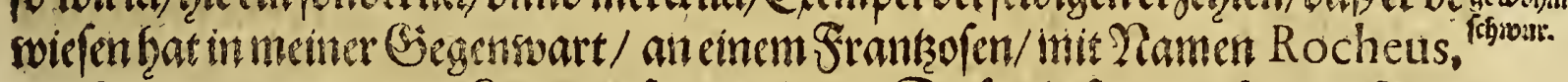

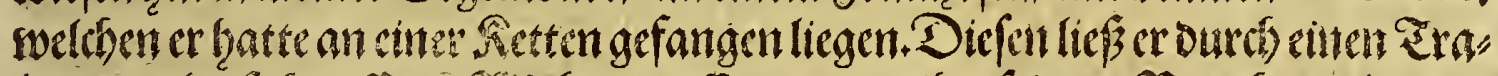

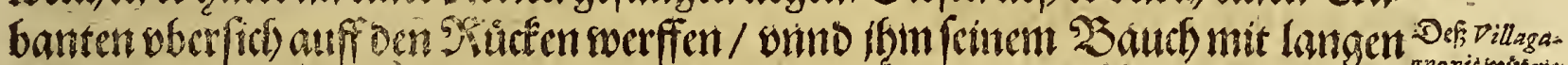

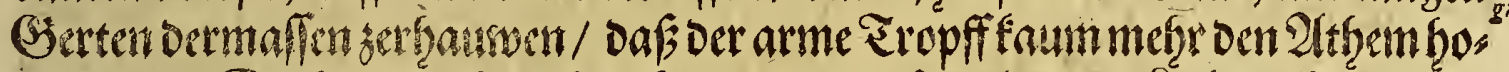

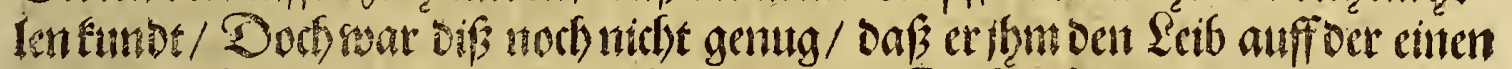

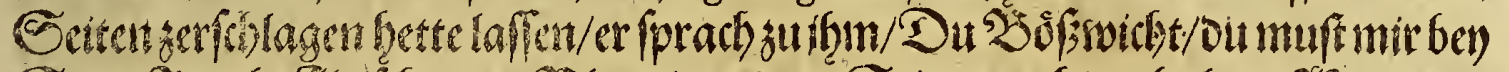

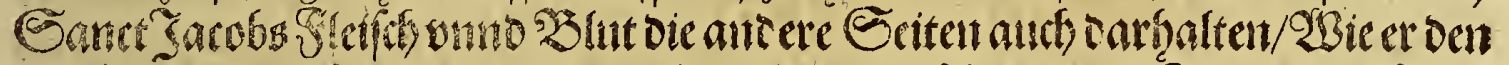

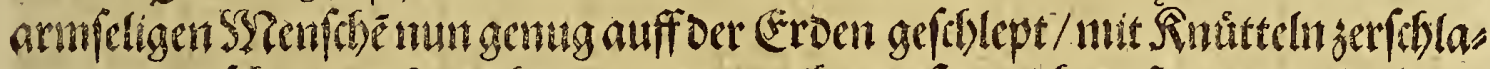

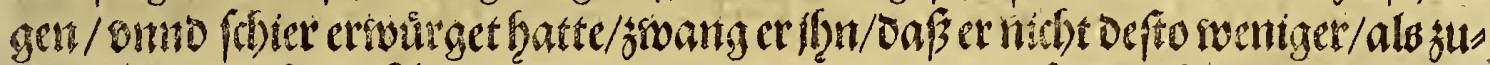

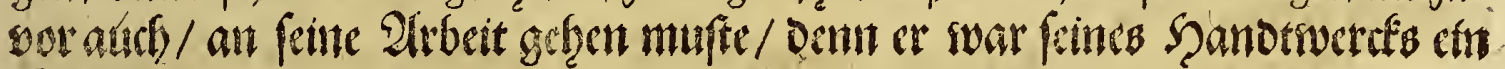
Eefgecinter.

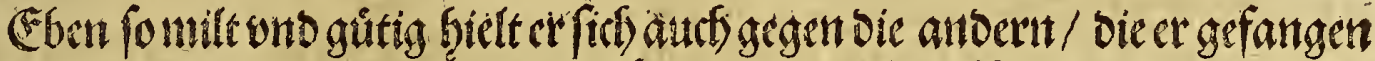

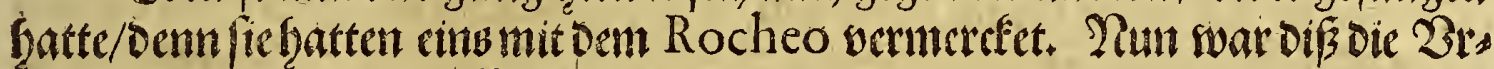
facte/Eb gatte firb oer Villagagno fo gar wbel gefalten/ ebce oann wir ba antas

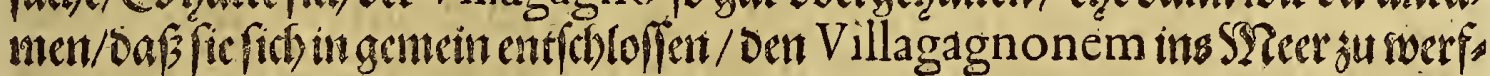

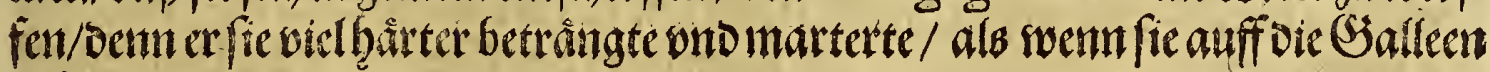
gefthinioetwereit.

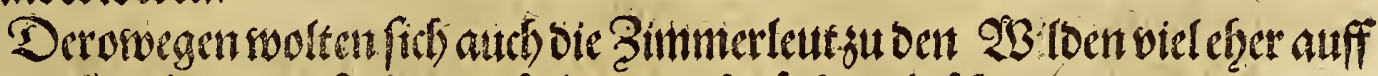
Das Sand begeben/weil fie bey) Denfelbigen nicht fo hart befebweret wourden/Dent Dấf fie Dalinger folten fo groffe Zurben tragen.

$$
3 \text { iif } \quad \text { Dief }
$$




\section{Bas britte Theil.}

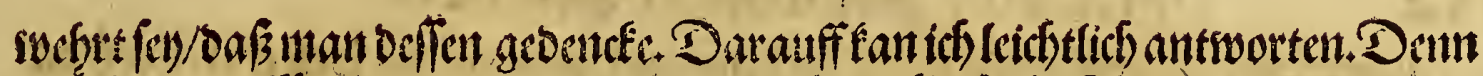

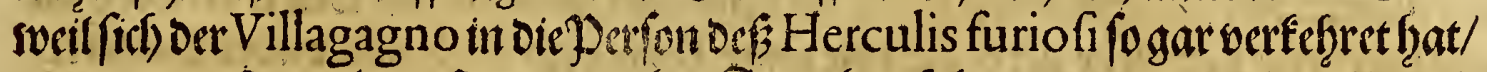

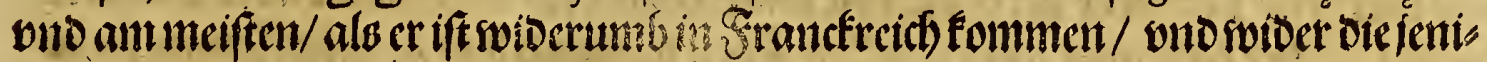

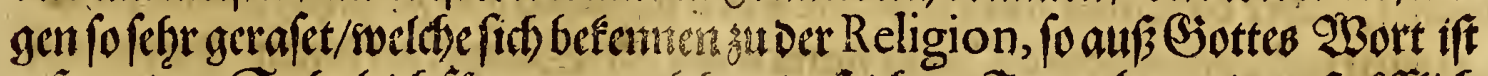

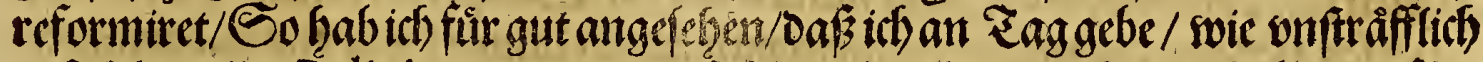

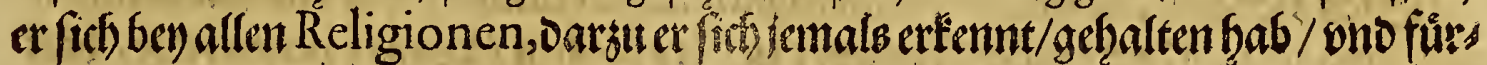

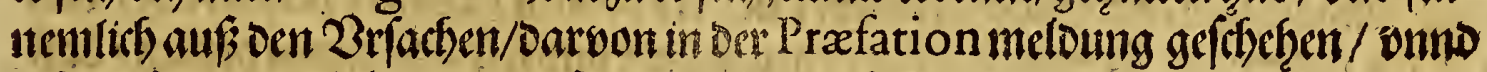

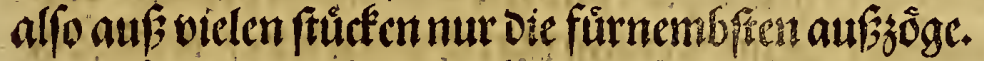

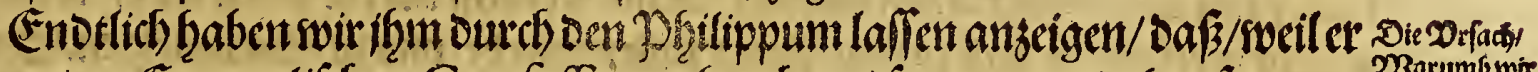

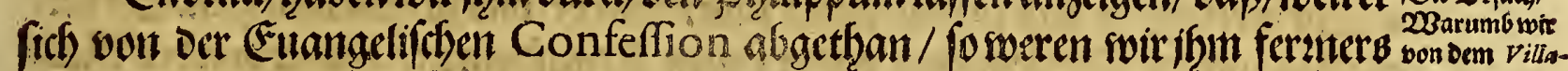

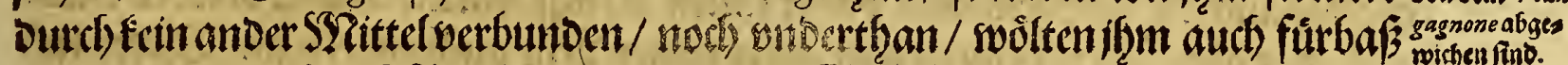

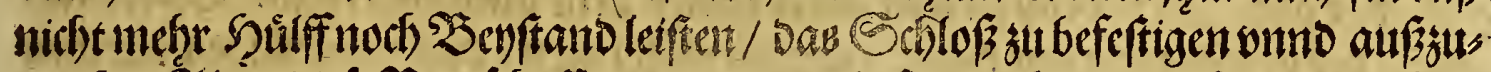

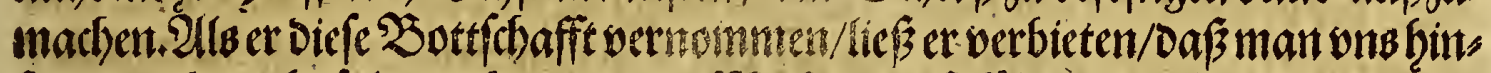

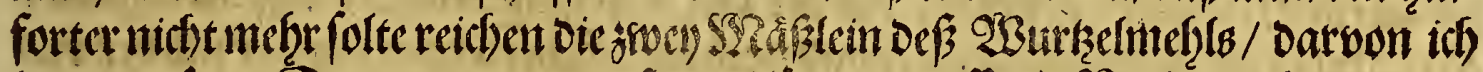

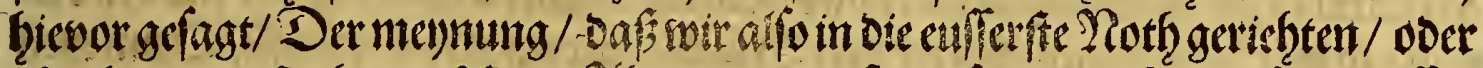

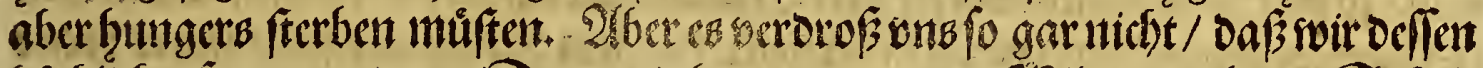

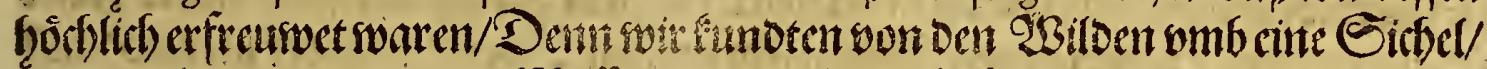

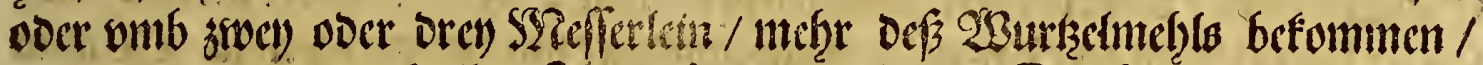

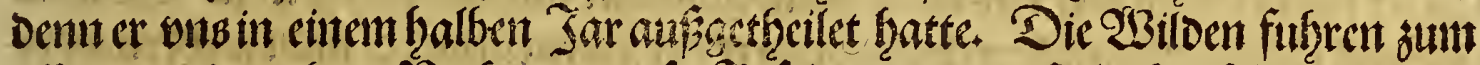

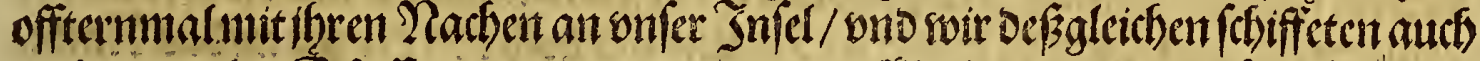

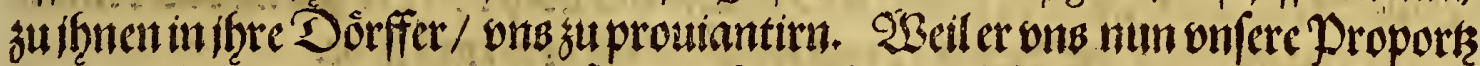

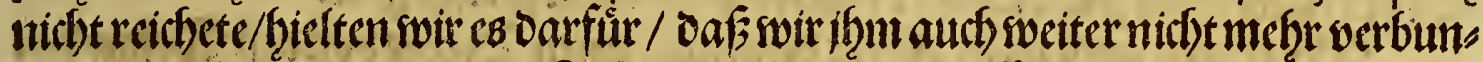

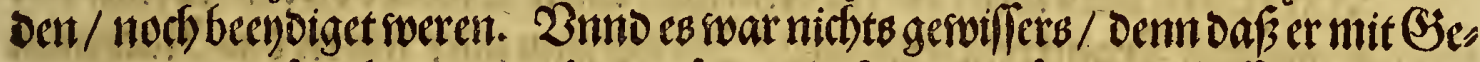

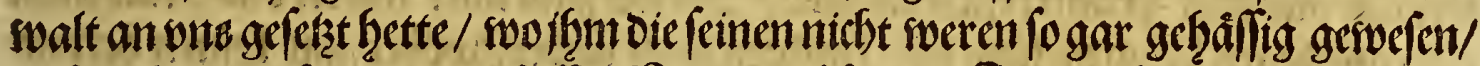

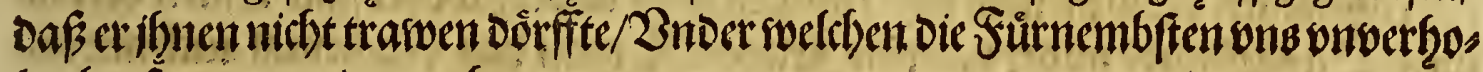
Ien bey)funden vilo gugethan soaren.

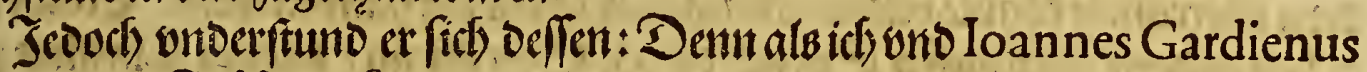

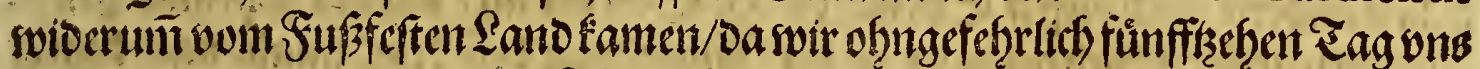
auffgebalten fiatten/ nam er fict) an / als soem er nichts swúlte/omb oic verlaubs

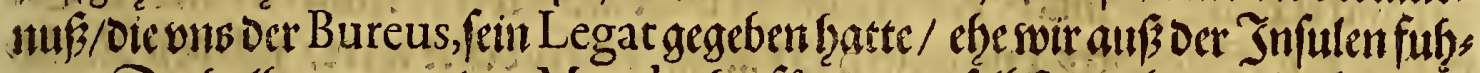
ren. Derfbalben zoge cr oas Mandat ferfúr/oaber felb/t gegeben / als obswir es

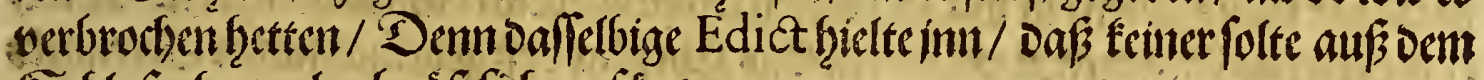

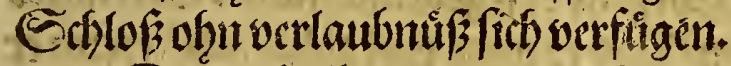

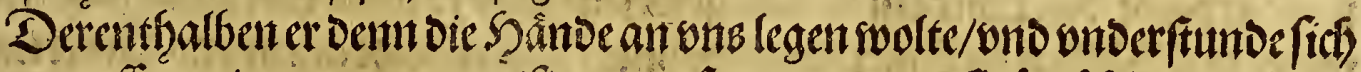

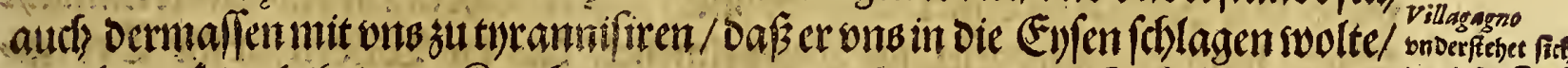

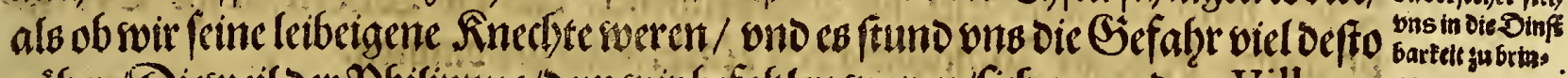
„nâber/Dierweil Der Philippus/Dem wir befohlen waren/fich gegen bem Villaga- gen.

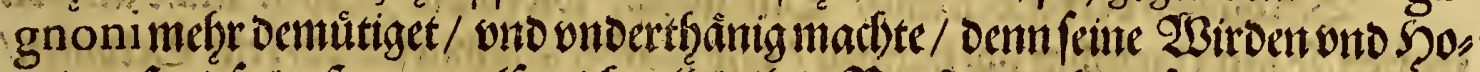

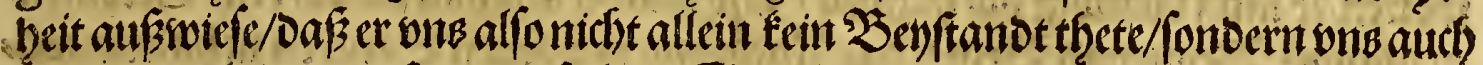

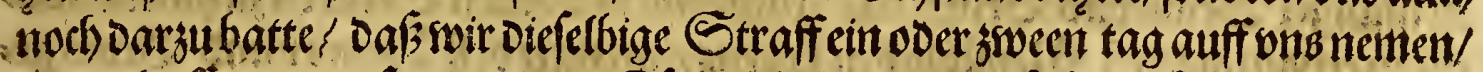

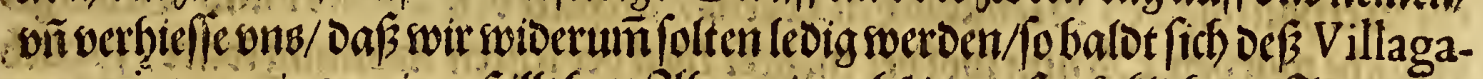

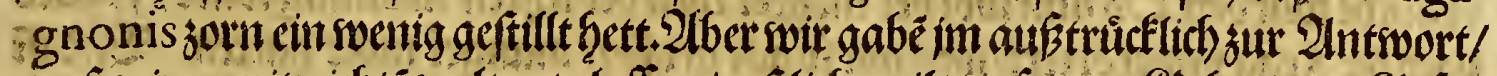

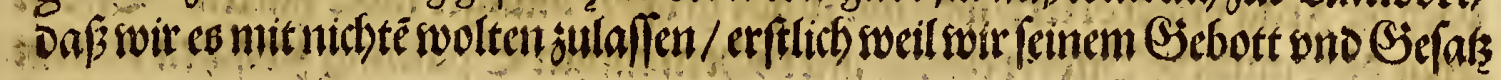
Mitit 


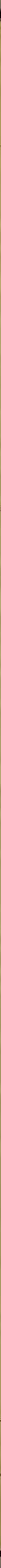




\section{Das britte TGetl.}

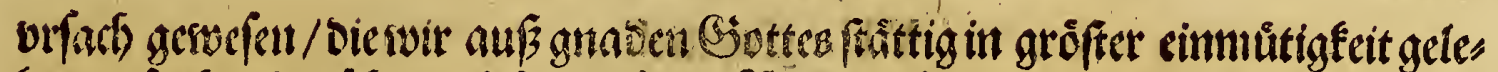

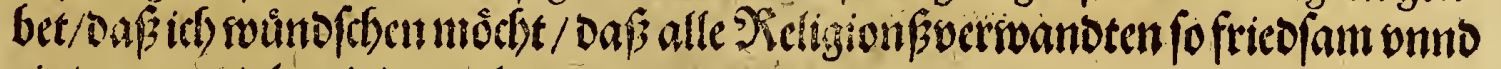
cinigsweter/als wir dantals waren.

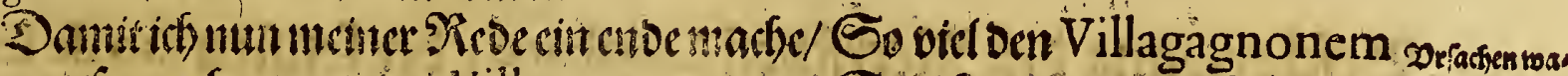

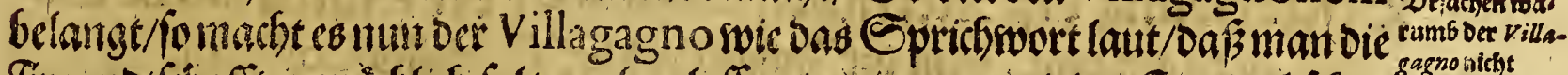

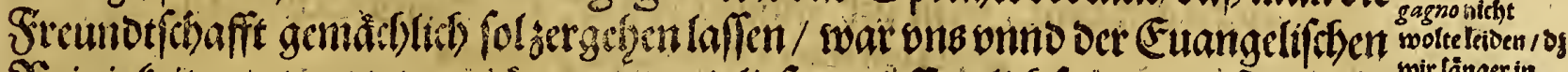

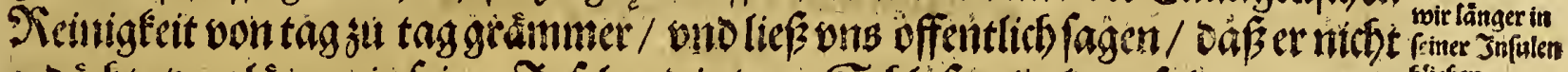

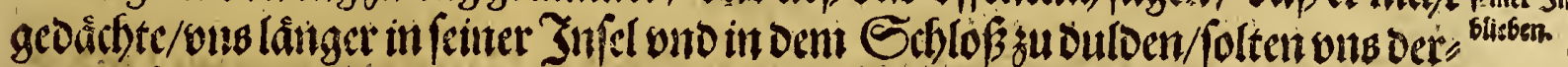

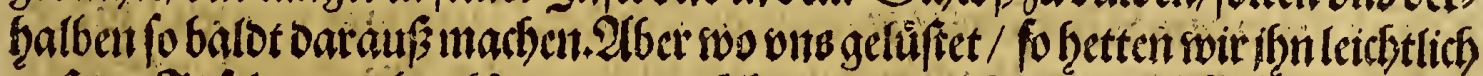

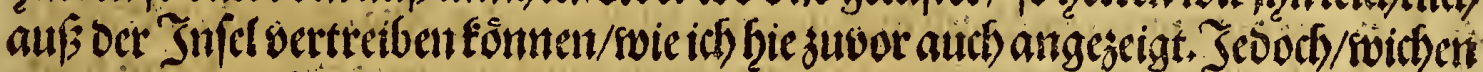

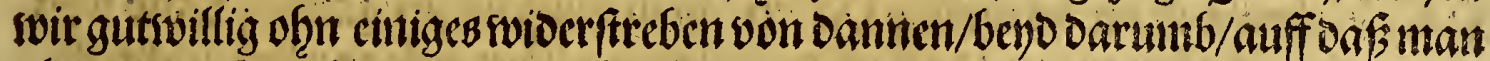

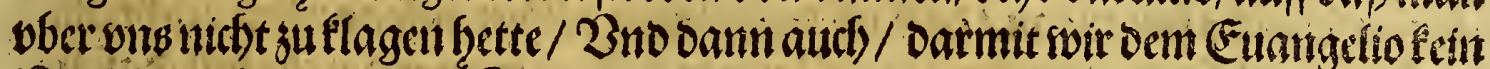

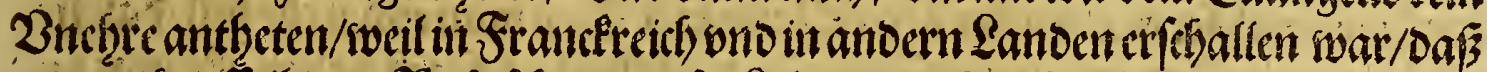

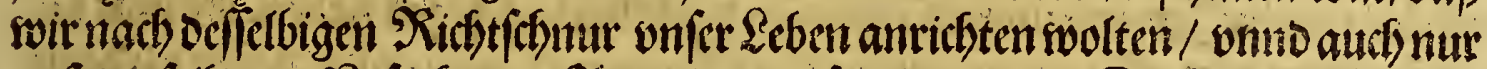

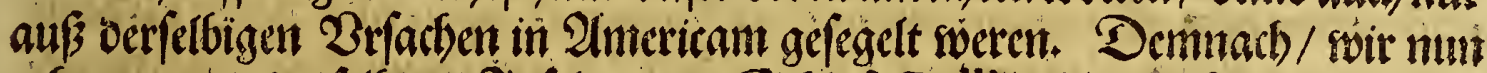

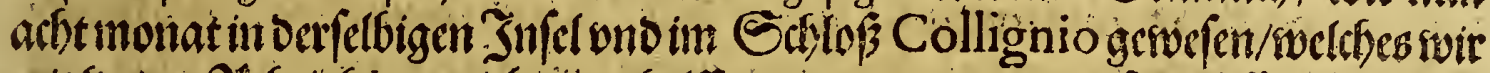

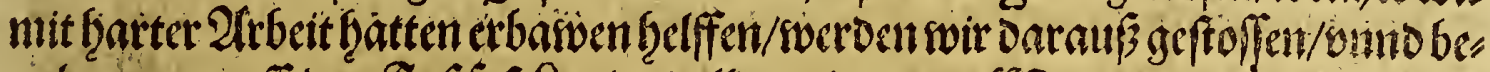

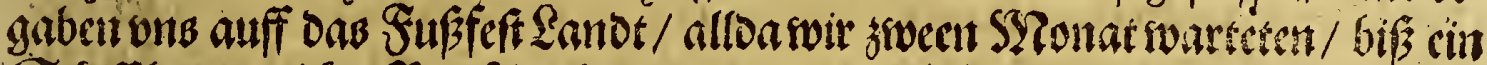

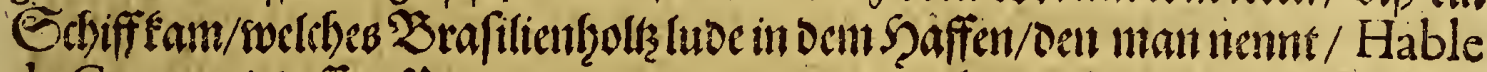

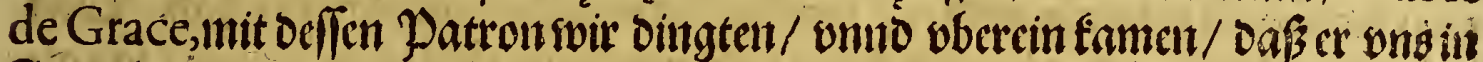

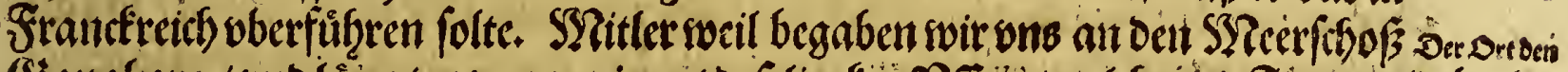
Sanabara / ond lägerten ons aut ein ort oes lintefeit 2 ffer

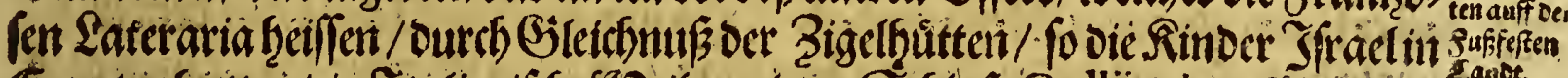

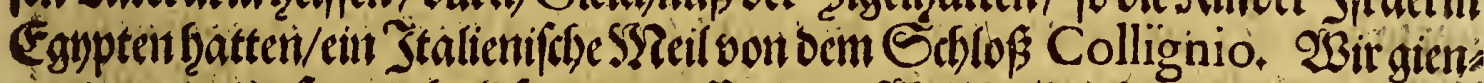

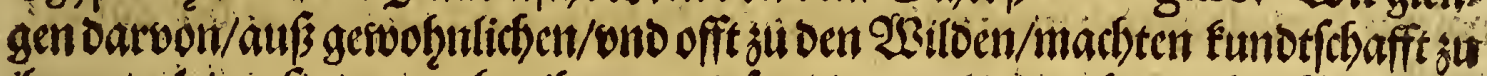

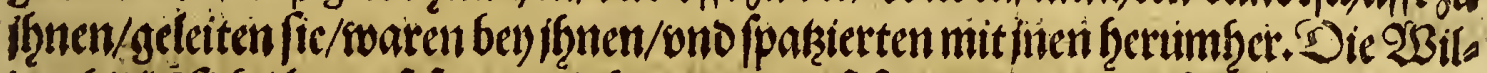

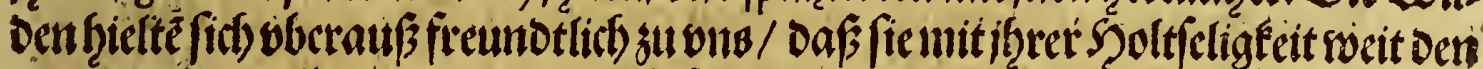
ienigen wertroffen/oer vns verftie//Foer Doch mit Dem geringften \&ort von bns nictst beleibiget fourd. Dennfie befulften ons als fiemboe bifit/ onno fiengen

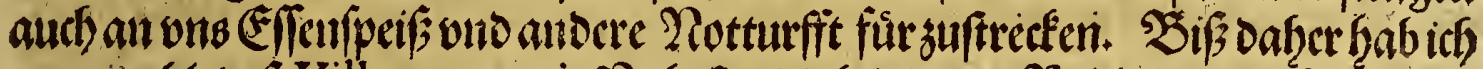

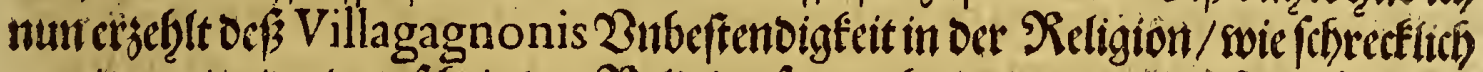

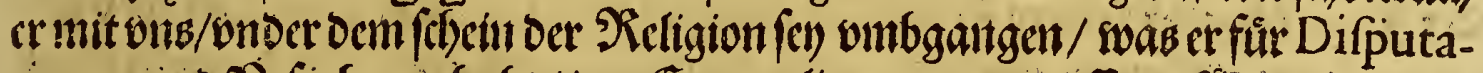

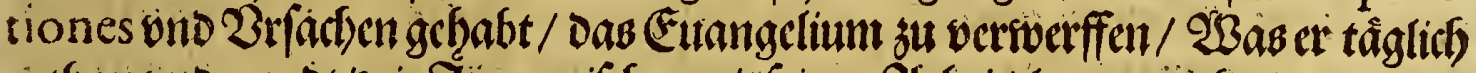

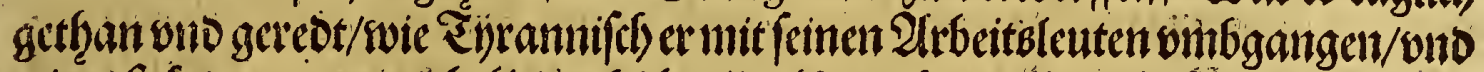

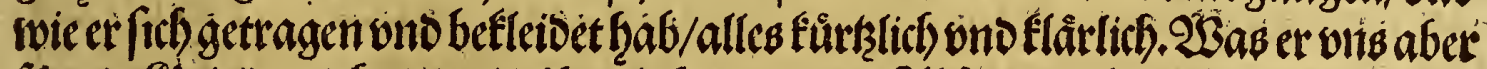

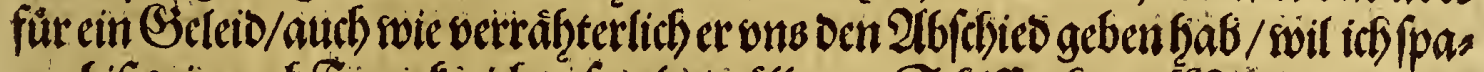

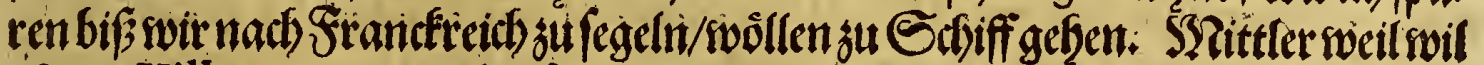

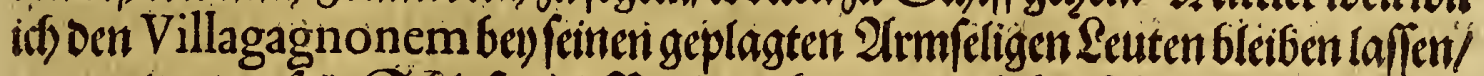

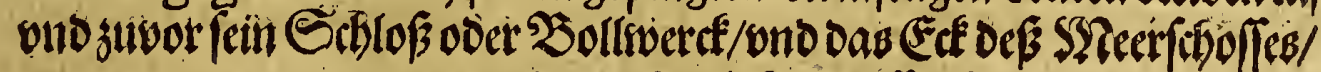
Darantes gelegen ift/etlicher maflenbes fáreiberi: 


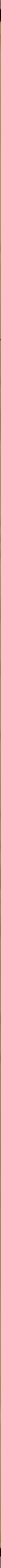




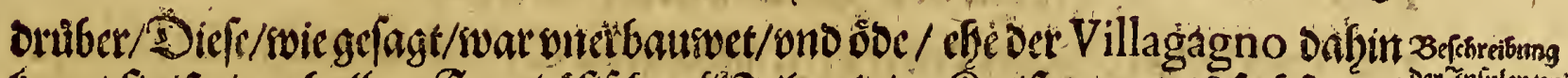

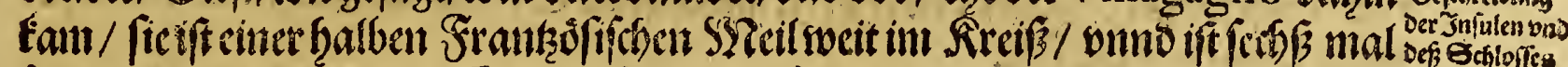

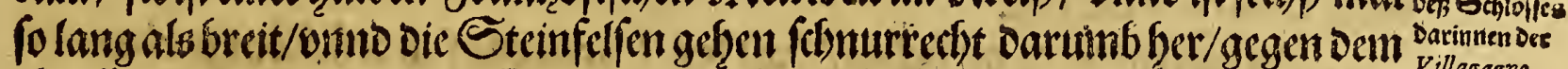

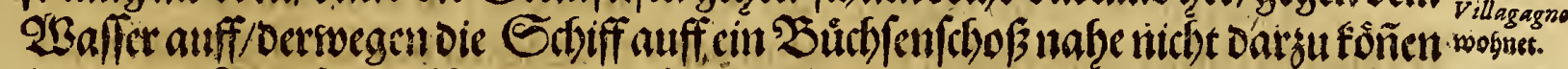

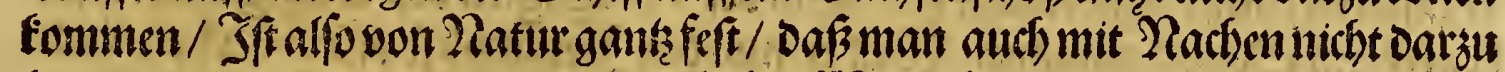

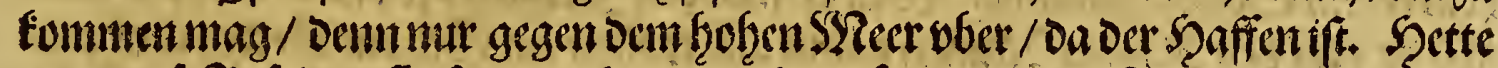

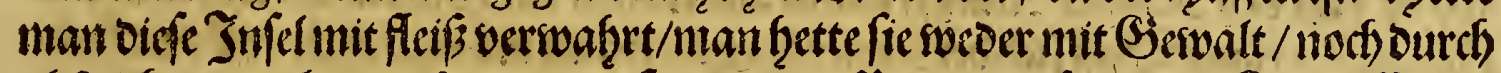

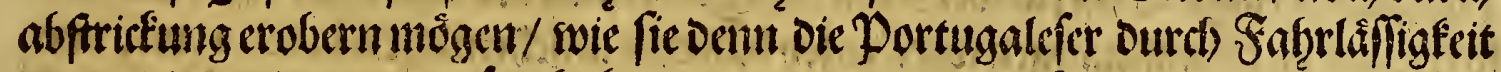
Deren/Dic Darinnen gervefen/Gaben inngenonmen / nach Dem swir swicderumb in

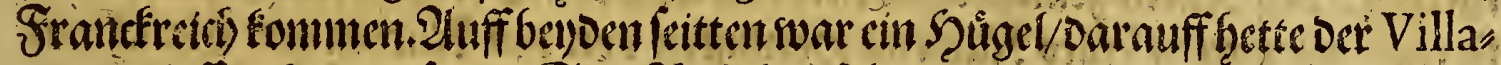

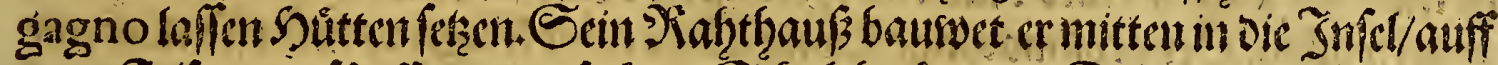

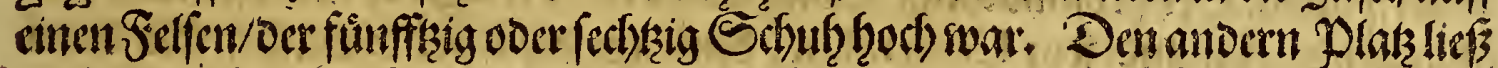

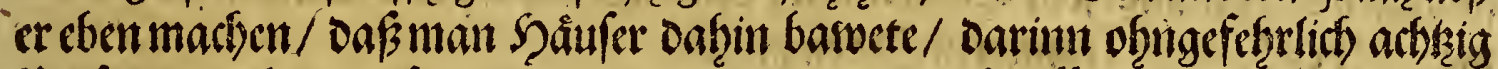

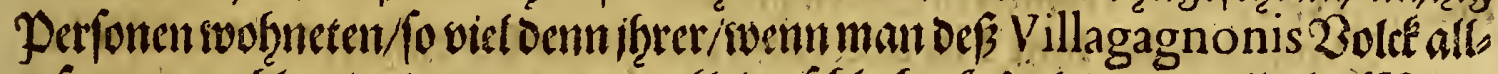

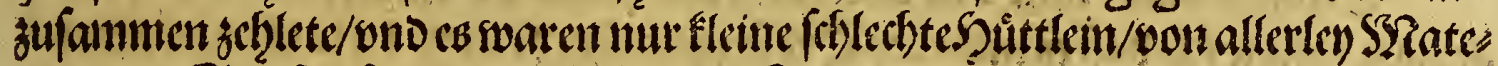

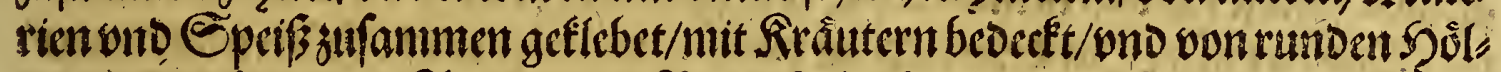

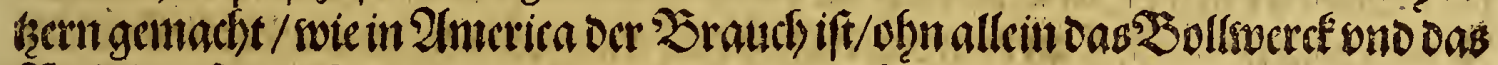

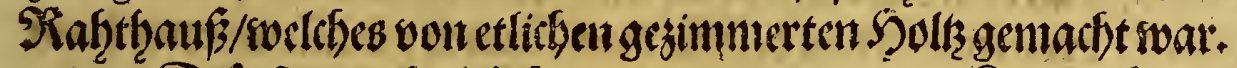

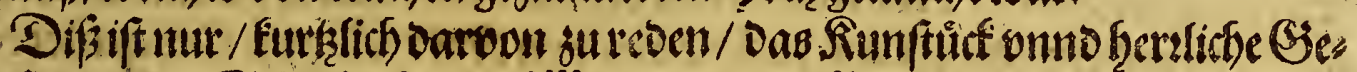

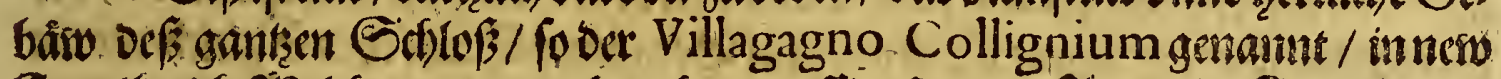

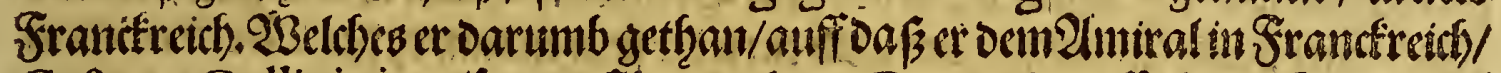

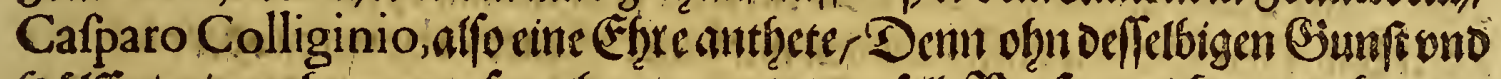

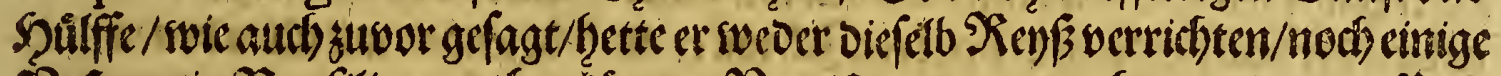

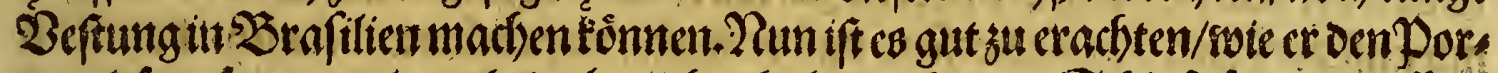

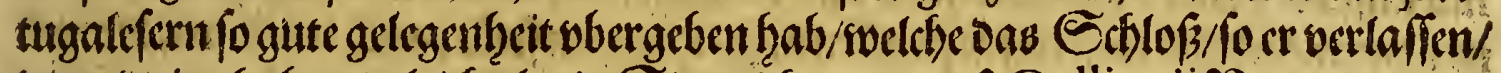

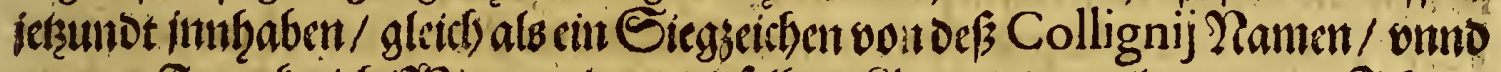

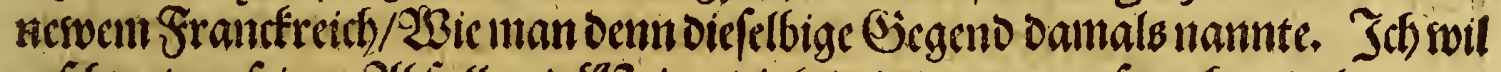

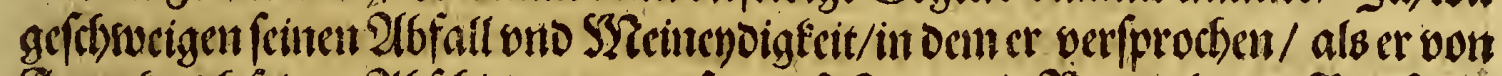

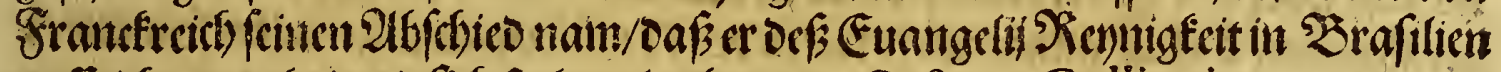

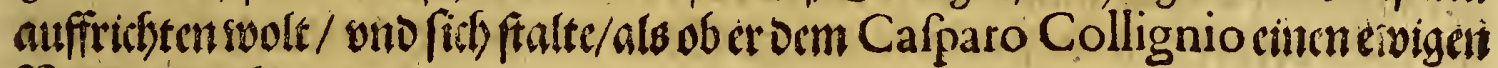
Raimenimadhen soolt.

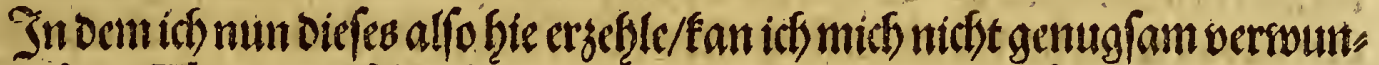

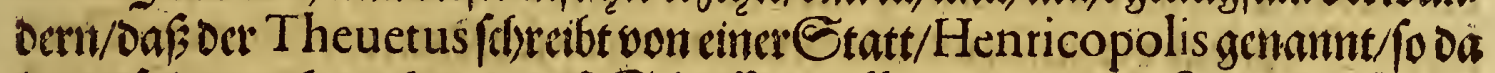

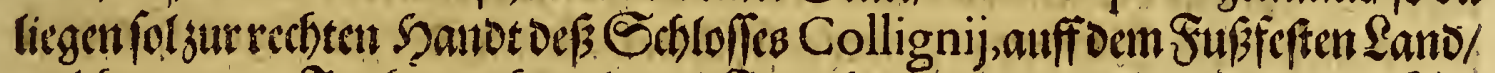

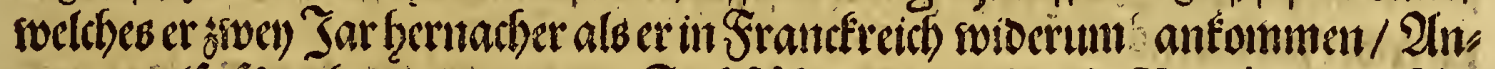

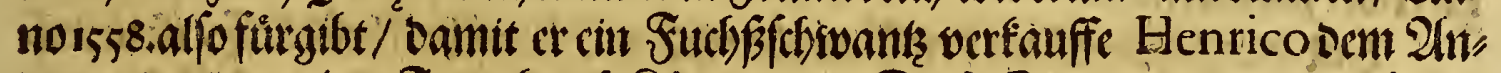

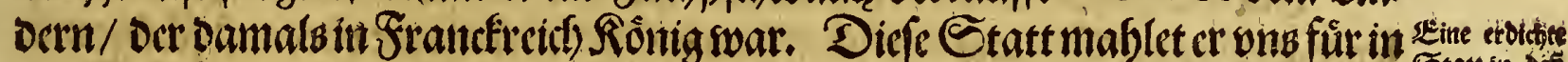

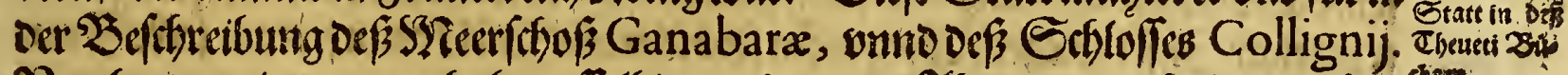

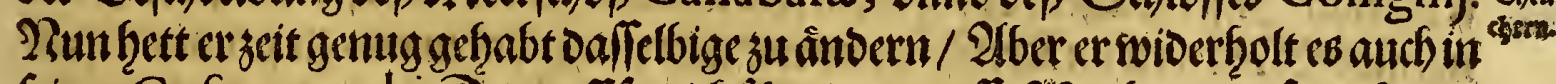

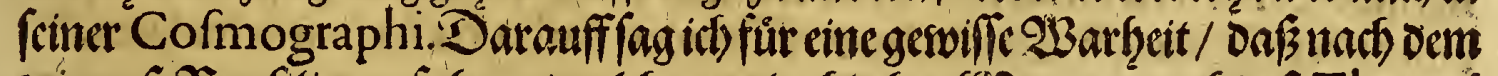

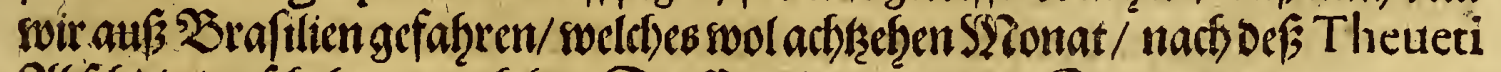

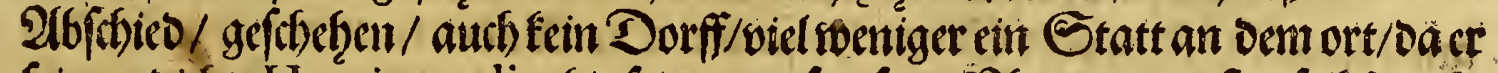

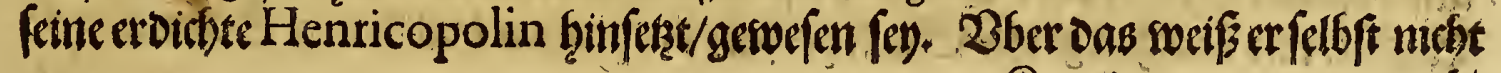

$$
\text { (i) refit }
$$




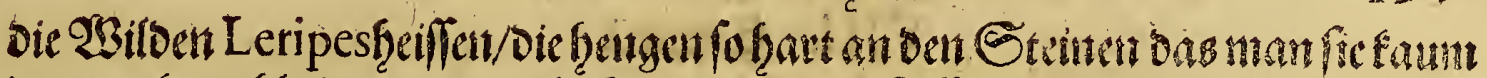

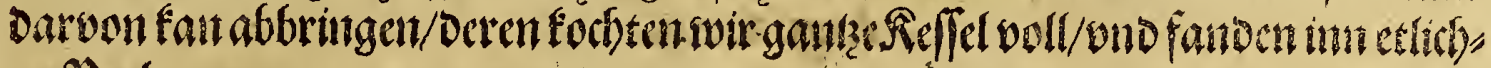
cu Perlert.

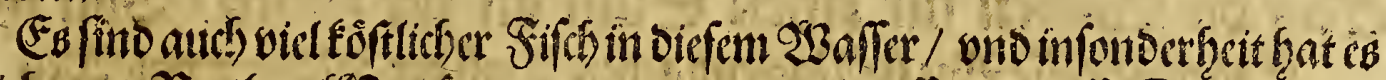

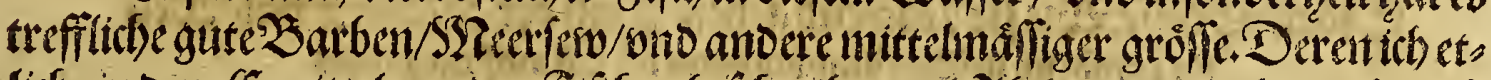

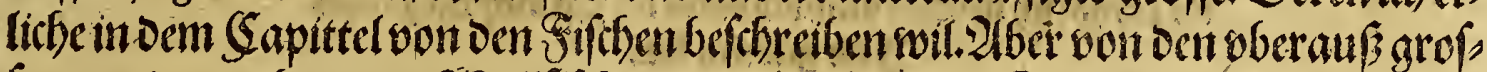

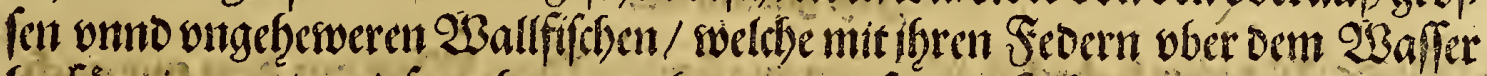
berfür giengen/wnno fo nabe su vns famen/ oaf man fie feette mit einem fleincit

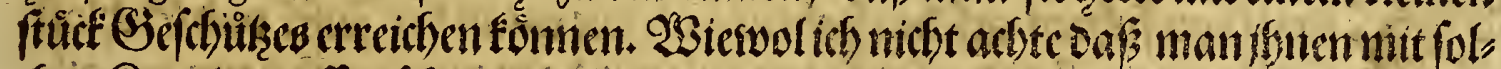

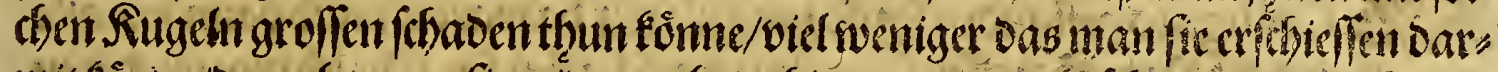

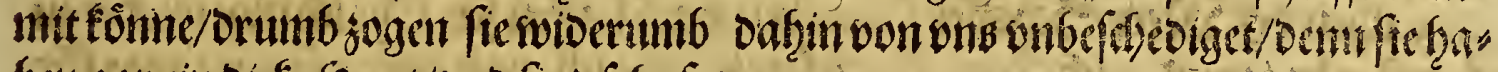
bengar cin oicfe Saut/onb fino fegcr fett.

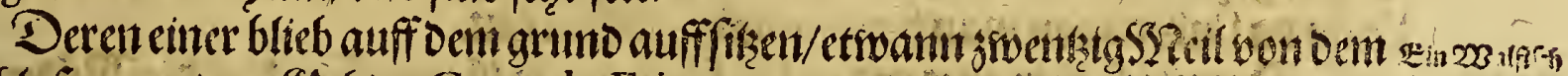

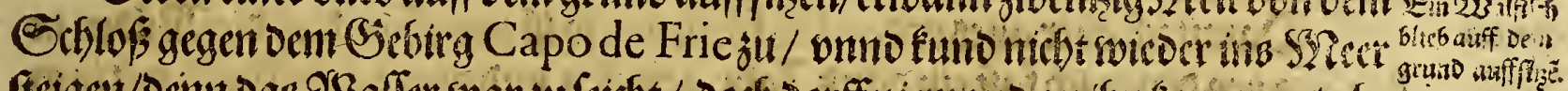

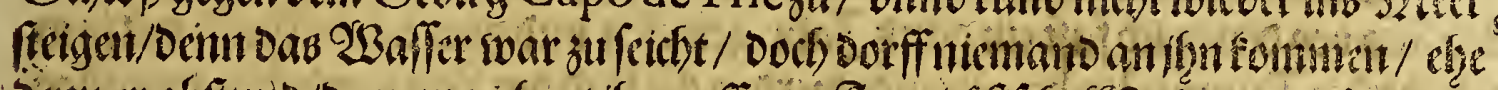

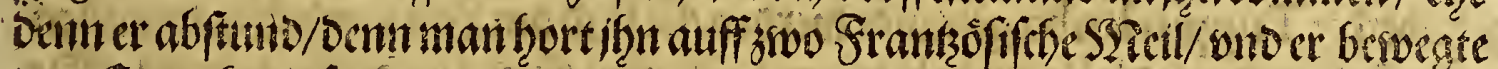

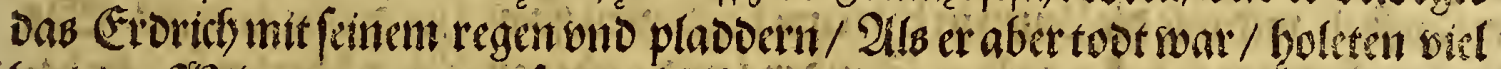

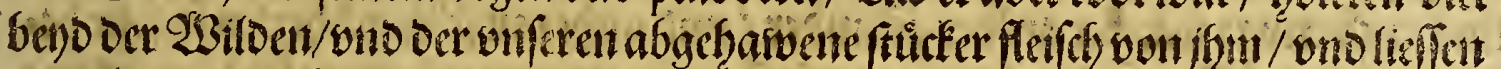

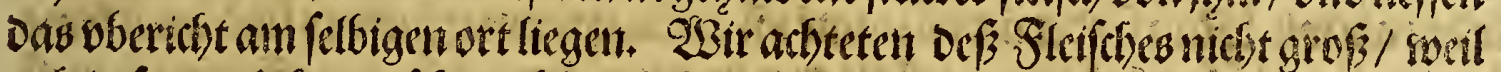

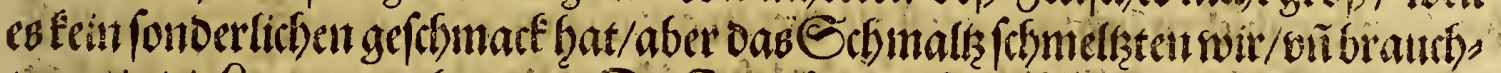

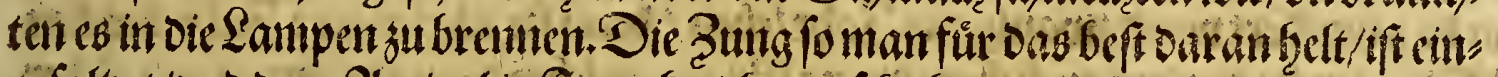

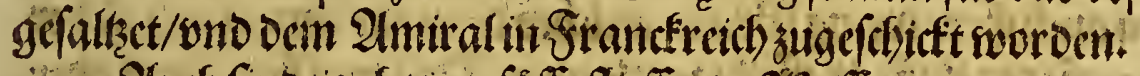

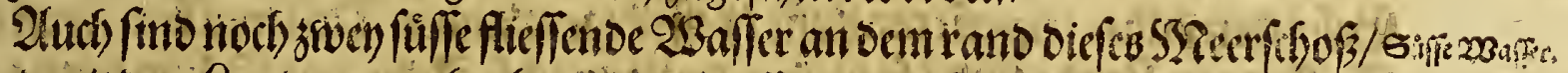

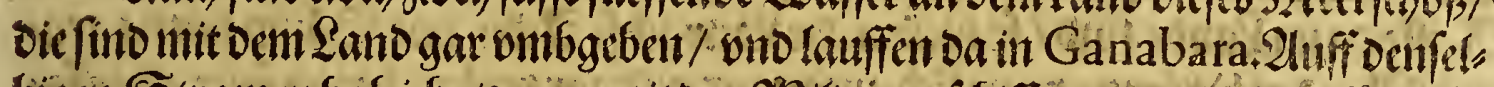

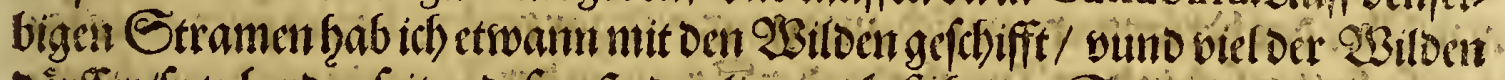
Derffer/fo zubeyoenfeiten de 3 geftaden liegen/ beficbtiget. So viel if es nut wa

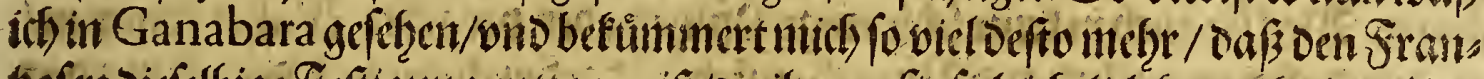

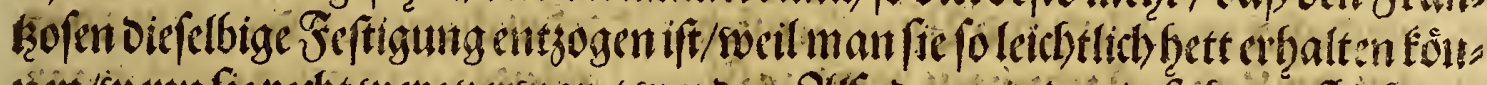

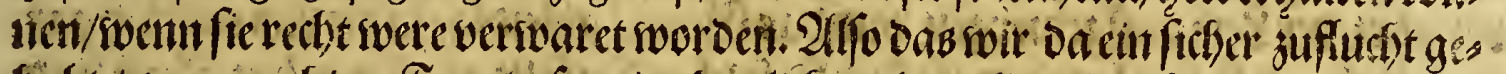

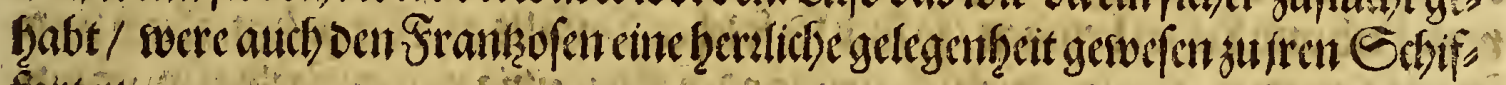
fartent.

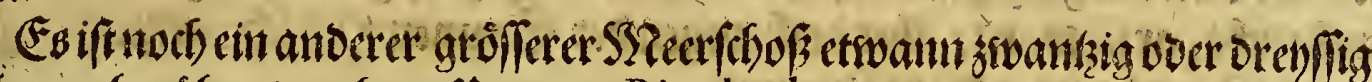

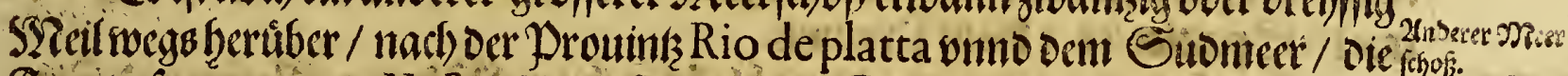

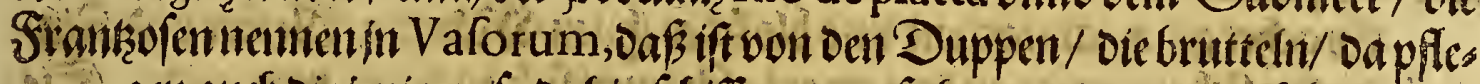

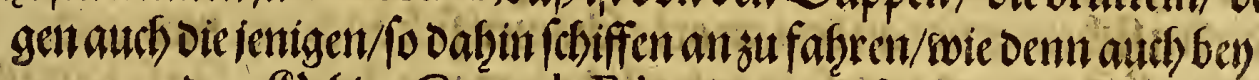
oen Siebirg Capo de Frie, oa wir autb zun erften anfamen/als woir nach Brafilien fubsent:

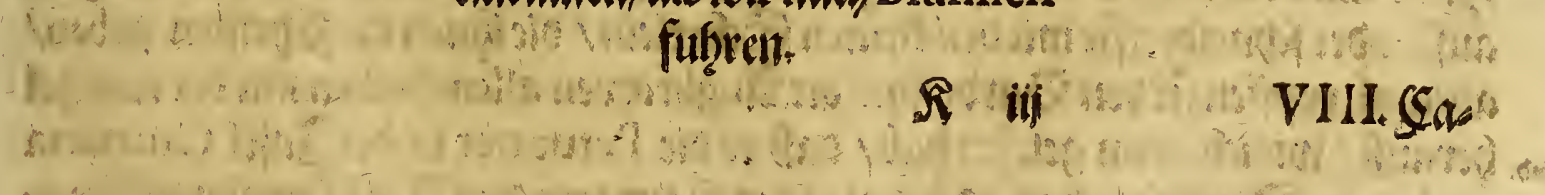




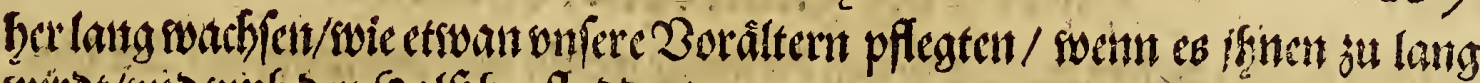

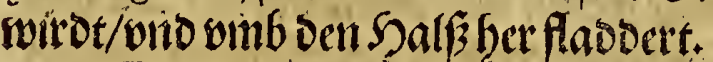

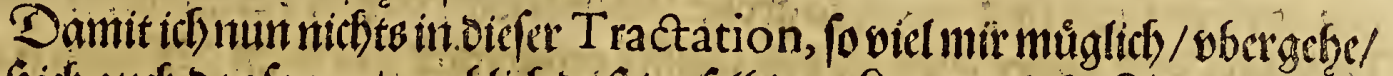

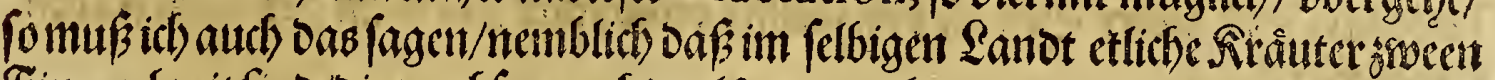

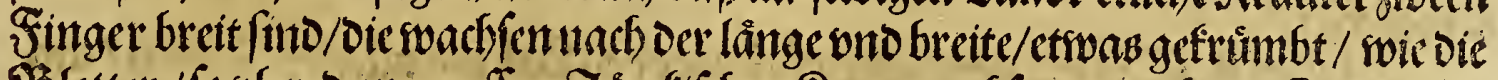

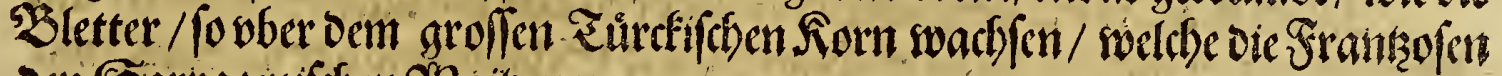
oen Sartacnifich 2 saizen nomteit.

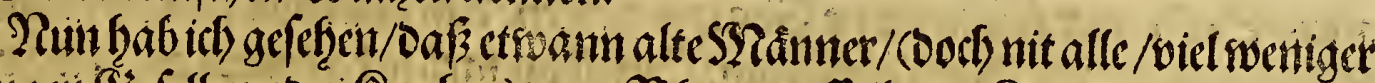

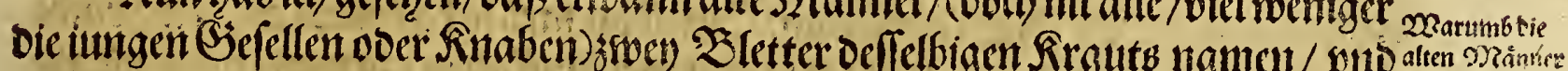

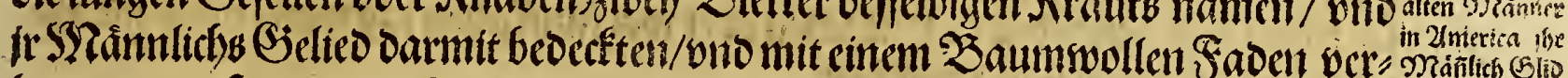

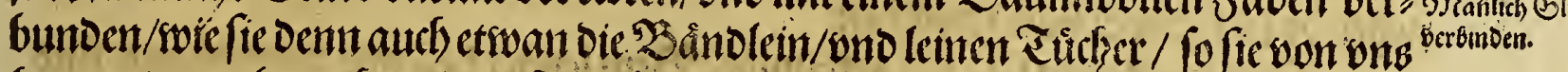

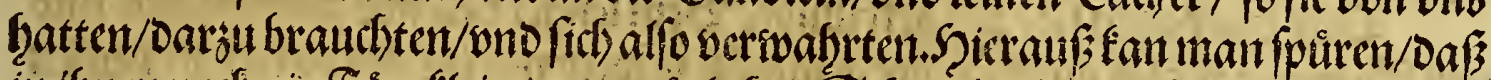

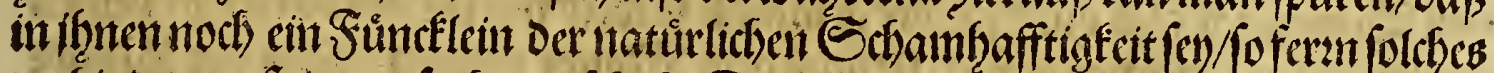

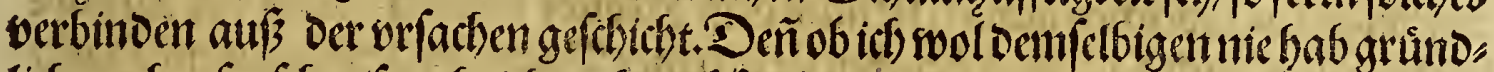

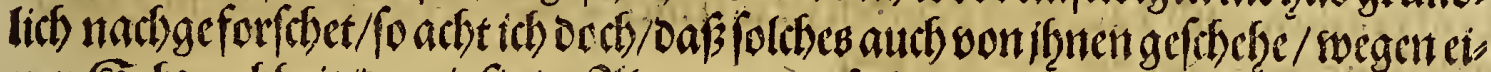

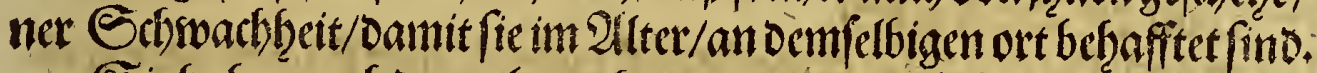

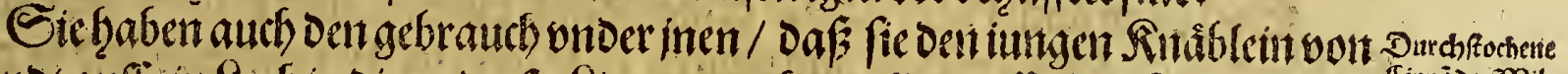

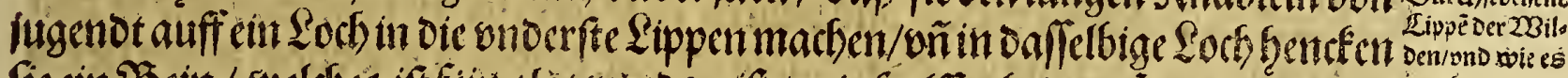

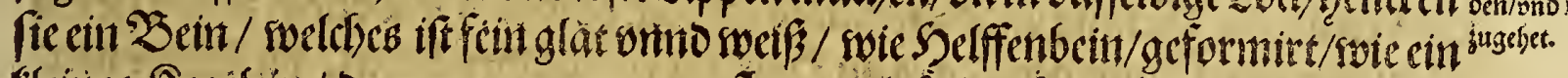

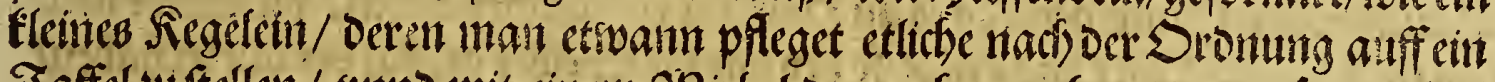

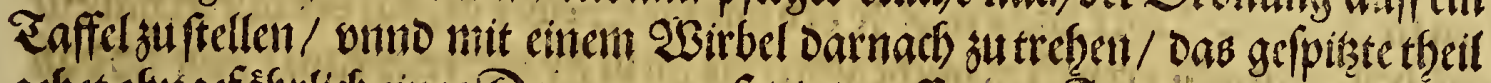

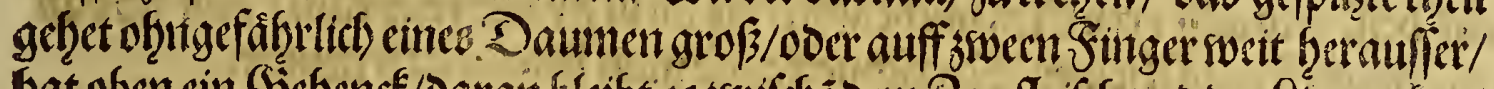

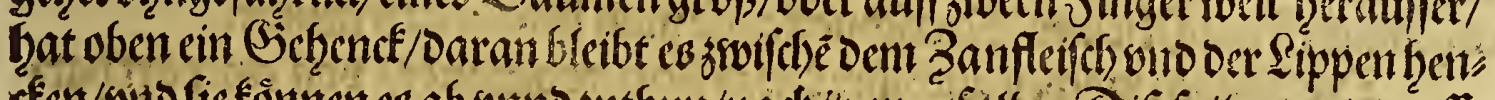

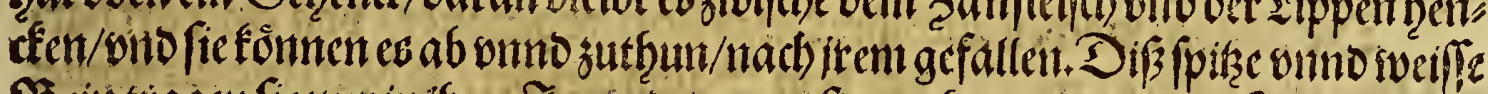

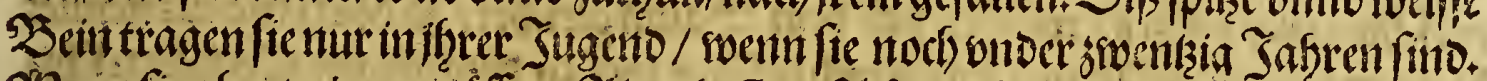

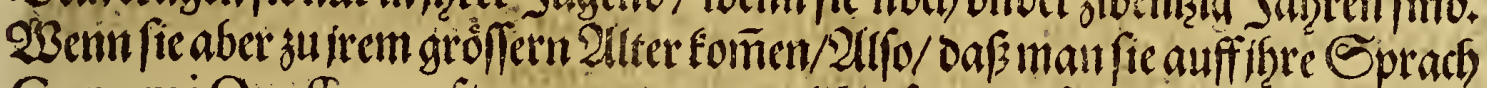
Conomi Quaffou anfengt sunenten/weld)es fo vid gefagt ift / als ein crswash:

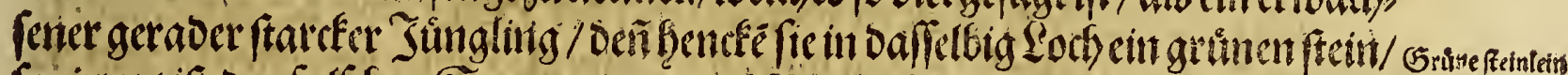

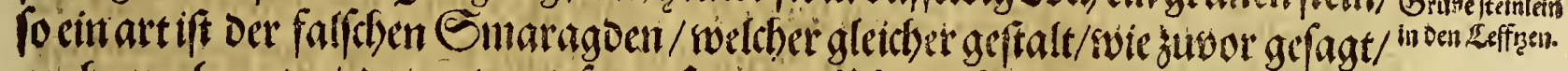

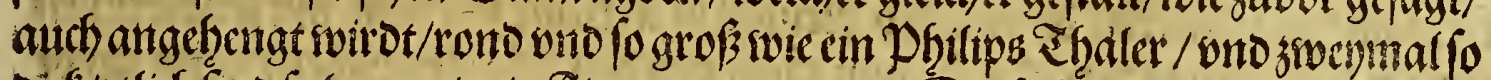

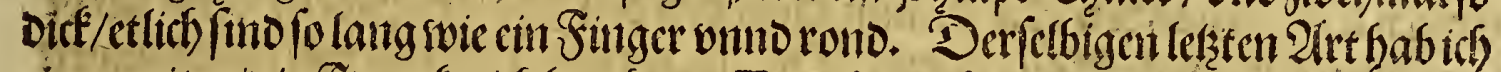

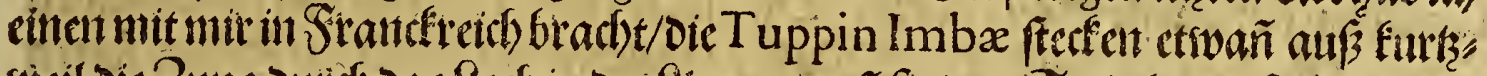

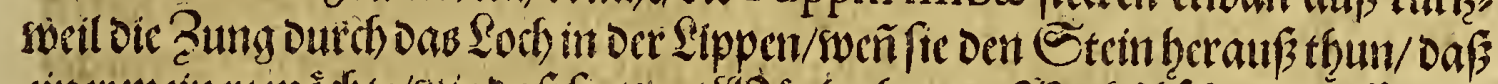

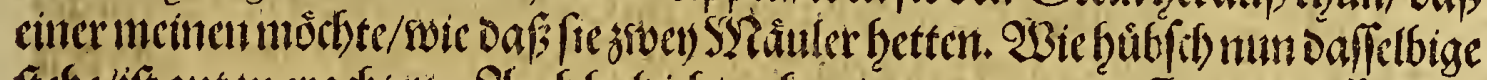

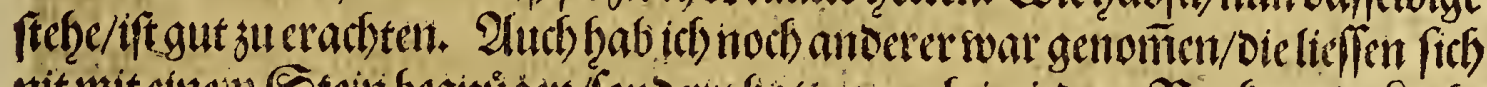

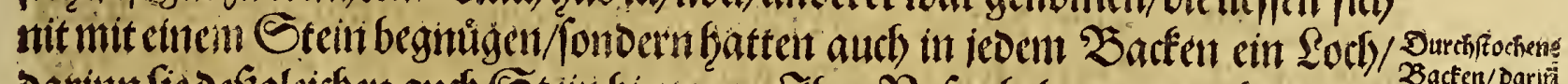

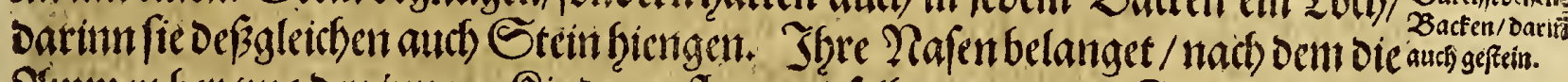
2linmen bey vons oen jungen Rindern plegen oiefelbigen mit oent Singer beraup

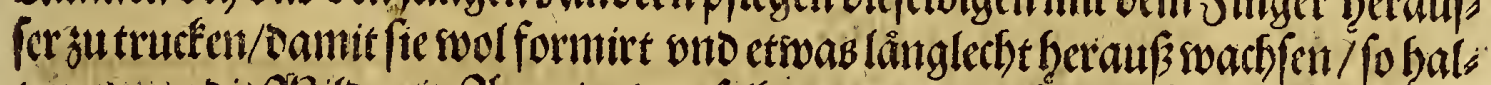

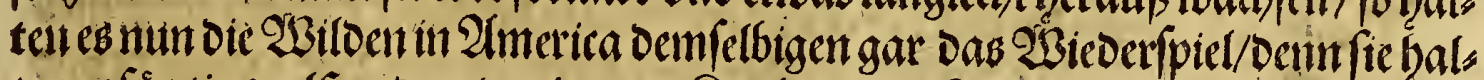

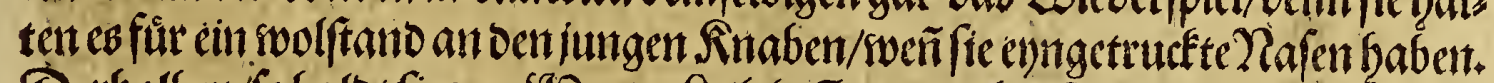

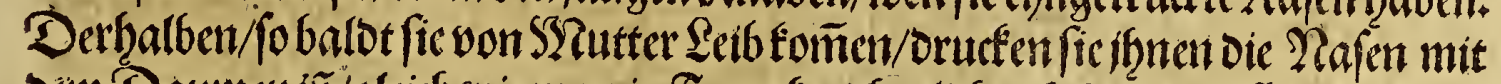

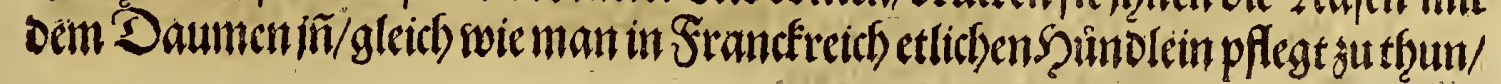

Diemart 


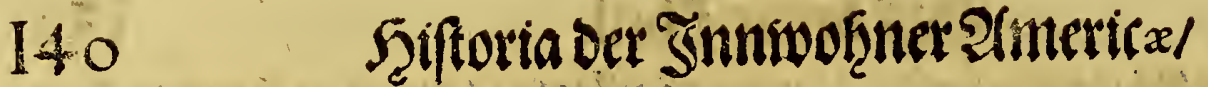

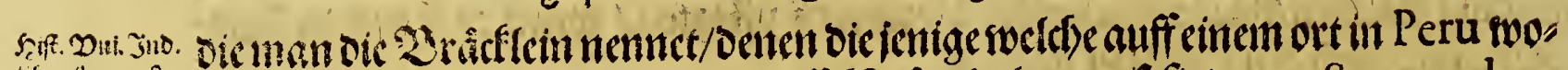

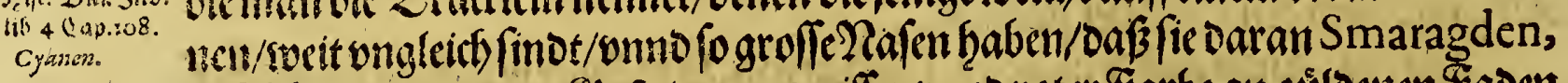
lafpides, wito ander Gefteri von weiffer vnno roter Farbe an gúlocnen Saden anfencici.

Mitibenge

Fhro:artzes yno mer allerter

Bnicre Brafilianer vermablen fich ober ben Seib mit allerley farben/am

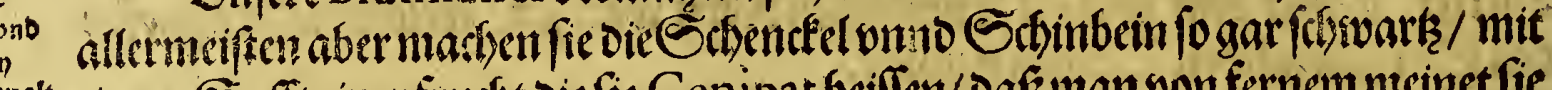

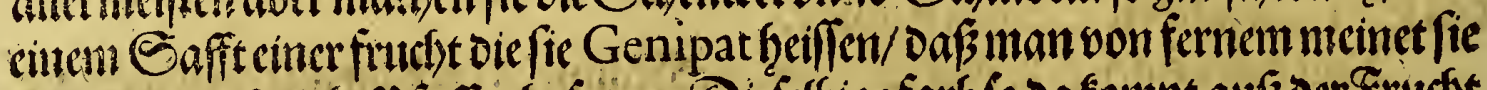

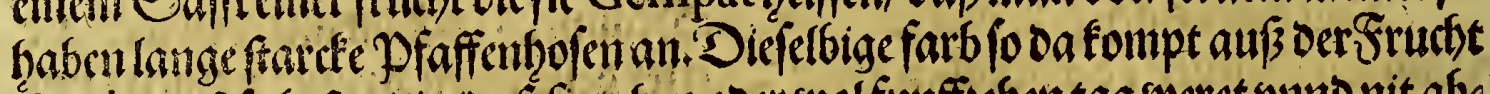

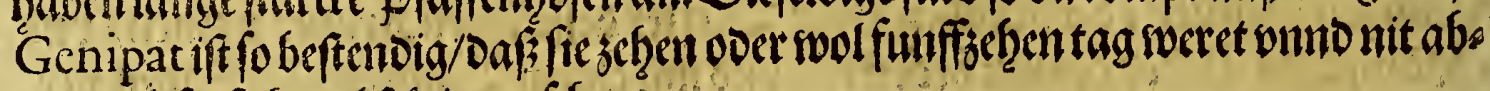

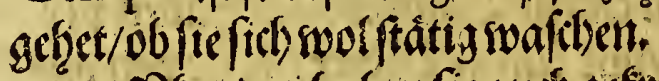

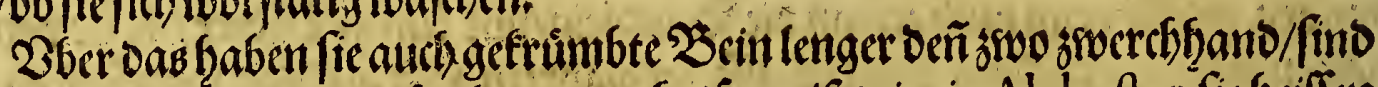

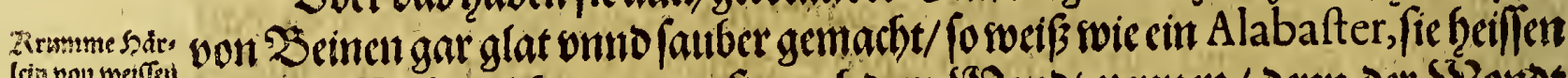

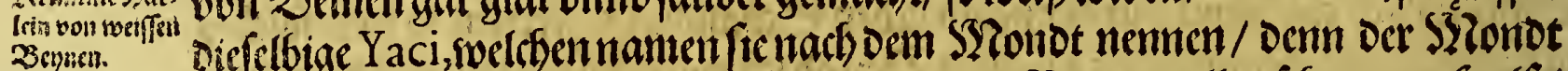

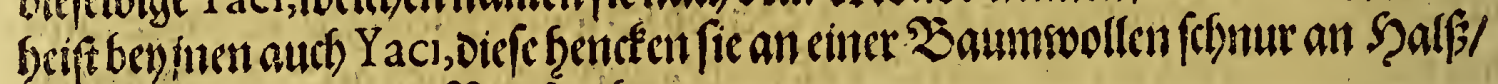
Dasfie vornen vber die Bruft geftent.

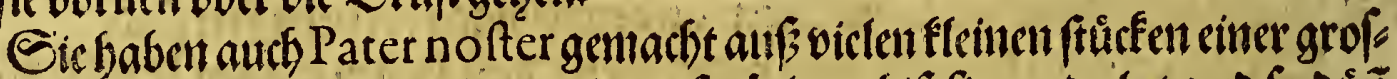

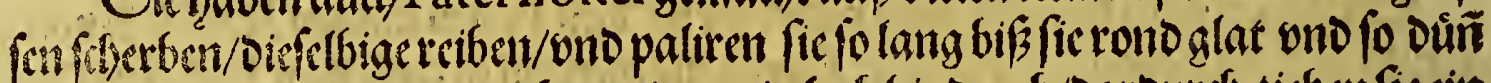

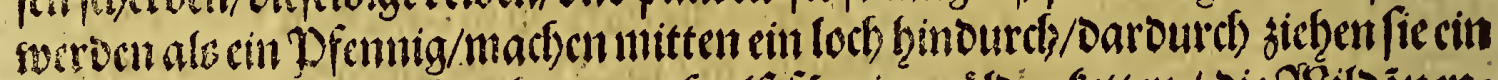

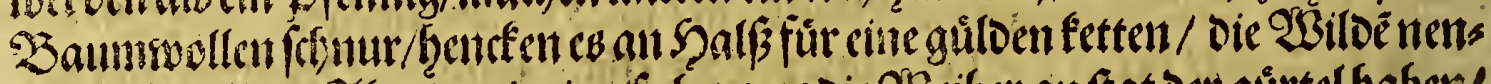
nenfie Bou-re. 2lber aasicnige/fo bey wns dic Weiber anftat Der gưrtel baber/

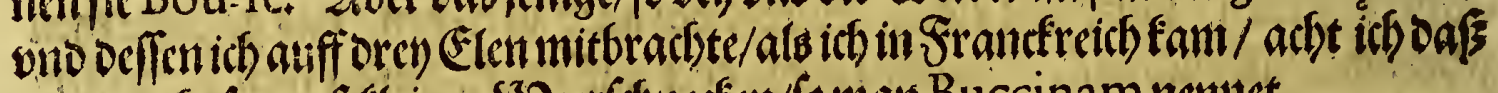

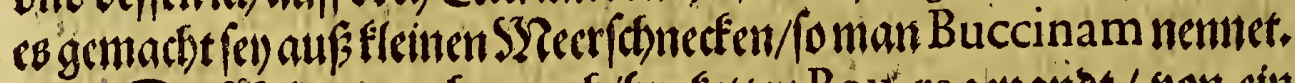

Bourecint

Shalkaes,

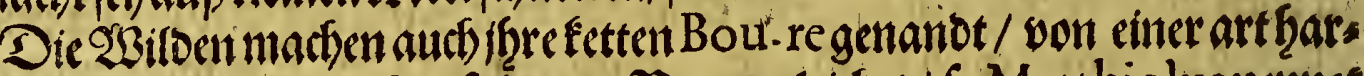

fogenceide

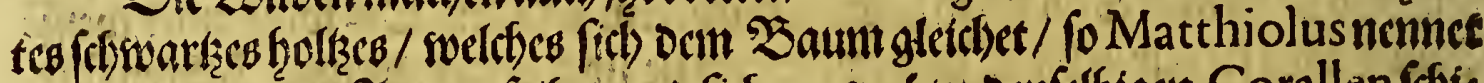

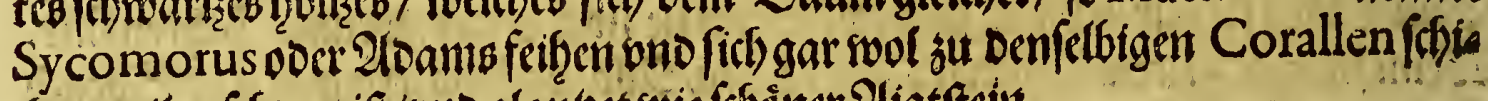

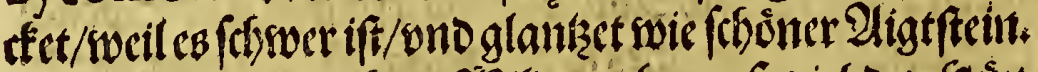

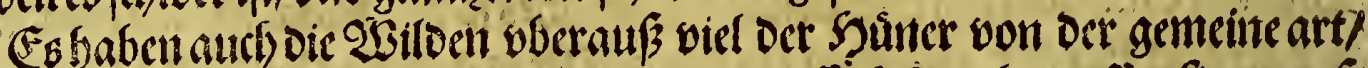

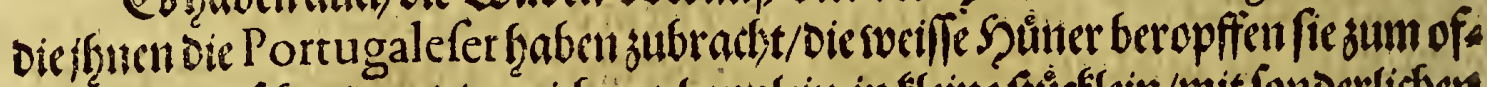

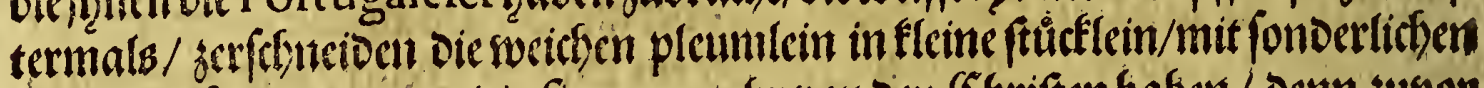

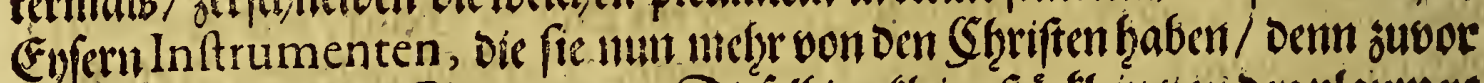

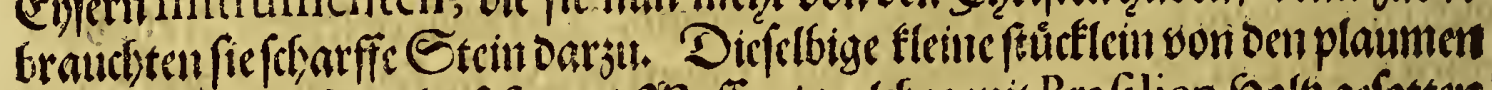

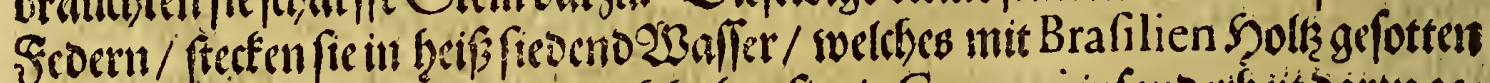

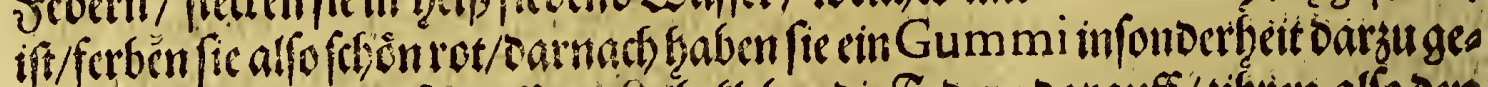

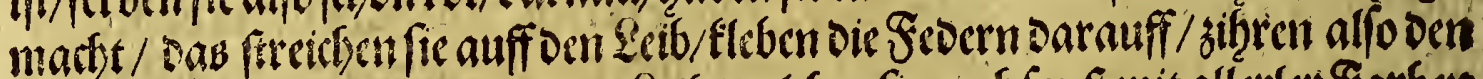

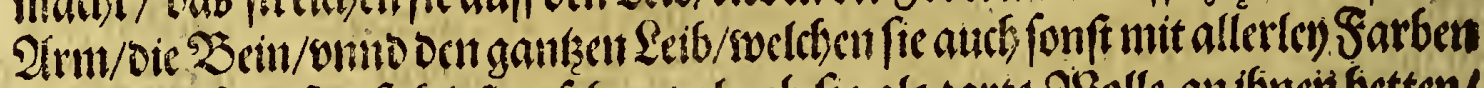

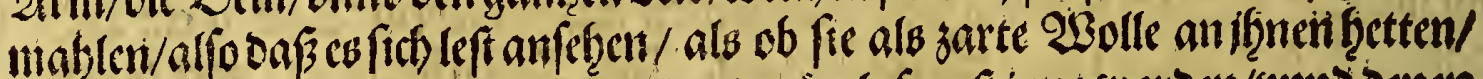

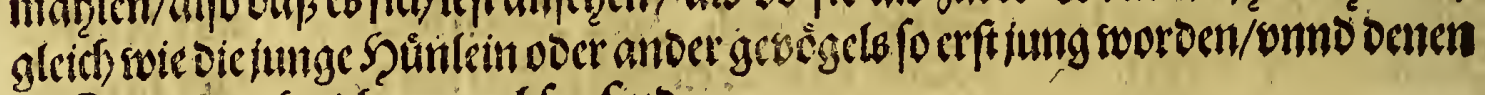

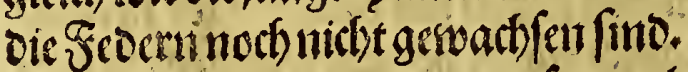

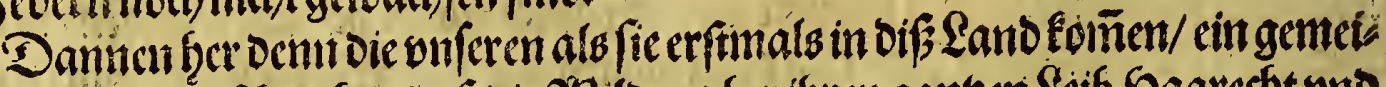

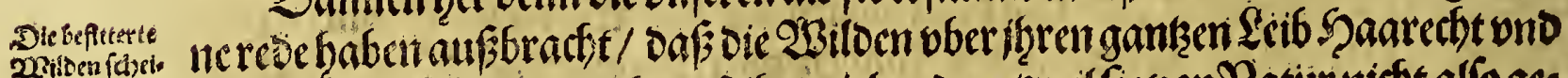

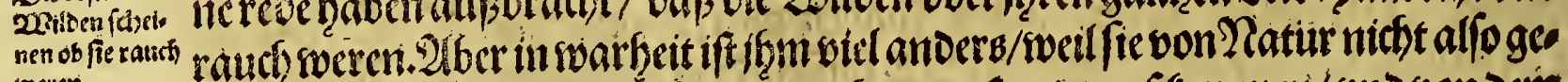

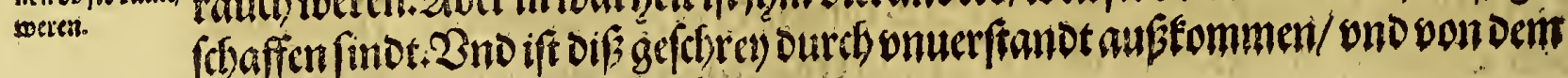
genemen S?annalfo geglaubt toorben. 


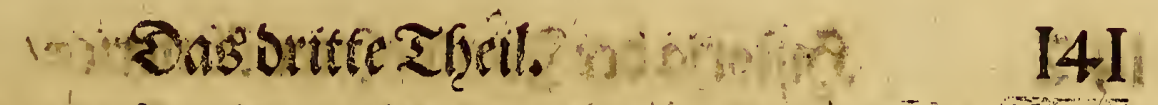

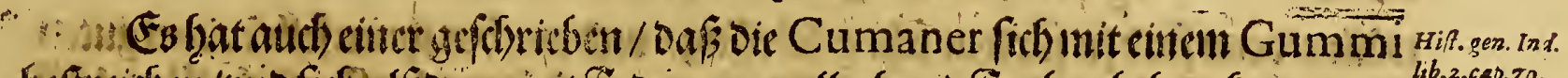

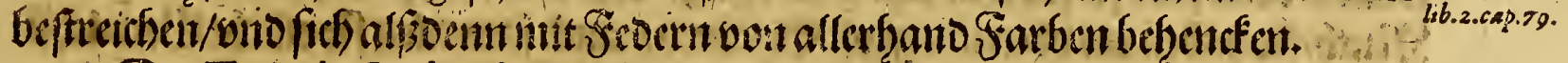

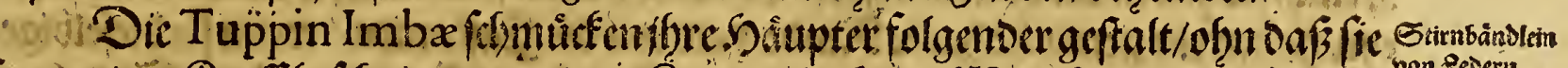

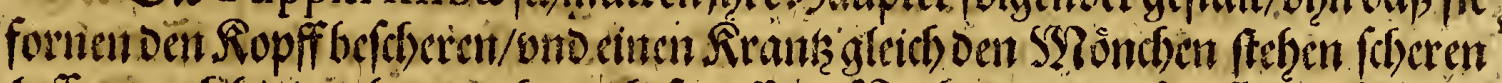

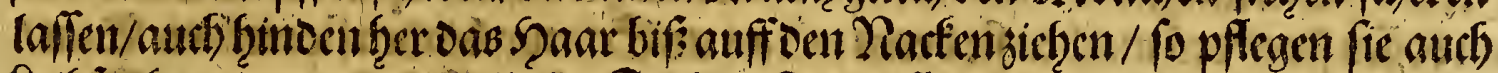
Scibfarb/roten/ond vonalletley Farben Bogelpflaumen artlich jufaunen jubin:

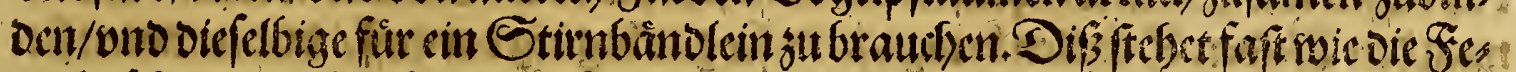

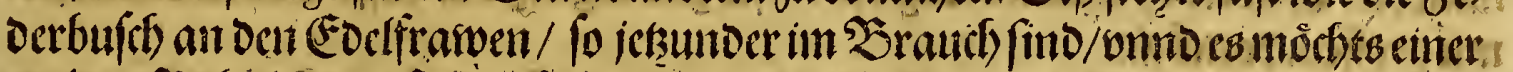

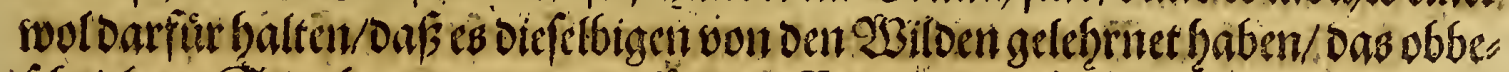
foriebene Stirnbano nennen dic QBillocin Yempe nambi.

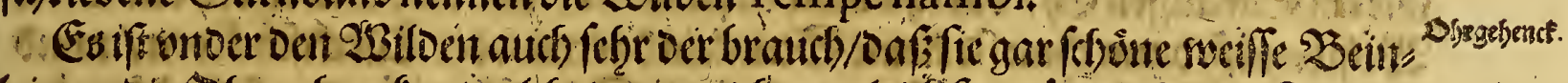

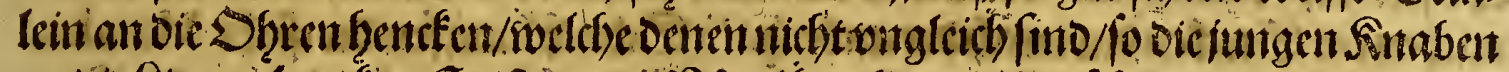

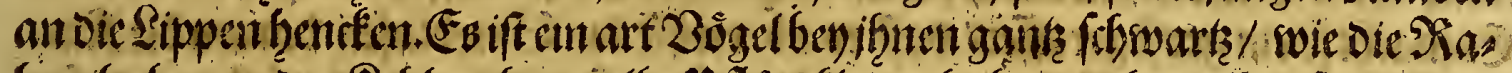

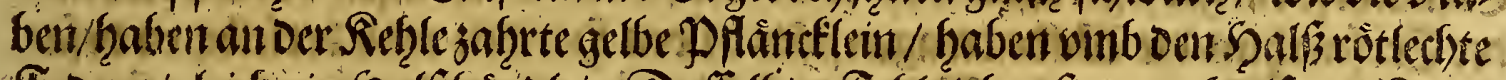

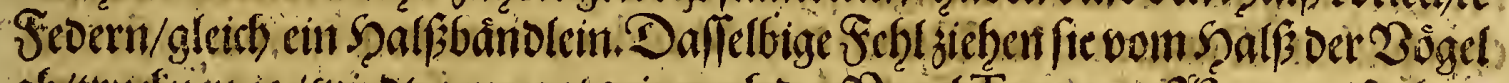

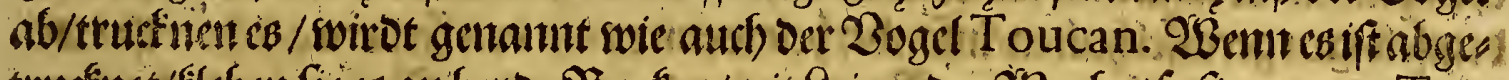

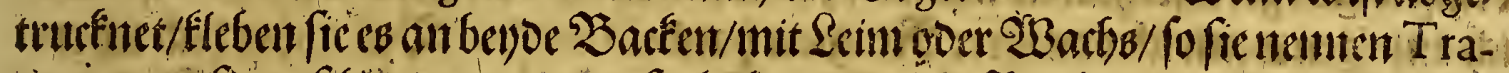

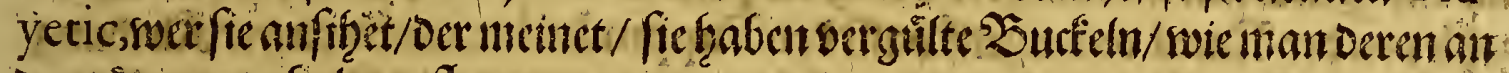

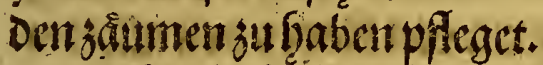

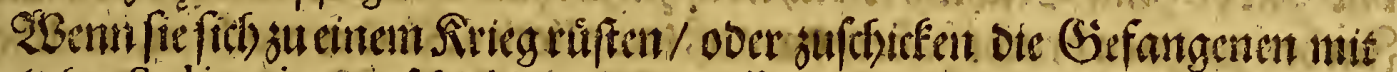

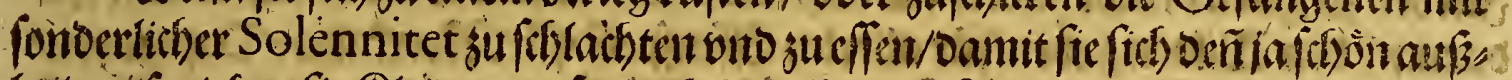

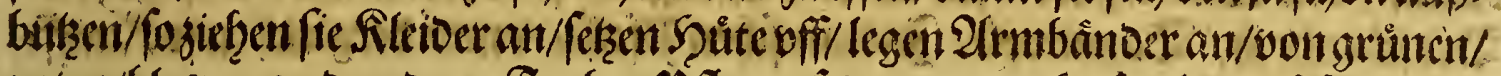

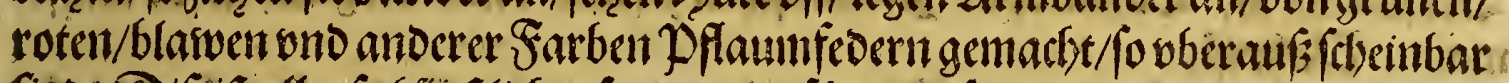

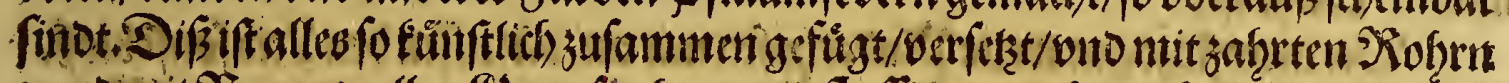

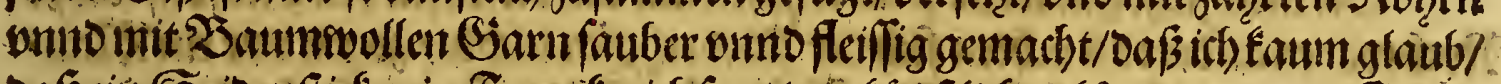

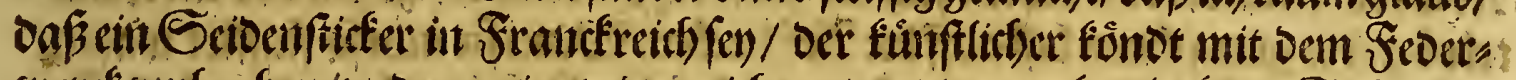

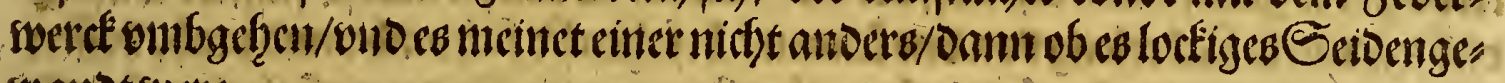
soand twere.

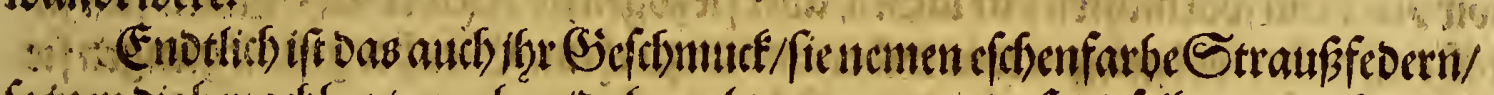
foinen ou bouach) bowtengeben/oaber abjunemmen/ Daf oiefelbige vngeferwere

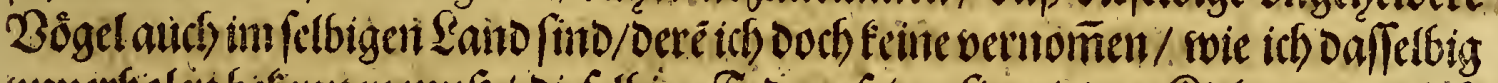

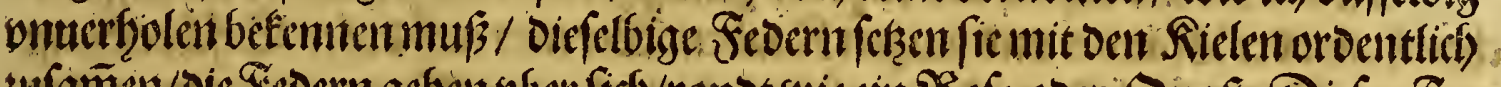

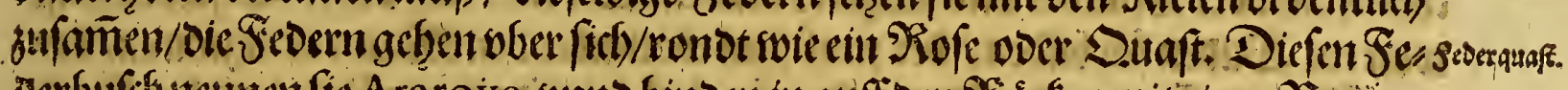

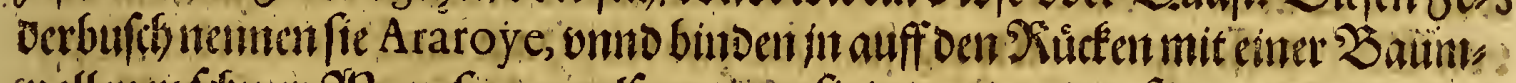

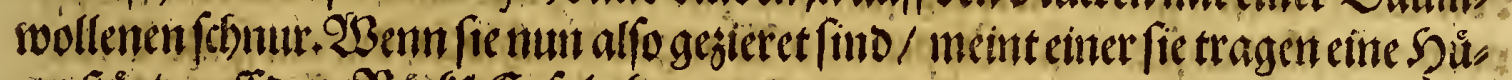

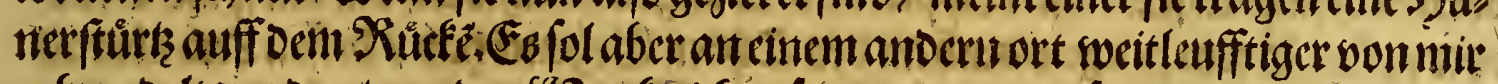

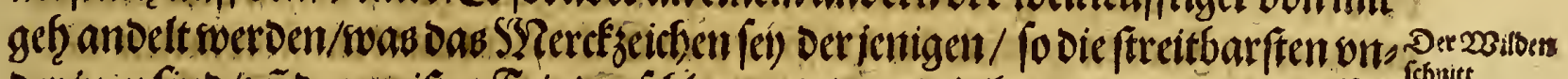

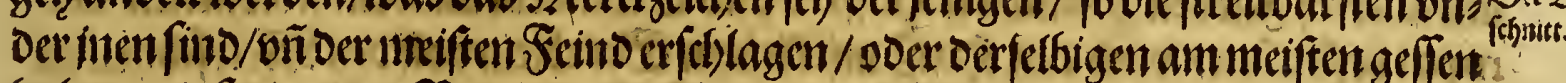

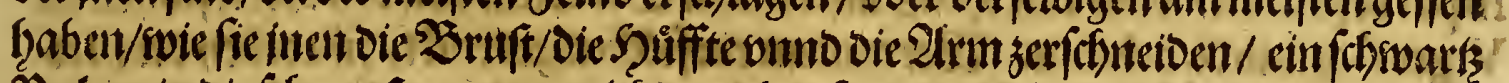

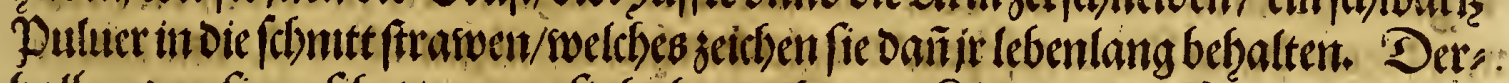

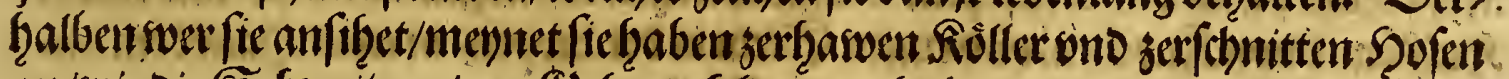

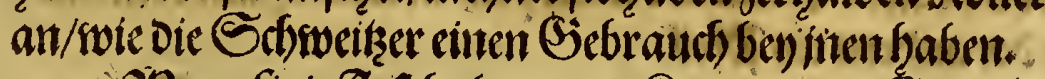

9Benn/ie ir Seft halten/ono Rawasvi Den Seind betrinden onno betantsen 


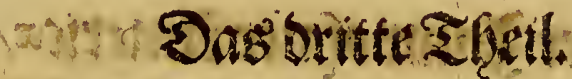

143

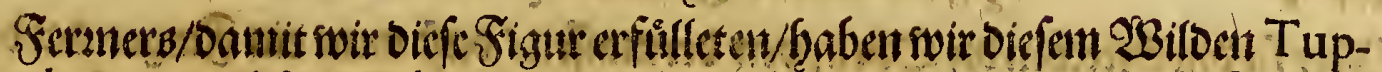

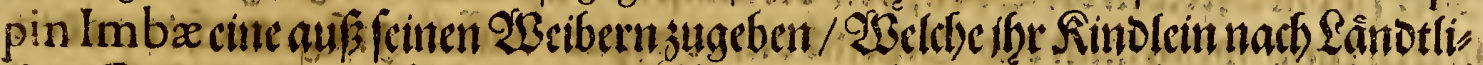

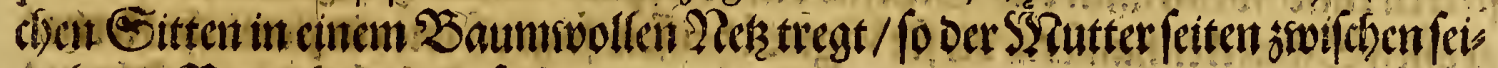

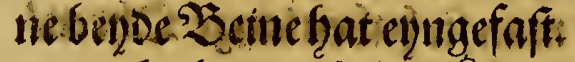

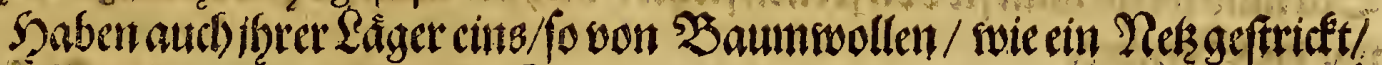

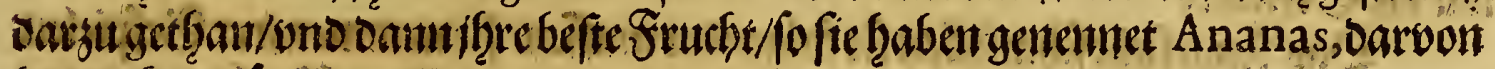
betruther gefagt nivt.

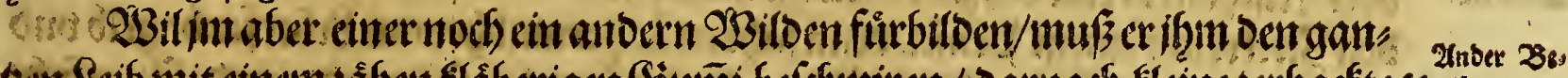

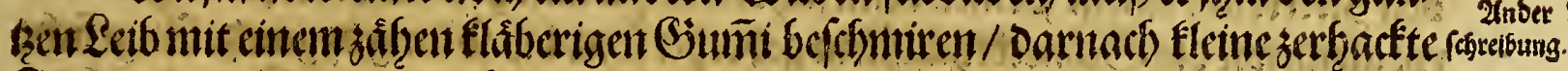

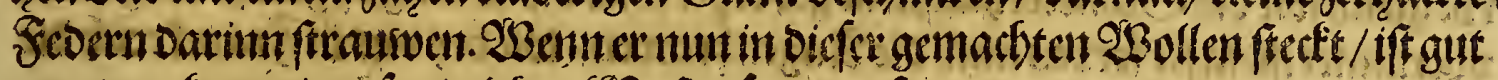

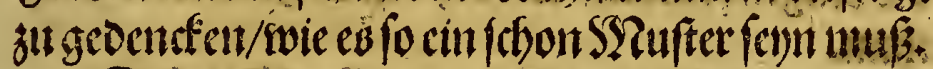

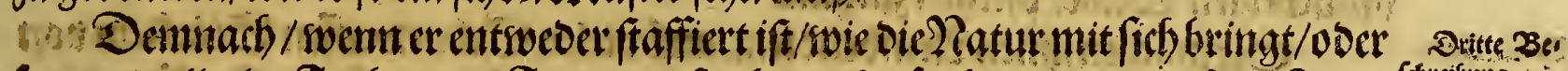

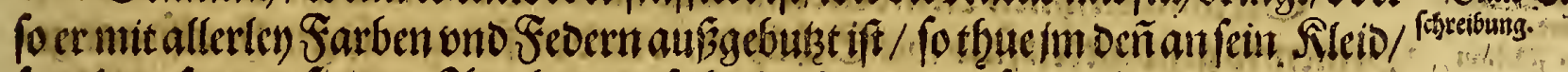

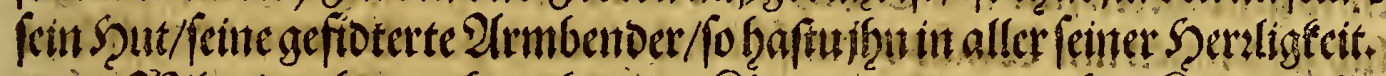

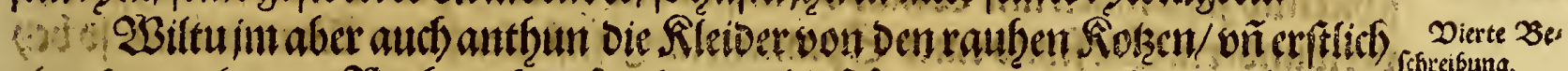

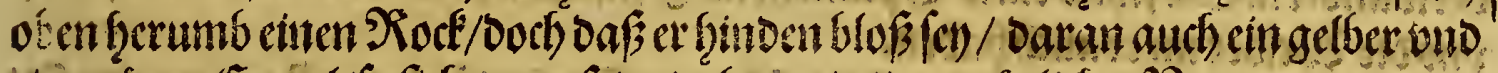

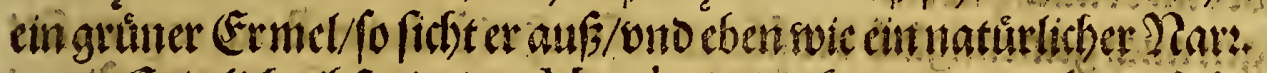

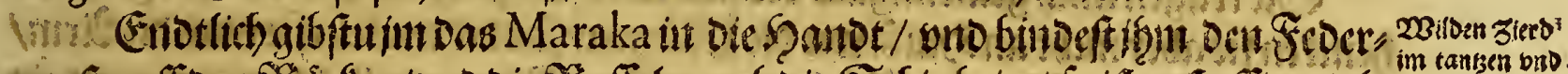

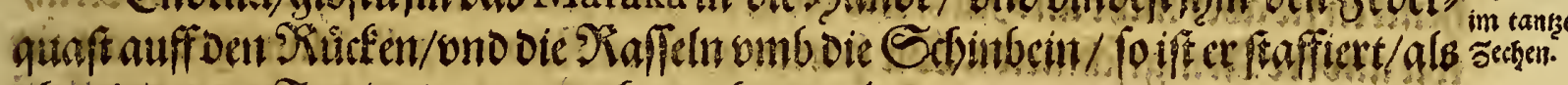

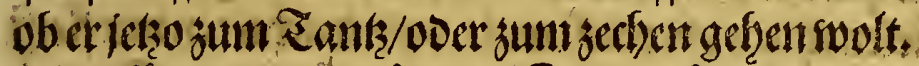

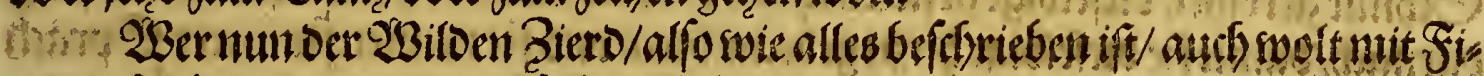

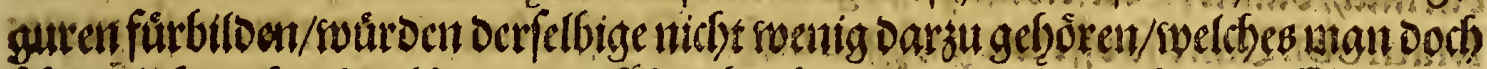

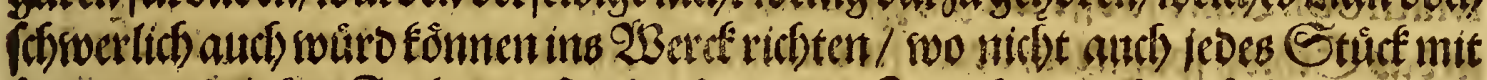

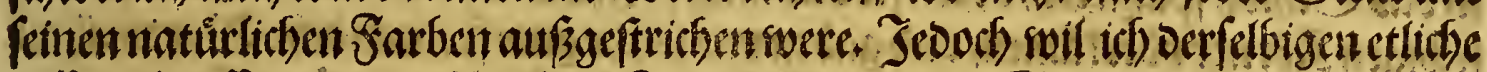

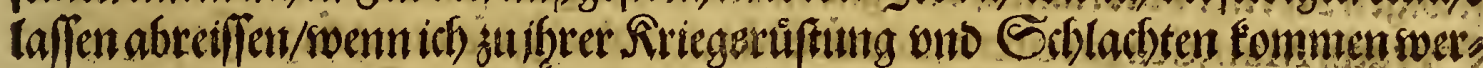

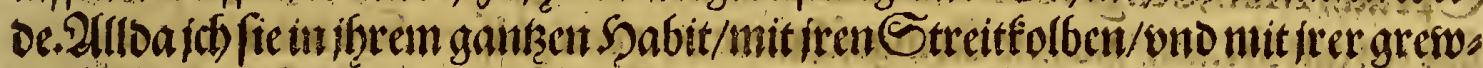

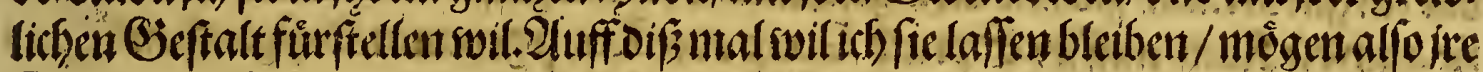

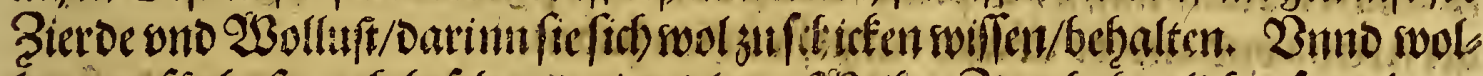

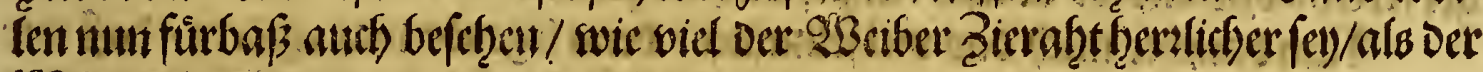
Sร2âuner.

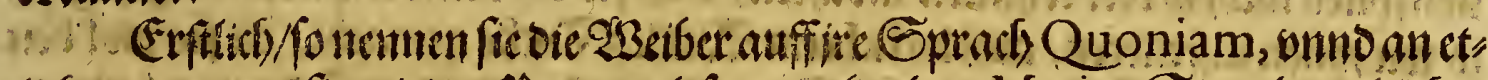

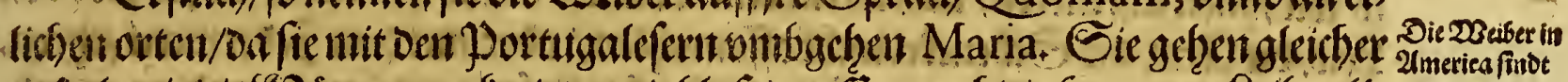

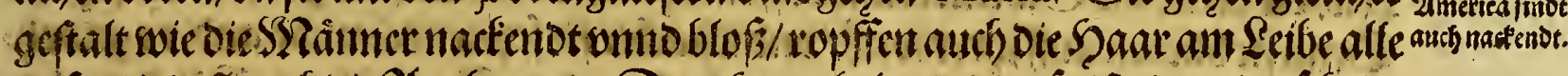

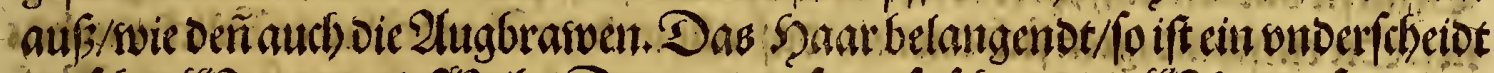

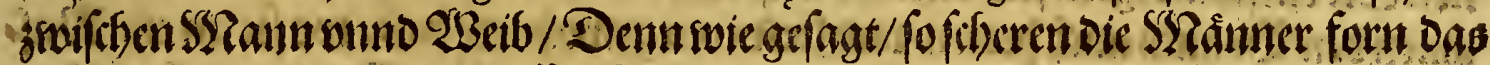

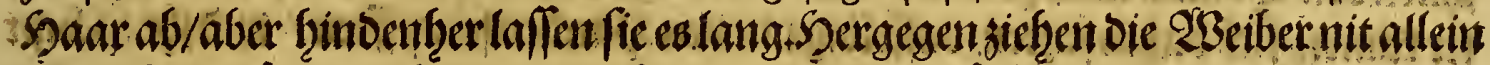

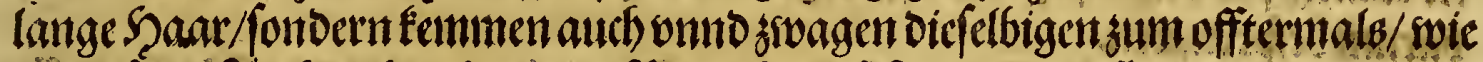

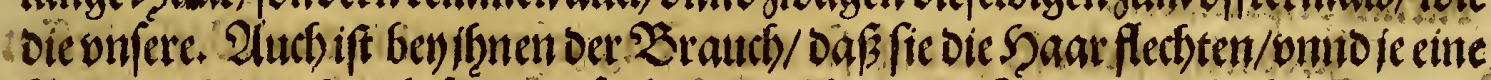

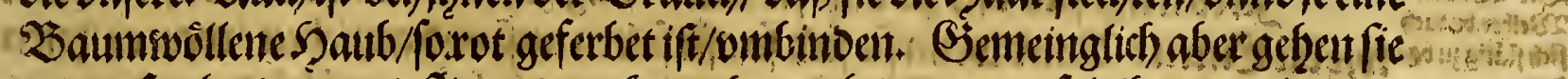
mit auf

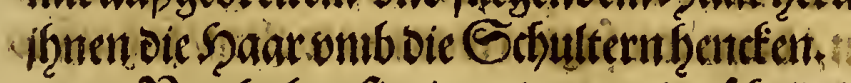

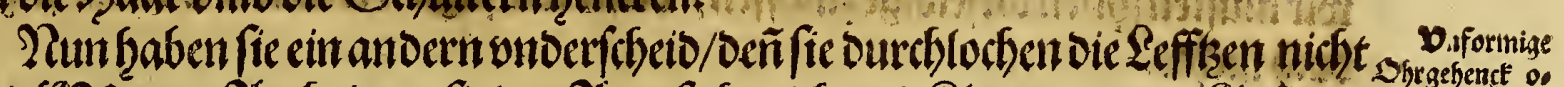

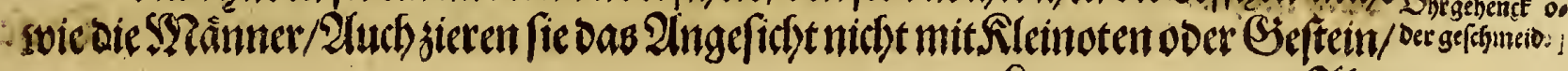

$$
\mathfrak{E}^{\prime} \text { if } \quad \mathfrak{A} \text { ber }
$$




\section{Das britte Theil.}

145

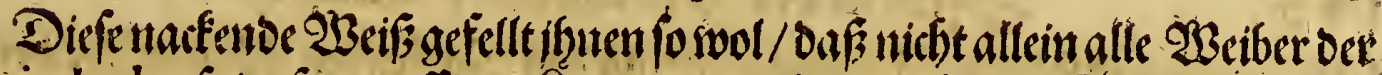

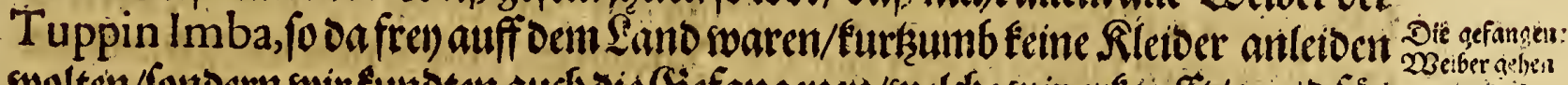

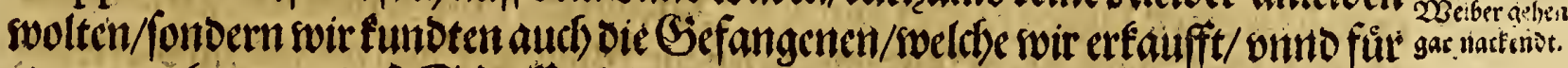

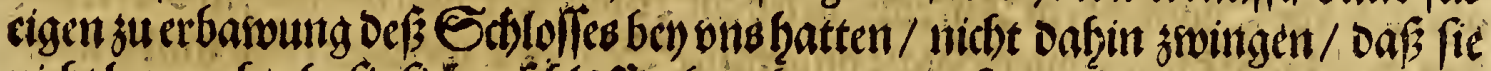

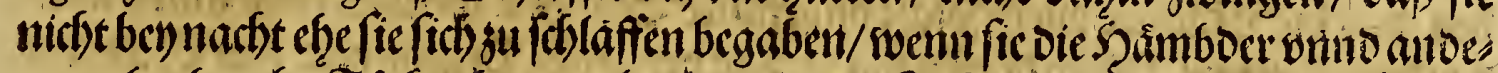

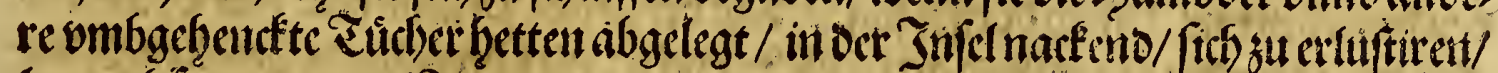

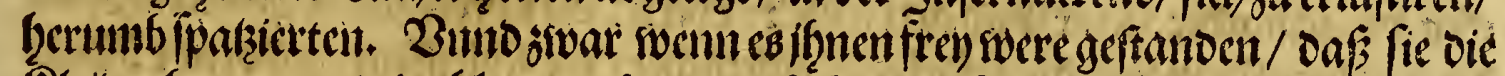

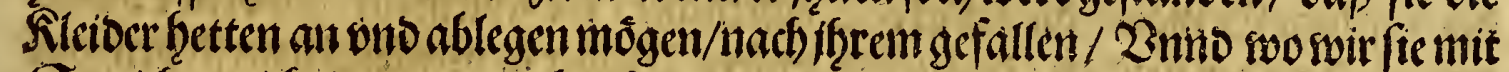

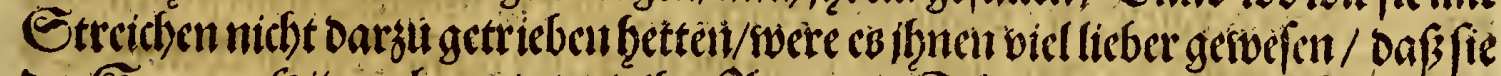

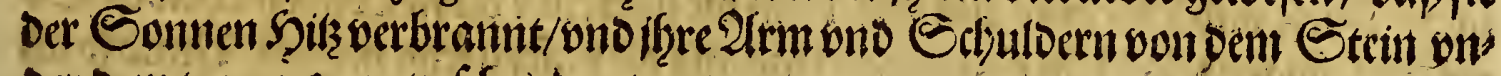
oer Dem tragen were juf frantengangen.

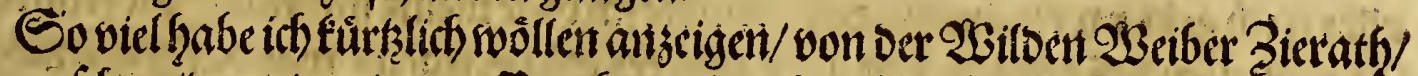

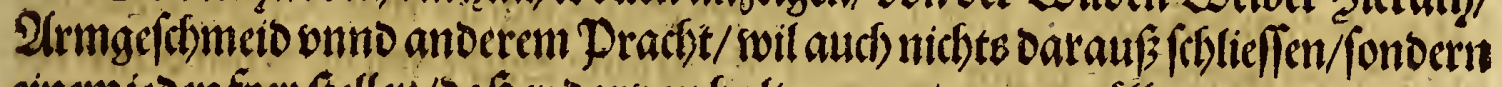

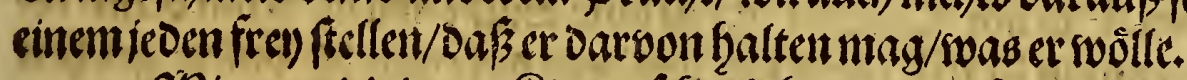

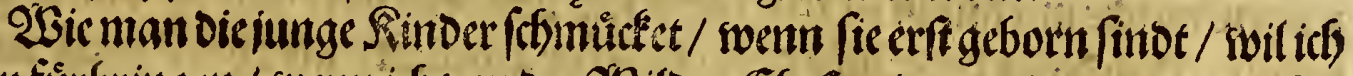

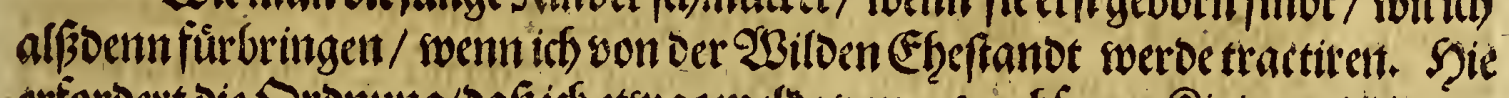

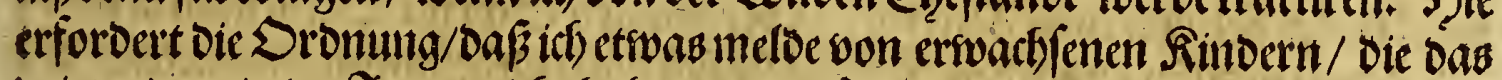

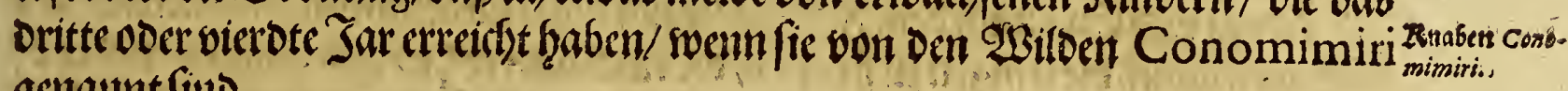
genaunt fino.

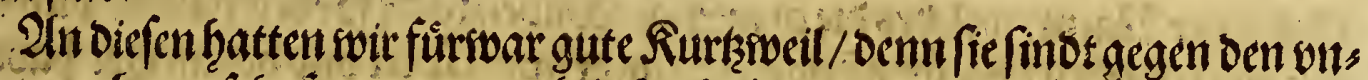

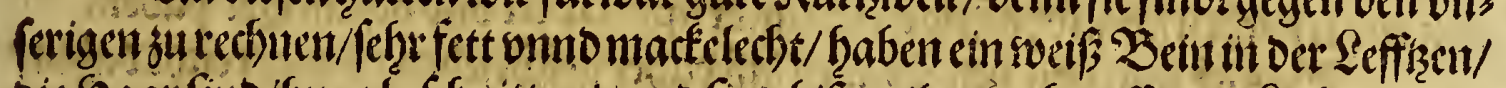

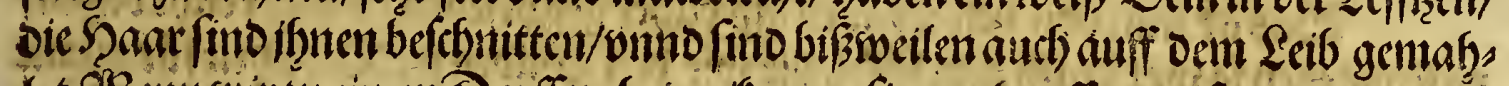

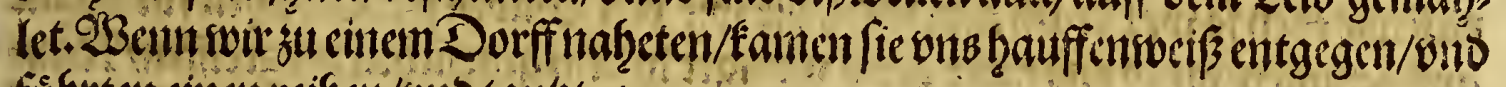
füfrten einen reiferi/ono tankzten.

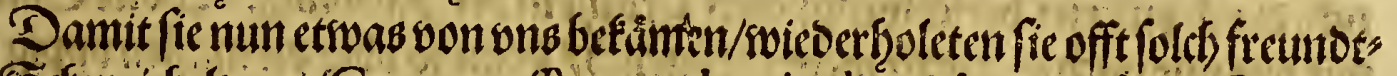
licte Schmeitfelroort/Coutouaffat, amabe pinda, if fo viclgefagt / Freuntot

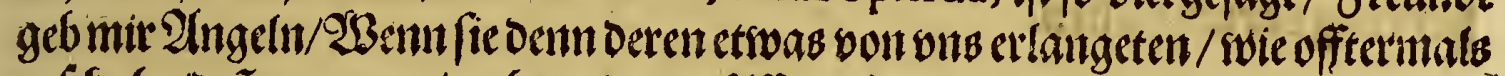

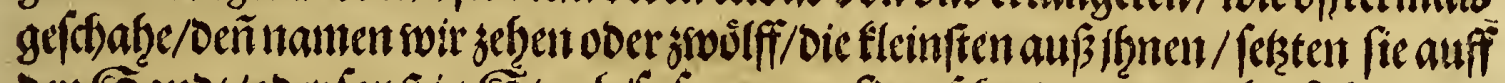

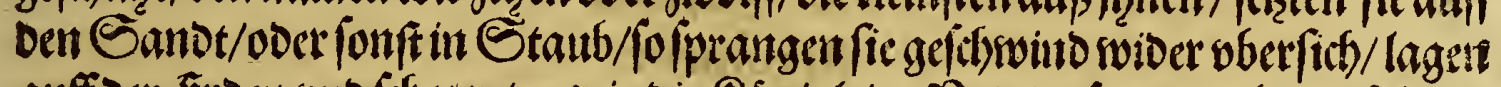

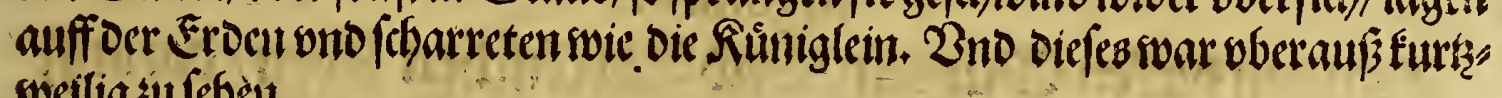
rovetliggufertit.

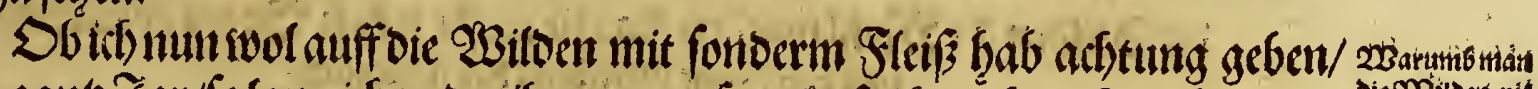

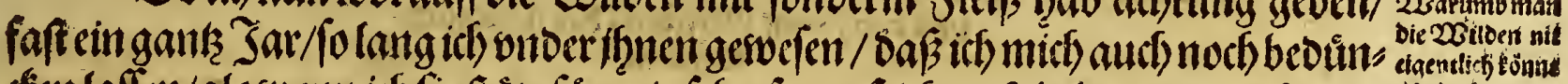

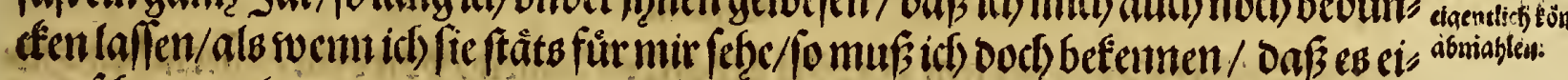

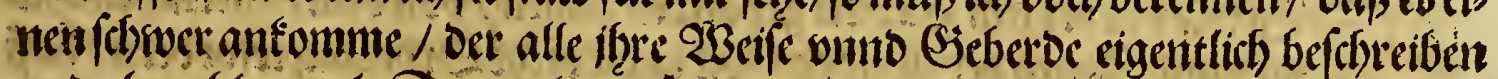

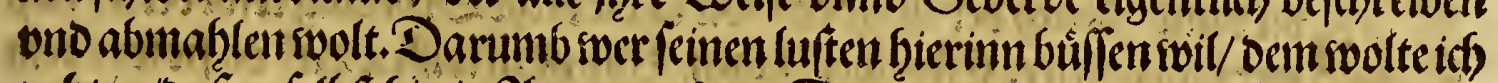

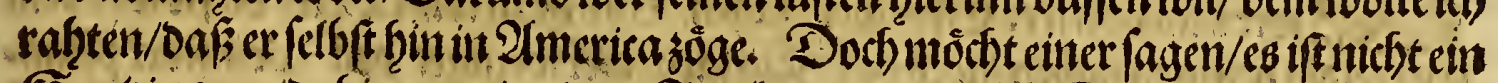

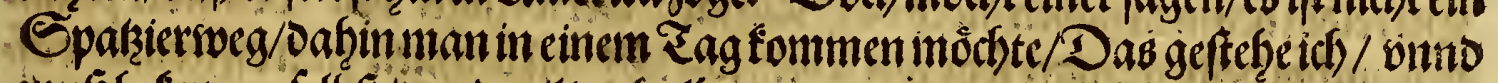

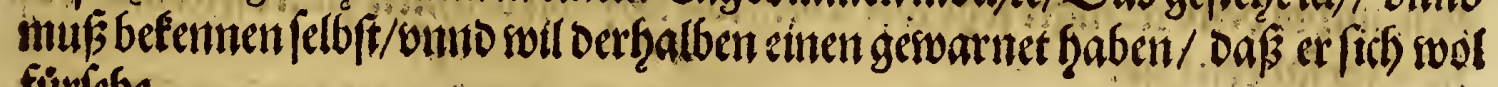
füref̧e.

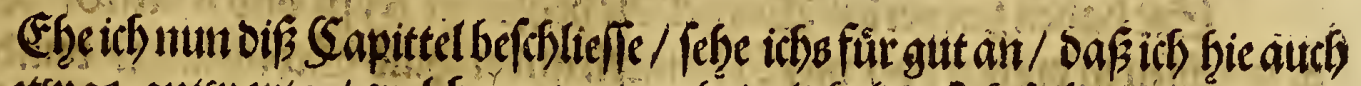

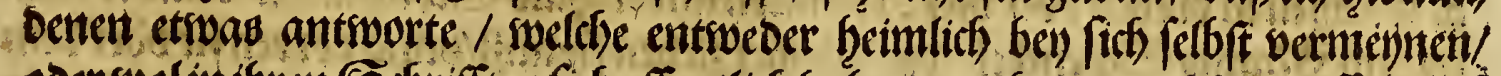

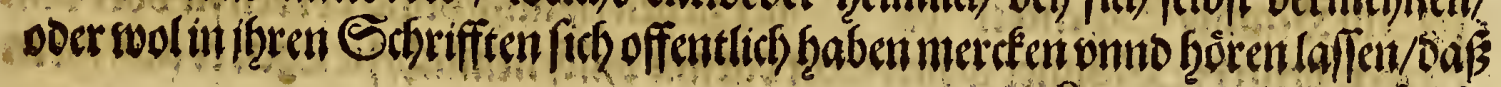

I iij foldéc 


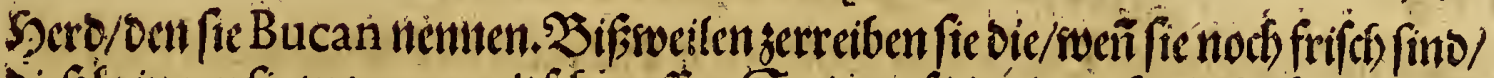

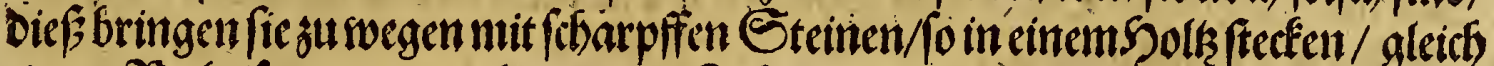

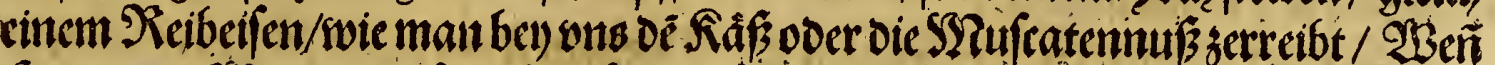

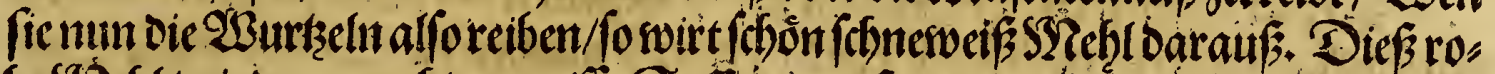

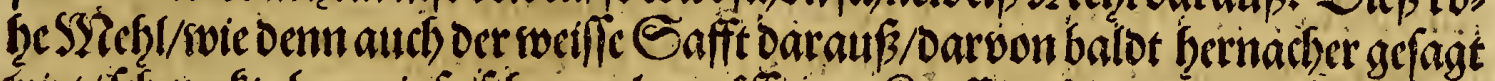

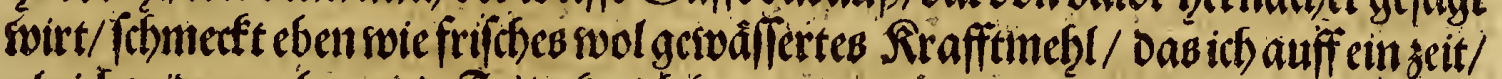

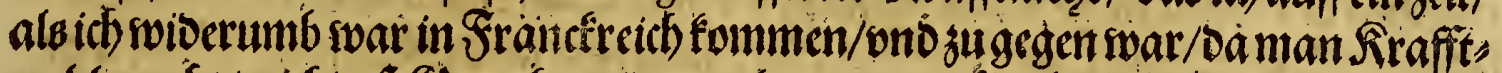

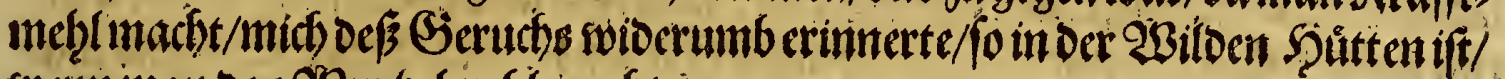

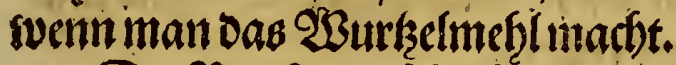

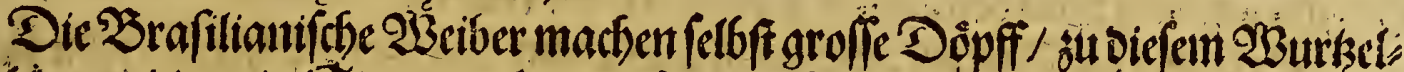

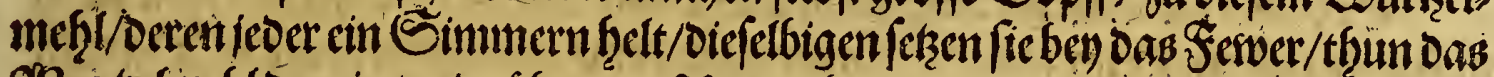

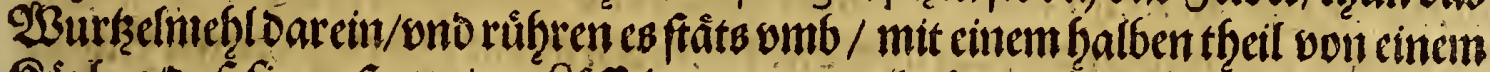

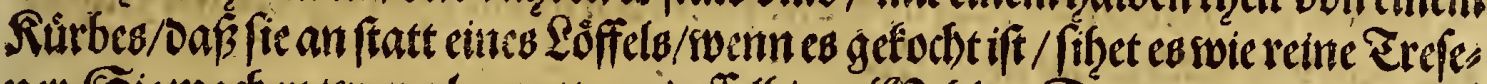
ney. Sie machen sweyerley gattung deffelbigen S? Zehlo. Dab cine wirt gar bart

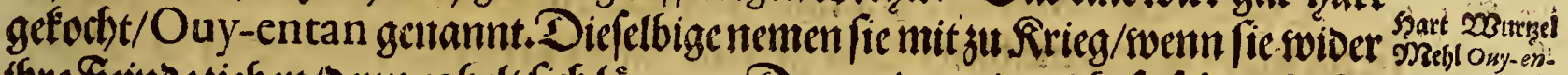

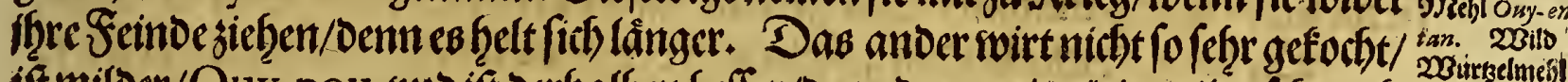

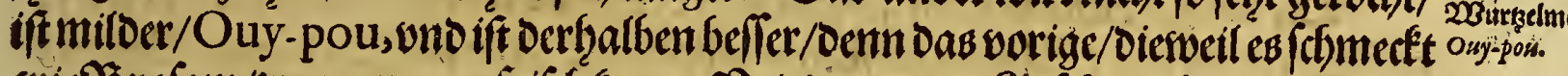

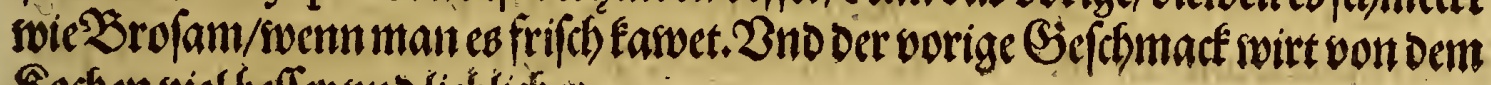
Rocben viel beffer wnolieblitier.

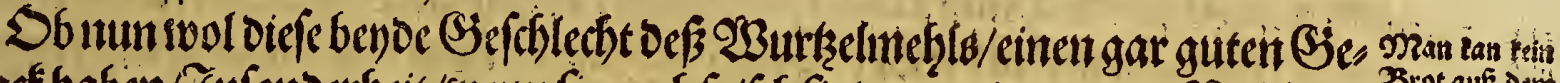

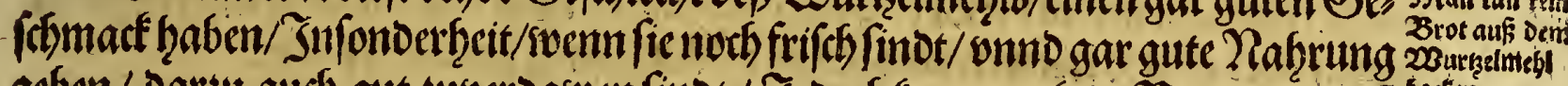

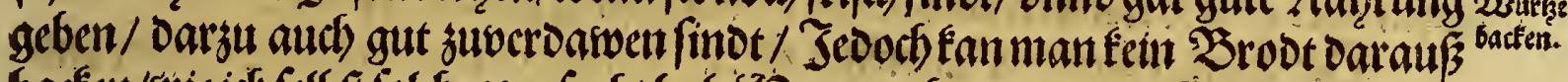

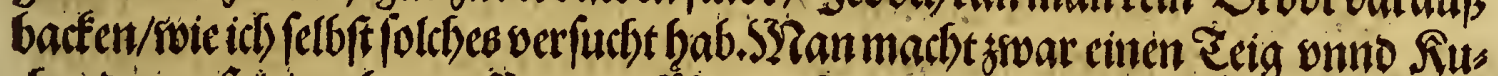

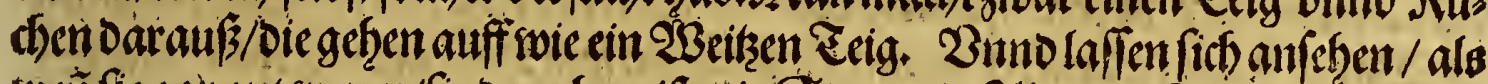

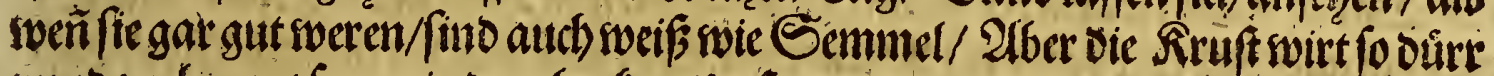

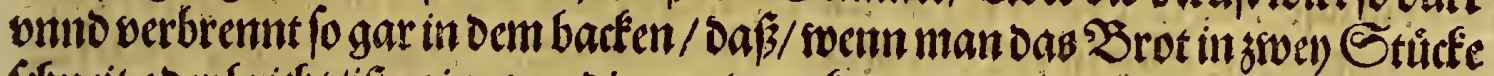

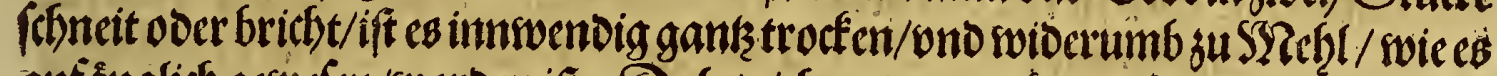

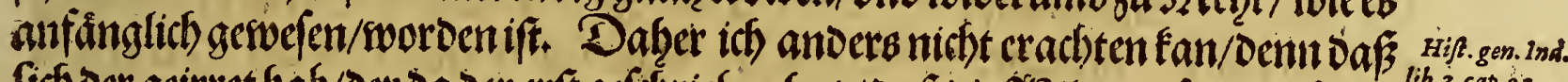

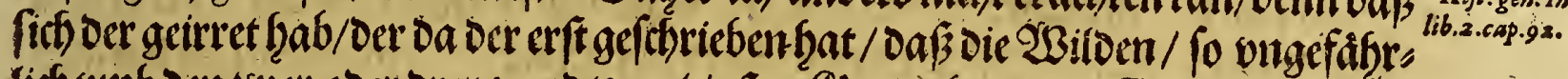

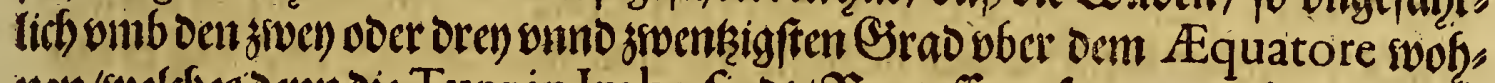

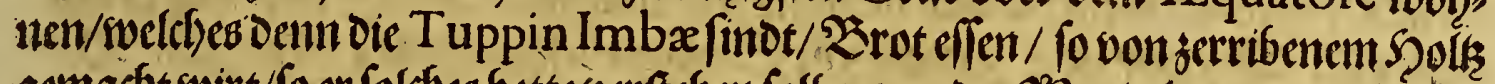

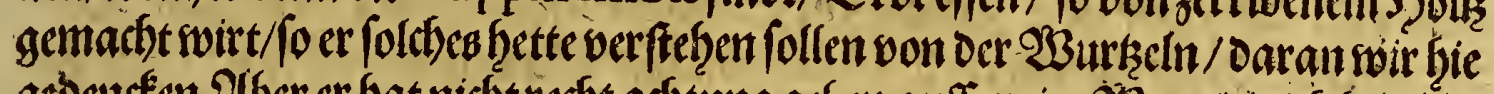

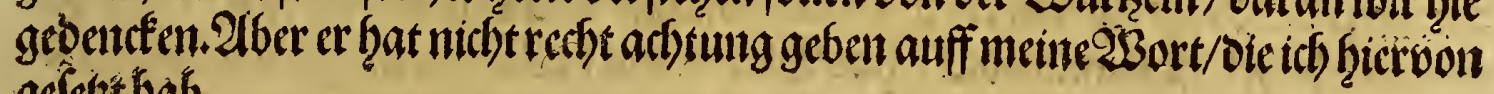
gejelzthab.

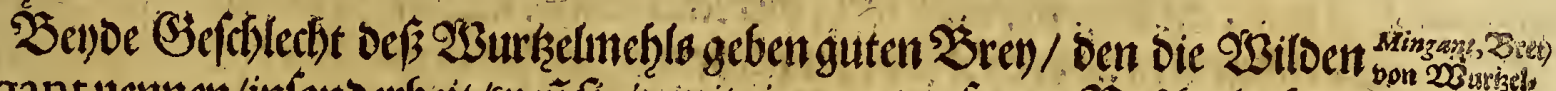

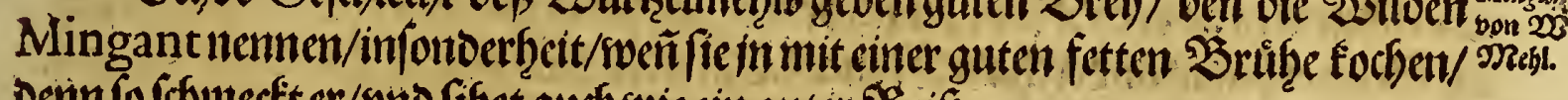

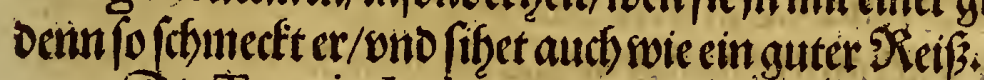

Die Tuppin Imbx, SYant ono \&seib/autch oiejungen Snaben/fino von Die wiben

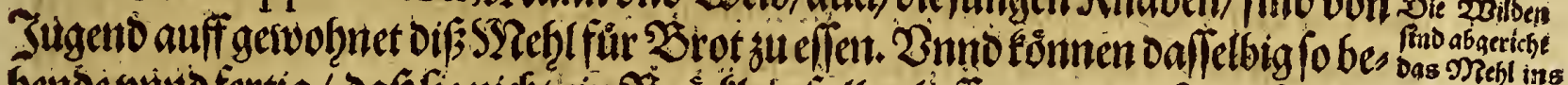

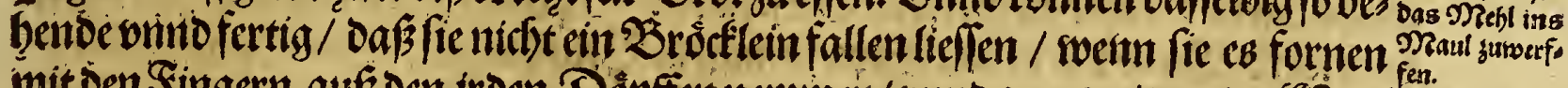
mit Den Singern auf oen iroen Dopfien nemmen/onno von weitem ins SY?aul Deesrangoen

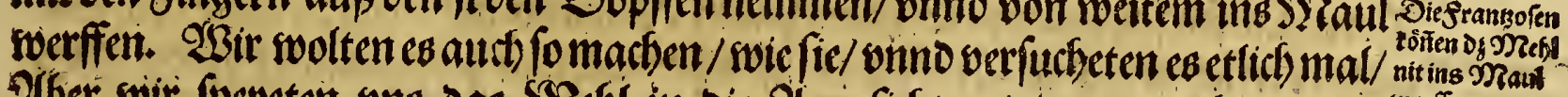

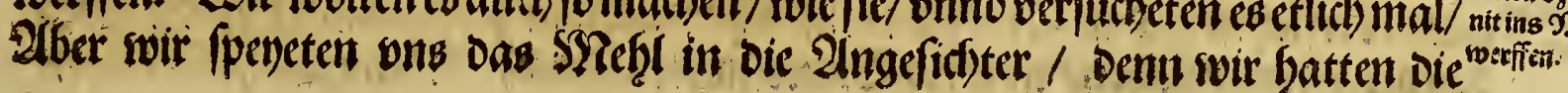

Rumit 


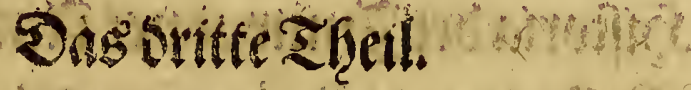

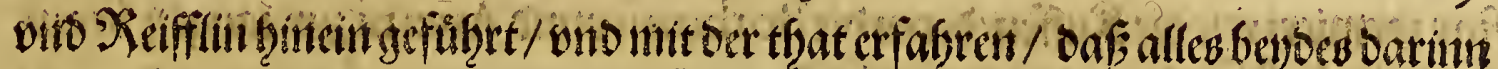

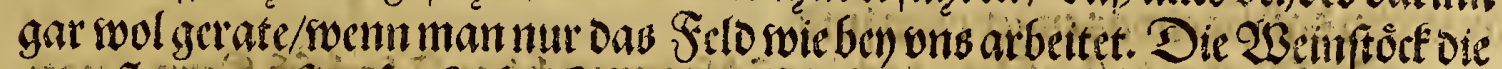

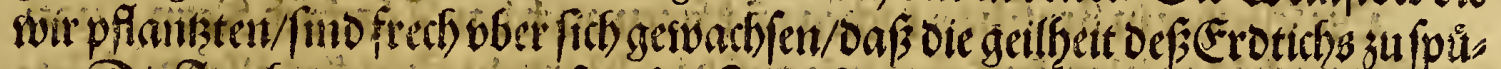

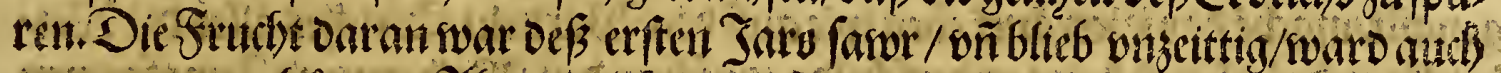

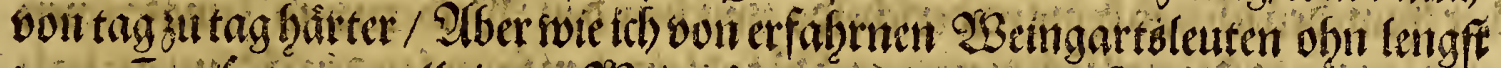

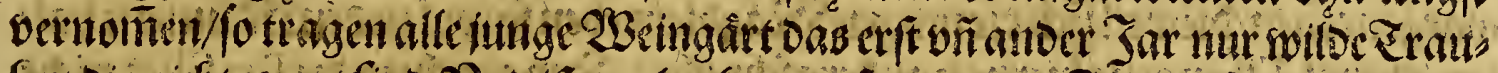

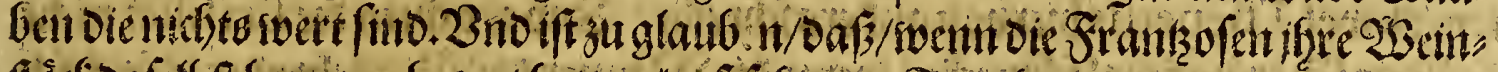

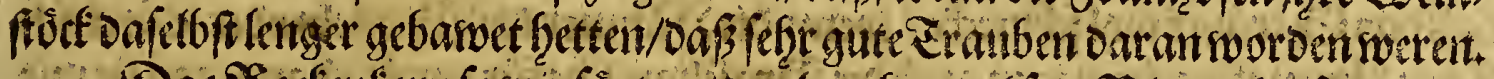

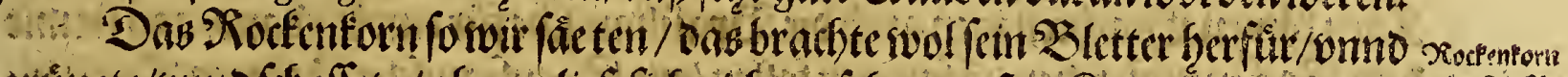

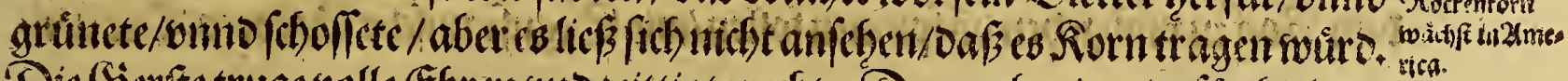

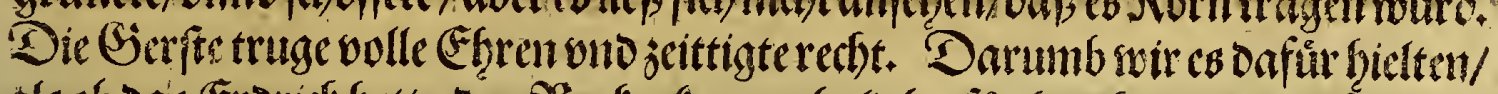

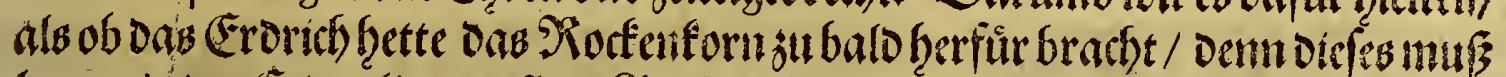

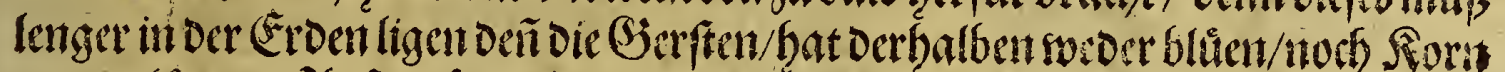

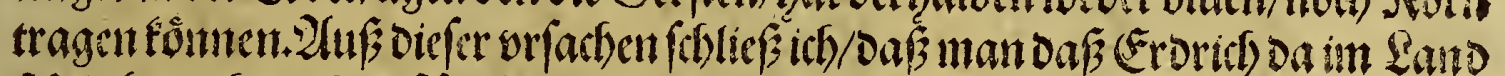

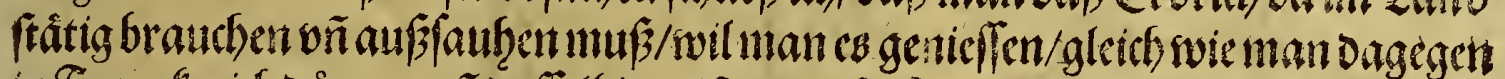

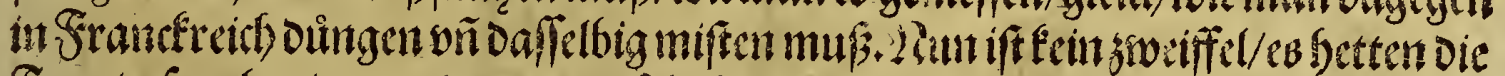

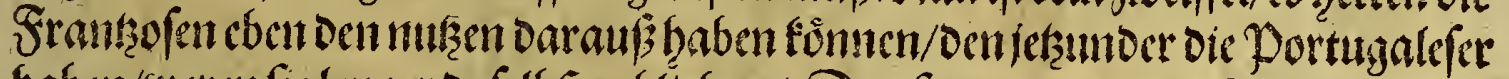

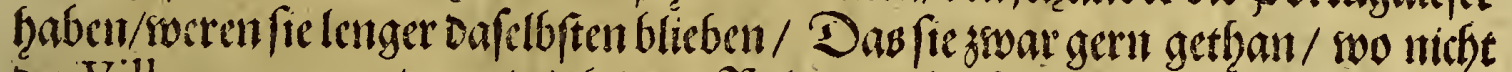
Der Villagagno won ocr reinigfeit ice Religion abgefallen were. Bno that oem

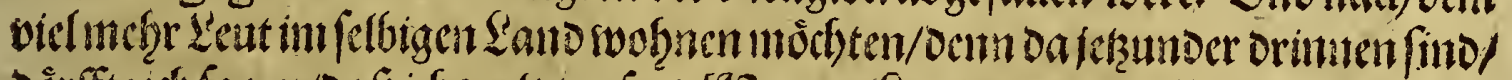
Dorffte ich) fagen/oafich wolt taufeno SYorgen \&ants inngenoñ

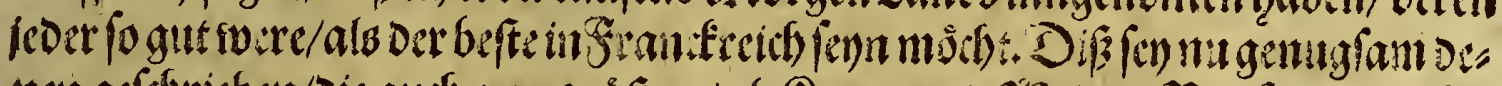

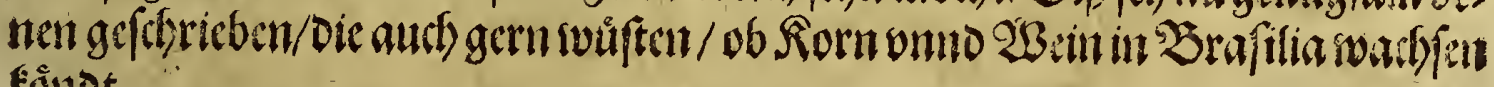
fồtot.

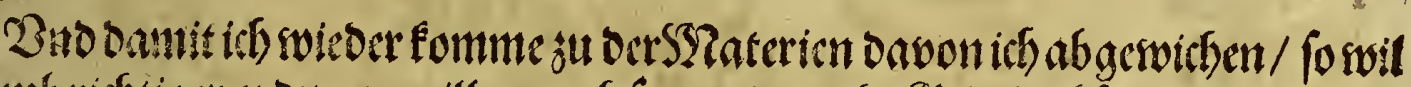

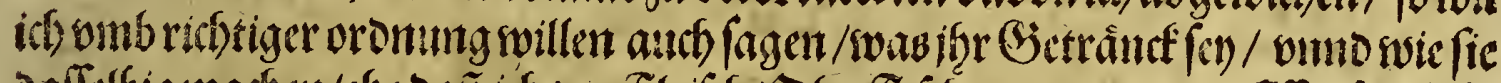

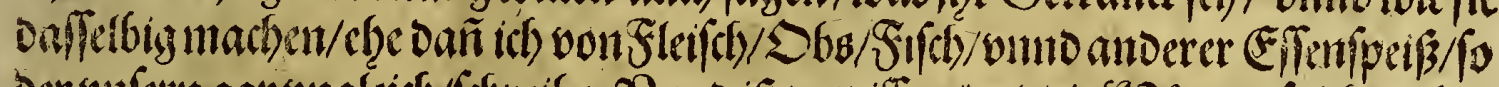

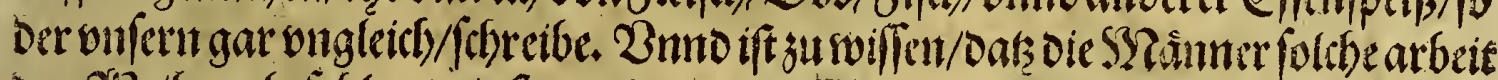

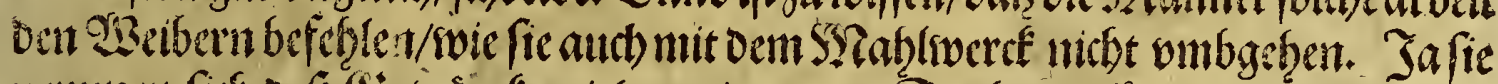

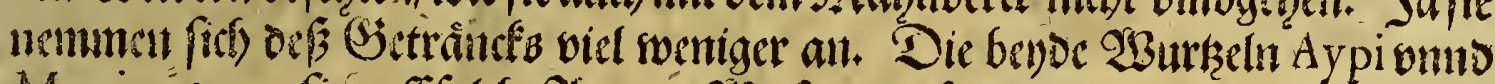

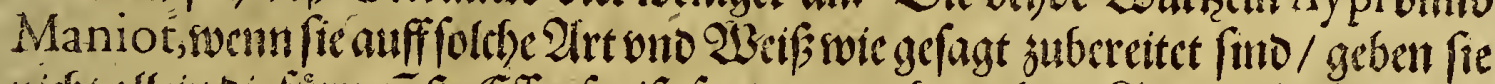

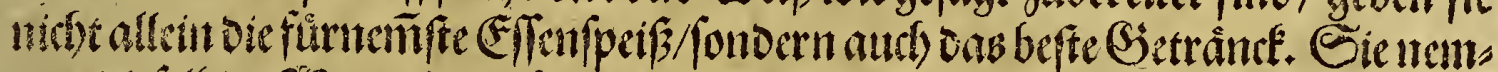

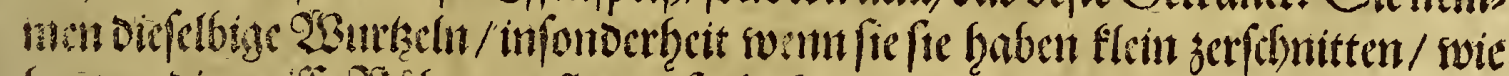

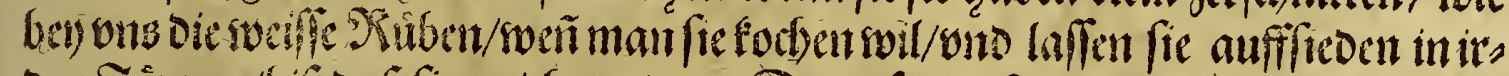

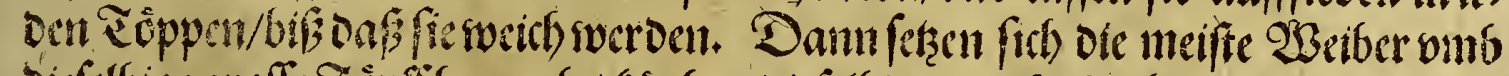

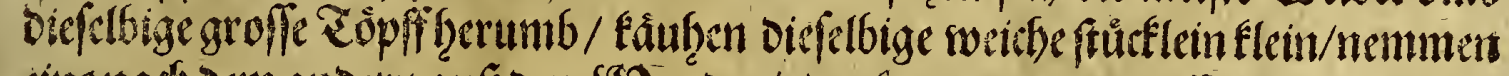

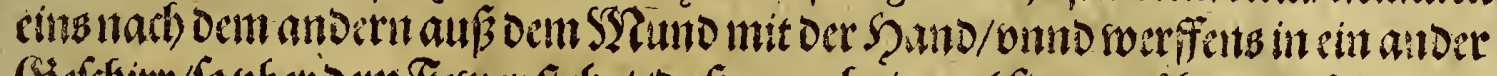

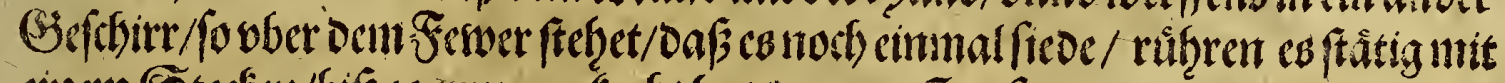

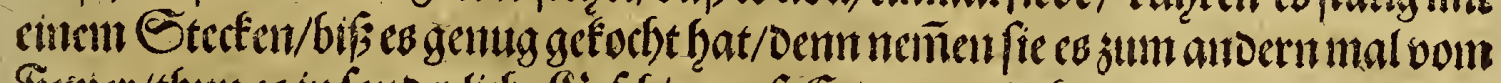

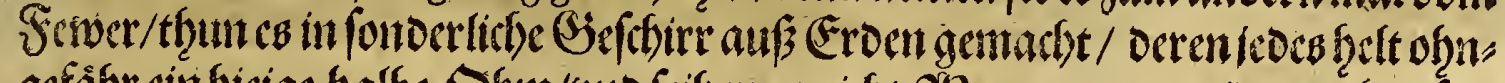

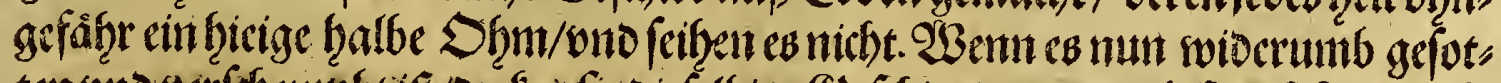

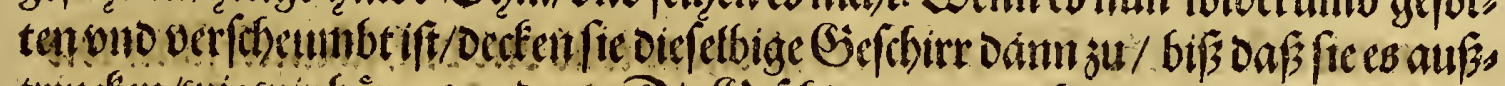

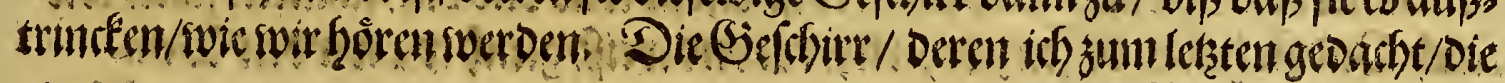

3...




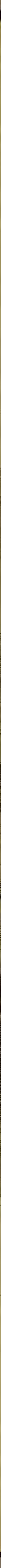


QBeil tum bife 3 unt

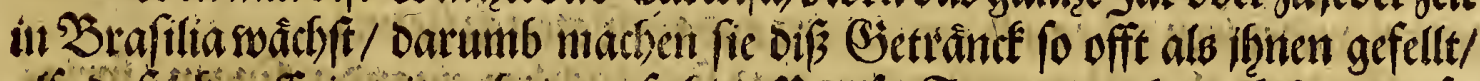

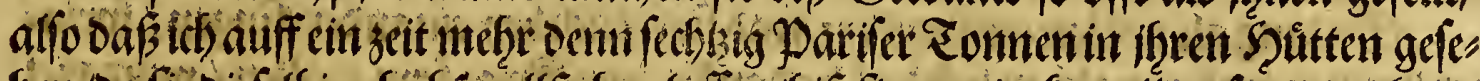

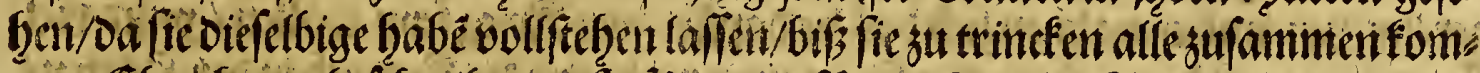

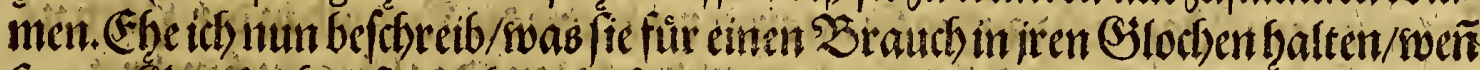

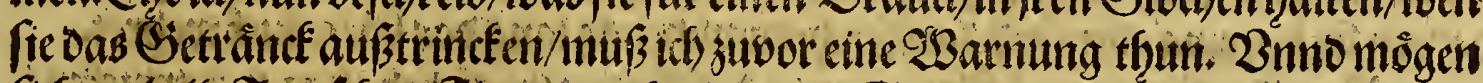

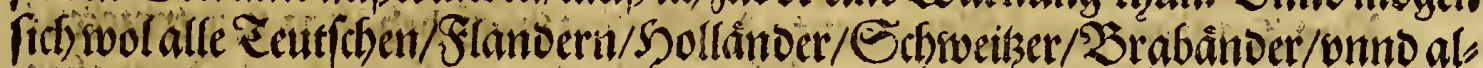

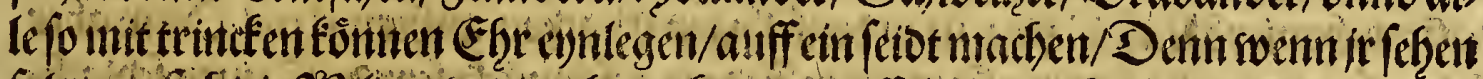

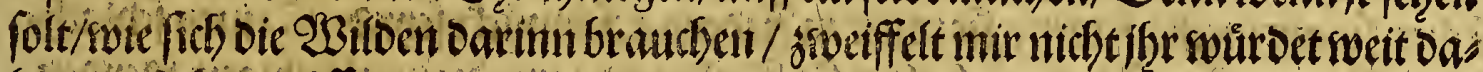
Ginoen fegentmiffen.

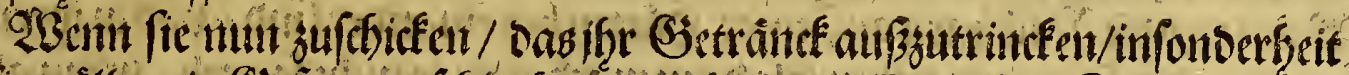

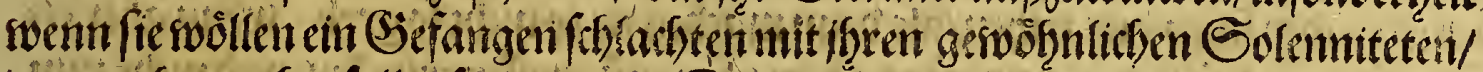

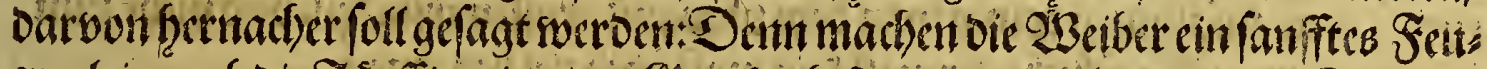

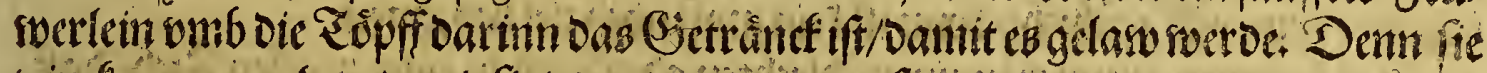

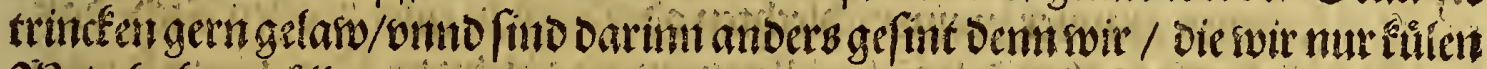

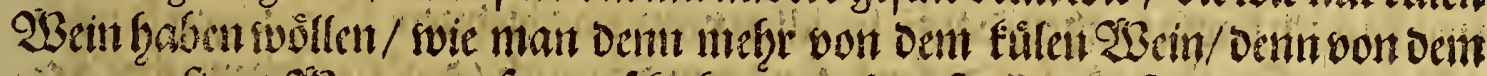

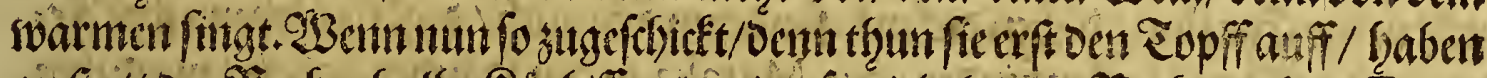

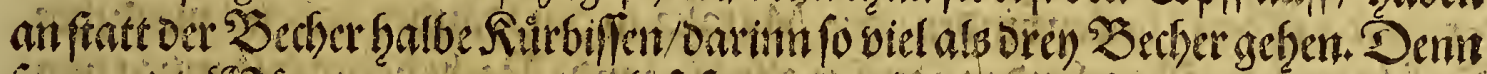

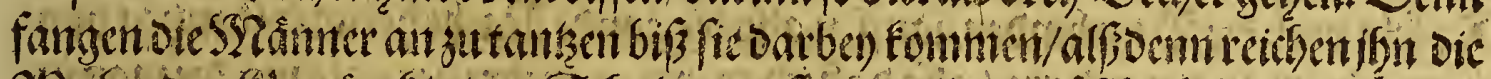

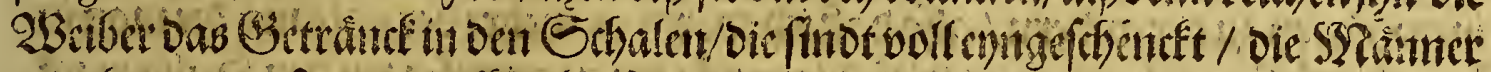

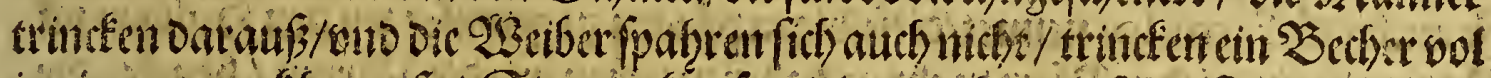

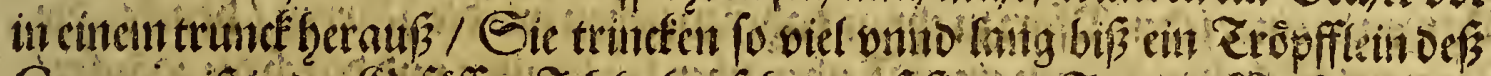

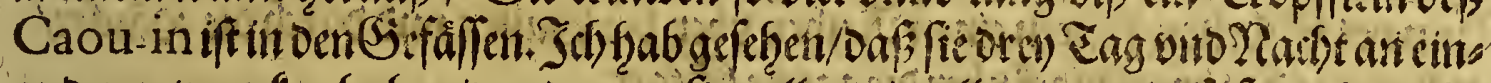

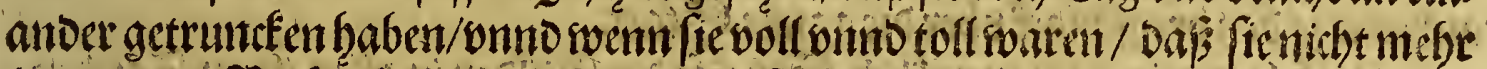

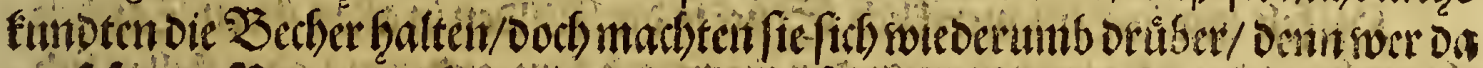

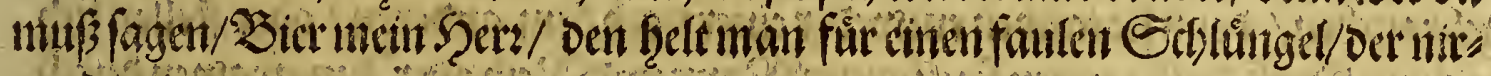
geno futang.

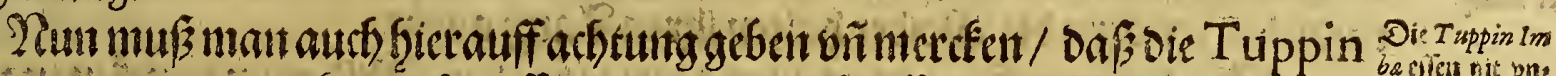

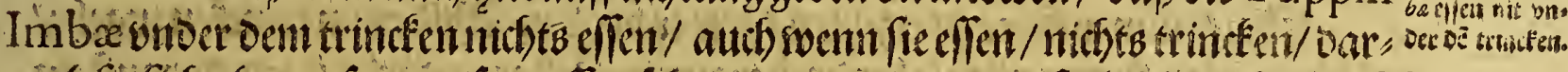

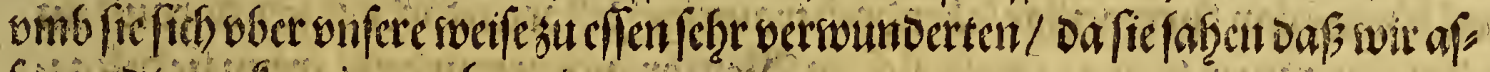
feri und trantefen cins vmbs ander.

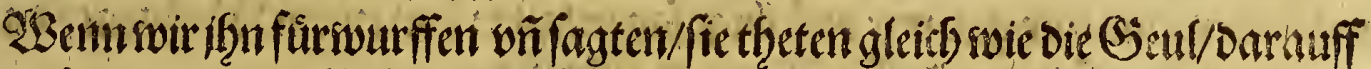

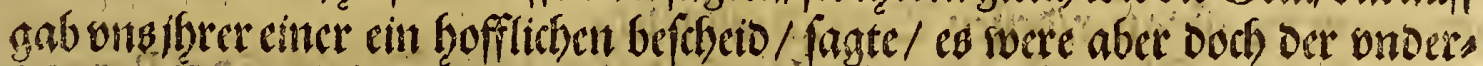

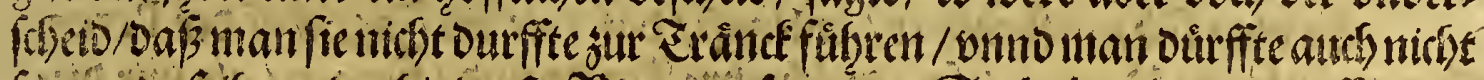

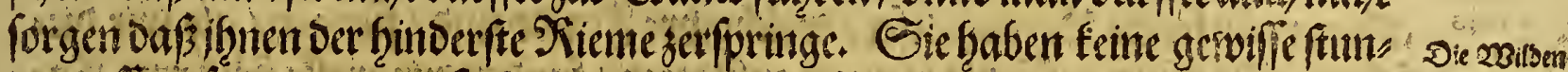

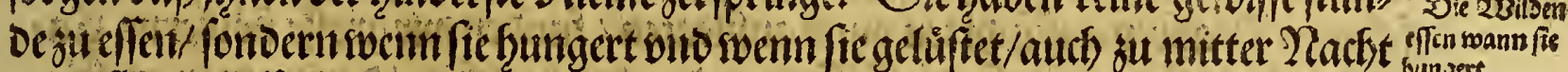

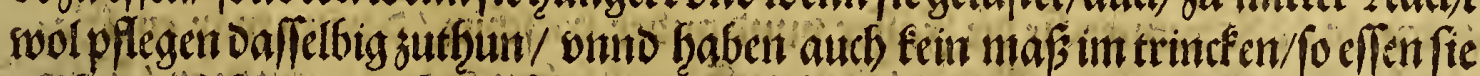

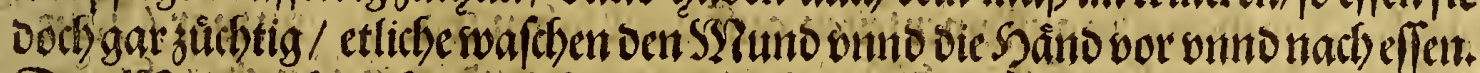

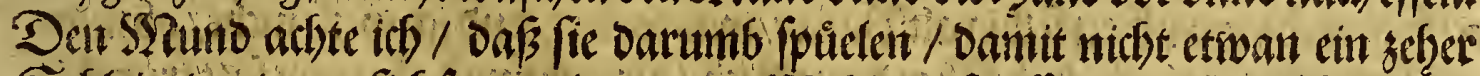

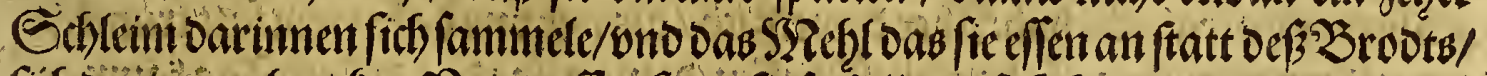

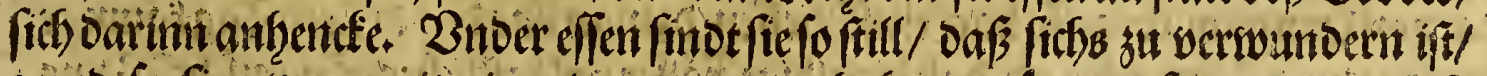
bnito fo fie etwas mit einander zu reben haben / fparen fie oas oartach.

Sil if 23no




\section{Das britte Thenl.}

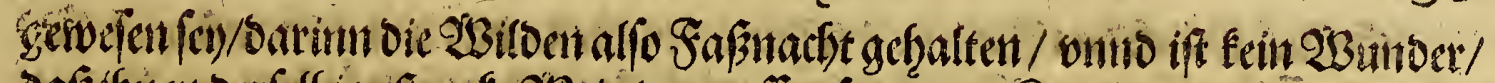

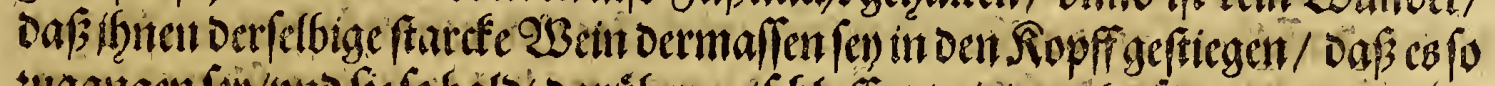

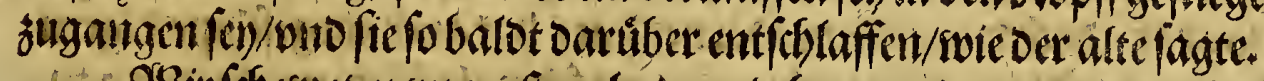

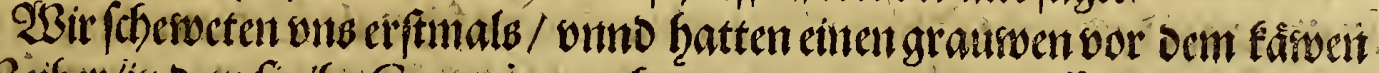

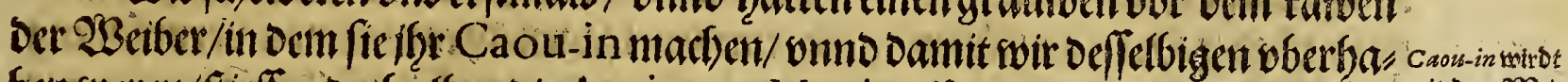

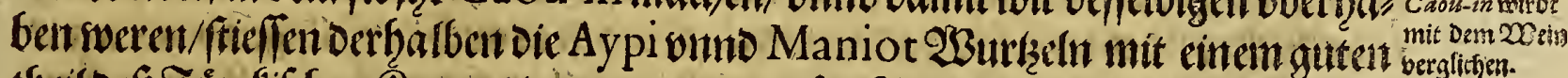

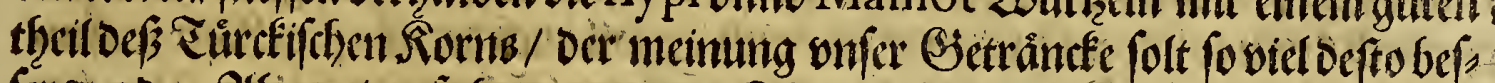

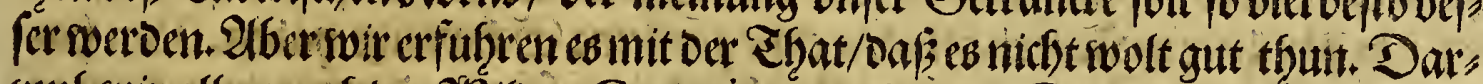

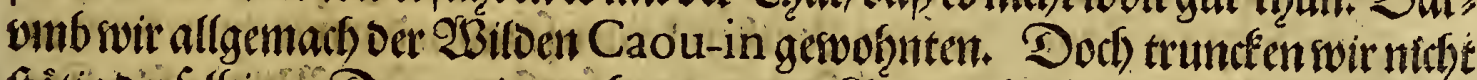

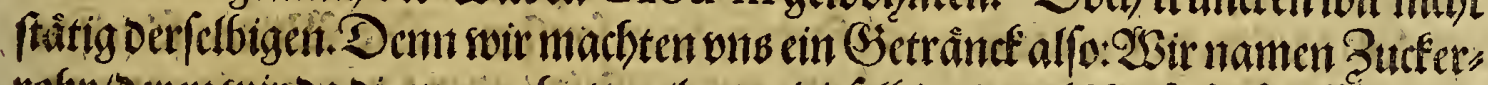

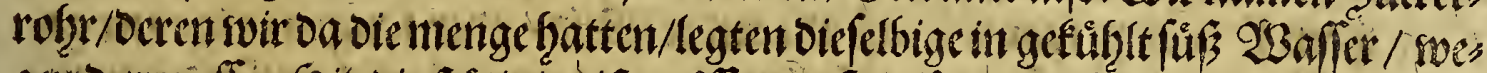

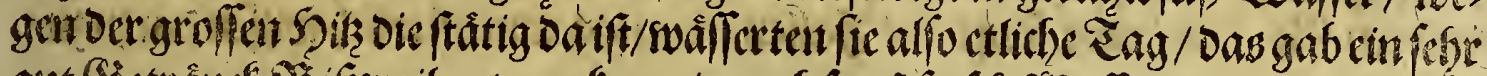

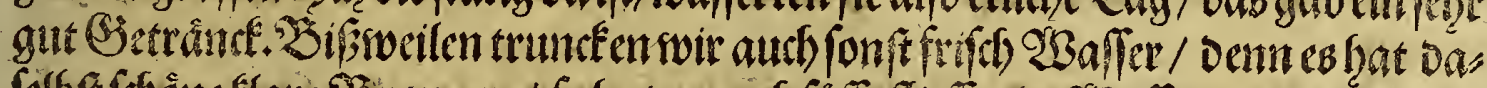

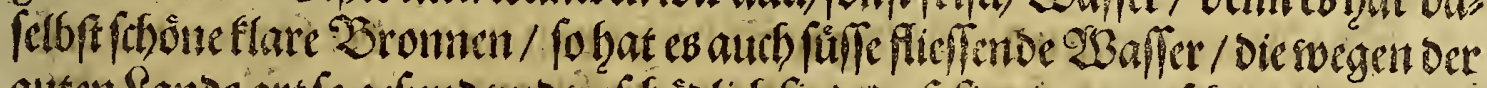

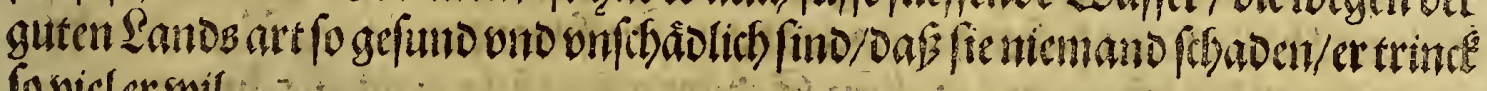
fo viderswil.

Die QBitocntteñen dab/ü 2 saffer Vhete,

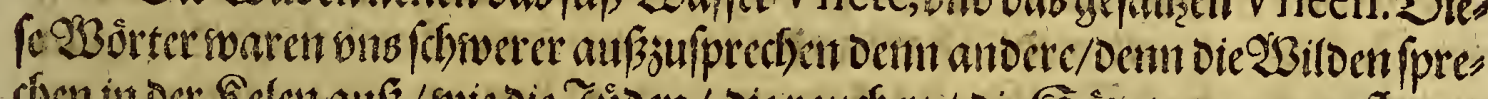

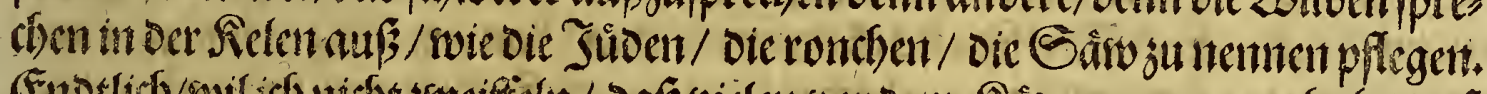

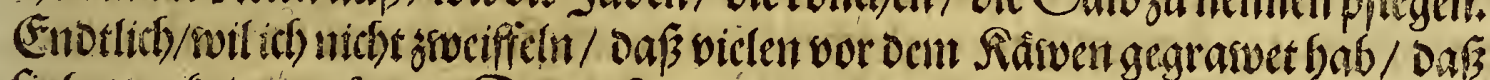

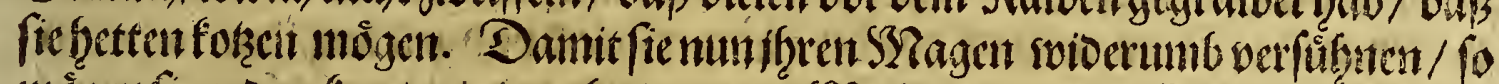

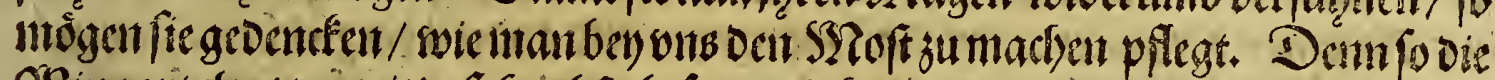

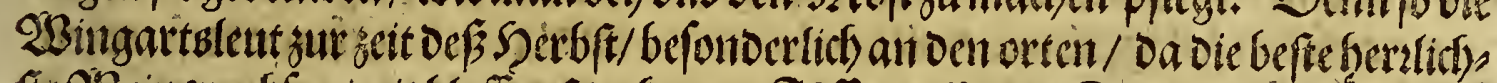

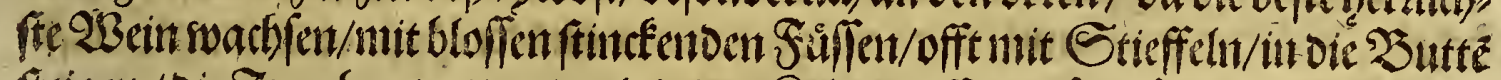

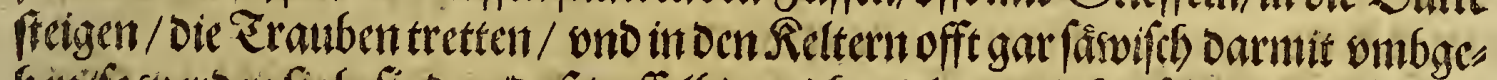

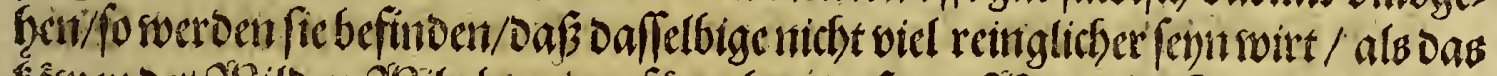

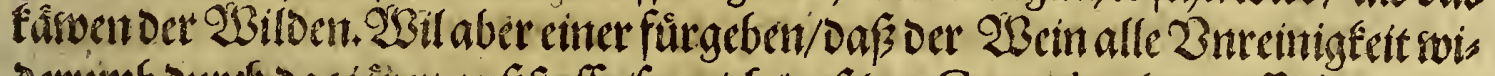

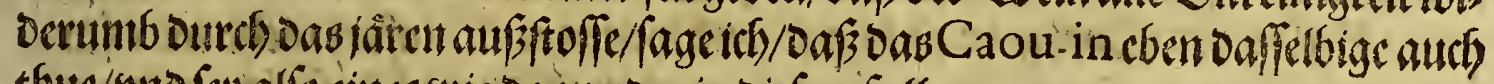
thuc/onto fes alfo cincs wie o as antoer in diefem fall.

\section{Sapittel.} Argument.

\section{Fon Dem SBtben oon bengroffen Etoren / Sthlan: gen/outo antoeren felfianten Thieren in} America.

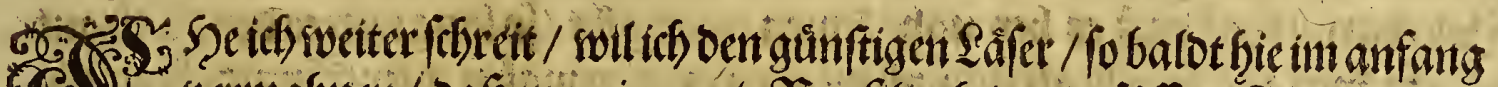

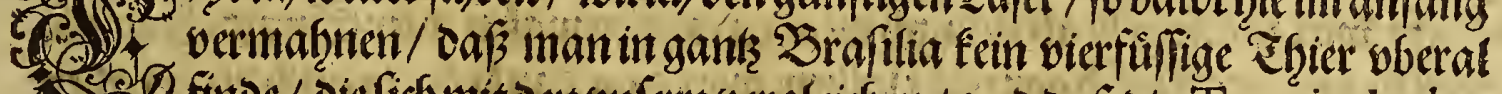

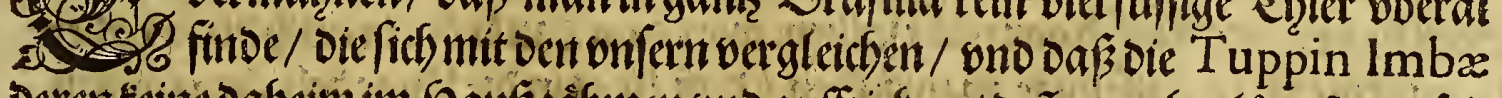

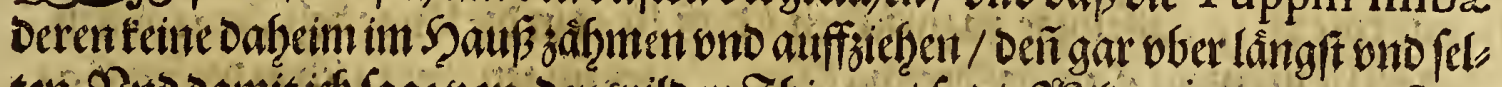

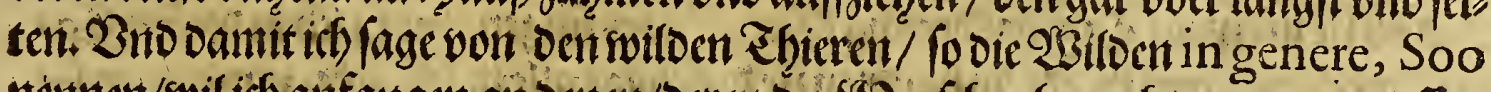
neenen/wil ich anfangen an benen/Deren oersyenfh gebrauchen onno genteffen tan.

SII iif Criftich 
Das bette Tfeil.

Iss

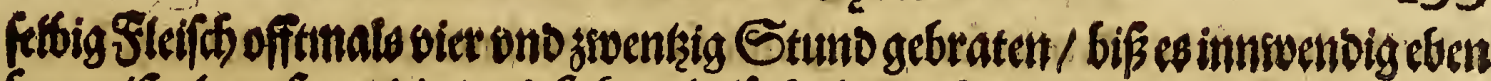

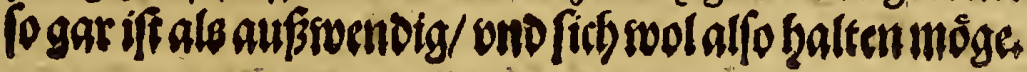

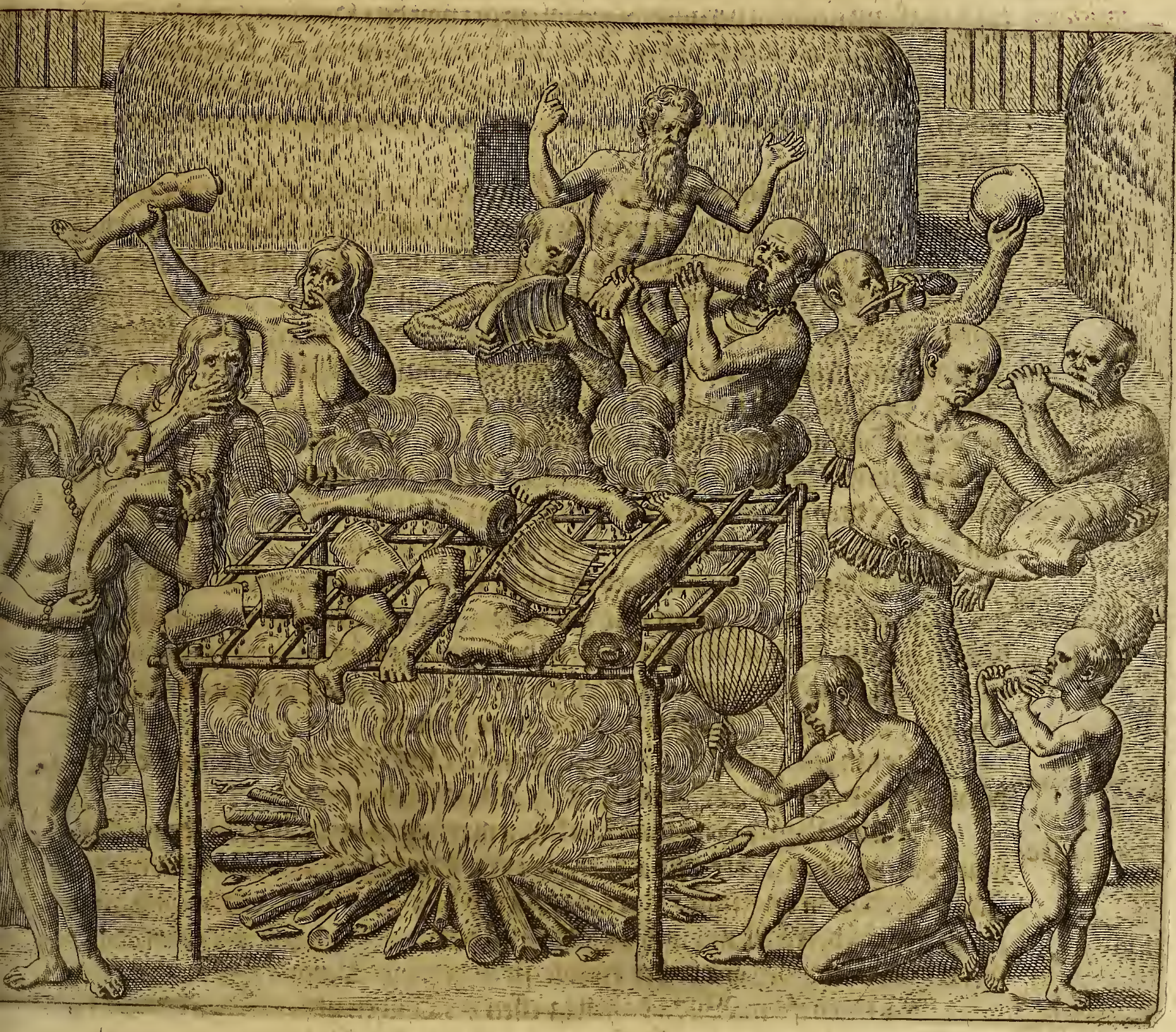

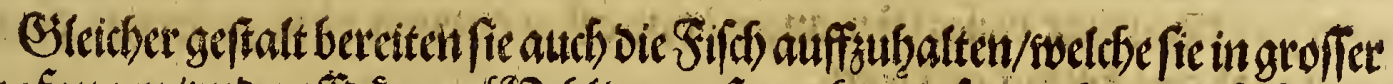

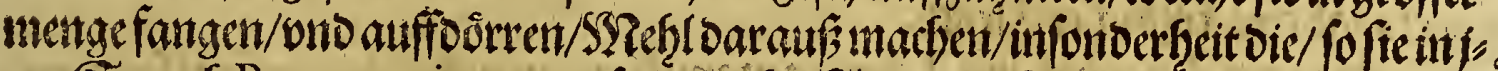

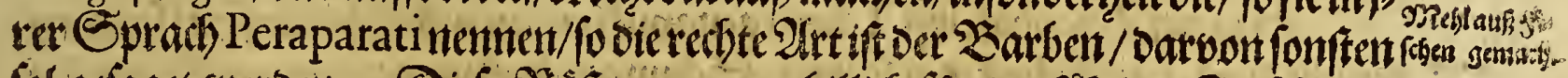

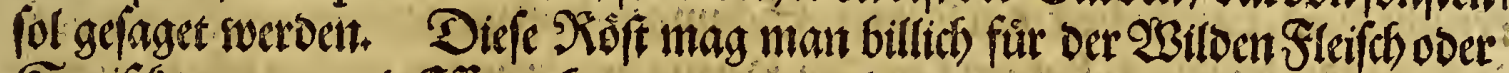

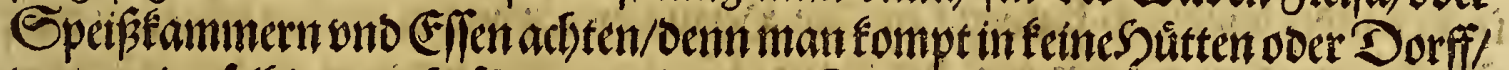

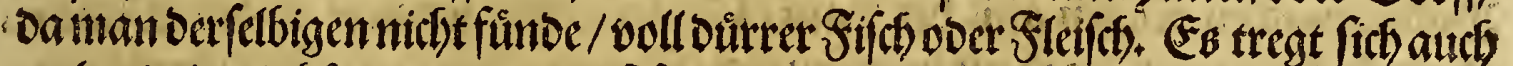

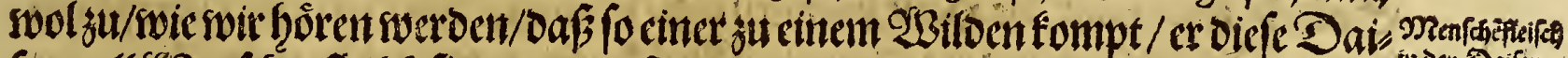

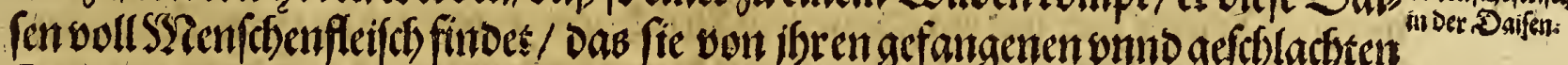
Seinden/gleich einem raub/genachthaben.

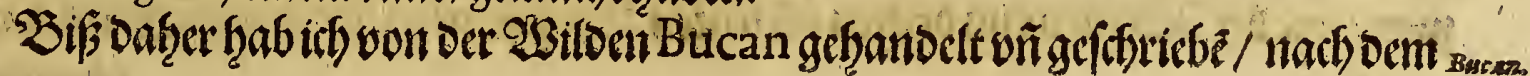
wodllen 


\section{Dith Das oritte Theil}

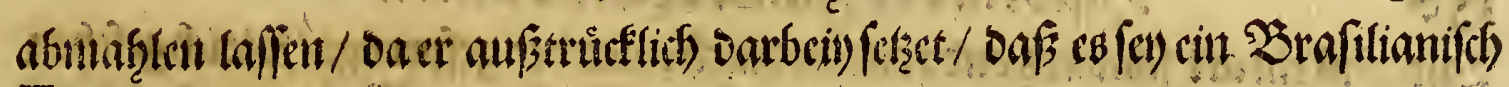
Tatu.

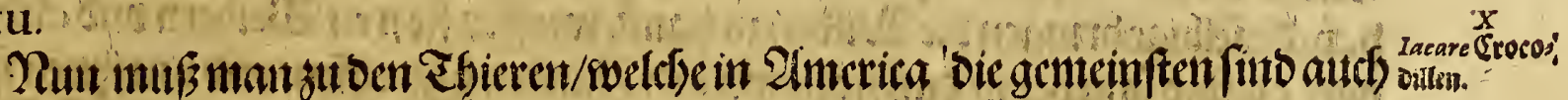

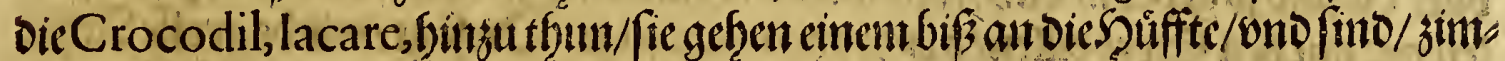

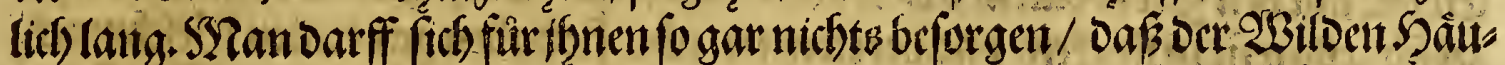

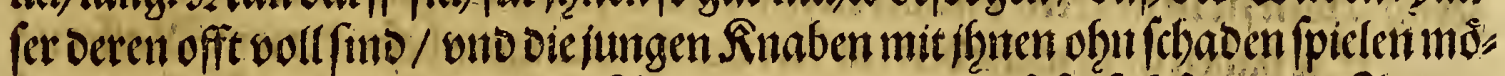

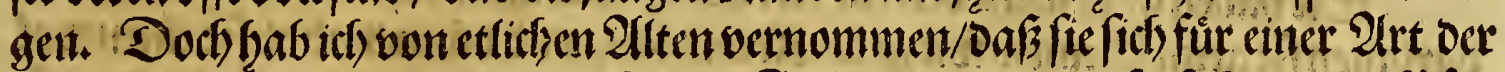

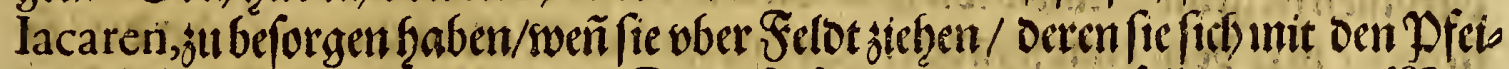

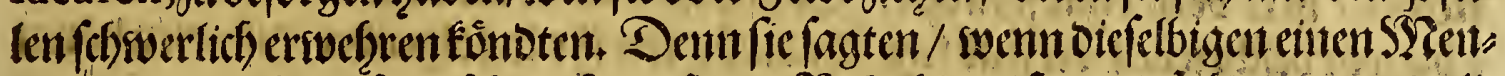

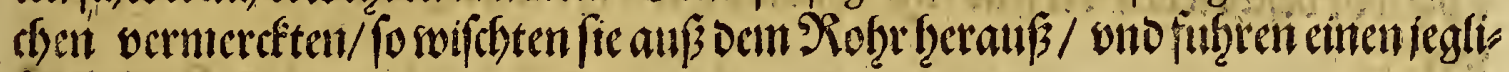
foben ongeftùmmiglict)enat.

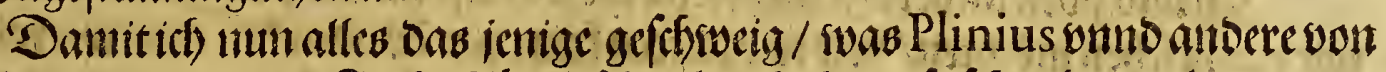

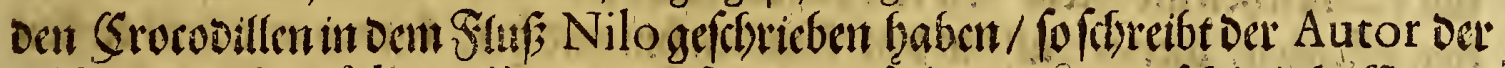

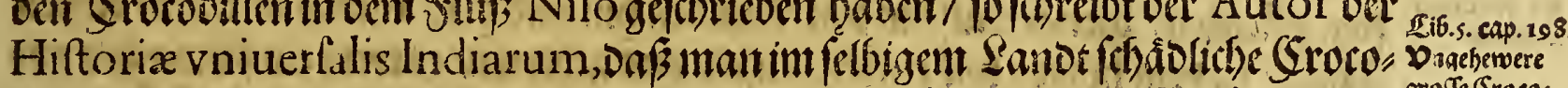

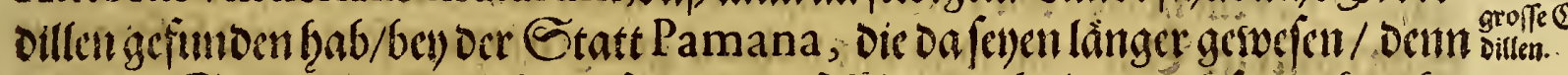

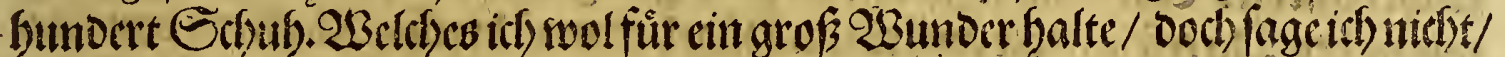

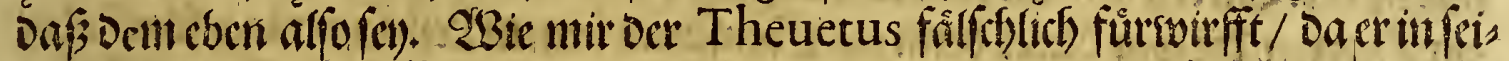

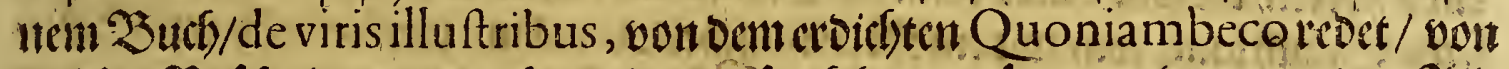

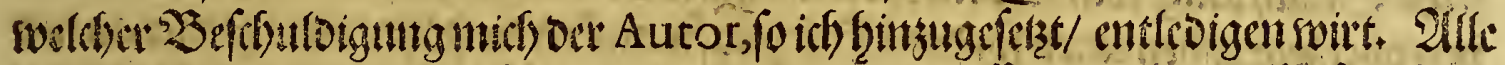
Die Srowoillan vie id gelchen hab/ batten ein groffen sociten auffgefperteten

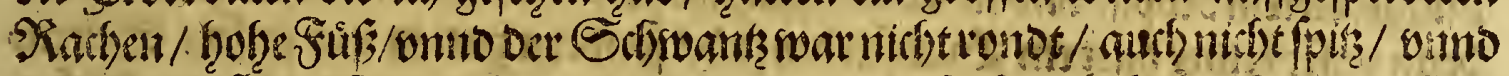

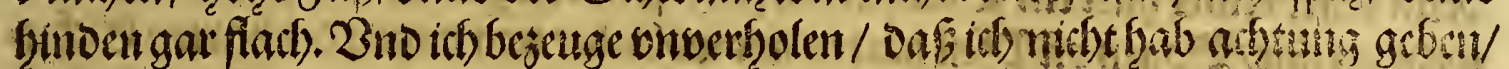

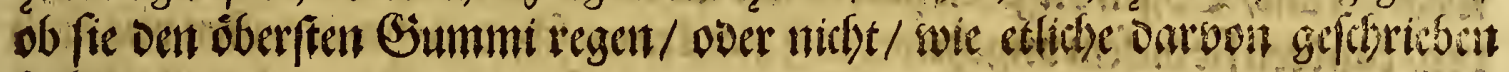
babert.

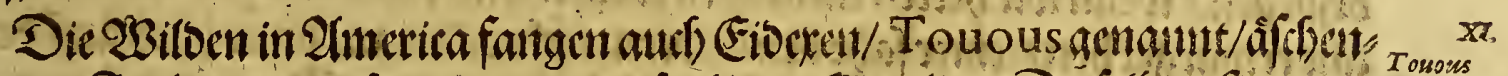

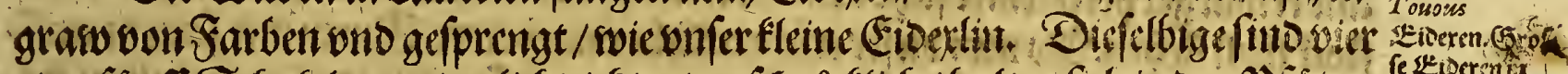

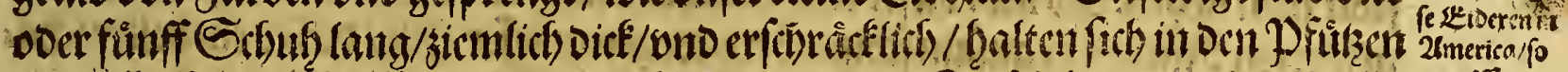

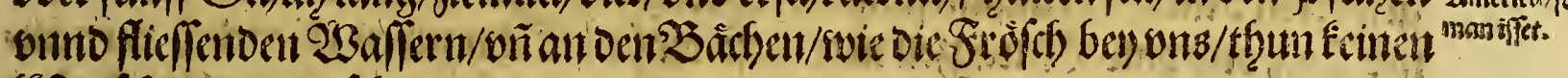

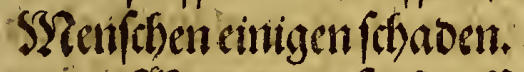

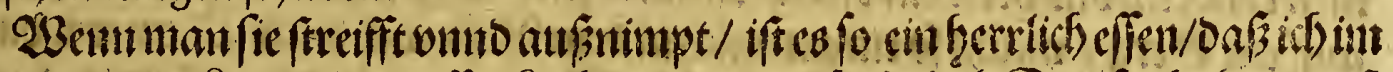

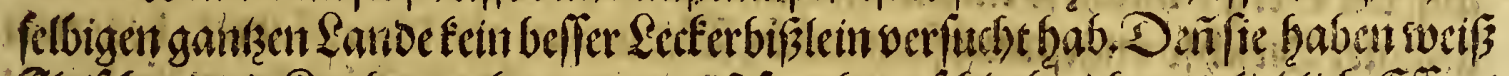

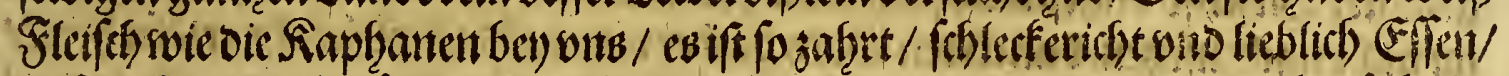

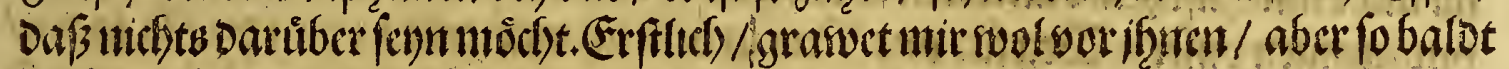

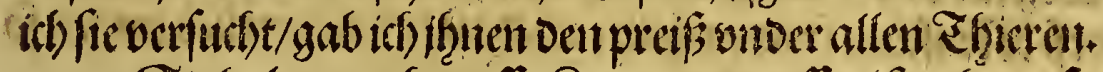

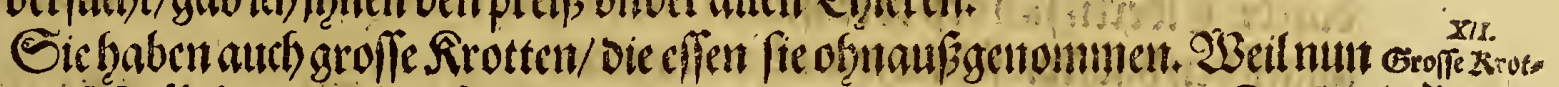

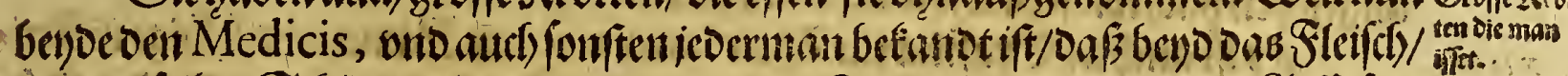

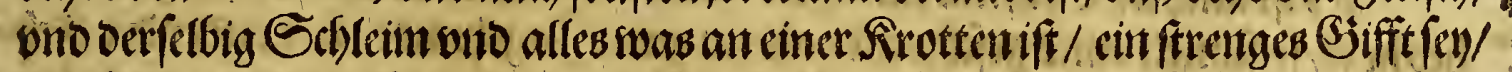
buto fan einfeber leichtlich abitemmen / sweint ich febont eben oaffelbig nict)t bie fa:

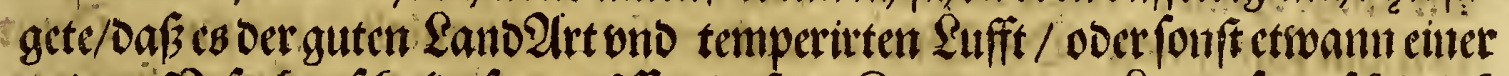

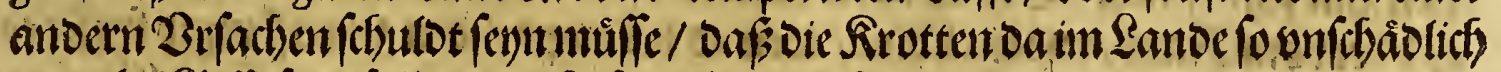

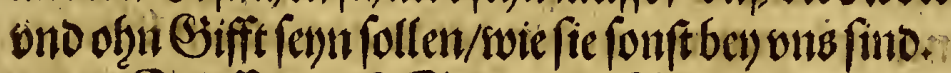

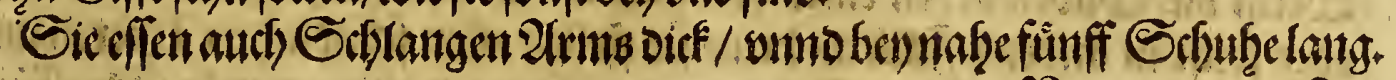
2 2110 


\section{Das britte Tferel.}

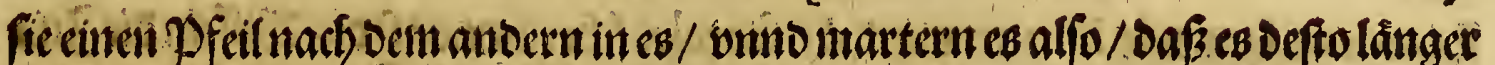

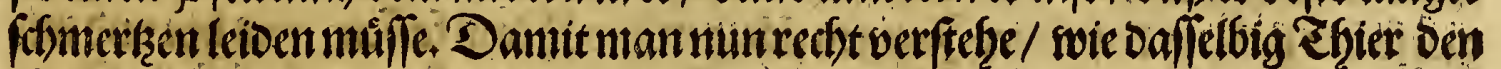

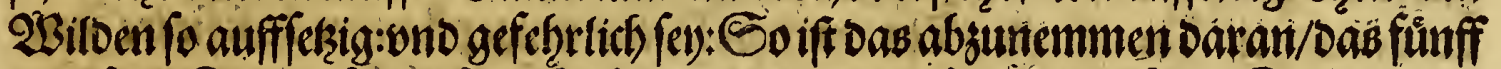

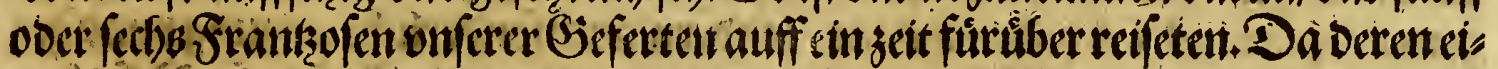

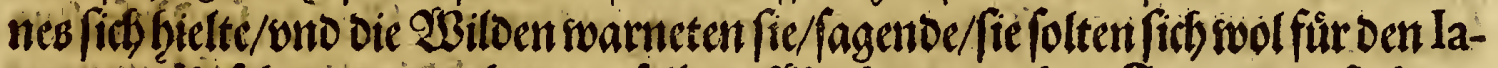

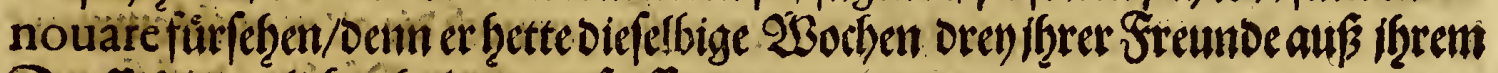
Dorffianmuerliefl gebolt ono gefreffen.

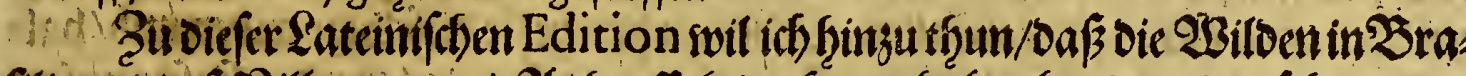

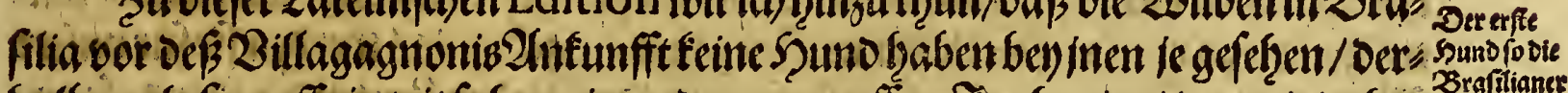

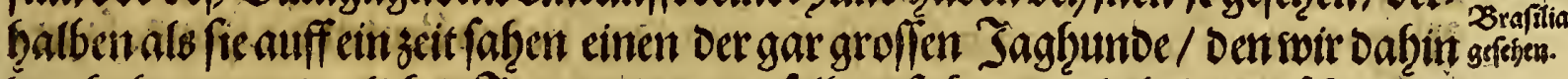

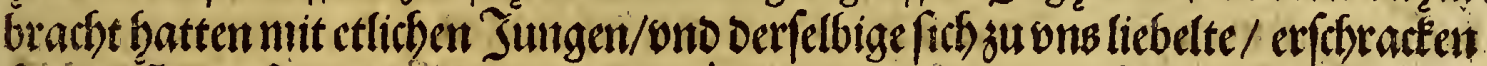
fic vito flofien für im/roetl et Dent lan-oure gleichete / swiegefagt. Dafer begetw get ritch Gamara in feiner General Hiftorien ocr Indien, oaf3, 2lnno taufeno/ fûnffítundert onno neun/alb Chriftophorus Columbus crfttich an bie Infel

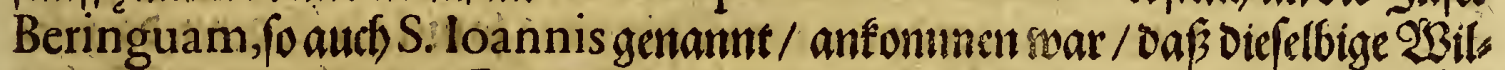
Den/ po damals mit oen Spaniern friegen mu/ten/fich ober Die malfen feler für

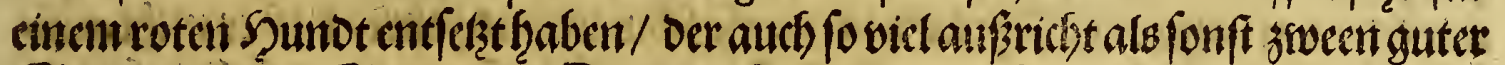

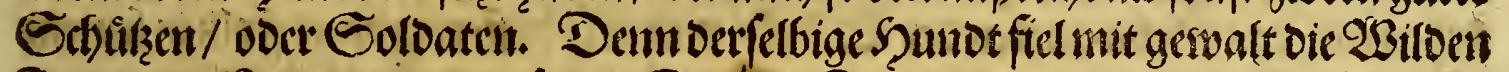

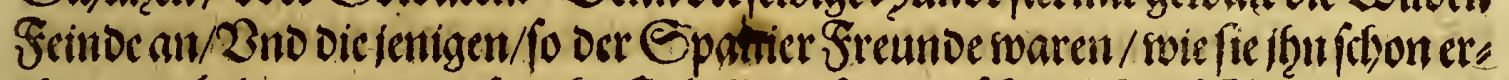

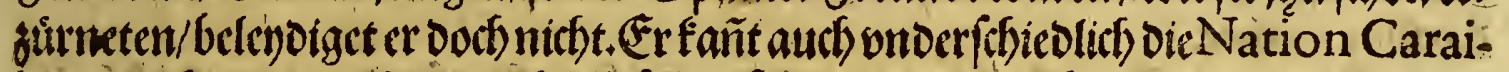

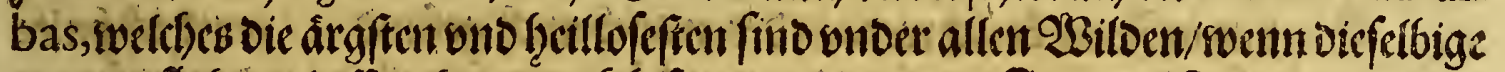

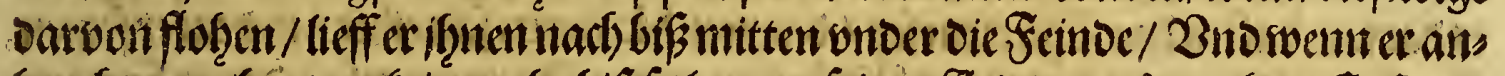

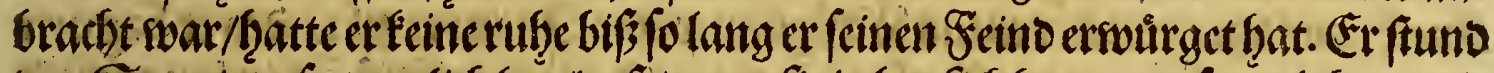
Den Spaniern fo trewolich bey/o a / / woem / fein bey/fich hatten/er fo viel thate/als

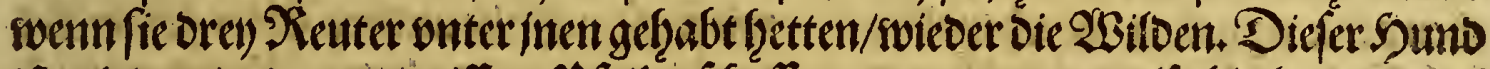

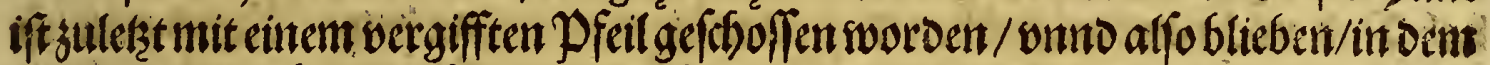

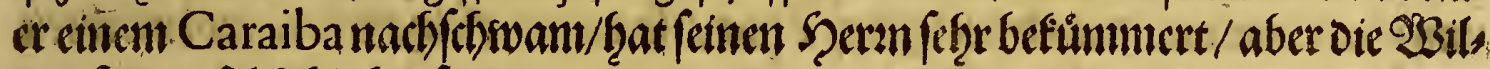

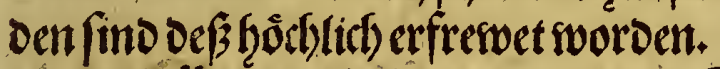

Vallonas cin Sqauptmann oer Spanier/fo ocr aller ftreitbar/tewar / als

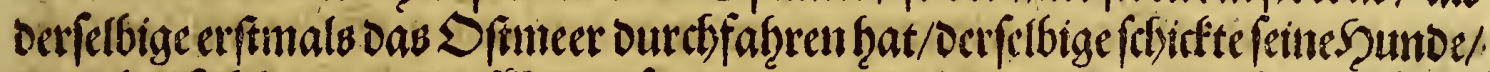

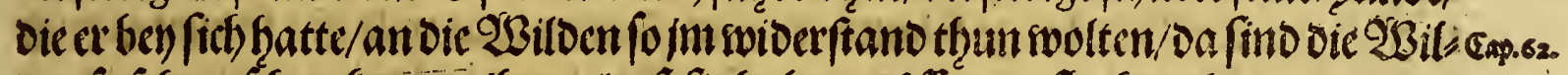

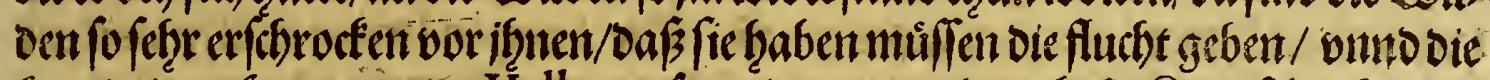

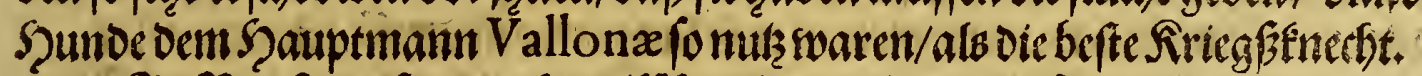

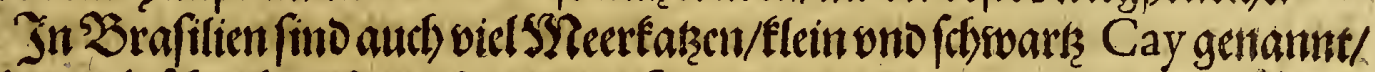

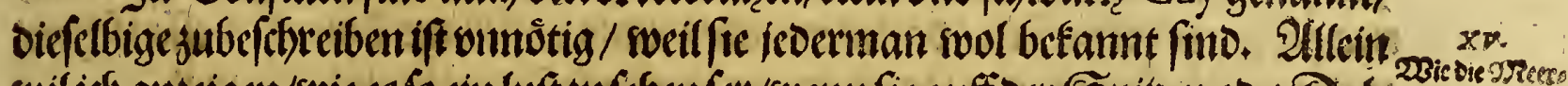

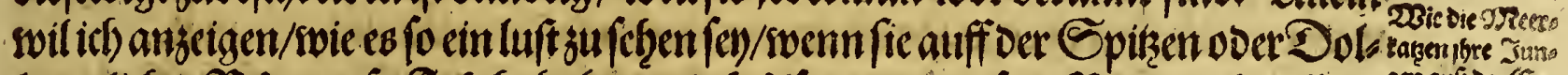

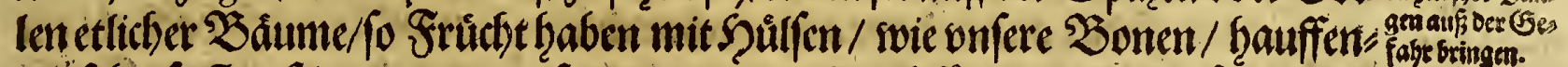

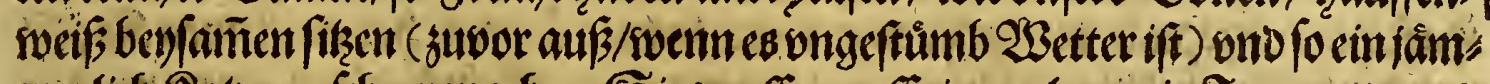

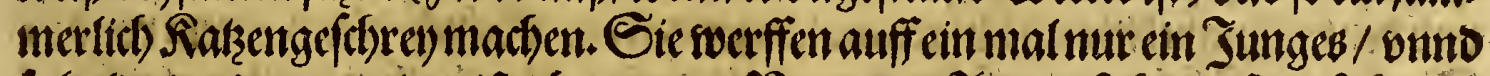

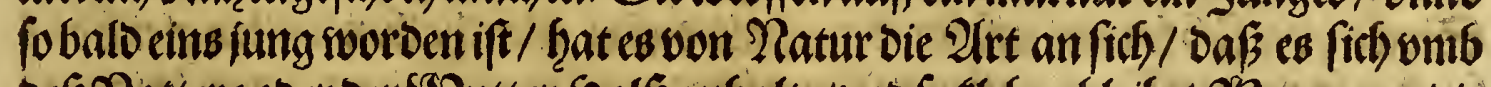

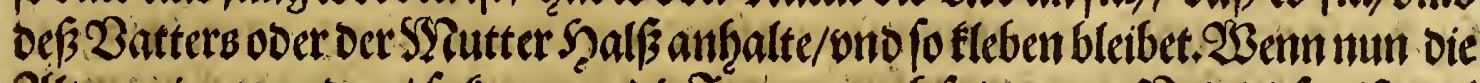
Ultengelagt foer ben / fo fommen bie Jungen auch fo Darvon. Bno biefes ift fool glâtubliç)/ Denn aucb) Matthiolus in feinen Sommentarien / ober Den Dio-

? ii fcoridem,




\section{Sas britte Tferl.}

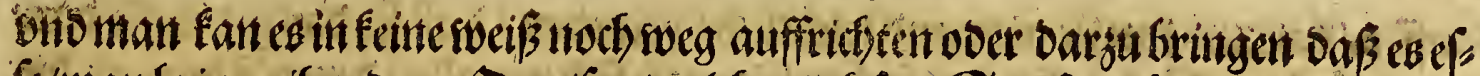

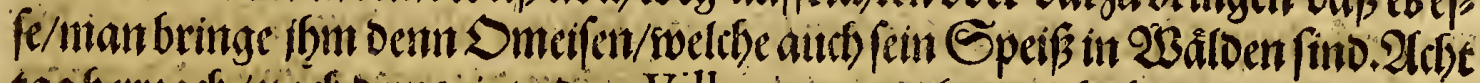

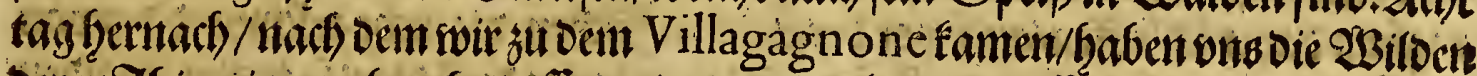

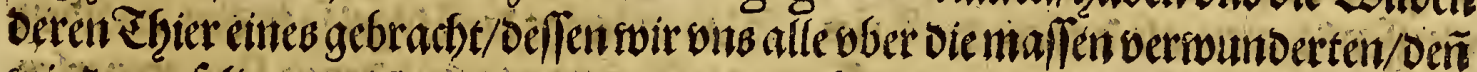

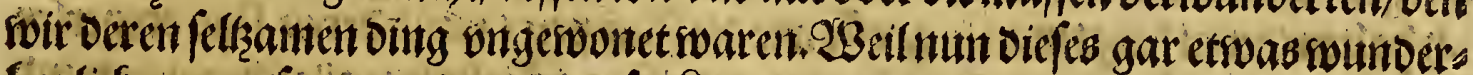
barlicles swar/fo ina ite gegen onfer \&ands art helt/Darumb hab ich offtuals an

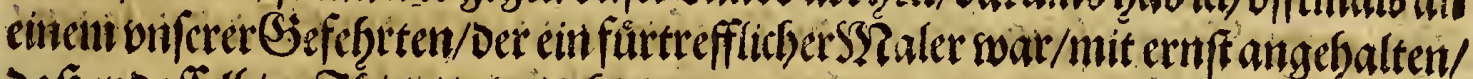

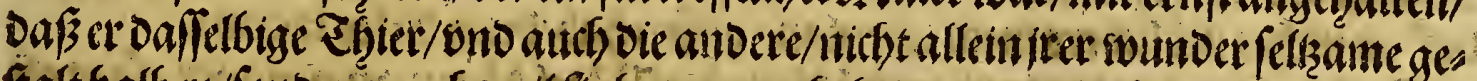

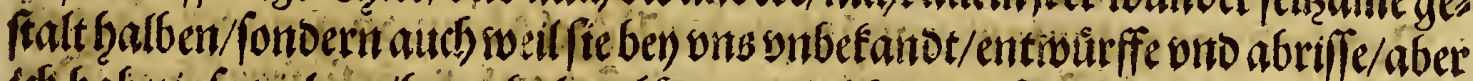

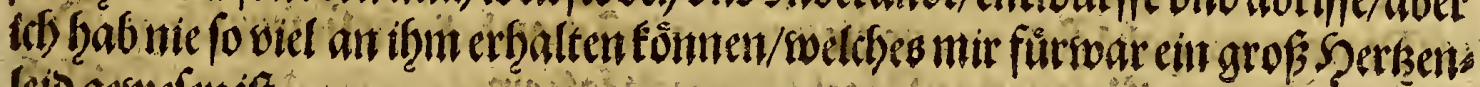
leib gewefonift.

$$
\text { XI. Capittel. }
$$

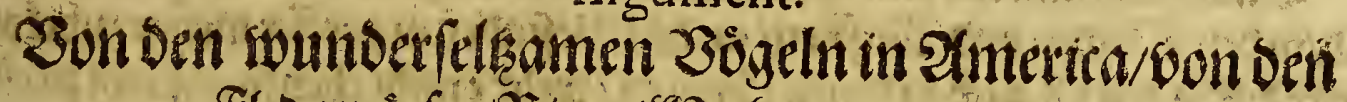 \\ Argument.

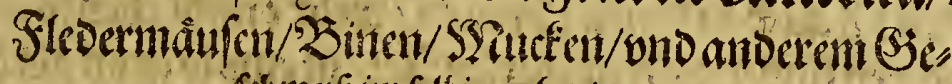

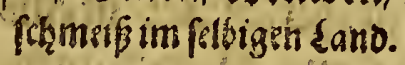

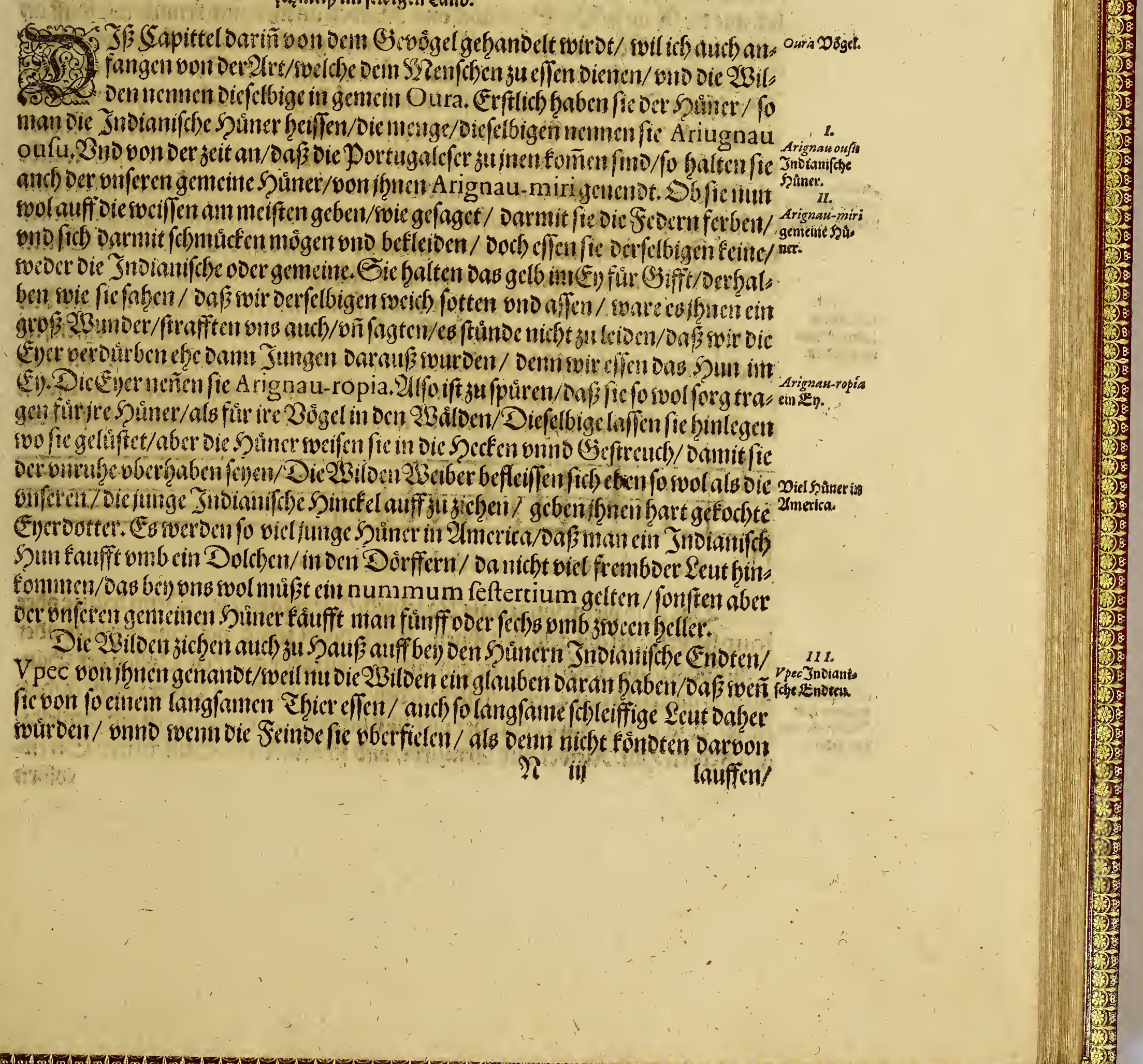




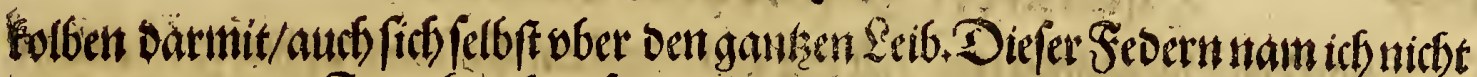

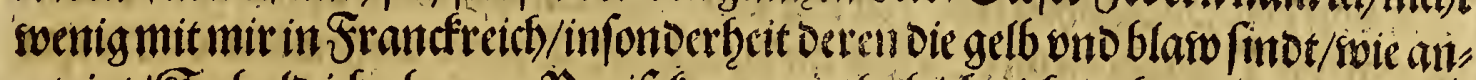

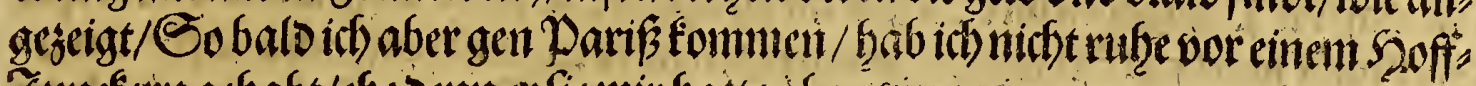

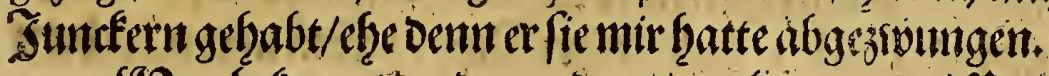

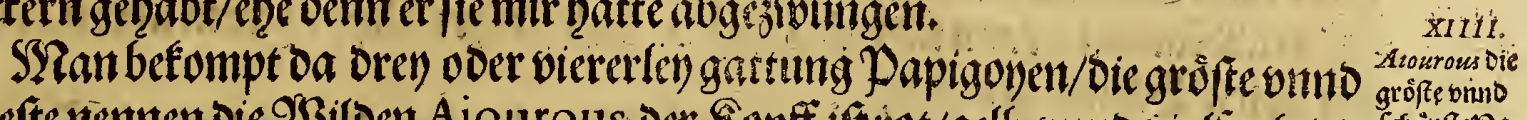

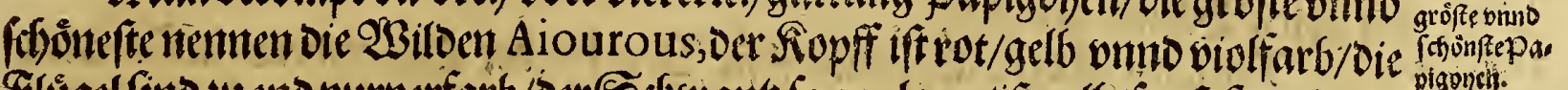
Flugel fino zueno purperfarb/orr Ectswant/ fo gar lang/ift gelb/fon/t fino ficant

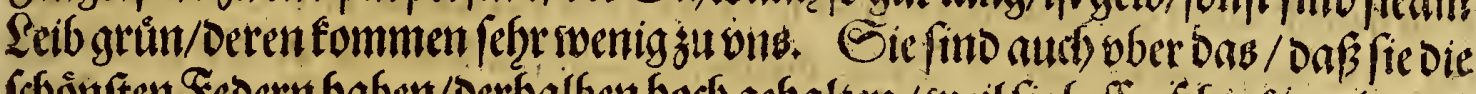

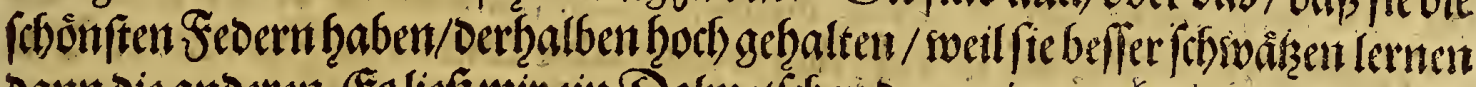

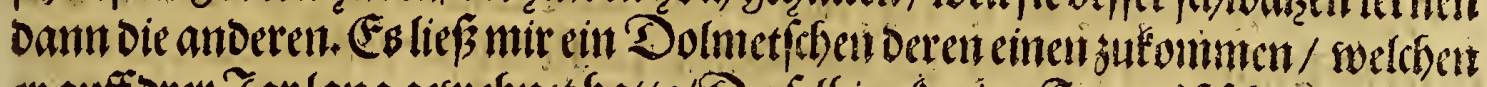

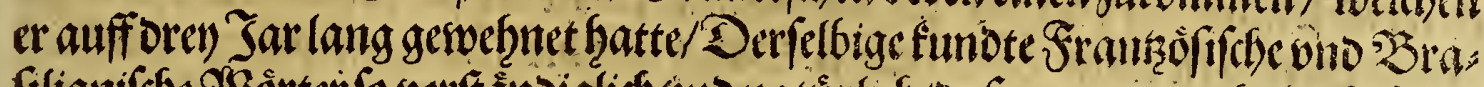

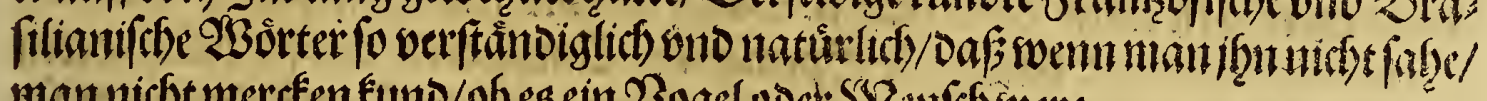

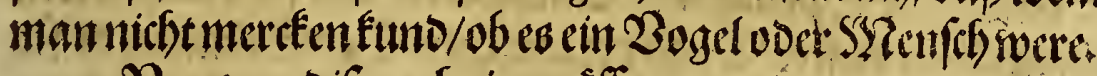

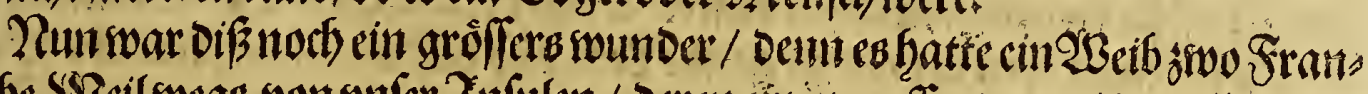

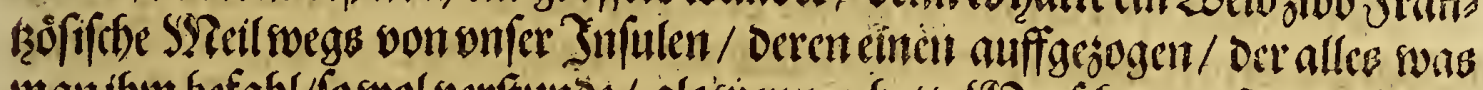

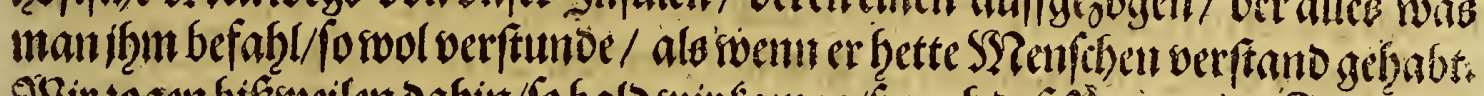

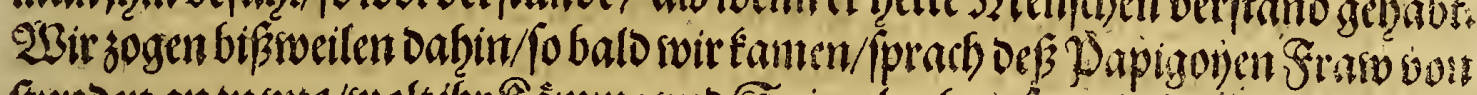

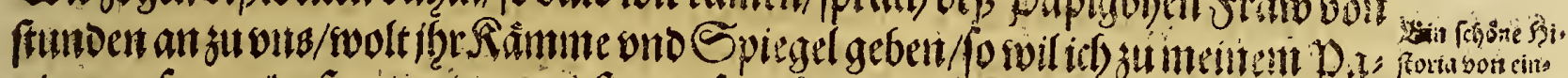

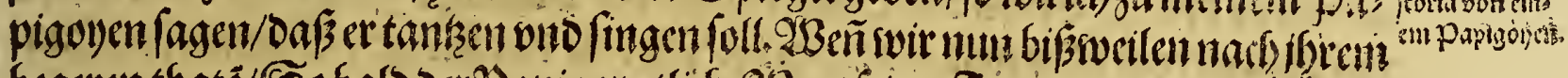

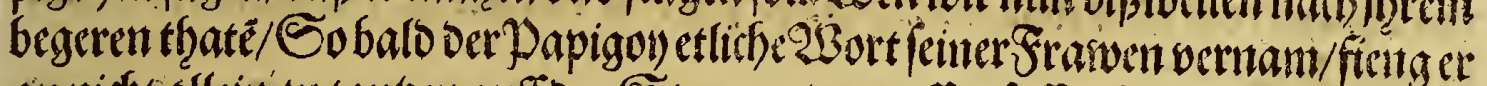

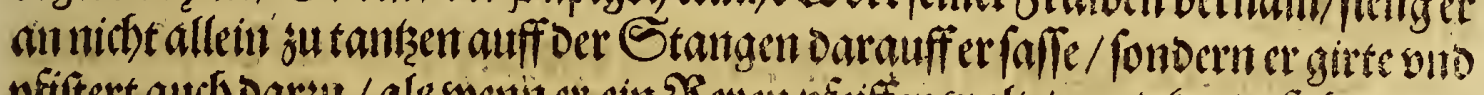

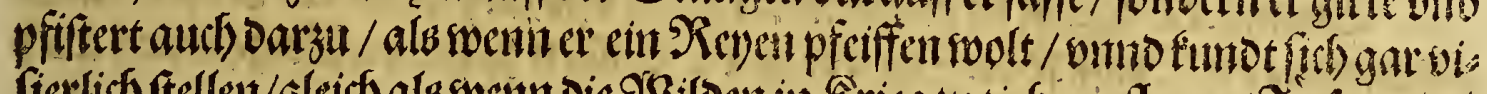

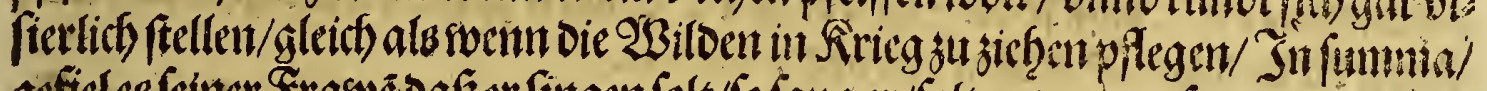

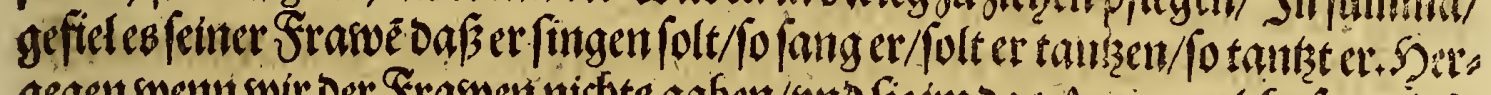

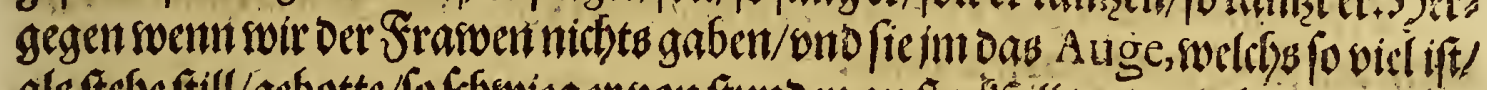

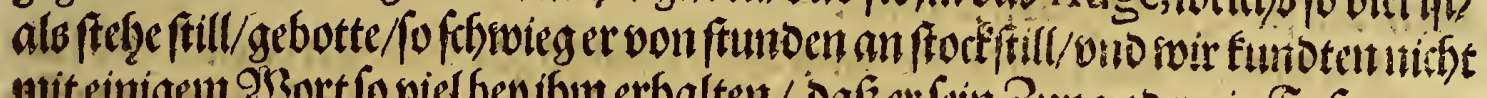

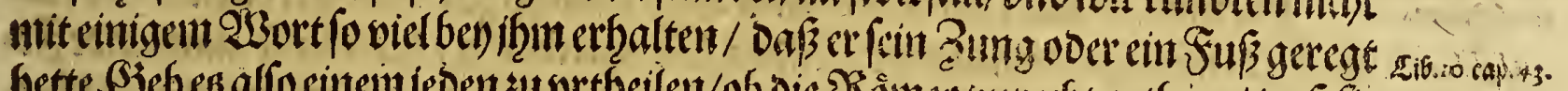

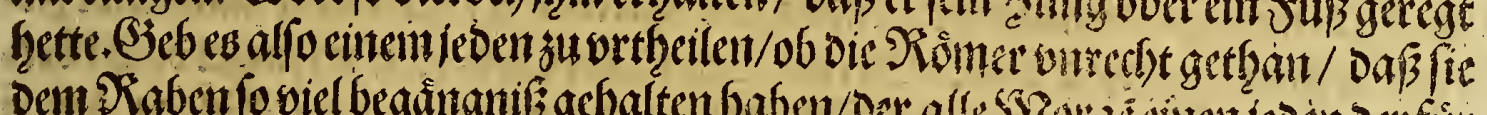

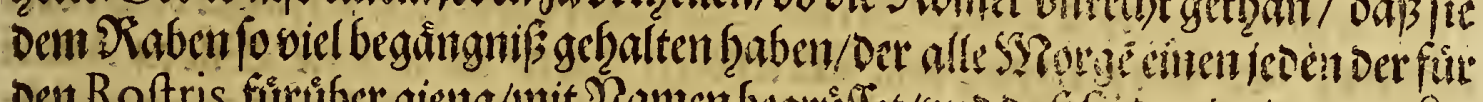

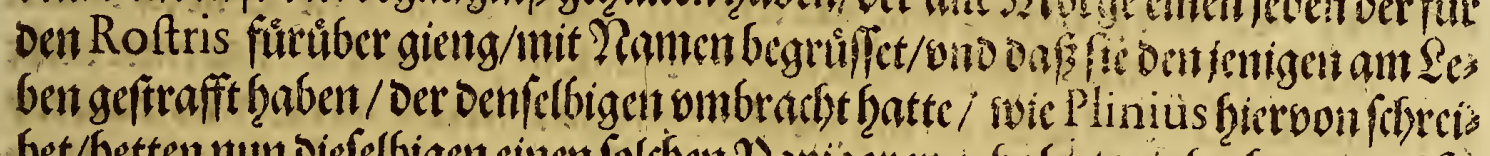

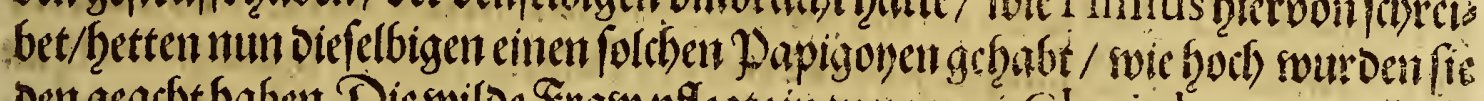

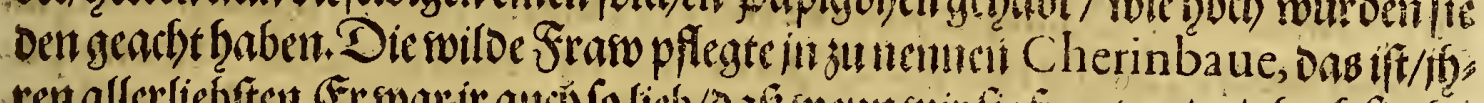

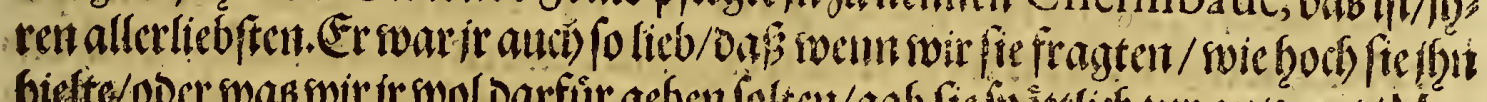

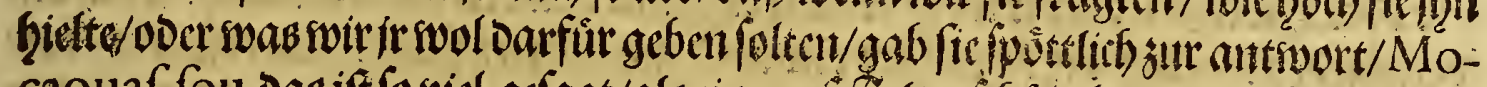

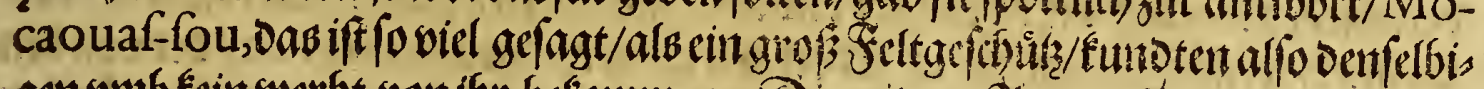

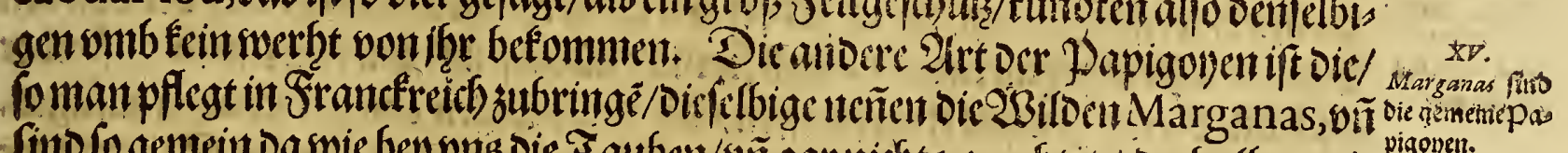

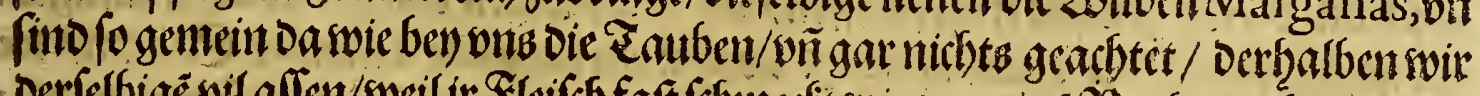

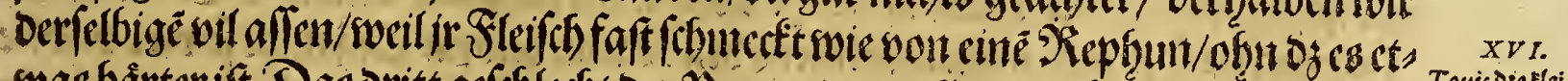

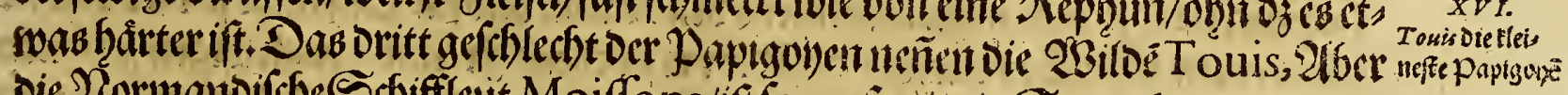

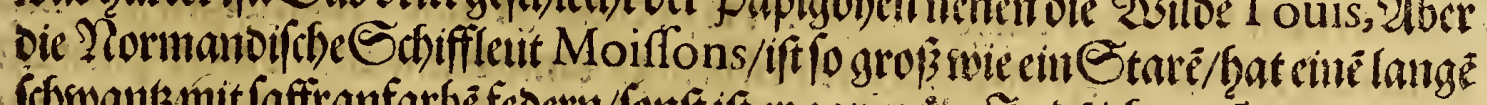

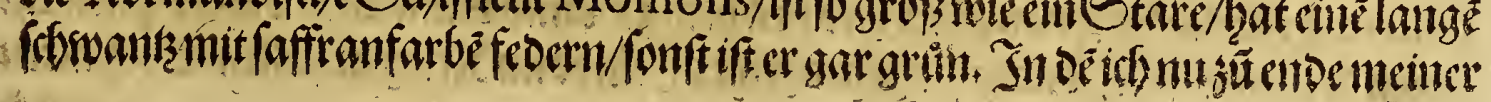

Rove 


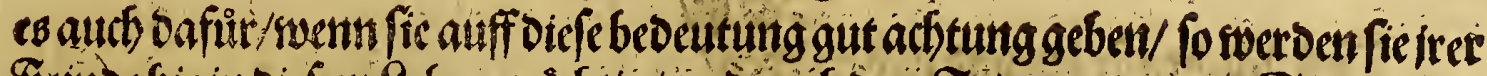

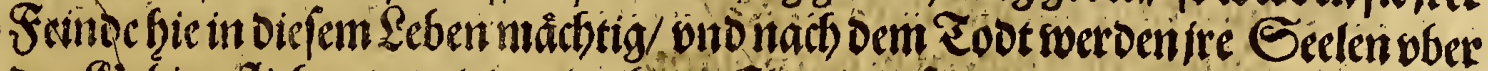
Das Bjebirg hiefen/ommo a mitefferen Eltern in freuben cinen esoigen Peifen fưfern.

Ebift mir begegnet auffeingeit/als ich in einê Dorff fo die SrantzolenVpec

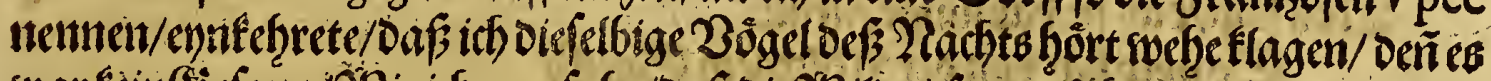
warfein(Se fang/

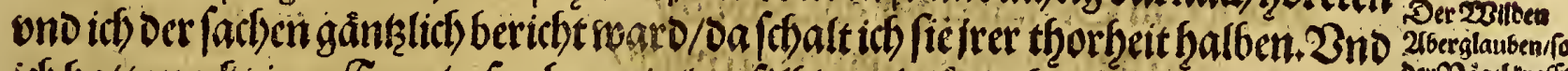

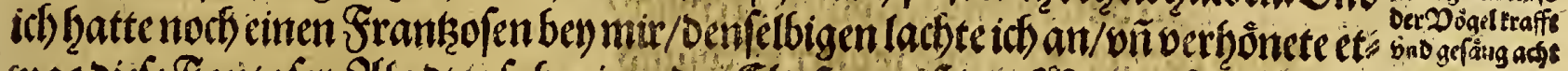

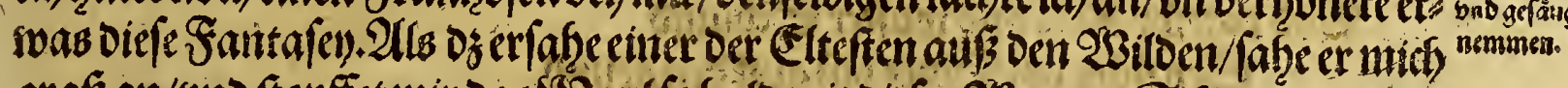

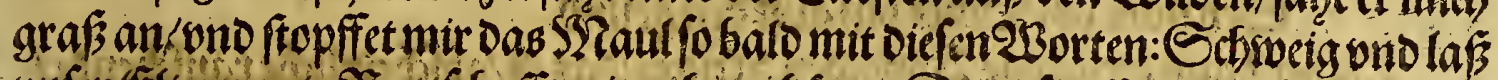

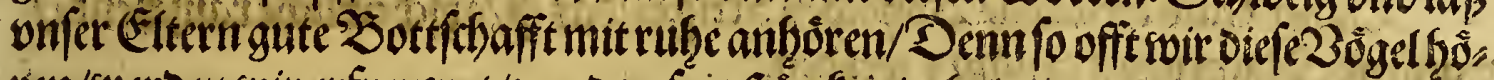

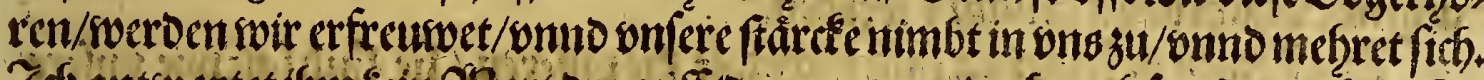

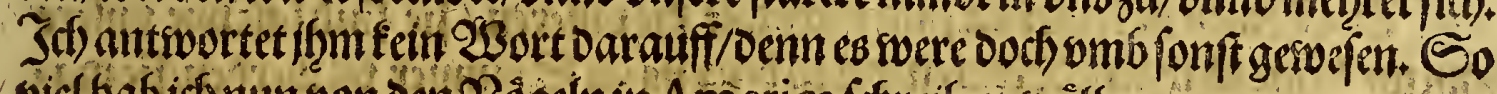
viel babidf num on oen 3 dogeln in A merica fabreiben woollen.

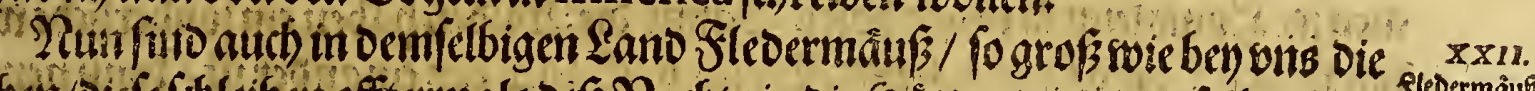

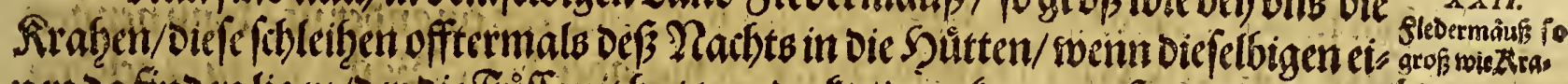

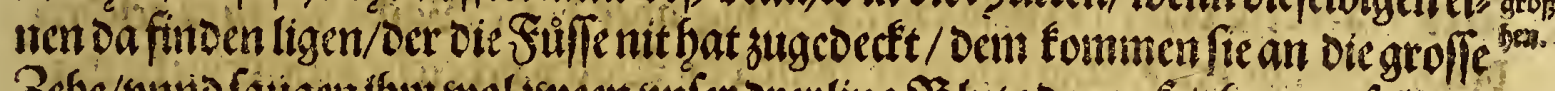

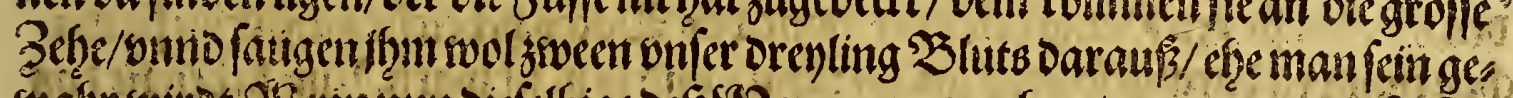

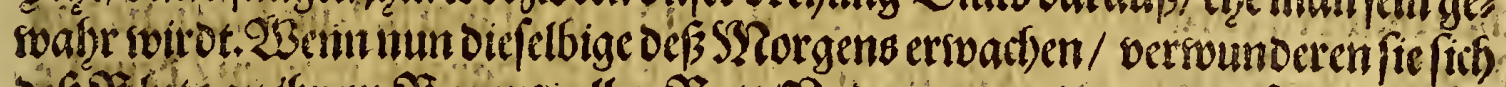

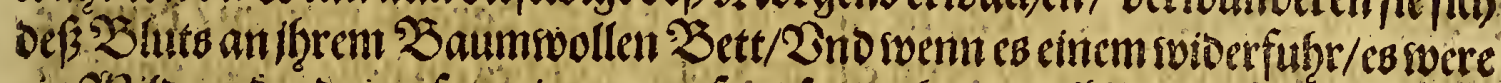

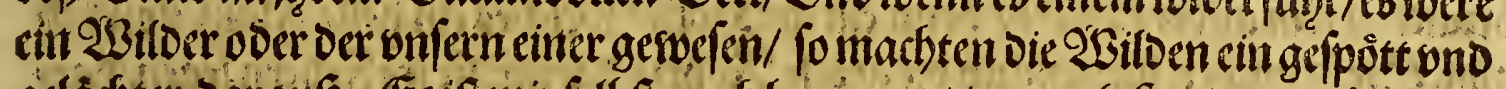
geldebter Darauk. Esift inir felbft auch begegnet / Darumb fiemein nicbtalleit

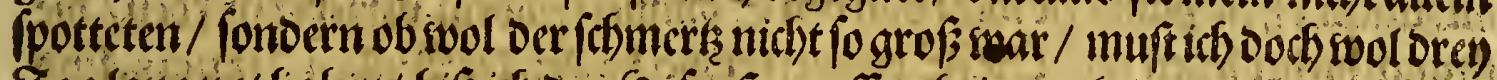
Jaglang not faben/ bif ich oen So/enftumpf anbringen funot/Dennolegrolle

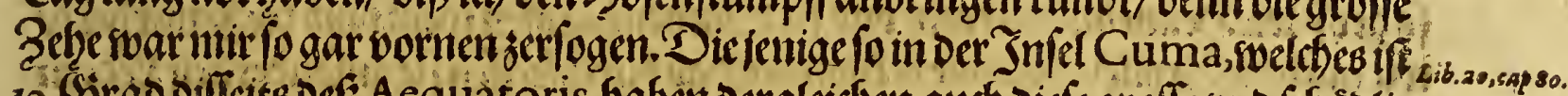

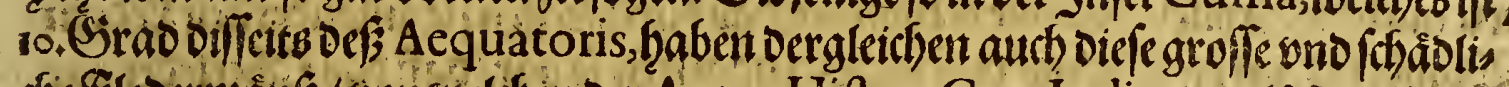

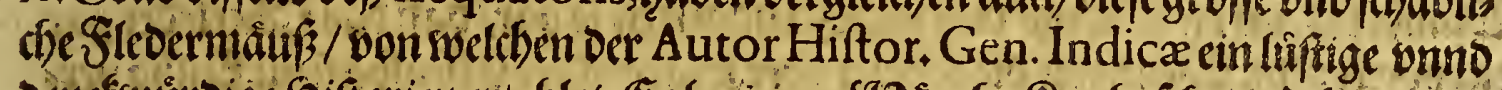

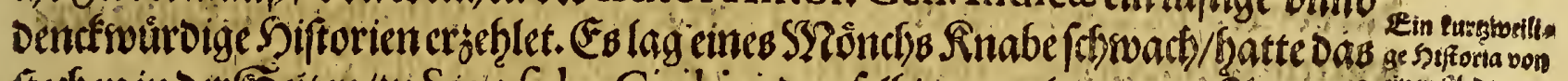

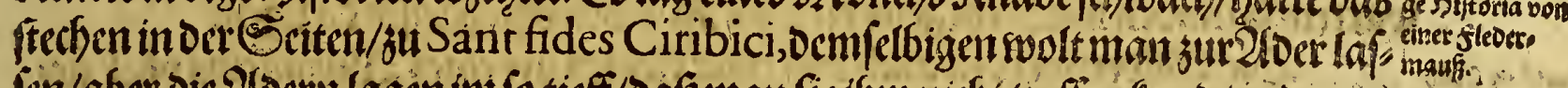

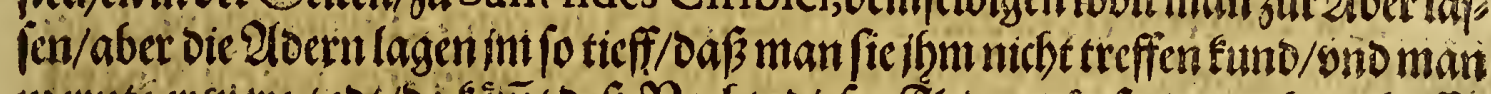

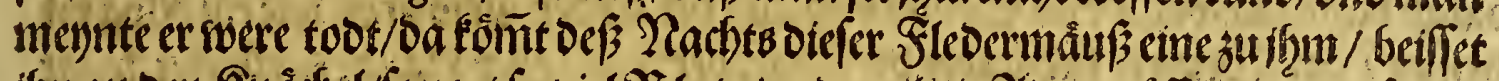

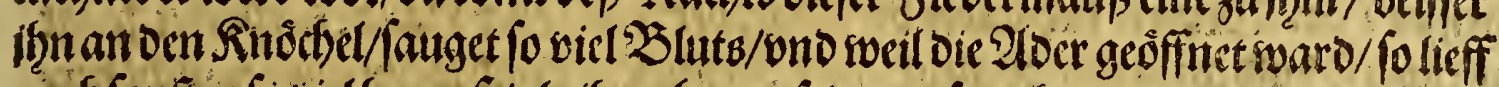

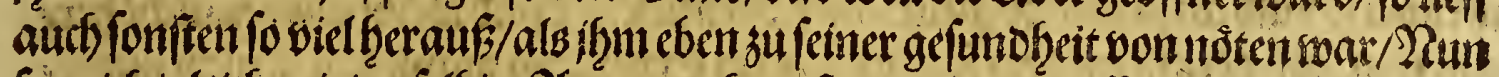

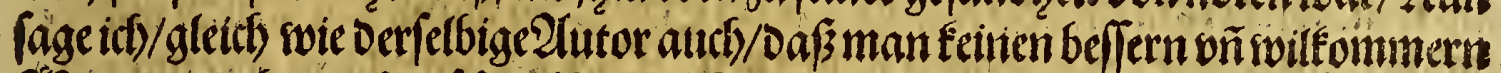

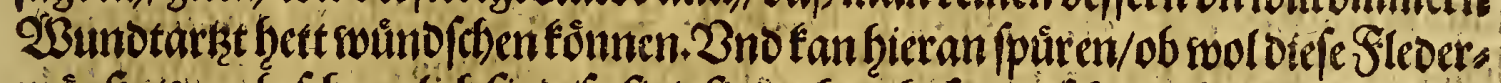

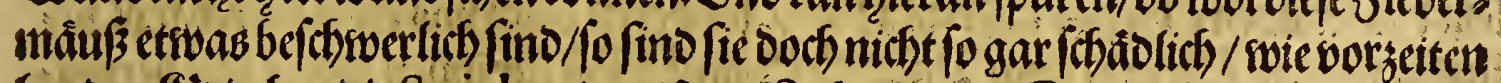

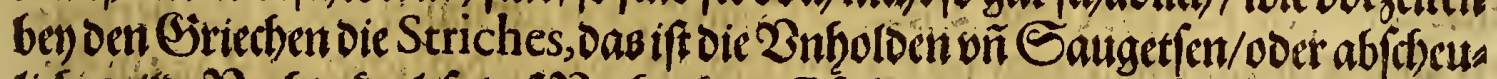

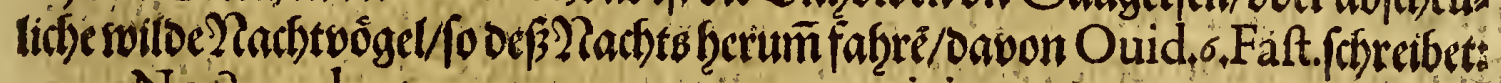

Nocte volant, puerosque petunt nutricis egentes, Et vitiant cunis corpora rapta fuis.

Carpere dicuntur lactentia vifcera roftris, Et plenum poto fanguine gutturhabent. 
Defistactstefie fin vono suiber flifen/

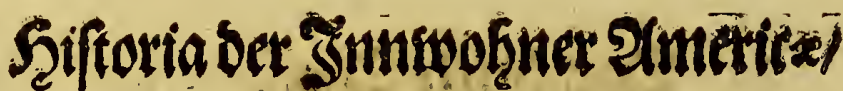

\author{
Dasitu
}

Zujungen Rinbern in ben 2 bigen/

Reiffenfie offtaufifrem \&ager/ Bejtgäbigen fie bann hernacher.

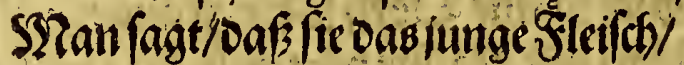
Eonoch fat won der SYRilch fein Epeißs

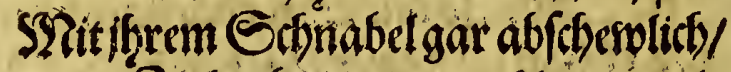
Berbacten vino zerswulen greswliçy

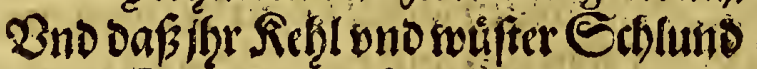

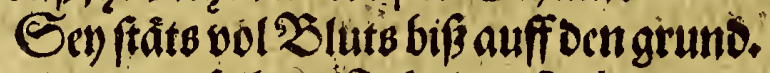

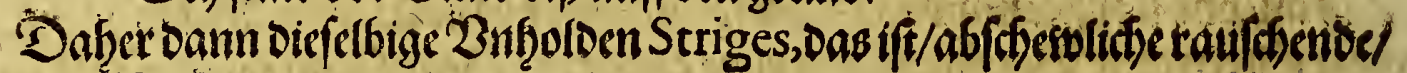

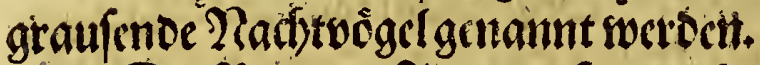

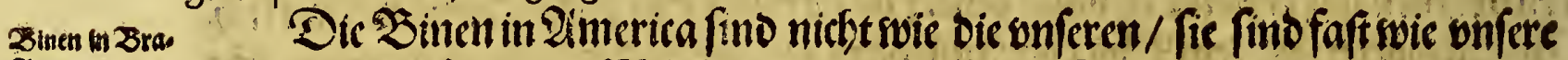

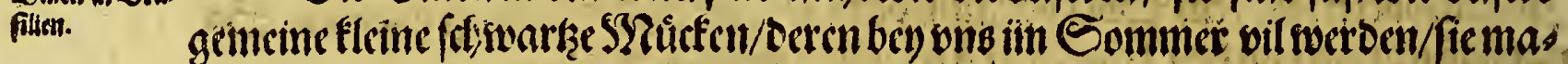

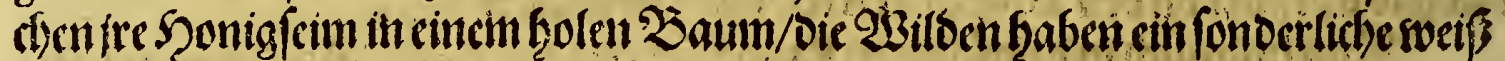

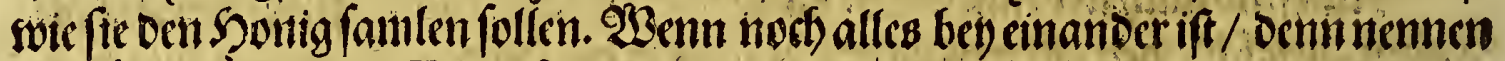

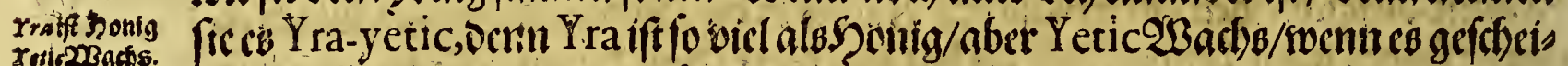

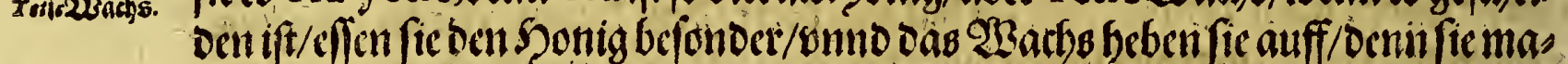

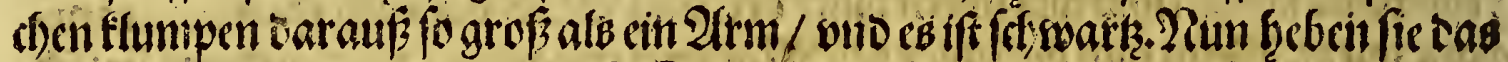

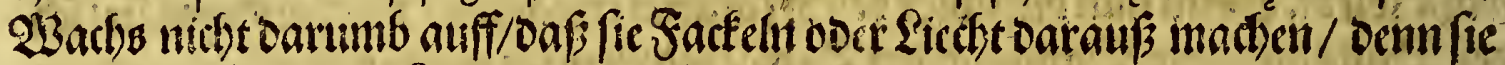

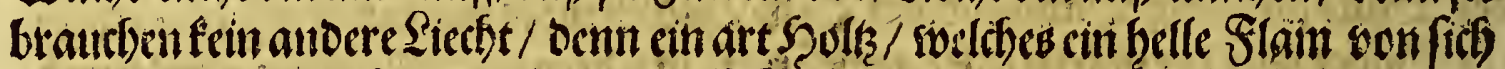

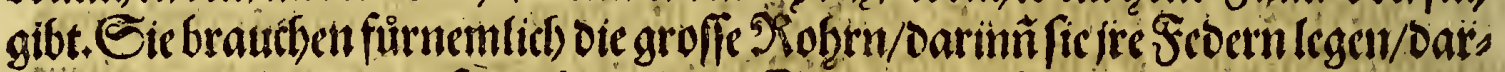

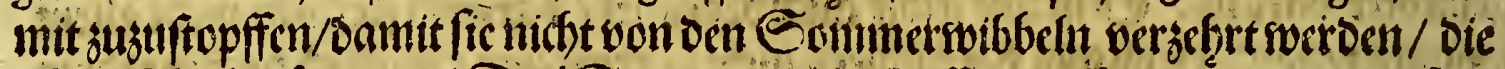
Errentse bit.

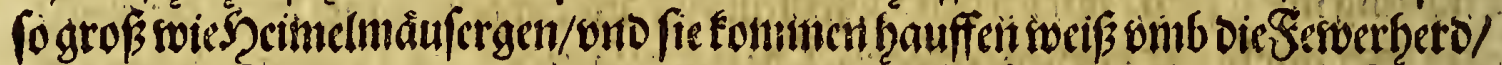

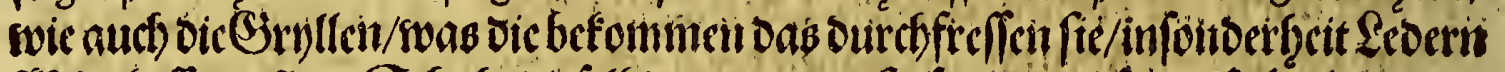

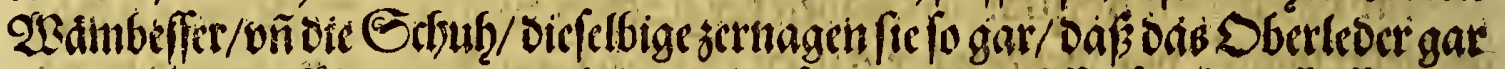

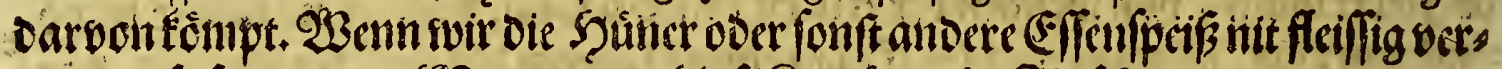

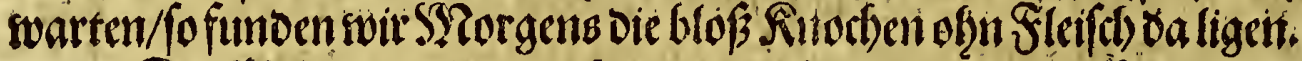

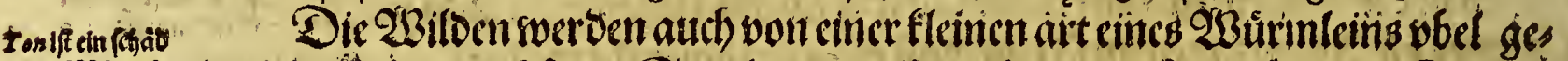

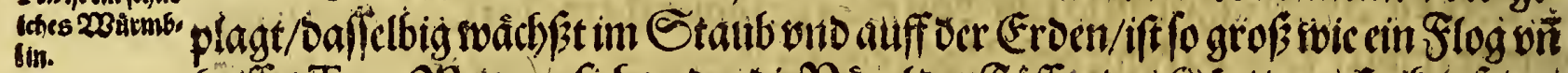

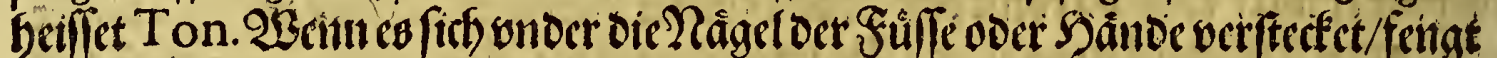

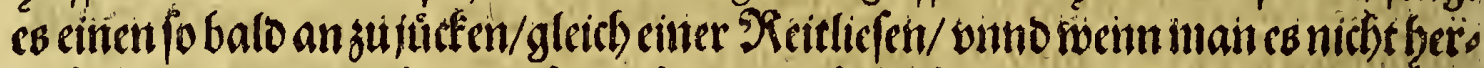

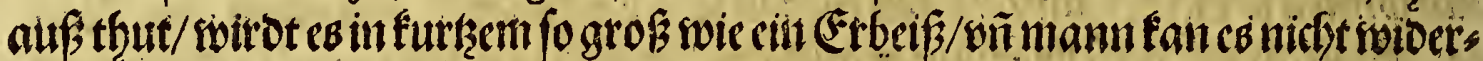

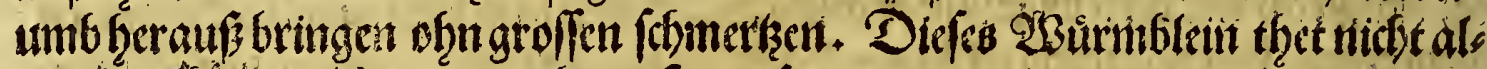

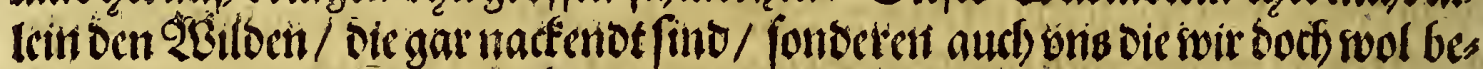

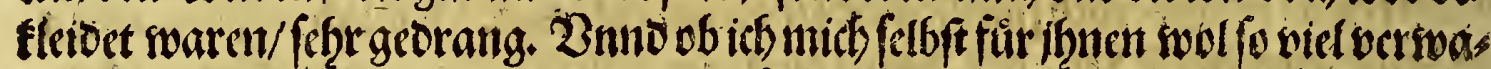

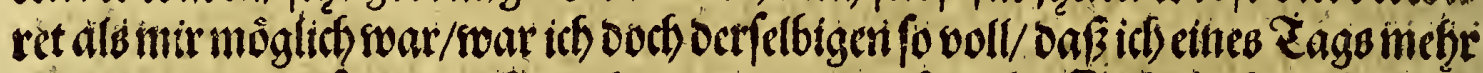

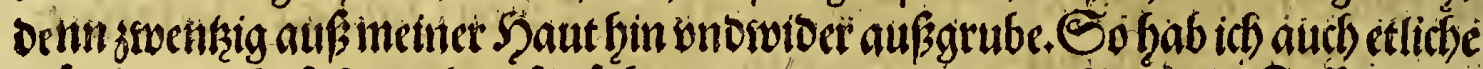

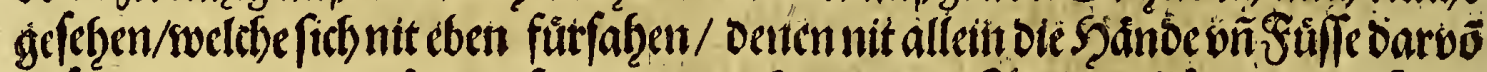

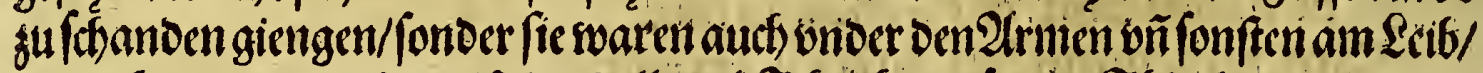

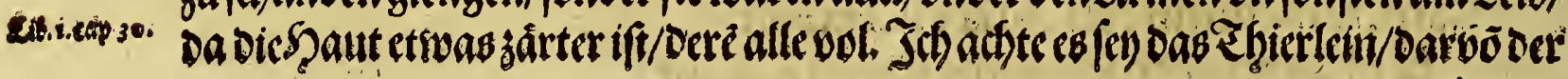
Autor 


\section{Das britte Theth.}

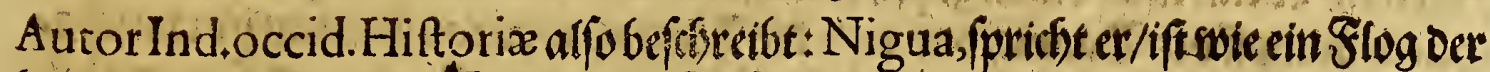

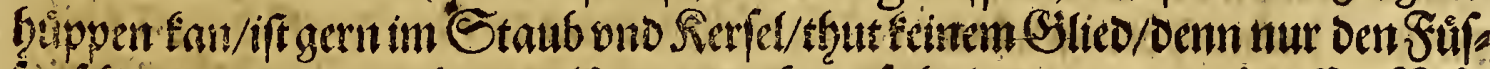

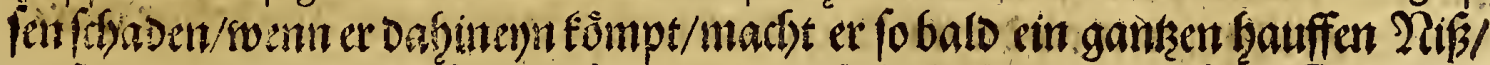
Daf es vnglaublith ift / fo man feine geringe Droports betractsen olt / Doch ver

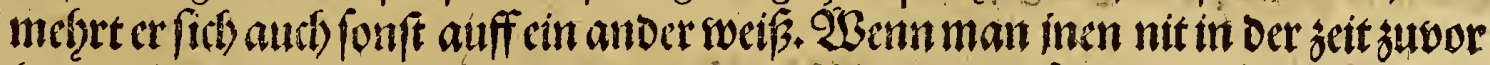

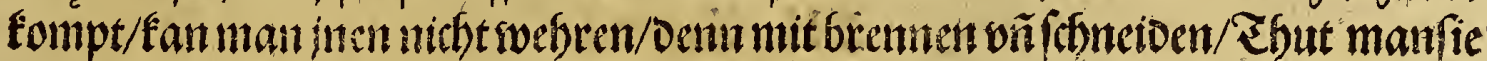

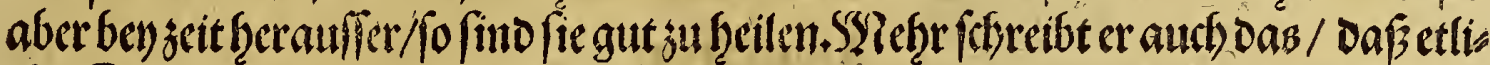

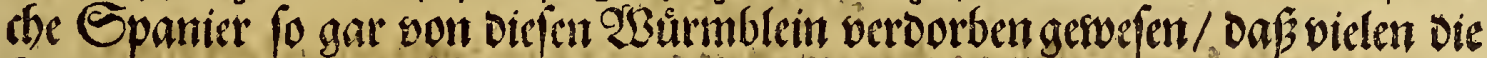

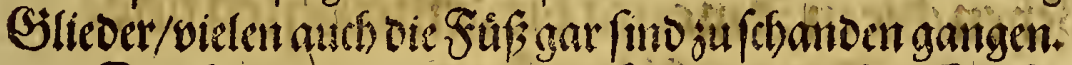

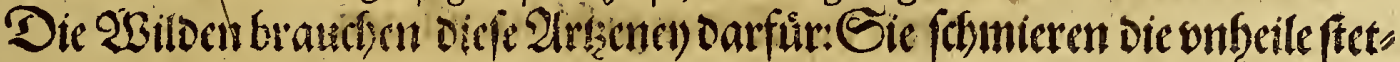

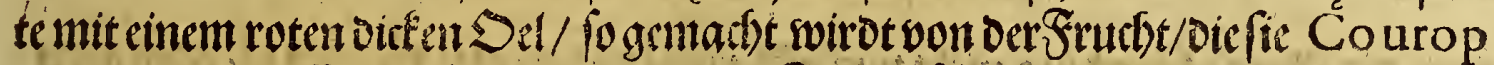

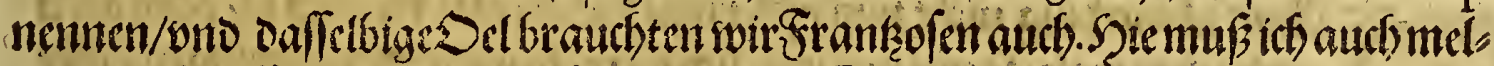

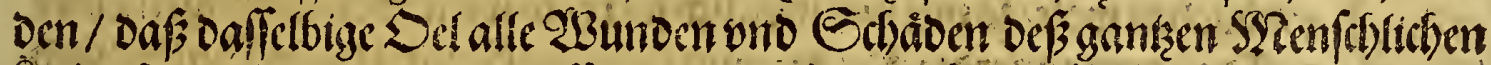

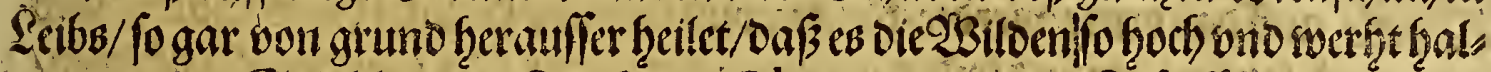

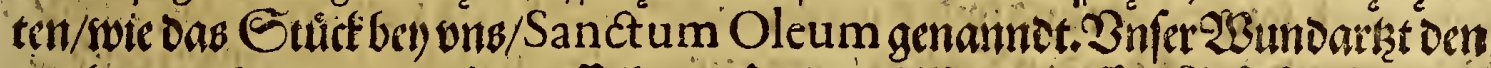

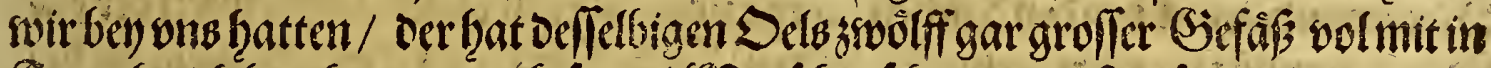

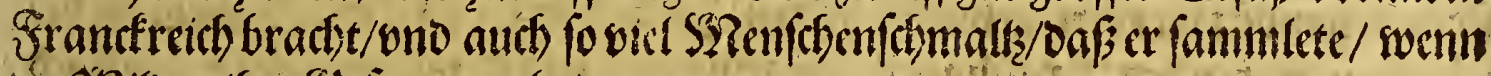
ole 2 Bifoenifere Sisfangene brieten.

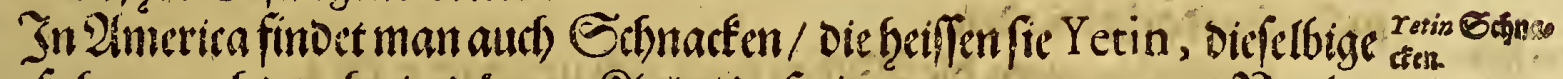

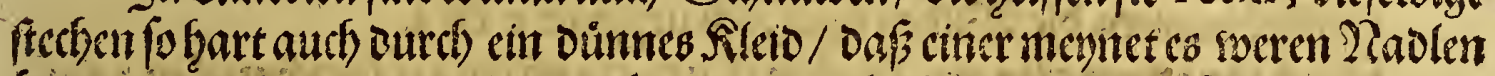

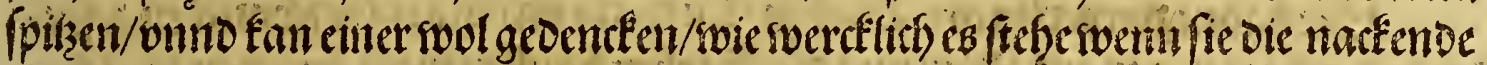

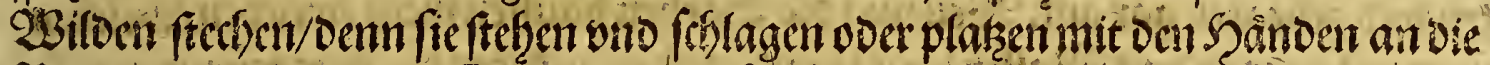

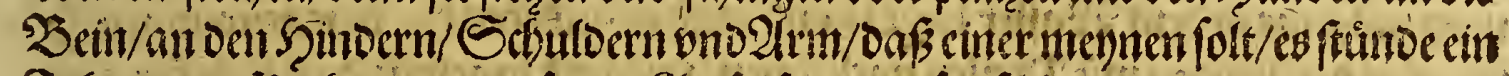

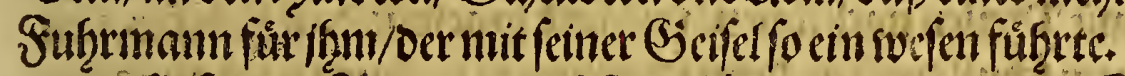

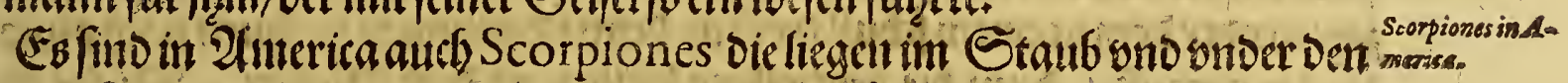

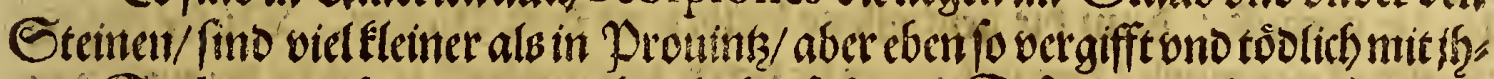
ren Strit) / wic ich oas ant ber that bab brfabren. Dif ongesteffer ift gern wo

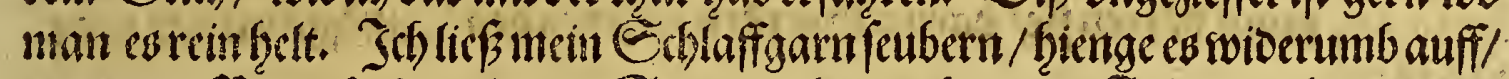

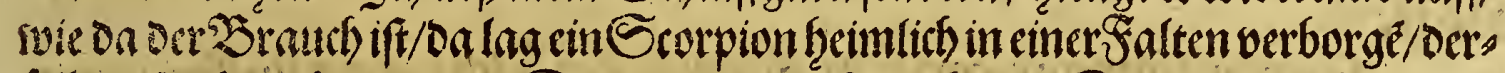

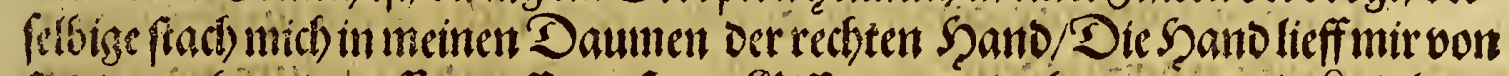

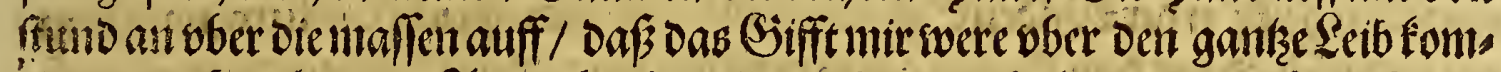

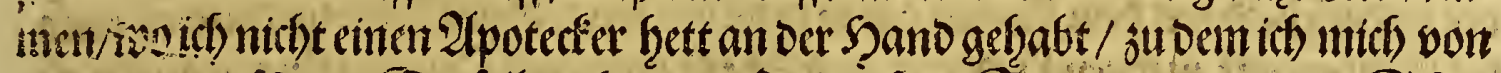

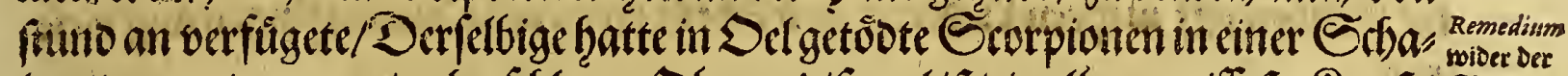

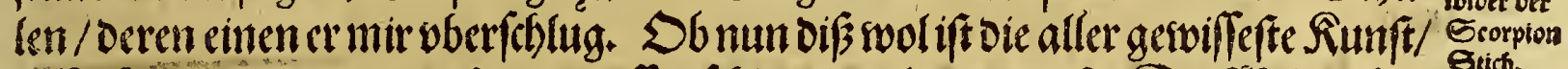

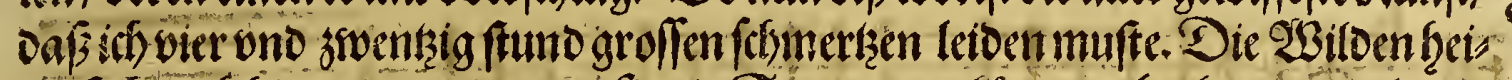

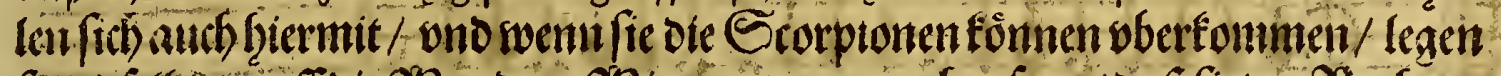

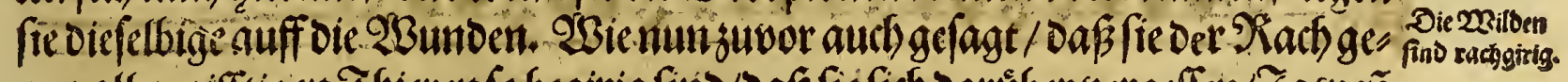

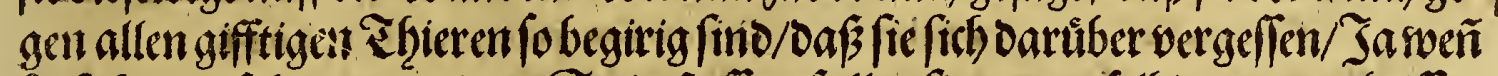

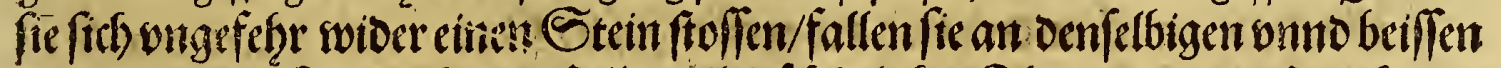

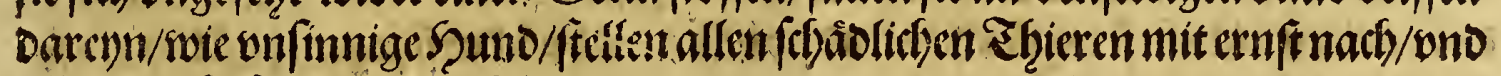
vertilgen fie fo viel minglict) ift.

36er Dis alles fino autb Erofrebs in America Ouffa genannt/fiefommen

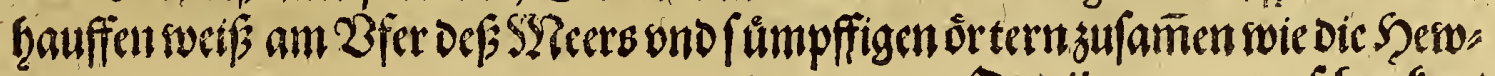
$\mathcal{D}$ ii (afjecter/. 
168

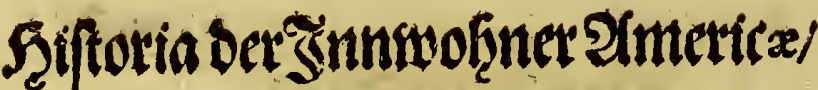

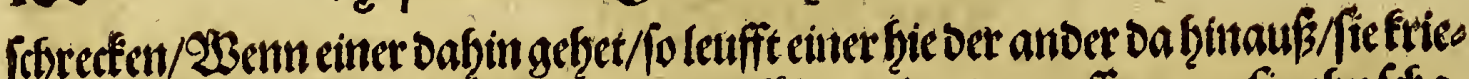

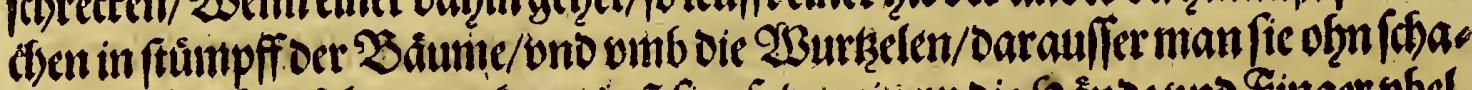

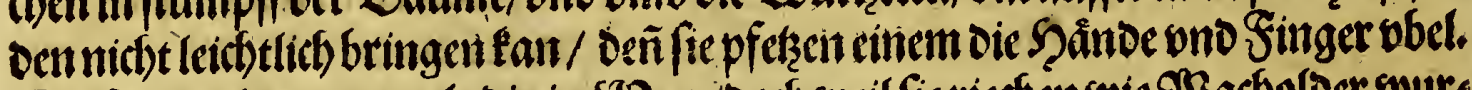

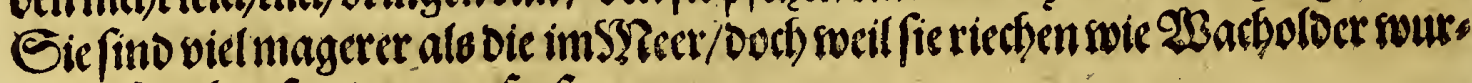
zelen/fogebenfiecingut gefrefs.

\section{Sapittel. \\ Argument.

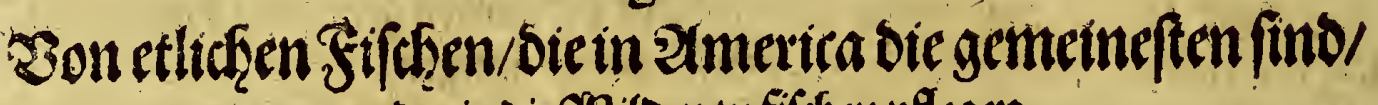

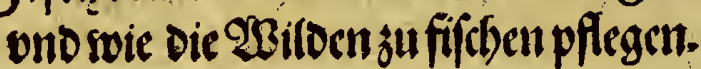

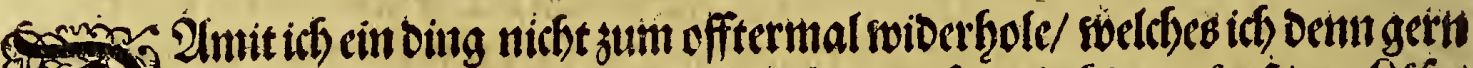

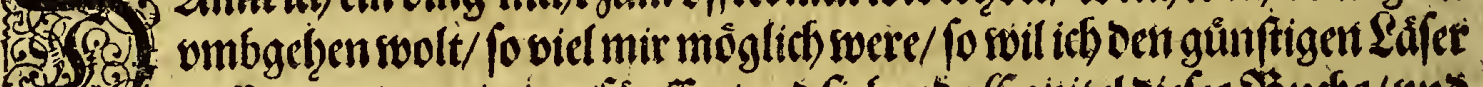

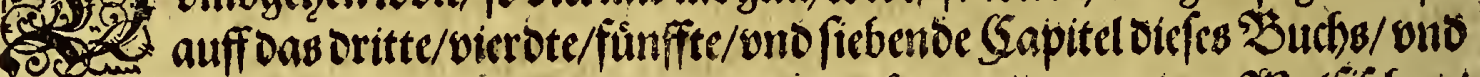

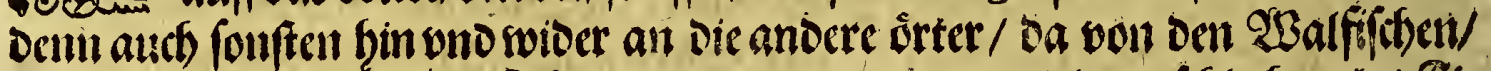

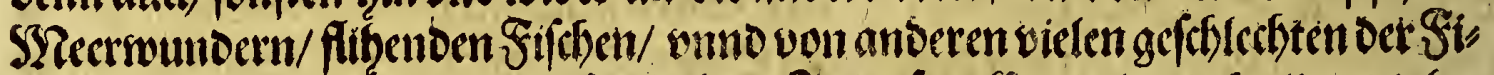

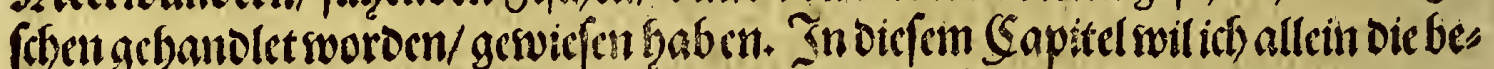

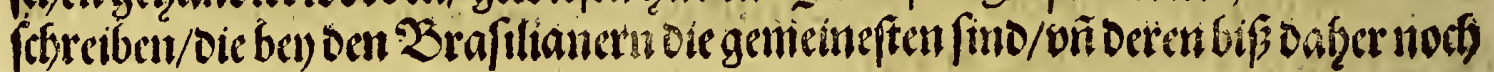
nict) if gedacht woroen.

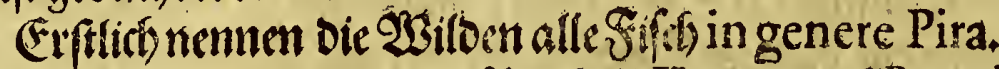

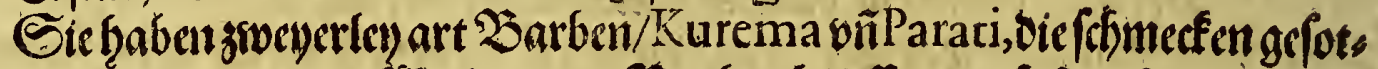

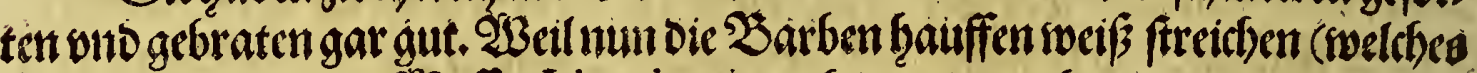
man vnlangb it ocm 2 affer Ligeri, wib auth in anderen feat wargenommen) fo

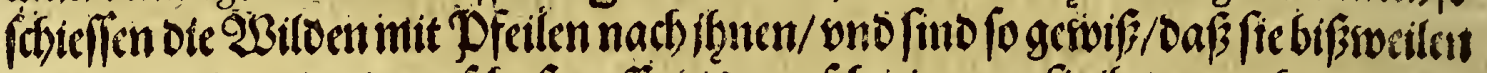

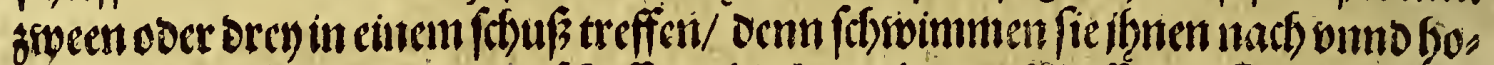

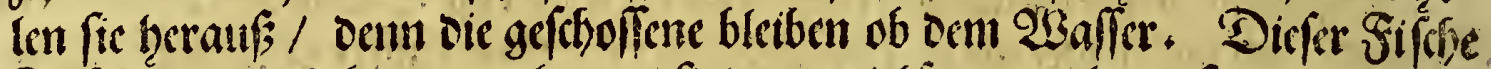

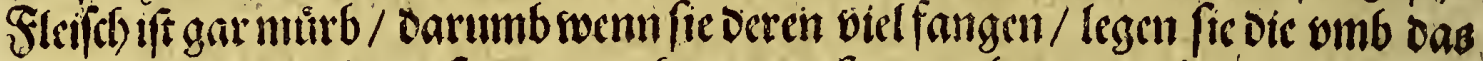

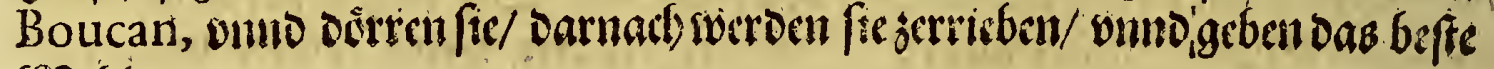
SIrf̨l.

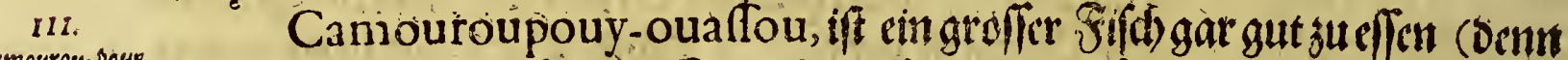

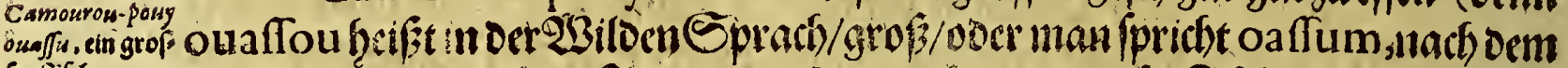

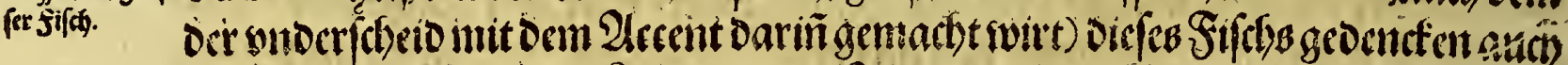

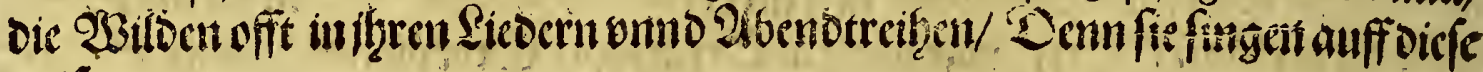
sveifi.

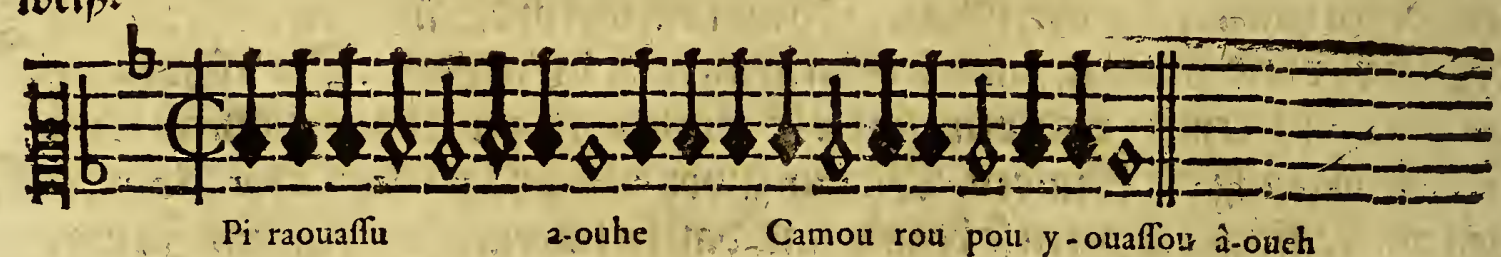

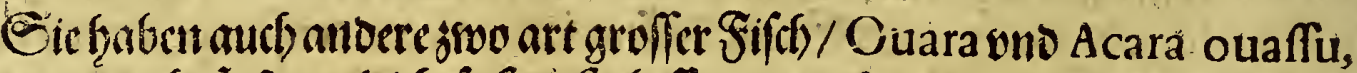

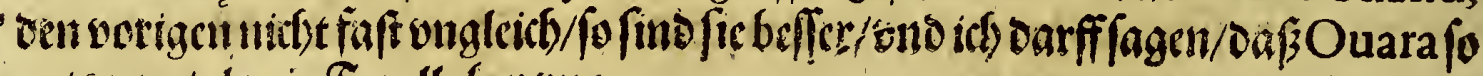
gut were als cin fordle bcu) ons. 


\section{Oas britte Thedl.}

169

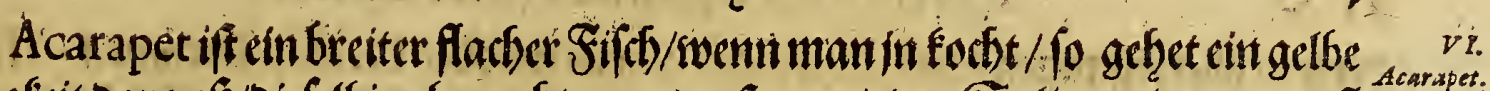

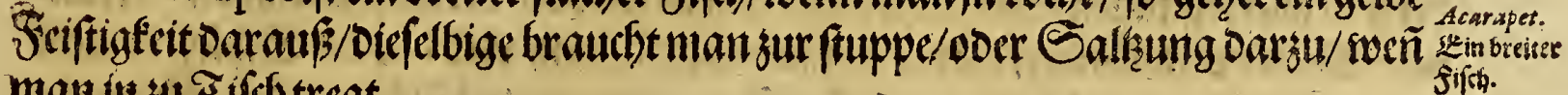
man it zu eif dh tregt.

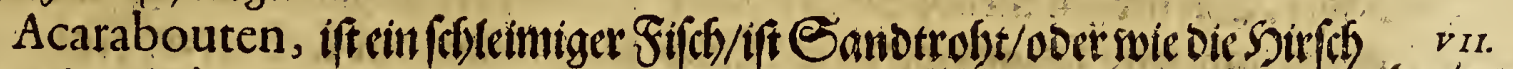

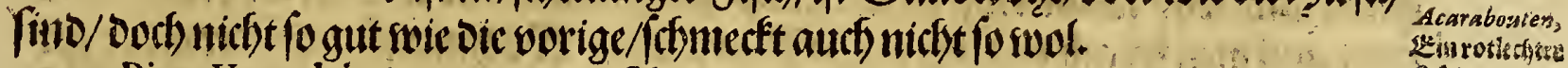

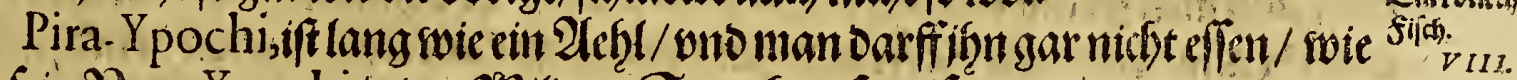

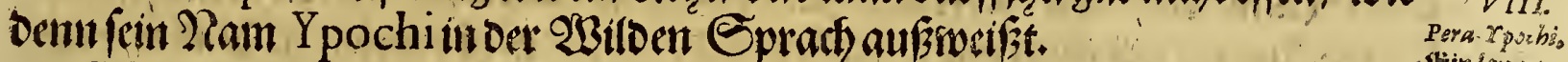

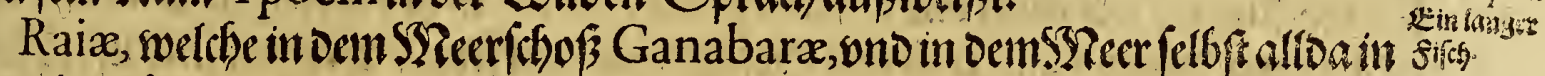

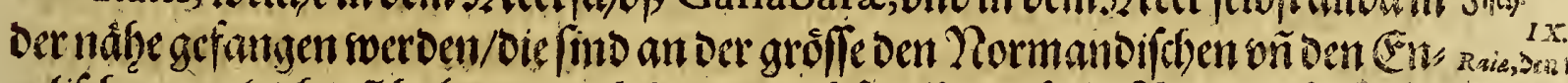

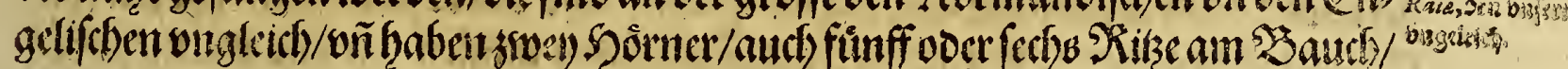
Die ciner anoer

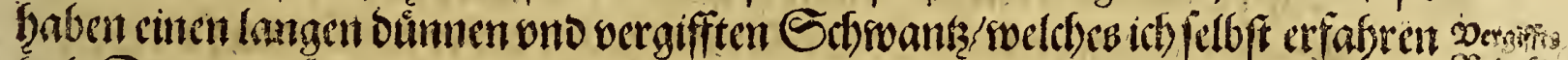

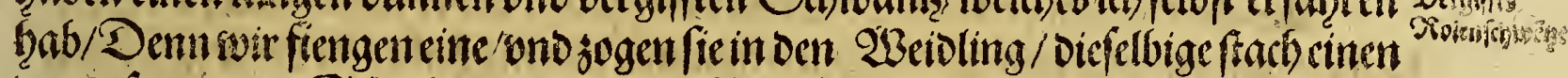

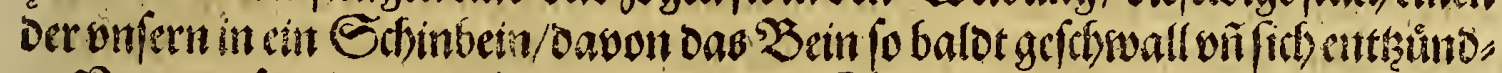

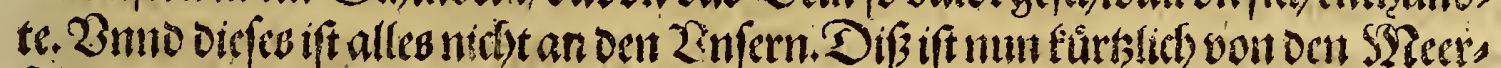

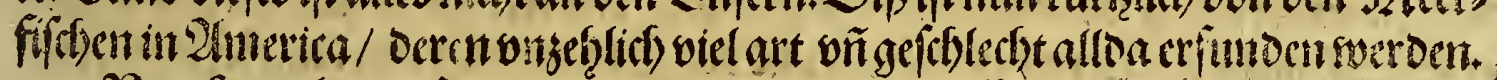

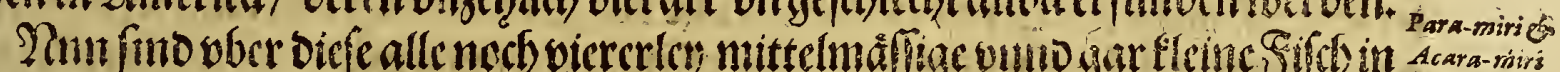

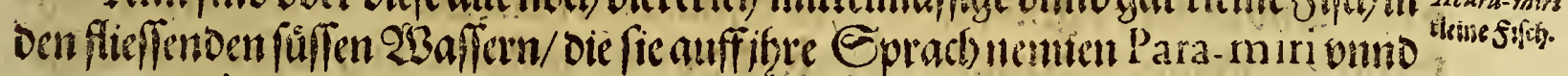

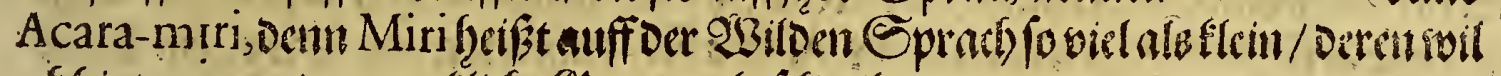

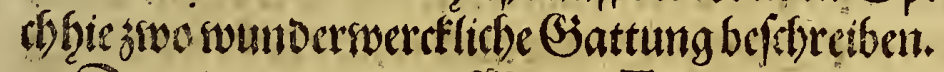

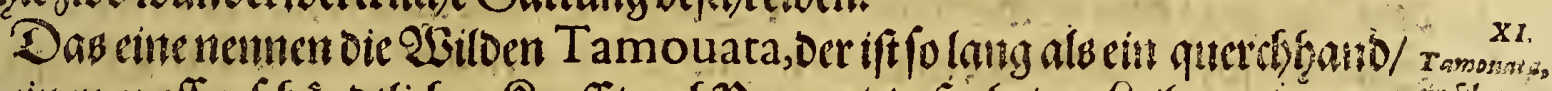

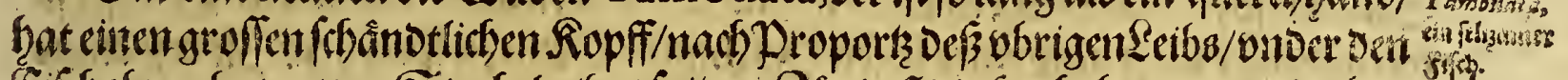

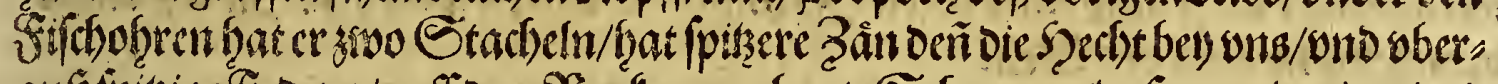

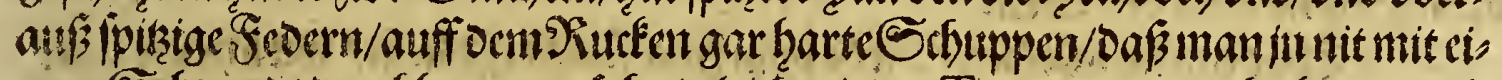

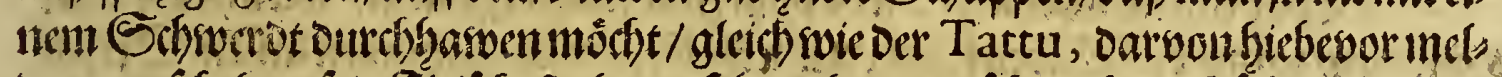

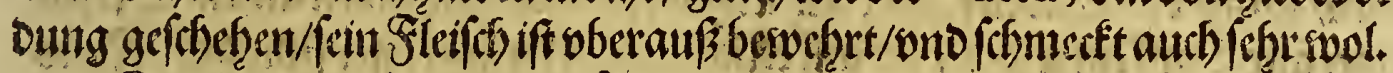

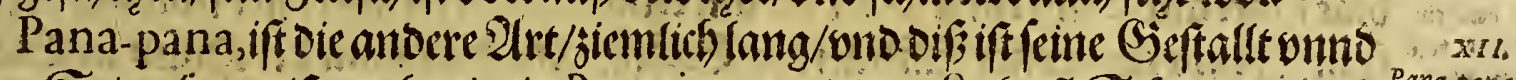

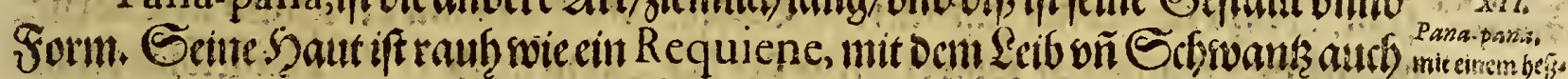

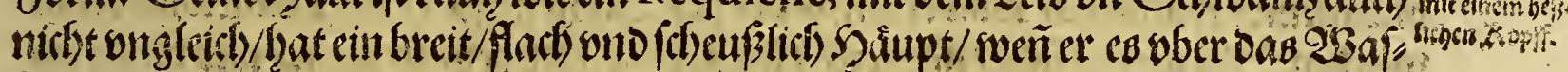

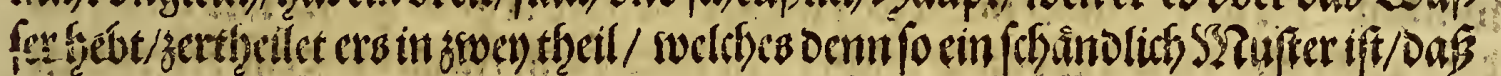

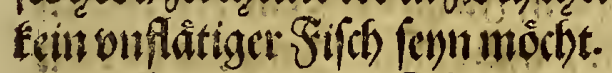

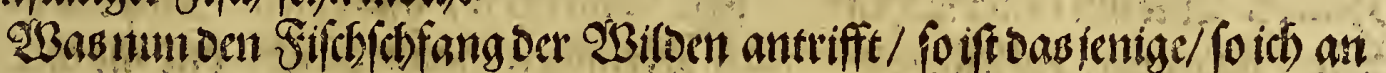
fangs won oen s3arbengelagt hab/audb von anoern allen/oie fie mit iren Pfeile

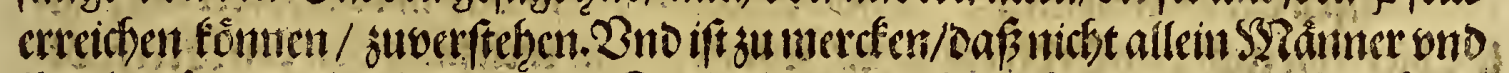

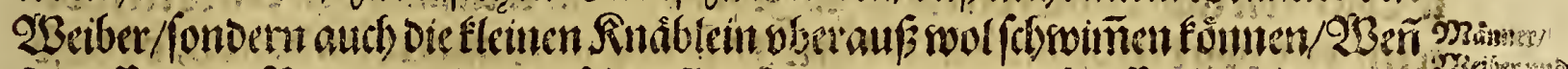

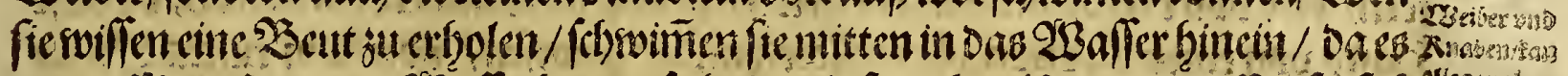

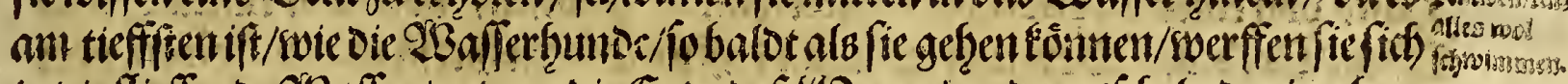

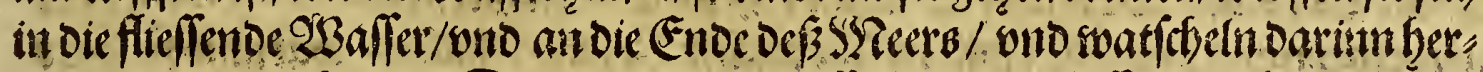
unnbher soie die Enden. Damit man mir oaffelbige oefto beffer glauben móntel swil ich Deflen ein Excmpel erzeflen. Uluff cinem Soutag zu STorgens / giens

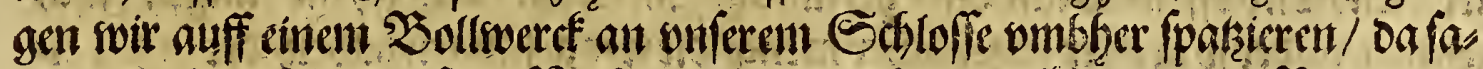

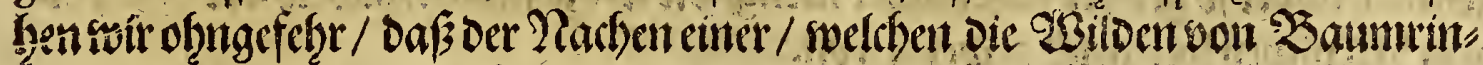

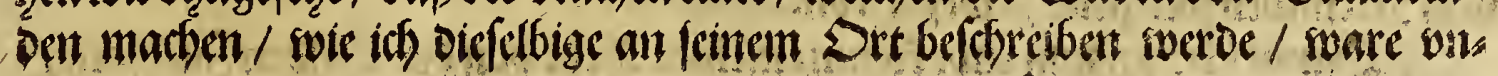
$D$ iif $\operatorname{oerft}$ 


\section{Das bitter Theil.}

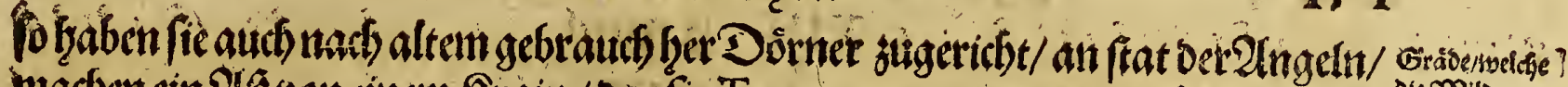

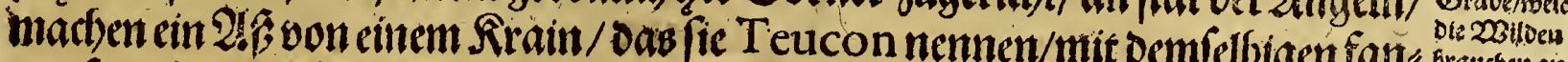

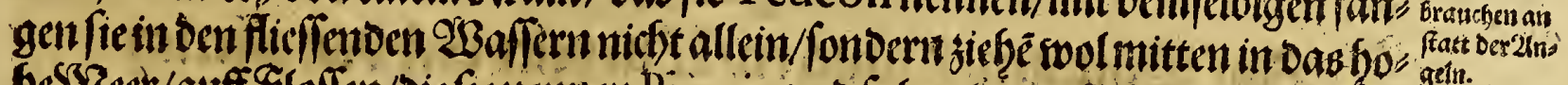

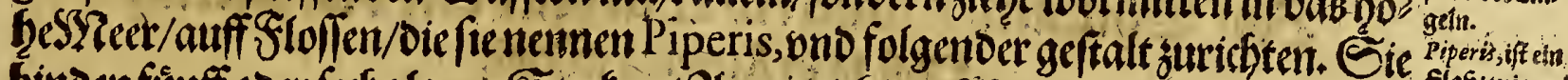

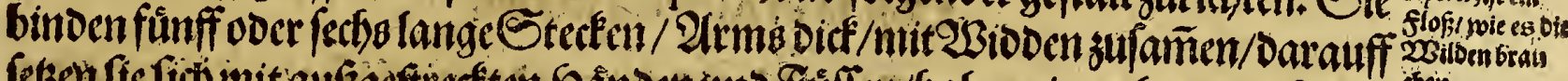

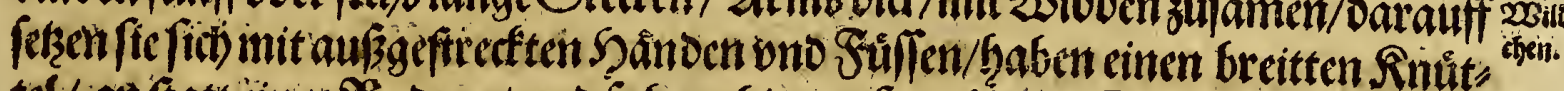

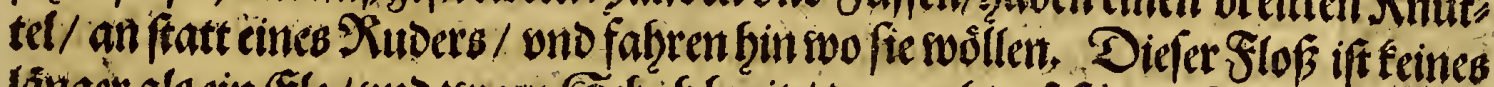

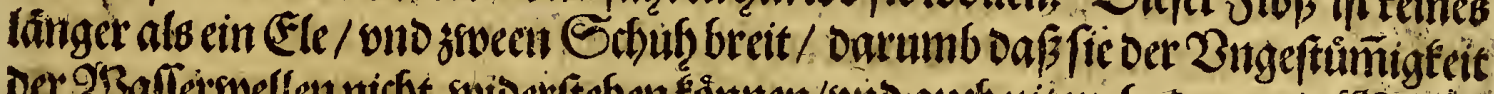

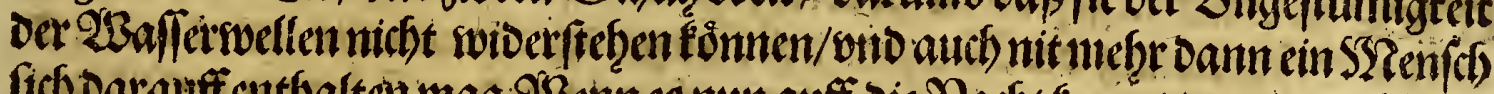

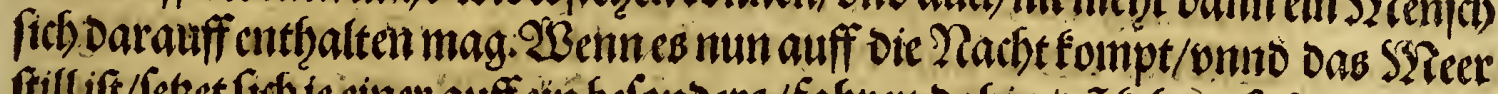

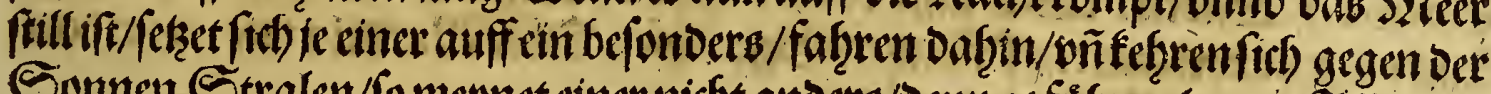

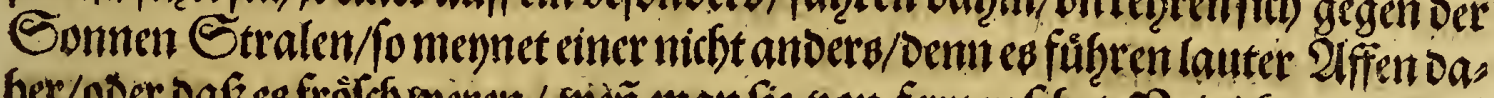

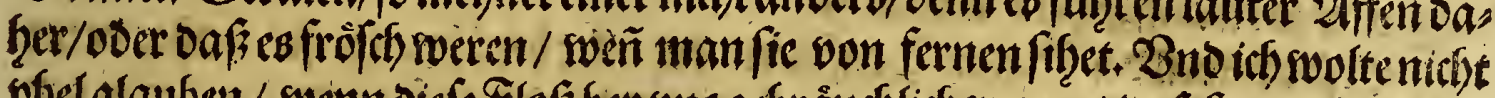

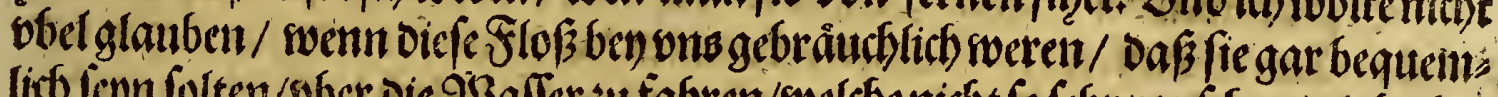

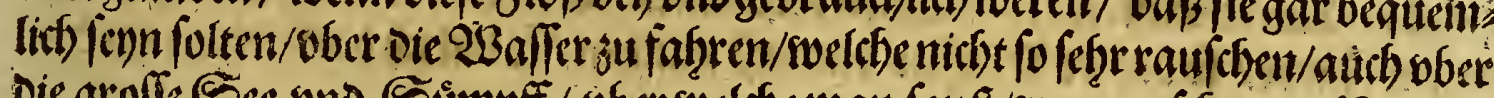

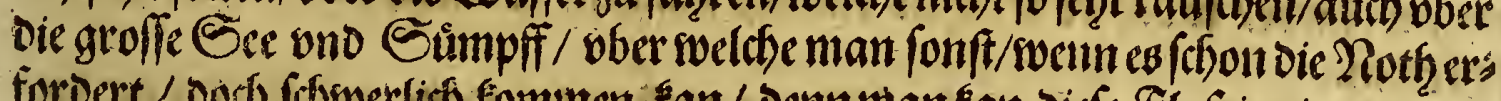

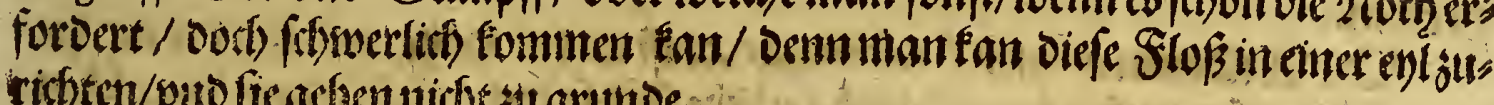
richter/ondo fie gregennichs at grunde.

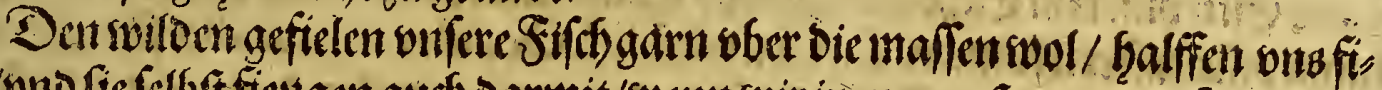

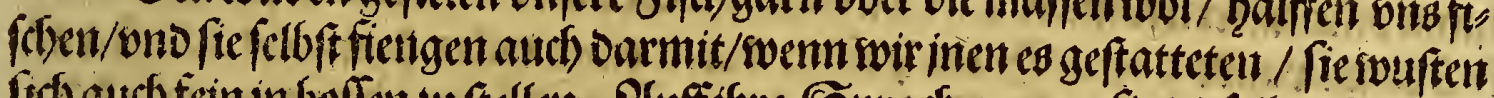

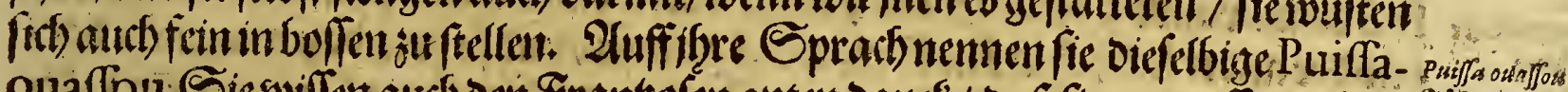

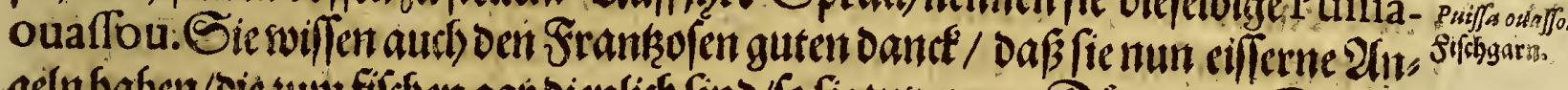

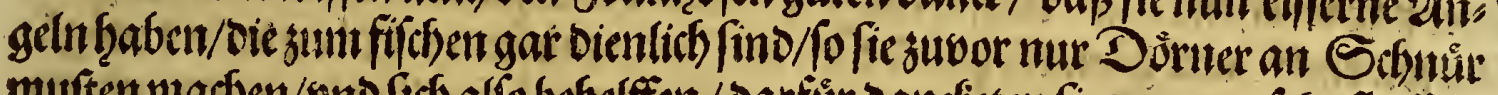

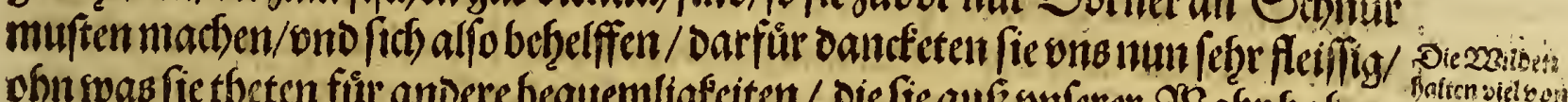

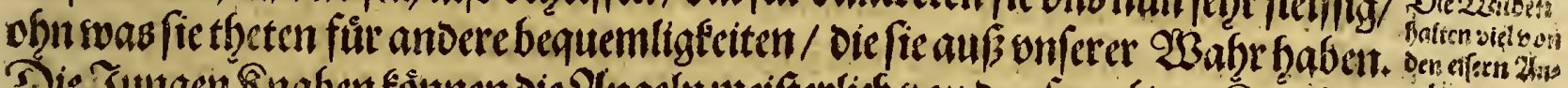

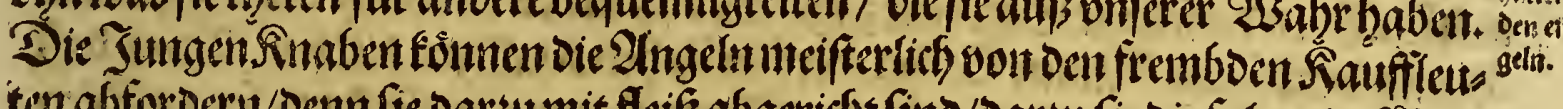

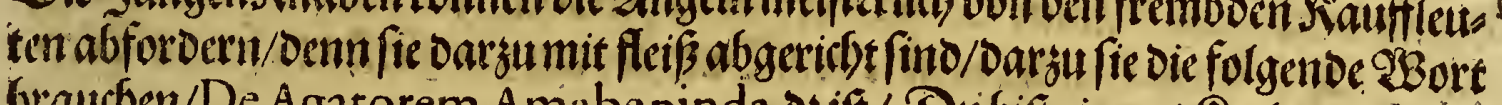
brauchen/De Agatorem Amabe pinda, os ift? Dubifie cin gut Rerle/ gicb mit

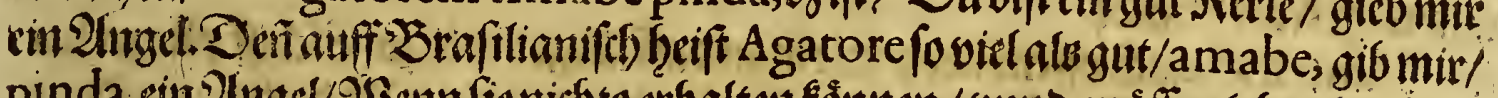

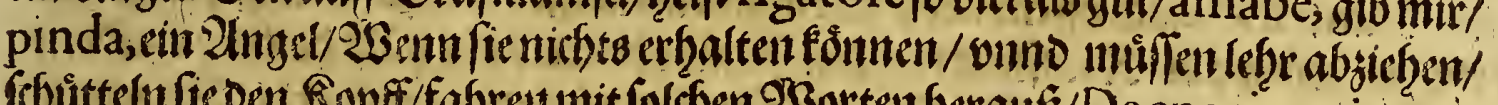

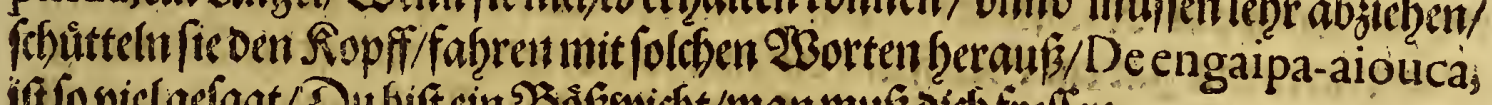

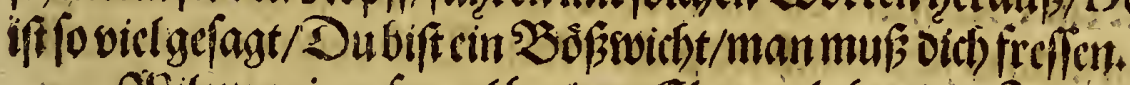

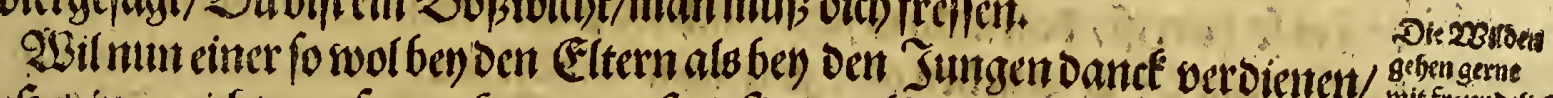

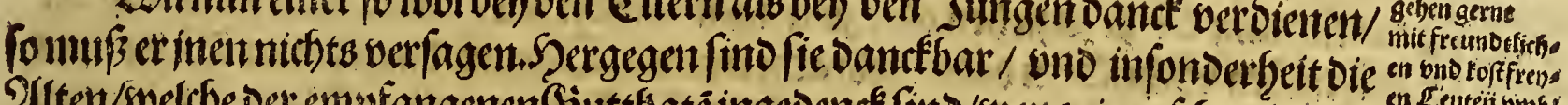

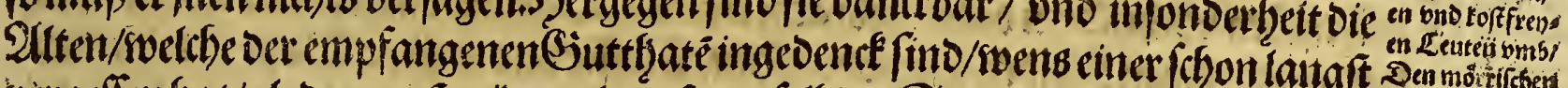

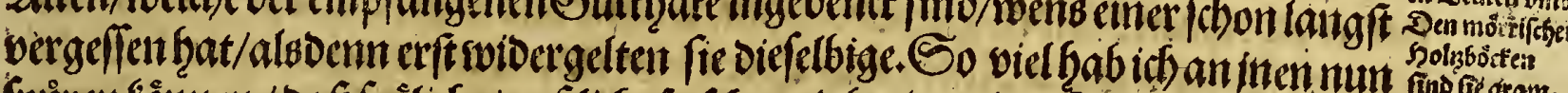

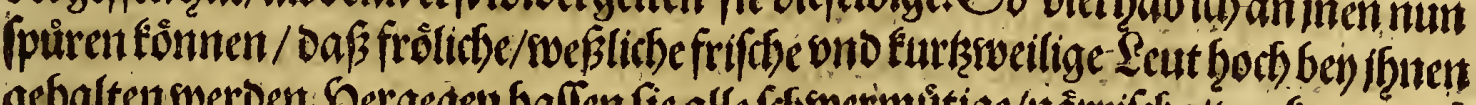

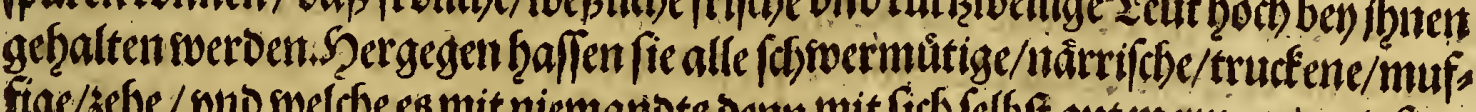

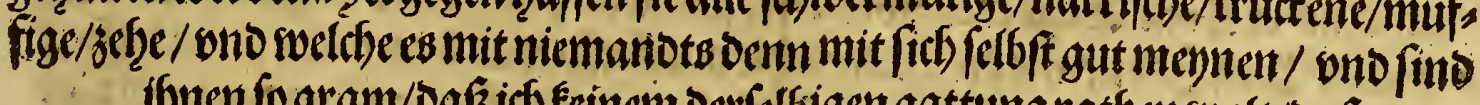

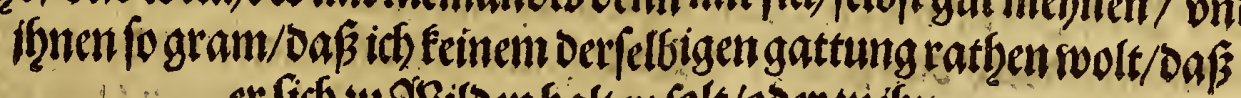

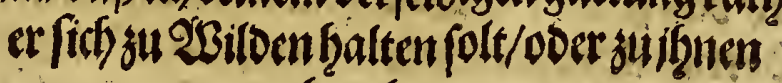
begeben: 


\section{Das Dritte Tferl.}

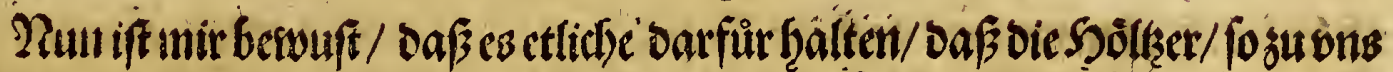

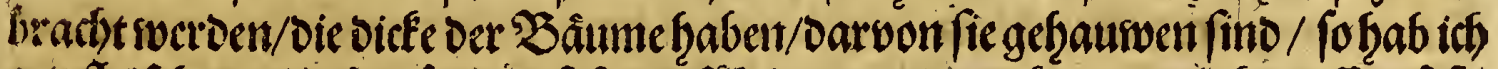

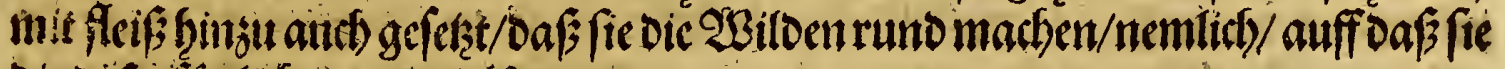
Die oeffo finglider tragen fônten.

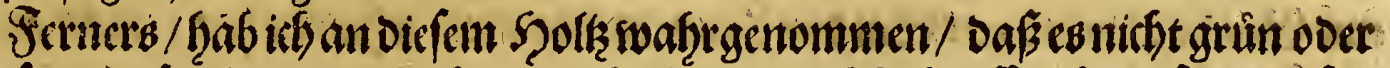

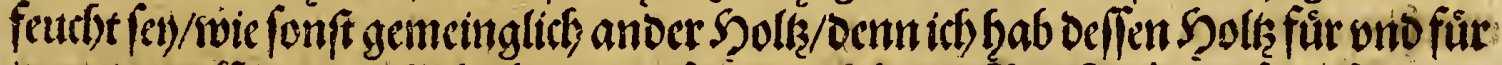

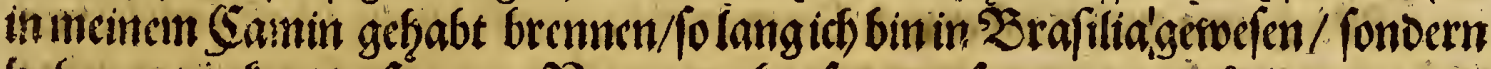

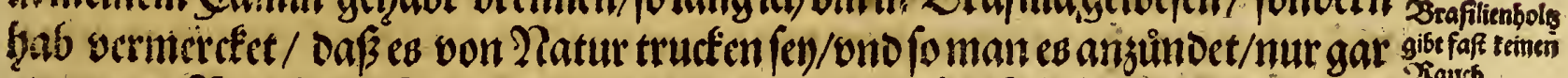
ein soenig Rautb) von fich gebe. Siergegen / soic Matthiolus fpricht / fat Syco:?

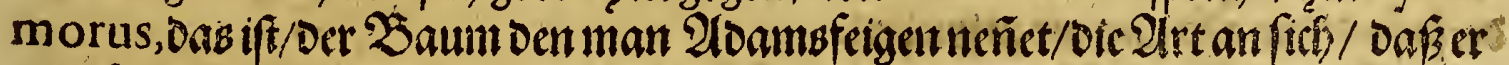

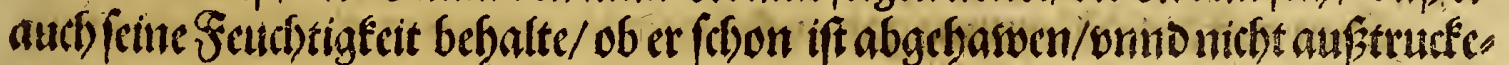

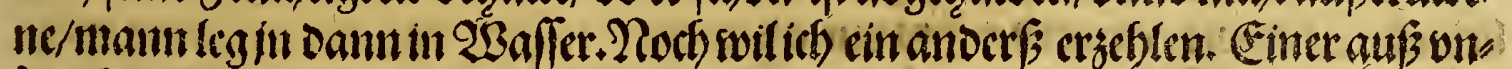

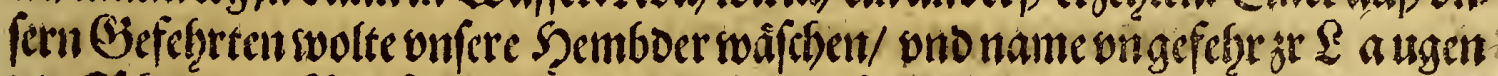

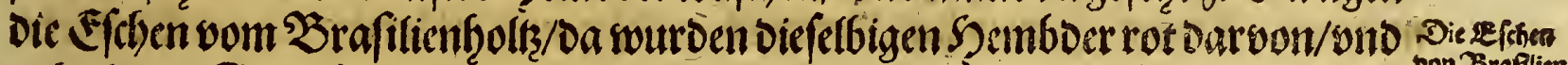

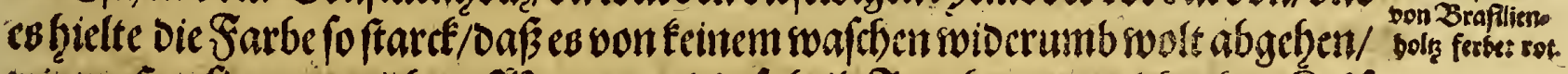

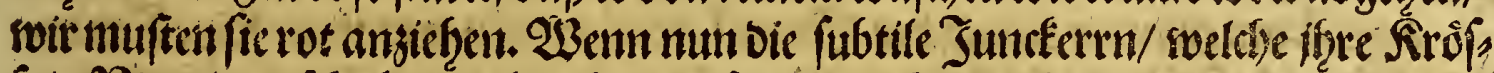

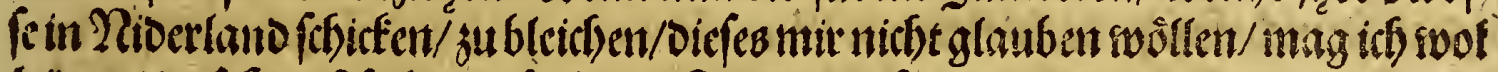

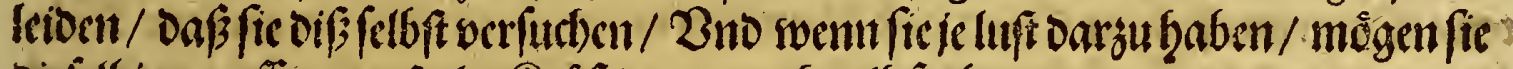
vicfelbigr grofle vongeftalte Rirés bar zu noch gelb ferbell.

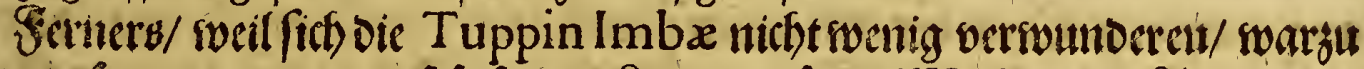

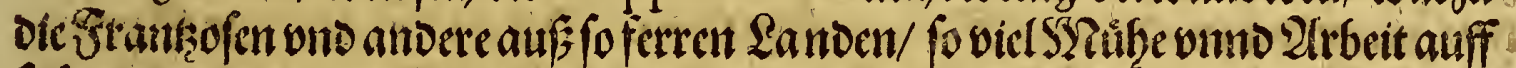

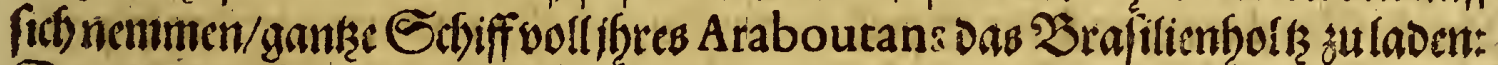

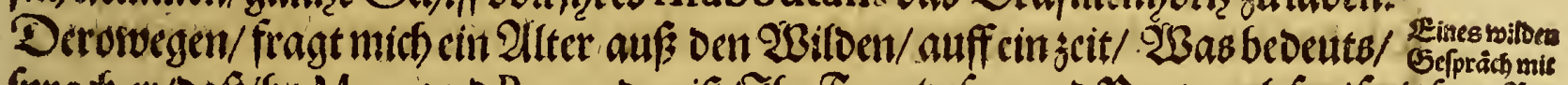

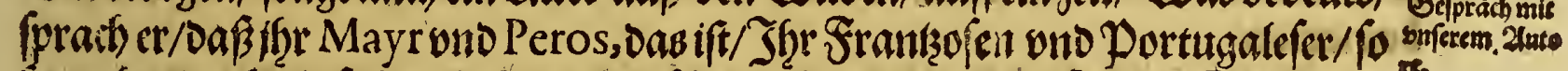

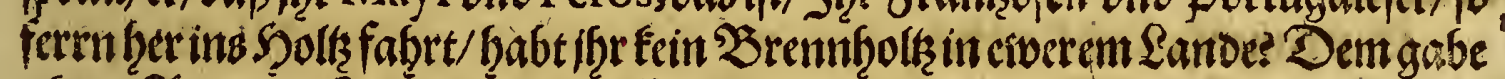

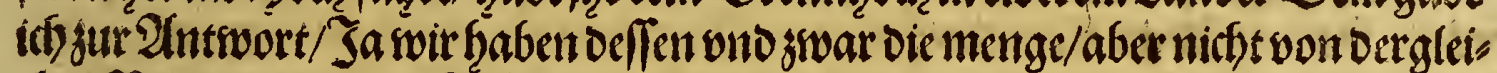

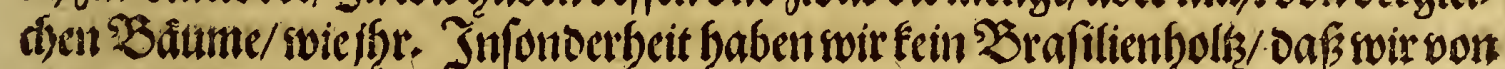

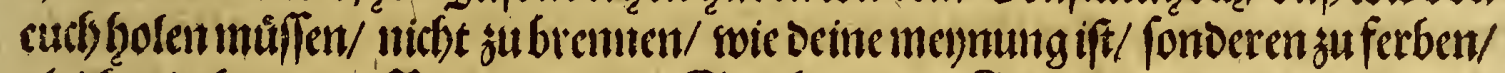

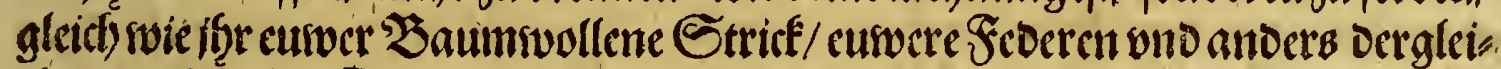

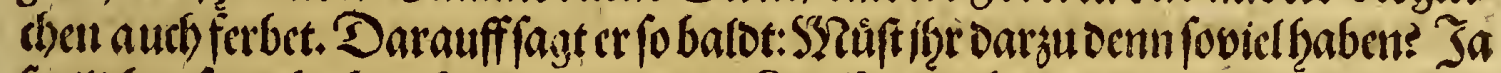

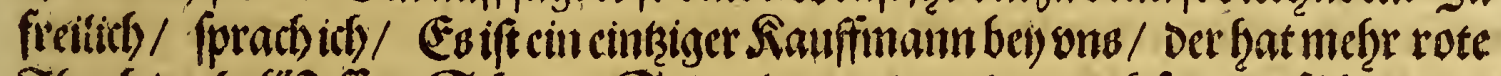

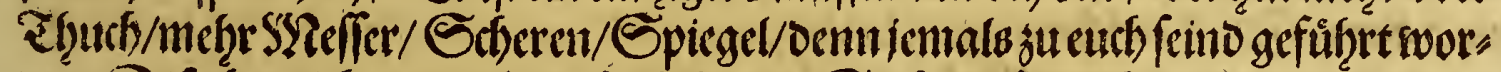

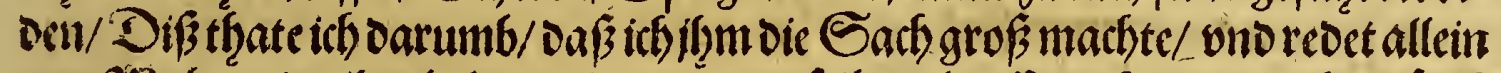

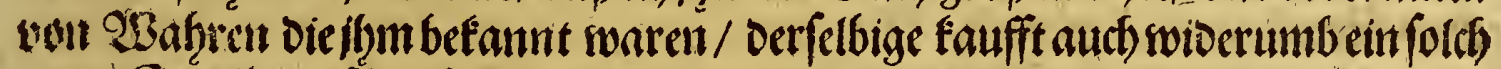

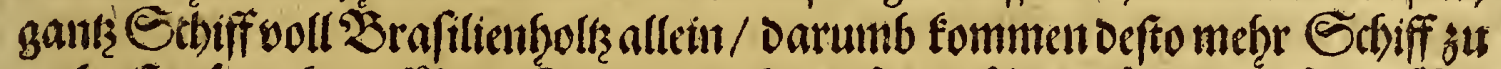

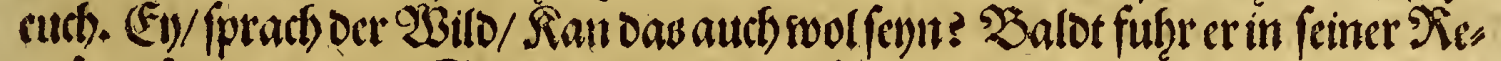

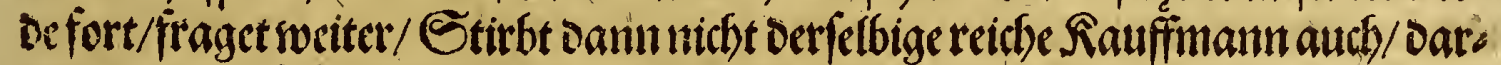

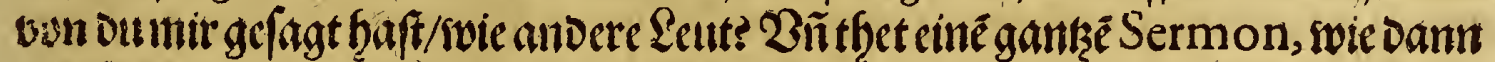

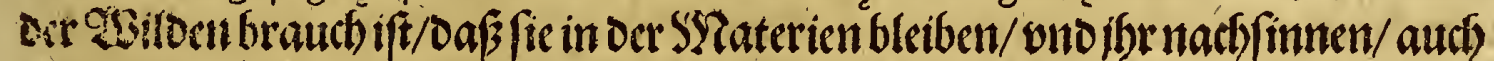

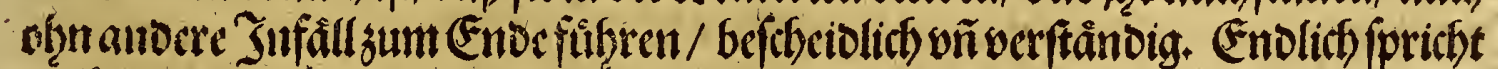

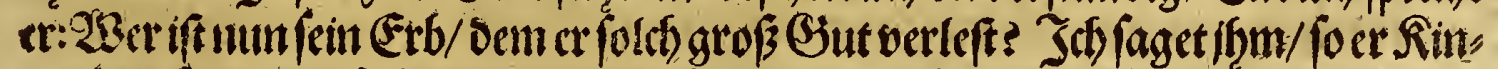

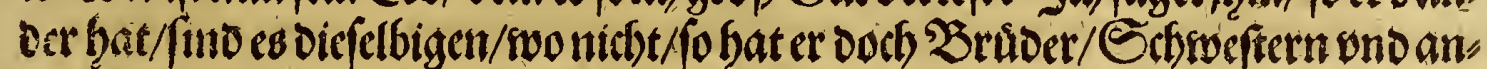

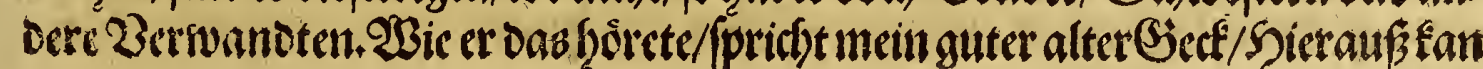
P ichleitft: 


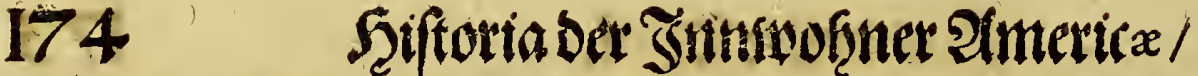

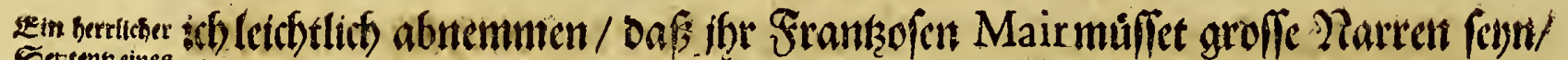

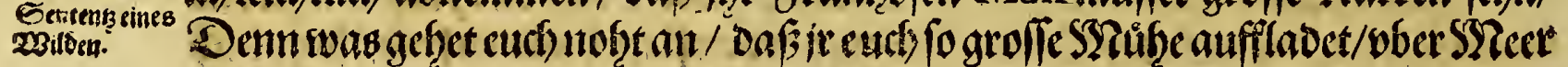

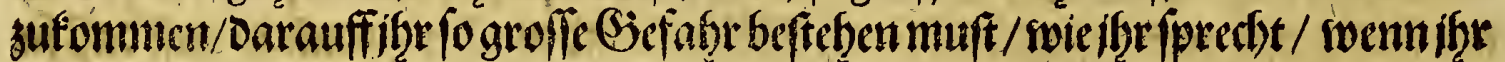

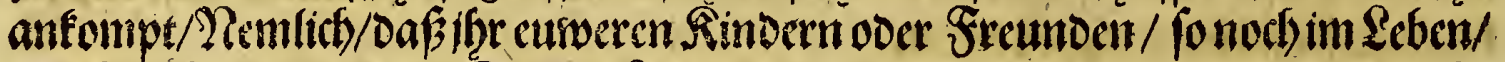

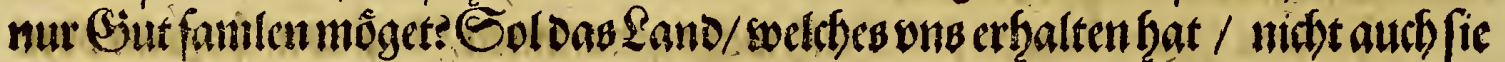
arndbren fónten.

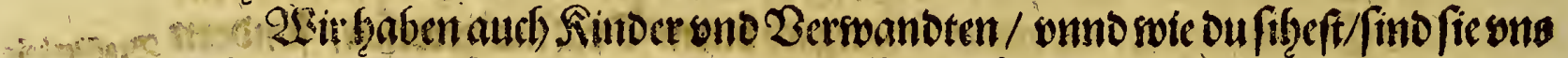

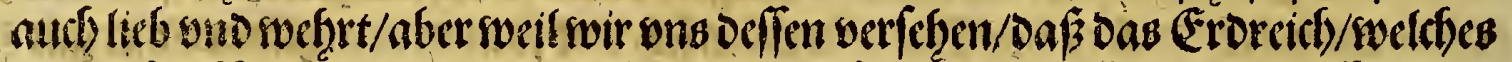

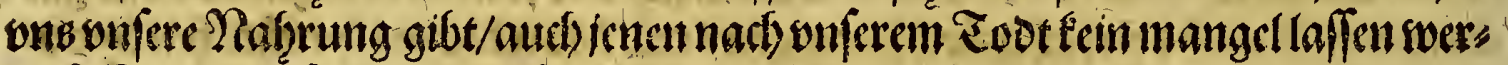
De/fo fino suir alfo darmit zufrieden.

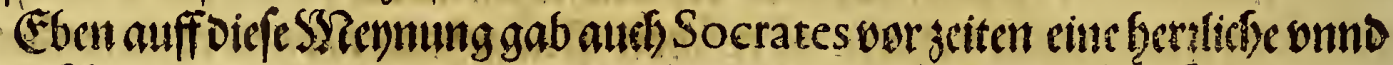

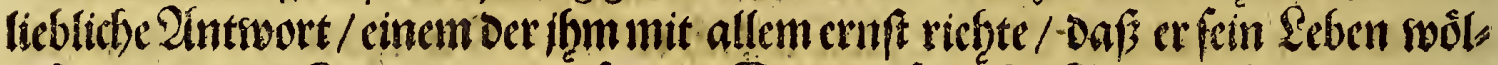

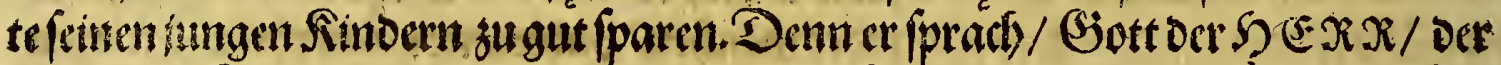
mir meite Rinder gegeben beat / Der wird mir fie aud wol ernebren wuno verfor: geti.

Agefilaus aber cin fionig ber Statt Lacedxm on ermalnte feine Freun.

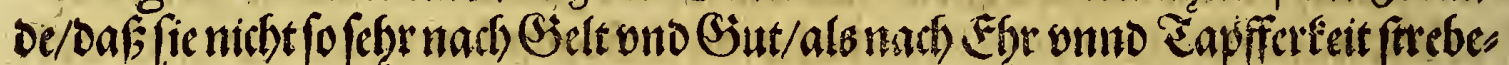

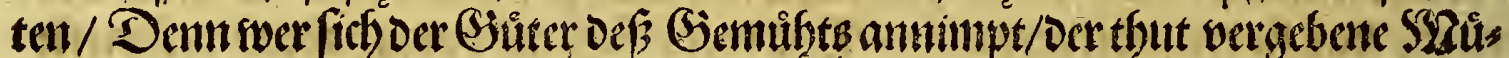

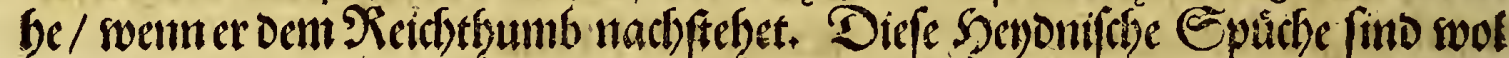

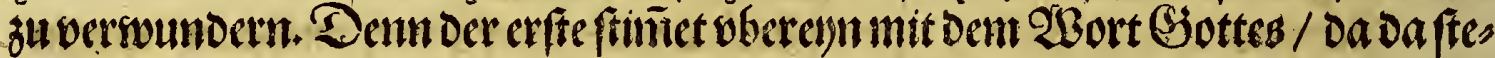

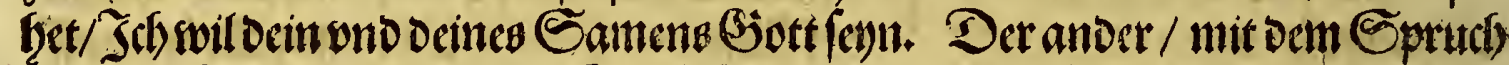
Sbrifti: Strebet nit nadh der Epeif/Fo vergânglith ift / fonoern nach Der Spets

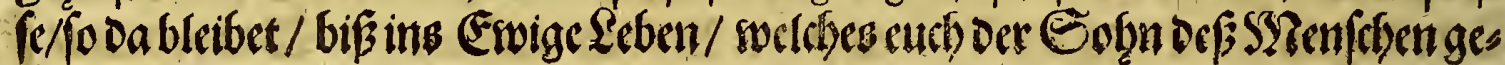
bentwirot.

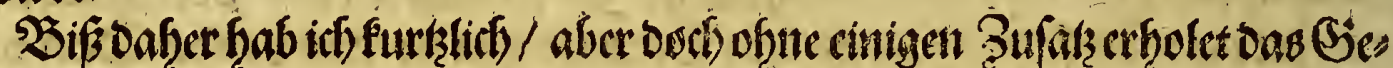

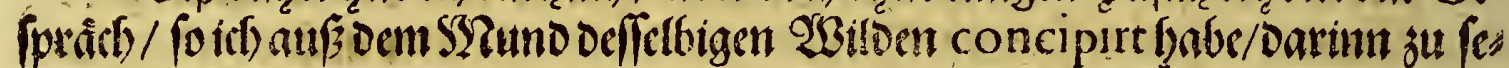

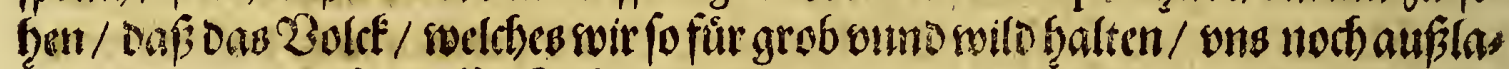

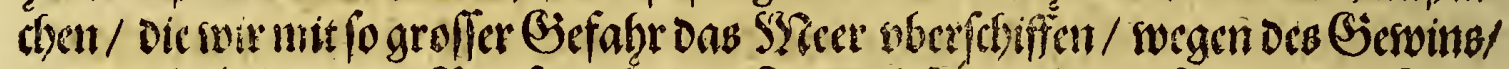

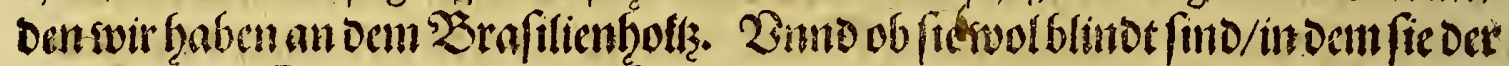

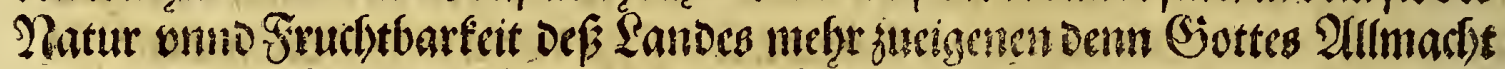

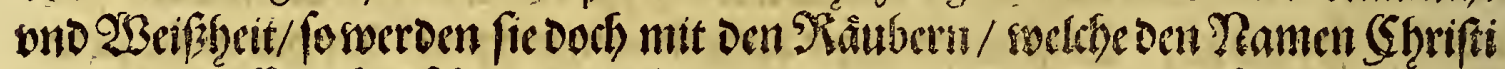

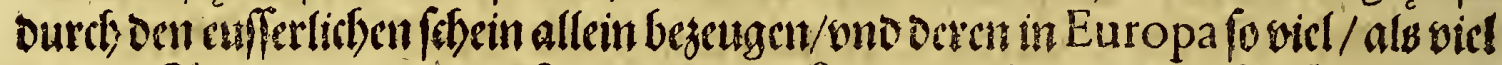

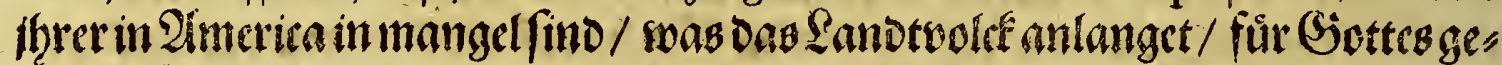

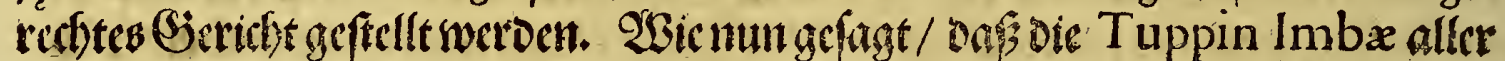

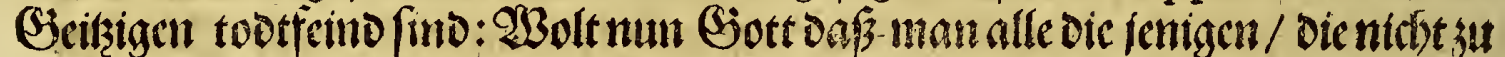

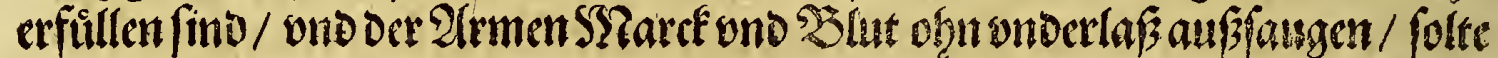

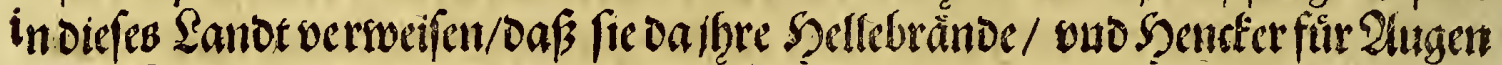

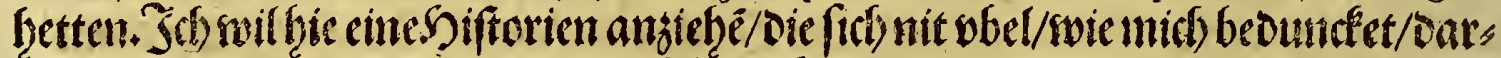
tib. 4. ea. yos.

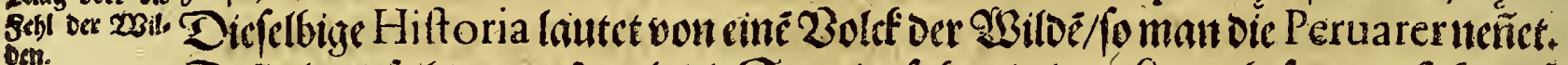

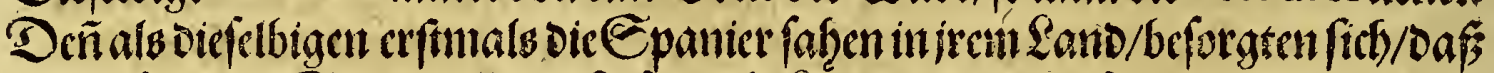

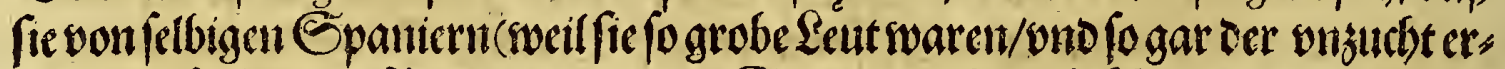

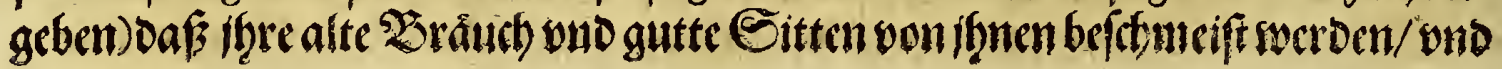

wervitu 


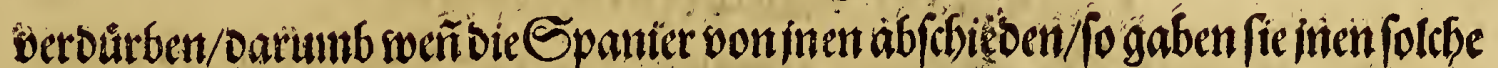

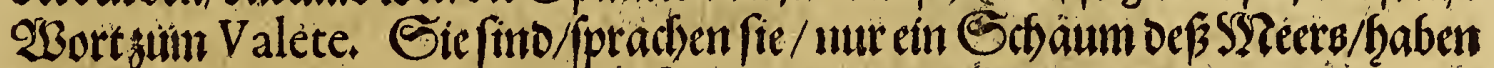

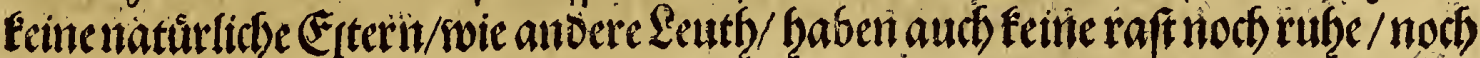

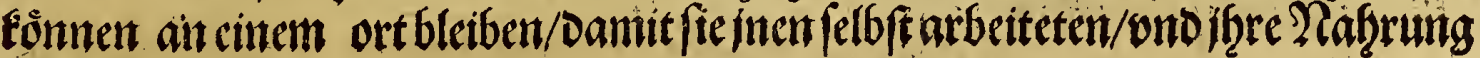
gerviumen.

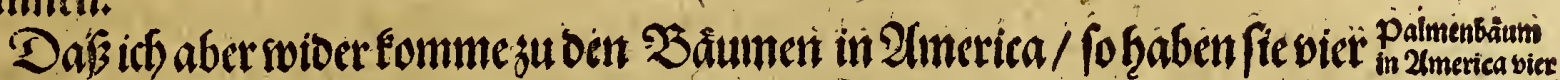

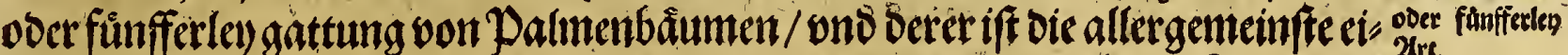

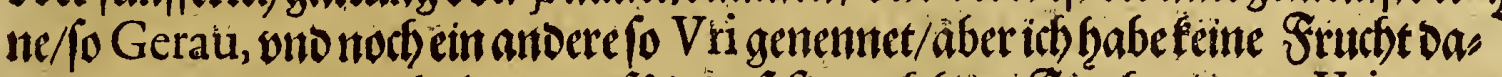

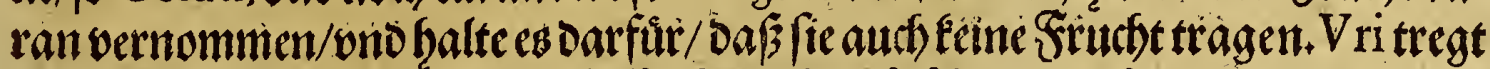

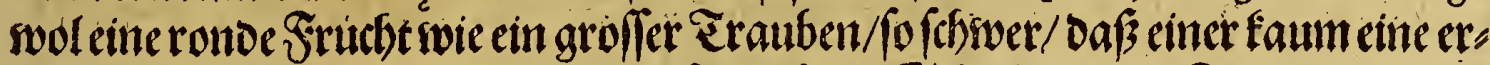

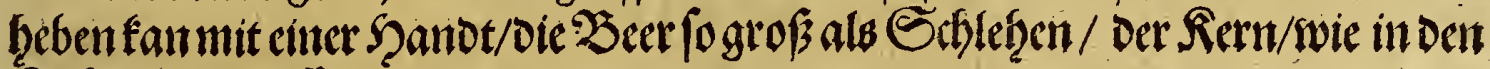

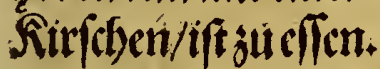

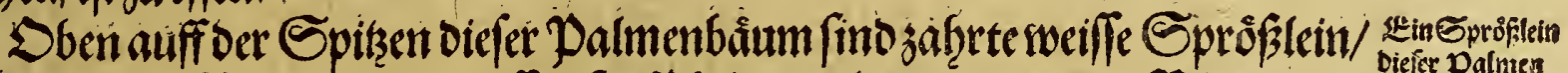

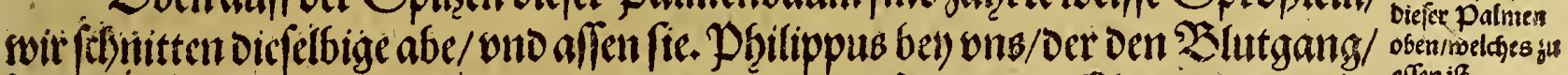

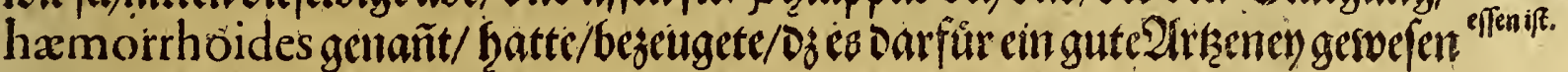
fey/Daruon die Medi ci iuditiren mogent.

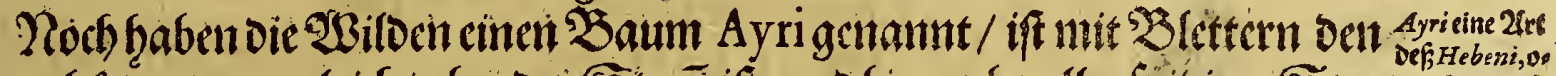

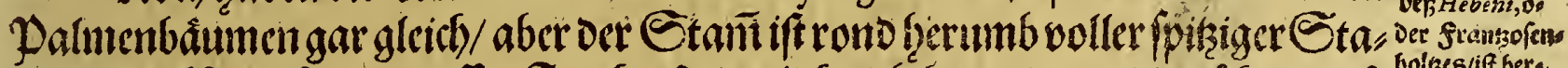

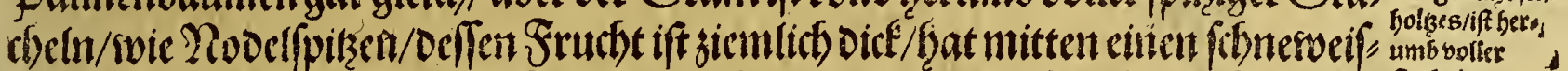

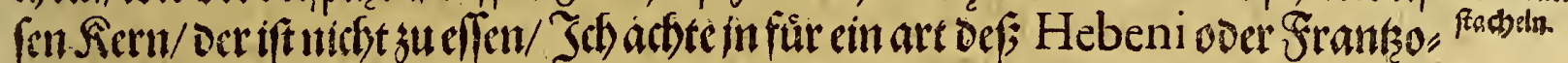

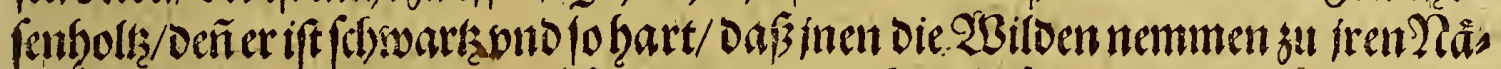

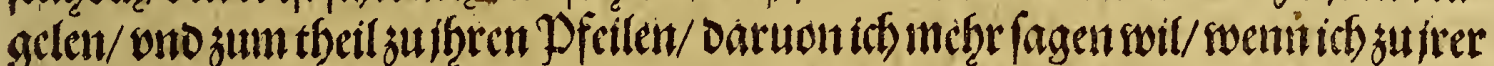

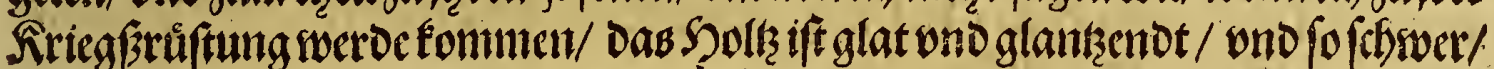
Daßswennmant es ins 2 Baffer swirfft/ es fo balot gu grundet fellt.

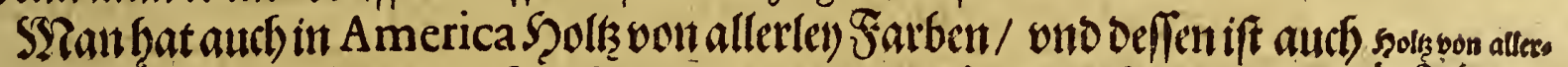

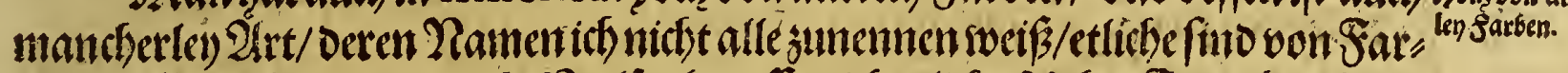

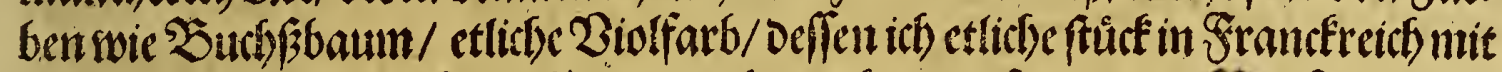

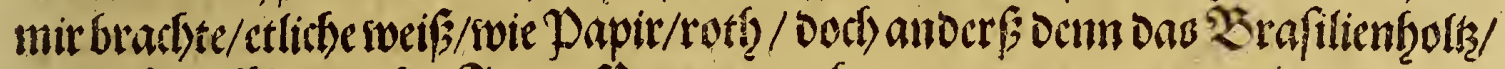

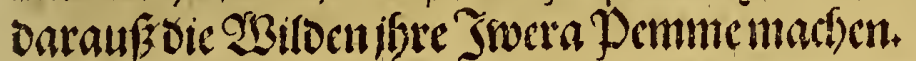

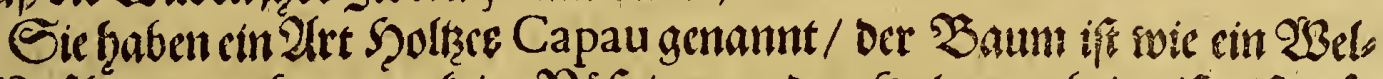

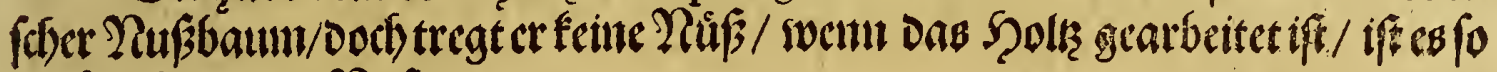
imaferichtswie cin $\Re$ ü

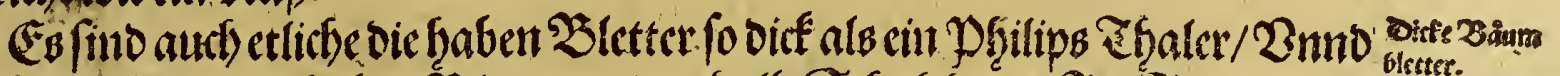

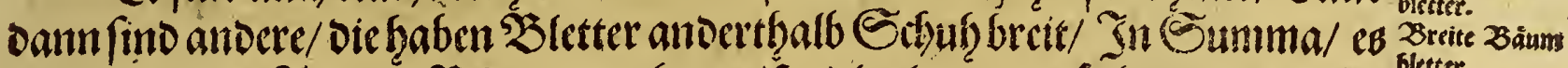

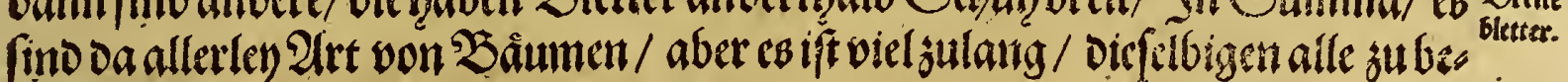
fichreiben.

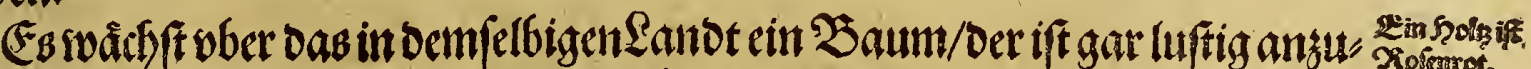

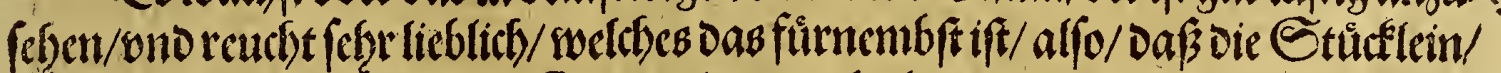

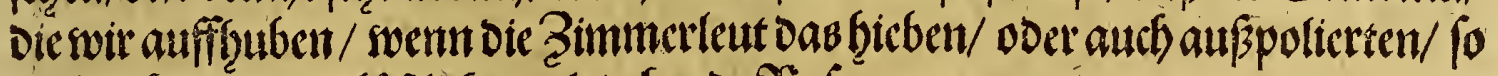

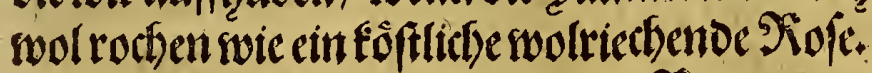

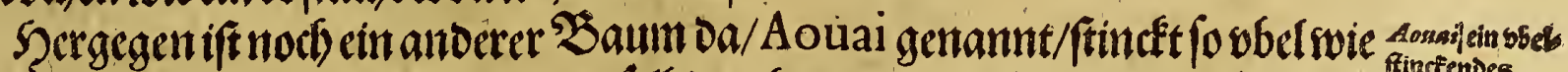

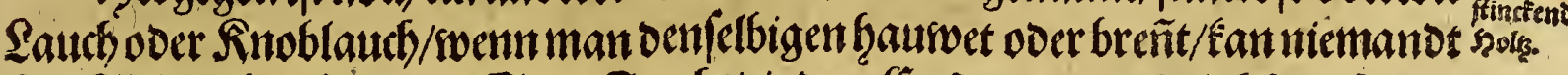

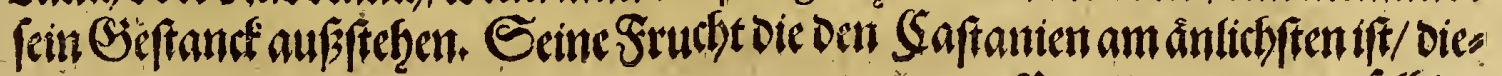
$P$ ij felbige 
176 Hetforta bet Snnmoliner Ximertiol

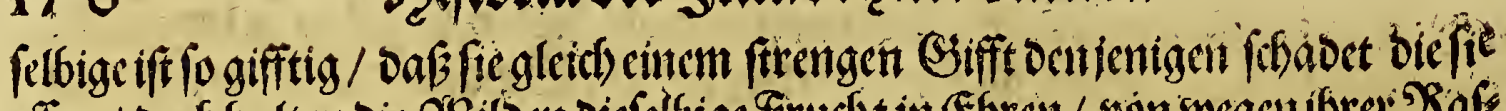

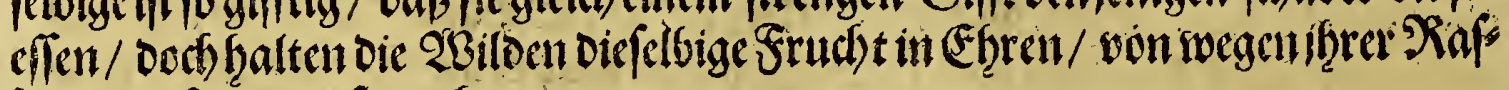
folen/bie fic Daraus machen.

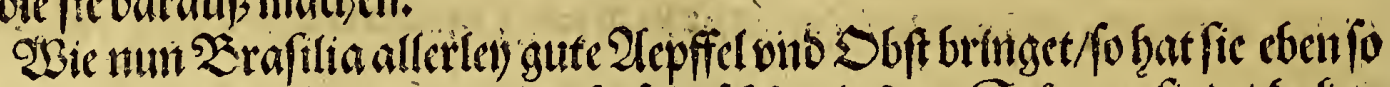

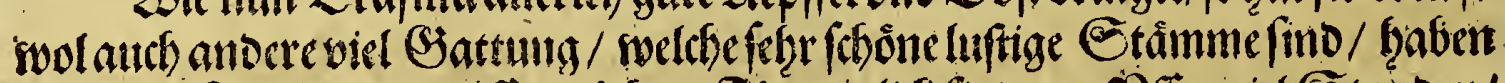

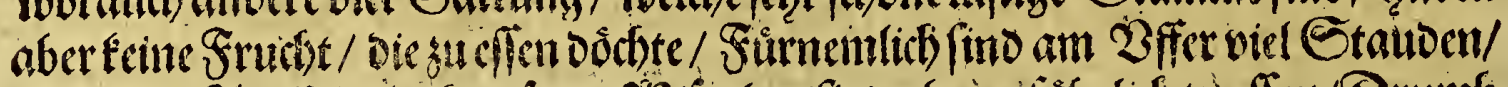

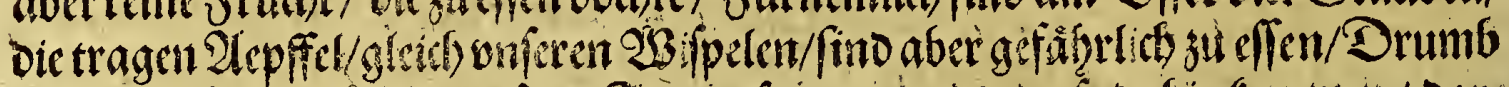

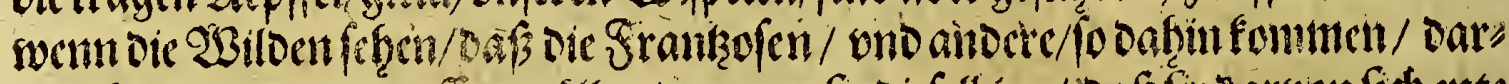

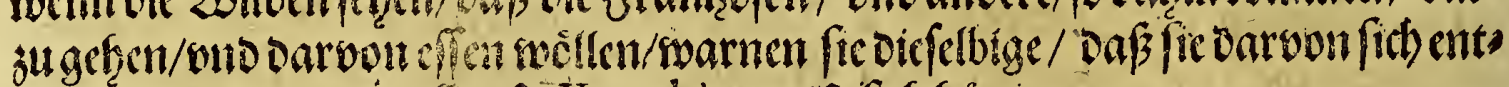

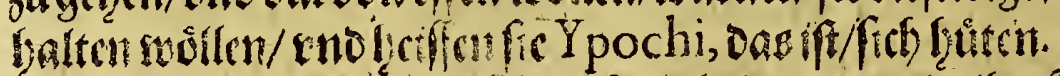

Hitusurae, ferholtris.

Cboyzeifte sin 3oum/anis

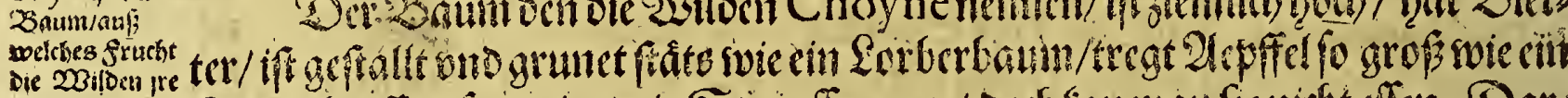

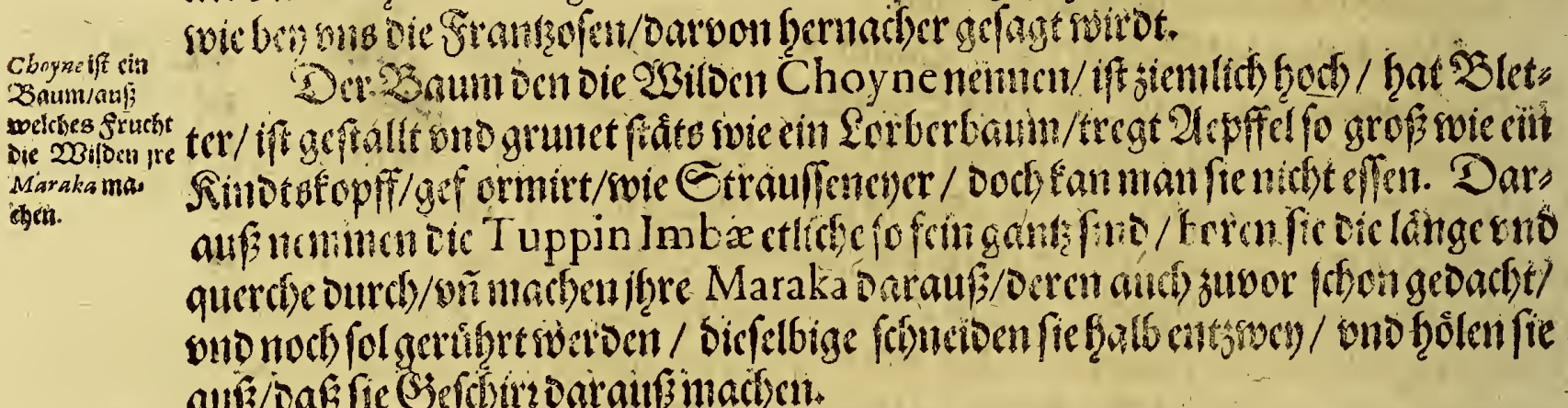

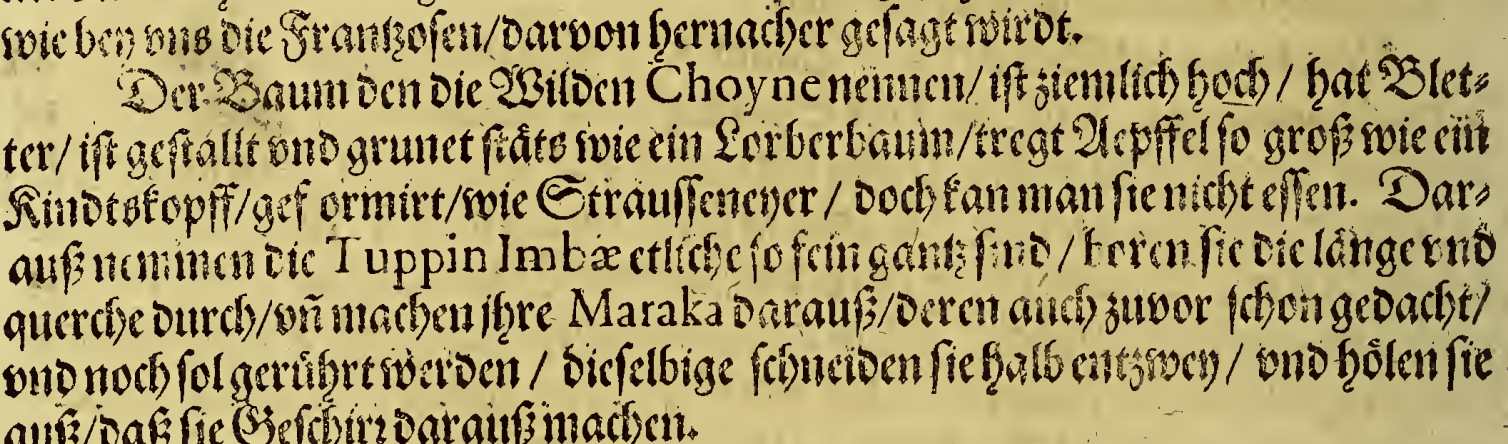

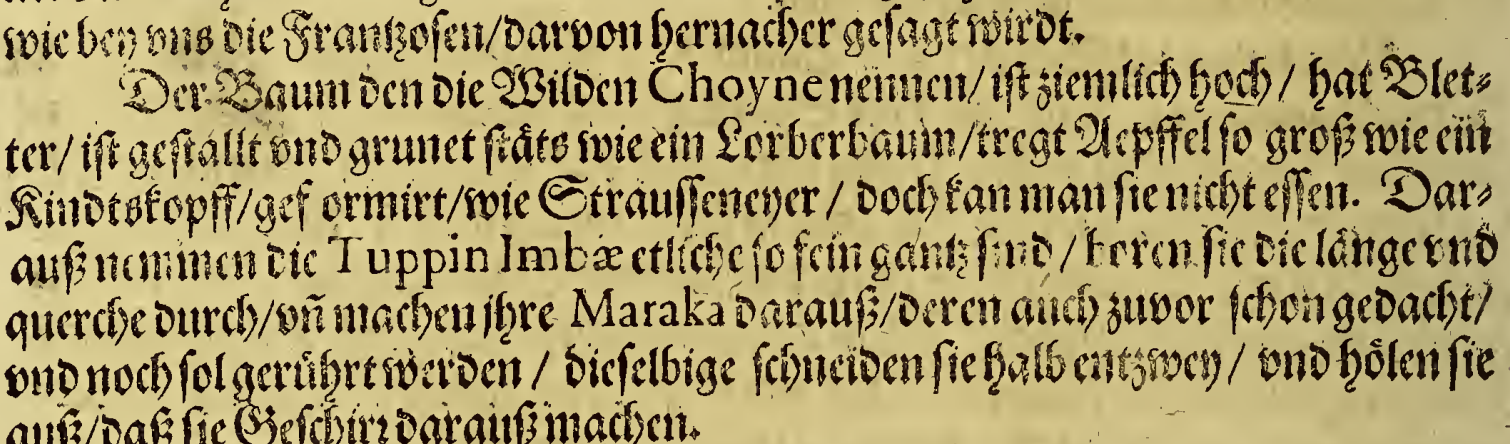

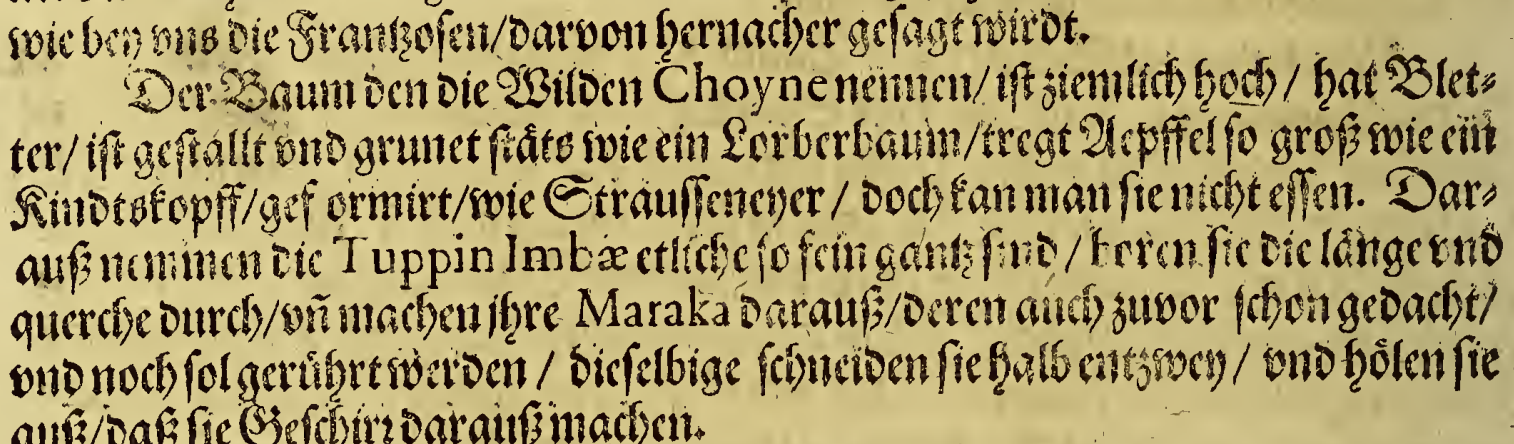

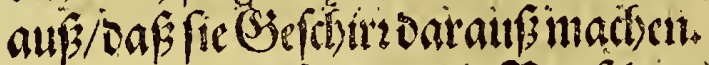

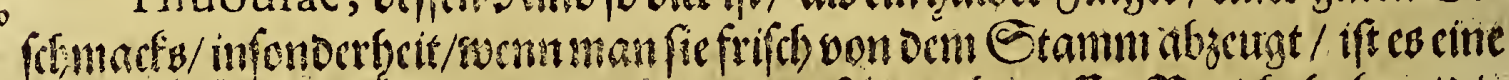

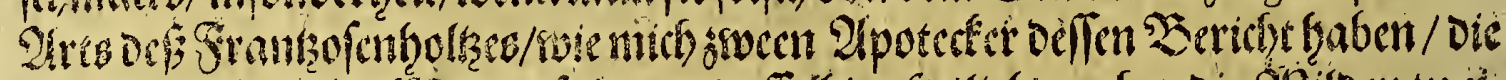

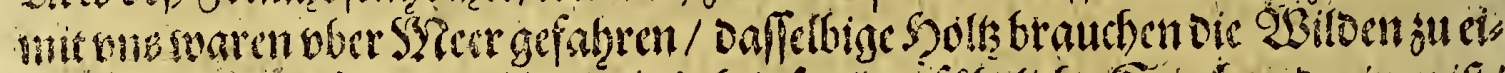

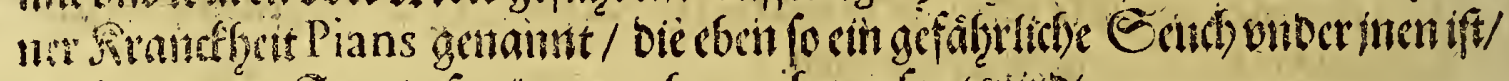

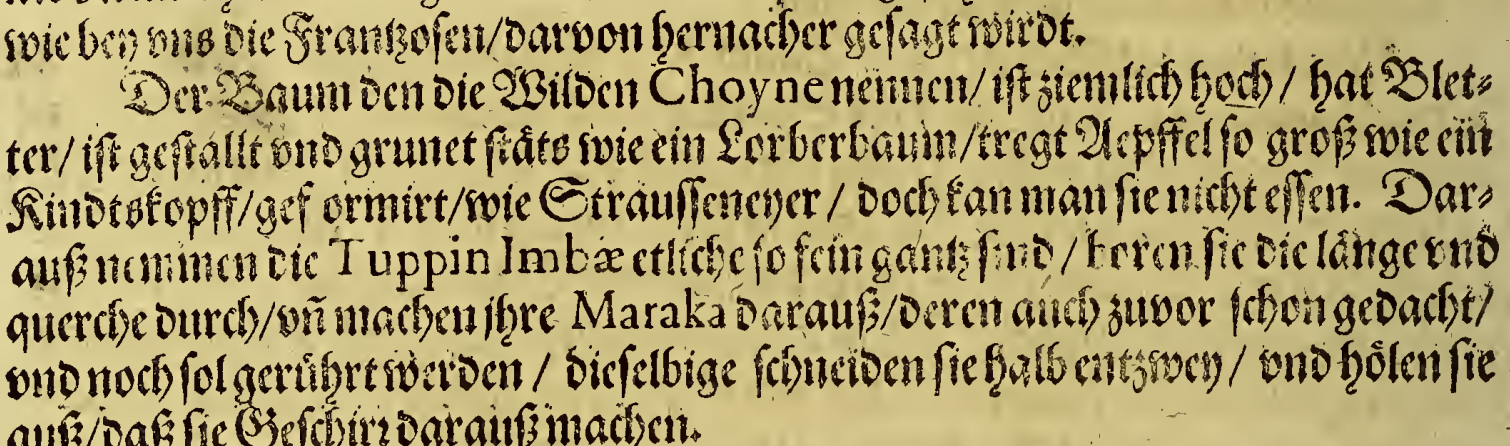

3ebaucaie : Liv S3auni Deffan fruebt Die Wilden

brauchen/ibre Sefdoirt Dars
aufj ju madjest.

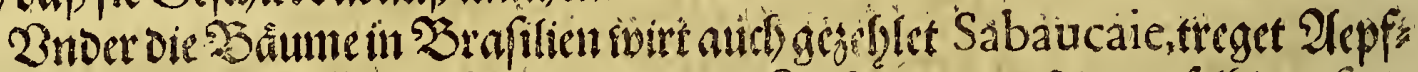

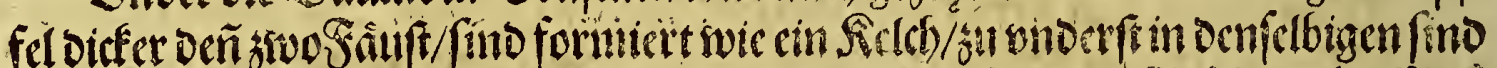

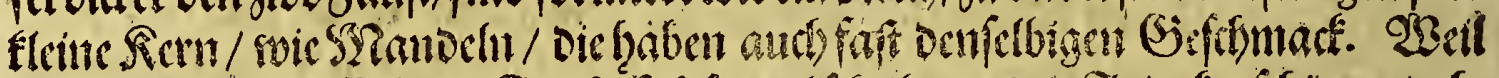

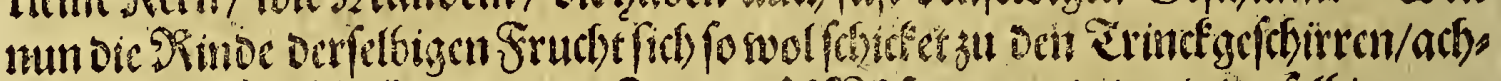

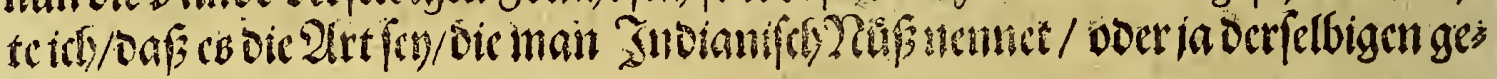
forlediterint.

Dent Matthiolusinfentu Commencarien voer ben Diofcoridem

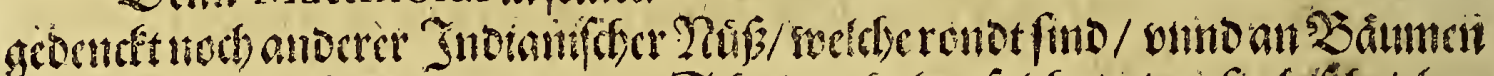

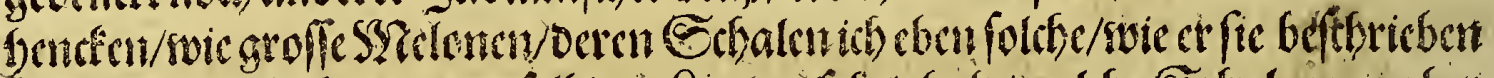

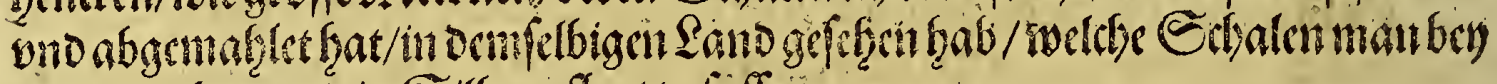

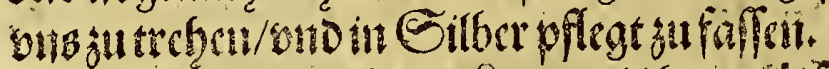

Petrus Bordoni

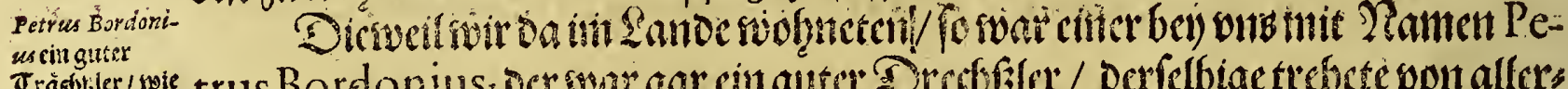

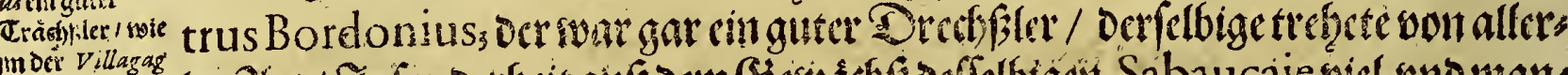

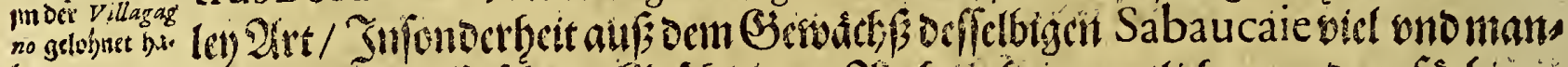
ne.

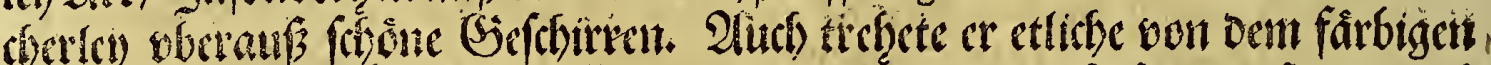

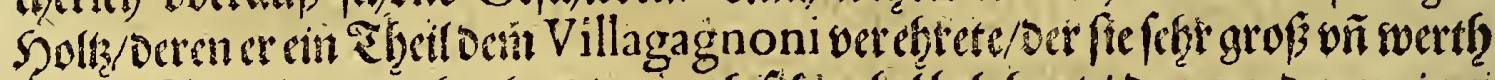

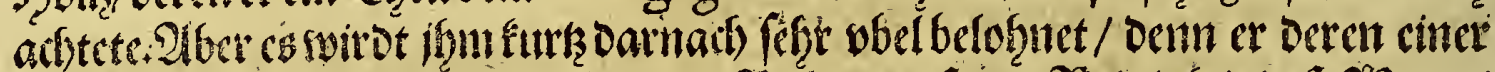

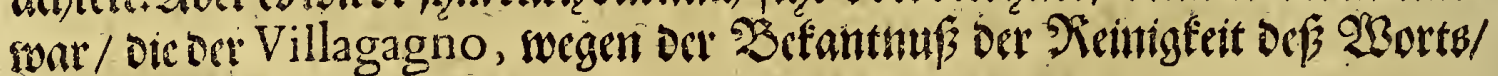
liefle in bab Sheer werffert.

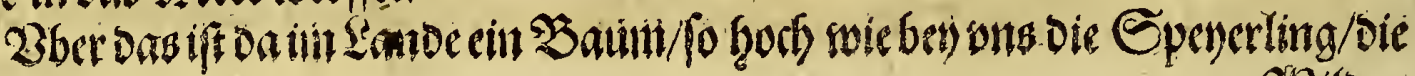
abillom 


\section{Dasbute Thenl.}

17.7

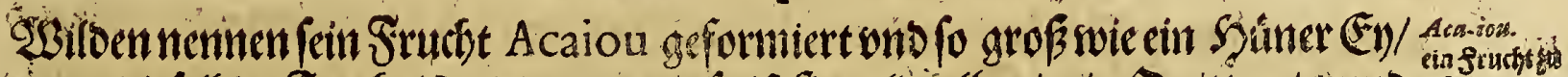

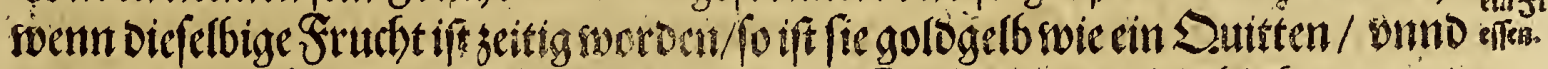

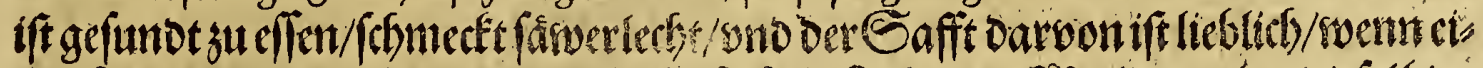

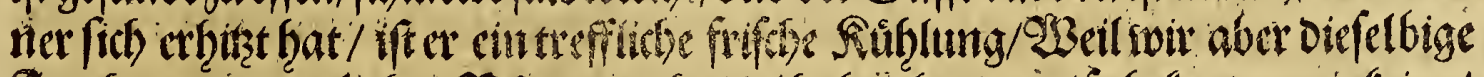

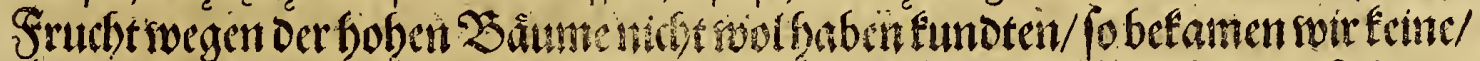

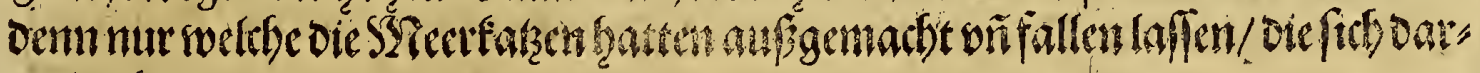
voutuefreit.

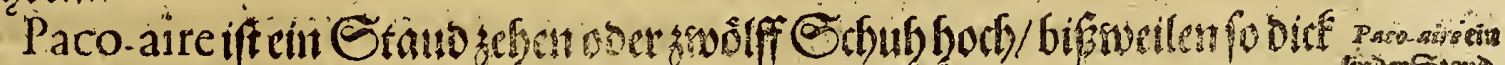

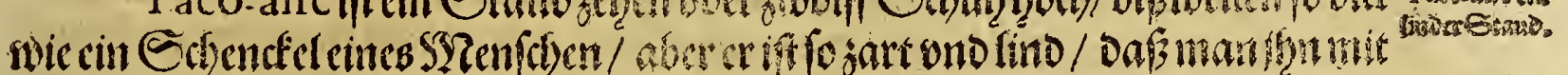

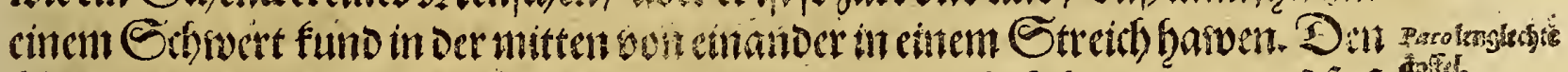

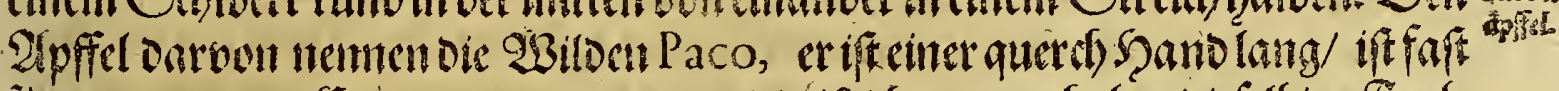
formirtswe cin Sucummer/ swemerseitig if / hat er auth eben biefelbige Sarb.

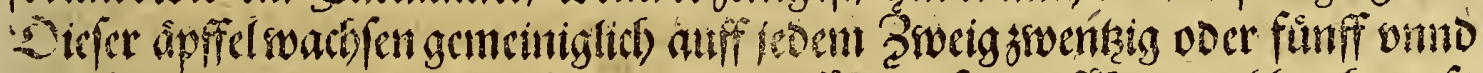

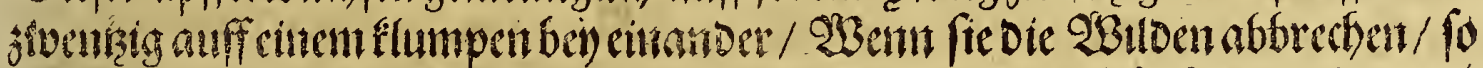

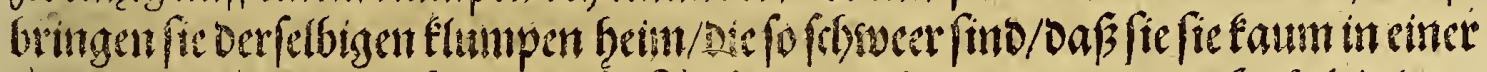

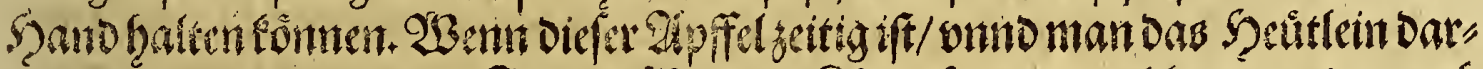

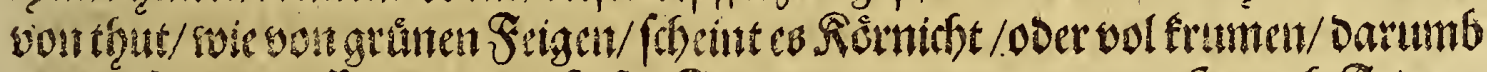

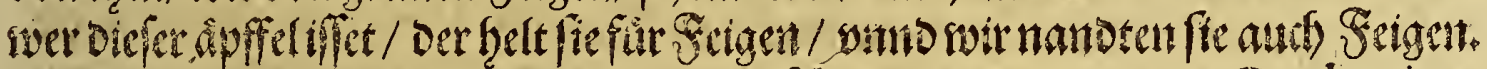

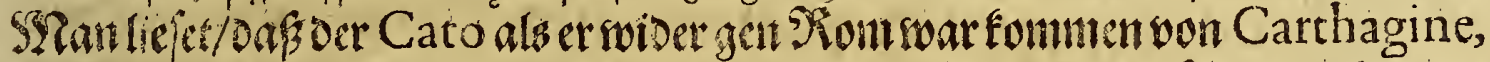

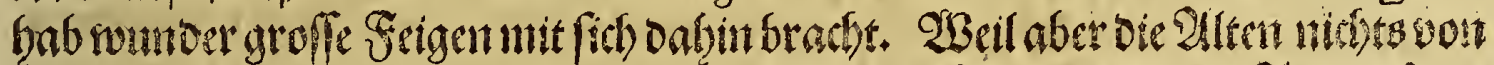

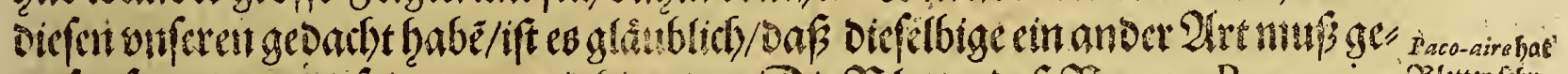

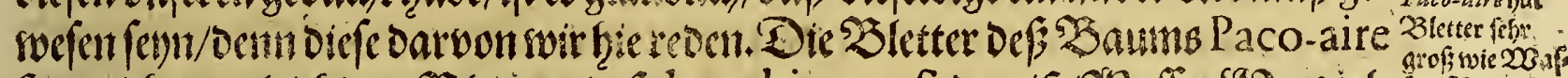

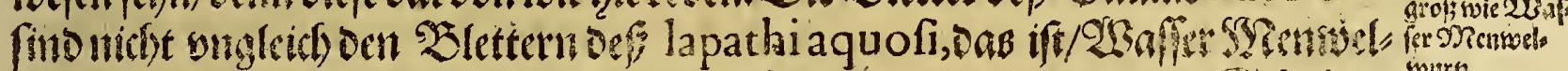

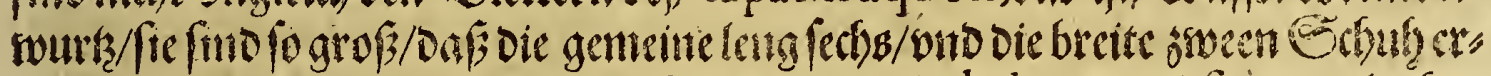

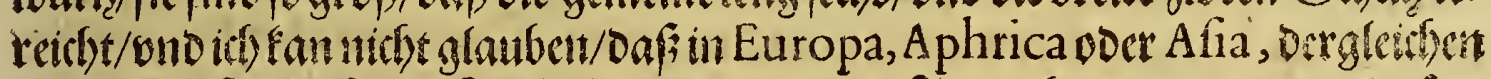

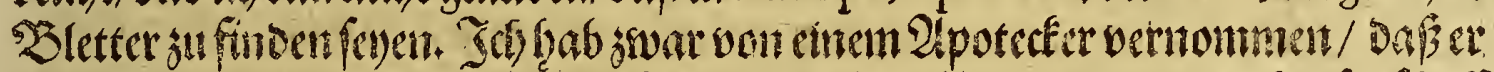

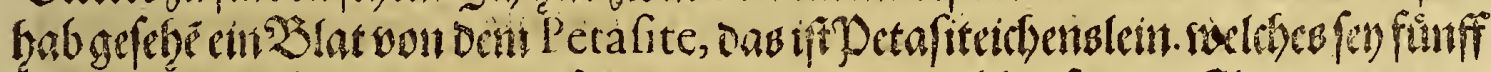

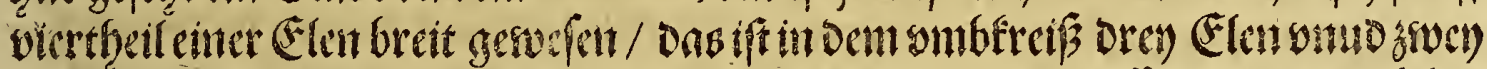

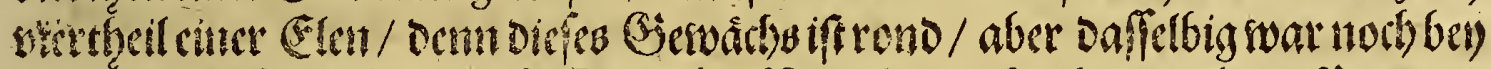

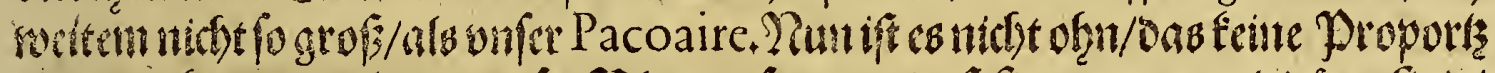

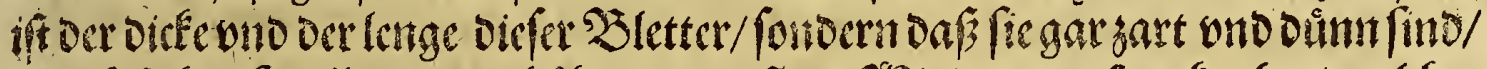

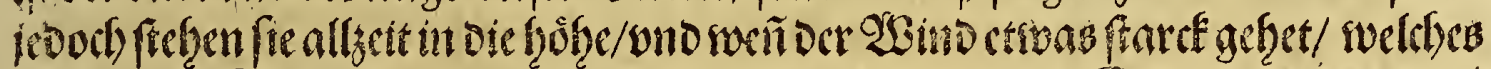

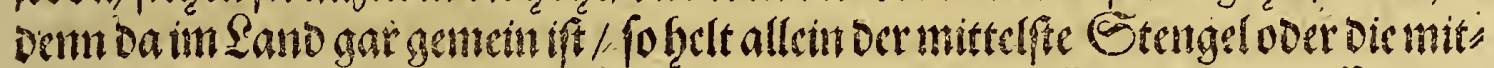

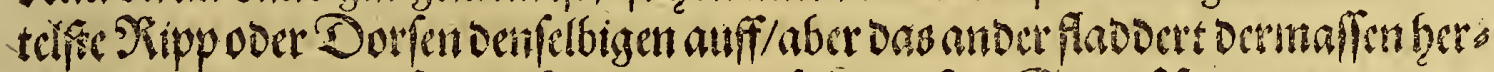

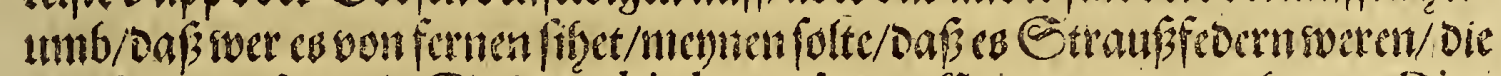
oer 2Binot alfo triebe. Da Matthiolus infeinen Sommentarien wer oenDio. fordiem Gandelt won Dan Palinenbaun wntwo von ben Datedn/fortibeter/

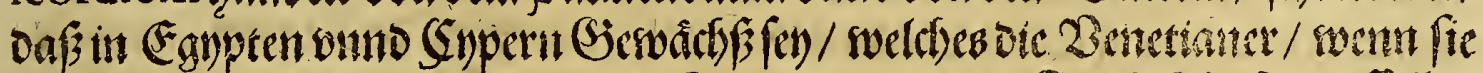

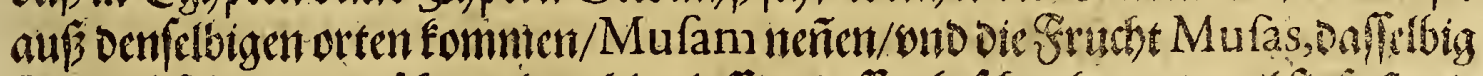

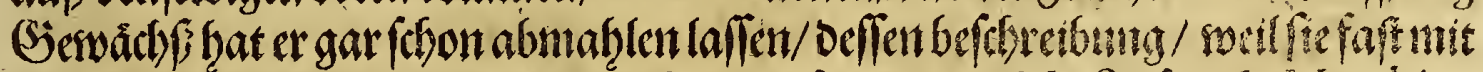

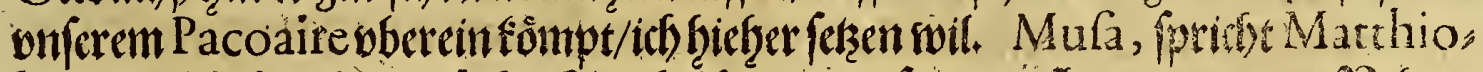

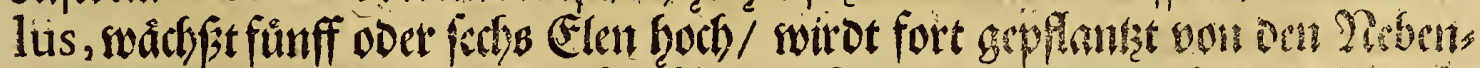

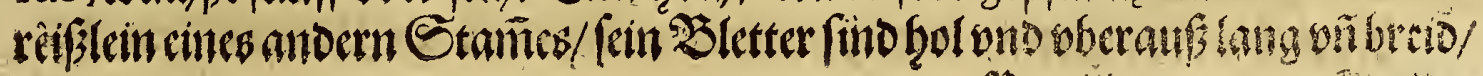

$$
\mathcal{D} \text { iil }
$$




\section{8 Ģiftoria ber Snnnwofiner Tmericx}

weroen offt oren Elen boch/wno anderbalb Elen breit/Inoer mitten iftein brets ter difer Stengel oder Rippe. In Sommer werden bie Bletter woninen felbft

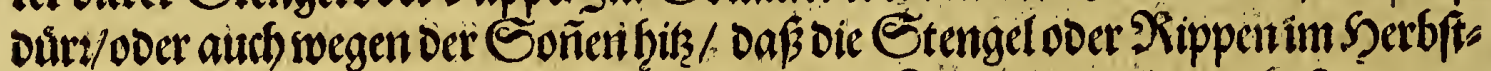
monat gar nacfent ono blo 3 oa fefeben/ ono Dab Rtaut gar oaroon ab ift/Dentes

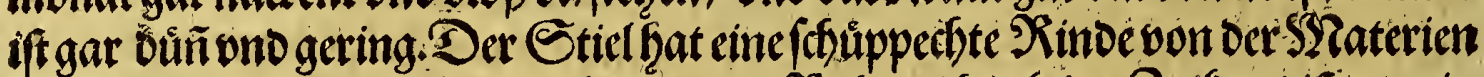

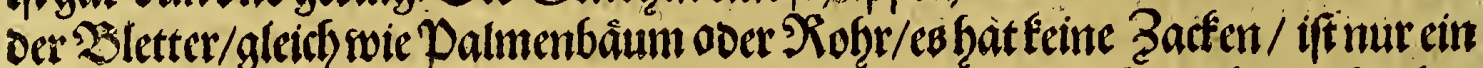
fracter Stengel/auffoer Dollen/tehet Der Samen/ift weich ond bein nahe eben

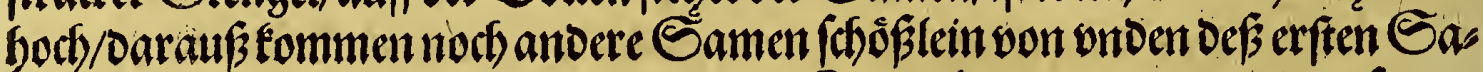

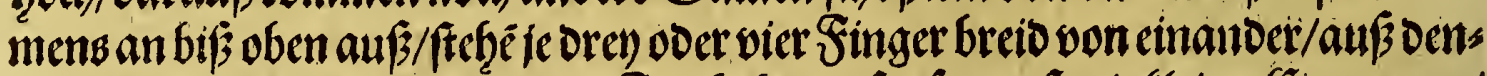

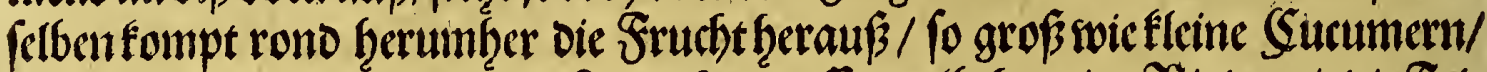

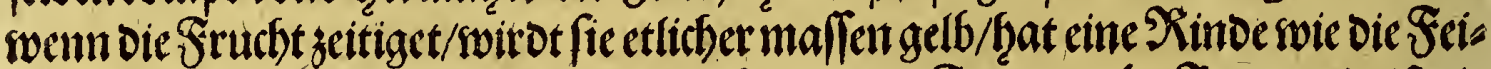

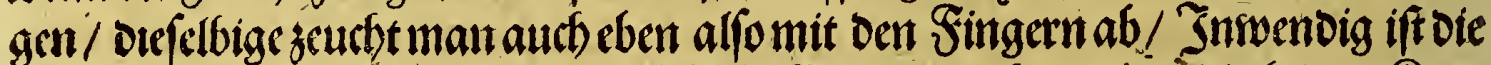

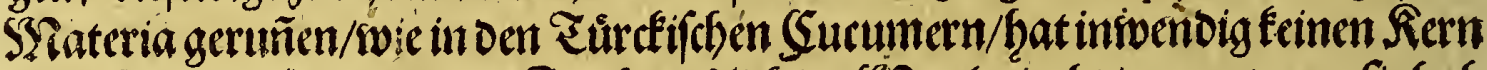

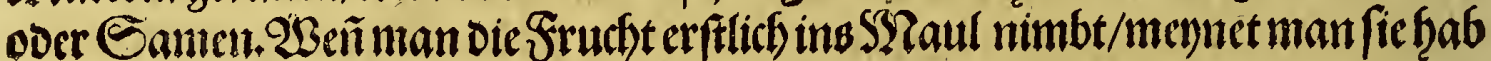

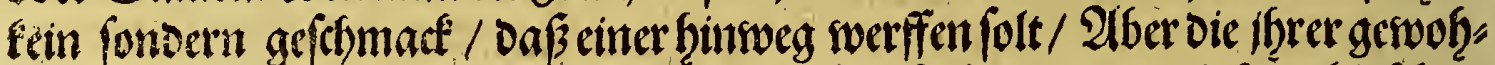

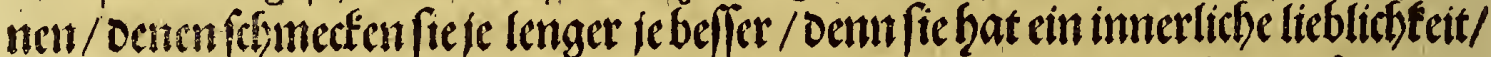

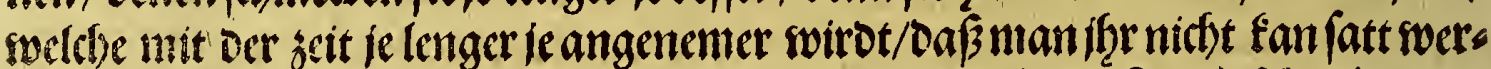

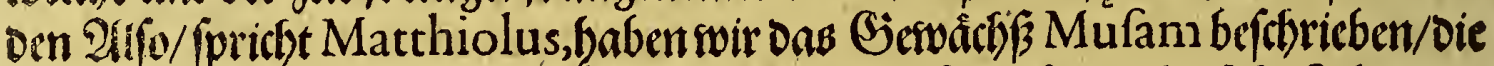

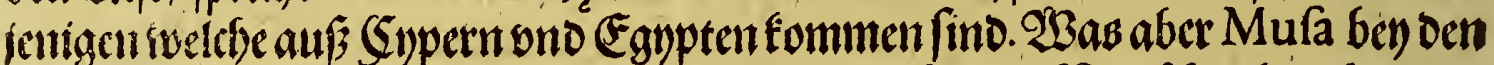

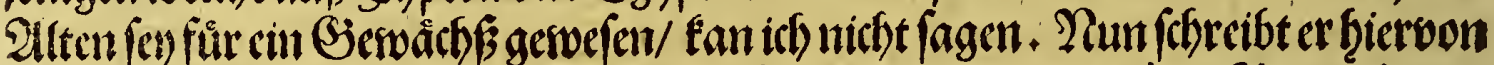

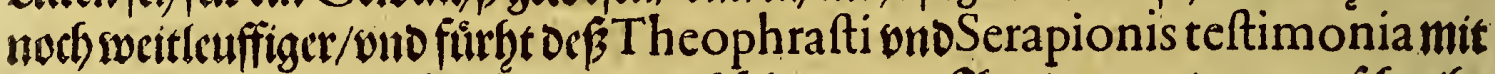

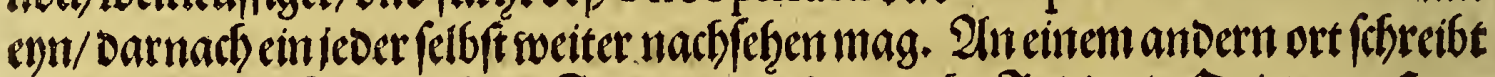
ar audb won ben Indianifichen Feigen/Da oeñ die rectite Jndien in Drient berftants

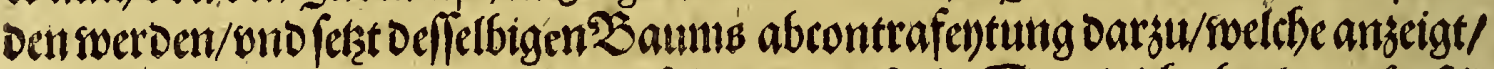
Dafisefen ein Baum einer wounderfelfamen geftalt. Danit icly aber ben gůnfti:

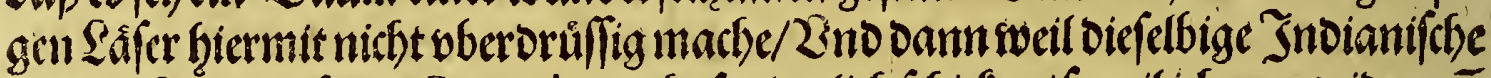

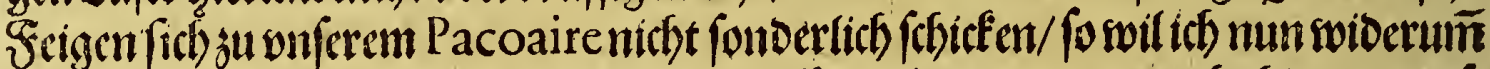

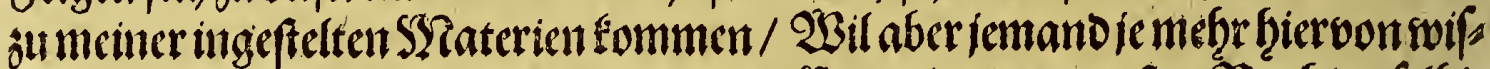

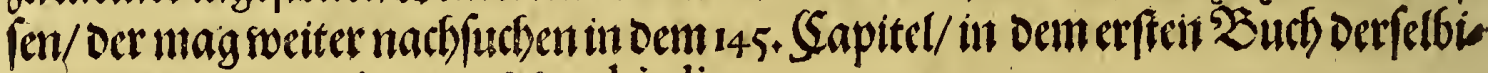
gen Commentariorum Matthioli.

Xyla Bànme lem Daran Die

Banumwoll

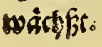

Amexi-iokir Soumbolls:

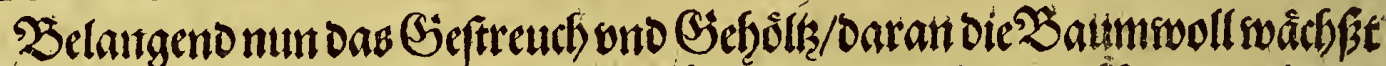

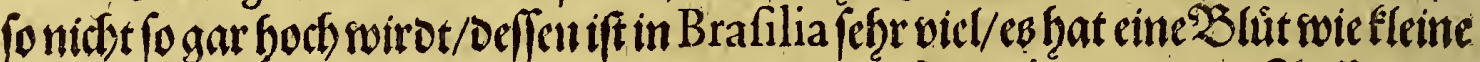

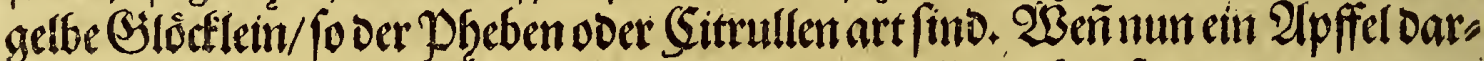

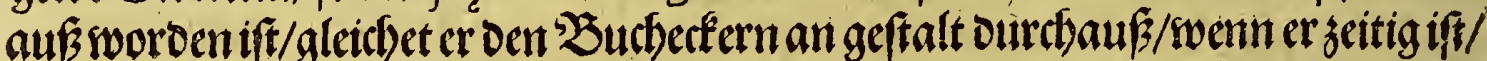
theilet er fich in wier theil/Darauß ift Die Baumwoll/welebe oie WBilden A meni-iou nennen/mitten in oen/elbigen

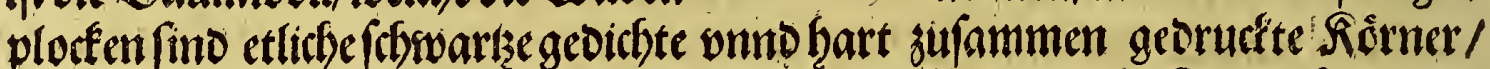

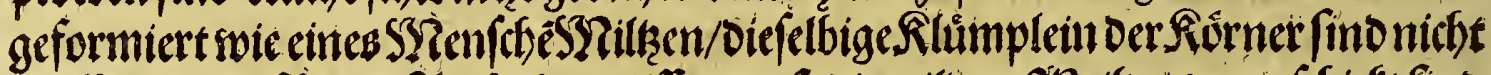

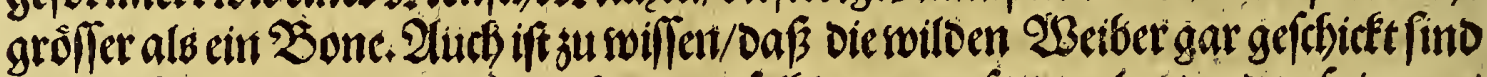

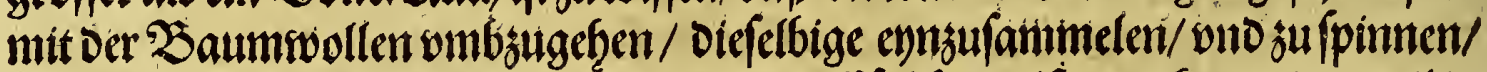

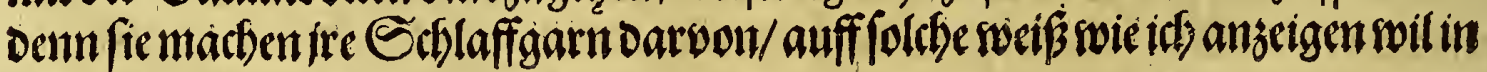
folgenden Sapitelit.

Fun ob wol vorzeiten/ woic ich Dennoernommen / Feine Pomeranken ober

Sitronen 


\section{Daa britte Tretil.}

179

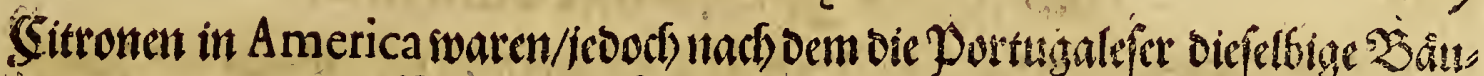

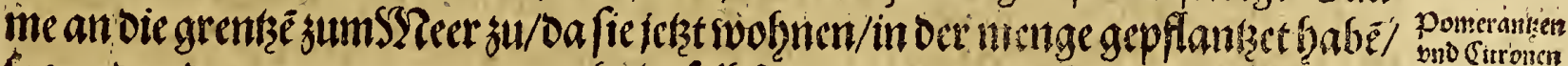

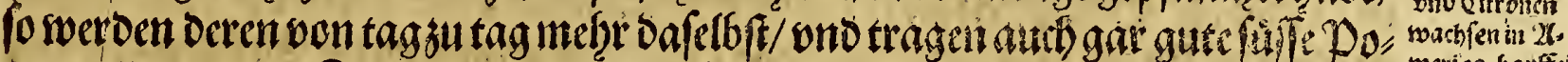

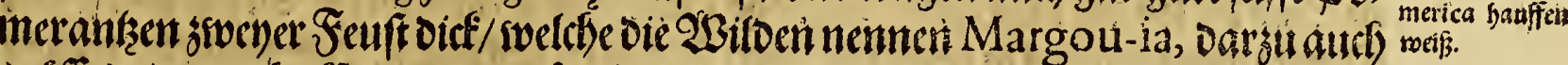
grôffere bno mehr Sitronen als onftert.

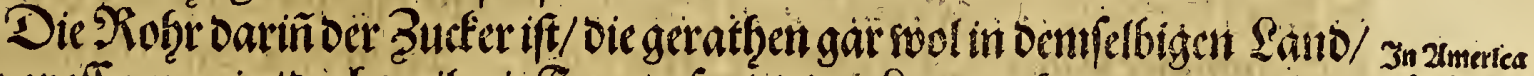

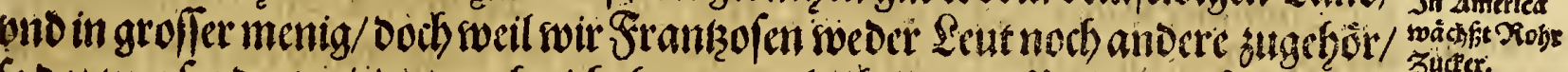

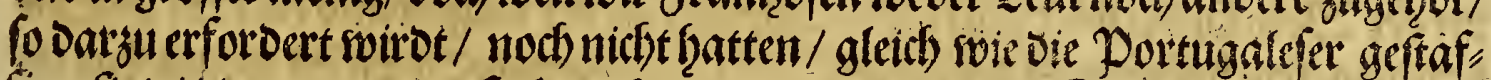

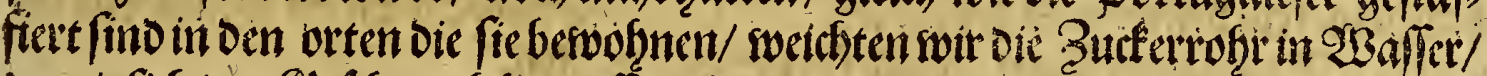

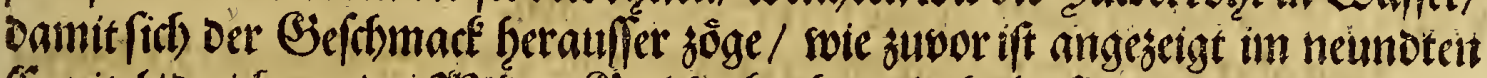

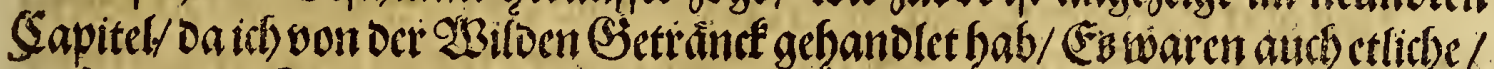

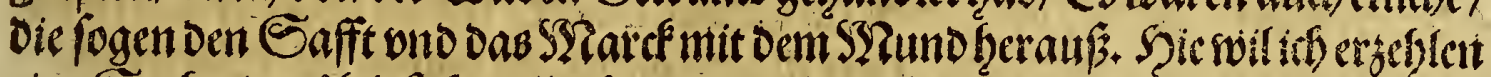

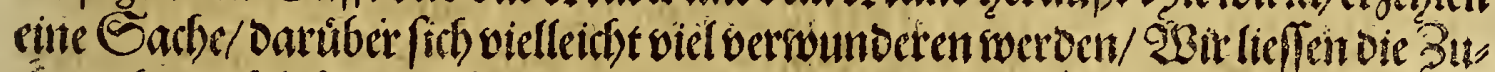

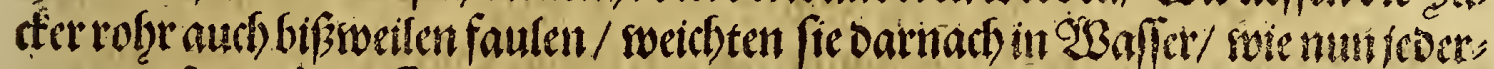

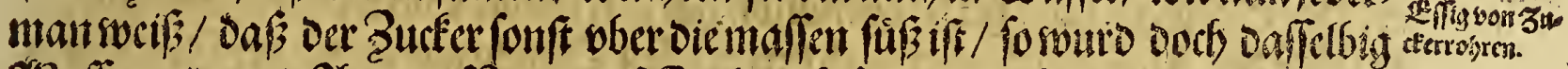

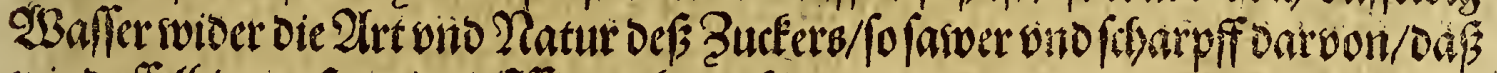
wir baffelfig an fat einte (Effige gebrauditett.

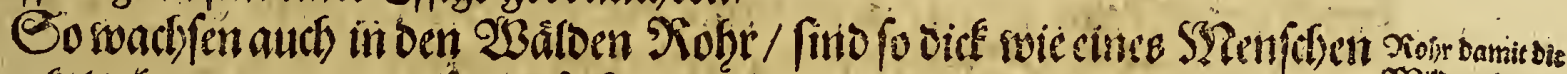

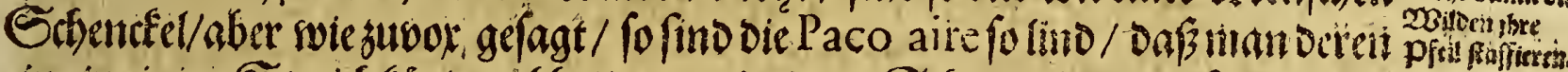

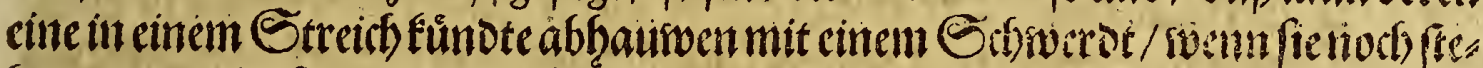

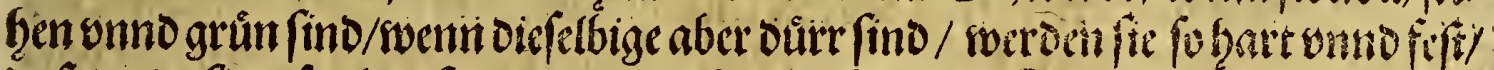

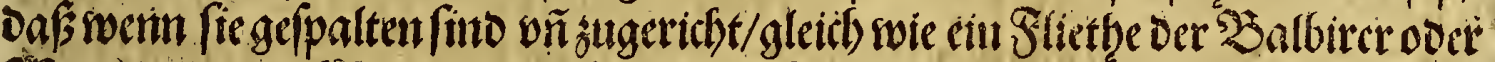

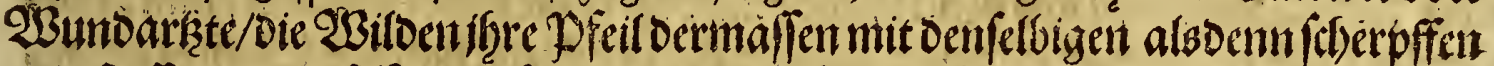

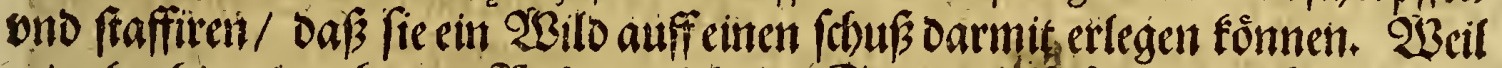

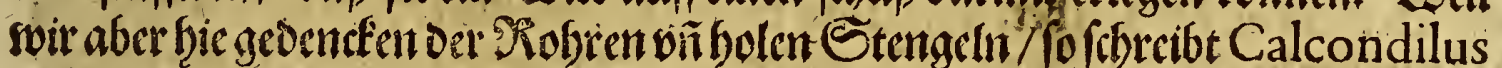

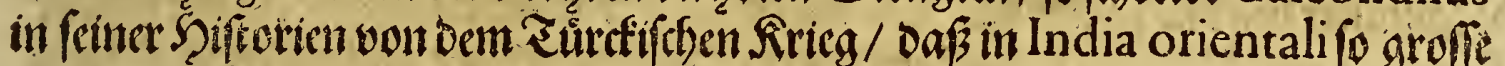

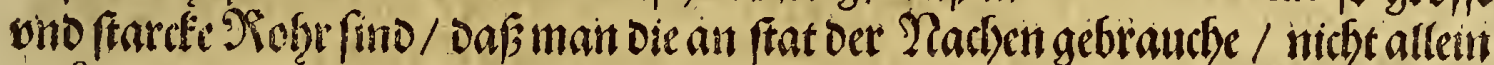

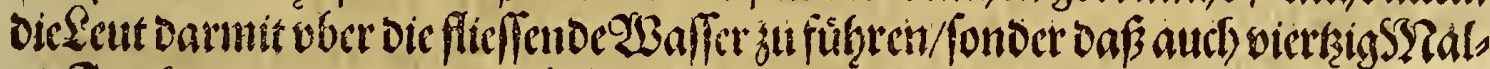

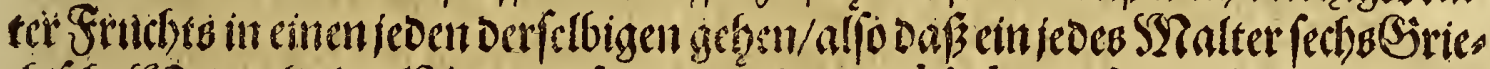

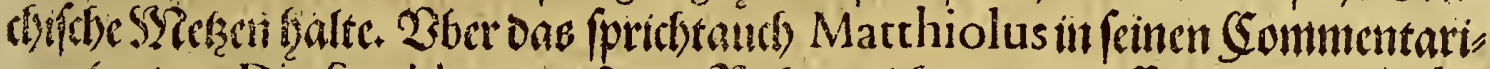

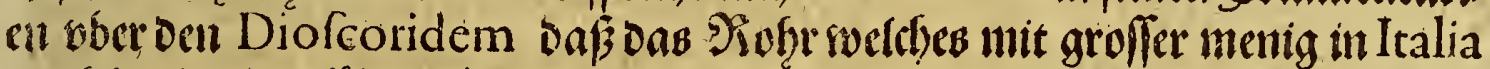

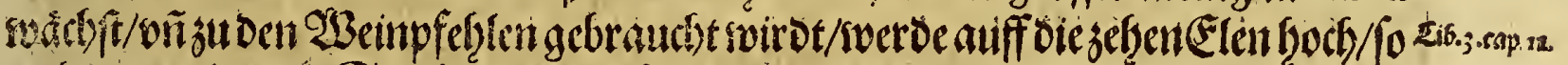

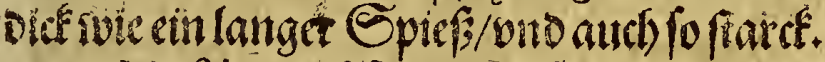

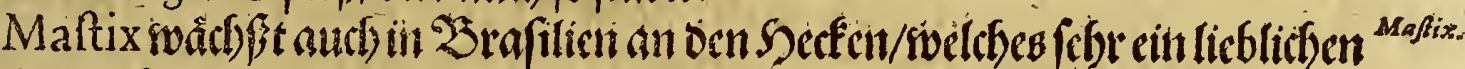

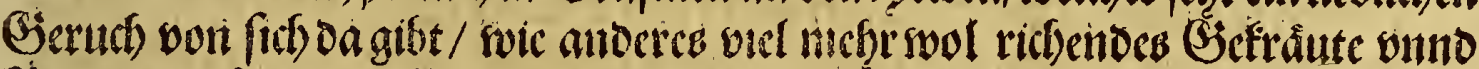

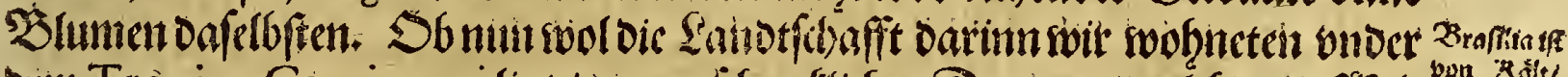

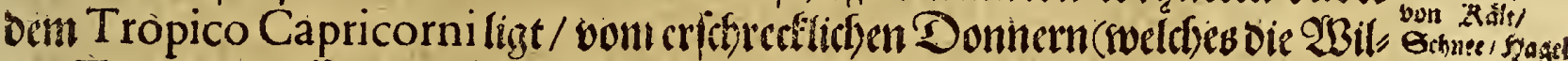

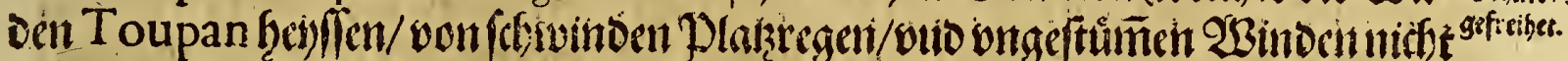

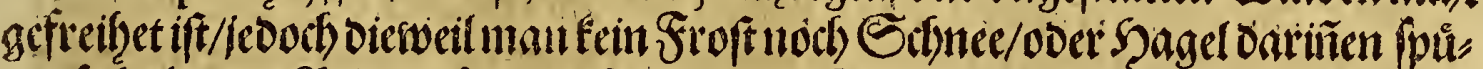

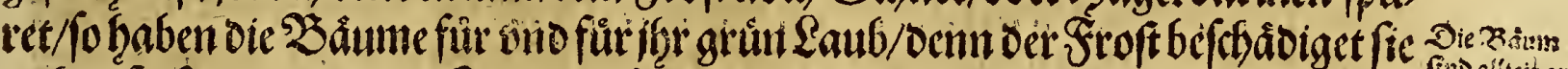

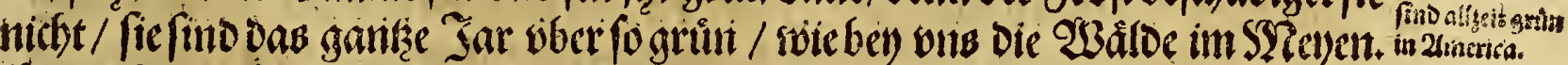

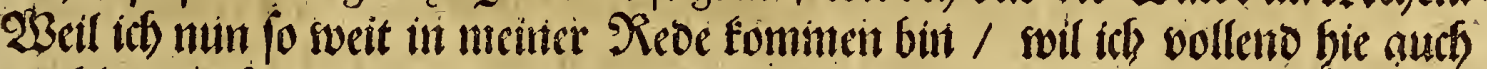

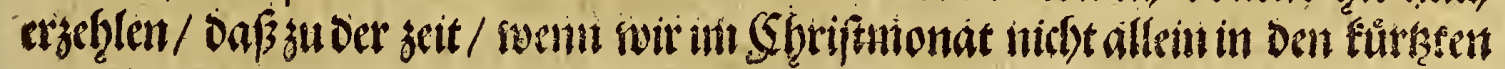




\section{Das britte Sheti.}

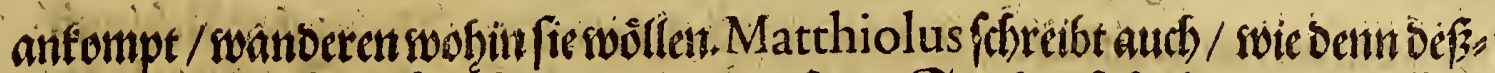

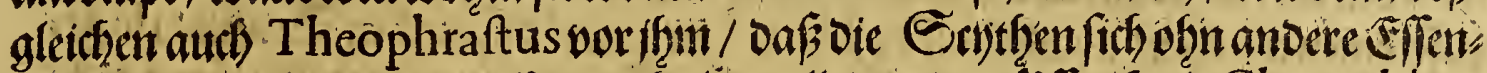

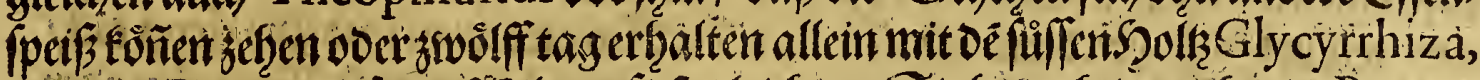

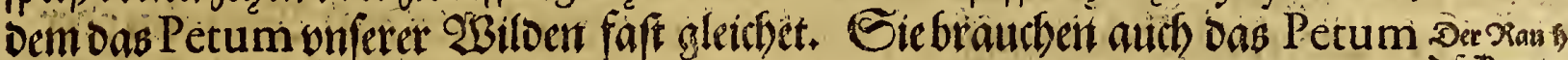

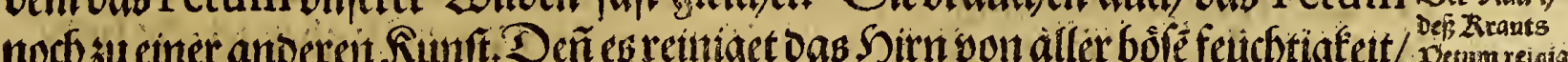

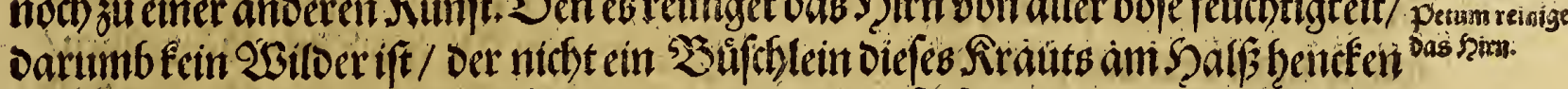

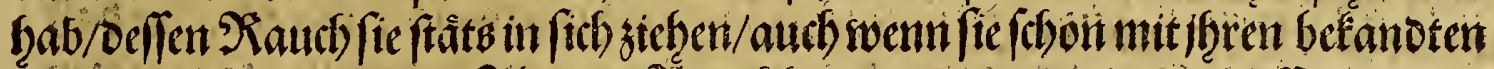

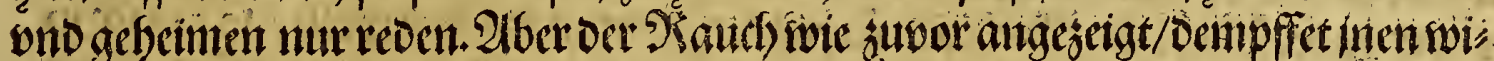

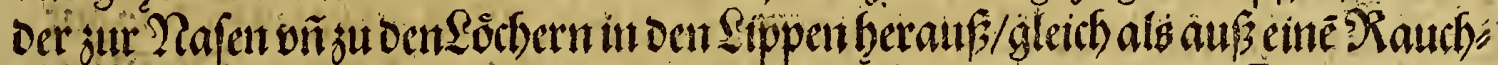

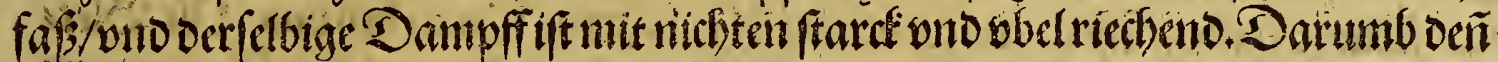

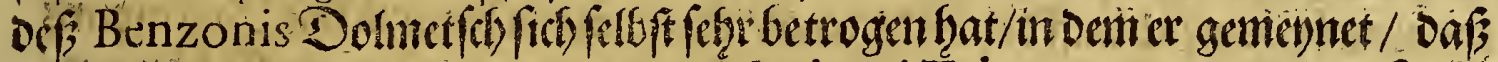

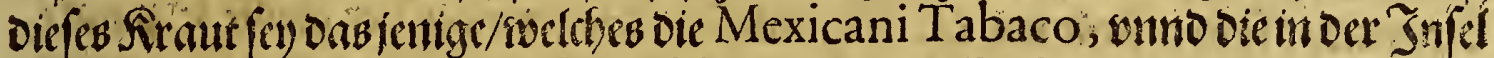

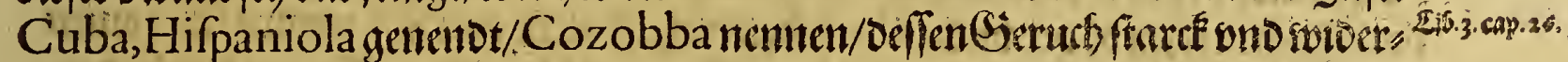

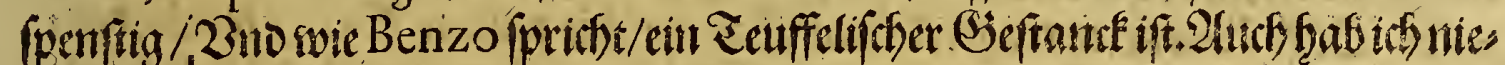

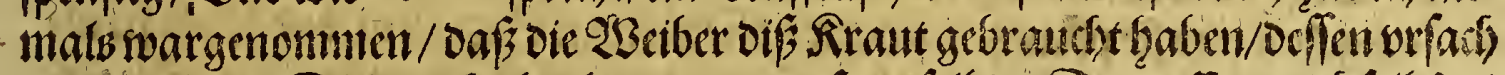

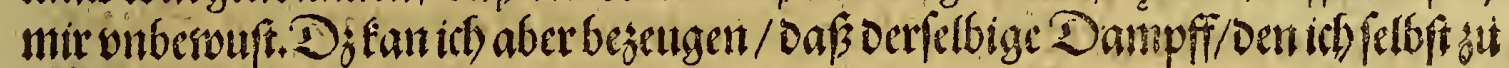
mir genommen/ oen funiger mit geroalt wioerfethe.

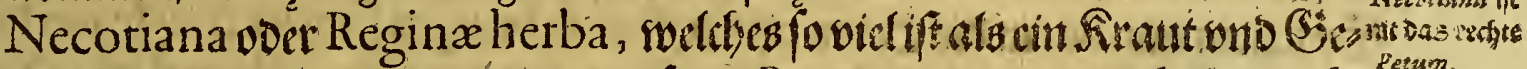

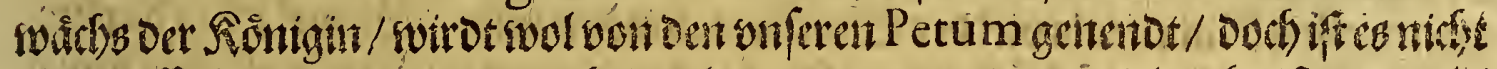

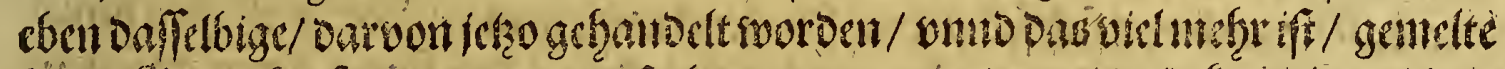

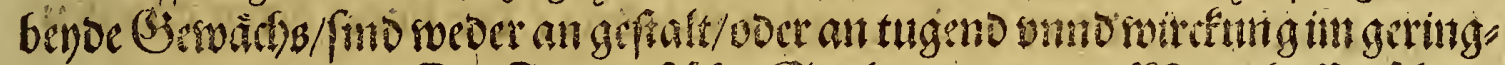

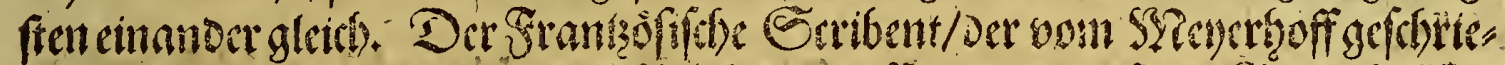

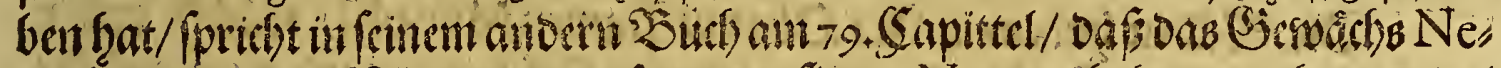

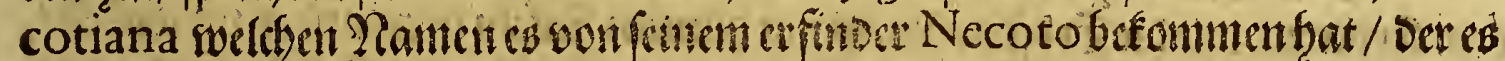

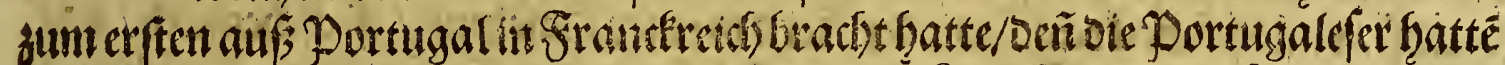

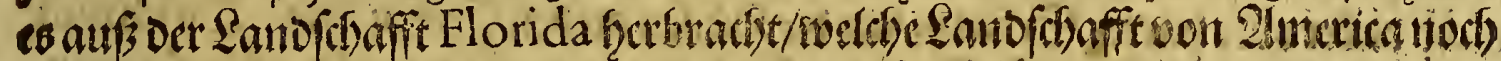

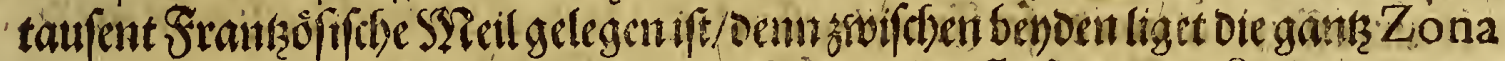

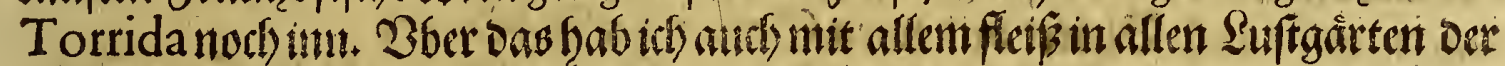

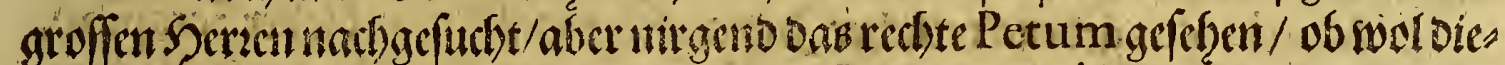

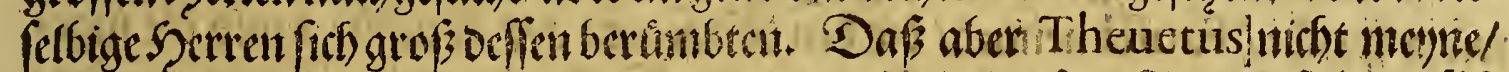

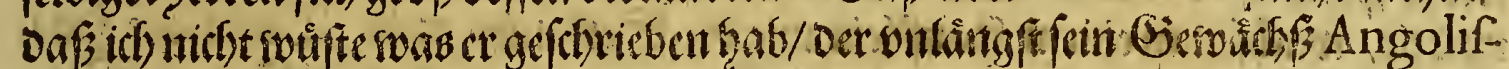

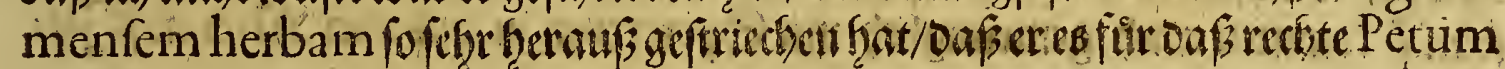
Dorffte ausgeben / fo balt ith eben audb alfo oarbon/ swe von oer Necotiana. Denn bic abconterfeitung/ oie er in feiter Cofmographifaat laffen abreffen/ weift viel anders aus

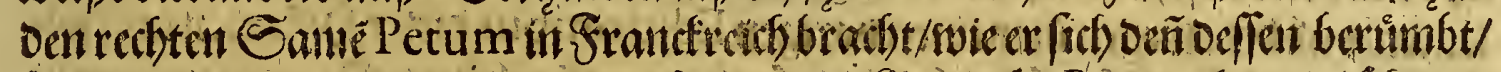

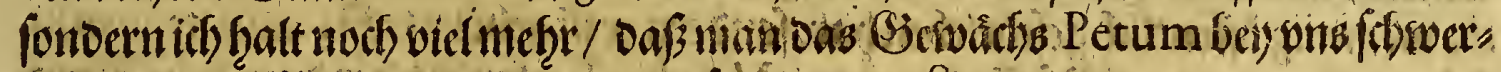

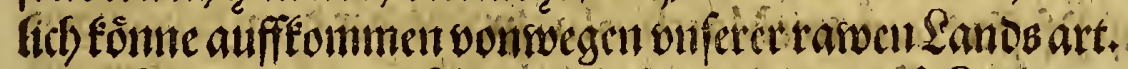

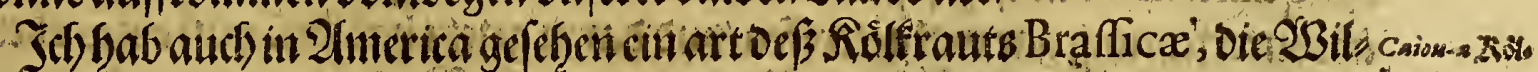

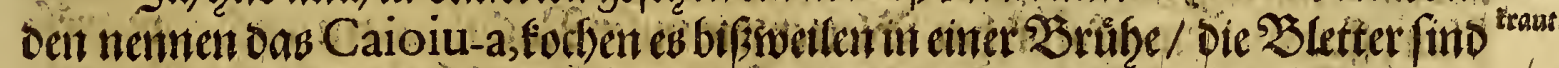

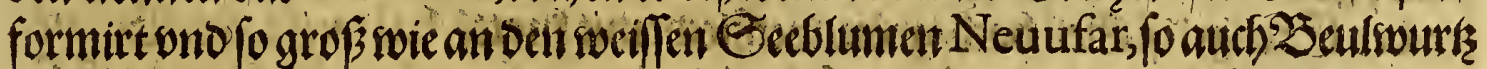
genanotift.

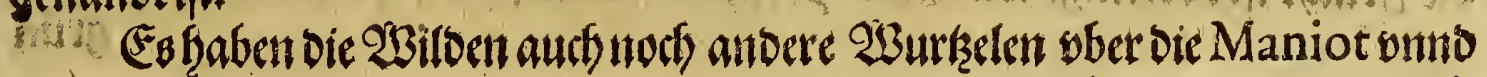

D. Aypi,


182

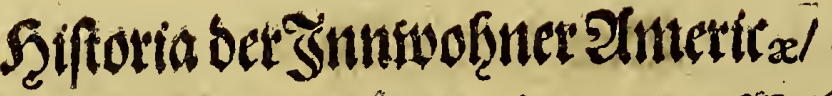

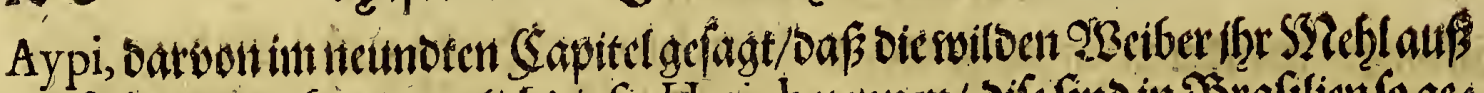

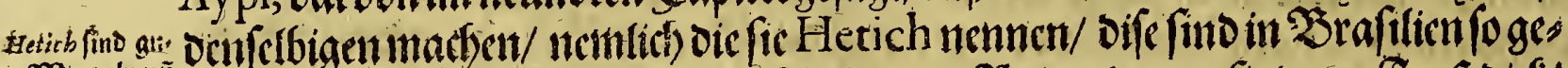

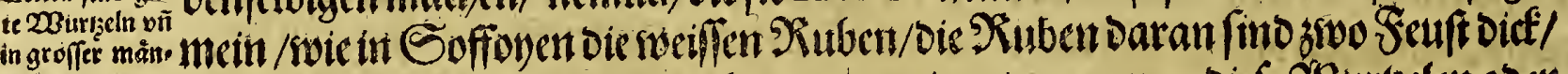

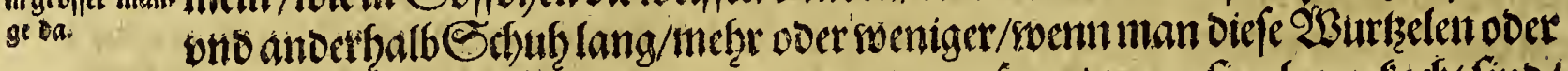

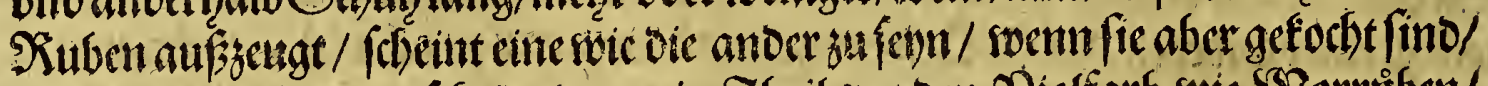

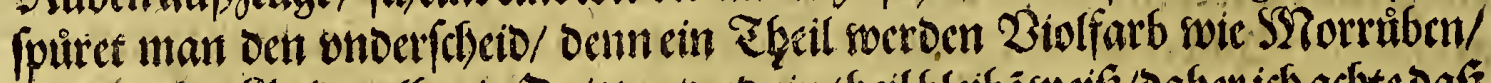

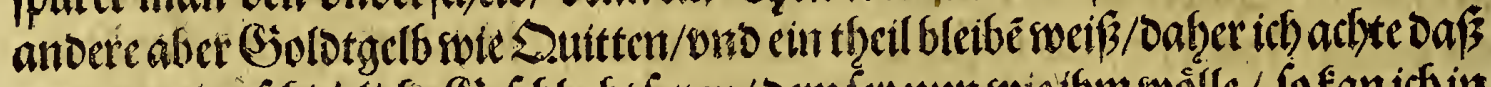

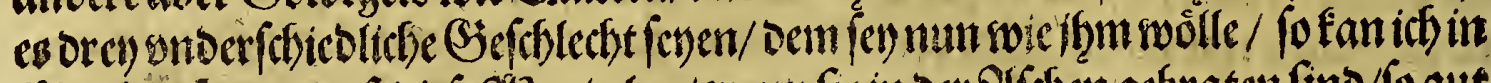

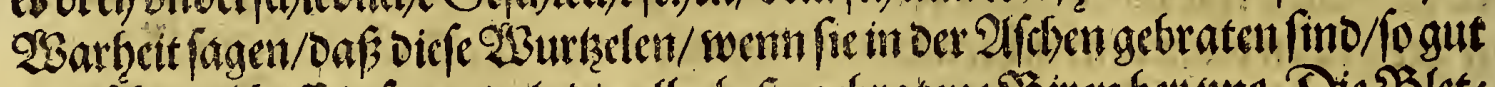

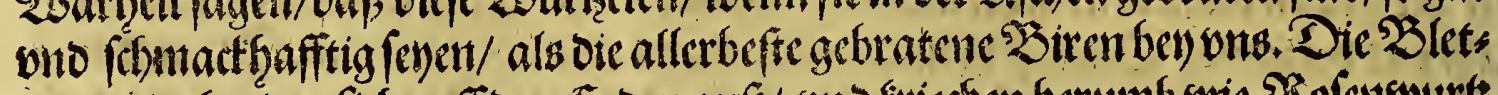

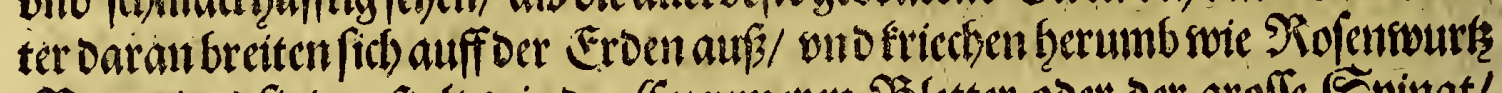
(Bryouin) fino geftalt swie oer Sucumeren Better ooer oer groffe Epinat/

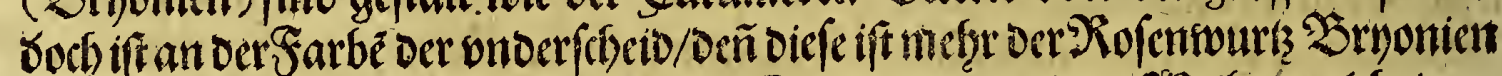

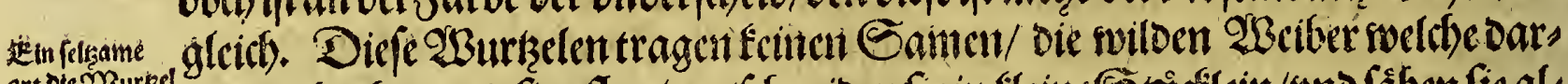

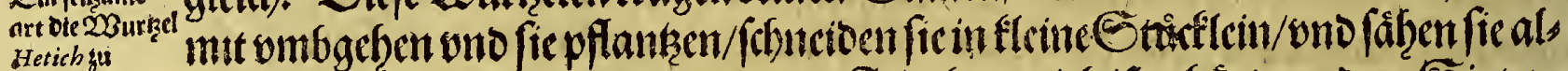

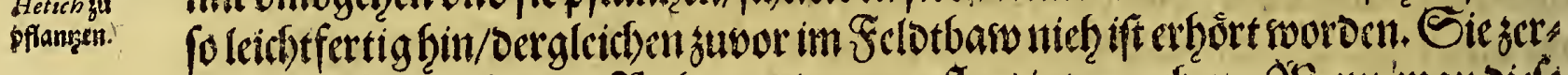

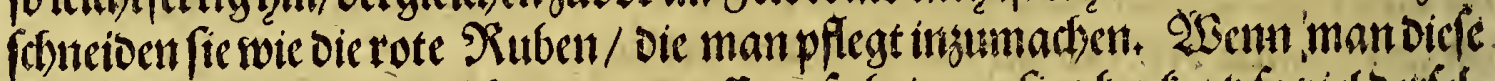

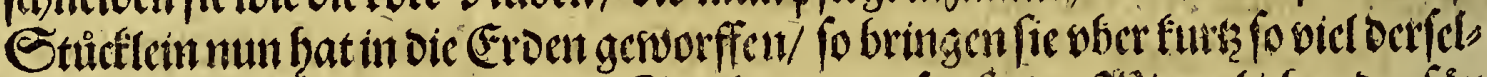

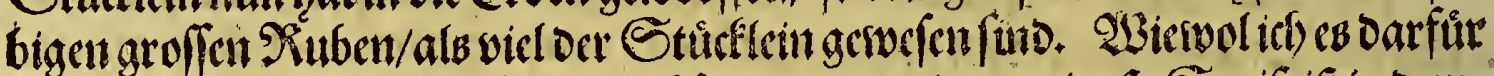

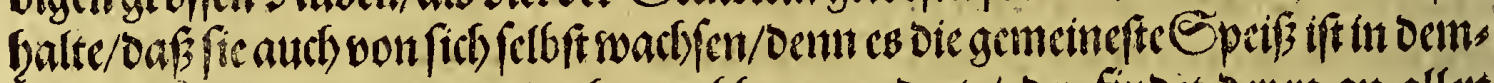

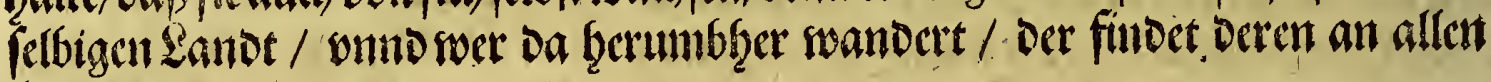
Orter.

Lanobi elin are

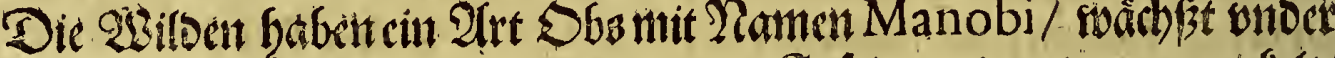

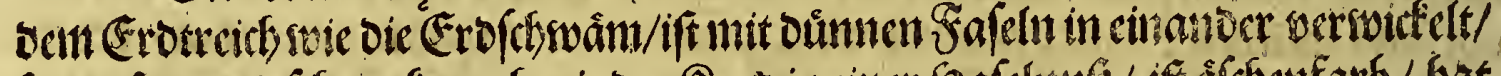
cer 2 reren

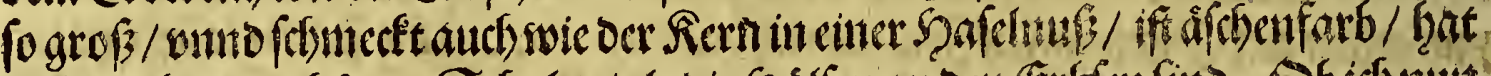

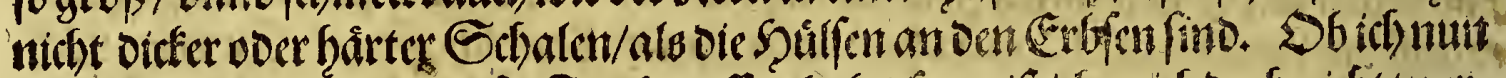

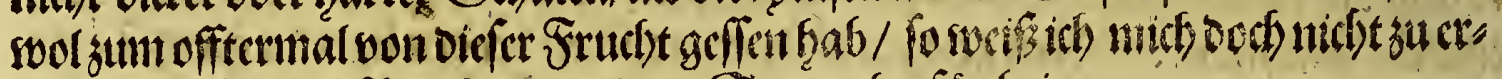
muerw/ob/ic audi Bletter buto cinen Samen farfur bringen.

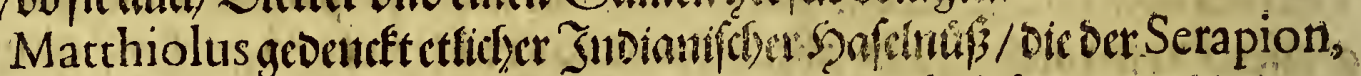

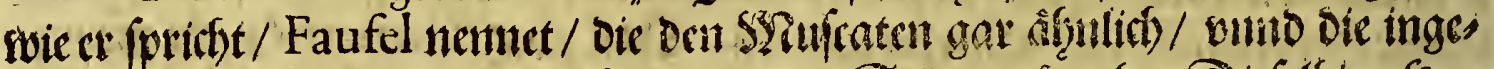

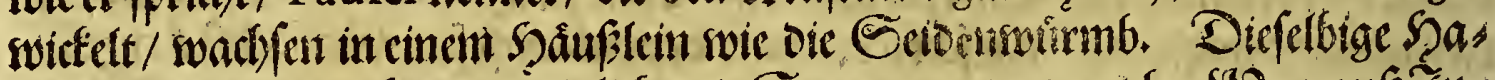

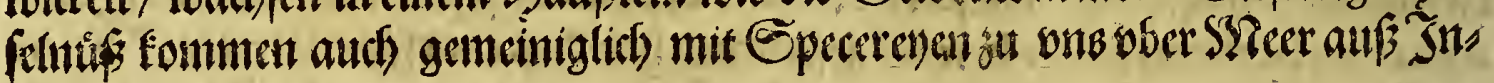
Dia.

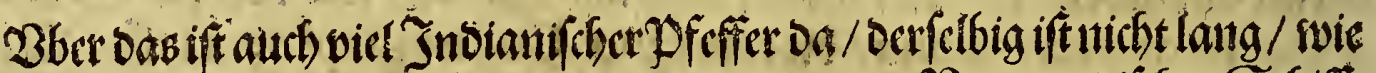

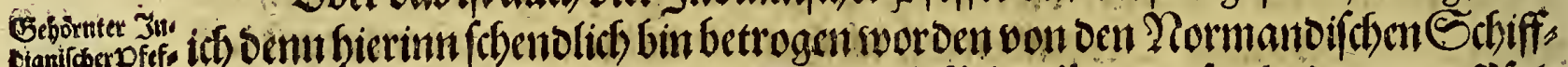
ter.

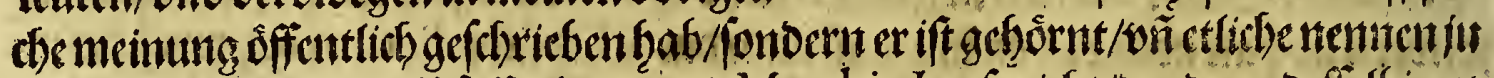

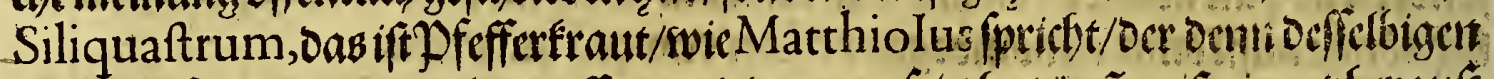
abconterfentung gar wol getroffen/onto oarju geferst bat/ocri cs ift cincs bberatis

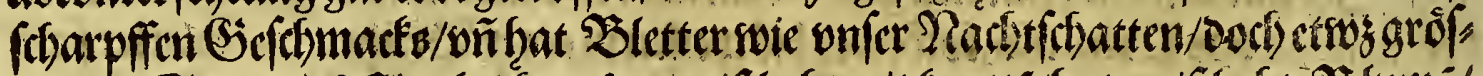

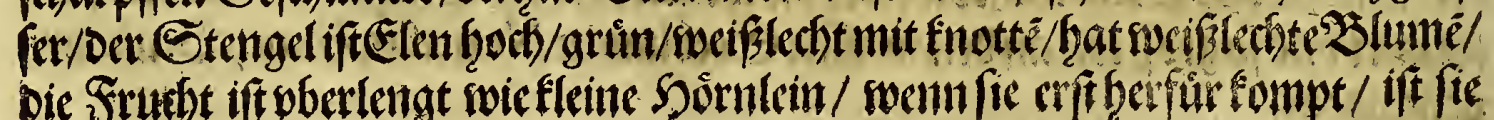
grư 


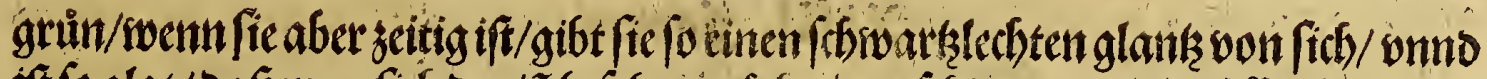

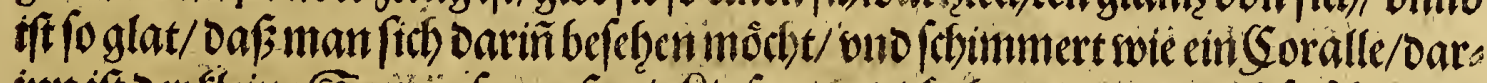

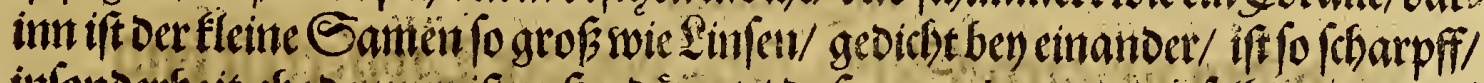

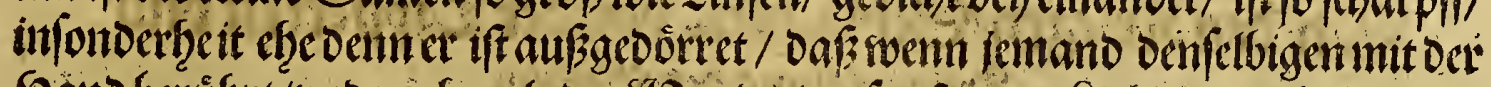

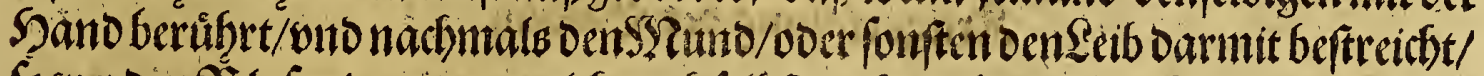

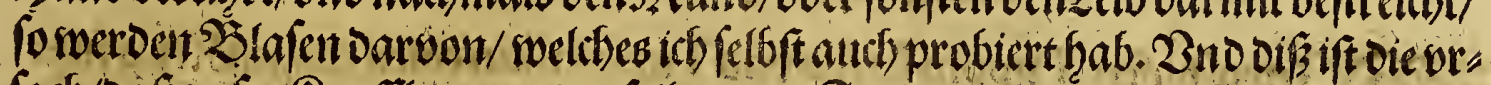

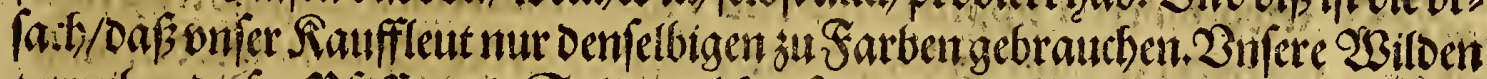

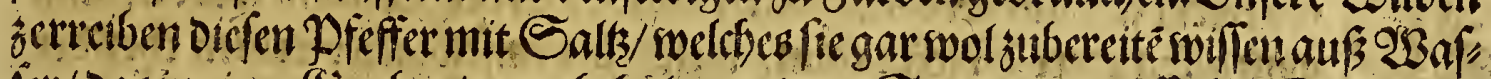

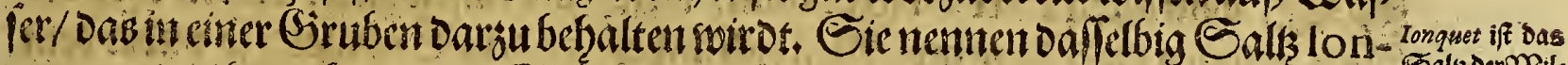

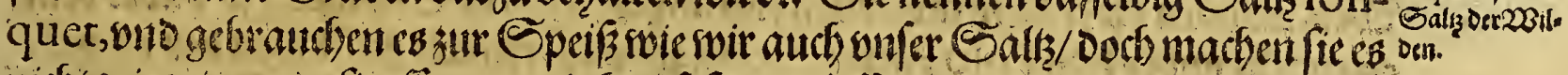

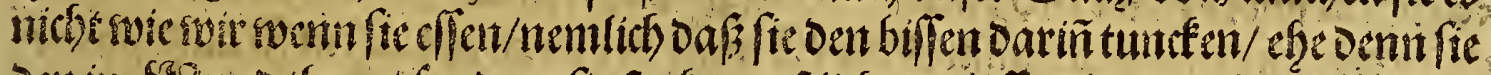

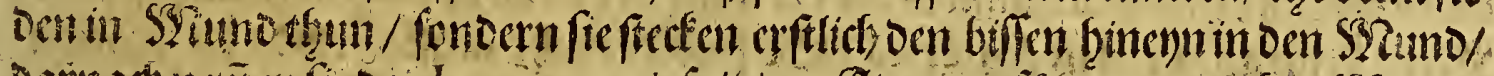

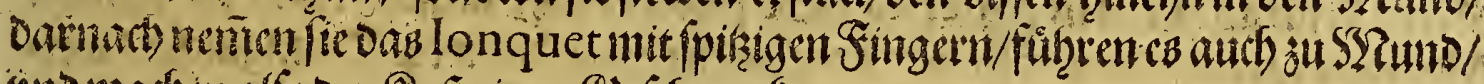

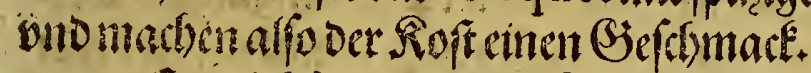

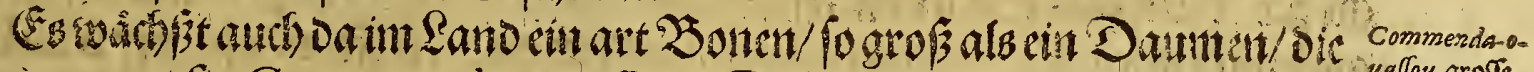

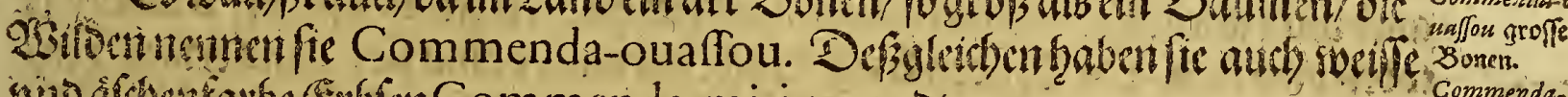

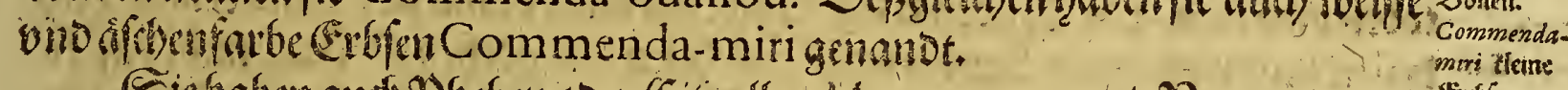

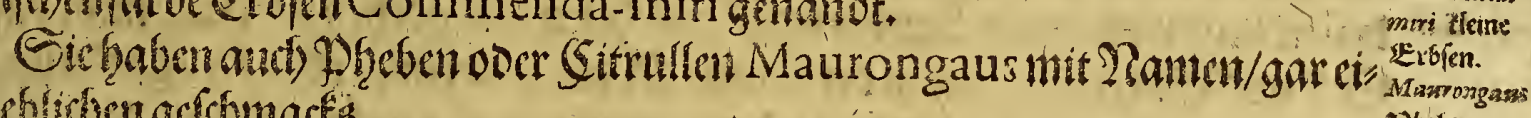
neslicblitiongefomactis.

Govid iftemm/ oafich in citten Jar pon 5 .

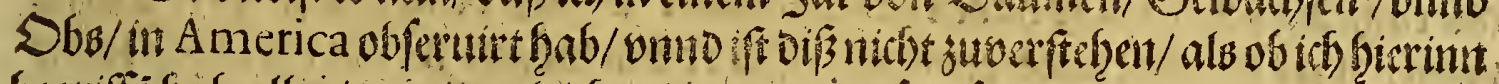

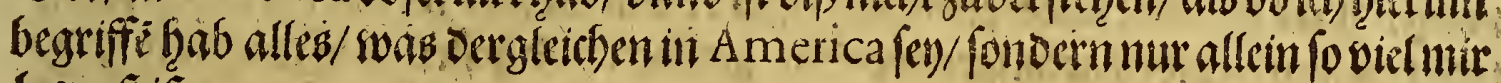
berouftifit.

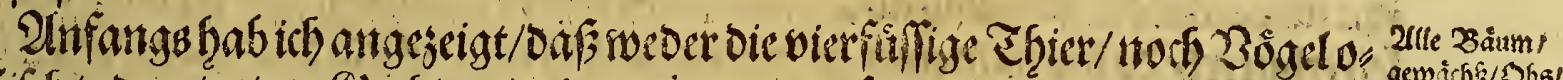

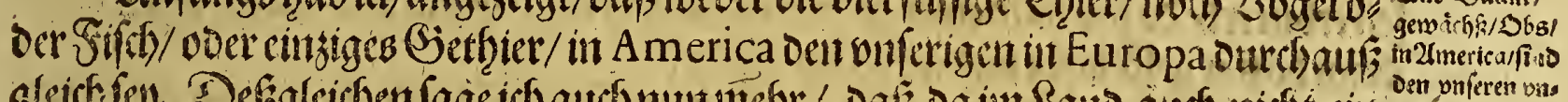

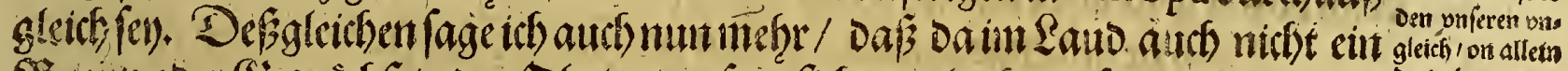

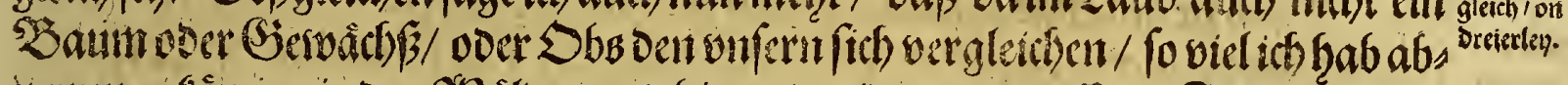

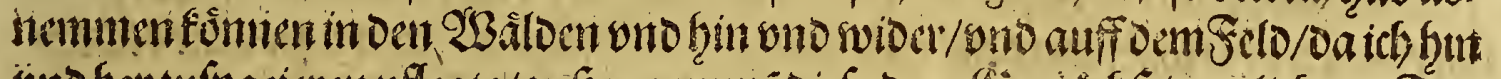

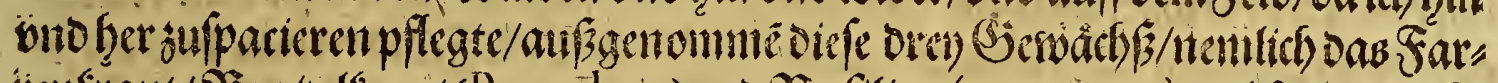

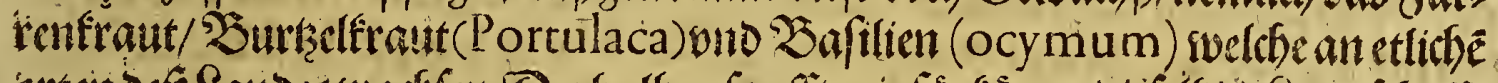

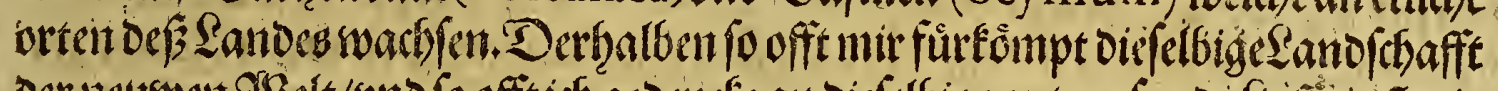

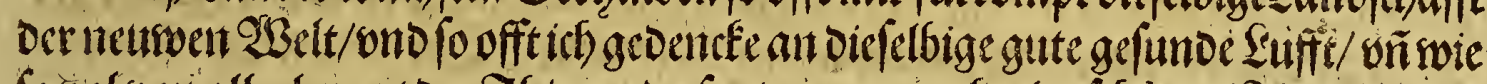

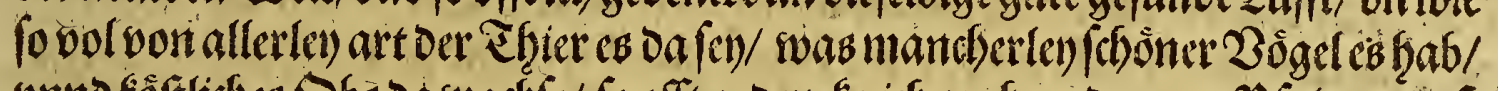

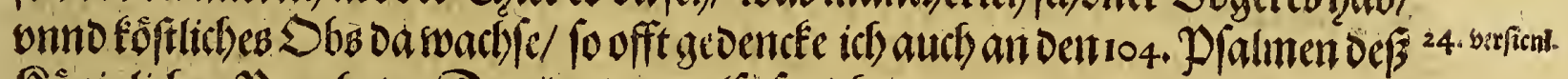
Fôniglichen Propheten Dauios/o a er alfo fprict)t:

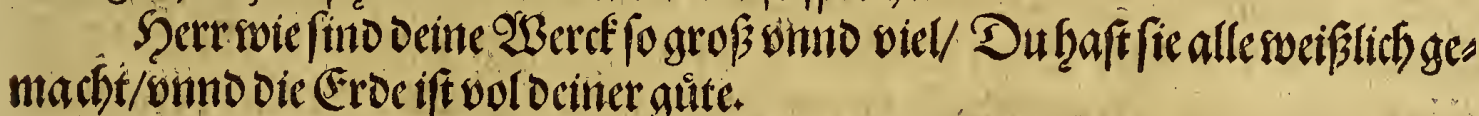

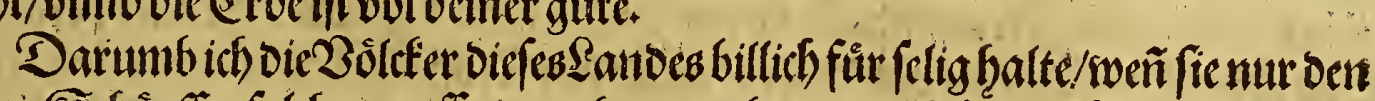
waren Eebopffer folcher groflen gutthaten erfennen mö́d)ten. QSil nun fürter

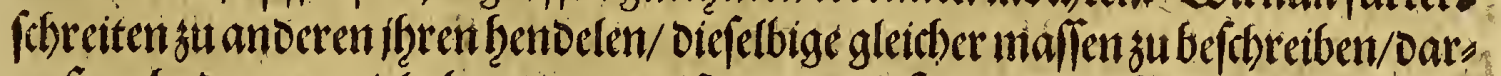

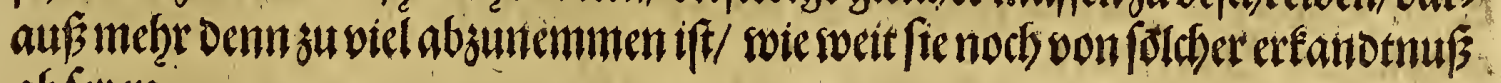
abjeyen.

$$
\text { D. ii XIIII }
$$




\section{Das britte Theil.}

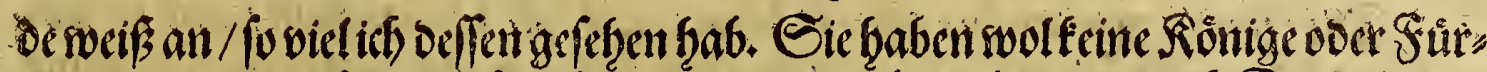

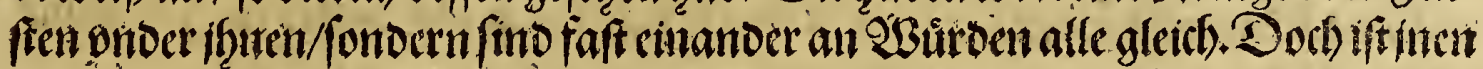

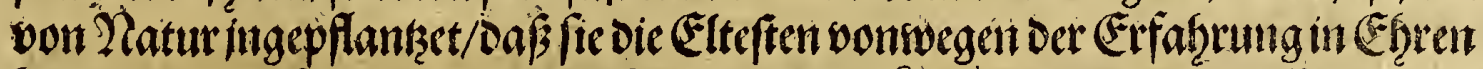

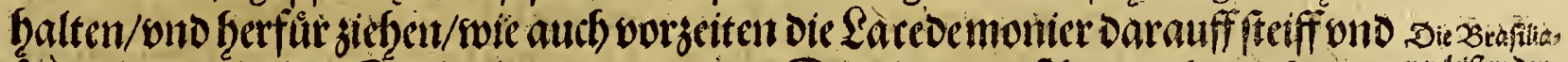

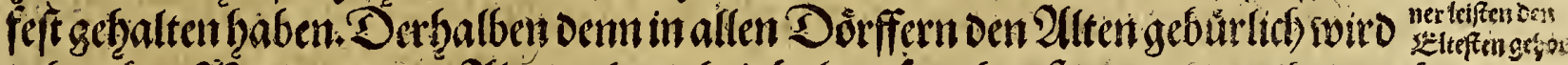

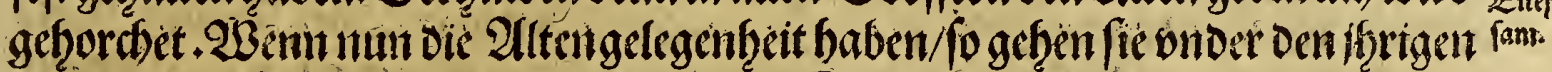

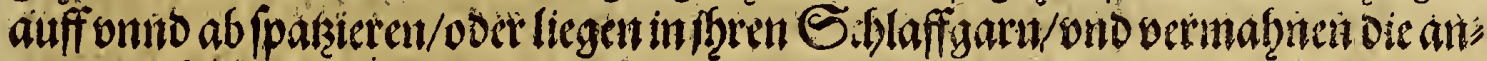

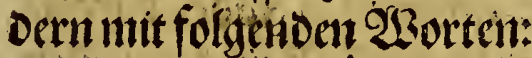

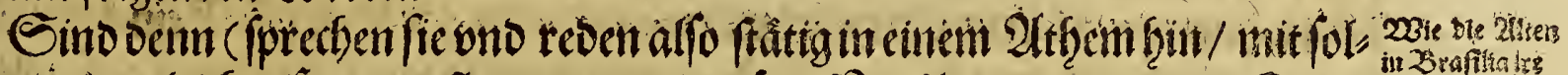

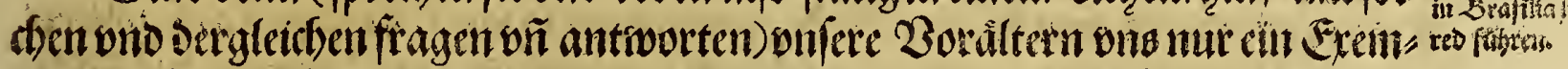

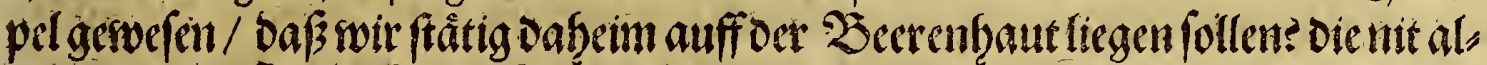

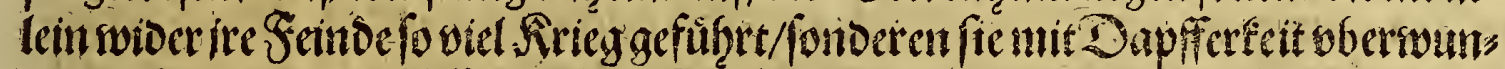

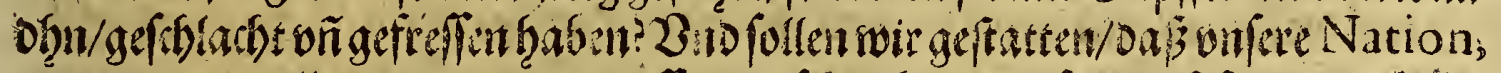

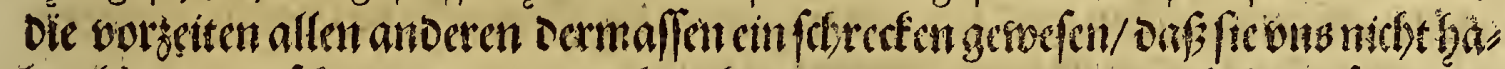

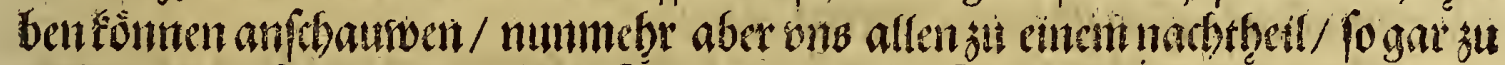

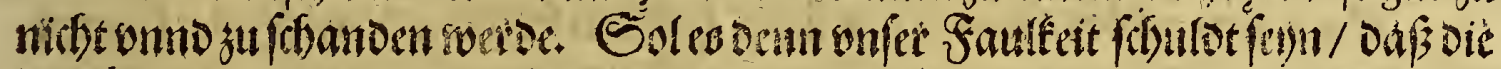

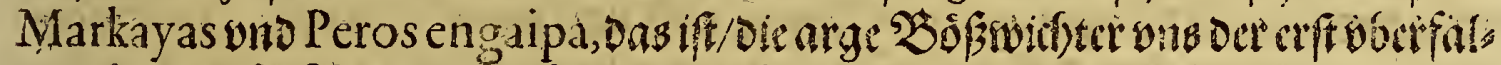

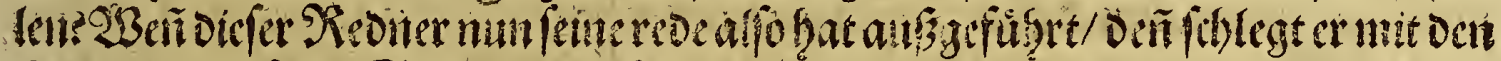

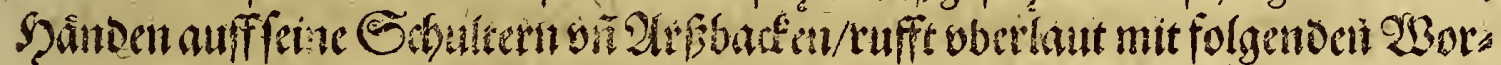
tèn. ErimaErima Tuppin Imba, Canoni ouaffou Tan Tan;iffovicl gefagt:

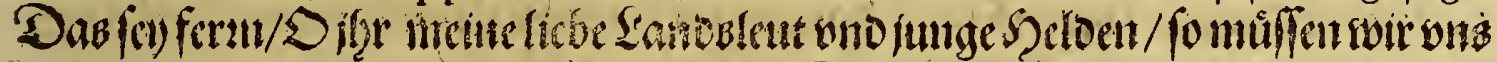

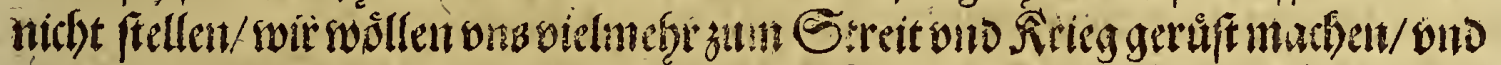

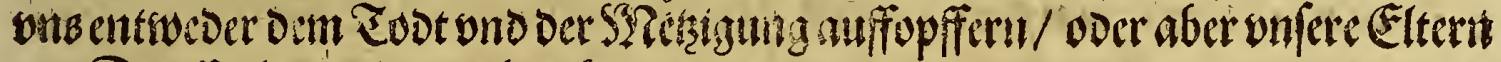
mit Dapiferfert soloerumb rectiel:

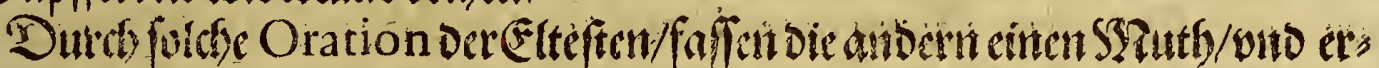

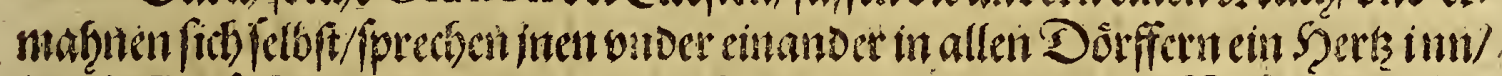

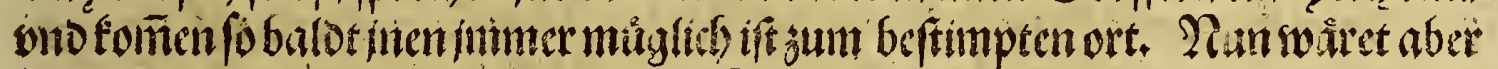

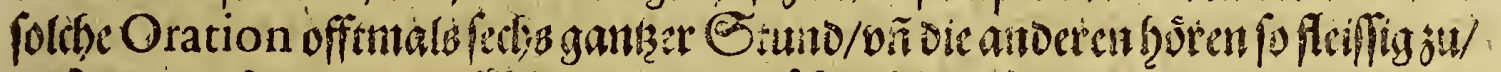

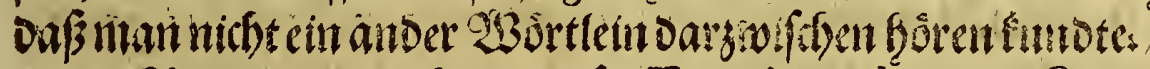

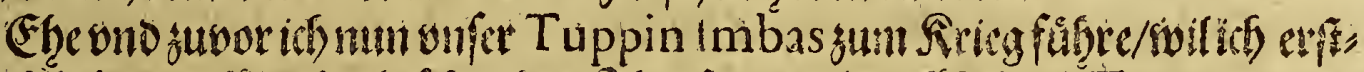

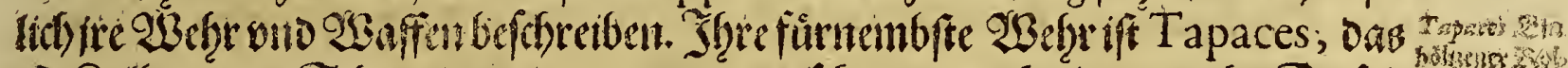

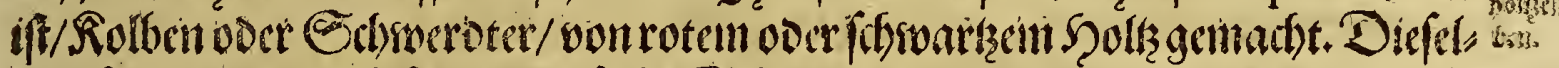

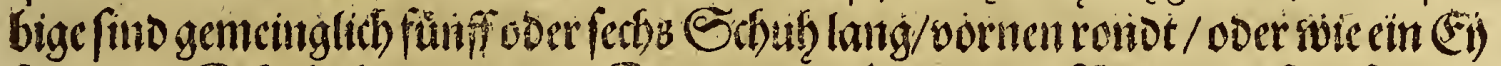

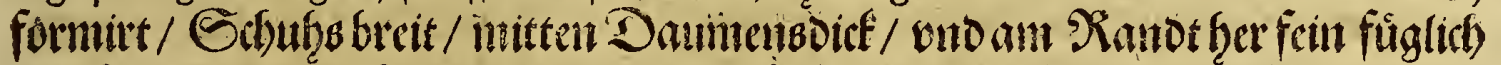

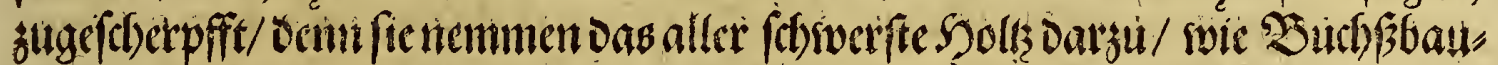

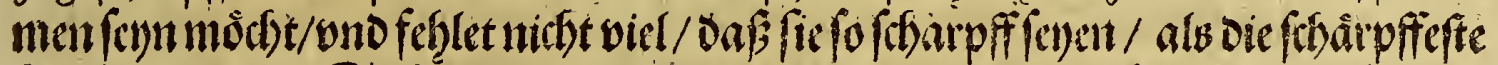

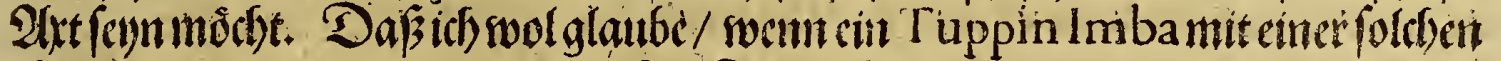

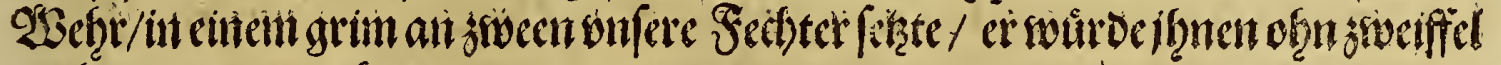
sut thut genug madben.

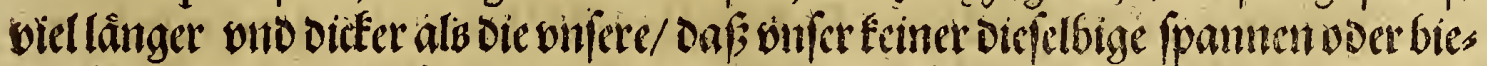

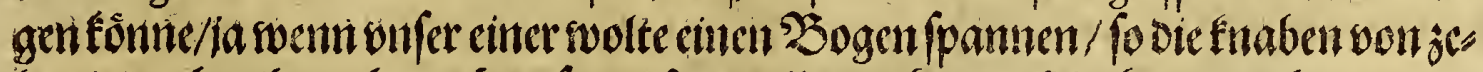

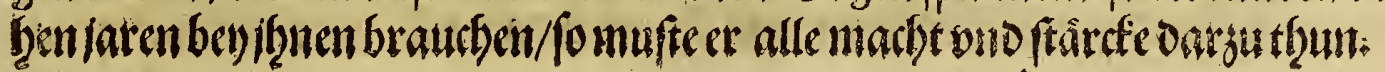

D. iii Dic 


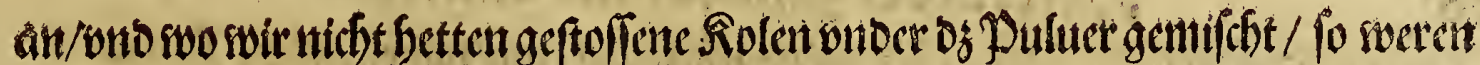

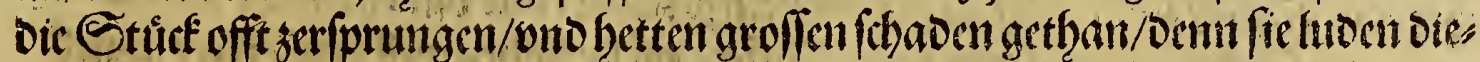

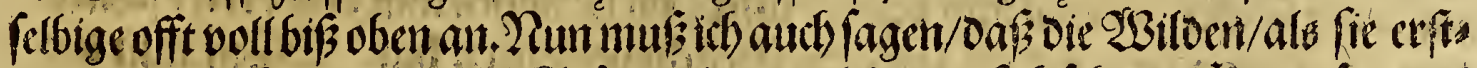

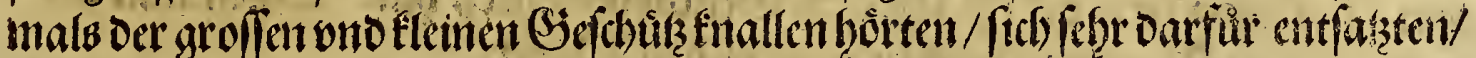

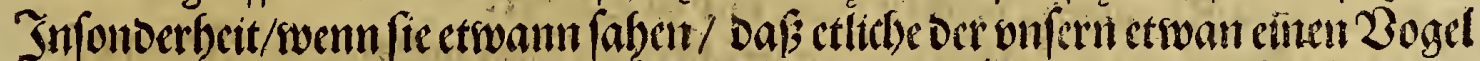

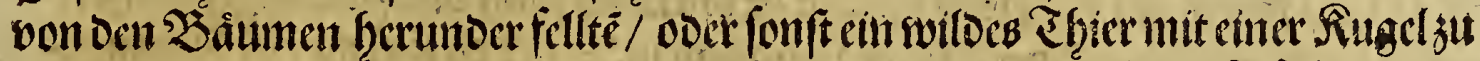

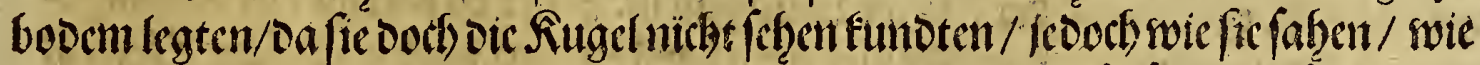

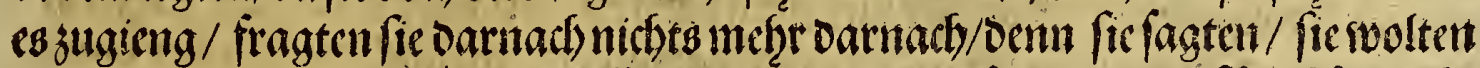

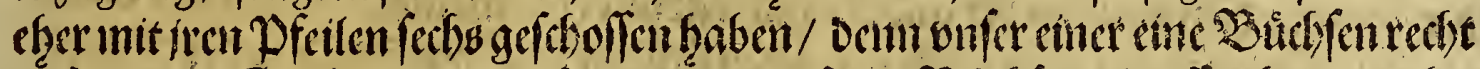

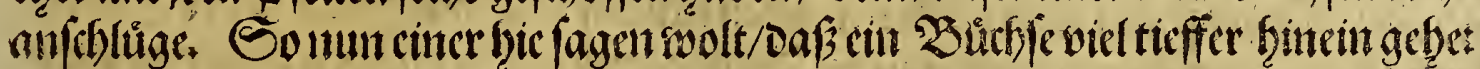

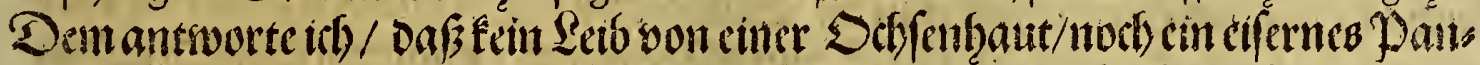

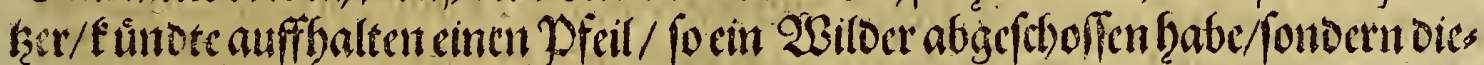

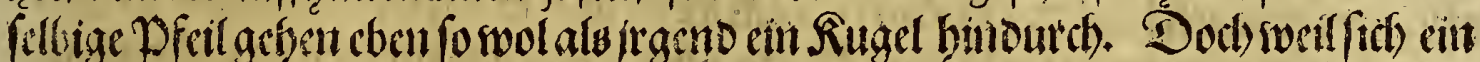

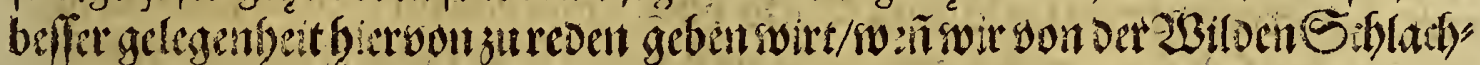

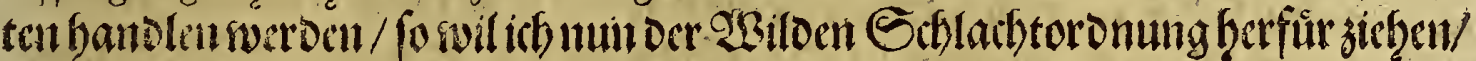
vuboarfreliw/ Danit chib auff bab ander beffer folgen mige.

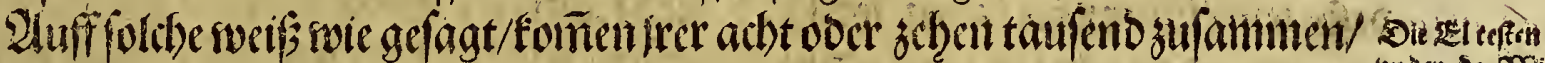

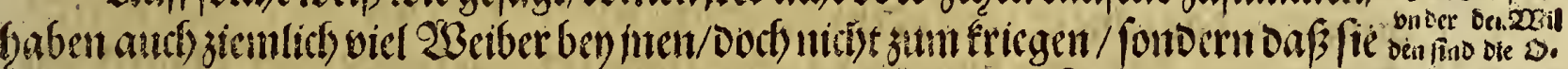

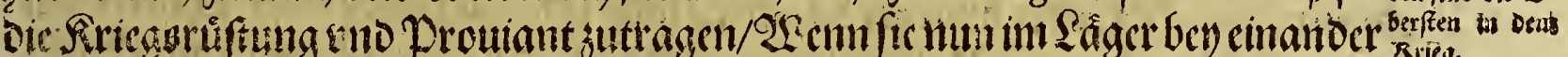

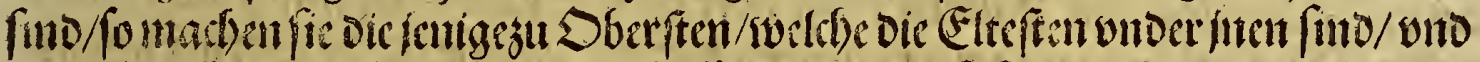

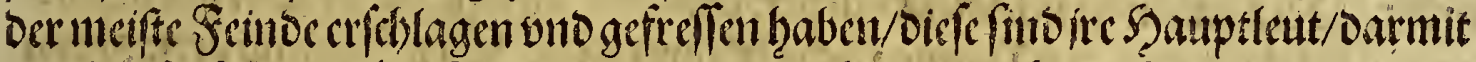

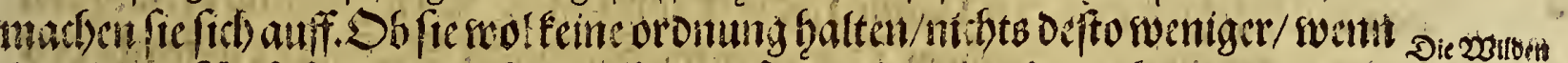

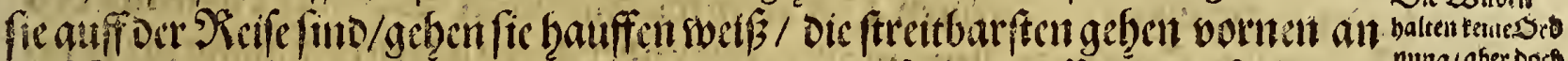

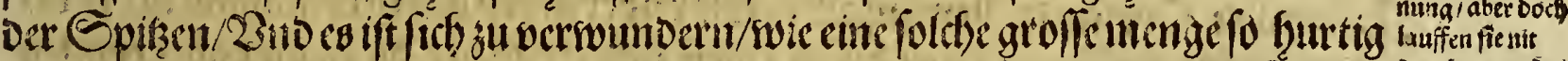

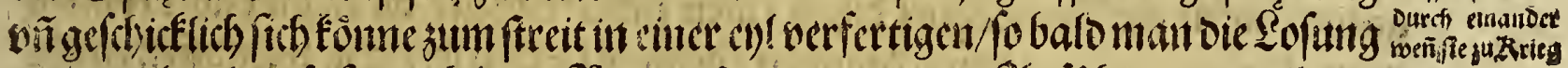

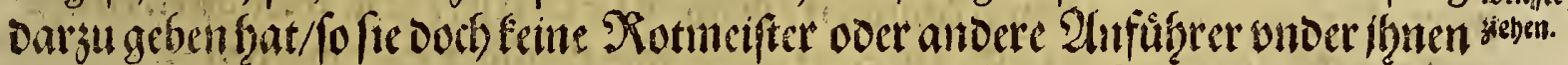

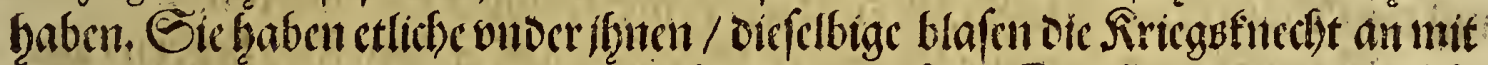

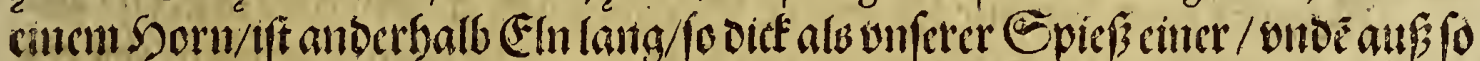

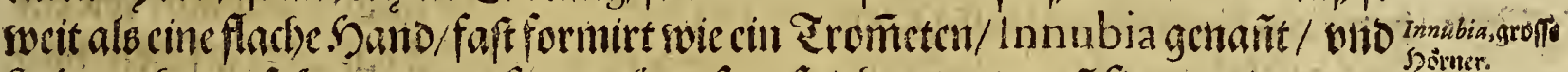

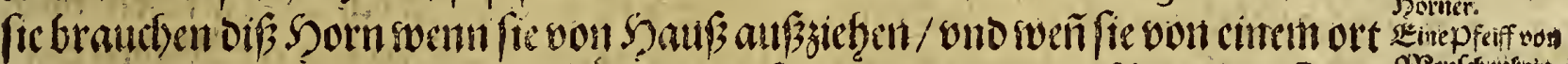

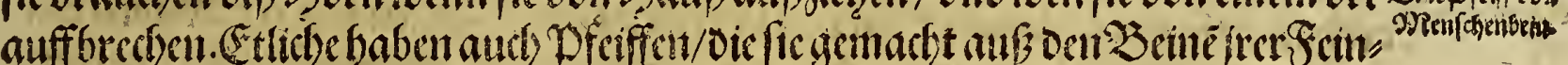

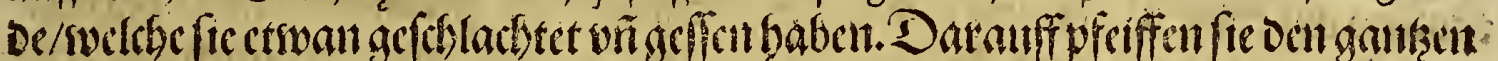

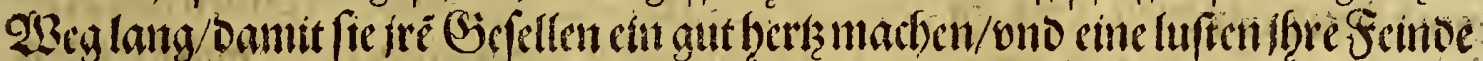

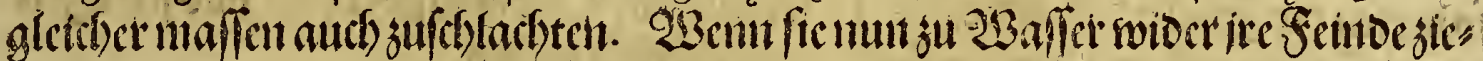

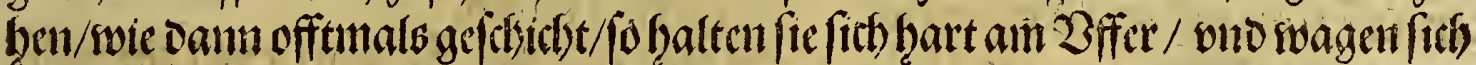

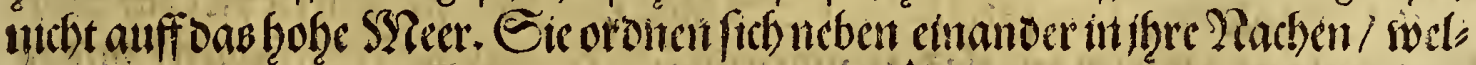

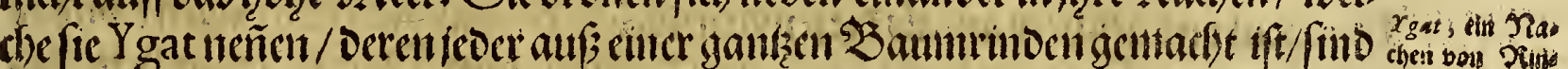

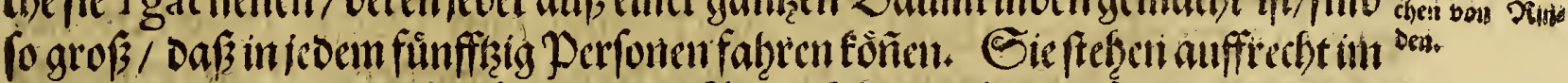

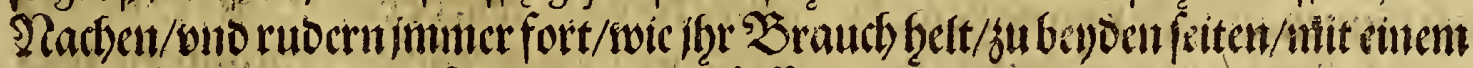
breiten Puocr/suelebes fie in der mitten faffen.

Diefe Nacben fino gut fort su treiben / Dem fie futo flact. Sbenit fic aber

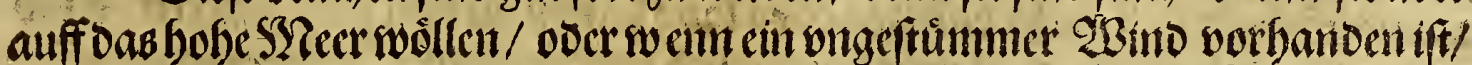

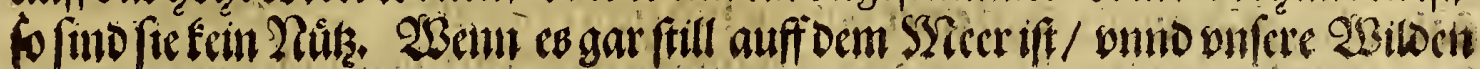


Das brifte Tfiet.

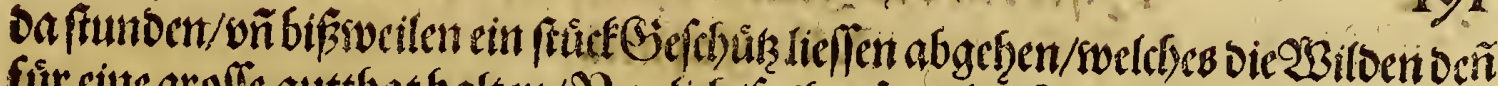

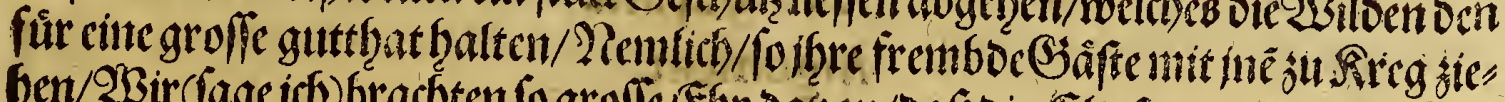

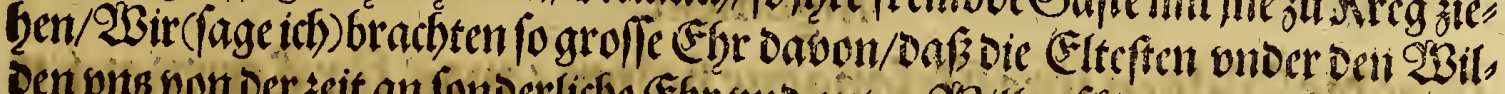
Den oits von oer seit an fonderlictse Ebr ono guten 98 illen fur andern er zeiaten.

Rach gehaltener Echlacht oroneten fie oic befangen einitten in ben bouf,

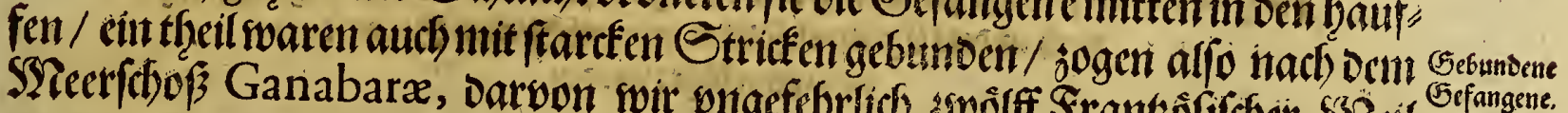

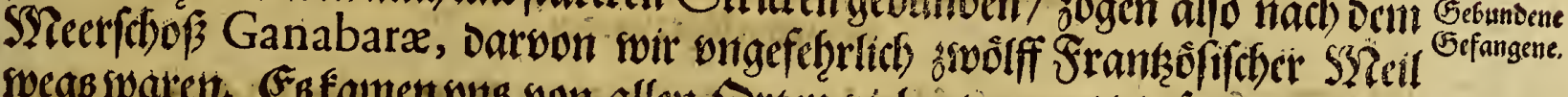

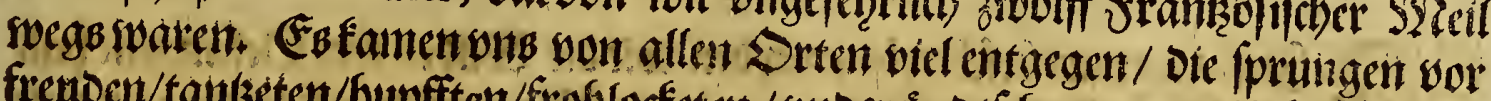

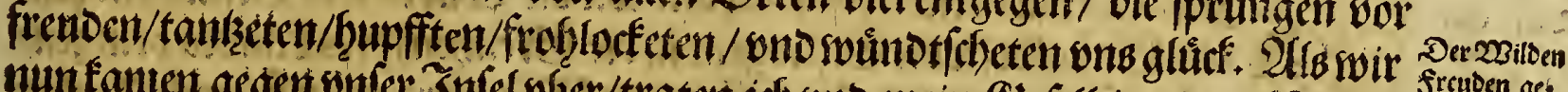

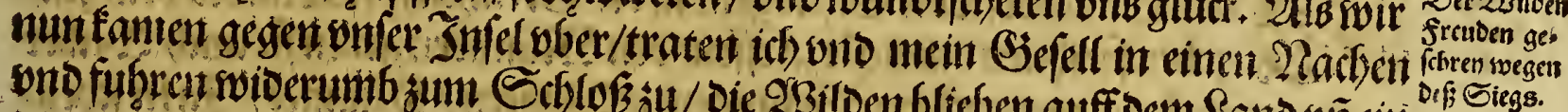

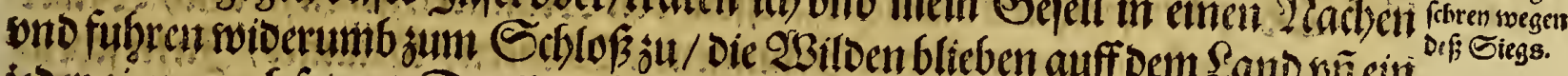

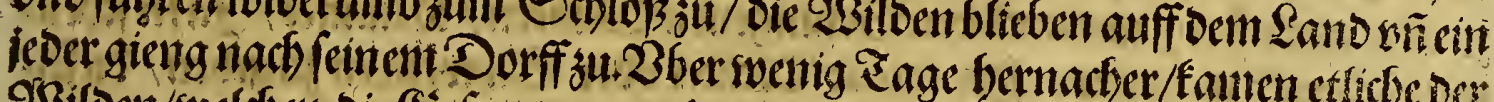

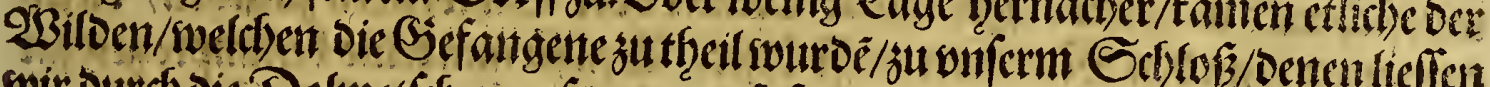

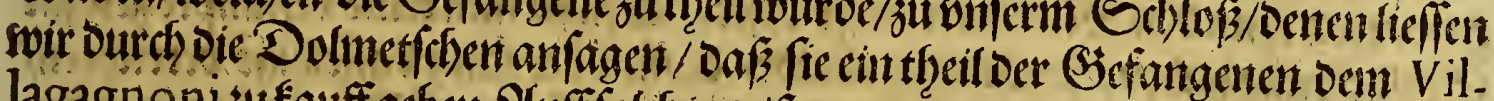

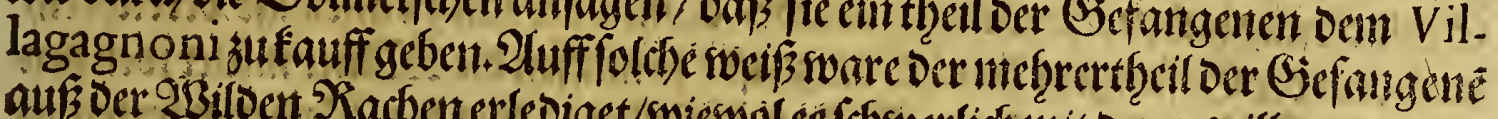

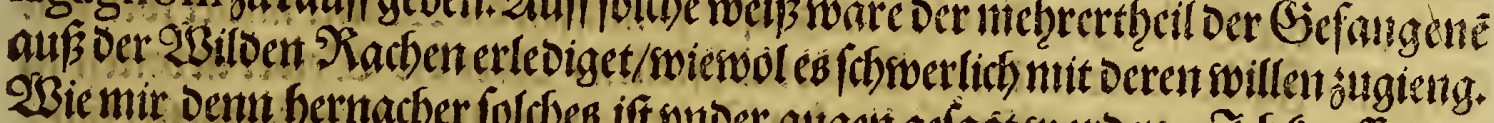

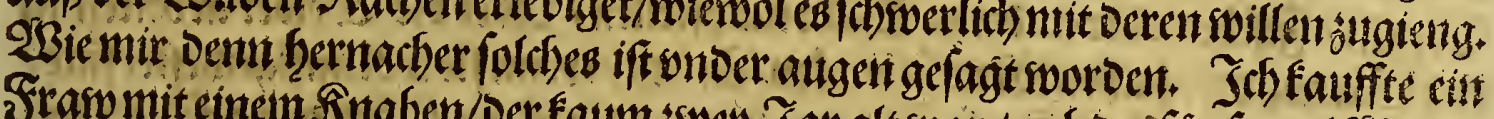

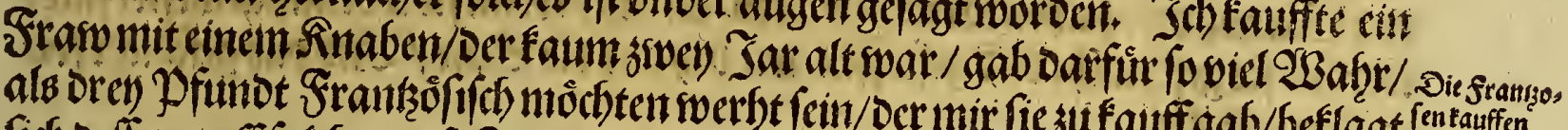

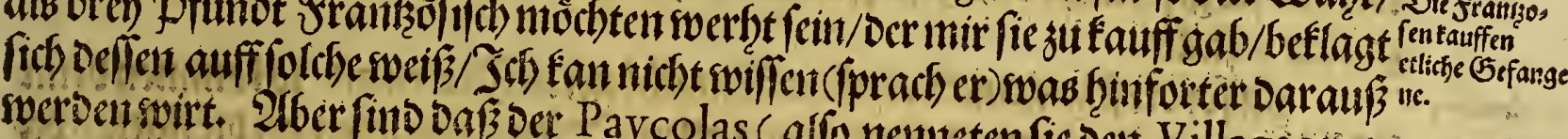
nem) fie if gervefent / Gaben soir faum oas (alfo nemteten fie bent Villagagno-

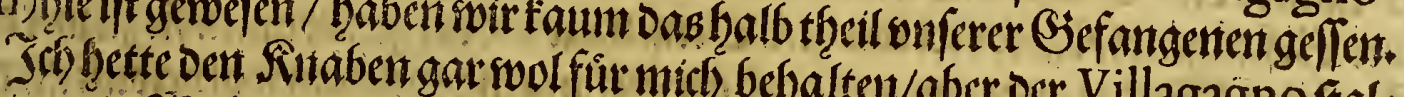
te mir mein 2 Sabr wotoeruntb

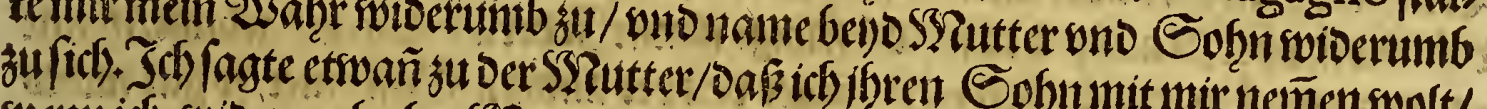

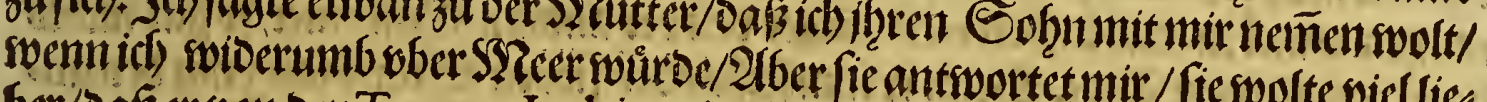

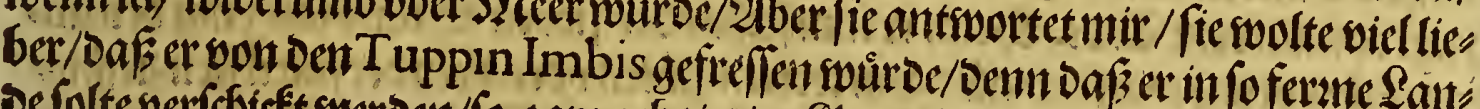

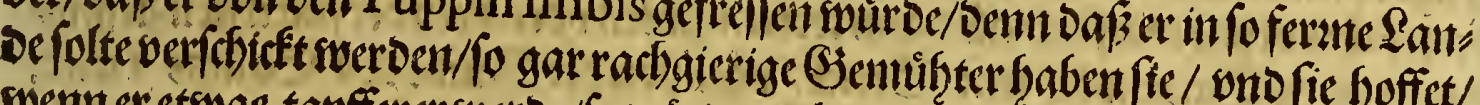

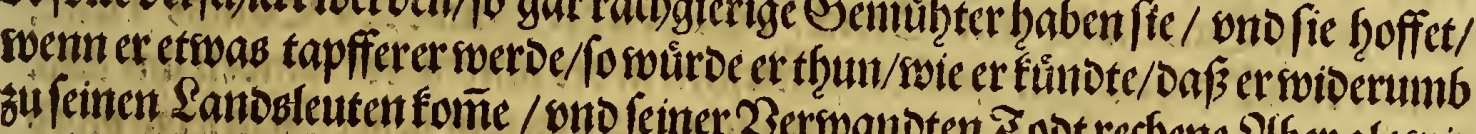
soolten abtructen / fint gleichsol lefe

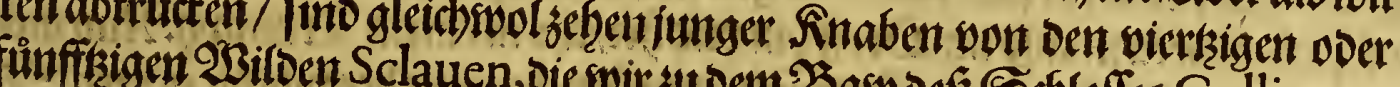

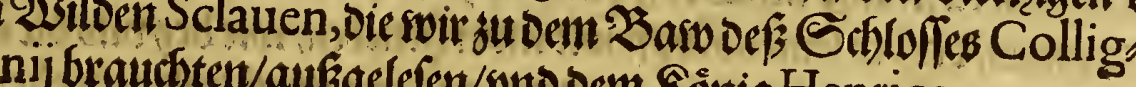
nij braudten/ausgelefen/wno oem fionig Henrico Secundo in Francfreich bract)t wor: Den.

Ri $\times$ XV.Sa




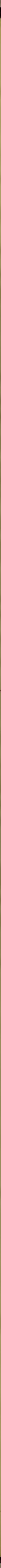


Dasbritte Theil.

I93

Endtlich / swenn ffrn nunjederman genug bat beffhauswet/ benn gehen bie

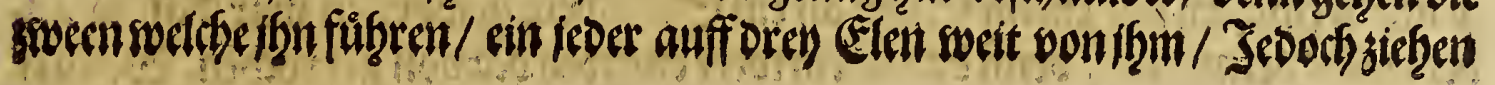

fie betsoedas Seil fo feiff

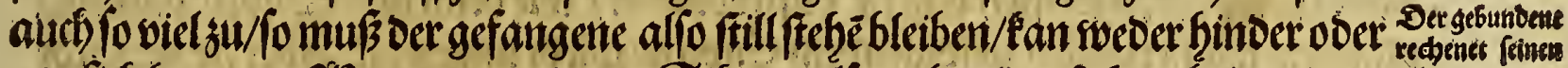

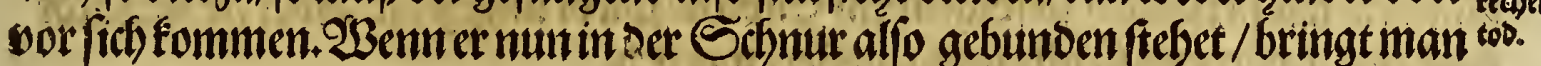
Steine ober serbrochene Seberbenzu im/oñ biein gefangen balté/baben Sefbilt

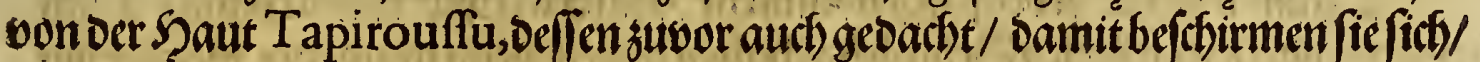

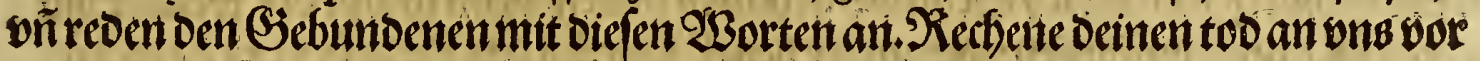

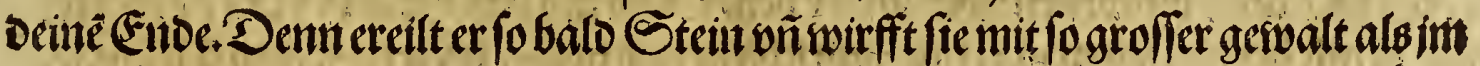

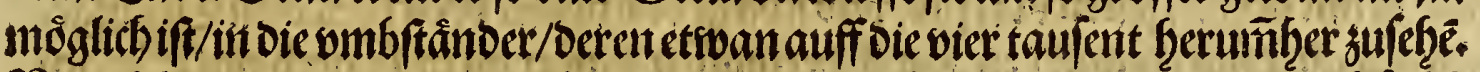

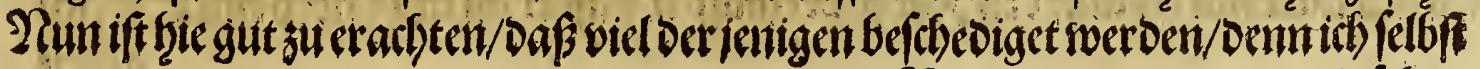

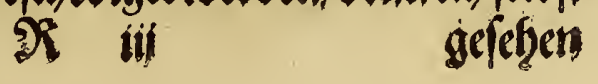


Das britte Theil.

195

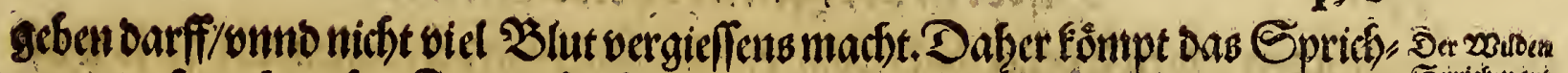

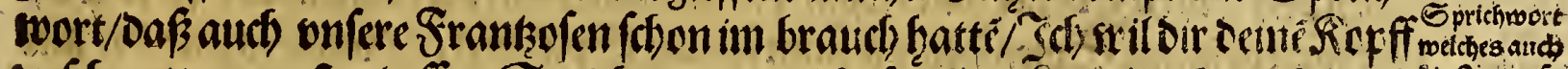

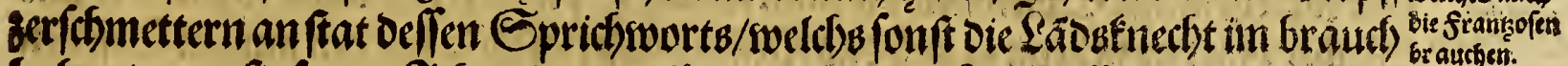

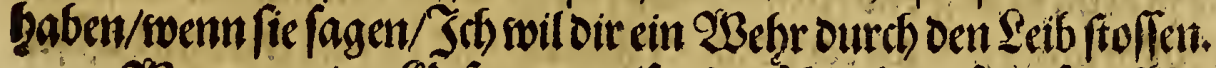

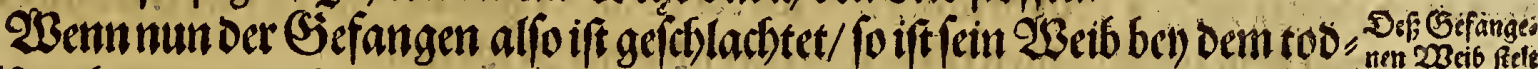

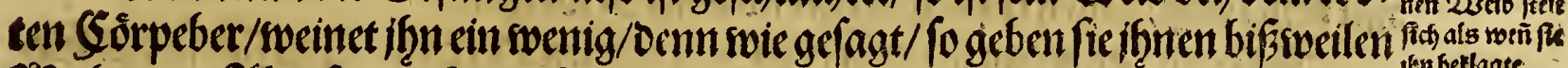

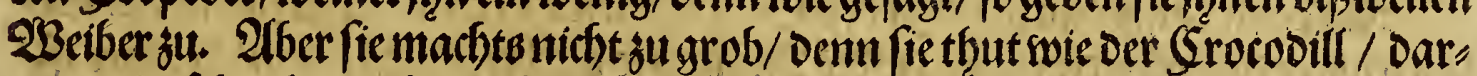

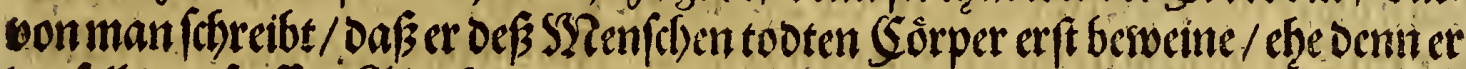

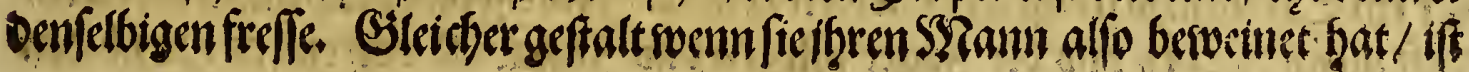

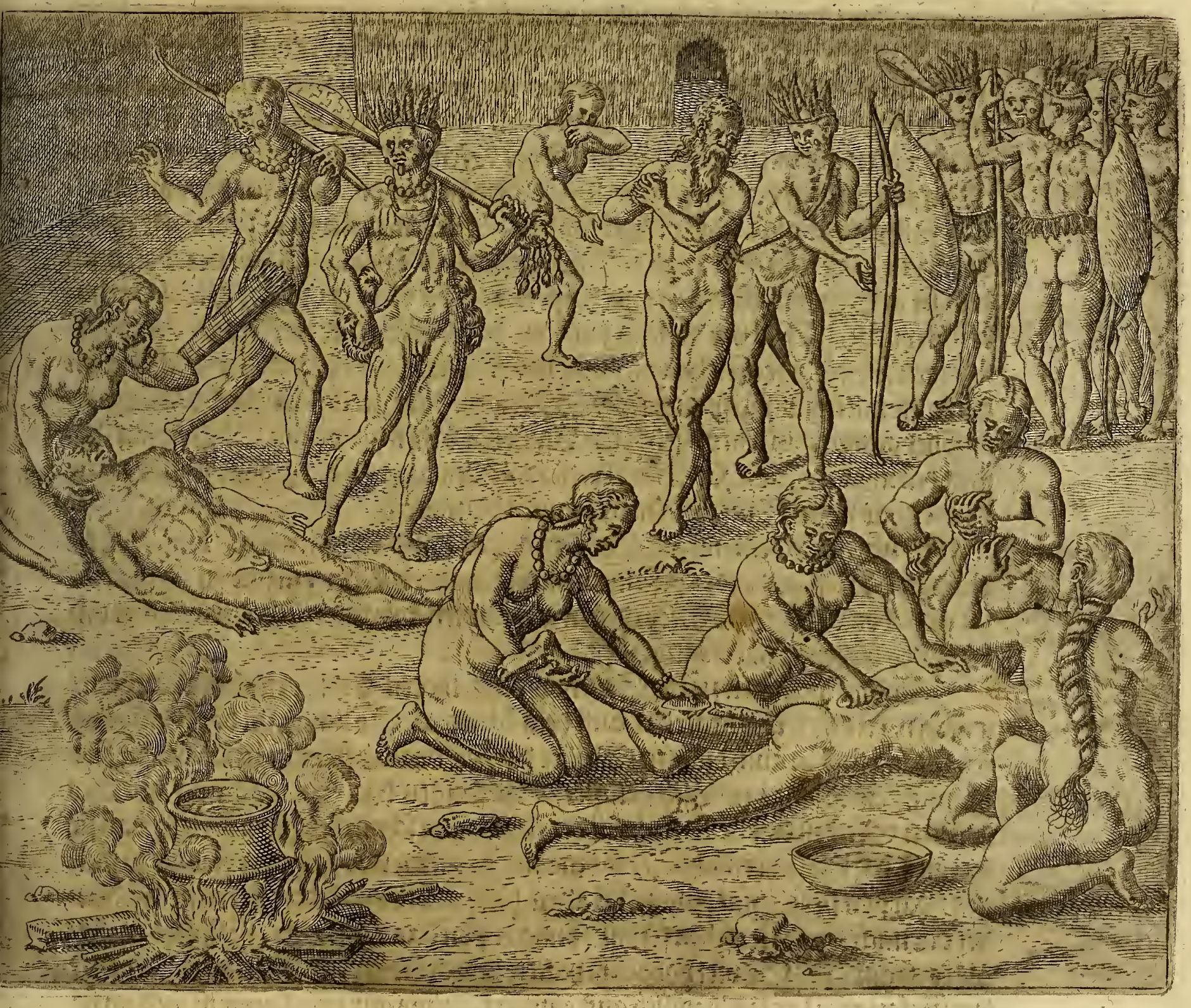

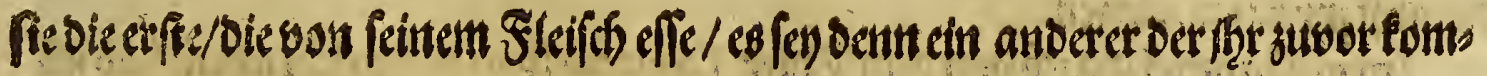
me.

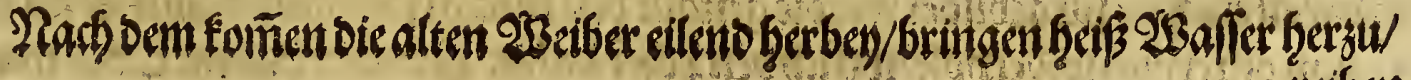
reiben 


\section{Sas britte Theril.}

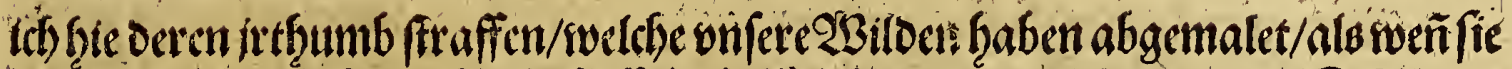

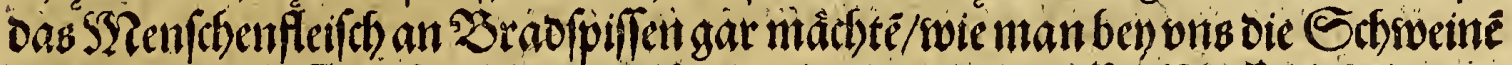

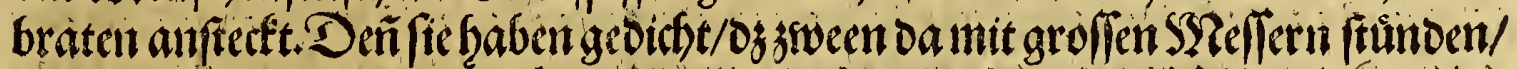

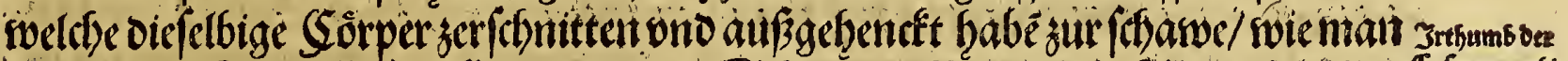

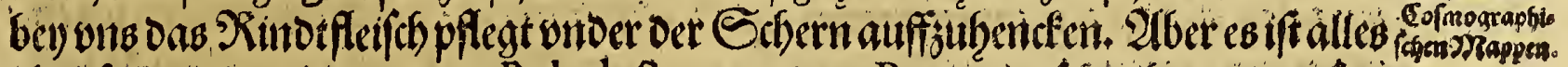

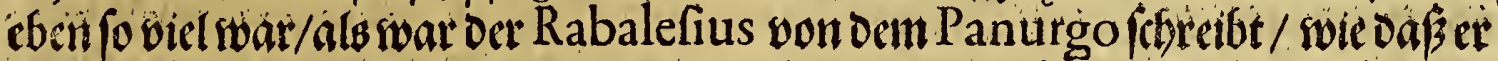

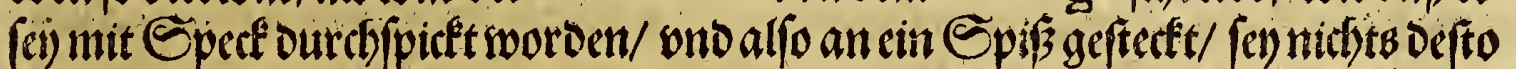
wertiger oaroun fommen/welches alles cin anteigung if t/ oafs oic autores foleber

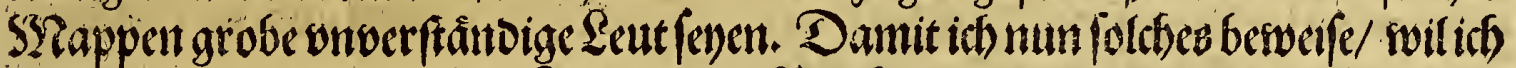

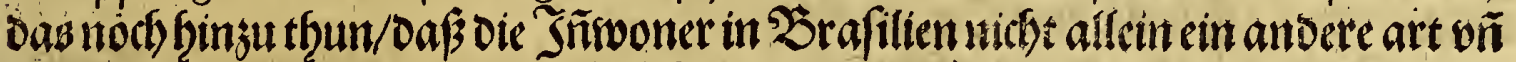

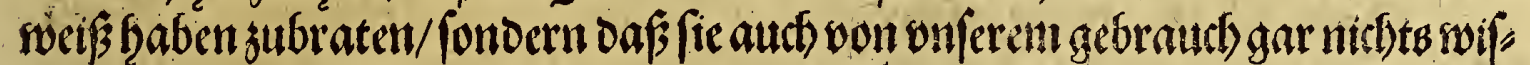

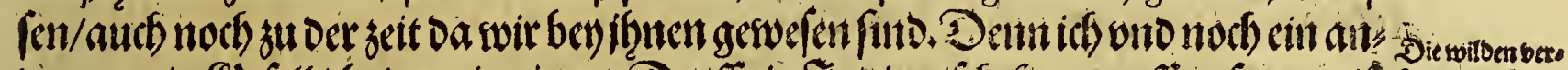

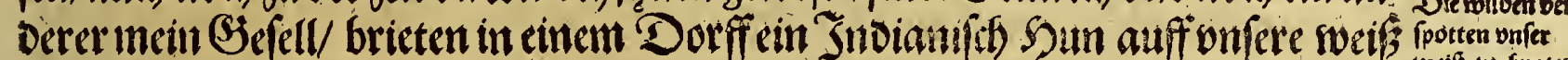

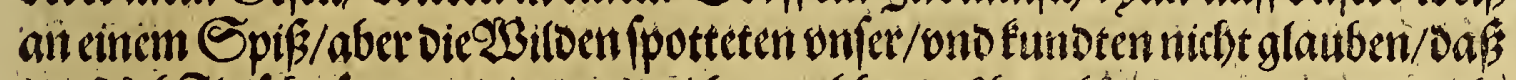

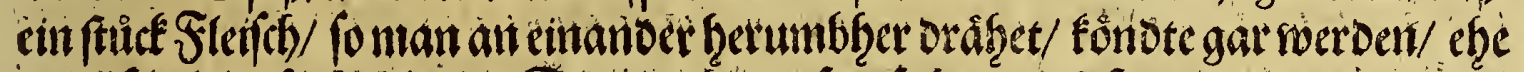

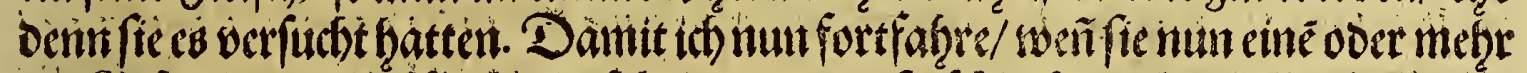

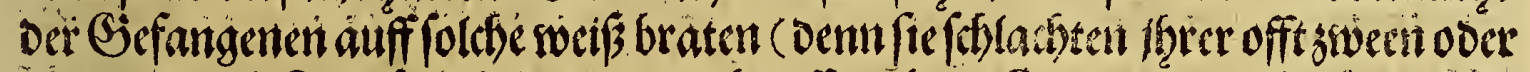

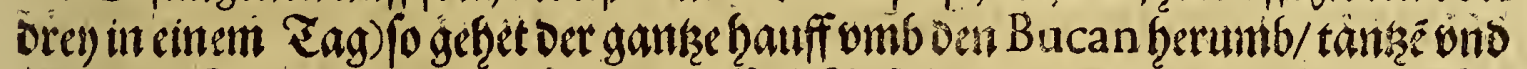

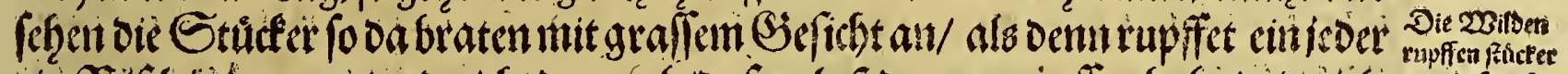

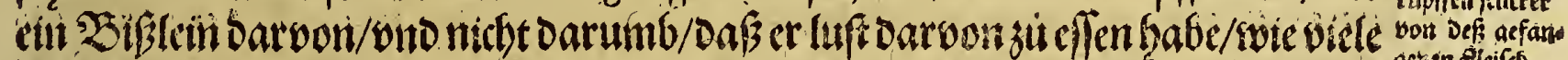
oaffelbig menten mogen/ Dem Das SP?

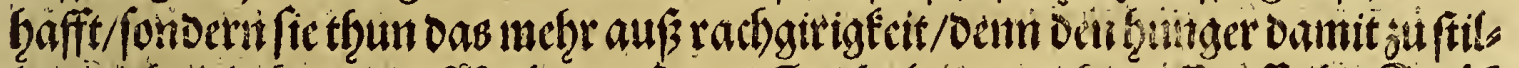

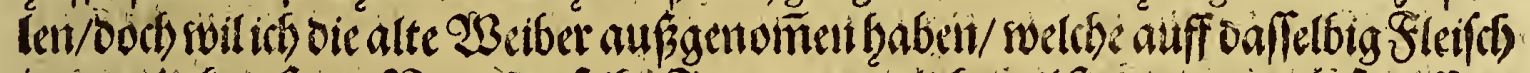

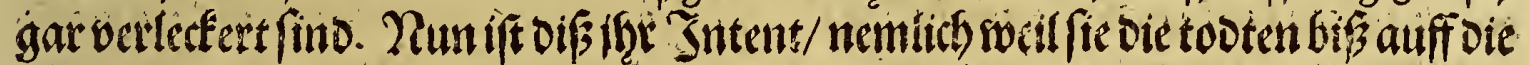

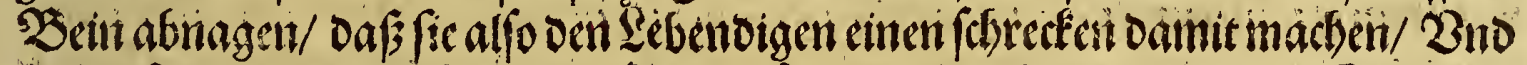

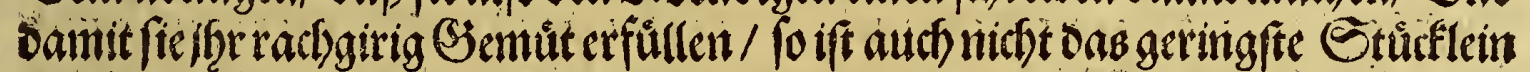

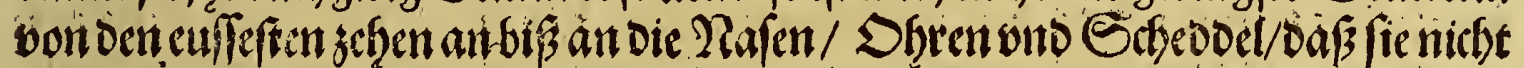

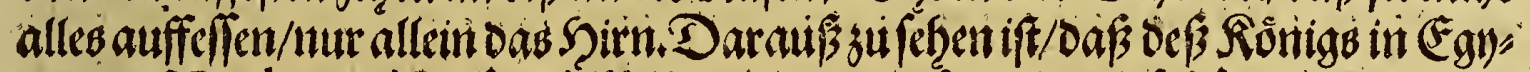
pten oes P tolomai Lathuri 28 uteren visl graulamer gervefen fey/weleber ob er

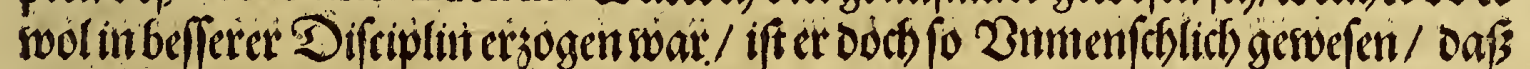

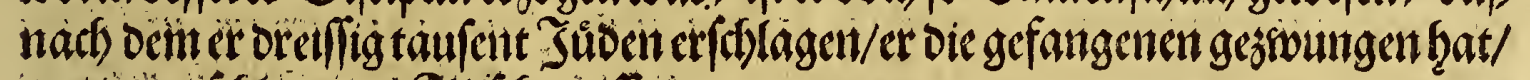

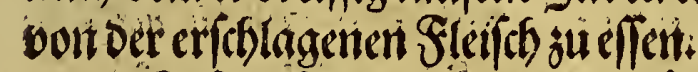

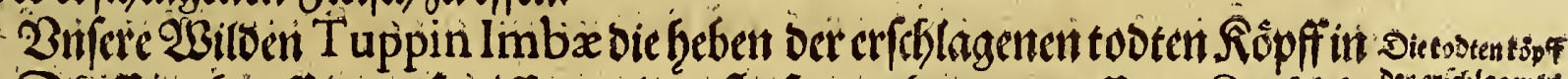

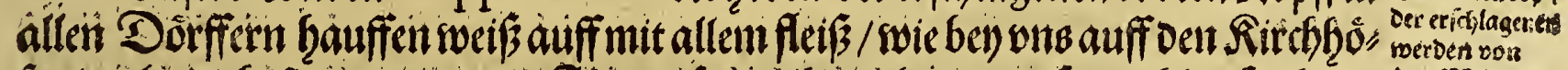

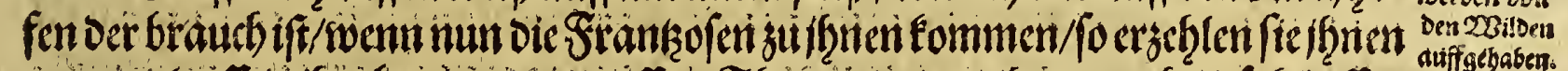

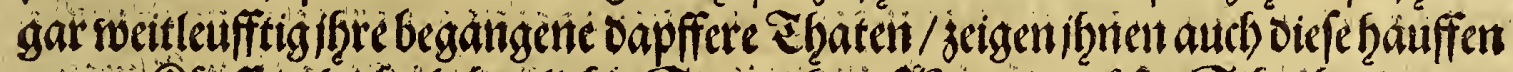

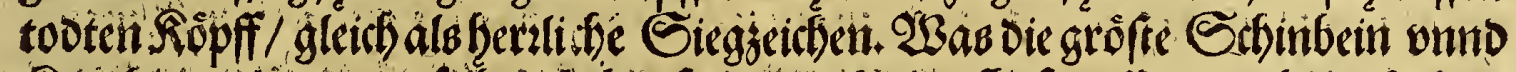

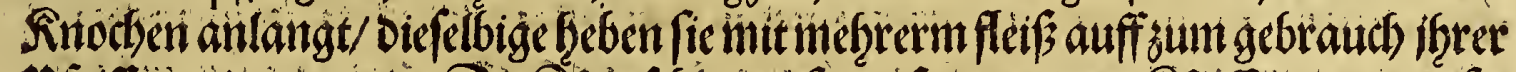

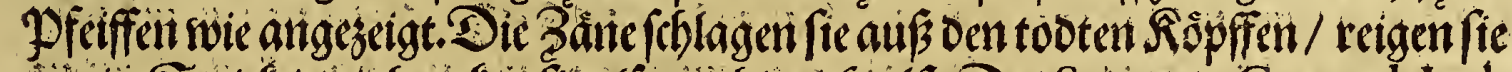

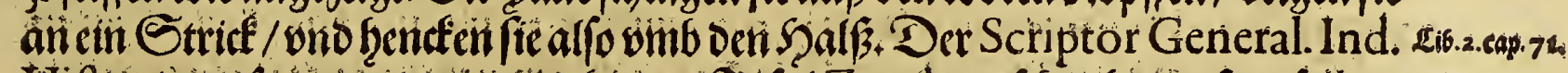

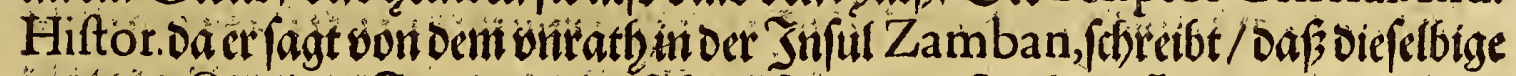

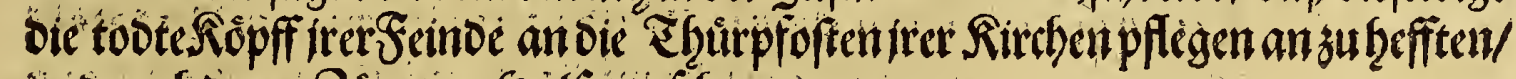

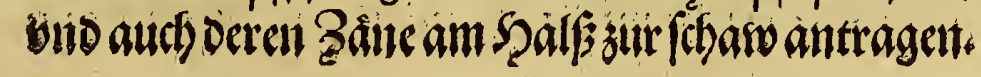

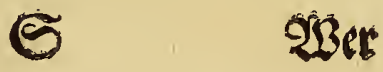




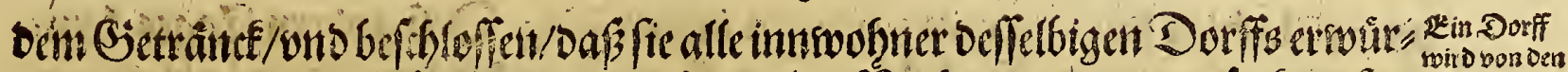

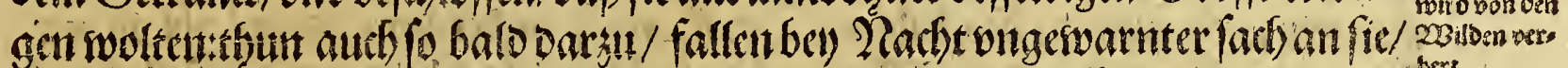

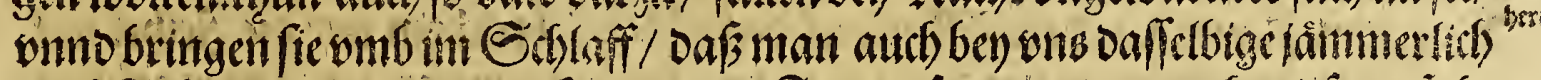

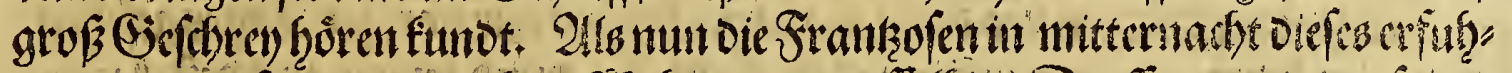

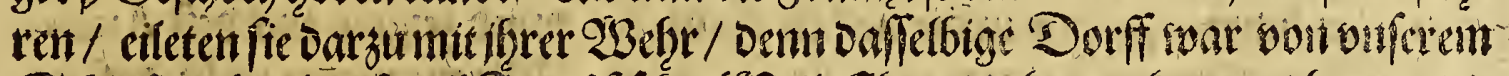

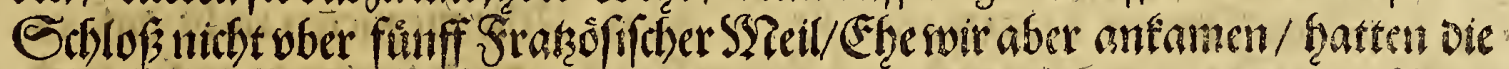

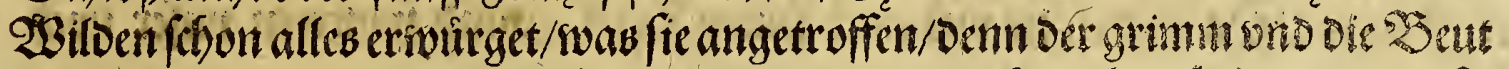

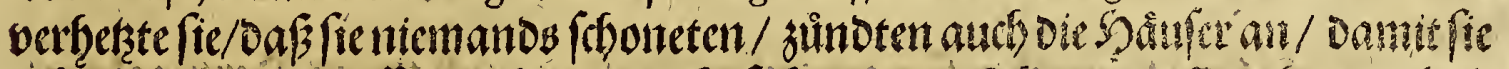

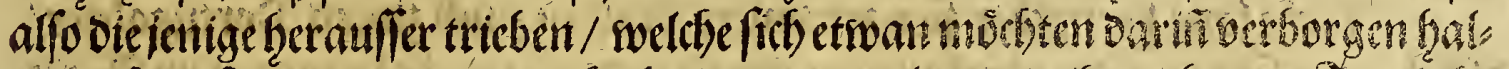

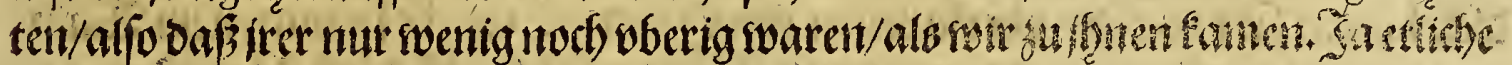

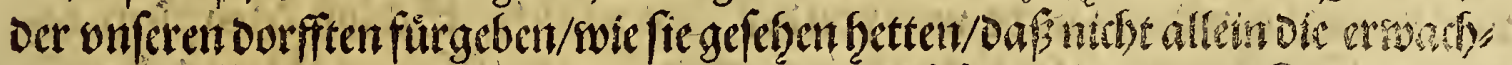

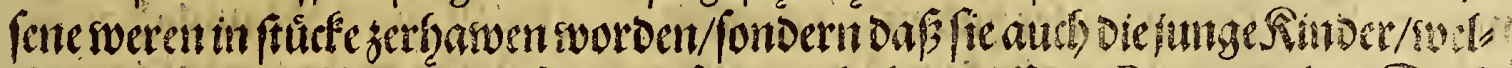

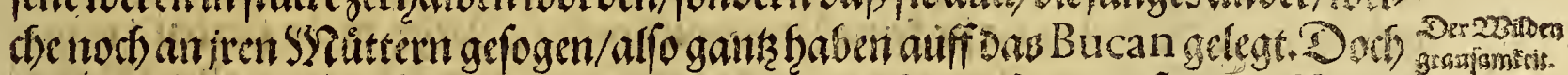

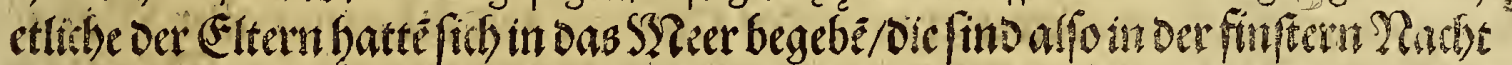

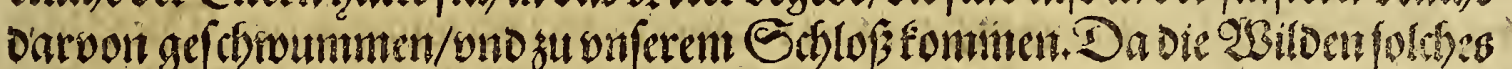

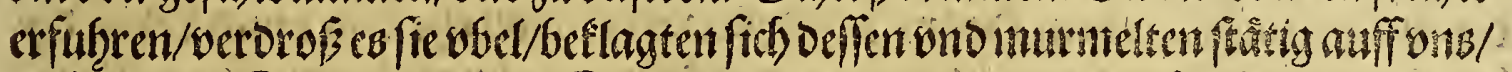

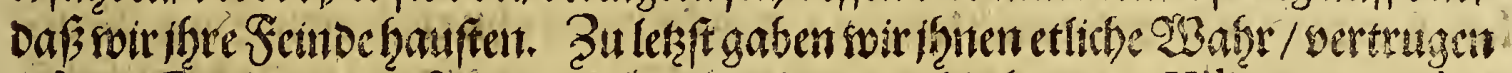

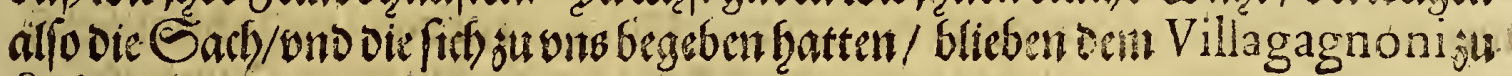
Seibeigen.

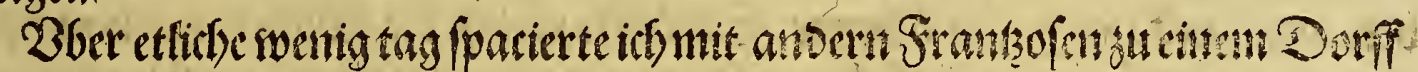

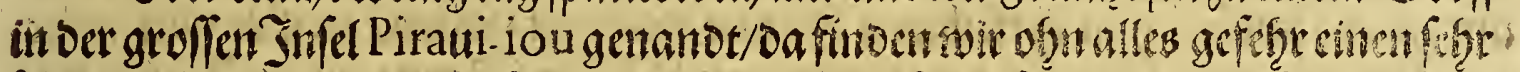

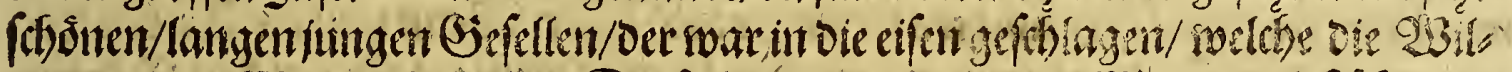

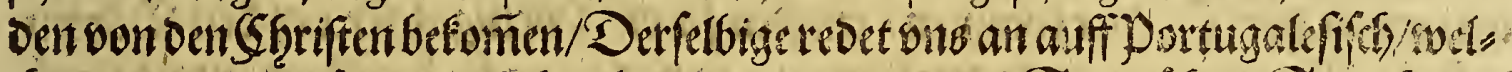

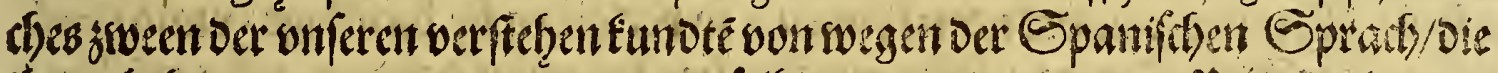

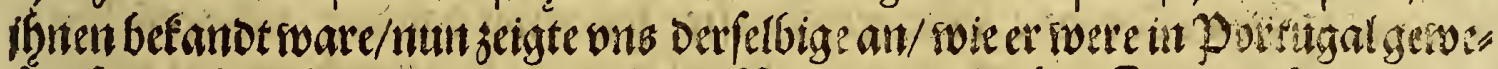

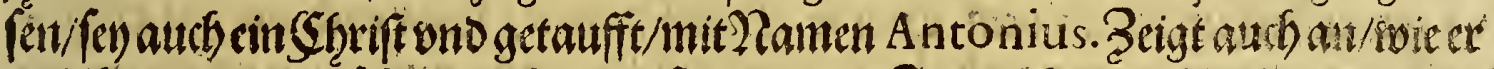

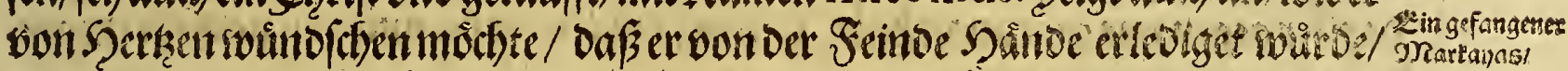

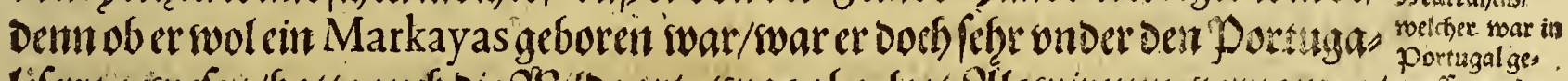

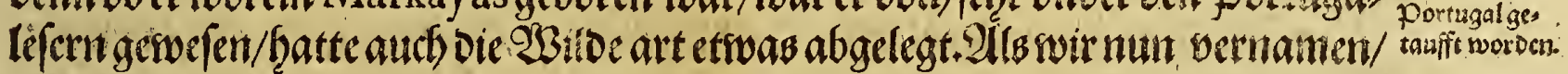

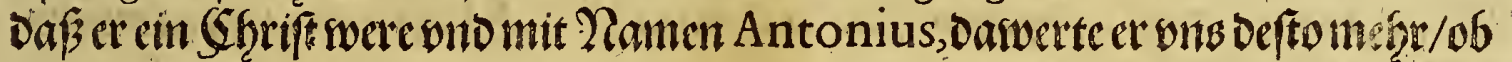

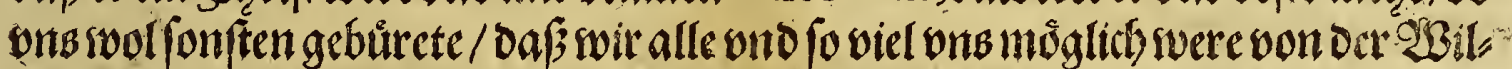
Den graulanteit erleoigen folten. Diefer biefangene war allein/ vit es berwaret

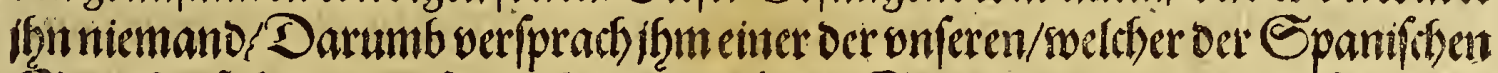

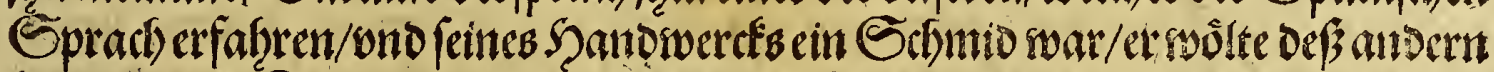

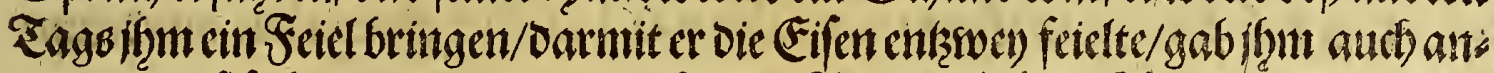

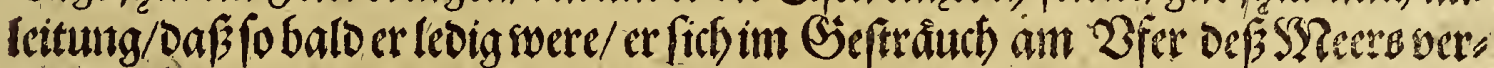

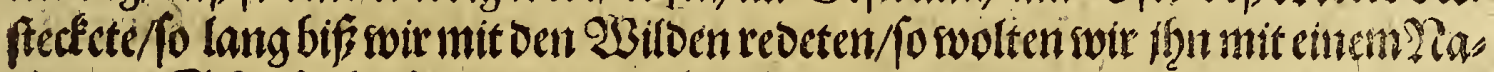

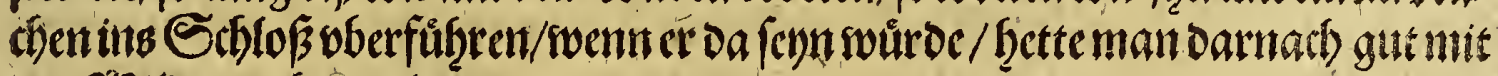
Den 2 Bildenzubzanoclen.

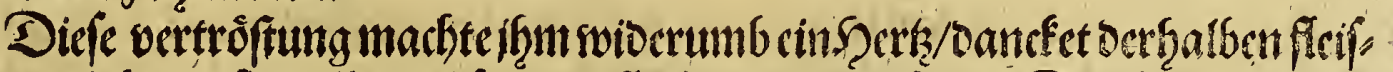

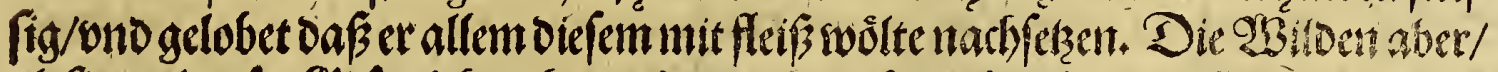

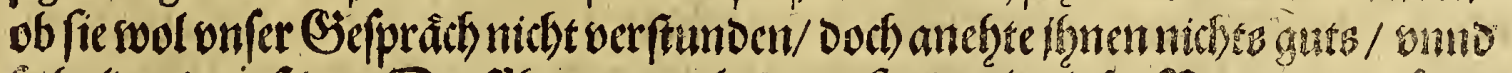

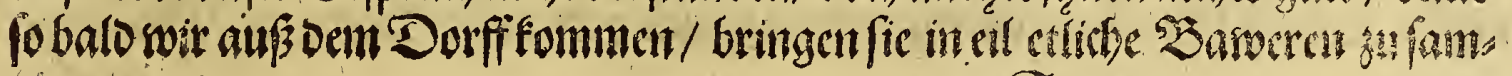

$$
\text { (i) } 1 \text { if }
$$




\section{Disbritte Tferil.}

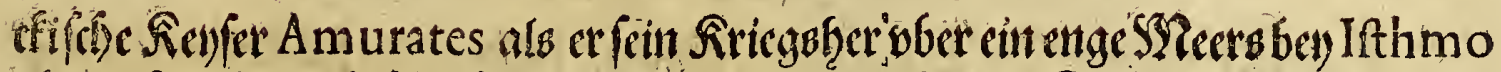

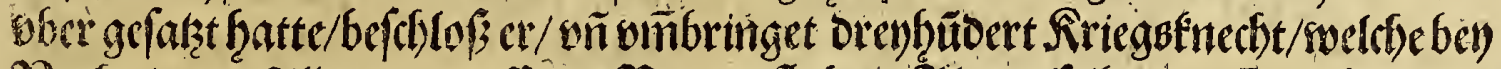

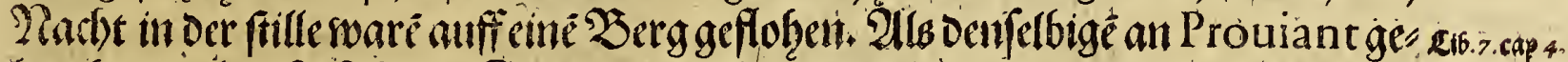

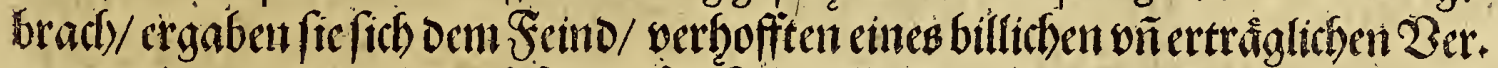

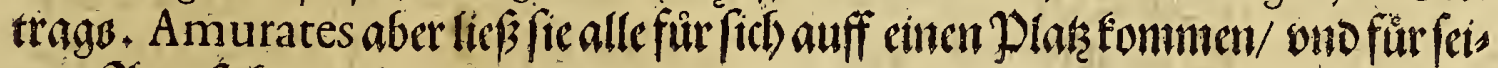
nem 2lingefict) crwoirget.

Amaratombento

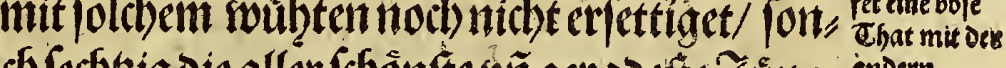

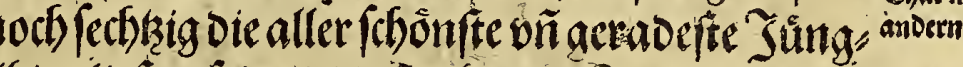

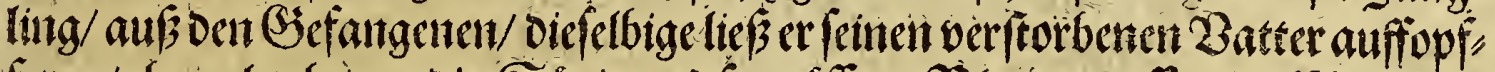

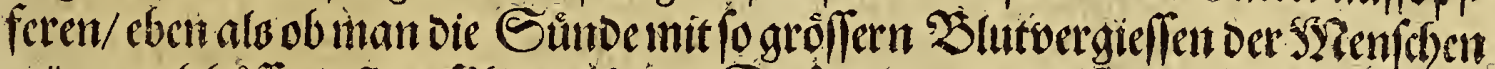

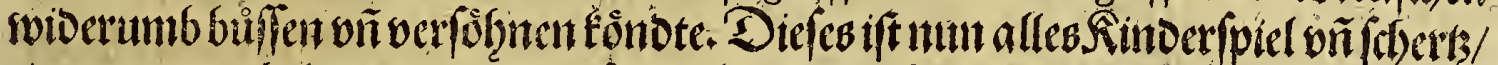

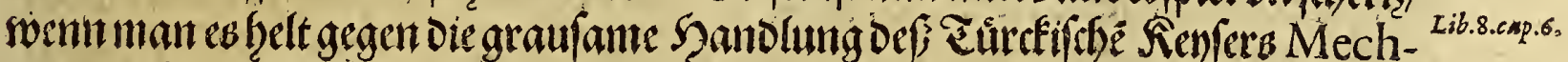

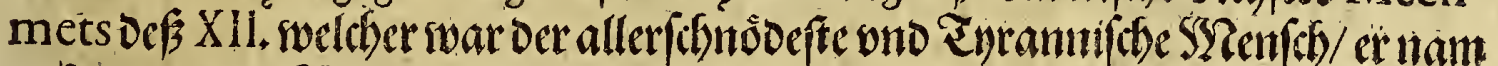
nicht allein bie Regictung von dem Amurato an / fonbern autb) alle fein voner"

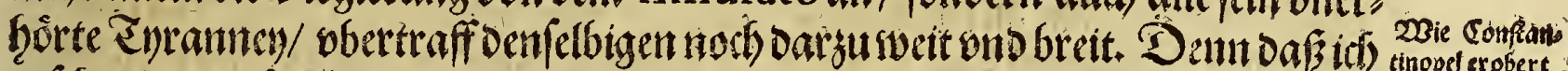

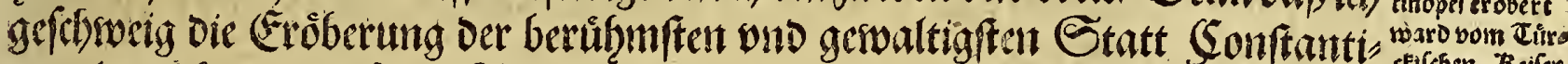

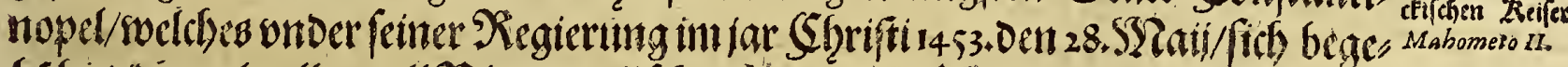

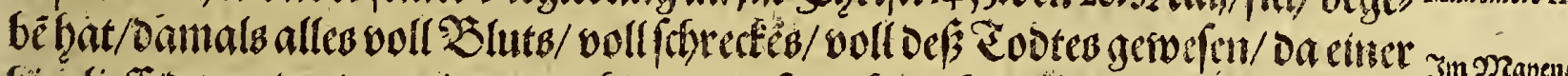

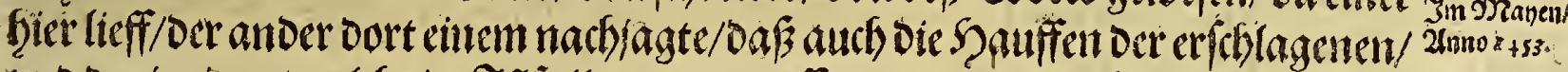

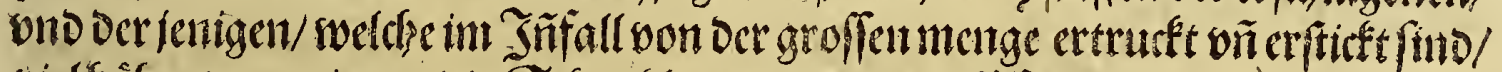

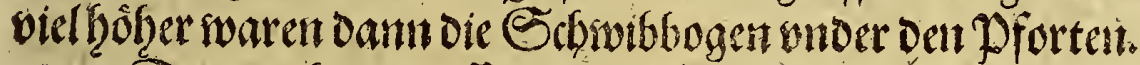

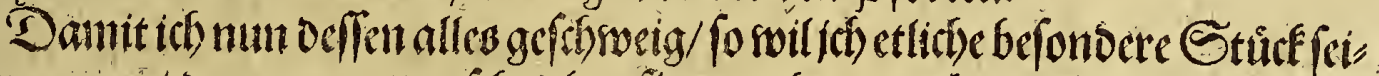

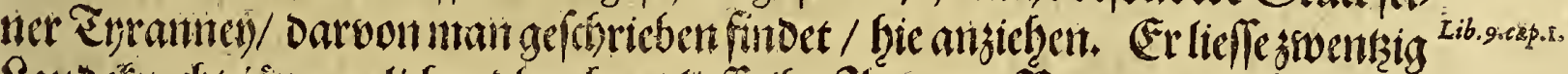

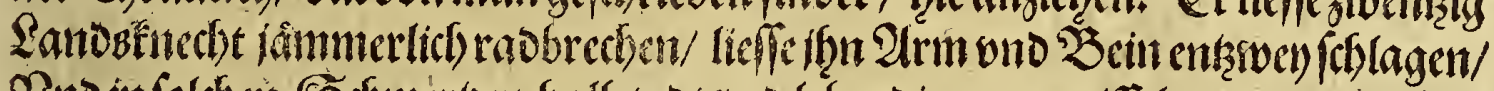

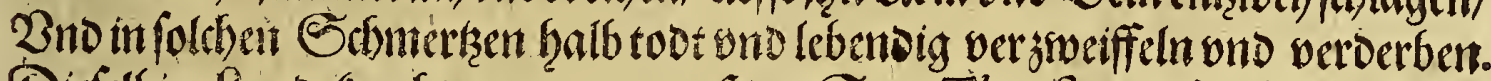

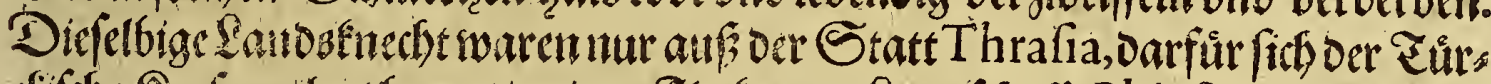

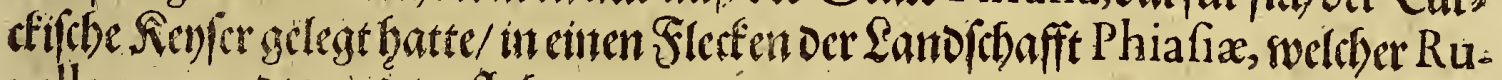
pella genamotruard/geflohen.

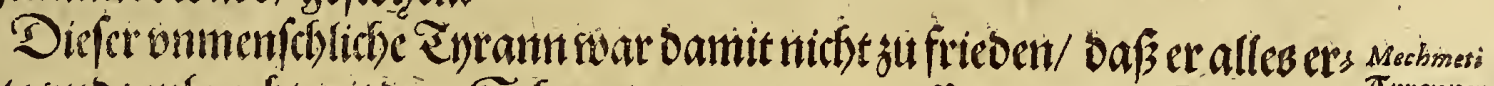

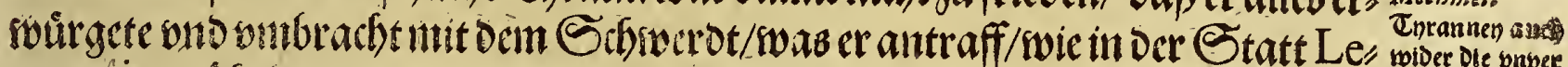

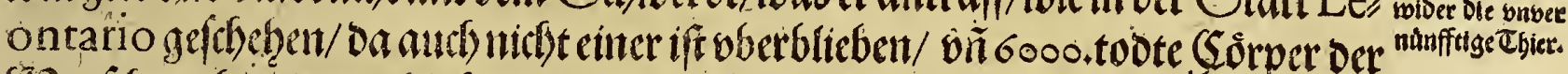

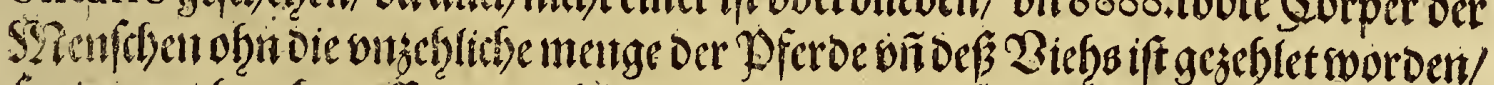

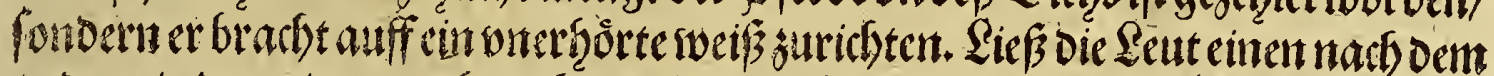

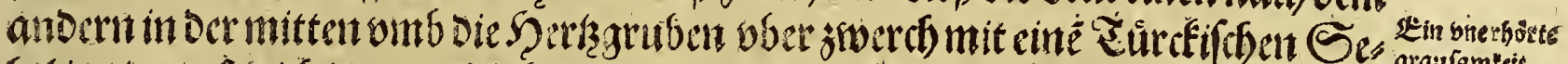

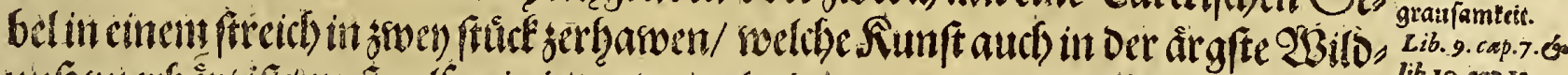

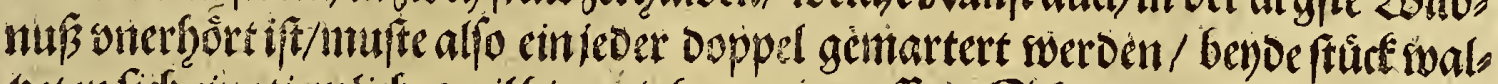

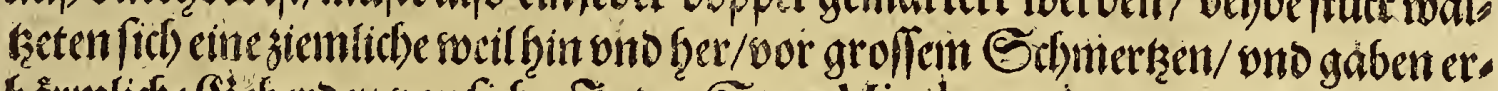
Gântiche (Seberden voufich. Inder Statt Mitylene, Anno 1459. Danalo dies

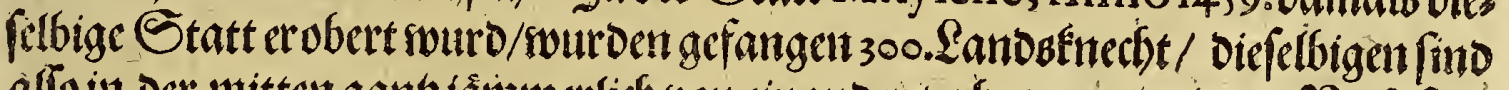

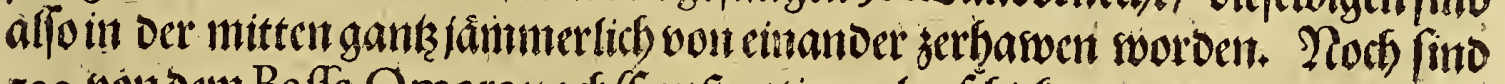

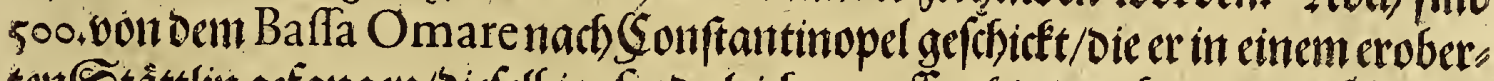
tent Stättliu gefangen/oiefelbige fino gleicher maflen hingericht sworben. 2 ls sun

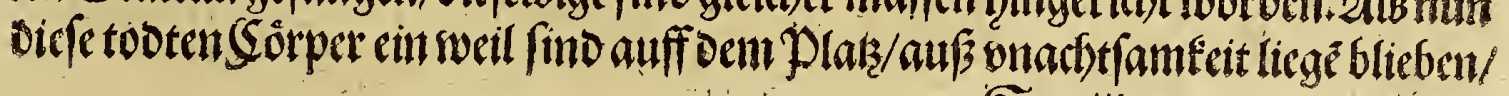

$$
\text { S ii) iftin }
$$




\section{Sas brifte Tfeil.}

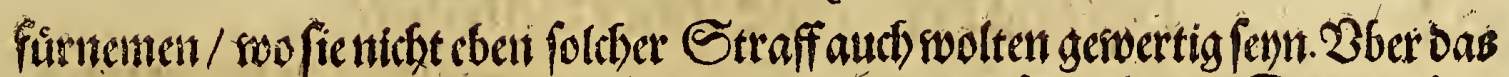

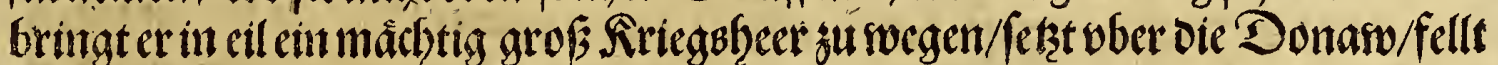

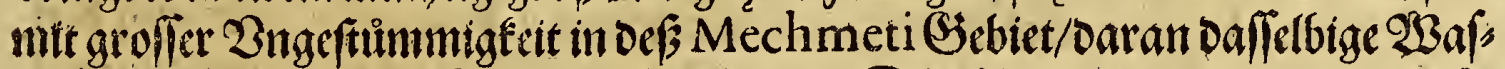

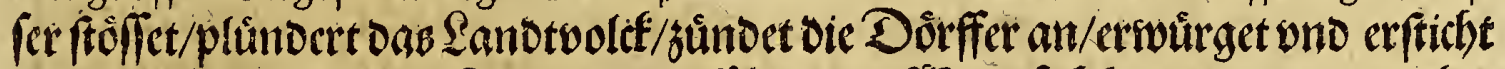

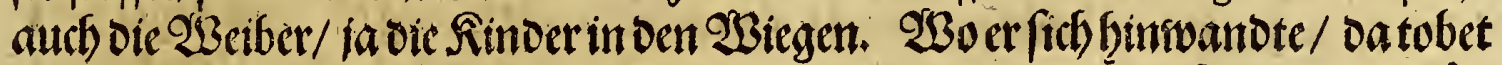

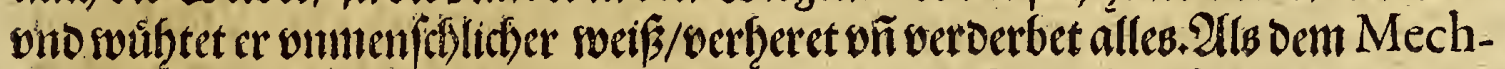

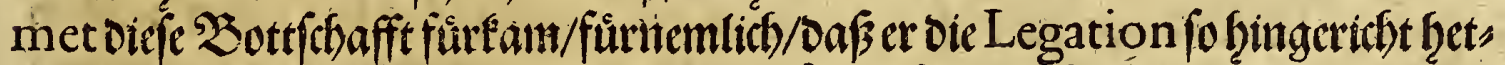

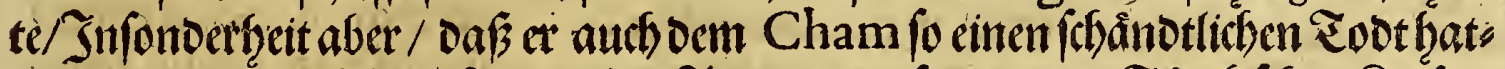

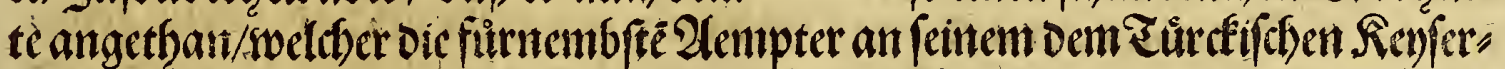
lichens off getragen batte / hat eb in vbber die maffenfefer berwegt/Bub infonder"

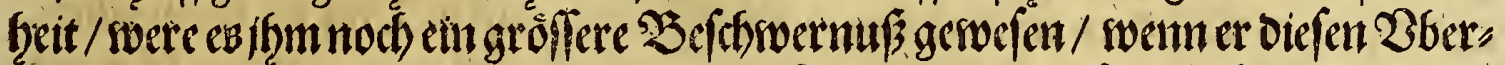

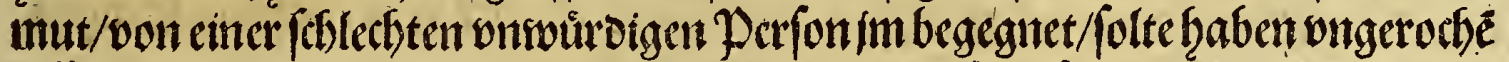

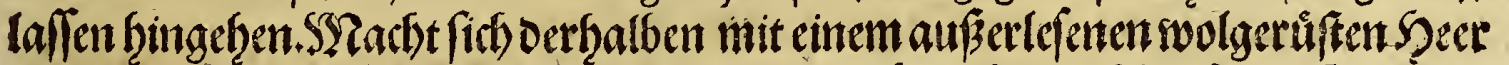
auff / fompt in dic Droum over 2 Ballact)en Valaquiam, fifet feiner Legaten

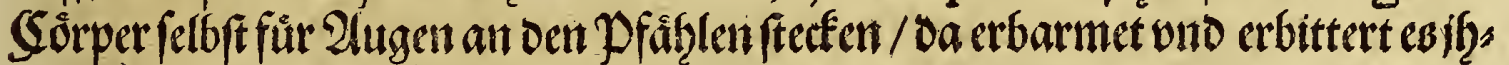

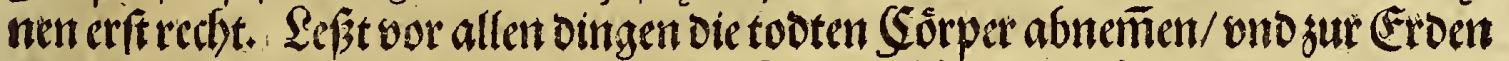

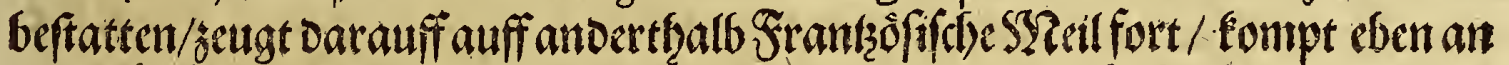
bas ort/Da Die S2etrigung feiner Bnertfanen von Dem Vlado begangen noar/

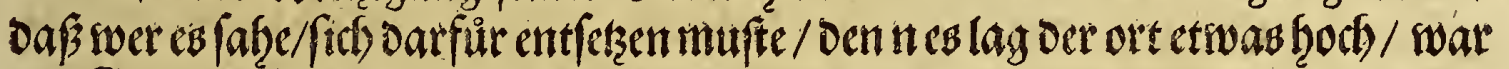

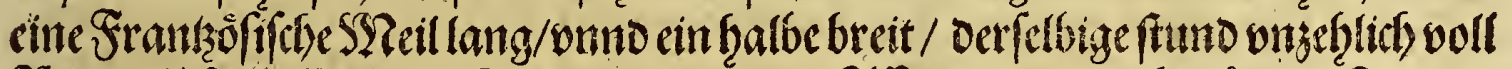

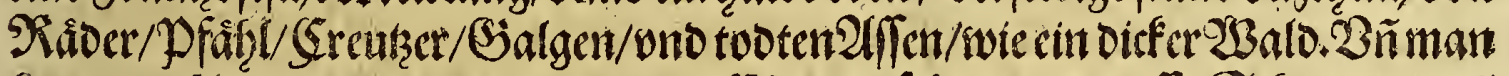

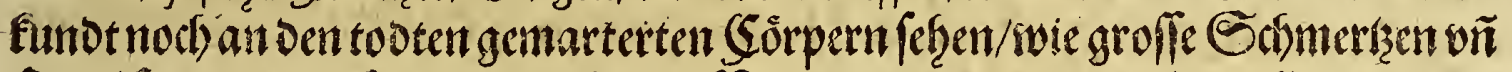
Dual fie borfitem Eno erlitten fetten. Nan waren der zermelzelten oñ genturters

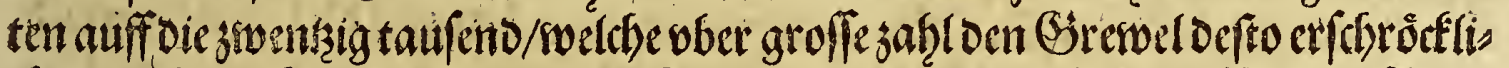

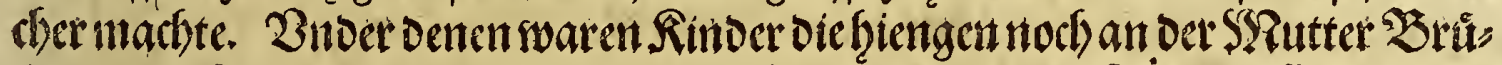

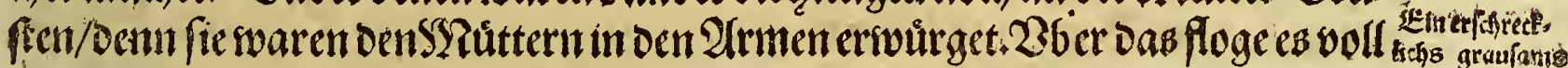

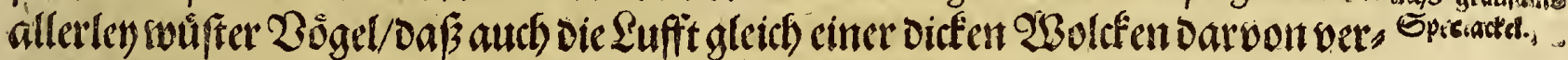

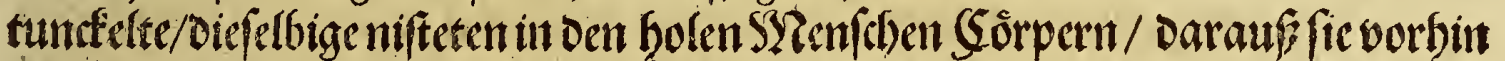

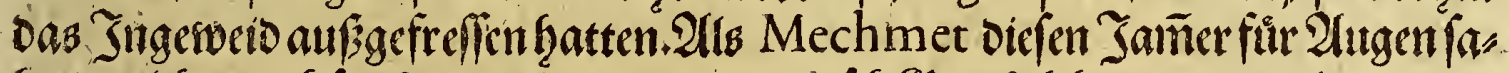

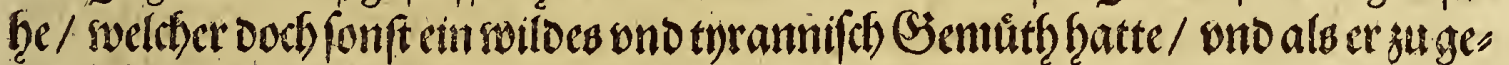

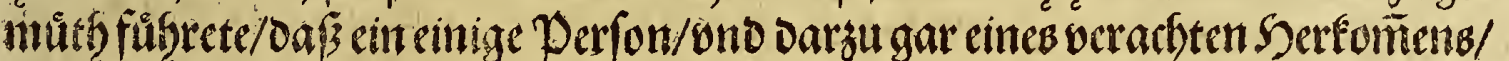

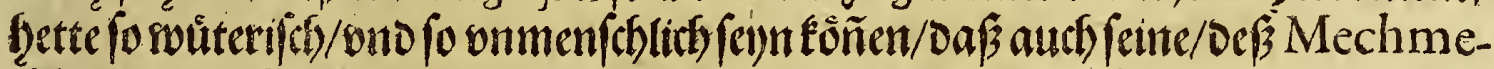

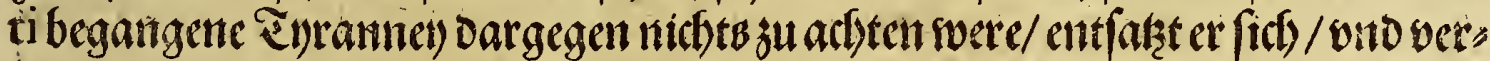

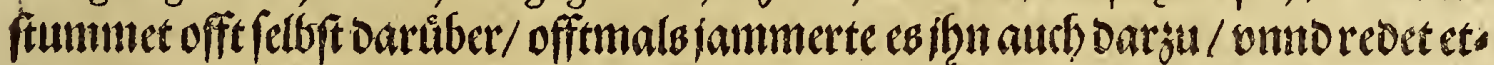

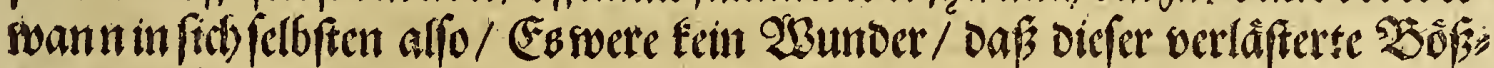
roicht ben feitten Bnoertianen in fogroffer Reputation were/ fintemal er fieb fo

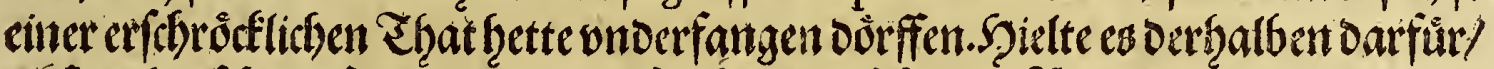

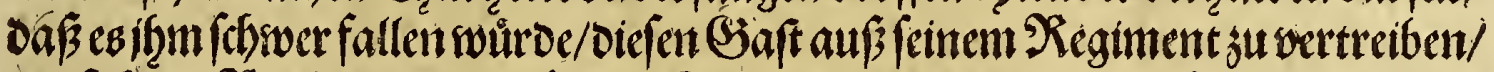
Der fief) oer Regierung wnno /einer Bnoertbanen guten willenfo tapfier ju ges

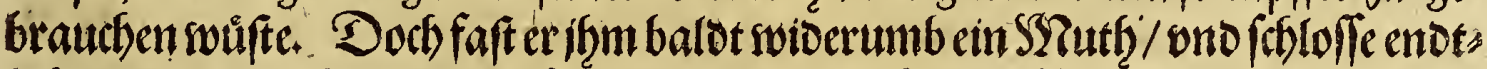

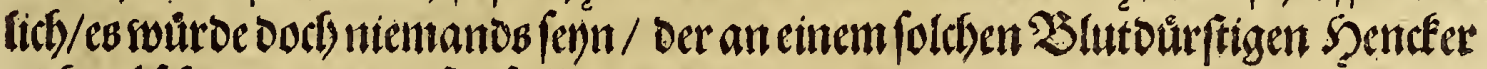

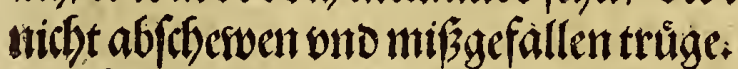

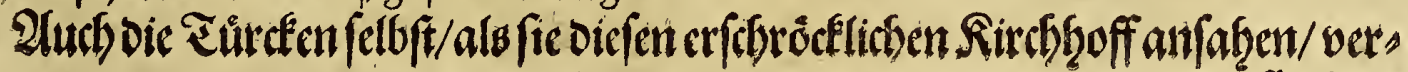
fluditer 


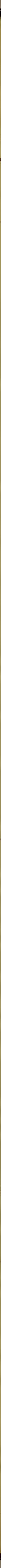




\section{Das britte Theil.}

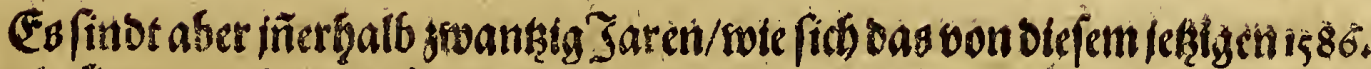

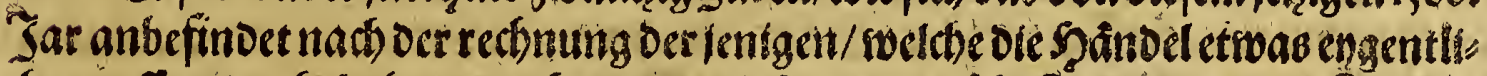

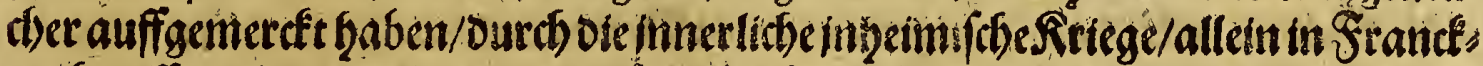
reich auff oter

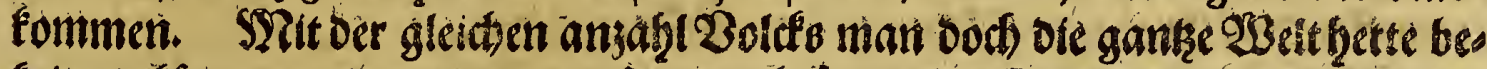

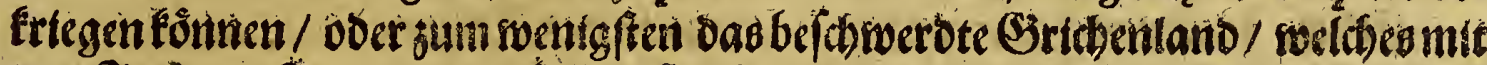

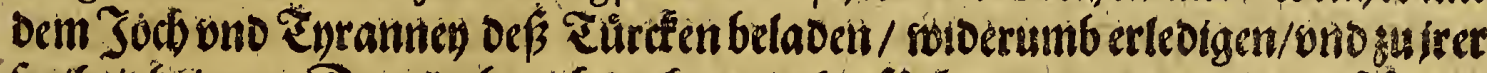

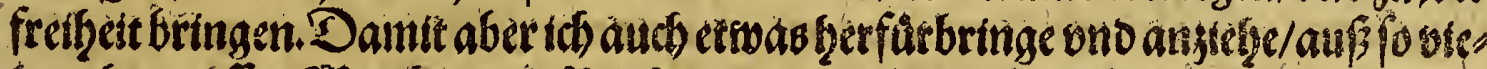

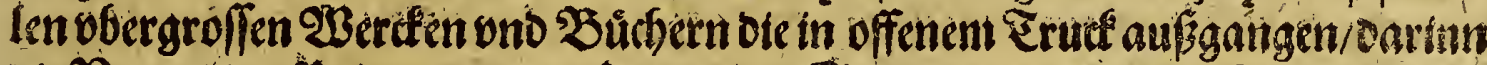

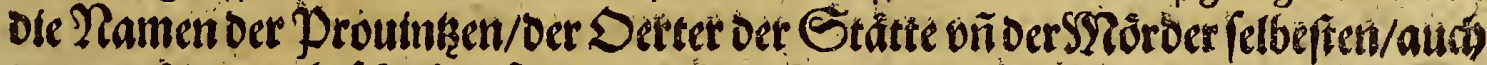

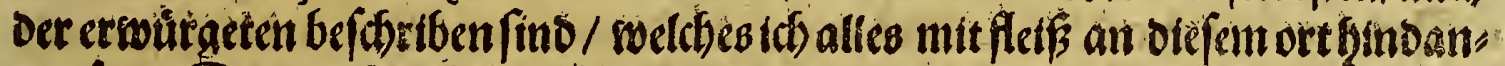

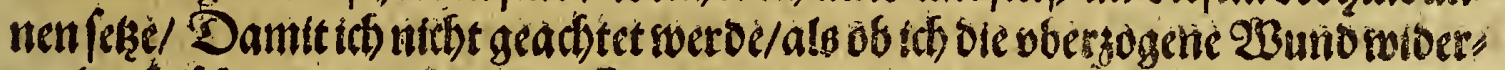

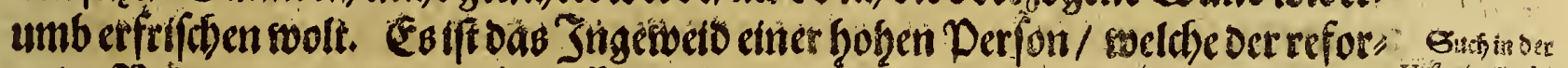

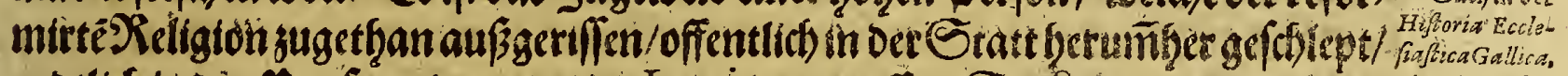

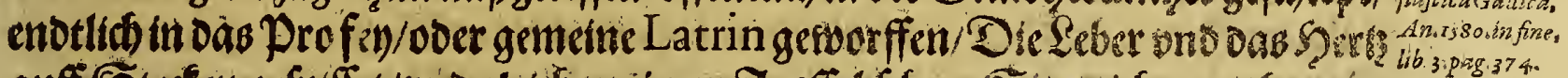

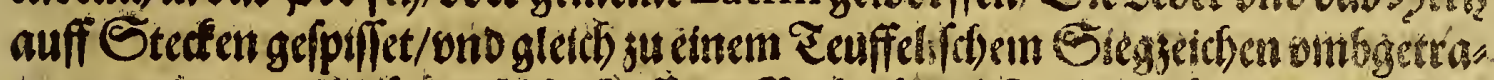

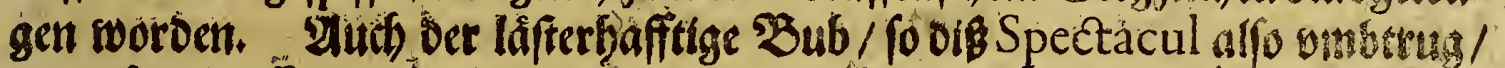

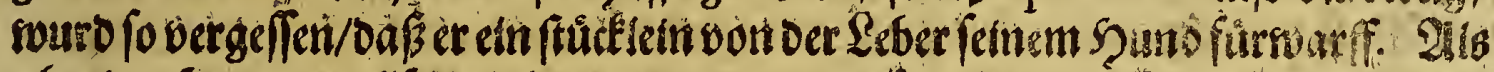

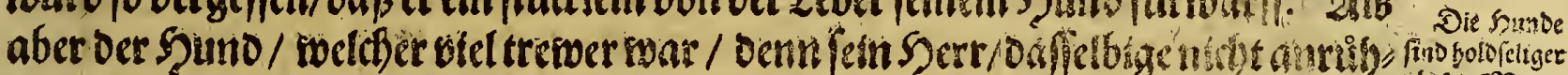

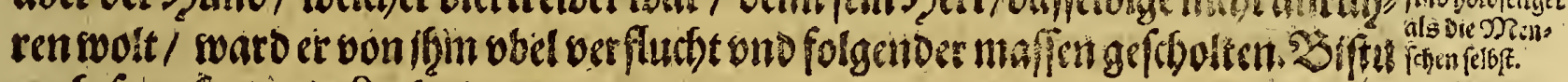
auch/pracher/ cin Lutherancer.

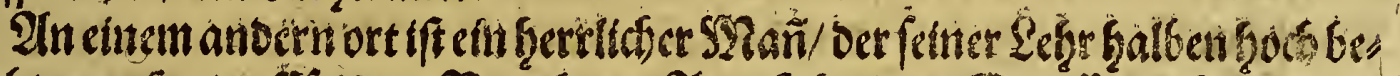

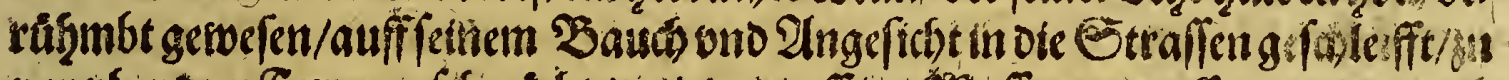

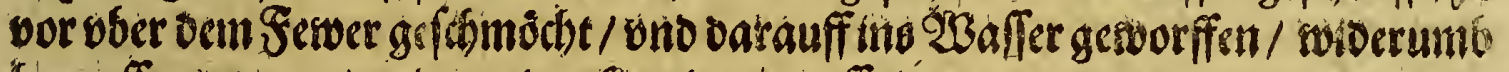
beraufer gefogen/ bovo von den Spundengerrifen woorden.

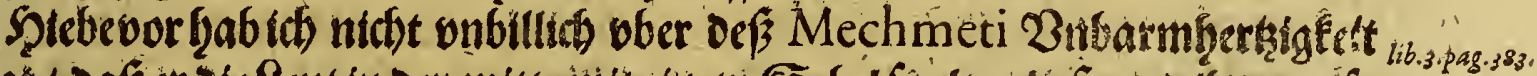

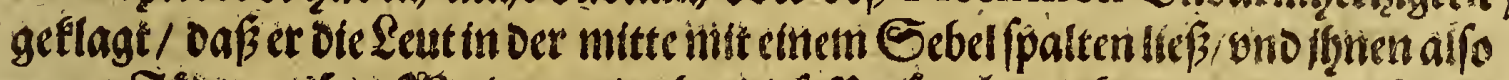

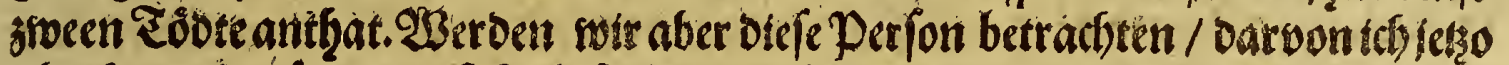

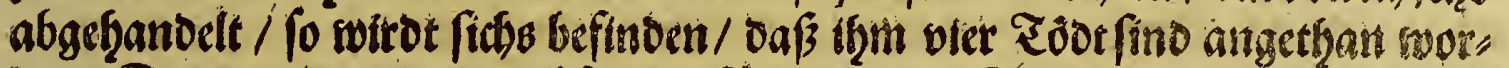

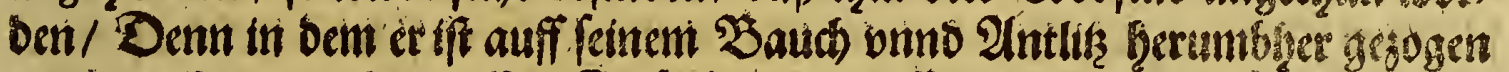

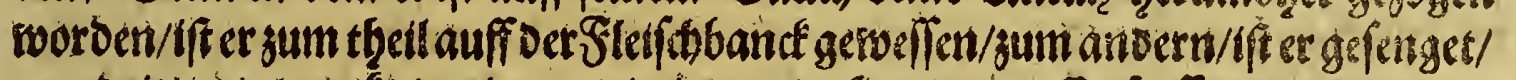

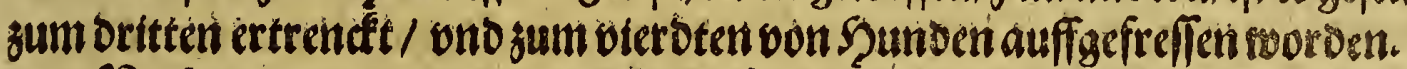

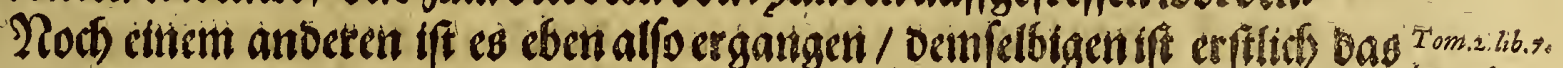

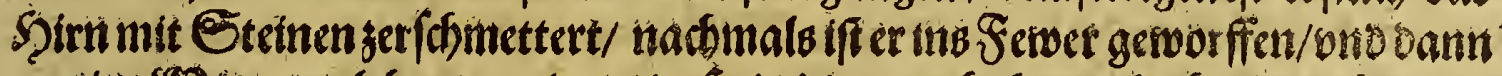

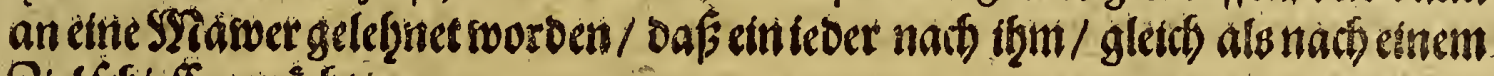
Bielfoteffenmódbte.

Gine Rinotbetterin if Den vier oten Eag/ nati Dem fie Darniber Êttmen/

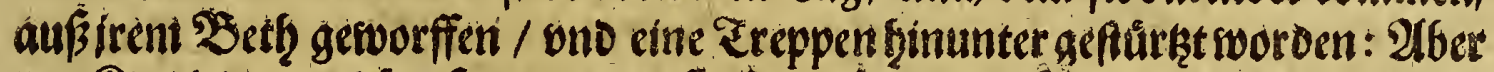

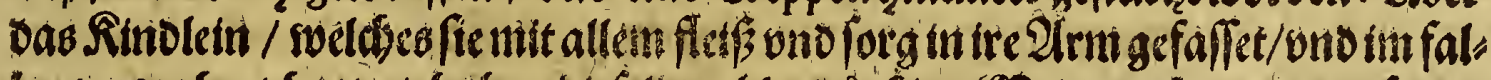

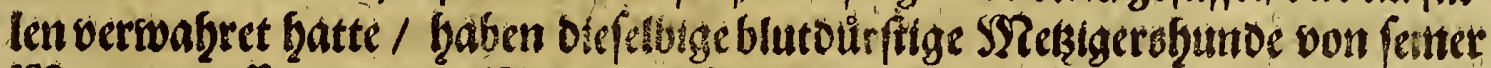

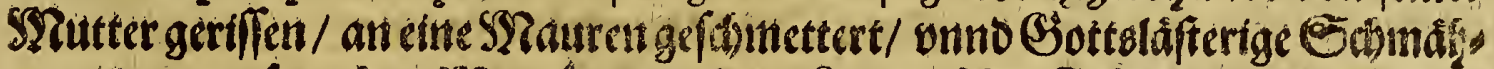

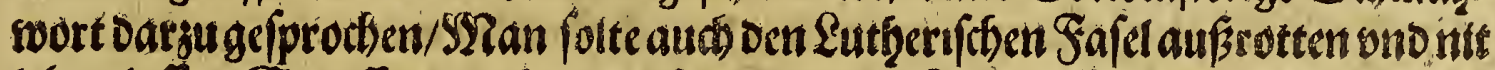

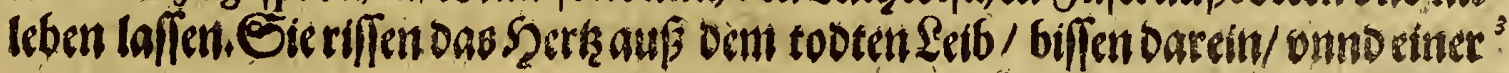




\section{Dab butte ₹fich}

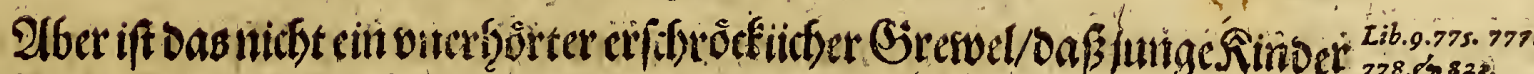

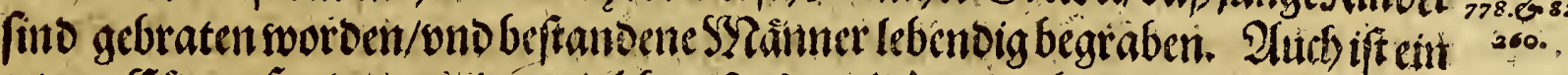

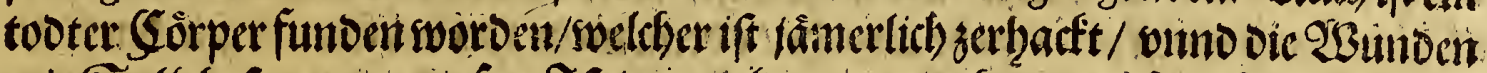

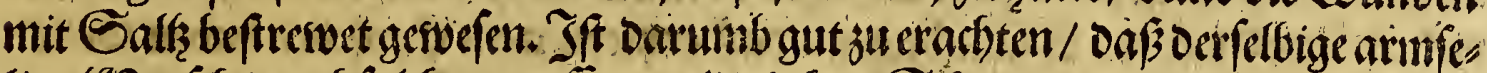

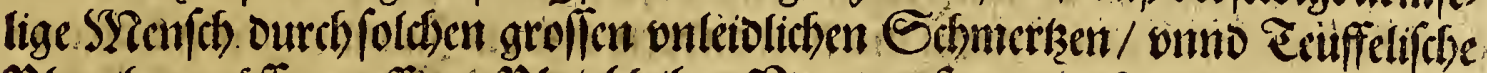

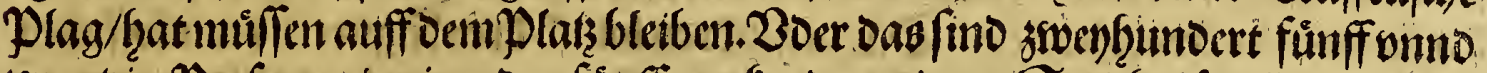
swentzig Perfonente vier ooer fünff narfeno an cinem Strič zufaumien gefop"

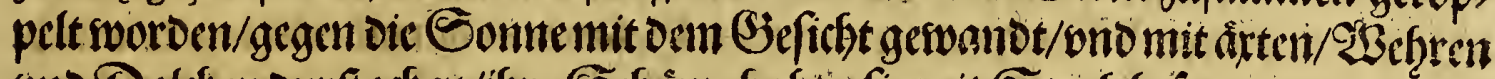

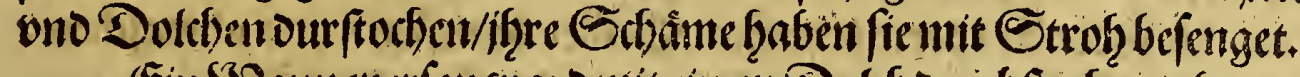

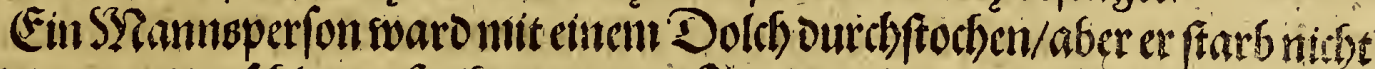

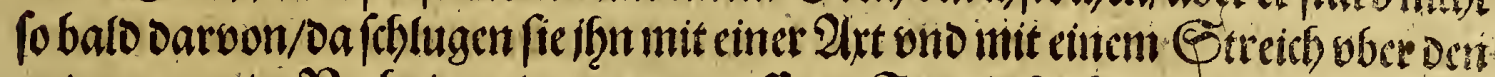

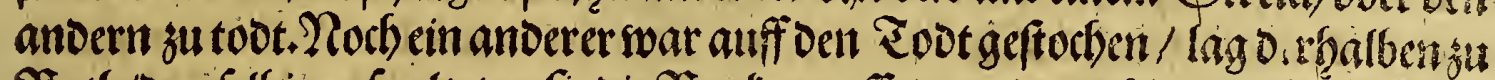

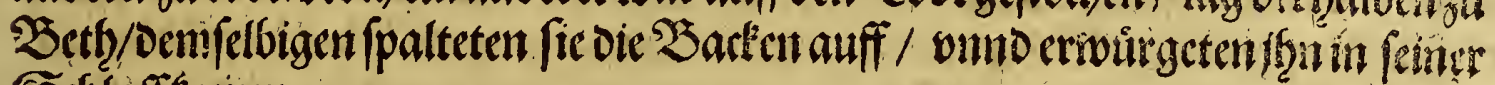
Siblaffécammer.

Damitiches mun nicht zulang mache mit diefen Shiftorien/ fo oa bierben

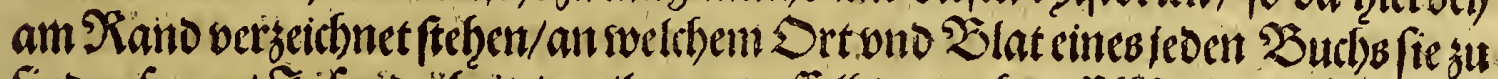

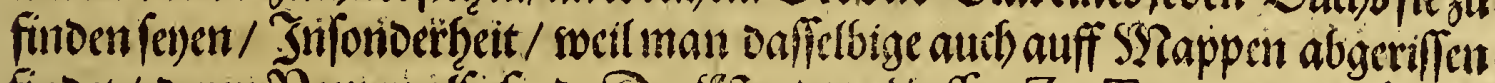

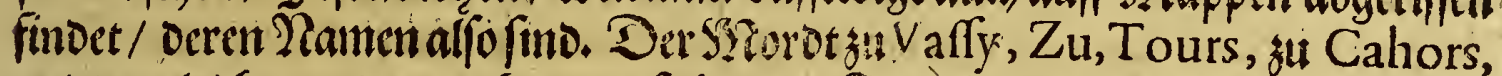

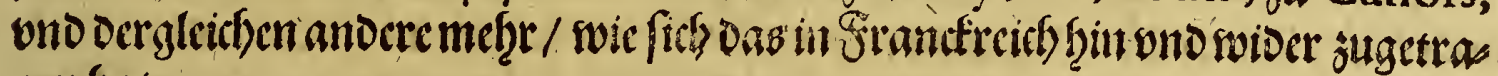
gen hat.

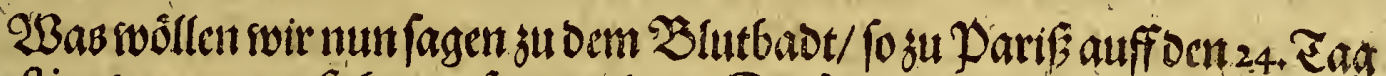

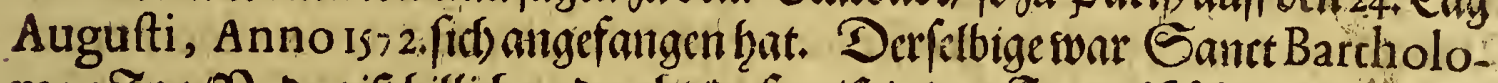

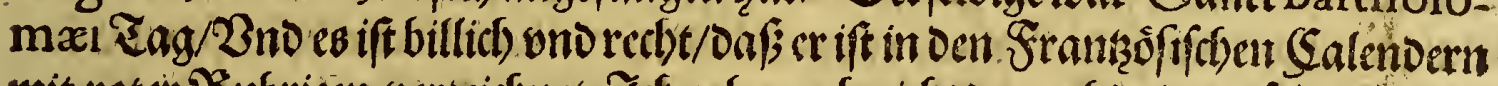

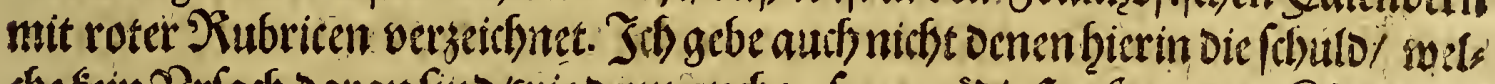

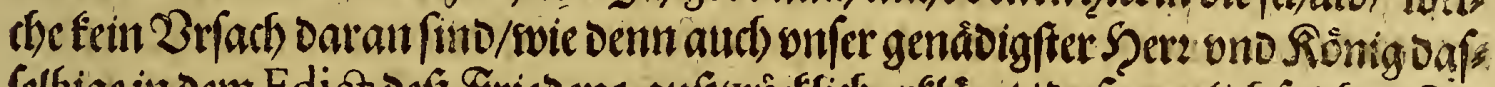

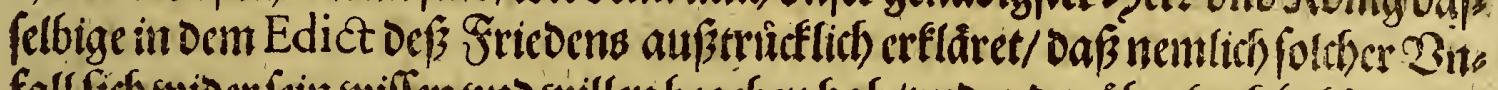

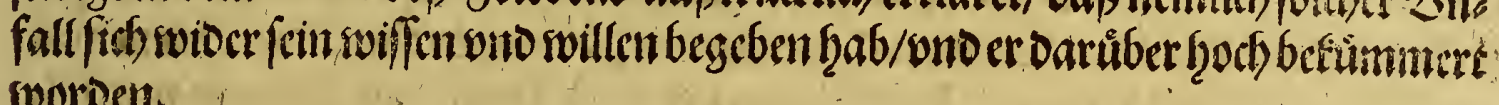
sooroen.

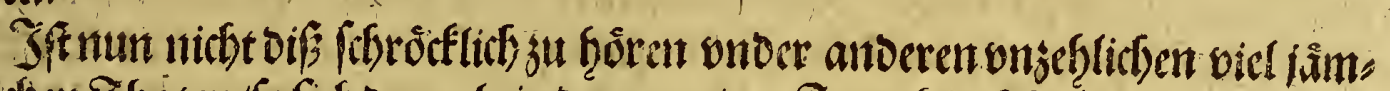

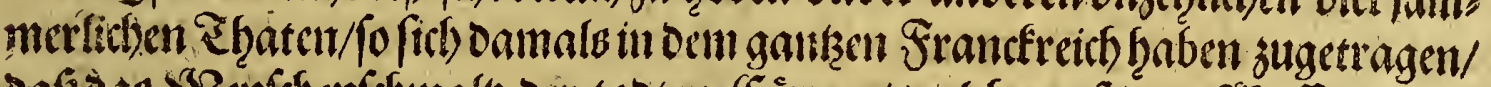

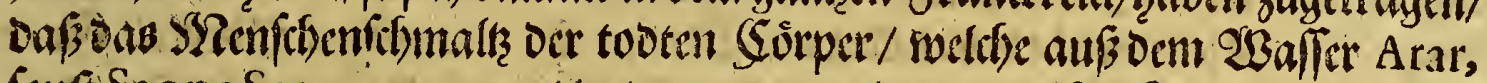

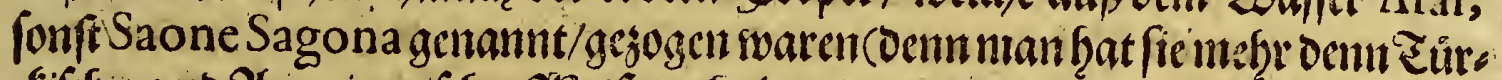

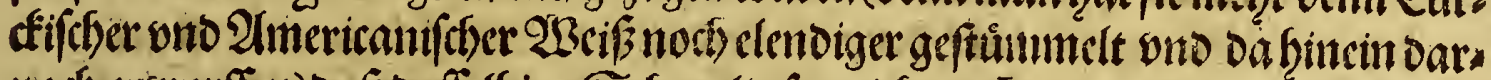

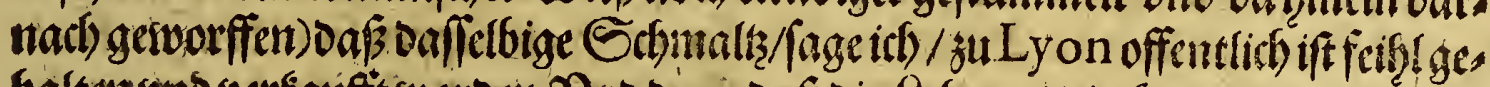

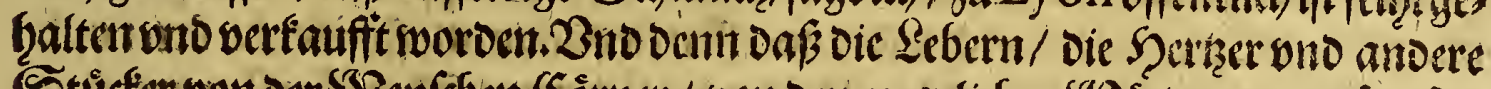

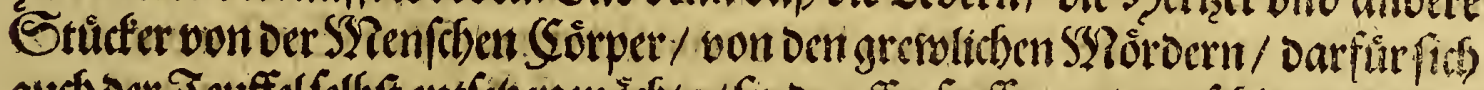

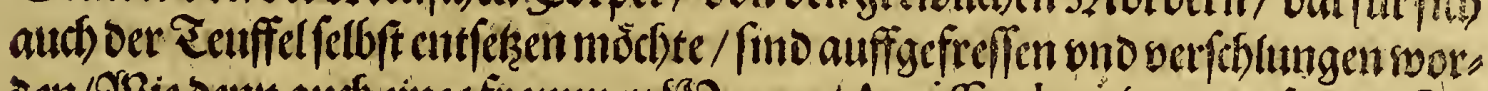

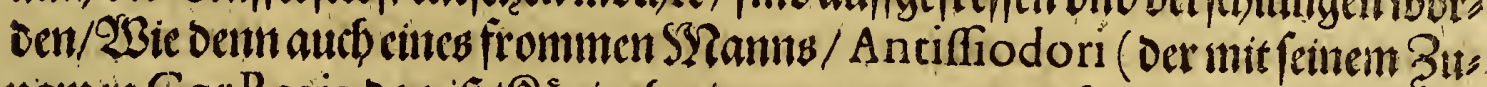

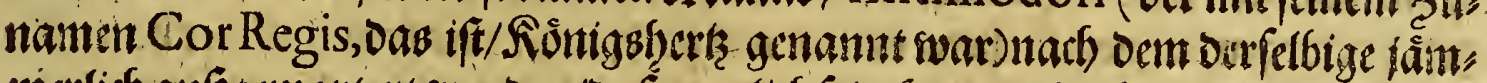

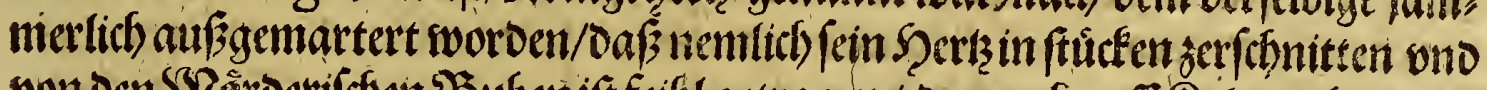

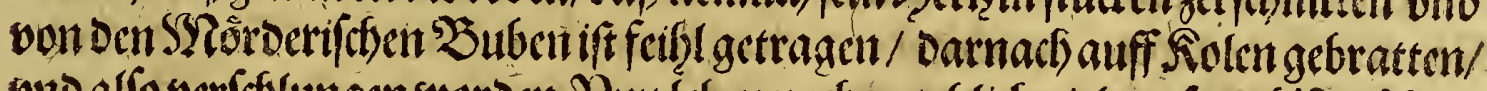

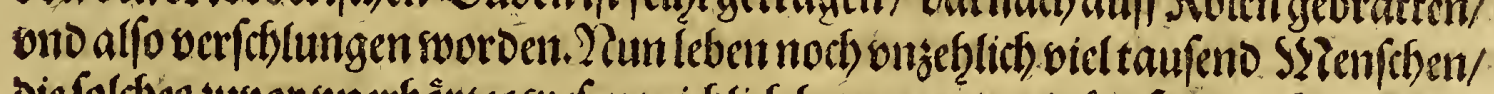

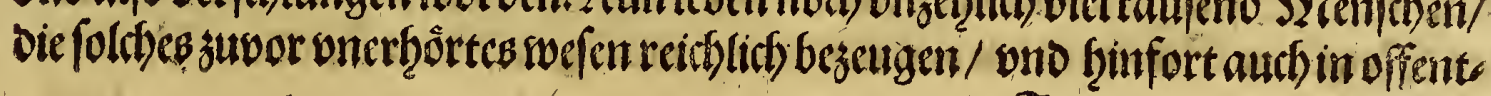

\section{inss}

795.

Biso

3is. 


\section{Oag britte Thath.}

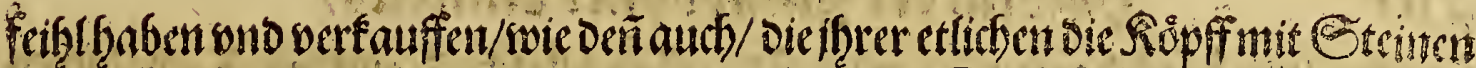

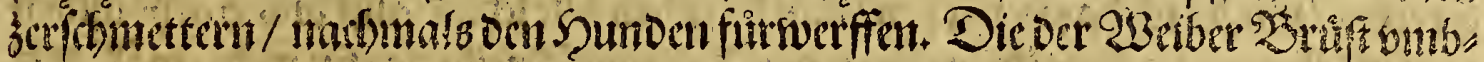

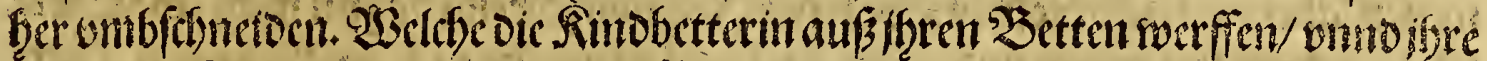

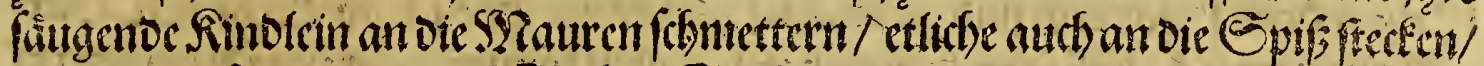

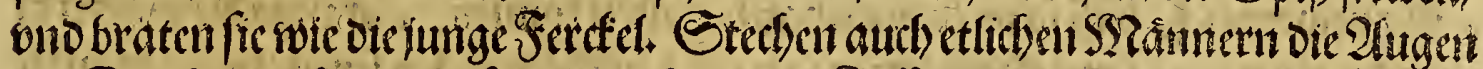

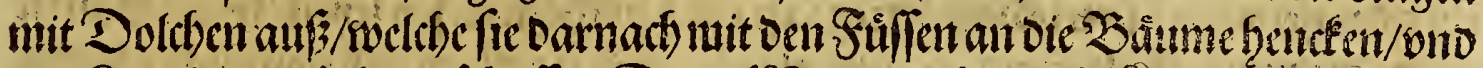

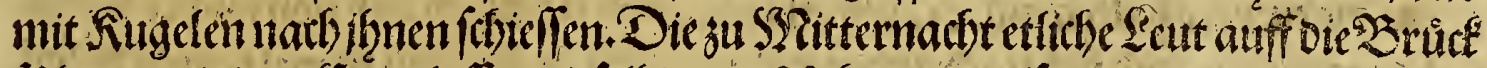

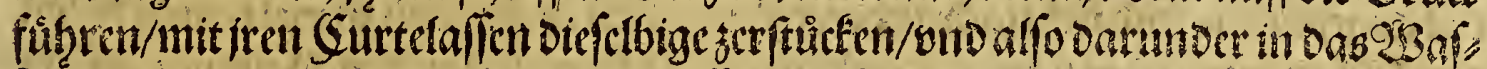

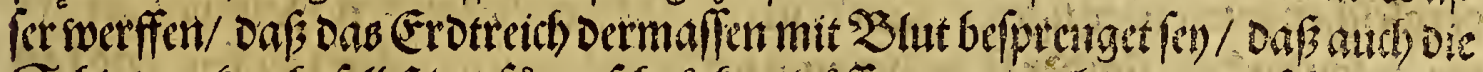

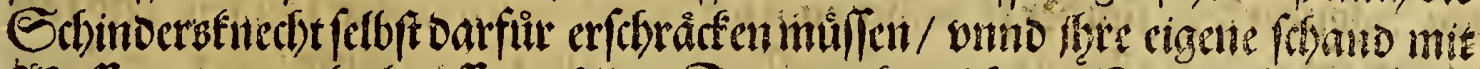

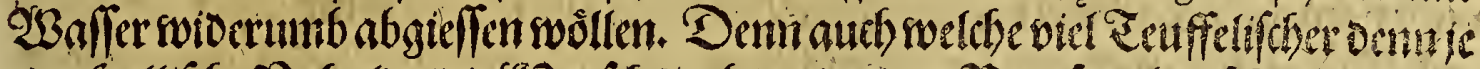

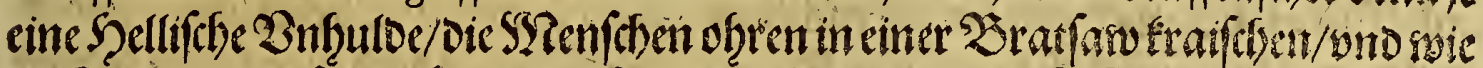

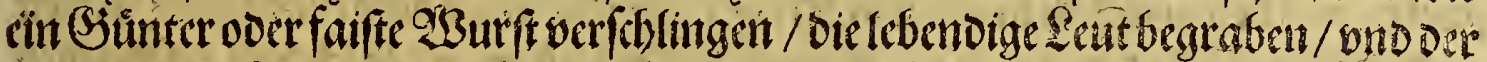

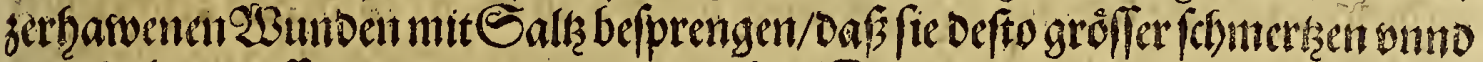

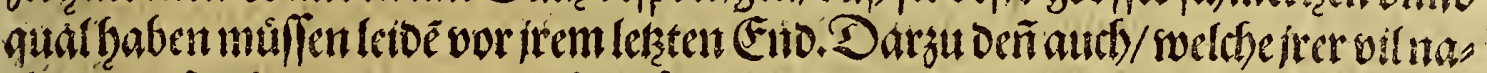

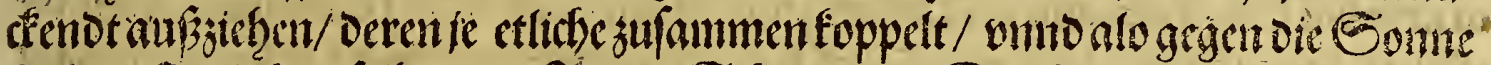

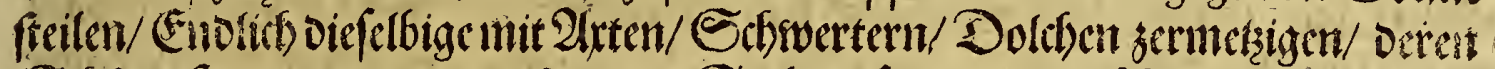

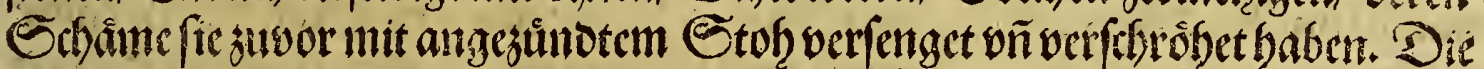

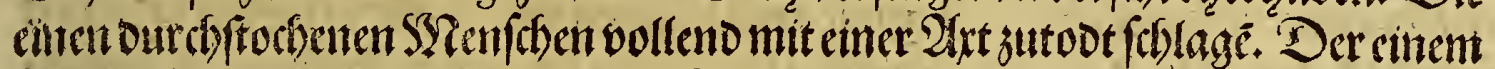

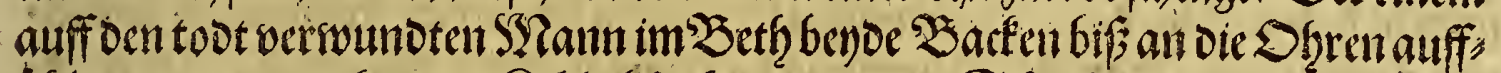

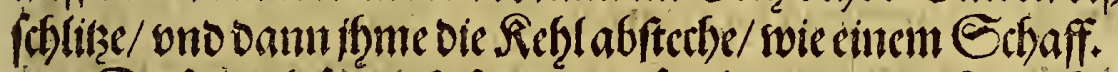

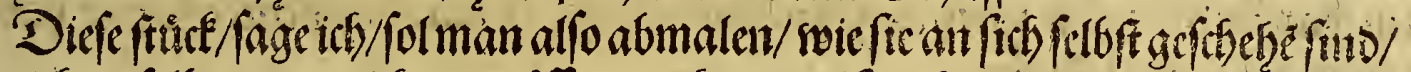

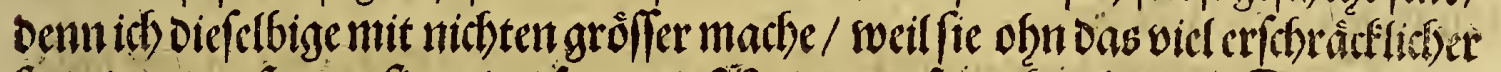

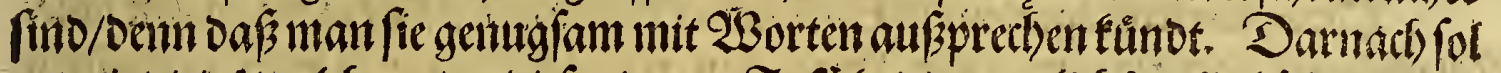

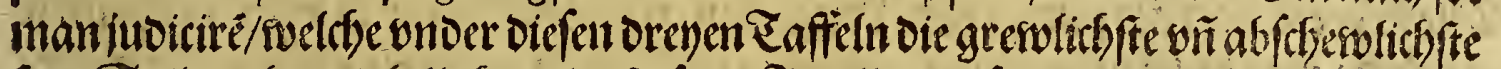

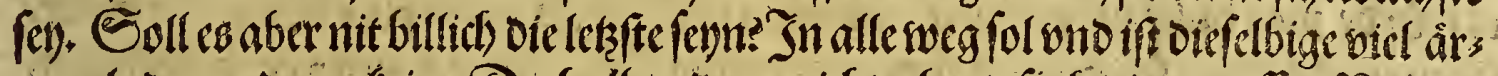

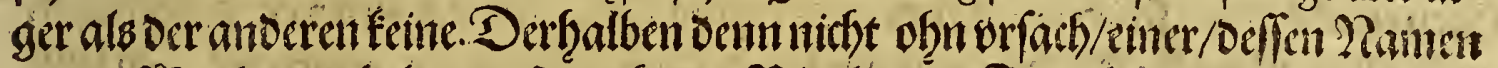

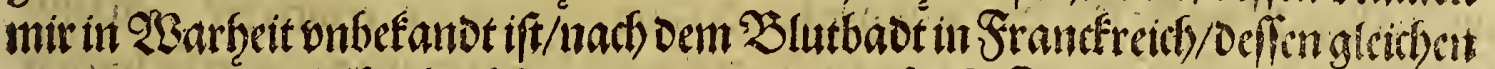

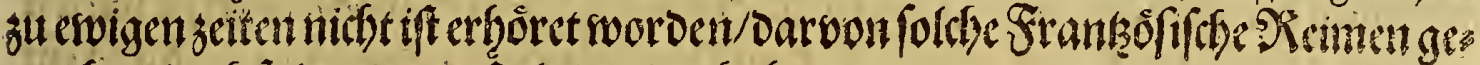
mactit/ Die ich folgender geftalt bertiert bab:

Fresu oich ou Rontig Pharad

Darzudu Renfer?ero\%

Sarodes/2lebaballebeno/

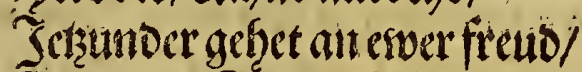

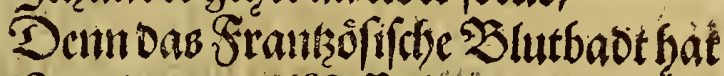

Bertilget erver Syifletf̨at.

Siergu fontot unan noch alle andere Exempel oef

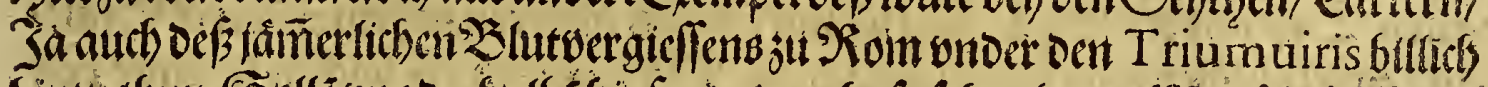

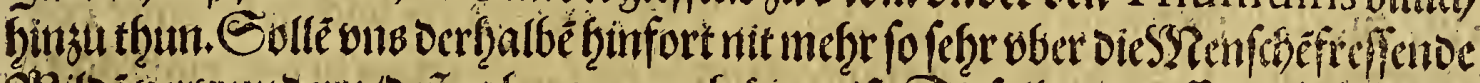

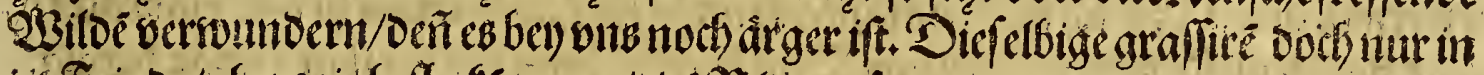

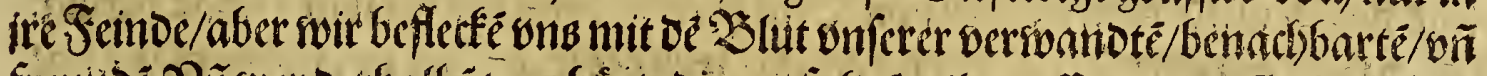

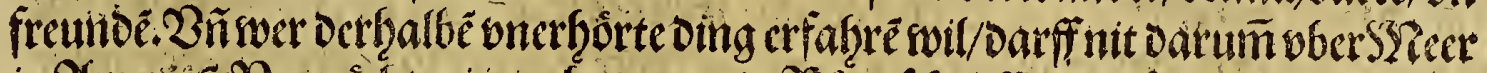

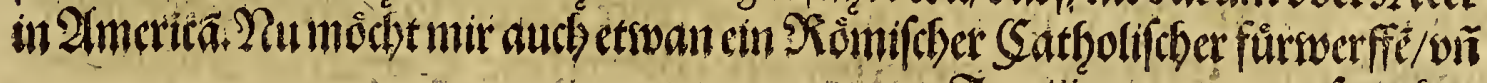

$$
\text { ifi fifection }
$$


Das britfe Ileth.

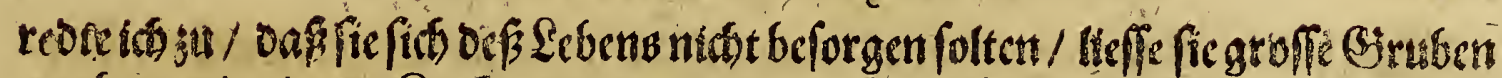

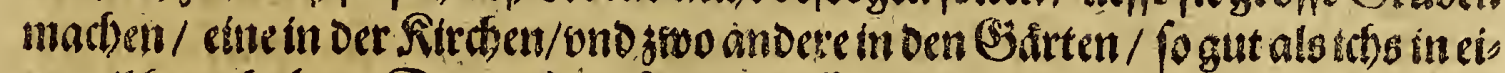

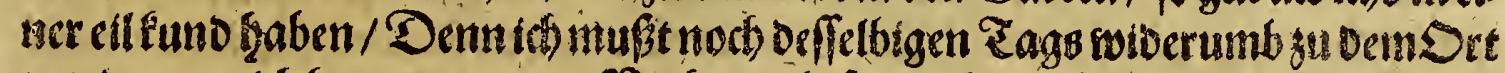

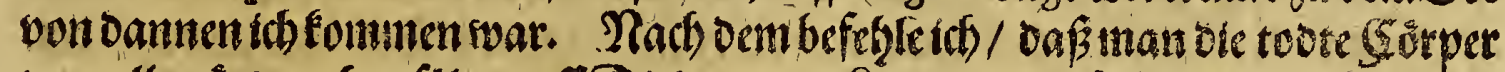

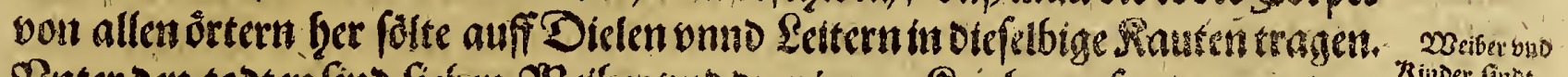

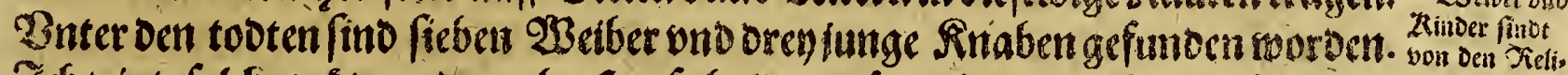

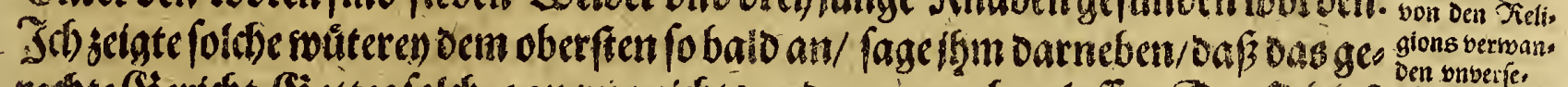

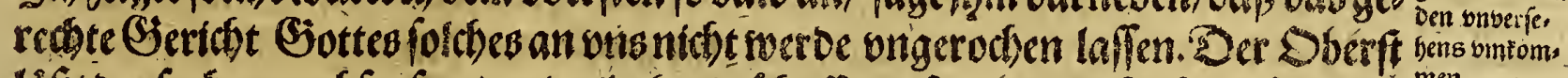

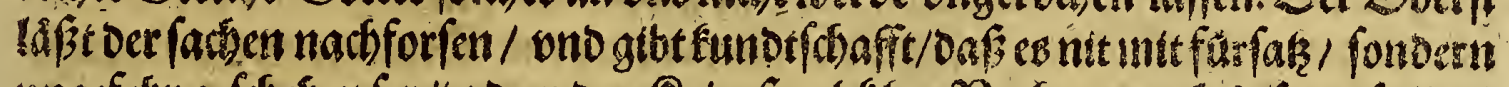

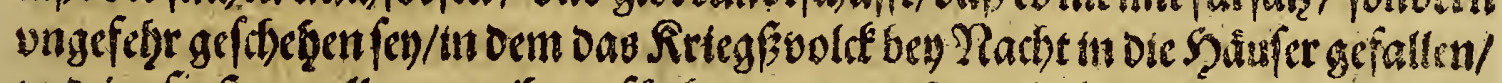
sulo im finftern alles cwasifnen für fommen ersourget haben/etwan aud wol in

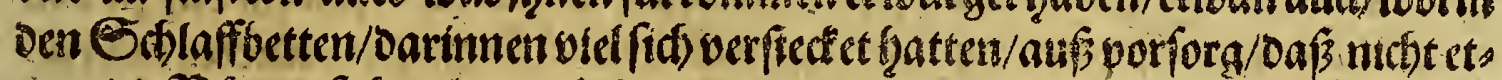

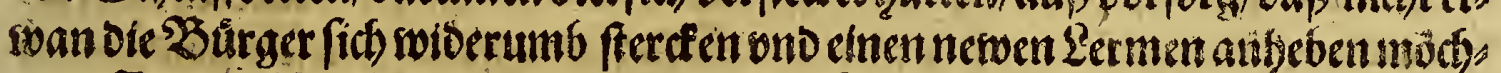

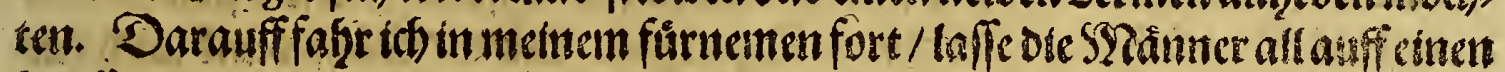

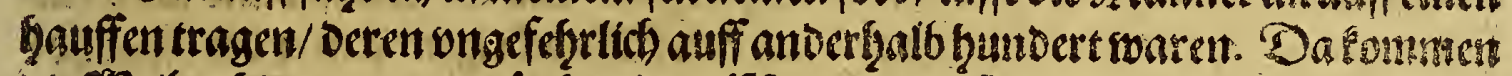

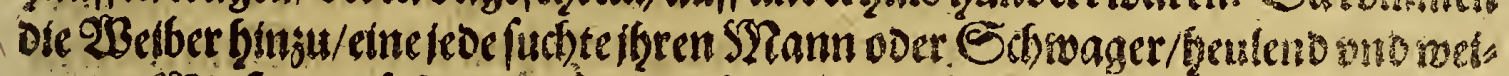

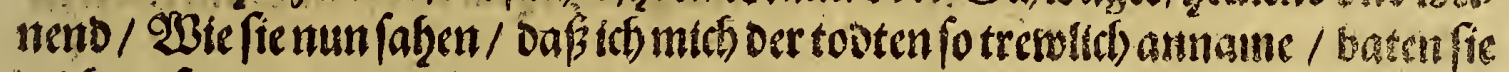

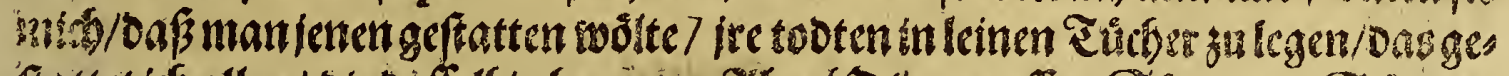

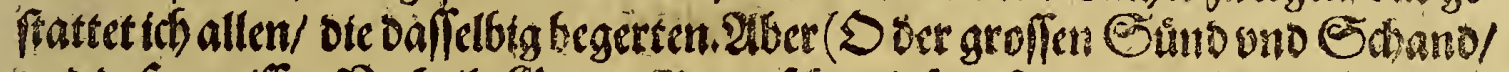

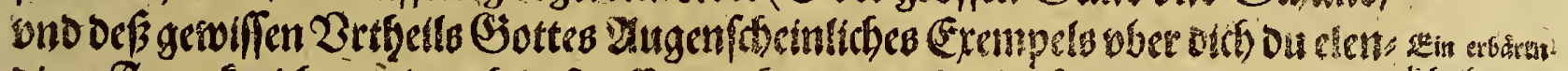

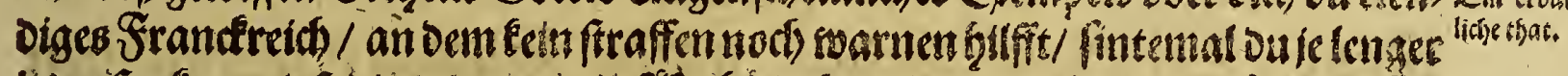

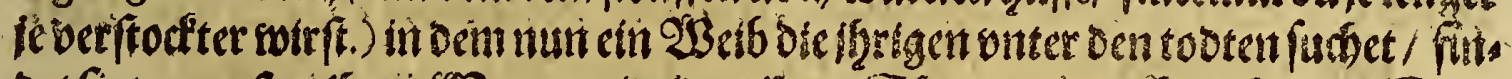

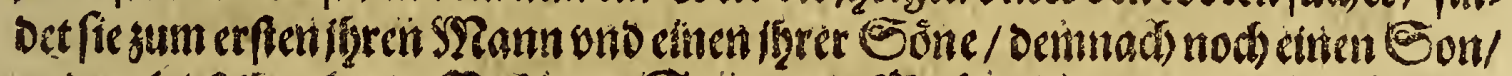

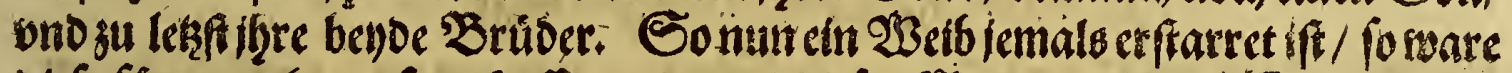

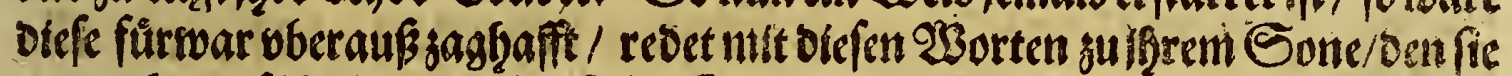

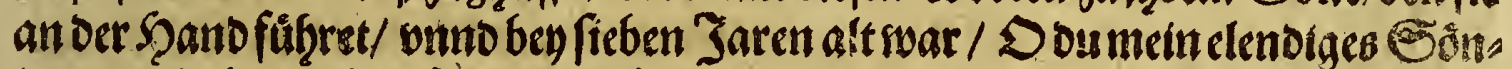

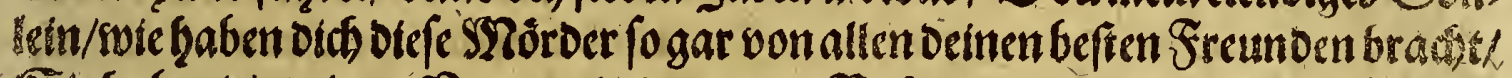
Sie haben oir oeinen $\mathfrak{B a t t e r} /$ oeine sween $\mathfrak{B}$ ruber/onno Deine stween Bettern

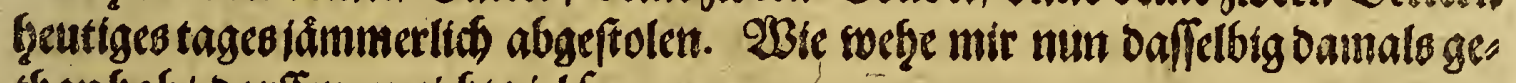
than hab/ Darfiman nicht viel fragen.

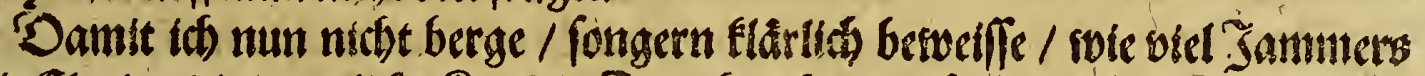

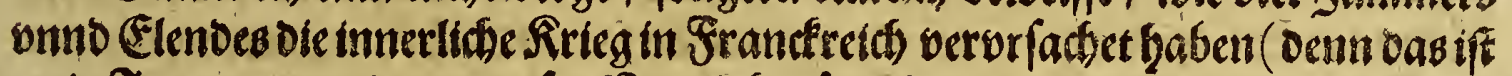

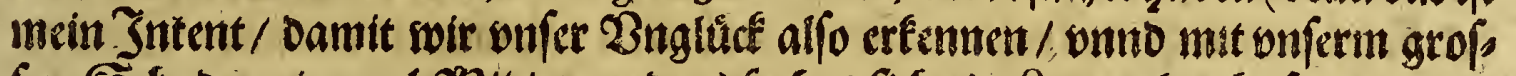

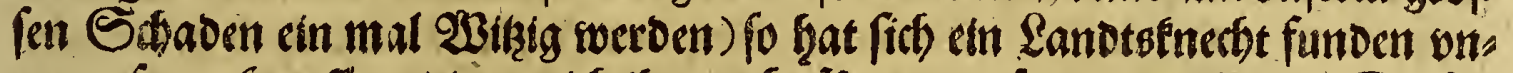
ter vnlerm Sauffen / Denn tidh ifn nidft für Der vofern einen bielte. Derfels

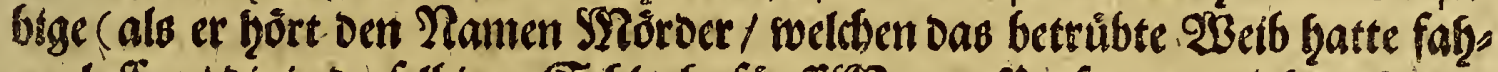

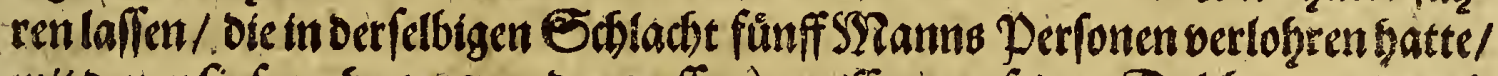

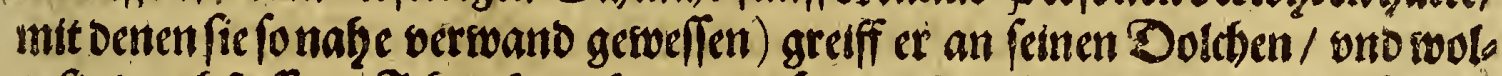

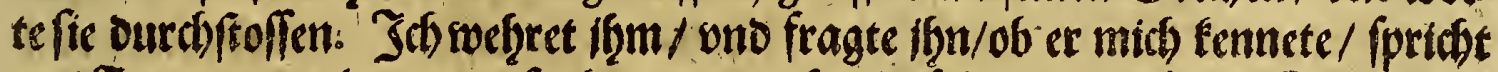

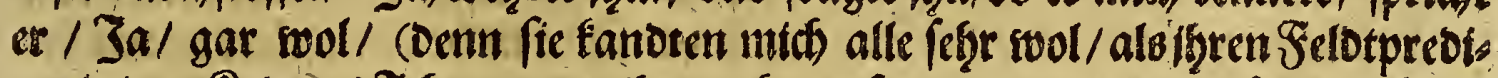

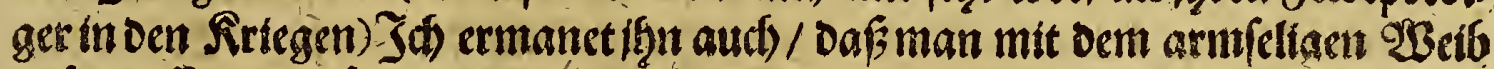

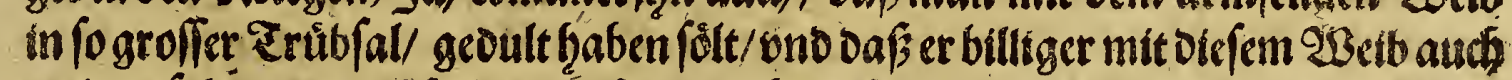

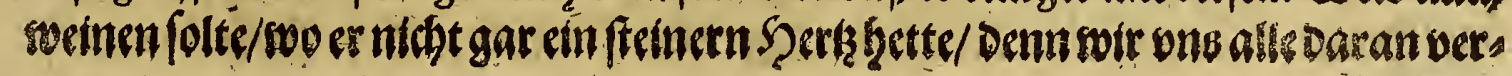

funpiget 


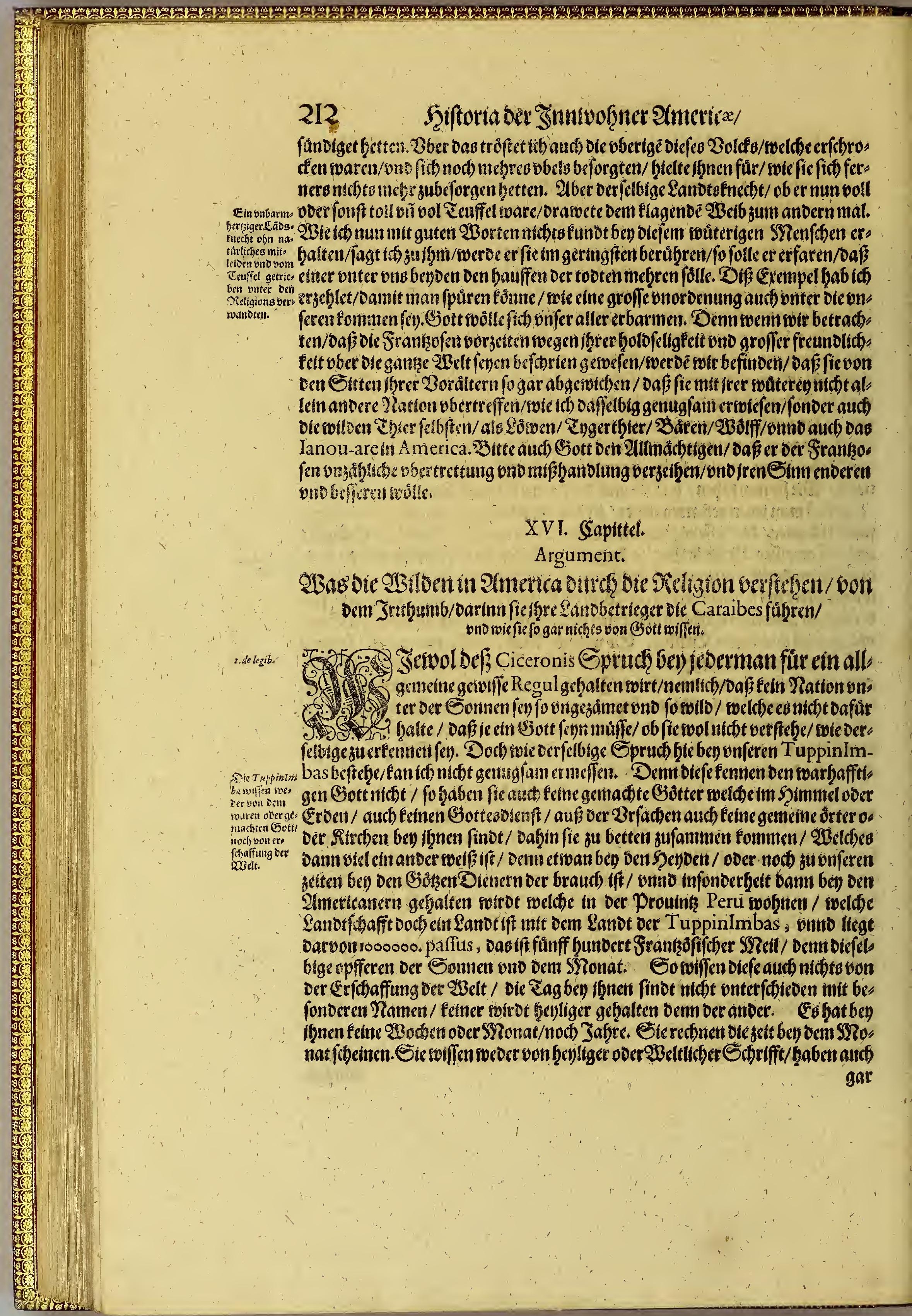




\section{Das britte Treil.}

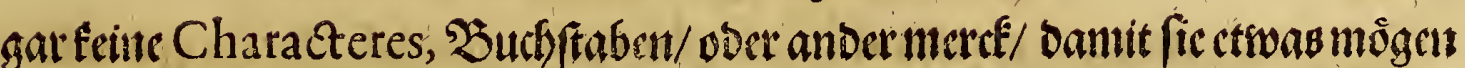

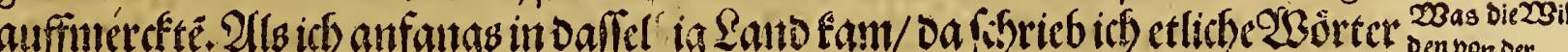

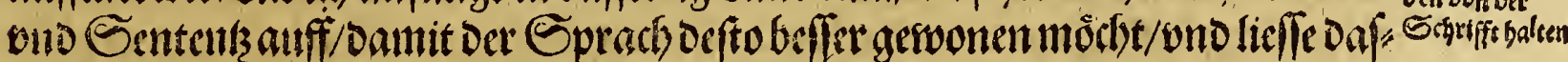

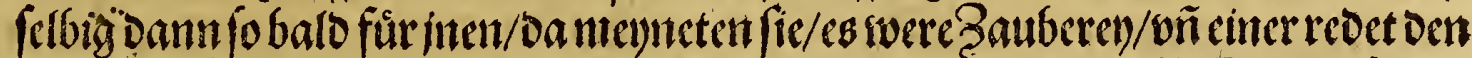

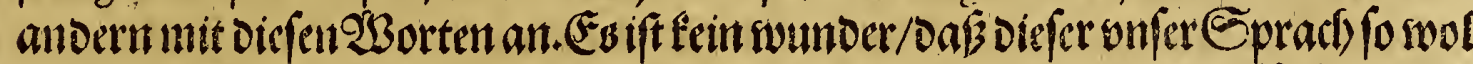

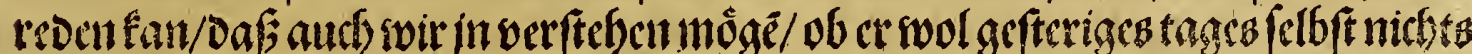

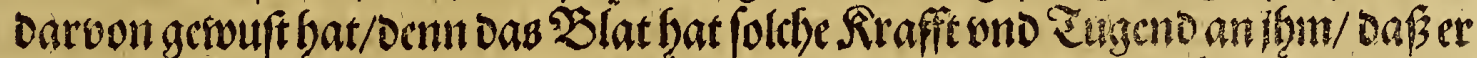

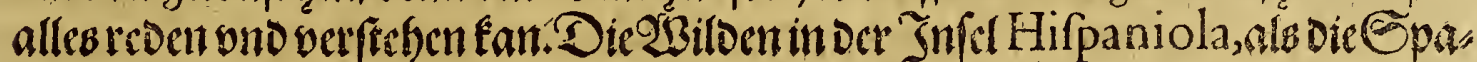

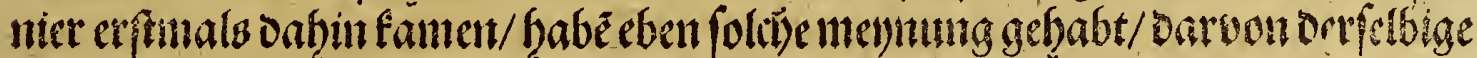
Siftorion fotreiber mit dicfen worten redet. 2lls bie 2lmericantr vernamen/Da/3

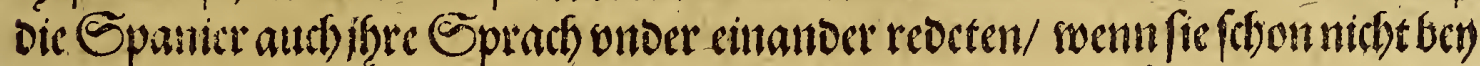

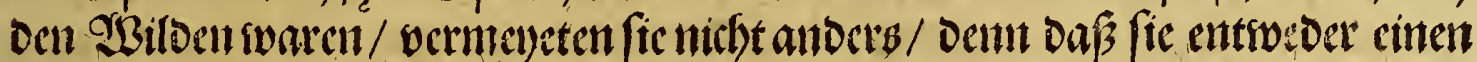

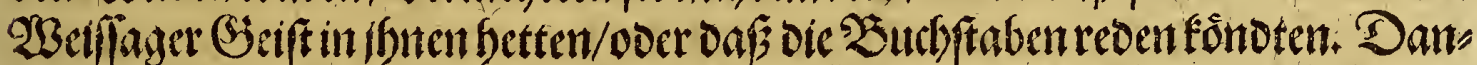

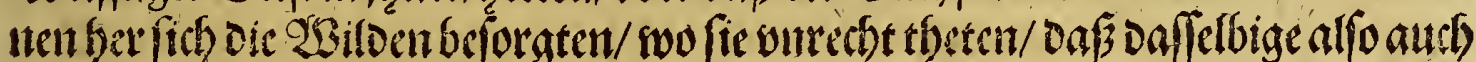

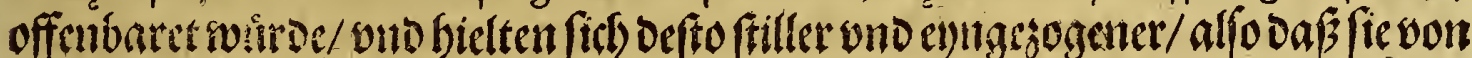

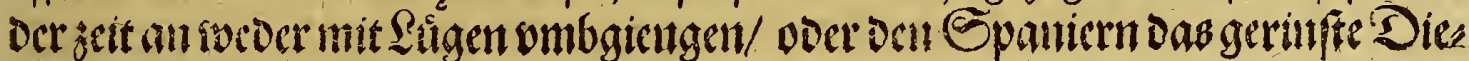
biffer weif entwanten.

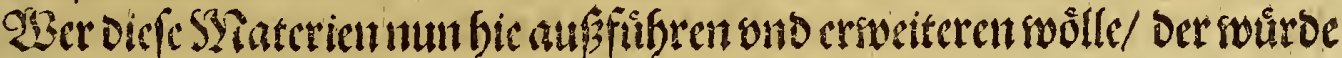

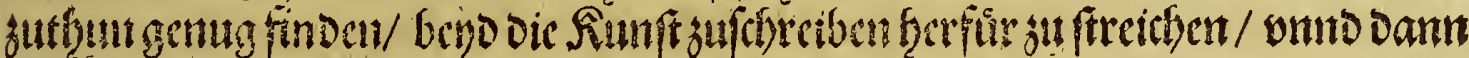

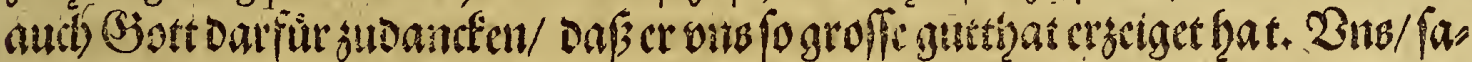

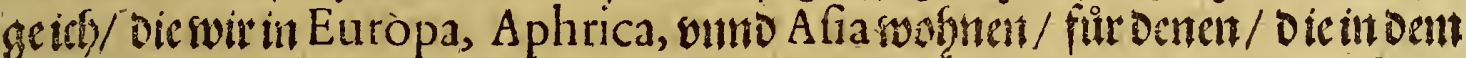

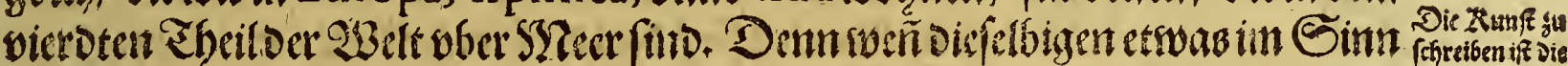

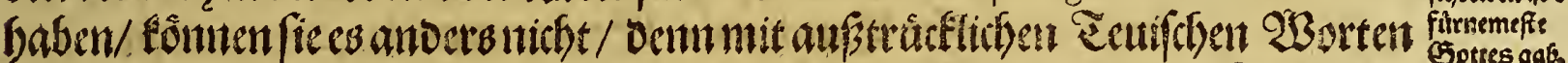

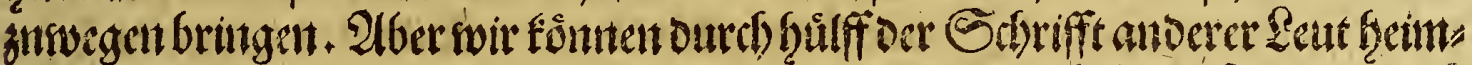

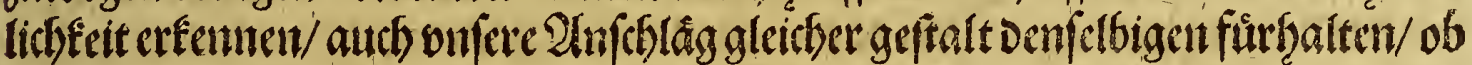

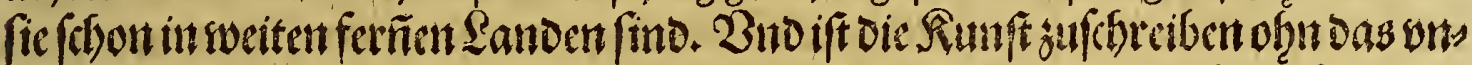

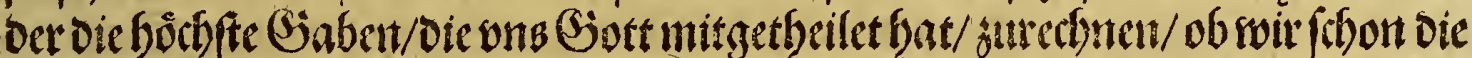

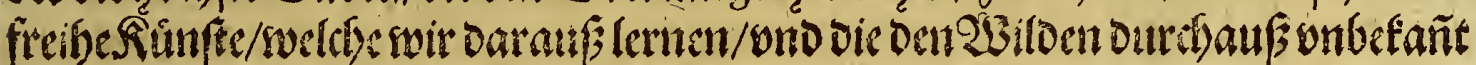

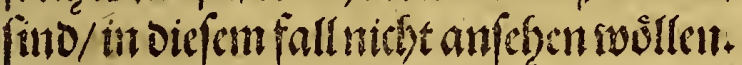

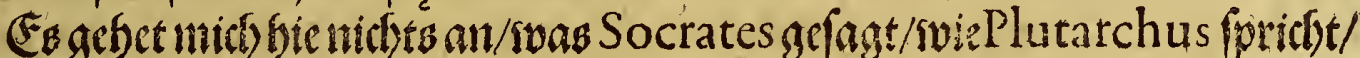

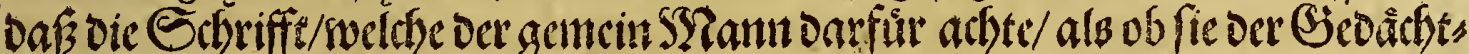

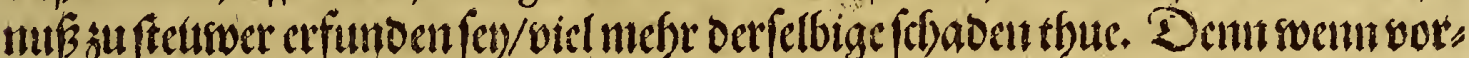

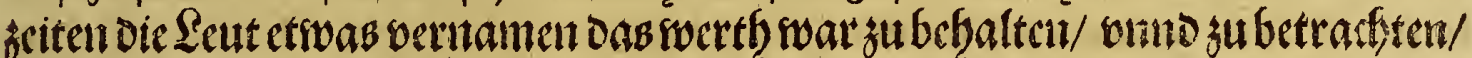

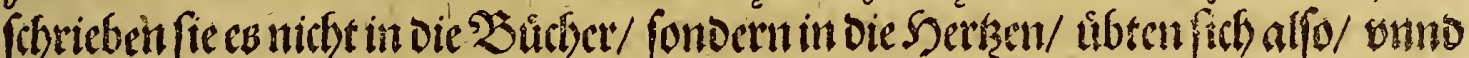

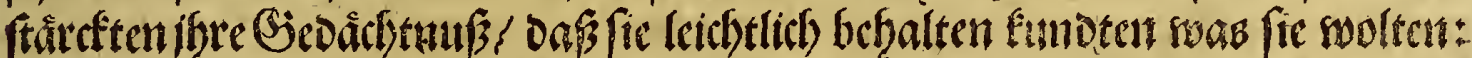

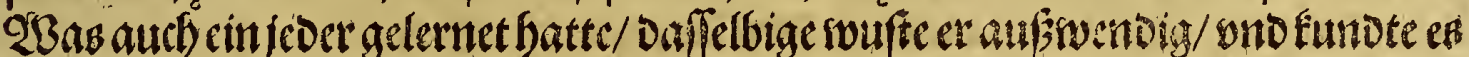

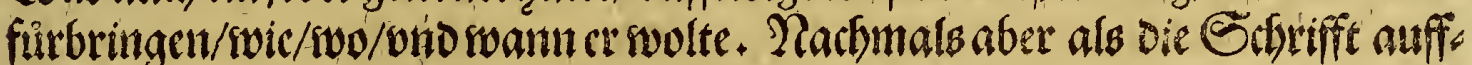

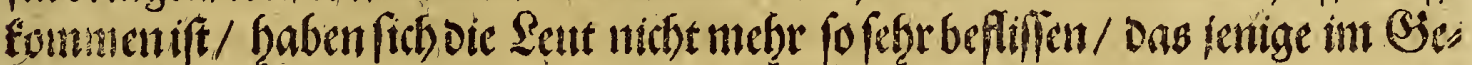

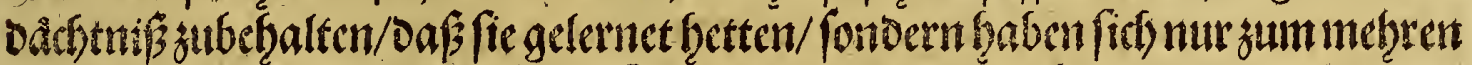

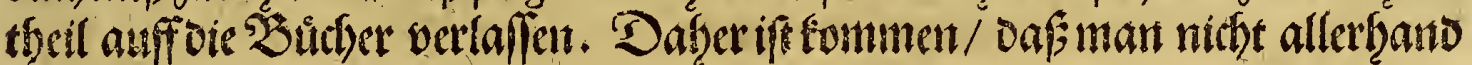

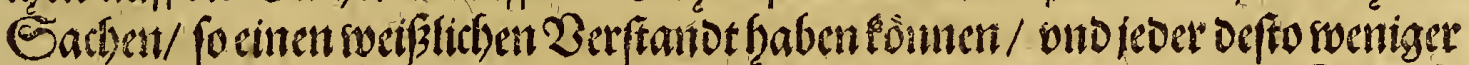

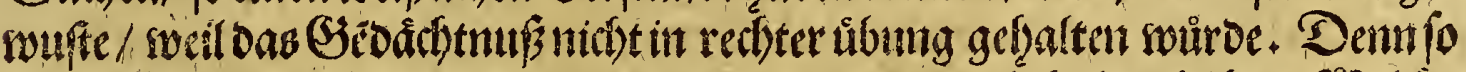

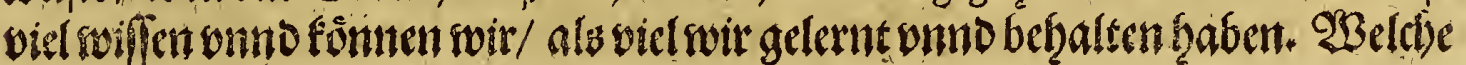




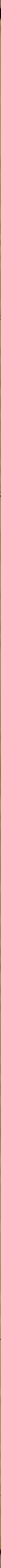




\section{Das britte Ificil.}

2IS

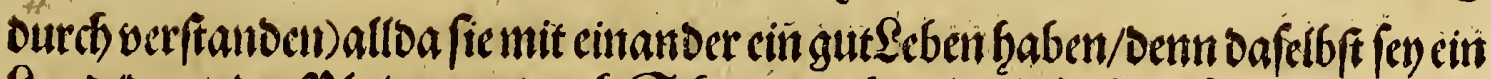

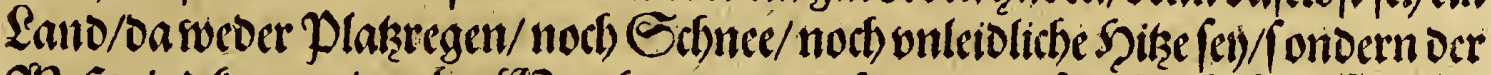

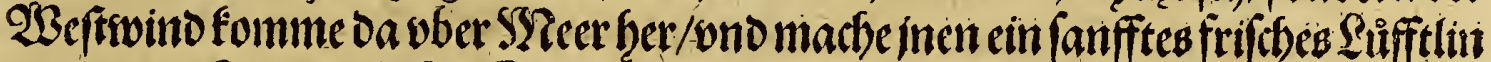

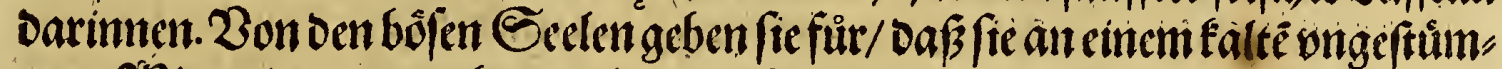

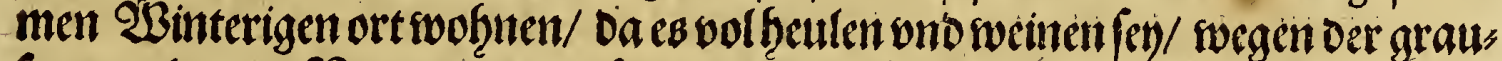

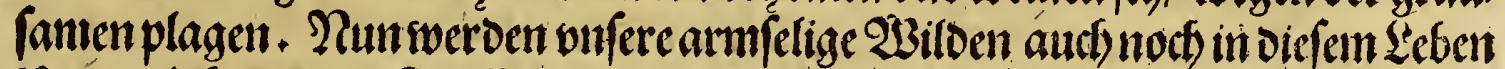
iâmmerlich won ocm Eeuffel geplagt/oem/ie fonft noeb) einen anbern ?amen ges

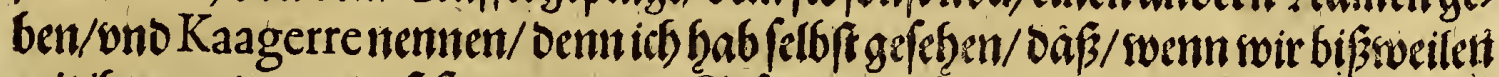
mitifinenteoetm/Daf fiebnoer betn fench fen/swic Die Shirntobige Leut/Hei, Hei, belffet onb/, Denn Der Aygnan feblegt virs.

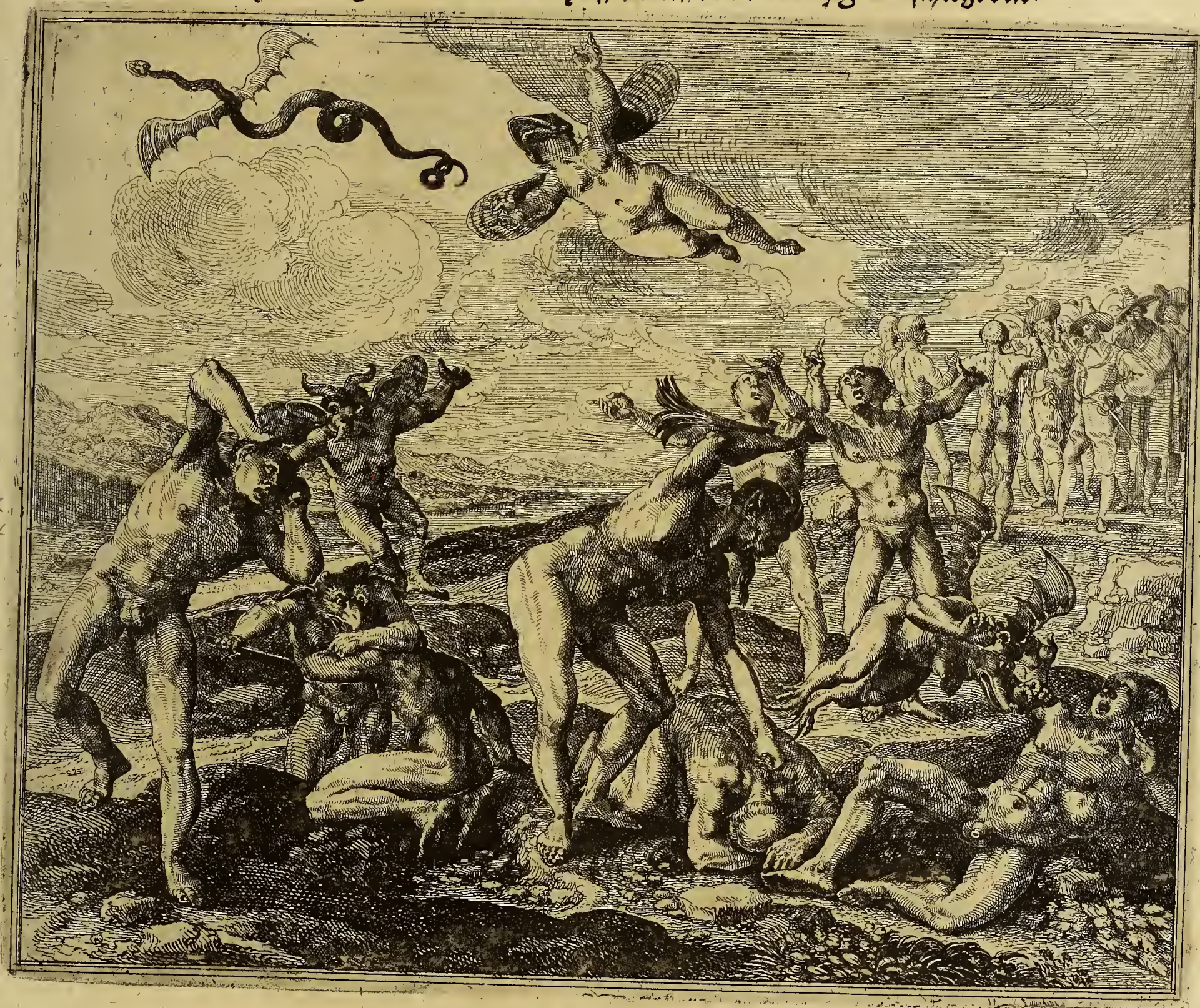

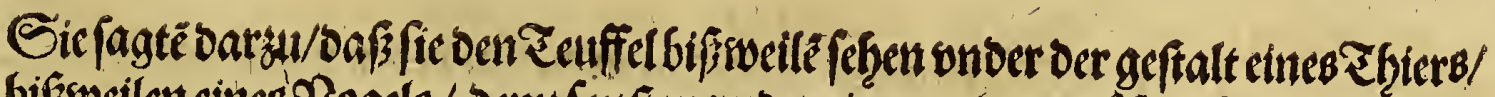

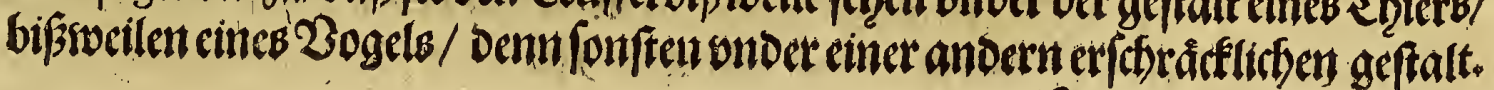
3 Sil 


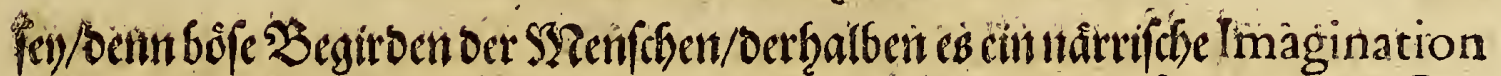

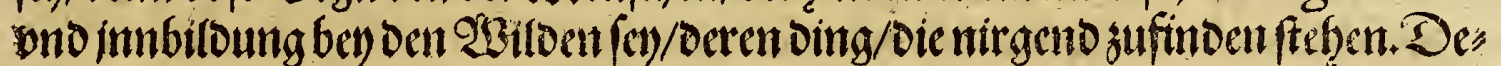

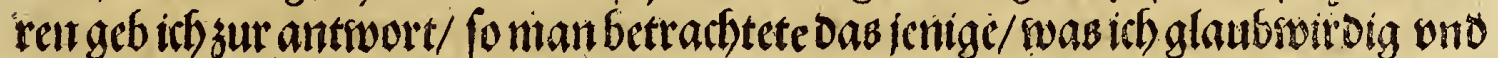

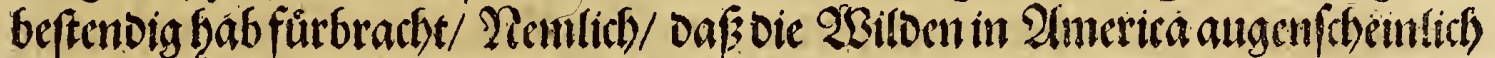

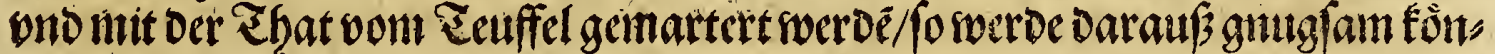

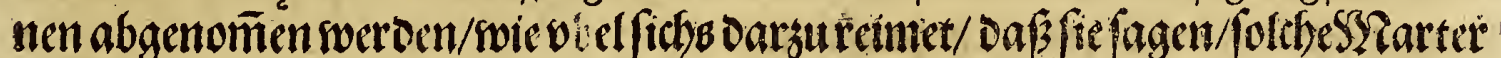

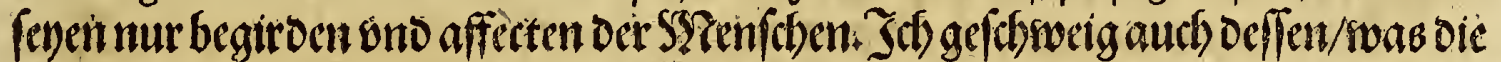

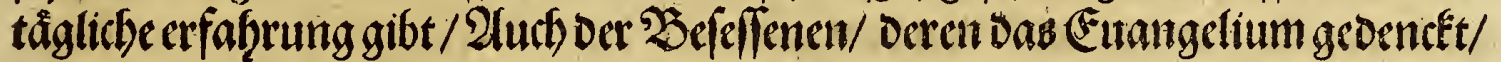

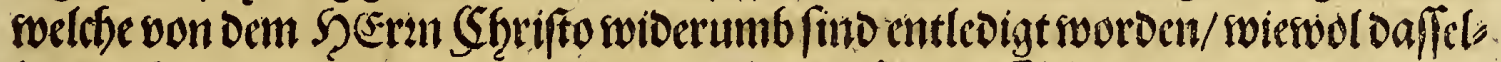

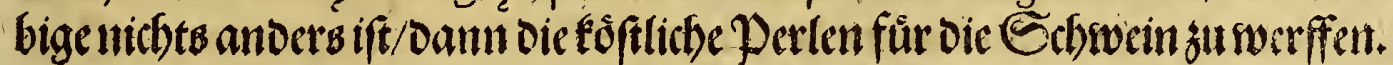

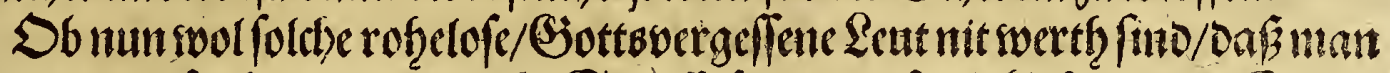

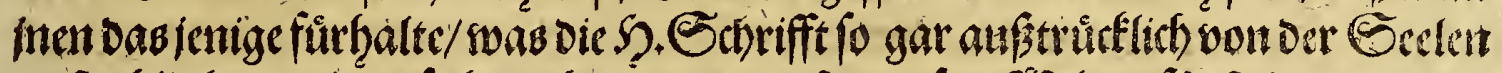

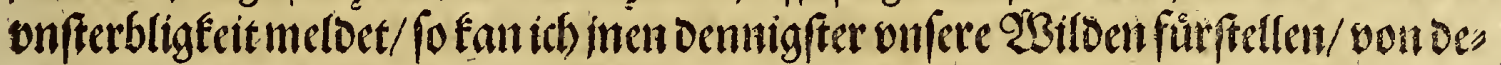

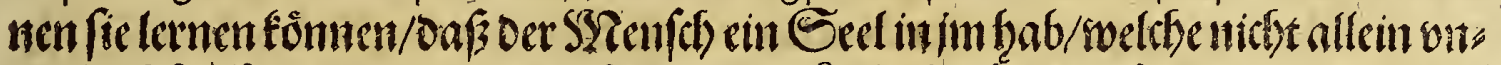

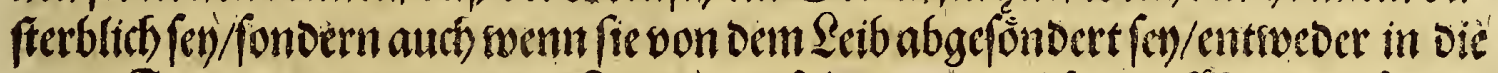

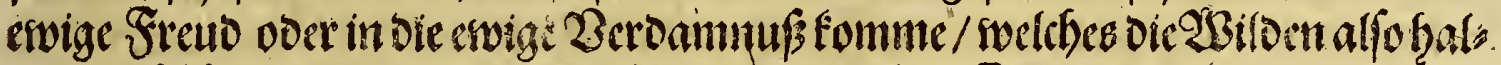

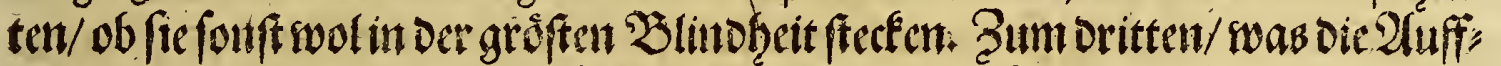

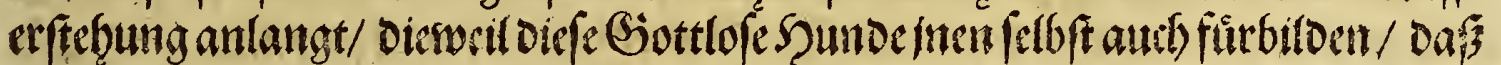

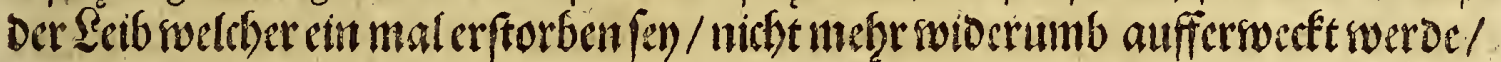

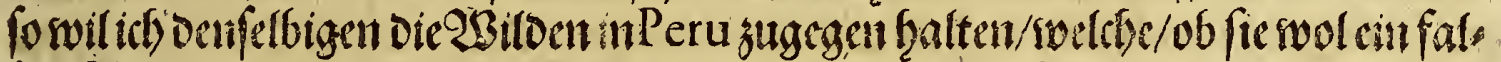

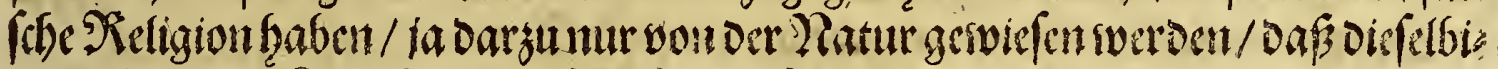

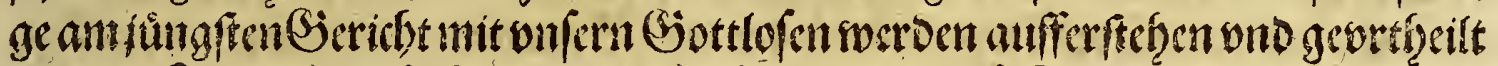

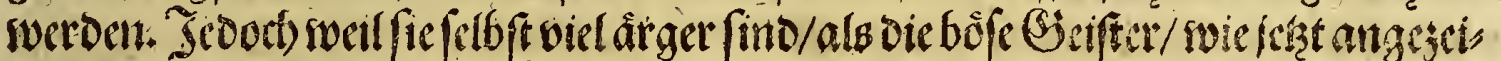

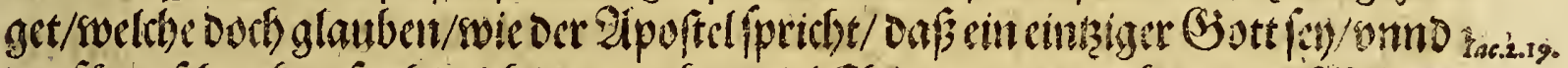

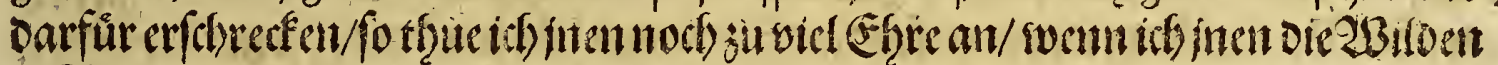

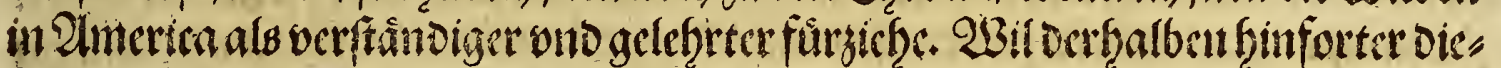

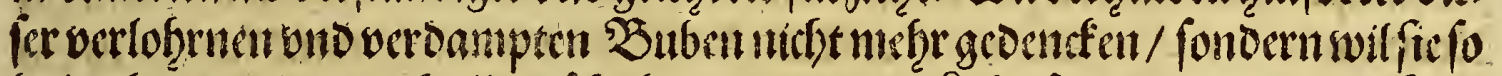

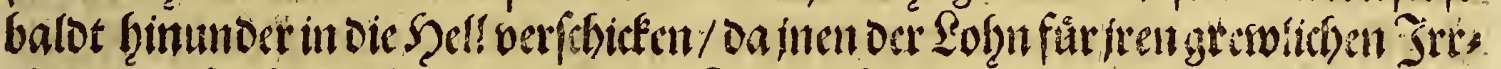

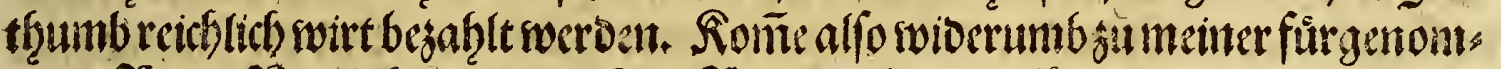

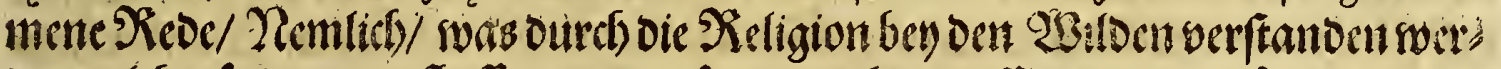

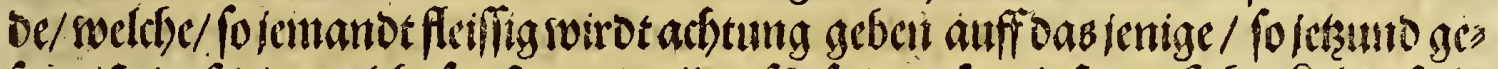

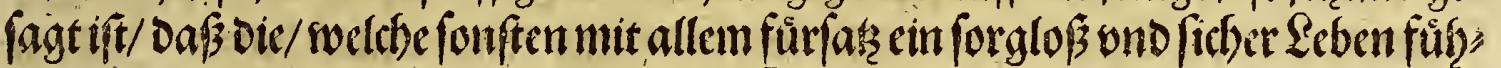

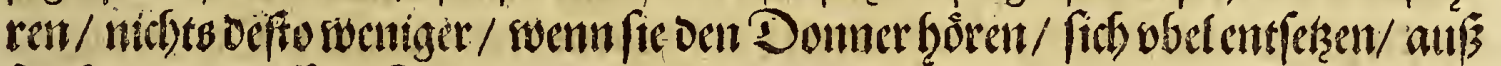

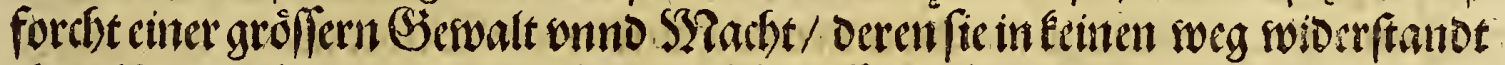

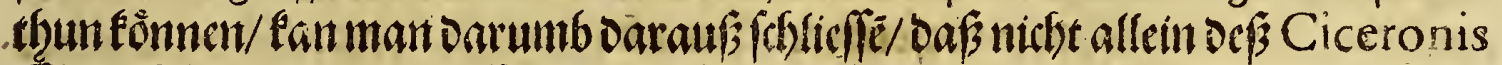

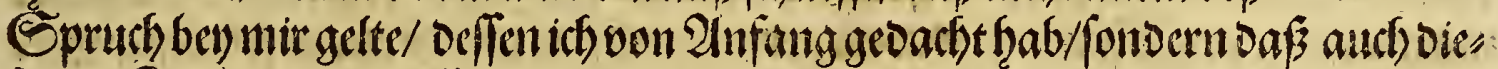

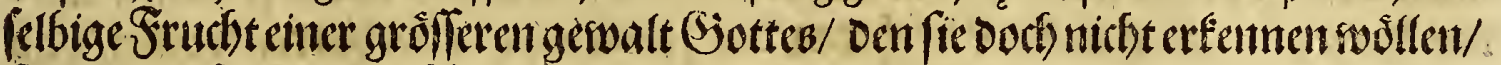

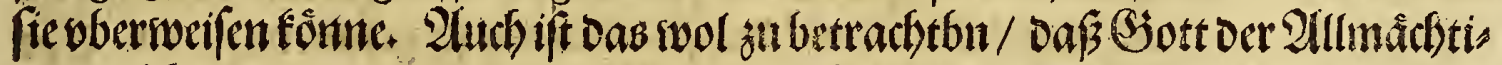

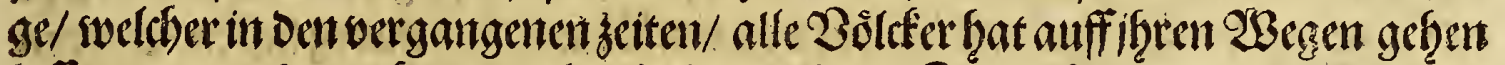

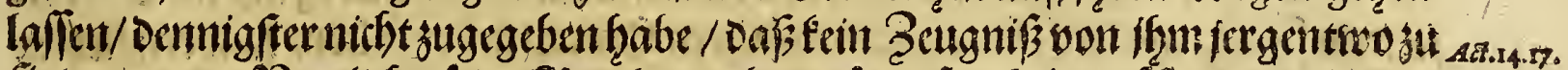

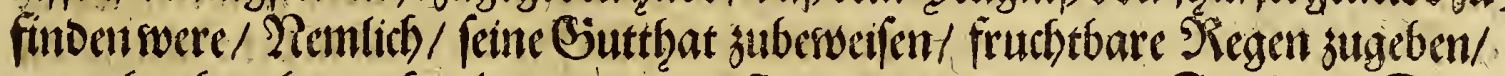
von obenterab/auch gelegene zeit ber (Ernote/ onno anoerer Fruebten. Das"

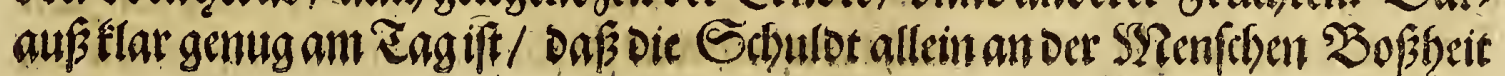

3 iif (col 


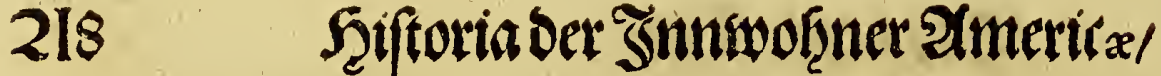

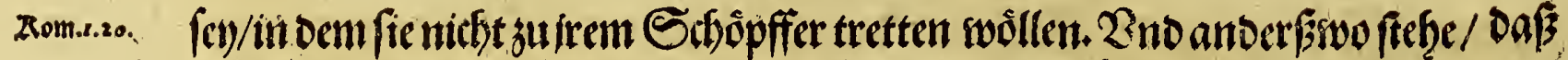

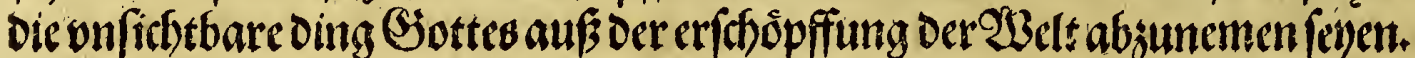

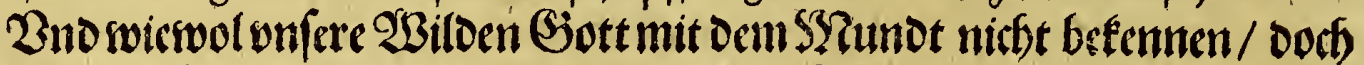

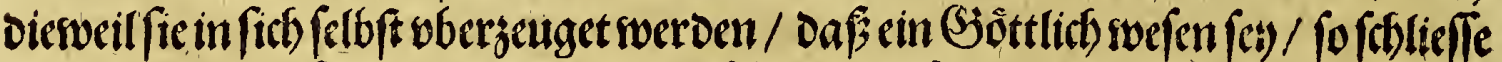

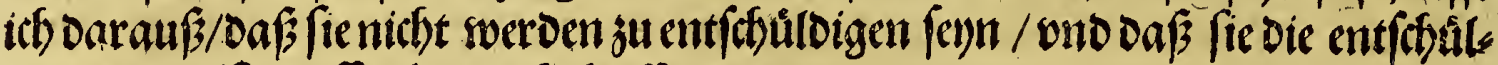
Digung oer 3 nwiffenteit nicht felfen werde.

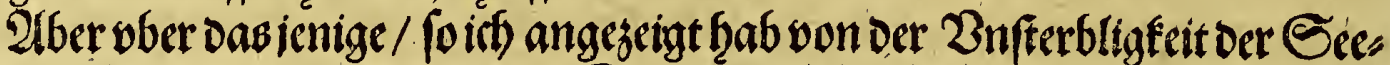

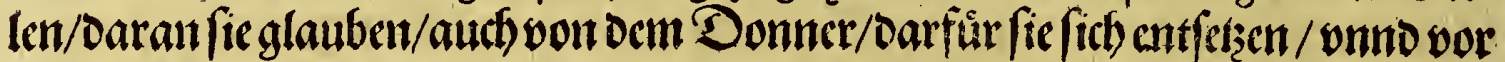
Den Seuffeln/ von Denen/ie geplagt werden/ welche oren Stucf Die fünemb/te

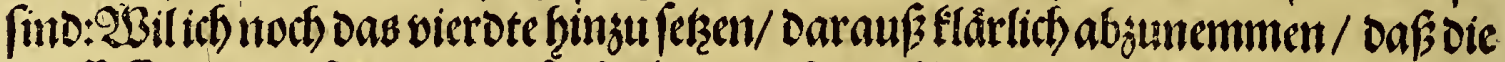

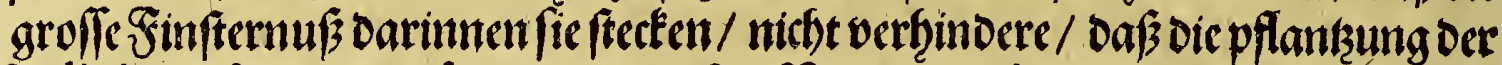
Religion (fo swir nur fo cinen ferslichen Ramen Diefen verouncfeltem 2 Bercé

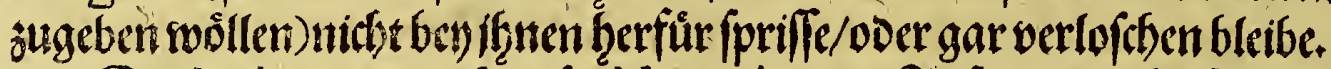

Caraibesfalfdis
proppecte.

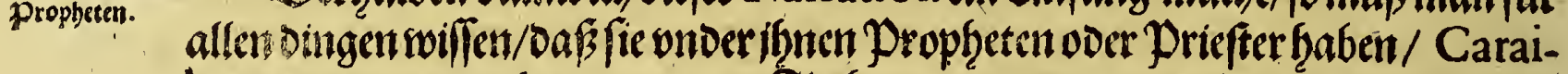
bes genennt/ oie getgen won einem flecten zum andern/ ono bereden das armfelis

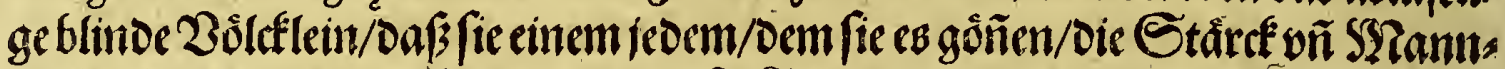
bafftigfeit fómen mittheilen( Dierweil fie (Seifter haben oamit fie omb̆geben) alfo

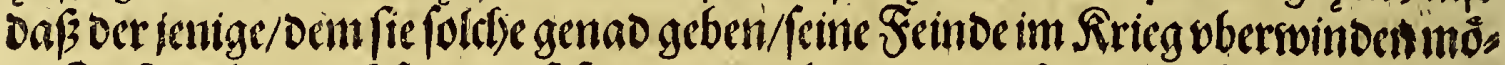

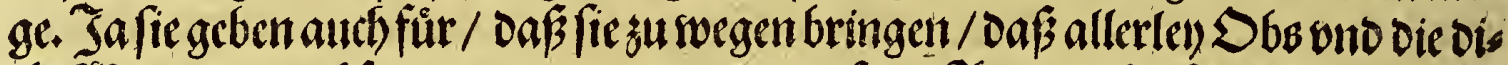

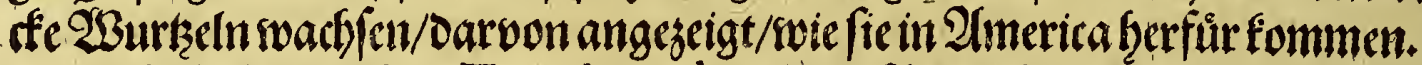

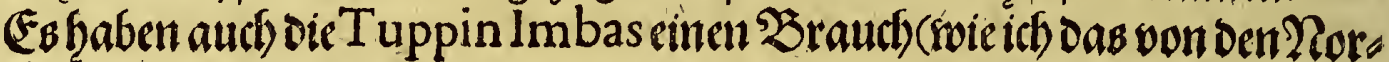

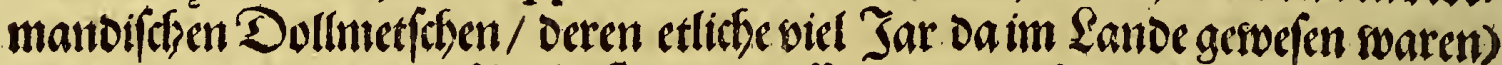

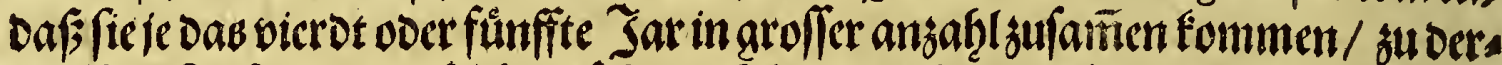

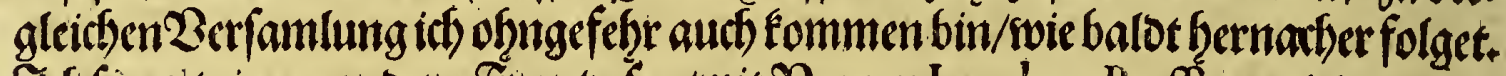

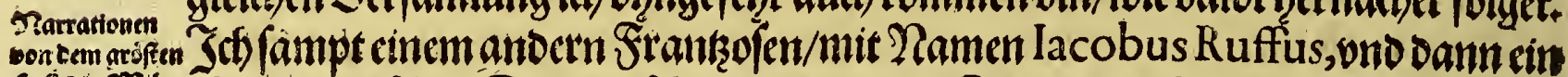

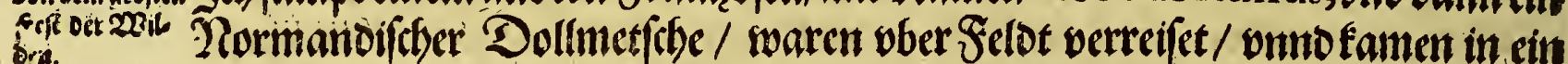
Dorff / folgendes SYorgenmatyten wir ons früfe wiberumb auf on/ere? Renfs/

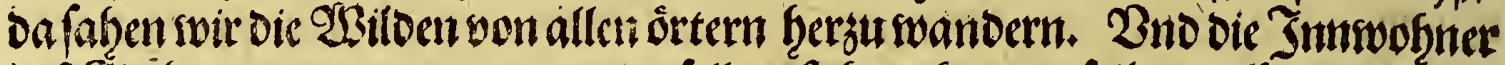

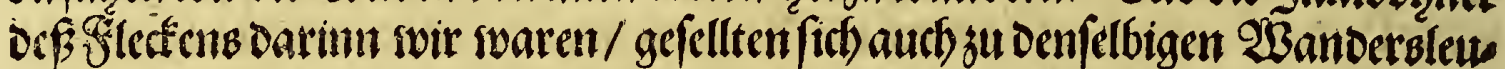

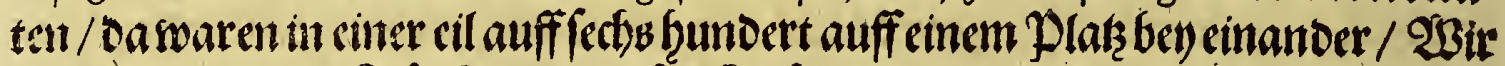

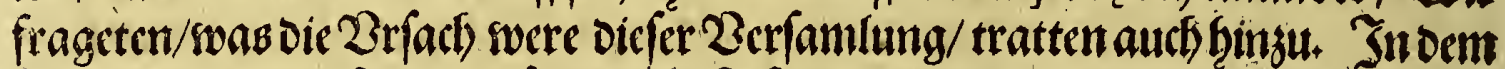

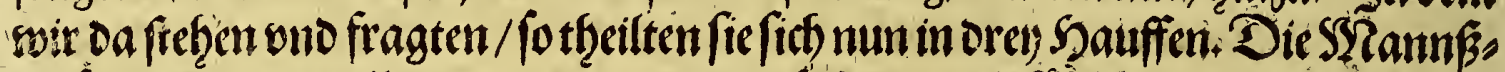
perfoneri giengen alle mit einanoer in eine Sütten / Die SBseiber in eine be fondere/.

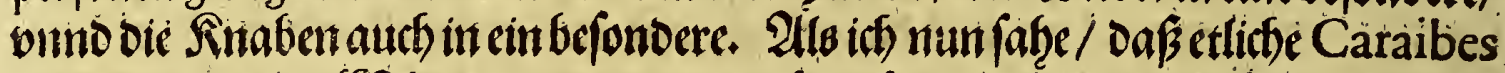

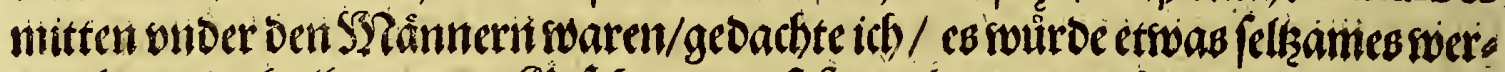

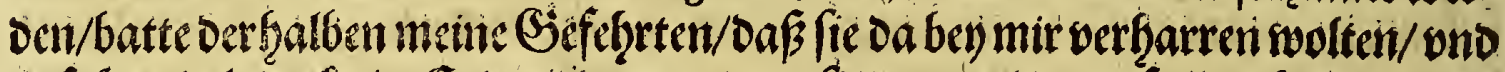

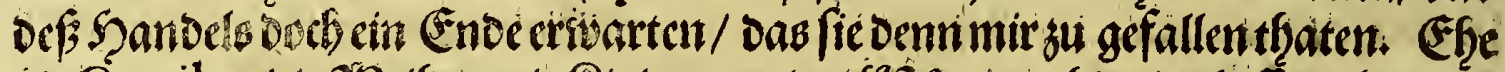

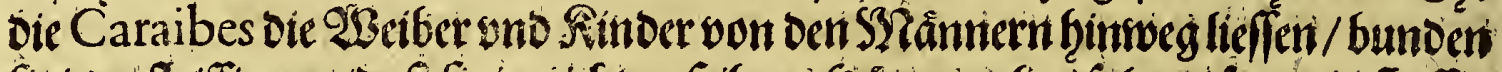

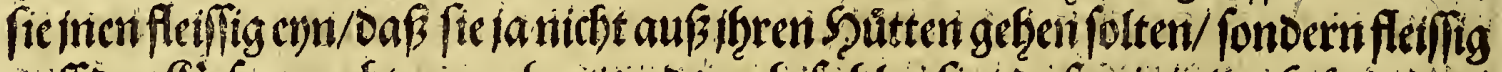

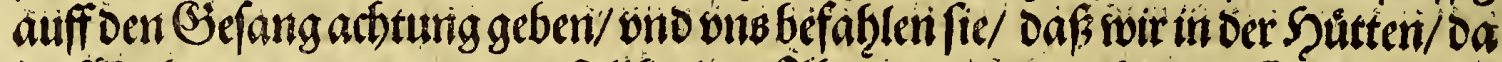

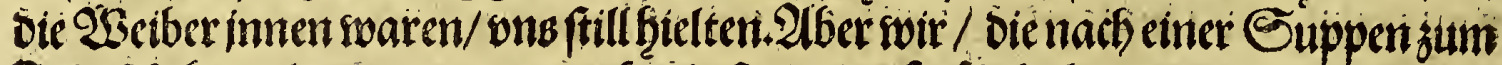

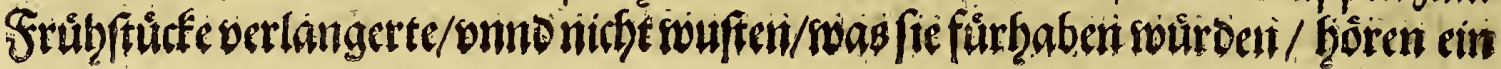
gemums 


\section{Sas britte Theil.}

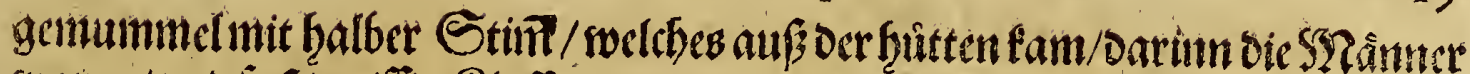

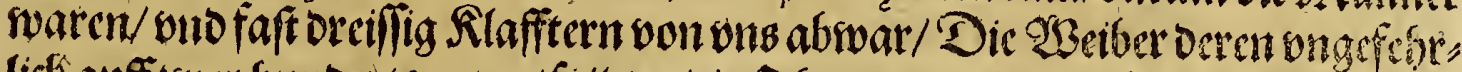

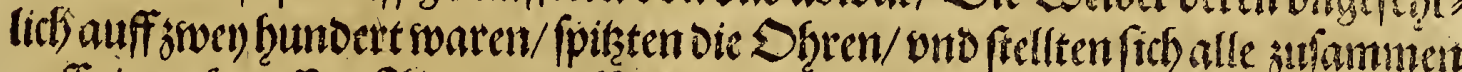

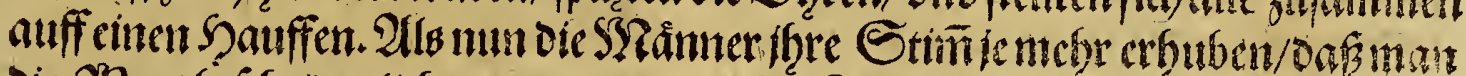

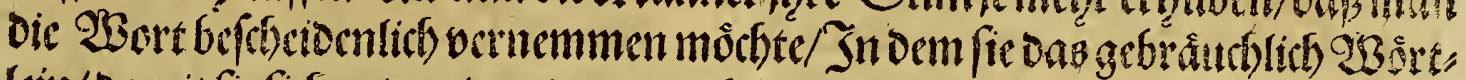

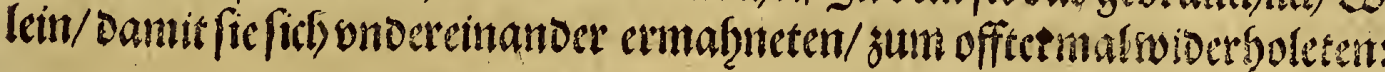

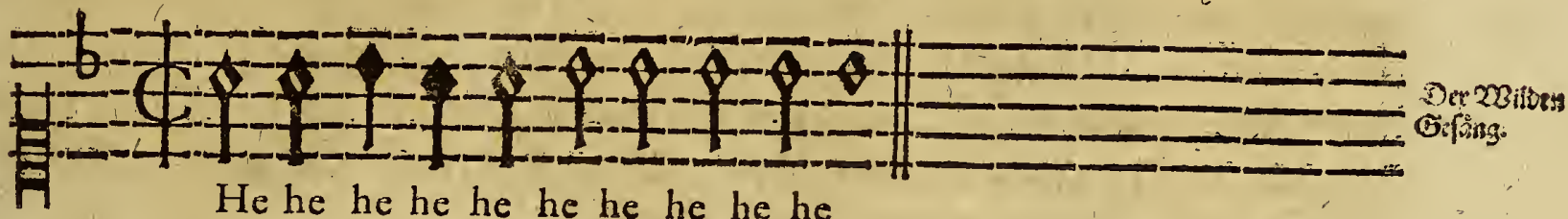

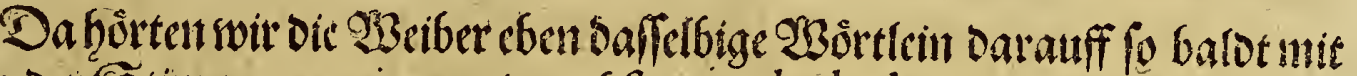

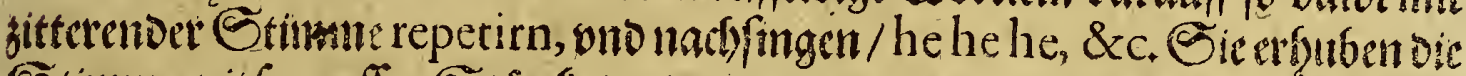

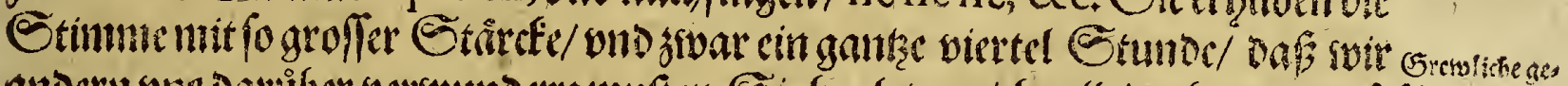

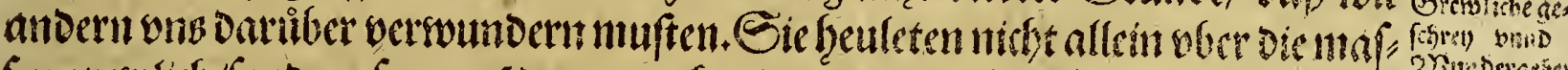

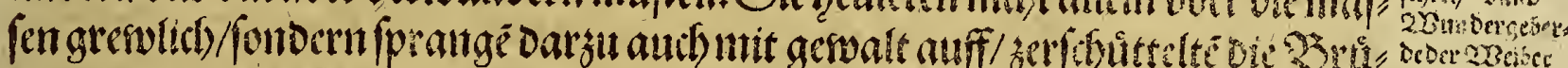

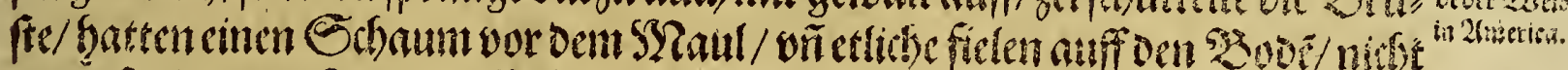

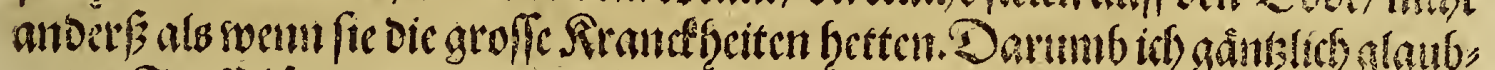

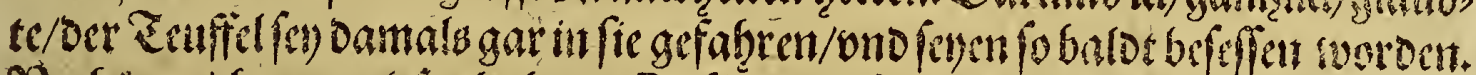

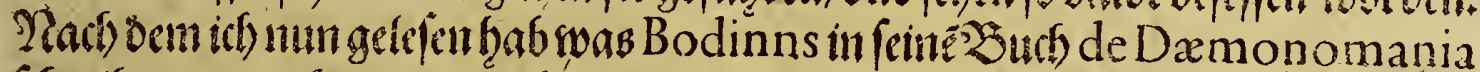

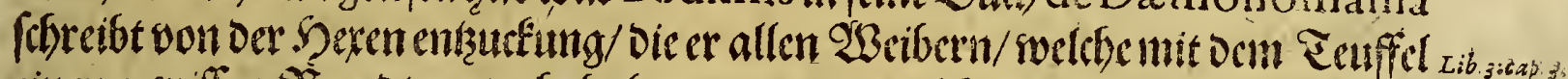

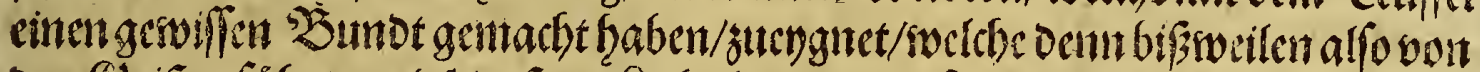

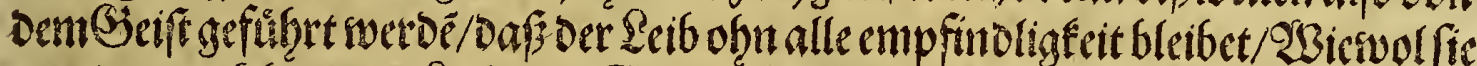

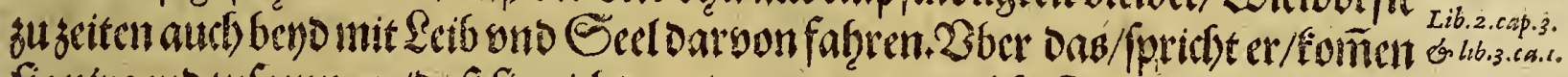

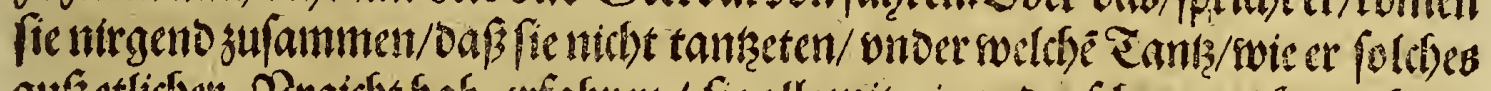

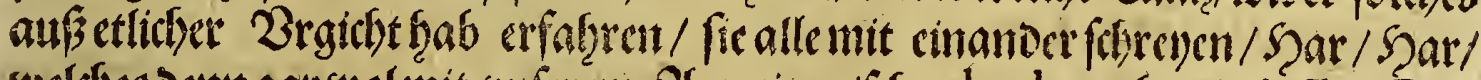

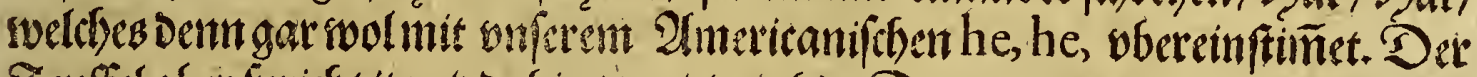

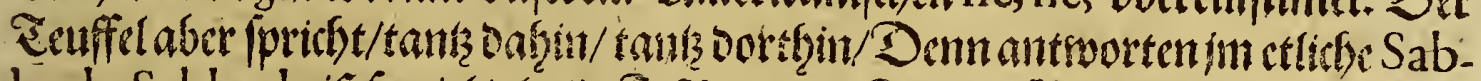

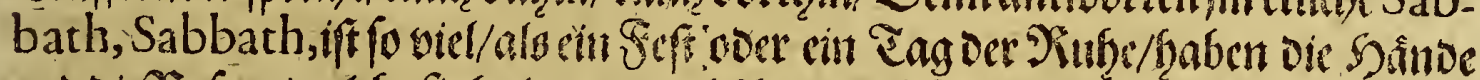

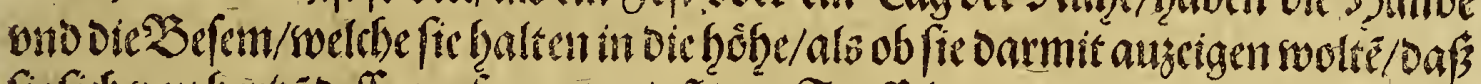

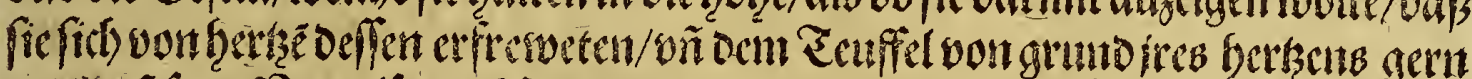

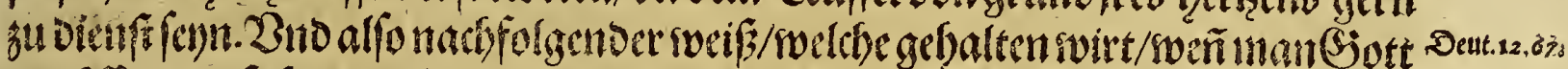

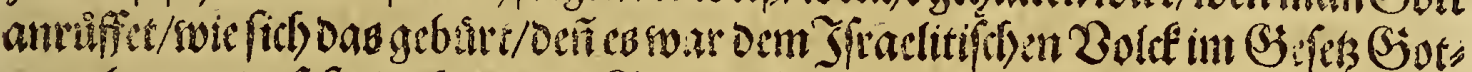

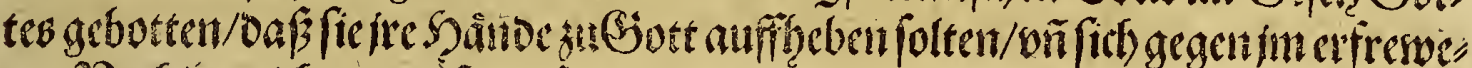

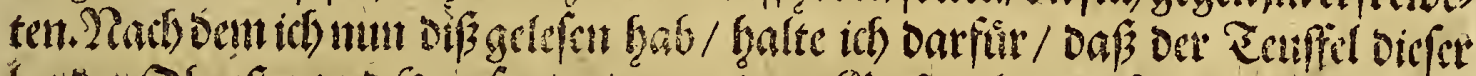

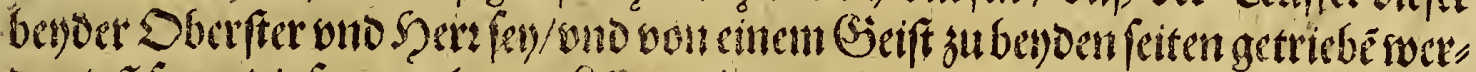

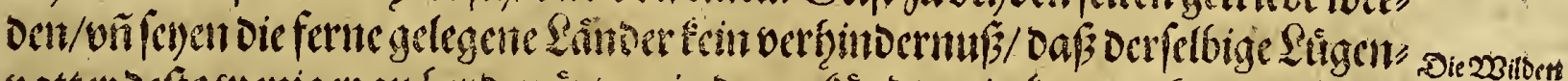

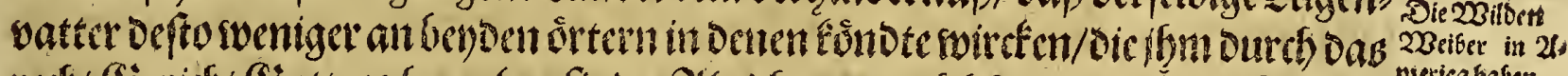

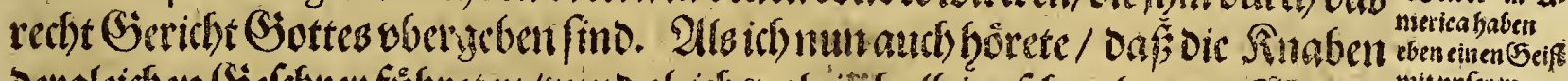

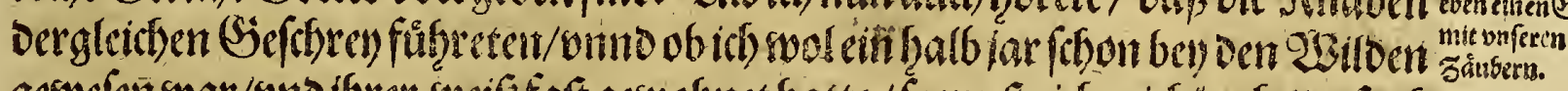

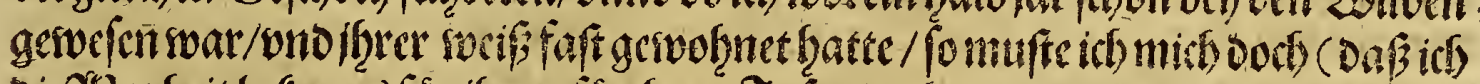

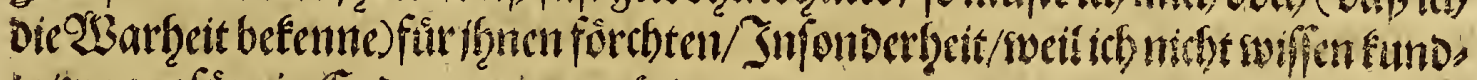

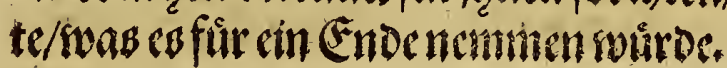




\section{Irmale Jas buttè Theth}

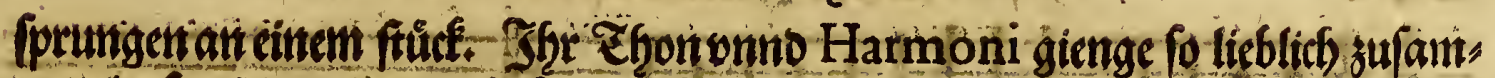

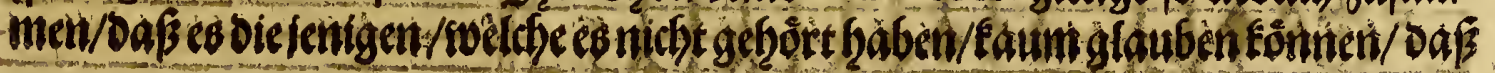

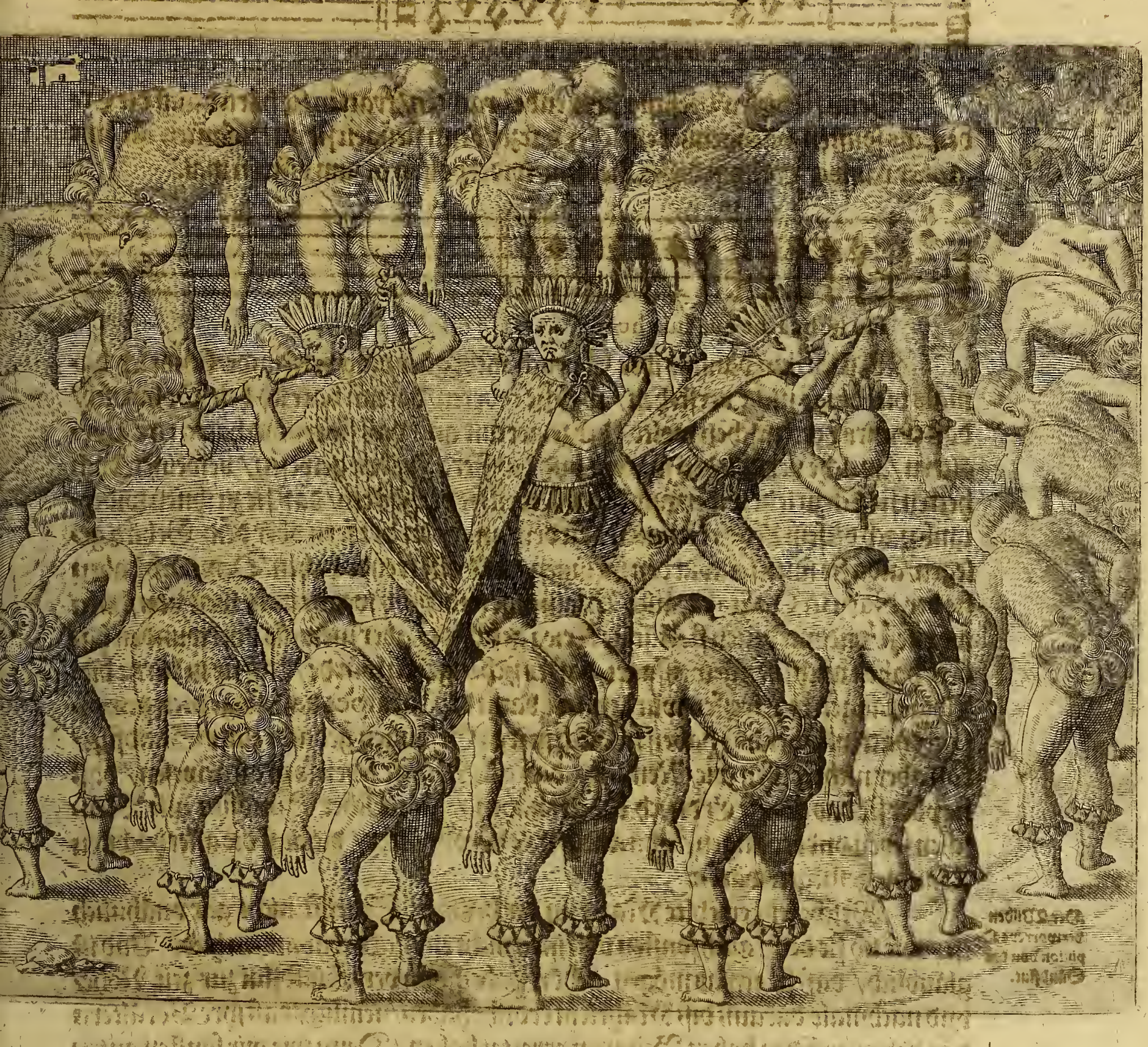

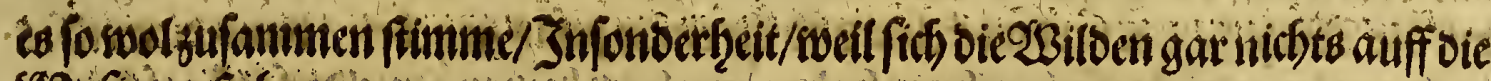
SPuffiturerteben.

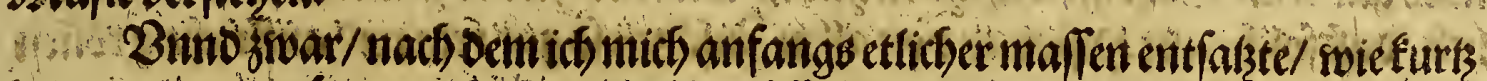

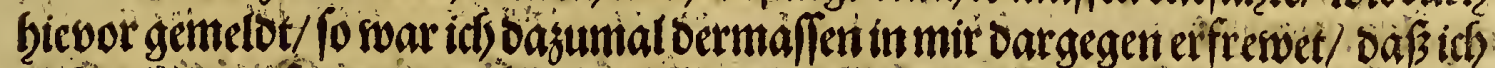

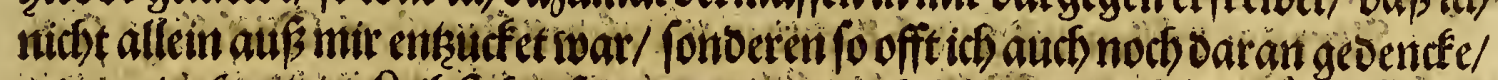

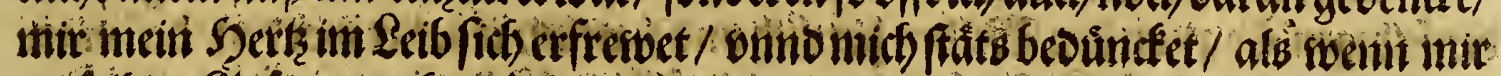

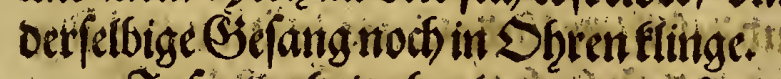

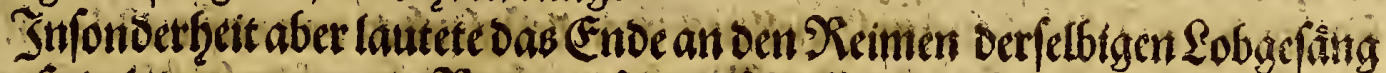

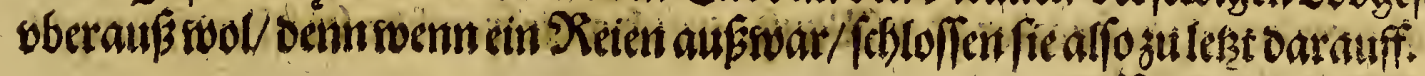

An $x_{2}, 93 \mathrm{~mm}$ arutertic 


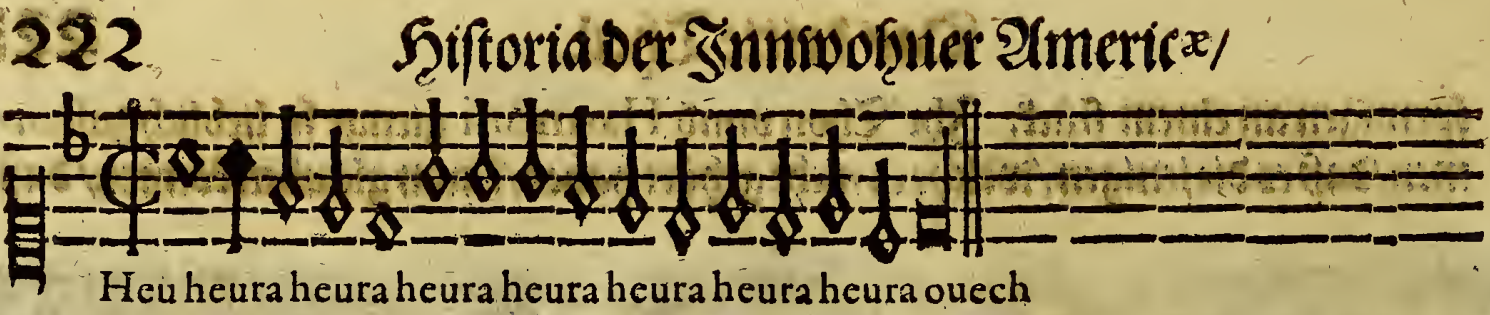

Q3ennfic oiefen Sicfang zum enoe brachten/tratten/ie bäter auff bie (Ets

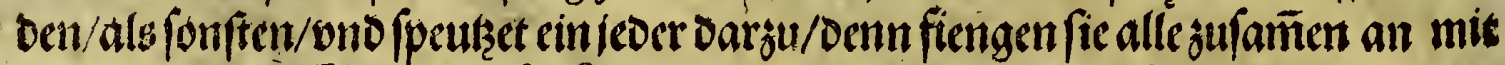
grober rauber Stimm diefes \&iedein/widocrb̨olten es junt offtern mal.

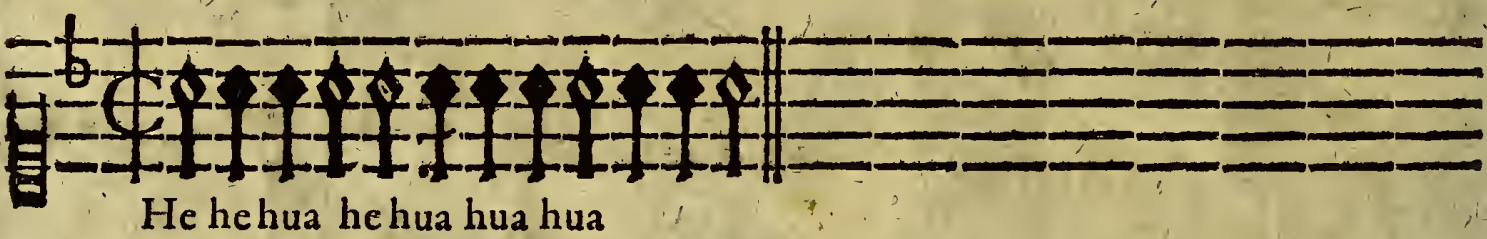

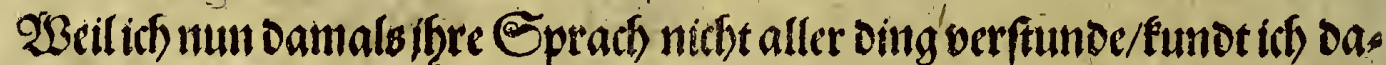

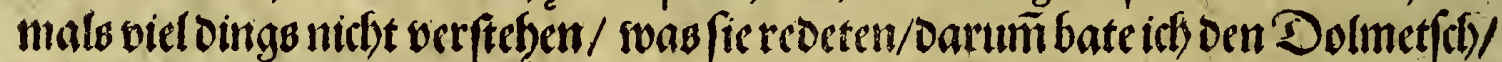

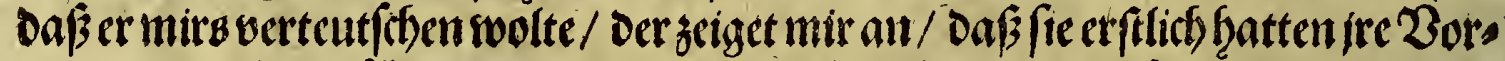

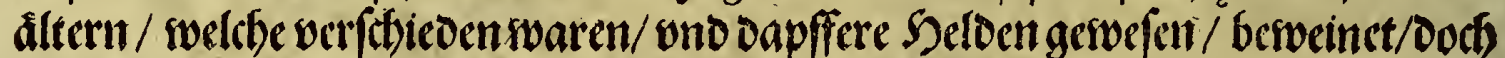

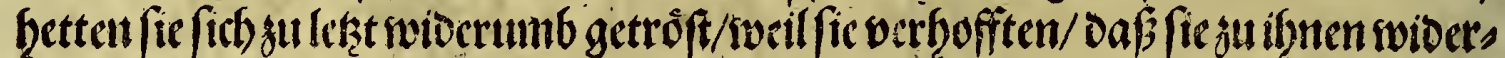
umb nact oiefem Seben fonmen wurden/an cinem ort fern ofer dent (Sebirages

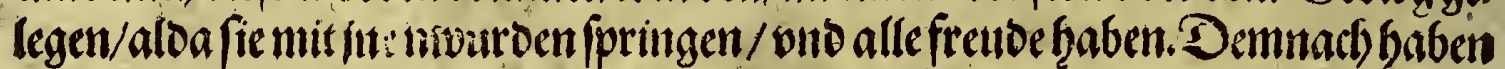

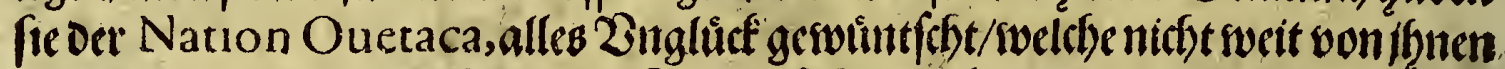

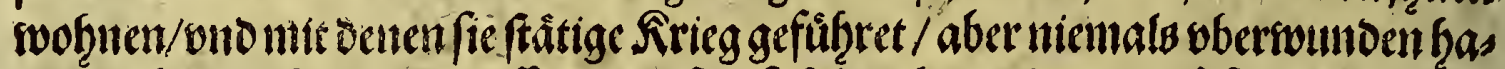

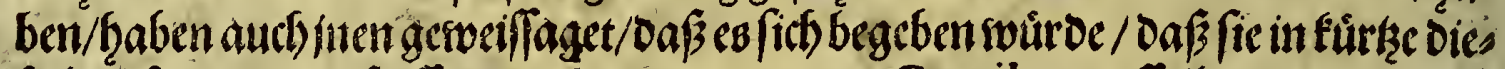

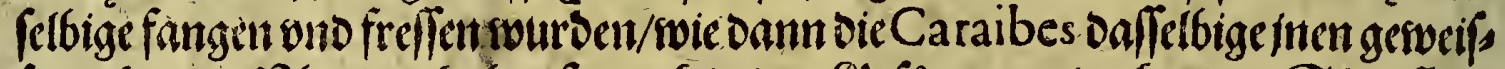
faget hatten. 36 er das haben fie audb in iren (3) fängen gebacht einer Sundflut)

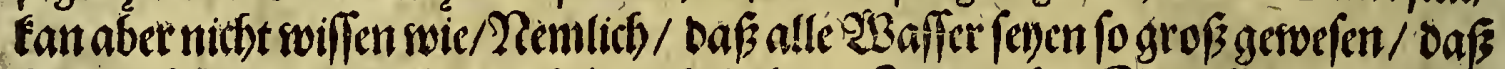

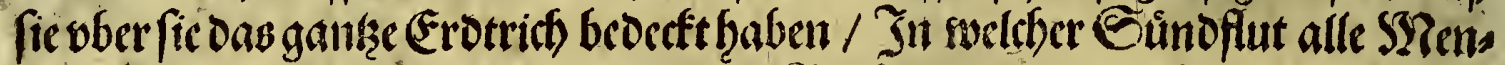

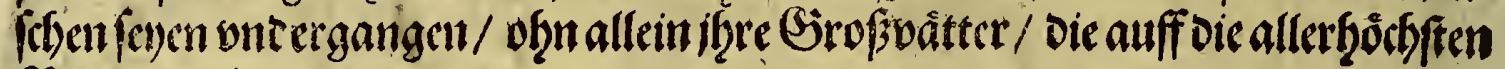
Bâme gefticgen waren.

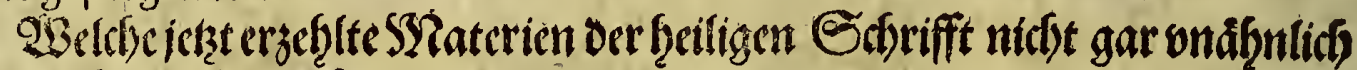

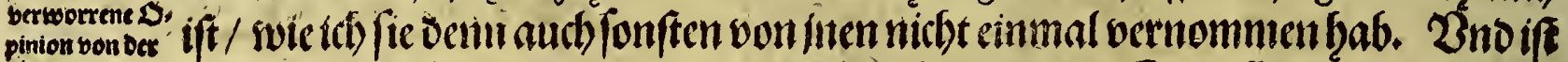

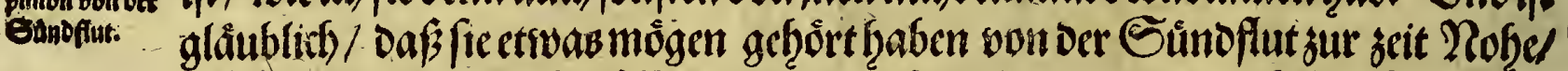

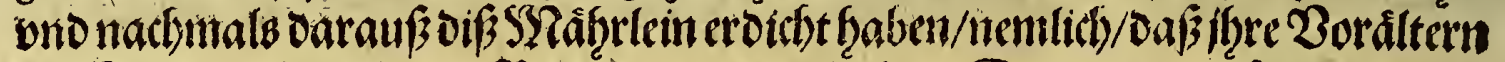
Das \&eben auf Den boben Şẩumen errettet beaben / Denn fvie wir fonften guten

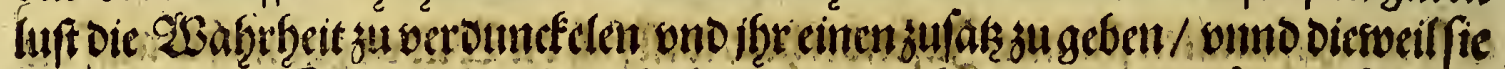

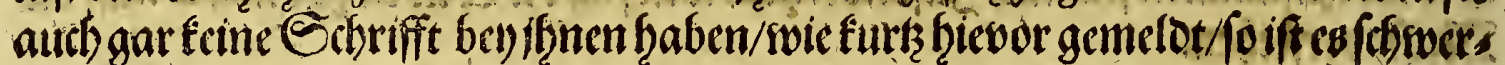

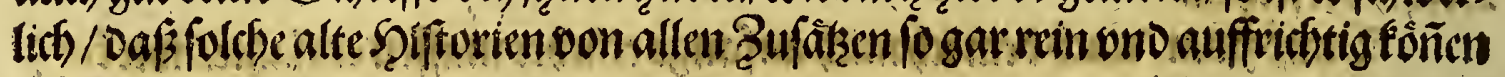
crbalten weroen.

Qlber wir woullen wiberumb fơmmen zu viferen Caraibes. Diefelbige finto

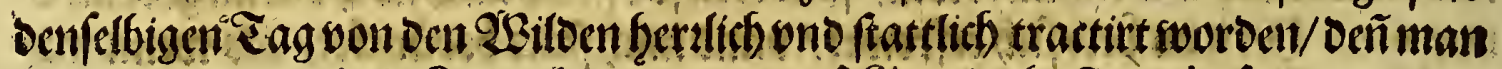

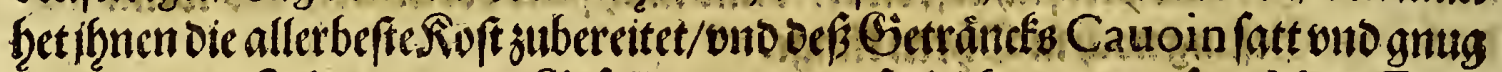

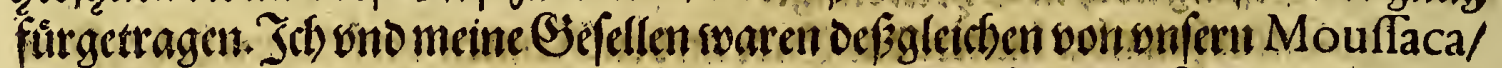

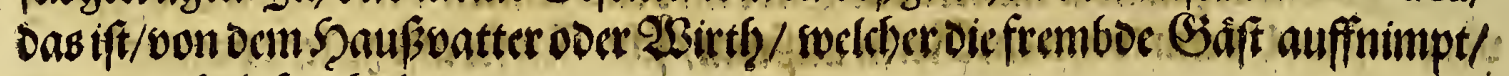
sool ono eb̨rlict) gef̧alten. 
Das britte Theil.

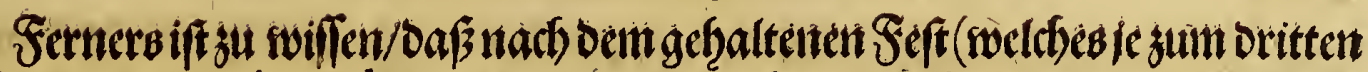

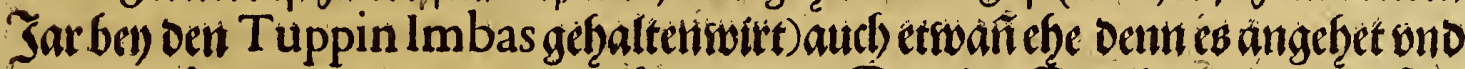

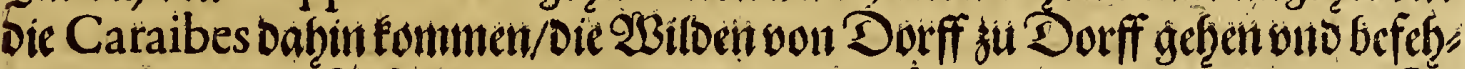

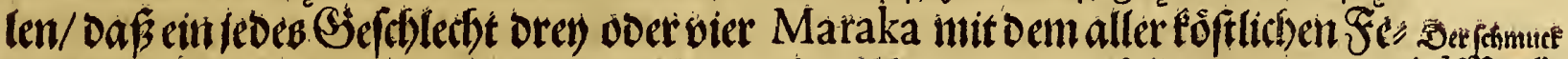

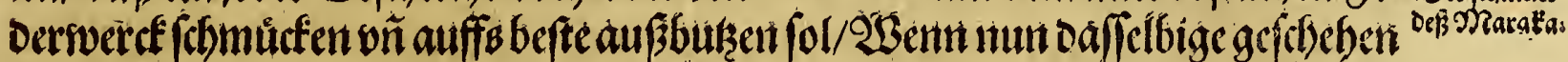

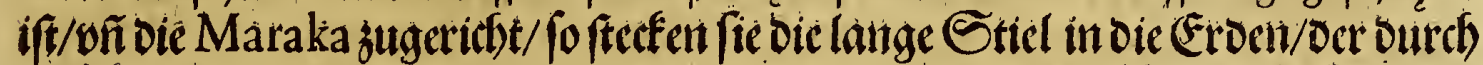
Die Maraka binge/tecte ift/ontogebent befeleb/ Daf3 man oen/clbigen Maraka fol

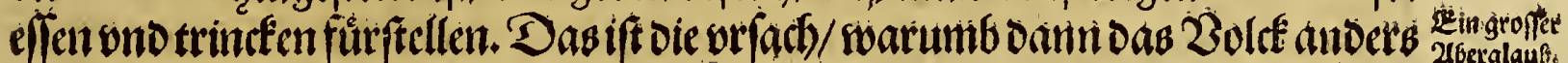

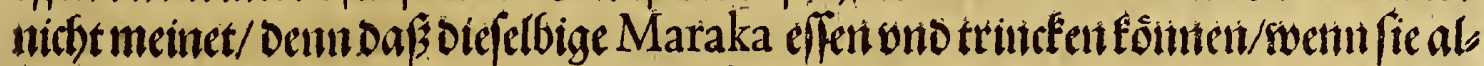

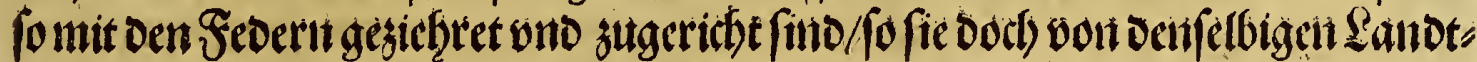
betriegern/ämmerfich bevortheilt werben.

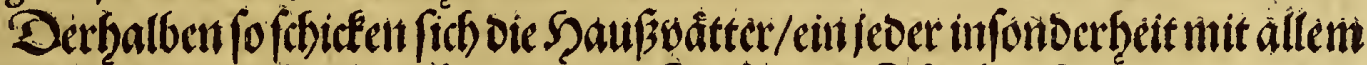

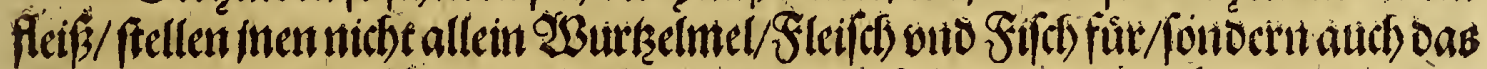

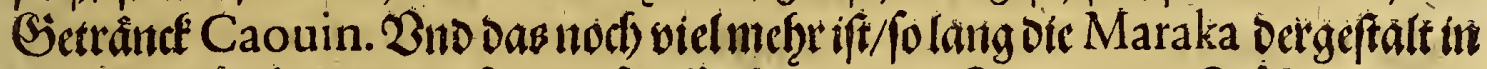

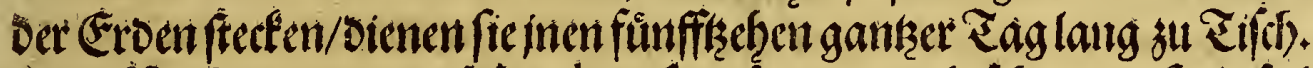

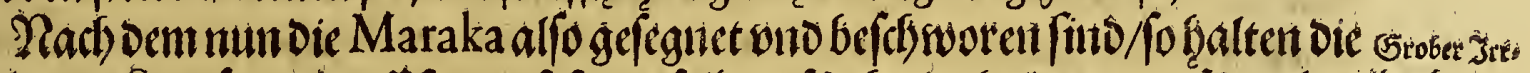

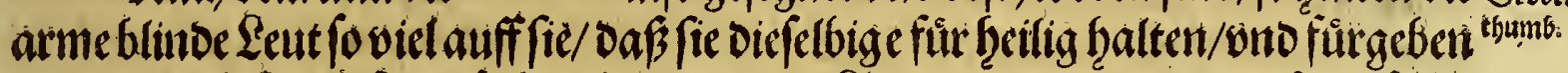

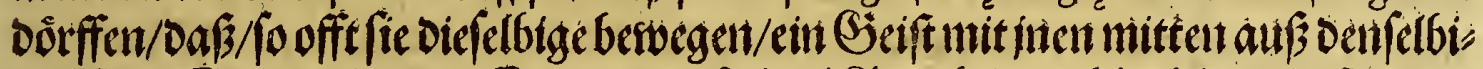

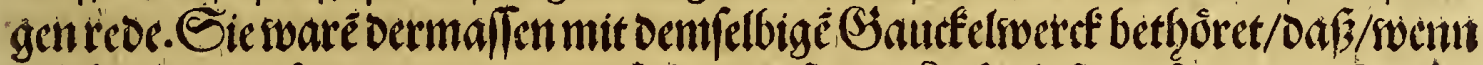

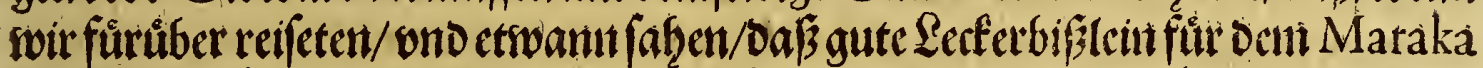

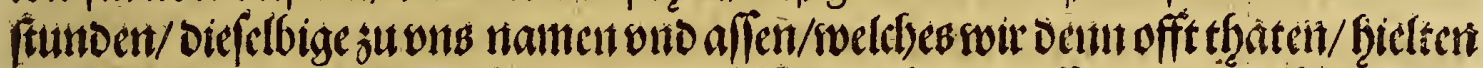

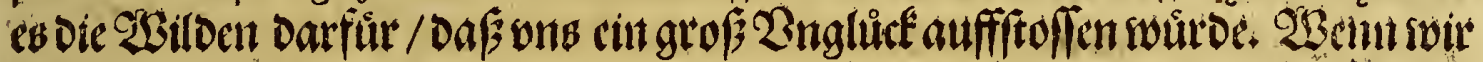

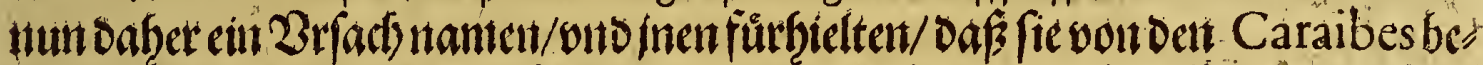

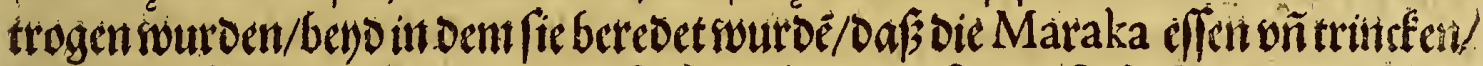

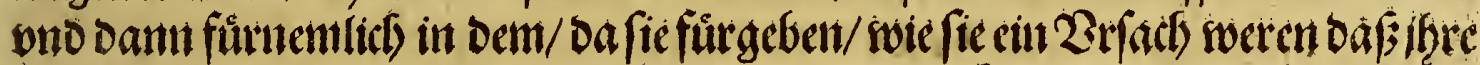

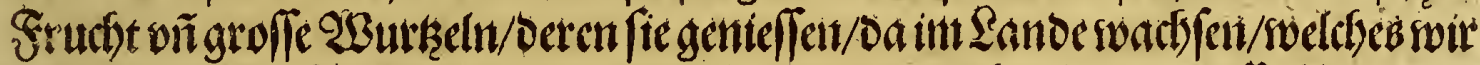

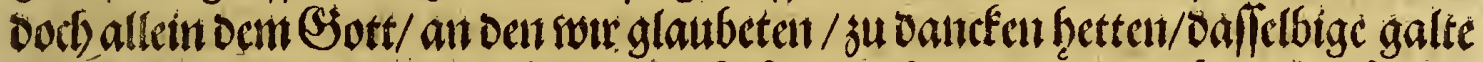

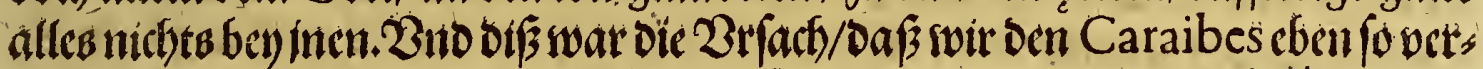

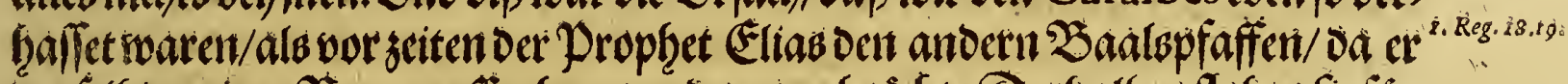

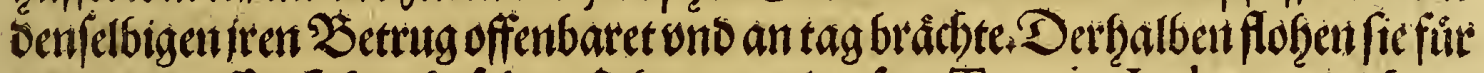

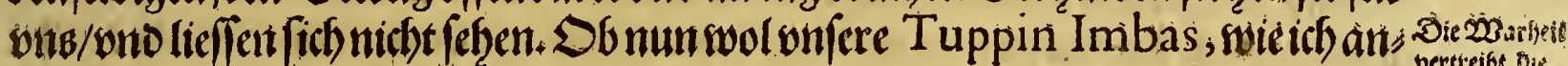

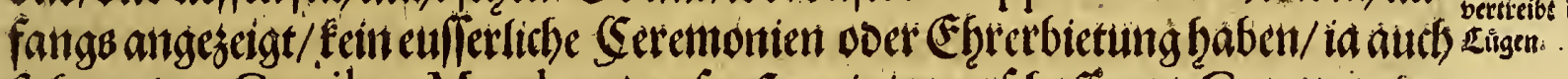
fich wor iren Caraibes; Maraka, ober fonften einiger etfiflaffenent Creatur obets

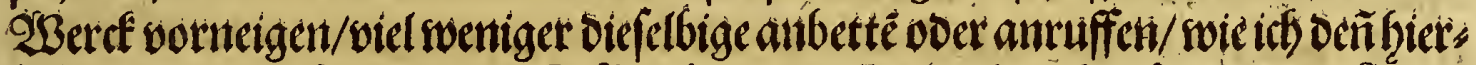

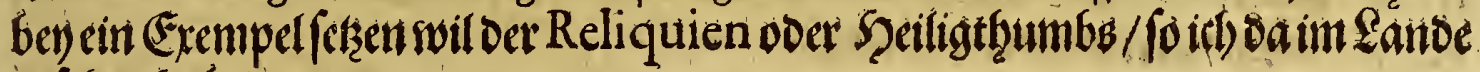
gcjetrentab.

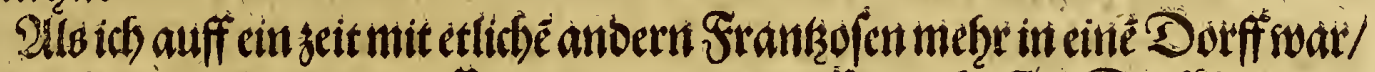

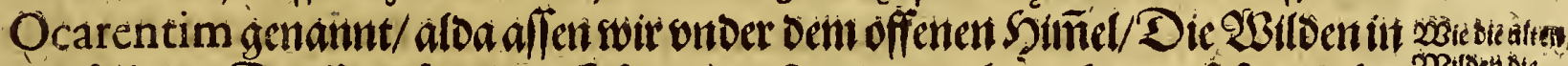

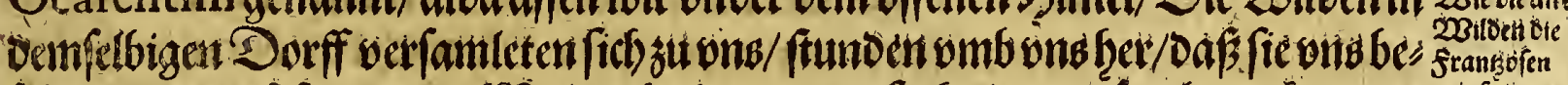

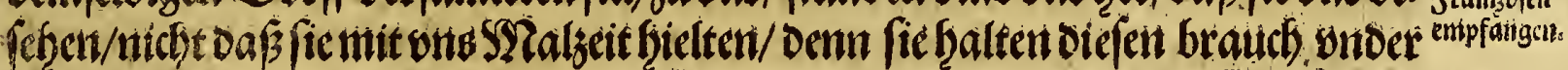

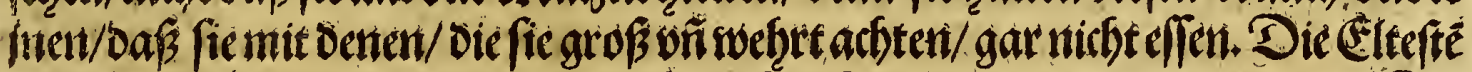

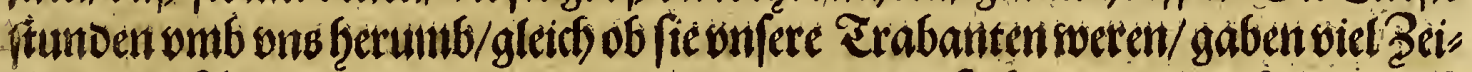

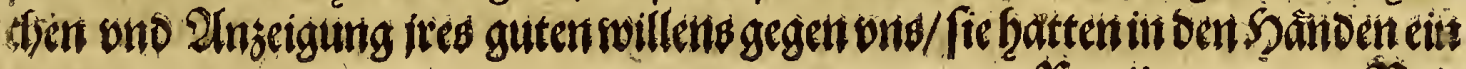
a if Seit 


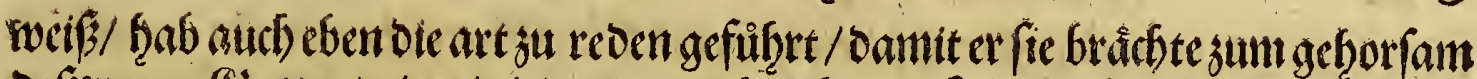

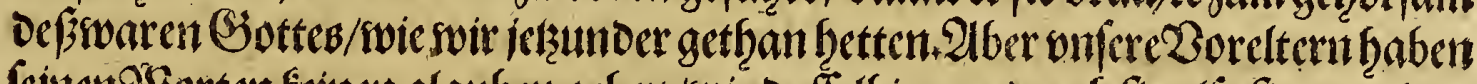

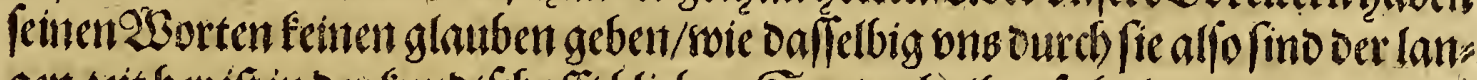

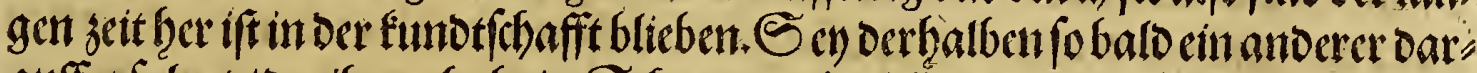

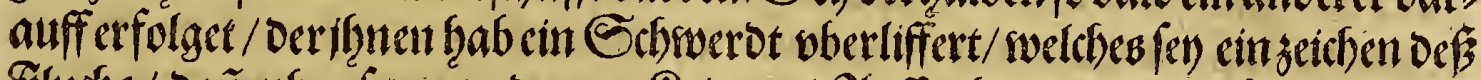

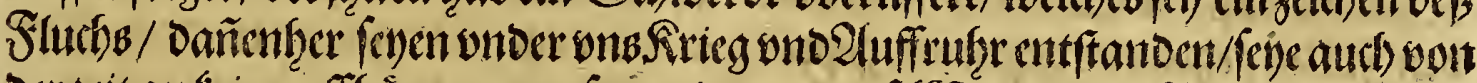

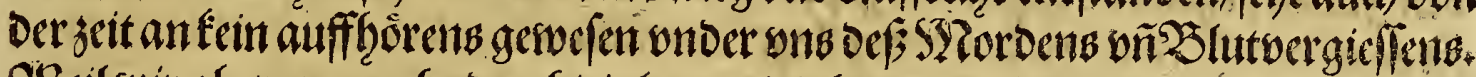
QBeil swir aber nun mefor butel oie langwirigfeit oer zcit barinn géwonet/on ons

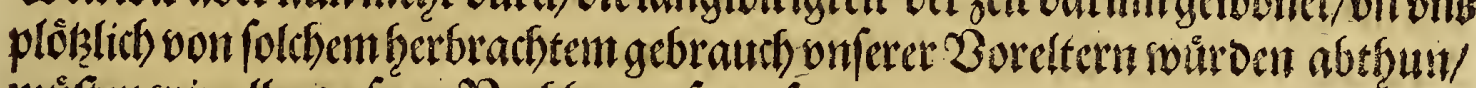
muiften wir aller onferer 2 acb baren jout fern.

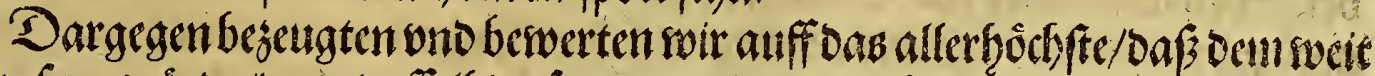

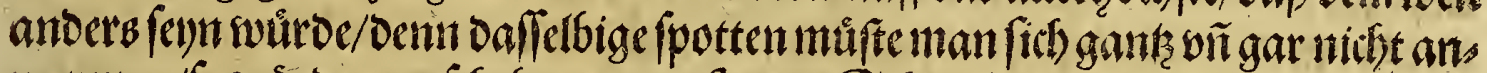

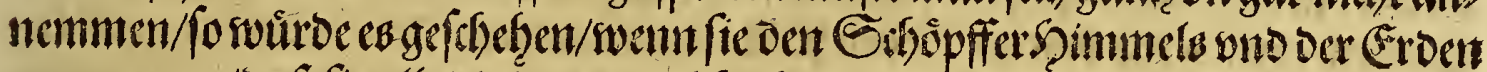

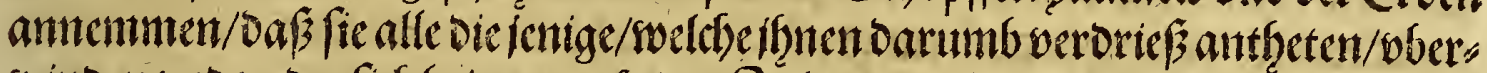

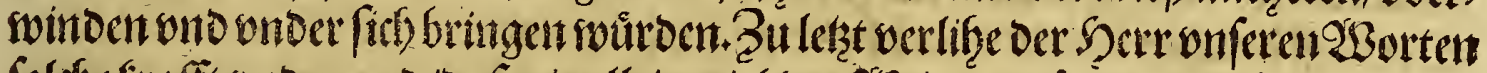

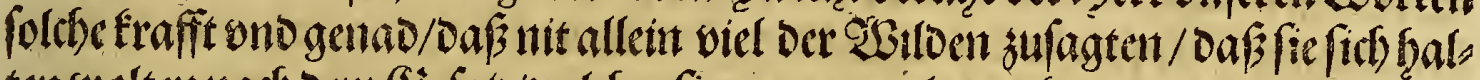

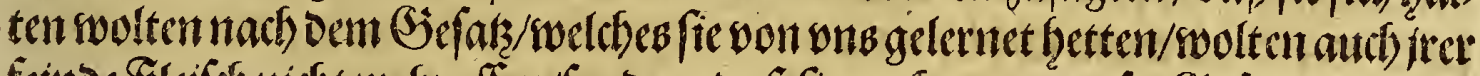

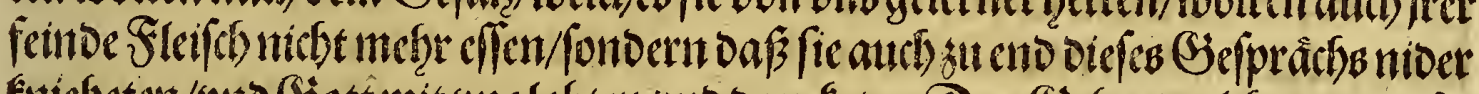

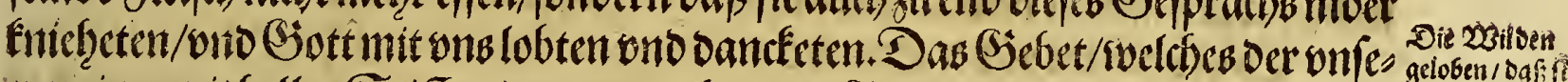

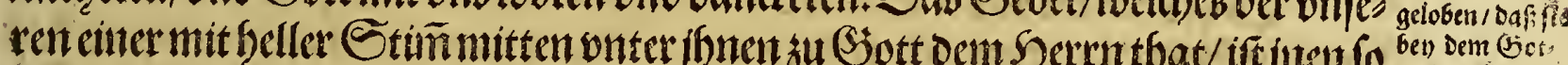

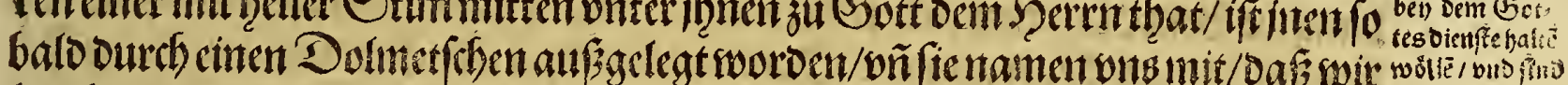

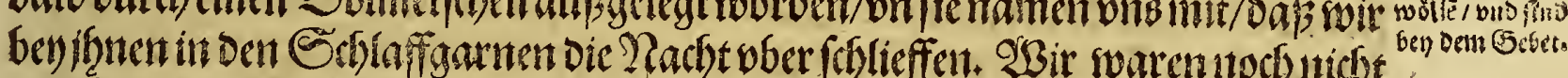

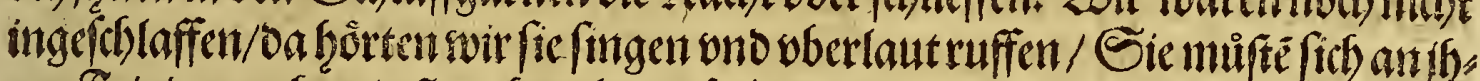

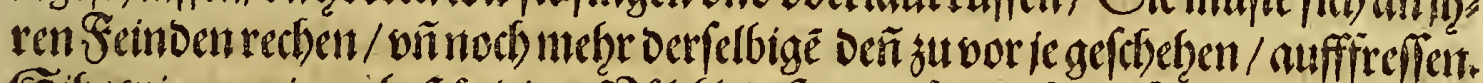

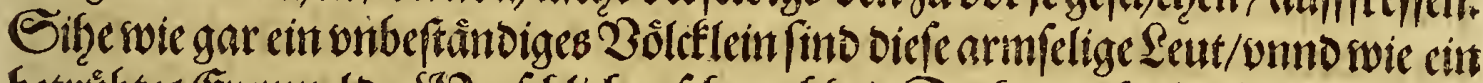

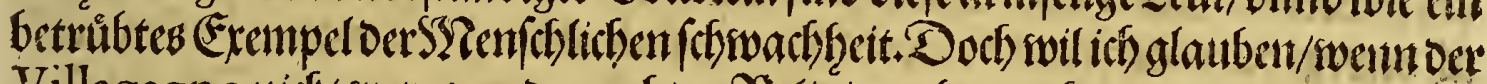

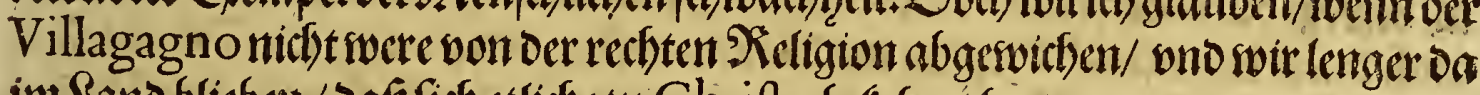

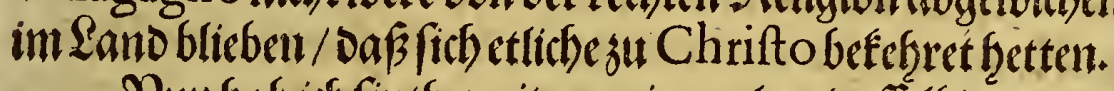

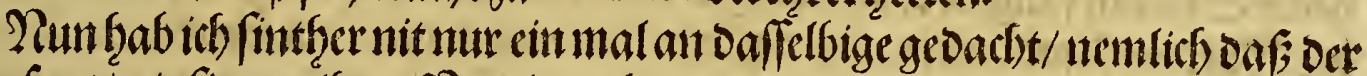

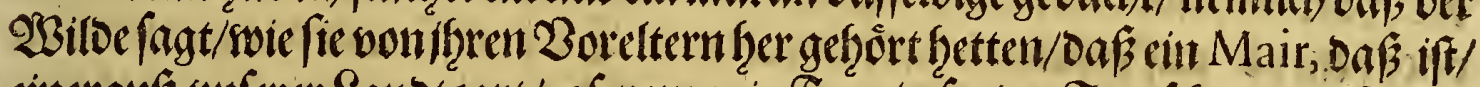

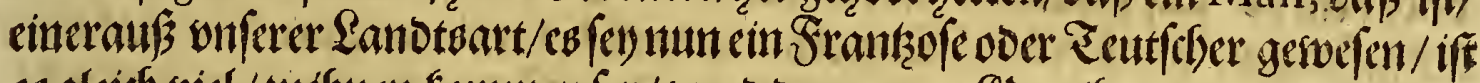

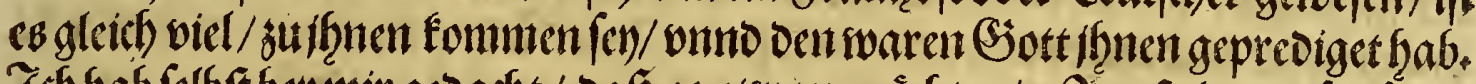

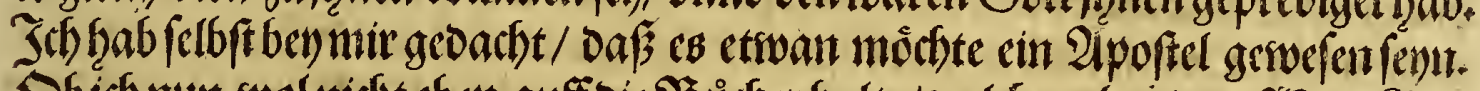

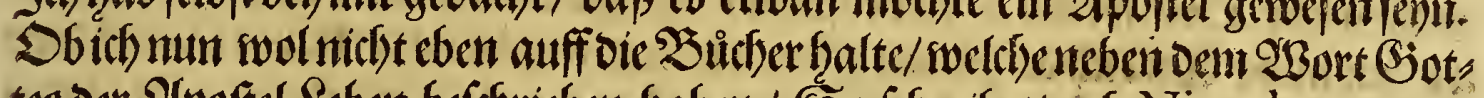

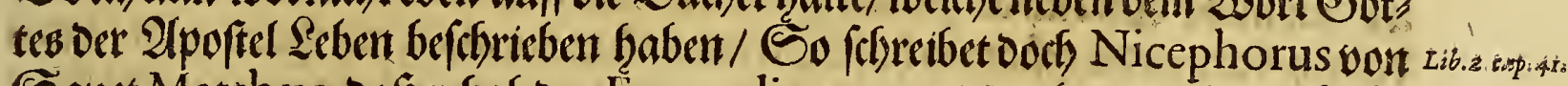

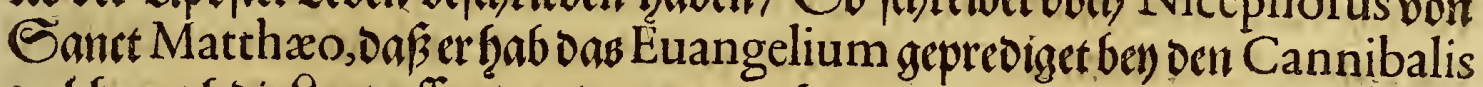

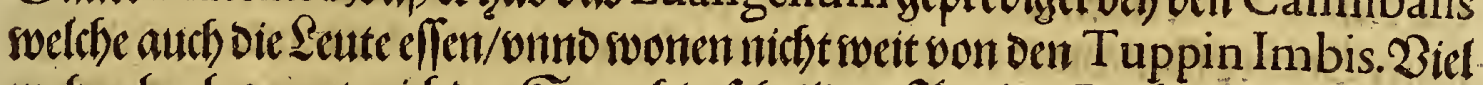

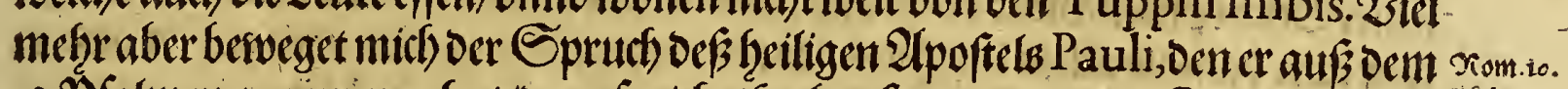

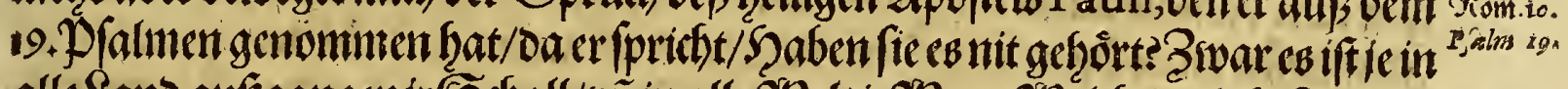

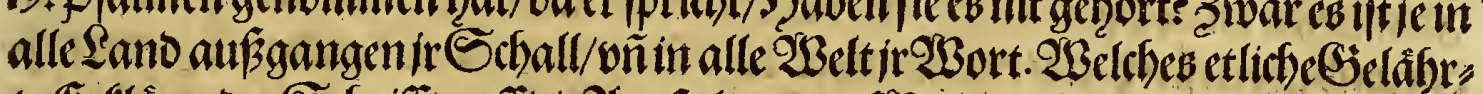

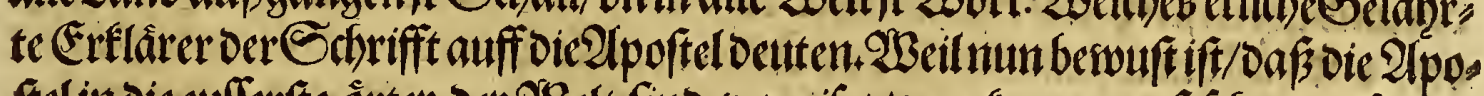

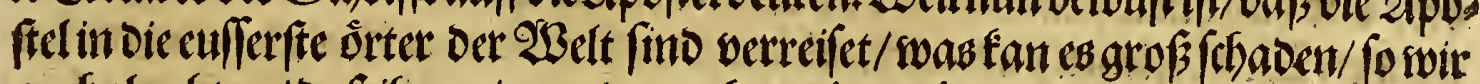

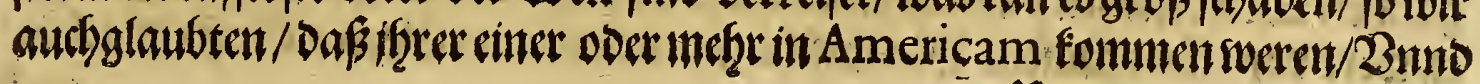
iif "Dafke 
Sasbritte?Geil.

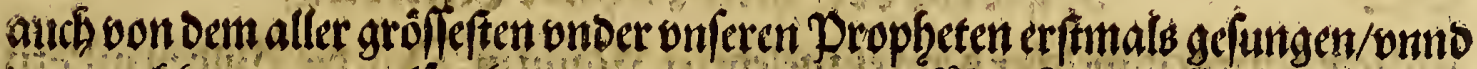

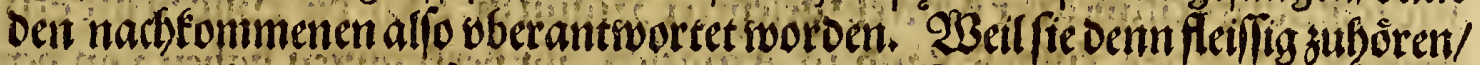

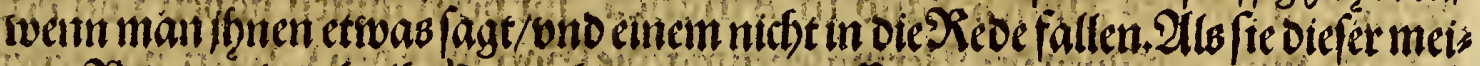
ner Rede sod cin balbe ftunbe hatten mit groffem oerlangenzugebort/fiengen

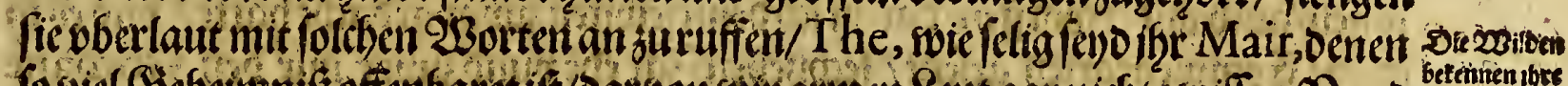

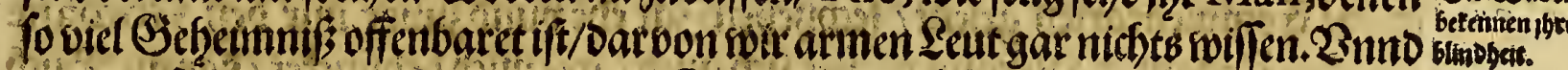

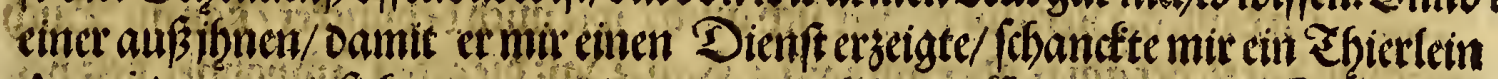

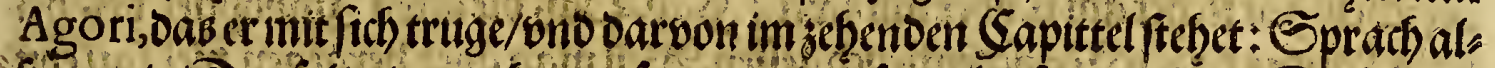
10 zumir/Pas fol ocin verehrung fenn/sweil ou fo wol gejungen haft / Diefes hab

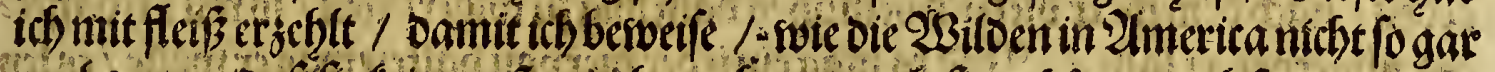

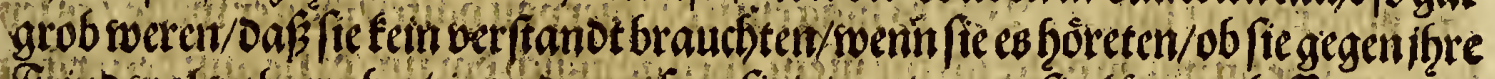

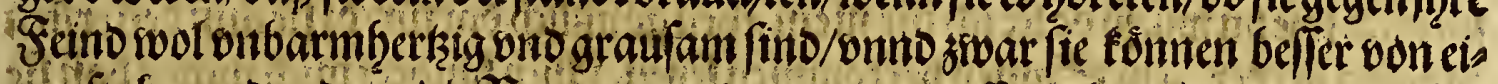

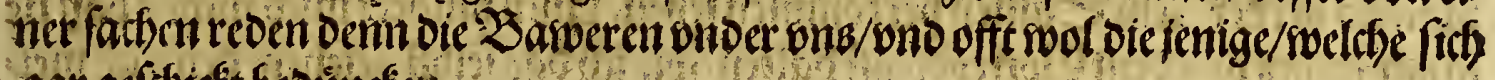
gar geforteft beouncten.

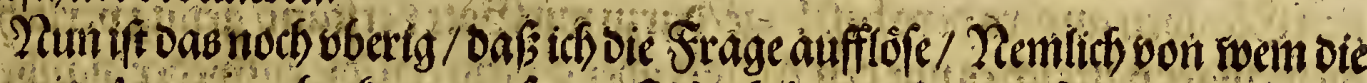

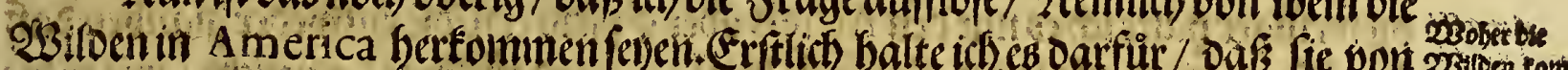

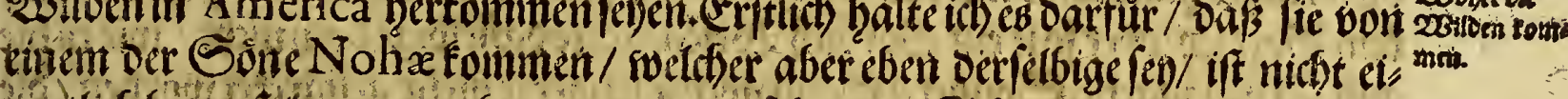

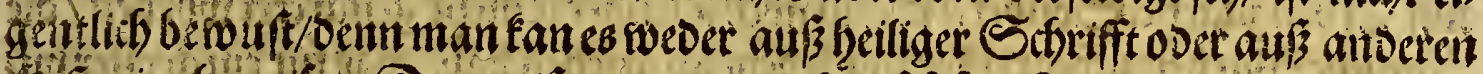

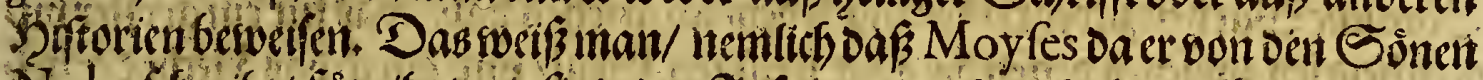

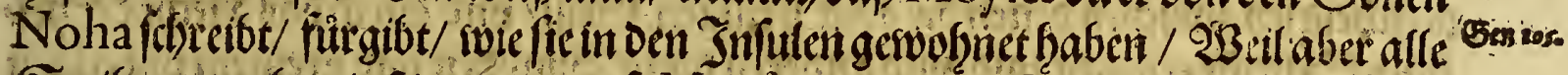

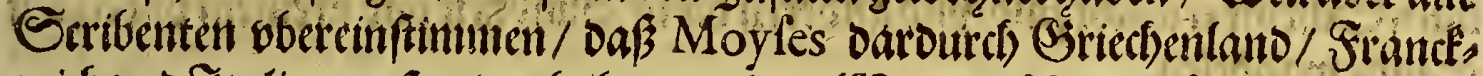

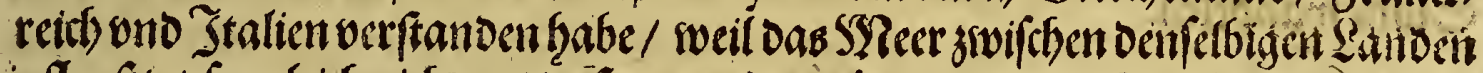

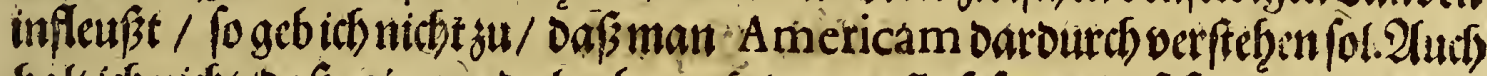

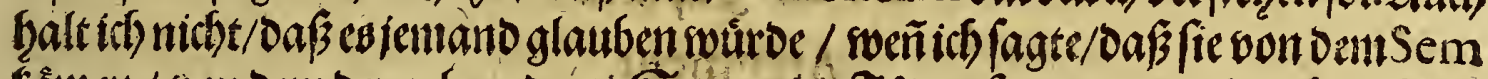

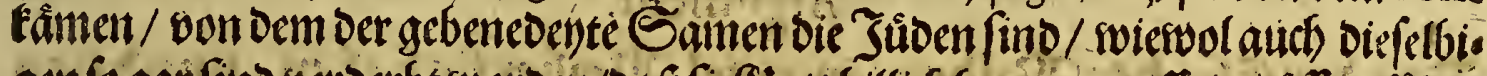

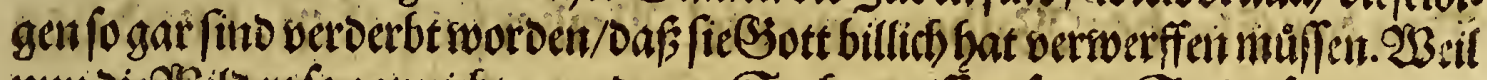

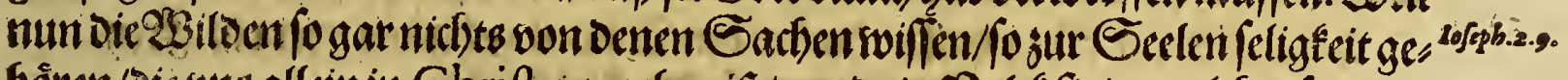

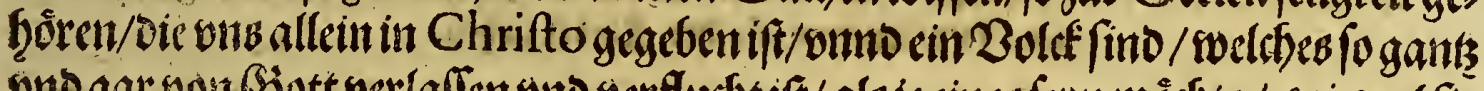

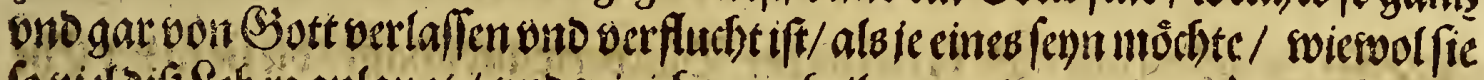

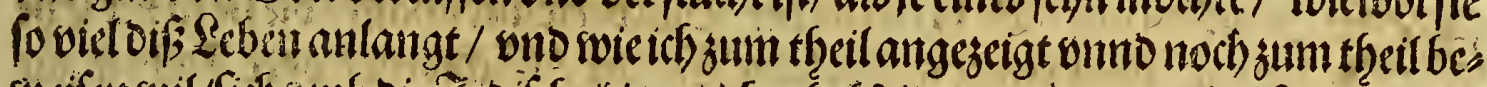

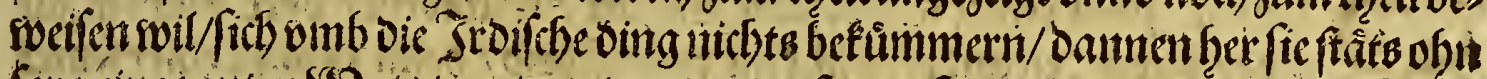

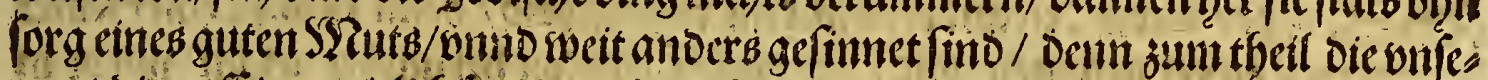

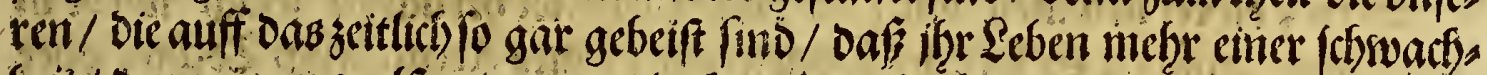

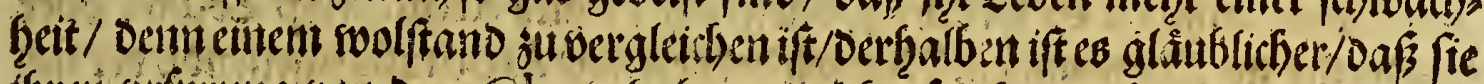
fhren orfprung oon oem Chath baben/ welebes fo ich ebuicht eben trefie/ if es

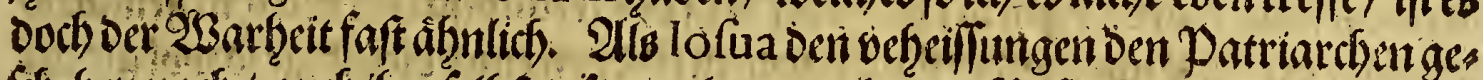

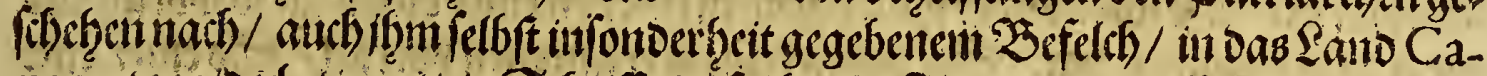

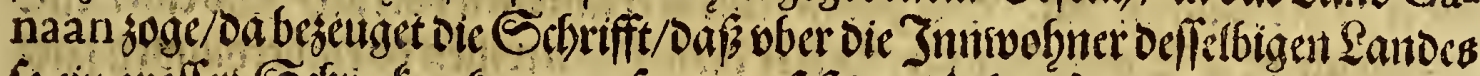
po cingroffer Gedrecten fommenfen / baffie verftoben /suen / auf forthe fure

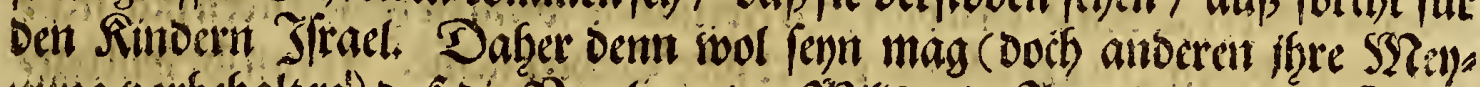

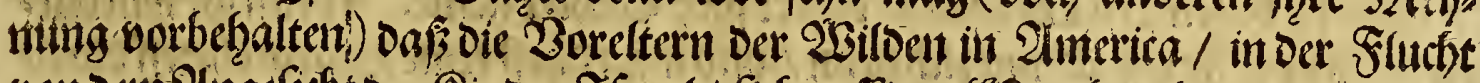

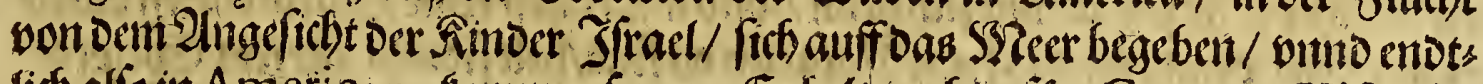

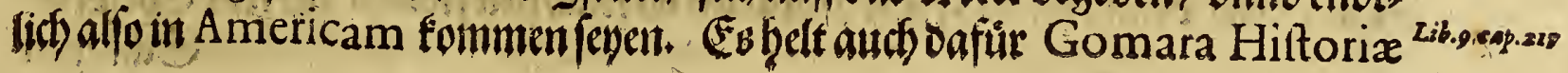
Indicæ 


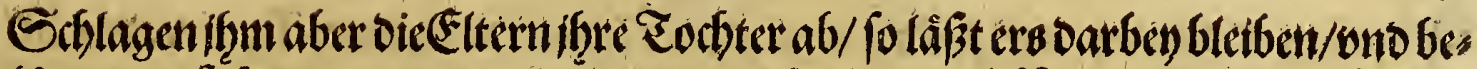

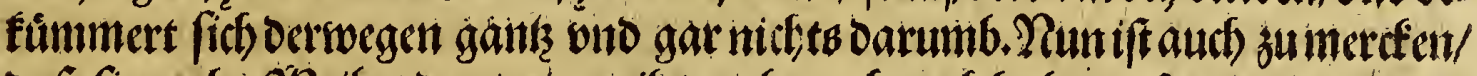

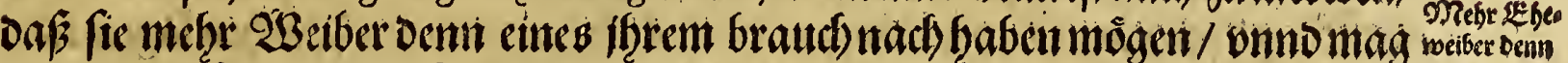

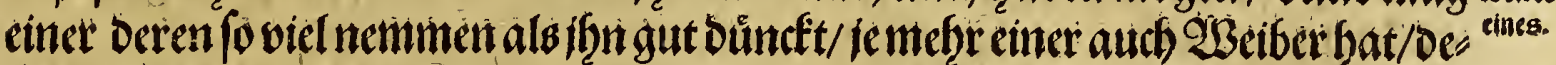

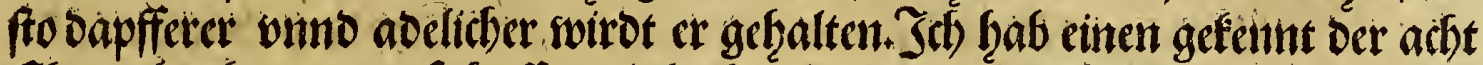

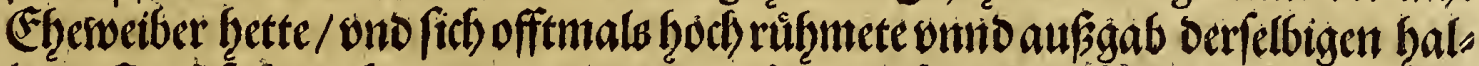

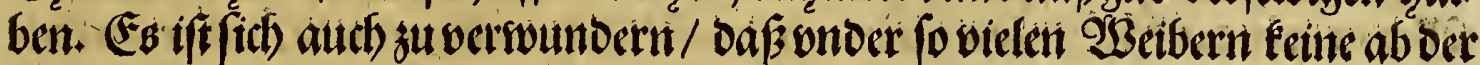

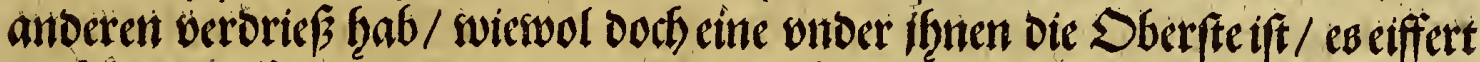

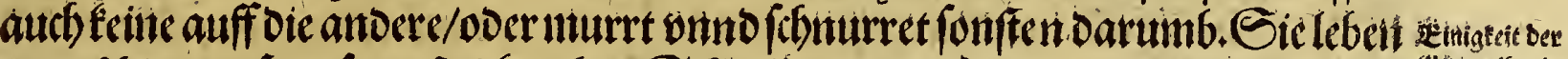

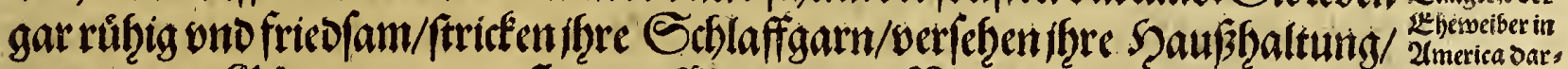

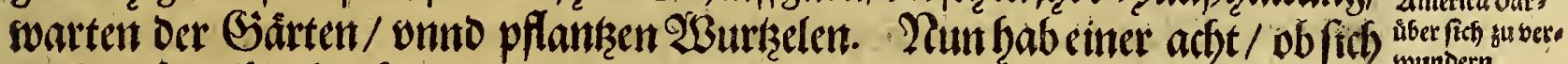

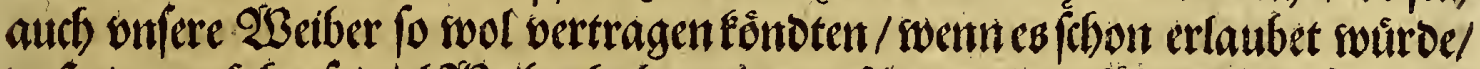

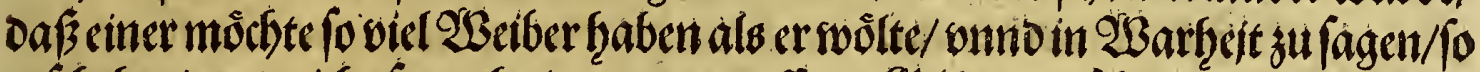

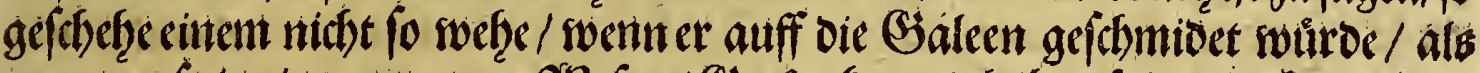

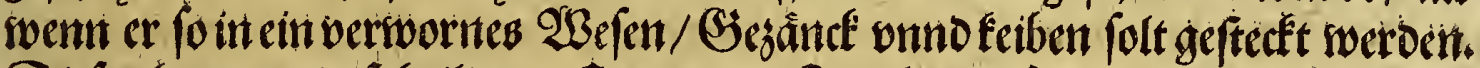
Dicfes beseuget def beiligen Errzoatters Jacobs vorforg onmo angft / als er Gen.29.3.

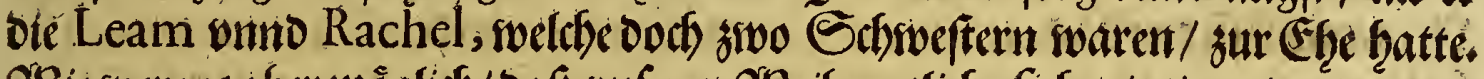

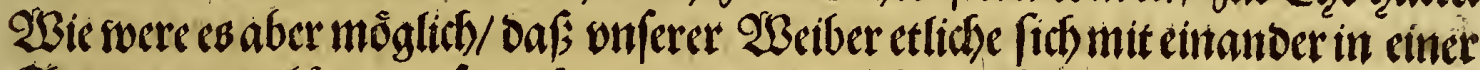

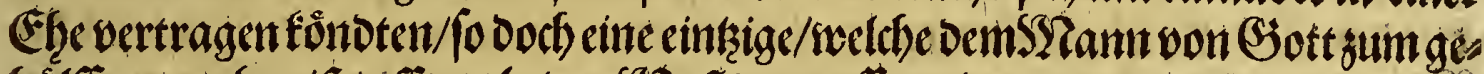

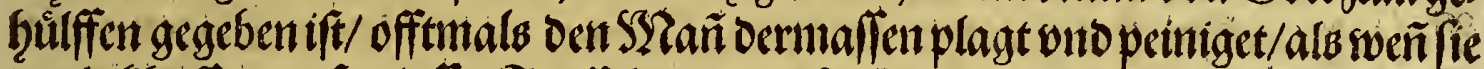

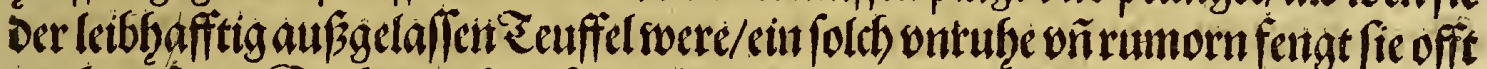

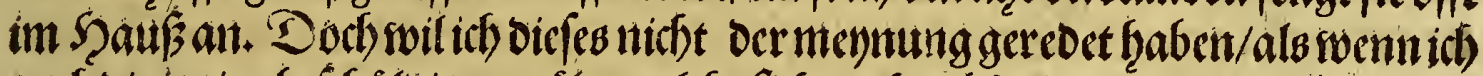

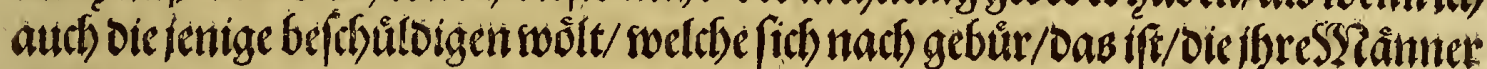

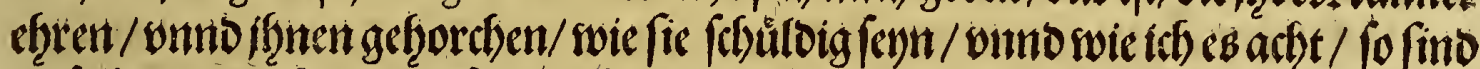

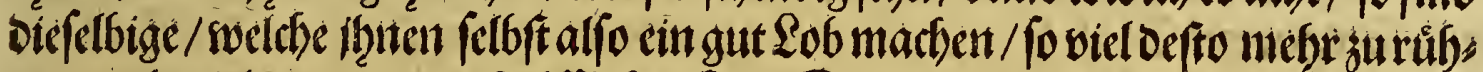
mett / als biel die anoeren fträfflicher fint. Damit idf aber meine Rebe wibets

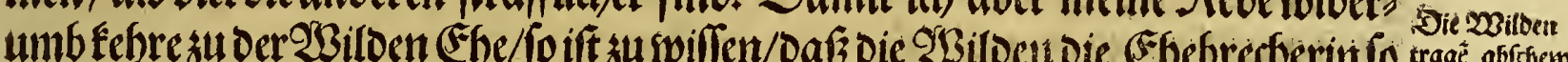

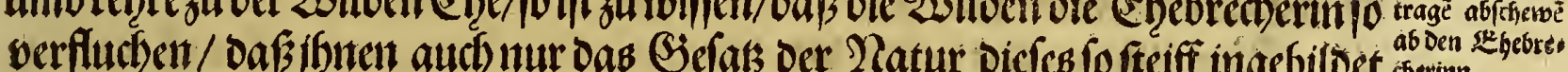

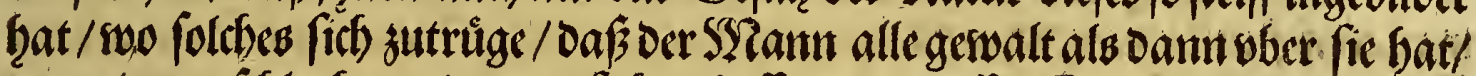

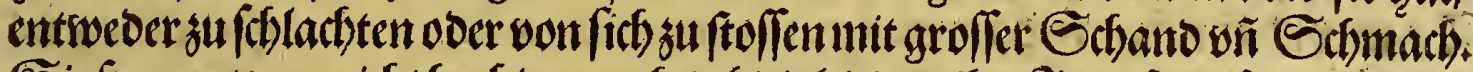

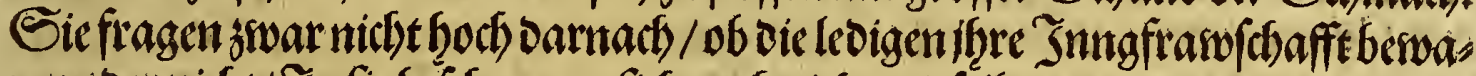

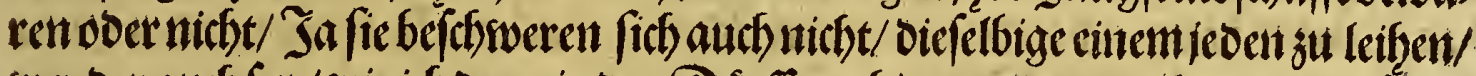

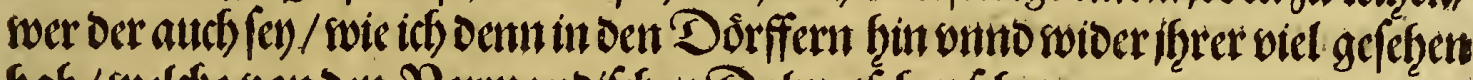

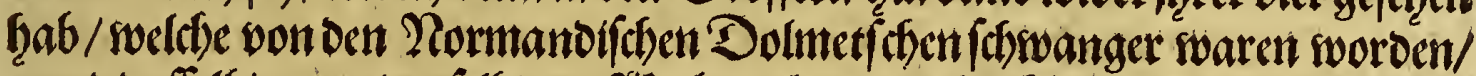

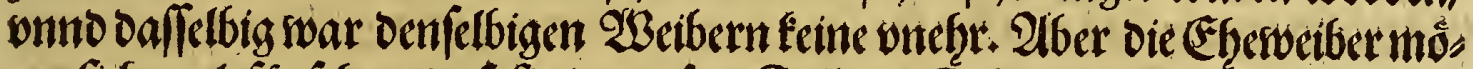

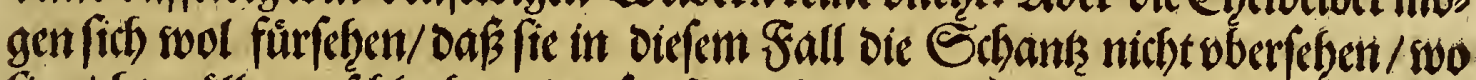

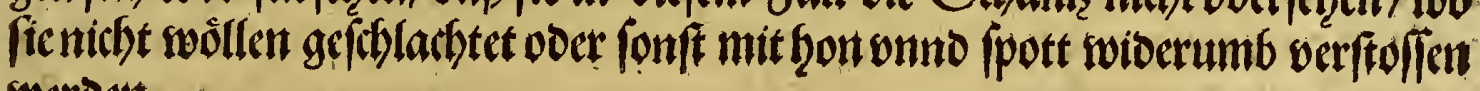
werden.

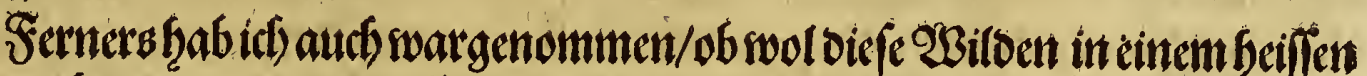

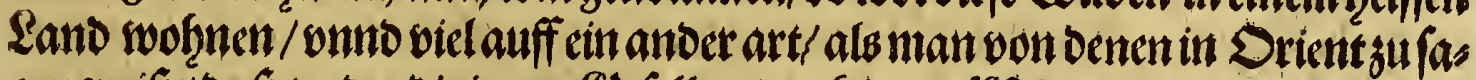

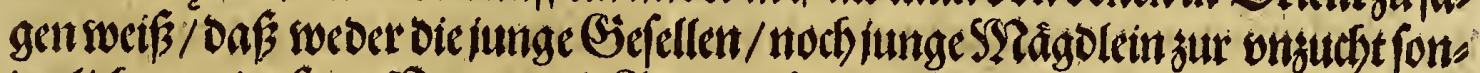

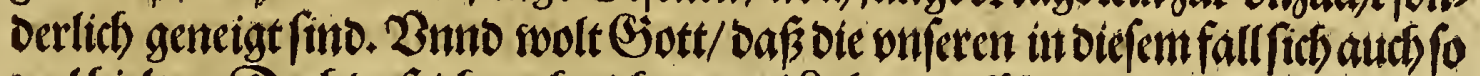

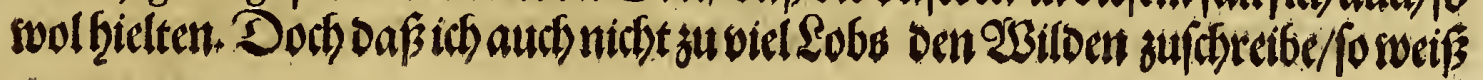


Sindein soest oon fids abfofafien/Darumb fie offtmals erfitict swetoen/ oder

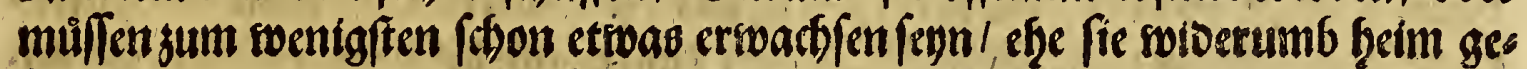

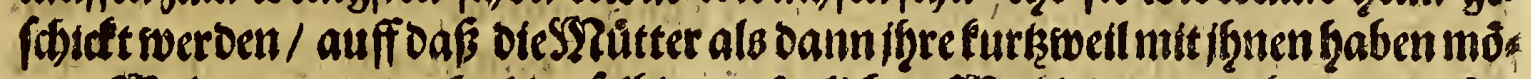

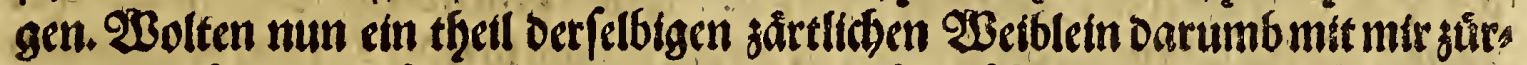

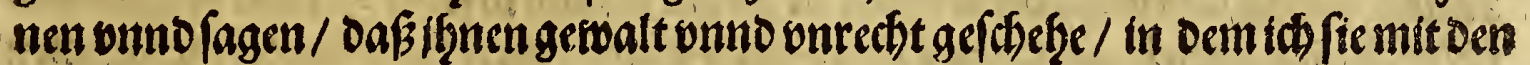

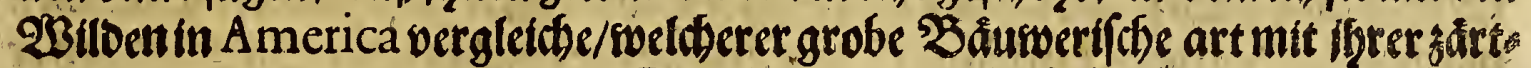

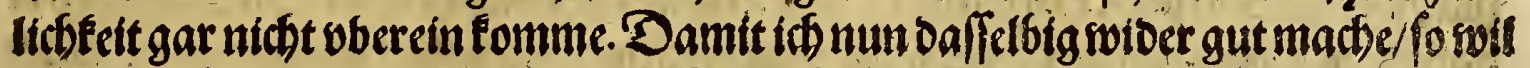

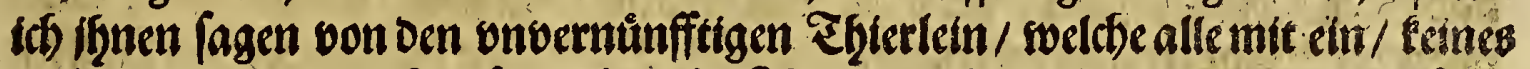

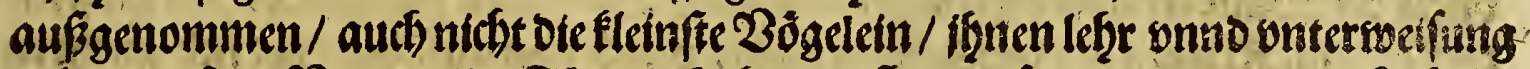

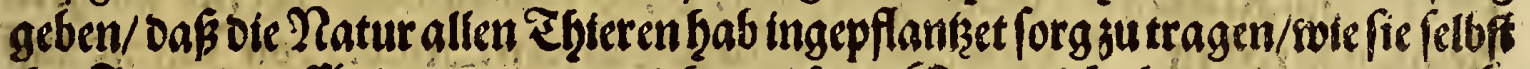

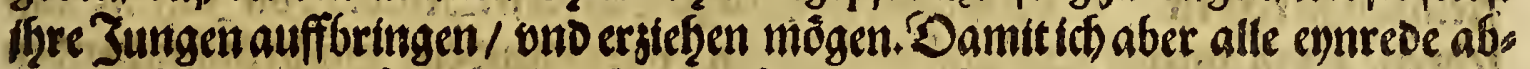

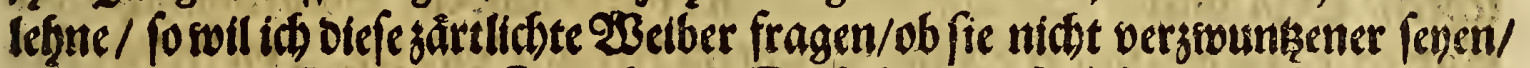

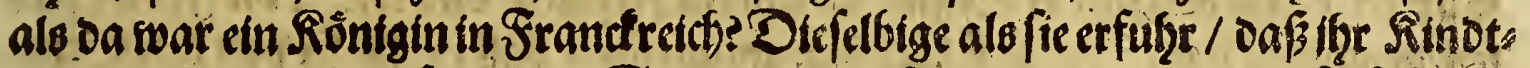
lett an einer anberen fremboen Seugmutter gefogen fiatte/erzurtenete fie fich Ders

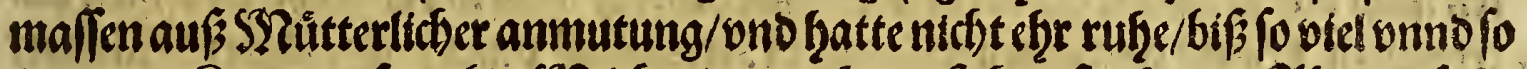

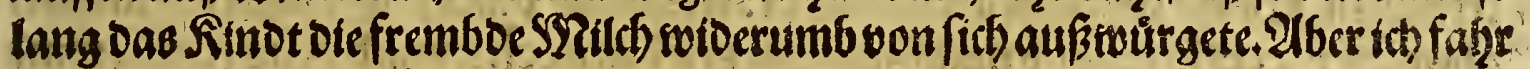

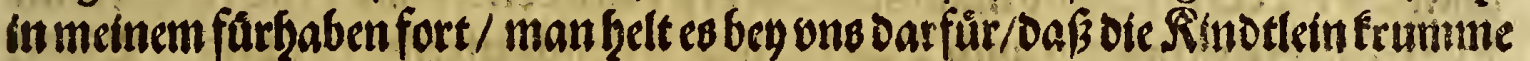

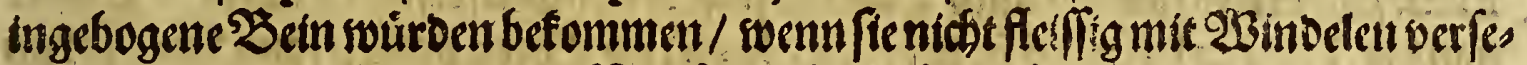

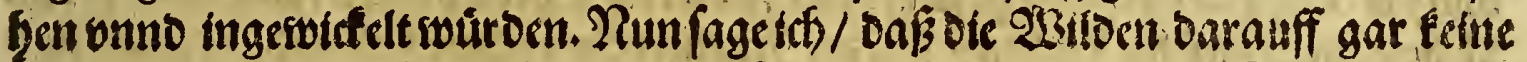
act)tung nod) geoanden geben / (Denn fie legen ote iuttggeborne Rintotlen ohne

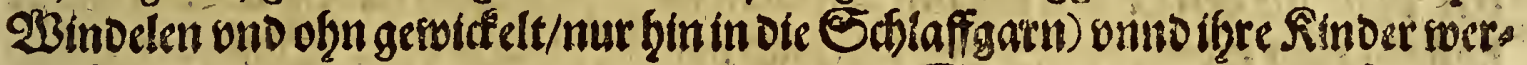
Den logerad ono ftaref / als irgeno soo onter ber Sonnenthes gletchen fennmos.

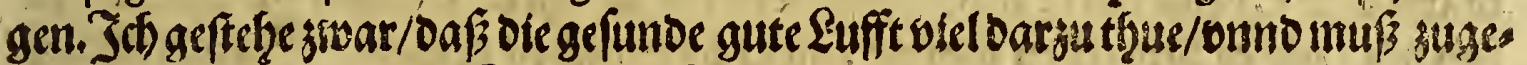

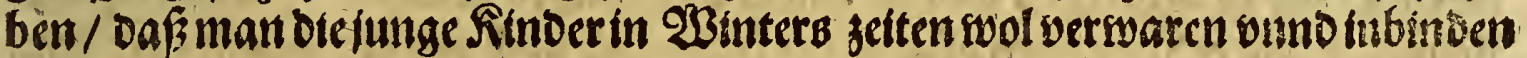

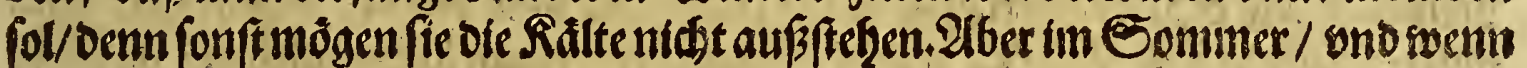

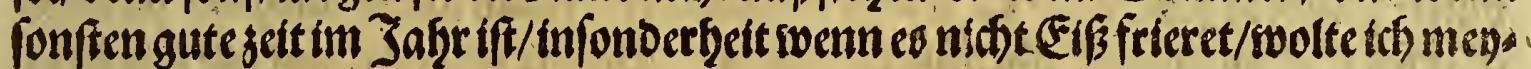

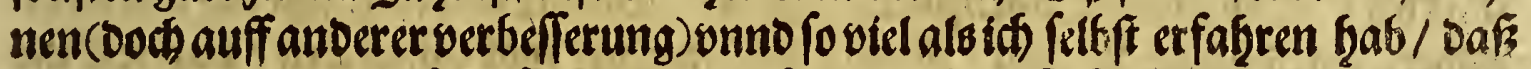
man ole Rinoer nied)t folte fo imperchen/ fondern folte fie fien leolgzabbeln onno

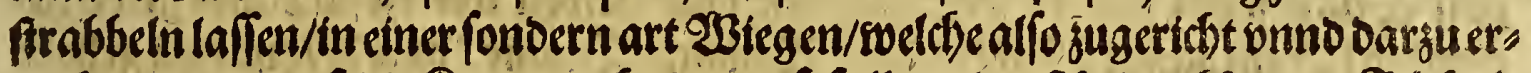

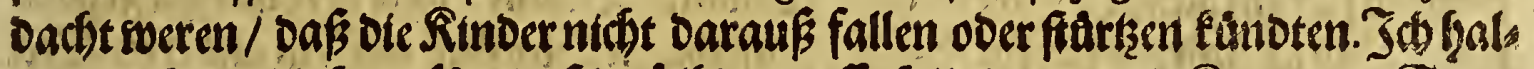

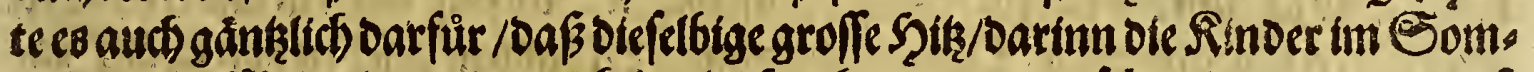

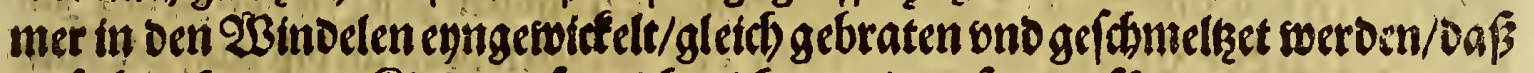

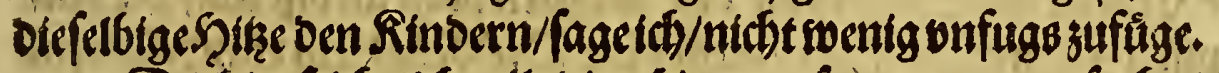

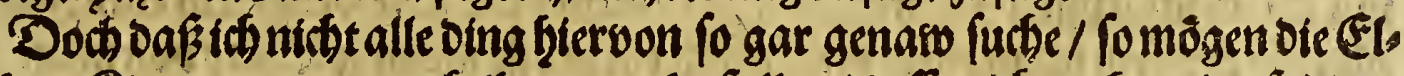

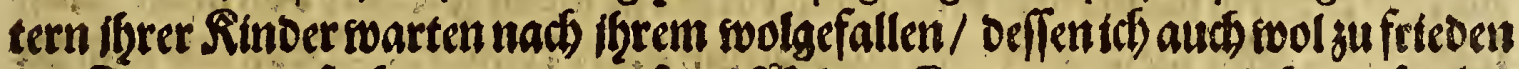

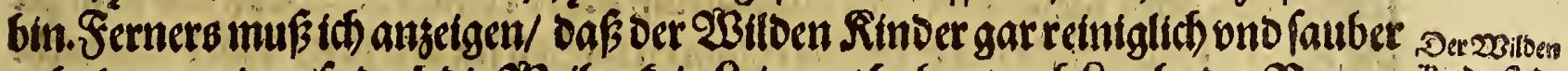

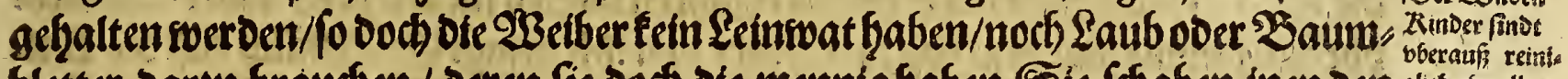

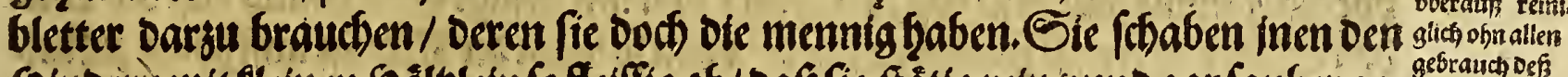

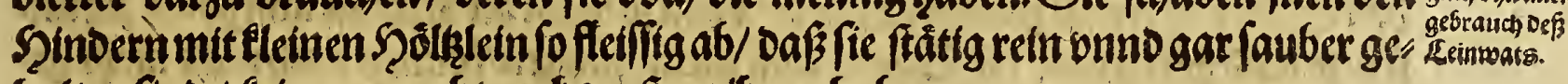
halten fino / feinen vnrabe nod swuft an fonen bुaben.

Die groffen onno errwads fene machen es eben auch alfo/ onno swell ich won

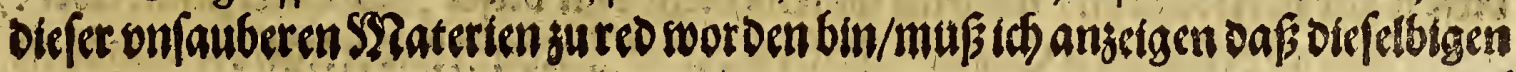

2.




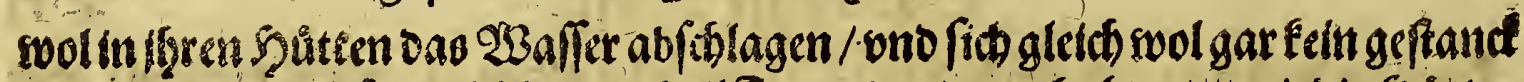

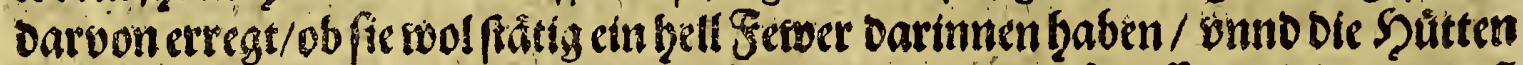

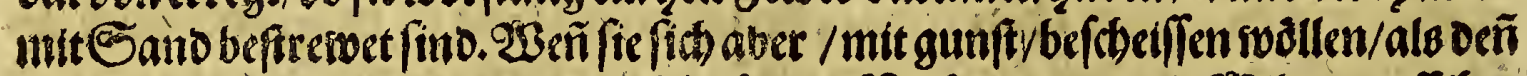

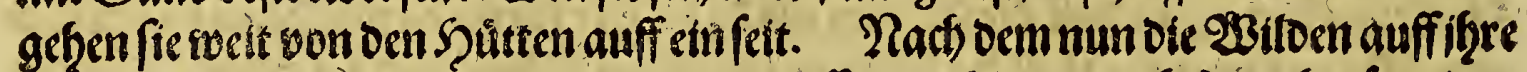
Sinder fleifig acb tung geben/oeren etn grofle antafl linleder Shitten bey/aminen

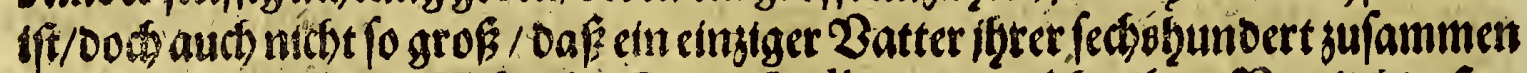

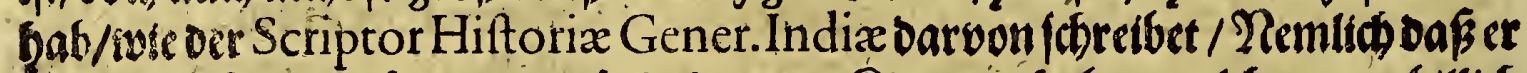

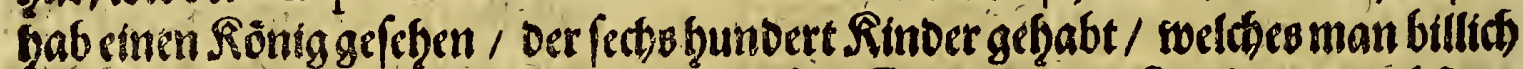
onter ofe 23 unoerweret seblen ono feçen fol. Sie haben oie Sinaben amlieb/ten/

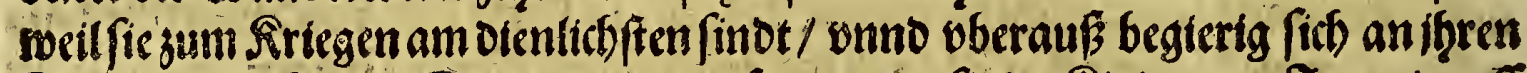
Fetroen zuredsen. Eoicmant nun fragt/swas/ic fre Rinder von Jugeno auff

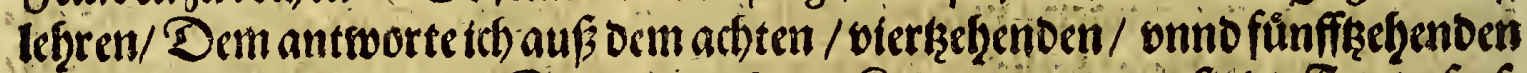

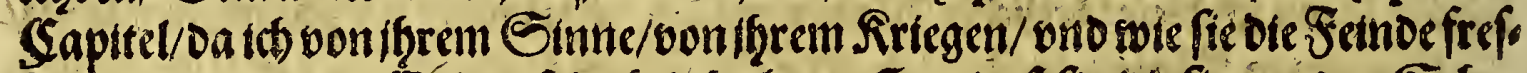

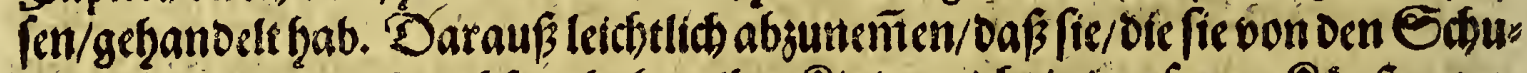

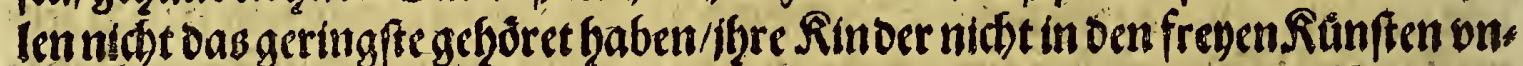

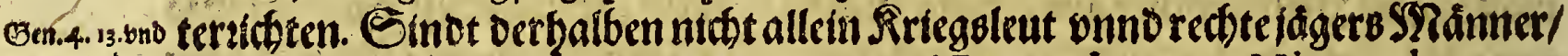
10.8.9. vnd 27. als ware fucceffo res vno nact) fommene bef Lamechs, wno Nim roths, wno

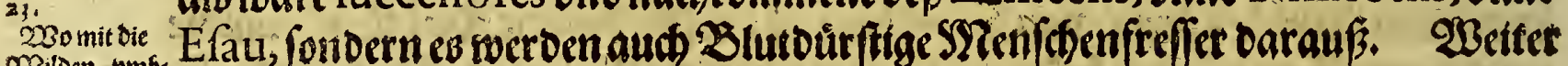

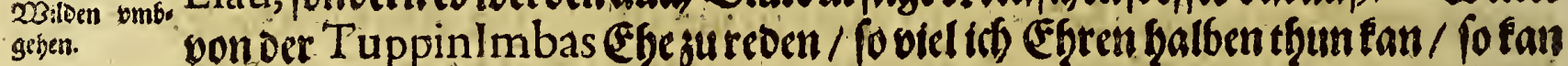

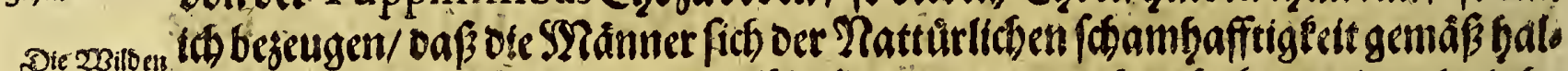

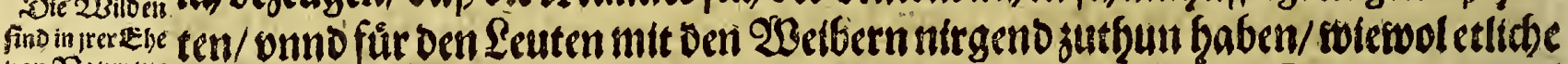

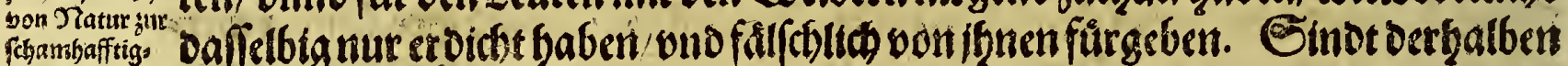

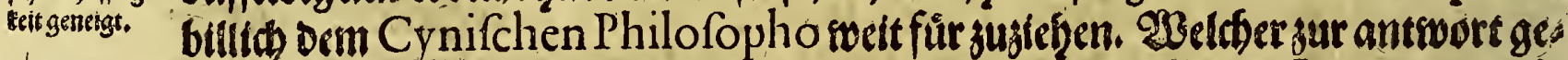
benbat / als er begrieffen swar in einem offentlichen gemeinen Sraumenhaußs/

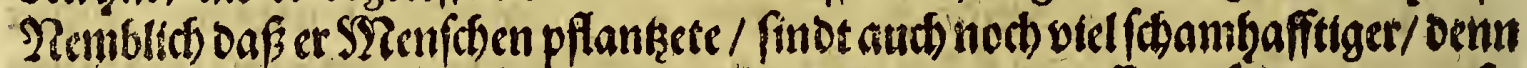

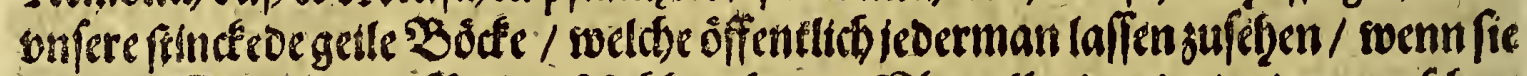

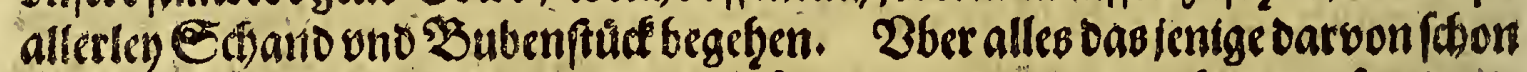

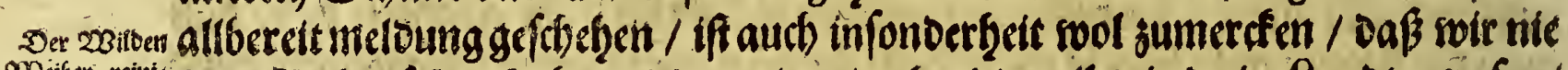

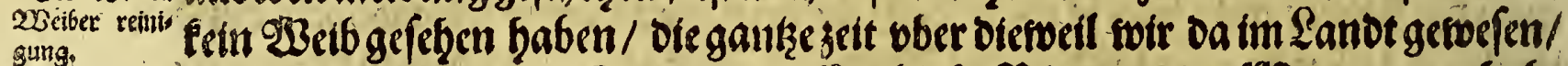

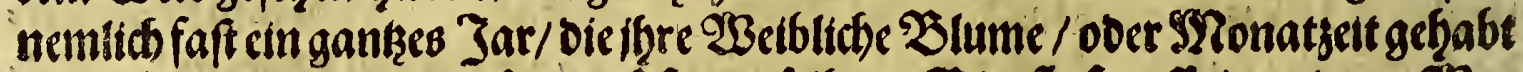

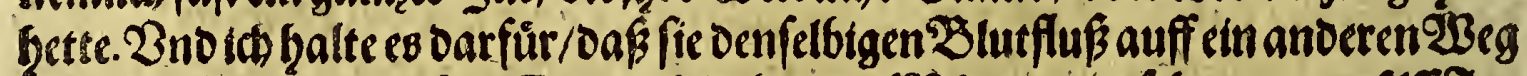

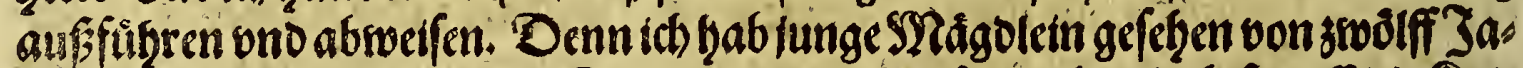

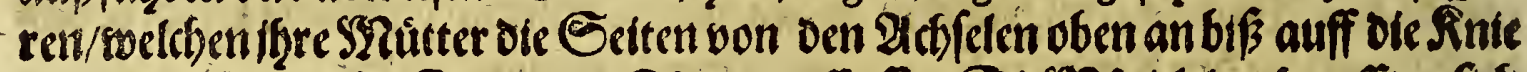

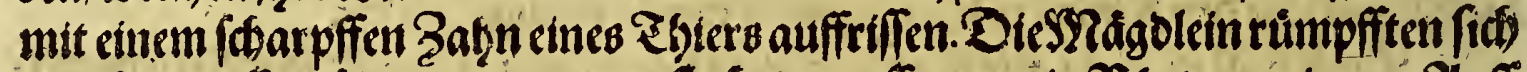

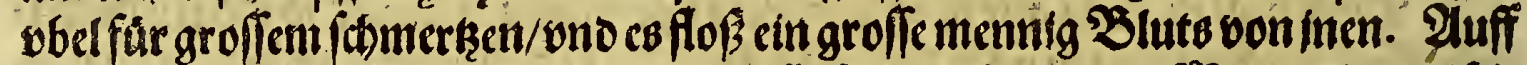

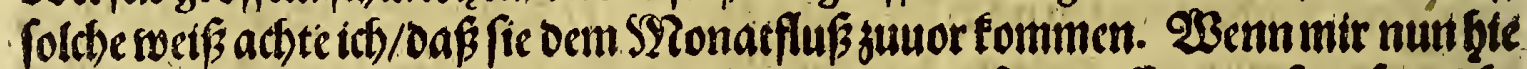

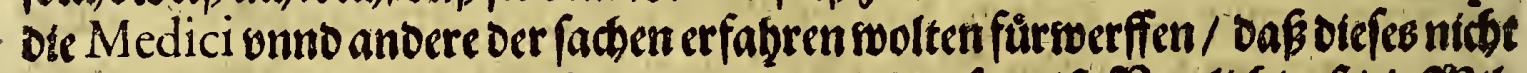

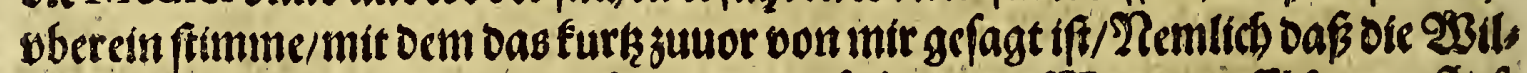

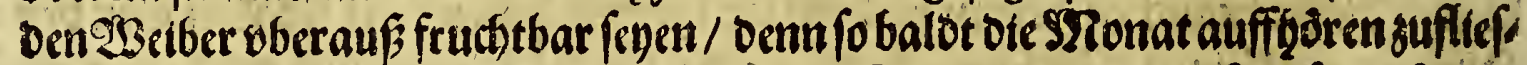

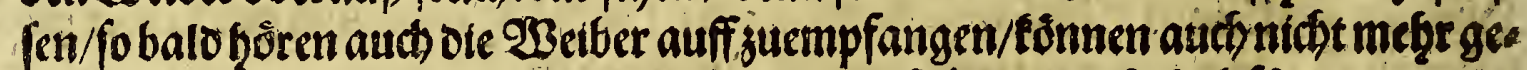

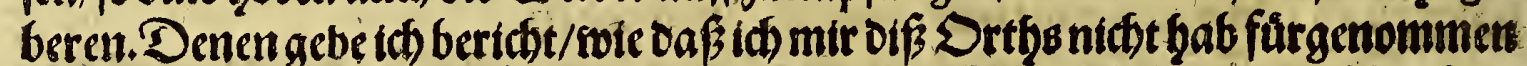
biefe fragezu refolutren / aud nit willens melgr von otefer SRaterten zufdoredben.

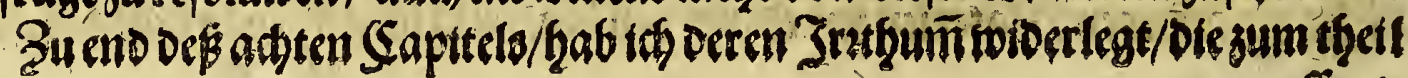
offents 


\section{Dab britte Tferl.}

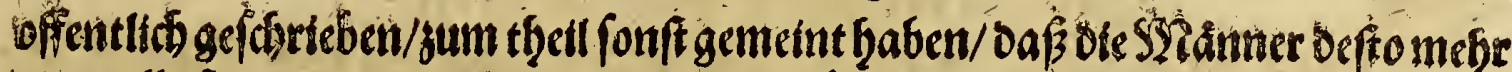

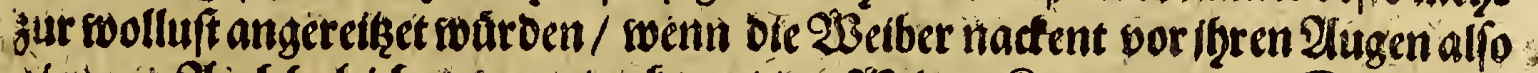

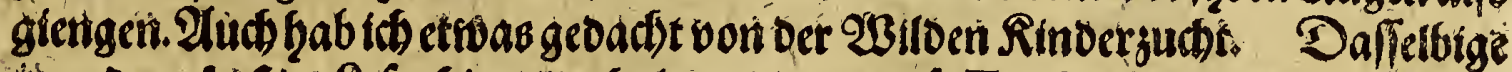

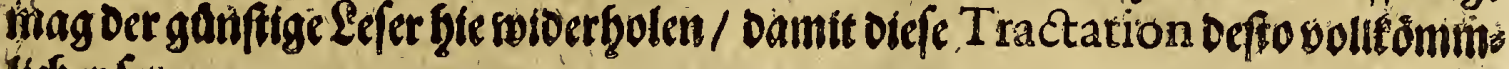
Vicher fey.

\section{Sapittol: Argument.}

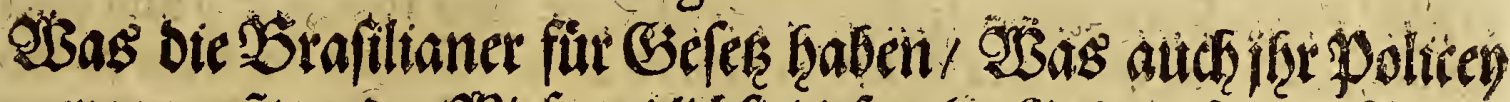

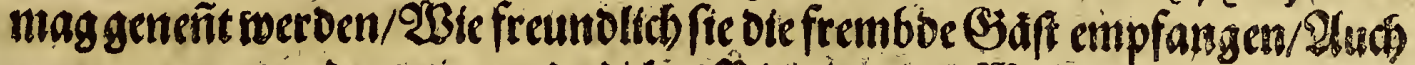

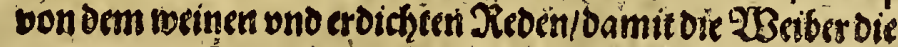
Srembiertifeiffen twitfommen fenn.

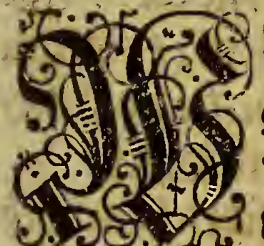
Fo ber gisiben Policel anlangt / fo fetiet es faum zu

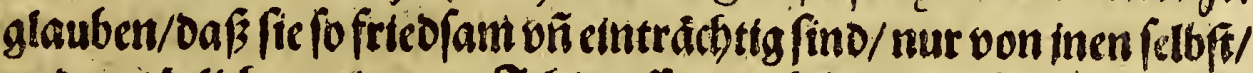

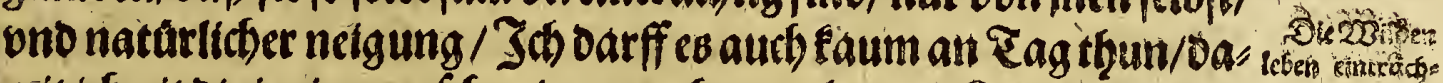

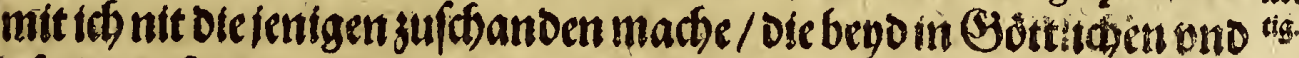

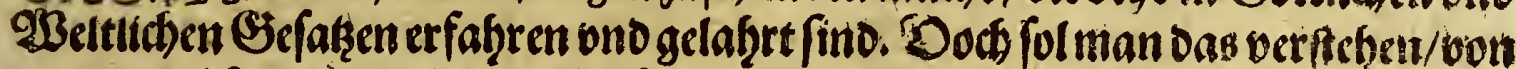

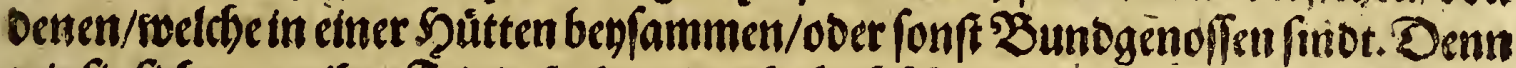

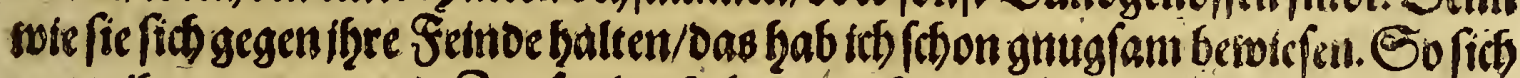

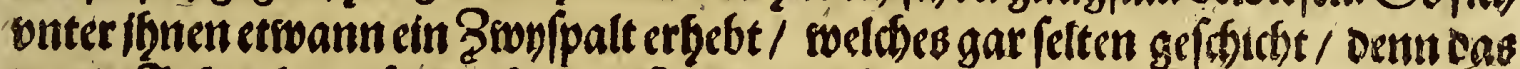

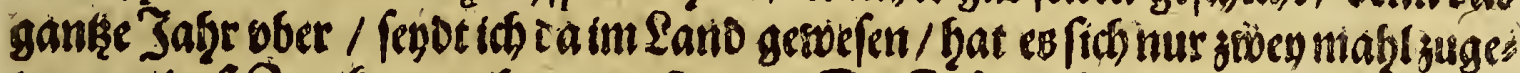

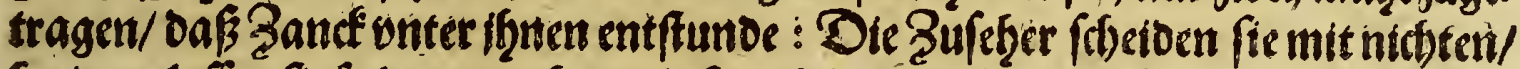

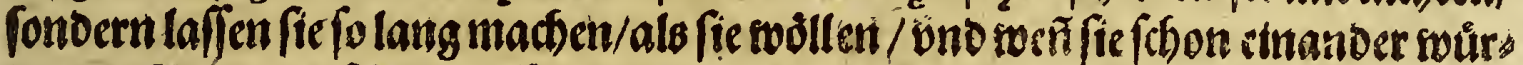

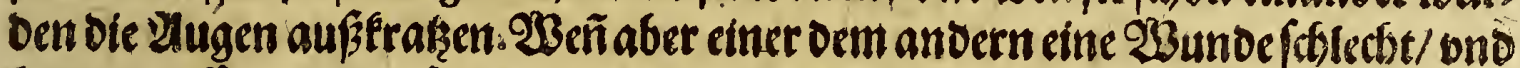

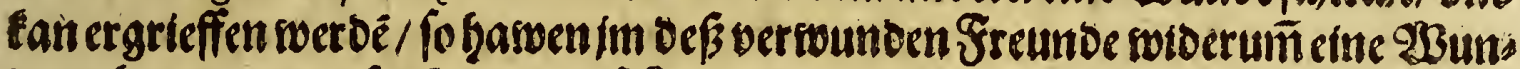

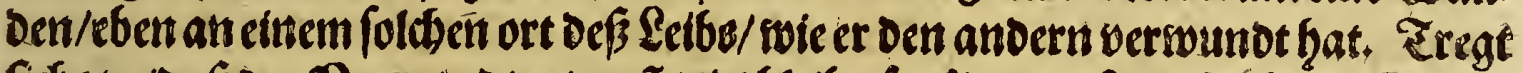

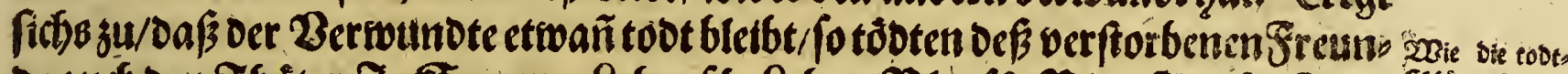

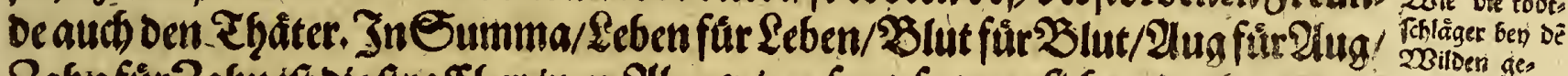

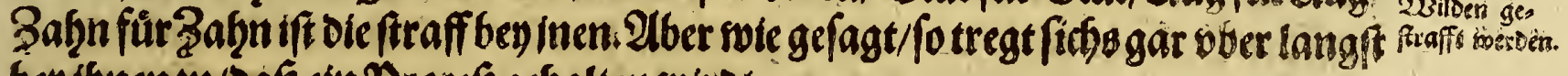

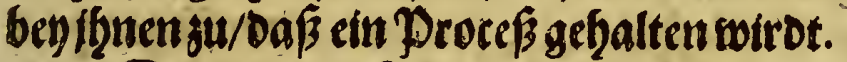

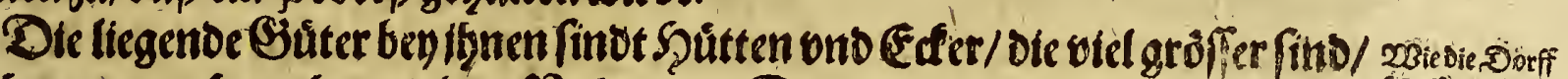

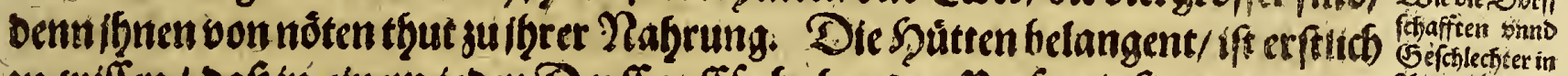

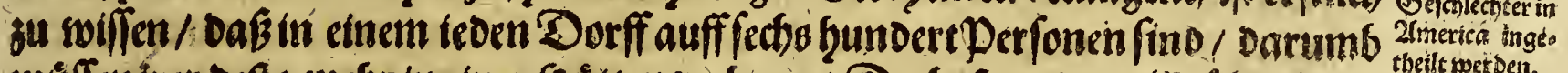

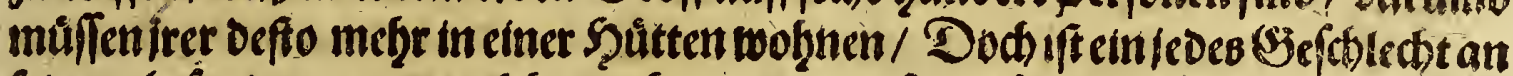

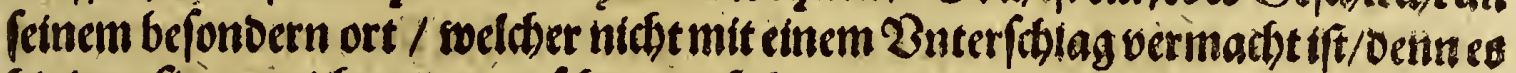

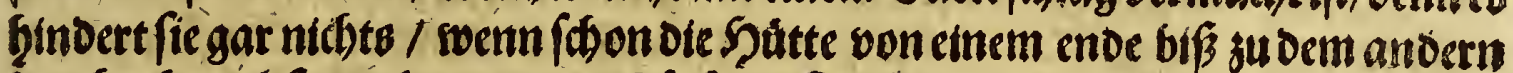

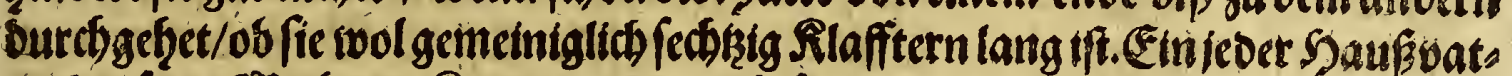

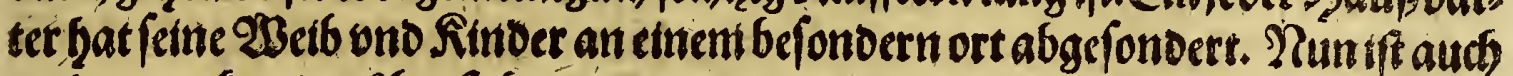

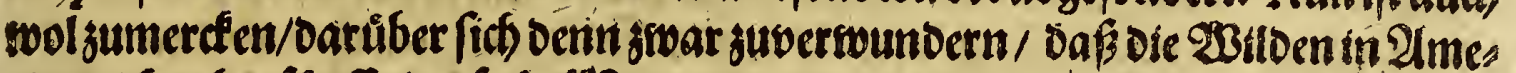

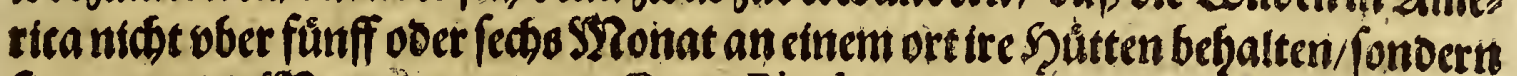

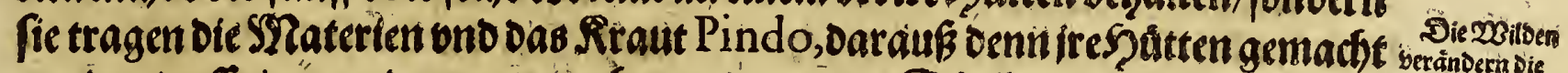

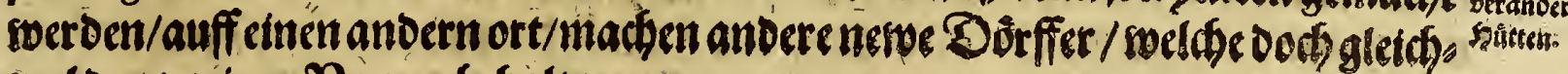
moloenvorigen Ramen betgaltem: 


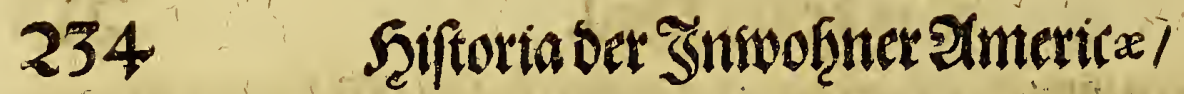

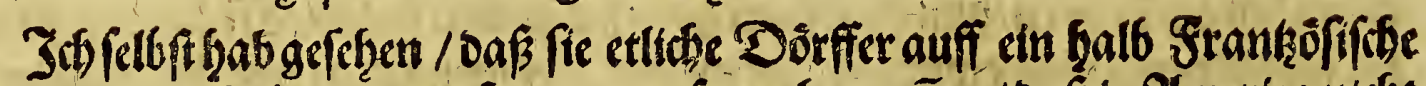

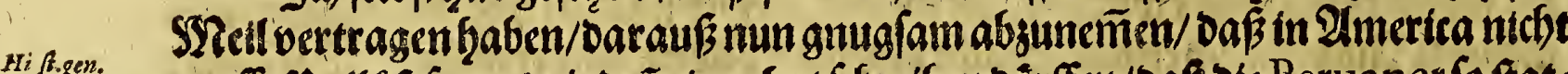

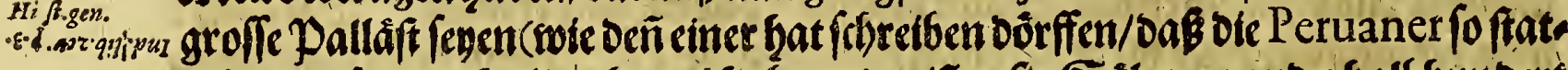

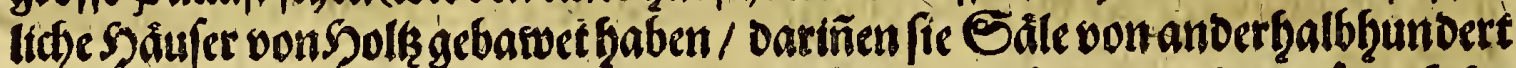

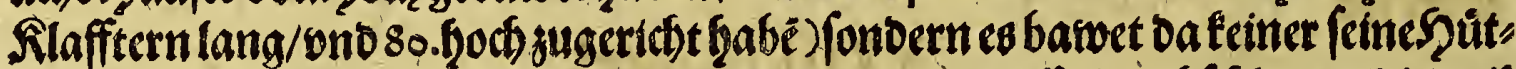

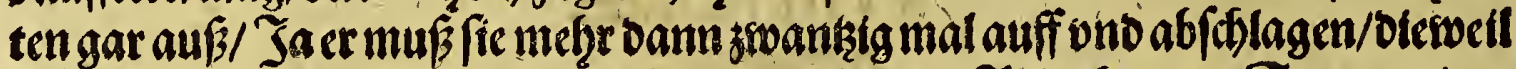

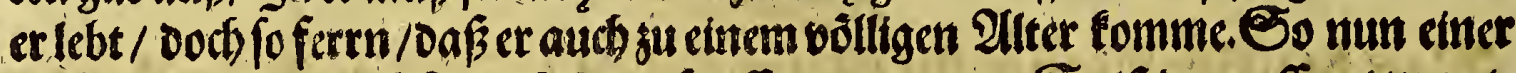
wiflentwolt/warumb fie ire Saútten fo offt vertragen. So if doarauf gut gu ants

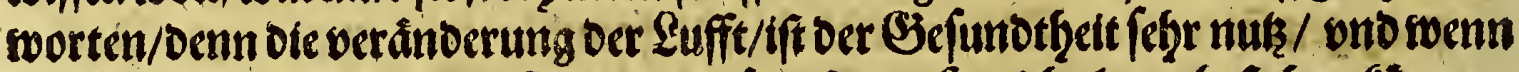

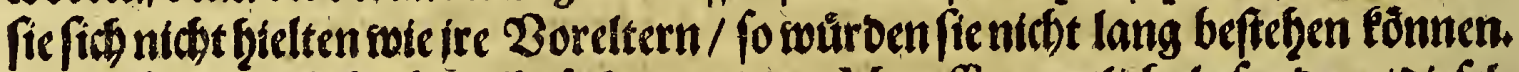

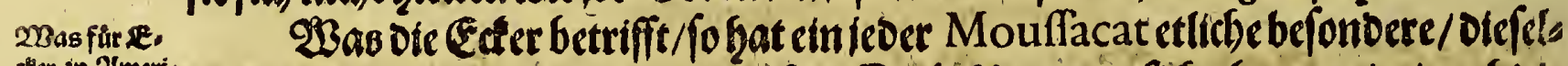

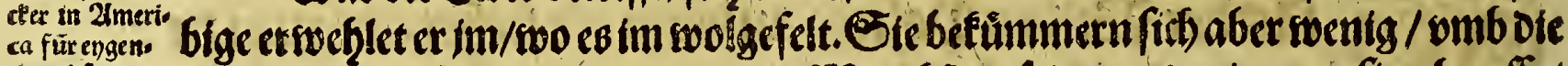

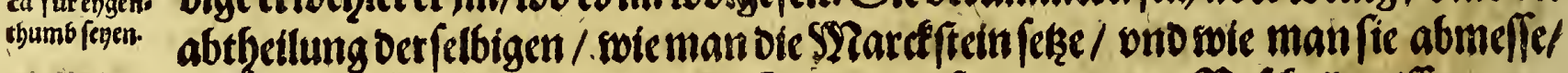

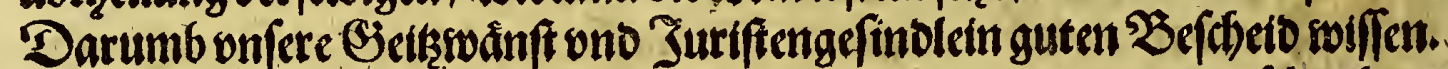

Jat bab fition on etlitb malen von iremS

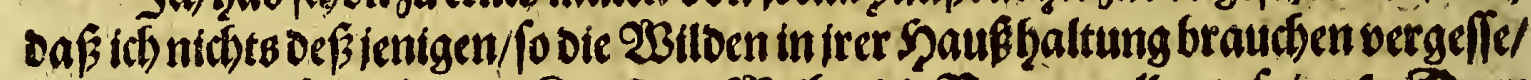

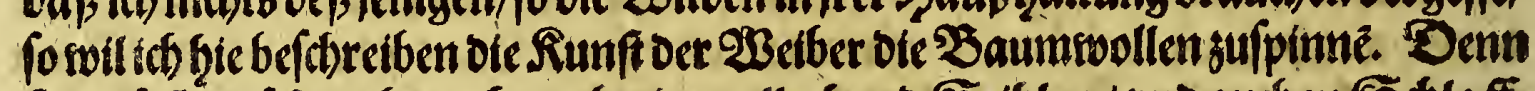

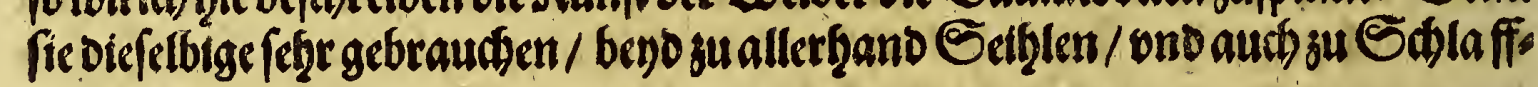
garmen.

$23 i c$ tie $23 i$ den 23 eiber

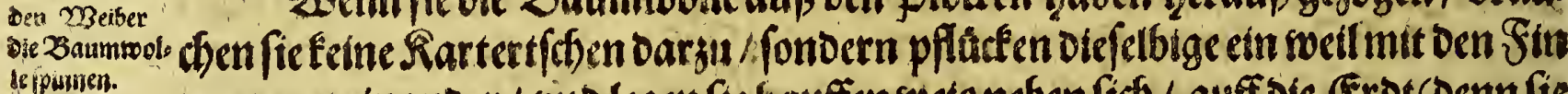

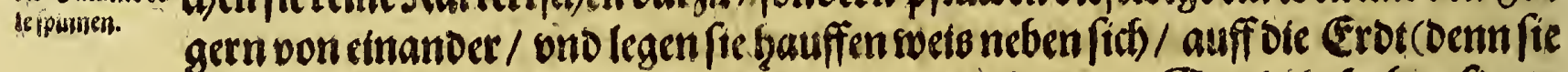
fònnen mit feinem Epinrodtu ombgefen / an fatt Der Epinoelnbaben fiecus

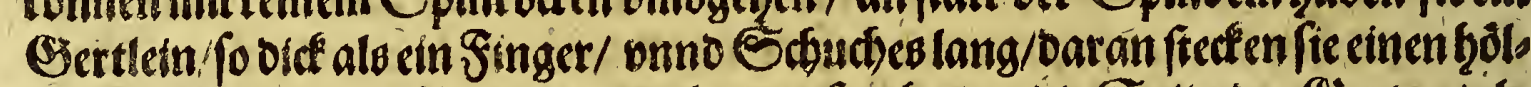

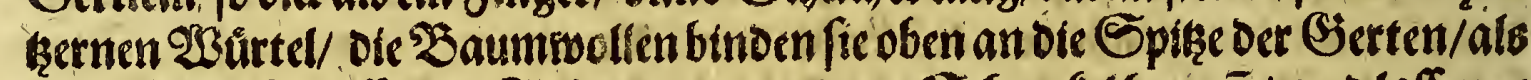
oenn treђ

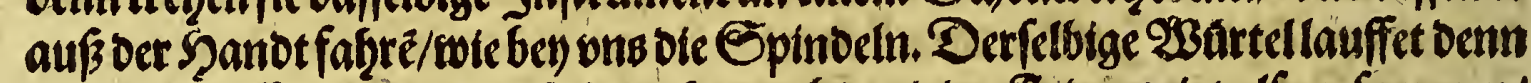
auff oer Galfen ooer in ber Shutten herumb/ ond der faben woirt alfo gefponnen/

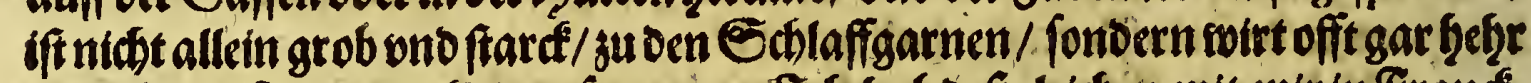

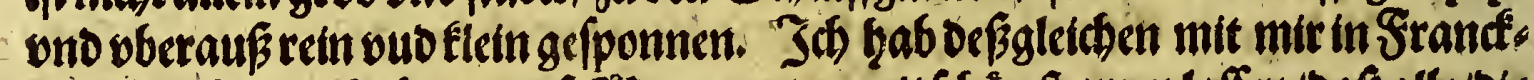

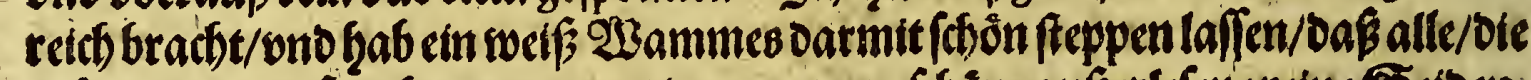

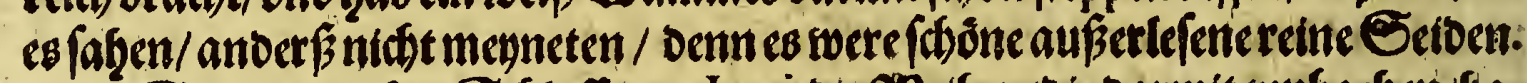

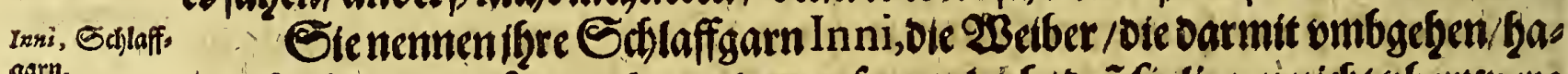
gatr.

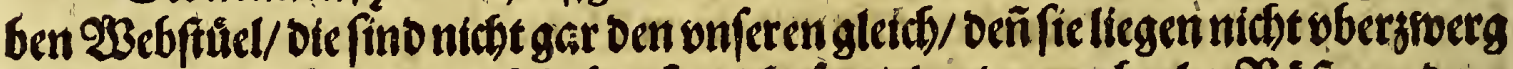

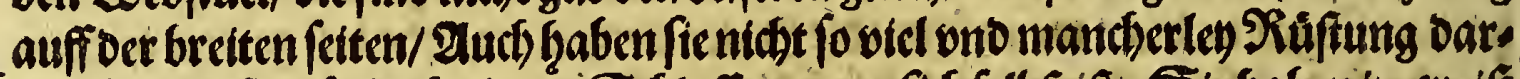
23air berefshafat

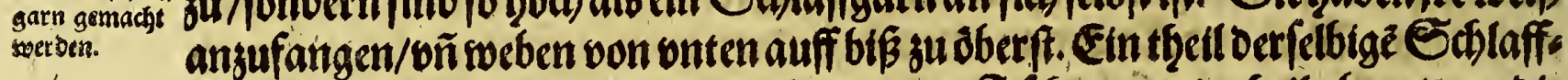

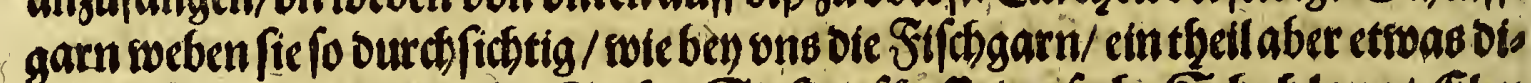

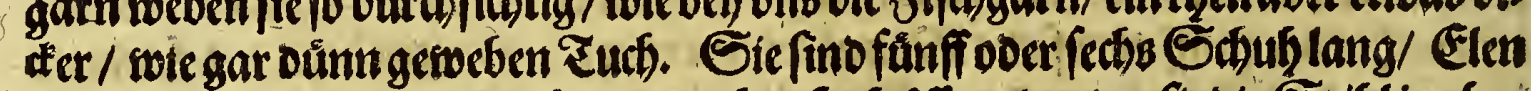

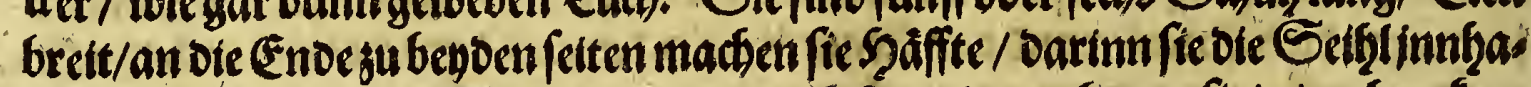

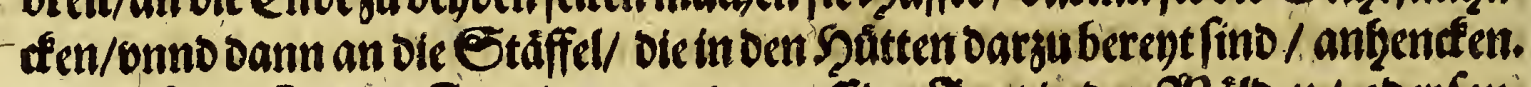

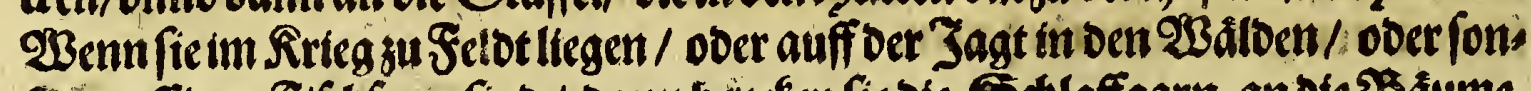

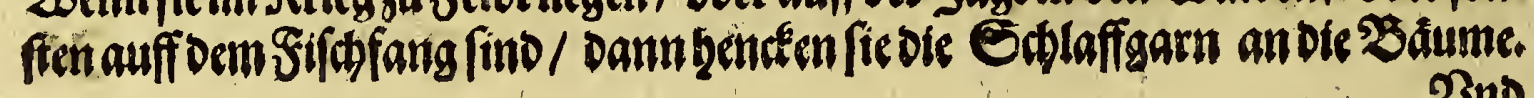




\section{Das britte Thetl.}

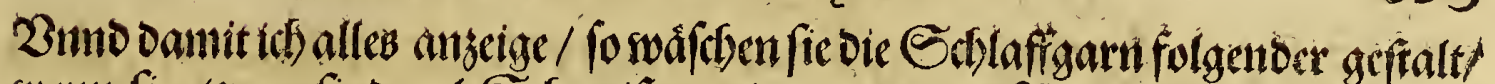

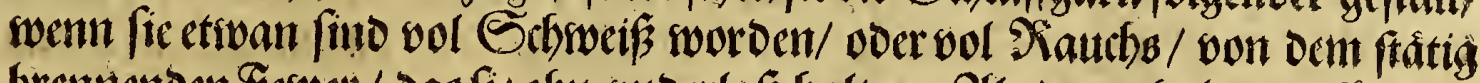

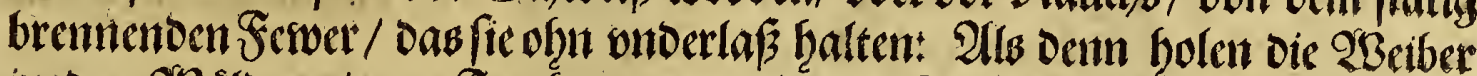

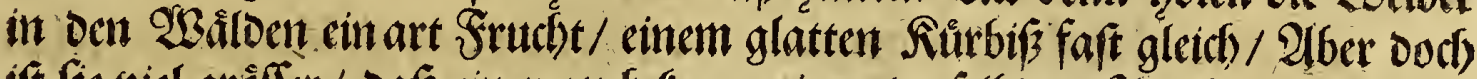

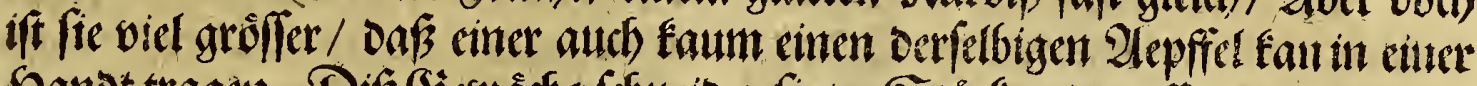

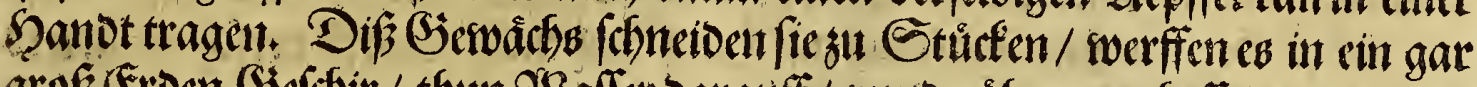

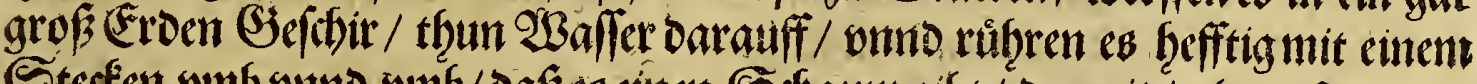

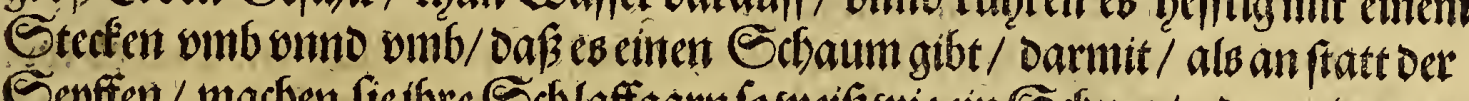

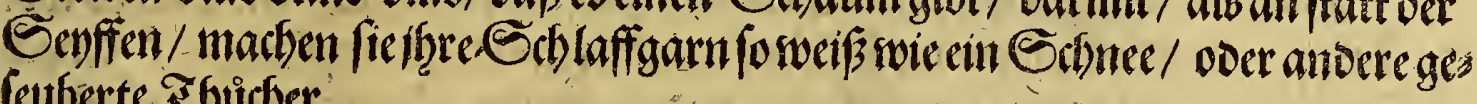
feuberte Efbutber.

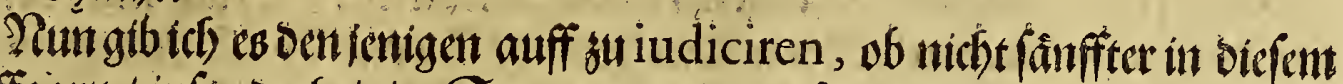
Schlaffgarn / infonderteit im Sommer/zuliegen/ey/als in vit/cren Seberbets

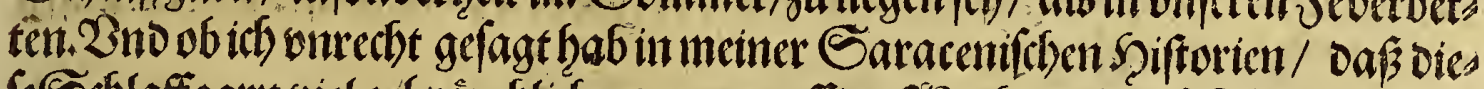

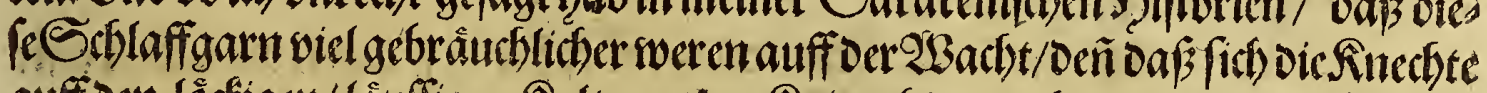

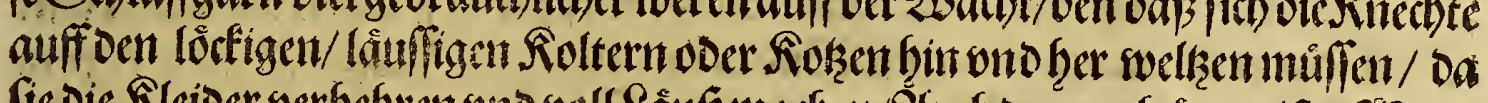

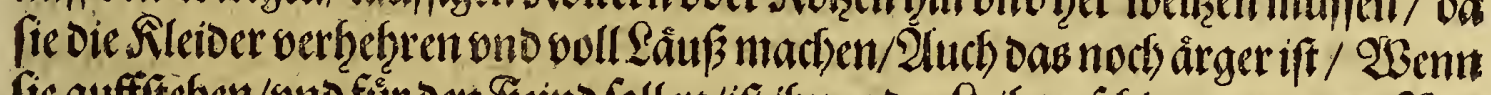

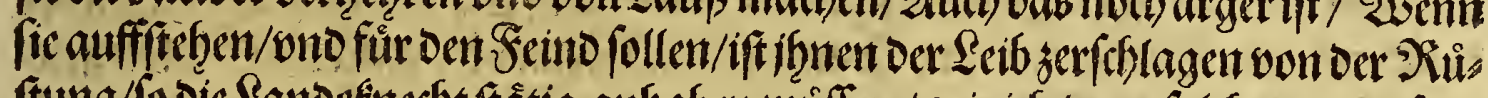
ftung/fo oie Santobnecht ftâtig anţaben muifen/ wie idb oenn foldbeg genuglant

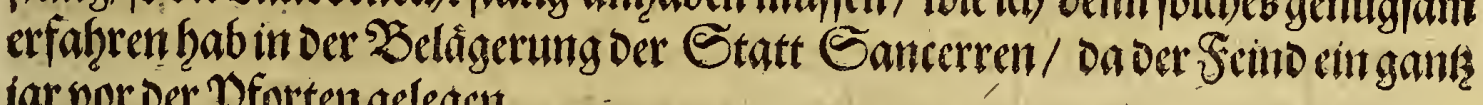
iar vor ber Pforten gelegent.

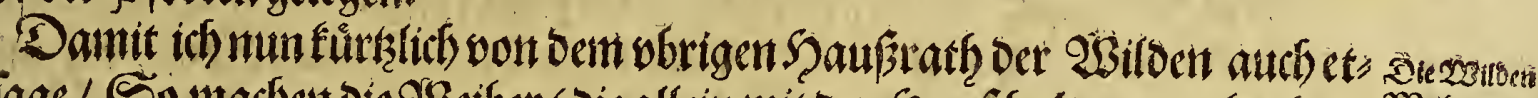

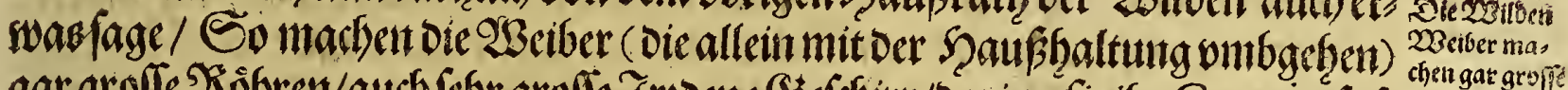

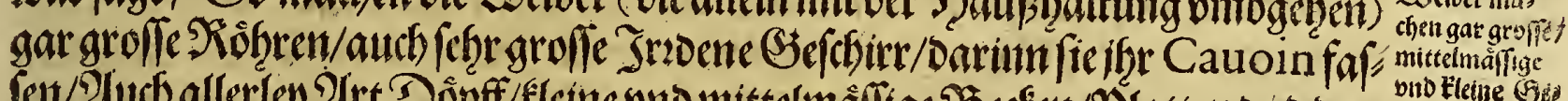

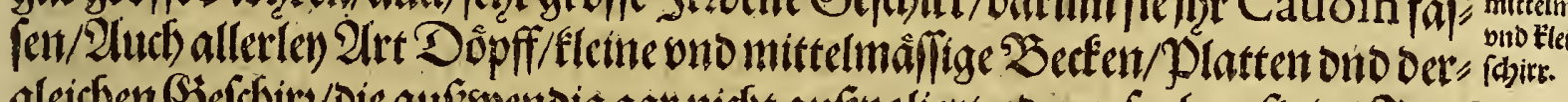

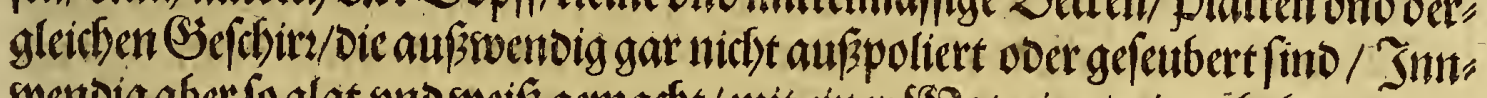
wenoig aber fo glat ono weif gemadt/ / Init einer SYaterien/mir onbefannt / oie

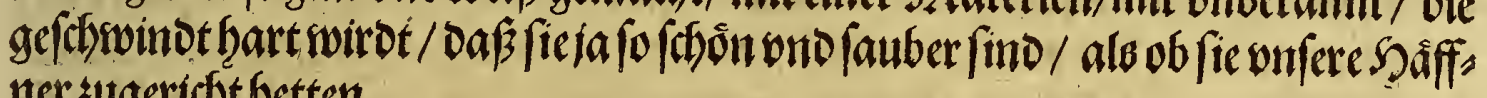
ner zugerict thetten.

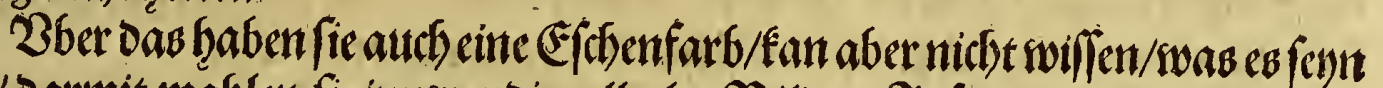

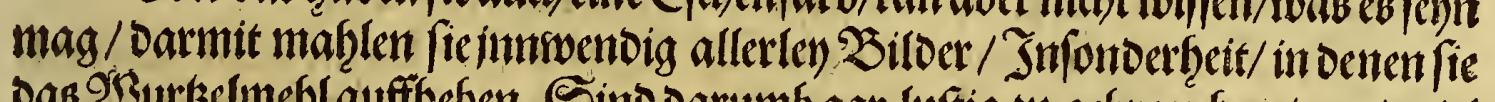

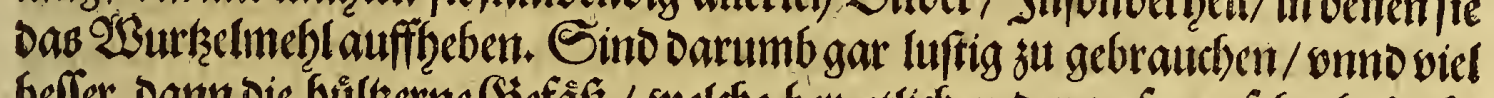

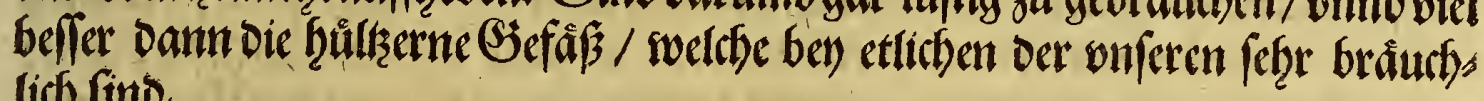
lich find.

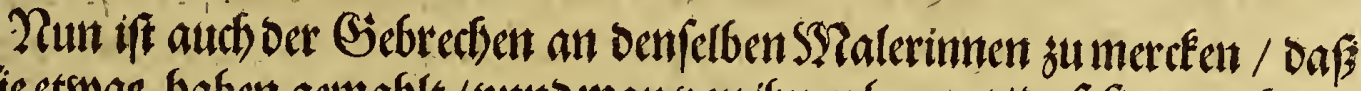

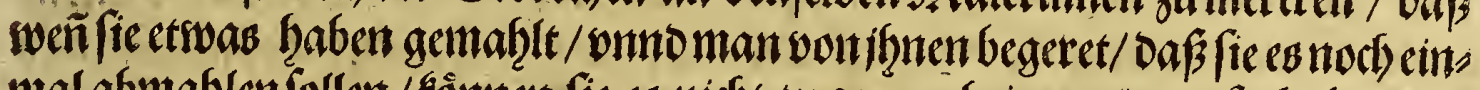

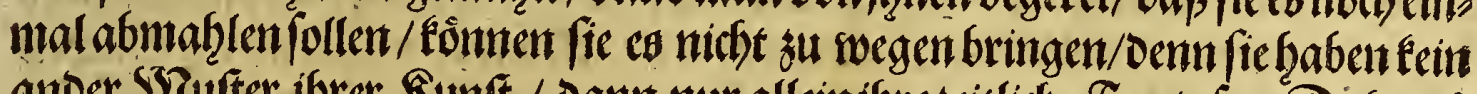

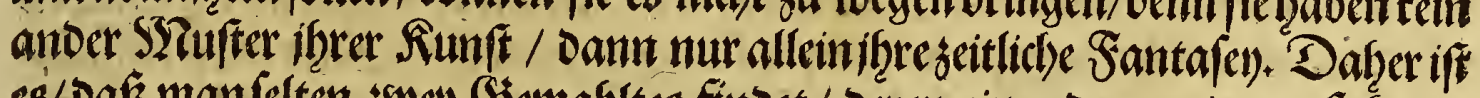

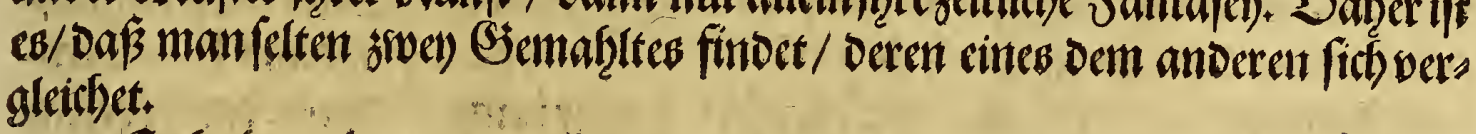

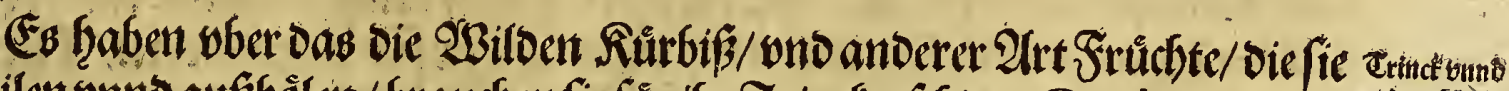

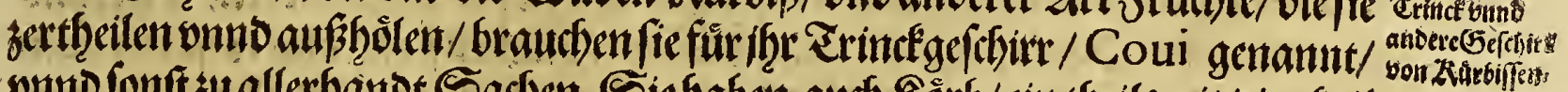

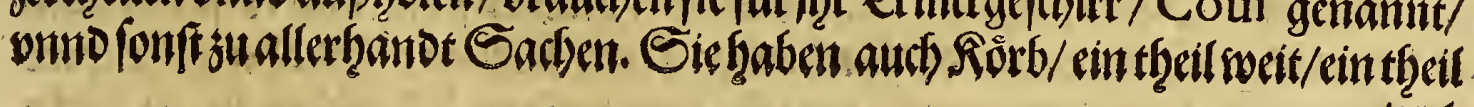


236

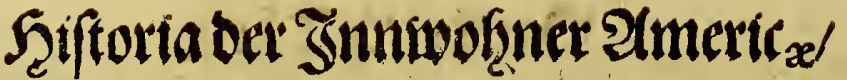

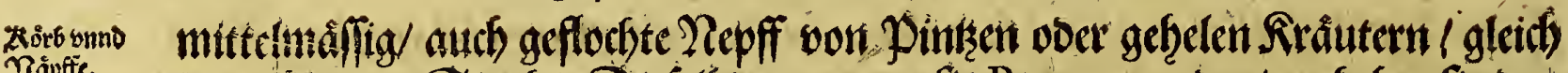

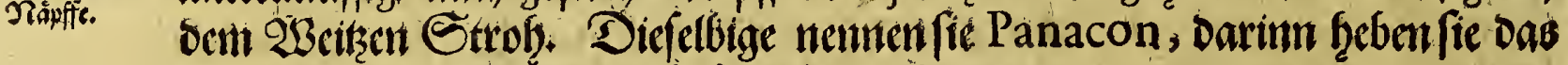

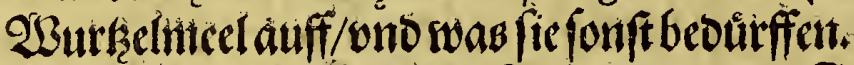

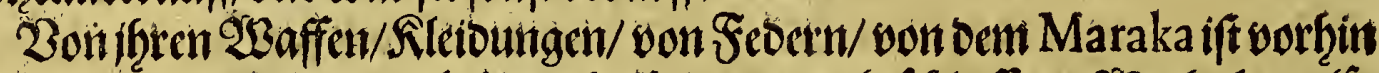

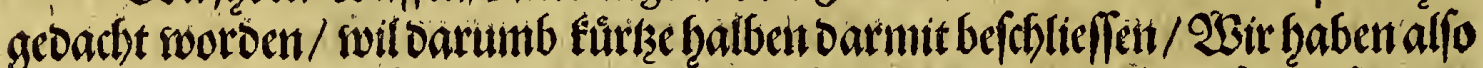

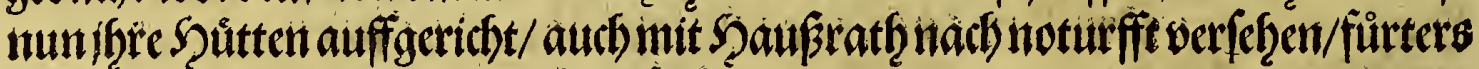
wollen wit fic felbft oariunen beimfuclent.

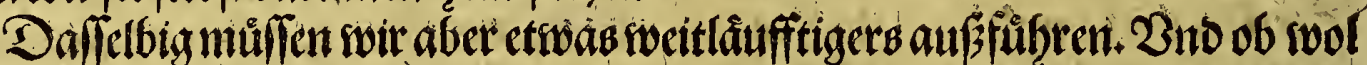

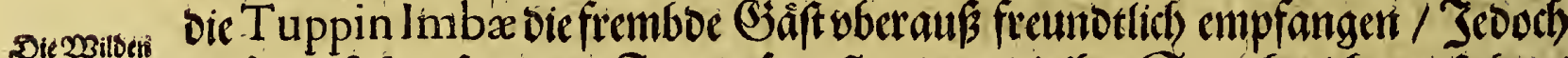

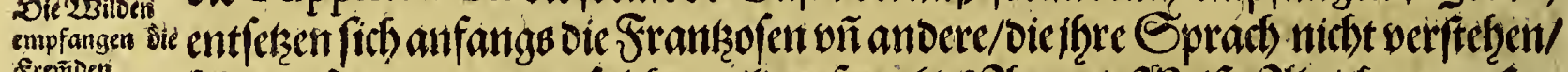

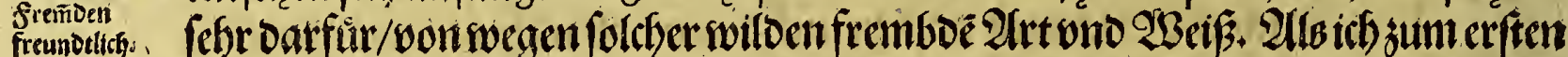

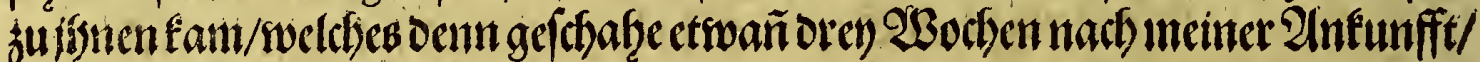
it das Seflofis Collignium.

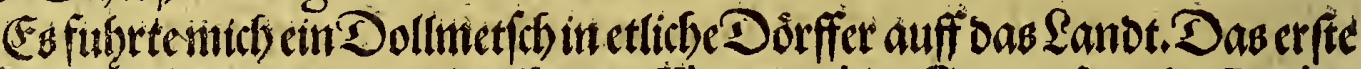

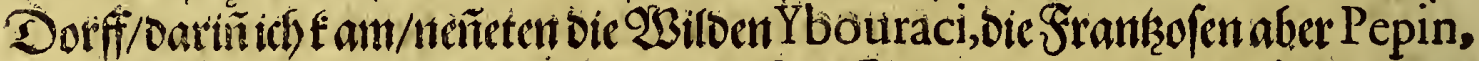

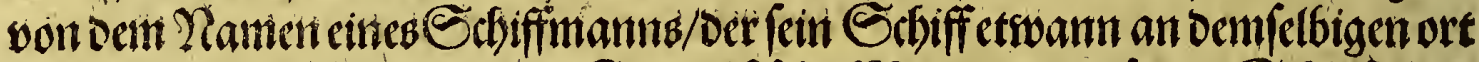

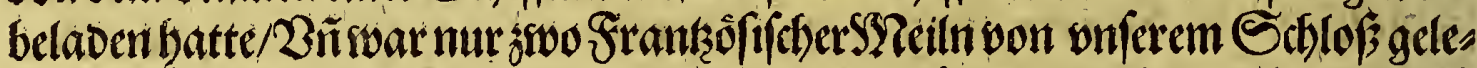

Zureşuerilige

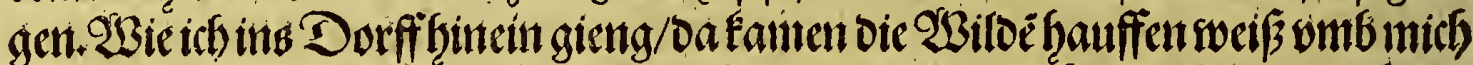
Narration,
swe es bnferent

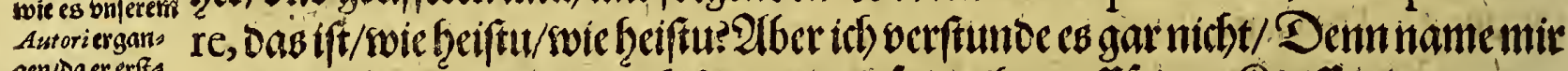

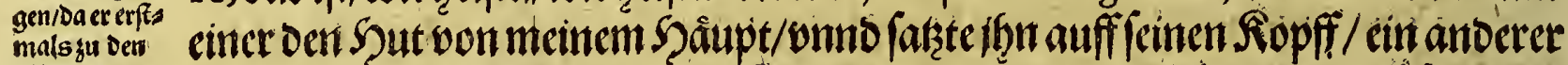

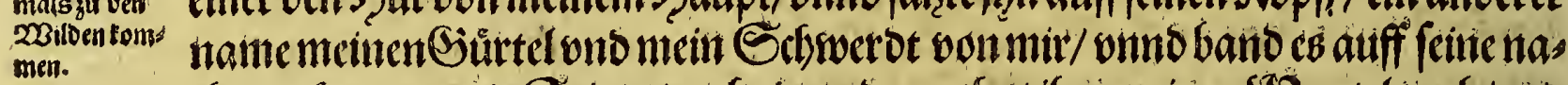
dfende Saut an bie Seiten/noch ein anderer that fbrim meinen SYantel vimb/ono

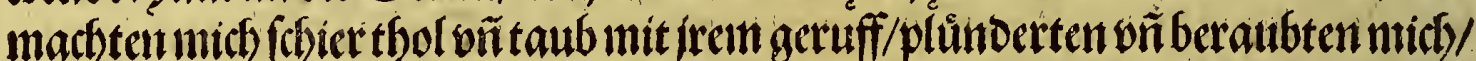

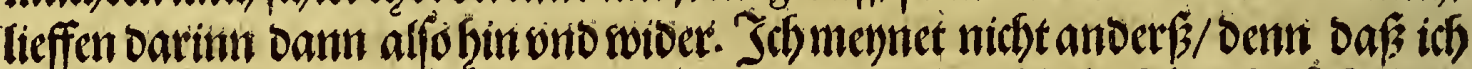

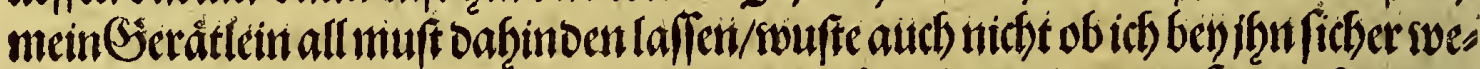

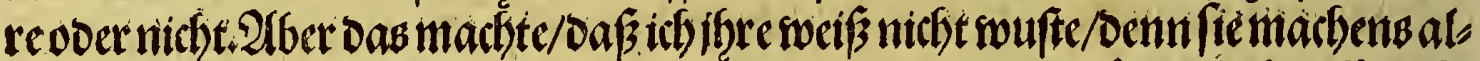

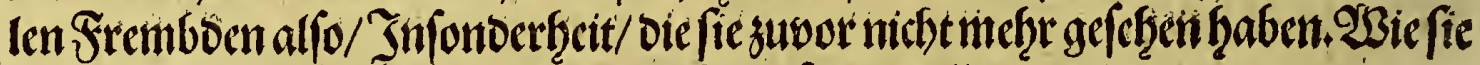

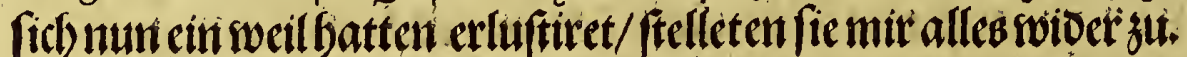

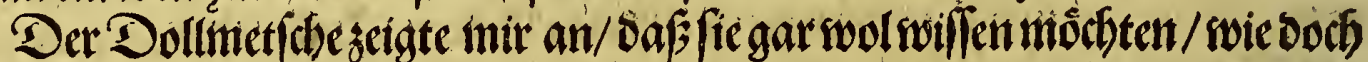

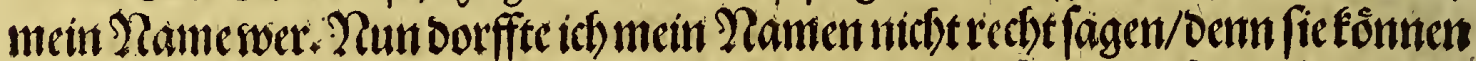

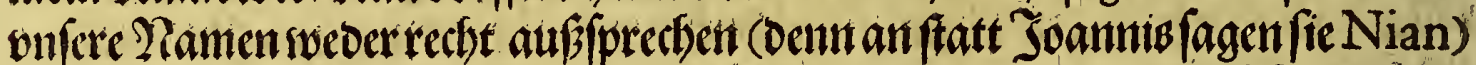

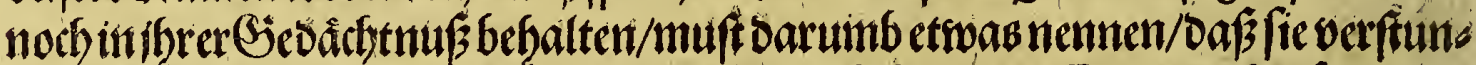
$\mathrm{Den} /$ Jeb traffe aber ebent gar wovl/ fagt ich bieffe Lery-ouffou, swelebeb fo viel ift

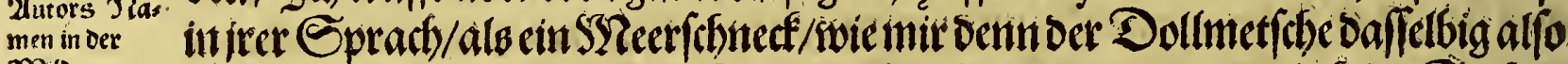

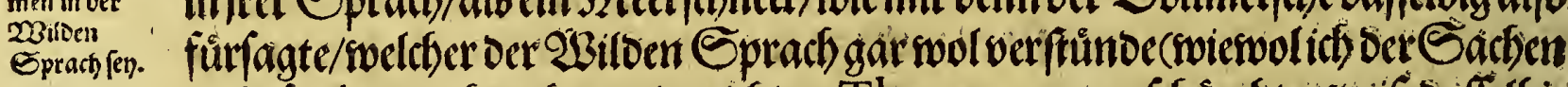

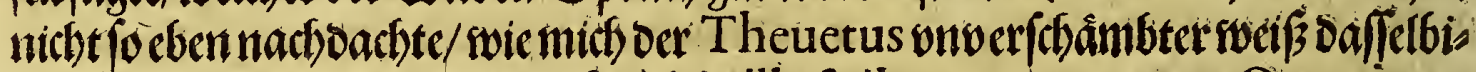

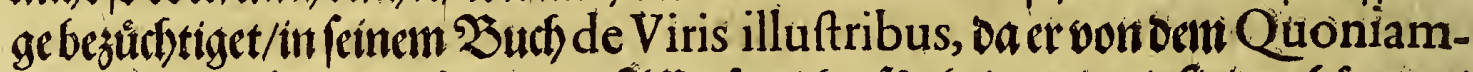

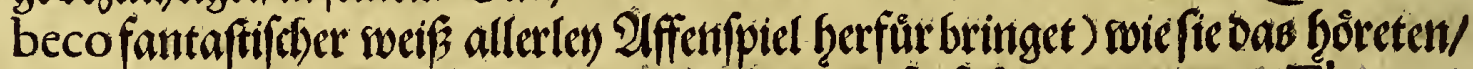

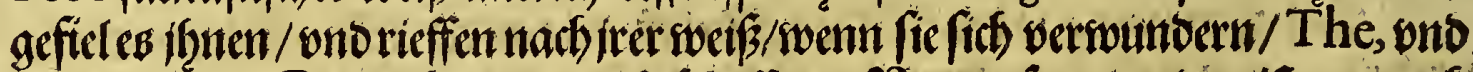

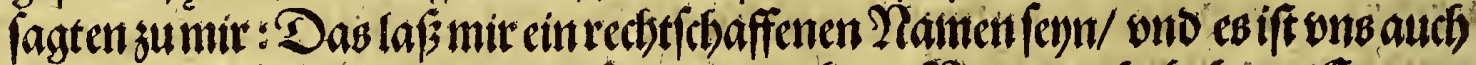

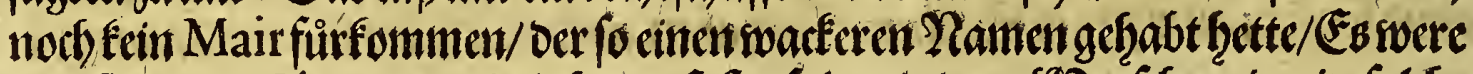

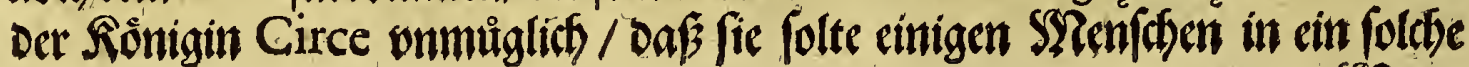




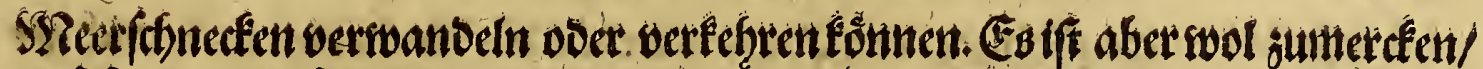

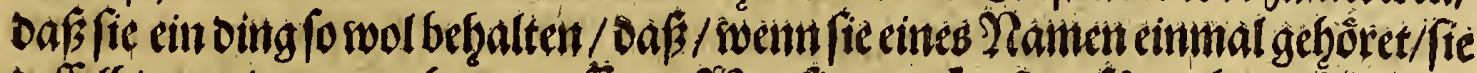

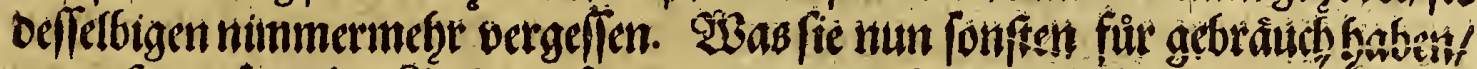

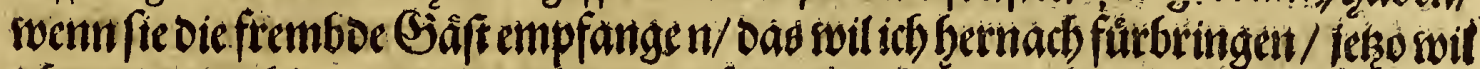

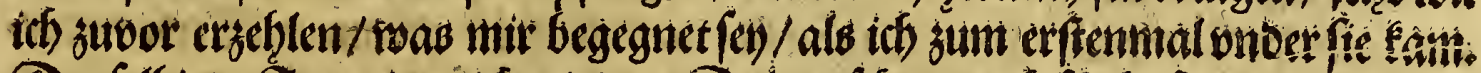

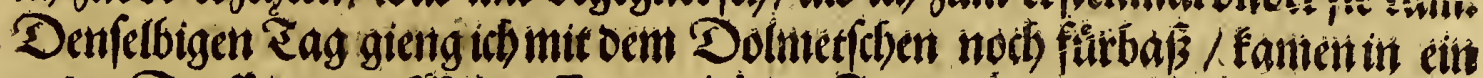
ander Dorff/Das bic 2 Bilden Euramiri, bie Srantzofen aber Gofet; nach eites

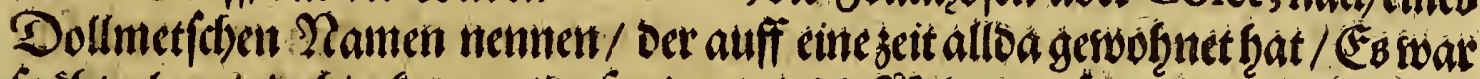

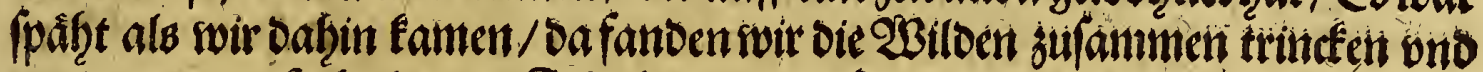

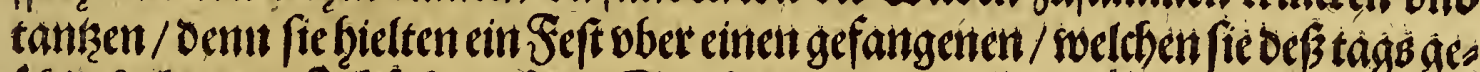

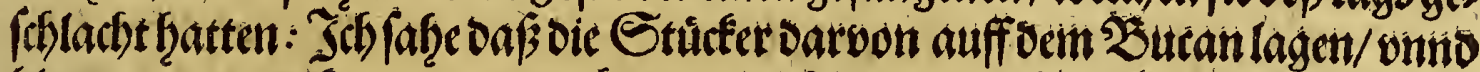

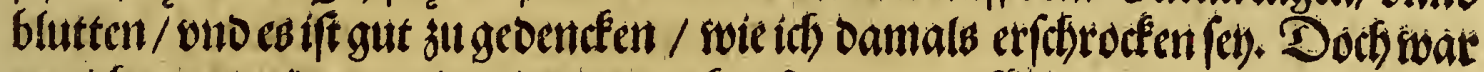

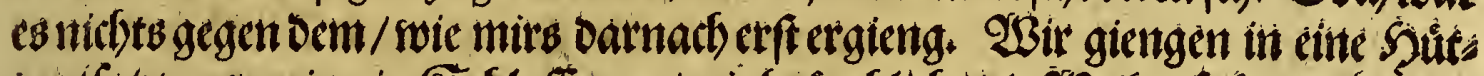

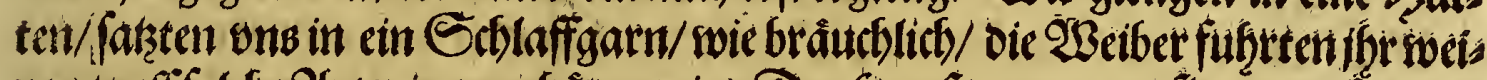

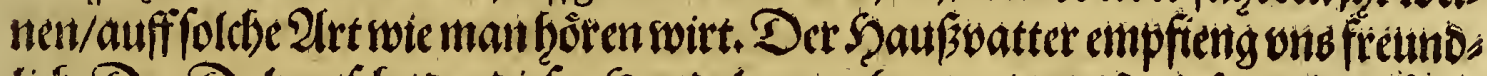

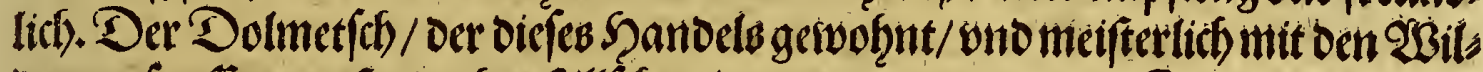

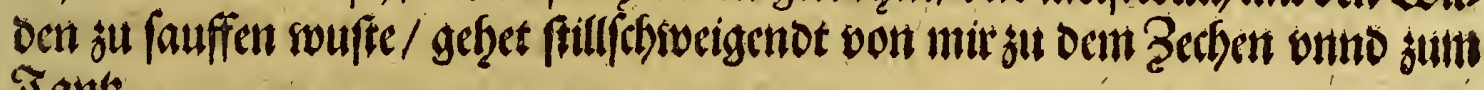
Sanks.

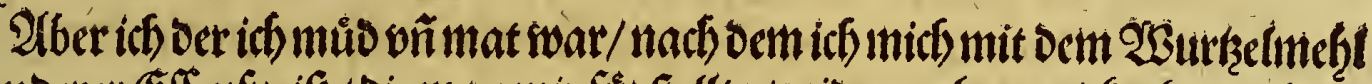

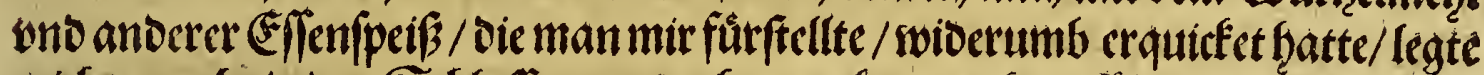

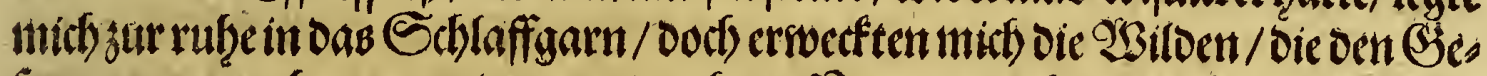

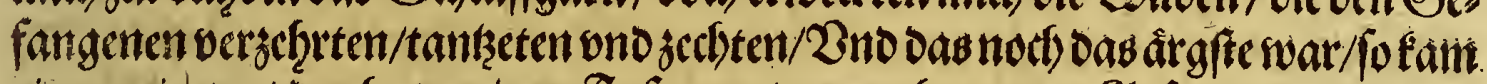

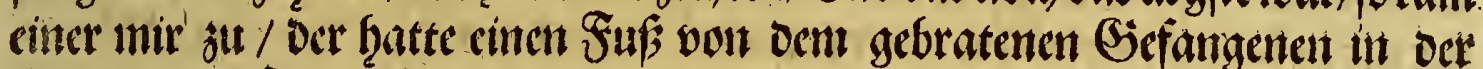

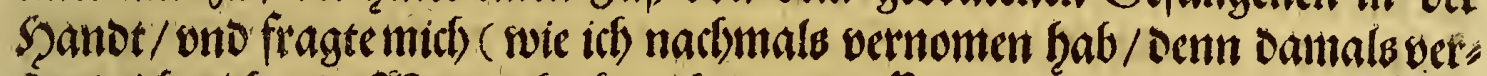

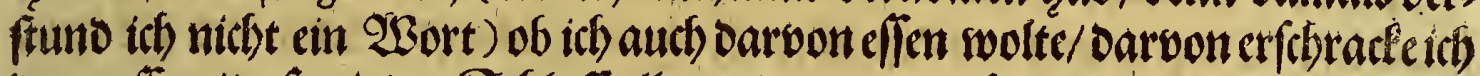

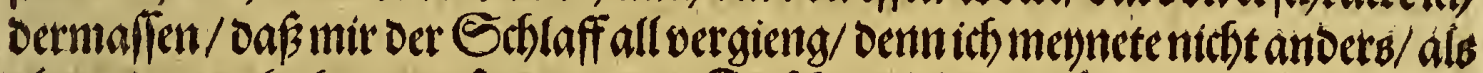

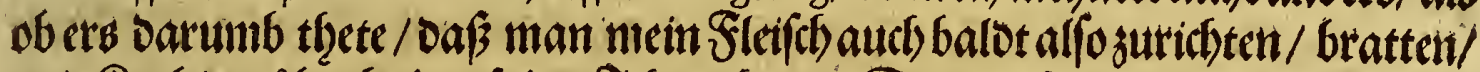

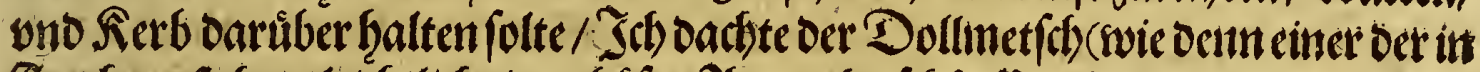

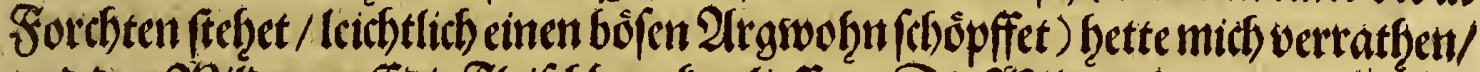

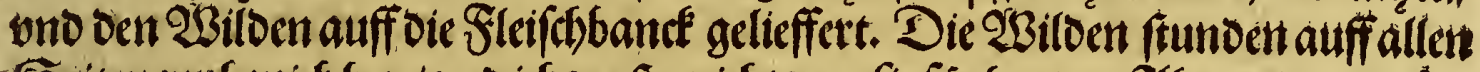

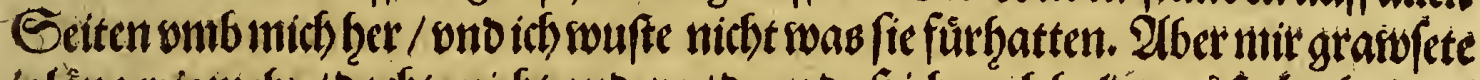

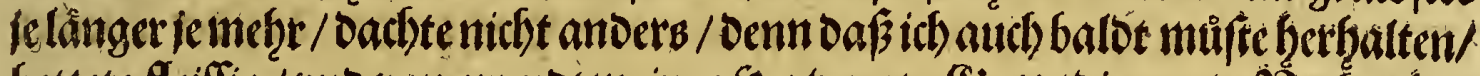

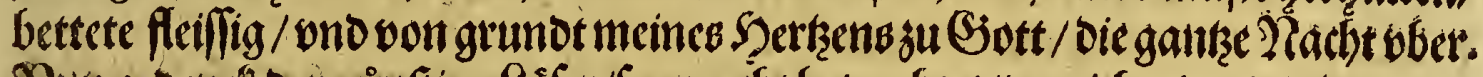

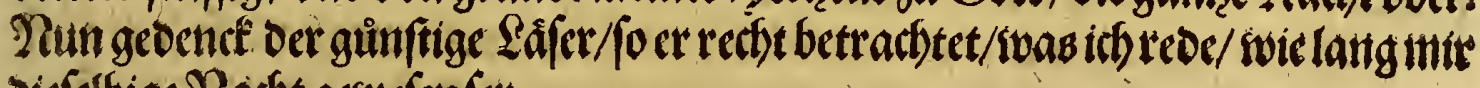
diefelbige Nacht gewe (en (e).

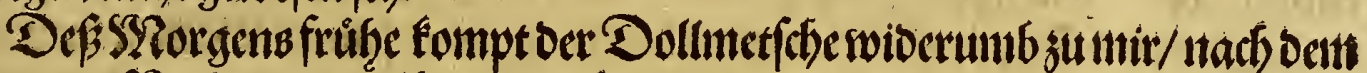

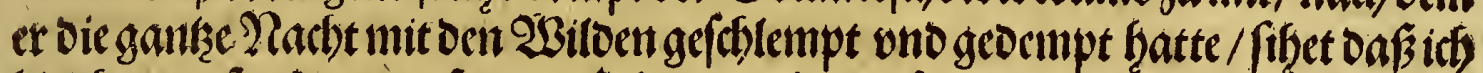

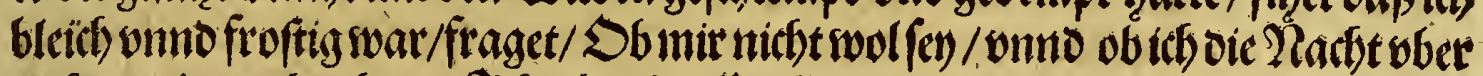

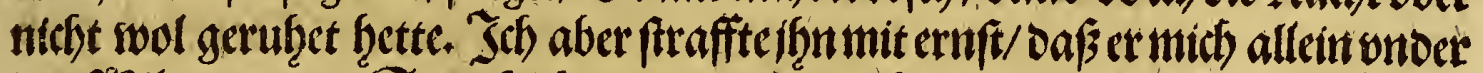

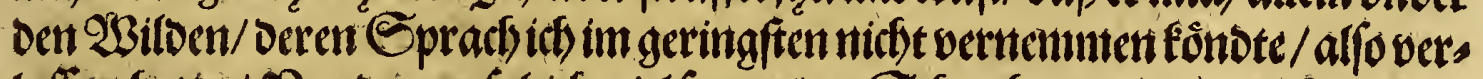

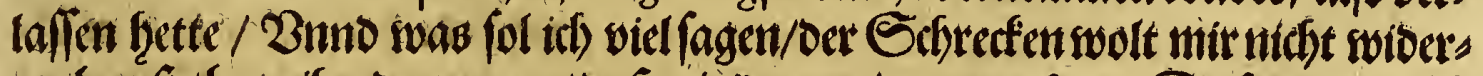

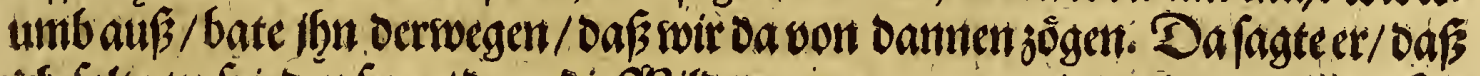

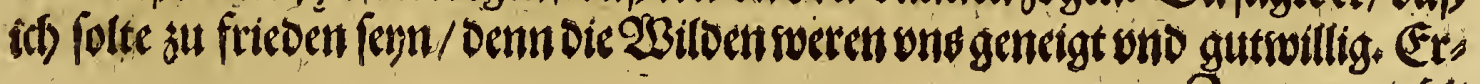




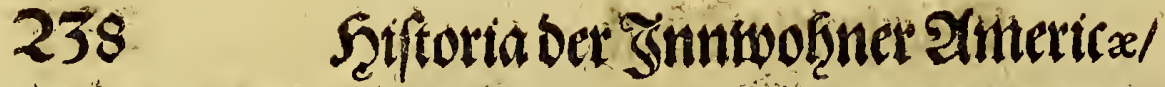

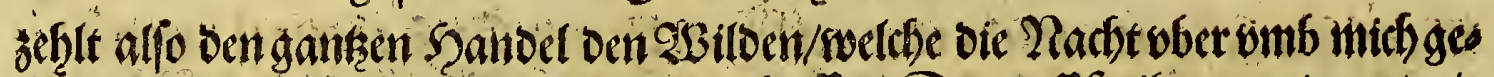

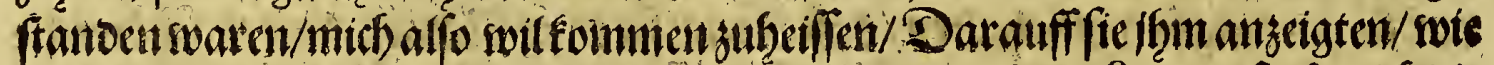

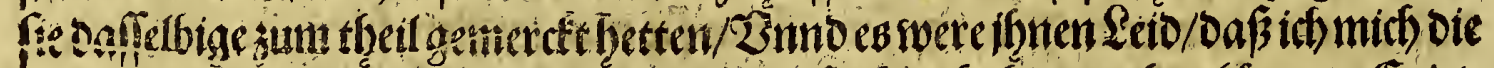

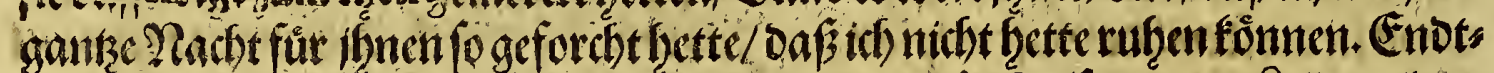

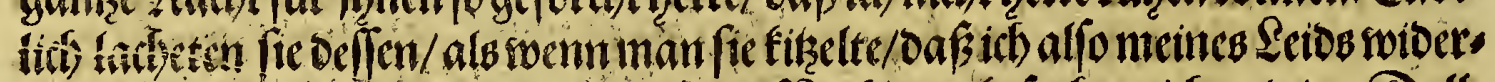

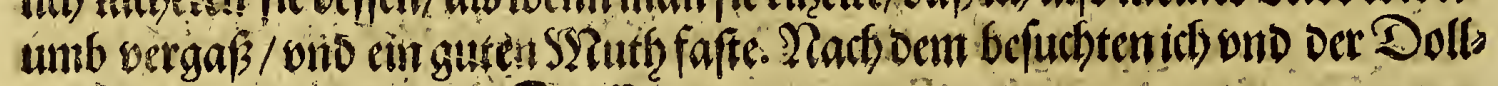
metiche nod etliche andere Dorffer.

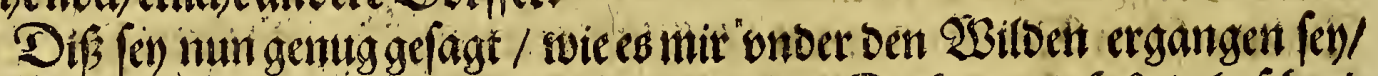
fürser/te mal. QBil itun fürthers audb oon anoeren Sachen ono Şändedn/ebreis ben ono redent.

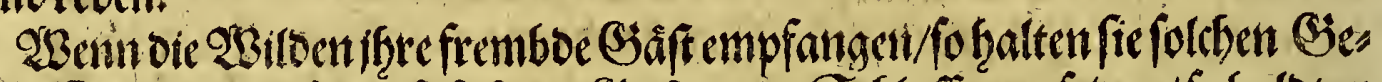

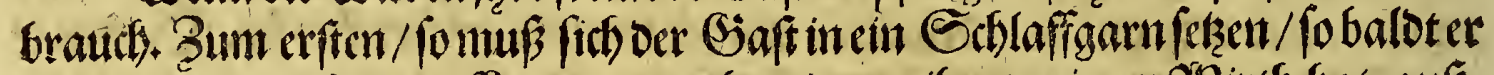

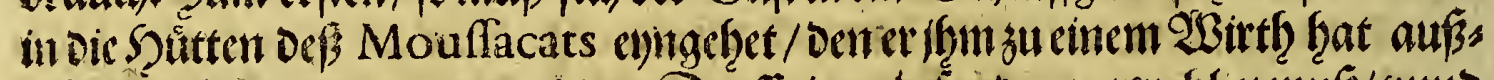

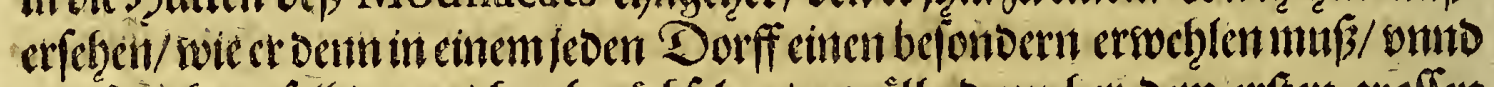

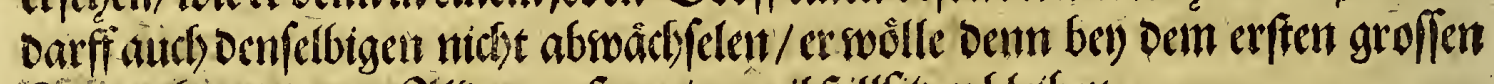

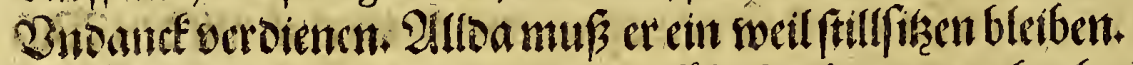

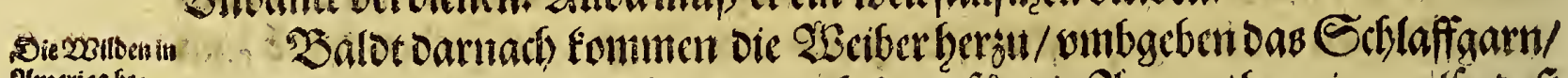

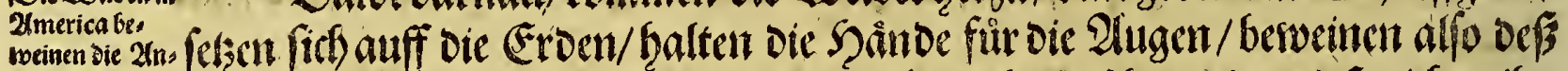

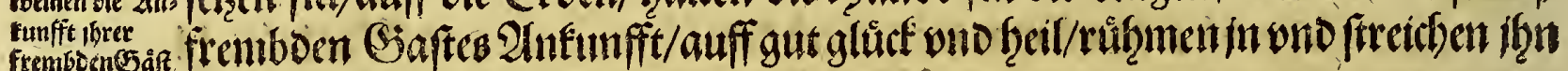

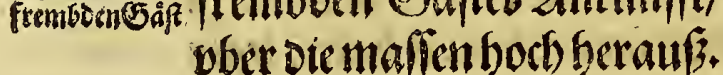

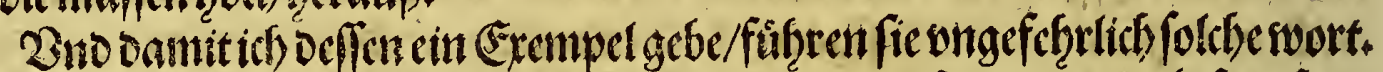

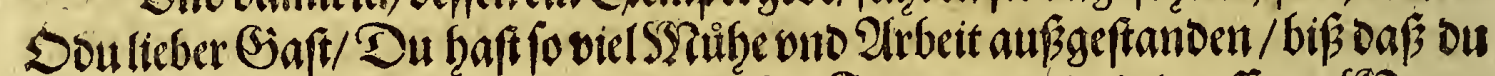

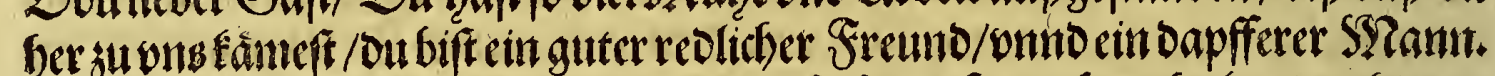

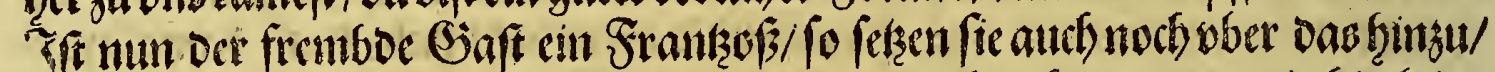

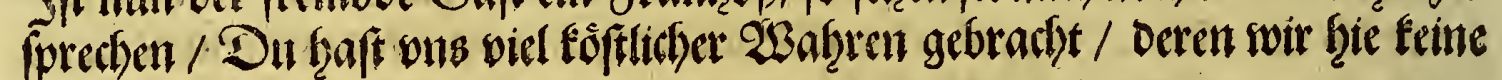
haben.

23iefichter

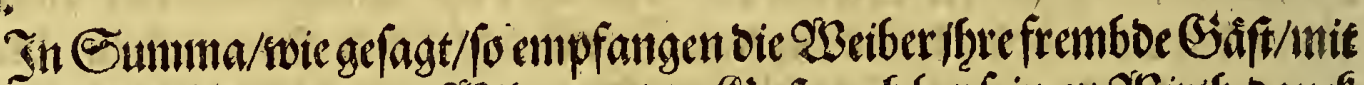

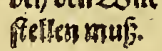

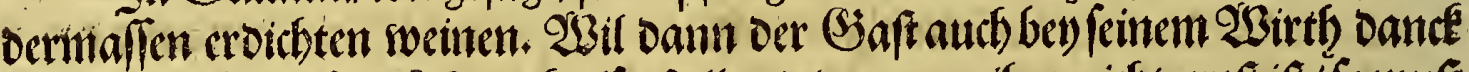

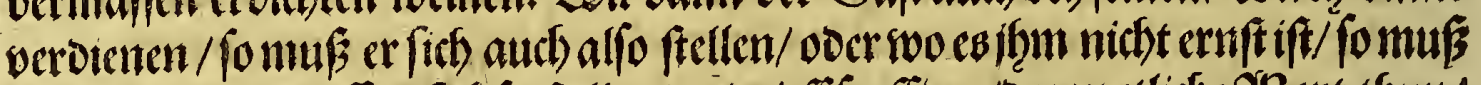

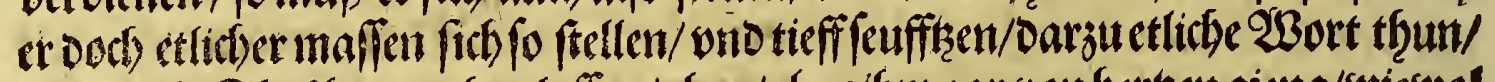

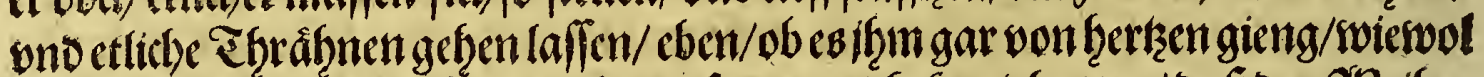

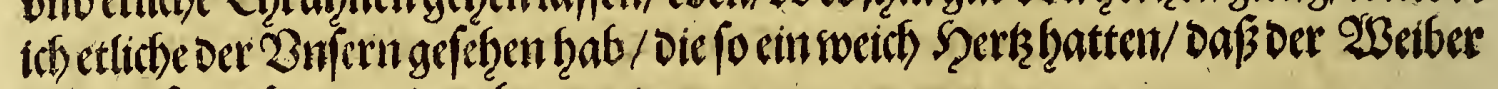
beulen fic rectit zurocinenberwegete.

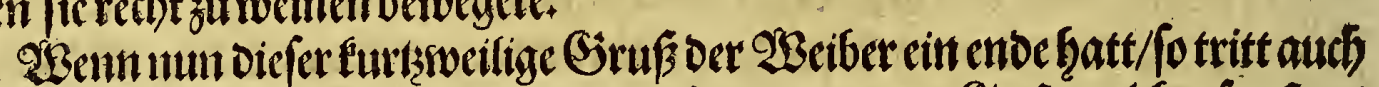

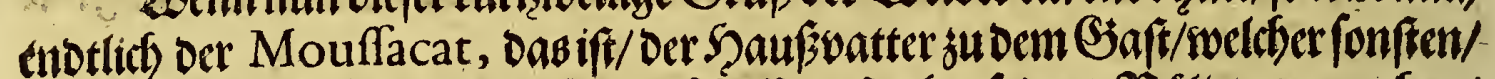

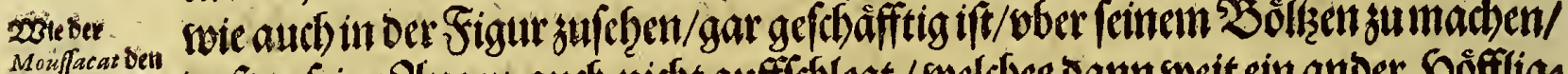

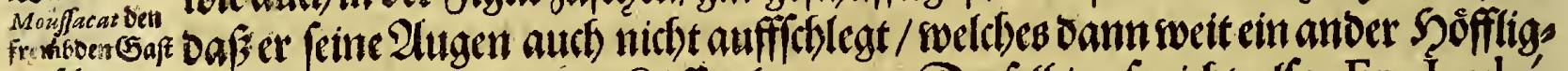
sumporibet.

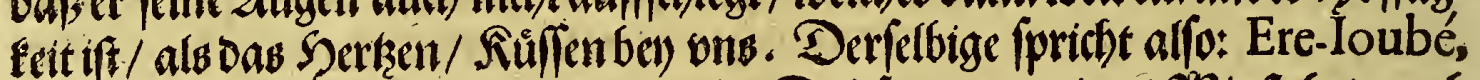

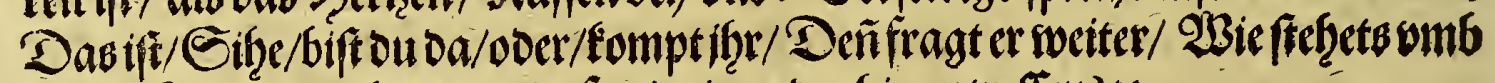

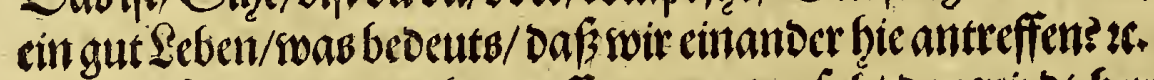

QBieman nun fierauff antworten fol / Das wirot bernacber in oem 2

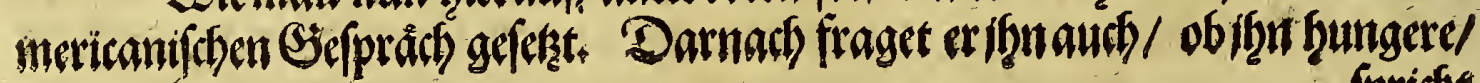
fpricft: 


\section{Das britte Treteil.}

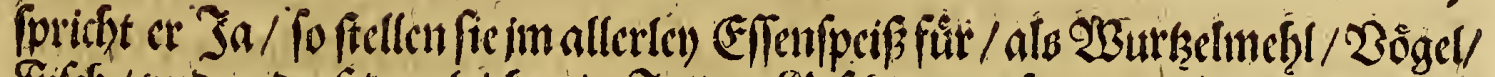

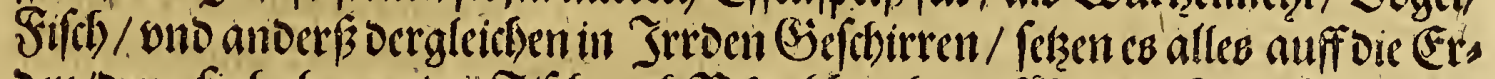

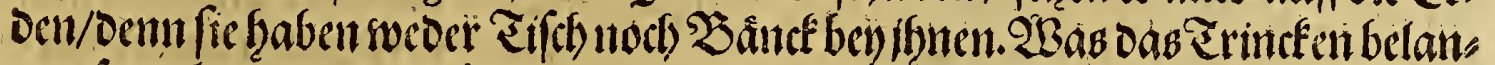

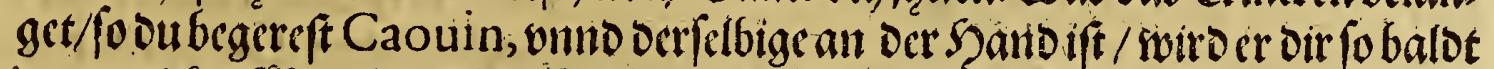

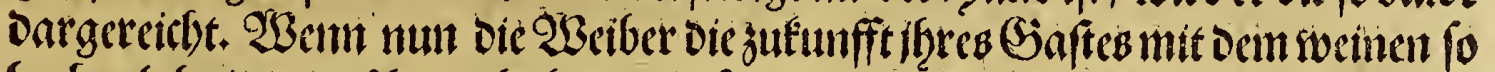

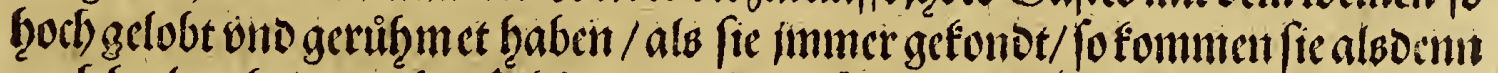

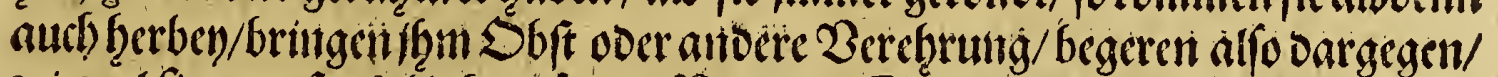

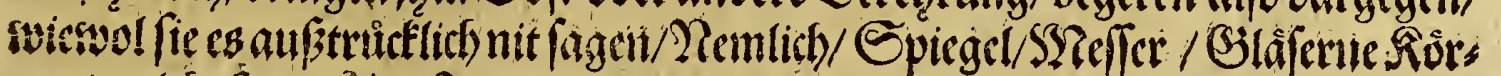

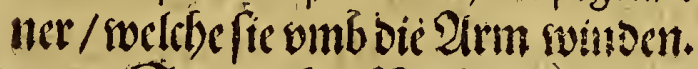

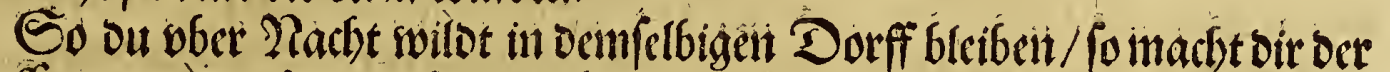

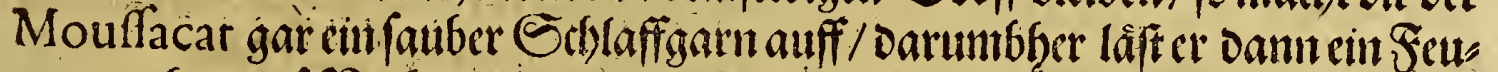

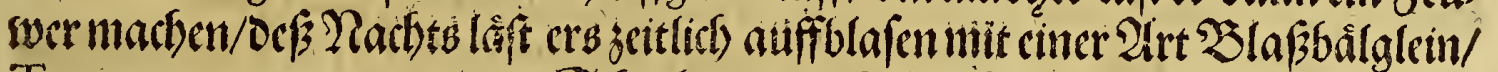

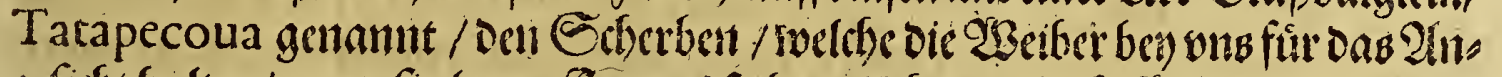

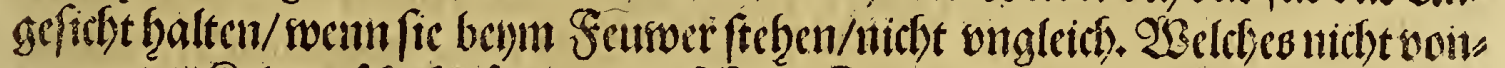

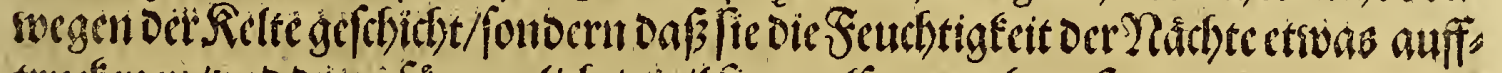

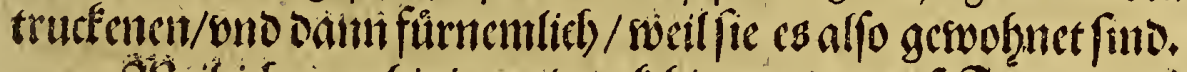

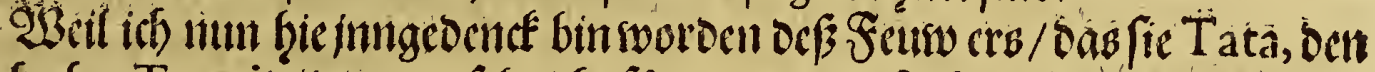

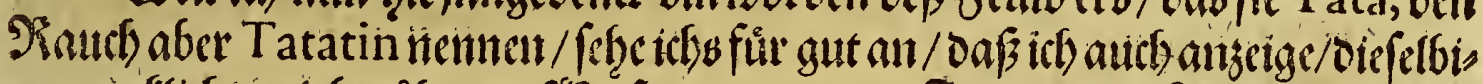

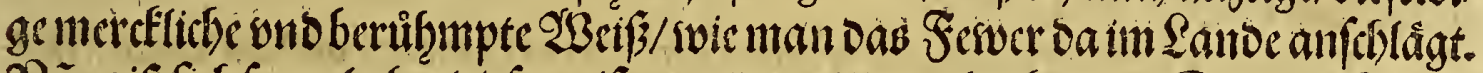

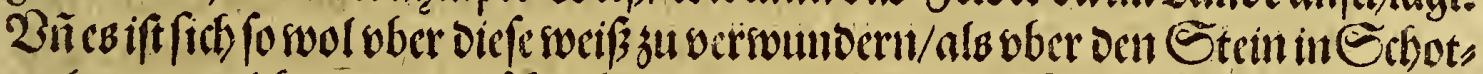

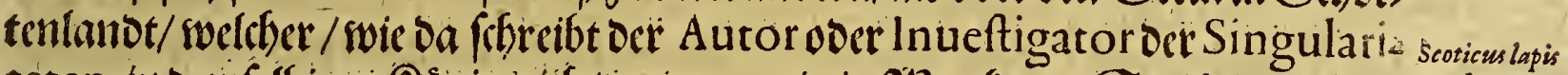

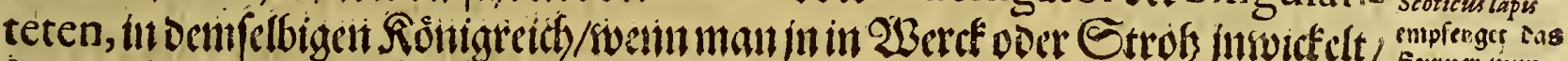

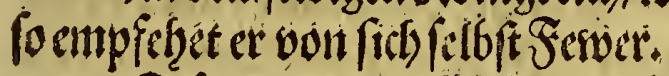

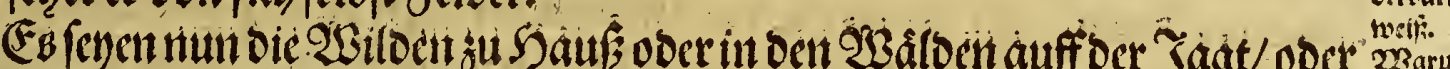

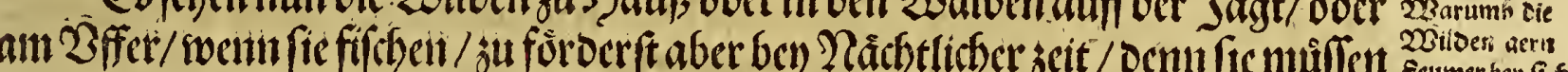

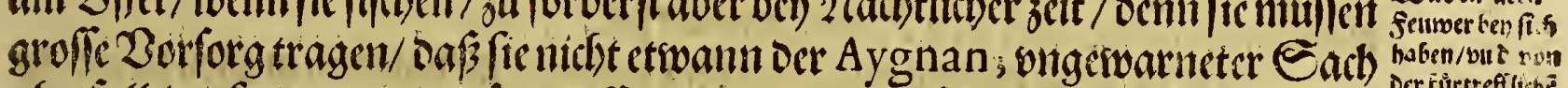

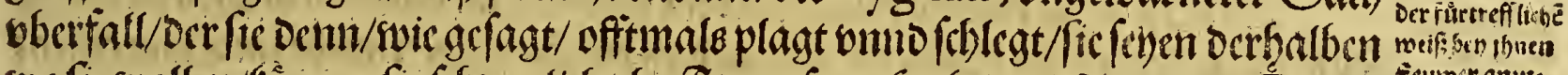

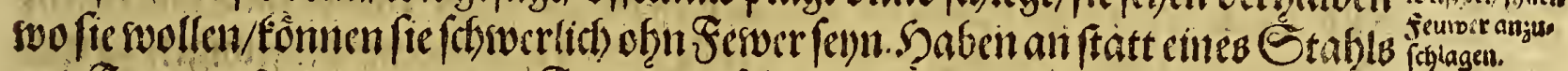

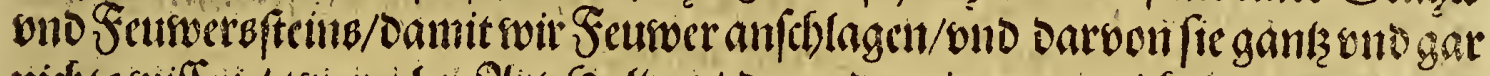

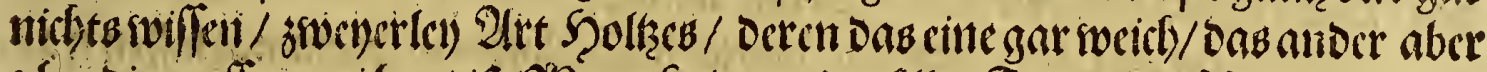

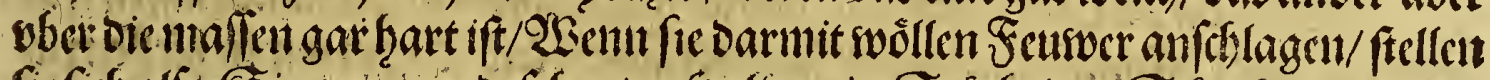

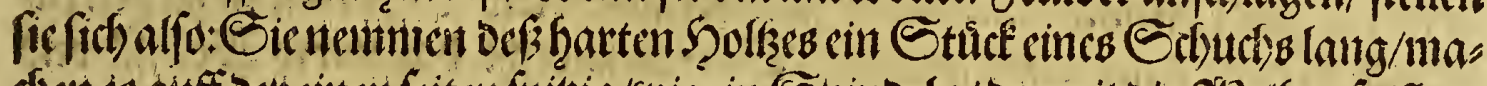

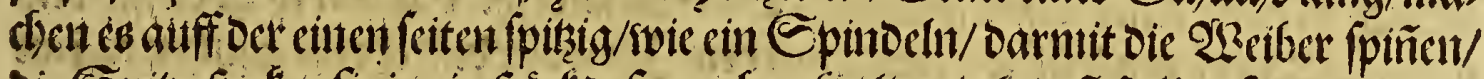

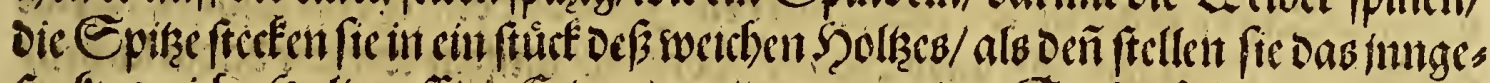

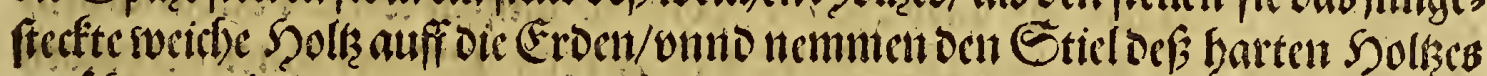

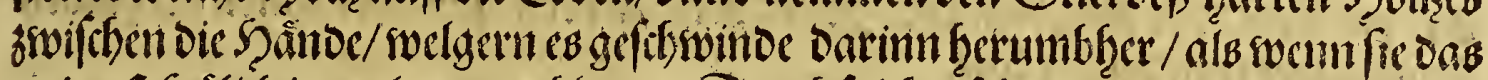

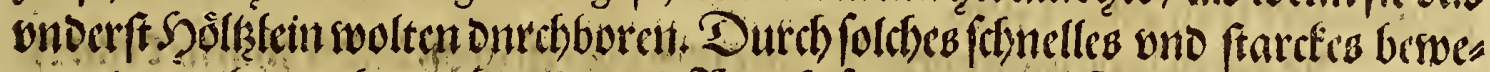

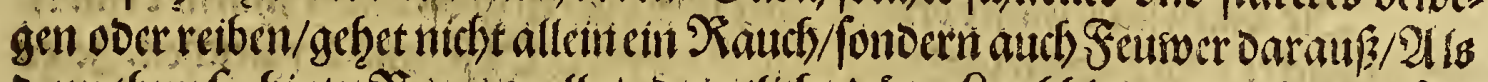

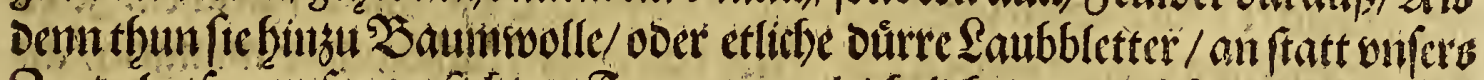

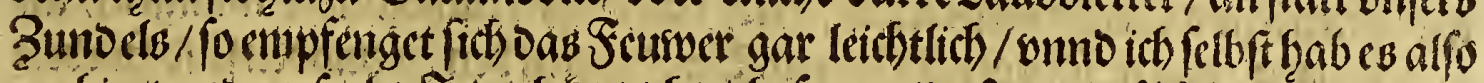

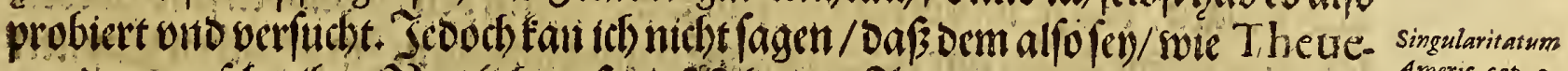

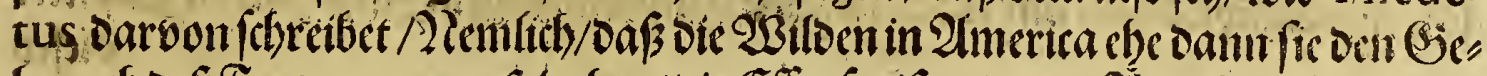

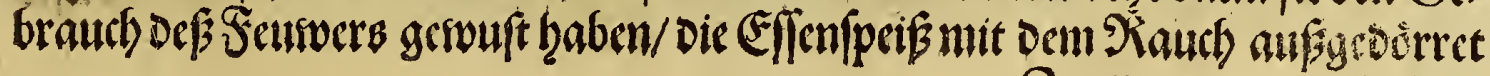
3 ii babcen 


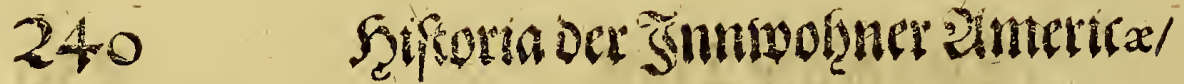

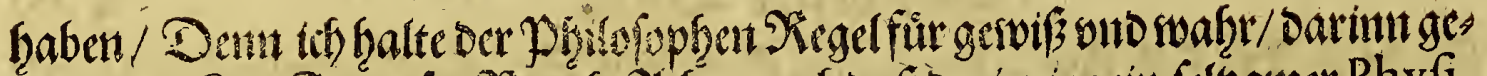

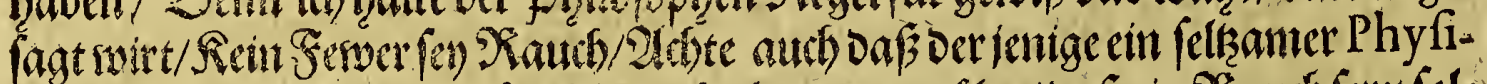

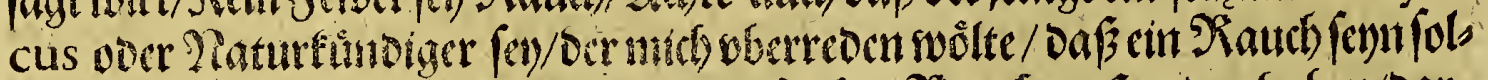

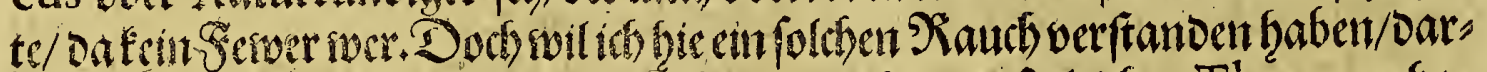

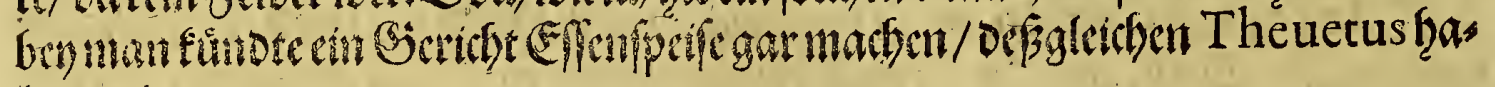
bentwil.

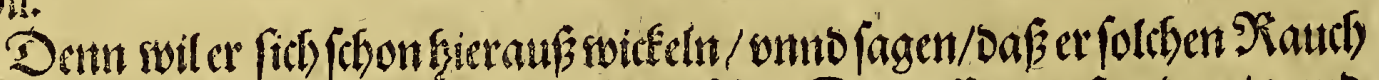

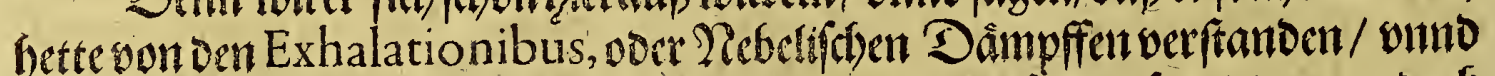

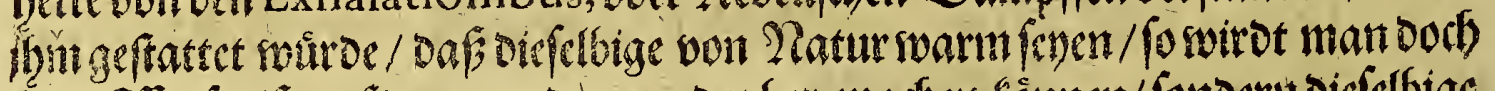

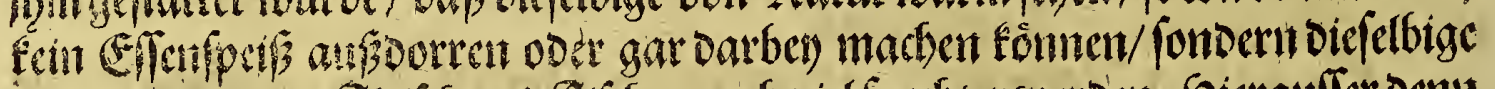

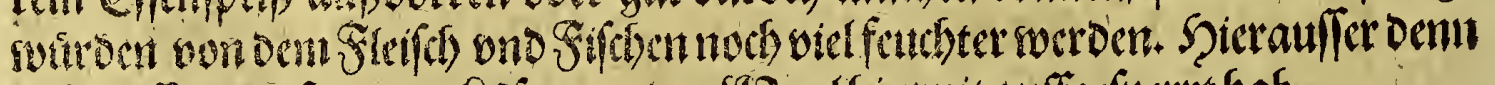

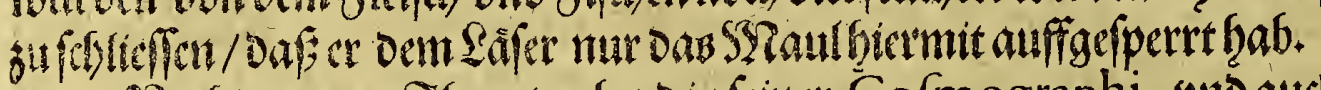

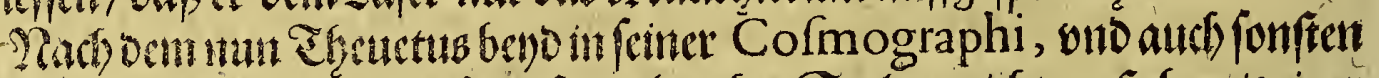

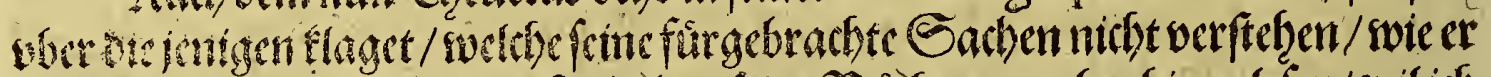

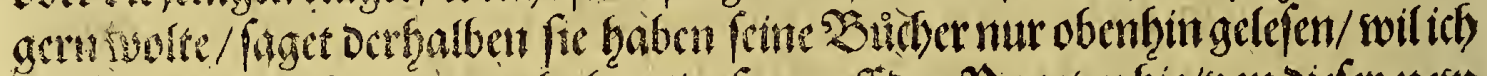

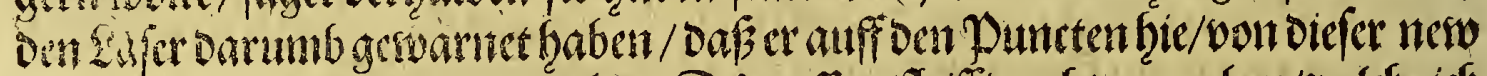

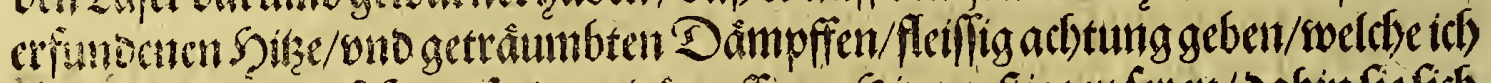
gânt sobctumbntoerlafen inogent.

203asbie

frembsen iren

2Wirtben wi,
Derumboer: efreti?

Die Wilbet tragen bie

fremben auf Den fexultern.

Sie 2Dilben fins ton Ratur cmabier trewo.

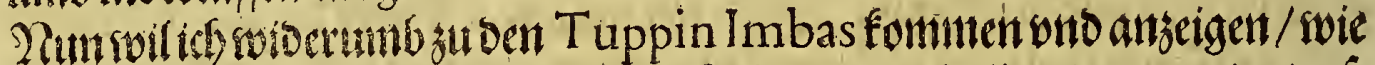

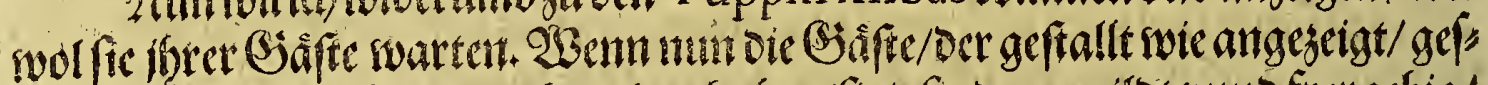

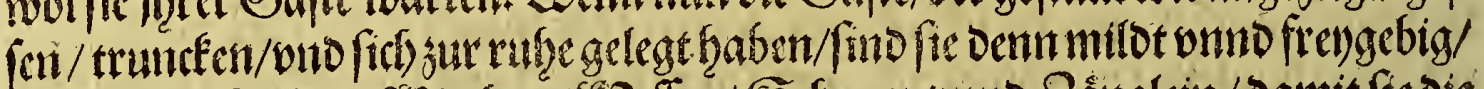

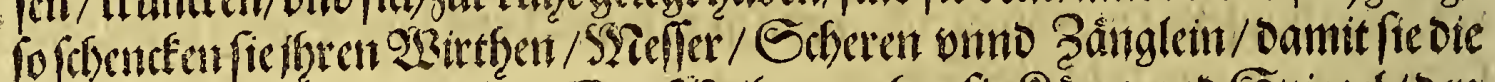

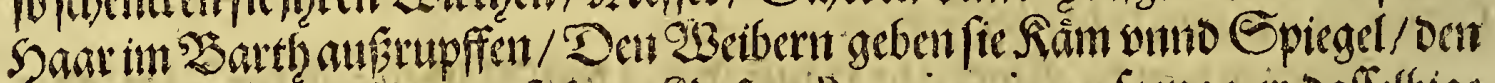

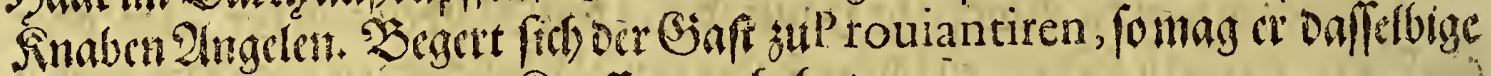
abbolew/ fobalot als cr oen fanffigemadtht hat.

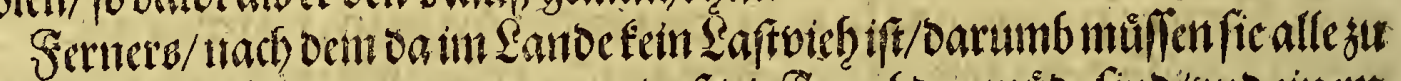

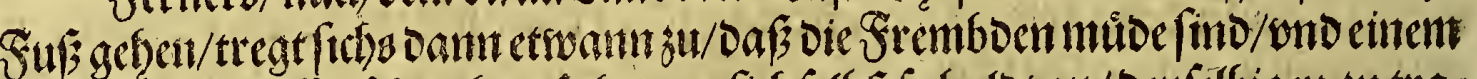

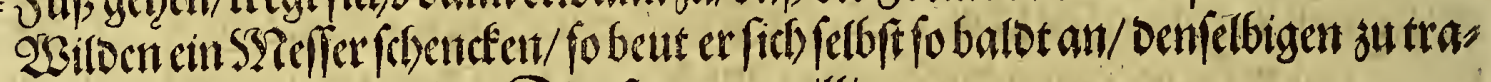
gen / oennficfinto mitiren Dienfect gar willig.

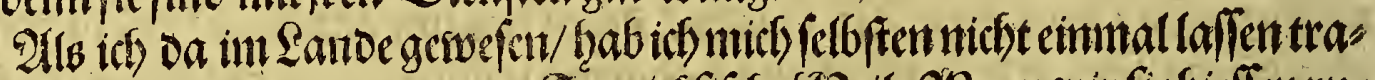

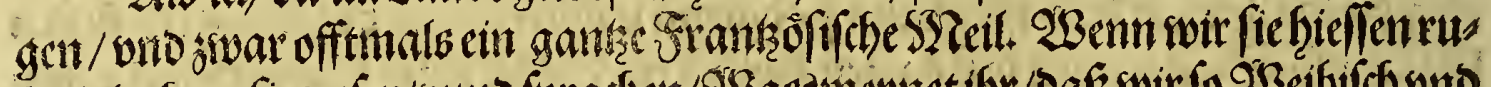

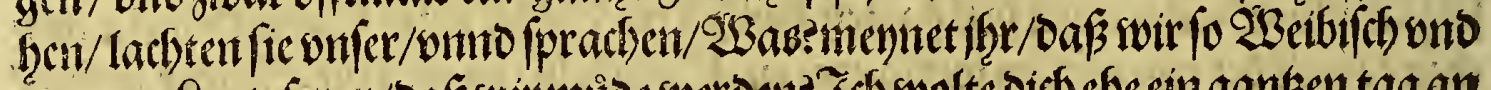

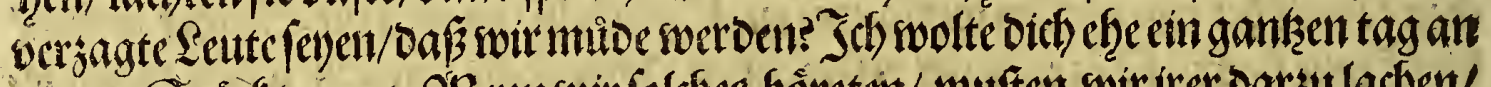

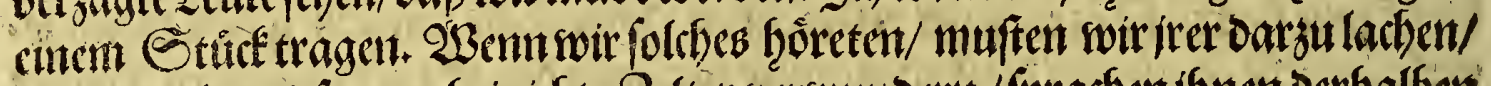

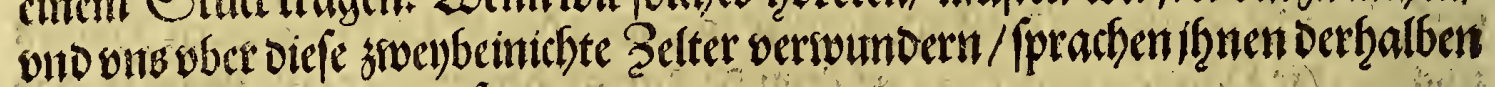
fo ju/immer fort/immer fort.

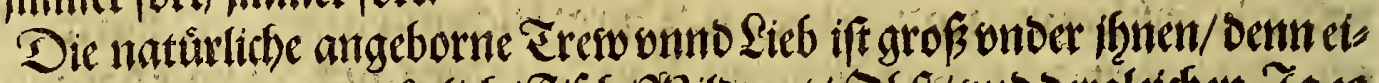

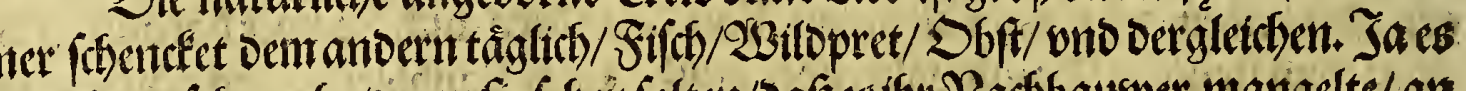

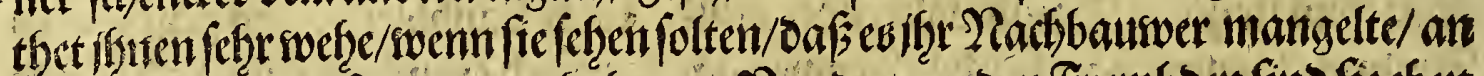
Dem ienigen / Dab /ie in vorrahethetteit. Bmo gegen oen fremboen / itto fie ebent

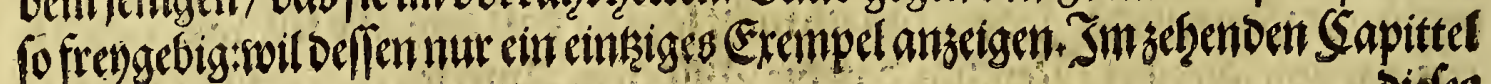
biefere 
Das britte Theil.

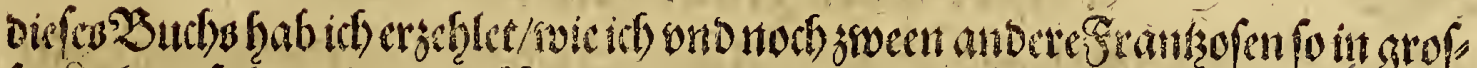

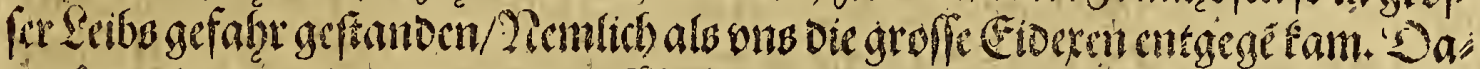

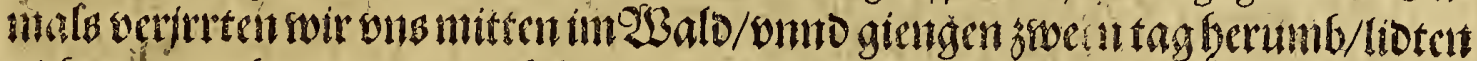

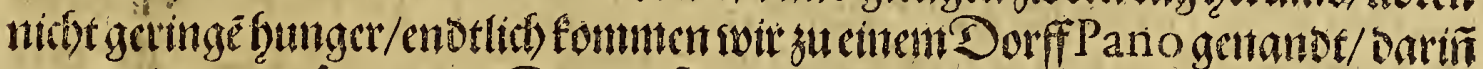

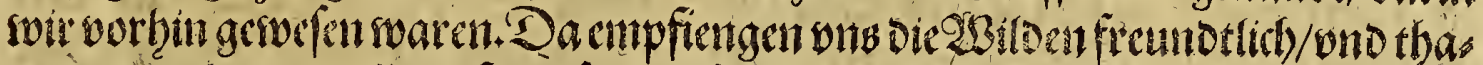

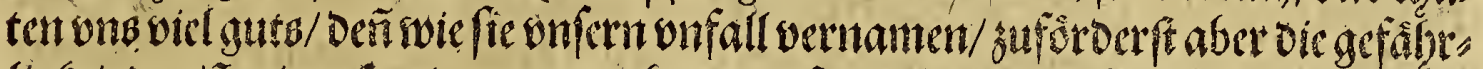

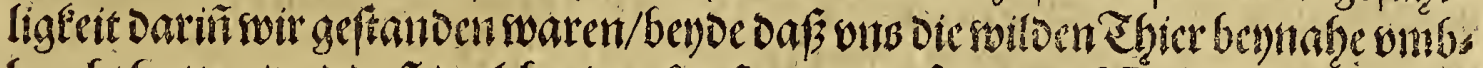

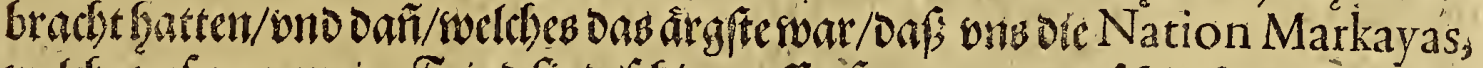

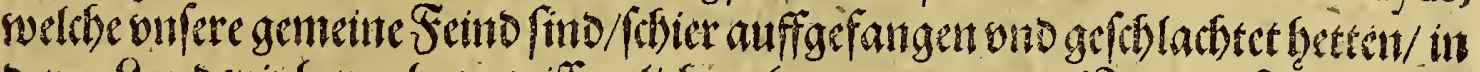

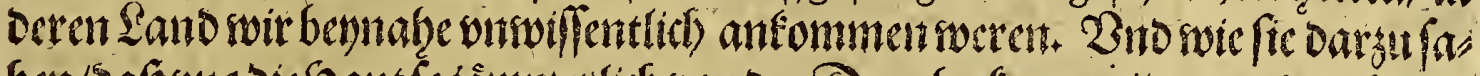

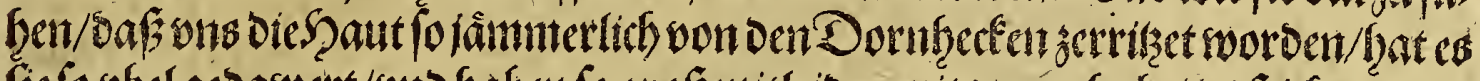

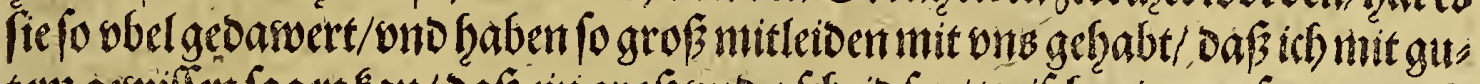

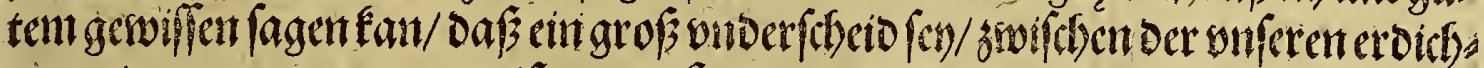

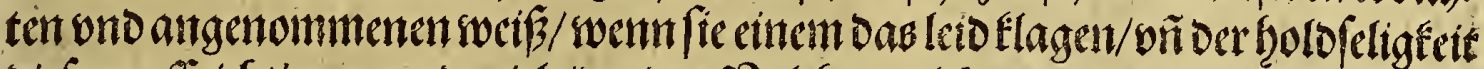

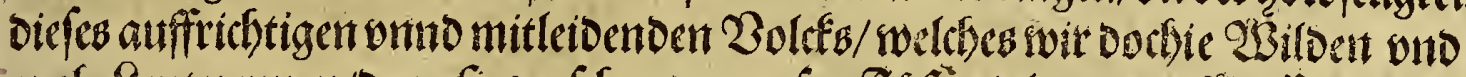

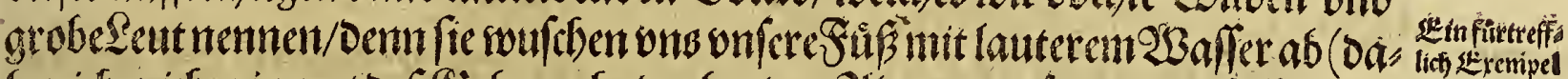

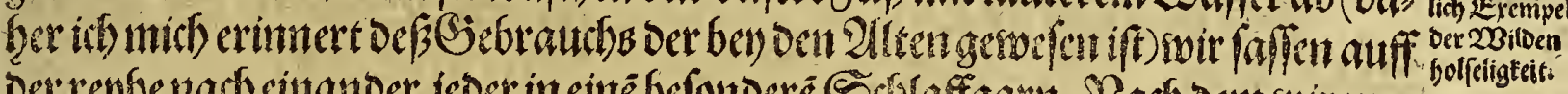

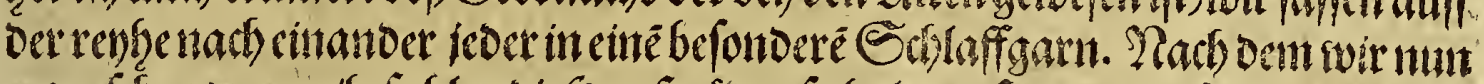

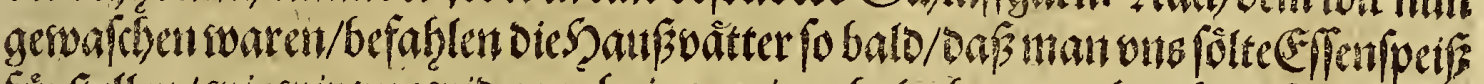

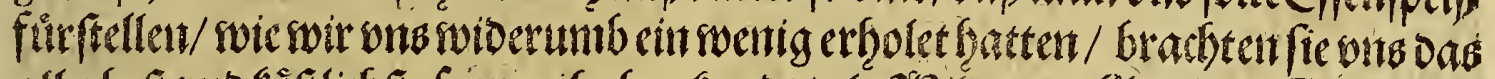

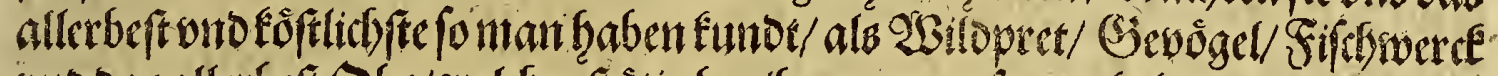

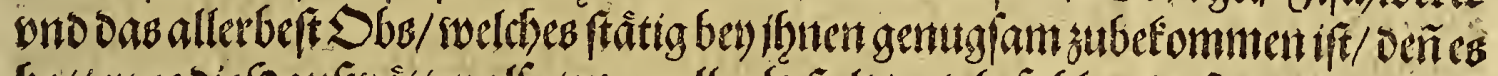

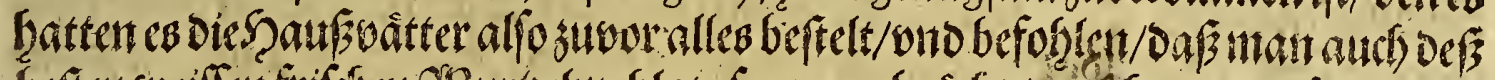

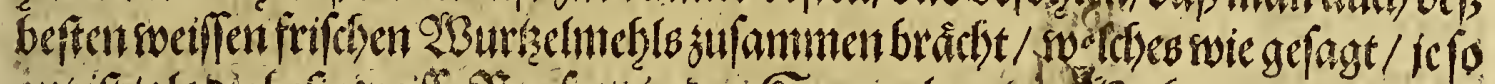

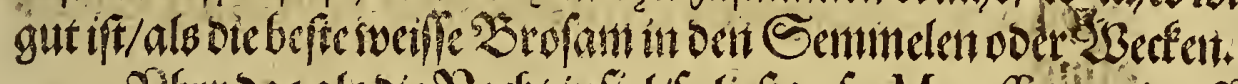

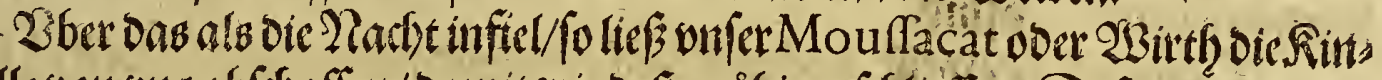

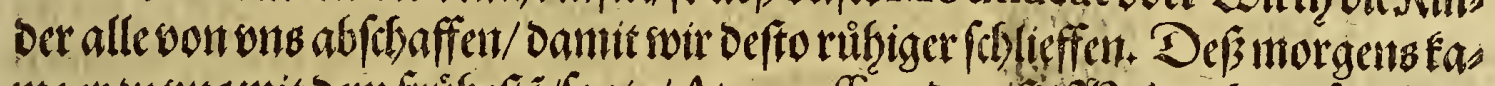

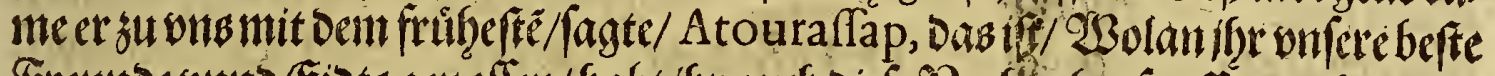

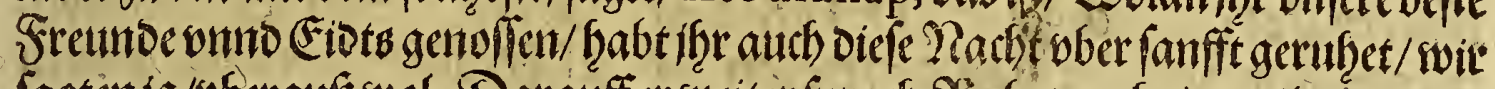

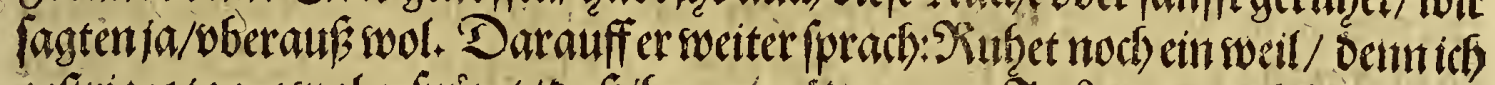

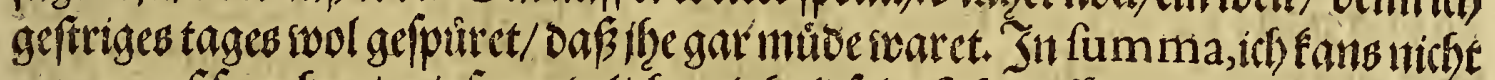

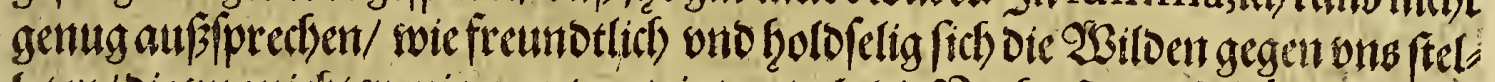

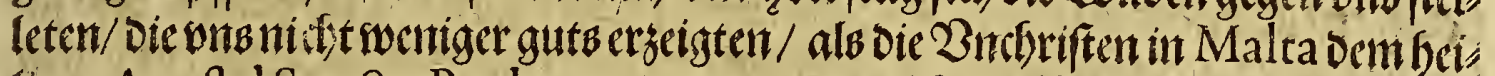

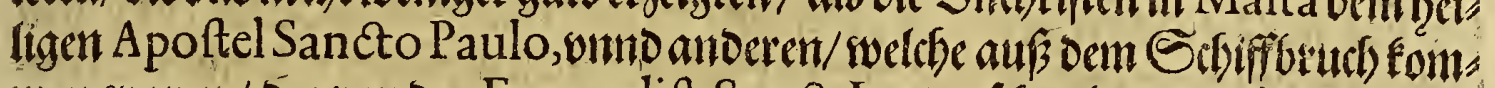

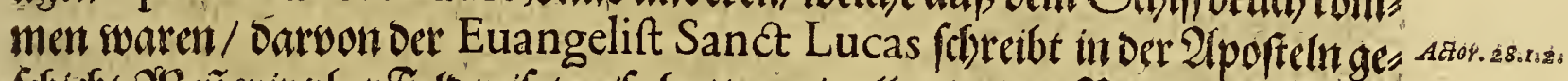

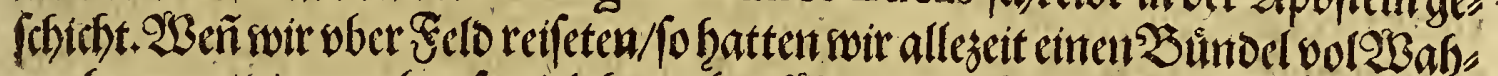

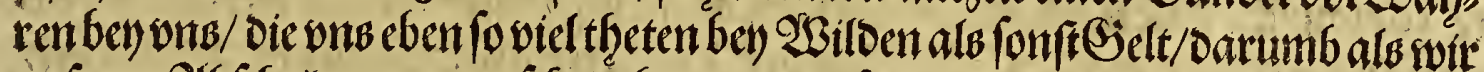

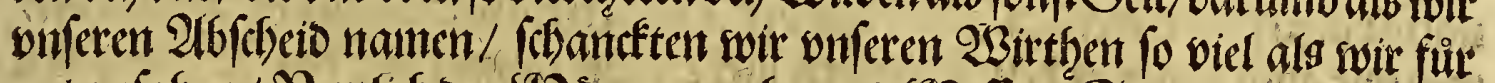

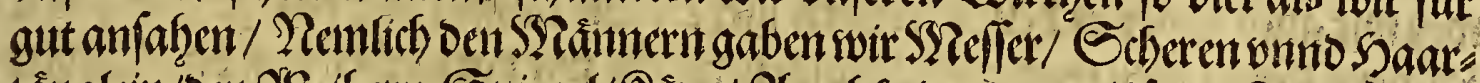

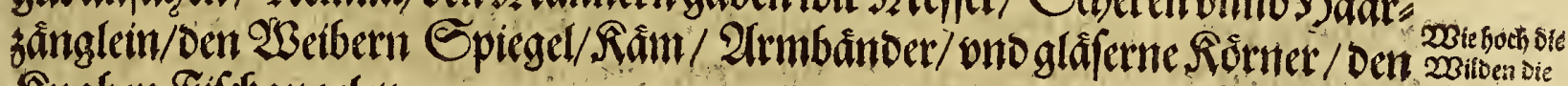
Sinaben Fif changelen.

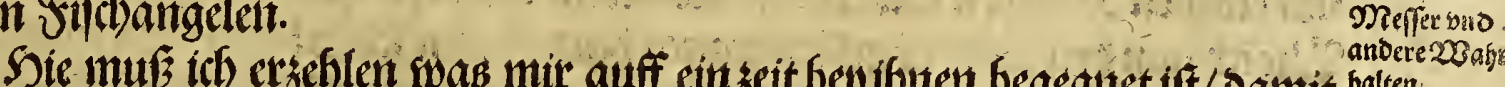

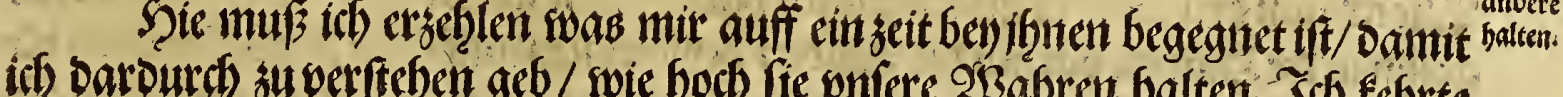
ren balten Jef febrte

$$
\text { 3. iif incinent }
$$


242 Giftoriader S̈nnwof̧ner Ŝmerical

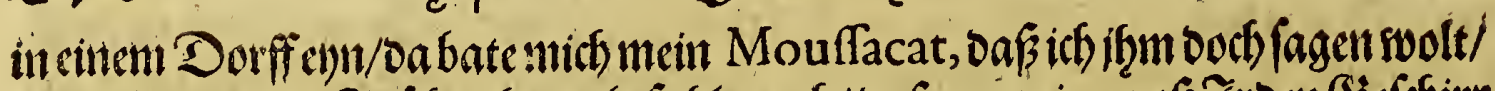

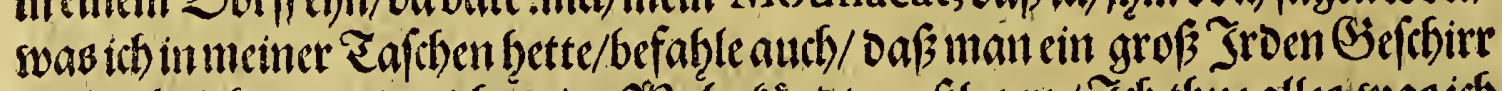

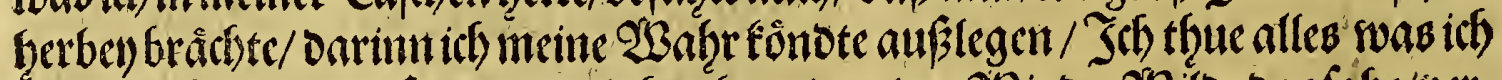

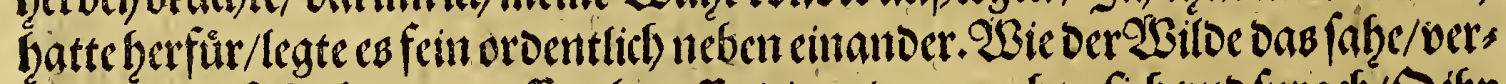

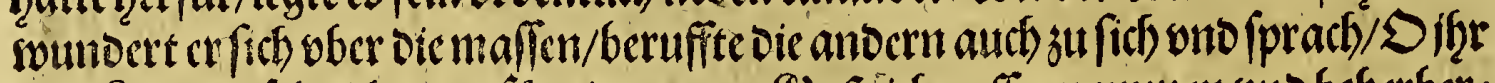

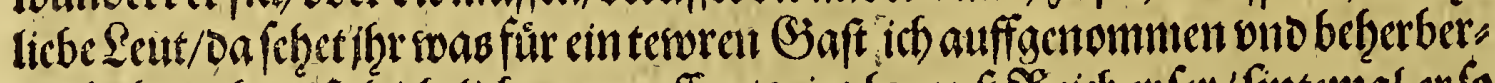

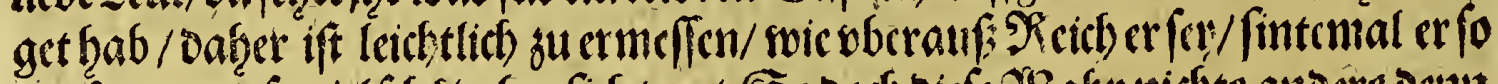

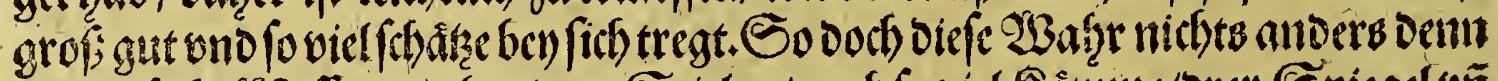

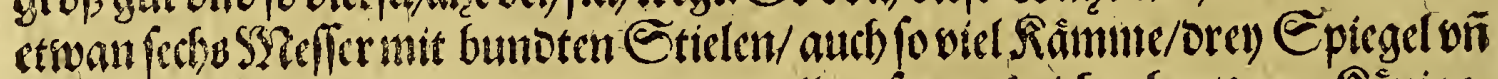

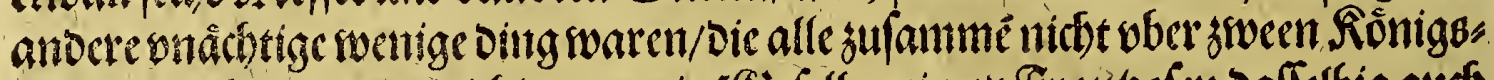

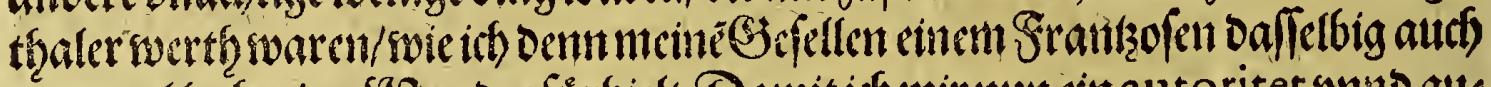

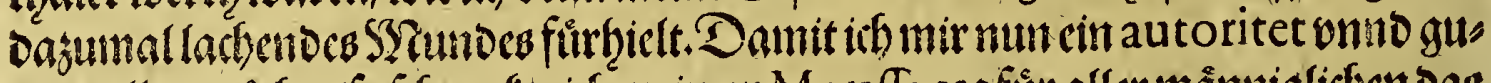

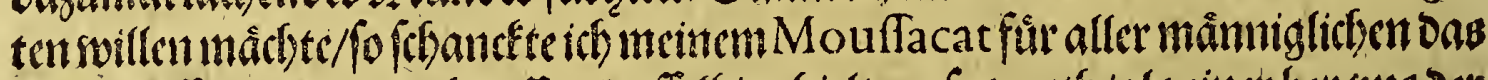

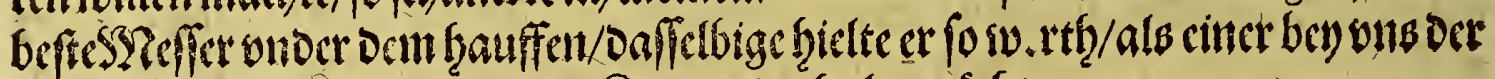

Sie zailoen find fliten §i cuiloen ube

gein Ssiforien - tiart gefaitr. beften/ voto terocrften gúlociten Setten cuite balte mòd)t.

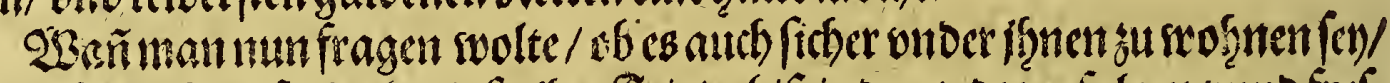

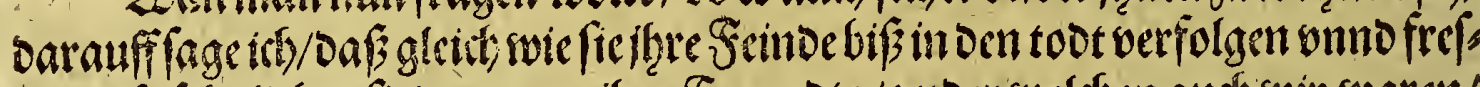

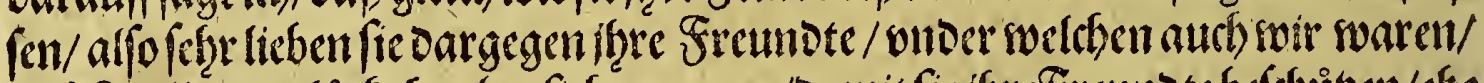

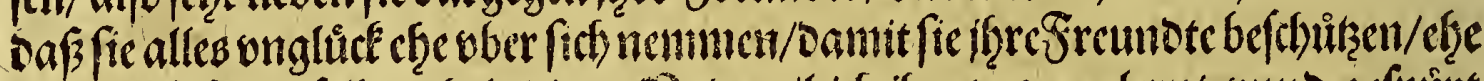

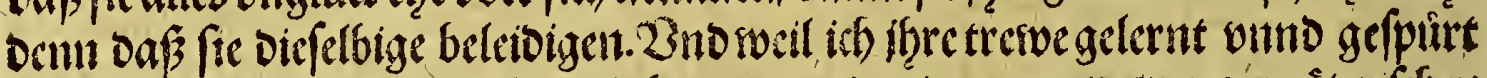

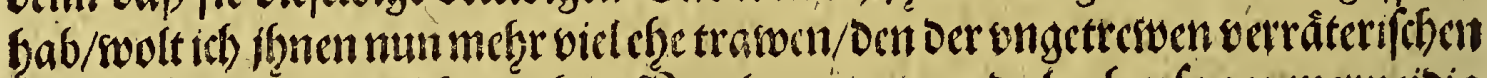

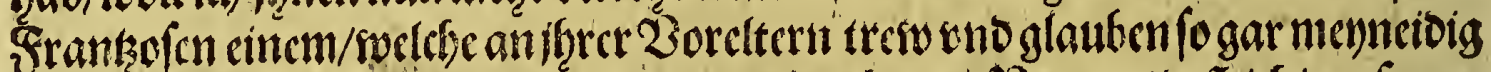

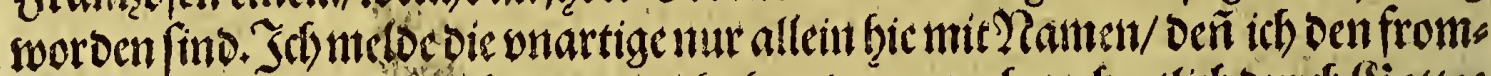

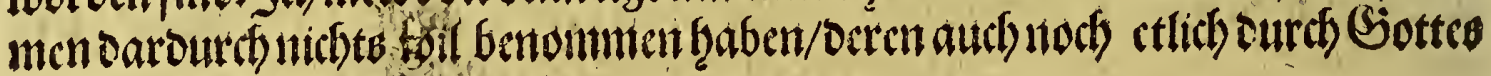
fegen in Frantefred fint.

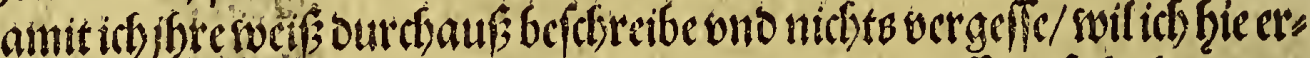

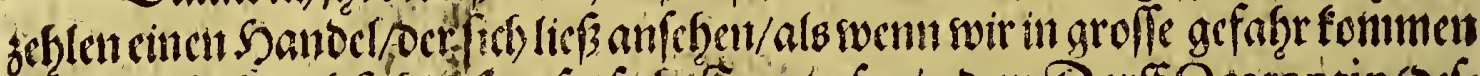

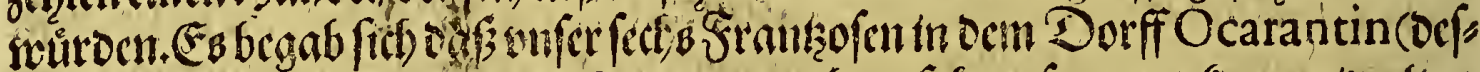

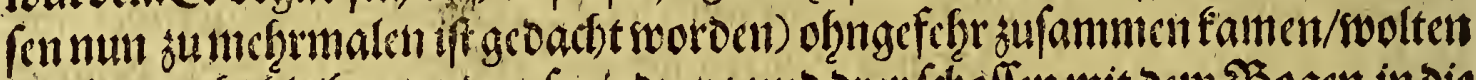

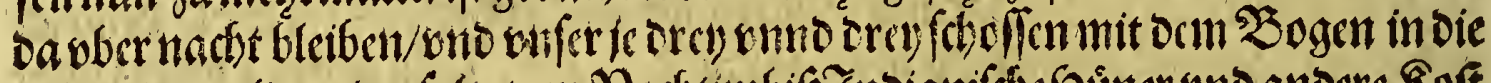

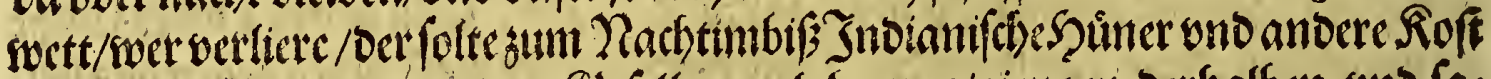

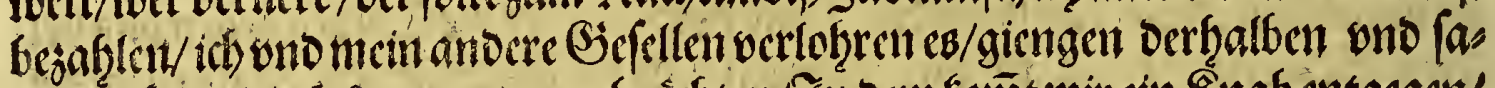

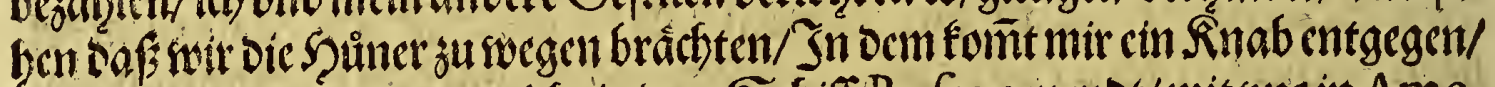

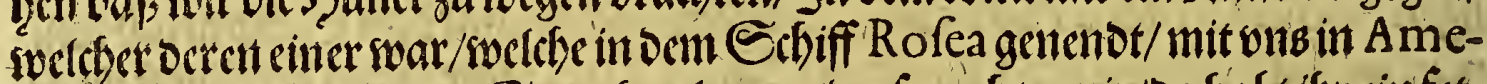

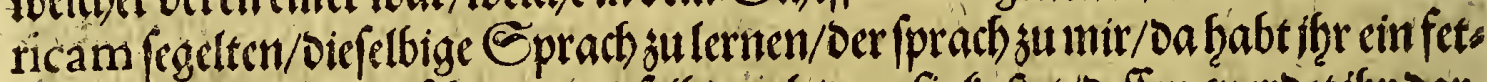

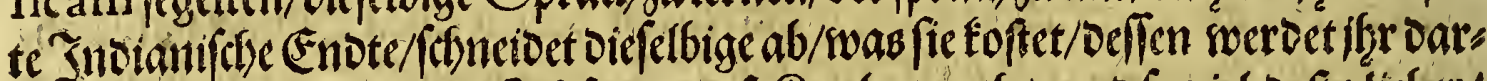
nach swol gu frioen werben. Jeb folgte Def Sinaben ratb/onno fo viel Deftolieber/ weil woir auds zu vor in ben Dorffern mefre oenn einmal mit oen Inoianiffyen Shunern oergleithen waren ombgangen/welehe wir barnacher von oen 2 Bitoen

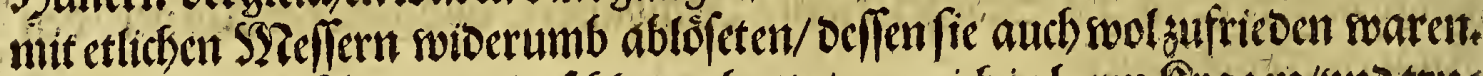

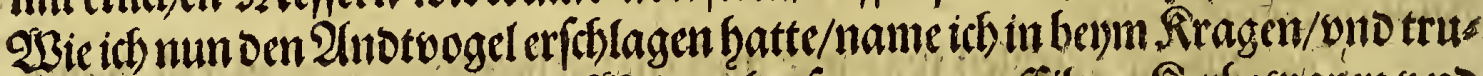

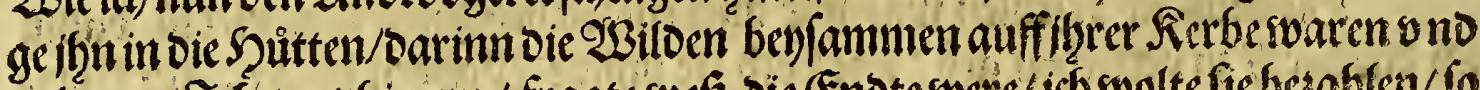

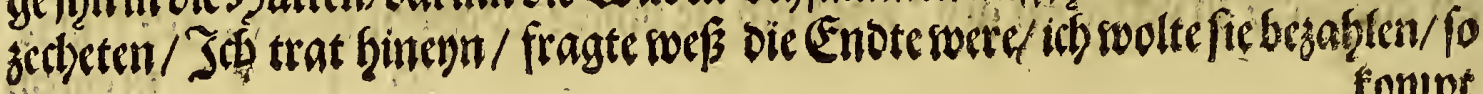
fompt 


\section{Das britte ₹}

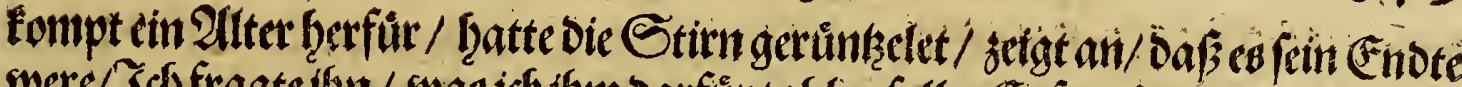

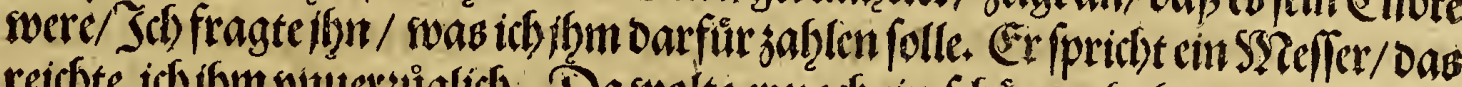

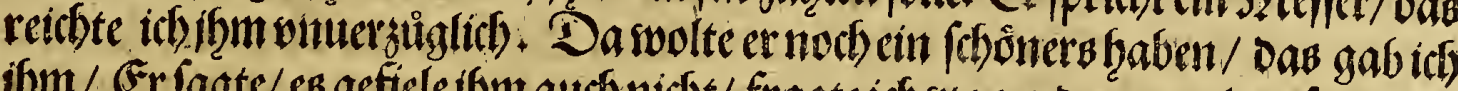

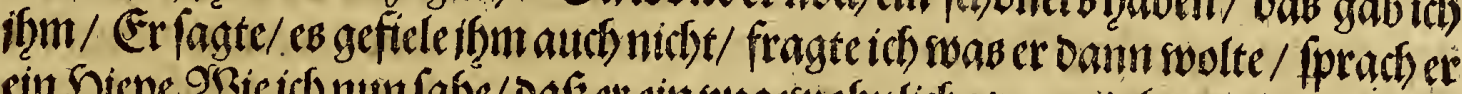

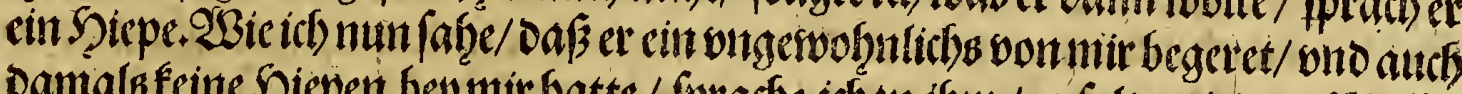
Damals feine Siepen bey mir fatte / fprache ich zu ifom/ er folte mit dein SYeffet

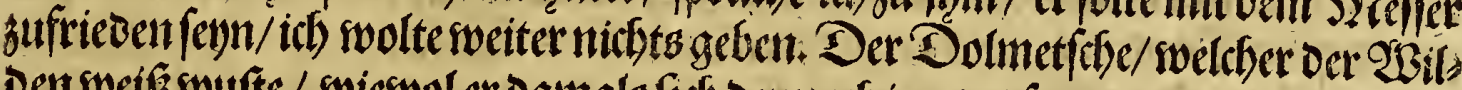

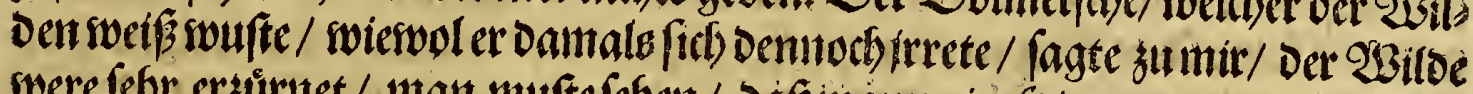

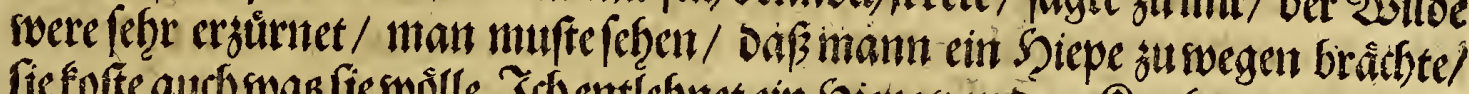

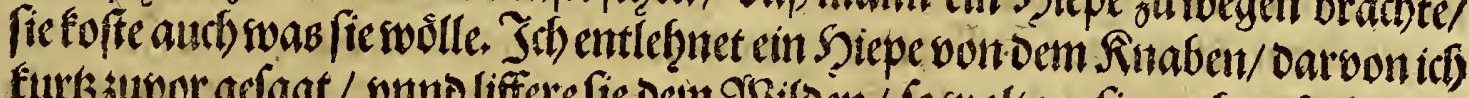

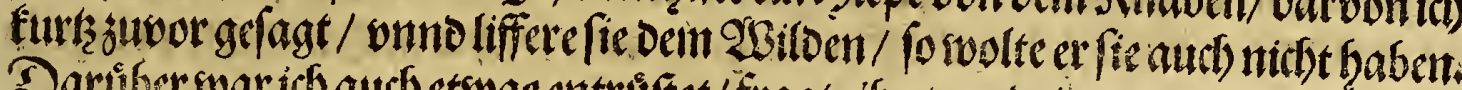

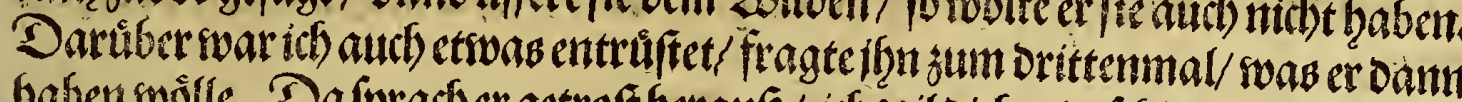

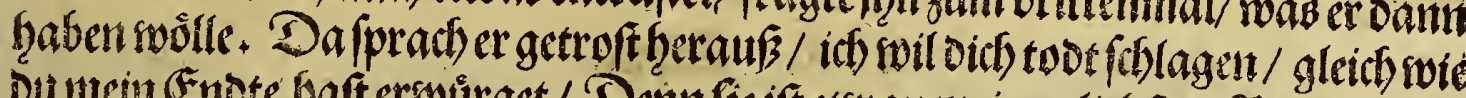

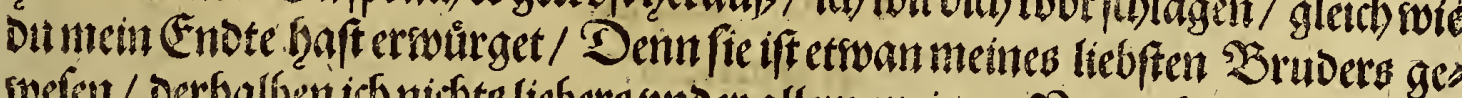

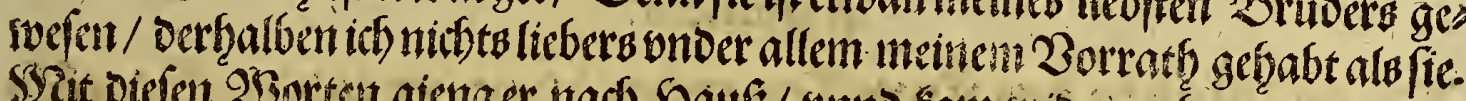

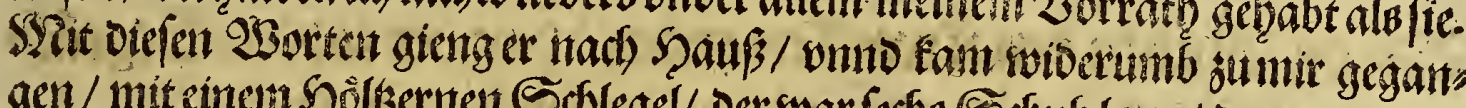

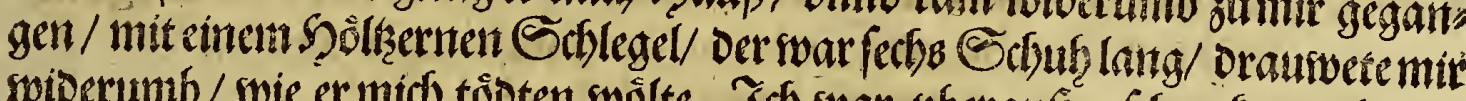

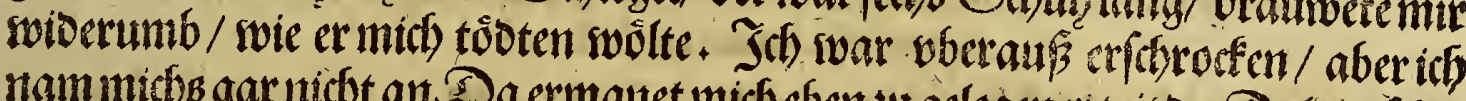

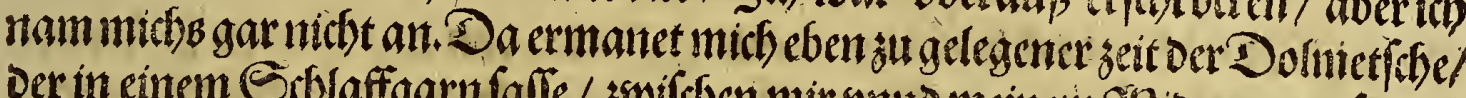

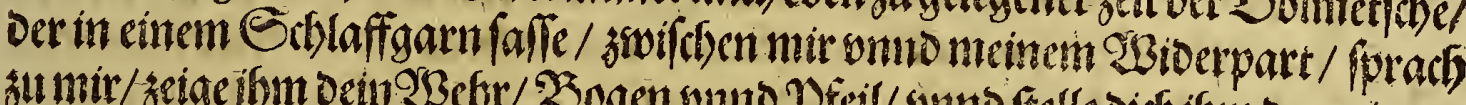

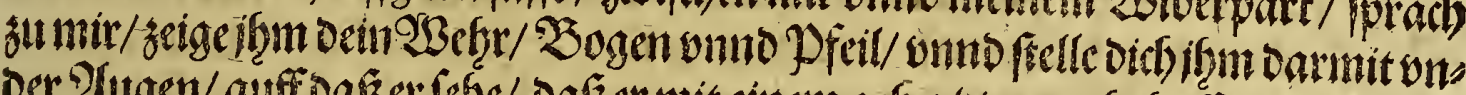

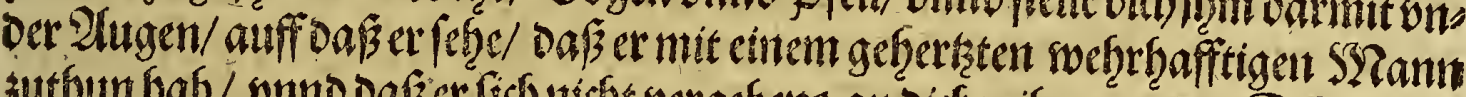

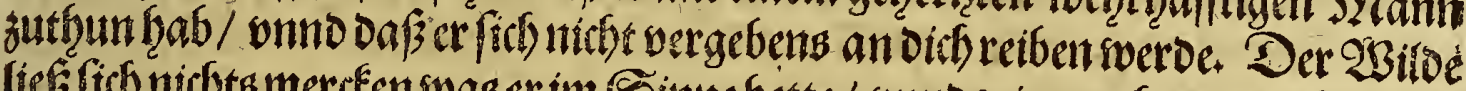

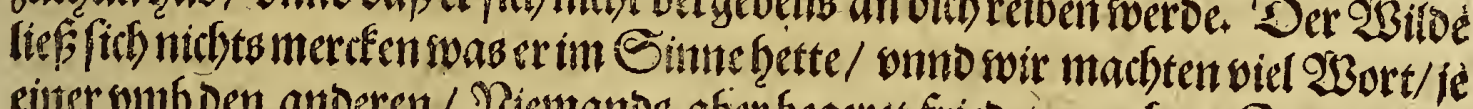

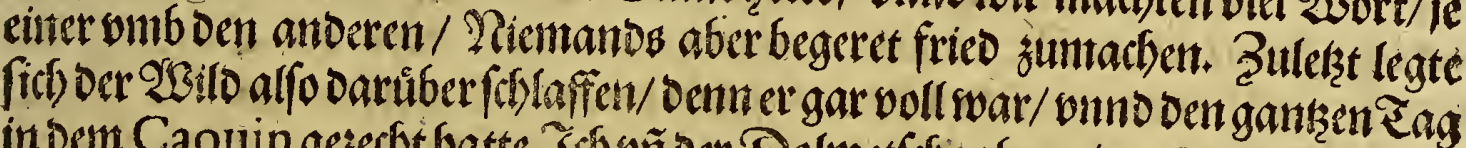

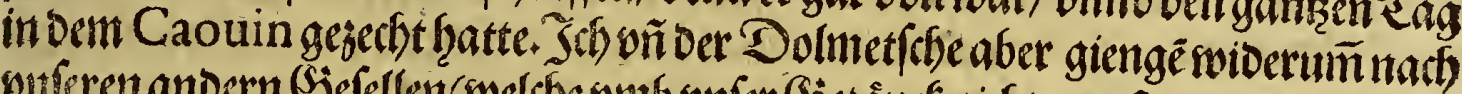

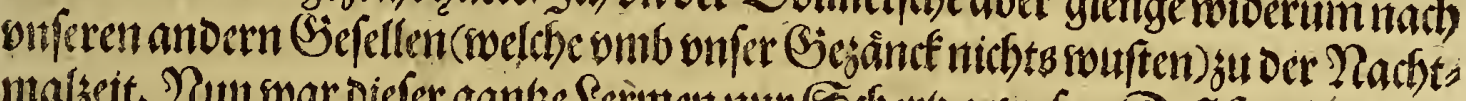

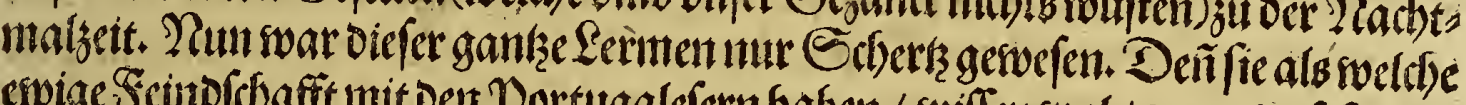

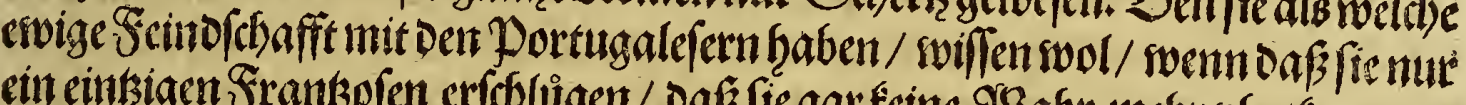

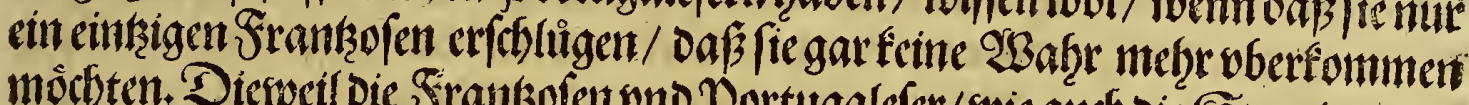

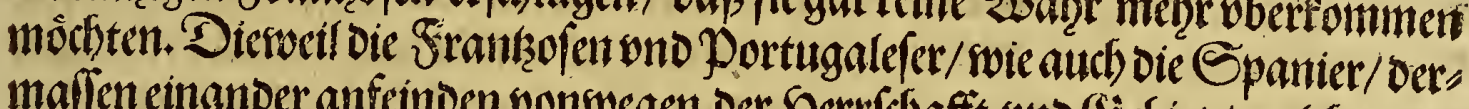

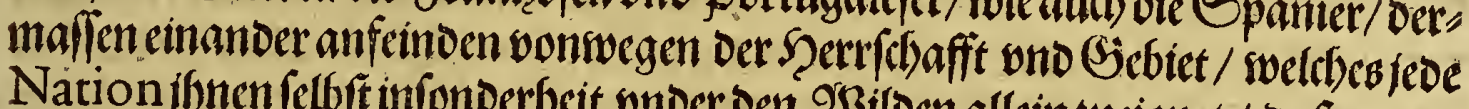

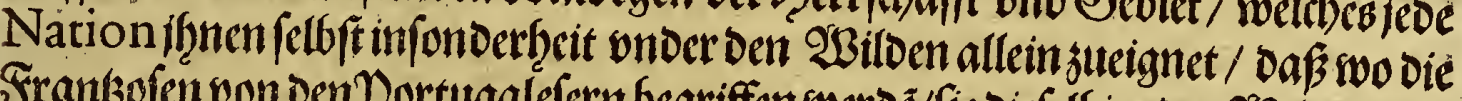

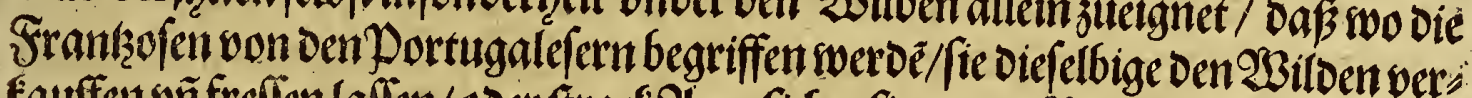

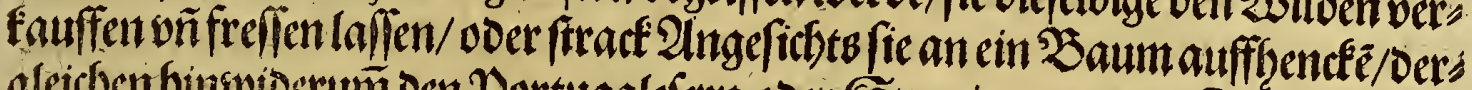
gleichen binfwiderum Den Portugalefern oder Spaniern von Den Frantwo/en bes

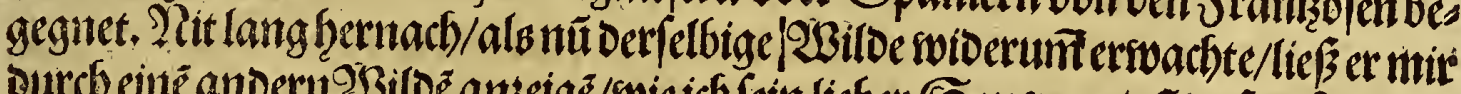

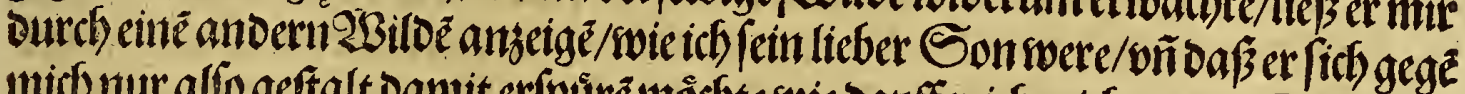

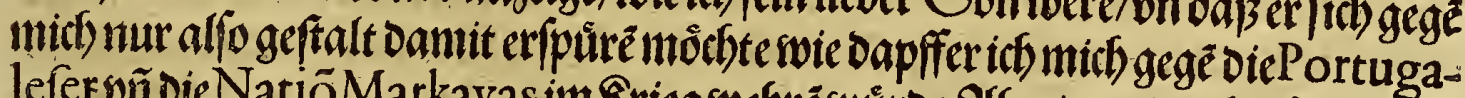

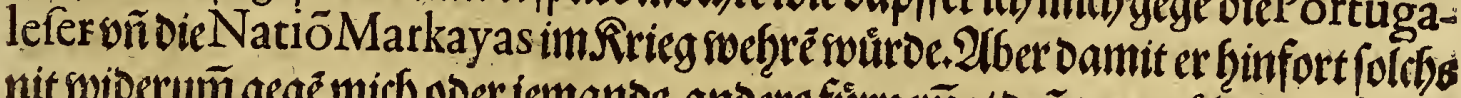

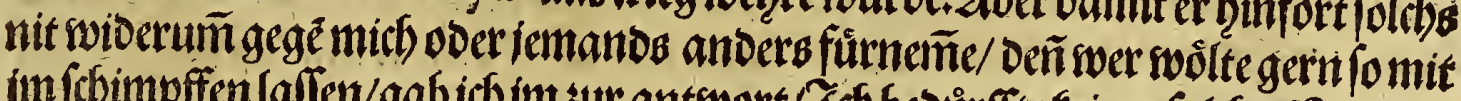

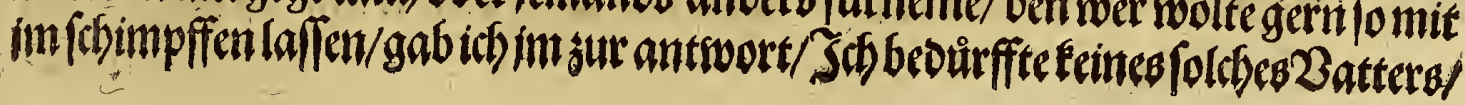




\section{Das britte Theth.}

245

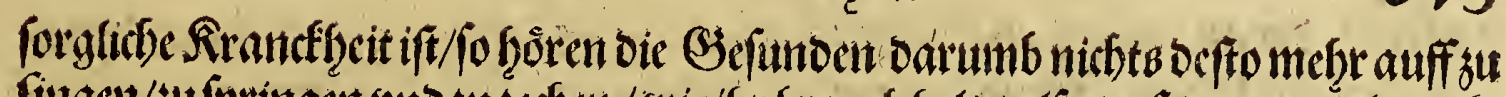

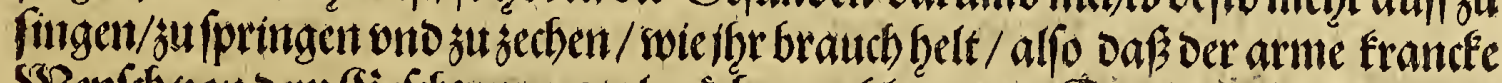

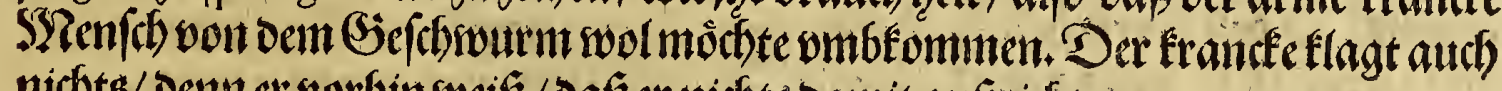

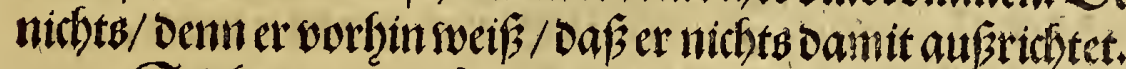

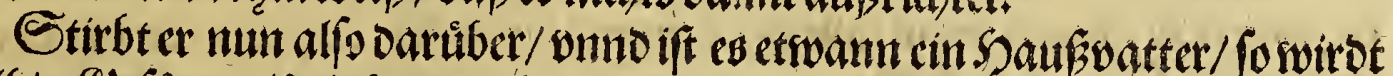

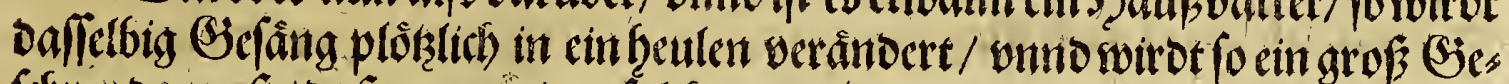

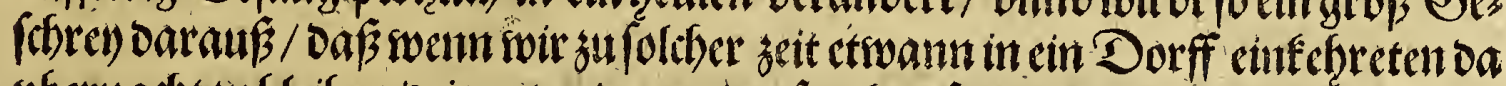

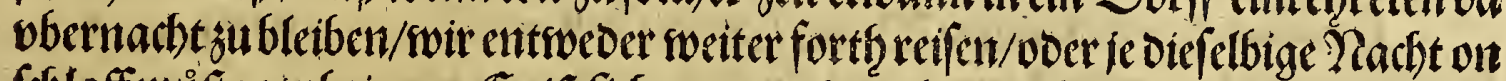

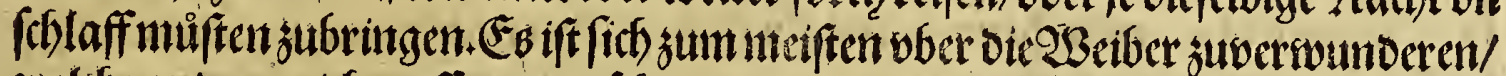

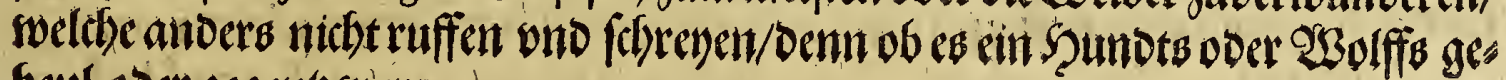
beul ober gegeukzwere.

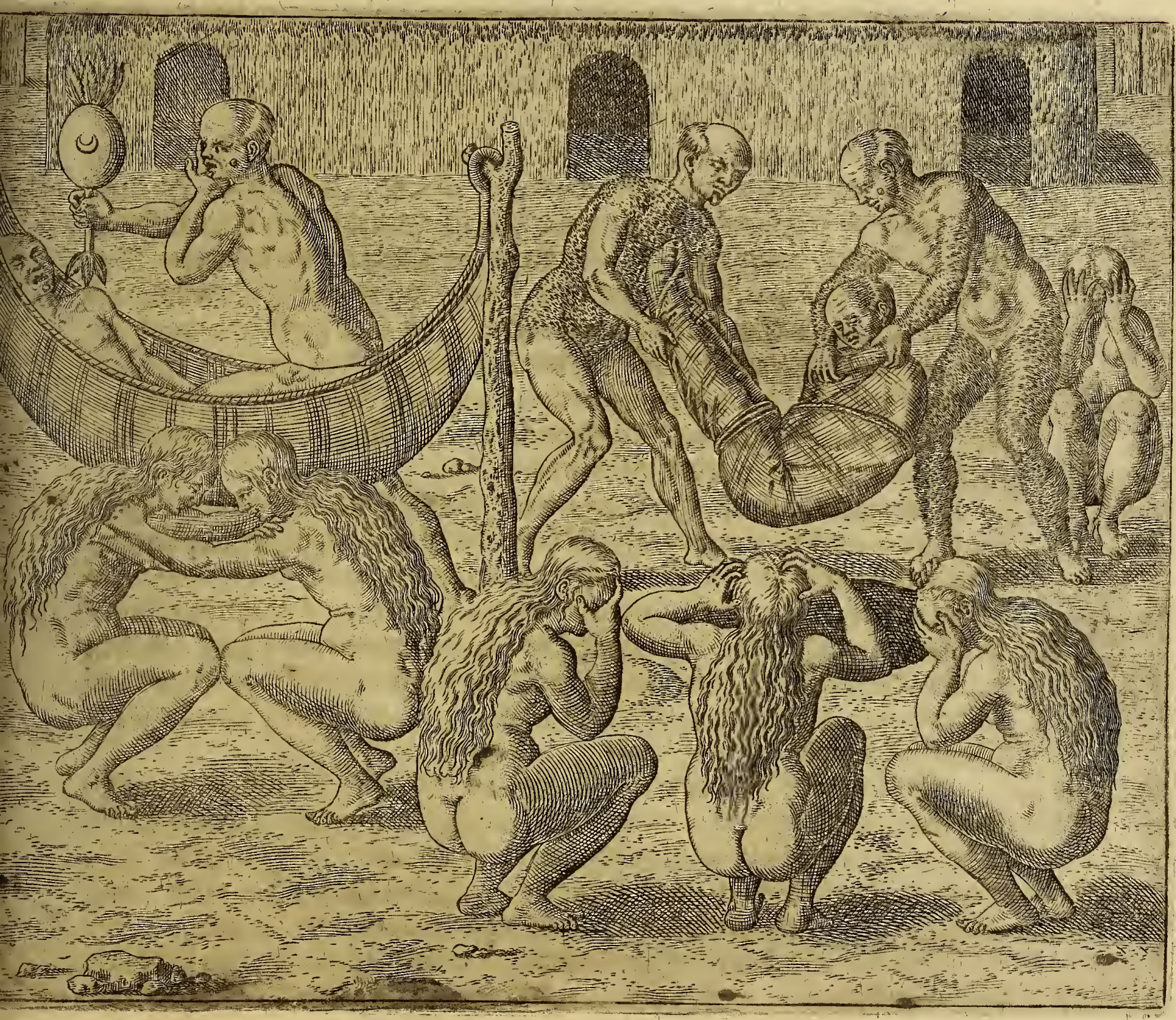

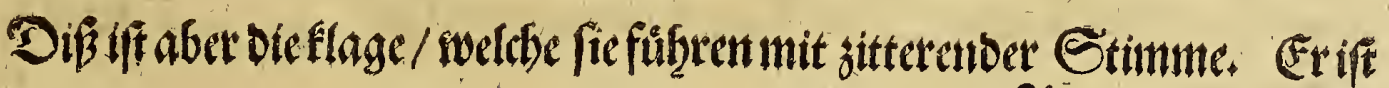
$\mathfrak{2} \mathfrak{a}$ Mun 


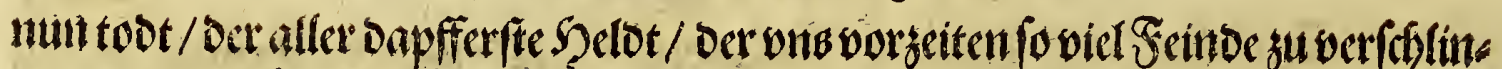
gen jurvegen braibt. Dent fangen bie andernan / Soefis gerwaltigen Jäger.

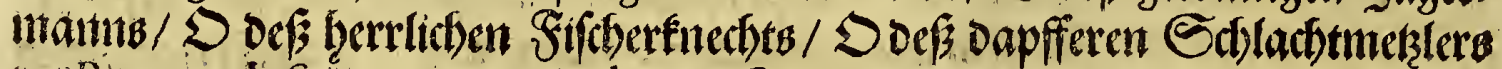
DerPortugalefer vimo oer Markayas. In fümma, fe eine ermanet vnno reiket

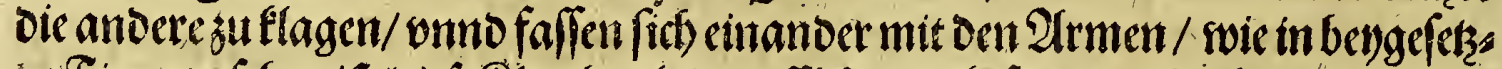

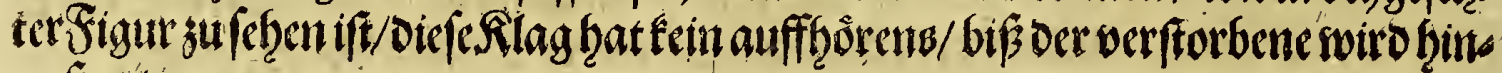
auß getragen.

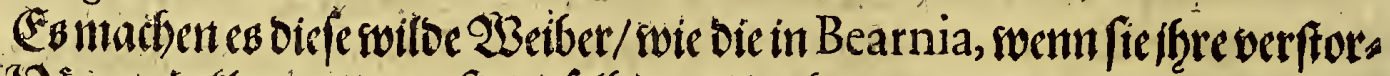

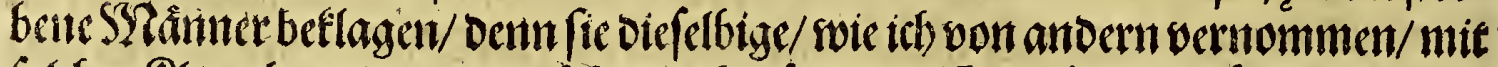

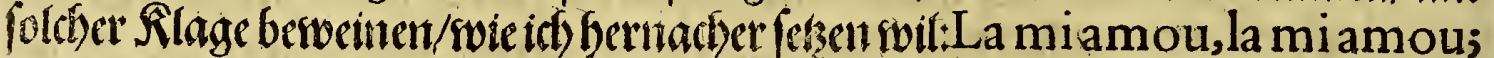
Cara rident oeil defplendou: Cama leugé, bet danfadou. Lo mé balen, lo m' esburbat: mati depes: fort tard cougat. Dae if $/$ STtein licber Freuno/

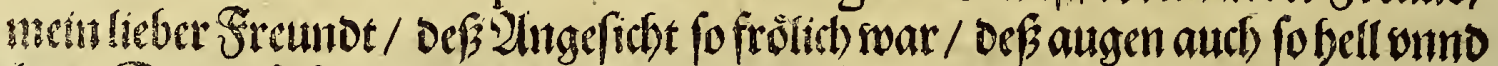

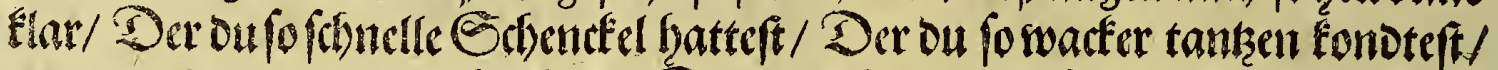

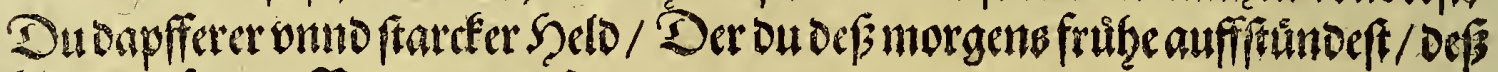
Albenotbipat

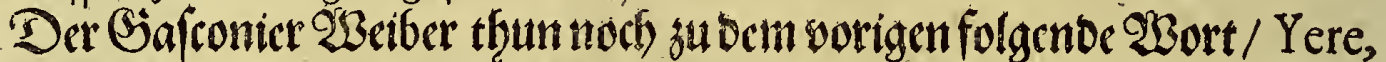

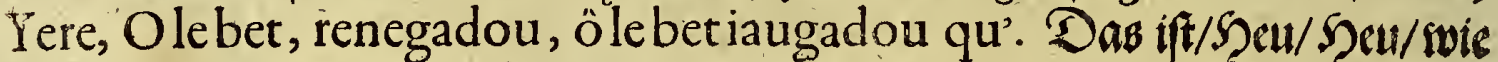

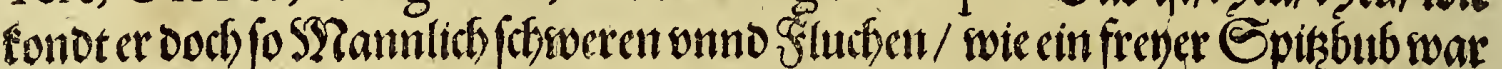

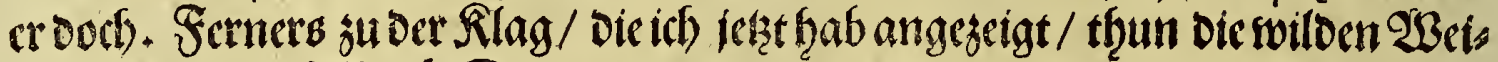

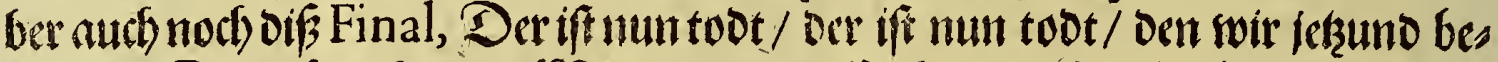

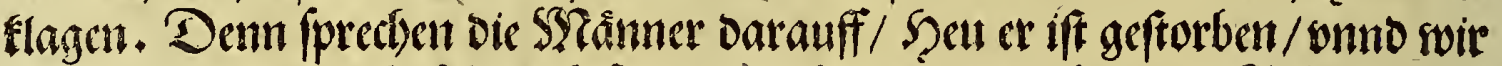

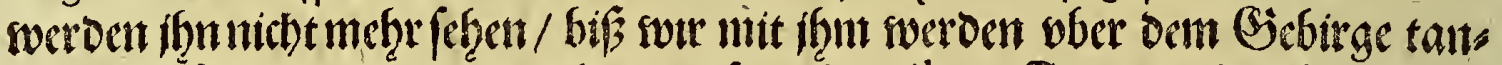

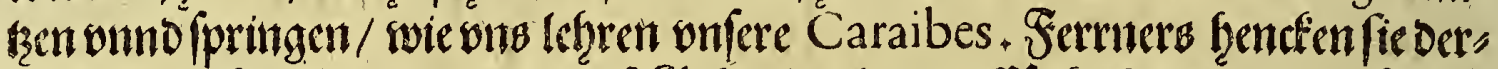

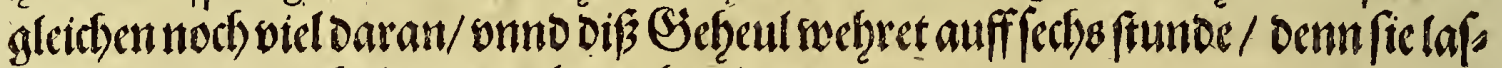
feniffre toden nictl tenger onbegraben ligen.

Demnach machenfiecine Raute/nicht oberlengt/ woie ben ons ber Brauds

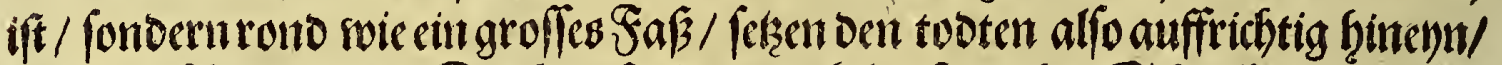

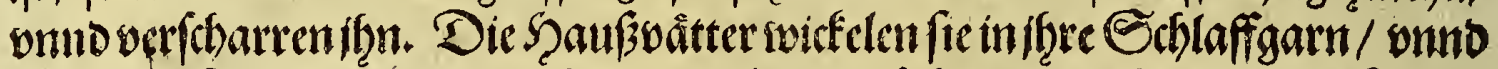

Jie Grä́ber/ onno wie die

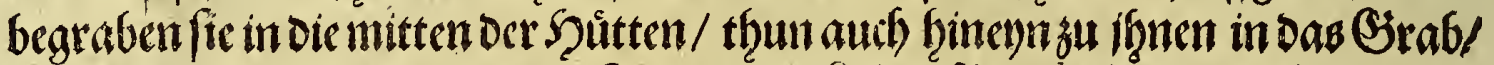

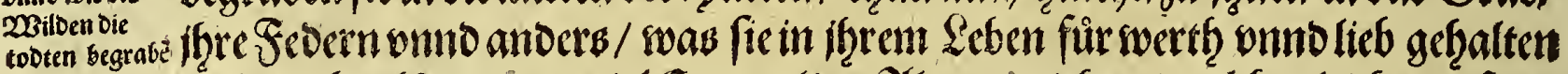

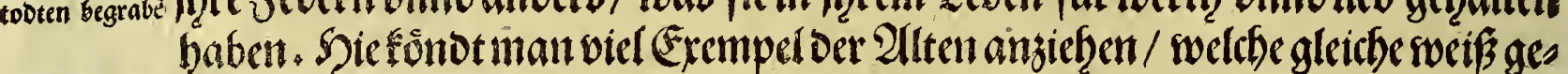

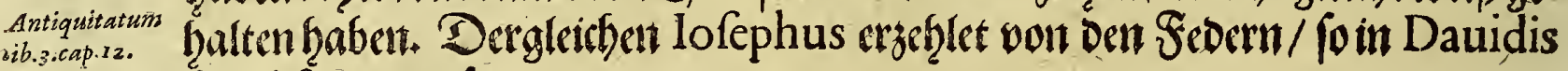

Der fermud" twirt nit Dë toos ten begraben. Grab finto gerwefent

Dif bezeugen auth andere Hiftorien, Daßsman bie fürnemb/ten verftors

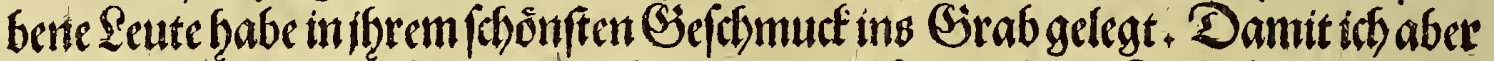
nicht zu weit won voleren Americanern ombfhrweiffe : So baben bie 2 ils

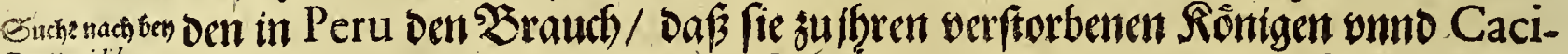

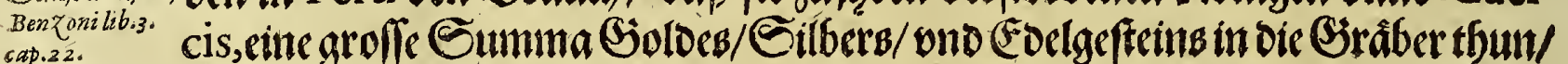

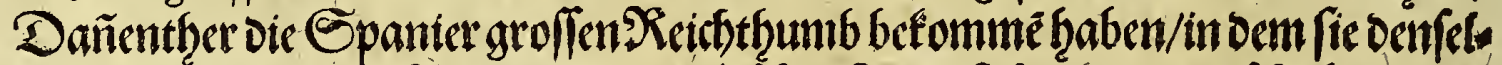

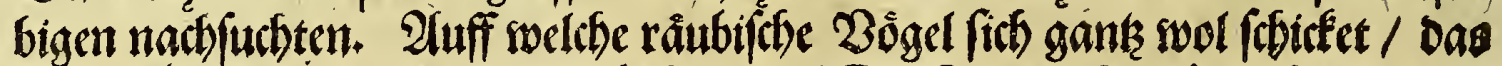
Plutarchus von oer Semiramide fofrectbet. Die Rơnigin Semiramis, von Der man liefet / Daf fie die Statt Babylon erbawet hab / b̧at auff ffor Monu-

ment 


\section{Dasbritte Thet.}

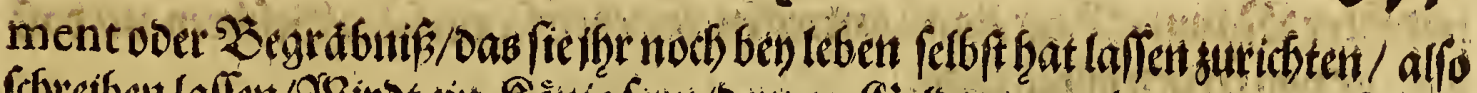

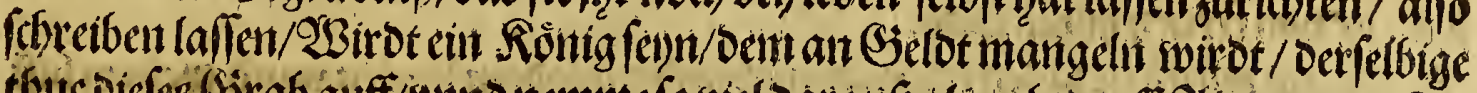

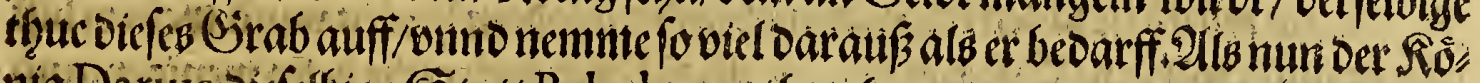

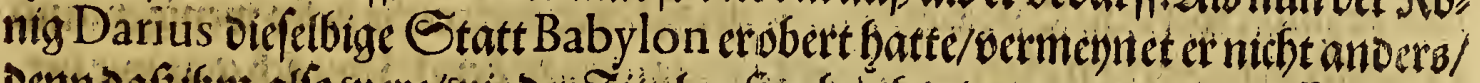

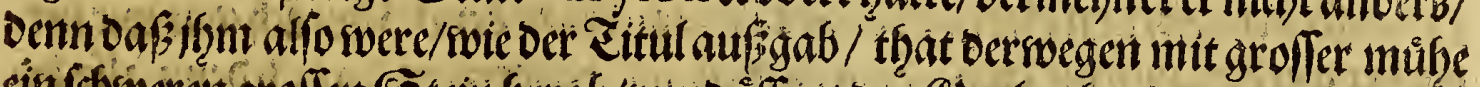

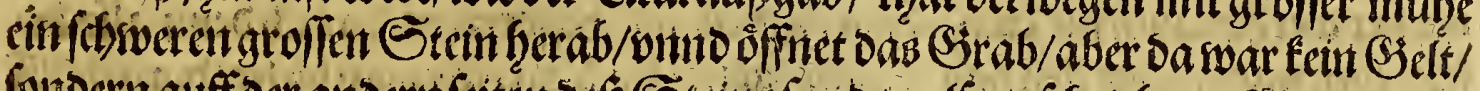

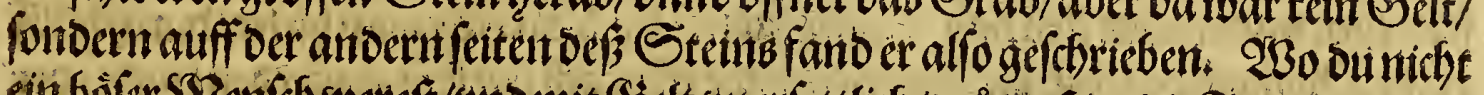

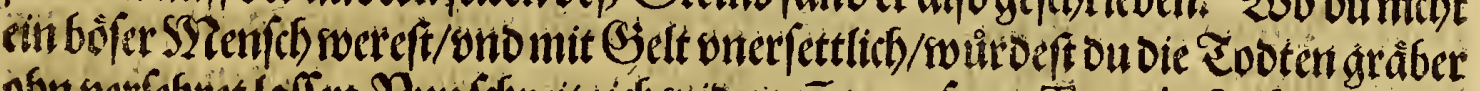

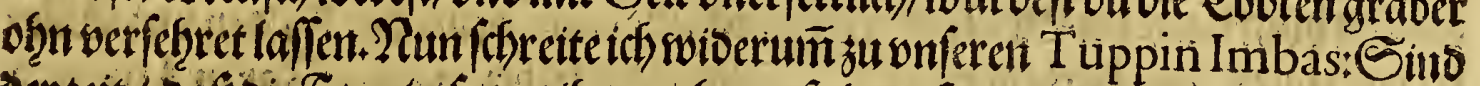

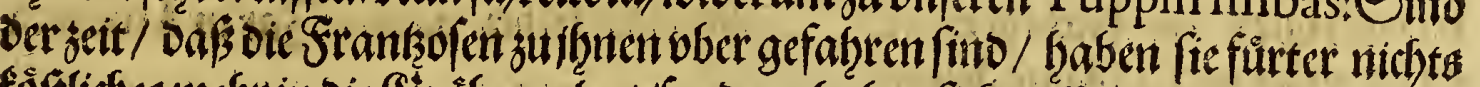

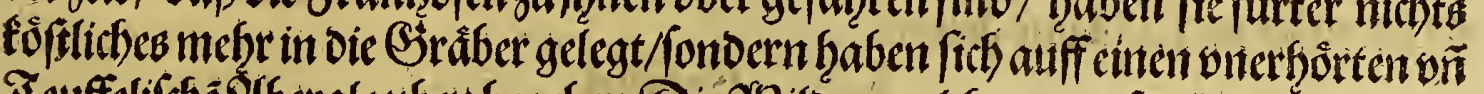

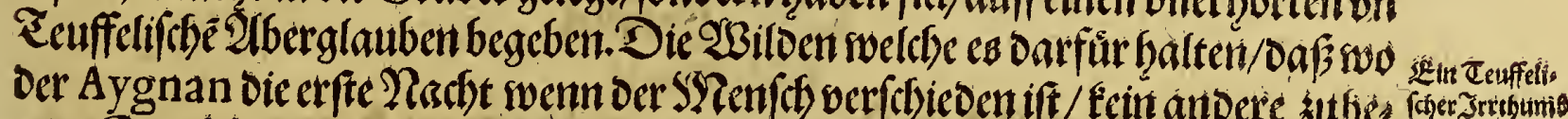

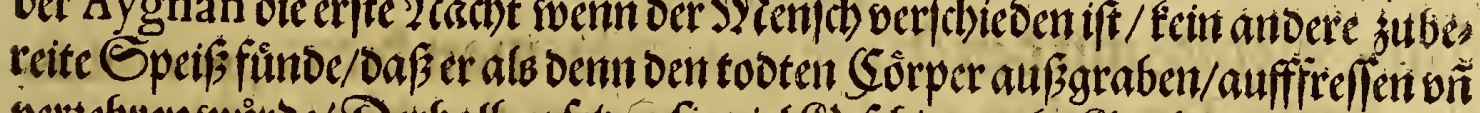

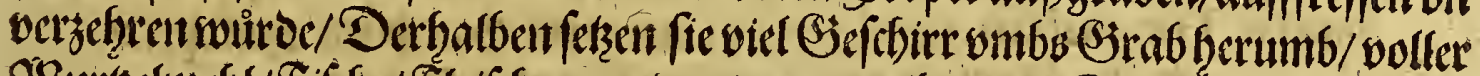

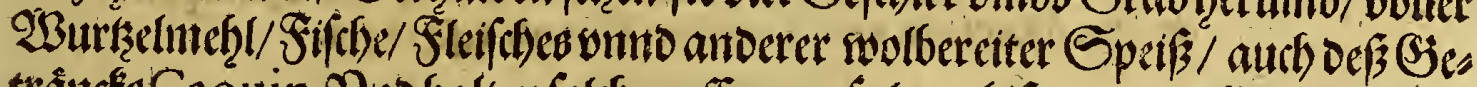

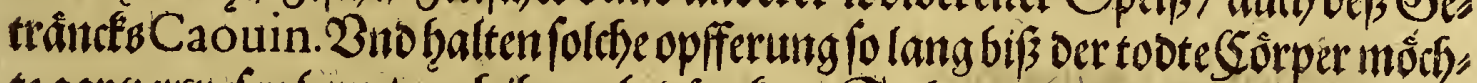

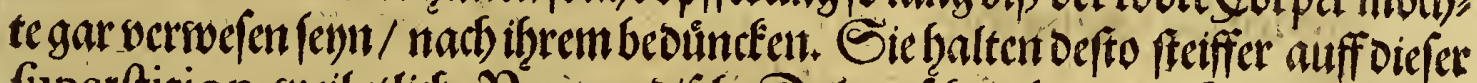

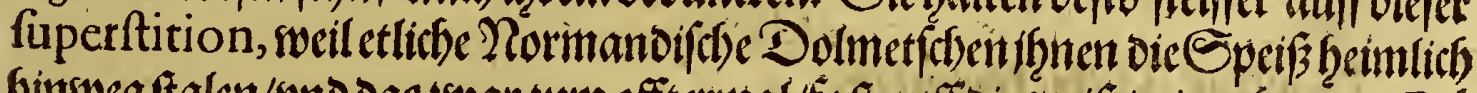

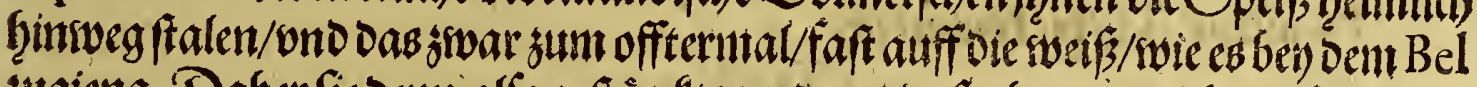

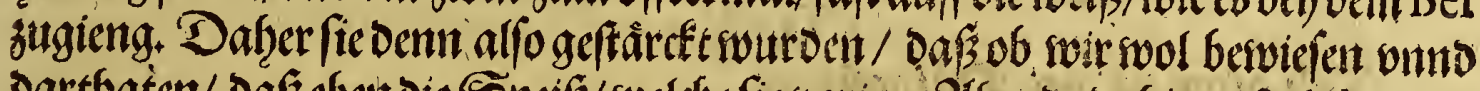

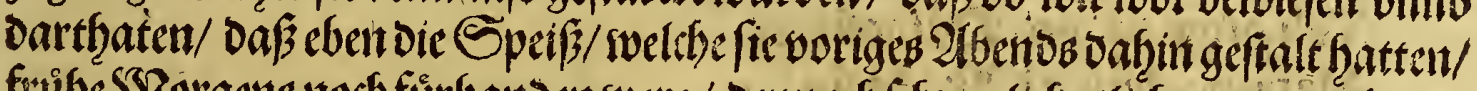

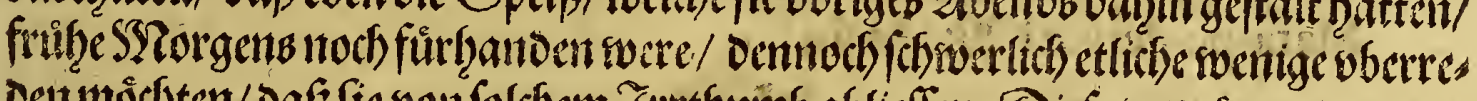

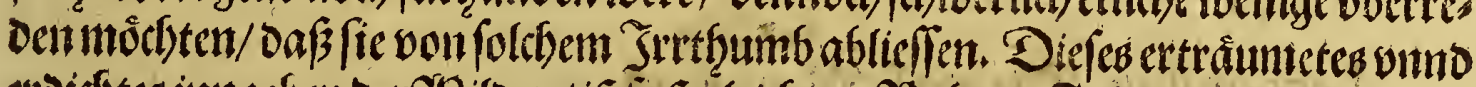

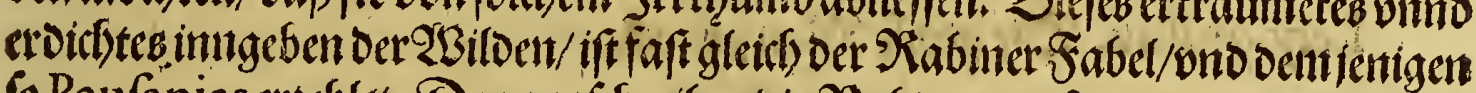

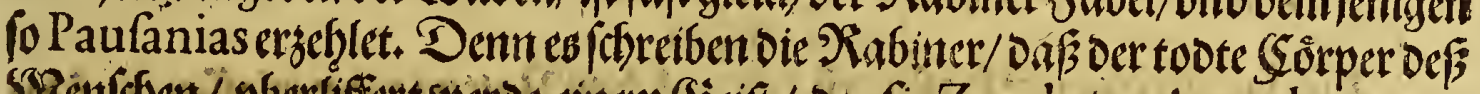

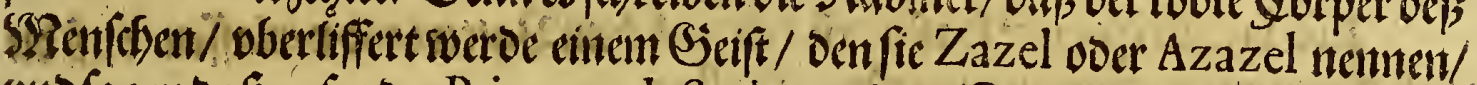

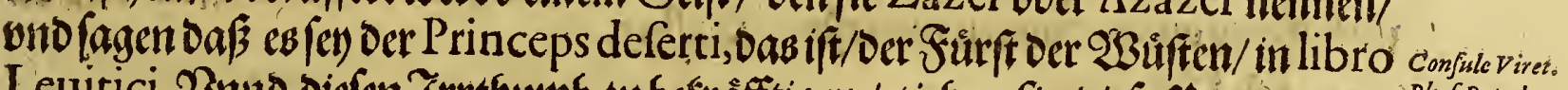

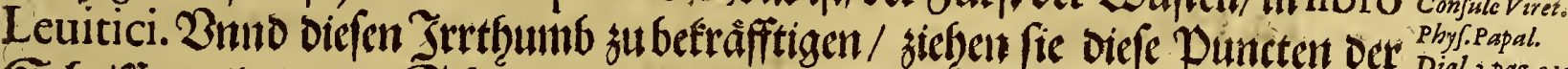

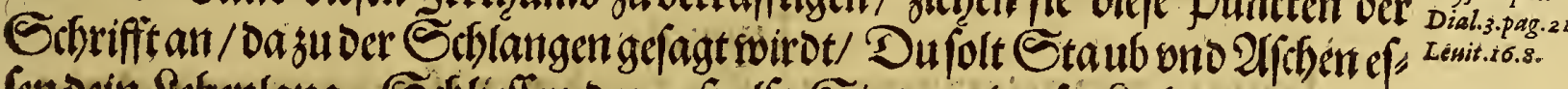

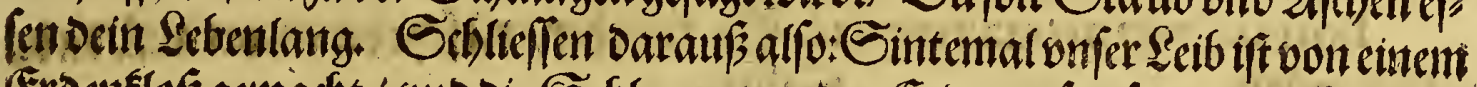

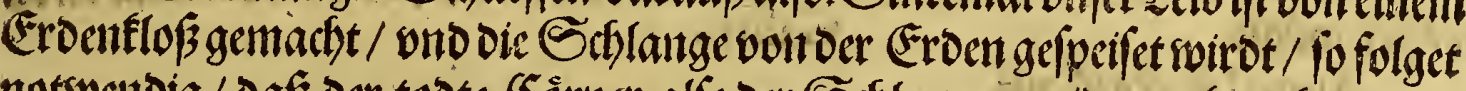

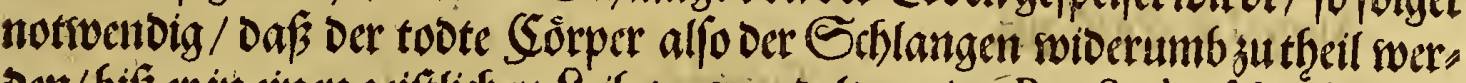

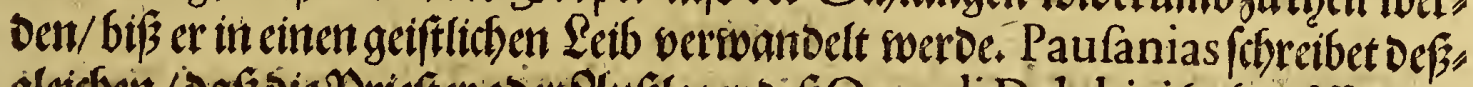

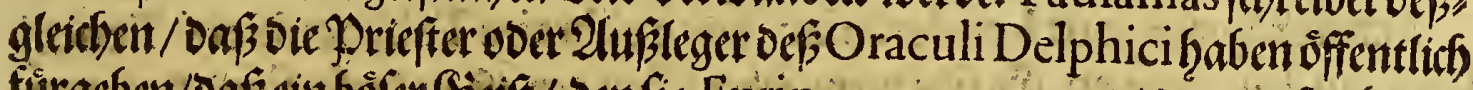
fürgeben/Dafain bôfer Beift/ denfie Eurinomum nemen/Der verftorbenen

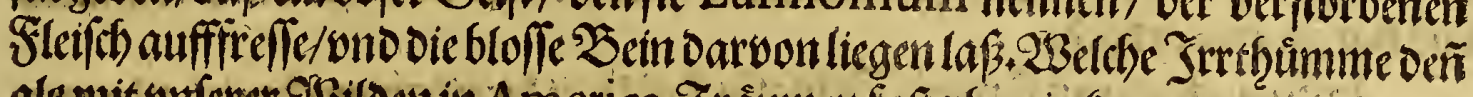
als mit vnferer 28 iloent in A merica Traumen faft oberein fommen.

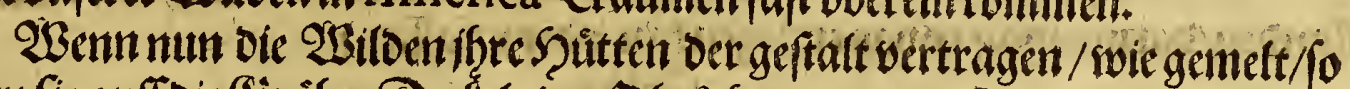
machen fie auff dic Šräber Dectel ooer Sbtâcher von Dem firaut Pindo. Dars

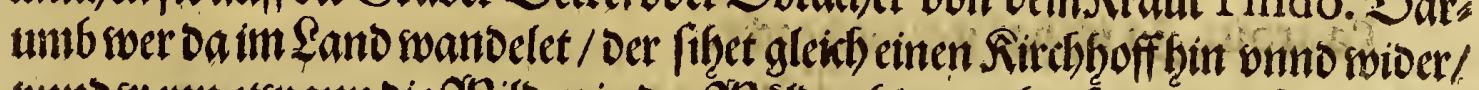

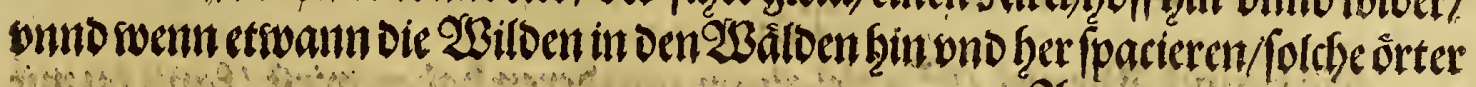

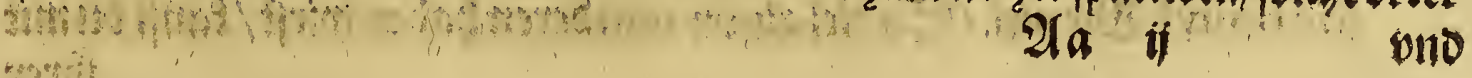
सह 


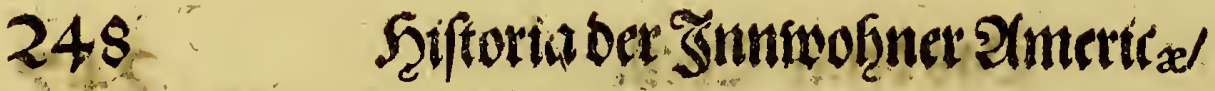

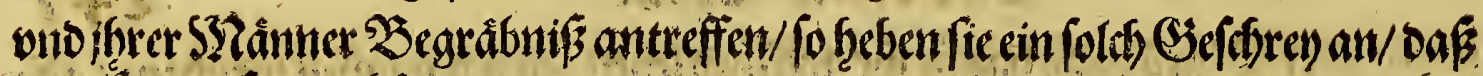
manfic von fernen forten mag.

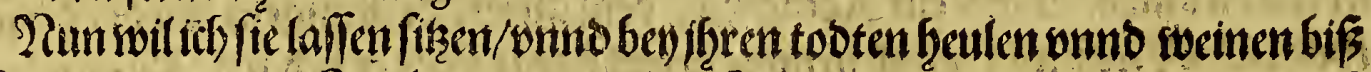

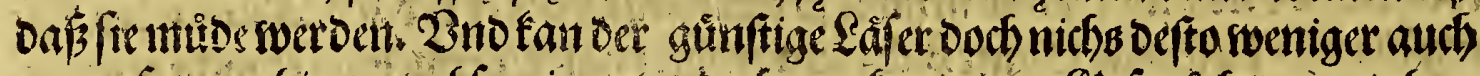

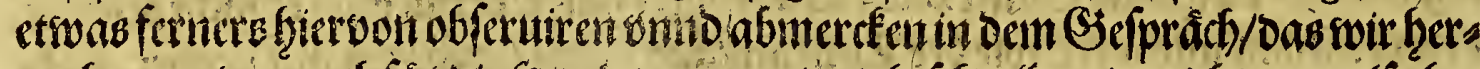

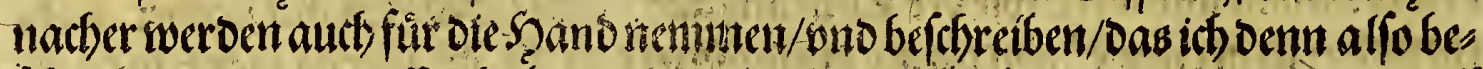

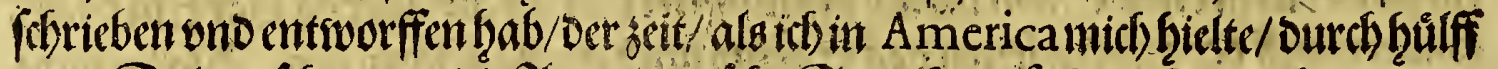

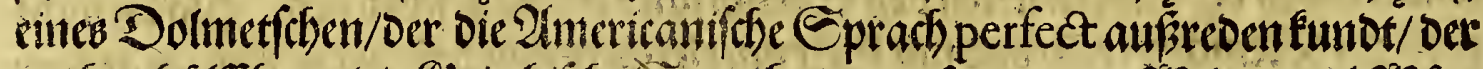

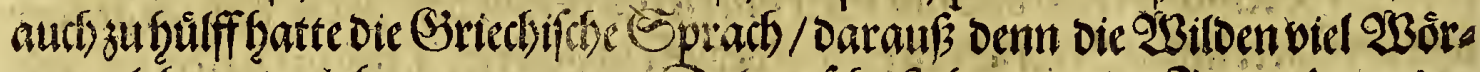

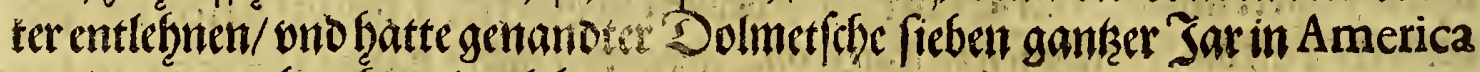

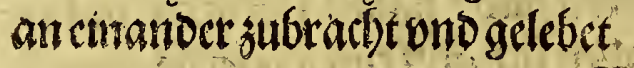

Ein Gejpråds mit ben $\mathfrak{B}$ rofulianent. $\mathrm{XX}$. Sapittl.

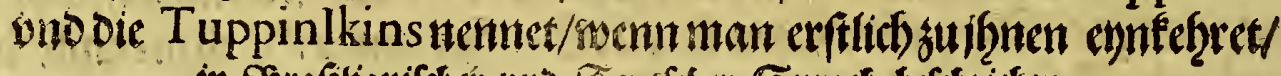

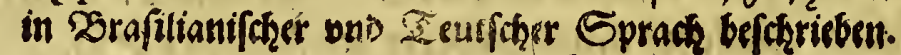

Ere-ioubé? Rómpftu? Tuppinlmba.

Pa-aiout. Ja/f̨ic fonme ich.

$$
\text { Gallus. }
$$

Teh,auge, ny po. Dufagft wool.

$$
\text { Tuppin。 }
$$

Mara-pe-dérérè? $\Re_{1 i}$ ḩeiftu?

$$
\text { Gallus. }
$$

Qnfers Auro:

ris Zunam auff

Lery-ouffou. Die grofle Ssiccrictuncef.

Zraflianifob. Tuppin.

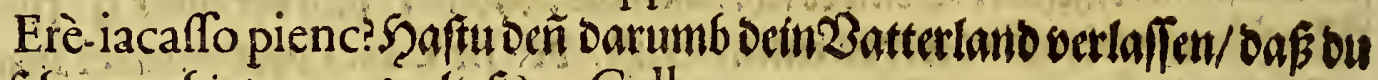

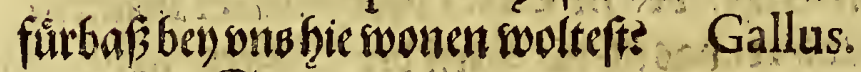

Pa. Soiftim.

\section{Tuppin.}

Eori-decretani ouani repiac. So fom hę /

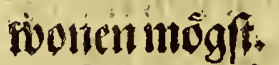

Gallus.

Auge-bè. Esiftgut.

$$
\text { Tuppin. }
$$

I-endérèpiac?aout $\mathrm{I}$-enderèpiac aut è ehèraire Teh, ocuèreté Teuoij Lery ouffou ymè en. Enfitze mein lieber Son/er ift in biefer Lano fonmeny sino héatan ons gedacts.

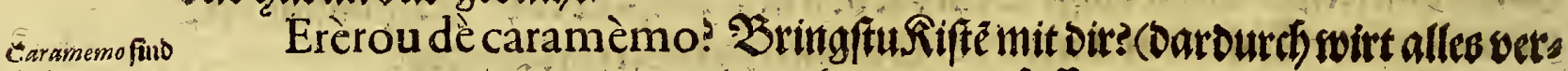

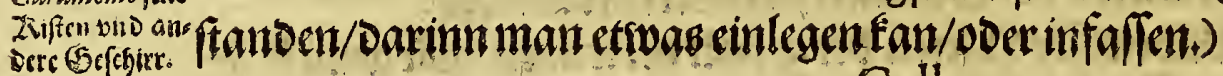

Berre Grchipre. Gallus.

Páarout, Ja ich h̨abirer mitbracht.

Tuppin.

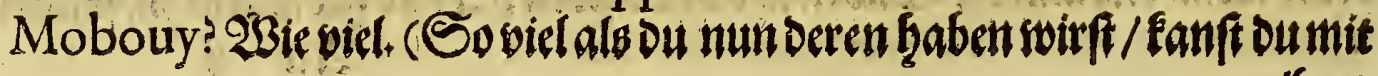
ighter 
Das britte Tfeth.

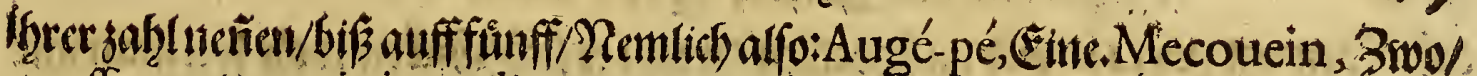

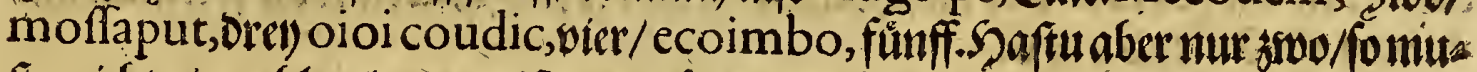

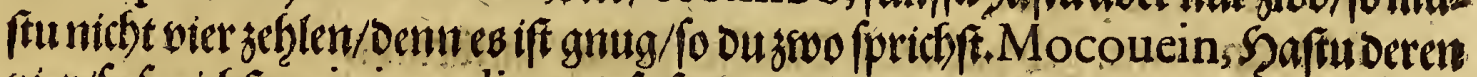

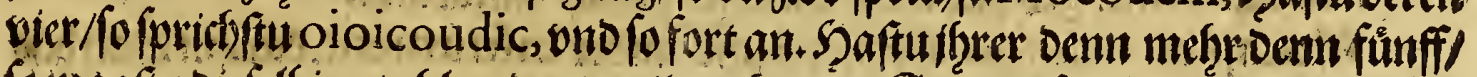

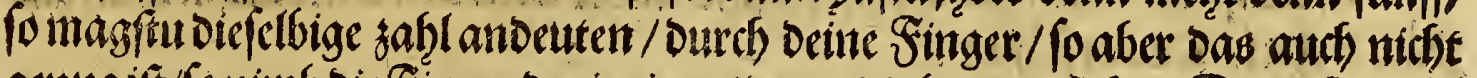
genug ift/fo nimb bie Finger Der ienigen/Darłu oie bey dir ftefen. Denn fie habe

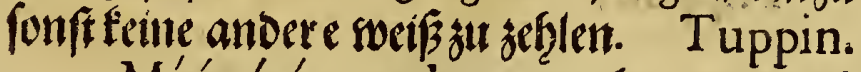
bractet?

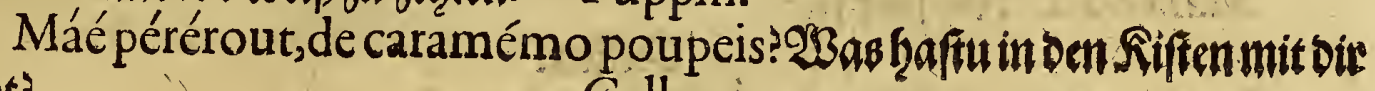
A-aub, flelyoer.

Mara vaé? $23 i e$ efenenfie?

$$
\text { Tuppin. }
$$

Sóbouy-été, Simmellolarw.

$$
\text { Gallus. }
$$

Pirenk, Fioth.

\title{
Ioup, (jecl.
}

Son, Echiswarks.

Sabony; maffou, Grith

Pirienlz, Allerlen farbert.

Pegaffou-aué, Esctemfatb.

Tin, $23 e i f$. Darmit meinen fie Soemboer.

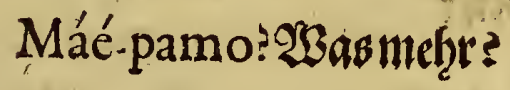

Tuppin.

Acang aubé-roupé, ḩưté.

Gallus.

Seta-pe: $\mathfrak{B i d l}$ ?

$$
\text { Tuppin. }
$$

Icatoupaué, $\mathfrak{B}$ intfflitff wiel.

$$
\text { Gallus. }
$$

Tuppin.

Ai pogno? Jit es daballeb?

Erimen, Sqzitnicften.

$$
\text { Gallus. }
$$

Effenon bat, Renne mirs alles.

$$
\text { Tuppin. }
$$

$$
\text { Gallus. }
$$

Coromo, $\mathfrak{B e r}$ sithe ein fleittes.

Nein, ?am fomach ḩer.

$$
\text { Tuppin. }
$$

\author{
Gallus.
}

Nocap, ober Mororocap, Feurwerbuichifenspuluer / von benberlen Ifrt.

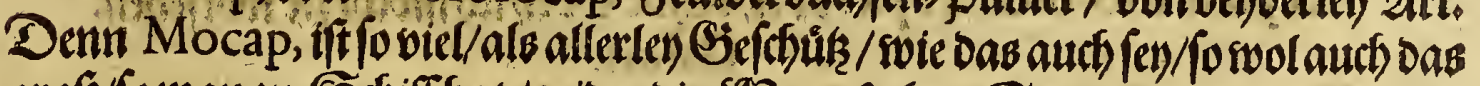

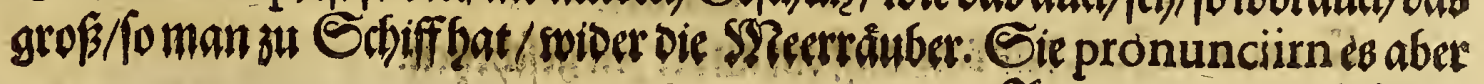




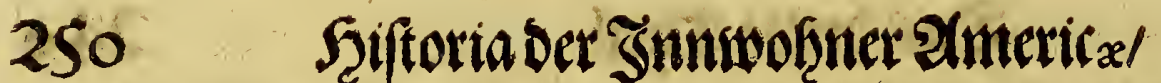

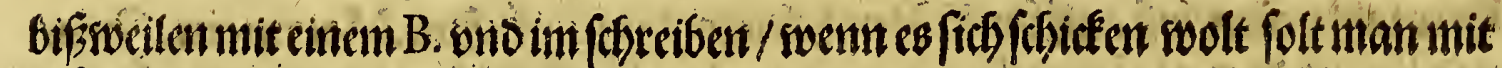

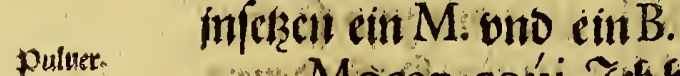

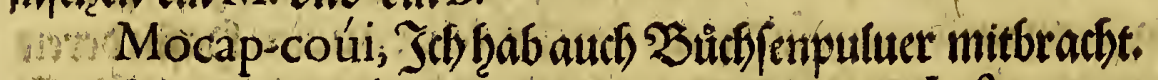

Mocap couiourou, Sobrner bnnt ander Inftrument, Darimman bo

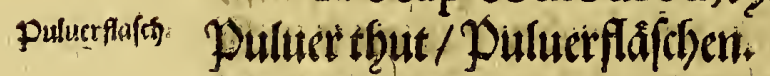

Mara-vaec, $\mathfrak{B B i e f i n o}$ fie? Tuppin.

sinesure Gallus.

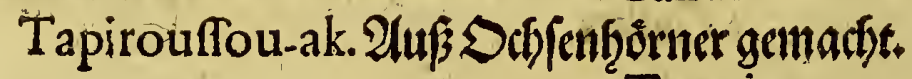

Augé-gatou-tégué, Das laut trol. Tuppin.

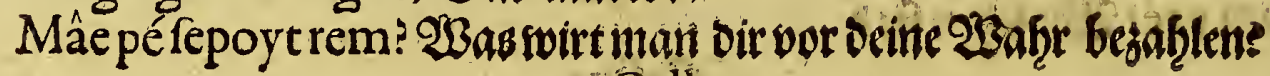

Gallus.

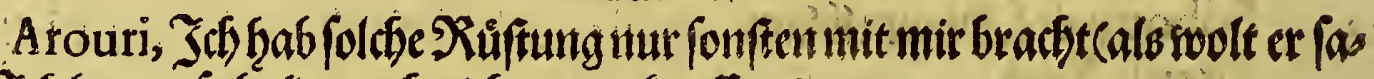

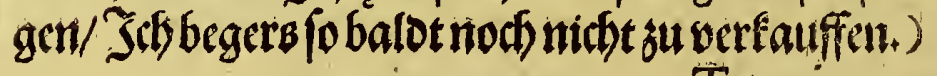

Tuppin.

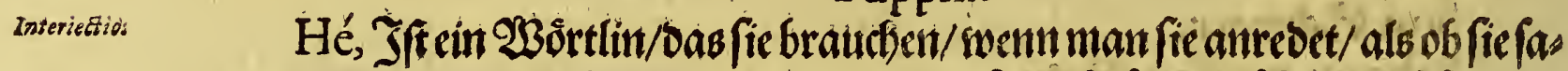

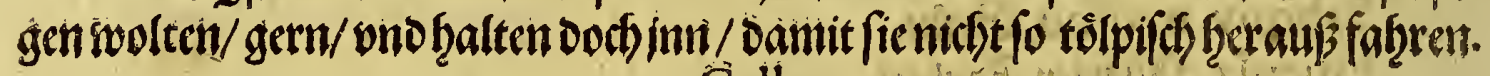
Gallus.

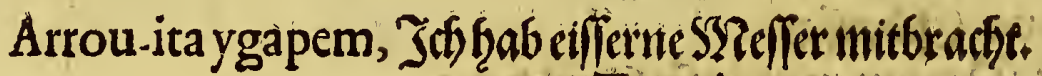

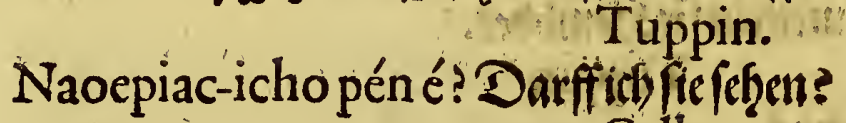
Gallus.

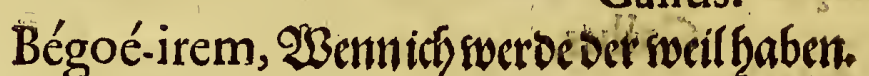

Tuppin.

Néréroúpeguya pat? Bringftuauth Șepen?

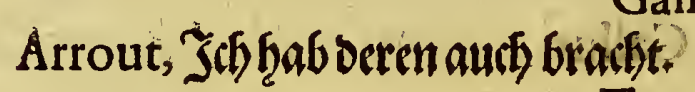
Gallus.

Igatou-pe! Sintofie frúbjgh?

Tuppin.

Guiparété, Bber biemalfent Gallus.

Aua-pomogaen? $\mathscr{W}$ er feat fie geffichiot? Tuppin.
Gefimitot?

Pagé-ouaffou remymognérieiner Denm ounicht fenteft/ onb bet alfo ந̧eif ber ḩat fie geftsmibt.

Augé terali, $\mathfrak{D} \mathfrak{a}$ lob ich).

Tuppin.

Acépionthopin.

anch Tuppin.

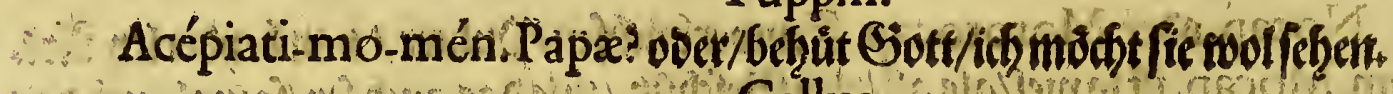

(a) Gallus.

Karamouffec, das fan auffeinanber seit gefdhelgen.

Tuppin. 


\section{Dag britte Theil.}

Tuppin.

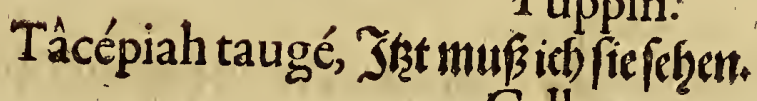

Gallus.

Eémbere ingué, 2 Barte bod nodb cin wentig.

Tuppin.

Erếroupéitaxéamo? : Bringftu audiss?effer?

$$
\text { Gallus. }
$$

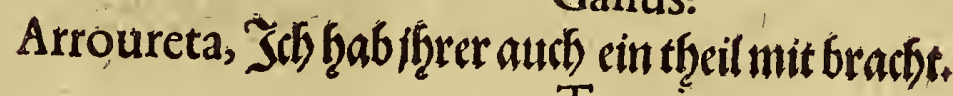

$$
\text { Tuppin. }
$$

Secouarantin vae? Spaben die Siteffer buntete beffe?

$$
\text { Gallus. }
$$

En. En, Reinl vetin, fie baben weiffeforalen.

Tax e miri, Rleine SYlterlein.

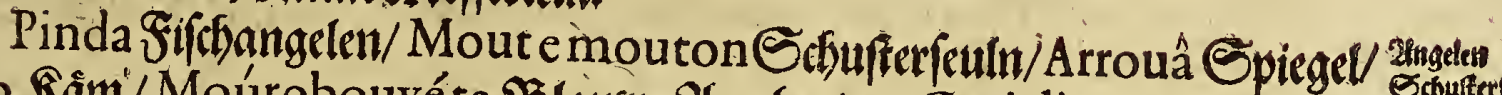

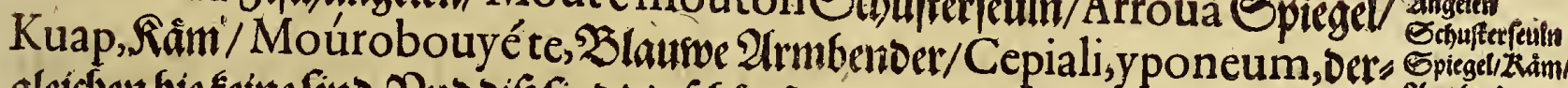

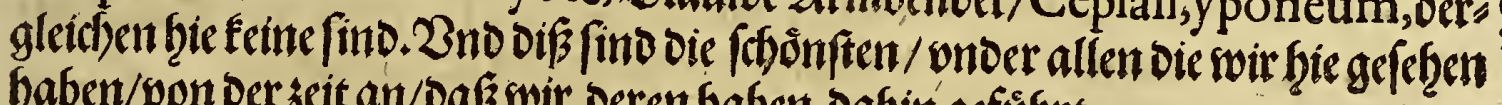

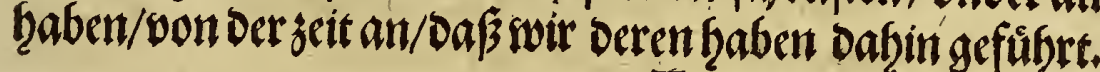

Tuppin. Tuppin.

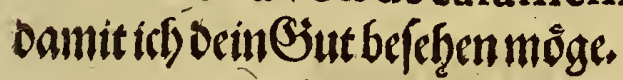

Gallus.

Aaimoffa énen, Jikh bab fonftenguthun.

Acèpiag-oucairen defue? Sonft auffen anoer mahl/ woenn ich woicoer wero un bir fommen/forvil ich oic Riften Dann auffinachen.

Tuppin. bringen.

Nárout ichop’ irémmaè defue? Sol ich ocnn etwan dir ander Sut

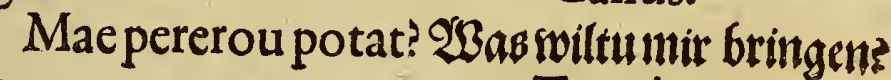

Gallus.

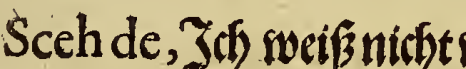

Tuppin.

Maè perei potat? $\mathscr{W} \mathfrak{a} a \mathfrak{s}$ wiltu?

$$
\text { Gallus. }
$$

\section{Tuppin.}

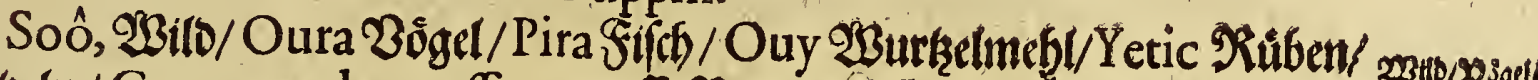

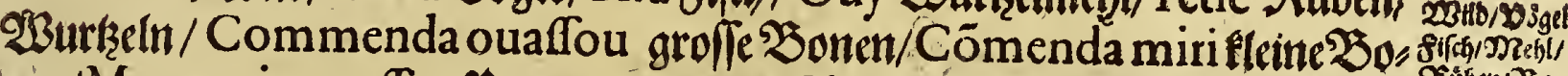

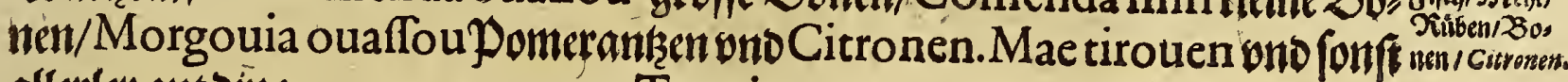
allerleygutoing. Tuppin.

Mara-vaè foo èrèiufceh? Bon waßz furriberer einem swiltu eflen? Gallus.

Nacèpiah que von-gouaaíre. Jof magnit von benen hite im and $_{\text {eflen. }}$ Tuppin.

Aaffenon defuoe, Jef woil bir cins nadb Dem antornher nennen.

Nein, Rumforodlan. Gallus. 
250

Tapirouffou.

Wascsfit

ein Thier.

2⿺辶ine 2lrt

Genibru.

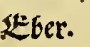

Agouti.

Pague.

Tapiti.

Drenerley

groffe Doghel.

Grofk Pieps

Gunct.

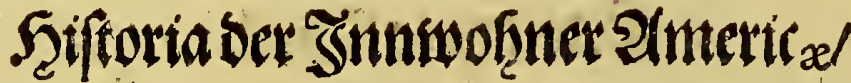

\section{Tuppin.}

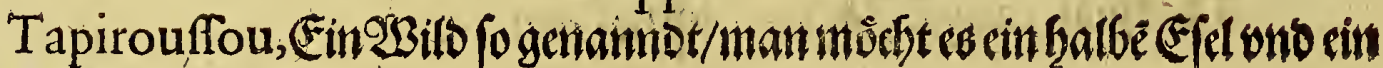

Balbe Ruth nenten.

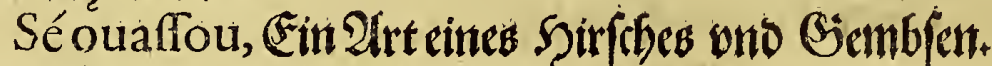

Taiaffou, Ein woilder Erer.

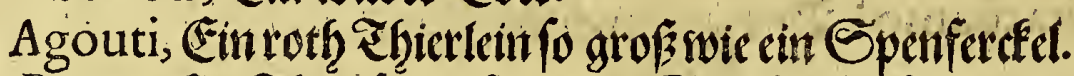

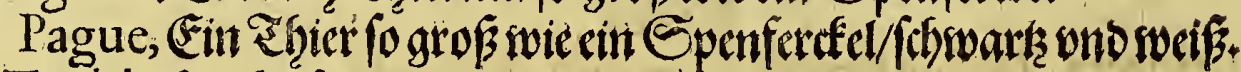

Tapiti, Ein Şajenart.

Gallus.

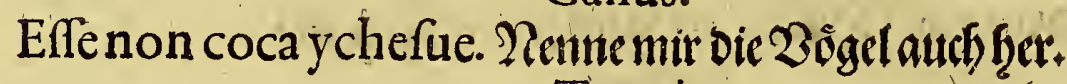

Tuppin.

Iacou, (Ein Zogel fogrof Remlicb/lacoutin, Iacoupem, wnmo lacou- ouaffou, find alle cines guten Ġes

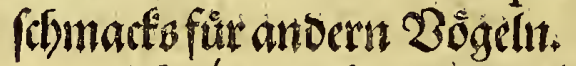

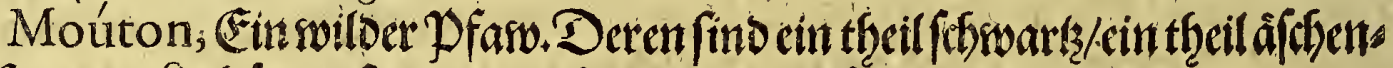

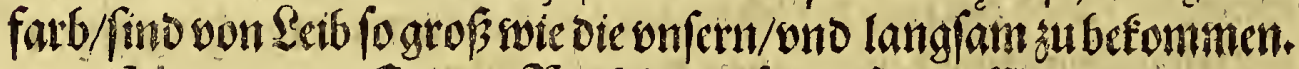

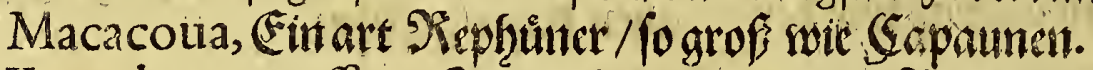

Ynąmbou-ouaffou, Sif noch ein ander swild Piepbun/ fo grofis swic bie vorigen.

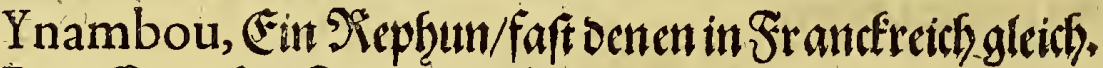

Turteltaube.

Pegaffou, (Ein Turtteltauben.

Paicauc, Roch ein fleiner art Surteltaubett. Gallus.

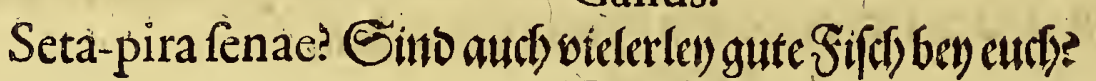

Nan, Govill finto beren. Tuppin.

Kurema, Sarben ober S\$ilulat.

Parati, $\mathfrak{B a r b e r i a r t} /$ beffer Denn bic vorigen.

Aaara-pep, ZZreite $F i f(\mathfrak{b}$ beffer als andere.

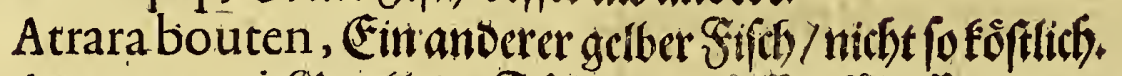

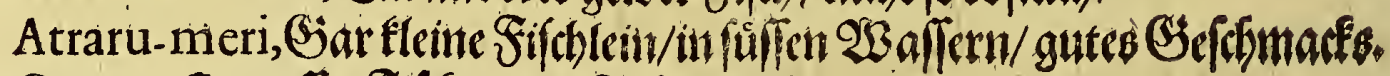

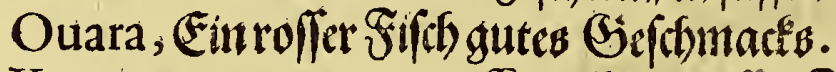

Kamourou pouy-ouaflon, (Ein groffer Siffoh. Gallus.

Mamo pe dérétam, $\mathfrak{i b}$ felelffitu diff ? Tuppin.

Kariauh, òra, ouaffou onée.lau-eu-uraffic piracā,opem,Eiraiaitanem, Ta racouir-apam,Sarapo-u. Diff fino Nament ber Dôrfer / soelche lies

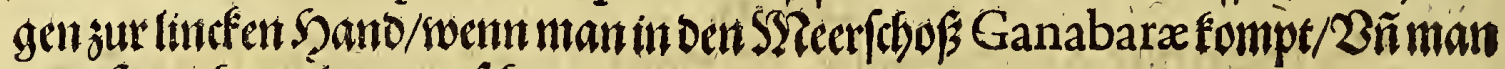
mag/ienticfterwol werteut fichen.

Keri-u, Ahar-u, Couroumouré, Ita, auh, Ioirarouten, Dôrffer am Bffer Defletbigen 23 affers sur rechten Spand.

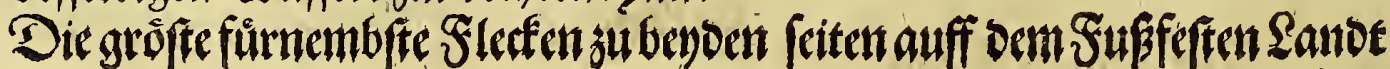


Das britte Theil.

find orfe: Sacouar-ouffou-tuue. Ocarentin,Sa-popem, Mourouue,Aralatuue, V fu-potuue. Bno fonftennoch andere viel/swelebe von benienigen / fo

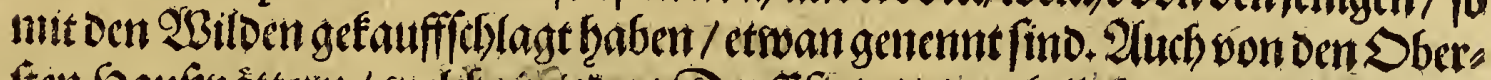

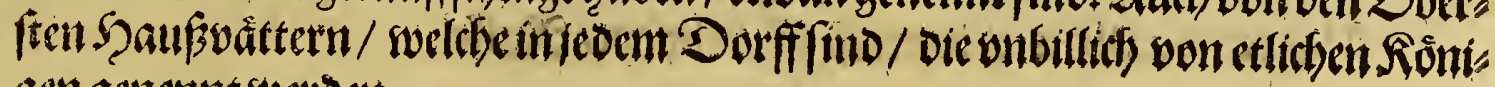
gengenentwetroen.

Gallus.

Móbouy-pé toupicha gatou heuou? Sates autí viel groflers Sånne: (oab ift tapfferc/fitarefe/freitbare)in bie/cm Eando?

Seta-goué,Giar wiel.

Tuppin.'

Gaillus.

Efle non auge pequoube ychefue, Yente mir beren einen.

Tuppin.

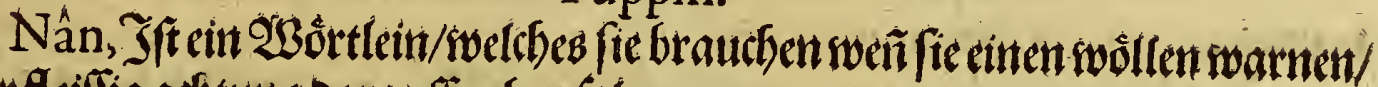
oaker fleiflig aeftung oarauffigeben fol.

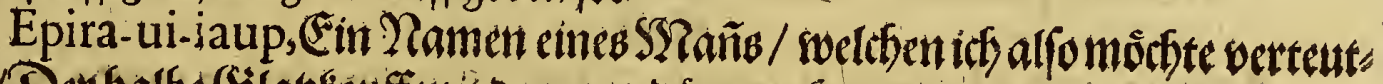

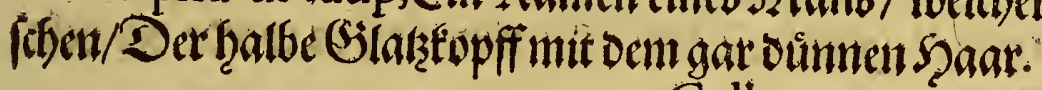

Gallus.

Mamo péfe tam, ơo wof̨nct berfelbige?

Tuppin.

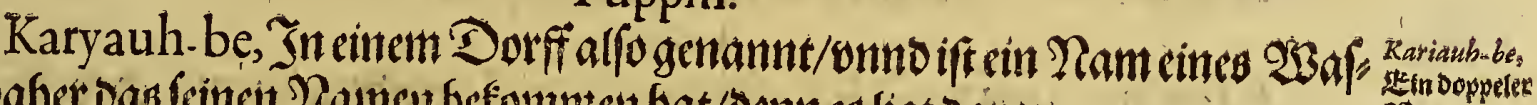
fers/oafer bas feineit Rancen befommen bat/Dennes ligt oaran.

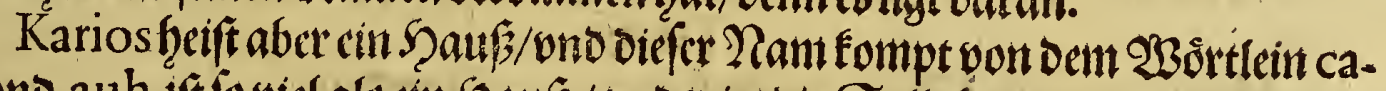
rioswno auh, ift foviel als cin Sauf / vno swit bic Syllaben os Darvongethan/

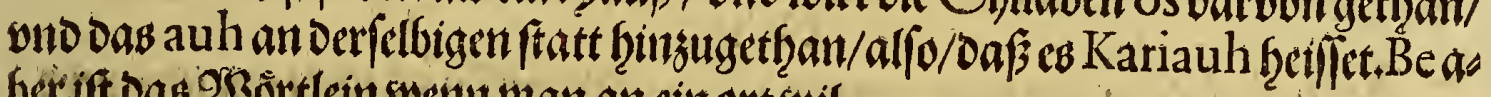
ber if bag soortlein soen man an ein ort woil.

\section{Tuppin.}

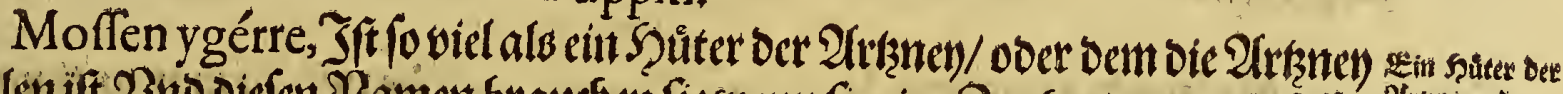

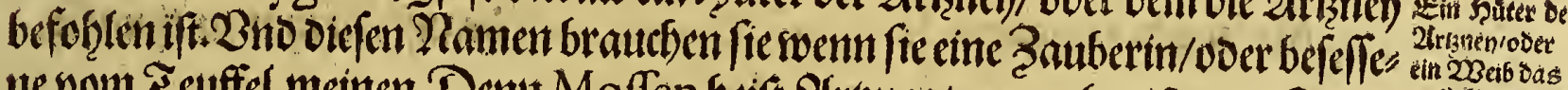

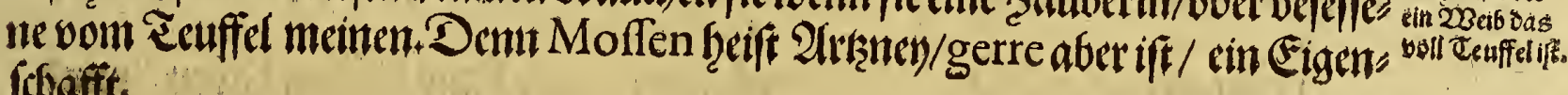
fichaffit.

Tuppin.

Tuppin.
Tuper fintoct.

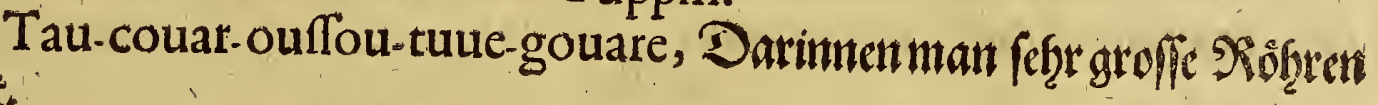

Tuppin. ตุåupt.

Ou-acan, Det fürnemb/te ort im feloigen Dorff/ift fo vid als/far Sbet: Tuppin.

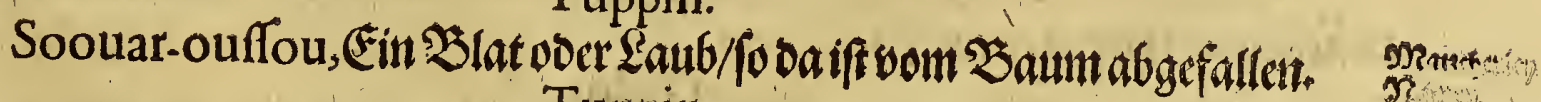
Tuppin. fein Ram.

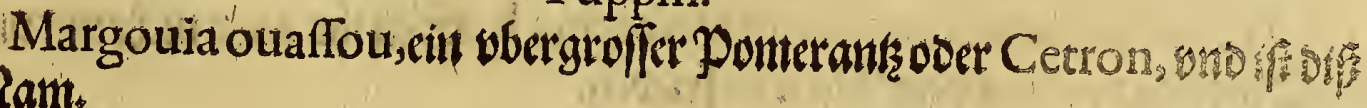

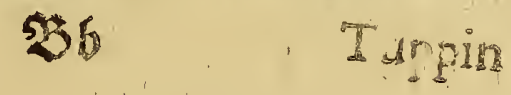


Maëdu, Ein Serwerflanmme.

\author{
Tuppin.
}

Tuppin.

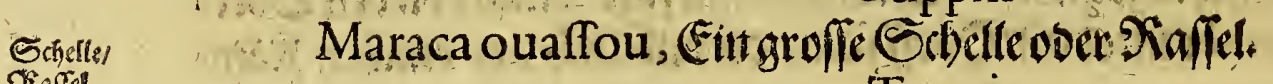

Tuppin.

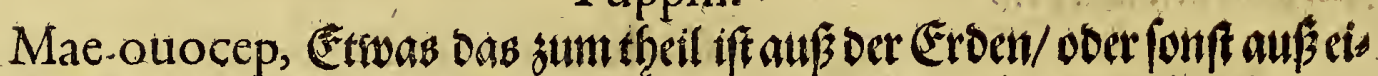

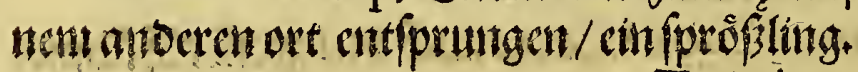

$$
\text { Tuppin. }
$$

Kariaupiarre, (Einsweg/nadb ber Nation Carios. 3 no esfind die Carj-

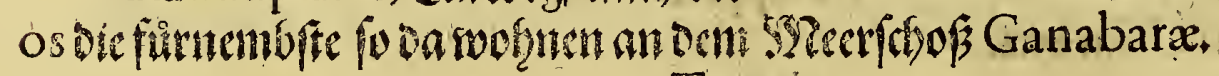

\title{
Tuppin.
}

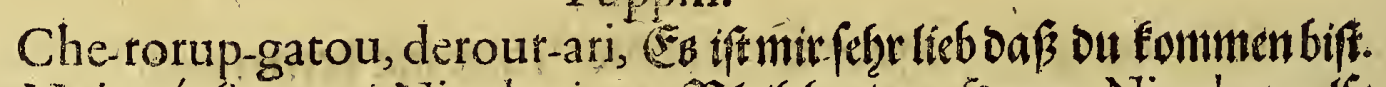

Pai Nicolds

gagno.

Ne in téréico, pai Nicolas iron, $2 \mathfrak{B l e i b}$ bay dem 5 ąren Nicolao, allo nennetcu fic oci Villagagnonem.

Nicere

Neré rompé déré miceco? Şaftu bein 9 Geib auth mit dir bracht?

Nicere

Gallus.

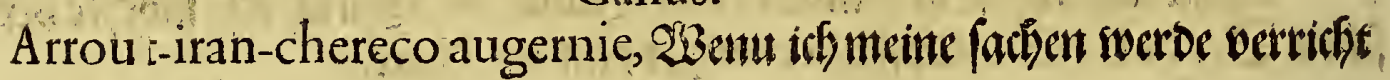

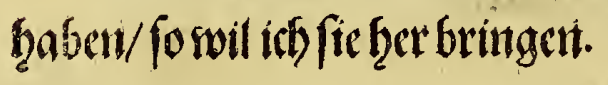

$$
\text { Tuppin. }
$$

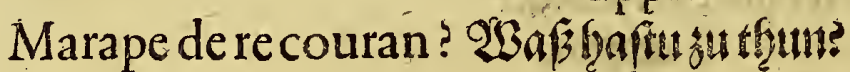

$$
\text { Gallus. }
$$

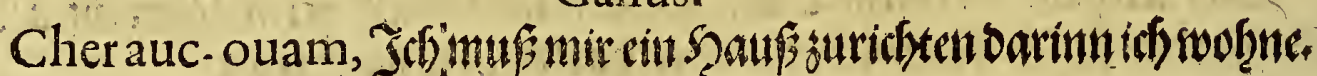

$$
\text { Tuppin. }
$$

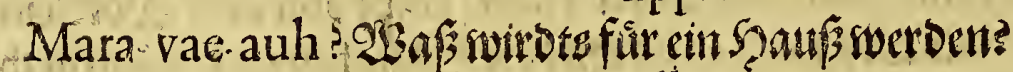

$$
\text { Gallus. }
$$
angreiffer.

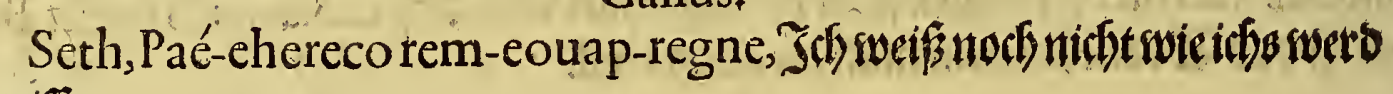
Tuppin.

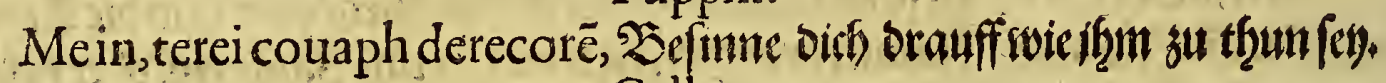

$$
\text { Gallus. }
$$

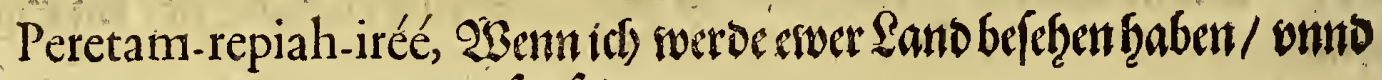
werd ein zetitlong Darimen geswefen fein.

Néréico icho pe deauem à irom ? $93 i(t u$ benn nicht ben) Den beinen/

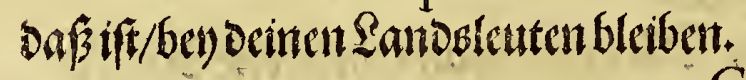

$$
\text { Gallus. }
$$

Maraui-amo-pé, \$̧arumb begerfiru bas ău wilfen?

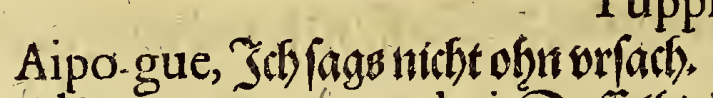

$$
\text { Tuppin. }
$$

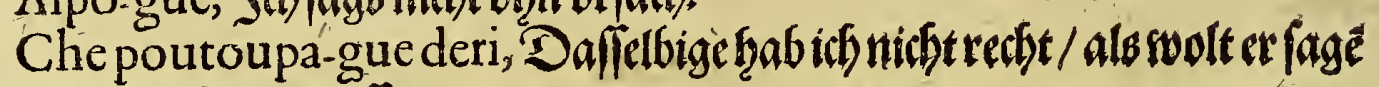
baffelfigrwoltich gern wiflen.

$$
\text { Gallus. }
$$

Nénpè amotareum-peore roubichech, Seitiģr bennnitfitmitonfes rem Dberfen doer mit bem 2liten fu frieben. 
Das britte Theril.

253

Erimen, \$rit nichtet.

Tuppin.

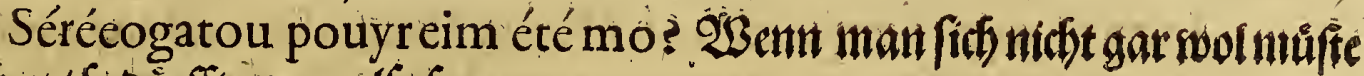
fürefen/ /o o örfftemanalfo fagen.

Gallus.

Sécouaé a poau-e eugat engatourérme, yporere cogatou;

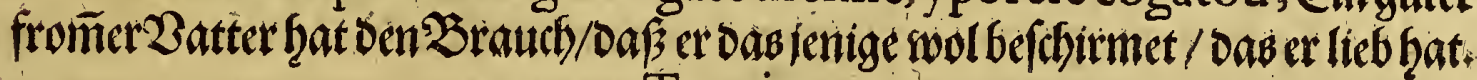

Tuppin:

Nerefco-icho pirem ouariui? 2 Biltu Denn barnath in Ririeg sieben?

Gallus.

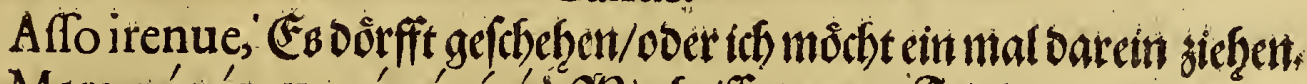

Mara-pé pérou agérré réré ? GBic heiflen enwere Feinoe?

Tuppin.

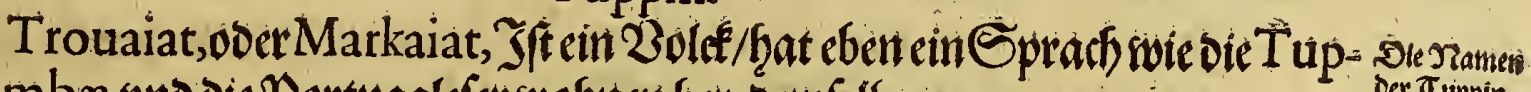
pin-Imbx, wno die Portugale er wobnten bey Dem/elbert. onto Parai.

Ouataca, Ginorechte orsiloen/unt Galten fich an iit $\mathfrak{B e r g e n t}$.

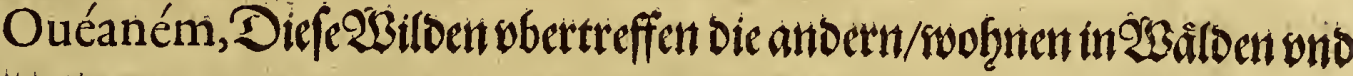

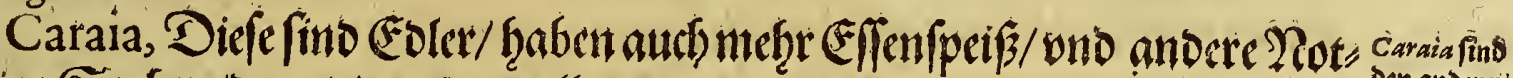
tưrffitige Sacben/oenn oie andernalle.

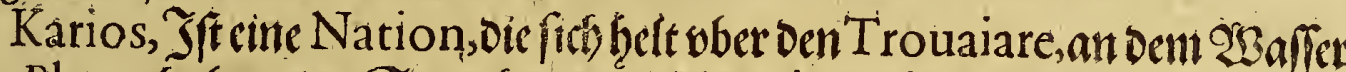
Rio de Platta, haben eitue Sprach nit oent Tuppin Imbas vno Tuppin Ikins.

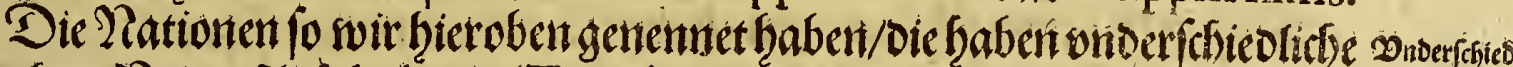
Sprachen/23no erftlich haben bie Tuppin Imbas, dic Tuppin lkins, oie Tou viñernand uaiarre, Die Tenreminon, ond dic Carios, beun nobe einer en Epract

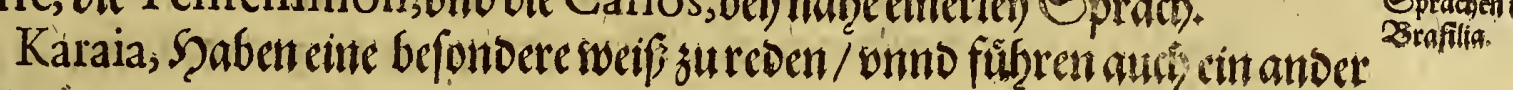
Sebent.

Oue taca, Diefelbige find von benderionderfefiedenmit der Spractionto mit Dem $L e b e n$.

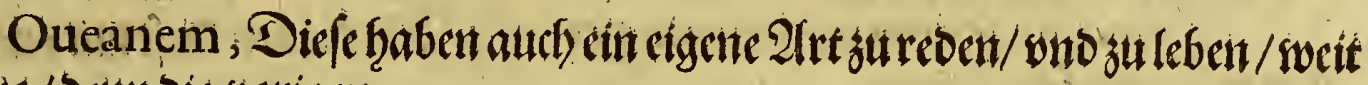
anders/Denn dic worigen.

Tuppin.

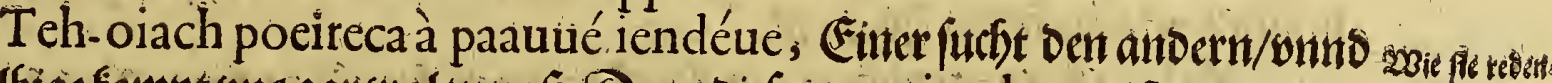
baffelbige fompt wns gar wol zupaßj. Denn oiefes wort iende-ue, iftein art von

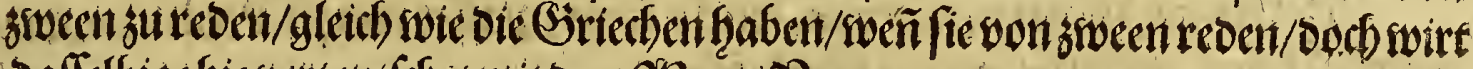
Daffelbige bie verteut/chet mit bent 2 Bort/ 3 ns. fulben.

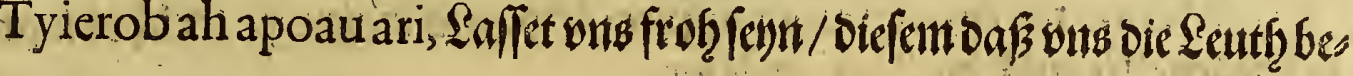

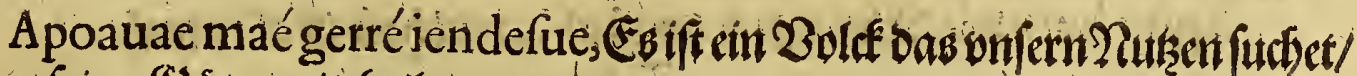
vito vinb feine Guter mittheilet.

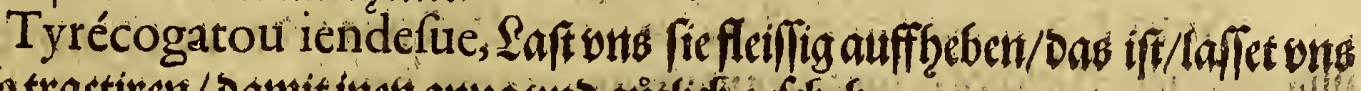

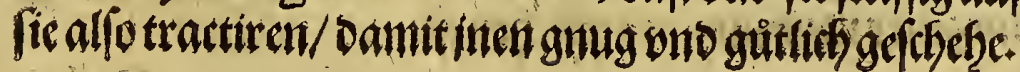

36 if . Iporene 


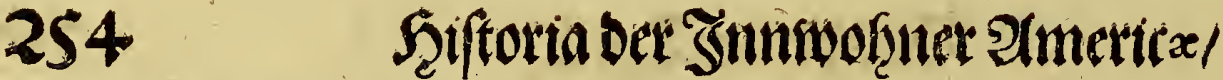

Sand.

Iporene éé-2m re-co iendefue, $\mathfrak{E}_{\mathfrak{b}}$ fompt whs ein herrlich facth bot bie

Ty maran-gatou apoaù-apé, Diefem Bolff laffen vns ons ergébent.

Ty momourou, mém ae gérre iendefue, Dafswir orm $\mathfrak{B o l d f}$ fein leio thuen/foons feitte 2 Babren zufübret.

Ty poich apoaue iendefue, Saffet onb inen Effenjpeip geben zulebert.

Ty poeraca apo aué, $\mathscr{E}$ affet vns flei bem iagroert fangen mogen. Das 28 ort Y porraca wiro gemeiniglict vom Sis

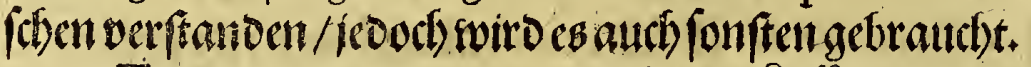

Tyreout mae ty ronam ani ape, Saffet wubif̨nenbringen/ soag foir bes fommen fôtutent.

Tyre comre moih-meiende-mae recouffa oue, Saffet vns bie nit bbel balten oie vits ires

Pé peróinh-auu-mecharaire oueh, Scitnidit fo versweb̨ntif̨e Rinoer.

Ta peré coih mae, 2luffoaßzir 2 Gaferc befommet.

Te recoih peraireamo; Ewer Finoer auch.

Nyrecoih ienderamouyn maé pouaire, $\mathscr{S}$ ir baben feint gutter bon wilrarn Borâltern.

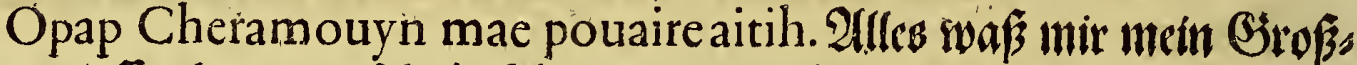

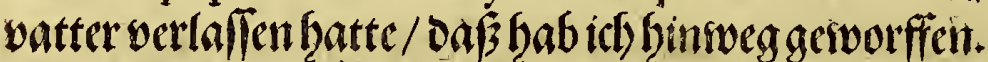
wirbt.

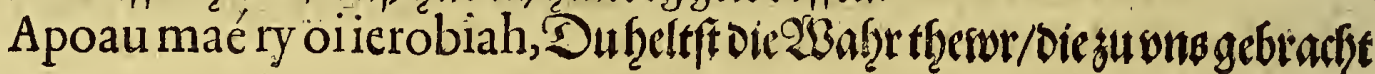

lenderamouyn remié piae potategue auo-acre, $\mathscr{Y}(\mathfrak{c l c h}$ eg/ obg fool bie

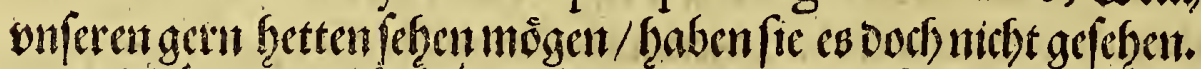

Teh oc otarhéré ienderamouyn recohiare eté iendefue. Dab if tecth/foviel befo beffer haben wirs/für vn/eren vorâltern.

Iendé porrau-ouffougerre, Das bringt $\mathfrak{u}$ woegen/baj soir fo groffe (Gârtenhaban.

En fafli piram, iendere meminon apé. (Es thut wnferen Rinoeren niçt mefresweterwennfie gef floten werden.

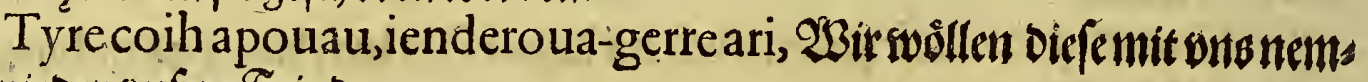
incrivieder onfere Feinoe.

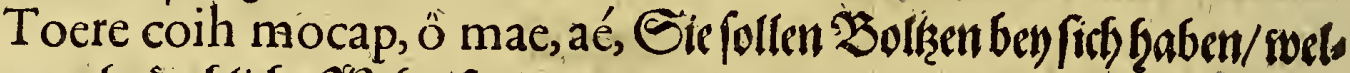

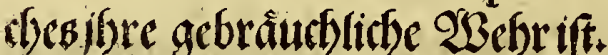

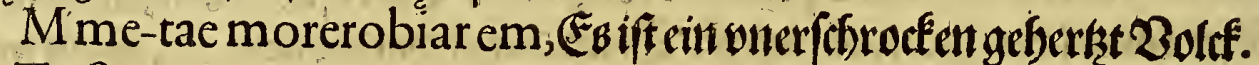

Ty fenencapouau, maram, iende-iron, $\mathcal{R a f l e t}$ ons fie Probiren, ftareffe/enen/wenn/te weroen bey ons/eit.

Ménré-taé moreroar roupiare, Siefino dielenige/folldbe bie anderen bofriegen/ iemlich oie Portugalefer.

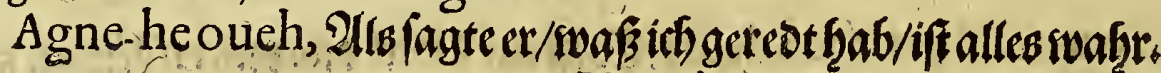

Tuppin.

Nein-tya-moueta iéndéré caffariri, Laft ons rebenvon benen bie ou

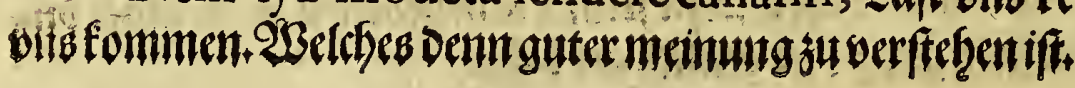




\title{
Das britte Thetl.
}

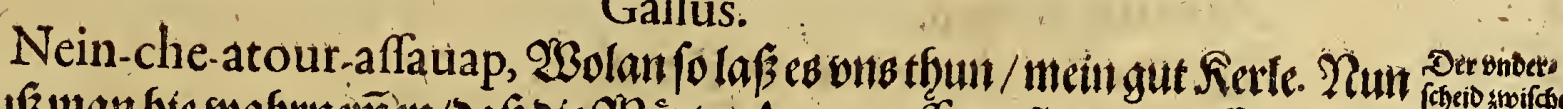
muß

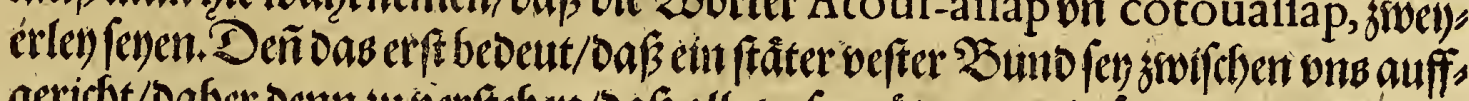

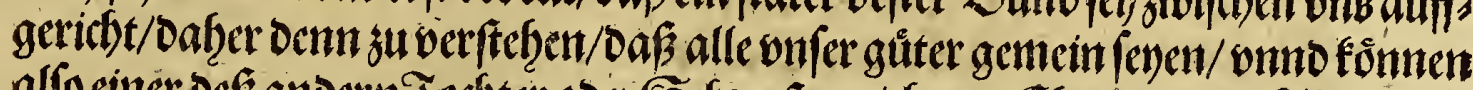

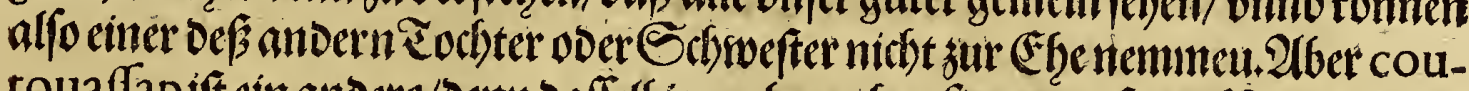

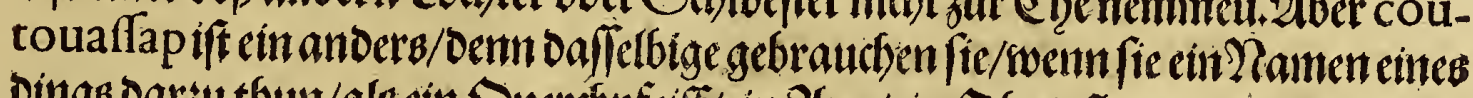

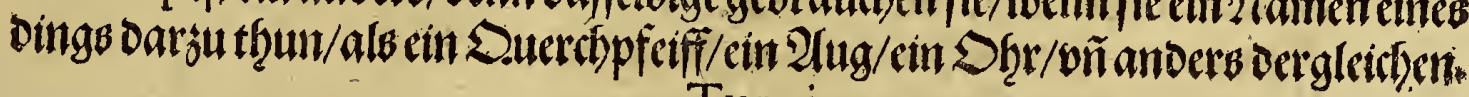

$$
\text { Tuppin. }
$$

Maié-reffe, iende moueta : Zon wellden swôllen fwir reden? Gallus.

Sceh macrouem-reffe, $\mathfrak{B}$ on vielenvito mandferlen bingen Tuppin.

Mara-pieng vvah rere?:3ienennet man oen Shimme?

Coelum, Şinmel.

Gallus.

Tuppin.

Gyh-rengne taffeuouh maetirouem defue.

Augebe, Rectht.

Gallus,

Man, oer Simmel.

Tuppin.

Couaraffi, oic Somite.

Iafce, ber SYionat.

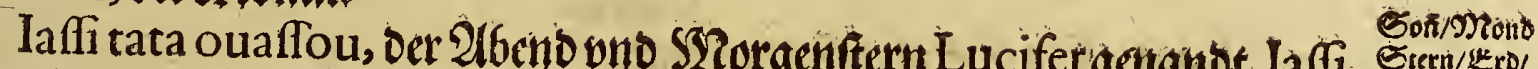

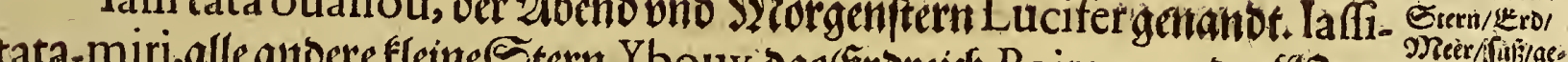
Vh bie Sifliffleut nennen Summague.

Itaif in feppin.

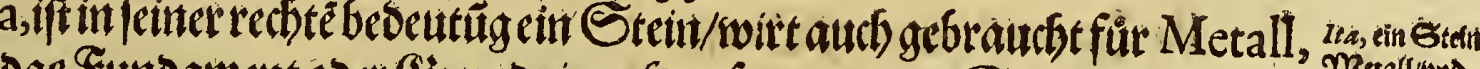

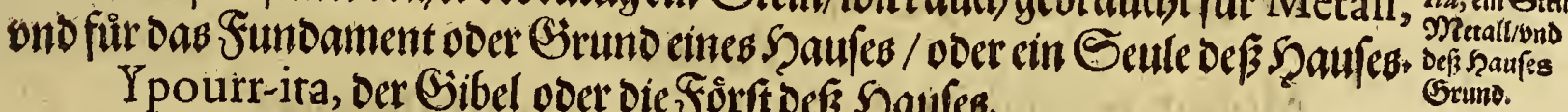

Ypourr-ita, der Sibel oder bie Fortet der Şaules.

Ioura ita, bie $\mathfrak{B a l c f e n}$ am Şauls. Igourah oder ybouirach, allerley Solls,

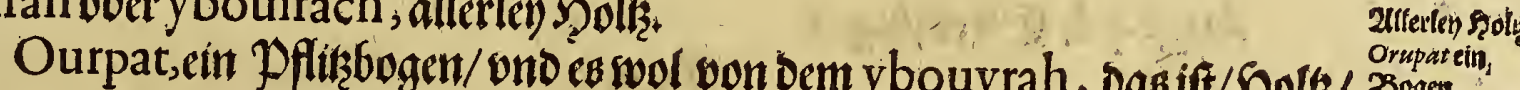

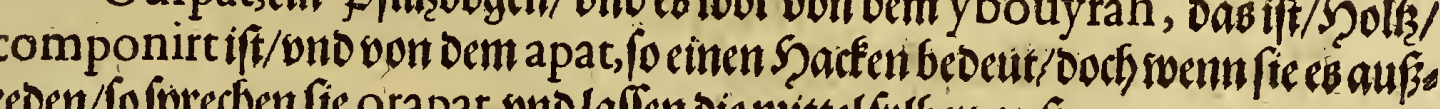
reden/fo/precben/ie orapat, ond laffen die nittel folben aufis.

Arre, bie \&ufft.

Arraip, $6 \hat{\text { ôf }} \mathfrak{Q} \mathfrak{u} f \mathrm{ft}$.

Amen, cin $\mathfrak{i e g e n}$.

Amen poytou, cin Siegeria.

Tou.pen, der Donner.

Toupen verap, iftoer $\mathfrak{B l i}$.

Yori-hu, $\mathscr{B}$ olden ober $R$ eiffer.

\author{
\$6 iif Ybueture
}


256

$28 \mathrm{crg}$

LEG fald.

Ybueture, Sicbirg.

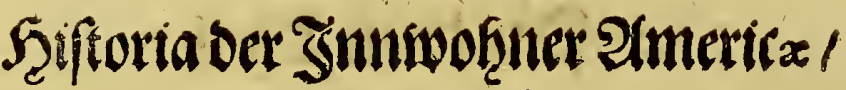

Quum; Ebenfelo/bafeine $\mathfrak{B}$ ergfinto.

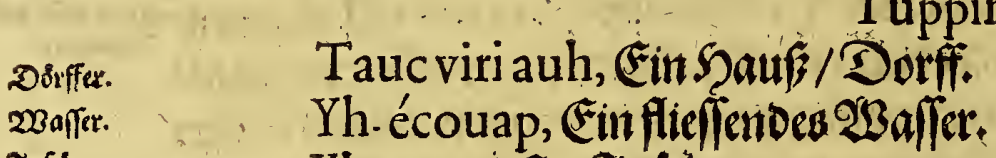

Infat . Yh-paou, Eim Jinfel.

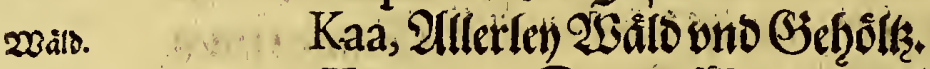

Kaa paou, Der im $\mathfrak{B}$ alb ift aufferzogen.

Der đeuffel. $\quad K a a g e r r e$, ift ein Ecuffel Der Fie vbel plaget.

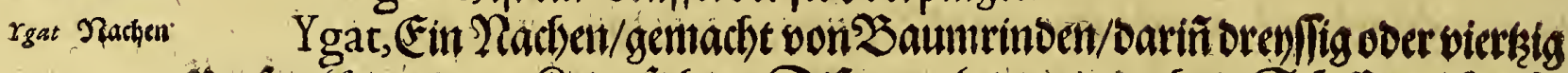

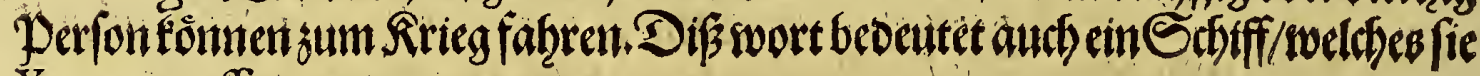
Yguerrouffou nennen.

fifchgarth

Pouiffa-ouaffou; (Ein Fiffrgarn.

lnguea, (Fin grofler $2 \mathfrak{B}$ eid ling.

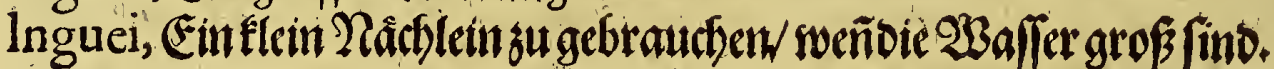

Tuppin.

Nomoquot, mactaffe nomi defue, Sieber nente mir nichts mefbr.

Emourbeou deretam iche füe, Pede nun von beinem $3 a$ atterland wn won ocitter wobnung. Gallus.

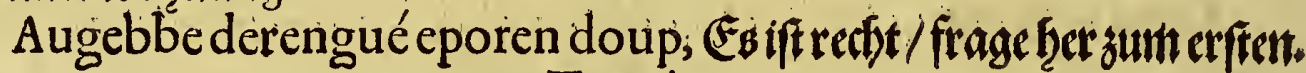
Tuppin.

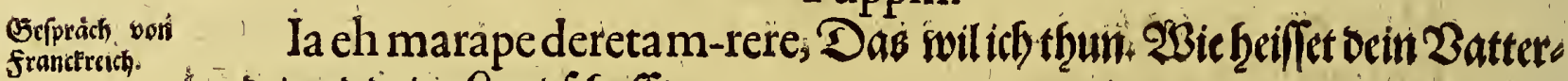
land/ond decine Eand fchafft.

Roan, Ein Stattin Frandfreict).

Gallus.

Tuppin.

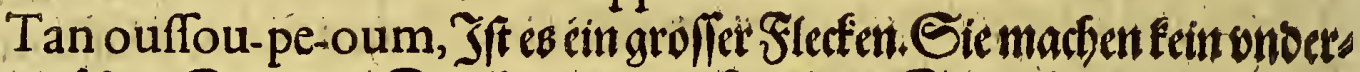

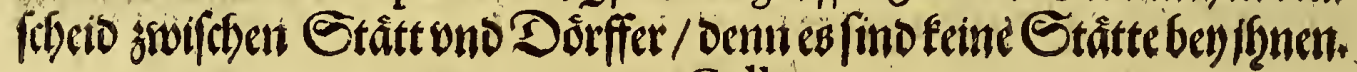
Gallus.

Pa. Jacsifteingroßß Dorfi.

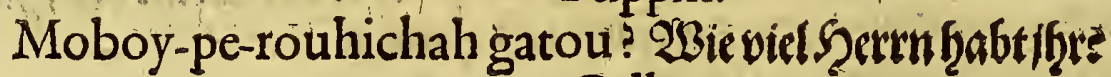

Augé-pé, Ein cinkzigent.

Gallus:

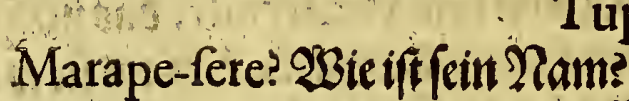

Tuppin.

Gallus.

Henricus.

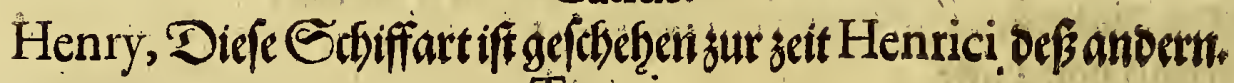
Tuppin.

Teré-porreè, Dasift ein hecrtlicher $\mathfrak{i a m}$.

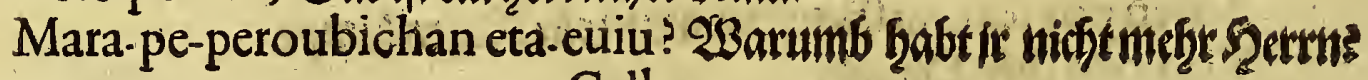
Gallus.

Moroére-chih-gue, 2Birf̧abenjf̧ret feinemef̧r.

Ore 


\section{Das britte Thatl.}

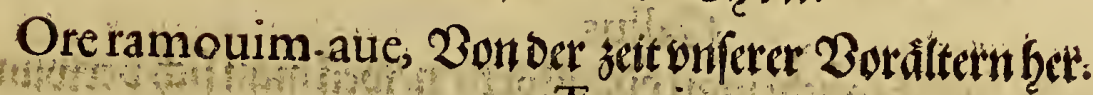

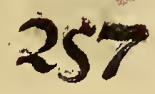

Mara pienh pee?gras thut ifuppin

20 oth Furifith uns Droentget

Gallus.

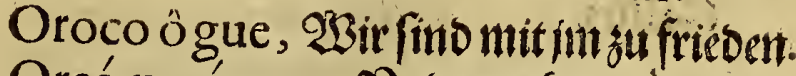

Oreé. maé-gerre, 3 no cegefit wniswol.

Tuppin.

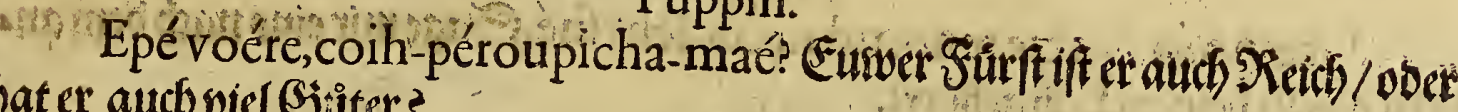
hat er auth wiel Giater?

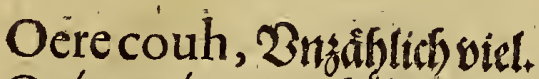

Gallus. ơufbaltem

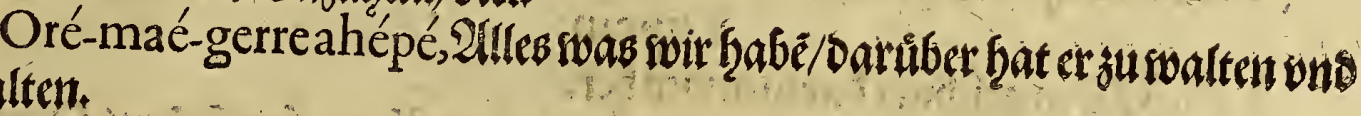

Tuppin
Oriuijpe ogépé? Zeugt erin Rrieg.

$\mathrm{Pa}, \mathfrak{J a}$.

Gallus:

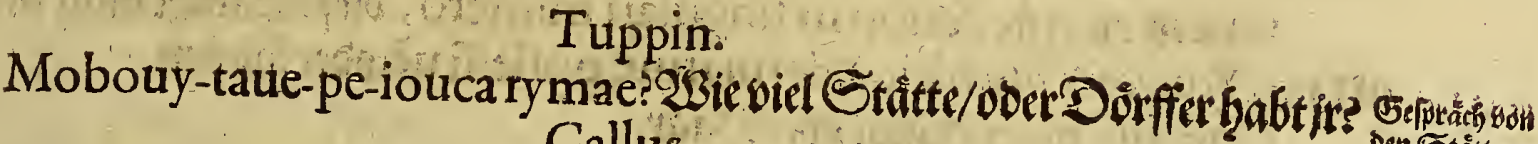
Gallus.

Setà-gatou, Slithredennich fagenfant.

Tuppin.

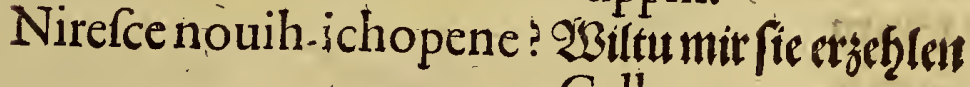

Gallus.

Ypo icopouy, Dag swurbe wiel sulang.

Tuppin.

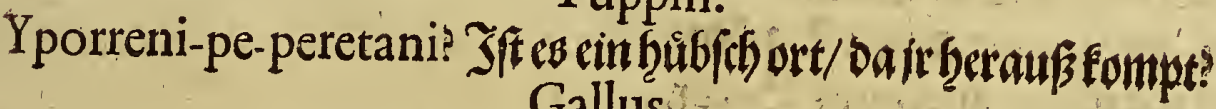

Ypóren-gatou, Garar cin fauber bing.

Tuppin.

Eugaya-pe-per-auce, Sind êtuer Shăifer soic pic onferen?

Oicoe-gatou, Ef fefflttweit, Gallus.

finofic bente Tuppin.

Ita-gepe, Sie fino gar Steinern.

Gallus.

Touroufou-pe, Eino ficgrofs?

Tuppin.

Gallus.

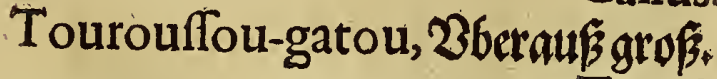

Vae-gatou-pe, Sinofieferbrf̧odf? 
Das britte Tferil.

Ché-puyac, mein SYagen oder \&eber.

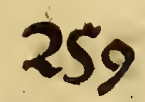

Ché-reguic, meit $\mathfrak{B} a u t(l)$.

Ché-pourou-âffeu, incin $2 a b$ cl.

Ché-cam, meine $\mathfrak{B r a j}$ tet.

Ché-oup,mein Shúfifte.

Ché-reduponam, incin Sinie.

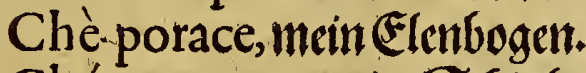

Ché-retemeu, mein Echinbeint.

Ché-pouy, mein Fur

Chè puftempé, mein 2 ẩgel an ben Fífien.

Ché-ponambe, mein $\mathfrak{R} \mathfrak{a g e l}$ an ben Singern.

Ché-guy-encg, meint Sictrįund \&unge.

Ché-encg, mein Secl vore Giomùt.

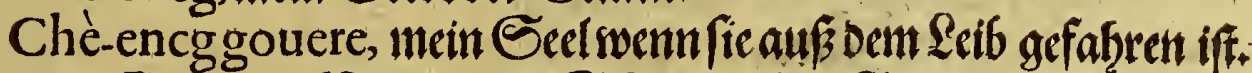

Ché-rencouem.

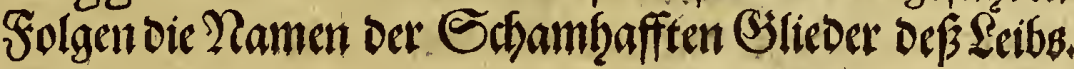

Ché-rementien.

Ché-rapoupit.

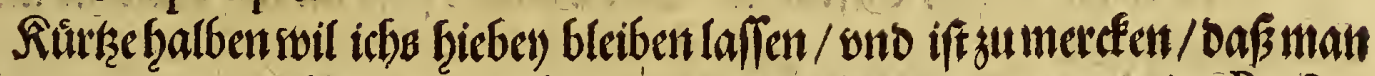

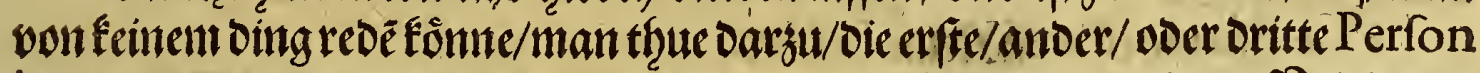
in vtroque numero, das if / man reve von vielen oder swenigen. 2 nd damit

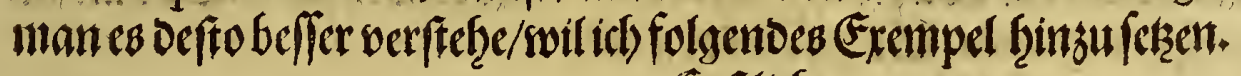

Che $\Im \mathfrak{s} / \mathrm{De}$ D $w$ / Ahe Det. (Erfitict).

Bonvielen.

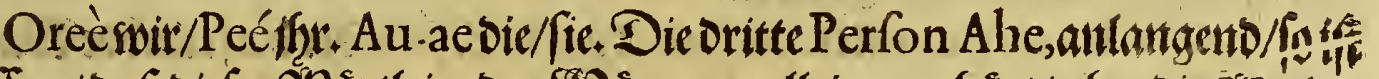

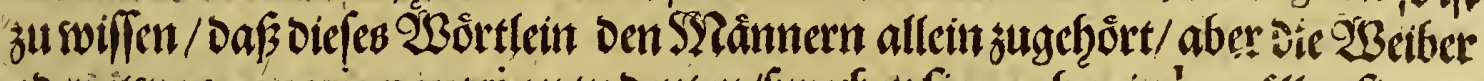

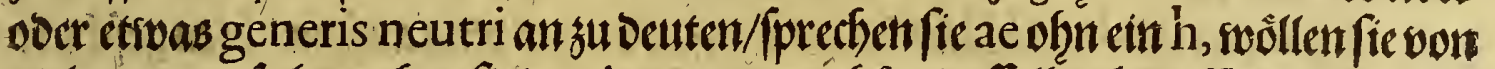

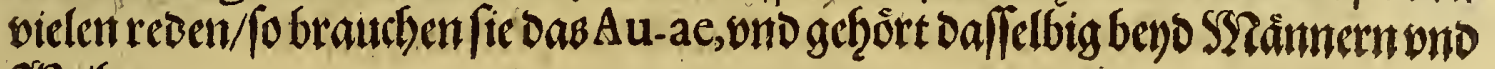

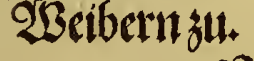

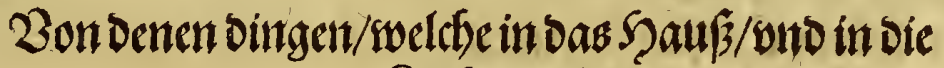
Rưchen gethôren.

Emiredu-tata, macht ein Ferwer.

Emo-goep-tata, lejthe bag Ferwer auf;

Erout-che, tata-rem, bring zunber/ baunitman Feswer an marfit.

Emog.pira, fod die Silfh.

Effeffit, Grade.

Emoui, fiede.

Fa vecu-ouy amo, mach SqRefl.

Emogip caouin amo, mact baß $\mathfrak{3}$ Getraintf.

Coeie vpé, gefé zumi Brumnert.

Erout-v-ichefue, f̧olmir $2 \mathfrak{B a f f e r}$.

Che-remi augepe, gib mir zutrindfen. 
Das britte Theil.

5261

Pagntan in ber Grammatica nenntet cinVerbum, oefleltgenentuen bie verbumitioes

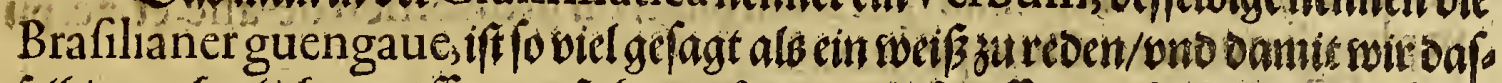

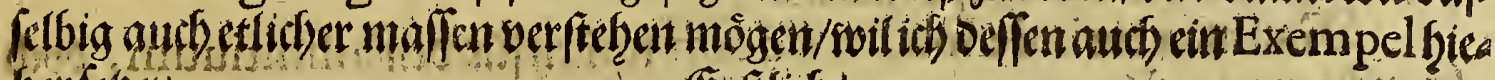
har fercet. bift. Oicoserift.

Singulariter Indicauèaut demonftratiuè, Aico iff bill. Areico ou

Pluralis,

Oreico warfino, Peico fter $\{$ end . Auraéoico biefind.

Dic oritte Perfon in fingulari on Plurali nnmero fino einantoer gleich/

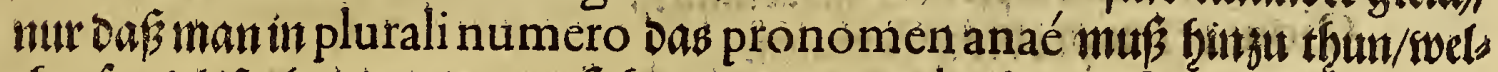
ches fo viel if als/oie/ rwieman ficht in oem praterito imperfecto numerifin. gularis, Das man refoluirt mit bem aduerbio, aquoéme, Damals.

Aico aquoémé, Damals war ith.

Ereícoaquoémé, damals wareftu.

Oíco aquoémé, damals rwar $\mathfrak{r}$.

Oroico aquoémé, bamals waren wir.

Plurale imperfectum,

Poico aquémé, Damalswaretiffer.

Aurae-oico-aquoéme, Dantals woaren fie.

Propraterito perfecto Singularis,

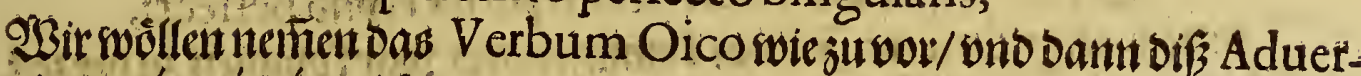

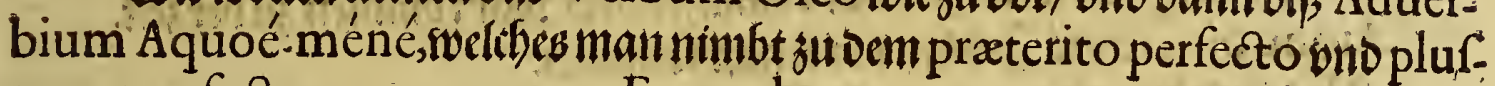
quamperfecto.

Exemplum,

Affauouffo-gatou-aquoéménè, Jch hab in bamals rect tgeliebt zut bet: scit. Quo-uénén-gatou-tégné, nuin aber mit nichten 2 (ls ob ich fagte/ ar folte

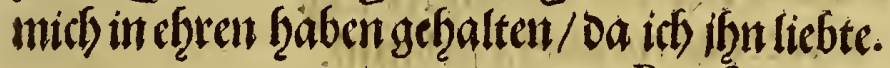

Pro futuro,

A co-iren, Ied wero hernacher fenen/ond alfo fortan in allen Perfonis beys fingul.ono plural.

Oico, fendu. Toico, fet $\mathfrak{e r}$

In Imperatiuo;

Pluraliter,

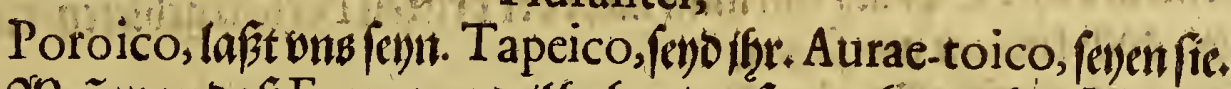

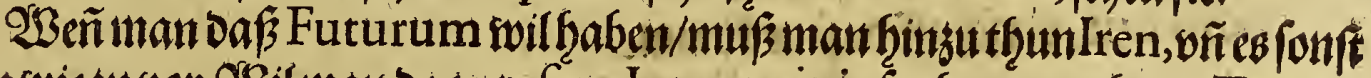

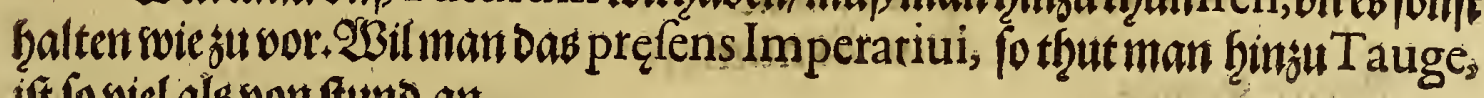
ift foviel ald von ftund an.

$$
\text { Pro Optatiuo, }
$$

Aico-mo-men, Jch mer gern/wno fo fort an. Der optatiuus foirt refol. uirtmit Dem Aduerbiolron.

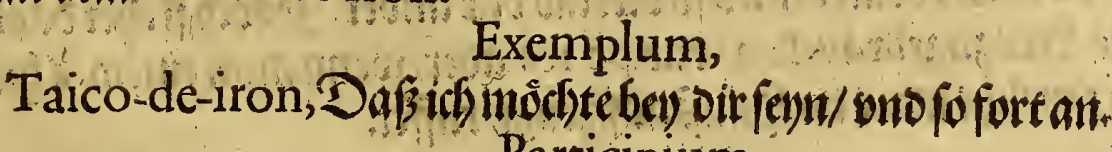

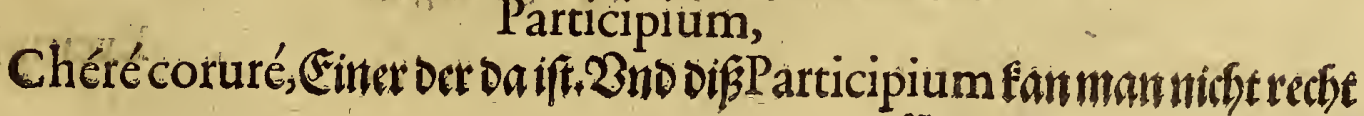

$$
\text { So if allecin }
$$


Dasbritte Thetl.

Exemplum Optatiui, Iftooch foft rwic cin Imperatiuus.

Aiout Singulariter.

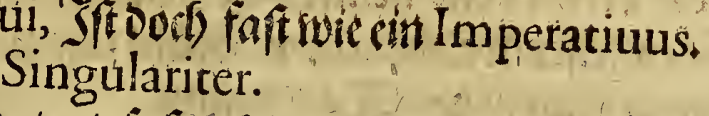

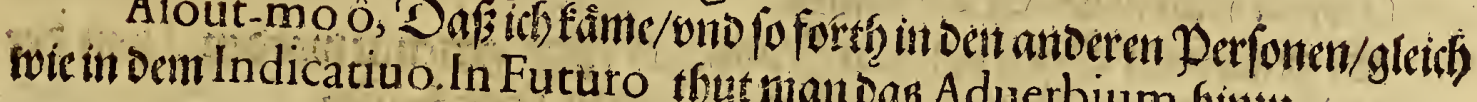
Eit Exeninel ocf Coniunctiui.

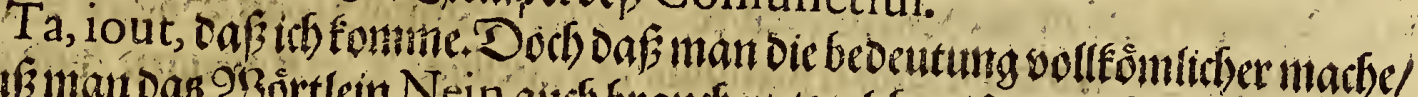

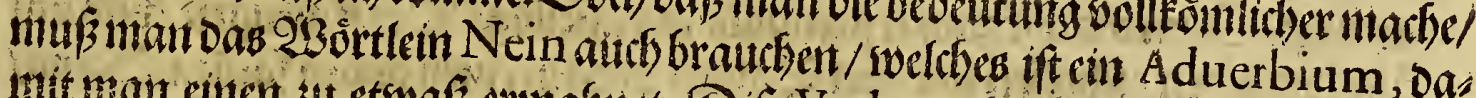

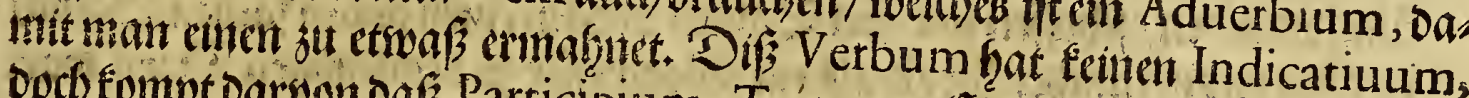
ooch fompt daroon oaf Participium, Touume Einer ber bafompt.

Che-roúrme-affaua-nitin. Ein Excmpil.

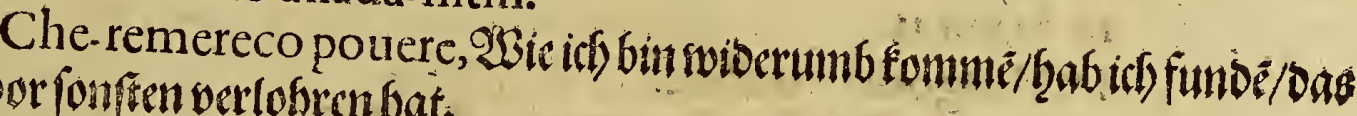
(if) jubor fonfon oer lohren bat.

Sonoyt-pé Hirude, Ein Saugêe.

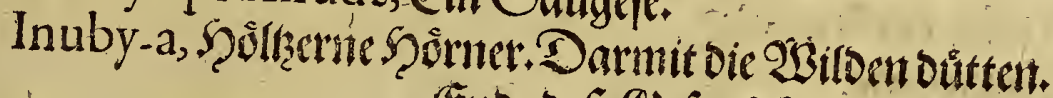

Enoedef Bjejprâthb.

$$
\begin{aligned}
& \text { Ende de } \\
& \text { (c) of Ganabara. }
\end{aligned}
$$

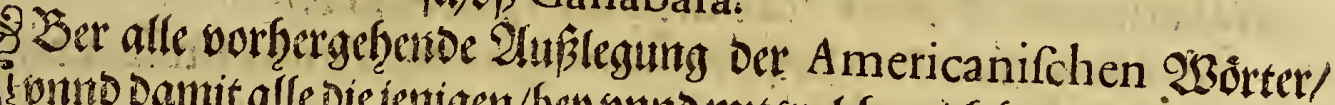

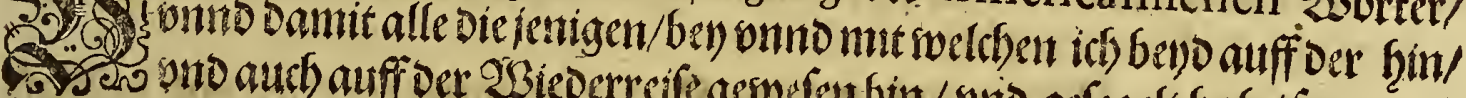

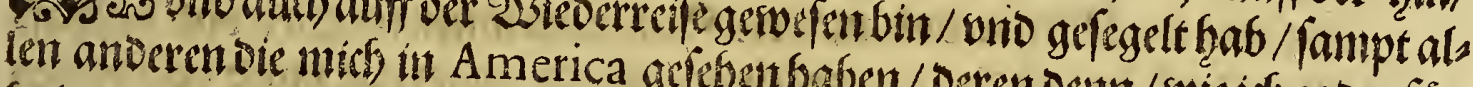

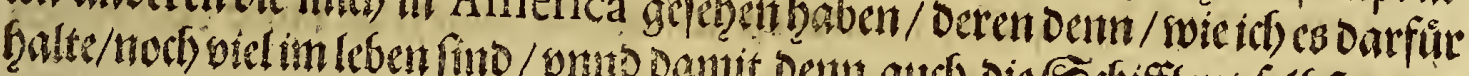

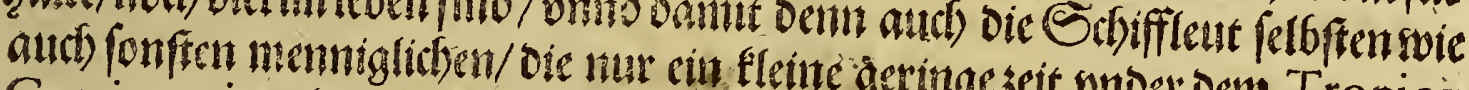

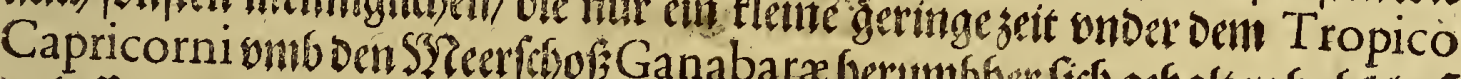

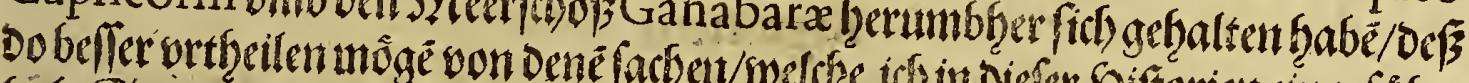

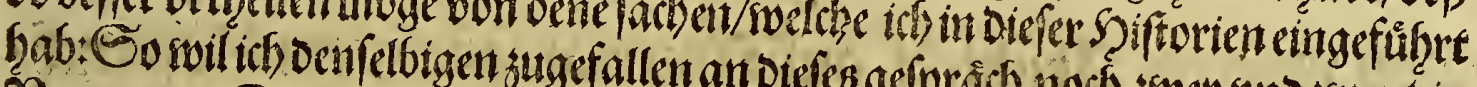

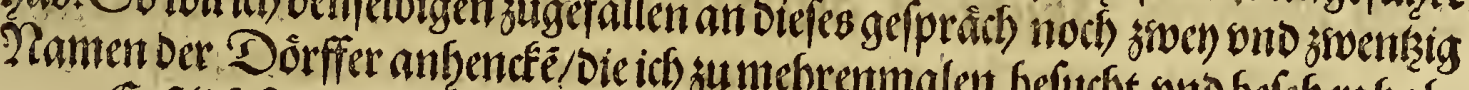

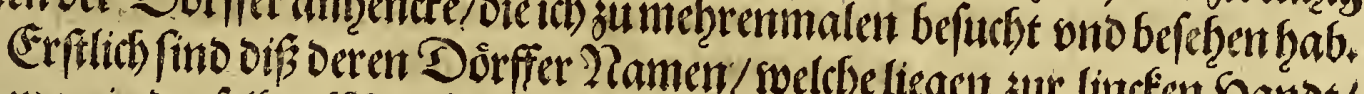

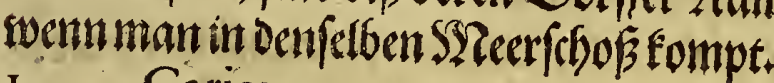

I. Cariauc.

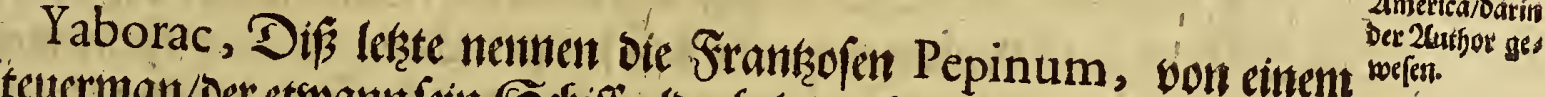
Steucrman/oer etroanmpein Eethifi alda beladen f̧atte.

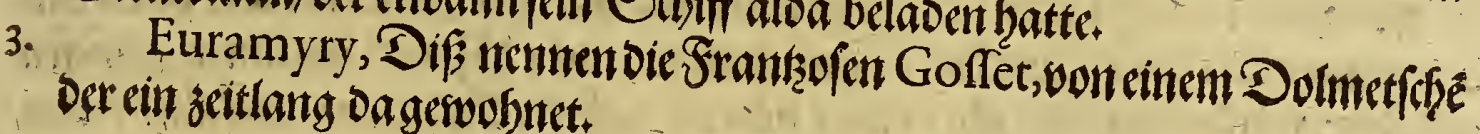
4.Pira-ouaffou.

5. Sapopem.

6. Ocarentin, Das aller Iuftigfte Dorff.

7. Oura ouaffou oueé,

8. Temimen.

9. Cotiua.

Io. Pauo.

II. Sarigoy。

Sc iif $12+200$ b 


\section{Dasbritte Tręl.}

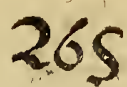

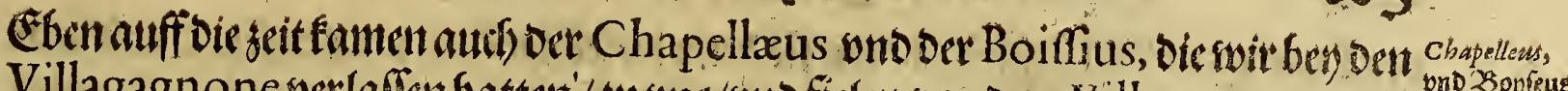

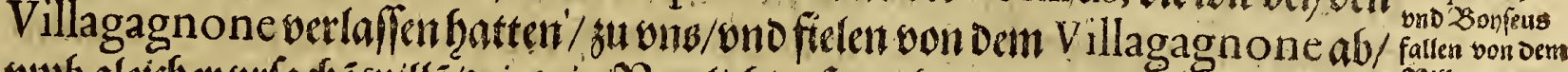

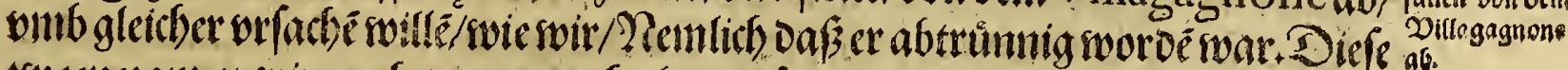

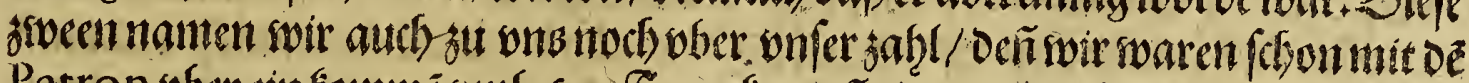

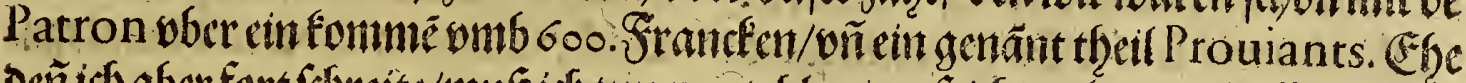

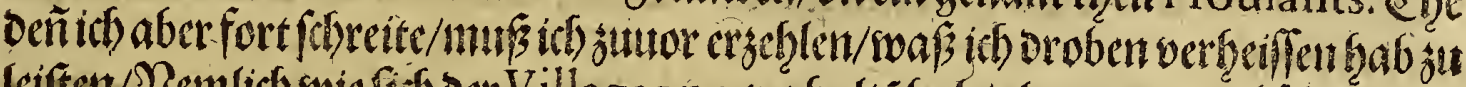

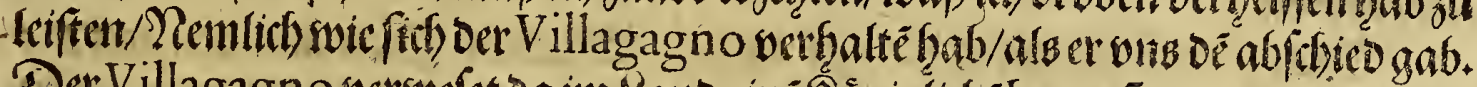

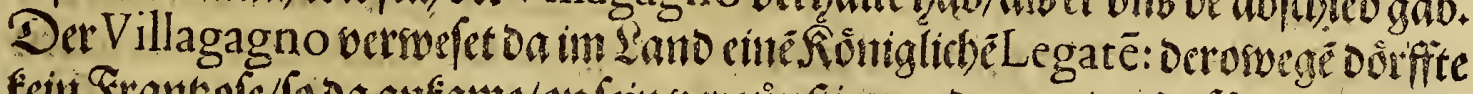

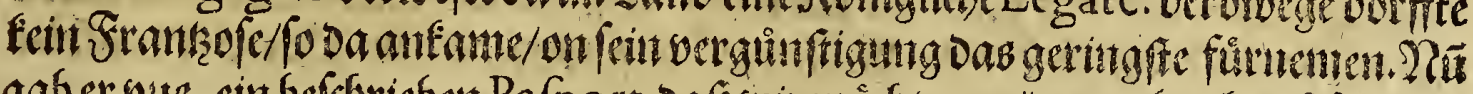

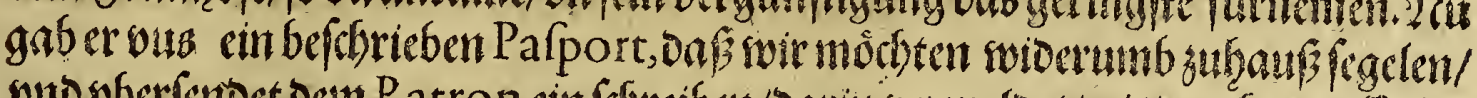

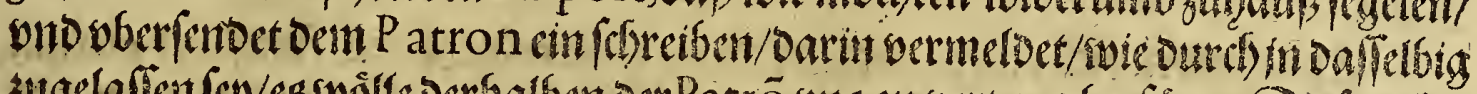

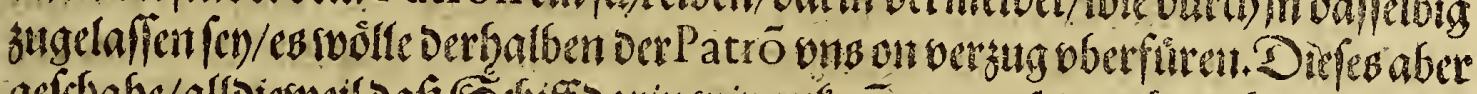

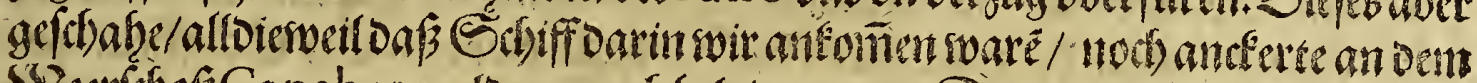

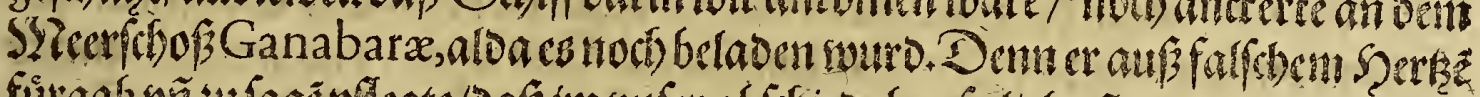

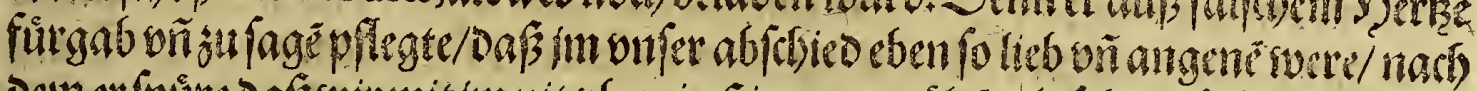

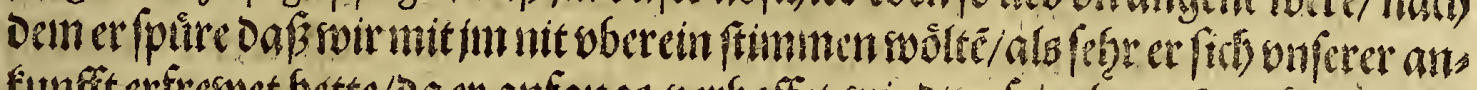

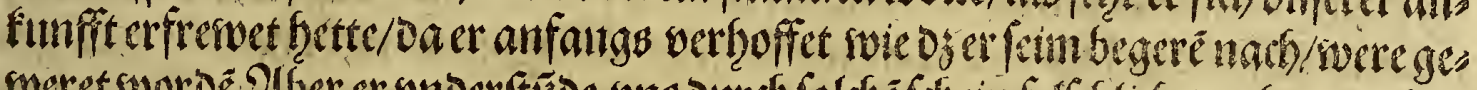

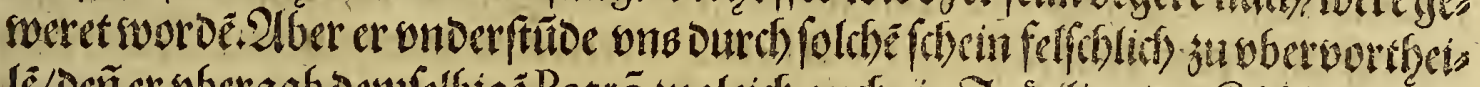

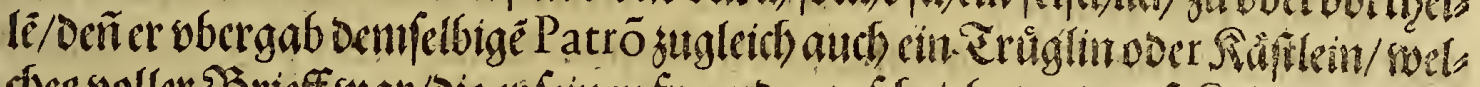

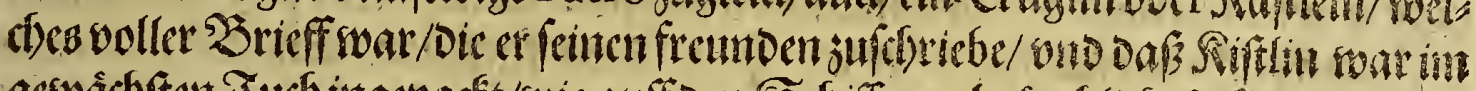

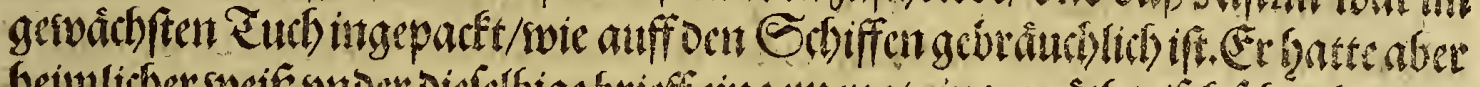

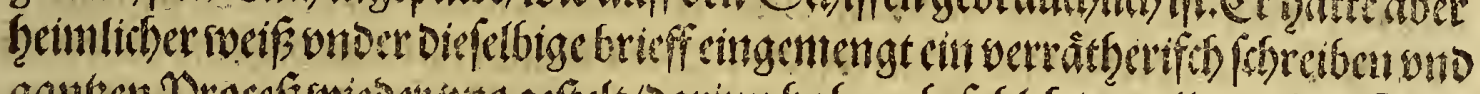

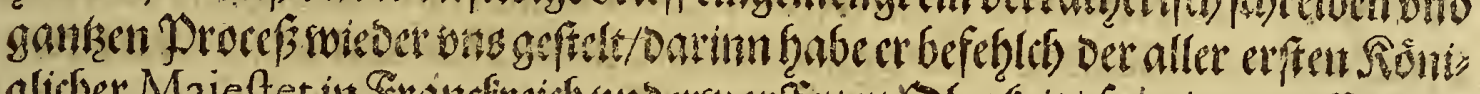

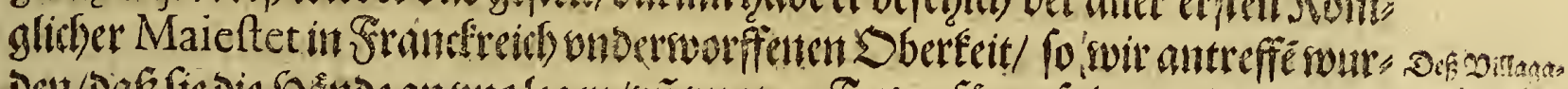

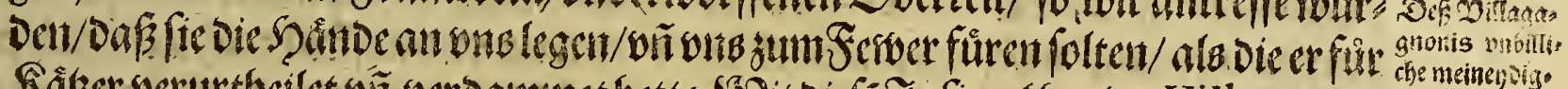

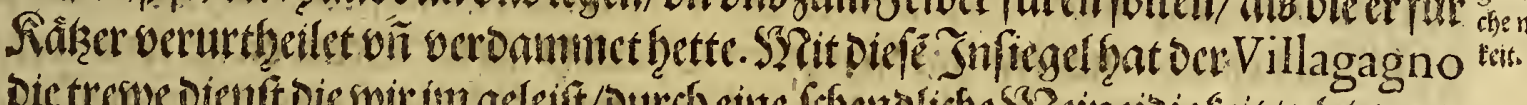

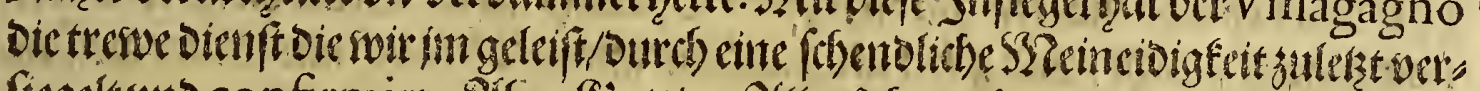

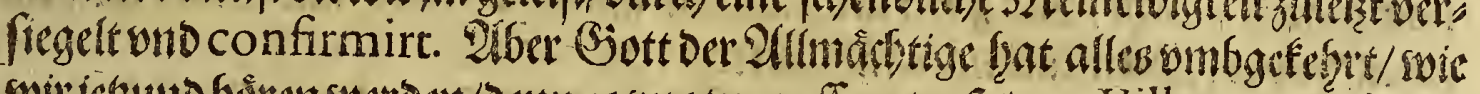

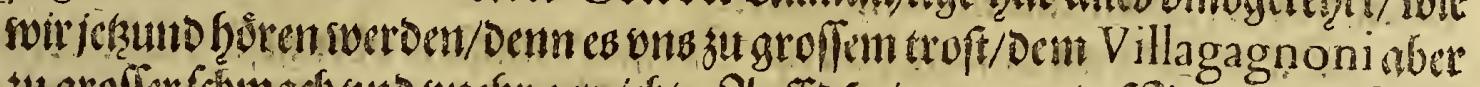

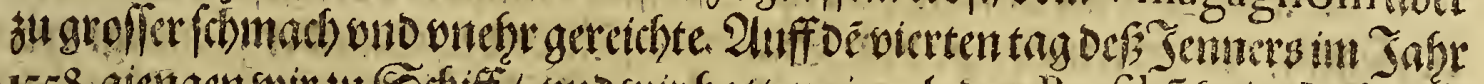

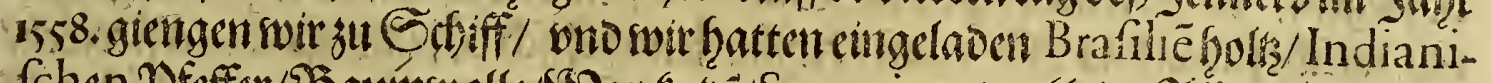
fchen Dfeffer/Saumwolle/SYeer

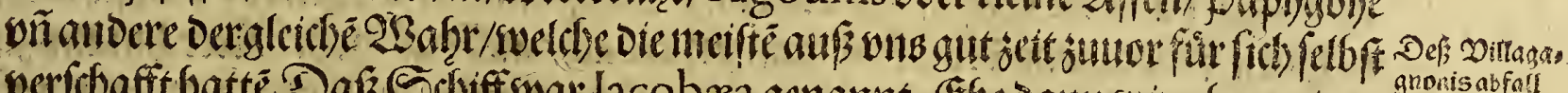

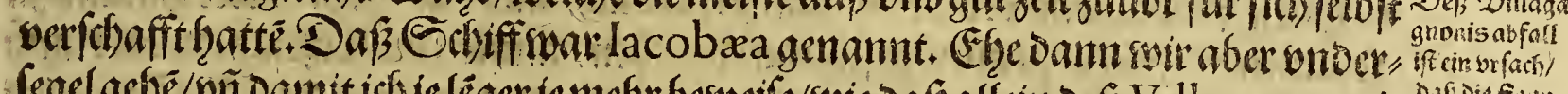

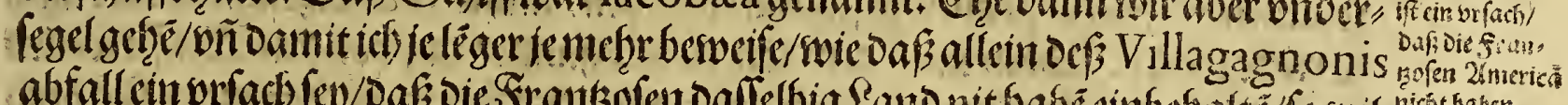

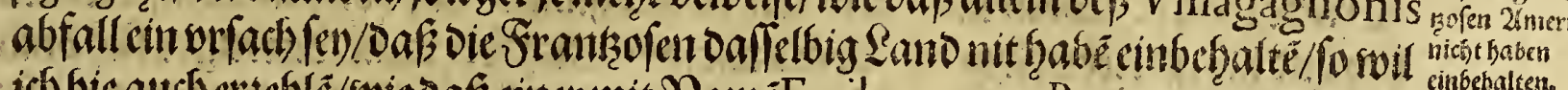

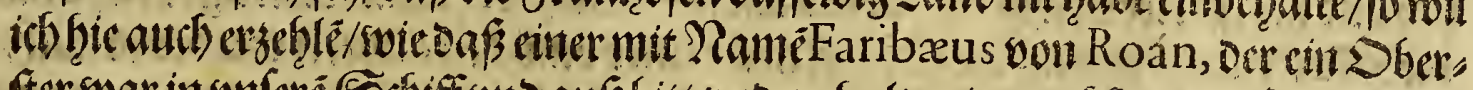
fter woar in wnlere Echiff ond anß

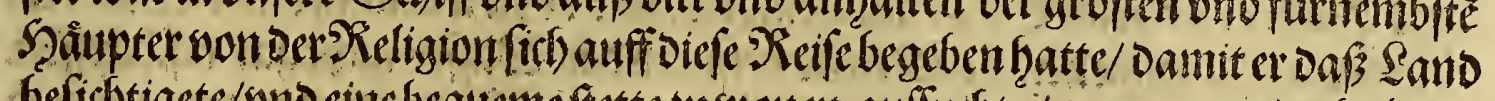

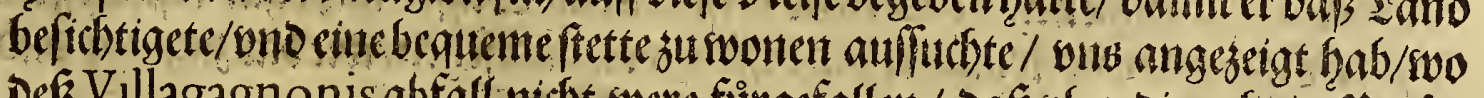

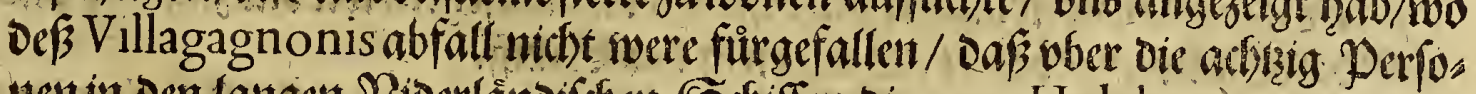
nen in ben langen Yiderlanoifoben Erbiffen die man Hulcken nemet / bets

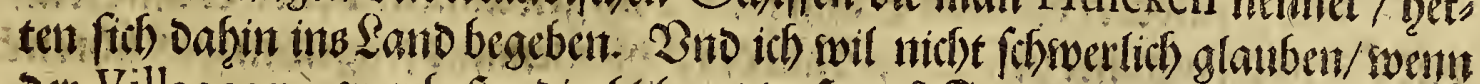

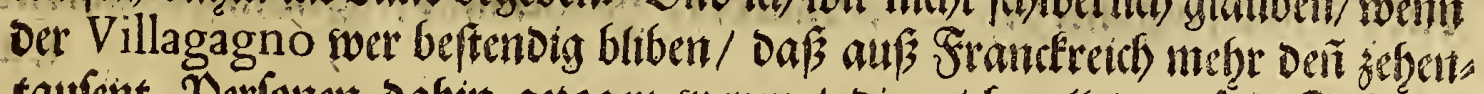

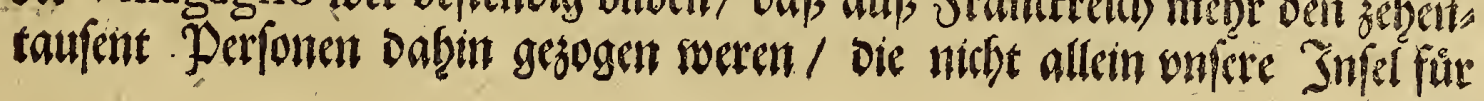

bers 


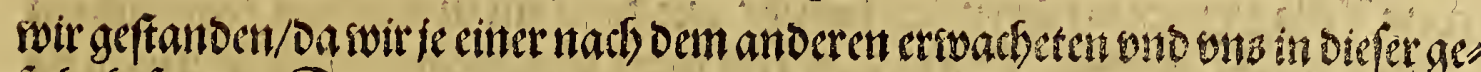

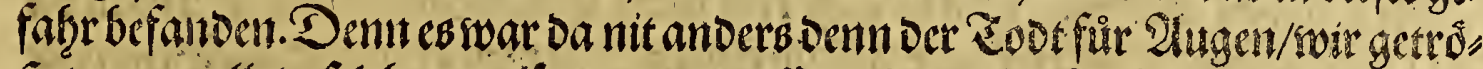

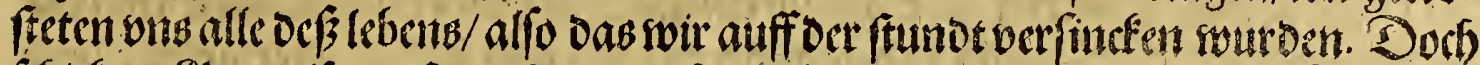

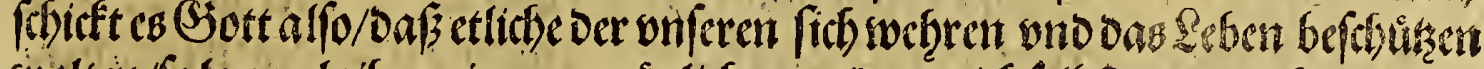

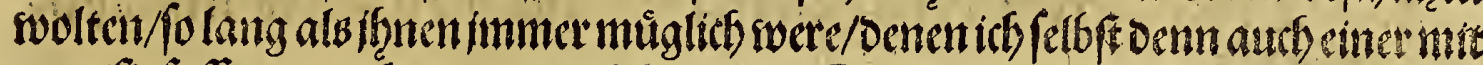

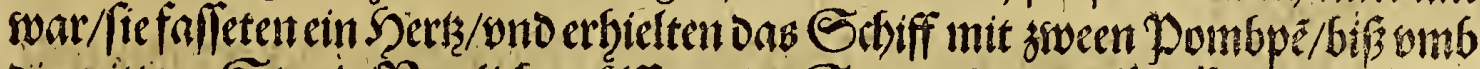

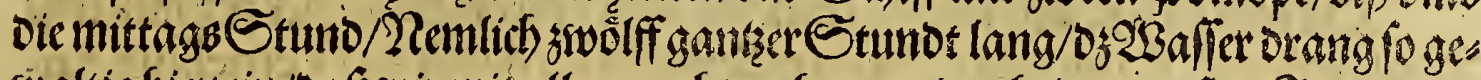

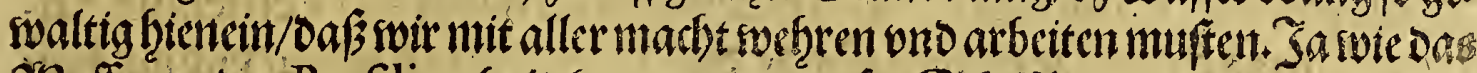

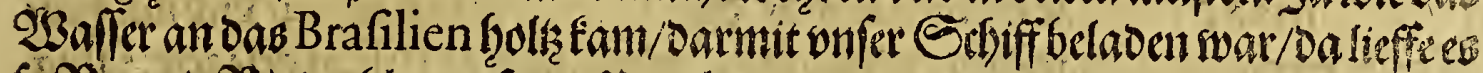

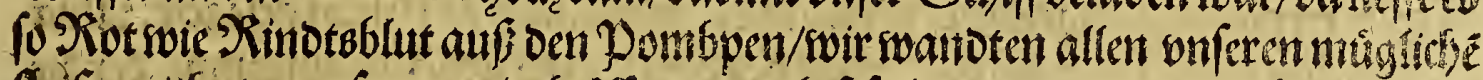
fleif an/thaten on/ere gantecteriffe oar

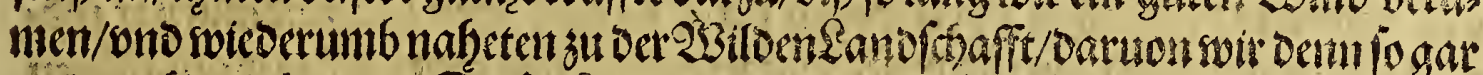

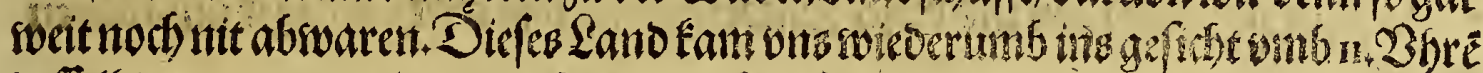

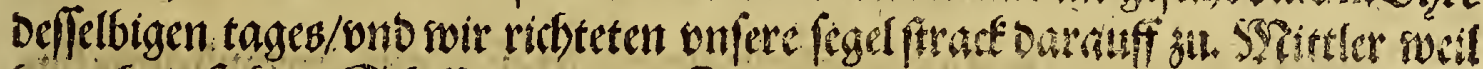

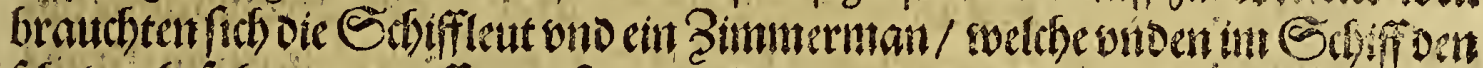

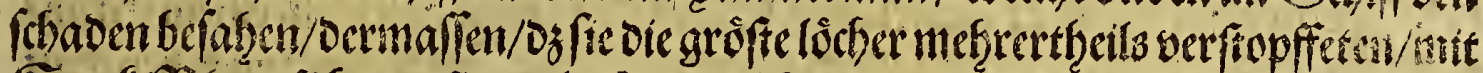

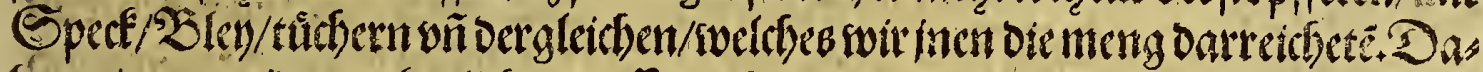

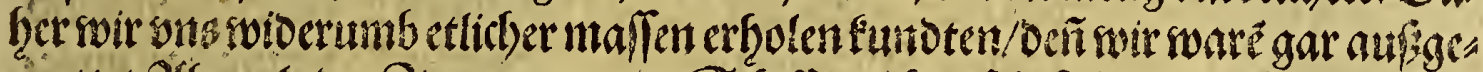

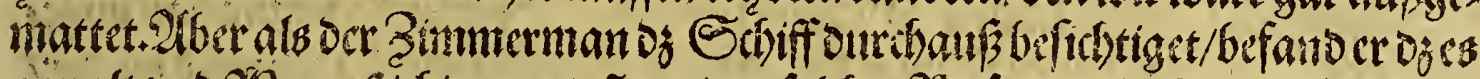

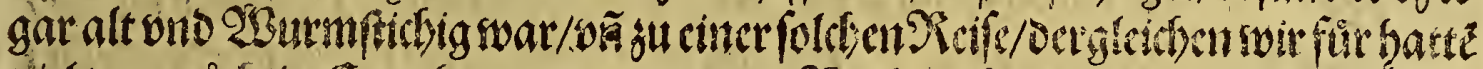

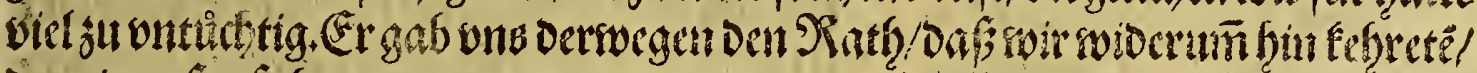

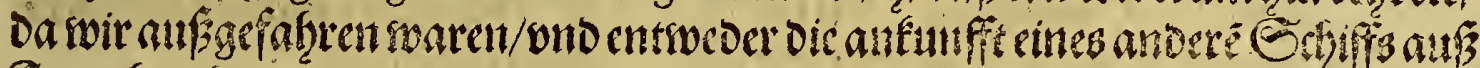

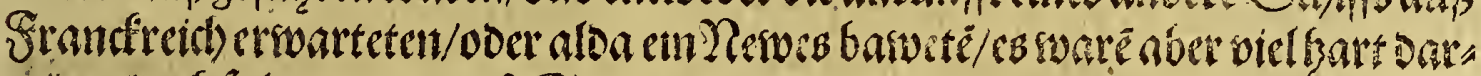

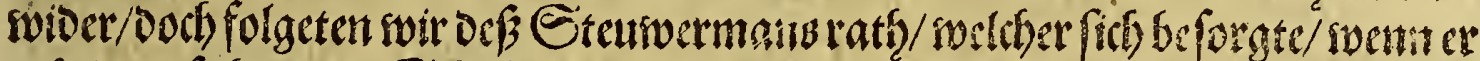

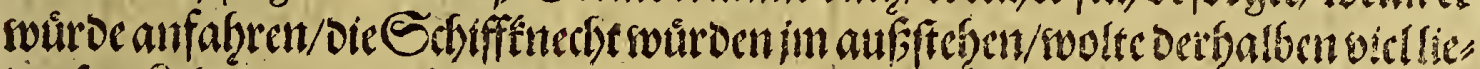

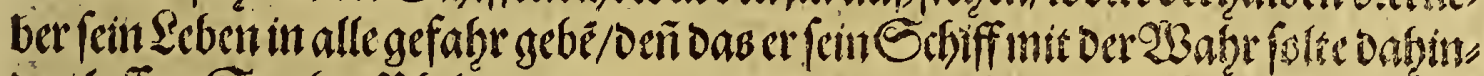
oenlaflen. So aber Philippus ono anocrewirorrmb in Americam bigesen/

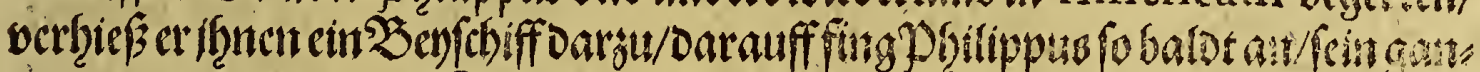

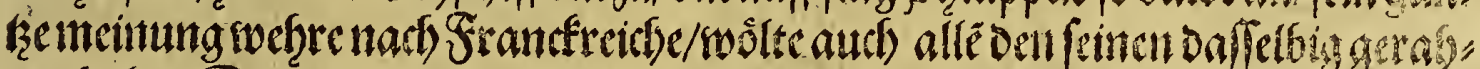

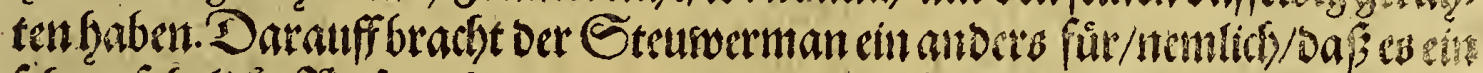

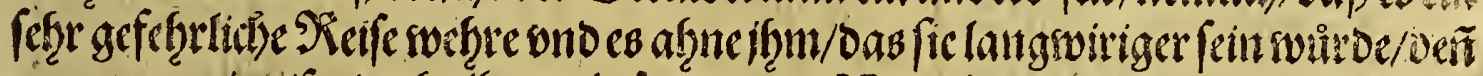

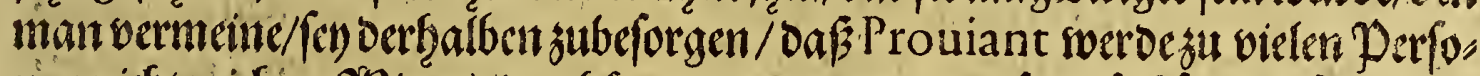

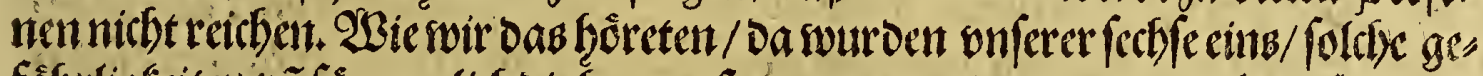

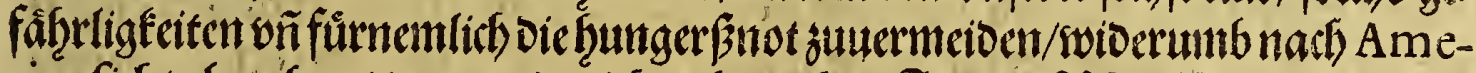

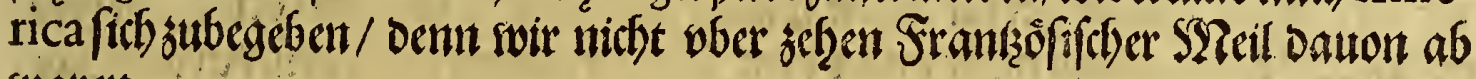
waren.

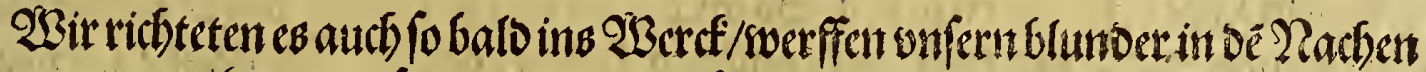

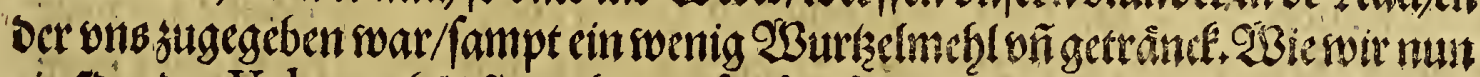

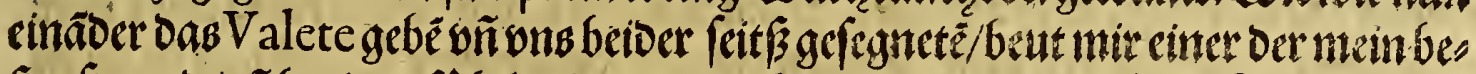

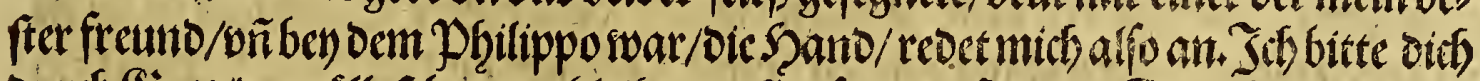

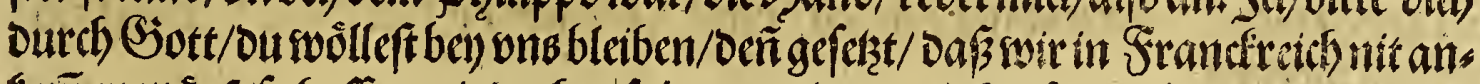

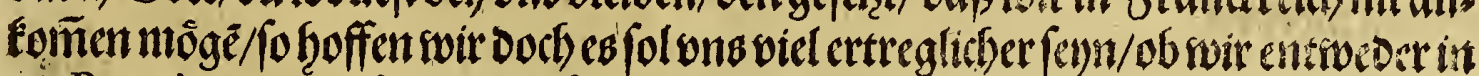

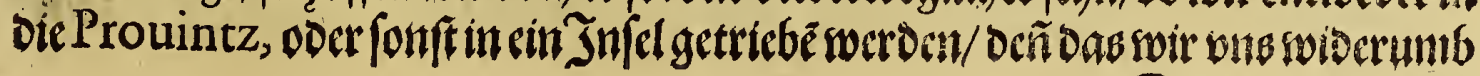


Das brifte Thatil.

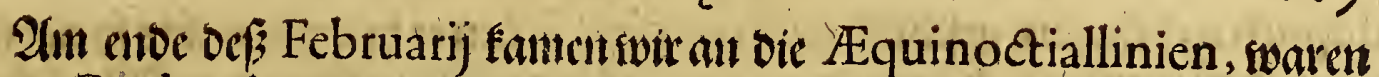
mur orey Grad noch oavon/ weil swir aber albereit funffisig tag auff oer fabrt ges

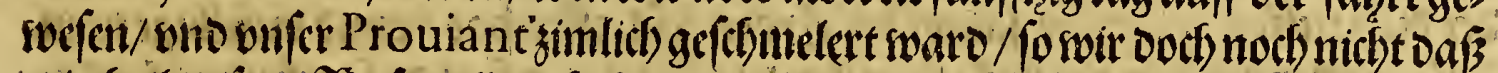

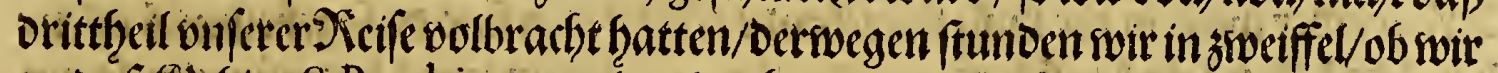

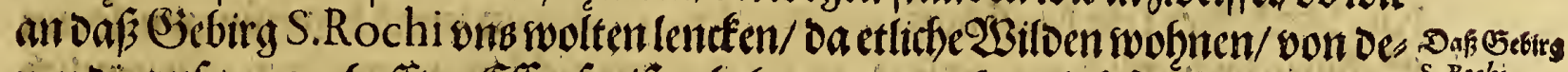

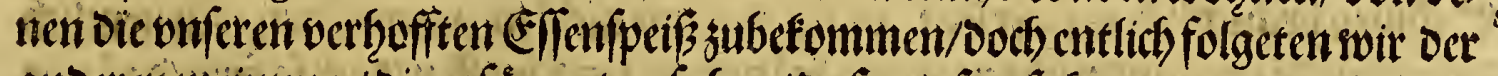

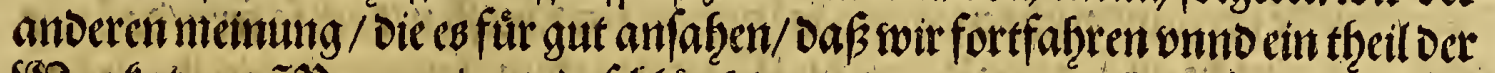
SIectfaken oñ Papygoien toot febliggé/Darmit wir mit oemProuiant ocfto befs fer butâtmen.

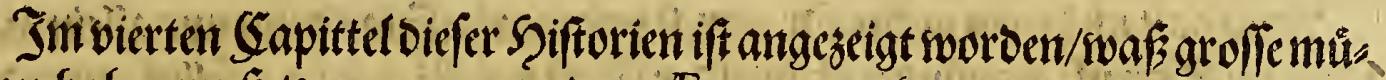
be man baben mus/soem man zu Dem Equatore fompt / soeil ich aber num feloft erfaftern/Daf eben fo argoarzu ift zufommen von oem Polo Antarctico,

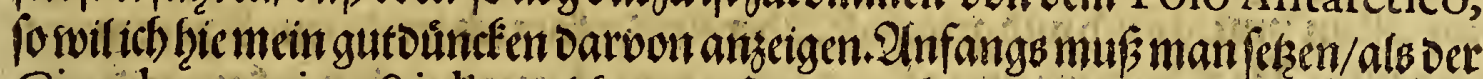

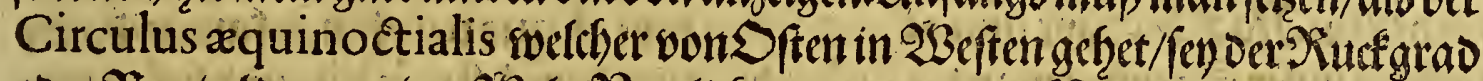

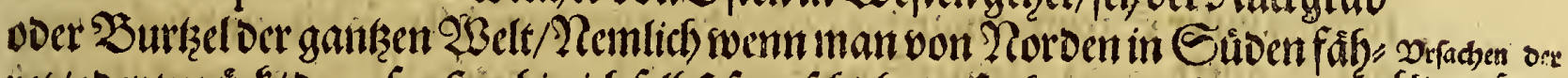

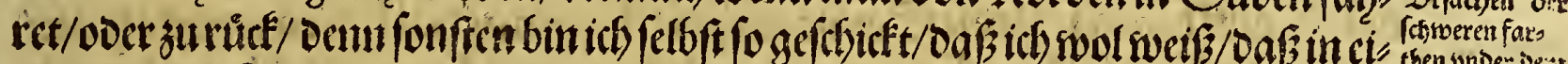

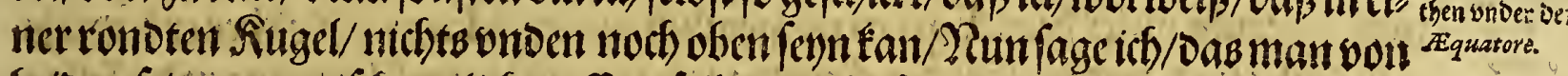

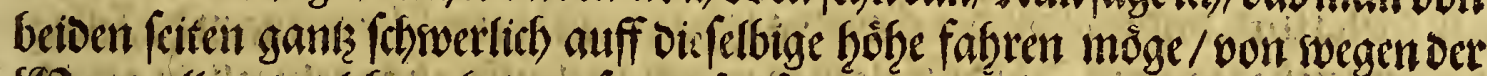

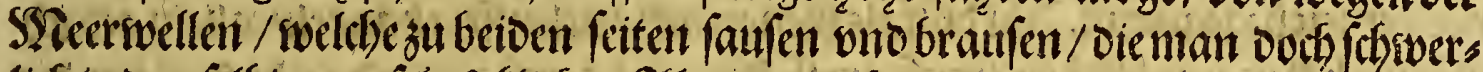

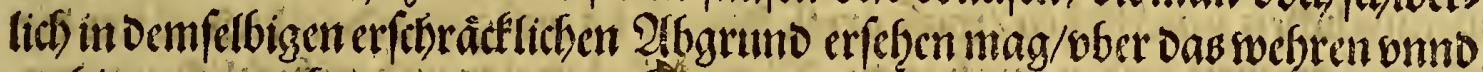

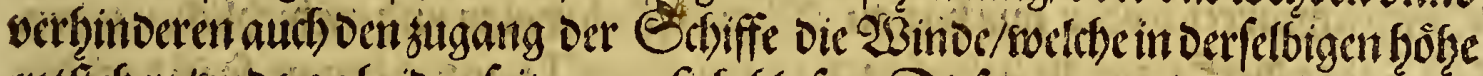

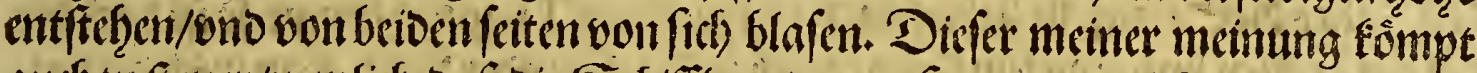

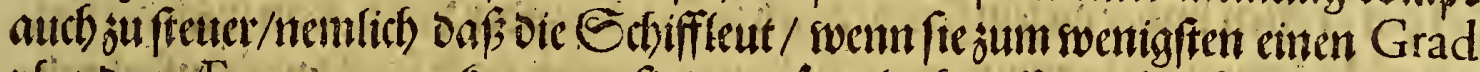
vber ben Equatorem fommen fint / eb fen gleich auff weldher feiten es foolle/

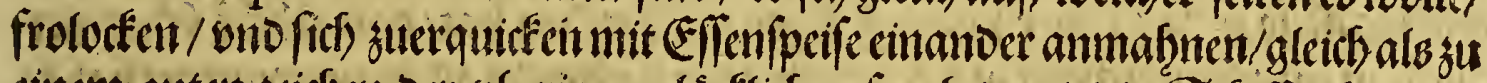

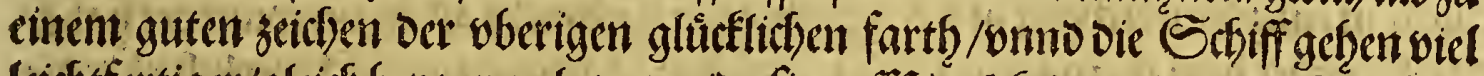

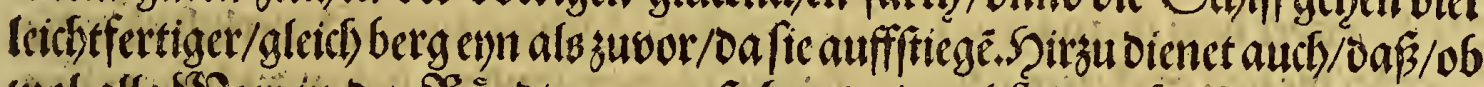
sod alle SYeer in ber Sionde cmpor ftehen (swieswol fie Durch swutberbarliche

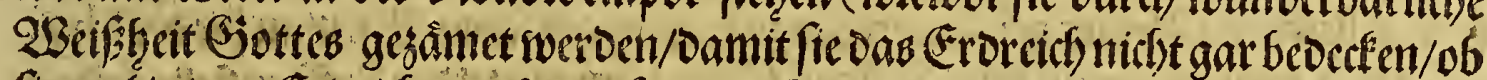

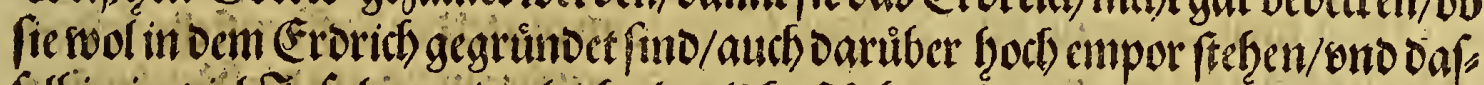

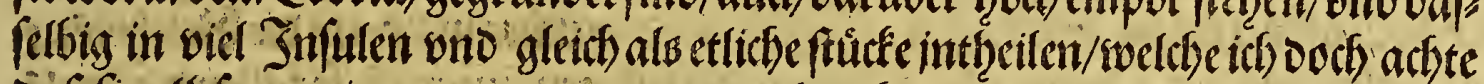
Dafs fie allefampt im grunt aneinanoer gehenten/we mit etlicten Fafelen ober

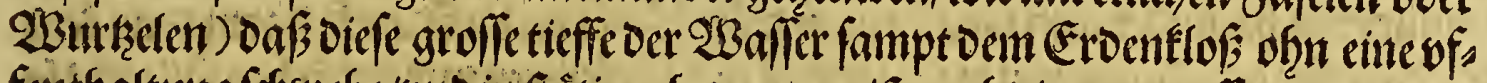

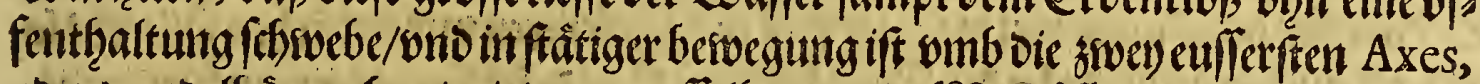

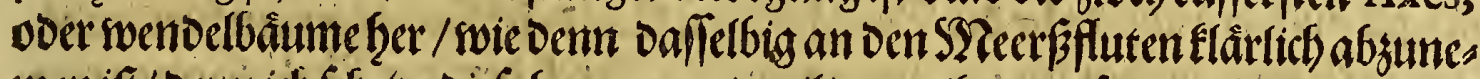

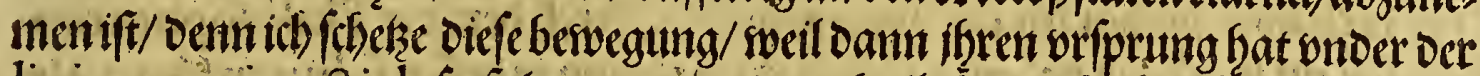

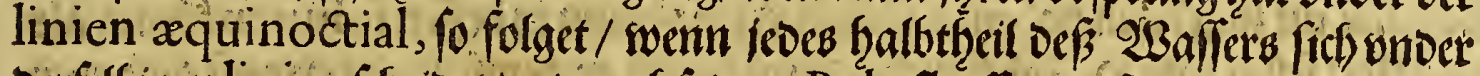

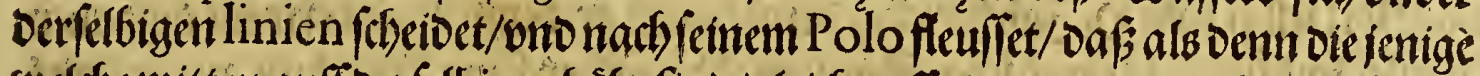
soelche mitten auff oerfelbigen hed he fino/gleich auffeiner swagen/Deftolenglamer ficf beswegen onb fort su fommen vermogen. (Es Dienen auch hiersu/swie ich) fon

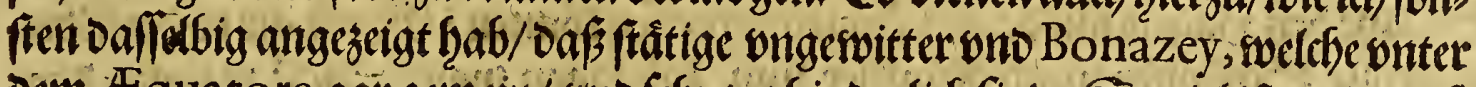

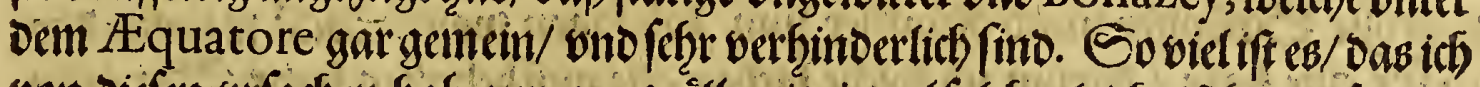

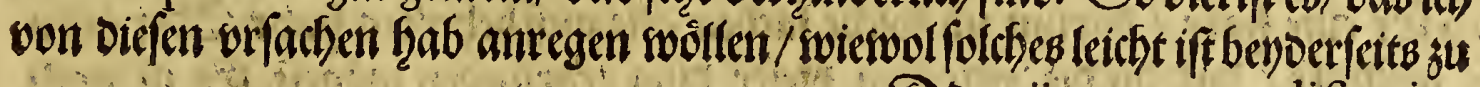

$$
\text { Do i difputirn }
$$


Das britte Tferil.

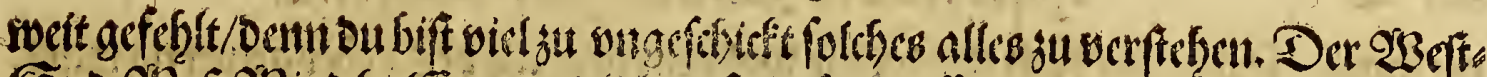

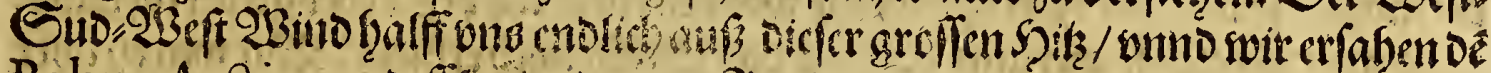

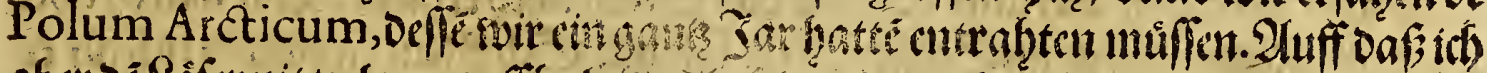

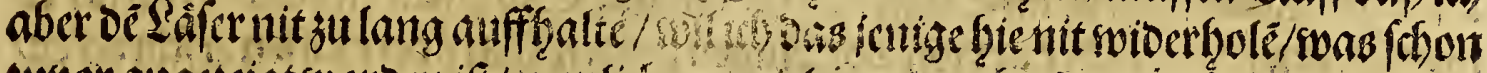

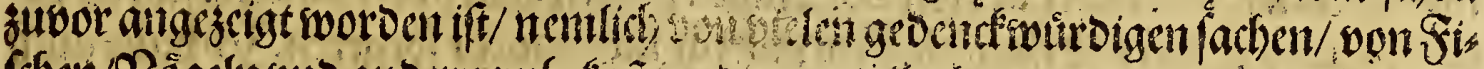

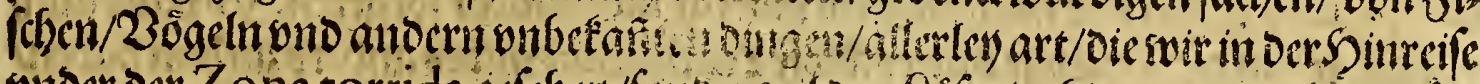

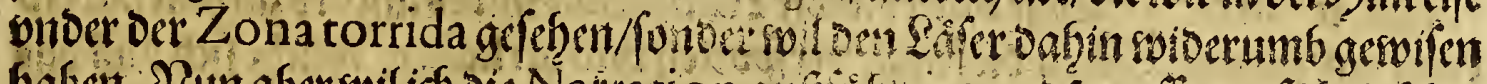

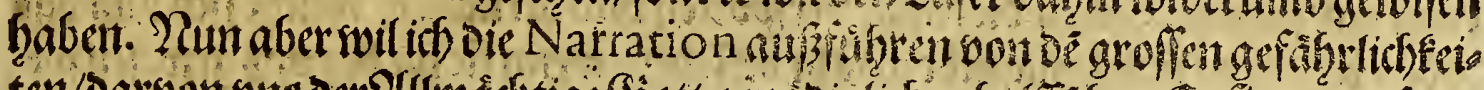

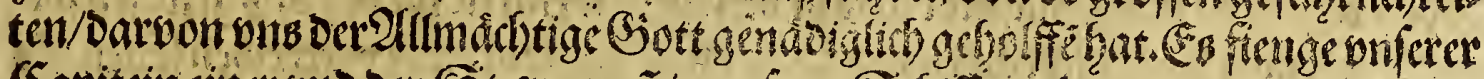

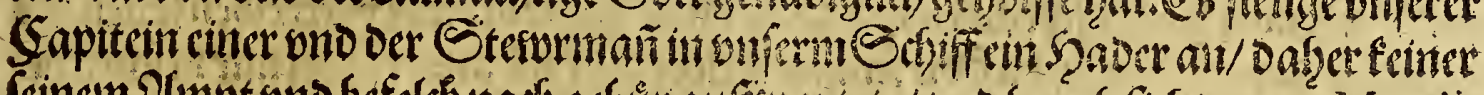

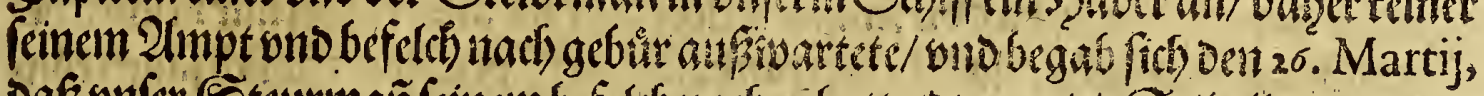

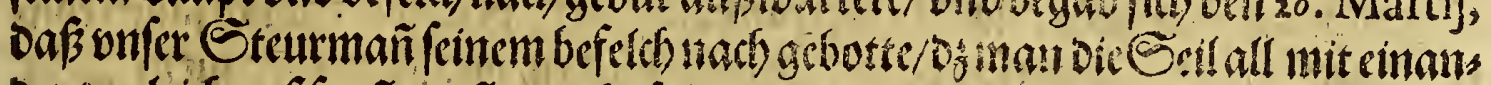

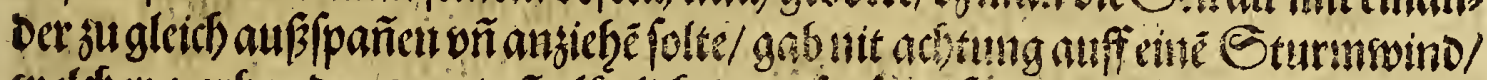

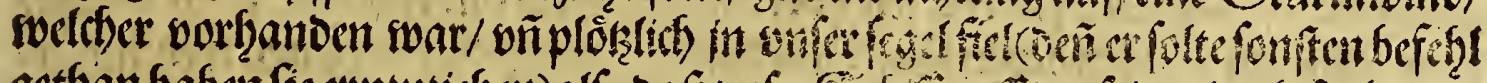

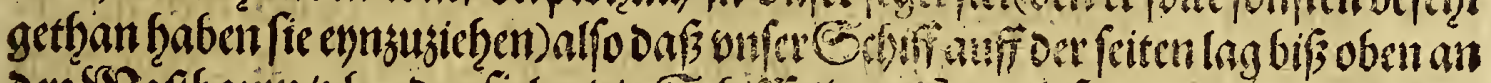

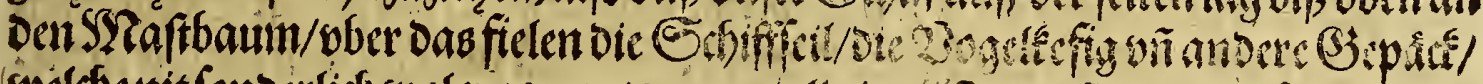

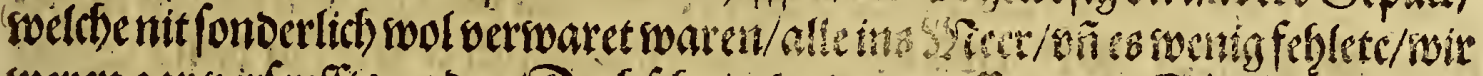

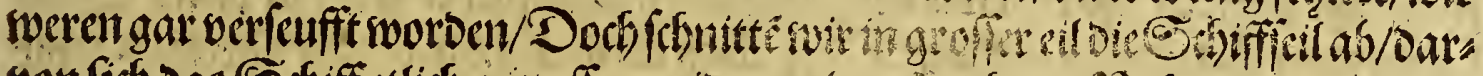

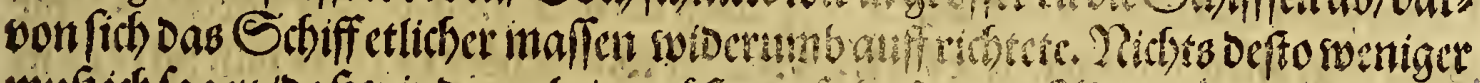

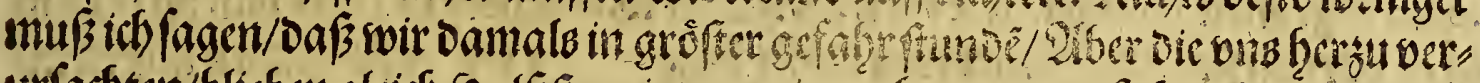

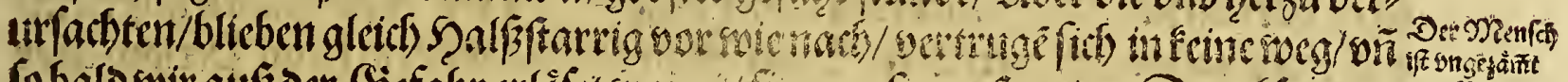

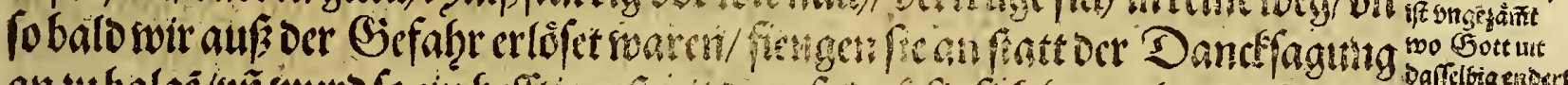

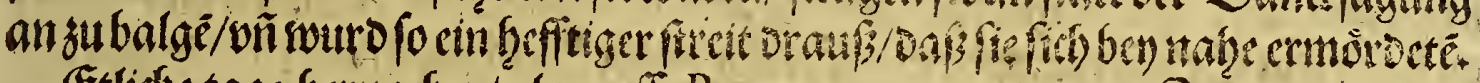

Etliche tage hernacher/alb grofe Bonacey wara/gieng eit Jimmernañ oñ

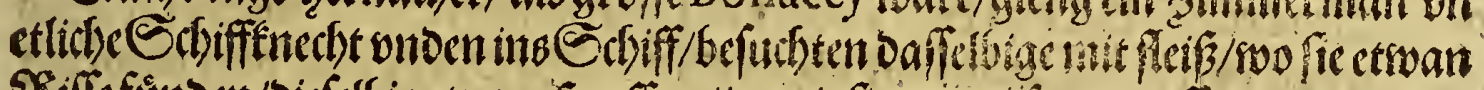

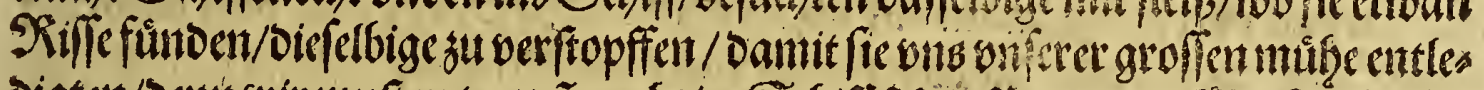

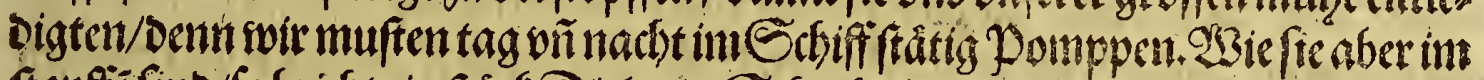

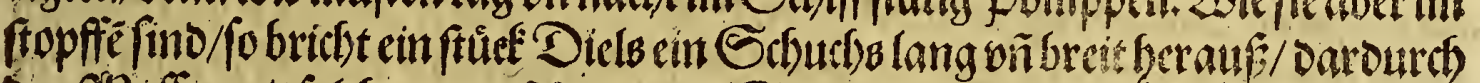

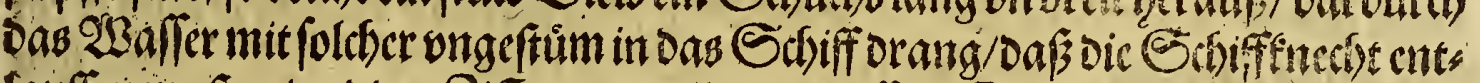

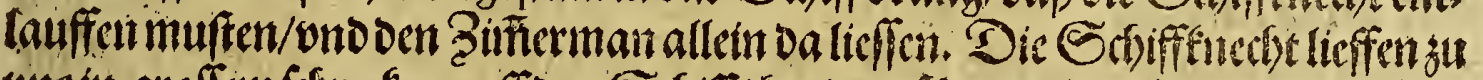

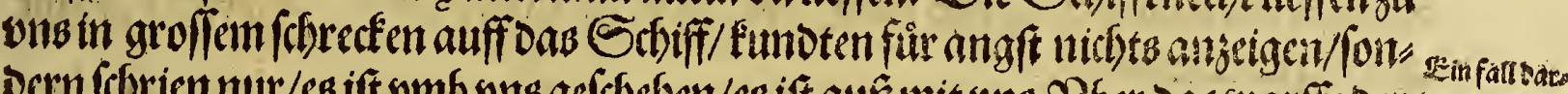

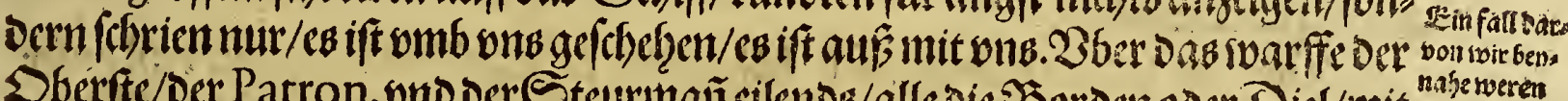

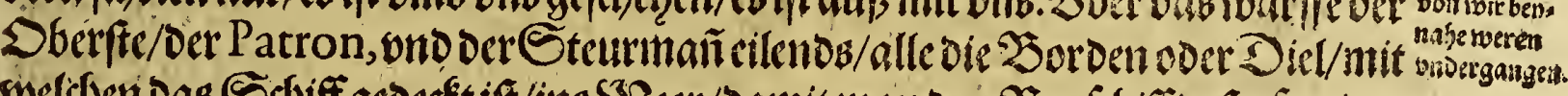

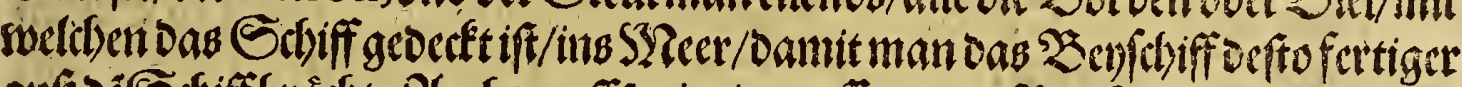

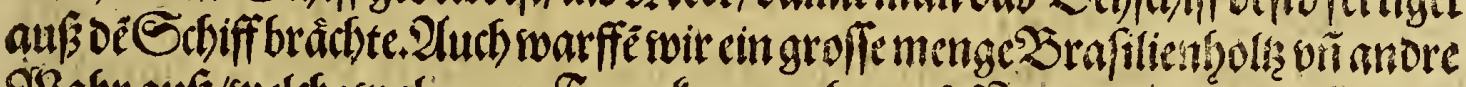

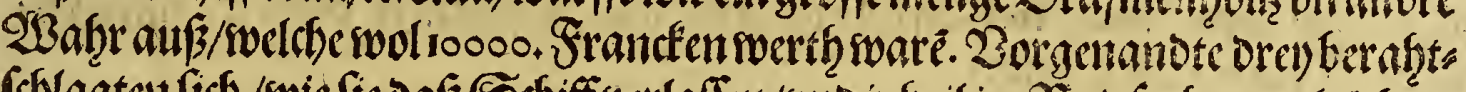

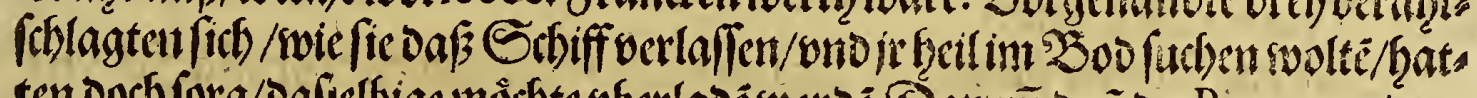

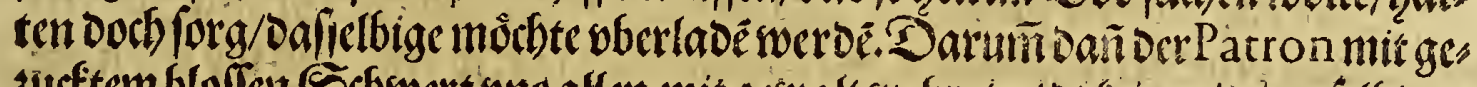

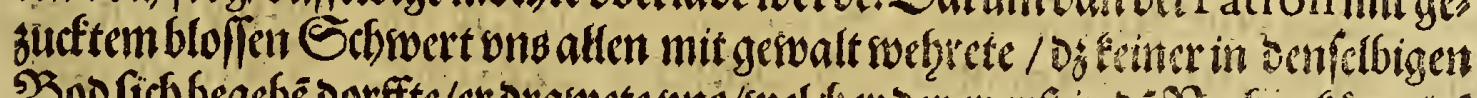

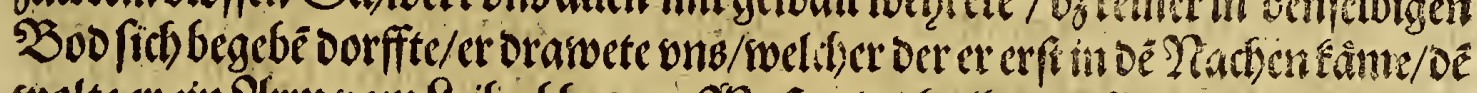

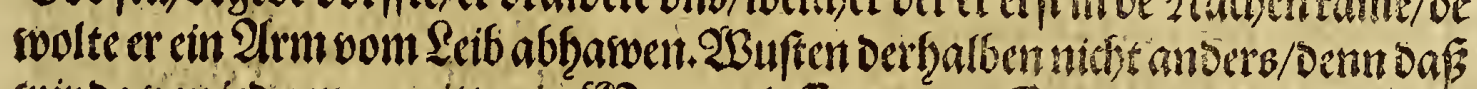

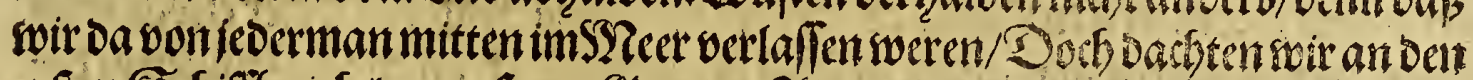

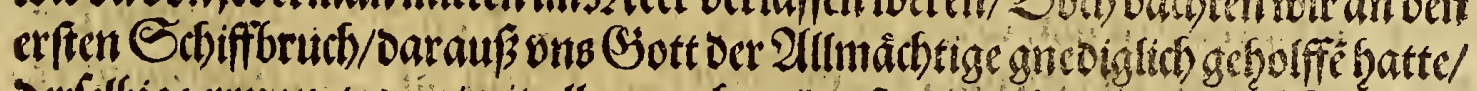

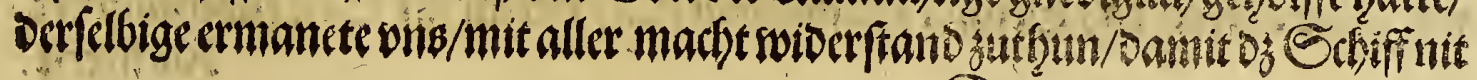

$$
30 \text { iti verjuts. }
$$


Das britte Ef̧etl.

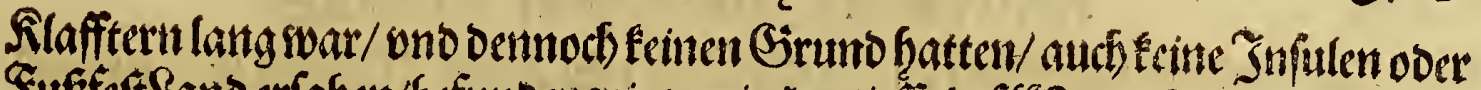

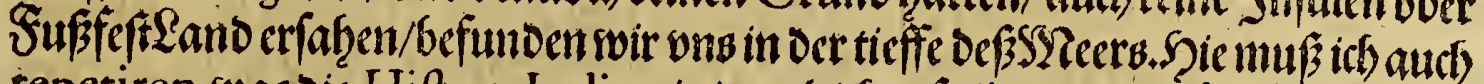

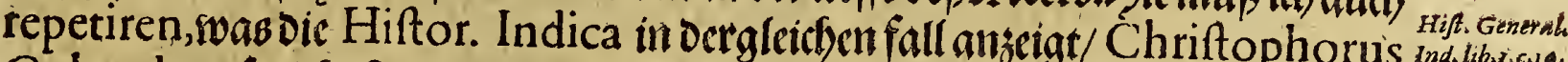

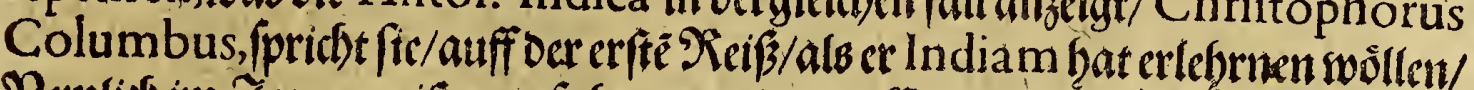

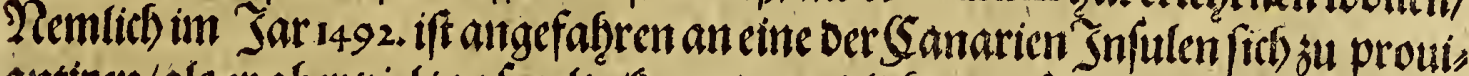
antiren/alb er aber biel tagfegelte/fompt er enolich in einfogar berwadb/ensicer/ Daßses einer 2 Biefen gleichete / Darfür er fich oennnit swenig ent/erzete/ob wol fein

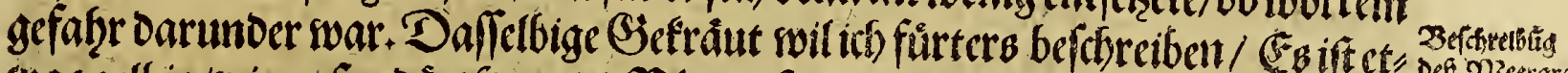

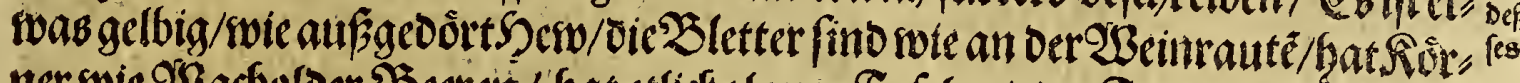

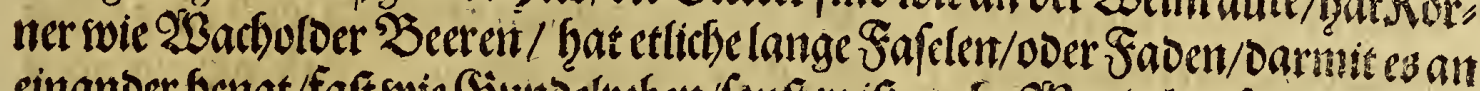

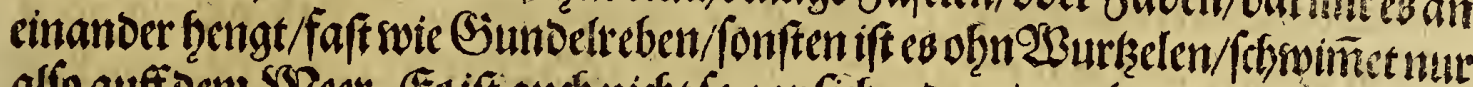
alfo auff ocm SYeer. Es ift auch niche fo gar ficher onmit omb ougeben.2fub fat

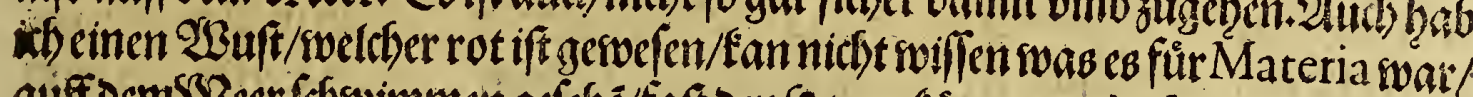

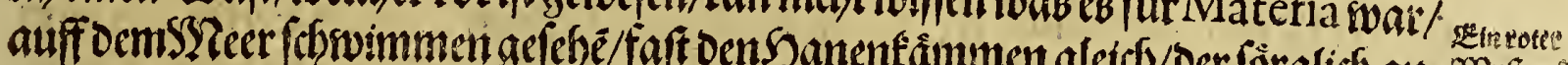

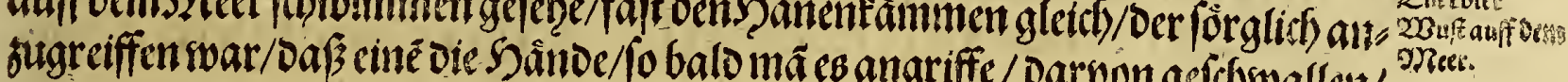

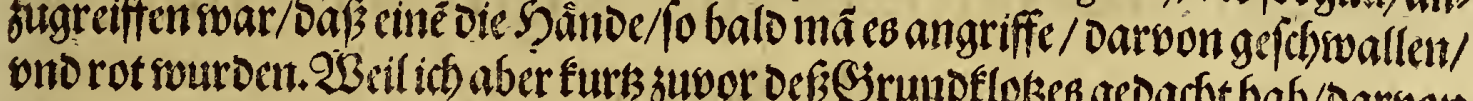

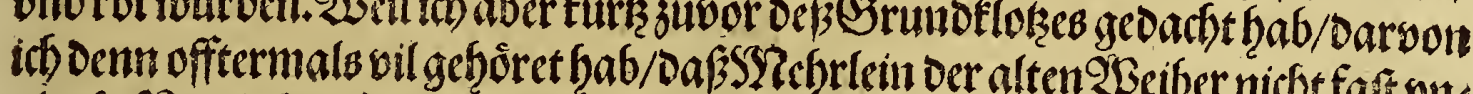

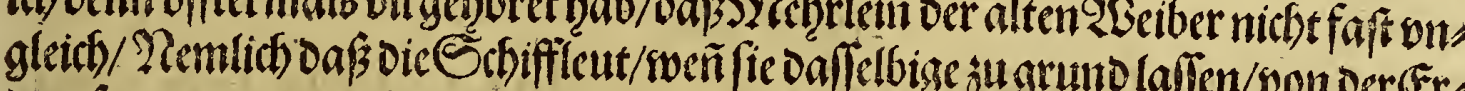

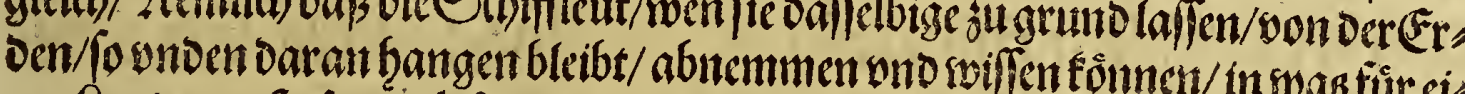

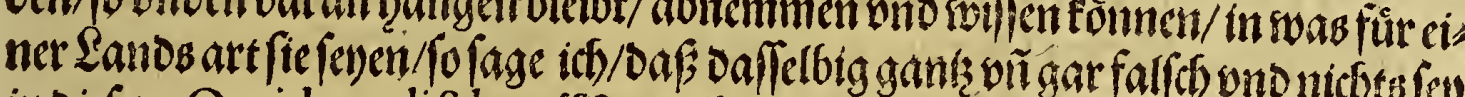

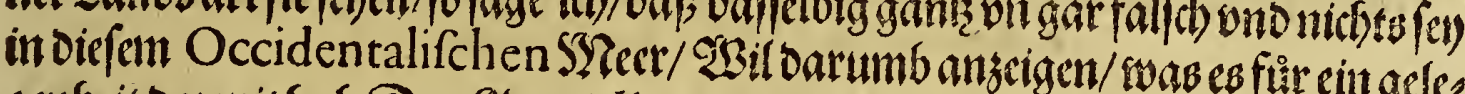

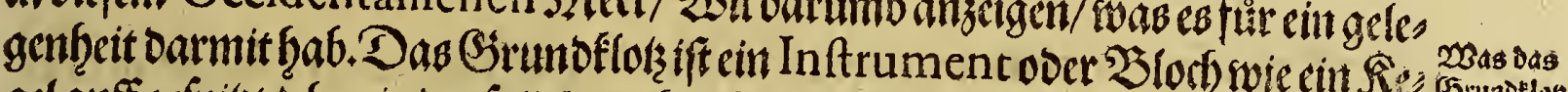

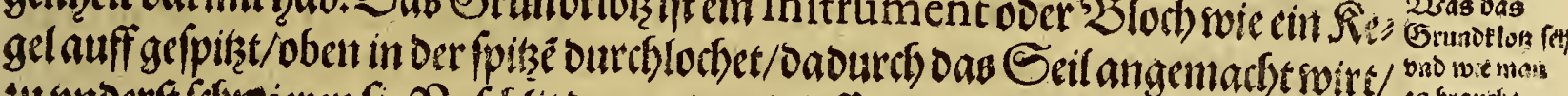

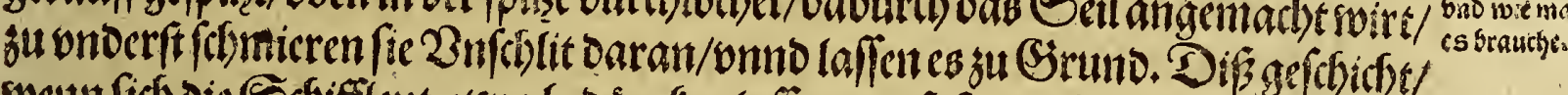

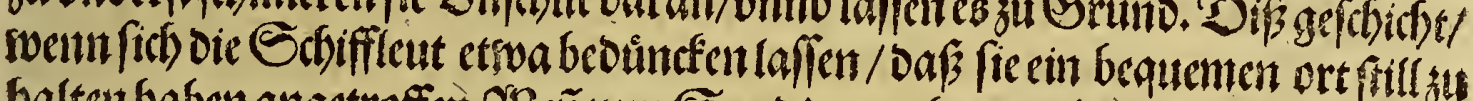

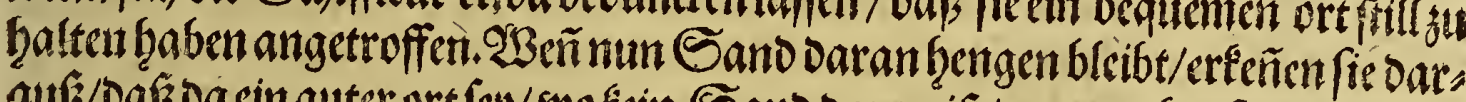

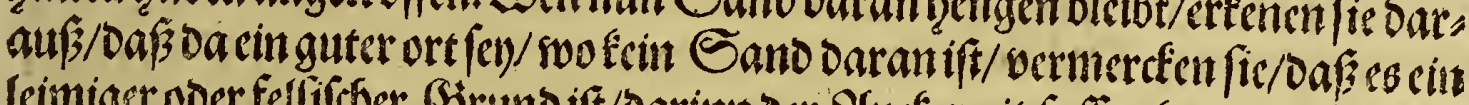

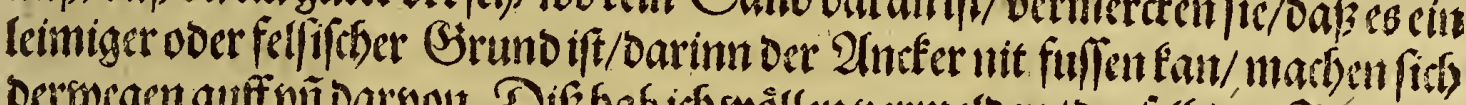

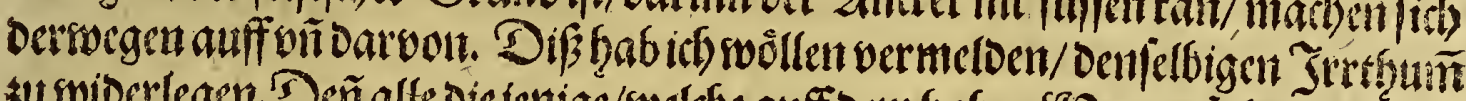

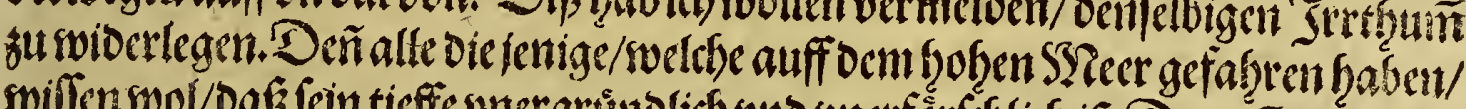

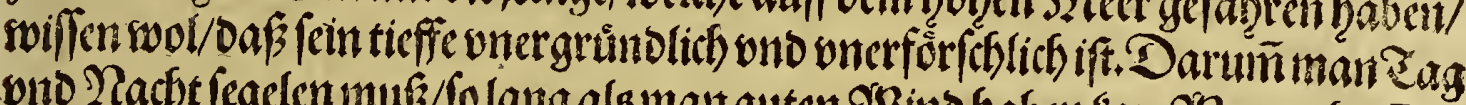

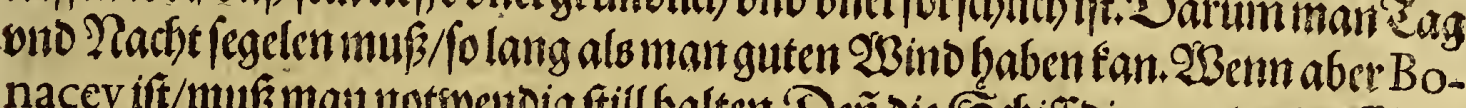
nacey ift/mus mant notwentoigftill halten. Deñ dic Sifhiff bie man oa in Subs meer brautbt/Die werden nit mit Siubern fort getrieben/woie fonft andere $/$ cts ndle

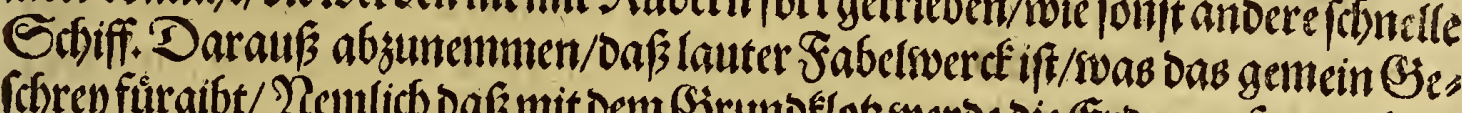

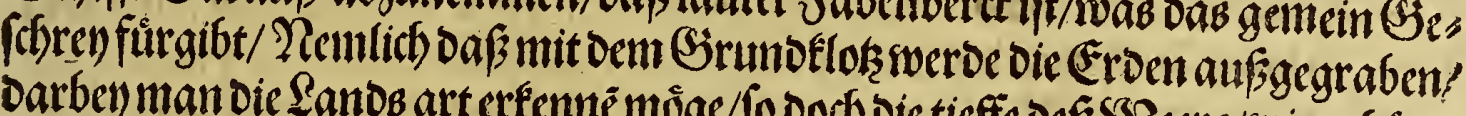

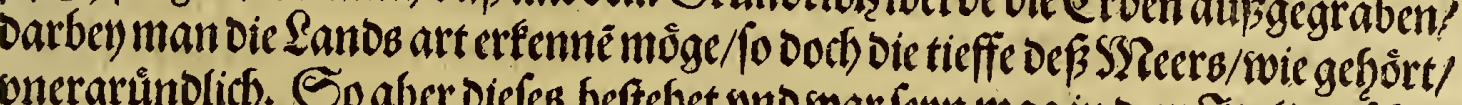

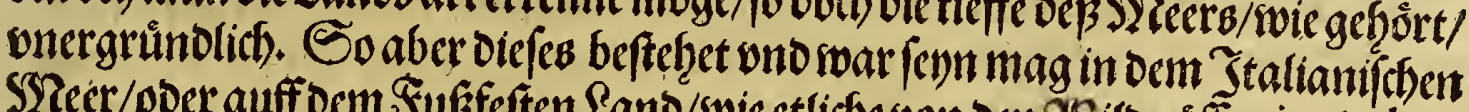

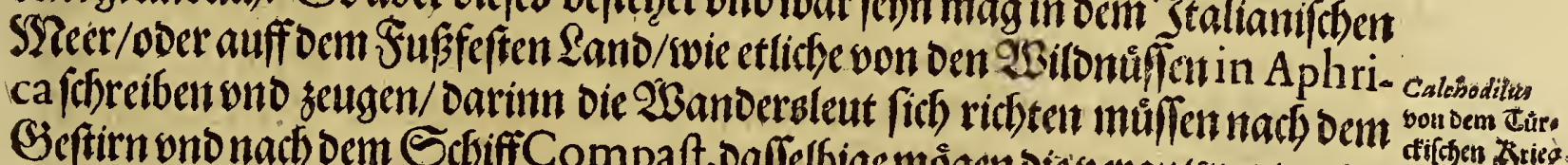

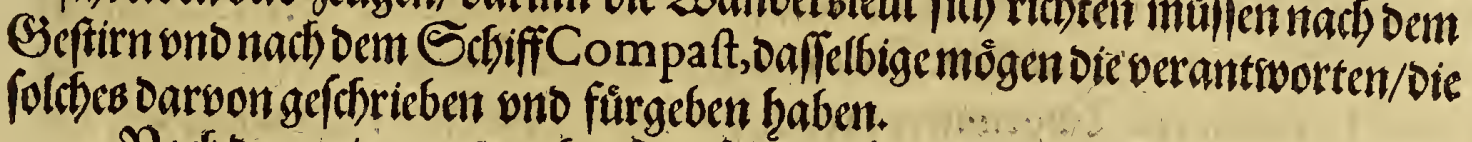

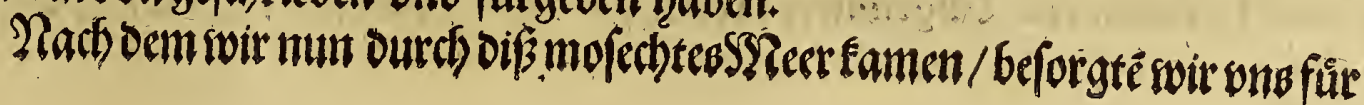

DerB 


\section{Das britte STenl.}

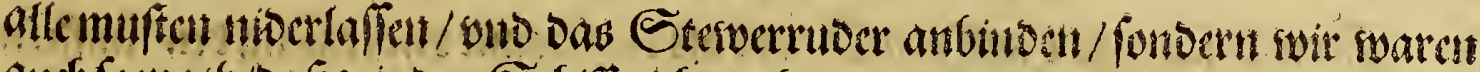

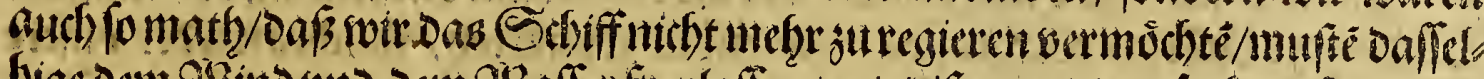

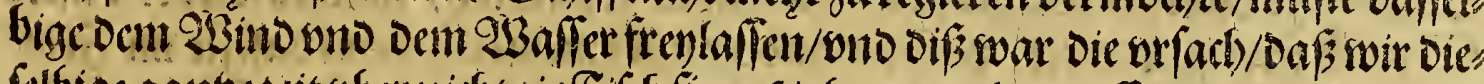

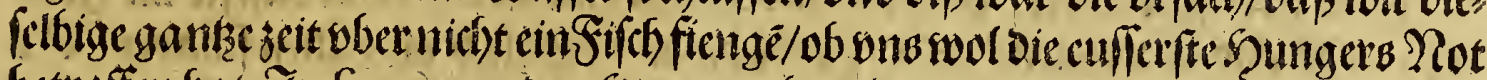

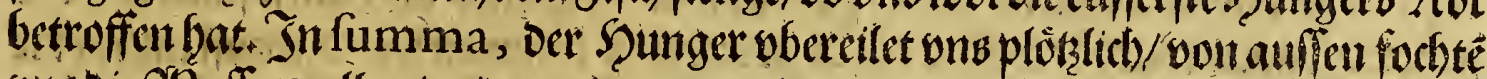

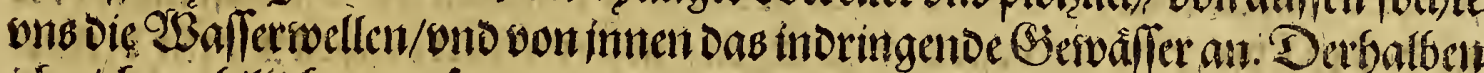

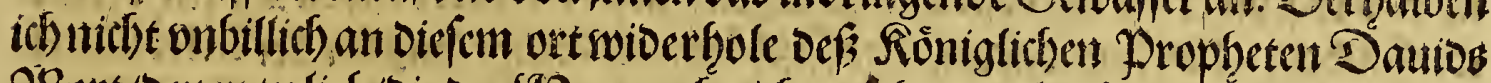

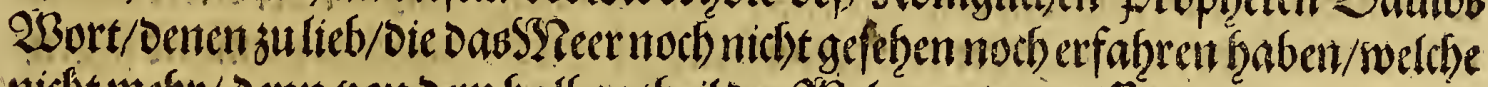

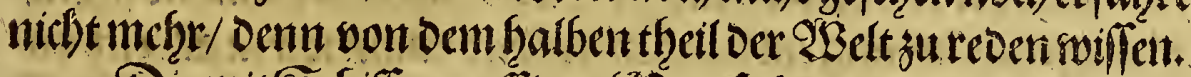

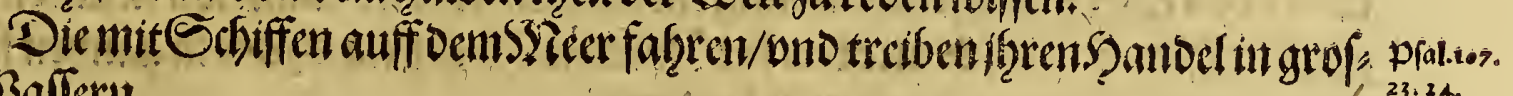
fen 2 afferit.

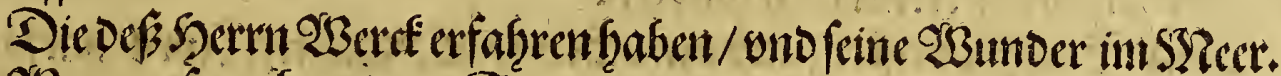

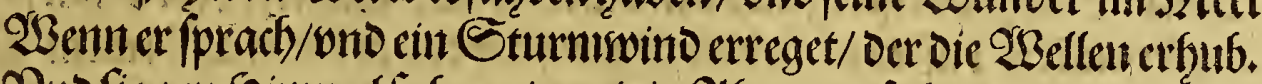

Bno fie gen Shinmel fubren/onno in Abgruto fuftren/D affif̨re Eeele vor angft verzagte.

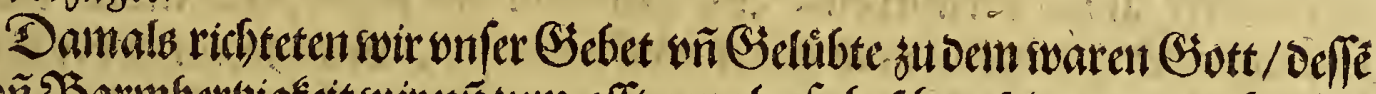

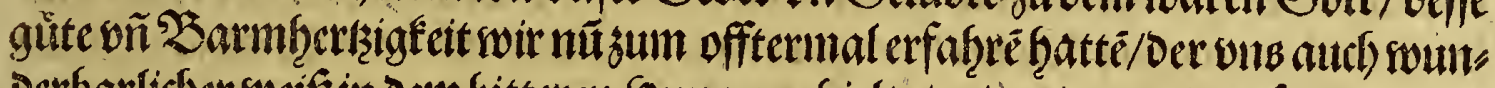

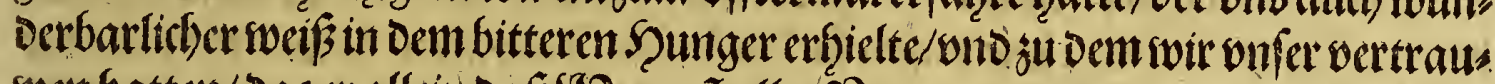

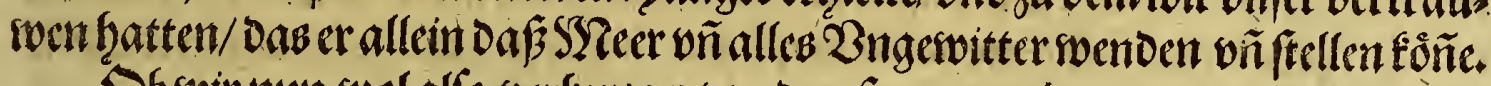

O.b swir nun wol alfo verfeutgert ond ausgenergelt waten / Das wir faum

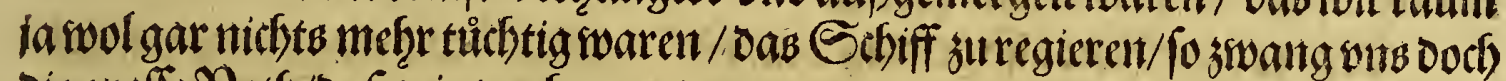

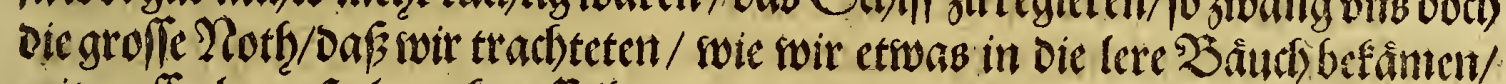

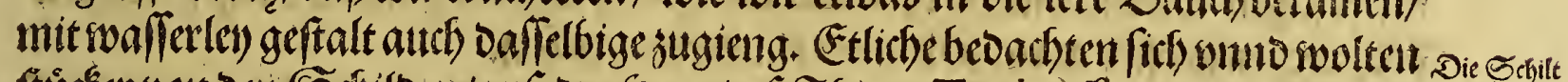

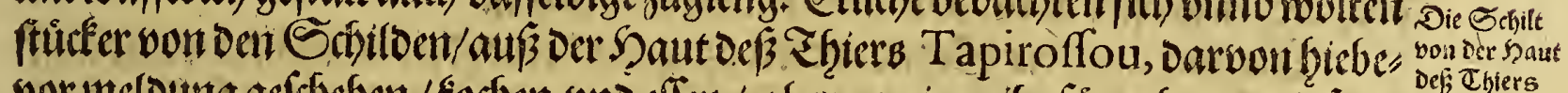

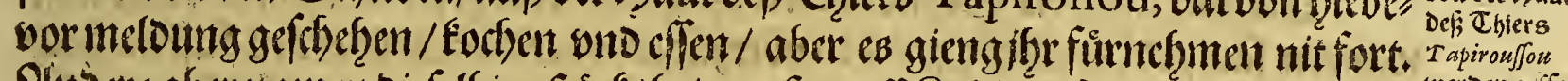

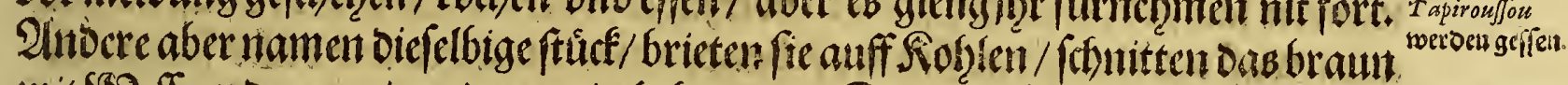

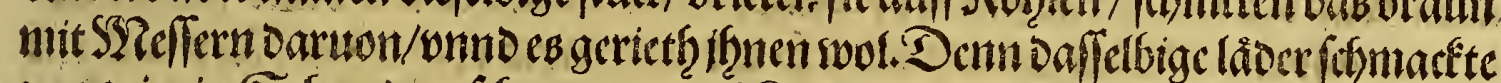

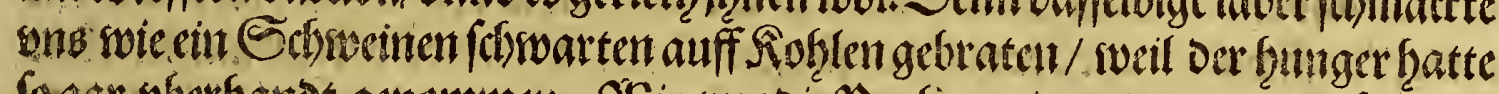

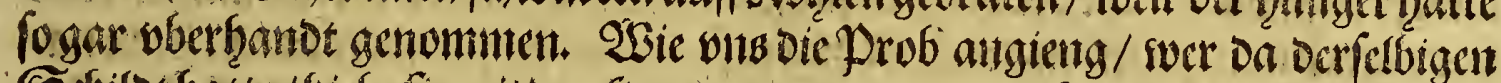

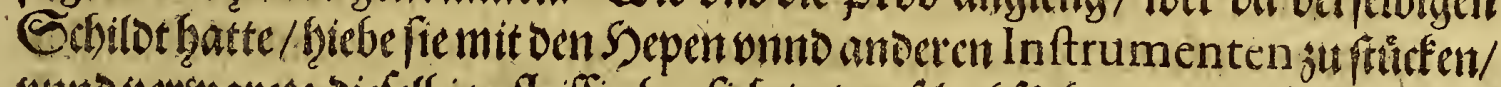

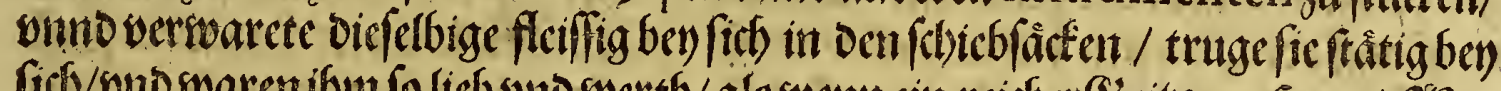

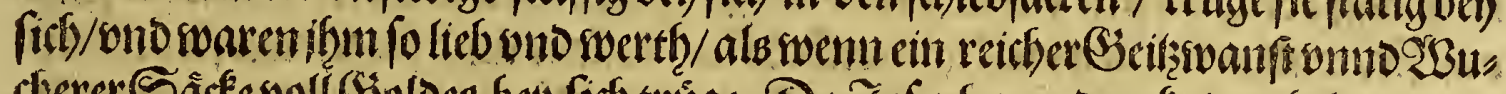

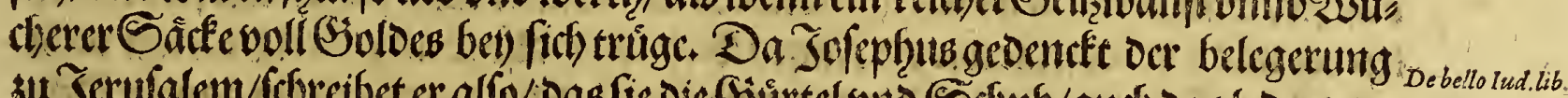

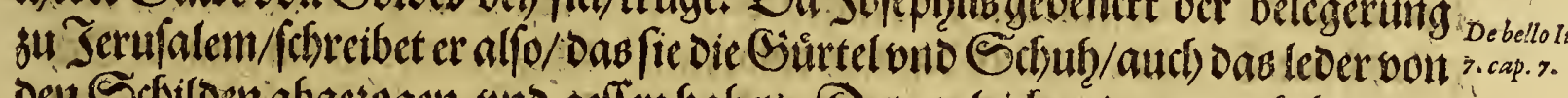

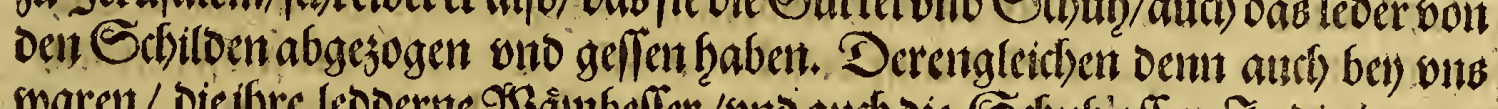

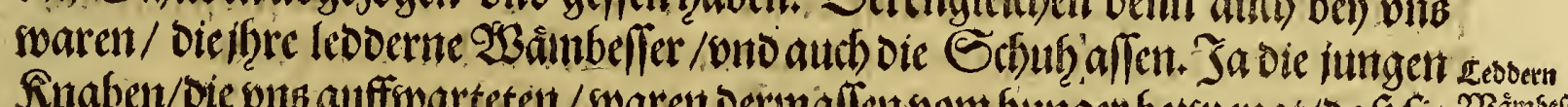

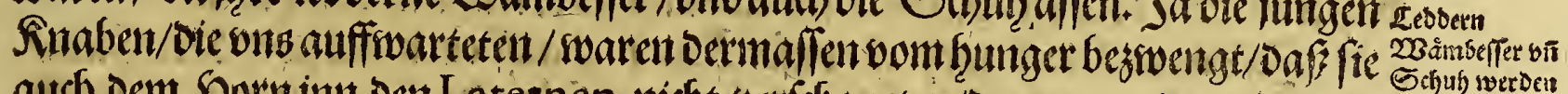

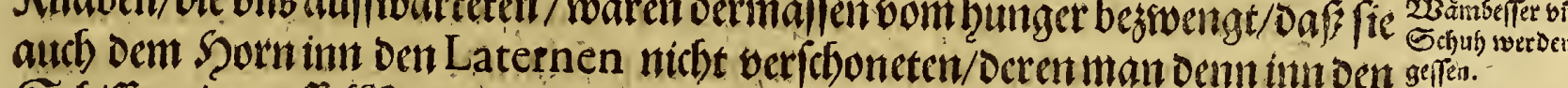

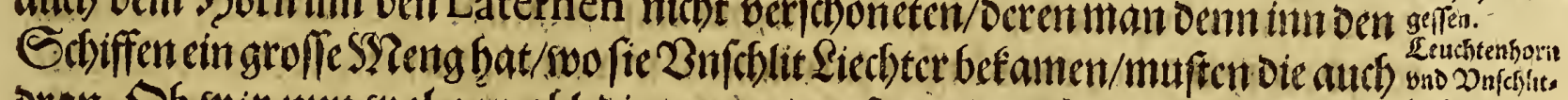

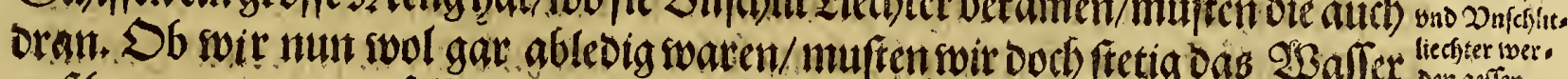

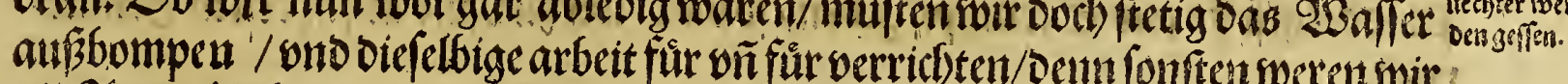

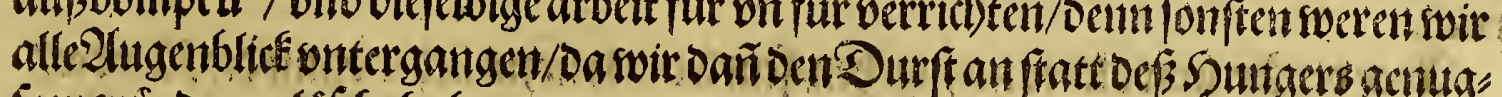

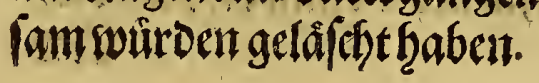


Das britte Tratl.

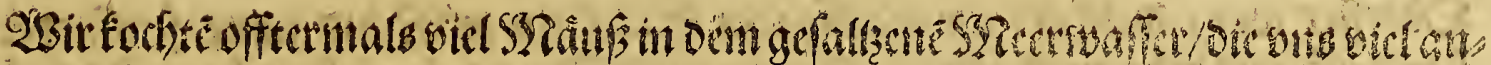

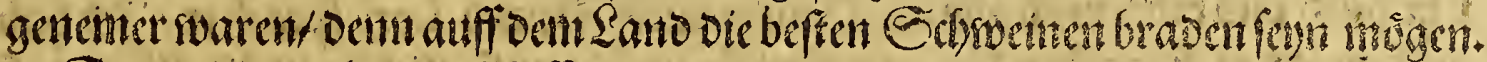

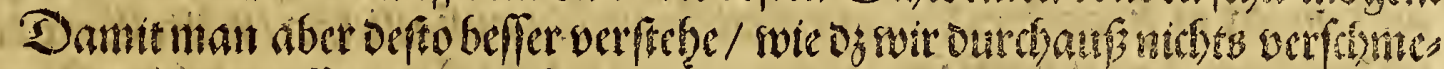

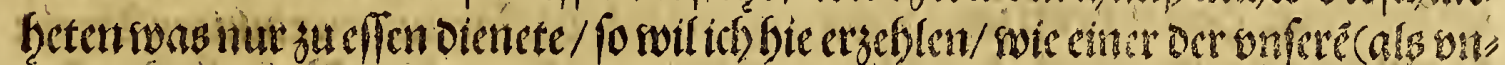

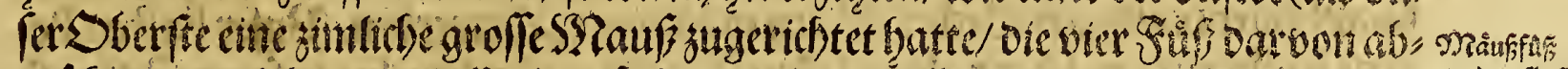

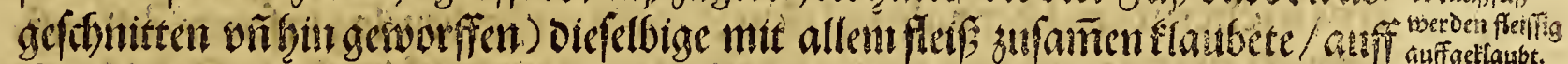

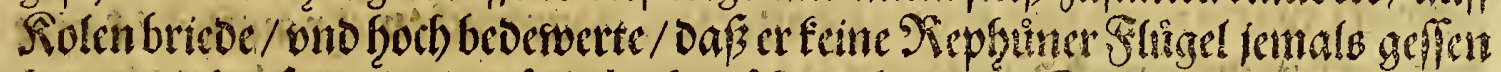

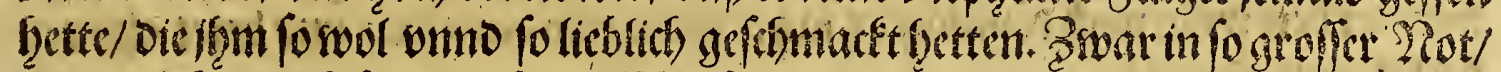

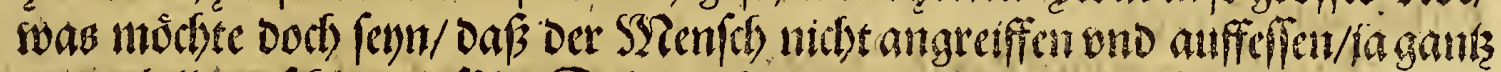

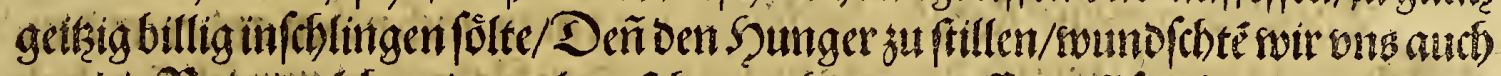

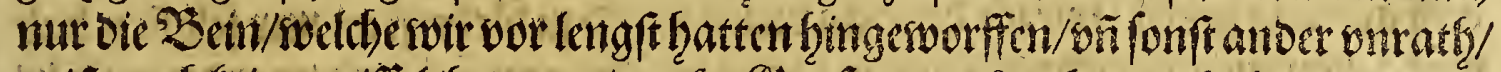

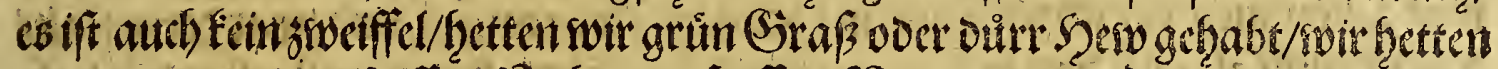

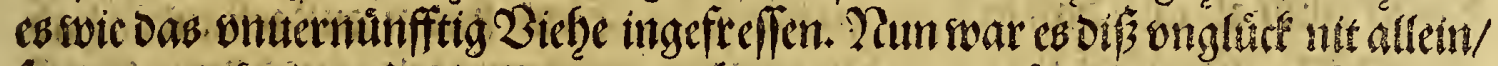

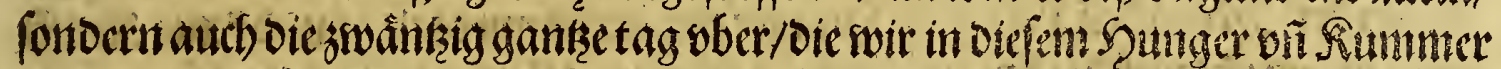

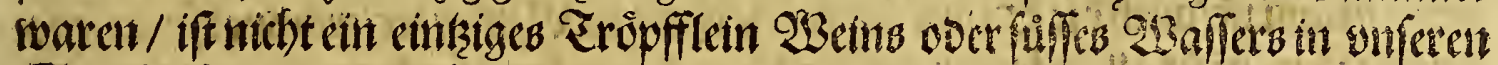

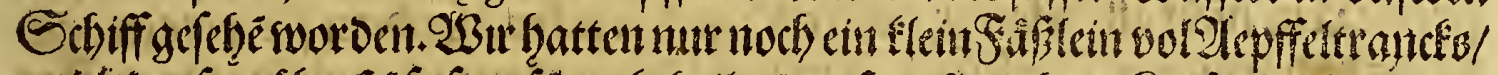

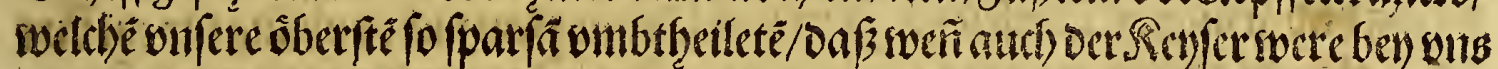

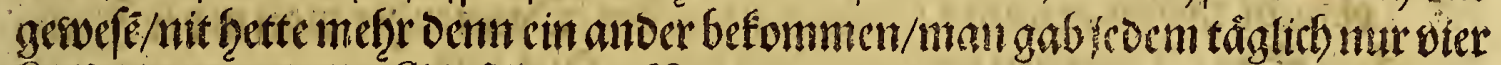

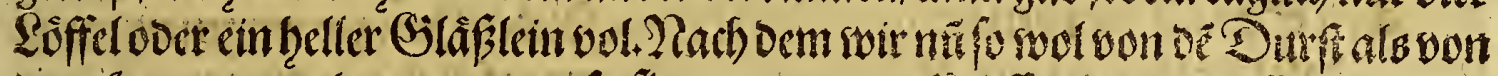

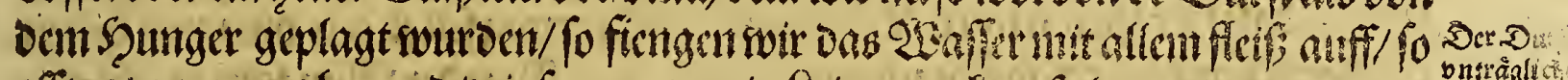

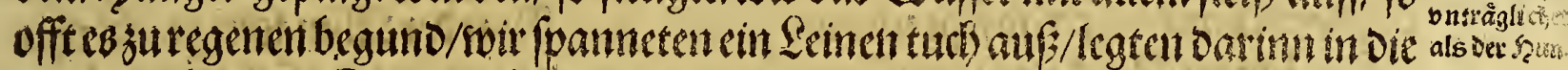

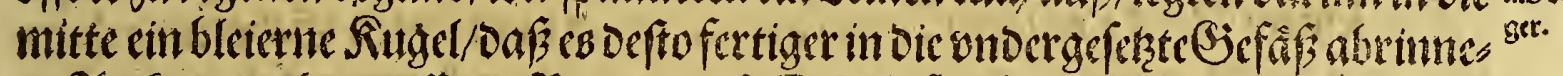

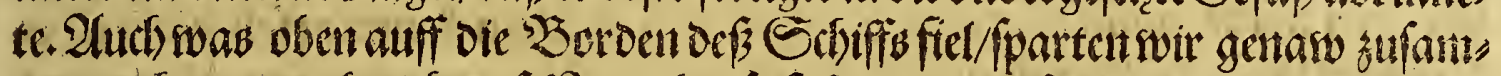

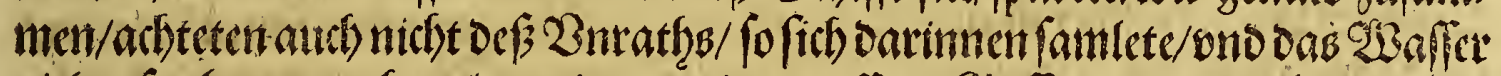
viel onfauberer madbete/oennirgeno cines auff oer Baffen/swit trancfen eb alles ofingraurwen estt.

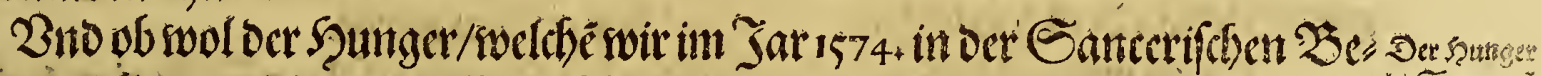

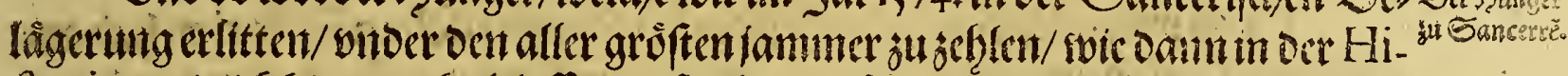

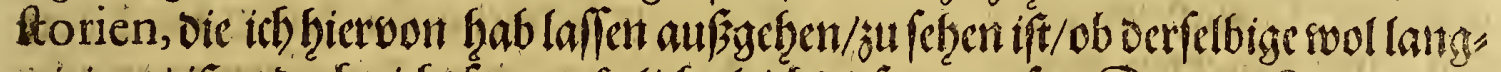

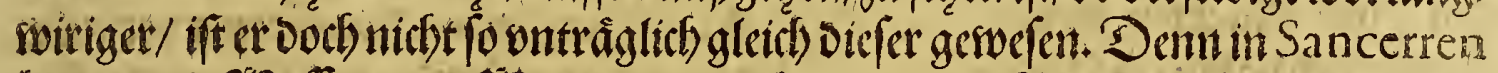

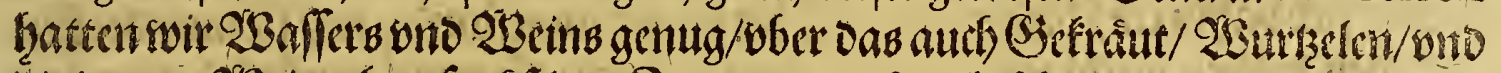

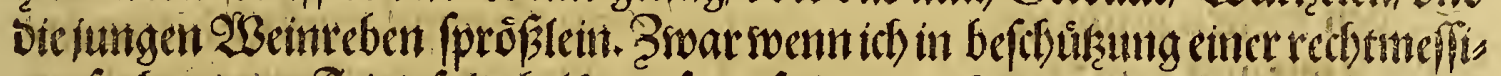

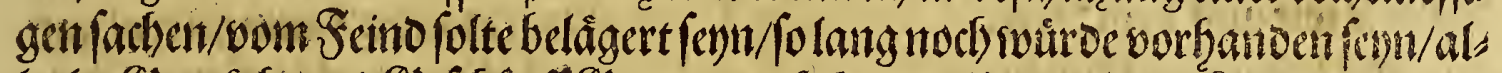

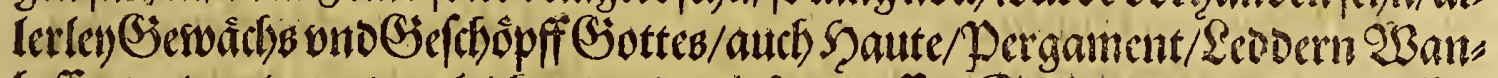
befler/ono anbercs oergleichen Daritetlicher maflen Gaft ift/ono ob wol baffers

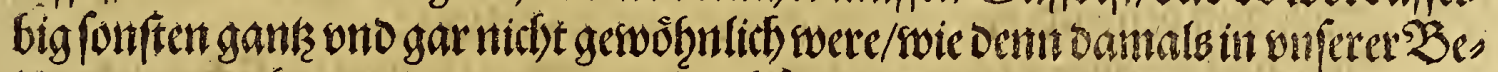

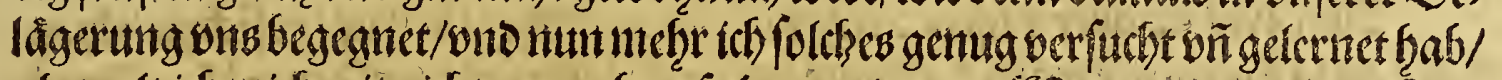

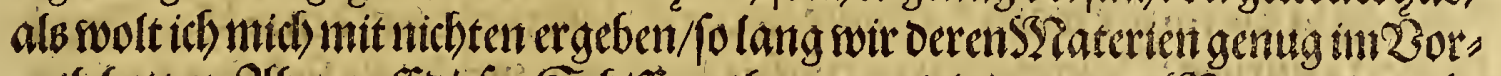

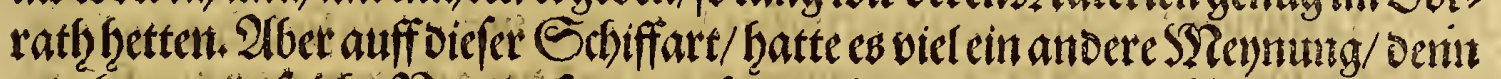

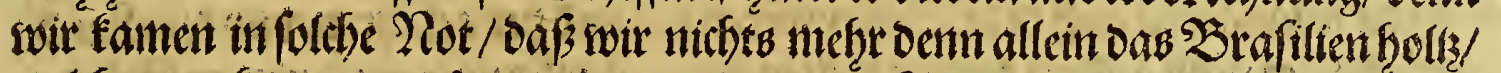

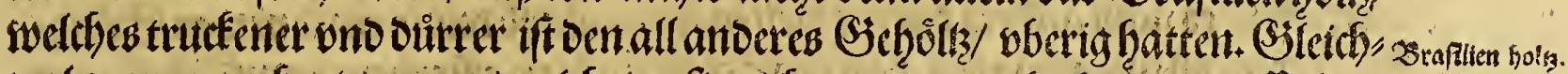

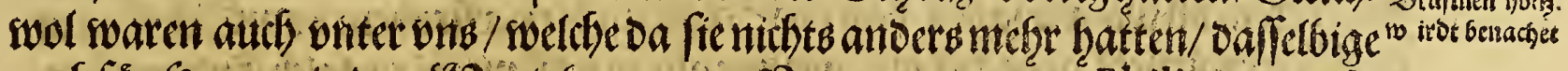

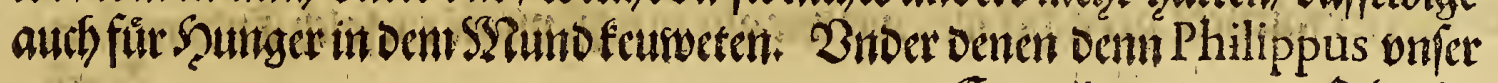

$$
\text { Ee if Sbarfter }
$$




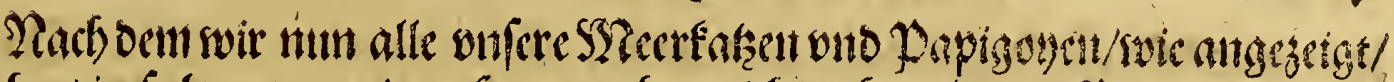

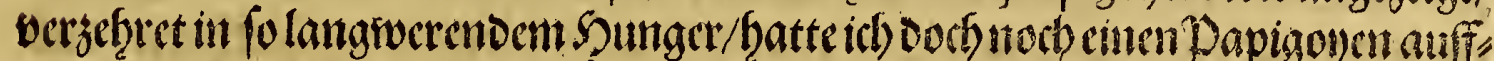

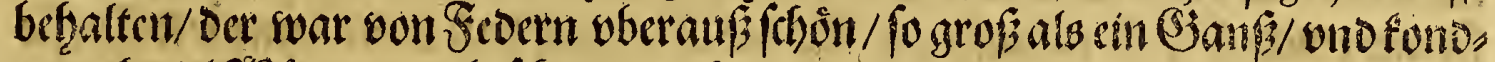

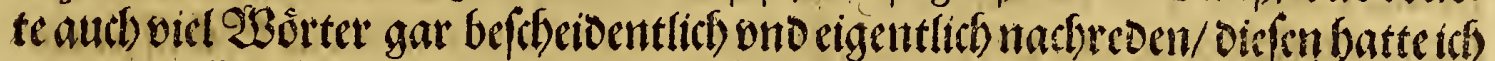

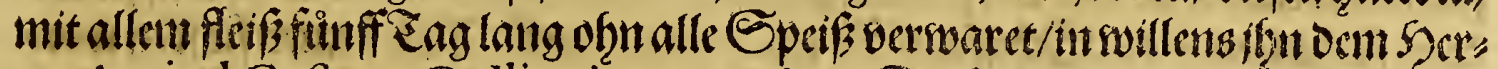
ven Amiral Cafparo Collignio zu verebrett. Derfelbige mufte oamals auté) zu

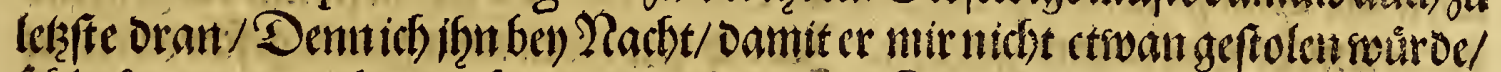

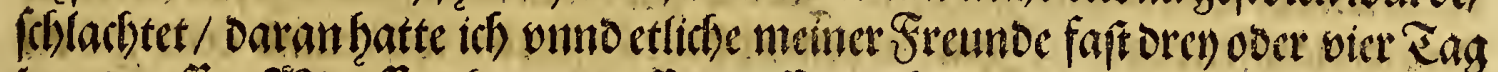

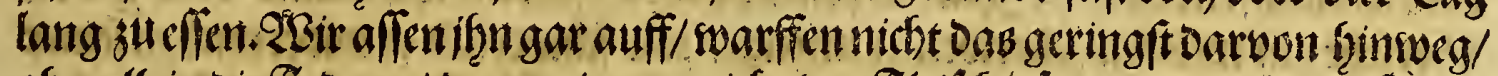

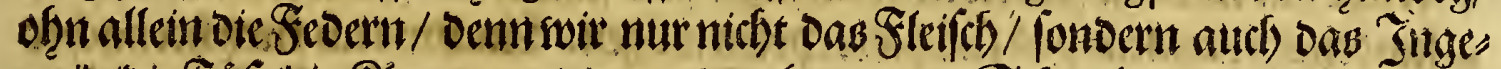

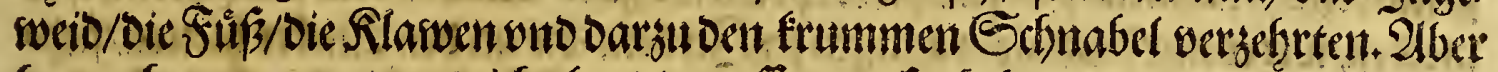

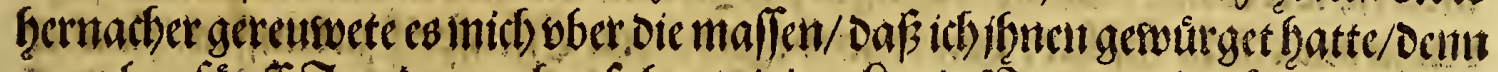

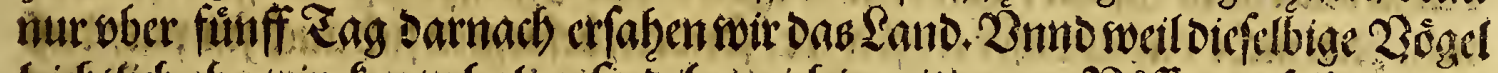

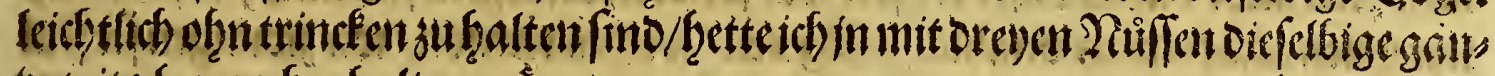

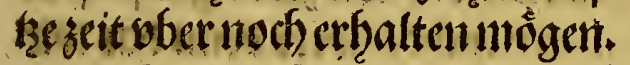

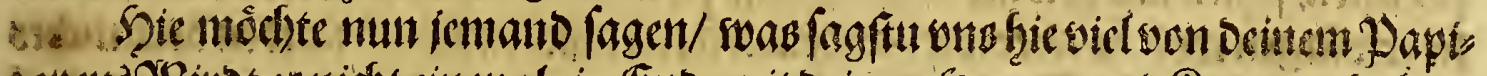

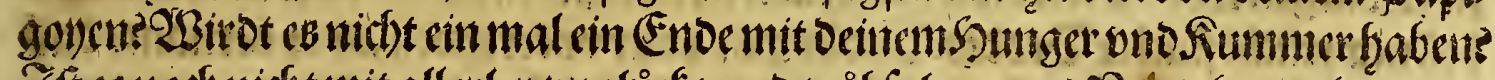

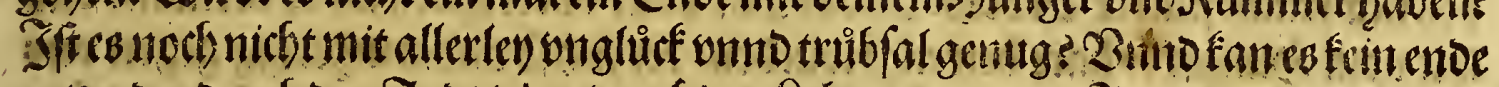

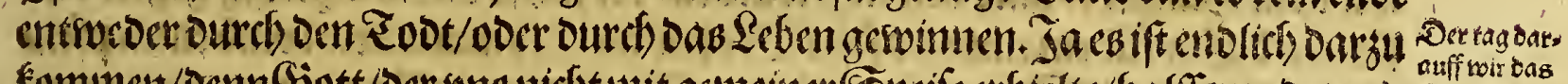

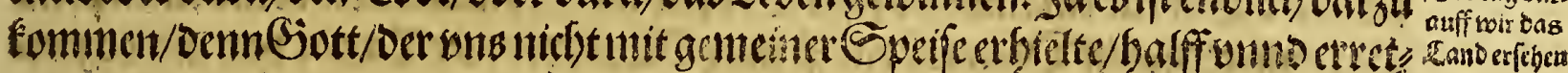

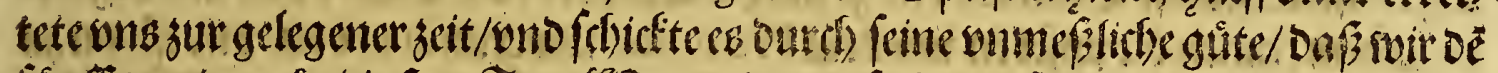

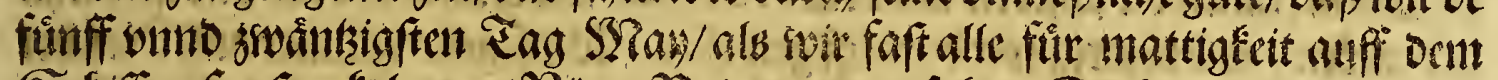

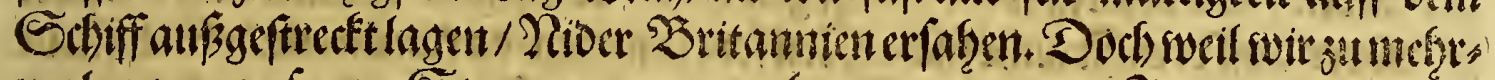
imalen von vnjerem Etcurntanu waten betrogentworben/ In dent ber Specu.

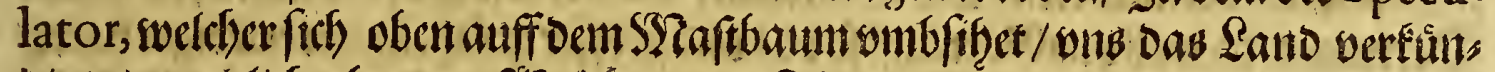

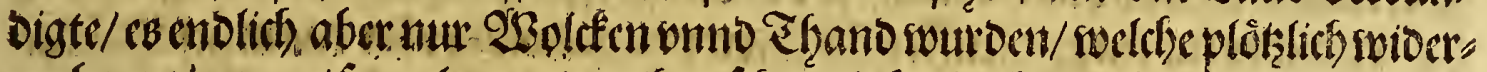

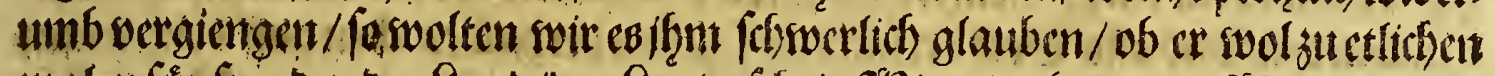

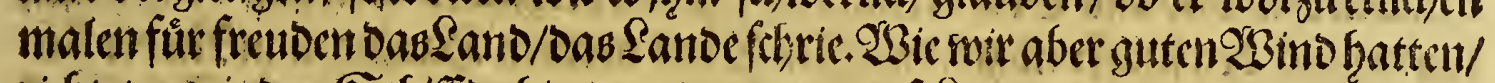

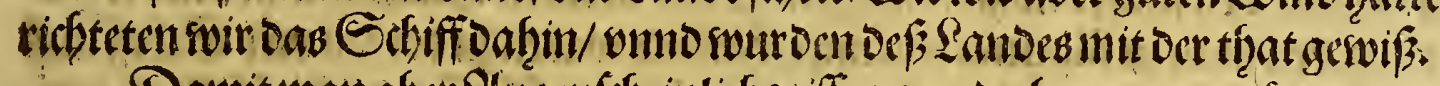

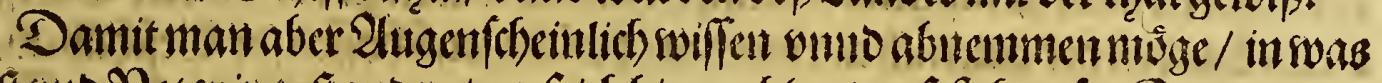

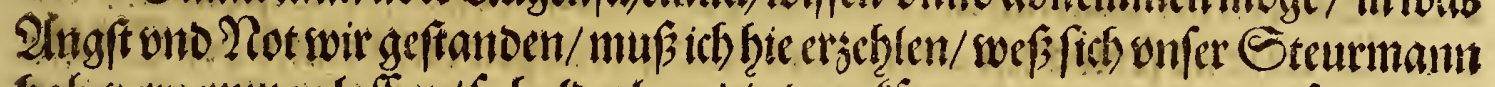

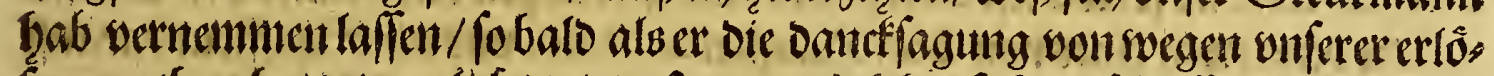

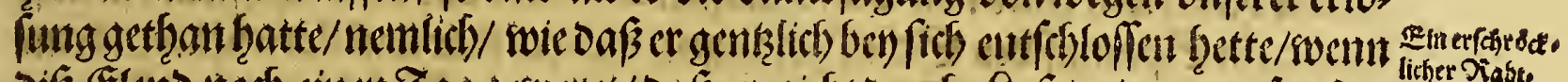

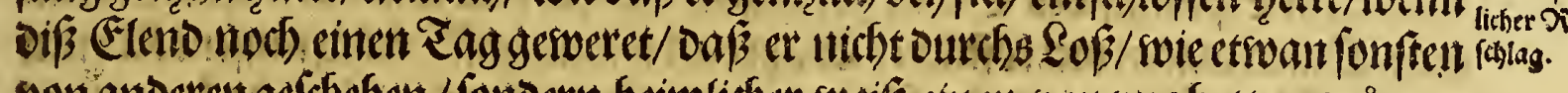

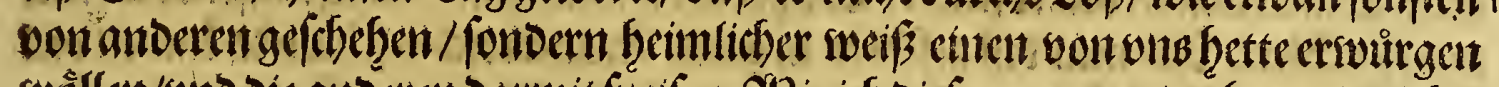

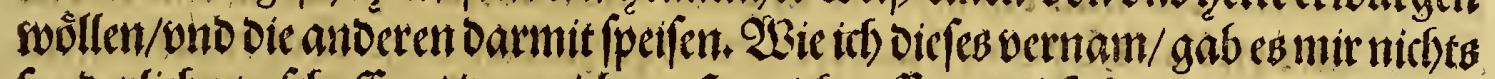

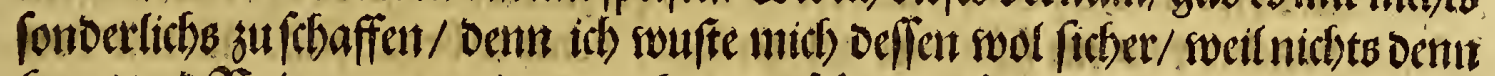

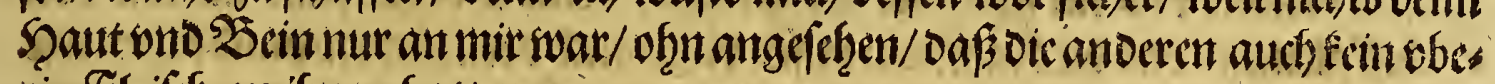

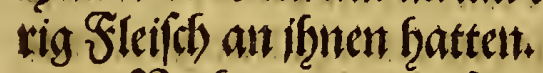

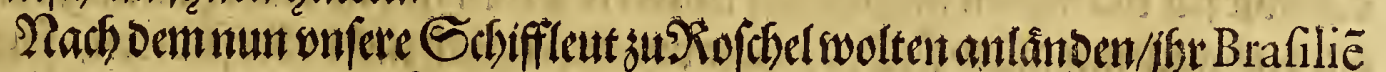

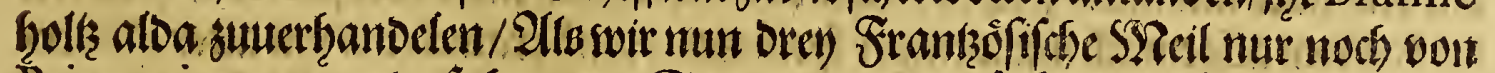
Britannien foaren/o a fuffert oer Steuerman ono Philippusin eitem ?arbet Ee ii a rubent 
Das britte Thent.

281

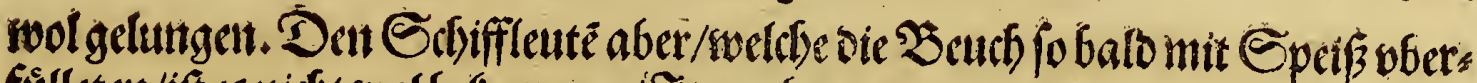

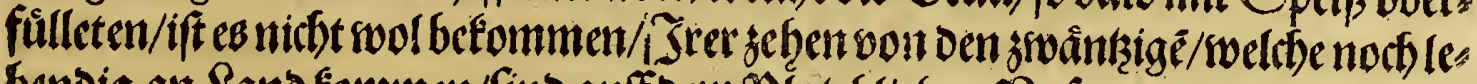
bendig an Sand fonumen/fino auff bem Plałz blicben. Buferer giengen anfango

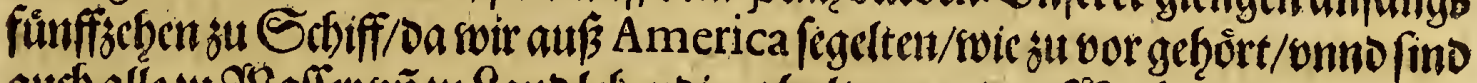

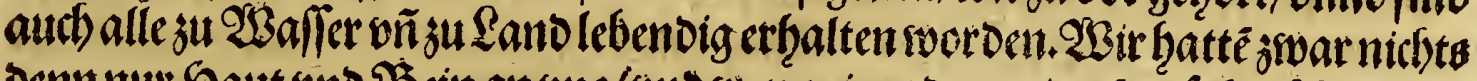

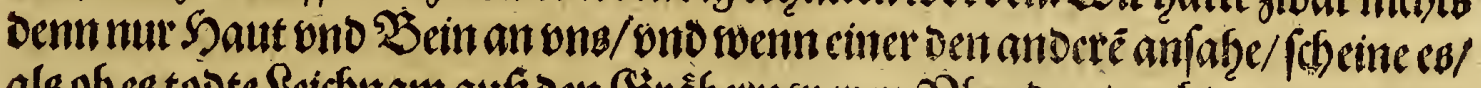

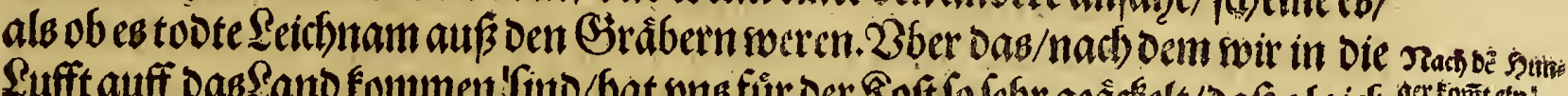

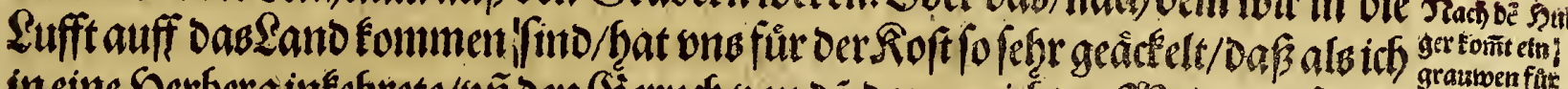

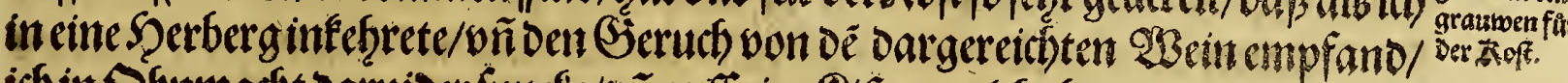

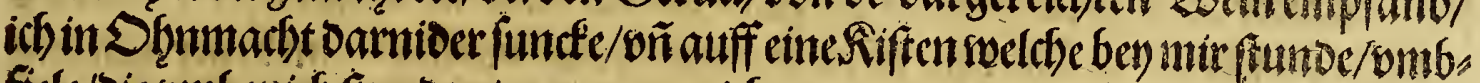

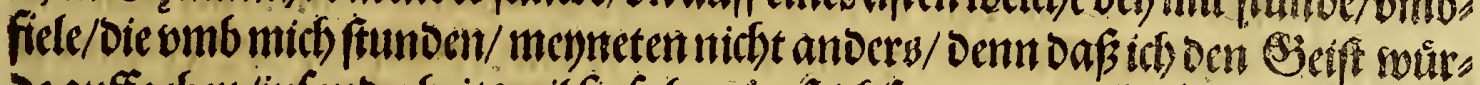
be auffgeben/infonberfeit weil /iefahen/oa/s ich fo mat ono ableibignar. Deros

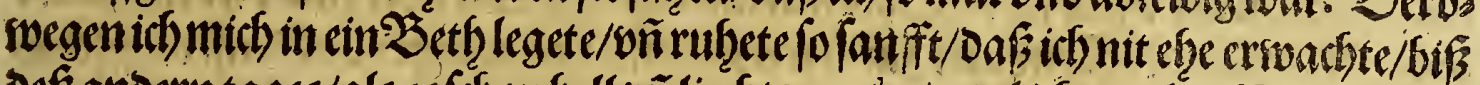

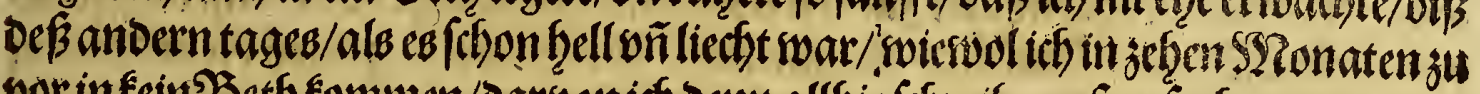

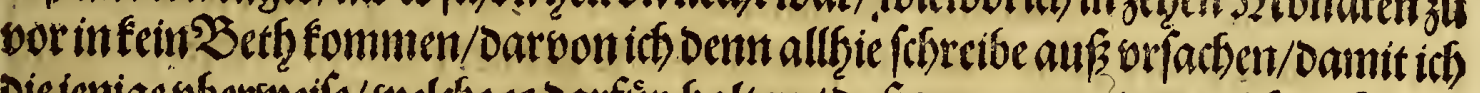

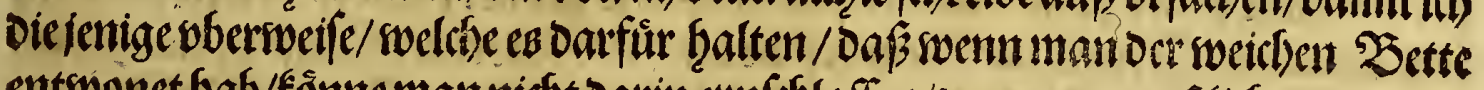

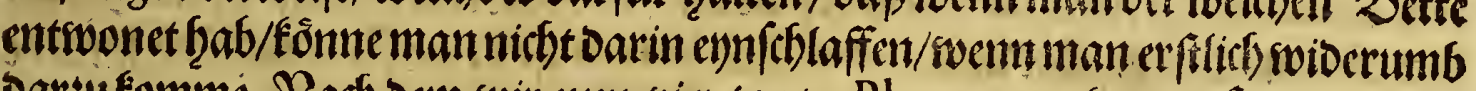

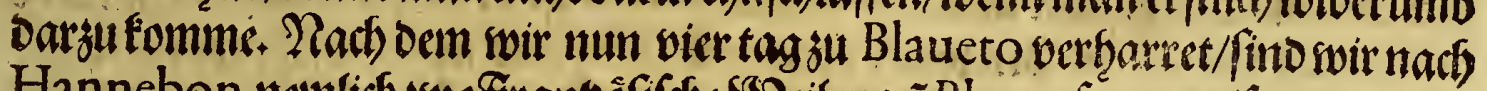

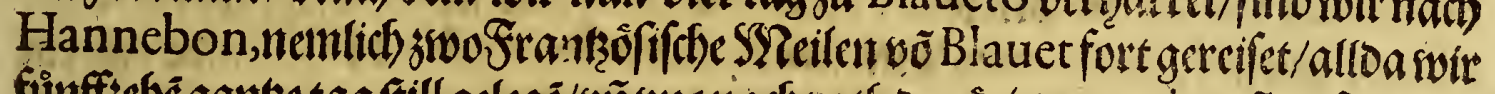

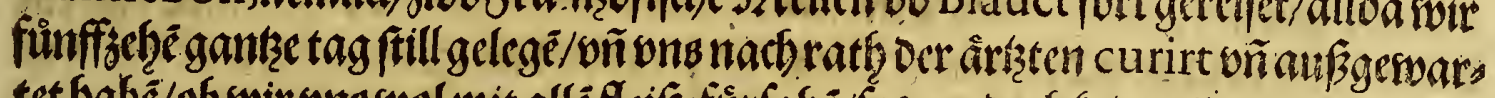

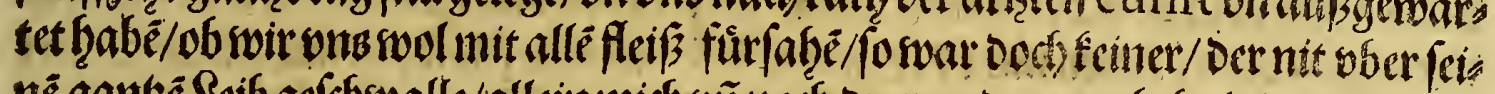

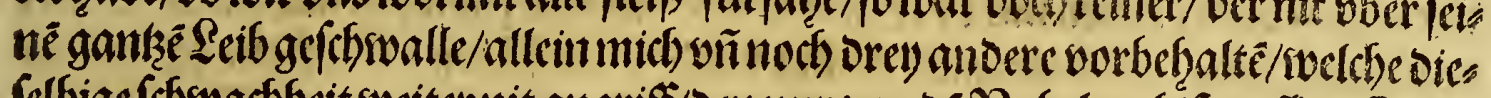

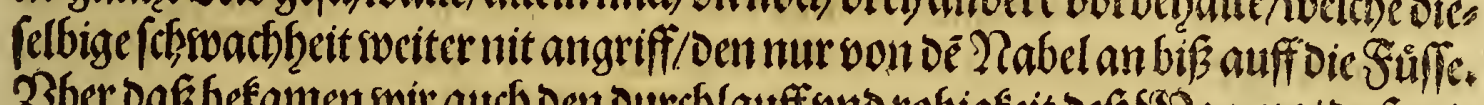

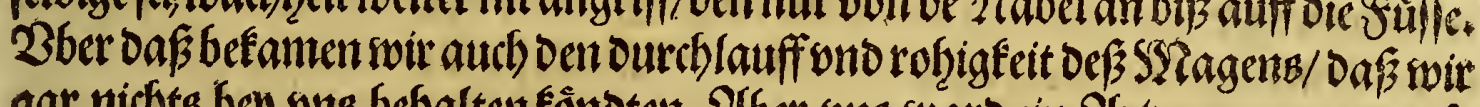
gar nichts bey ons beb̧alten fôndten. 2Aber wns waro ein 21rfzney angezeigt/ fo ballo soir oiefelbige brautbeten / ifteb won fatmo an mit bng allen beffer worben.

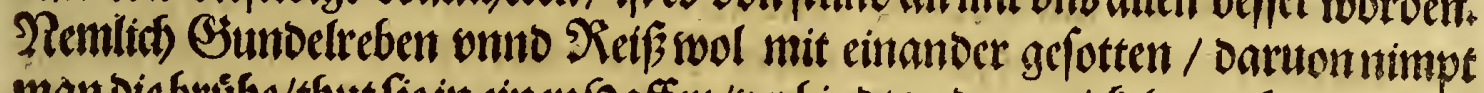
man die brúbe/thut fie in einenSaffen/werbinot ono verswictelt Den Şaffé geheb

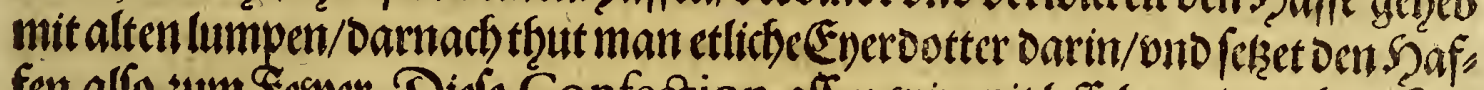
fen alfo sum Serwer. Diefe Confection affen wir mit leffelen wie cin bren. Iet)

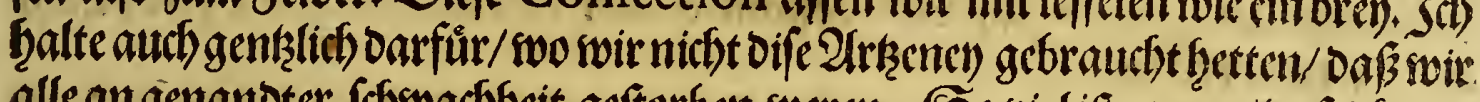

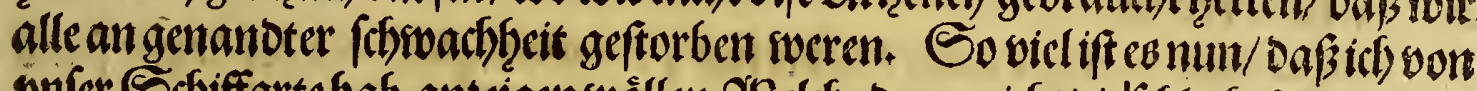

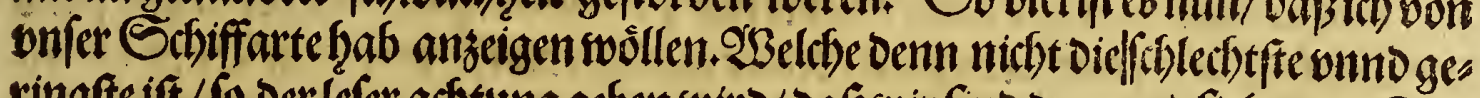

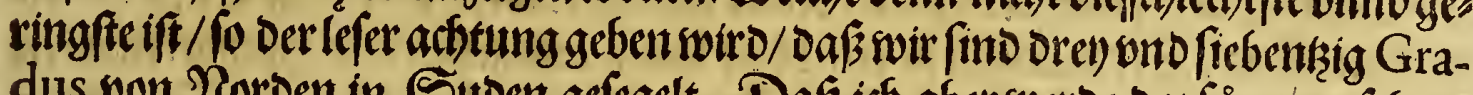

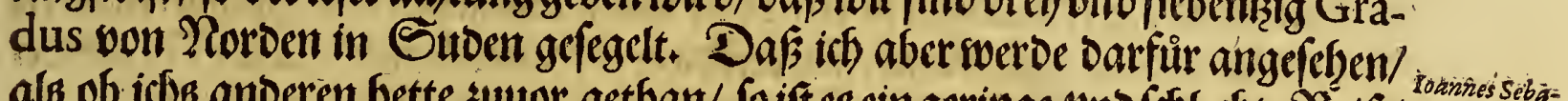

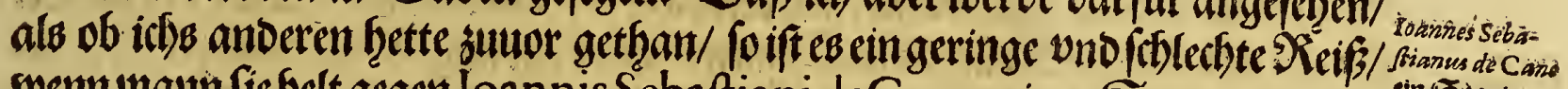

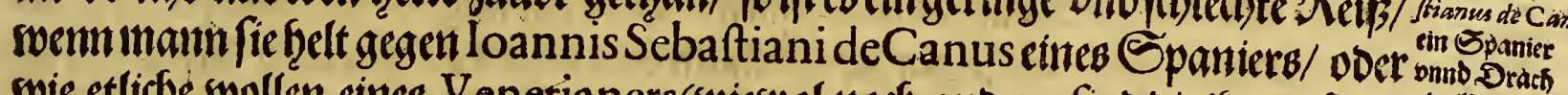

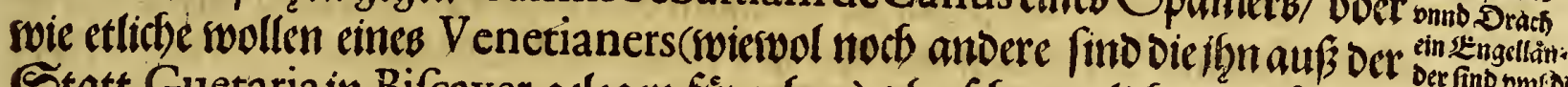

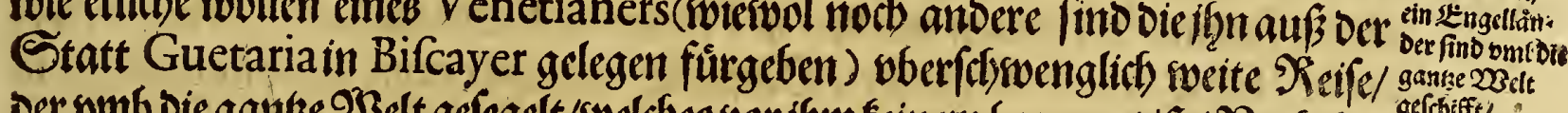

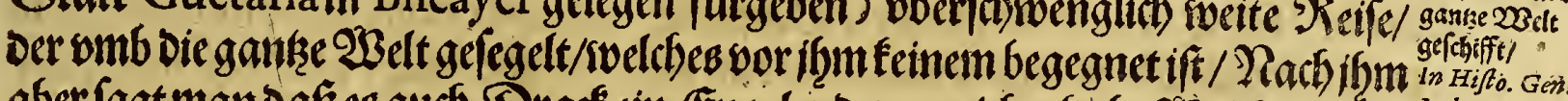

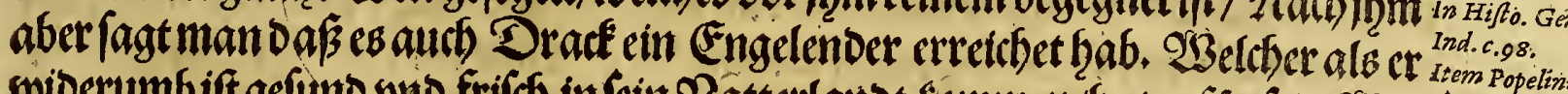

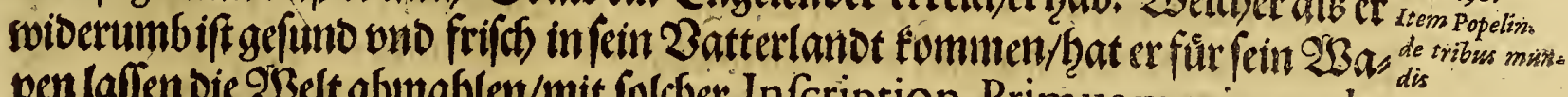
penlaffen bie \$selt abinab̨len/mit foleber Infcription, Primus me circunde-

$$
\text { (Ee iii dilit }
$$




\section{Dab britte Thet.}

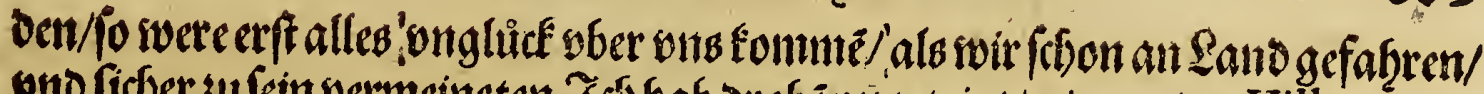

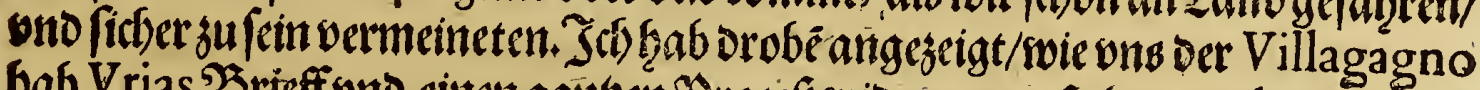

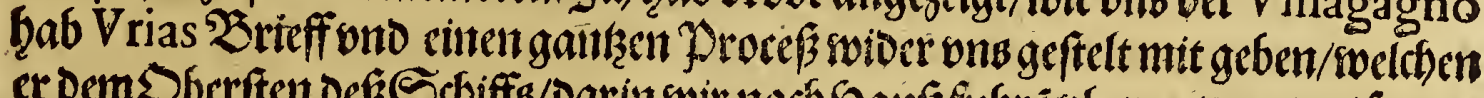

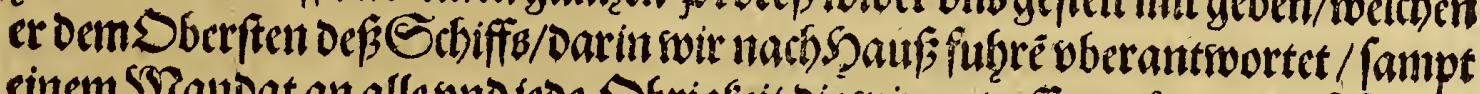
cinem SYandat an alle ono fede Sbrigfeit die soir antreffen wourben/oaf f fie ong

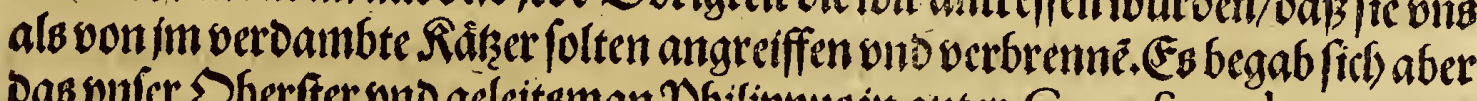
Das onfer Dberfer ono geleitsman Dhilippus in guter Correfpondentur vno

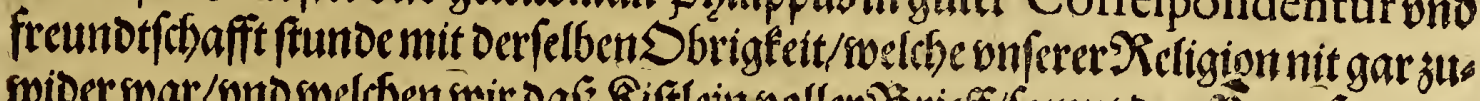

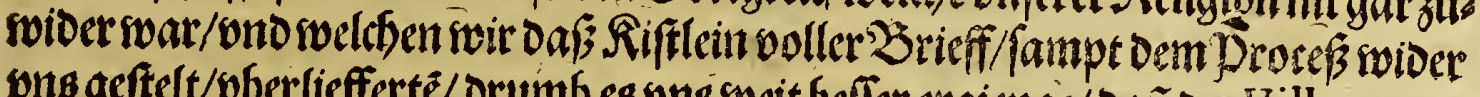
bne geftelt/wberliefferte/ orumb es ons soeit befler ergienge/ oañ ber Villagagno verboffte/ fintemal wir vonine sool ono freundich) auffigenommen oñ empfange

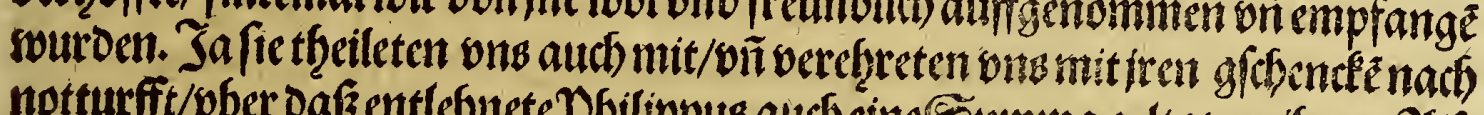

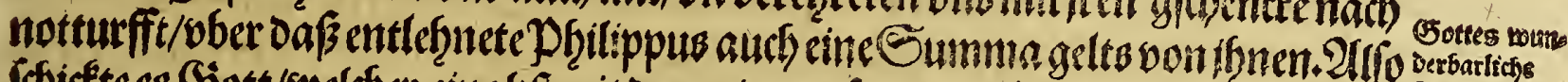

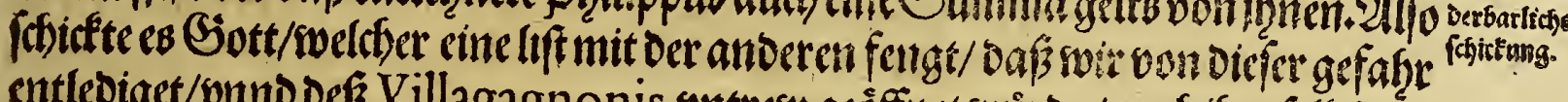

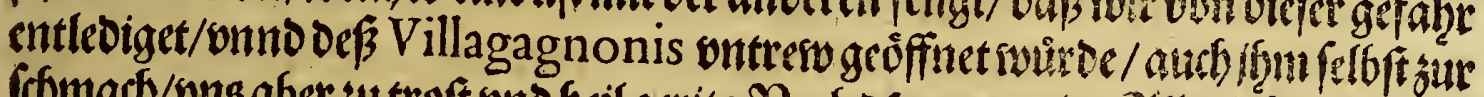

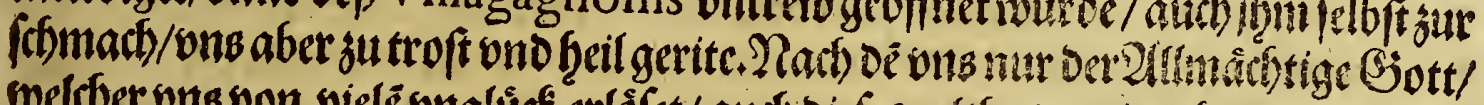

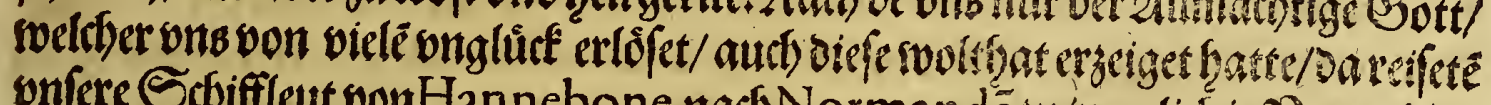

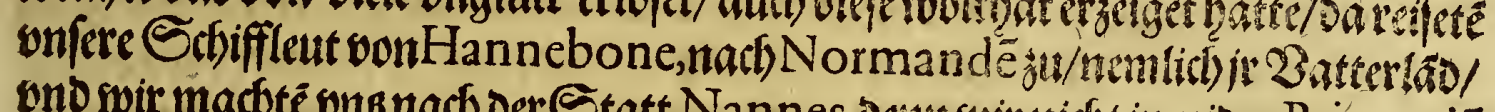

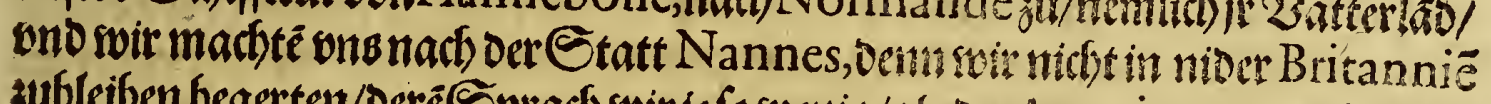

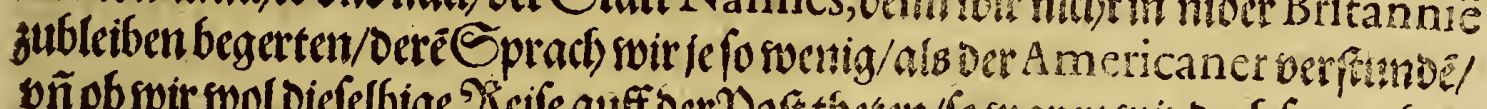

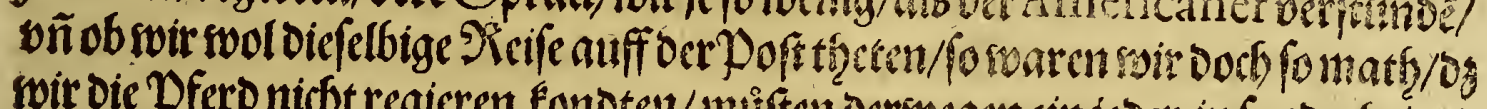

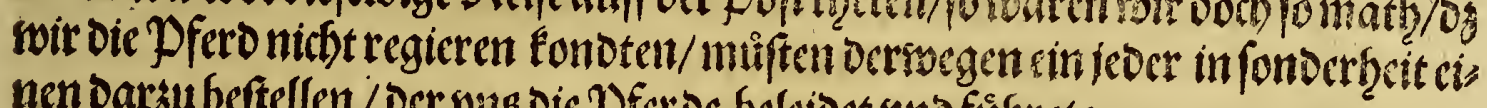
nen Darzu beftellen / ocr van dic D fer oc beleibet vno fübrete.

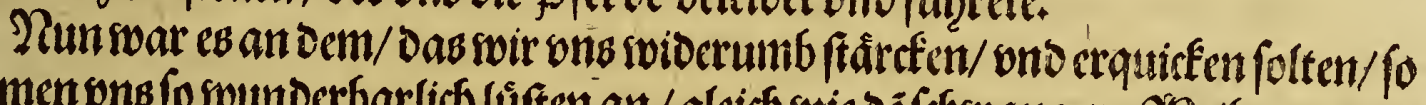

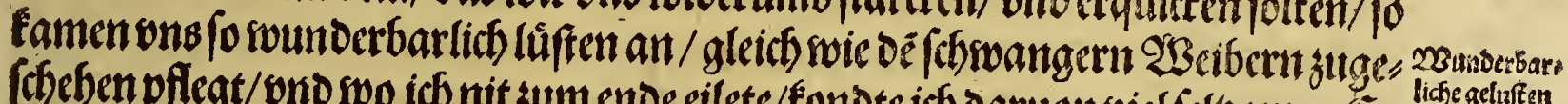

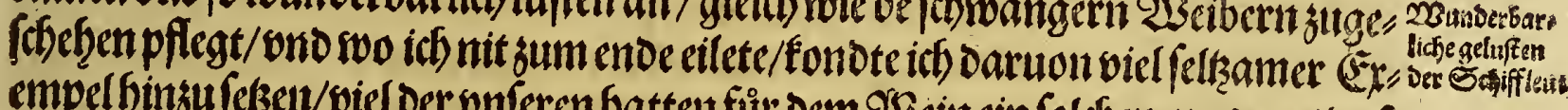

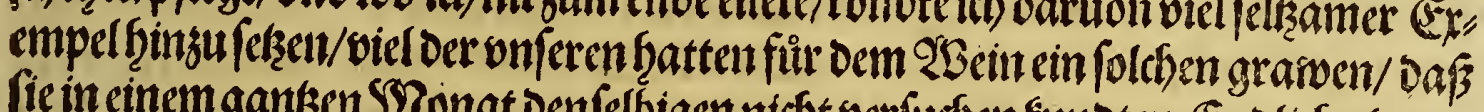

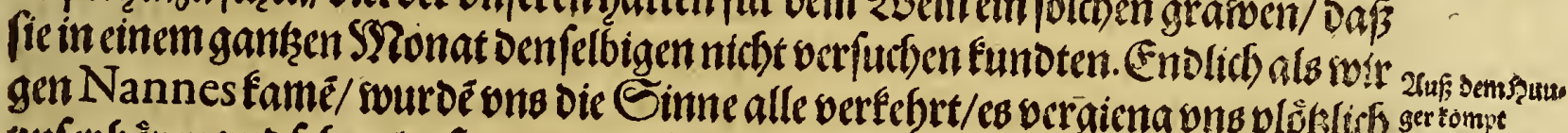

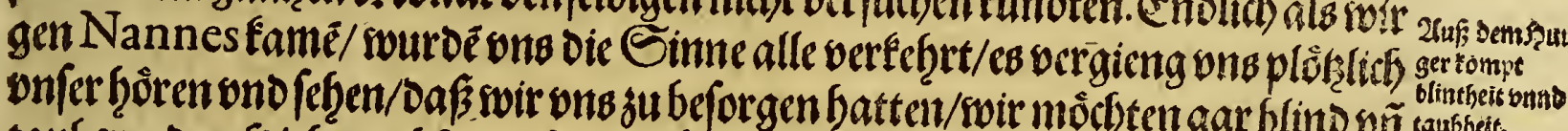

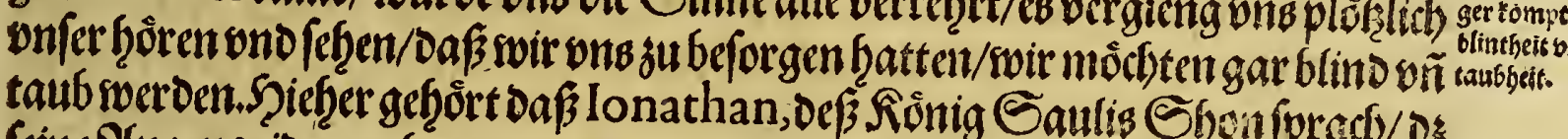

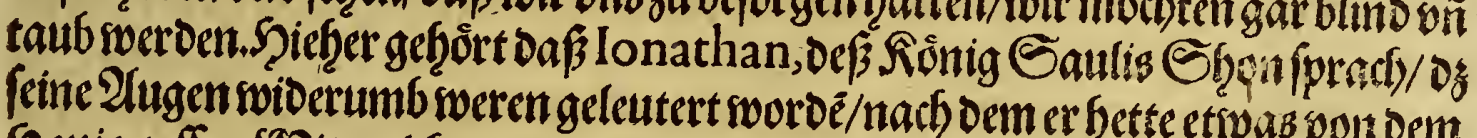

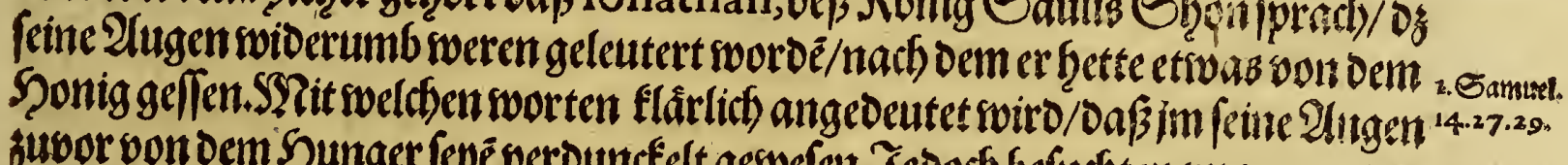

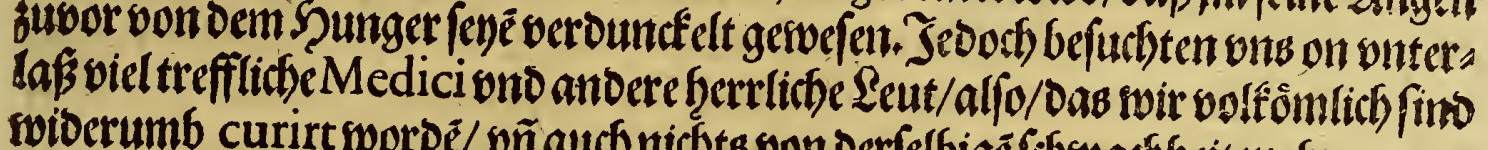

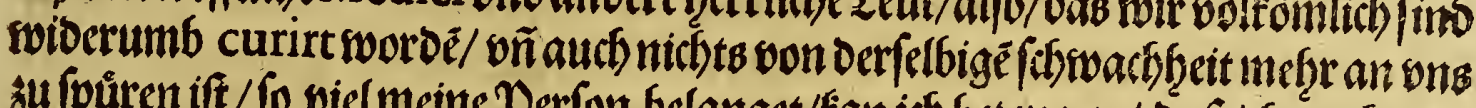

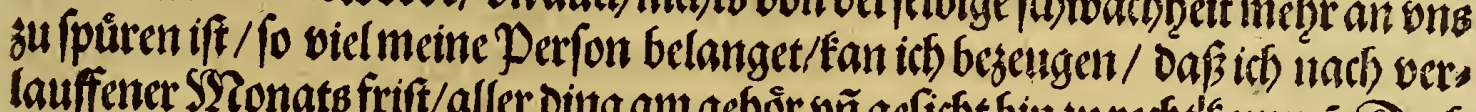

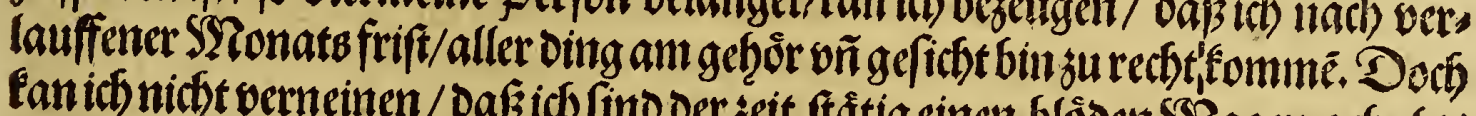

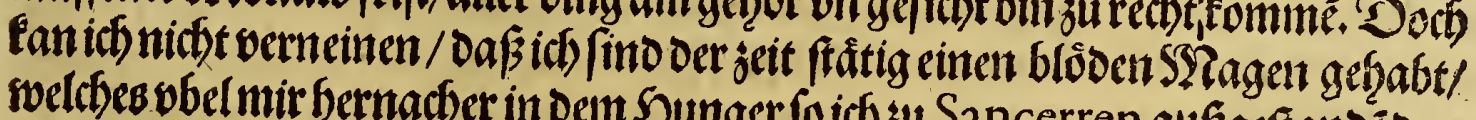

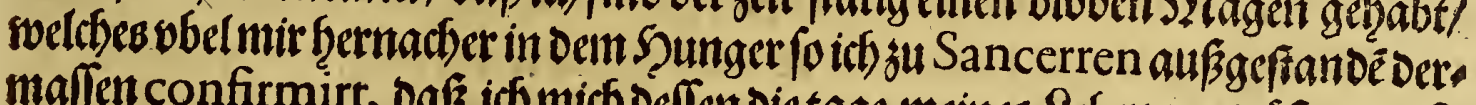

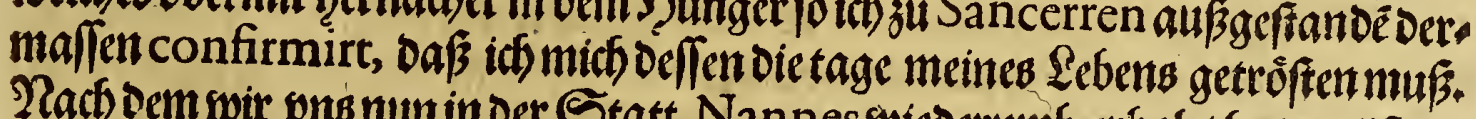

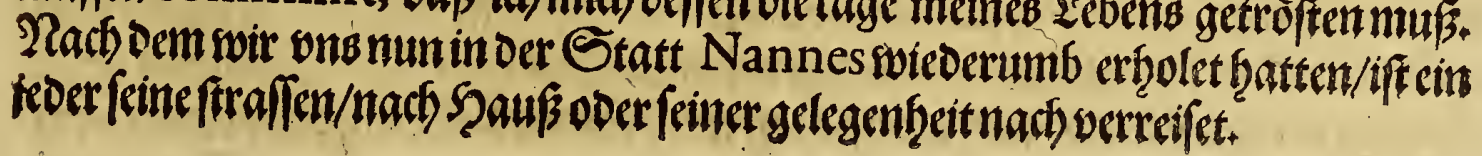

Ebe 


\section{Das oritte Theil.}

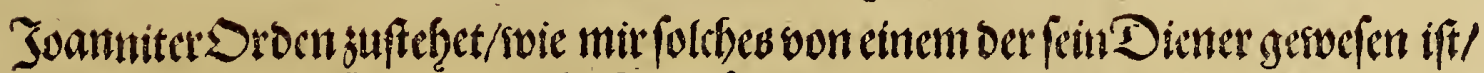

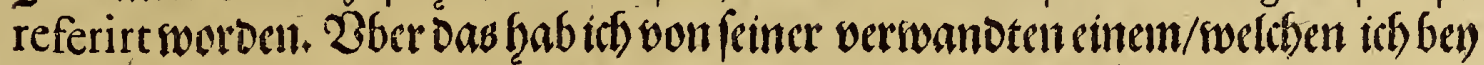

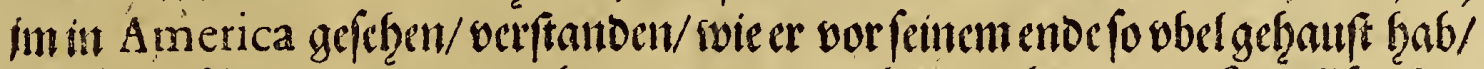

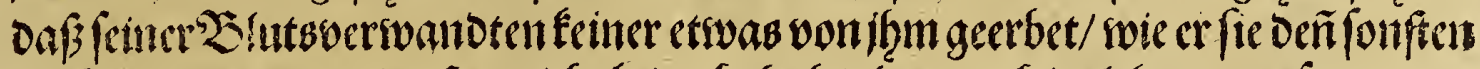

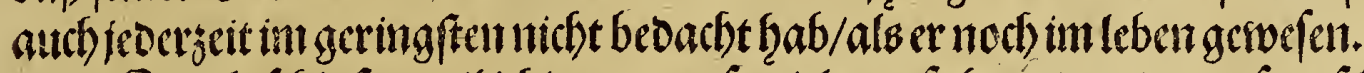

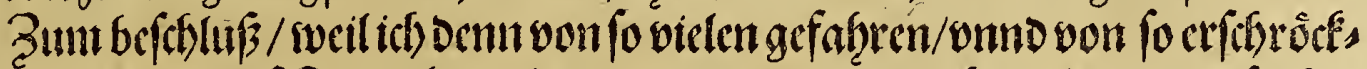

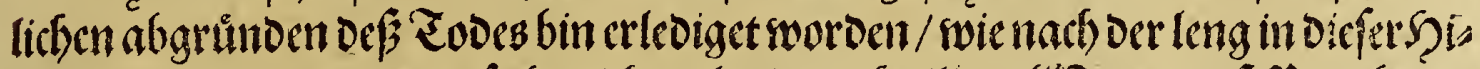

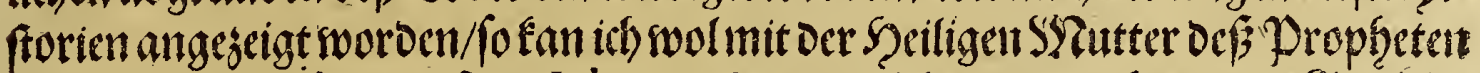

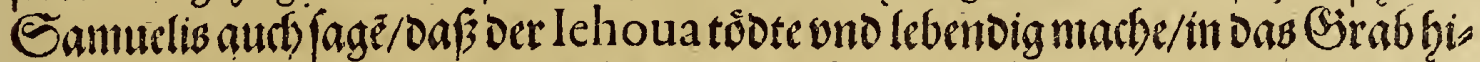

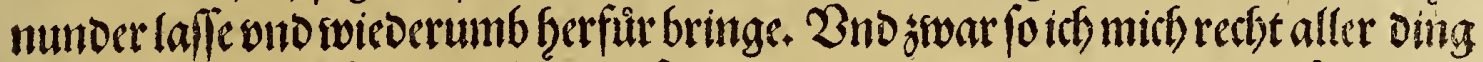

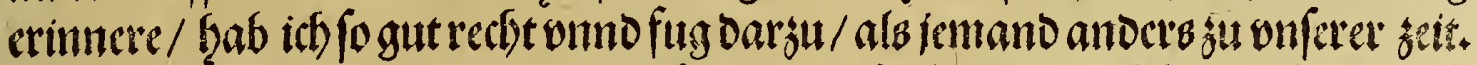

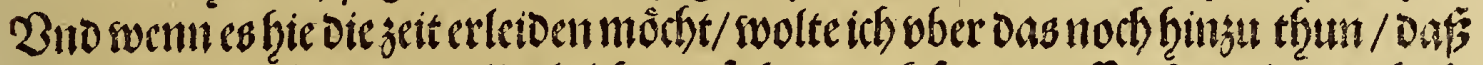

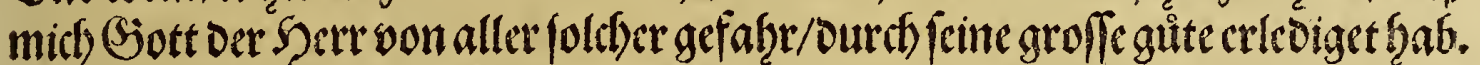

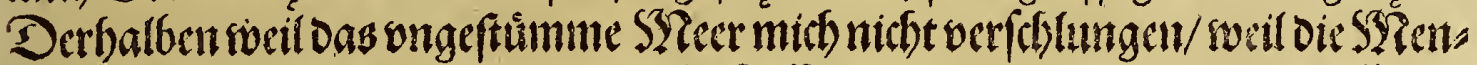

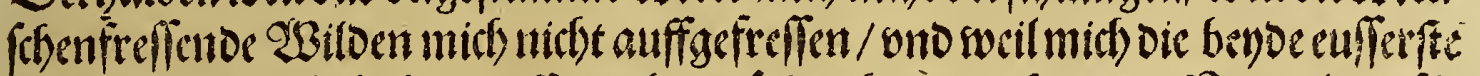

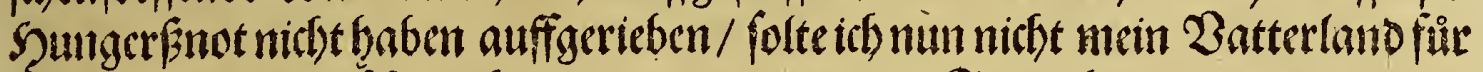

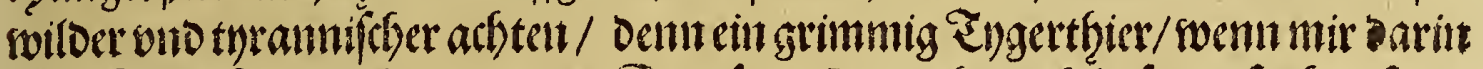

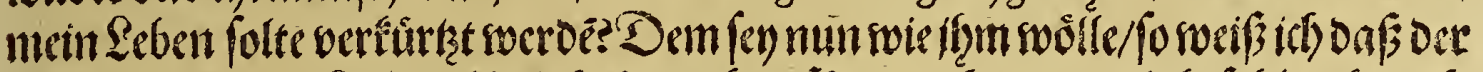

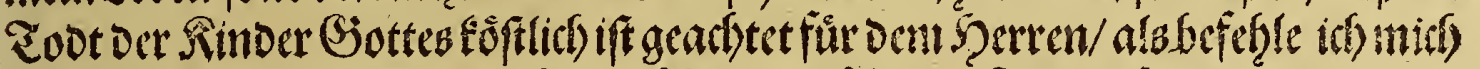

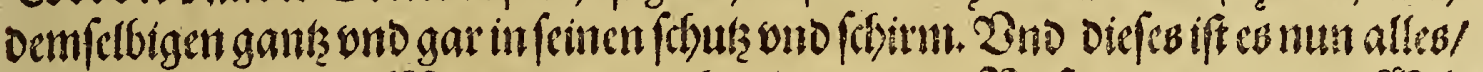

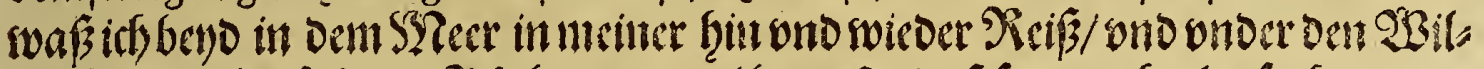

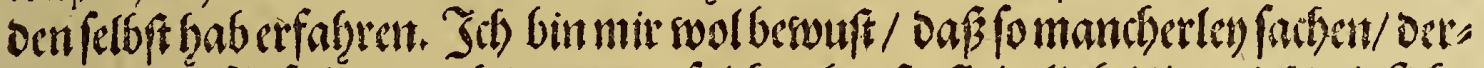

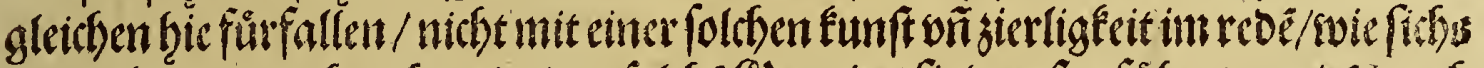

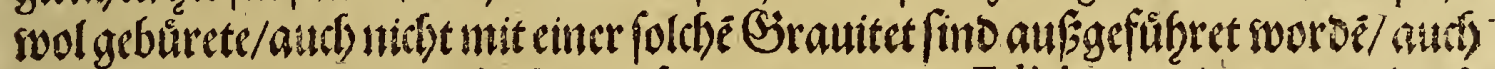

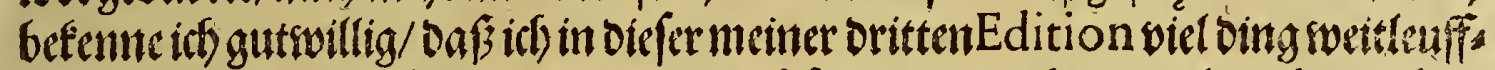

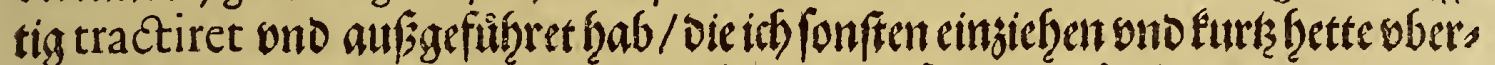
gebenfollen. Sergegen auth wiederumb in Dent gefeblet/ Dafich os fentige bartion

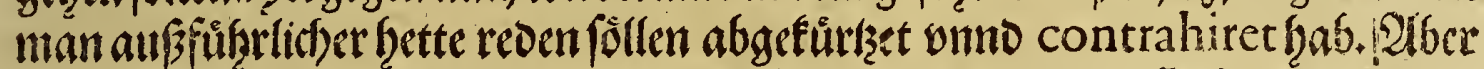

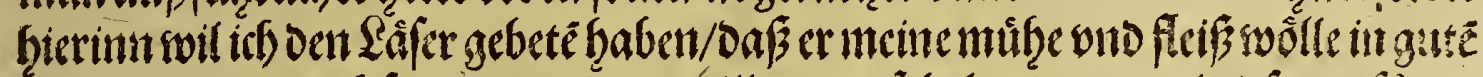

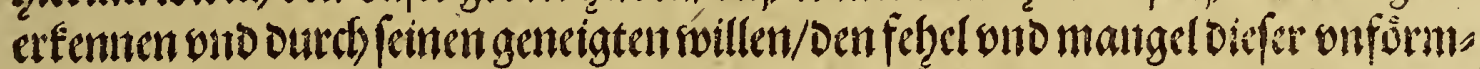

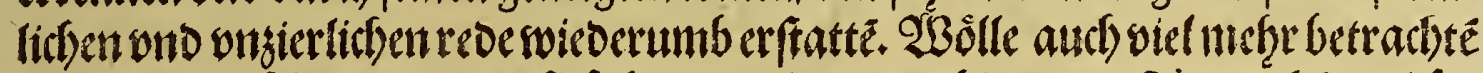

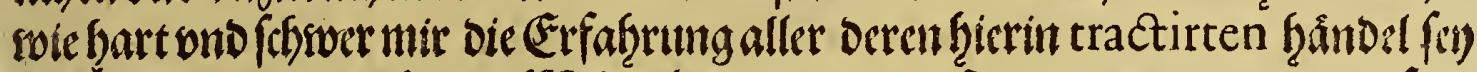

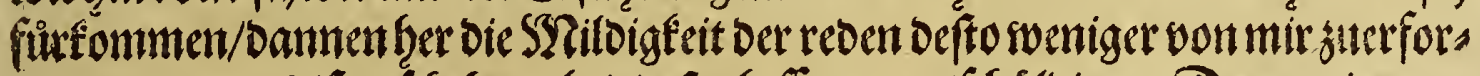

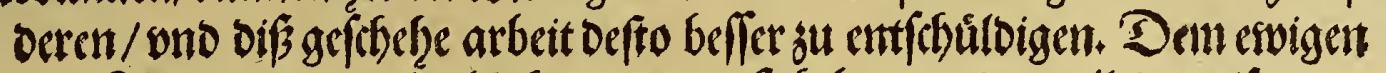

Riōnige/ oemt vn/terblichen/ oem on/ichtbaren/ Dem allein weifent

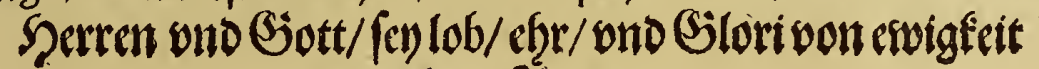
fueswigfeit/2imen.

Erfaf̧rung ift beffer benn biel haben.

$\mathfrak{E} \mathfrak{R} \mathfrak{D}$. 


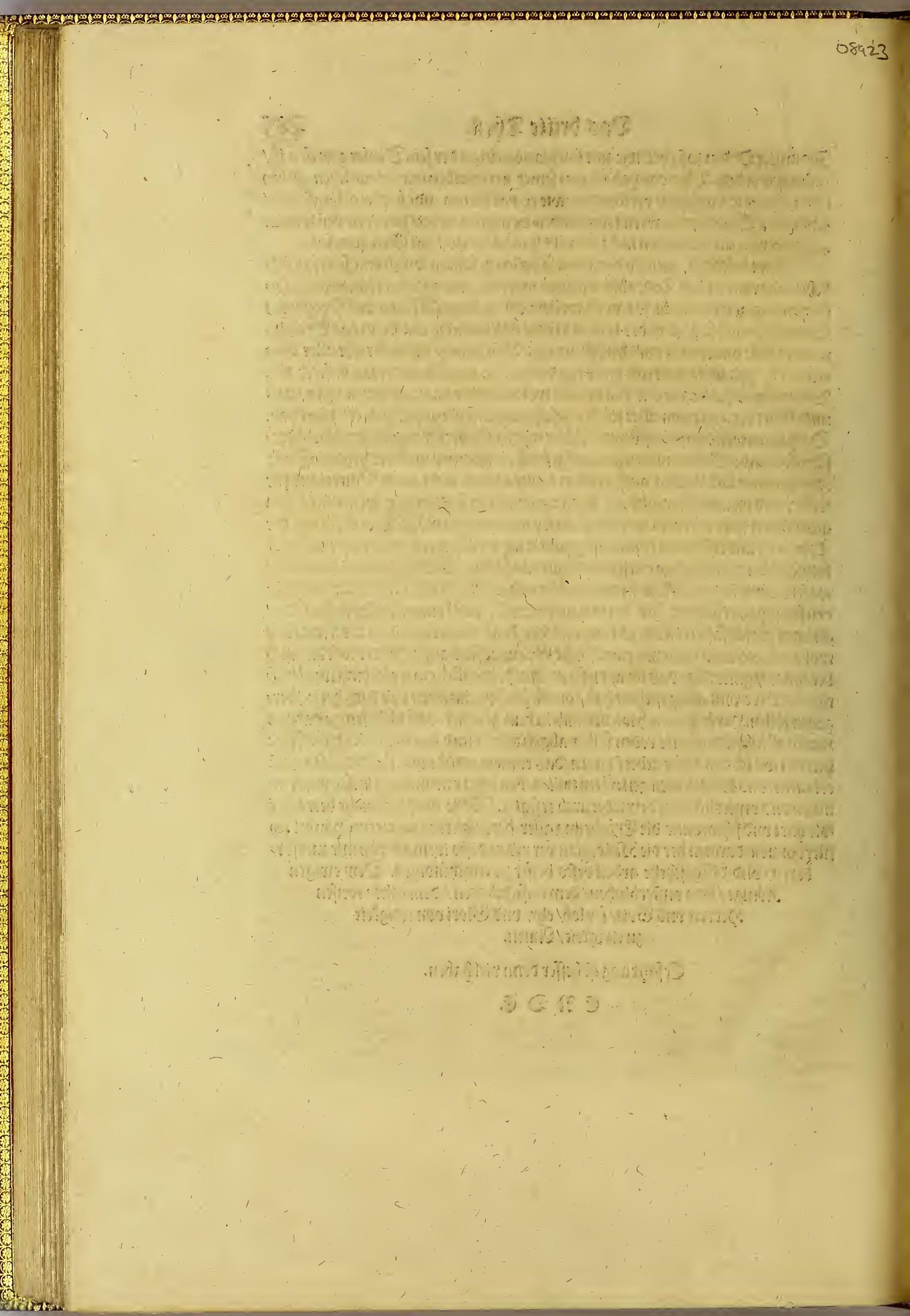



acescers

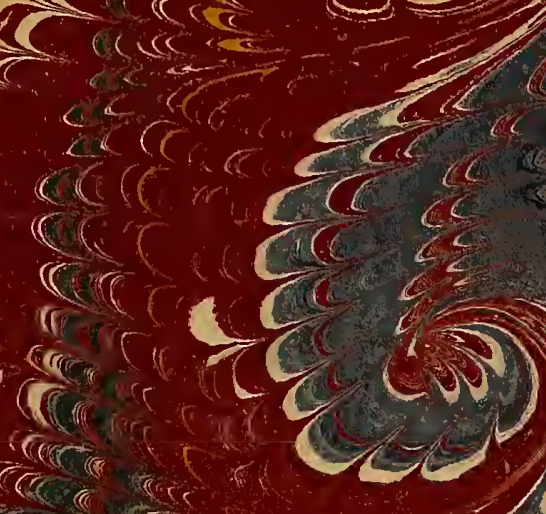

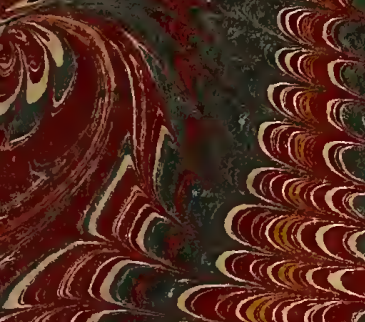

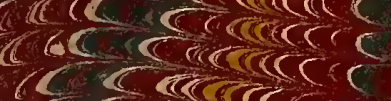
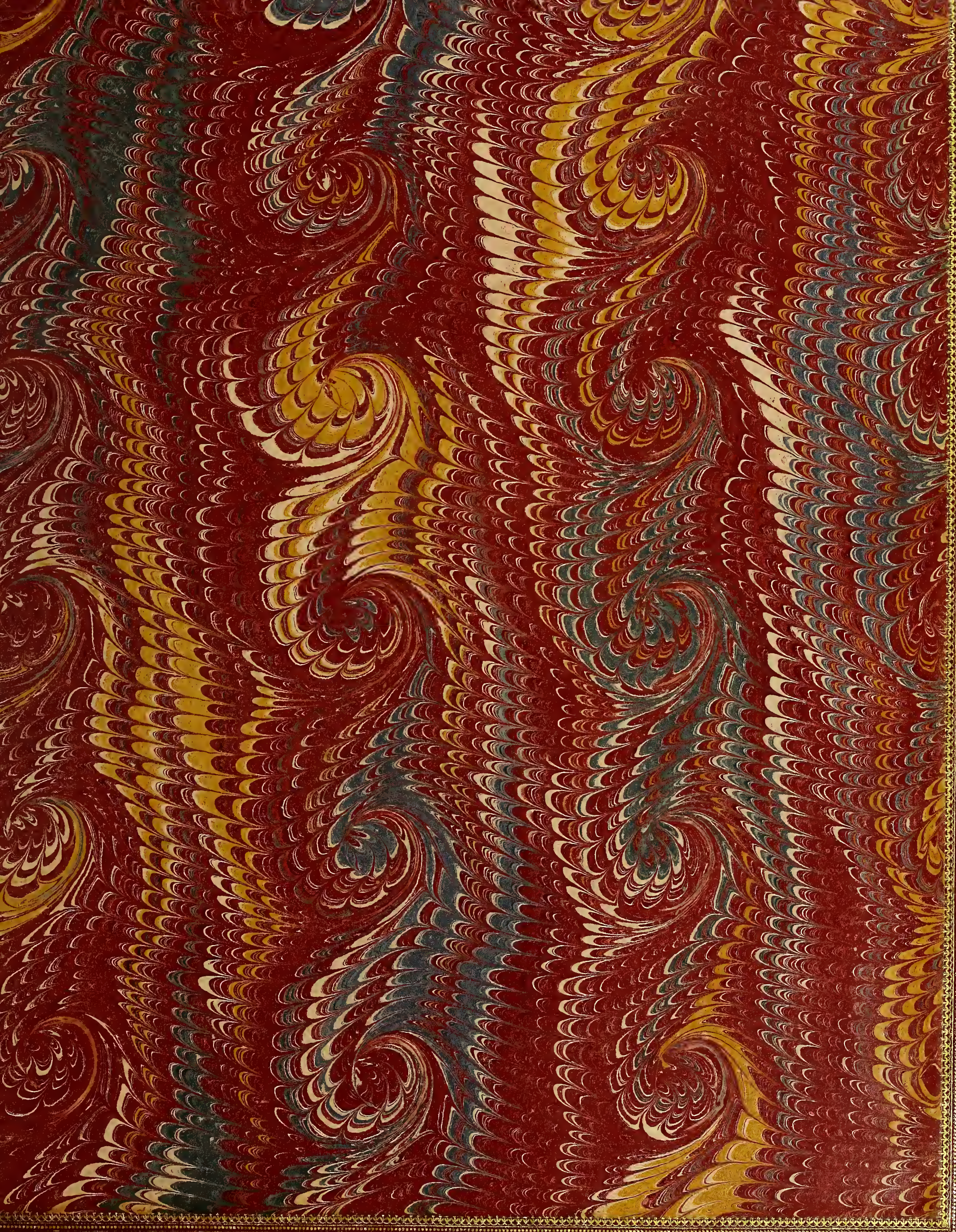

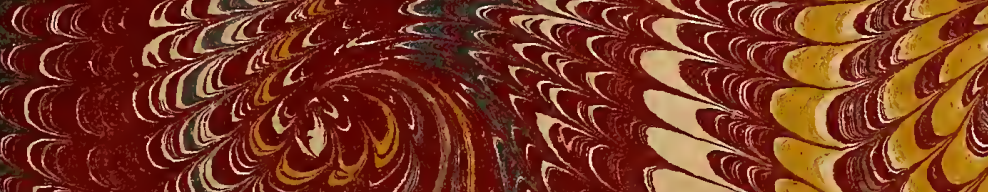

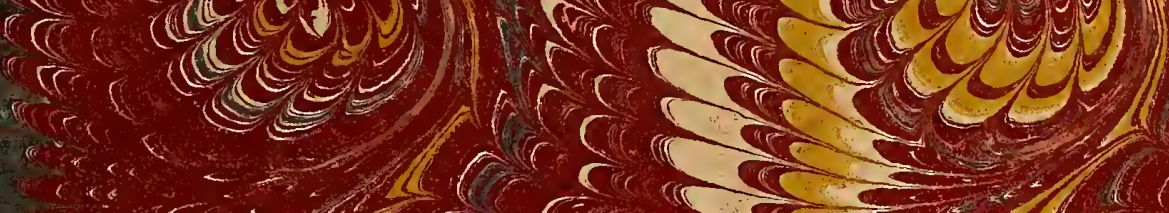




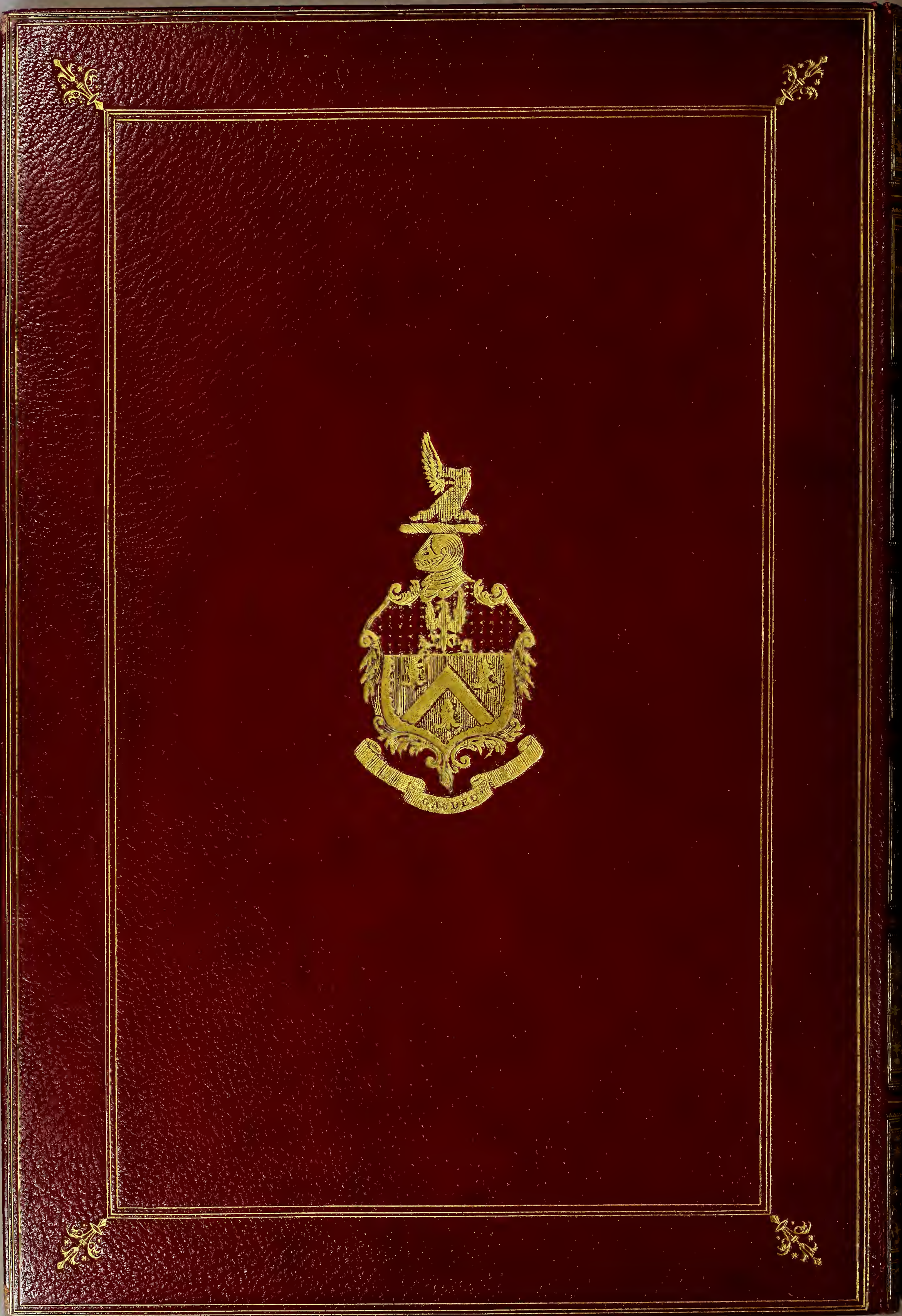

